\title{
FIELD TESTING OF ACTIVATED CARBON INJECTION OPTIONS FOR MERCURY CONTROL AT TXU'S BIG BROWN STATION
}

\author{
Final Report \\ (for the period March 2, 2005, through March 31, 2008) \\ Prepared for: \\ Pierina Noceti \\ U.S. Department of Energy \\ National Energy Technology Laboratory \\ 626 Cochrans Mill Road \\ PO Box 10940, MS 342C \\ Pittsburgh, PA 15236 \\ Cooperative Agreement No. DE-FC26-05NT42305
}

Prepared by:

John H. Pavlish Jeffrey S. Thompson Christopher L. Martin Mark A. Musich Lucinda L. Hamre

Energy \& Environmental Research Center University of North Dakota 15 North 23rd Street, Stop 9018

Grand Forks, ND 58202-9018 


\section{DOE DISCLAIMER}

This report was prepared as an account of work sponsored by an agency of the United States Government. Neither the United States Government, nor any agency thereof, nor any of their employees makes any warranty, express or implied, or assumes any legal liability or responsibility for the accuracy, completeness, or usefulness of any information, apparatus, product, or process disclosed or represents that its use would not infringe privately owned rights. Reference herein to any specific commercial product, process, or service by trade name, trademark, manufacturer, or otherwise does not necessarily constitute or imply its endorsement, recommendation, or favoring by the United States Government or any agency thereof. The views and opinions of authors expressed herein do not necessarily state or reflect those of the United States Government or any agency thereof.

\section{ACKNOWLEDGMENT}

This report was prepared with the support of the U.S. Department of Energy (DOE) National Energy Technology Laboratory Cooperative Agreement No. DE-FC26-05NT42305. However, any opinions, findings, conclusions, or recommendations expressed herein are those of the authors(s) and do not necessarily reflect the views of DOE.

\section{EERC DISCLAIMER}

LEGAL NOTICE This research report was prepared by the Energy \& Environmental Research Center (EERC), an agency of the University of North Dakota, as an account of work sponsored by DOE, Luminant Power, ADA-ES, Inc., Babcock \& Wilcox Company, and the Electric Power Research Institute. Because of the research nature of the work performed, neither the EERC nor any of its employees makes any warranty, express or implied, or assumes any legal liability or responsibility for the accuracy, completeness, or usefulness of any information, apparatus, product, or process disclosed, or represents that its use would not infringe privately owned rights. Reference herein to any specific commercial product, process, or service by trade name, trademark, manufacturer, or otherwise does not necessarily constitute or imply its endorsement or recommendation by the EERC. 


\title{
FIELD TESTING OF ACTIVATED CARBON INJECTION OPTIONS FOR MERCURY CONTROL AT TXU'S BIG BROWN STATION
}

\begin{abstract}
The primary objective of the project was to evaluate the long-term feasibility of using activated carbon injection (ACI) options to effectively reduce mercury emissions from Texas electric generation plants in which a blend of lignite and subbituminous coal is fired. Field testing of ACI options was performed on one-quarter of Unit 2 at TXU's Big Brown Steam Electric Station. Unit 2 has a design output of $600 \mathrm{MW}$ and burns a blend of $70 \%$ Texas Gulf Coast lignite and 30\% subbituminous Powder River Basin coal. Big Brown employs a COHPAC configuration, i.e., high air-to-cloth baghouses following cold-side electrostatic precipitators (ESPs), for particulate control. When sorbent injection is added between the ESP and the baghouse, the combined technology is referred to as TOXECON ${ }^{\mathrm{TM}}$ and is patented by the Electric Power Research Institute in the United States. Key benefits of the TOXECON configuration include better mass transfer characteristics of a fabric filter compared to an ESP for mercury capture and contamination of only a small percentage of the fly ash with AC. The field testing consisted of a baseline sampling period, a parametric screening of three sorbent injection options, and a monthlong test with a single mercury control technology.
\end{abstract}

During the baseline sampling, native mercury removal was observed to be less than $10 \%$. Parametric testing was conducted for three sorbent injection options: injection of standard AC alone; injection of an EERC sorbent enhancement additive, SEA4, with ACI; and injection of an EERC enhanced AC. Injection rates were determined for all of the options to achieve the minimum target of $55 \%$ mercury removal as well as for higher removals approaching $90 \%$. Some of the higher injection rates were not sustainable because of increased differential pressure across the test baghouse module. After completion of the parametric testing, a monthlong test was conducted using the enhanced $\mathrm{AC}$ at a nominal rate of $1.5 \mathrm{lb} / \mathrm{Macf}$. During the time that enhanced AC was injected, the average mercury removal for the monthlong test was approximately $74 \%$ across the test baghouse module. ACI was interrupted frequently during the monthlong test because the test baghouse module was bypassed frequently to relieve differential pressure. The high air-to-cloth ratio of operations at this unit results in significant differential pressure, and thus there was little operating margin before encountering differential pressure limits, especially at high loads. This limited the use of sorbent injection as the added material contributes to the overall differential pressure. This finding limits sustainable injection of AC without appropriate modifications to the plant or its operations. Handling and storage issues were observed for the TOXECON ash-AC mixture. Malfunctioning equipment led to baghouse dust hopper plugging, and storage of the stagnant material at flue gas temperatures resulted in self-heating and ignition of the $\mathrm{AC}$ in the ash. In the hoppers that worked properly, no such problems were reported. Economics of mercury control at Big Brown were estimated for astested scenarios and scenarios incorporating changes to allow sustainable operation. This project was funded under the U.S. Department of Energy National Energy Technology Laboratory project entitled "Large-Scale Mercury Control Technology Field Testing Program - Phase II." 


\section{TABLE OF CONTENTS}

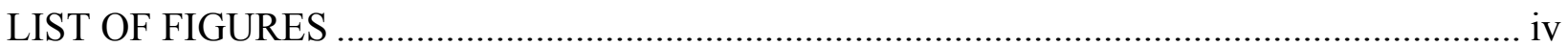

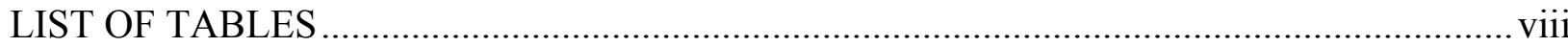

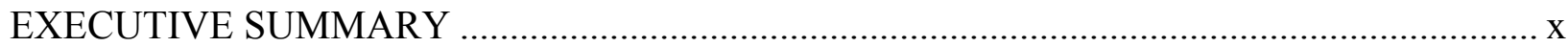

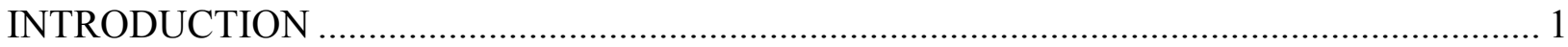

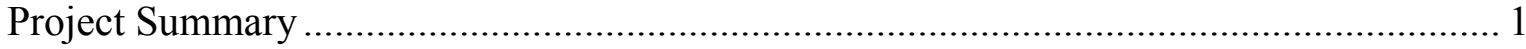

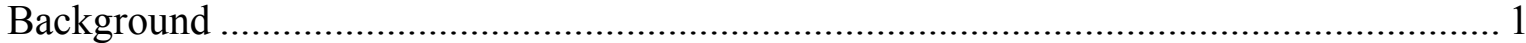

Lignite-Mercury Challenge ……………………………………………….... 2

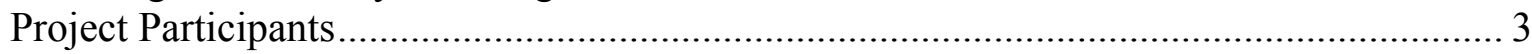

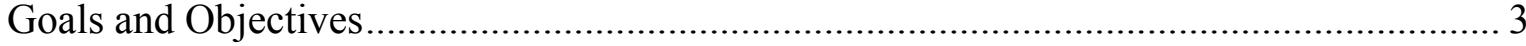

DESCRIPTION OF TEST UNIT AND SAMPLING LOCATIONS........................................... 3

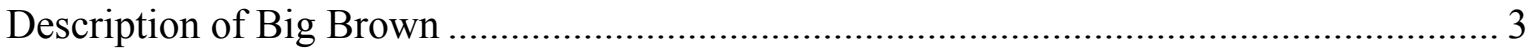

Particulate Control Devices at Big Brown ................................................................... 4

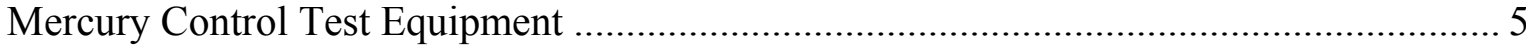

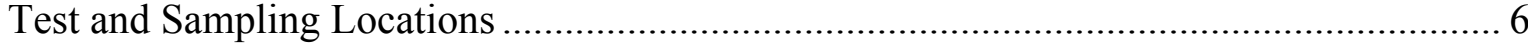

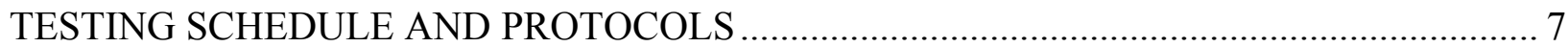

Baseline, Parametric, and Monthlong Tests................................................................. 7

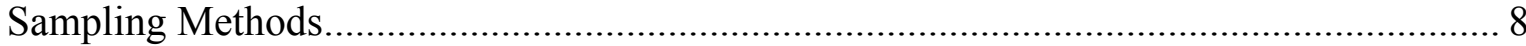

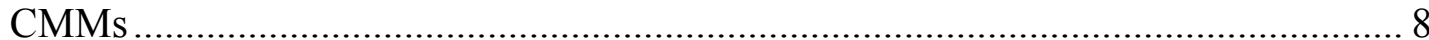

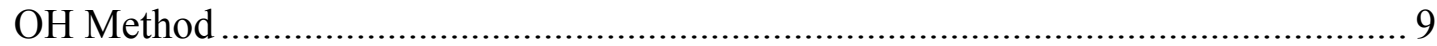

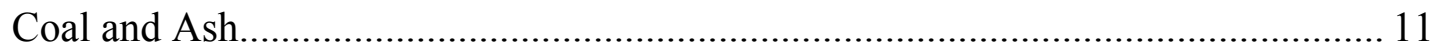

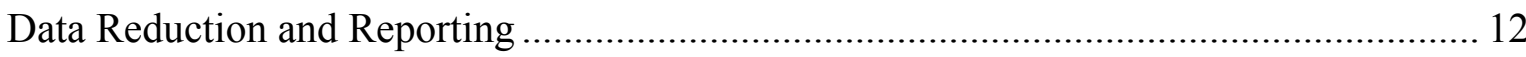

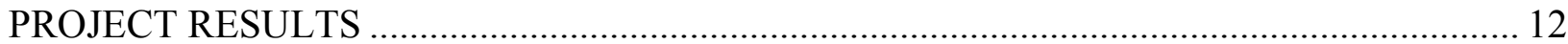

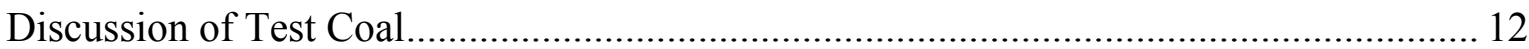

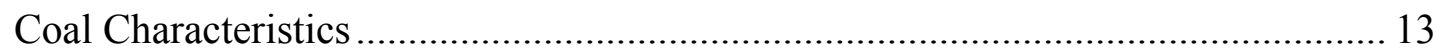

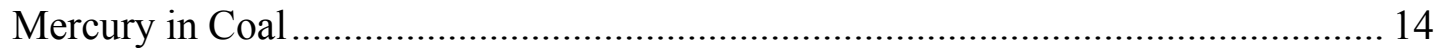

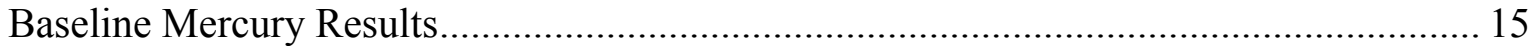

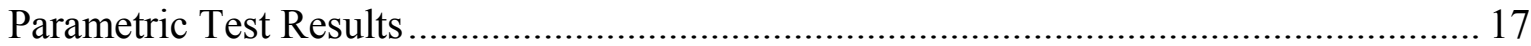

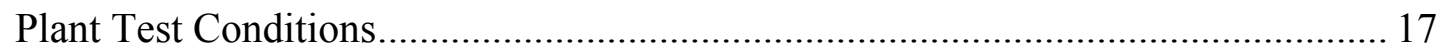

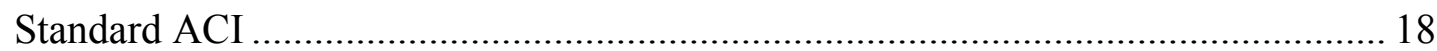

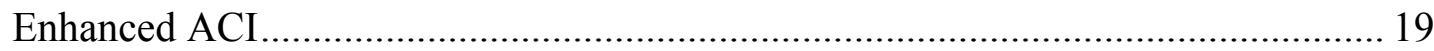

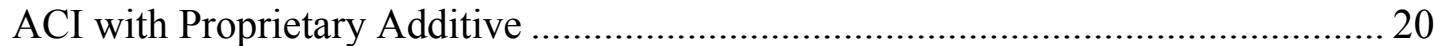

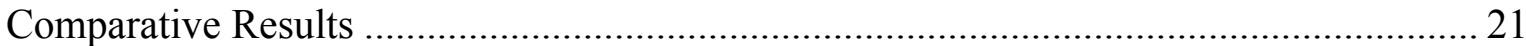

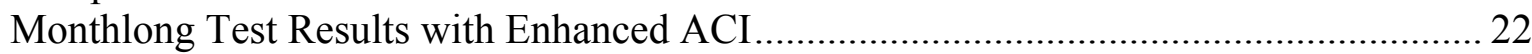

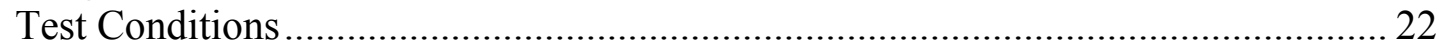

Continued... 


\section{TABLE OF CONTENTS (continued)}

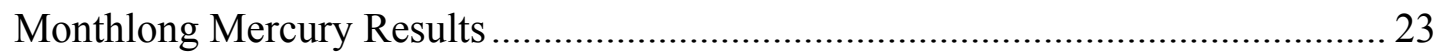

Monthlong Results According to EPA Regulations .................................................. 26

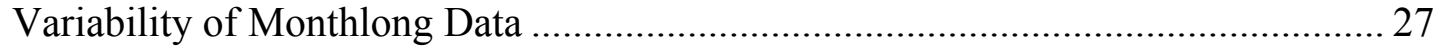

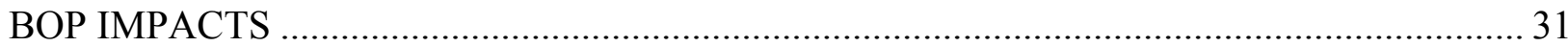

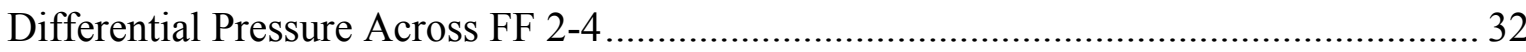

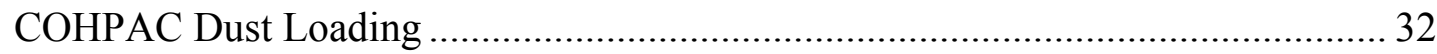

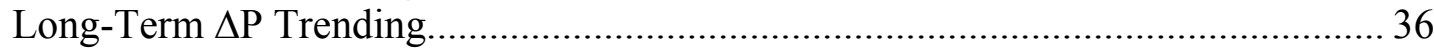

Assessment of FF Bags................................................................................... 40

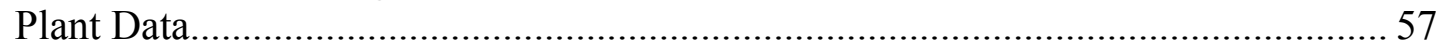

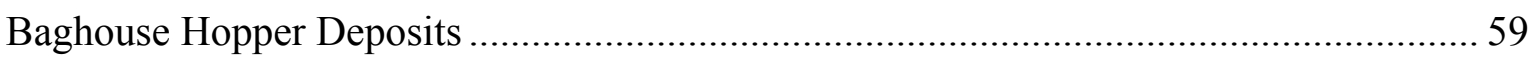

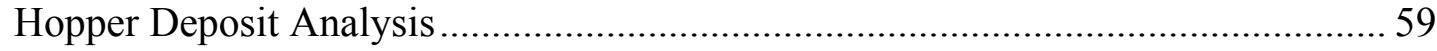

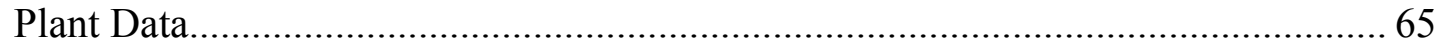

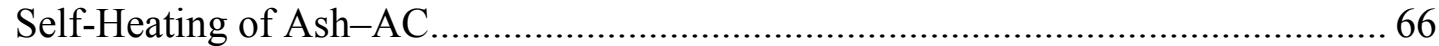

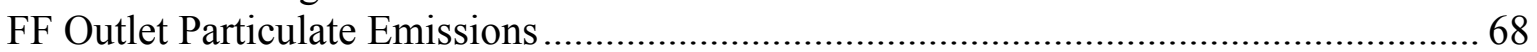

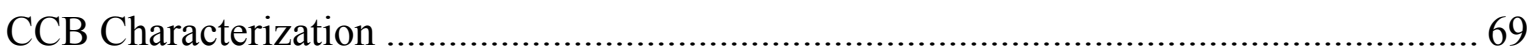

Direct Leaching of Mercury .............................................................................. 70

Elevated-Temperature Mercury Release ………………………………………..... 71

Microbiologically Mediated Mercury Release .......................................................... 72

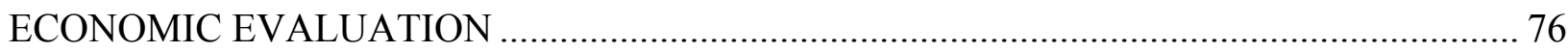

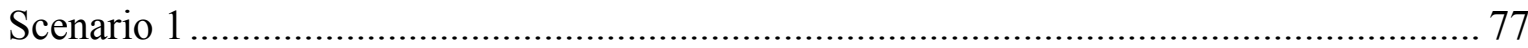

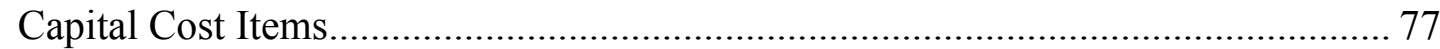

Fly Ash Disposal (and lost revenue)................................................................. 78

Mercury Monitoring and Reporting....................................................................... 79

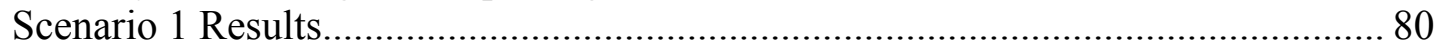

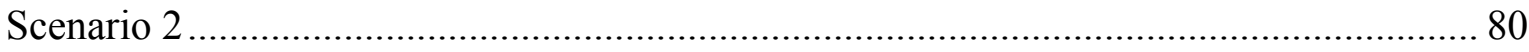

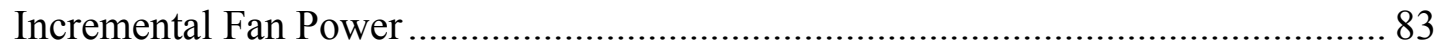

Increased Maintenance of Existing COHPAC …………......................................... 83

COHPAC Upgrades for Improved Safety and Performance with ACI ..................... 84

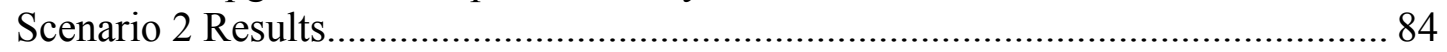

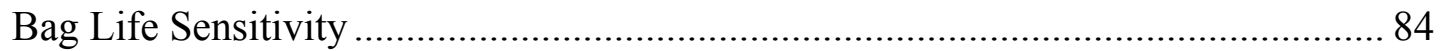

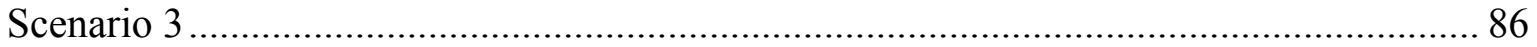

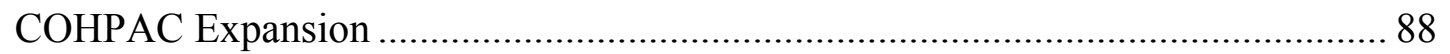

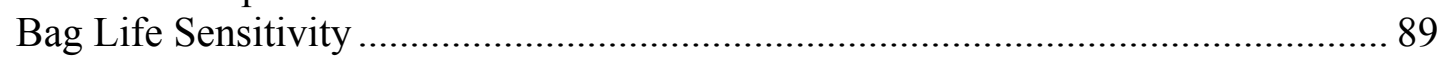

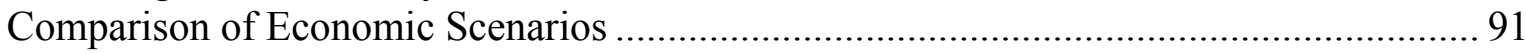

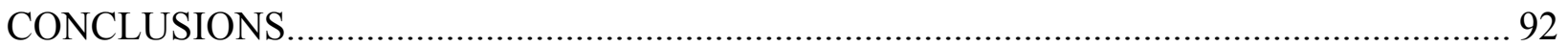

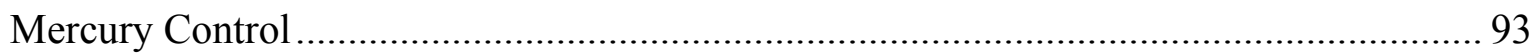

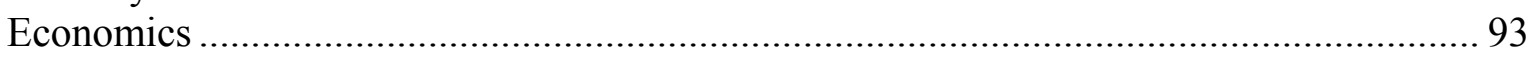

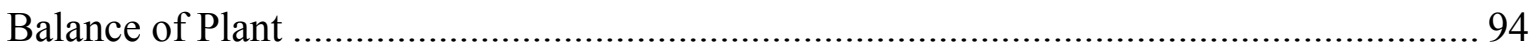

Continued ... 


\section{TABLE OF CONTENTS (continued)}

PROJECT RECOGNITION AND TECHNOLOGY TRANSFER _...........................................95

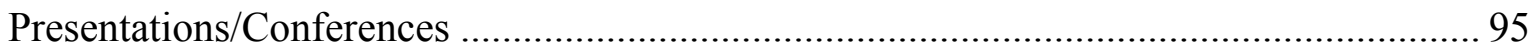

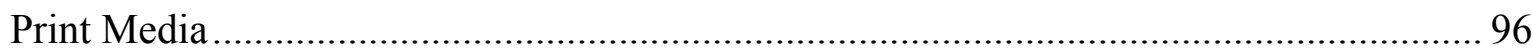

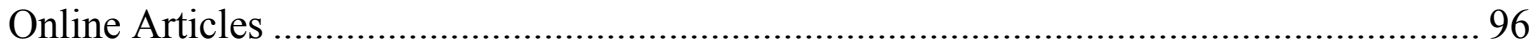

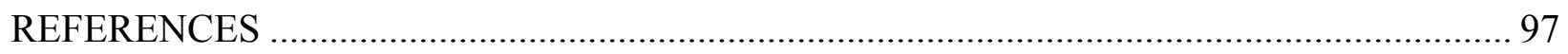

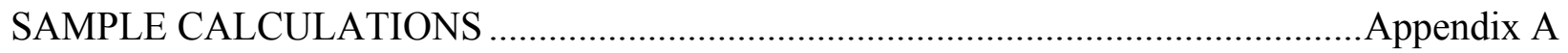

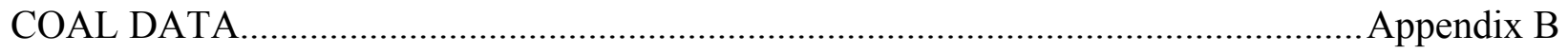

ONTARIO HYDRO MEASUREMENT DATA .......................................................... Appendix C

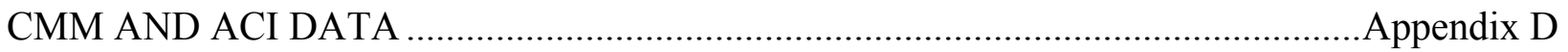

ESP AND FF ASH DATA …………….......................................................... Appendix E

RELEVANT PLANT OPERATING DATA ............................................................... Appendix F

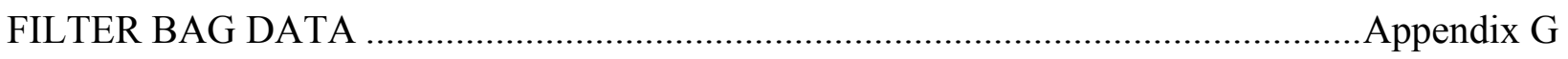

GRUBB FILTRATION TESTING SERVICES, INC., LABORATORY

REPORT NO. 4226/4282, MAY 22, 2006

Appendix G-1

ADA-ES, TRIP REPORT MAY 23-24, 2006, JUNE 5, 2006

Appendix G-2

SEM-EDX ANALYSIS OF FILTER CROSS SECTIONS AND

Appendix G-3

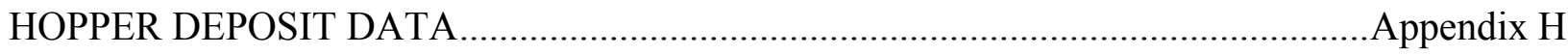

SUPPLEMENTARY ECONOMIC INFORMATION .................................................... Appendix I 


\section{LIST OF FIGURES}

1 Schematic of Big Brown Unit 2 showing sampling and injection locations......................... 7

2 Comparison of Unit 2 coal mercury values for the 70-30 Texas lignite-PRB

blended fuel ............................................................................................................... 15

3 Averaged baseline $\mathrm{Hg}$ concentration data across FF 2-4 for January 18, 19, and 20 with the 70-30 Texas lignite-PRB blend at Big Brown Unit 2 .................................. 16

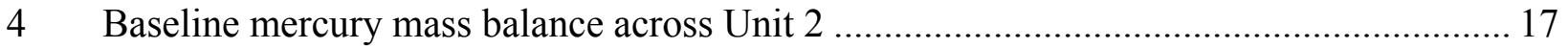

5 Summary of $\mathrm{OH}$ method test results from the parametric testing with AC only ................ 19

6 Summary of $\mathrm{OH}$ method test results from the parametric testing with enhanced AC ........ 20

7 Summary of $\mathrm{OH}$ method test results from the parametric testing with the additive

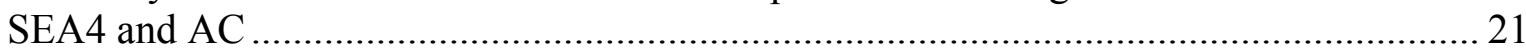

8 Comparison of observed $\mathrm{Hg}$ removals across FF 2-4 during the parametric tests with the 70-30 Texas lignite-PRB blend at Big Brown Unit 2 ........................................ 22

9 Comparison of coal-based, $\mathrm{OH}$ method, and CMM Hg concentrations for the sampling during the monthlong test ........................................................................... 24

10 Mercury mass balance across Unit 2 during the monthlong test, based on measurements from the B side ESPs and FF 2-4 .......................................................... 25

11 Hourly average mercury emissions from FF 2-4 computed according to EPA

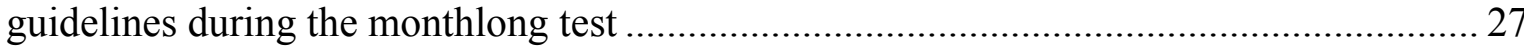

12 Histograms of the FF 2-4 inlet and outlet $\mathrm{Hg}$ concentration readings during the

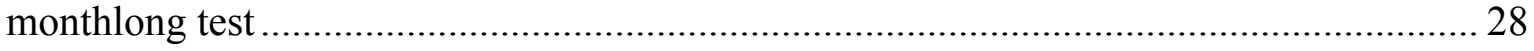

13 Distribution of mercury removal during the monthlong test............................................... 29

14 Normalized covariance for the statistically relevant parameters compared to mercury removal across FF 2-4 .......................................................................... 29

15 Sorted mercury removal data as a function of continuous injection time ........................... 30

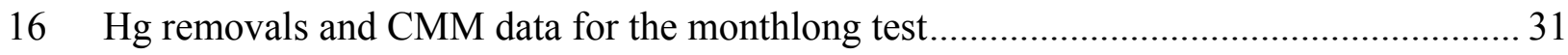

Continued ... 


\section{LIST OF FIGURES (continued)}

17 Record of FF 2-4 bypass setting during the monthlong test and through the

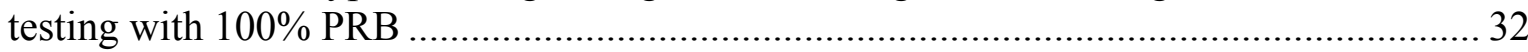

18 Log of the number of hours Unit 2 was above 600-MW output, per day, during the monthlong test and through the testing with $100 \%$ PRB …………………………...... 33

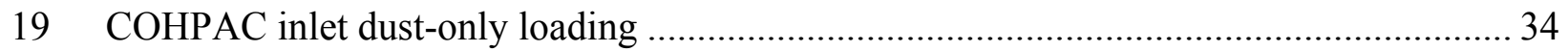

20 B-side COHPAC inlet opacity data during the period of the February 8, 2006, ESP trip …….......................................................................................................... 34

21 FF 2-4 inlet dust-only loading (determined from $\mathrm{OH}$ method measurements) as a

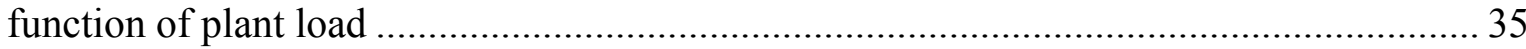

22 Trends of FF 2-4 differential pressure versus FF 2-4 A/C ratio, total FF 2-4 inlet dust loading, and the ratio of $\mathrm{AC}$ to fly ash in the inlet dust load...................................... 36

23 Comparison of module $\Delta \mathrm{P}$ versus computed $\mathrm{A} / \mathrm{C}$ ratio (proportional to module flow)

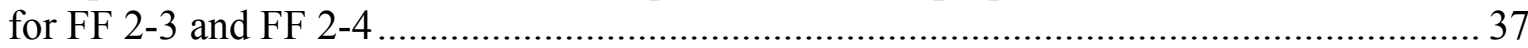

24 Comparison of module $\Delta \mathrm{P}$ versus computed $\mathrm{A} / \mathrm{C}$ ratio (proportional to module flow) for FF 2-3 and FF 2-4.

25 Computed differential pressures across FF 2-3 and 2-4 at a consistent $\mathrm{A} / \mathrm{C}$ ratio of $11 \mathrm{ft} / \mathrm{min}$

26 FF 2-4 $\Delta \mathrm{P}$ trends for prior to the monthlong test, no ACI, and the average of those during the monthlong test with ACI................................................................................... 40

27 Photograph of the bag sections received by the EERC ...................................................... 44

28 Sulfate content of FF bulk ash and the residual dust from FF 2-3 and 2-4 filter samples

29 Average $\mathrm{pH}$ level for solutions of the $\mathrm{FF}$ ash and the residual dust from FF 2-3 and 2-4 filter samples

30 Ammonia content of FF bulk ash and the residual dust from FF 2-3 and 2-4 filter samples 


\section{LIST OF FIGURES (continued)}

31 Carbon content of FF bulk ash and the residual dust from FF 2-3 and FF

2-4 filter samples

32 Selenium content of FF bulk ash and the residual dust from FF 2-3 and

2-4 filter samples. 48

33 Trends of residual dust sulfate and ammonia concentrations with bag exposure time ....... 48

34 Magnified view of the outer surface of a bag sample from FF 2-3 November 2005 ........... 50

35 Magnified views of the outer surfaces of March 2006 bag samples from

FF 2-3 (left) and FF 2-4 (right) 50

36 Magnified view of a scraped nodule showing layered structure ......................................... 51

37 Composite microscopic images across the cross section of each of the bag samples..........52

38 Differences in composition between the embedded dust from the November 2005 to the March 2006 bag samples. 54

39 SEM image and element maps for the outer surface of a sample from FF 2-3 March 2006 55

40 Diffraction pattern of residual dust removed from a FF 2-3 March 2006 filter sample...... 56

41 Plot of sulfate and ammonia concentrations in the residual dust for several Unit 2 bag samples 57

42 Recorded sulfur trioxide and ammonia injection rates during the period of monthlong and $100 \%$ PRB testing 58

43 Cross-sectional diagram of a representative baghouse compartment and, in Detail A, a diagram indicating the possible extent of ash accumulation based on observations of the contractors who cleaned Compartment 2-4 C.

44 Photos of representative deposit samples collected from Hopper C. On the left is a sample of the monolithic deposit, and on the right is a sample of the hard popcorn deposit that has been rinsed. Images are not to the same scale

45 Diagram showing the approximate layering (as observed by plant contractors) in the bottom of Hopper C 61

Continued... 


\section{LIST OF FIGURES (continued)}

46 Photos of representative deposit samples collected from Hopper H............................... 62

47 Diffraction patterns for the popcorn and monolith deposits from Hopper C ................... 63

48 Diffraction patterns for the orange deposit and gray deposit from Hopper H ................. 63

49 XRF composition data for samples of the Hopper C deposits and the two ash types........ 64

50 XRF composition data for samples of the Hopper $\mathrm{H}$ deposits and the two ash types ........ 65

51 Hopper bottom cone external temperatures for Hoppers $\mathrm{C}$ and $\mathrm{H}$ before and after

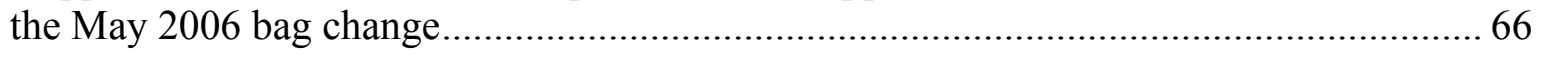

52 Mercury thermal desorption apparatus............................................................... 71

53 CCB-soil mercury vapor release collection apparatus .......................................... 73

54 Elemental mercury vapor release rate in CCB-soil microbiologically mediated release

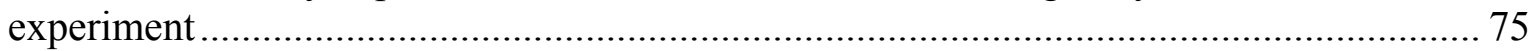

55 Organomercury vapor release rate in CCB-soil microbiologically mediated release

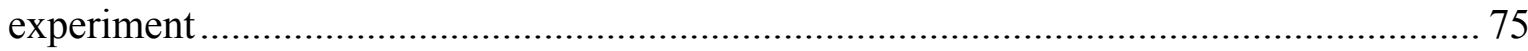

56 Incremental cost of electricity and cost of mercury reduction for sorbent injection for the $70-30$ lignite-PRB fuel blend ................................................................ 82

57 Distribution of operating costs for 90\% mercury removal with the 70-30

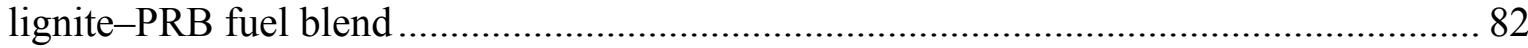

58 Distribution of operating costs when considering BOP costs and COHPAC upgrades under Scenario 2 with 90\% mercury control using enhanced ACI.................... 87

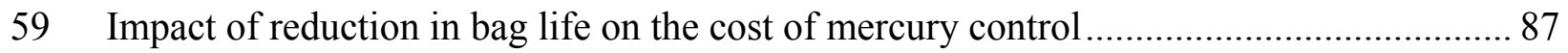

60 Added cost for mercury control as a function of COHPAC $\mathrm{A} / \mathrm{C}$ ratio ........................... 90

61 Sensitivity of the incremental cost for bag replacement and the incremental cost of electricity as a function of bag life

62 Incremental cost of electricity because of mercury control and the cost for removed mercury for the scenarios considered 


\section{LIST OF TABLES}

1 Time Line of Field Testing Events at Big Brown ........................................................ 7

2 OH Sampling Matrix for the 70-30 Texas Lignite-PRB Testing at Big Brown ................. 10

3 Average Coal Values for the Nominal 70-30 Texas Lignite-PRB Blend at Big

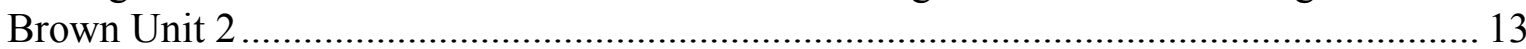

4 Baseline Oxide Compositions (WDXRF analysis) of the 70-30 Blend Coal, ESP

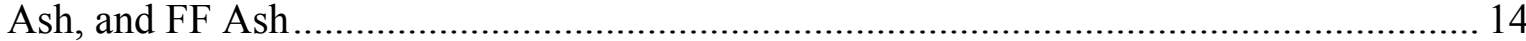

5 Flue Gas Hg Concentration Estimates Based on the Average Values for all 70-30

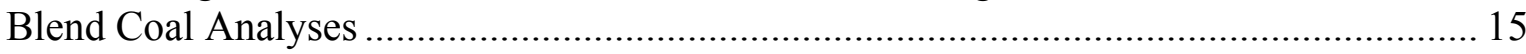

$6 \quad$ Summary of Parametric Test Results with Standard ACI (DARCO Hg) ............................. 18

$7 \quad$ Summary of Parametric Testing Results with the Enhanced AC......................................... 19

8 Summary of Parametric Testing Results with ACI and SEA4 .......................................... 20

9 Summary Figures for the Monthlong Testing with the 70-30 Texas Lignite-PRB Blend and a Targeted Enhanced ACI Rate of $1.5 \mathrm{lb} /$ Macf................................................ 25

10 Combination of Baseline Oxide Compositions (WDXRF analysis) of the 7030 Blend Coal, ESP Ash, and Composition of the Monthlong FF Ash ............................... 26

11 Linear Curve Fit Parameters for the Observed Relationship Between Module $\Delta \mathrm{P}$ Versus A/C Ratio for Selected Days Before and During Field Testing................................ 38

12 Event Time Line for the FF 2-4 BOP Investigation........................................................ 42

13 In Situ Residual Drag Measurements for Unit 2 COHPAC Modules ................................... 43

14 Summary of Bag Data from Independent Consultant ...................................................... 43

15 Summary of CHN Results for Bag Surface Sampling .................................................... 52

16 Point EDX Averages for the Embedded Material in 2-4C and 2-3C Bag Samples and Bulk XRF Analyses for the Corresponding FF 2-4 Ash .............................................. 53

17 Summary of Analyses for the Bag Samples from Module 2-1 Compared to Averages for Modules 2-3 and 2-4. 56

Continued... 


\section{LIST OF TABLES (continued)}

18 Summary of Events for the Ash-Conditioning Settings ....................................................58

19 Measured Carbon Content of the FF Ash During Field Testing .......................................... 64

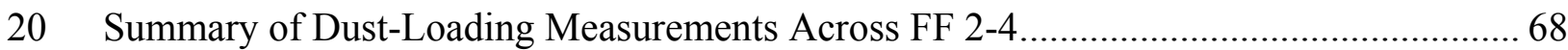

21 CCB Description and Characterization of FF 2-4 Ash Samples ............................................ 69

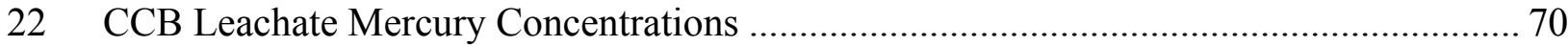

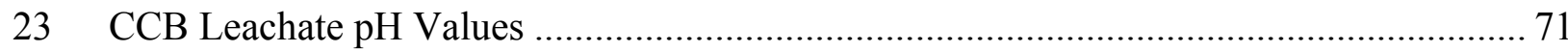

24 First Mercury Release Peak Noted in Elevated-Temperature Mercury Release

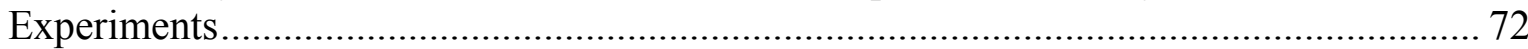

25 CCB-Soil Experiment Characterization Data of CCBs, Soil, and CCB-Soil Mixtures Consisting of a 20\% Addition of CCB to Soil.................................................... 74

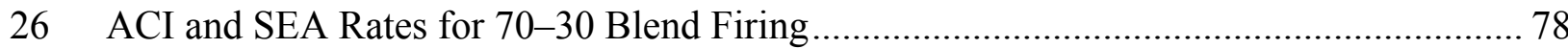

27 Summary of Compliance Monitoring System Costs ......................................................... 79

28 Summary of Costs for Mercury Control: 70-30 Fuel Blend, Scenario 1 Assumptions....... 81

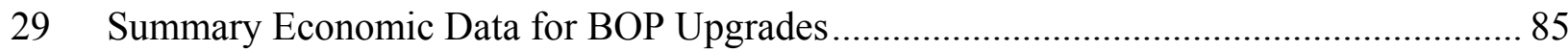

30 Mercury Control Cost Comparisons for Scenarios 1 and 2, Not Including and Including Costs for BOP and COHPAC Upgrade Costs, Respectively .............................. 86

31 Cost Summary Associated with COHPAC Expansion, Scenario 3 …………………......... 89

32 Summary of Economic Data for the Scenarios Considered ................................................ 91 


\section{FIELD TESTING OF ACTIVATED CARBON INJECTION OPTIONS FOR MERCURY CONTROL AT TXU'S BIG BROWN STATION}

\section{EXECUTIVE SUMMARY}

This project supports the objectives set forth by the U.S. Department of Energy (DOE) National Energy Technology Laboratory (NETL) to field-test mercury control technologies that may prove effective for Texas lignites. The project was led by the Energy \& Environmental Research Center (EERC), with a highly skilled team consisting of TXU Power, the Electric Power Research Institute (EPRI), ADA-ES, Inc., Acid Gas Solutions, and the Babcock \& Wilcox Company and the collective support of a consortium of utilities that combust lignite.

The primary objective of the project was to evaluate the long-term feasibility of using activated carbon injection (ACI) options to effectively reduce mercury emissions from Texas electric generation plants in which a blend of lignite and subbituminous coals is fired. Testing was conducted on Unit 2 of TXU's Big Brown Steam Electric Station, which is located near Fairfield, Texas, and is composed of two identical 600-MW units. The test unit utilizes a COHPAC configuration for particulate control, i.e., a high air-to-cloth (A/C) fabric filter (FF) of $12 \mathrm{ft} / \mathrm{min}$ following a cold-side electrostatic precipitator (ESP). When these control technologies are coupled with ACI, the EPRI-patented technology is referred to as TOXECONTM in the United States.

In early 2006, team members field-tested several AC and AC-plus-additive options to determine performance relative to injection rates and mercury emission reductions, determine balance-of-plant (BOP) impacts, and gather data that allowed for an economic evaluation of the commercial application of the proposed technologies. Field testing began with a baseline sampling period to determine the uncontrolled mercury emissions from Big Brown Unit 2. Native mercury removal was measured to be less than $10 \%$ of the mercury entering in the coal, and most of the native removal was across the ESP.

Following baseline sampling, a series of parametric testing was conducted, consisting of a standard AC only, an EERC sorbent enhancement additive (SEA4) with and without AC, and an EERC-enhanced AC. The AC used was DARCO ${ }^{\circledR} \mathrm{Hg}$ supplied by NORIT Americas Inc.; the SEA and enhanced AC treatment are proprietary technologies of the EERC. Sorbent injection was between the ESP and one of the four FF modules on Unit 2 Module FF2-4. During parametric testing, injection rates began low with a minimum injection target of $0.5 \mathrm{lb} / \mathrm{Macf}$ and were increased incrementally to determine mercury removal. Injection rates were determined for all of the options to achieve the minimum target of 55\% removal as well as for higher removals approaching $90 \%$. Some of the higher injection rates were not sustainable because of increased differential pressure $(\Delta \mathrm{P})$ across the test $\mathrm{FF}$ module. The parametric testing results are summarized in Figure ES-1.

After completion of the parametric testing, the most attractive sorbent injection option was determined based on parametric $\mathrm{Hg}$ removals, a preliminary economic analysis of sorbent performance, and input from project team members. A monthlong test was then conducted to 
determine the long-term mercury capture and assess BOP effects of the technology. The chosen technology was the enhanced ACI at a nominal target rate of $1.5 \mathrm{lb} / \mathrm{Macf}$. During the monthlong test, ACI was interrupted frequently for a bypass of the test FF to relieve $\Delta \mathrm{P}$ which appeared to increase during the monthlong test. Enhanced $\mathrm{AC}$ was injected for $58 \%$ of the available time (not accounting for plant outages), and the overall average mercury removal across FF 2-4 during this time was 74\%. This monthlong average removal is also included in Figure ES-1.

The BOP investigation centered around the increased $\triangle \mathrm{P}$ related to ACI and the selfheating of the high-carbon TOXECON ash that was observed. After a thorough investigation, it was determined that ACI at the monthlong injection rate added approximately $0.8-1.3$ inches of $\mathrm{H}_{2} \mathrm{O}$ to FF 2-4 $\Delta \mathrm{P}$ at a Unit 2 load of $600 \mathrm{MW}$. However, there was also a component of $\Delta \mathrm{P}$ that appeared to be gradually accumulating across FF 2-3 and FF 2-4, prior to and during field testing. Investigation of the plant data and bag samples indicates that this gradual increase in $\Delta \mathrm{P}$ over time was due to continual buildup of residual dust that was not cleaned off the bags. This gradual buildup of material on the bags appeared to accumulate at the same rate when compared to pretest and test periods, indicating that ACI had minimal impact on residual $\Delta \mathrm{P}$.

Another BOP issue that arose was the observed self-heating of the TOXECON ash-AC mixture which was caused primarily because of malfunctioning hopper heaters and level detectors. Further analysis of the plant data shows two of the eight hoppers were not being heated, which led to moisture intrusion and eventual plugging of both hoppers. The level detectors on these two hoppers failed to indicate abnormally high levels, allowing the hoppers to be filled with ash and enhanced AC that was injected during the test.

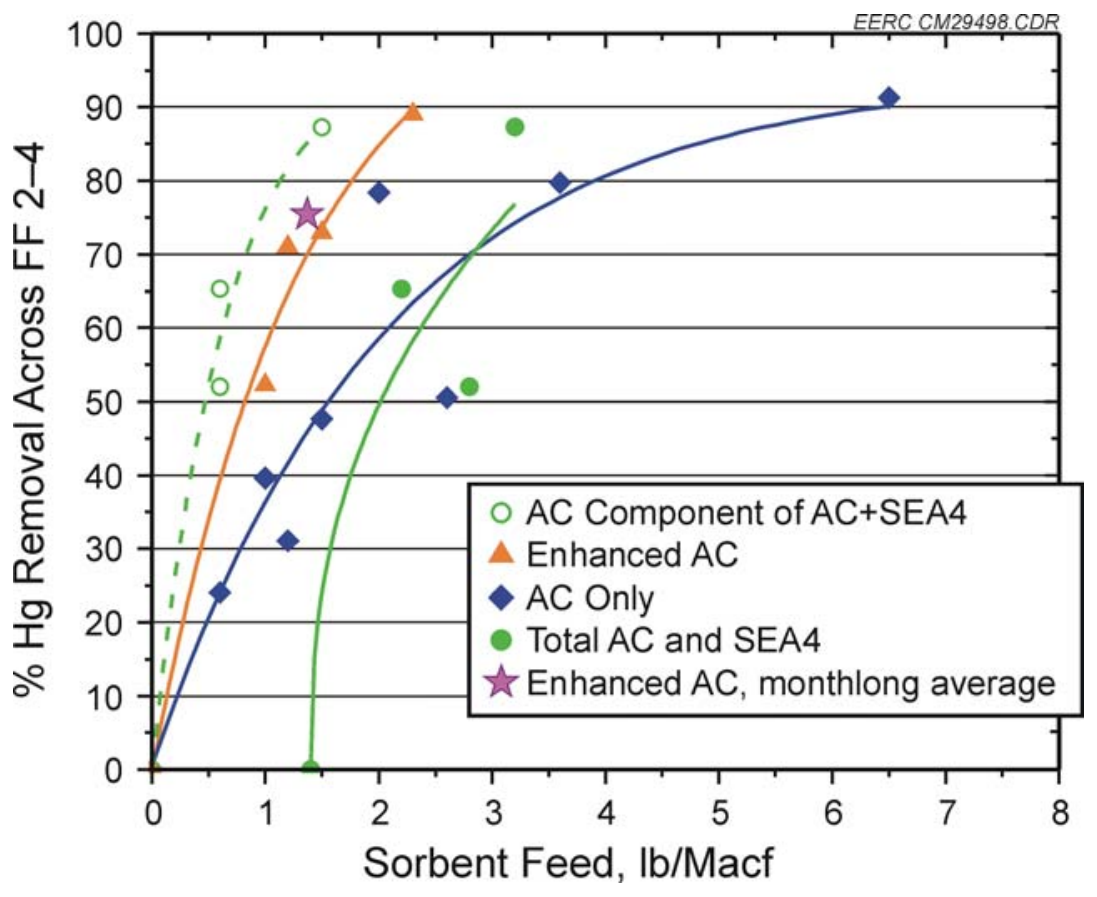

Figure ES-1. Comparison of observed Hg removals across FF 2-4 during the parametric tests with the 70-30 Texas lignite-PRB blend at Big Brown Unit 2. 
When these hoppers were opened for service, unusual deposits were found mixed with the loose ash, and the ash itself was reported to be very hot and smoldering. Analysis of the hopper deposits indicates high-temperature formation and, when pieced together with other evidence, suggests that the mixtures in both plugged hoppers generated significant temperatures because of self-heating of the AC in the ash. Further analyses suggested that higher proportions of AC in the ash, such as those typically found in TOXECON, may lead to self-heating problems, unless careful monitoring and more frequent hopper ash unloading is implemented. This is supported by the remaining six hoppers that were working properly, did not plug, and had no self-heating problems reported.

Samples of FF 2-4 ash from the monthlong test were evaluated for mercury stability under the following conditions: leaching with water, elevated-temperature thermal desorption, and microbiologically mediated release. All synthetic groundwater-leaching tests resulted in low leachate mercury concentrations which showed the mercury is stable under the test conditions. Thermal desorption tests indicated that the mercury was more stable in the samples with AC than in the baseline samples containing only fly ash. These results indicated that the mercury is not likely to be released unless the fly ash-activated carbon mixture is used in a high-temperature application. The microbiologically mediated release tests indicate the potential for mercury release in ash-AC-soil mixtures, but the amount of mercury released is low and is not expected to impact management options for the ash-AC mixture.

Preliminary economic analysis indicates that mercury removal for Big Brown in the configuration tested would be approximately $\$ 4000 / 1 b$ of mercury removed (assuming a $90 \%$ removal target with the enhanced $\mathrm{AC}$ option). However, as indicated by the monthlong testing, the COHPAC at Big Brown does not have the $\triangle \mathrm{P}$ margin to operate with continual ACI, so other strategies must be investigated. One option considered in the economic analysis was to increase the size of the COHPAC to achieve a lower operating $\mathrm{A} / \mathrm{C}$ ratio. Enlarging the $\mathrm{FF}$ to reduce the $\mathrm{A} / \mathrm{C}$ ratio to today's design values, approximately $6 \mathrm{ft} / \mathrm{min}$, is estimated to increase the mercury removal cost to approximately $\$ 7500 / \mathrm{lb}$ of mercury removed if all the costs, including $\mathrm{FF}$ expansion, were accounted for as mercury removal costs.

While the observed mercury removals were very encouraging and the economics for the as-tested scenario were attractive, sorbent injection in the TOXECON configuration at Big Brown does not appear to be a viable option because of $\Delta \mathrm{P}$ limits of the high $\mathrm{A} / \mathrm{C} \mathrm{FF}$. While the amount of added $\Delta \mathrm{P}$ from sorbent injection appears manageable, when combined with high $\mathrm{A} / \mathrm{C}$ operation $(12 \mathrm{ft} / \mathrm{min})$ and the continual increase of residual $\Delta \mathrm{P}$, there is little to no operating margin before encountering $\Delta \mathrm{P}$ limits, especially at high loads. This finding limits sustainable injection of $\mathrm{AC}$ without appropriate modifications to the plant or its operations. 


\section{FIELD TESTING OF ACTIVATED CARBON INJECTION OPTIONS FOR MERCURY CONTROL AT TXU'S BIG BROWN STATION}

\section{INTRODUCTION}

\section{Project Summary}

The primary objective of the project was to evaluate the long-term feasibility of using activated carbon injection (ACI) options to effectively reduce mercury emissions from Texas electric generation plants in which a blend of lignite and subbituminous coal is fired. Field testing of ACI options was performed on one-quarter of Unit 2 at TXU's Big Brown Steam Electric Station. Unit 2 has an output of $600 \mathrm{MW}$ and burns a blend of $70 \%$ Texas Gulf Coast lignite and 30\% subbituminous Powder River Basin (PRB) coals. Big Brown employs a COHPAC configuration, i.e., high air-to-cloth (A/C) baghouses following cold-side electrostatic precipitators (ESPs), for particulate control. When sorbent injection takes place between the ESP and the baghouse, the Electric Power Research Institute (EPRI)-patented technology is referred to as TOXECONTM in the United States. Key benefits of the TOXECON configuration include better mass transfer characteristics of a fabric filter (FF) compared to an ESP for mercury capture and contamination of only a small percentage of the fly ash with AC. The field testing consisted of a baseline sampling period, a parametric screening of three sorbent injection options, and a monthlong test with a single mercury control technology. Balance of plant (BOP) effects of the control technology were also examined, and the economics of the process were estimated. This project was funded under the U.S. Department of Energy (DOE) National Energy Technology Laboratory (NETL) project entitled "Large-Scale Mercury Control Technology Field Testing Program - Phase II."

\section{Background}

Mercury is an immediate concern for the U.S. electric power industry because of the U.S. Environmental Protection Agency's (EPA's) December 2000 decision that regulation of $\mathrm{Hg}$ from coal-fired electric utility steam-generating units is appropriate and necessary under Section 112 of the Clean Air Act. EPA determined that Hg emissions from power plants pose significant hazards to public health and must be reduced (1). The EPA Mercury Study Report to Congress (2) and the Utility Hazardous Air Pollutant Report to Congress (3) both identified coal-fired boilers as the largest single category of atmospheric $\mathrm{Hg}$ emissions in the United States, accounting for about onethird of the total anthropogenic emissions. In May 2005, EPA issued the Clean Air Mercury Rule (CAMR) which established nationwide requirements to significantly reduce mercury emissions from coal-fired power plants. These mandated reductions will clearly have a major impact on plants burning Texas lignite, as $\mathrm{Hg}$ emissions from these plants are possibly the most difficult to control because the emitted mercury is primarily in elemental form, and based on EPA's information collection request (ICR) data (4), these plants have the potential to emit the highest concentration of mercury. Recent field monitoring data also support this and further suggest that $\mathrm{Hg}$ emissions can be highly variable, thus presenting even more of a control challenge (5). Texas combusts over 40,000,000 tons of Gulf Coast lignite annually for electric generation to serve more than 5,000,000 businesses and homes. Texas currently uses more coal for electricity 
generation than any other state in the United States-25\% of the electricity produced is a result of combusting GC lignite.

Despite the fact that $\mathrm{Hg}$ regulations for coal-fired utilities have been promulgated, significant issues must be resolved. DOE NETL has acknowledged that data gaps exist for lignite and PRB subbituminous coals and blends, which represent almost $50 \%$ of the coal fired in the United States. In a presentation, DOE stated a need for additional field testing of $\mathrm{Hg}$ control technologies for low-rank coals (LRCs), specifically PRB subbituminous and Texas lignite coals $(6,7)$. EPA published a white paper and echoed a similar statement that "Development and demonstration of low-cost sorbents, impregnated sorbents, and innovative sorbents that are effective in controlling $\mathrm{Hg}$ emissions from subbituminous coal and lignite are needed and should continue" (8). These coals produce gases high in $\mathrm{Hg}^{0}$, which is most difficult to control (9-13). Field monitoring and pilot-scale data have proven this to be especially true for GC lignites (5). Questions still exist regarding the impact of various air pollution control devices (APCDs) and technologies for lignite-fired units. This project was funded to begin to fill these data gaps and obtain BOP and economic data that can be used by utilities as they develop their mercury control strategies.

\section{Lignite-Mercury Challenge}

In general, lignites are unique because of a highly variable ash content, ash rich in alkali and alkaline-earth elements, high moisture levels, and low $\mathrm{Cl}$ content. Compared to bituminous coals, lignite coals typically contain comparable or higher levels of $\mathrm{Hg}$, but significantly lower levels of $\mathrm{Cl}-\mathrm{Cl}$ concentrations often well below $200 \mathrm{ppm}$ - whereas bituminous coals often have $\mathrm{Cl}$ levels in excess of $1000 \mathrm{ppm}$. Lignite coals are also distinguished by much higher Ca contents. Texas lignite coal also exhibits relatively high Se concentrations.

These differences in composition have important effects on the form of $\mathrm{Hg}$ emitted from a boiler and on the capabilities of different control technologies to remove $\mathrm{Hg}$ from flue gas $(9,14$, 15). Coal containing $\mathrm{Cl}$ levels greater than $200 \mathrm{ppm}$ (Appalachian and Illinois Basin coals) produce $\mathrm{Hg}$ in flue gas dominated by more easily removable oxidized compounds $\left(\mathrm{Hg}^{2+}\right)$, most likely $\mathrm{HgCl}_{2}$. Conversely, experimental results indicate that flue gases generated from combustion of low-Cl $(<50 \mathrm{ppm})$ coal contain predominantly $\mathrm{Hg}^{0}$, which is substantially more difficult to remove than $\mathrm{Hg}^{2+}(3,12,13,16)$. The level of $\mathrm{Cl}$ in GC lignite tested at the EERC was on the order of 20 ppm on a dry basis. Additionally, the high Ca contents of lignite coals may reduce the oxidizing effect of the already-low $\mathrm{Cl}$ content by reactively scavenging $\mathrm{Cl}$ species $\left(\mathrm{Cl}, \mathrm{HCl}\right.$, and $\left.\mathrm{Cl}_{2}\right)$ from the combustion flue gas.

Lignite-fired power plants have shown a limited ability to control $\mathrm{Hg}$ emissions in currently installed ESPs and ESP-FF systems (4). As stated earlier, this low level of control can be attributed to the high variability and proportions of $\mathrm{Hg}^{0}$ and low levels of $\mathrm{Cl}$ present in the flue gas. Speciation of $\mathrm{Hg}$ in flue gases for lignites analyzed as part of the EPA ICR for $\mathrm{Hg}$ data showed that $\mathrm{Hg}^{0}$ concentration ranged from $56 \%$ to $96 \%$ and the $\mathrm{Hg}^{2+}$ ranged from $4 \%$ to $44 \%$. Typically, the form of $\mathrm{Hg}$ in pulverized and cyclone-fired units is dominated by $\mathrm{Hg}^{0}$, which can be greater than $85 \%$ of the total. Recent field and pilot-scale test data obtained by the Energy \& Environmental Research Center (EERC) show that combustion of GC lignite and 70\% lignite- $30 \%$ subbituminous 
blends results in $\mathrm{Hg}^{0}$ levels of $70 \%$ to $80 \%$. Furthermore, the relatively high total $\mathrm{Hg}$ content of lignites (on a Btu basis) and high degree of variability as seen in field monitoring data make $\mathrm{Hg}$ control even more difficult and costly compared to other coals.

\section{Project Participants}

This project was conducted by the EERC, an entity of the University of North Dakota. Support for this project was provided by DOE NETL through Cooperative Agreement No. DEFC26-05NT42305 and TXU Power. TXU also provided the test unit and related in-kind support. Other project contributors included ADA-ES, Inc.; the Babcock \& Wilcox Company; and EPRI. Special assistance was also provided by NORIT Americas and Acid Gas Solutions.

\section{Goals and Objectives}

The goal of this project was to evaluate the long-term feasibility of using ACI to effectively reduce mercury emissions from Texas electric generation plants in which a blend of lignite and subbituminous coals were fired.

The specific objectives of the project were to:

- Evaluate the feasibility of ACs, enhanced carbons, and additives as technologies for mercury removal when a Texas lignite blend is fired and a TOXECON (AC injection between an ESP and an FF) configuration is used.

- Achieve a mercury removal greater than 55\% above baseline over the long-term test.

- Evaluate BOP impacts when ACs are used.

- Collect data that will allow for a preliminary economic assessment of the commercial application of the tested technologies.

- Gather coal combustion by-products (CCBs) for later characterization.

\section{DESCRIPTION OF TEST UNIT AND SAMPLING LOCATIONS}

Testing was performed at TXU's Big Brown Steam Electric Station located in Freestone County, Texas, near Fairfield, Texas.

\section{Description of Big Brown}

Big Brown Station comprises two 600-MW units: Units 1 and 2. Summary details of the plant are provided below:

Plant capacity: $\quad$ Approximately 1200-MW total capacity with two 600-MW units

Test unit: $\quad$ Big Brown Unit 2, Side B, FF Module 2-4 
Boiler type:

Typical fuel:

$\mathrm{SO}_{2}$ control: $\quad$ None

$\mathrm{NO}_{\mathrm{x}}$ control: $\quad$ Low- $\mathrm{NO}_{\mathrm{x}}$ burners

Particulate control: COHPAC ${ }^{\mathrm{TM}}$ configuration. Each unit has four parallel ESPs followed by four $\mathrm{FF}$ modules operating at a nominal $\mathrm{A} / \mathrm{C}$ ratio of 12:1 and operated in parallel. Each ESP has two fields with four hoppers each for a total of eight hoppers; each FF module has eight compartments, each with its own hopper. Injection of $\mathrm{SO}_{3}$ and $\mathrm{NH}_{3}$ is used for ash conditioning; $\mathrm{SO}_{3}$ is injected prior to the air heater while $\mathrm{NH}_{3}$ is injected into the ESP. High-perm bags are used in the FFs.

\section{Particulate Control Devices at Big Brown}

Big Brown uses a COHPAC configuration for particulate control, which consists of a high A/C baghouse following cold-side ESPs. The ESPs have a specific collection area (SCA) of $156 \mathrm{ft}^{2} / \mathrm{kacfm}$ and are original to the plant but undersized for the boiler flows that they receive (17). Ash conditioning through injection of sulfur trioxide and ammonia is used to improve ESP particulate removal efficiency. The reported ESP removal efficiency is $98 \%$ (17) which was confirmed during the baseline measurements of this project. However, it was also observed during this project that the ESP efficiency is not static and is sensitive to plant operating conditions, primarily load and temperature.

In order to meet more stringent opacity requirements, COHPAC baghouses were added to Unit 2 in November 1995 and to Unit 1 in April 1996. Each unit's COHPAC baghouse consists of four parallel modules, and each module comprises eight compartments with each compartment having its own ash hopper. Compartments are taken off-line for cleaning and are cleaned with a rotating arm that pulses the bags with a nominal 12-psig burst of air. There are typically 312 bags per compartment, and each bag has approximately $25 \mathrm{ft}^{2}$ of surface area, so each module has approximately $54,600 \mathrm{ft}^{2}$ of net surface area, assuming one compartment is offline for cleaning. Bag-cleaning strategy at Big Brown changes with time and the condition of the bags; when the bags are new, cleaning frequency is controlled by maintaining a drag set point across each module. As the bags age and build up a residual drag, the cleaning frequency reaches its maximum value where it stays for the remainder of the bag's service life. When the maximum cleaning frequency cannot maintain an acceptable drag, a bypass valve is opened to relieve differential pressure. Each baghouse module is equipped with four bypass valves; however, only one of these valves is instrumented and used to maintain acceptable $\Delta \mathrm{P}$ values. The bypass allows a slipstream of flue gas to pass directly from the inlet duct to the outlet duct and not pass through the filters. 
It was decided before field testing to set the cleaning frequency to a continuous-cleaning setting in order to minimize the variable of bag cleaning on $\mathrm{Hg}$ capture. At the continuouscleaning frequency, all eight compartments of a module can be cleaned in approximately 18 minutes, and one compartment is always off-line.

The bags used in FF module 2-4 at Big Brown are made from a high-permeability felted fabric that uses fibers made from polyphenylene sulfide (PPS). PPS has excellent resistance to heat and acid corrosion. The bags were singed on the dust collection side, and they used a $100 \%$ polytetrafluorethylene (PTFE) felt bottom disc. They are oval in cross section and are supported by an internal wire cage. Their flat width is approximately 7.5 inches, and their overall length is approximately $20.3 \mathrm{ft}$.

The design $\mathrm{A} / \mathrm{C}$ ratio for the COHPAC at Big Brown is $15.5 \mathrm{ft} / \mathrm{min}$ (net-net) or $13.3 \mathrm{ft} / \mathrm{min}$ (net) which is rather high compared to current design practice for similar applications. Actual observed A/C ratios had a net value of $12 \mathrm{ft} / \mathrm{min}$ at $600-\mathrm{MW}$ load. Because of the high gas velocity and other problematic conditions, Big Brown has experienced continual problems with high baghouse differential pressures and short bag lives. The current operating conditions (e.g., high permeability bags, PPS bag material, cleaning air pressure, etc.) are the result of approximately 10 years of effort toward resolving these issues. Because of the marginal COHPAC design, field testing with sorbent injection was closely monitored by the EERC and the plant. A set of operating constraints were defined for sorbent testing, but the plant had overriding authority to shut down the injection systems in case of problems.

\section{Mercury Control Test Equipment}

Field testing included baseline sampling and parametric testing of three sorbent injection options: AC-only injection; an EERC sorbent enhancement additive (SEA), SEA4, both with and without AC; and an EERC-enhanced AC. The AC used was DARCO $\mathrm{Hg}^{\circledR}$ supplied by NORIT Americas Inc.; the SEA and enhanced AC treatment are proprietary technologies of the EERC.

Injection of $\mathrm{AC}$ and the enhanced $\mathrm{AC}$ was performed with the EERC's pneumatic conveying system manufactured by NORIT. The AC was stored in a 80,000-lb-capacity storage silo which was filled pneumatically using a suitable blower-tanker truck. The conveying system is integrated into the base of the silo and is made up of two parallel feeder trains. Each train dispenses carbon into an eductor using a volumetric screw feeder. Motive air to the eductor is provided by a centrifugal blower. The entire silo was mounted on load cells to measure the quantity of AC remaining.

Multipoint calibration of the ACI was completed on-site via measurement of weight versus time. Calibration verification took place after setup, after the parametric testing, and at the end of the long-term test. The calibration was within the specification of $\pm 15 \%$ for each of the verification measurements. The data collection system recorded the AC system feeder screw speed for the entire test period, along with the load signal from the plant. The AC feed rate in $\mathrm{lb} /$ Macf was calculated based on the feeder screw feed, calibration data correlating feeder screw speed to pounds of carbon per hour, and flue gas flow data. 
The ACI location was into the duct upstream of FF 2-4 but downstream of the split in the inlet ductwork for FF 2-3/2-4 and the FF inlet sampling location. The duct at the injection location is $16 \mathrm{ft} 4 \mathrm{in} . \times 12 \mathrm{ft} 11 \mathrm{in}$. Six ports were used to inject the carbon into the duct at up to 12 points using a $6 \times 2$ grid. Entrained AC from the silo was transported to the injection location with 2.5-inch-i.d. convey hose, and two 6-way line splitters were used to distribute the AC feed to the six ports.

The additive SEA4 used an independent dry injection system manufactured by Nol-Tec. The additive was in powdered form and arrived in bulk bags weighing approximately $1200 \mathrm{lb}$ each. The injection system used an integral bulk bag unloader to fill the feed hopper. The motive air for conveying the additive was dried using a dehumidifier and was pressurized using a positive displacement, roots-type blower. A 3-inch-i.d. hose was used to convey entrained additive to the injection location where a 6-way splitter was used to distribute the additive to each injection port on the inlet duct. Common ports were used for the injection of AC and SEA4, but each material had separate injection lances.

Metering of the SEA4 was achieved using a rotary valve with gravimetric feedback provided by a loss-in-weight hopper. Calibration of the SEA4 feed rate was completed on-site via measurements of known weights with the loss-in-weight scale. The calibration was verified two separate times on-site, once after setup and after parametric testing. The calibration verification was within the specification of $\pm 15 \%$ at each check. The SEA4 control panel was integrated with the data collection and control system to receive signals from the plant and allow the SEA4 injection rate to be set and controlled proportionally to the unit load in megawatts. The SEA4 injection rate was logged continuously using an output signal from the skid's controller. The SEA4 feed rate in lb/Macf was computed using the recorded injection rate, calibration data, and plant data of flue gas flow.

The enhanced ACI also used the NORIT conveying system to transport the carbon to the injection site. There is additional equipment associated with the enhanced $\mathrm{AC}$; however, the form, chemical makeup, and method of delivery of the AC enhancement system are proprietary. Appropriate calibration verification checks were performed consistent with the protocols of the other injection systems.

\section{Test and Sampling Locations}

A schematic of Unit 2, highlighting injection and sampling locations, is shown in Figure 1. As indicated in the figure, sorbent testing was performed on one-quarter of the unit flue gas, across one of the four FF modules, which is designated as Unit 2, FF Module 4 or FF 2-4. Mercury sampling with continuous mercury monitors (CMMs) was performed at the common inlet to Modules FF 2-3 and FF 2-4 and at the outlet of FF 2-4. Ontario Hydro (OH) sampling took place at ports adjacent to those used for the CMMs at the FF inlet and outlet. Limited OHmethod sampling was also performed at the inlet to the ESP. Samples of coal and FF 2-4 ash were also collected on a daily basis. 


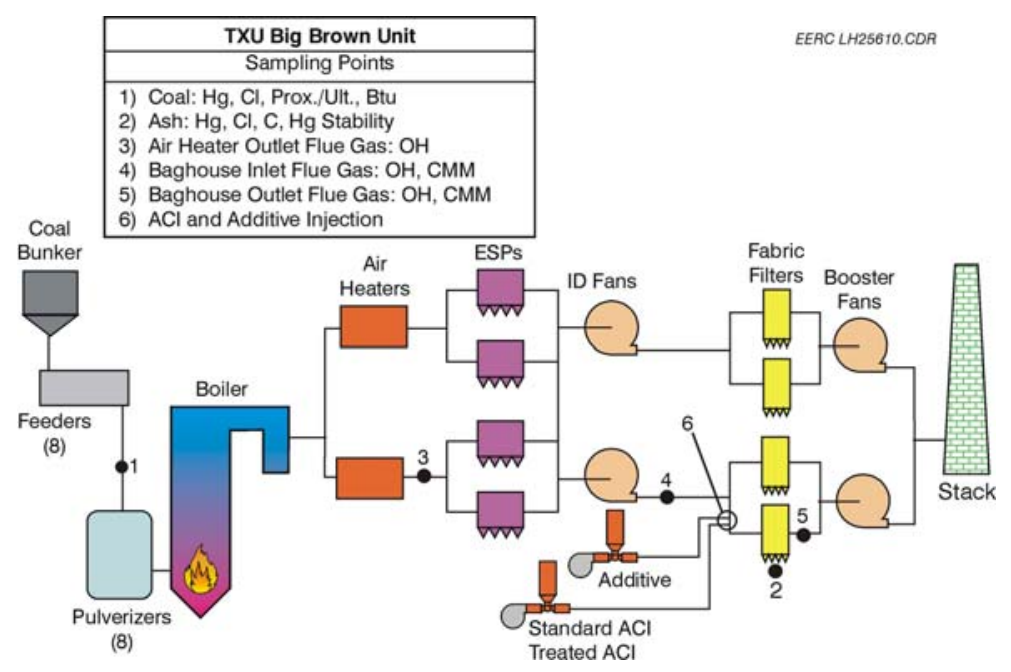

Figure 1. Schematic of Big Brown Unit 2 showing sampling and injection locations.

\section{TESTING SCHEDULE AND PROTOCOLS}

\section{Baseline, Parametric, and Monthlong Tests}

Field testing was carried out according to the approved test plan (18), with some minor exceptions. The time line of events is summarized in Table 1. The most significant discrepancy between the actual course of events and those outlined in the test plan was the addition of a week of parametric testing (February 13-20, 2006) to conduct makeup testing that was missed because of unscheduled plant outages.

To summarize the events of Table 1, field testing began with a baseline sampling period to determine the uncontrolled mercury emissions from Big Brown. Following baseline sampling, a series of parametric testing with the three sorbent injection options was conducted. During parametric testing, injection rates began low with a minimum injection target of $0.5 \mathrm{lb} / \mathrm{Macf}$ and were increased incrementally to determine mercury removal. Injection rates were determined for all of the options to achieve the minimum target of 55\% removal as well as for higher removals approaching 90\%.

Table 1. Time Line of Field Testing Events at Big Brown

\begin{tabular}{lc}
\hline Test Dates & Activities \\
\hline January 9-17, 2006 & Setup \\
January 18-20, 2006 & Baseline sampling \\
January 23-29, 2006 & Parametric testing: standard ACI \\
January 30-February 5, 2006 & Parametric testing: EERC SEA4 and ACI \\
February 6-12, 2006 & Parametric testing: EERC-enhanced ACI \\
February 13-20, 2006 & Makeup parametric tests \\
February 27- March 29, 2006 & Monthlong test with EERC-enhanced ACI \\
March 30 - April 8, 2006 & Testing with 100\% PRB coal \\
\hline
\end{tabular}


After completion of the parametric testing, the most attractive sorbent injection option was determined based on parametric $\mathrm{Hg}$ removals, a preliminary economic analysis of sorbent performance, and input from project team members. A monthlong test was then conducted to determine the long-term mercury capture and assess BOP effects of the technology. Table 1 indicates testing with $100 \%$ PRB fuel at the conclusion of the monthlong test with the 70 30 blend. The dates of this testing are mentioned because this testing has some bearing on the BOP investigation to be discussed. However, details and results from this testing are discussed and reported separately by Pavlish et al. (19).

\section{Sampling Methods}

CMMs were the primary source of data for evaluating $\mathrm{Hg}$ control across the unit. The EERC also used the $\mathrm{OH}$ method to monitor flue gas mercury concentrations. $\mathrm{OH}$ method samples were collected to provide validation of CMM data, speciation data where applicable, and limited data upstream of the ESP. The short-term duration of $\mathrm{OH}$ method sampling limits the use of the $\mathrm{OH}$ method data, so it was not used to evaluate mercury removal.

\section{CMMs}

The EERC assisted TXU personnel with the setup of two CMMs across FF 2-4: one at the FF inlet (upstream of the AC injection location) and the other at the FF outlet. These CMMs ran continuously except for minor interruptions for the duration of the project. The CMMs were used primarily to monitor total gas-phase mercury but had the additional ability to monitor $\mathrm{Hg}^{0}$.

Since the CMMs were used to generate the primary data for evaluation of the mercury control technologies and traversing was not feasible with the CMMs, placement of the probes was critical. The flow distribution in the ducts was characterized by acquiring a velocity, oxygen, and temperature profile $(12 \times 3$ points at the FF inlet and $9 \times 3$ at the FF outlet) across the ducts at the sampling locations. These data were documented and evaluated to place the $\mathrm{CMM}$ and $\mathrm{OH}$ method sampling probes in ports representative of the average velocity and temperature for each location.

The Horiba DM-6B, an atomic absorption-based $\mathrm{Hg}$ vapor analyzer, was used in conjunction with a wet-chemistry conversion scheme developed by the EERC and Horiba in conjunction with TXU personnel specifically for this project. The use of this wet system was necessary because of known interferences to the catalytic conversion of $\mathrm{Hg}$ present in the flue gas from the Texas lignite fuel burned at Big Brown Station. The modified conversion unit used the existing mechanical parts from the Horiba dry catalytic conversion system (without the catalyst) so that the unit was integrated with the analyzer as a complete instrument. The conversion unit used two separate liquid flow paths: one to continuously reduce $\mathrm{Hg}^{2+}$ to $\mathrm{Hg}^{0}$, resulting in a total gas-phase $\mathrm{Hg}$ sample, and the other to continuously scrub out $\mathrm{Hg}^{2+}$, resulting in an $\mathrm{Hg}^{0}$ sample. This conversion unit allowed the instrument to continuously monitor total $\mathrm{Hg}$

and $\mathrm{Hg}^{0}$ concentrations at each of the sample locations. The conversion unit also used a Peltier thermoelectric cooler module to cool and dry the sample gases prior to transport to the analyzer. The system was calibrated daily using $\mathrm{Hg}^{0}$ as the primary standard. $\mathrm{Hg}^{0}$ is contained in a closed vial which was held in a thermostatic bath. The temperature of the $\mathrm{Hg}^{0}$ was monitored and controlled so that the concentration of $\mathrm{Hg}^{0}$ was constant based upon vapor pressure calculations. 
Upon initial setup of the mercury-sampling systems, the leak rate was verified to be less than $2.0 \%$ of total sample flow rate. Calibration of the instrument was done at least weekly following the procedures described in the operator's manual. This involved setting the zero and span response of the instrument. Following instrument calibration, a zero and span calibration verification was performed and recorded. The zero of the sampling system was checked by sampling ambient air. The returned value was less than $5 \%$ of the span value. The span gas was supplied by a Nippon calibration gas generator (Model MG-1) and was adjusted to supply a mercury concentration roughly $50 \%$ higher than the concentration expected in the flue gas. The span of the mercury analyzers was checked at the instrument to verify accuracy of calibration to $\pm 5 \%$. The zero and span of the instrument was verified daily by applying the zero and span calibration gases at the instrument. If the span gas read within 5\%, no action was required. If the span was outside $5 \%$ and within $10 \%$ of value, the previous data were validated, but the instrument was recalibrated. If the span was outside $10 \%$ of value, the previous data were flagged as invalid, and the instrument was recalibrated. For filter and system integrity check, blank and span gas was sampled through the filter. This was done to identify possible biases in the system. If the blank (ambient) gas read within $5 \%$ of the span value (or $\pm 1 \mu \mathrm{g} / \mathrm{m}^{3}$, whichever is least restrictive) and the recovered span gas read within $15 \%$ of the span value, the recovery was noted in the log book and the CMM was put back into operation. If either the blank or span was out of range, the CMM conversion/conditioning unit, probe, heated line, and associated filters were checked and maintenance performed as necessary. The blank and span were then rechecked to verify proper operation.

All maintenance procedures and downtime were entered into a log book maintained for each instrument. Routine preventive maintenance was performed at each CMM installation in accordance with procedures developed at the EERC.

\section{OH Method}

The $\mathrm{OH}$ method was also used to periodically measure flue gas mercury concentrations. The $\mathrm{OH}$ method data were used to validate the CMM readings and provide mercury speciation data. Sampling occured simultaneously at the FF inlet and FF outlet. Additional measurements at the ESP inlet, when pertinent, were also performed concurrent with the FF sampling. Table 2 outlines the $\mathrm{OH}$ method sampling completed during the 70-30 blend testing. Three sets of $\mathrm{OH}$ measurements were performed during baseline conditions. OH measurements were also made during selected parametric tests, and three sets of three $\mathrm{OH}$ samples were taken throughout the monthlong test. Additional flue gas analysis results were determined as part of $\mathrm{OH}$ method testing, including oxygen, carbon dioxide, moisture, and dust load concentrations.

$\mathrm{OH}$ method samples were withdrawn from the flue gas stream isokinetically through a probe/filter system, maintained at the flue gas temperature, followed by a series of impinger solutions in an ice bath. Particle-bound mercury $\left(\mathrm{Hg}_{\mathrm{p}}\right)$ was collected on a quartz filter in the front half of the sampling train. $\mathrm{Hg}^{2+}$ was collected in impingers containing a chilled aqueous potassium chloride solution. $\mathrm{Hg}^{0}$ was collected in subsequent impingers (one impinger containing a chilled aqueous acidic solution of hydrogen peroxide and three impingers containing chilled aqueous acidic solutions of potassium permanganate). 
Table 2. OH Sampling Matrix for the 70-30 Texas Lignite-PRB Testing at Big Brown

\begin{tabular}{lccc}
\hline Condition & ESP Inlet & FF 2-3 and 2-4 Inlet & FF 2-4 Outlet \\
\hline Baseline & 3 & 3 & 3 \\
Parametric Testing & & 3 & 3 \\
Standard ACI & - & 2 & 2 \\
EERC SEA4 and ACI & - & 1 & 1 \\
EERC Enhanced ACI & - & & \\
Monthlong Test & - & 3 & 3 \\
Week 1 & - & 2 & 2 \\
Week 3 & - & 4 & 4 \\
Week 4 & & & \\
\hline
\end{tabular}

Samples were recovered and analyzed for mercury in the EERC mobile lab set up on-site. The $\mathrm{OH}$ method samples were typically prepared and analyzed the same day of collection or the following day. $\mathrm{Hg}$ was determined by cold-vapor atomic absorption spectroscopy (CVAAS) using a Leeman Labs Hydra AA automated $\mathrm{Hg}$ analyzer. Results were initially reported as $\mu \mathrm{g} / \mathrm{L}$ and then converted to $\mu \mathrm{g} / \mathrm{dNm}^{3}$.

The instrument used in the field for mercury determination was a Leeman Hydra AA. The instrument was set up for absorption at $253.7 \mathrm{~nm}$, with a carrier gas of nitrogen and $10 \%$ stannous chloride in $10 \% \mathrm{HCl}$ as the reductant. Each day the tubing was checked and the rinse container was cleaned and filled with fresh solution of $10 \% \mathrm{HCl}$. After the pump and lamp were turned on and warmed up for 45 minutes, the aperture was set to manufacturer specifications. A four-point calibration curve was then completed. The detector response for a given standard was logged and compared to specifications to ensure the instrument had been properly set up. A quality control (QC) standard of a known analyte concentration was analyzed immediately after the instrument was standardized in order to verify the calibration. This QC standard was prepared from a different stock than the calibration standards. It was required that the values obtained read within $5 \%$ of the true value before the instrument was used for sample analysis. After the initial QC standardization was completed, a check standard was run every ten samples to check the slope of the calibration curve. This check fell within $\pm 10 \%$ of the current calibration curve or recalibration was required. One in every ten samples was run in triplicate and spiked to verify analyte recovery. Triplicate results fell within $10 \%$ of the average, and spiked samples were within $\pm 15 \%$ of the true value or recalibration was required. A QC chart has also maintained at the EERC to monitor the long-term precision of the instrument.

All data sheets, volumetric flasks, and petri dishes used for sample recovery were marked with preprinted labels to ensure proper cross-referencing. The liquid samples were recovered into premarked volumetric flasks, logged, and then analyzed on-site. The filter samples were placed in premarked petri dishes or suitable sample containers and then taken back to the EERC, where they were analyzed. The labels contained identifying data including date, time, run number, sample port location, and project identifier.

All glass volumetric flasks and transfer pipets used in the preparation of analytical reagents and calibration standards were designated as Class " $\mathrm{A}$ " to meet federal specifications. Prior to being used for sampling, all glassware was washed with soapy water, rinsed with deionized (DI) 
water three times, soaked in $10 \% \mathrm{~V} / \mathrm{v}$ nitric acid for a minimum of 4 hours, rinsed an additional three times with DI water, and dried. The glassware was stored in closed containers until it was used at the plant.

All acids used for the analysis of mercury were trace metal grade. Other chemicals used in the preparation of analytical reagents were analytical reagent grade. The calibration standards used for instrument calibration and the QC standards used for calibration verification were purchased commercially and certified to be accurate within $\pm 0.5 \%$ and traceable to the National Institute of Standards and Technology (NIST) standard reference materials.

As part of quality assurance (QA)/QC, a field blank was associated with sampling at each location for each test condition. A field blank is defined as a complete impinger train, including all glassware and solutions that are taken to the field during sampling and exposed to ambient conditions. These sample trains were then taken apart and the solutions recovered and analyzed in the same manner as those sample trains used for sampling activities. Field blanks are used to identify contamination. For this project, all field blank samples were at or below the detection limits of the instrument, thus no effort to reduce contamination was required.

Also as part of QA/QC, a field spike was associated with each $\mathrm{OH}$ test day. A field spike was prepared by the field manager at a level similar to the field samples. These sample trains were taken apart and the solution recovered and analyzed in the same manner as those sample trains used for sampling activities. The target range, as per the method, for recovery of the field spike is $\pm 20 \%$. All field spike recoveries were within the target range.

\section{Coal and Ash}

Coal samples were collected from the available six out of eight feeders and combined into a daily composite by EERC personnel. To obtain a representative sample of the coal feed, 1-quart samples from each of the available feeders were combined and mixed in a 2-gallon sample. Selected daily coal samples were taken to the EERC for analysis. The coal samples were analyzed for $\mathrm{Hg}, \mathrm{Cl}$, proximate, ultimate, and Btu analyses using standard ASTM International (ASTM) or EPA methods.

Proximate and ultimate analyses were conducted on the composite coal samples using ASTM Methods D3172, D5142, and D3176. A Mitsubishi Model TOX-100 total chlorine analyzer was used to perform ASTM Method D6721-01 (Standard Test Method for Determination of Chlorine in Coal by Oxidative Hydrolysis Microcoulometry). Coal $\mathrm{Hg}$ contents were determined using CVAAS according to EPA Method 245.1 and EPA SW-846 Method 7470. A limited number of coals were analyzed using wavelength-dispersive x-ray fluorescence (WDXRF) spectrometry to determine elemental oxide composition as described in ASTM Method D4326.

EERC personnel collected ash samples from the hoppers of the FF when representative of continuous test conditions. A 1-quart representative split of each of the ash samples was stored in a glass jar and archived for the duration of the project. Additionally, two sets of three FF ash samples were collected according to DOE requirements: one set during baseline sampling and the other set during the monthlong evaluation. 
The particle-bound $\mathrm{Hg}$ in the hopper ash samples was determined using EPA Method 7473 (Mercury in Solids and Solutions by Thermal Decomposition Amalgamation and Atomic Absorption Spectrophotometry). $\mathrm{Hg}$ concentrations were reported as $\mu \mathrm{g} / \mathrm{g}$ on a dry basis. Additionally, a limited number of samples were analyzed for $\mathrm{Cl}$ and $\mathrm{C}$ using standard ASTM or EPA methods at the EERC.

Bottom ash was not sampled since it was assumed to contain a negligible amount of mercury. Big Brown employs a pyrite trap which rejects a small portion of the coal feed. Prior on-site sampling by the EERC (20) on Unit 1 revealed that the mercury content of this pyrite stream was negligibly small in comparison to the overall unit mercury balance and was, therefore, not sampled during this testing.

\section{Data Reduction and Reporting}

The EERC was responsible for all data collection, reduction, and reporting. Data reduction occurred in two separate phases. The first phase involved on-site calculations to validate data and generate preliminary results. On-site data reduction was performed by sampling and analytical personnel and by team leaders. Preliminary calculations included velocity, moisture, stack gas flow, sample gas volume, percent isokinetic sampling, and flue gas mercury concentrations. Calculations were generally performed using spreadsheets on portable computers; some averaging was typically done with a calculator. Standardized spreadsheets were used on this program. Evaluation of the results took place on-site to direct ongoing testing. This was critical during the parametric testing phase, but was also carried out during the monthlong test to maintain the target mercury removal.

The second phase of data reduction occurred after field testing was complete. This included review of the field data entry and input of laboratory results to complete the calculated mercury concentrations for the coal and ash samples. In addition, the mercury speciation calculations that were done in the field were rechecked and put into a predefined data sheet. Equations used in the calculations are contained in the method. The field data along with results from analyses of coal and ash were reviewed and verified before final calculations for reporting purposes were completed.

All data, data entry, and calculations were double-checked by the originator. Reviews included recalculation of results, data entry checks, and calculation of known and accepted data sets using the existing spreadsheet. Data sheets were kept in the custody of the originator, the program manager, or in locked storage until return to the office. The original data sheets were used for report preparation, and any additions were initialed and dated.

\section{PROJECT RESULTS}

\section{Discussion of Test Coal}

The coal burned during this project was the typical fuel used at Big Brown which is a blend of $70 \%$ Texas GC lignite and 30\% PRB. At the conclusion of the monthlong test, the plant did switch to $100 \%$ PRB fuel. The switch to $100 \%$ PRB was part of a separate but related 
project, and those results are discussed in a separate report (19). However, the change in fuels does impact the BOP investigation, and those aspects are mentioned in this report.

\section{Coal Characteristics}

The typical coal burned by Big Brown is nominally described as a $70 \%-30 \%$ blend of Texas GC lignite and a subbituminous PRB coal, respectively. The Texas lignite is mined locally at the Big Brown strip mine, while the PRB typically comes from the Rawhide or Buckskin Mines in northeastern Wyoming. Both coals are delivered to the crusher with coal haulers, and it is the ratio of lignite versus PRB coal hauler loads that determines the overall fuel blend. Mixing of the coal blend is not explicitly controlled; it inherently occurs as a result of the downstream crushing and handling processes.

Averages of the 70-30 Texas lignite-PRB coal blend analyses are presented in Table 3; unless otherwise noted, the averages are based on the analysis of 31 daily samples from the period January 18, 2006, to March 28, 2006. A noteworthy observation from Table 3 is the relatively low average chlorine content of the coal blend, only $20 \mathrm{ppm}$. More reactive coals such as eastern bituminous can have chlorine values in excess of $1000 \mathrm{ppm}$. The low reactivity of the 70-30 blend results in the generation of high proportions of elemental mercury which is more difficult to capture and typically requires an oxidation mechanism to aid removal.

Table 3. Average Coal Values for the Nominal 70-30 Texas Lignite-PRB Blend at Big Brown Unit 2. All values are averages of 31 samples unless otherwise noted

\begin{tabular}{lcccc}
\hline & \multicolumn{2}{c}{ As-Received Basis } & \multicolumn{2}{c}{ Moisture-Free Basis } \\
Parameter & Average & Std. Dev. & Average & Std. Dev. \\
\hline $\mathrm{Hg}, \mathrm{ppm}$ & 0.158 & 0.025 & 0.232 & 0.036 \\
$\mathrm{Se}, \mathrm{ppm}^{\mathrm{a}}$ & 2.46 & 0.40 & 3.61 & 0.58 \\
$\mathrm{Cl}, \mathrm{ppm}^{\mathrm{b}}$ & 14 & 4 & 20 & 6 \\
\hline Proximate Analysis, wt $\%$ & & & & \\
Moisture & 31.66 & 0.62 & $\mathrm{n} / \mathrm{a}$ & $\mathrm{n} / \mathrm{a}$ \\
Volatile Matter & 29.19 & 1.03 & 42.72 & 1.55 \\
Fixed Carbon & 28.47 & 1.10 & 41.66 & 1.69 \\
Ash & 10.67 & 1.52 & 15.61 & 2.15 \\
\hline Ultimate Analysis, wt $\%$ & & & & \\
Hydrogen & 6.71 & 0.13 & 4.68 & 0.17 \\
Carbon & 41.45 & 1.11 & 60.65 & 1.66 \\
Nitrogen & 0.92 & 0.09 & 1.35 & 0.12 \\
Sulfur & 0.77 & 0.12 & 1.13 & 0.18 \\
Oxygen & 39.47 & 1.13 & 16.57 & 1.27 \\
Heating Value, Btu/lb & 7194 & 271 & 10,529 & 410 \\
\hline
\end{tabular}

${ }^{a}$ Based on 12 measurements.

${ }^{\mathrm{b}}$ Based on eight measurements. 
Coal inorganic composition was determined using WDXRF analysis on baseline samples of the ashed coal, ESP ash, and FF ash. The results are presented in Table 4 on the basis of assumed oxide forms. The closure for the coal sample is quite good; however, because of the presence of carbonates in the ESP and FF ash samples, their closures are less than $100 \%$ using the assumed oxide forms. Inspection of the quantities of $\mathrm{SO}_{3}$ also indicate that some $\mathrm{SO}_{2}$ may be captured across the FF where it could form additional, unidentified compounds. Additionally, some of the $\mathrm{SO}_{3}$ reported in the FF ash may be due to $\mathrm{SO}_{3}$ slip across the ESP from the ashconditioning injection.

\section{Mercury in Coal}

Coal mercury content was determined for all samples submitted for analysis, and the summary mercury content was presented in Table 3. Estimates of mercury concentration levels on a flue gas basis and a heating value basis have been prepared using the Fd factor method of flue gas volume calculation and the measured heating value, respectively. These values are summarized in Table 5.

Figure 2 is a plot of the daily coal mercury values for the 70-30 blend during the time of field testing. Values measured by the EERC and TXU-measured data for Unit 2 coal feed are shown. Agreement between the two is fair, but the TXU data indicate a larger range in mercury values than the EERC values do. Some natural variation in the coal feeds is present; however, significant short-term changes in coal mercury could be attributed to the approximate fuel

Table 4. Baseline Oxide Compositions (WDXRF analysis) of the 70-30 Blend Coal, ESP Ash, and FF Ash

\begin{tabular}{lccc}
\hline Oxide & $\begin{array}{c}\text { Ashed Coal, } \\
\%\end{array}$ & $\begin{array}{c}\text { ESP Ash } \\
\text { Row 1, } \%\end{array}$ & $\begin{array}{c}\text { FF Ash, } \\
\%\end{array}$ \\
\hline $\mathrm{SiO}_{2}$ & 45.2 & 46.4 & 42.6 \\
$\mathrm{Al}_{2} \mathrm{O}_{3}$ & 14.4 & 17.0 & 17.7 \\
$\mathrm{Fe}_{2} \mathrm{O}_{3}$ & 3.32 & 5.30 & 6.05 \\
$\mathrm{TiO}_{2}$ & 1.03 & 1.13 & 1.17 \\
$\mathrm{P}_{2} \mathrm{O}_{5}$ & 0.19 & 0.19 & 0.34 \\
$\mathrm{CaO}$ & 17.9 & 14.9 & 14.7 \\
$\mathrm{MgO}$ & 3.26 & 2.65 & 2.76 \\
$\mathrm{Na}$ & 0.79 & 0.77 & 0.63 \\
$\mathrm{~K}_{2} \mathrm{O}$ & 0.56 & 0.89 & 0.88 \\
$\mathrm{SO}$ & 12.70 & 1.49 & 7.53 \\
$\mathrm{BaO}$ & 0.23 & 0.24 & 0.27 \\
$\mathrm{SrO}$ & 0.34 & 0.30 & 0.30 \\
Unknowns & 0.08 & 8.73 & 5.17 \\
\hline
\end{tabular}


Table 5. Flue Gas Hg Concentration Estimates Based on the Average Values for All 70-30 Blend Coal Analyses

\begin{tabular}{lcc}
\hline Parameter & Average $^{\mathrm{a}}$ & Std. Dev. \\
\hline $\mathrm{Hg}, \mathrm{ppm}$ (in coal, dry basis) & 0.232 & 0.036 \\
$\mathrm{Fd}$, dscf $/ 10^{6} \mathrm{Btu}$ & 9817 & 275 \\
Heating Value, Btu/lb (dry basis) & 10,529 & 410 \\
\hline $\mathrm{Hg}$ Concentration Estimates & & \\
\hline$\mu \mathrm{dgNm}{ }^{3}, 3 \% \mathrm{O}_{2}$ & 30.81 & 4.73 \\
$\mathrm{lb} \mathrm{Hg} / \mathrm{TBtu}$ & 22.01 & 3.29 \\
\hline
\end{tabular}

${ }^{a}$ Average values are based on 31 samples.

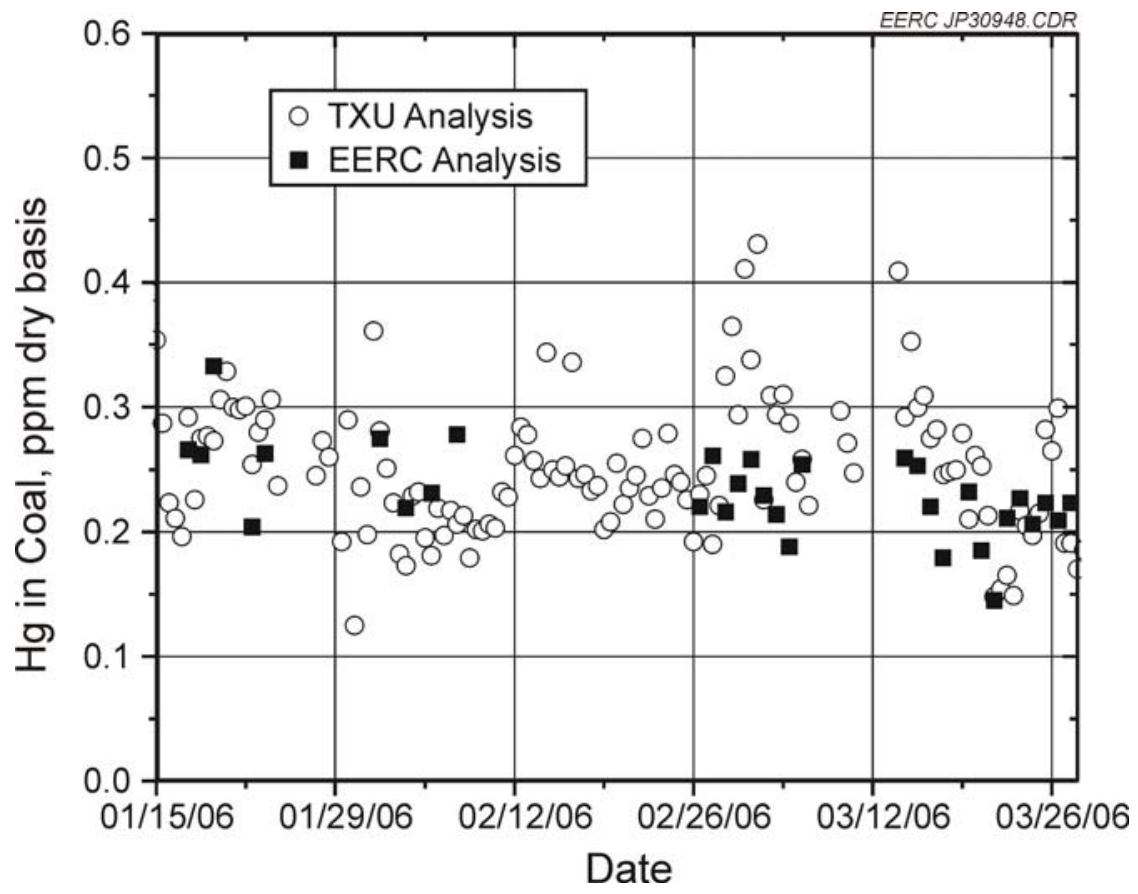

Figure 2. Comparison of Unit 2 coal mercury values for the 70-30 Texas lignite-PRB blended fuel.

blending methods mentioned previously and the different sampling schedule. The EERC data appear to indicate a slight decrease in coal mercury values during the time of testing. Since the switch to $100 \%$ PRB fuel occurred immediately at the conclusion of the test period shown in Figure 2, the data may have captured a premature increase in the proportion of PRB in the blend.

\section{Baseline Mercury Results}

Baseline sampling occurred prior to parametric testing and any sorbent injection and consisted of continuous $\mathrm{CMM}$ monitoring and three sets of simultaneous $\mathrm{OH}$ method measurements at the ESP inlet, the FF 2-4 inlet, and the FF 2-4 outlet. A comparison of the coal- 
derived $\mathrm{Hg}$ concentration in the flue gas (using the baseline coal samples) and the average CMM and $\mathrm{OH}$ method values are presented in Figure 3.

The data of Figure 3 indicate fair agreement with the coal-derived estimate of flue gas mercury concentration and the FF inlet $\mathrm{OH}$ method value, indicating little native $\mathrm{Hg}$ removal as bottom ash or across the ESP. The FF inlet CMM average appears to be biased low relative to the $\mathrm{OH}$ method value and the outlet $\mathrm{CMM}$ average. The outlet $\mathrm{OH}$ method and $\mathrm{CMM}$ data are again in fair agreement considering the variation observed with the $\mathrm{OH}$ method data. $\mathrm{FF}$ inlet $\mathrm{OH}$ method data compared to FF outlet data indicate little native removal, less than $10 \%$ across theFF. The speciation data provided by the $\mathrm{OH}$ method measurements indicate a majority of the mercury was elemental (62\%) at the FF inlet and elemental (49\%) at the FF outlet.

The overall baseline mercury mass balance is presented in Figure 4. The mercury balance across Unit 2 was computed based on the inlet coal mercury values, the ESP ash mercury content, CMM flue gas concentration measurements at the outlet of FF 2-4, and the mercury content of the FF ash. Further details regarding the mercury mass balance are provided in Appendix A.

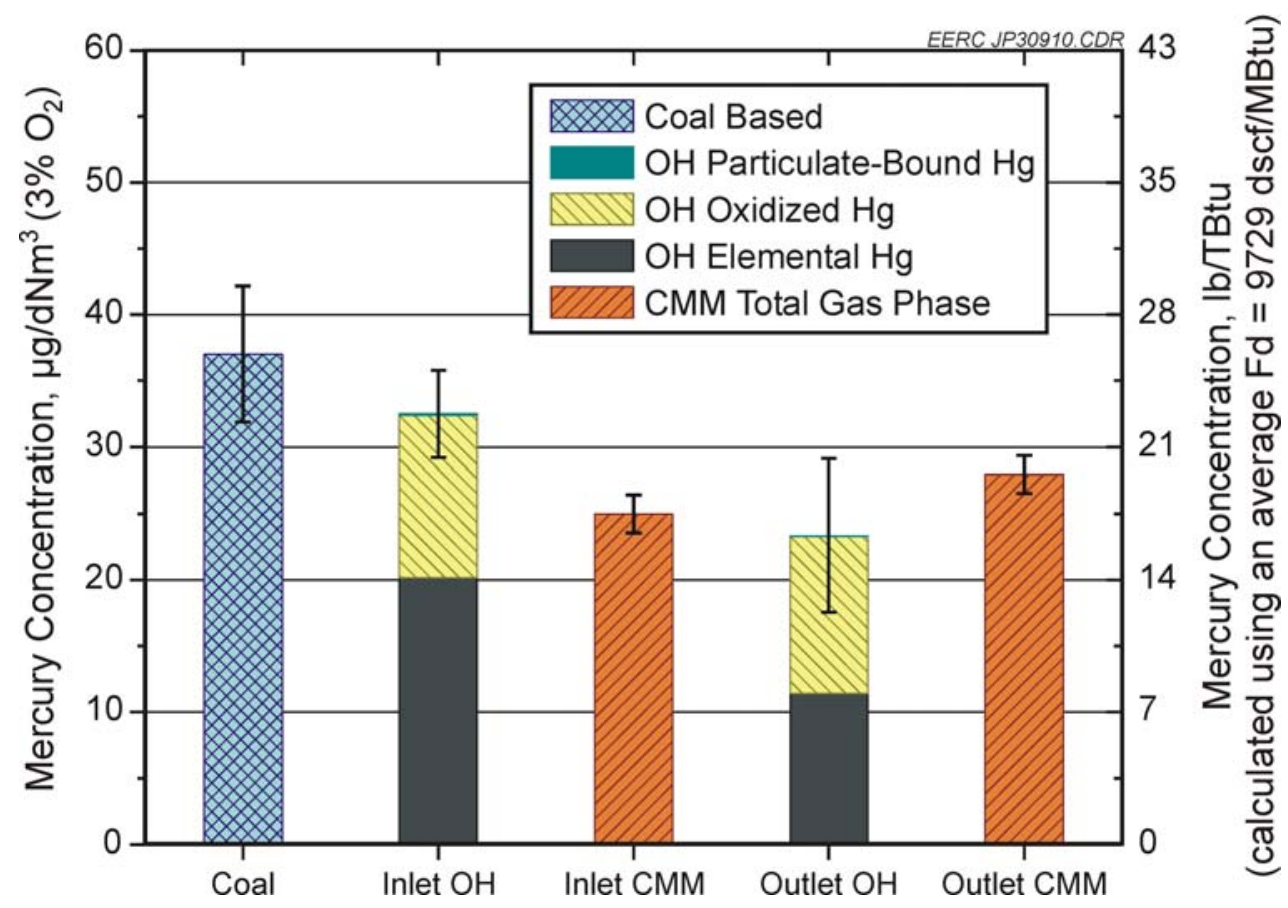

Figure 3. Averaged baseline Hg concentration data across FF 2-4 for January 18, 19, and 20 with the 70-30 Texas lignite-PRB blend at Big Brown Unit 2. 


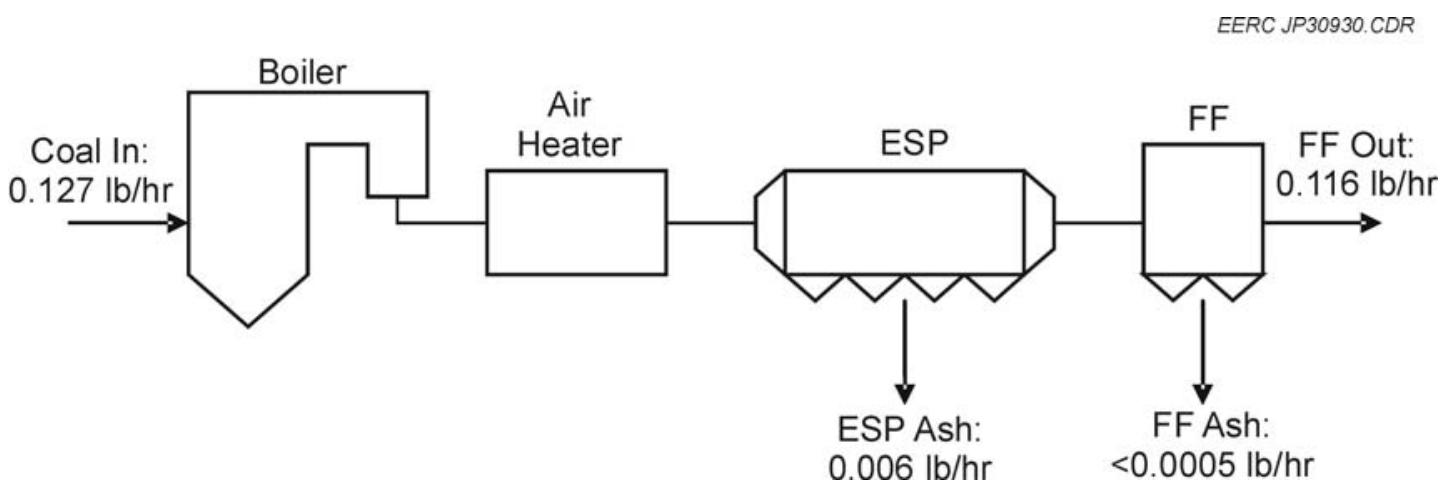

Figure 4. Baseline mercury mass balance across Unit 2, based on measurements across FF 2-4.

The baseline mercury balance has a closure of $96 \%$, indicating a sufficient accounting of the mercury throughout the plant. The balance indicates that approximately $5 \%$ of the inlet mercury in the coal is captured and removed with the ESP, and while the mercury content of the baseline FF ash was similar to the ESP ash, very little mercury was removed in that stream because of the much lighter dust load into the COHPAC. As shown in Figure 4, most mercury that entered in the coal was emitted to the stack.

The measured dust loading during baseline conditions at the ESP inlet averaged $5.1 \mathrm{gr} / \mathrm{dscf}$ (at $3 \% \mathrm{O}_{2}$ ), while it was $0.12 \mathrm{gr} / \mathrm{dscf}\left(\right.$ at $3 \% \mathrm{O}_{2}$ ) at the $\mathrm{FF}$ inlet. This results in an average ESP efficiency of $98 \%$ which is in agreement with other reported efficiencies for Big Brown's precipitators.

\section{Parametric Test Results}

Parametric testing was conducted after the baseline sampling to determine the sorbent injection rates necessary to achieve the targeted removal of greater than $55 \%$ above baseline. Each parametric test was conducted long enough for the FF outlet CMM to reach an apparent steady state, typically for durations of 0.5 to 4 hours. During a limited number of parametric tests, simultaneous $\mathrm{OH}$ measurements were made to again provide speciation data and verify CMM readings.

\section{Plant Test Conditions}

Efforts were made to only perform parametric testing under comparable conditions; however, transients in plant operation (e.g., significant changes in load) during testing could not be controlled, and some of this variability is reflected in the parametric results. Before testing began, a set of criteria were established in the QA/QC plan that defined valid plant test conditions. The operations checklist included the following:

- Unit load must be greater than $80 \%$ of full load. 
- CMMs must be verified and operational.

- FF 2-4 operating parameters must be within acceptable ranges; i.e., a flange-to-flange differential pressure of less than 10 inches $\mathrm{H}_{2} \mathrm{O}$ and the bypass must be closed.

While most of the testing was done at the stated criteria, because of some of the difficulties encountered at Big Brown, exceptions were made in some cases to the above criteria and are noted in the remainder of this report.

\section{Standard ACI}

Parametric testing began with injection of standard AC (DARCO Hg) provided by NORIT Americas Inc. Table 6 presents a summary of results with the AC testing.

For selected tests, an $\mathrm{OH}$ method measurement was also performed to provide speciation data with the control technology; these results are presented in Figure 5. For the $1.2 \mathrm{lb} / \mathrm{Macf}$ result in Figure 5, the change in speciation across the FF with the control technology is not significant. For the other two AC feed rates, however, the speciation change is shifted significantly toward oxidized mercury at the FF outlet, but there is also a significant portion of particulate-bound mercury, indicating that some $\mathrm{AC}$ may have migrated through the $\mathrm{FF}$ and collected on the $\mathrm{OH}$ method sample filter. Unfortunately, $\mathrm{AC}$ on the $\mathrm{OH}$ method sample filter will bias the measured speciation by oxidizing mercury before it is captured in the impinger train. This invalidates any outlet speciation information from the 2.0- and 3.6-lb/Macf injection rates in Figure 5.

Table 6. Summary of Parametric Test Results with Standard ACI (DARCO Hg)

\begin{tabular}{lcccc}
\hline $\begin{array}{l}\text { AC Rate, } \\
\text { lb/Macf }\end{array}$ & $\begin{array}{c}\text { FF 2-4 Inlet } \\
\mathrm{Hg} \mathrm{CMM},\end{array}$ & $\begin{array}{c}\text { FF 2-4 Outlet } \\
\mathrm{Hg} \text { CMM, }\end{array}$ & $\begin{array}{c}\text { FF 2-4 } \\
\text { Hemoval, } \%\end{array}$ & $\begin{array}{c}\text { FF 2-4 Outlet } \\
\text { Emissions, } \\
\text { lb/TBtu }\end{array}$ \\
\hline 0.6 & $26.9^{\mathrm{a}}$ & 20.4 & 24 & 12.5 \\
1.0 & $32.3^{\mathrm{a}}$ & 19.5 & 40 & 12.0 \\
1.0 & 27.5 & 16.6 & 40 & 10.2 \\
1.2 & 25.5 & 17.6 & 31 & 10.8 \\
1.5 & 33.1 & 17.3 & 48 & 10.6 \\
2.0 & 25.6 & 5.53 & 78 & 3.39 \\
2.6 & 28.5 & 14.1 & 50 & 8.64 \\
3.6 & 32.6 & 6.61 & 80 & 4.05 \\
6.5 & 20.4 & 1.78 & 91 & 1.09 \\
\hline a For these cases, the inlet CMM values are either unavailable or unable to be confirmed so the average outlet \\
CMM value prior to testing has been substituted and used to compute removal.
\end{tabular}




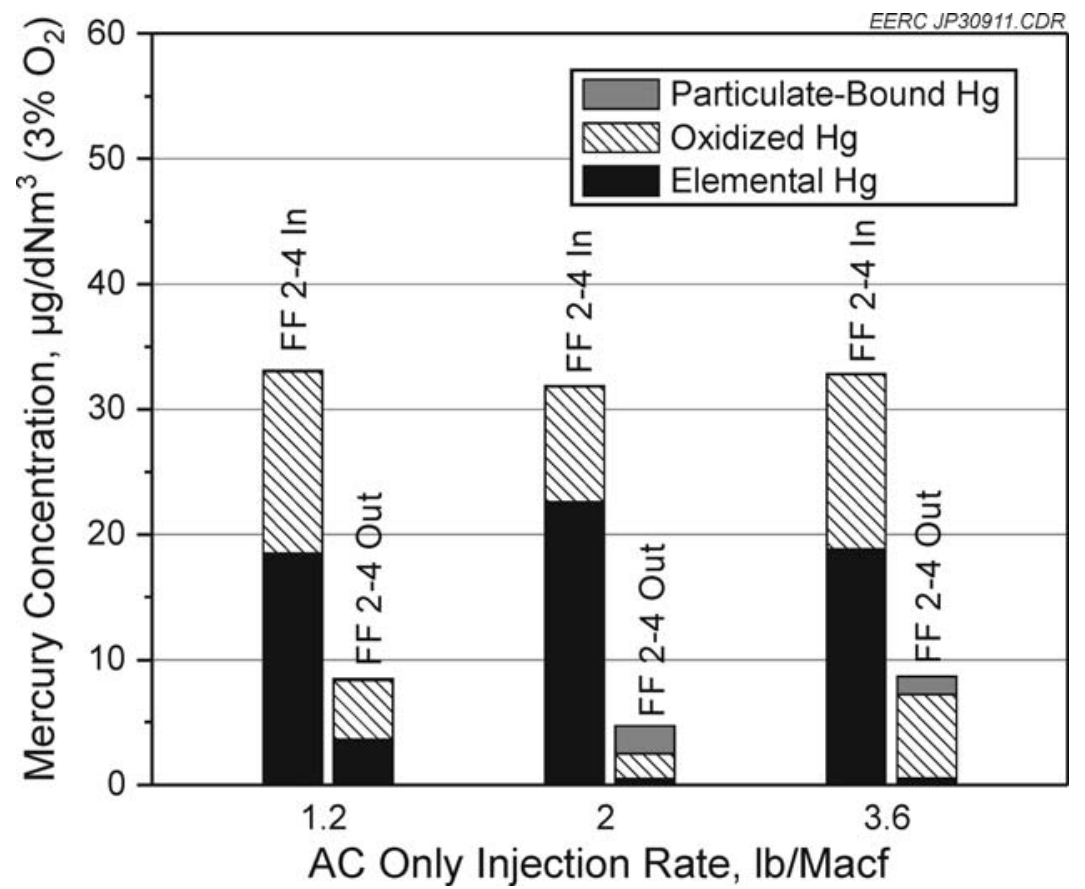

Figure 5. Summary of $\mathrm{OH}$ method test results from the parametric testing with $\mathrm{AC}$ only.

\section{Enhanced ACI}

An enhanced AC was tested at Big Brown to test the hypothesis that its enhanced reactivity would compensate for the relatively low reactivity of the 70-30 blend flue gas and improve overall mercury capture. The enhanced carbon was produced from DARCO Hg by the EERC using a proprietary process. Results from the enhanced ACI testing are summarized in Table 7.

An $\mathrm{OH}$ method measurement was also performed during one of the enhanced $\mathrm{ACI}$ parametric tests, and the results are presented in Figure 6. Based on the high amount of particulate-bound $\mathrm{Hg}$ at the outlet, it appears that some $\mathrm{AC}$ may have been caught on the $\mathrm{OH}$

Table 7. Summary of Parametric Testing Results with the Enhanced AC

\begin{tabular}{|c|c|c|c|c|}
\hline Enhanced & FF 2-4 Inlet & FF 2-4 Outlet & & FF 2-4 \\
\hline $\begin{array}{l}\text { AC Rate, } \\
\text { lb/Macf }\end{array}$ & $\begin{array}{c}\mathrm{Hg} \text { CMM, } \\
\mu \mathrm{g} / \mathrm{dNm}^{3}, 3 \% \\
\mathrm{O}_{2}\end{array}$ & $\begin{array}{c}\mathrm{Hg} \text { CMM, } \\
\mu \mathrm{g} / \mathrm{dNm}^{3}, 3 \% \\
\mathrm{O}_{2}\end{array}$ & $\begin{array}{l}\text { FF 2-4 } \\
\text { Removal, } \\
\%\end{array}$ & $\begin{array}{c}\text { Outlet } \\
\text { Emissions, } \\
\text { lb/TBtu }\end{array}$ \\
\hline 1.0 & 22.5 & 10.7 & 52 & 6.59 \\
\hline 1.2 & 28.9 & 8.37 & 71 & 5.13 \\
\hline $1.5^{\mathrm{a}}$ & $30.6^{\mathrm{b}}$ & 8.28 & 73 & 5.08 \\
\hline $2.3^{\mathrm{a}}$ & $30.6^{\mathrm{b}}$ & 3.35 & 89 & 2.06 \\
\hline
\end{tabular}




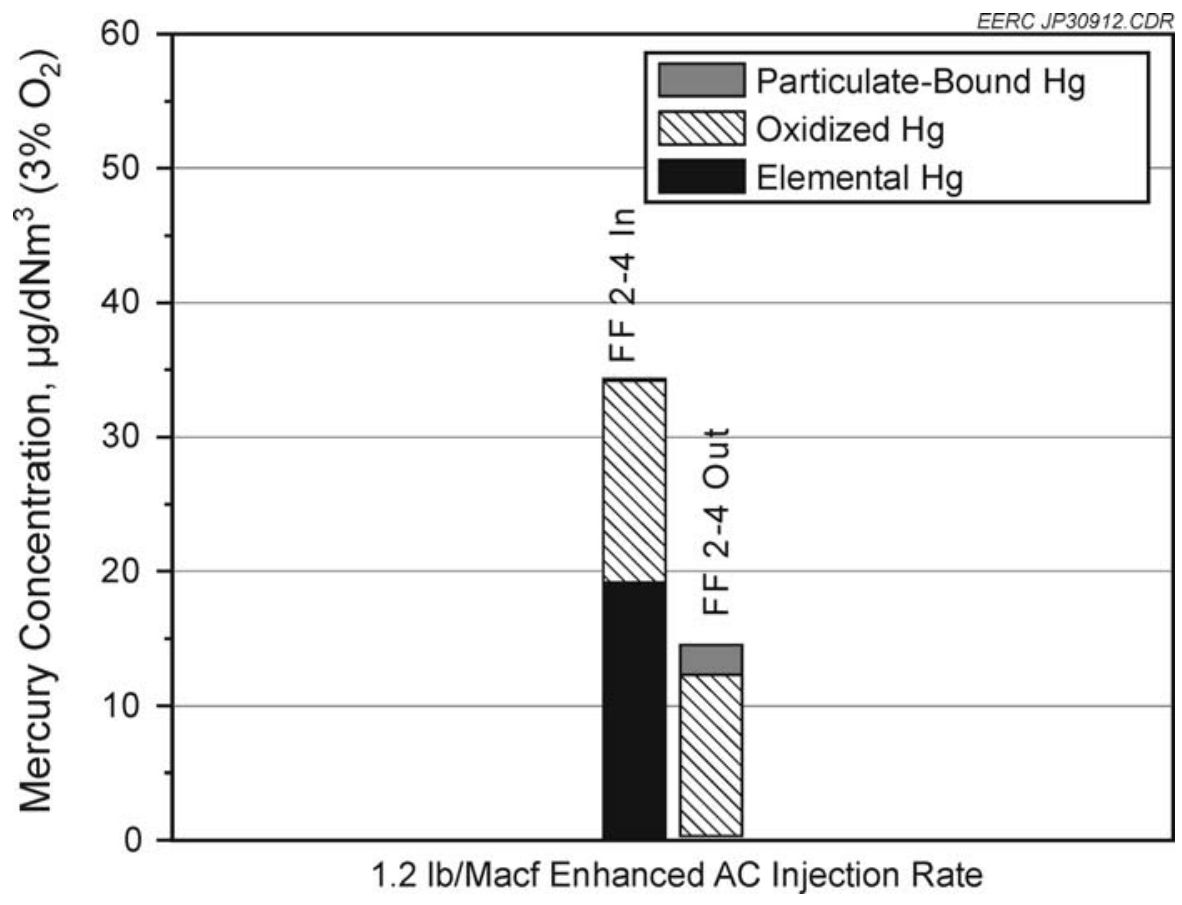

Figure 6. Summary of $\mathrm{OH}$ method test results from the parametric testing with enhanced AC.

method sample filter and, as with the AC-only testing, caused a bias in the outlet speciation. Therefore, the outlet speciation values are probably not indicative of the actual flue gas speciation.

\section{ACI with Proprietary Additive}

The final control technology tested at Big Brown was a combination of standard ACI (using DARCO Hg) and injection of an EERC SEA (designated SEA4 by the EERC). SEA4 is a low-cost additive which improves mercury capture with $\mathrm{AC}$ and is intended to improve the economics of mercury control using sorbent injection. It is an EERC proprietary technology. Results for ACI with SEA4 are presented in Table 8.

Table 8. Summary of Parametric Testing Results with ACI and SEA4

\begin{tabular}{|c|c|c|c|c|}
\hline $\begin{array}{l}\text { AC/SEA4 } \\
\text { Rate, } \\
\text { lb/Macf }\end{array}$ & $\begin{array}{c}\text { FF 2-4 Inlet } \\
\mathrm{Hg} \mathrm{CMM}, \\
\mu \mathrm{g} / \mathrm{dNm}^{3}, 3 \% \mathrm{O}_{2}\end{array}$ & $\begin{array}{c}\text { FF 2-4 Outlet } \\
\text { Hg CMM, } \\
\mu \mathrm{g} / \mathrm{dNm}^{3}, 3 \% \mathrm{O}_{2}\end{array}$ & $\begin{array}{c}\text { FF 2-4 } \\
\text { Removal, \% }\end{array}$ & $\begin{array}{c}\text { FF 2-4 Outlet } \\
\text { Emissions, } \\
\text { lb/TBtu }\end{array}$ \\
\hline $0.0 / 1.4$ & $17.6^{\mathrm{a}}$ & 17.8 & 0 & 10.9 \\
\hline $0.6 / 1.6$ & 23.3 & 8.10 & 65 & 4.97 \\
\hline $0.6 / 2.2$ & 21.2 & $10.1^{\mathrm{b}}$ & 52 & 6.17 \\
\hline $1.5 / 1.7$ & 30.7 & 3.90 & 87 & 2.39 \\
\hline
\end{tabular}


The $\mathrm{OH}$ method measurements during AC/SEA4 testing are shown in Figure 7. While there is some particulate-bound $\mathrm{Hg}$ present in both the outlet measurements, which could indicate $\mathrm{AC}$ on the $\mathrm{OH}$ sample filter, there does not appear to be a bias toward oxidized $\mathrm{Hg}$, and there is little change in speciation from inlet to outlet for both measurements. With the injection rates of $0.6 / 1.6 \mathrm{lb} / \mathrm{Macf} \mathrm{AC} / \mathrm{SEA} 4$, the oxidized $\mathrm{Hg}$ speciation is $29 \%$ at the inlet and $36 \%$ at the outlet. For the $06 . / 2.2 \mathrm{lb} / \mathrm{Macf}$ rates, the oxidized $\mathrm{Hg}$ portion is $40 \%$ and $51 \%$ at the inlet and outlet, respectively.

\section{Comparative Results}

A summary of the parametric test results is provided in the graph of $\mathrm{Hg}$ removals versus injection, shown in Figure 8. From the figure, the AC-only results indicate a removal trend which rises rapidly to approximately $70 \%$ capture with $3 \mathrm{lb} / \mathrm{Macf}$ and then tapers to maximum captures of approximately $90 \%$ with high injection rates ( $>6 \mathrm{lb} / \mathrm{Macf}$ ). Results with enhanced AC produce a much steeper curve, with captures reaching $70 \%$ at injection rates between 1.0 and $1.5 \mathrm{lb} /$ Macf. Based on the collected data, it appears that $90 \%$ capture could be achieved with an enhanced ACI rate of approximately $2.5 \mathrm{lb} /$ Macf.

AC and SEA4 removal data are presented two ways in Figure 8: the first is as a function of only the AC component of the total injection, and the second is by plotting removal against the total (AC plus SEA4) sorbent injection. The rationale behind the two presentations is that SEA4

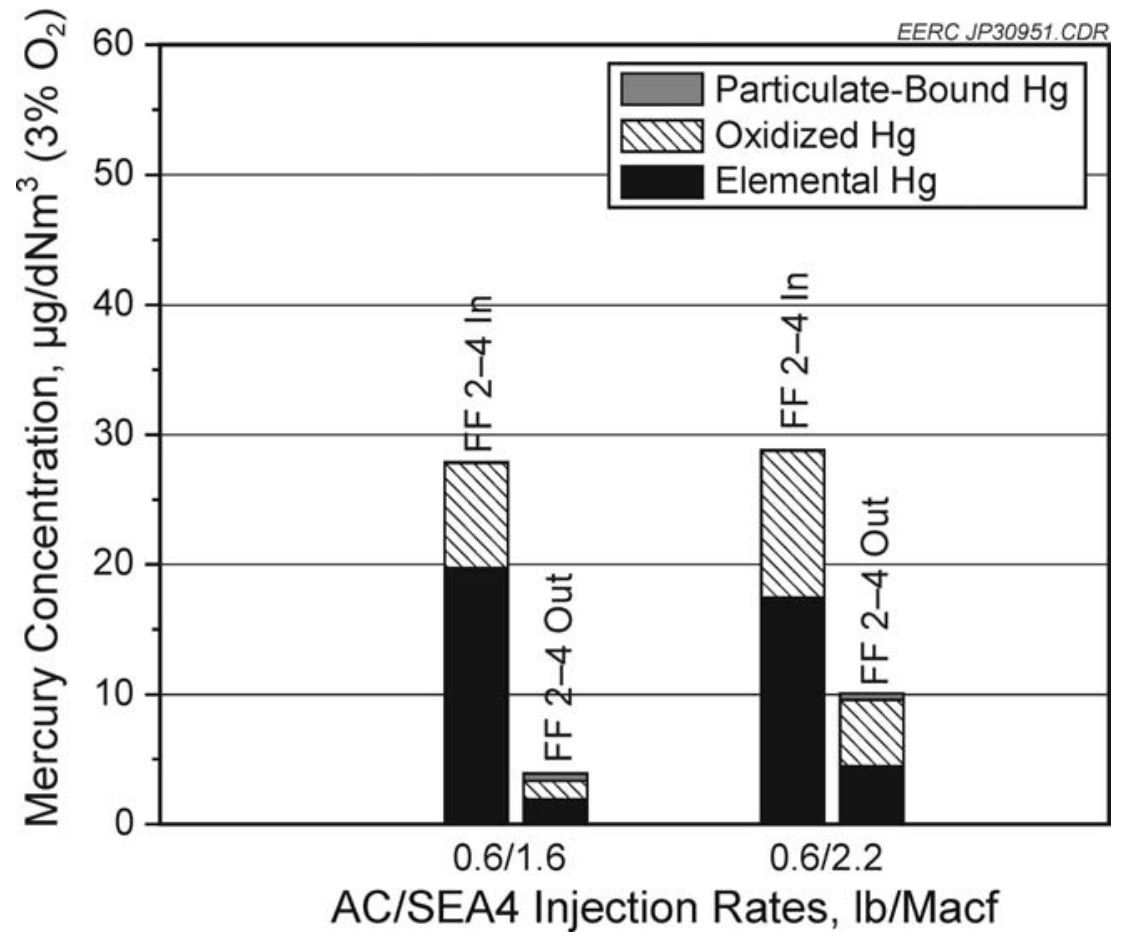

Figure 7. Summary of $\mathrm{OH}$ method test results from the parametric testing with the additive SEA4 and $\mathrm{AC}$. 


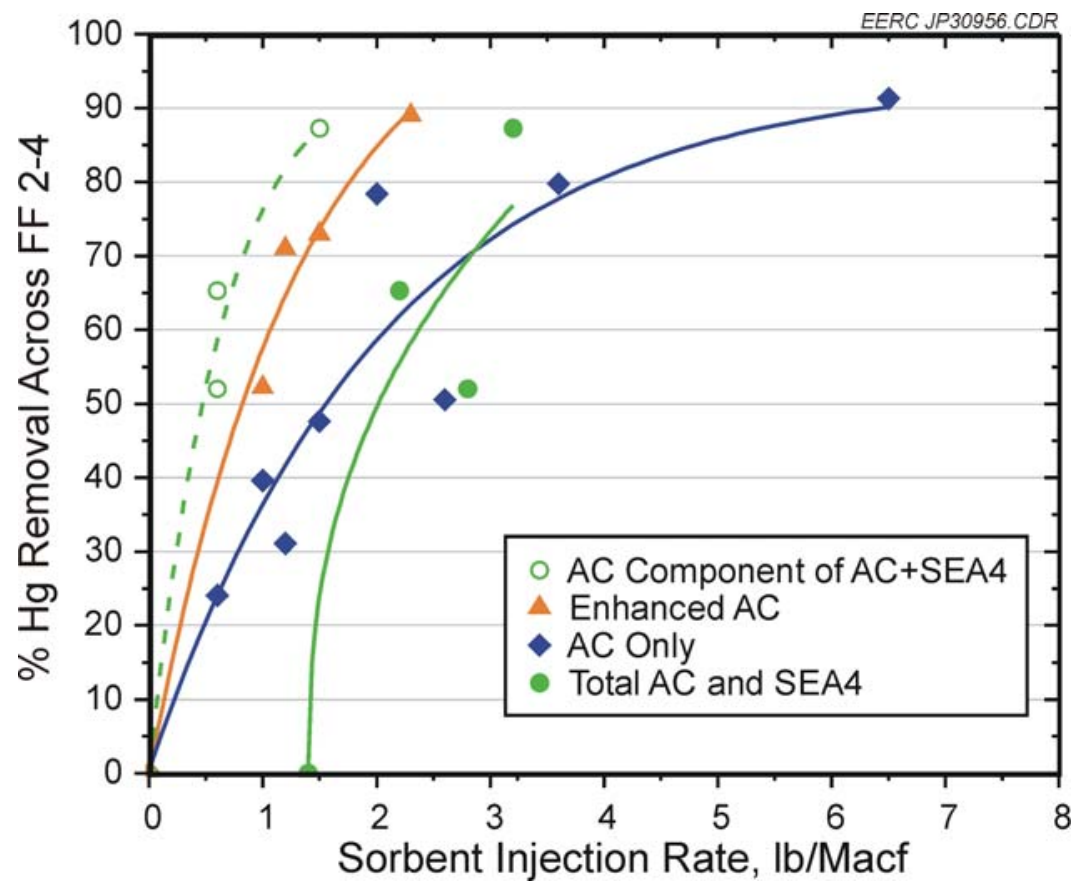

Figure 8. Comparison of observed $\mathrm{Hg}$ removals across FF 2-4 during the parametric tests with the 70-30 Texas lignite-PRB blend at Big Brown Unit 2.

is a low-cost additive (estimated to be an order of magnitude cheaper than standard AC) that can be injected with $\mathrm{AC}$ to enhance $\mathrm{Hg}$ removal in comparison to $\mathrm{AC}$ alone. However, at Big Brown, the total amount of injected material (regardless of cost) is more important since that directly affects $\Delta \mathrm{P}$ across the $\mathrm{FF}$, which is the limiting factor for sustainable injection.

Short-term effects of sorbent injection on FF 2-4 $\Delta \mathrm{P}$ were also monitored during parametric testing. These tests indicated that a maximum injection of about $2 \mathrm{lb} / \mathrm{Macf}$ of sorbent could be injected with no immediate effect on FF 2-4 $\Delta \mathrm{P}$. Tests with injection rates much higher than this caused a significantly increased $\Delta \mathrm{P}$ and were intentionally short in duration to avoid exceeding $\Delta \mathrm{P}$ limits.

\section{Monthlong Test Results with Enhanced ACI}

\section{Test Conditions}

After parametric testing at Big Brown, a monthlong test with a single mercury control technology at a constant targeted injection rate was conducted to obtain data regarding long-term mercury control performance and balance of plant (BOP) effects. The control technology selected for the monthlong test was the enhanced ACI because results of parametric testing indicated that it provided the best balance between key factors, including mercury removal, preliminary economics, and minimizing BOP effects. 
Mercury removal with the enhanced AC was shown during the parametric study to be very good compared to the standard AC and comparable to the AC-SEA4 combination, but with much lower total injection rates. The lower injection rate for the enhanced AC had two major benefits: first, it made the option appear more attractive on a cost-per-pound-of-mercuryremoved basis since the sorbent consumption costs are typically the largest contributor to sorbent-based mercury control systems (21) and, secondly, it minimized the amount of added particulate loading into FF 2-4 which is an important concern and limitation since under normal operating conditions, the baghouse operates at a high nominal A/C ratio of $12 \mathrm{ft} / \mathrm{min}$.

The nominal injection rate of the enhanced $\mathrm{AC}$ was chosen to be $1.5 \mathrm{lb} / \mathrm{Macf}$ since this rate indicated good mercury removal, $>70 \%$, during the parametric screening and, during the shortterm tests, did not have an appreciable effect on FF 2-4 $\Delta \mathrm{P}$. The injection system was set up to load-follow based on a load signal provided by the plant. Also, the plant supplied a trip signal which was used to suspend sorbent injection if it became necessary to open a bypass damper on FF 2-4 to relieve differential pressure.

The monthlong test commenced in the afternoon of February 27, 2006, and was considered complete at midnight on March 28, 2006. The test was interrupted during an unscheduled, 6-day outage of Unit 2 and when injections were suspended as a result of FF 2-4 bypass opening.

\section{Monthlong Mercury Results}

As with the parametric testing, CMMs were used to continuously record mercury concentrations at the inlet and outlet of FF 2-4, while $\mathrm{OH}$ method measurements were conducted to provide speciation data and verify CMM readings. Mercury-sampling conditions at Big Brown were difficult in comparison to other plants with different coal types. Difficulty in obtaining good agreement between $\mathrm{Hg}$ measurements (CMM and $\mathrm{OH}$ method) was experienced before with pilot-scale testing (22) of the 70-30 blend and previous on-site sampling at Big Brown (20). The difficulty is believed to be caused by the high selenium content of the Texas lignite, which can condense out of the gas phase on sampling probes, lines, and equipment, causing selective and unpredictable adsorption of mercury. Short-term CMM-OH method comparisons, e.g., during the 2-hour $\mathrm{OH}$ method test window, typically had greater variability than has been experienced at other plants. Averages of multiple measurements for longer time periods (normally three $\mathrm{OH}$ method measurements over 3 days) provided more consistent and less variable data. These multiple-day averages of the monthlong readings are provided in Figure 9. The only significant disagreement in Figure 9 is between the inlet $\mathrm{OH}$ method and CMM values for the March 16-17, 2006, sampling. While not a definitive reason for the difference, the anomaly is that the inlet CMM was off-line for a significant period on March 16, approximately 14 hours.

As Figure 9 shows, the monthlong $\mathrm{OH}$ measurements at the outlet of FF 2-4 are significantly biased toward oxidized and particulate-bound mercury. This is consistent with observations from the $\mathrm{OH}$ sampling performed during the parametric testing and is believed to be caused by AC penetrating the high-perm filters in FF 2-4 and collecting on the sample filter used during $\mathrm{OH}$ sampling. This carbon could capture relatively significant quantities of mercury from 


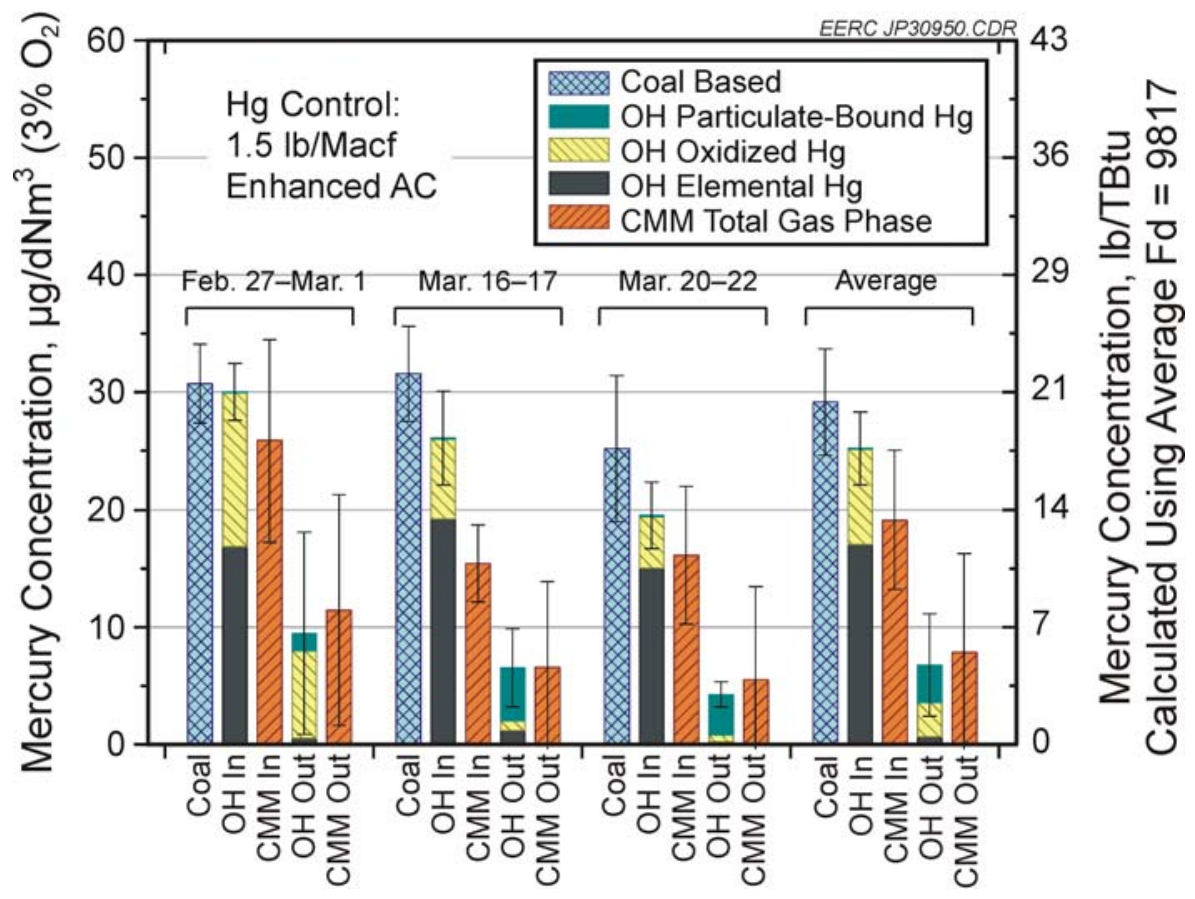

Figure 9. Comparison of coal-based, $\mathrm{OH}$ method, and $\mathrm{CMM} \mathrm{Hg}$ concentrations for the sampling during the monthlong test.

the flue gas sample and, therefore, bias the amount of particulate-bound mercury. It could also serve as a catalytic site for mercury oxidation. Because of this perceived bias, the speciation data for monthlong $\mathrm{OH}$ measurements at the FF 2-4 outlet is not considered to be reliable. Additional supporting evidence for particulates, specifically AC, breaking through the filters of FF 2-4 is discussed in the section "FF Outlet Particulate Emissions."

The monthlong test was conducted over the period of February 27 to March 28, 2006. A 6-day outage occurred roughly from March 8 to 14, so there were approximately 23 days, or 561 hours, of available test time; however, not all of this time was utilized for testing since ACI was frequently interrupted for FF 2-4 bypass opening. Of the available 561 hours, enhanced AC was injected for 324 hours, or $58 \%$ of the available time.

To better evaluate test data, the CMM data set was edited to remove periods when the control technology was idle (e.g., during a bypass opening). The overall average $\mathrm{Hg}$ values from the complete and modified data sets are presented in Table 9. It should be noted that the first column in Table 9 shows data averages for the entire month (excluding the 6-day plant outage), whereas the second column shows averages only when enhanced AC was being injected. As shown in Table 9, the overall monthlong average $\mathrm{Hg}$ removal was $64 \%$ for the complete data set and $74 \%$ for the times when enhanced $\mathrm{AC}$ was injected, both of which exceed the minimum targeted value of $55 \%$ above baseline removal. 
Table 9. Summary Figures for the Monthlong Testing with the 70-30 Texas Lignite-PRB Blend and a Targeted Enhanced ACI Rate of $1.5 \mathrm{lb} / \mathrm{Macf}$

\begin{tabular}{lcc}
\hline & $\begin{array}{c}\text { Complete } \\
\text { Monthlong Data }\end{array}$ & $\begin{array}{c}\text { Monthlong Data with } \\
\text { Active ACI Only }\end{array}$ \\
\hline Average FF 2-4 Hg Inlet, $\mu \mathrm{g} / \mathrm{dNm}^{3}, 3 \% \mathrm{O}_{2}$ & 19 & 18 \\
Average FF 2-4 Hg Outlet, $\mu \mathrm{g} / \mathrm{dNm}^{3}, 3 \% \mathrm{O}_{2}$ & 9.2 & 5.2 \\
Average Hg Removal Across FF 2-4, \% & 64 & 74 \\
Average Coal-Based Inlet $\mathrm{Hg}, \mu \mathrm{g} / \mathrm{dNm}^{3}, 3 \% \mathrm{O}_{2}$ & 31 & 31 \\
Average Coal In to FF 2-4 Out Hg Removal, \% & 70 & 83 \\
Average FF 2-4 Outlet Hg Emissions, lb/TBtu & 5.7 & 3.2 \\
\hline
\end{tabular}

${ }^{a}$ Does not include plant outage time.

${ }^{\mathrm{b}}$ Computed with the average Fd factor for all of the monthlong coal samples, $9817 \mathrm{dscf} / 10^{6} \mathrm{Btu}$.

With enhanced ACI, the monthlong mercury mass balance changes significantly from the baseline condition. The balance, shown in Figure 10, was calculated in the same manner as the baseline balance of Figure 4, and supporting information is provided in Appendix A. The key change is the sizable stream of particulate-bound $\mathrm{Hg}$ leaving with the FF ash. The closure of the monthlong mass balance was $72 \%$, which indicates a slight incomplete accounting of the outlet mercury. Significant variability was observed in the FF ash $\mathrm{Hg}$ content, and it is believed that this contributed to the low mass balance closure.

The FF ash was sampled throughout the monthlong test; the composition, based on a WDXRF analysis, is reported using standard reporting conventions in Table 10 along with the baseline coal and ESP ash analyses (repeated from Table 4). There are no significant changes to the FF ash when compared to the baseline measurements (Table 4); however, the unknown fraction is higher because of the addition of $\mathrm{AC}$ which is not detected by this method. The carbon content of the FF ash was tracked by performing $\mathrm{CHN}$ analyses of the ash samples. The baseline sample carbon content was $0.30 \%$ (two samples), while the average carbon content was $7.93 \%$ (19 samples) for the monthlong samples. Hydrogen and nitrogen contents were insignificant for all samples.

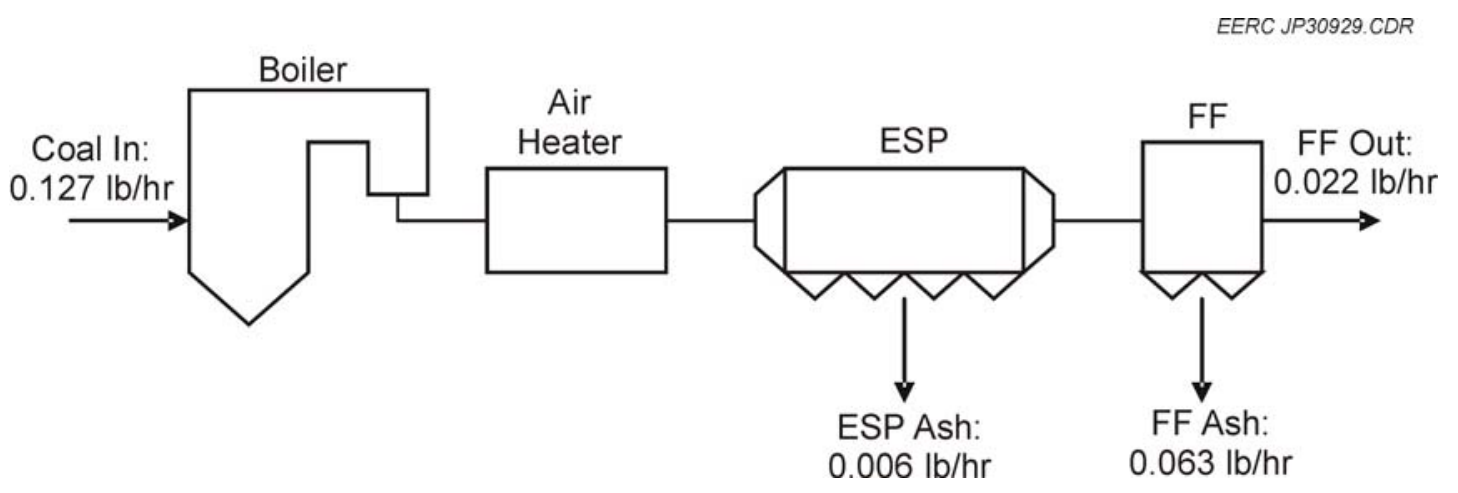

Figure 10. Mercury mass balance across Unit 2 during the monthlong test, based on measurements from the B side ESPs and FF 2-4. 


\begin{tabular}{|c|c|c|c|}
\hline Oxide & $\begin{array}{c}\text { Ashed Coal, } \\
\%\end{array}$ & $\begin{array}{l}\text { ESP Ash } \\
\text { Row } 1, \%\end{array}$ & $\begin{array}{c}\text { FF Ash, } \\
\%\end{array}$ \\
\hline $\mathrm{SiO}_{2}$ & 45.2 & 46.4 & 43.2 \\
\hline $\mathrm{Al}_{2} \mathrm{O}_{3}$ & 14.4 & 17.0 & 17.5 \\
\hline $\mathrm{Fe}_{2} \mathrm{O}_{3}$ & 3.32 & 5.30 & 4.72 \\
\hline $\mathrm{TiO}_{2}$ & 1.03 & 1.13 & 1.07 \\
\hline $\mathrm{P}_{2} \mathrm{O}_{5}$ & 0.19 & 0.19 & 0.31 \\
\hline $\mathrm{CaO}$ & 17.9 & 14.9 & 13.0 \\
\hline $\mathrm{MgO}$ & 3.26 & 2.65 & 2.71 \\
\hline $\mathrm{Na}_{2} \mathrm{O}$ & 0.79 & 0.77 & 0.69 \\
\hline $\mathrm{K}_{2} \mathrm{O}$ & 0.56 & 0.89 & 0.94 \\
\hline $\mathrm{SO}_{3}$ & 12.70 & 1.49 & 5.42 \\
\hline $\mathrm{BaO}$ & 0.23 & 0.24 & 0.28 \\
\hline $\mathrm{SrO}$ & 0.34 & 0.30 & 0.27 \\
\hline Unknowns & 0.08 & 8.73 & 9.93 \\
\hline
\end{tabular}

\section{Monthlong Results According to EPA Regulations}

According to EPA's CAMR, Part 75 continuous emission monitoring for mercury will be required for all affected coal-fired electric generating units. Quarterly reports of the ounces of mercury emitted and an annual cumulative total mass emission of mercury will be required. Since the data reduction for the official reporting guidelines differs from those used in previous sections, in this section the results have been sorted according to EPA guidelines to serve as a representative example for future reporting requirements even though a certified CMM was not used.

EPA reporting requires that hourly averages must be computed from the measured data, which in this case was recorded in 1-minute intervals. To qualify as a valid hourly average, there must be at least one valid data point in each quarter of the hour. For hours where valid averages cannot be calculated because of missing data, substitute values must be computed and are based on the following criteria: 1) is the mercury monitor operating in the "initial" or "standard" operating modes and 2) is the installed control technology functioning properly? The mercury monitor transitions from the "initial" operating regime to "standard" after it has collected 720 hours of quality-assured data. Since the FF outlet monitor at Big Brown did not collect 720 hours of quality data (under a consistent condition) and the correction procedures become more punitive during the "standard" period, the rules for "initial" data substitution were used for this exercise. Under these rules, if parametric data are available that show the control technology was functioning, then the missing data can be replaced with the average of the hourly averages immediately before and immediately after the missing data. However, if the parametric data indicate that the control technology was not working, then the maximum possible hourly 
emission must be substituted. This maximum emission value is based on coal analyses from, at a minimum, the prior 12 months. Out of this data set, the flue gas mercury concentration is calculated using the maximum coal mercury value and the minimum gross calorific value. For this case, the maximum and minimum values were selected from the 31 samples of the 70-30 lignite-PRB blend. The computed mercury concentration using these values was $44 \mu \mathrm{g} / \mathrm{dNm}^{3}$ at $3 \% \mathrm{O}_{2}$, which is high compared to the measured mercury levels.

Using EPA guidelines (and the modifications noted), the hourly average emissions of mercury during the monthlong test are plotted in Figure 11. The total quantity of EPA-reported mercury emissions from FF 2-4 was $148.8 \mathrm{oz}$, or $9.3 \mathrm{lb}$ over the approximately 23 days of available testing. For comparison, if the EPA-estimated maximum emission of mercury was assumed for the entire monthlong test, the reported mercury emission would be $576.8 \mathrm{oz}$, or $36 \mathrm{lb}$, from FF 2-4. Peak emission rates were approximately $1.25 \mathrm{oz} / \mathrm{hr}$ from FF $2-4$ and correspond to times when outlet CMM data were unavailable and the ACI system log indicated that injection was not occurring; therefore, the maximum emission value was substituted.

\section{Variability of Monthlong Data}

While useful for judging the average performance during the monthlong test, the onedimensional numbers of Table 9 do not reflect the observed variability in $\mathrm{Hg}$ concentrations. To

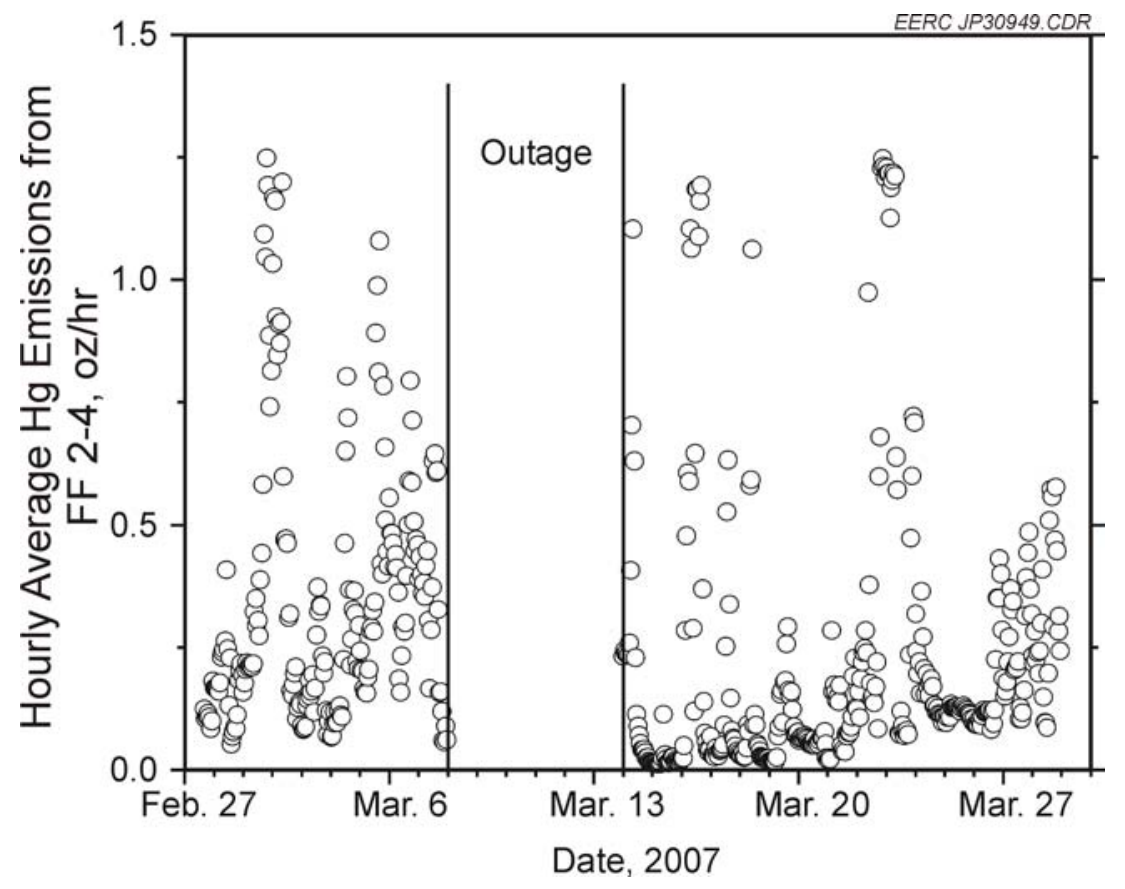

Figure 11. Hourly average mercury emissions from FF 2-4 computed according to EPA guidelines during the monthlong test. 
quantitatively show these variations, histograms of the FF inlet and outlet CMM data are provided in Figure 12 while the corresponding removal histogram is presented in Figure 13. The broad distributions of Figures 12 and 13 highlight the variability of $\mathrm{Hg}$ concentrations and resulting removals across FF 2-4 observed during the monthlong test.

The monthlong CMM and plant data were examined statistically to identify causes for the observed variability in FF 2-4 mercury removals. The normalized covariance was calculated between mercury removal values and many of the measured parameters collected for this project, some of which included FF inlet/outlet mercury concentrations, flue gas temperatures, $\mathrm{SO}_{2}$ levels, Unit 2 load, and ACI rate. The normalized covariance values for the most relevant parameters are presented in Figure 14. The covariance value indicates the correlation between two sets of data. High covariance values indicate high levels of correlation. Uncorrelated or independent data have a covariance value of zero. In this case, ACI rate had the highest value and was normalized to a value of one. The sign of the covariance value, positive or negative, indicates the direction of the relationship between the two variables. For instance, ACI loading, which has a positive covariance value, indicates that when values for ACI loading were high, values for mercury removal were also higher. It should be noted that this analysis only correlates data and does not imply a true cause-and-effect relationship.
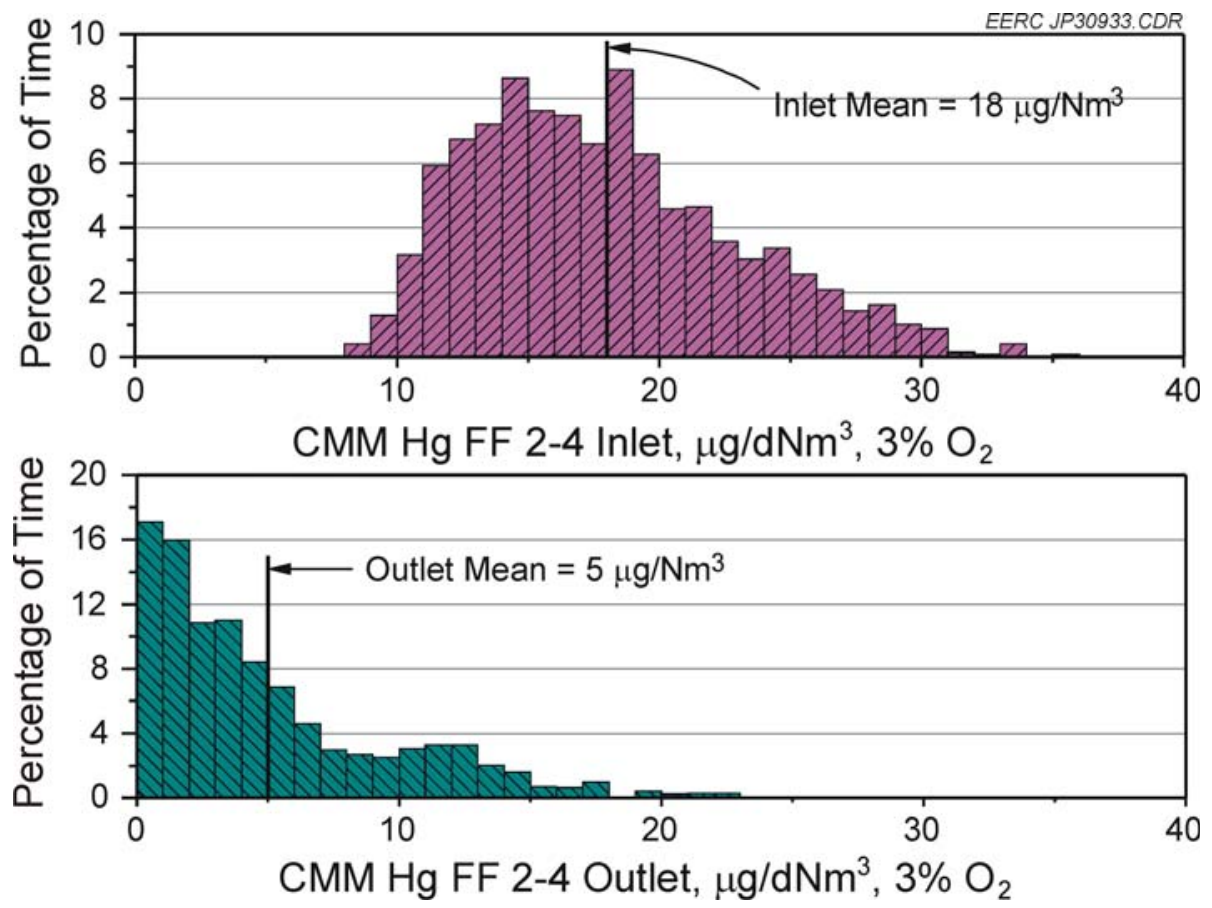

Figure 12. Histograms of the FF 2-4 inlet and outlet $\mathrm{Hg}$ concentration readings during the monthlong test. 


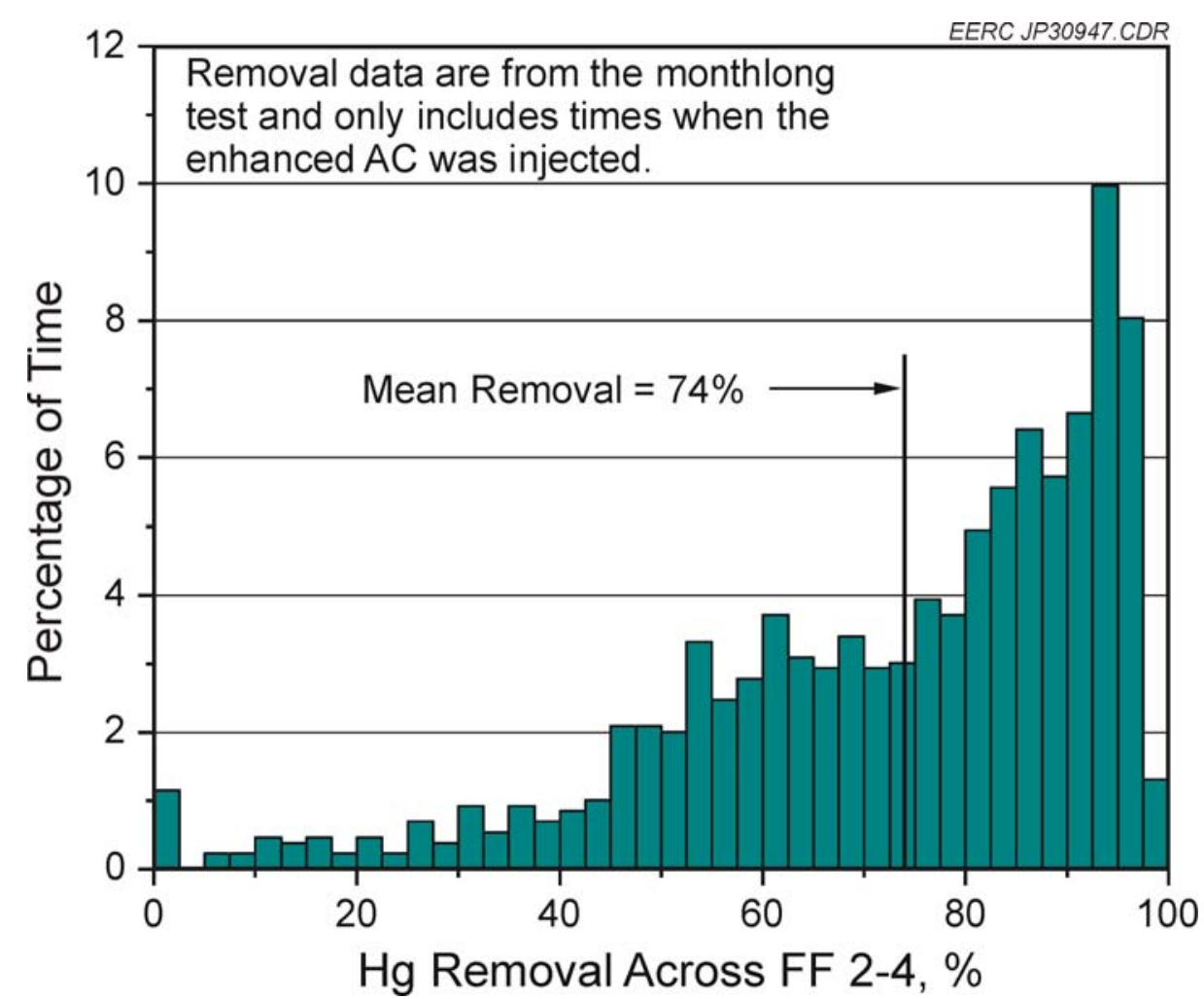

Figure 13. Distribution of mercury removal during the monthlong test.

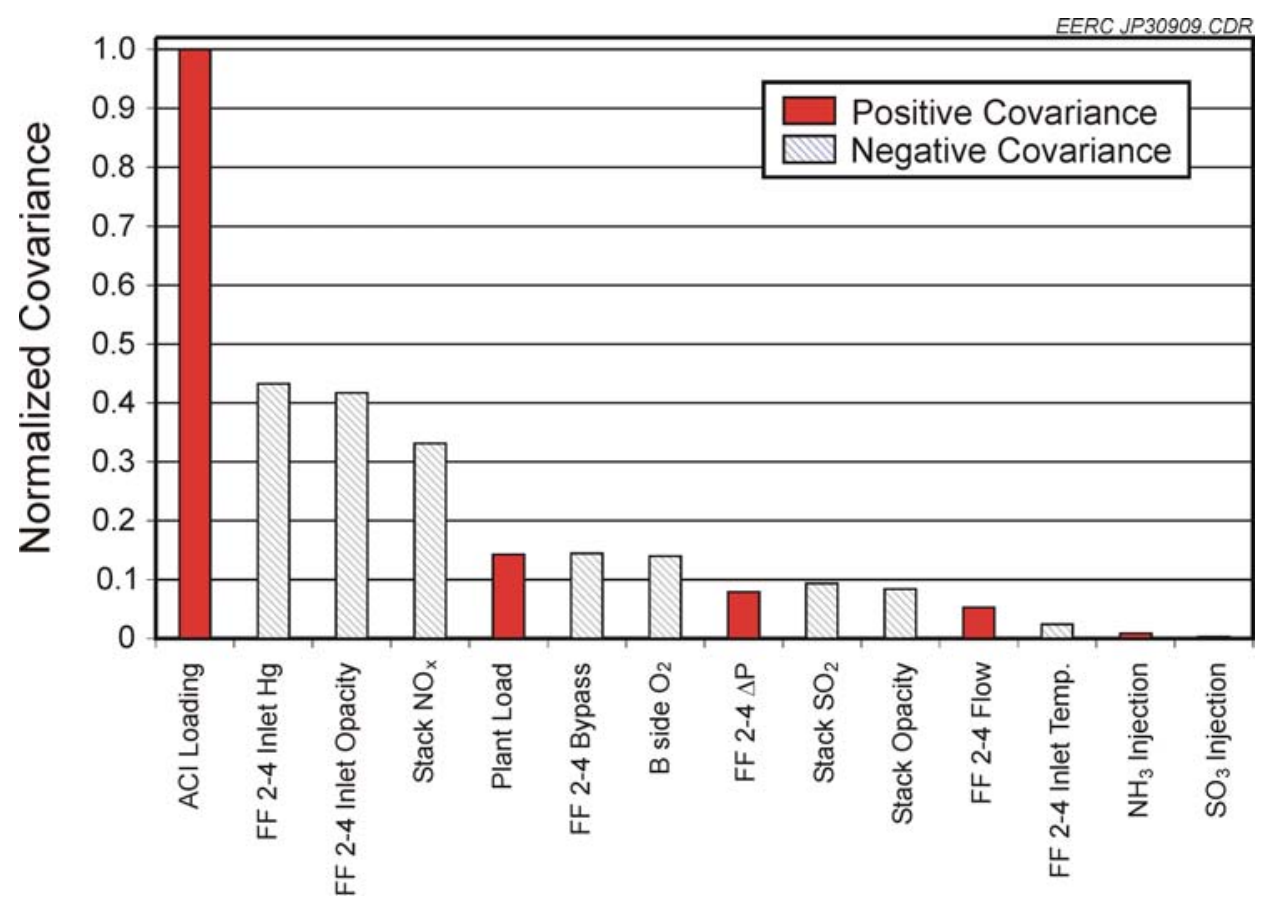

Figure 14. Normalized covariance for the statistically relevant parameters compared to mercury removal across FF 2-4. 
To test for cause-and-effect dependence, individual parameters were compared to mercury removal across FF 2-4. As shown in Figure 14, the most significant relationship with mercury removal was with ACI loading; to investigate this further, periods of uninterrupted, active injection were cataloged. Twenty-eight periods of ACI were identified and ranged in length from 10 minutes to 52 hours. The average mercury removal during these periods is plotted against period length in Figure 15. When viewed in this way, periods less than 8-10 hours in length show significant variation in mercury removal, while longer periods converge to steady-state values. This would seem to indicate the importance of establishing AC coverage on the entire dust layer of the FF and minimizing the interruptions to ACI for maximum $\mathrm{Hg}$ control.

The data of Figure 15 also provide an indication that some of the variability is due to the injection equipment itself; for approximately the first week of testing, the average sorbent injection was $1.1 \mathrm{lb} /$ Macf, which was slightly below the target of $1.5 \mathrm{lb} /$ Macf. However, this was corrected, and for the remainder of the monthlong test, rates were as specified, and the overall average ACI rate was $1.4 \mathrm{lb} /$ Macf. It should be noted that at the intended rate of $1.5 \mathrm{lb} / \mathrm{Macf}$ and after the transient period, $\mathrm{Hg}$ removals across FF $2-4$ are consistently above $80 \%$ and greater than $90 \%$ in some cases.

While ACI loading correlates strongly to $\mathrm{Hg}$ removals, other relationships identified as statistically significant in Figure 14 appear to be more coincident in nature rather than truly correlated. For example, consider the next most significant parameter, FF 2-4 inlet mercury concentration. When examined in relation to FF 2-4 mercury removal on a chronological time scale, as in Figure 16, periods of high mercury removals do roughly correspond to periods of low

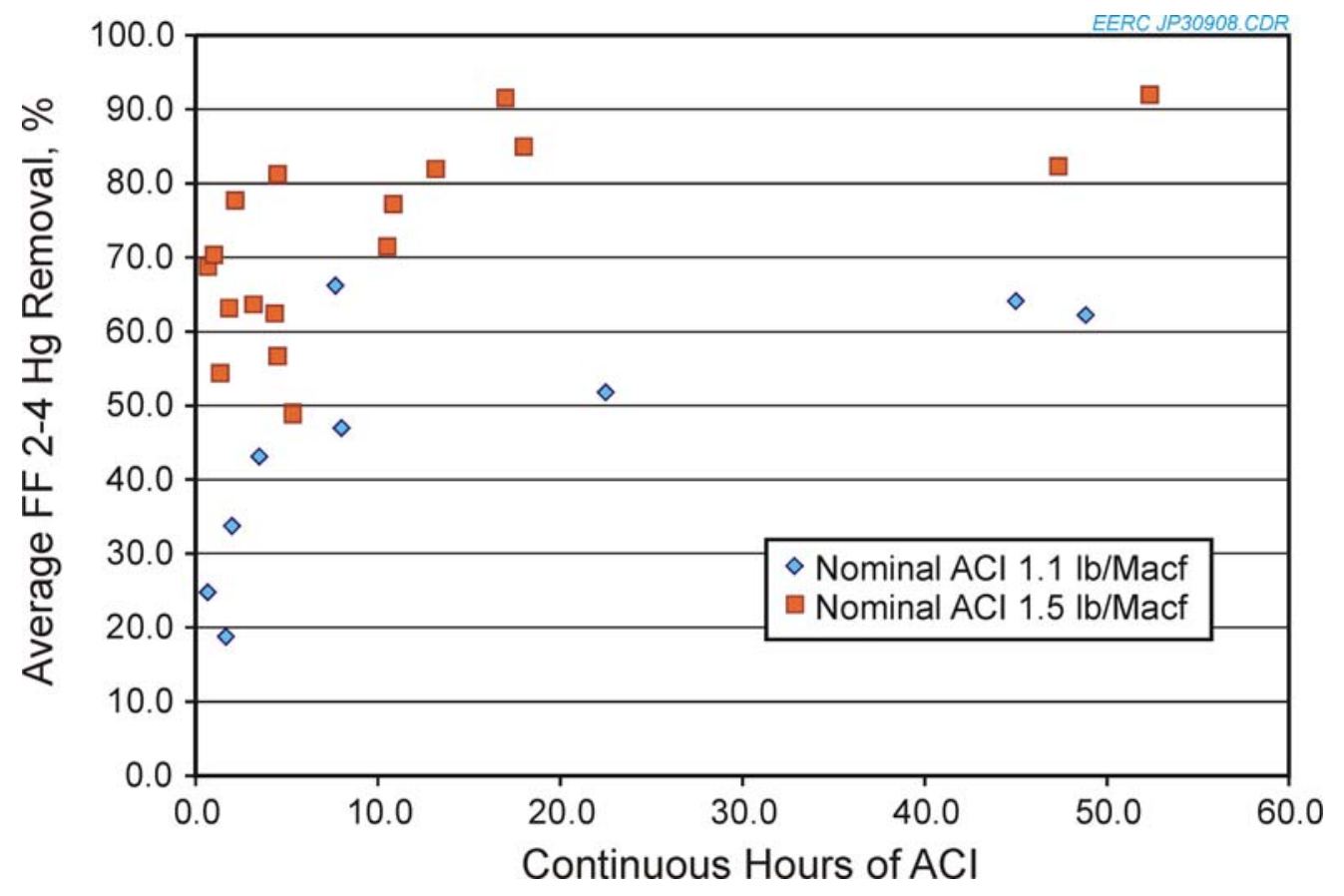

Figure 15. Sorted mercury removal data as a function of continuous injection time. 


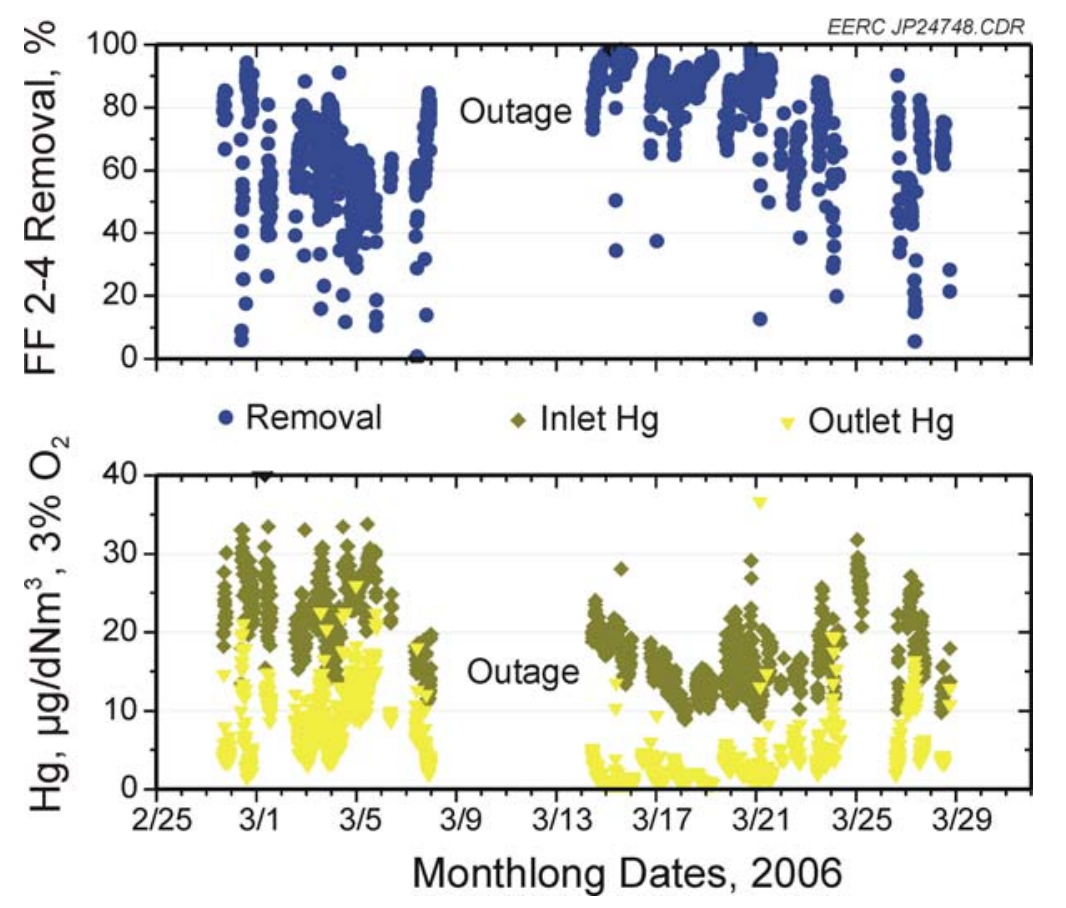

Figure 16. Hg removals and CMM data for the monthlong test.

inlet mercury. For instance, in comparing the data prior to the outage, March 2-6, and following the outage, March 17-20, average inlet mercury values decrease from approximately 24 to $15 \mu \mathrm{g} / \mathrm{dNm}^{3}$, and removals increase from approximately $60 \%$ to $85 \%$. However, as established during the discussion of ACI loading, the actual reasons for the increase in mercury removals are due to the correction of the ACI rate, i.e., switching from 1.1 to $1.5 \mathrm{lb} / \mathrm{Macf}$ following the outage and the longer periods of continuous injection that were experienced immediately after the outage period. The fact that inlet mercury values changed, possibly because of a temporary variation in coal blend, seems coincidental, as do the other significant parameters (aside from $\mathrm{ACI}$ ) in Figure 14 when examined in more detail.

\section{BOP IMPACTS}

This section discusses changes to plant equipment and operations that were observed, other than mercury emissions, because of the application of the mercury control technologies. These BOP effects typically have a cost or other penalty (load reduction, operational limit, etc.) associated with them that must be weighed against the benefit provided by mercury control. For this project, the BOP impacts include both anticipated and unexpected effects. Anticipated impacts included known (but not quantified) effects of ACI into baghouse module FF 2-4, such as added $\Delta \mathrm{P}$ from the extra dust loading and changing the composition and properties of the collected FF ash. Unexpected effects included adverse effects on bag life and self-heating of the $\mathrm{AC}$ in the baghouse ash that may have resulted from the ACI. 


\section{Differential Pressure Across FF 2-4}

During the course of field testing and following its conclusion, the plant experienced increased need to bypass FF 2-4 due to high $\Delta \mathrm{P}$, as indicated in Figure 17, which is a plot of FF 2-4 flue gas bypass position versus time. By the end of all mercury testing, the residual $\Delta \mathrm{P}$ across FF 2-4 had reached a point where TXU was not confident in its performance for the upcoming summer season; therefore, the plant initiated a full bag replacement of FF 2-4 in May 2006, approximately 8 months ahead of schedule.

Some of the increased need for bypass can be explained by the increased demand for load as indicated by the cumulative hours above $600 \mathrm{MW}$ for the monthlong time period (Figure 18). Higher load results in higher flow and, often, higher dust loading to the FF. However, analysis of bag samples and in situ drag measurements confirmed an unexpected increase in the residual drag component such that higher $\Delta \mathrm{P}$ values were encountered for lower loads compared to operation in November 2005. Because this increase in drag was coincident with ACI, the contribution of ACI to FF 2-4 $\Delta \mathrm{P}$ was investigated.

\section{COHPAC Dust Loading}

The investigation of FF 2-4 $\Delta \mathrm{P}$ begins with the dust loading into the COHPAC, and while determining the dust loading into FF 2-4 was not an explicit goal of this testing, total particulate

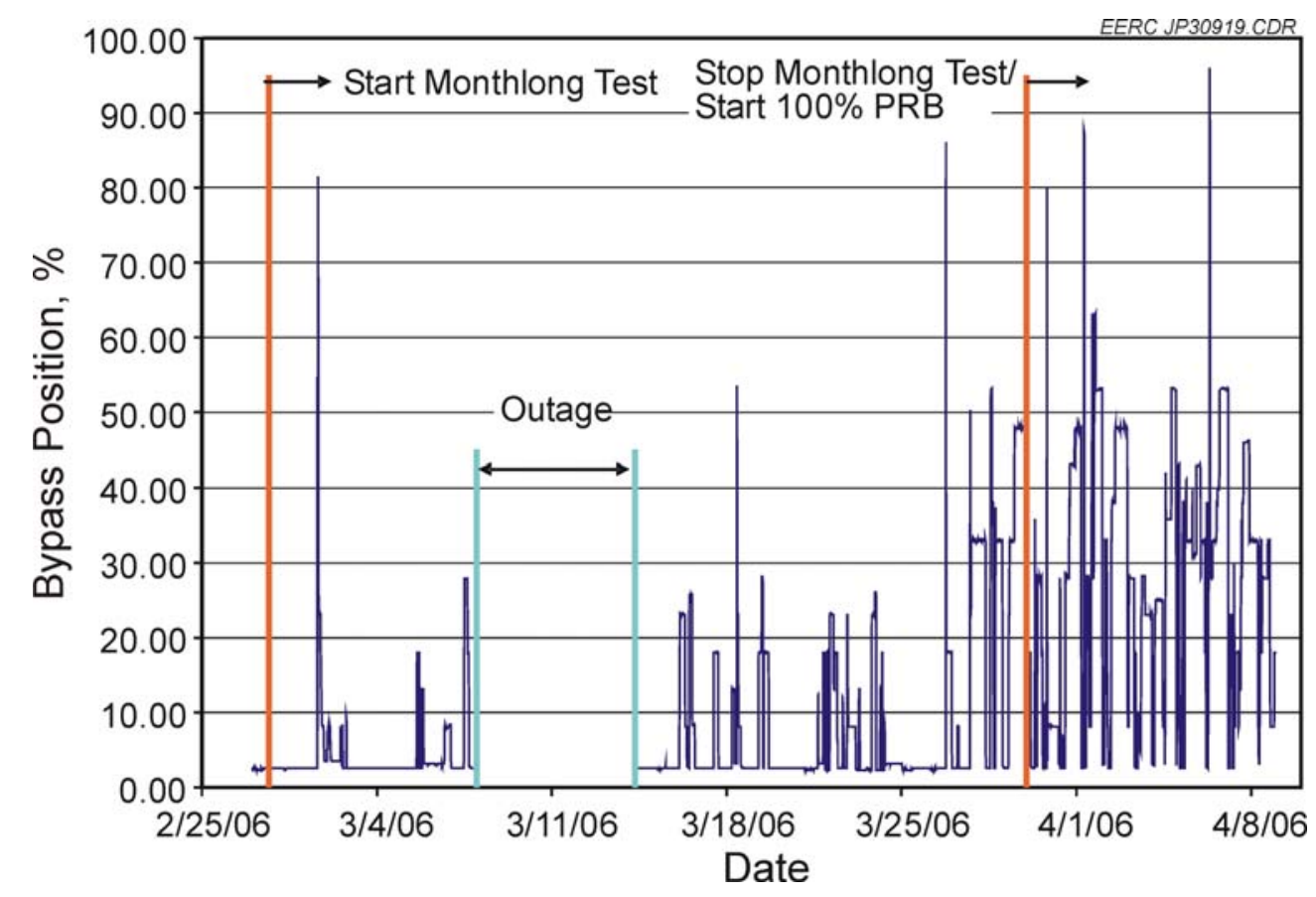

Figure 17. Record of FF 2-4 bypass setting during the monthlong test and through the testing with $100 \%$ PRB. 


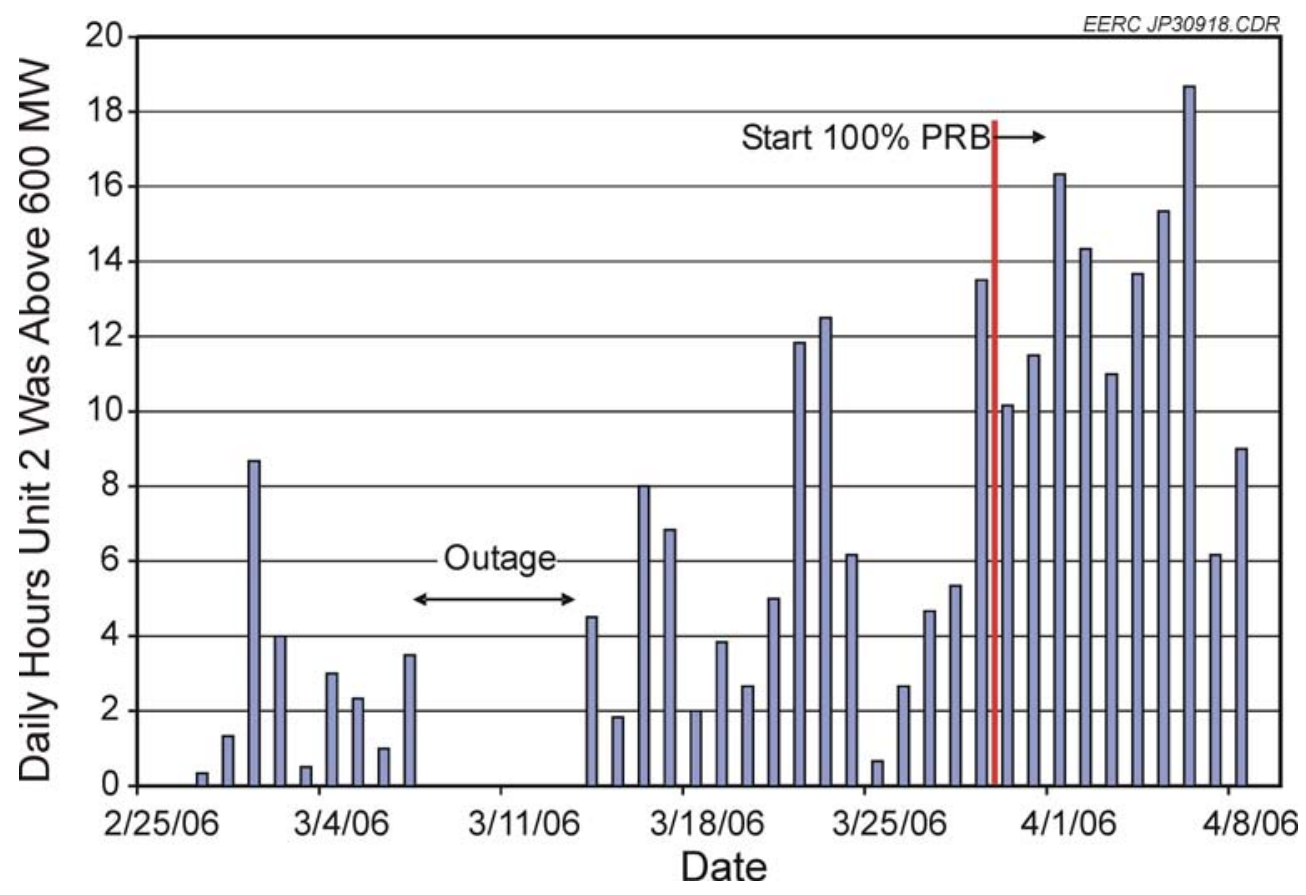

Figure 18. Log of the number of hours Unit 2 was above 600-MW output, per day, during the monthlong test and through the testing with $100 \%$ PRB.

loading data were collected using the filter weights from the $\mathrm{OH}$ method measurements (EPA Method 5 equivalent). These dust-only (no ACI) data have been summarized and are presented in Figure 19 as a function of the testing time line.

Some variation is observed with the data of Figure 19; however, aside from the switch to the $100 \%$ PRB fuel, there is no obvious trend in the particulate data. The abnormally high reading on February 8 was taken just prior to an unscheduled B-side ESP trip. This breakdown appears to have been a short-term incident since the other dust load measurements before and after the outage indicate normal dust levels, including the COHPAC inlet opacity levels shown in Figure 20.

The same inlet dust-only loading data from Figure 19 are presented as a function of plant load in Figure 21. A clear trend of increasing dust being introduced to the COHPAC with plant load is indicated in this presentation of the results. This indicates that at least the B-side ESP performance deteriorates with increasing load. Some of the factors that could affect ESP performance with load include increased gas flow, increased particulate loading, and increased temperatures which may affect ash resistivity. The trend with 100\% PRB fuel is similar, although the total dust loading is lower. 


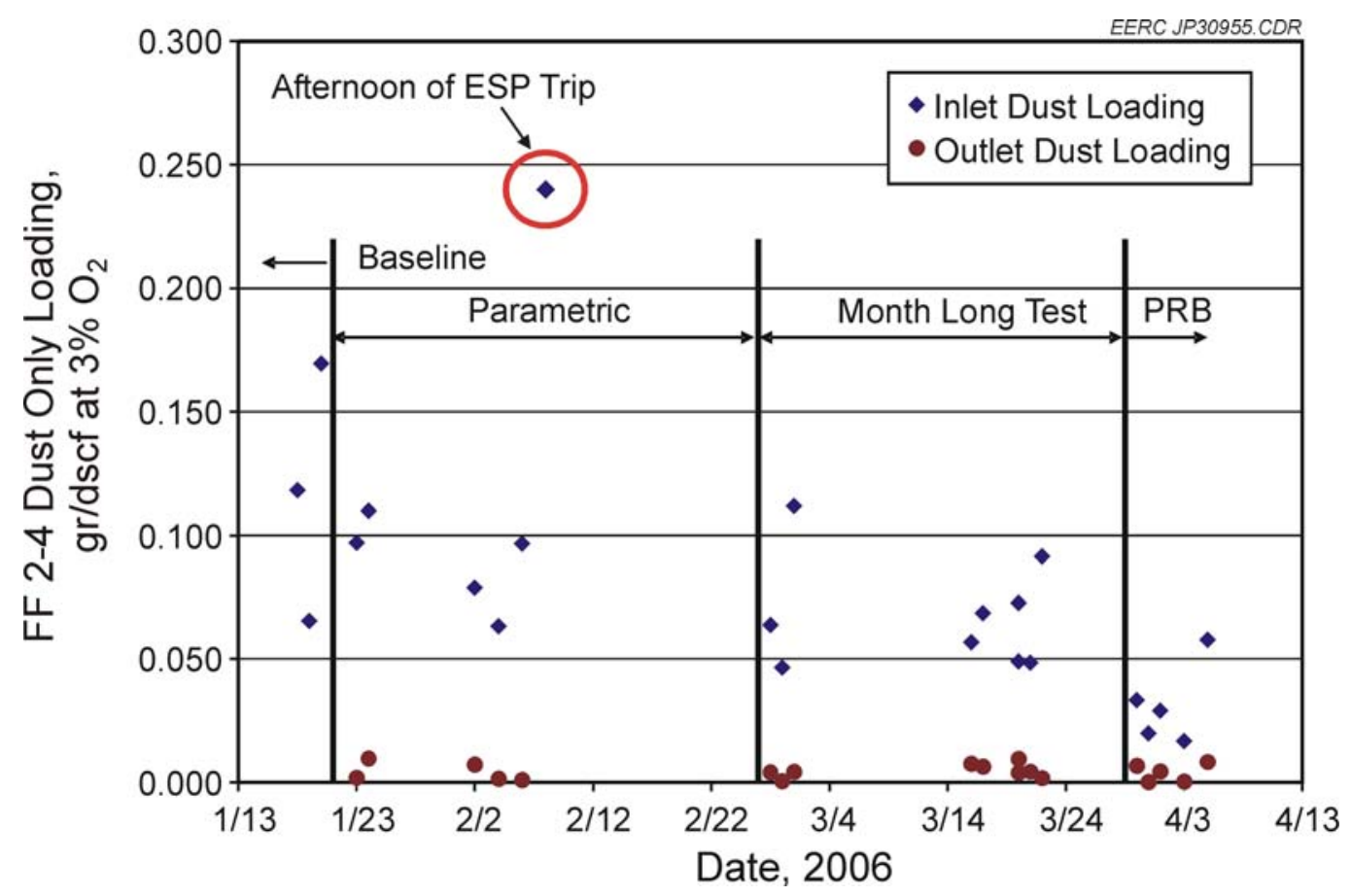

Figure 19. COHPAC inlet dust-only loading, as determined from $\mathrm{OH}$ method measurements.

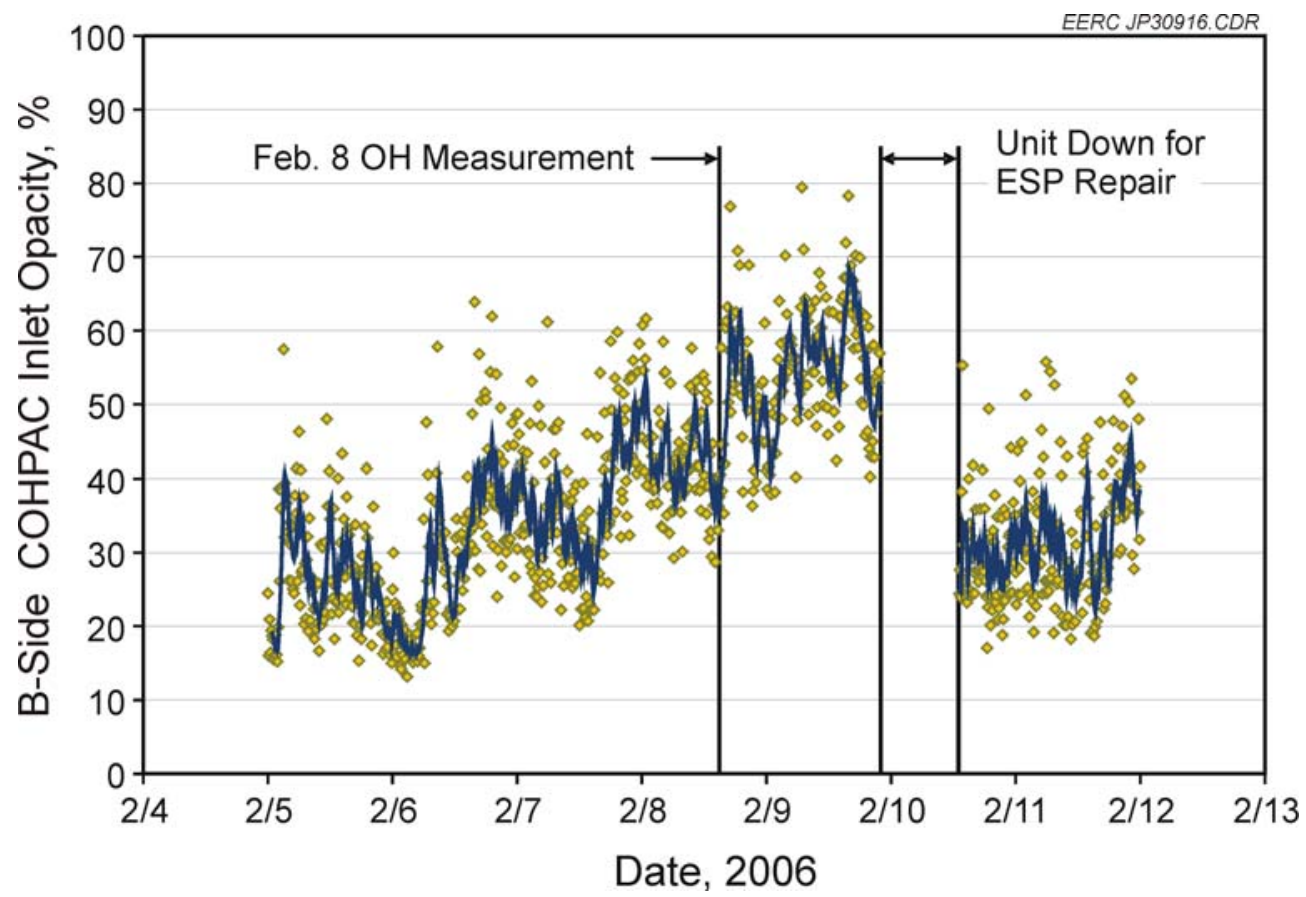

Figure 20. B-side COHPAC inlet opacity data during the period of the February 8, 2006, ESP trip. 


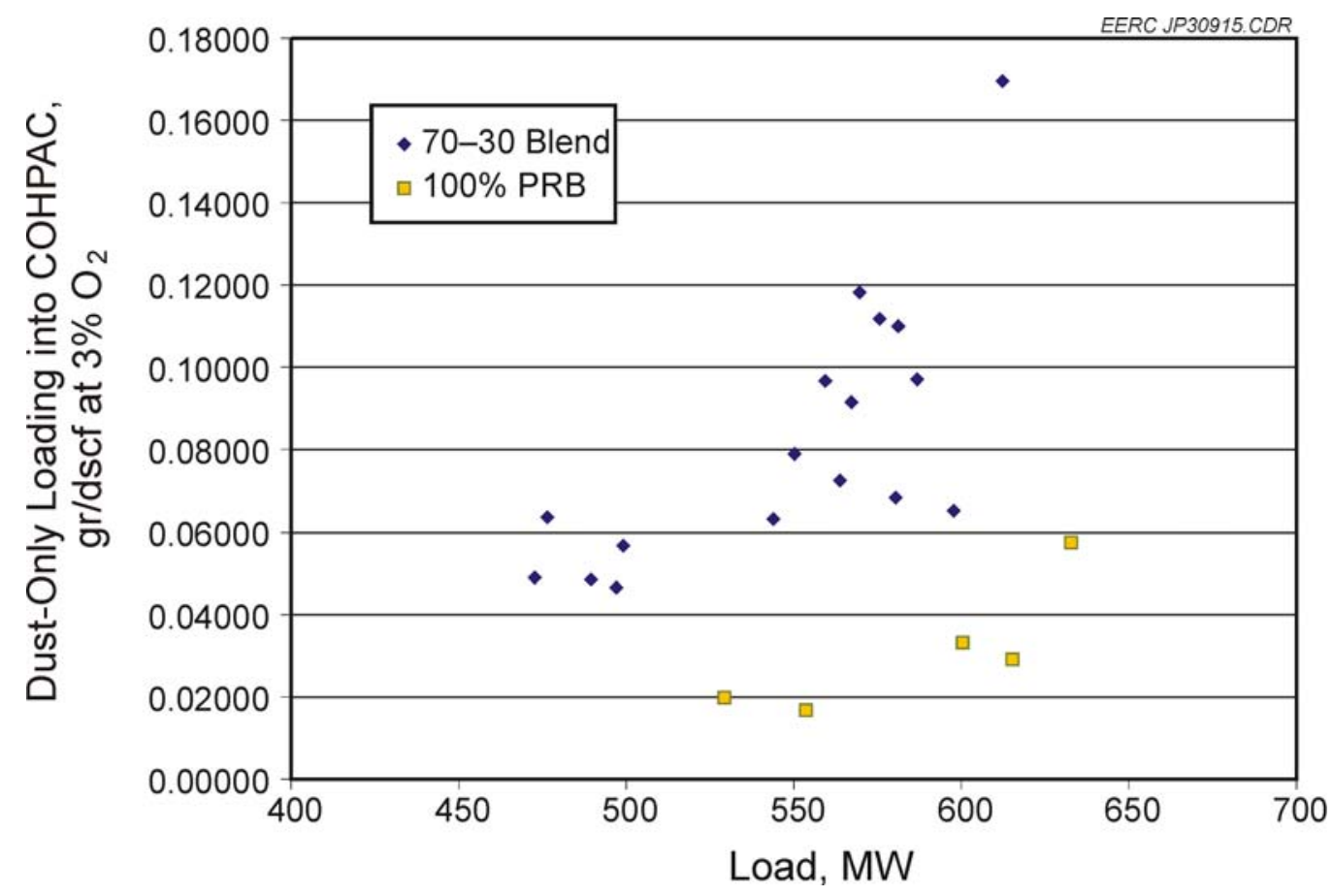

Figure 21. FF 2-4 inlet dust-only loading (determined from $\mathrm{OH}$ method measurements) as a function of plant load.

To evaluate the effect of $\mathrm{AC}$ content on $\mathrm{FF} \Delta \mathrm{P}$, the available flow and dust-loading data are presented in Figure 22 along with the AC:fly ash ratio. The dust-loading data are from the $\mathrm{OH}$ filter weights, and the plant data, i.e., FF 2-4 $\Delta \mathrm{P}$ and $\mathrm{A} / \mathrm{C}$ ratio, are averages corresponding to the $\mathrm{OH}$ method sample time.

As shown in Figure 22, the observed differential pressure across FF 2-4 was strongly correlated to the operating $\mathrm{A} / \mathrm{C}$ ratio of the baghouse, or since the filtration area is constant, $\Delta \mathrm{P}$ was a strong function of FF flow (or equivalently, unit load). There is also a correlation between $\Delta \mathrm{P}$ and inlet particulate loading because added dust increases the dust cake resistance.

However, when the particulate loading is segregated by the ratio of AC to fly ash, as in the right-hand frame of Figure 22, no clear pattern emerges. There does appear to be a mild effect of decreasing $\triangle \mathrm{P}$ with increasing $\mathrm{AC}$ content, but this is due to the fact that at low flows (and low $\triangle \mathrm{P}$ ), the particulate loading was also lower and the $\mathrm{AC}$ made up a larger percentage of the total dust load. At higher $\mathrm{A} / \mathrm{C}$ ratios with consistent $\Delta \mathrm{P}$ values, data show the $\mathrm{AC}$ ratio ranging between approximately $15 \%$ and $50 \%$ of the fly ash loading; these data would indicate that the $\Delta \mathrm{P}$ trends of FF 2-4 were dominated by flow through the module and the total particulate loading into the module. AC contributed to total particulate loading, but behaved much like fly ash in terms of its effect on FF $\Delta \mathrm{P}$. 

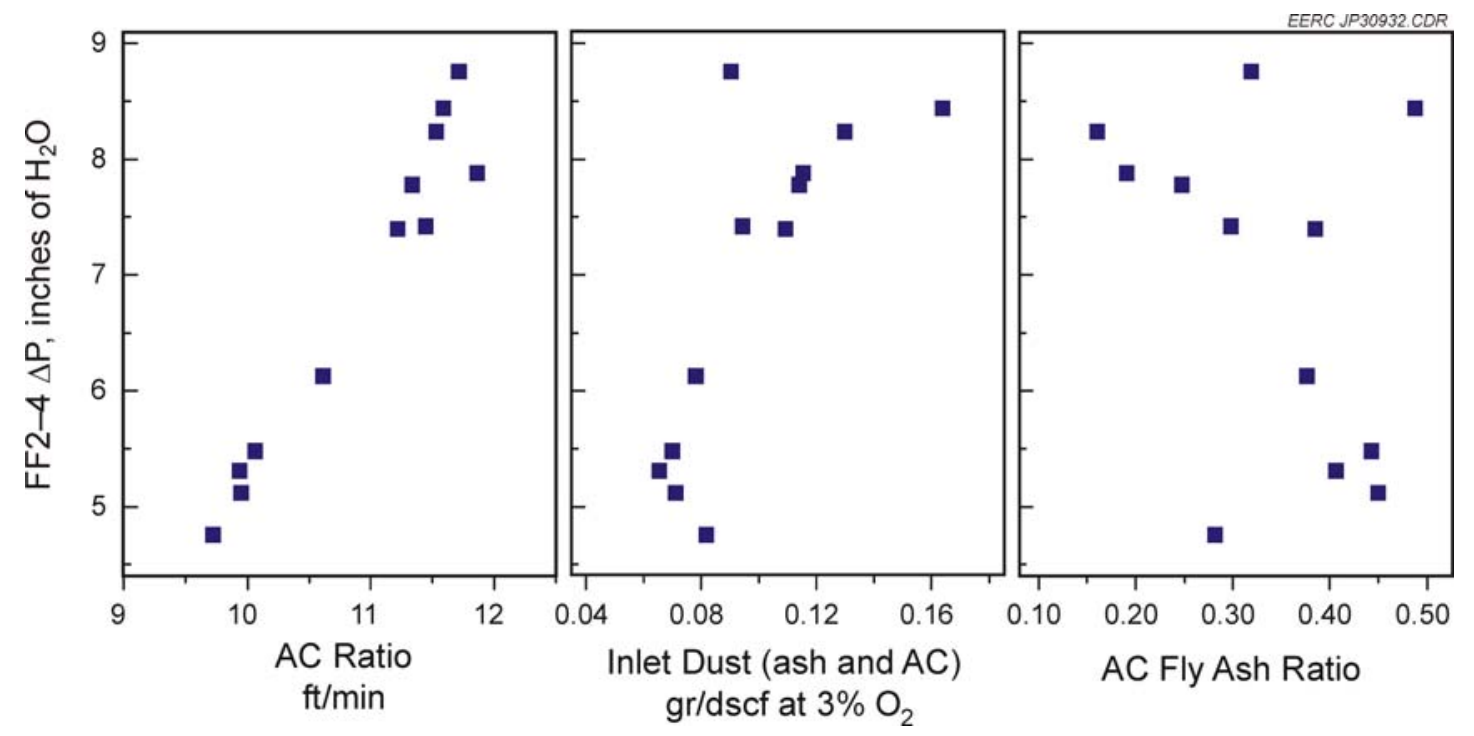

Figure 22. Trends of FF 2-4 differential pressure versus FF 2-4 A/C ratio, total FF 2-4 inlet dust loading, and the ratio of AC to fly ash in the inlet dust load.

\section{Long-Term $\triangle P$ Trending}

Trending the condition of the bags from November 2005 to March 2006 provided useful insight into the bag-blinding issue. However, finding directly comparable data throughout the period of interest was difficult. To simplify comparisons, the trends of module $\Delta \mathrm{P}$ versus $\mathrm{A} / \mathrm{C}$ ratio were evaluated at specific points in time for both FF 2-4 and FF 2-3. Examples of these trends for January 29, 2006, and March 25, 2006, are presented in Figures 23 and 24. When based on theoretical considerations, the relationship between $\mathrm{FF} \Delta \mathrm{P}$ and $\mathrm{A} / \mathrm{C}$ ratio should have a quadratic form instead of linear, according to Equation 1, which is for an individual filter:

$$
\Delta P=\left(K_{f}+K_{2} W_{R}\right) V+K_{2} C V^{2} t
$$

Where $\mathrm{K}_{\mathrm{f}}$ is the fabric/dust resistance, $\mathrm{K}_{2}$ is the specific dust cake resistance, $\mathrm{W}_{\mathrm{R}}$ is the residual dust cake weight, $\mathrm{C}$ is the dust loading, $\mathrm{t}$ is the time since last cleaning, and $\mathrm{V}$ is the filter face velocity, or the $\mathrm{A} / \mathrm{C}$ ratio. However, when the data were analyzed according to Equation 1, physically significant parameters could not be determined, so a pure empirical fit of the data was used, and sufficient accuracy was obtained with linear approximations. Curve fits were calculated for dates throughout the test period, and the coefficients are presented in Table 11.

To create a $\Delta \mathrm{P}$ trend versus time, $\Delta \mathrm{P}$ values were calculated at a common $\mathrm{A} / \mathrm{C}(11$ in this case) using the linear curve fits of Table 11 and then plotted as a function of time. The resulting plot of these values is shown in Figure 25 for both FF 2-3 and FF 2-4 and includes the time period beginning after Unit 2's return from the scheduled November 2005 outage and into the monthlong test in 2006. 


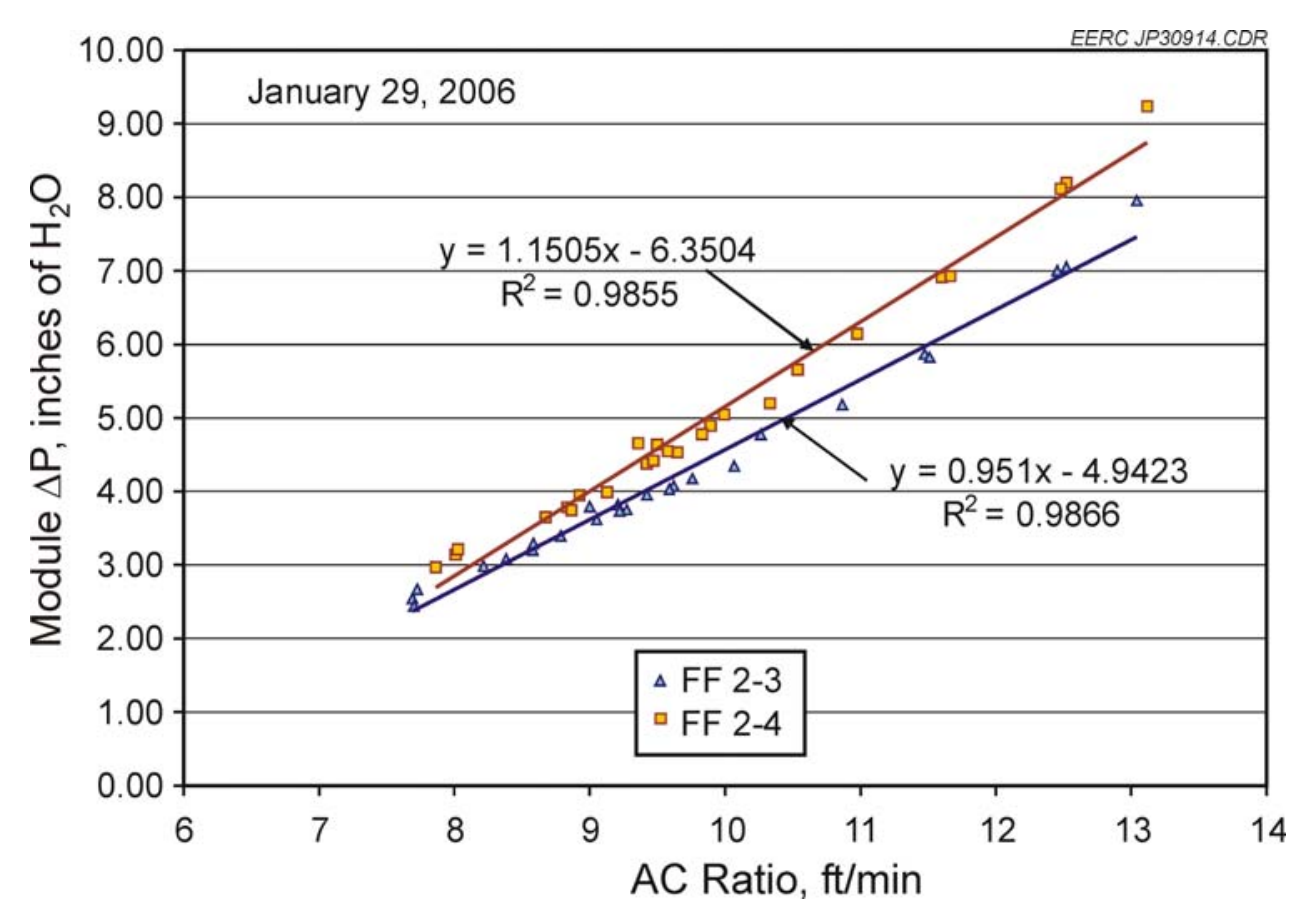

Figure 23. Comparison of module $\Delta \mathrm{P}$ versus computed $\mathrm{A} / \mathrm{C}$ ratio (proportional to module flow) for FF 2-3 and FF 2-4. Data are from January 29, 2006, no ACI.

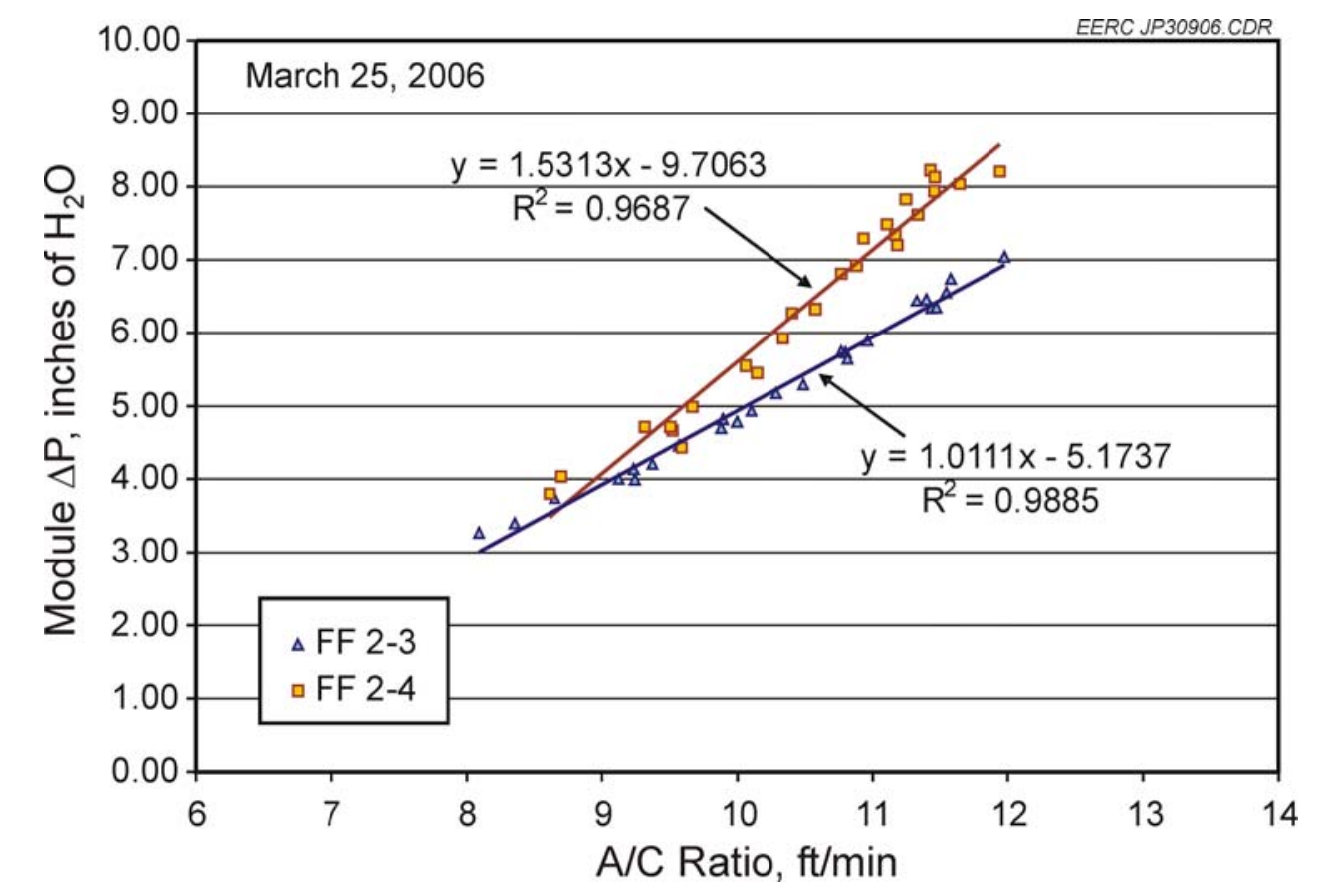

Figure 24. Comparison of module $\Delta \mathrm{P}$ versus computed $\mathrm{A} / \mathrm{C}$ ratio (proportional to module flow) for FF 2-3 and FF 2-4. Data are from March 25, 2006, near the conclusion of monthlong testing, ACI into FF 2-4. 
Table 11. Linear Curve Fit Parameters for the Observed Relationship Between Module $\Delta \mathrm{P}$ Versus A/C Ratio for Selected Days Before and During Field Testing

\begin{tabular}{l|ccc|ccc}
\hline & \multicolumn{3}{c}{ FF 2-3 } & \multicolumn{3}{c}{ FF 2-4 } \\
\cline { 2 - 7 } & $\begin{array}{c}\text { Slope, inches } \\
\text { Date }\end{array}$ & $\begin{array}{c}\text { Intercept, } \\
\text { inches }\end{array}$ & \multicolumn{3}{c}{$\begin{array}{c}\text { Slope, } \\
\text { inches } \mathrm{H}_{2} \mathrm{O} / \\
\mathrm{ft} / \mathrm{min}\end{array}$} & $\begin{array}{c}\text { Intercept, } \\
\text { inches }\end{array}$ \\
\hline $11 / 25 / 05$ & 0.82 & -4.08 & 0.99 & 0.90 & -3.72 & $\mathrm{H}_{2} \mathrm{O}$ \\
$12 / 2 / 05$ & 0.80 & -3.83 & 0.98 & 0.92 & -3.85 & 0.99 \\
$12 / 7 / 05$ & 0.92 & -5.08 & 0.99 & 1.03 & -4.89 & 0.98 \\
$12 / 10 / 05$ & 0.94 & -5.40 & 0.93 & 1.07 & -5.44 & 0.96 \\
$12 / 12 / 05$ & 0.88 & -4.61 & 0.93 & 0.99 & -4.55 & 0.90 \\
$12 / 13 / 05$ & 1.15 & -7.21 & 0.91 & 1.18 & -6.42 & 0.96 \\
$12 / 15 / 05$ & 1.09 & -6.44 & 0.98 & 1.10 & -5.75 & 0.99 \\
$12 / 19 / 05$ & 0.95 & -5.40 & 0.98 & 1.11 & -5.97 & 0.92 \\
$12 / 22 / 05$ & 1.14 & -7.41 & 0.99 & 1.06 & -5.27 & 0.98 \\
$12 / 29 / 05$ & 0.91 & -4.69 & 0.98 & 0.97 & -4.31 & 0.97 \\
$1 / 7 / 06$ & 0.97 & -5.13 & 0.96 & 1.02 & -4.57 & 0.97 \\
$1 / 15 / 06$ & 0.86 & -3.90 & 0.99 & 0.95 & -3.54 & 0.99 \\
$1 / 17 / 06$ & 0.98 & -4.99 & 0.99 & 1.07 & -4.66 & 0.99 \\
$1 / 19 / 06$ & 1.05 & -7.32 & 0.98 & 1.26 & -7.33 & 0.99 \\
$1 / 21 / 06$ & 0.97 & -6.46 & 0.97 & 1.25 & -7.16 & 0.97 \\
$1 / 23 / 06$ & 0.88 & -5.29 & 0.99 & 1.09 & -5.46 & 0.96 \\
$1 / 28 / 06$ & 0.95 & -5.08 & 0.99 & 1.15 & -6.39 & 0.97 \\
$1 / 29 / 06$ & 0.95 & -4.94 & 0.99 & 1.15 & -6.35 & 0.99 \\
$2 / 3 / 06$ & 0.96 & -4.74 & 0.99 & 1.17 & -6.55 & 0.98 \\
$2 / 5 / 06$ & 0.85 & -3.80 & 0.92 & 1.14 & -6.00 & 0.98 \\
$2 / 15 / 06$ & 1.01 & -5.12 & 0.95 & 1.36 & -7.99 & 0.96 \\
$2 / 27 / 06$ & 0.89 & -4.27 & 0.99 & 1.08 & -5.60 & 0.97 \\
$3 / 4 / 06$ & 0.96 & -4.74 & 0.99 & 1.31 & -7.55 & 0.97 \\
$3 / 15 / 06$ & 0.99 & -5.32 & 0.97 & 1.55 & -9.71 & 0.94 \\
$3 / 25 / 06$ & 1.01 & -5.17 & 0.99 & 1.53 & -9.71 & 0.97 \\
\hline
\end{tabular}

Figure 25 shows that shortly after the end of the outage on November 20, 2005, the calculated differential pressure across FF 2-4 was approximately 6.2 inches of $\mathrm{H}_{2} \mathrm{O}$ and 4.9 inches of $\mathrm{H}_{2} \mathrm{O}$ for FF 2-3 at an $\mathrm{A} / \mathrm{C}$ ratio of $11 \mathrm{ft} / \mathrm{min}$, which corresponds to a Unit 2 load of approximately $540 \mathrm{MW}$. As time progressed, the $\Delta \mathrm{P}$ values at the same $\mathrm{A} / \mathrm{C}$ ratio increased for both modules. This trend is highlighted by the linear curve fits and was considered to be representative of the increase in residual $\Delta \mathrm{P}$ across each module. In addition to showing a longterm trend, the data of Figure 25 also show short-term effects, e.g., the apparent recovery and subsequent increase in FF 2-4 $\Delta \mathrm{P}$ between the end of the parametric sorbent injections and the start of the monthlong $\mathrm{ACI}$ test. It must also be noted that, after the increase in $\Delta \mathrm{P}$ at the beginning of the monthlong test, FF 2-4 $\Delta \mathrm{P}$ values appear to level off with the increased dust 


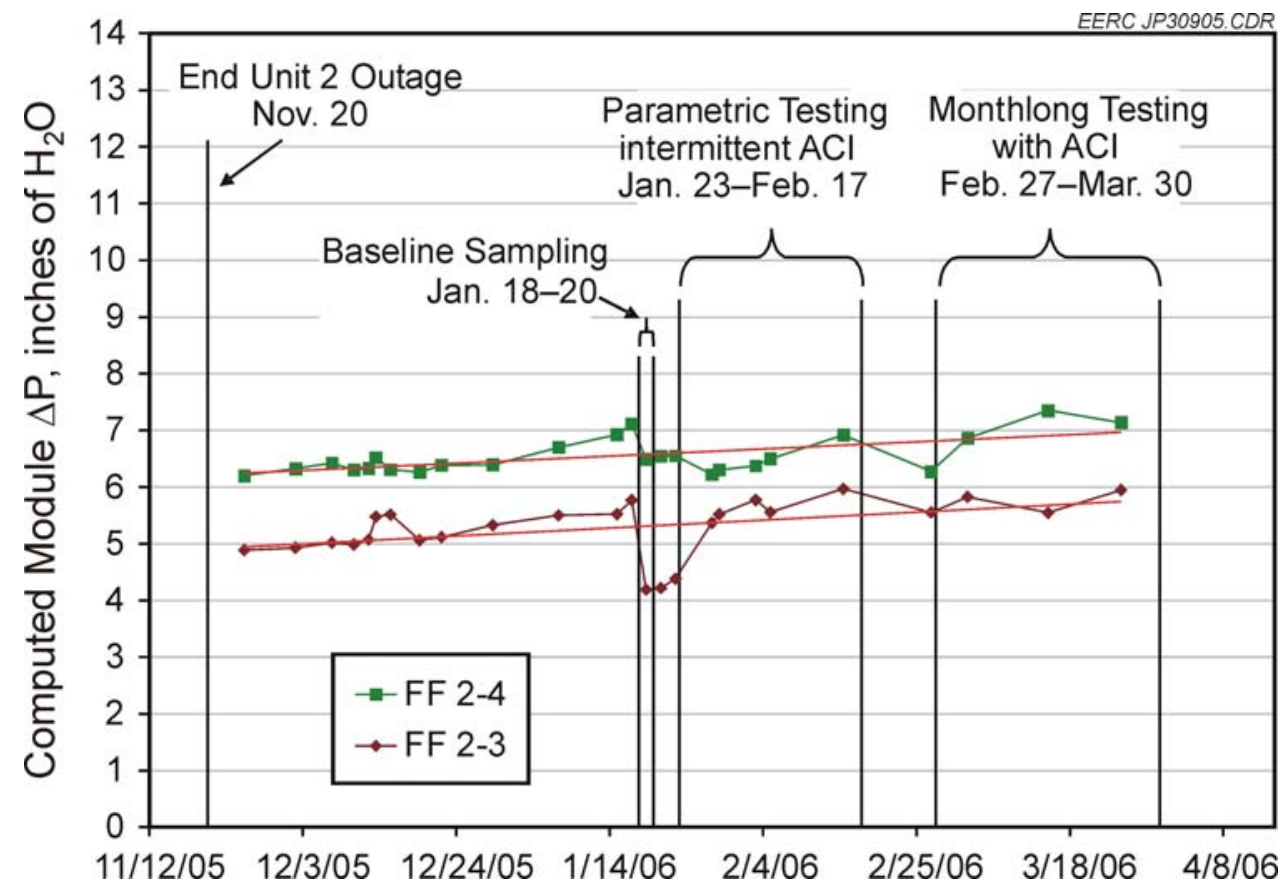

Figure 25. Computed differential pressures across FF 2-3 and 2-4 at a consistent $\mathrm{A} / \mathrm{C}$ ratio of $11 \mathrm{ft} / \mathrm{min}$ (corresponds to an approximate Unit 2 load of $540 \mathrm{MW}$ ).

load from ACI. While the resolution of the data in Figure 25 is not ideal, the data suggest that a mechanism for residual $\Delta \mathrm{P}$ increase was in place prior to the start of sorbent injection, for both FF 2-3 and FF 2-4, and the overall $\Delta \mathrm{P}$ trend related to residual dust does not appear to have been accelerated by ACI testing.

Beyond March 25, 2006, several things happen that confound the bag analysis. One was that the load profile increased for Unit 2 and the bypass was opened much more frequently, which invalidates $\Delta \mathrm{P}$ and flow data. Flow through the modules was not directly measured, but was computed from the difference between the independent parameters of module $\Delta \mathrm{P}$ and the average of the individual compartment $\Delta \mathrm{Ps}$. This difference was correlated to actual flow through the module by plant personnel. When the bypass is open, it alters the $\Delta \mathrm{P}$ difference and, therefore, invalidates any flow values or parameters such as module drag, which are calculated using flow data. It should be noted that prior to January 24, 2006, two of the compartment $\Delta \mathrm{P}$ measurements for FF 2-4 were out of calibration and biased the flow calculations by a calculated average value of $+6 \%$. Appropriate corrections were made; see Appendix F for details. Also, on March 29-30, the plant began to burn 100\% PRB, and a 9-day field test, including additional sorbent testing, began. Following the field testing with $100 \%$ PRB, FF 2-4 was in bypass through the remainder of April 2006. Insufficient evidence was available following the $100 \%$ PRB burn to draw conclusions about the condition of the bags or the effects of ACI. Based on actions of the plant and the in situ residual drag measurements by ADA-ES, it appears that the residual drag had increased to an unacceptable level by the end of field testing and could not recover during April before the bag change of FF 2-4 was started on April 30, 2006. 
The data of Figure 25 were also the best available measurements of the increased $\Delta \mathrm{P}$ because of ACI. If it is assumed that the trend from February 27, 2006 (represented by the data point immediately prior to the start of the monthlong test in Figure 25) can be considered a baseline condition without ACI, then the following data points, i.e., March 4, 15, and 25, represent essentially the same bag condition but with ACI. Based on these data, the monthlong ACI rate added approximately $0.6-0.9$ inches of $\mathrm{H}_{2} \mathrm{O}$ to $\Delta \mathrm{P}$ at an $\mathrm{A} / \mathrm{C}$ of $11 \mathrm{ft} / \mathrm{min}$, which corresponds to an approximate Unit 2 load of $540 \mathrm{MW}$. At an A/C ratio of $12 \mathrm{ft} / \mathrm{min}$ (Unit 2 load of $600 \mathrm{MW})$, ACI added approximately $0.8-1.3$ inches of $\mathrm{H}_{2} \mathrm{O}$ to FF 2-4 $\Delta \mathrm{P}$. When the linear trends are plotted as a function of $\mathrm{A} / \mathrm{C}$ ratio, as in Figure 26, the sensitivity of increased dust loading because of ACI at high flows is evident.

\section{Assessment of FF Bags}

Bag samples from FF 2-4 were collected and examined to provide insight regarding the increase in residual $\triangle \mathrm{P}$. An accurate time line of events prior to, during, and following the field testing and BOP discoveries is presented in Table 12. Key items to note from the event time line were the in situ residual drag measurements made before testing started in November 2005 and again after all testing and the completion of the 100\% PRB burn in May 2006. The May 2006 measurements were made during the online bag change of FF 2-4. Pretest bag samples were collected at the time of the November drag measurements; however, posttest samples were collected at the end of the monthlong test prior to initiation of the $100 \%$ PRB testing. No in situ drag measurements were made at this time, and during the drag measurements made in May 2006, no bag samples were collected.

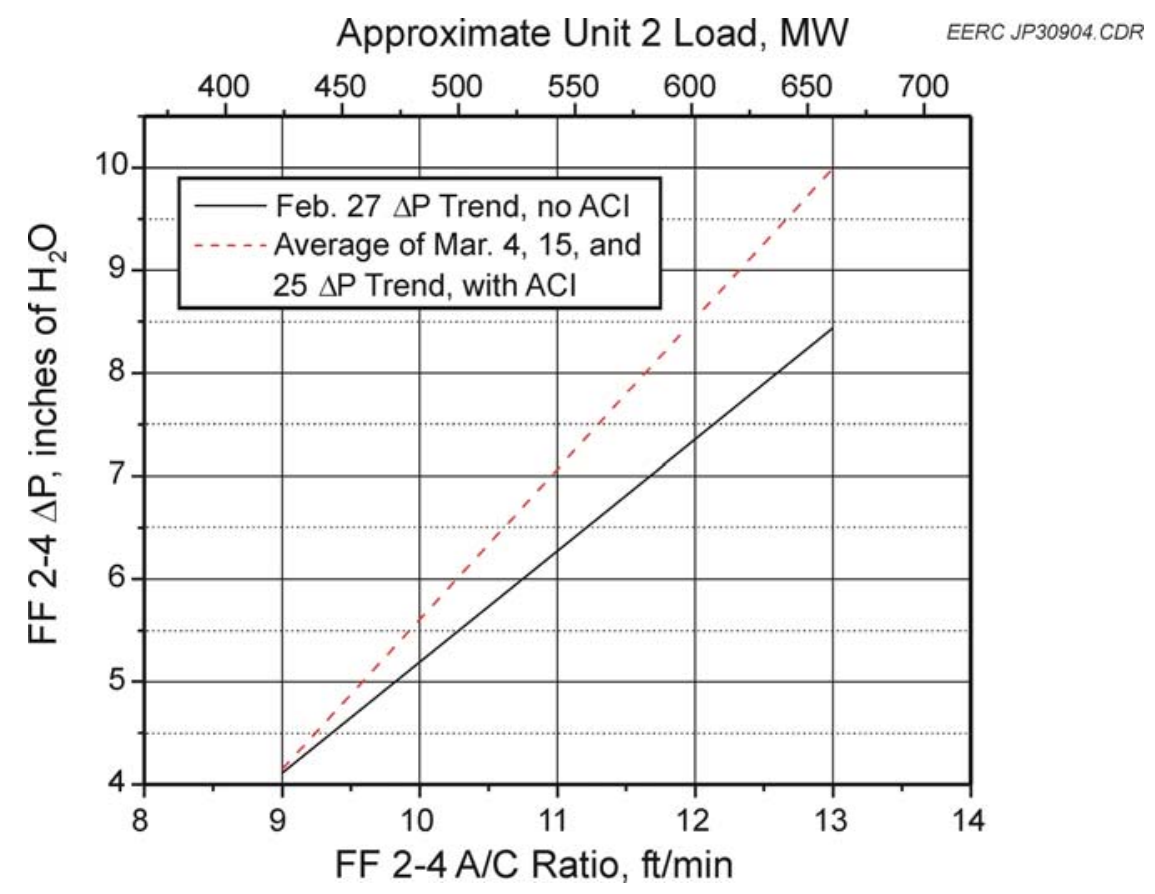

Figure 26. FF 2-4 $\Delta \mathrm{P}$ trends for prior to the monthlong test, no ACI, and the average of those during the monthlong test with ACI. 


\section{Bag Analysis}

As indicated in Table 12, in situ residual drag measurements were performed by ADA-ES under a separate long-term program to monitor Big Brown's COHPAC units (17). Relevant in situ measurements occurred 2 months prior to field testing, in November 2005, and again during the bag change of FF 2-4 in May 2006. These measurements were summarized in a report by ADA-ES that has been included in Appendix G. Data excerpts regarding in situ drag measurements for the Unit 2 bags are presented in Table 13. Measurements from compartment 24 indicate an increase in residual drag, nearly doubling during the period from November 2005 to May 2006. It should be noted that for FF 2-4, the same compartment was not sampled during both measurements; Compartment $\mathrm{F}$ was substituted in May because the bags in $\mathrm{C}$ had already been replaced by that time. A similar substitution was made for Compartment 2-1 $\mathrm{H}$, where during the May 2006 measurement, it appeared that the cleaning system was not functioning properly. The drag increase across FF 2-3 was very similar to 2-4, and the increases across 2-1 and 2-2, while not as severe as for 2-3 and 2-4, were also higher than expected. The values reported by ADA-ES indicate a change in bag condition from good (i.e., having enough $\Delta \mathrm{P}$ margin to not encounter the module $\Delta \mathrm{P}$ limit of 10 inches of $\mathrm{H}_{2} \mathrm{O}$ ) in November 2005 to having very little operating margin in May 2006.

Also as part of the long-term COHPAC monitoring, bag samples were taken as indicated in Table 12. Bag samples were taken from FF 2-3 and FF 2-4 prior to field testing in November 2005 at the same time that residual drag measurements were made. Bag samples were taken again at the end of the monthlong test, but no corresponding in situ residual drag measurements were made.

A total of four bag sample sets were collected from Big Brown: two sets from compartments 2-3 C and two sets from 2-4 C, with the first samples taken November 3, 2005, and the remaining samples taken March 30, 2006. Each bag sample was cut down to three segments representing top, middle, and bottom sections of the bag (see Figure 27). Bag samples collected prior to field testing and after the monthlong condition were analyzed by an independent filtration consultant (Grubb Filtration Testing Services, Inc.) and the EERC. The consultant's report is included in Appendix G; results for permeability, residual dust weight, and fabric strength are summarized in Table 14.

A key observation from Table 14 is that the permeabilities for 2-3 and 2-4 did decrease significantly: $43 \%$ for $2-3$ and $58 \%$ for $2-4$ during the time period from November 2005 to March 2006. However, when all four samples were vacuumed and washed, the permeabilities improved to levels close to or higher than those for new fabric, indicating that the reduced permeability was a result of embedded residual dust. This conclusion is also supported by the increase in residual dust weight between both sets of November and March samples. While the November samples showed significant loss of strength compared to new fabric, no significant loss of strength was observed from November to March. 
Table 12. Event Time Line for the FF 2-4 BOP Investigation

\begin{tabular}{|c|c|c|}
\hline Date & Event & How Determined \\
\hline November 3, 2005 & $\begin{array}{l}\text { Pretest bag samples taken and } \\
\text { residual drag measurements } \\
\text { made }\end{array}$ & Trip report by ADA-ES ${ }^{\mathrm{a}}$ \\
\hline November 20, 2005 & $\begin{array}{c}\text { Unit } 2 \text { restart after scheduled } \\
\text { outage }\end{array}$ & Plant data \\
\hline January 18-20, 2006 & $\begin{array}{l}\text { Baseline sampling with } 70-30 \\
\text { blend }\end{array}$ & EERC test log \\
\hline $\begin{array}{l}\text { January } 23-\text { February } 17, \\
2006\end{array}$ & Blend parametric testing & EERC test log \\
\hline $\begin{array}{l}\text { February } 27 \text { - March } 30, \\
2006\end{array}$ & Monthlong test injection & EERC test log \\
\hline Overnight of March 29, 2006 & Switch to $100 \%$ PRB & $\begin{array}{l}\text { FF 2-4 inlet Hg CMM } \\
\text { and TXU coal data }\end{array}$ \\
\hline March 30, 2006 & Collect posttest bag samples & Plant data \\
\hline March $30-$ April 1, 2006 & $\begin{array}{c}\text { Baseline sampling with } 100 \% \\
\text { PRB }\end{array}$ & EERC test log \\
\hline April 2-8, 2006 & $\begin{array}{c}\text { Parametric testing with } 100 \% \\
\text { PRB }\end{array}$ & EERC test log \\
\hline April 8, 2006 & End field testing & EERC test log \\
\hline April 23, 2006 & $\begin{array}{c}\text { End } 100 \% \text { PRB burn, switch } \\
\text { back to } 70-30 \text { blend }\end{array}$ & TXU coal data \\
\hline April 30, 2006 & $\begin{array}{l}\text { Begin online bag change of } \\
\text { FF 2-4 }\end{array}$ & Plant data \\
\hline April 30 - May 1, 2006 & Compartment A off-line & Plant data \\
\hline May $1-5,2006$ & Compartment C off-line & Plant data \\
\hline May 7-9, 2006 & Compartment B off-line & Plant data \\
\hline May $10-11,2006$ & Compartment A off-line & Plant data \\
\hline May $14-16,2006$ & Compartment D off-line & Plant data \\
\hline May $16-19,2006$ & Compartment H off-line & Plant data \\
\hline May $21-24,2006$ & Compartment G off-line & Plant data \\
\hline May 23-24, 2006 & $\begin{array}{l}\text { Measure posttest in situ residual } \\
\text { drag for all Unit } 2 \text { modules }\end{array}$ & Trip report by ADA-ES ${ }^{a}$ \\
\hline May 24, 2006 & Review meeting at Big Brown & EERC records \\
\hline May $24-25,2006$ & Compartment F off-line & Plant data \\
\hline May 29-31, 2006 & Compartment E off-line & Plant data \\
\hline May 31, 2006 & FF 2-4 bag change complete & Plant data \\
\hline
\end{tabular}

${ }^{\mathrm{a}}$ Bustard and Grubb (2006), Appendix G. 
Table 13. In Situ Residual Drag Measurements for Unit 2 COHPAC Modules

\begin{tabular}{|c|c|c|c|c|c|}
\hline Comp. & Bag Type/Bag Batch & $\begin{array}{c}\text { Drag, in. } \\
\text { WG/ft/min } \\
05 / 17 / 05\end{array}$ & $\begin{array}{c}\text { Drag, in. } \\
\mathrm{WG} / \mathrm{ft} / \mathrm{min} \\
11 / 02 / 05\end{array}$ & $\begin{array}{c}\text { Drag, in. } \\
\mathrm{WG} / \mathrm{ft} / \mathrm{min} \\
05 / 23 / 06\end{array}$ & $\begin{array}{c}\text { Est. Oper } \\
\text { Hours } \\
05 / 23 / 06\end{array}$ \\
\hline $2-1 \mathrm{H} / \mathrm{G}$ & $\begin{array}{l}\text { 7-denier Torcon (May } \\
\text { 2005) }\end{array}$ & N/A & $0.19(\mathrm{H})$ & $0.25(\mathrm{G})$ & 7375 \\
\hline $2-2 \mathrm{C}$ & $\begin{array}{l}\text { 7-denier Torcon (Apr. } \\
\text { 2004) }\end{array}$ & 0.18 & N/A & 0.31 & 16,427 \\
\hline $2-3 C$ & $\begin{array}{l}\text { 7-denier Torcon (Mar. } \\
\text { 2005) }\end{array}$ & N/A & 0.21 & 0.37 & 9392 \\
\hline $2-4 \mathrm{C} / \mathrm{F}$ & $\begin{array}{l}\text { 7-denier Torcon (Jan. } \\
\text { 2005) }\end{array}$ & N/A & $0.21(\mathrm{C})$ & $0.39(\mathrm{~F})$ & 10,064 \\
\hline
\end{tabular}

Table 14. Summary of Bag Data from Independent Consultant

\begin{tabular}{|c|c|c|c|c|c|c|}
\hline Bag Sample & $\begin{array}{l}\text { FF 2-3 } \\
\text { (C) } \\
\text { Nov. } \\
2005\end{array}$ & $\begin{array}{l}\text { FF 2-3 } \\
\text { (C) } \\
\text { Mar. } \\
2006\end{array}$ & $\begin{array}{l}\text { New } \\
\text { Fabric } \\
\text { FF 2-3 } \\
\text { Bags }\end{array}$ & $\begin{array}{l}\text { FF 2-4 } \\
\text { (C) } \\
\text { Nov. } \\
2005\end{array}$ & $\begin{array}{l}\text { FF 2-4 } \\
\text { (C) } \\
\text { Mar. } \\
2006\end{array}$ & $\begin{array}{l}\text { New } \\
\text { Fabric } \\
\text { FF 2-4 } \\
\text { Bags }\end{array}$ \\
\hline Installed Life, months & 7.5 & 12.5 & 0 & 9 & 14 & 0 \\
\hline $\begin{array}{l}\text { Permeability, } \mathrm{cfm} / \mathrm{ft}^{2} \\
\text { As Received, } \\
\text { vacuumed and } \\
\text { washed }\end{array}$ & $\begin{array}{c}5.30 \\
108\end{array}$ & $\begin{array}{l}3.03 \\
116\end{array}$ & $\begin{array}{l}\mathrm{N} / \mathrm{A} \\
113^{\mathrm{a}}\end{array}$ & $\begin{array}{l}5.84 \\
139\end{array}$ & $\begin{array}{r}2.43 \\
137\end{array}$ & $\begin{array}{l}\mathrm{N} / \mathrm{A} \\
128^{\mathrm{a}}\end{array}$ \\
\hline $\begin{array}{l}\text { Washed Fabric } \\
\text { Weight, oz/yd }\end{array}$ & 14.8 & 13.9 & $14.9^{\mathrm{a}}$ & 15.0 & 16.5 & $16.0^{\mathrm{a}}$ \\
\hline $\begin{array}{l}\text { Residual Dust } \\
\text { Weight, oz/yd }\end{array}$ & 12.8 & 17.4 & $\mathrm{~N} / \mathrm{A}$ & 14.8 & 21.5 & $\mathrm{~N} / \mathrm{A}$ \\
\hline $\begin{array}{l}\text { Mullen Burst } \\
\text { Strength } \\
\text { Average, actual, psi, } \\
\text { net }\end{array}$ & 132 & 124 & 378 & 164 & 161 & 310 \\
\hline
\end{tabular}

${ }^{\mathrm{a}}$ New fabric values, not washed and vacuumed.

\section{Residual Dust Chemical Analysis}

Sample splits of the bags analyzed by the filtration consultant were also sent to the EERC for study. These samples are pictured in Figure 27. To investigate the composition of the residual ash in the filter samples, a procedure was developed by the EERC to extract and analyze the residual dust from the filters. First, horizontal strips of the filters (approximately 2.5 inches) were cut from the bag samples, soaked in DI water, sonicated for 0.5 hours, and then agitated overnight to remove the residual dust and leach out the compounds of interest. Samples of the 


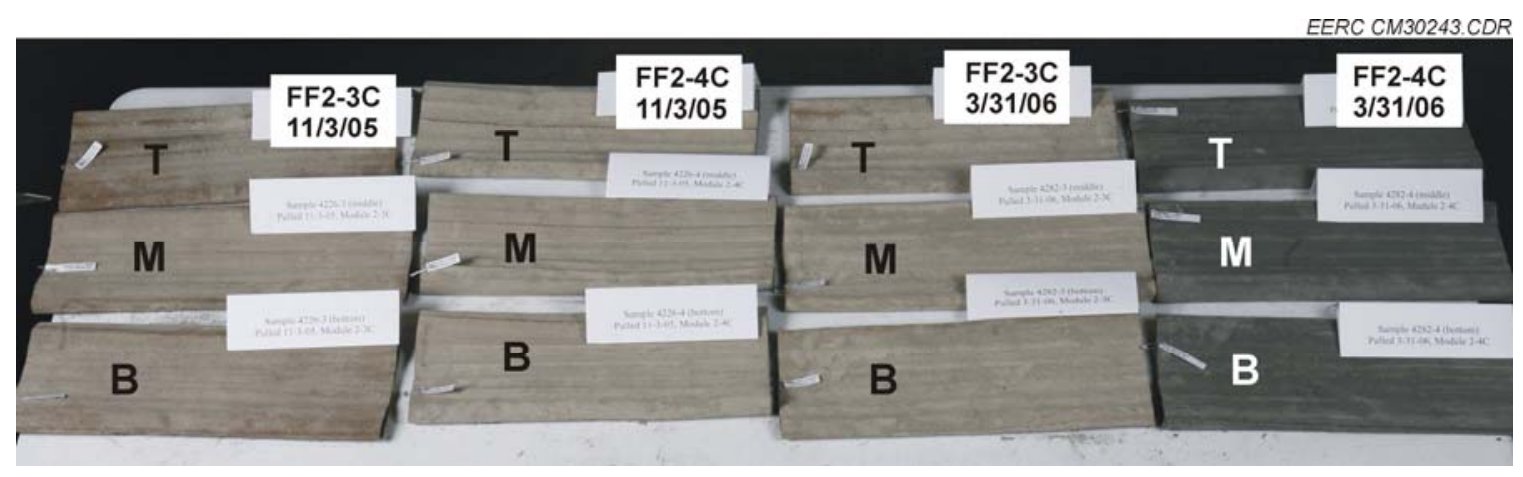

Figure 27. Photograph of the bag sections received by the EERC. Each column of samples represents a single bag sample. From left to right, the bag samples are FF 2-3 (C) November 2005, FF 2-4 (C) November 2005, FF 2-3 (C) March 2006, and FF 2-4 (C) March 2006. Each row contains the top, middle, and bottom sections from each bag.

solution were then analyzed for the various compounds of interest. During development of the procedure, water leaching and acid leaching were both evaluated; determination of ammonia and sulfates was not sensitive to the leaching method. Selenium, on the other hand, was not released with water leaching, so an additional digestion procedure was incorporated to evaluate selenium. For samples where the residual dust itself was subjected to more testing, the dislodged ash in solution was collected by filtering and then drying. Finally, the filter sample was rinsed of any remaining ash, dried, and weighed to get the clean fabric weight. The residual dust weight was then determined by difference.

The water leachate of samples of the FF was used to determine the water-soluble sulfates, ammonia, and leachate $\mathrm{pH}$ for all of the bag samples. Unless otherwise noted, the average values presented comprise at least four analyses and include samples from the top, middle, and bottom sections of each bag sample. No significant trending of these parameters with bag length was observed, so results were combined into bag averages.

Water-soluble sulfate levels are presented in Figure 28. When compared to bulk ash sulfate levels (44,100 ppm baseline and 32,700 ppm monthlong), there appear to be 1) a higher concentration of sulfates in the bag residual dust, 2) an increase in the residual dust sulfate concentration from November 2005 to March 2006, and 3) similar trending for Modules 2-3 and $2-4$.

The increase in sulfates is at least qualitatively supported by the residual dust $\mathrm{pH}$ measurements, which are provided in Figure 29. The corresponding bulk ash $\mathrm{pH}$ measurements are 8.01 for baseline and 7.43 for monthlong. While it appears that the November 2005 residual dust is slightly more basic than the bulk ash, the more pronounced trend was that the residual dust became more acidic, even changing to a slightly acid $\mathrm{pH}$ level from November 2005 to March 2006. 


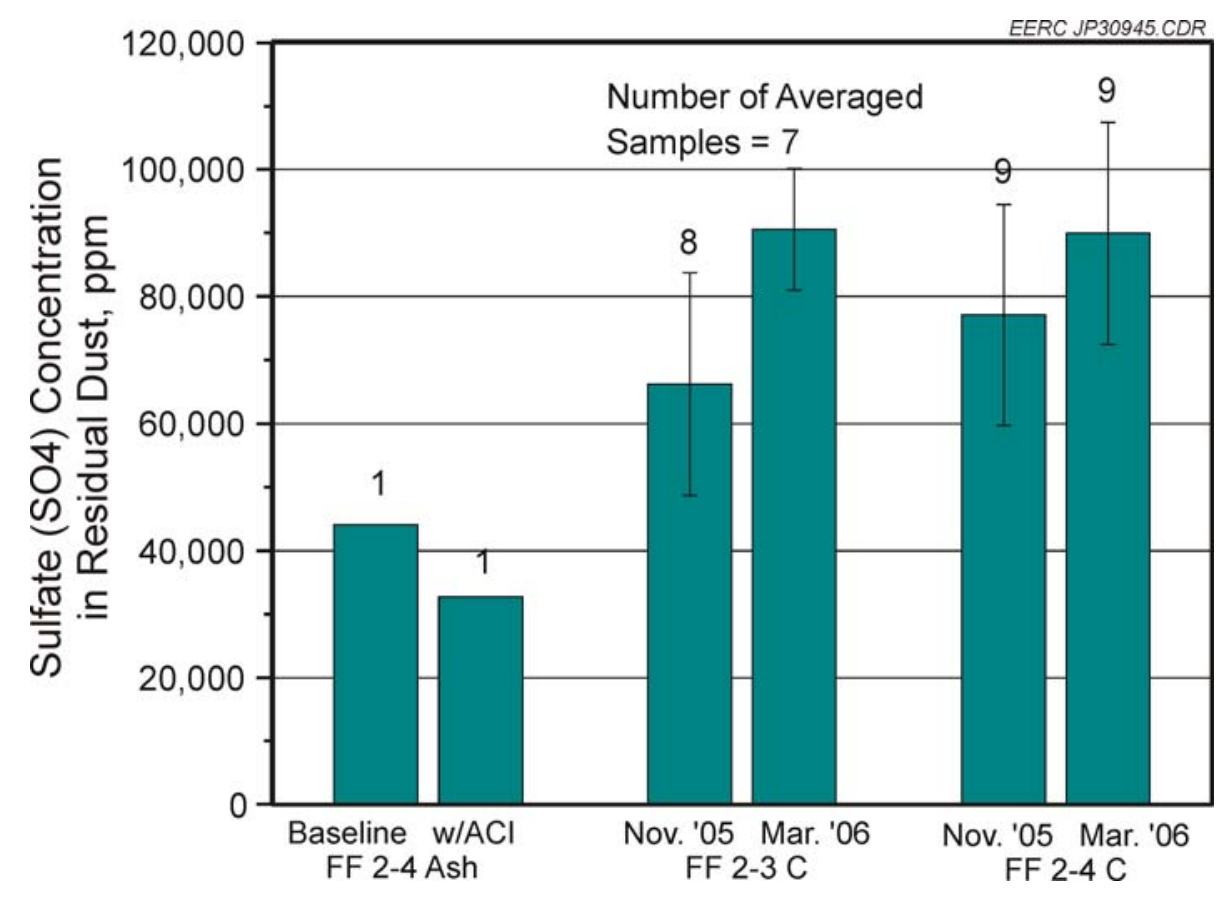

Figure 28. Sulfate content of FF bulk ash and the residual dust from FF 2-3 and 2-4 filter samples.

Ammonia levels in the residual dust of the bag samples are presented in Figure 30. The ammonia levels in the bulk ash are $1990 \mathrm{ppm}$ for baseline and $1740 \mathrm{ppm}$ for monthlong samples. Three observations were made: 1) ammonia appears to be concentrated in the residual dust as compared to the bulk ash, 2) the concentration increased from November 2005 to March 2006, and 3) the trends for Modules 2-3 and 2-4 were similar. The presence of ammonia in the COHPAC ash indicated ammonia carryover from the upstream ESP conditioning system.

Figure 31 presents the results for the carbon content of the residual dust for each bag sample and samples of the bulk ash from FF 2-4. As indicated by the low level of carbon in the baseline FF ash, the unburned carbon content of the ash was low, and this is reflected in the residual dust samples that were not exposed to ACI. For FF ash samples taken during the monthlong test, denoted as "w/ACI," the carbon content is much higher because of the contribution of the AC. This increase is also reflected in the residual dust from the March 2006 FF 2-4 sample, which is the only bag sample that was exposed to ACI. This indicated that some of the AC injected for mercury control was retained in the residual dust of FF 2-4.

Selenium content of the FF residual dust is presented in Figure 32. The exact role of selenium is not well understood, but it has been suggested that selenium hinders mercury removal with AC. Figure 32 shows that the residual dust from the bag samples that were not 


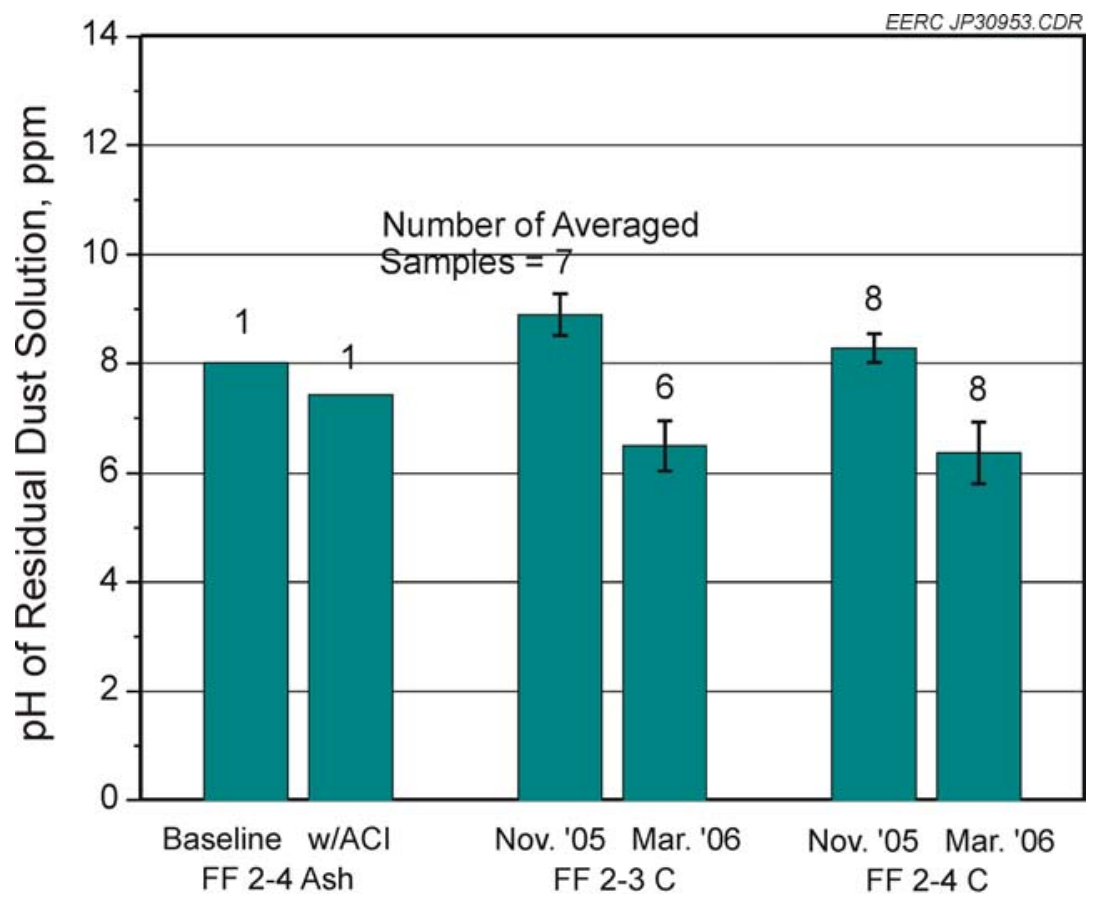

Figure 29. Average $\mathrm{pH}$ level for solutions of the FF ash and the residual dust from FF 2-3 and 24 filter samples.

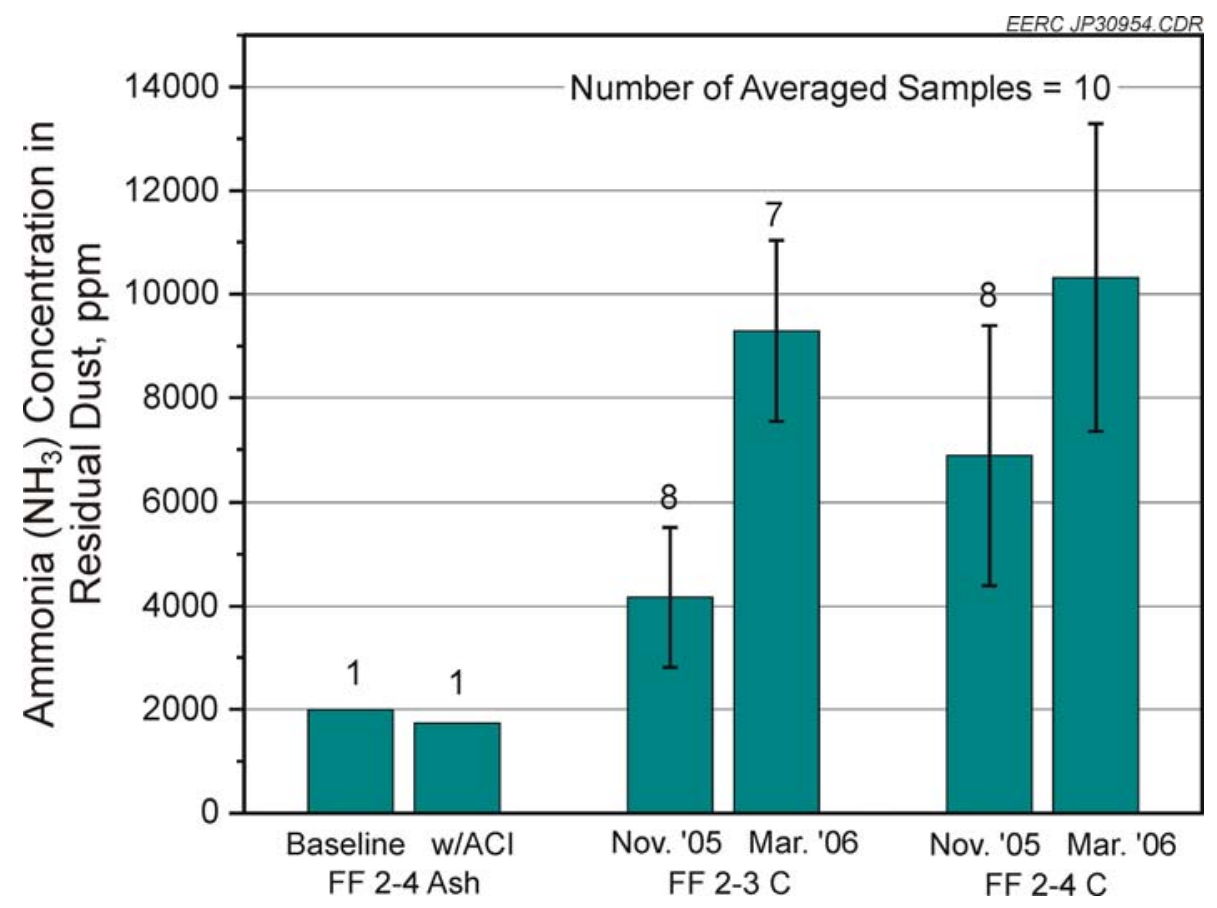

Figure 30. Ammonia content of FF bulk ash and the residual dust from FF 2-3 and 2-4 filter samples. 


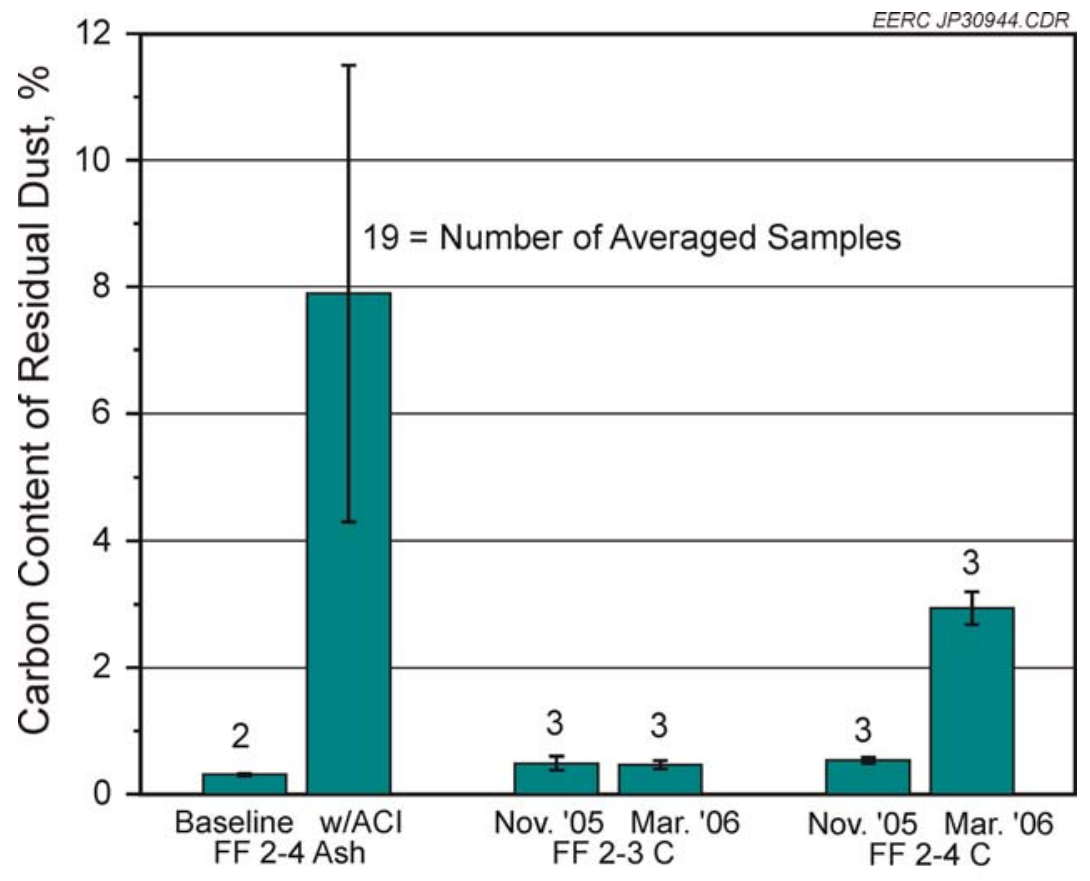

Figure 31. Carbon content of FF bulk ash and the residual dust from FF 2-3 and FF 2-4 filter samples.

exposed to ACI have selenium contents in the range of that found in the baseline FF ash. A slight increase in selenium concentration occurred from November 2005 to March 2006 according to the FF 2-3 bag samples. The significant increase from November 2006 to March 2006 for the FF 2-4 bag samples was due to the exposure of the latter to AC.

Figure 31 indicates a clear trend of increased carbon content in the residual dust that is directly attributed to the mercury control tests. Other linked trends were noted, such as selenium (Figure 32), which also appears to be adsorbed by AC. However, other chemical constituents of interest do not appear to correlate to ACI, for example, sulfates and ammonia, as shown in Figures 28 and 30. These compounds instead appear to be more related to flue gas exposure time; that is, bag samples that have been in service for a longer period of time appear to have higher concentrations of sulfates and ammonia. There was no evidence to indicate that ACI increased the rate of accumulation of sulfates and ammonia, as shown in Figure 33 for the test and nontest modules, FF2-4 and FF2-3, respectively.

\section{In Situ Investigation of Residual Dust}

In addition to the chemical analysis of the residual dust in the bag samples, inspections were conducted using a variety of techniques including visual inspection, optical microscope examination, and other spectroscopic techniques such as scanning electron microscopy (SEM)energy-dispersive x-ray analysis (EDX). 


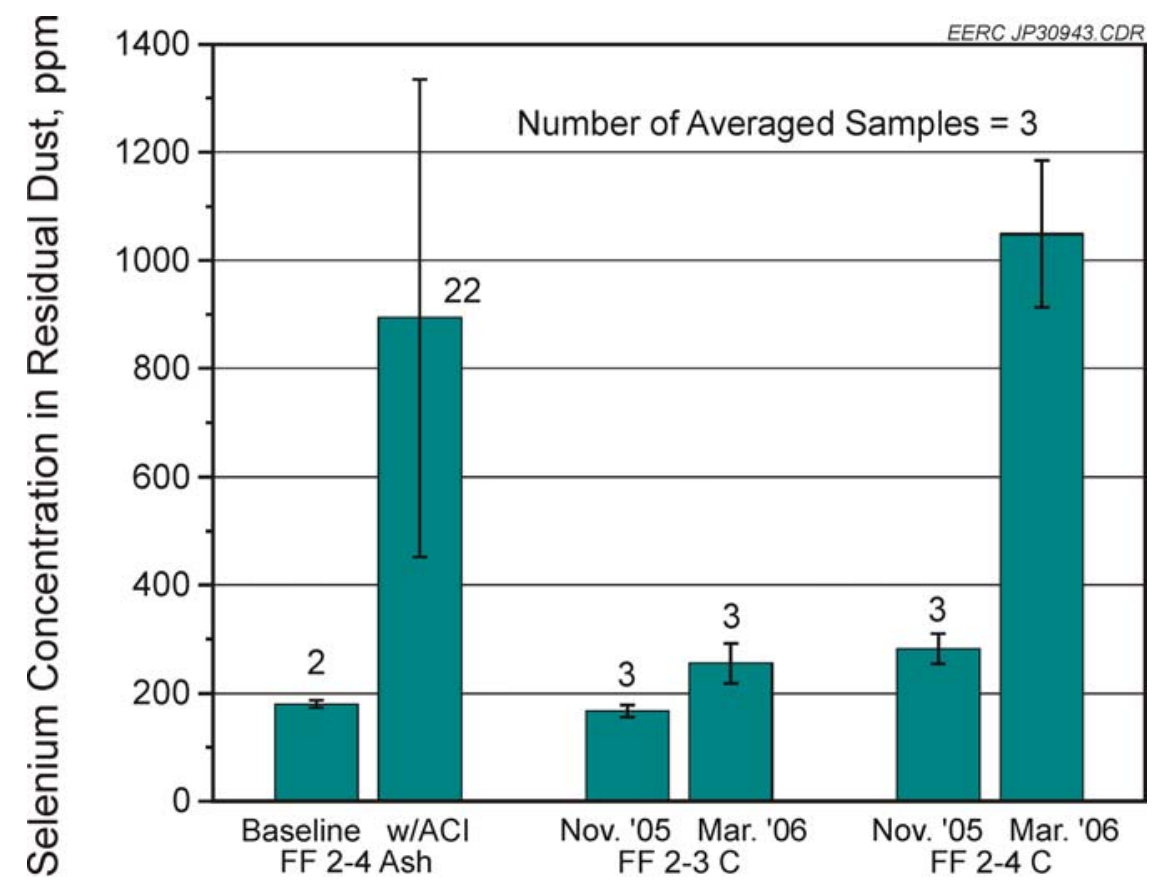

Figure 32. Selenium content of FF bulk ash and the residual dust from FF 2-3 and 2-4 filter samples.

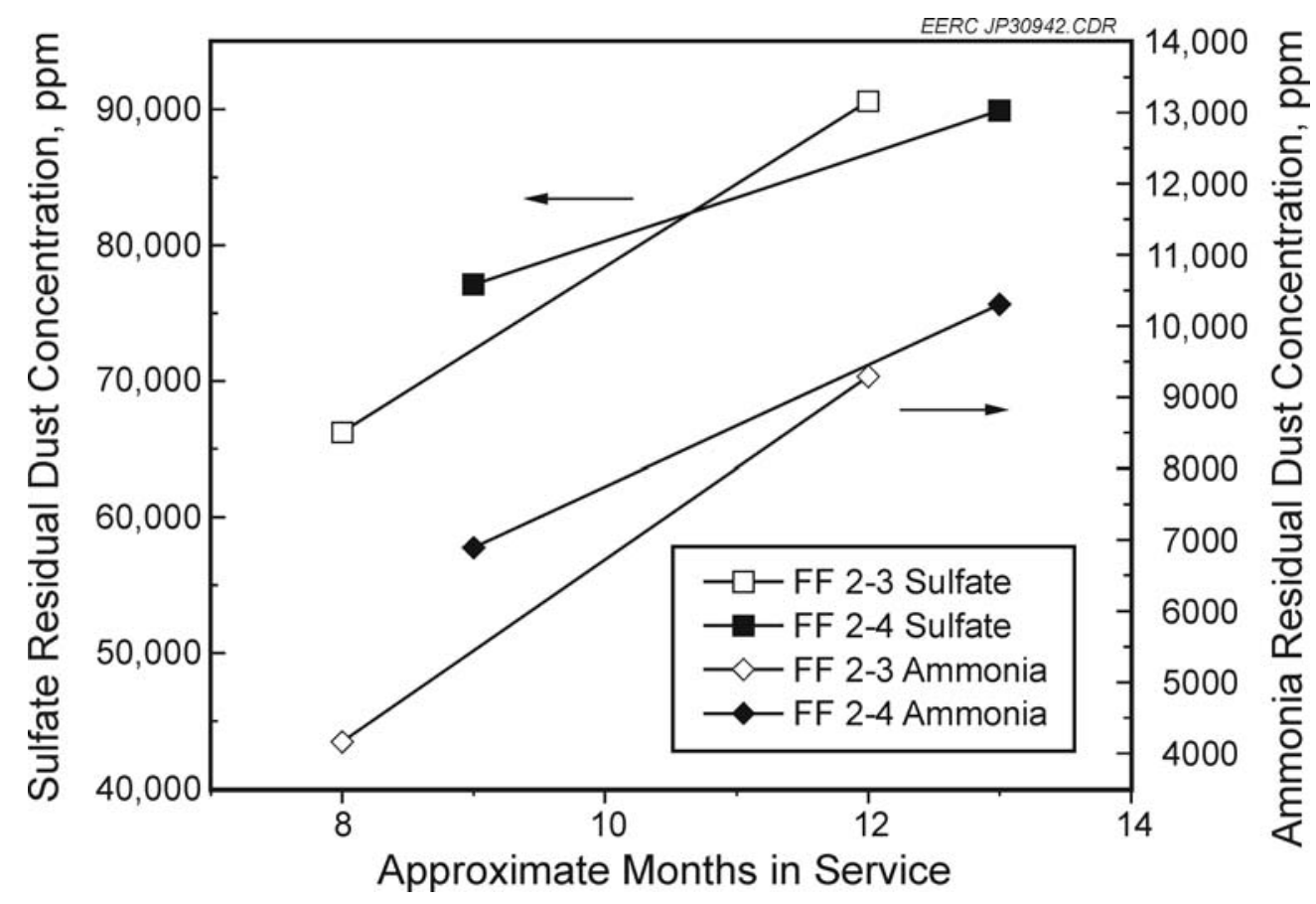

Figure 33. Trends of residual dust sulfate and ammonia concentrations with bag exposure time. 
Overall visual inspection of the bag samples resulted in several observations: 1) the fabric material for the FF 2-3 bags was supplied by a different manufacturer than that used for the FF 24 bags, and the FF 2-4 fabric was slightly heavier and stiffer than that of FF 2-3 (this is substantiated by the new fabric weights given in Table 14, 14.9 versus $16.0 \mathrm{oz} / \mathrm{yd}^{2}$ ); 2) bag samples not exposed to ACI were light tan in color, consistent with the baseline ash color, as indicated in Figure 27; 3) the dust layers for all of the March 2006 samples (FF 2-3 and 2-4) were noticeably heavier and thicker than their November 2005 counterparts. Furthermore, the dust layers on the March 2006 samples had formed dust "nodules" in the areas with heavy dust retention.

Inspection of the samples using an optical microscope at relatively low magnification was performed on samples of each bag. Regarding the November 2005 samples, the surface dust layers were thin and fairly uniform for both FF 2-3 and 2-4. When the outer collection surface of these samples was examined under the microscope, the dust was again fairly uniform in its distribution, and individual fabric fibers were visible through the dust. A representative image is provided in Figure 34, which is a magnified view of the surface of a FF 2-3 November 2005 bag sample. The fabric fibers can be clearly seen through the light dust layer in Figure 34.

On visual inspection, differences were noted between the March 2006 and November 2005 bag samples from both FF 2-3 and 2-4. The dust layers for these samples were substantially deeper, and bag fibers could no longer be seen from the surface (Figure 35). Also, both samples from March 2006 show formation of nodular structures (loosely bound agglomerations of ash 1-2 $\mathrm{mm}$ in size) in the accumulated ash layer.

The March 2006 bag from FF 2-4 (right image in Figure 35) was dark gray in color, consistent with a mix of AC and fly ash. However, when the dust layer on the March FF 2-4 bag is scraped away, there is a distinguishable layer of uncontaminated dust below. Furthermore, there are a substantial number of nodules, approximately $1-2 \mathrm{~mm}$ in size on the surface of the March FF 2-4 bag that appear concentrated in the depressions between the wire cage supports. The areas near the wire cage supports suffered the most wear during handling since they stand pronounced from the filter surface. As a result, reliable observations could not be made for these areas of the bag. The nodules appeared to be loosely bound agglomerations of ash; i.e., they could be broken apart, but had enough strength to stay intact if manipulated with the edge of a spatula. When individual nodules from the FF 2-4 sample had their surfaces carefully scraped away, a core of apparently uncontaminated fly ash was exposed. This is shown in Figure 36 which is an image taken after one of the surface nodules has been carefully cut in half. The dotted outlines in Figure 36 show the surface layer of darker ash surrounding an inner core of much lighter ash. Presumably, the darker material was a mixture of fly ash and AC, while the inner, lighter material is fly ash without AC.

To confirm the composition of the two distinct layers in Figure 36, careful sampling of the two dust layers was performed under the microscope to obtain enough material for a $\mathrm{CHN}$ analysis. The results of this sampling are shown in Table 15 and clearly indicate that carbon 


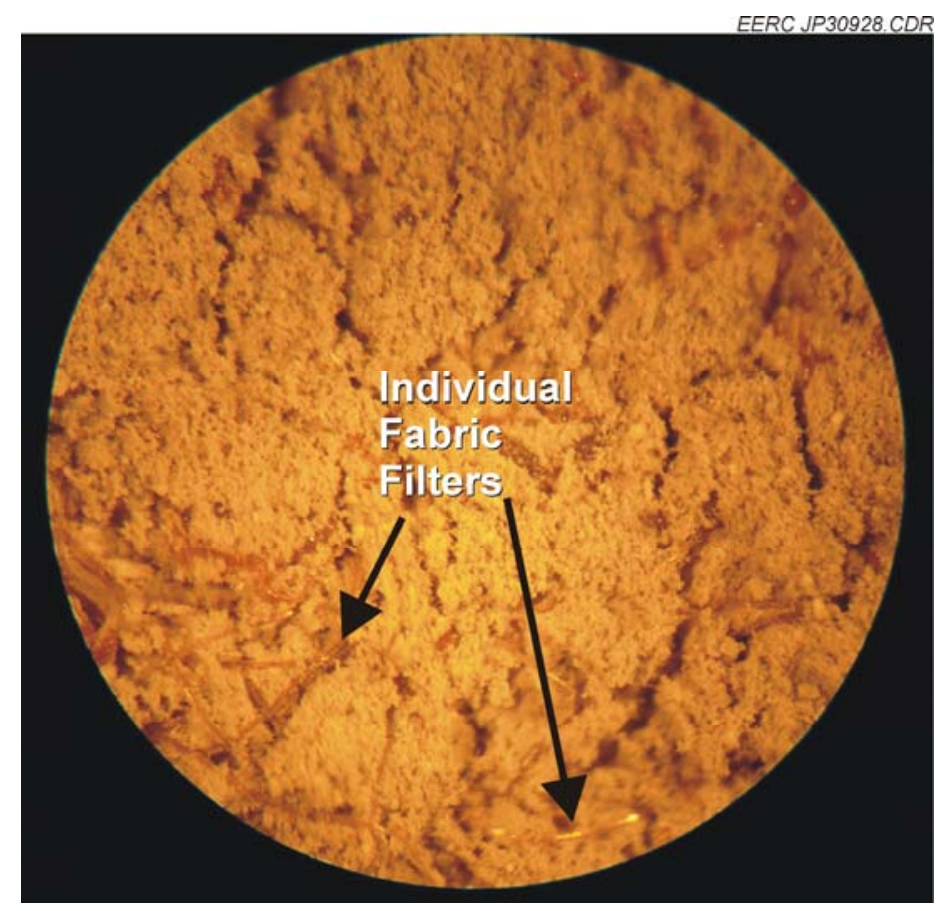

Figure 34. Magnified view of the outer surface of a bag sample from FF 2-3 November 2005. Field of view is approximately $4 \mathrm{~mm}$.

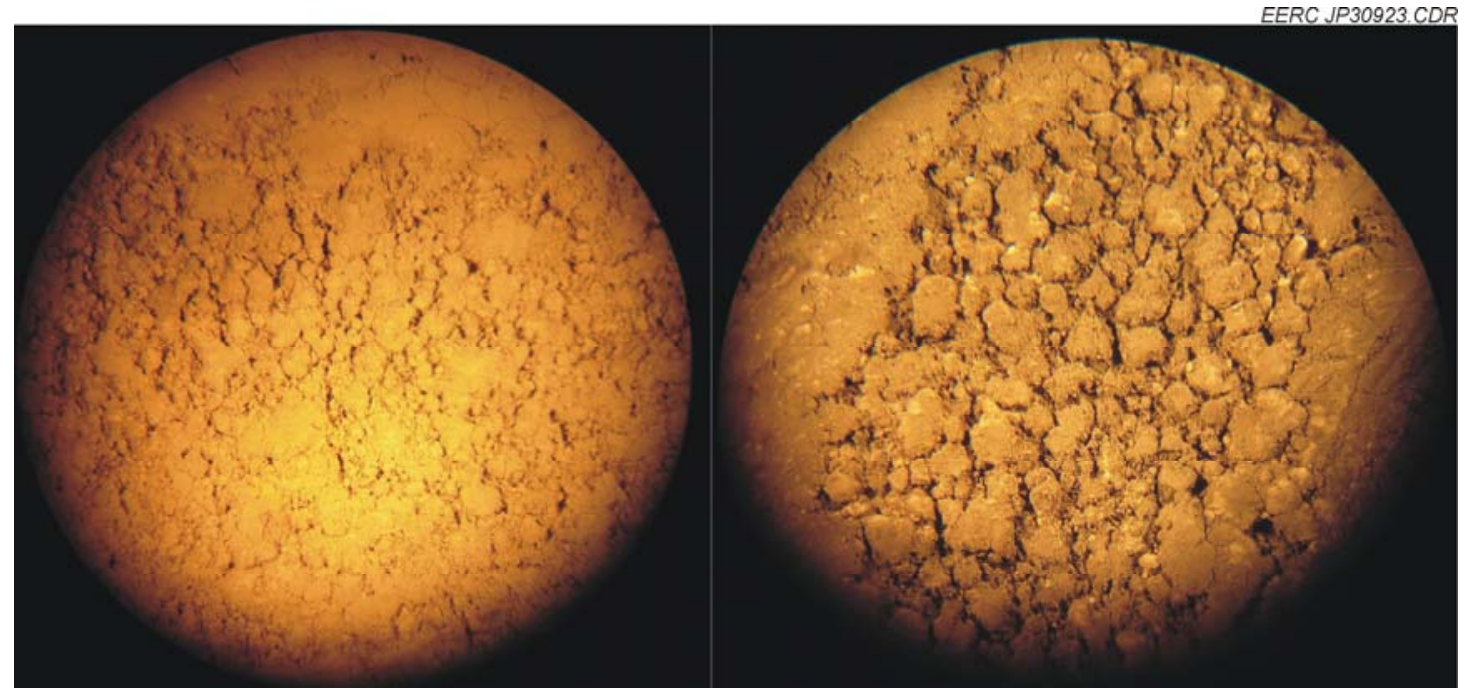

Figure 35. Magnified views of the outer surfaces of March 2006 bag samples from FF 2-3 (left) and FF 2-4 (right). Field of view for each image is approximately $28 \mathrm{~mm}$. 
content was a distinguishing factor between the two layers. This indicated that the inner core of light ash was deposited prior to sorbent injection testing and that dust retention on the filter surface was occurring prior to initiation of field testing.

Higher-magnification microscopic analysis of the filter cross sections was performed using SEM. Figure 37 shows representative composite, cross-sectional images through each bag sample. The string of images clearly shows the exterior dust layer, embedded dust, and fabric fibers. Particulate matter is observed to be embedded throughout all of the filter cross sections. The noticeable difference between the November 2005 samples and their March 2006 counterparts is the depth of the exterior dust layer, which is shown in the images on the left side of each image row.

SEM-EDX analysis was used to analyze the composition of the embedded dust in each filter sample at selected points. Scattered point measurements, approximately 80 per bag sample cross section, were made on the embedded material. An overall average composition was then

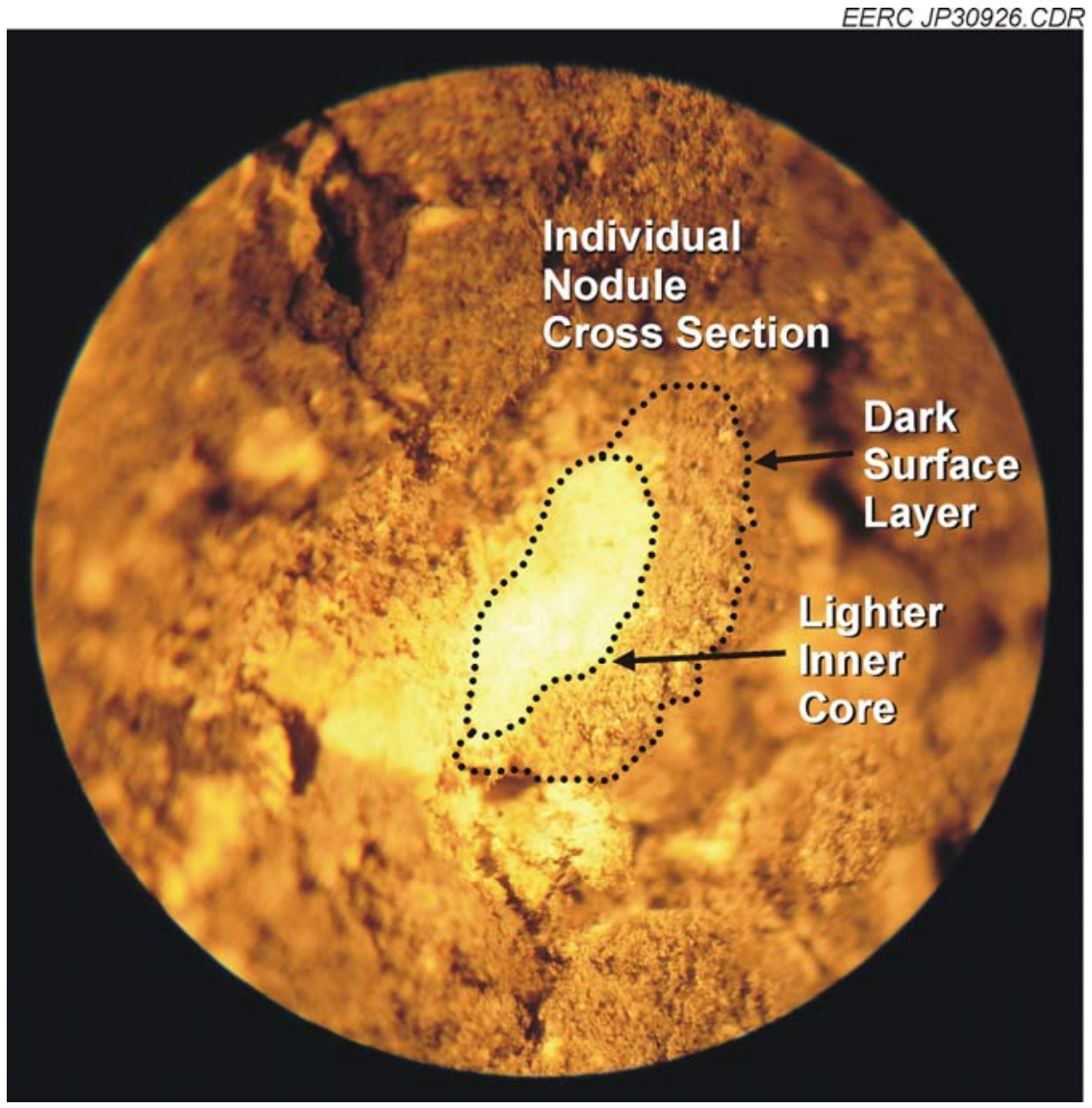

Figure 36. Magnified view of a scraped nodule showing layered structure. Image is from the surface of a FF 2-4 sample from March 2006. Field of view is approximately $10 \mathrm{~mm}$. 


\section{Table 15. Summary of CHN Results for Bag Surface Sampling}

\begin{tabular}{lc}
\hline Sample & Percentage Carbon \\
\hline FF 2-4 March '06 Bag Surface Samples & \\
Outer, Darker Surface Layer & 2.25 \\
Inner, Lighter Layer & 0.55 \\
Other Comparative Values & \\
FF 2-4 Baseline Ash (prior to ACI) & 0.30 \\
FF 2-4 Monthlong Test Ash Average (with ACI) & 7.93 \\
Residual Dust Average for FF 2-4 March '06 Samples & 2.94 \\
\hline
\end{tabular}

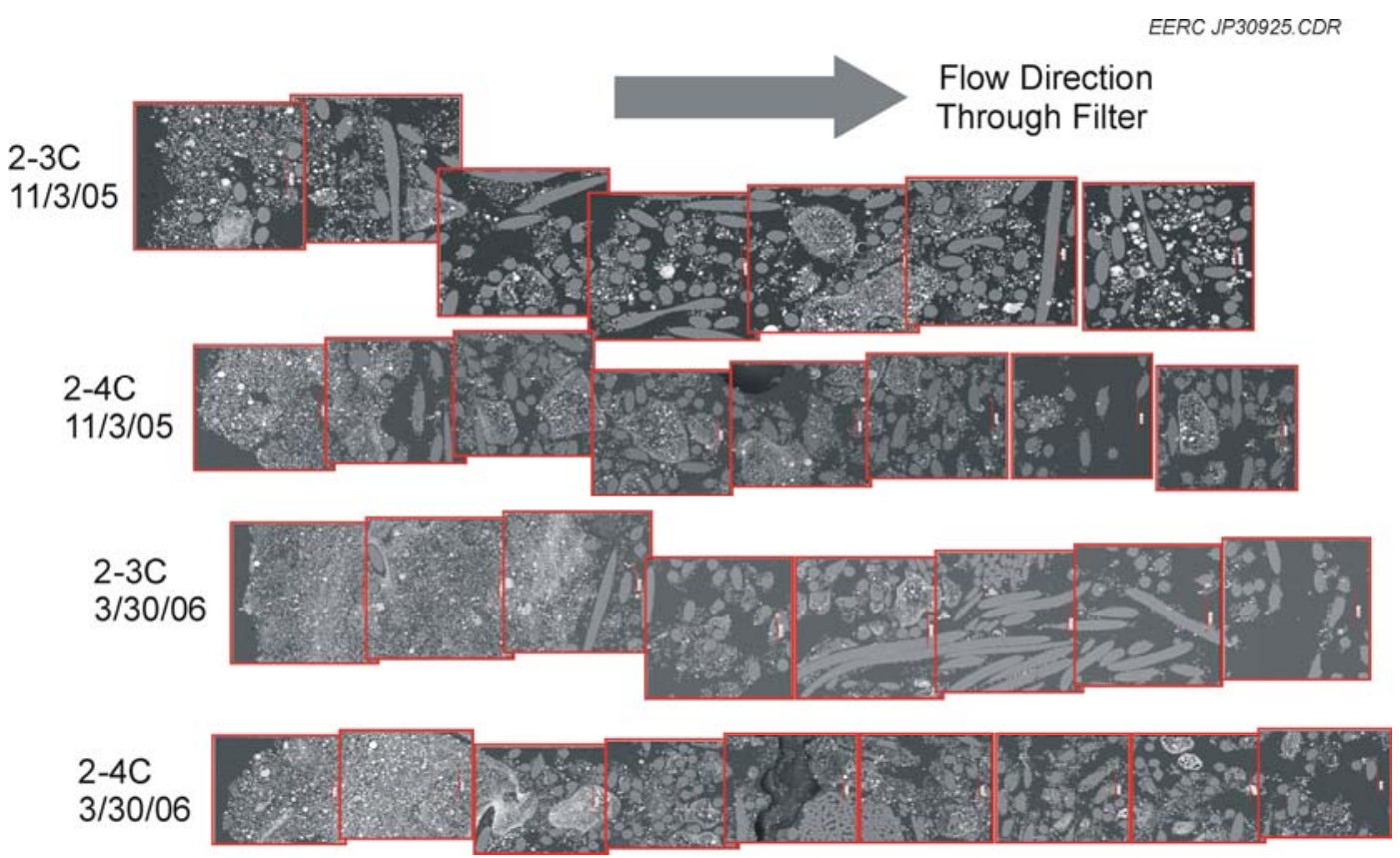

Figure 37. Composite microscopic images across the cross section of each of the bag samples.

calculated to represent the embedded material. Table 16 contains these composition data along with bulk XRF analyses of corresponding FF 2-4 ash. For the samples with AC content, i.e., the 2-4 C bag and 2-4 ash samples from March 2006, the carbon is not accounted for in the composition data of Table 16. EDX was not successful in distinguishing AC particles, and carbon is not detected by XRF. When the residual dust composition for samples from both FF 23 and 2-4 are compared, there were increased concentrations of sulfur and calcium relative to the bulk ash. 
Table 16. Point EDX Averages for the Embedded Material in 2-4C and 2-3C Bag Samples and Bulk XRF Analyses for the Corresponding FF 2-4 Ash (assumed oxide forms)

\begin{tabular}{|c|c|c|c|c|c|c|c|c|c|c|}
\hline Bag & $\mathrm{MgO}$ & $\mathrm{Al}_{2} \mathrm{O}_{3}$ & $\mathrm{SiO}_{2}$ & $\mathrm{SO}_{3}$ & $\mathrm{~K}_{2} \mathrm{O}$ & $\mathrm{CaO}$ & $\mathrm{TiO}_{2}$ & $\mathrm{Fe}_{2} \mathrm{O}_{3}$ & $\mathrm{Na}_{2} \mathrm{O}$ & $\mathrm{P}_{2} \mathrm{O}_{5}$ \\
\hline \multicolumn{11}{|c|}{ Bag Samples Taken 11/3/05, Ash Sampled 1/20/06 } \\
\hline $2-4 C$ & 1.6 & 15.1 & 40.1 & 15.1 & 0.8 & 21.6 & 1.0 & 4.2 & 0.1 & 0.4 \\
\hline $\begin{array}{l}2-3 C \\
2-4\end{array}$ & 1.9 & 14.3 & 41.7 & 13.2 & 0.8 & 23.2 & 0.8 & 3.7 & 0.1 & 0.2 \\
\hline Ash & 2.93 & 18.7 & 45.1 & 7.98 & 0.94 & 15.6 & 1.24 & 6.41 & 0.67 & 0.36 \\
\hline \multicolumn{11}{|c|}{ Bag Samples Taken 3/30/06, Ash Sampled 3/27/06 } \\
\hline 2-4C & 1.3 & 13.3 & 35.7 & 24.8 & 0.6 & 18.5 & 1.4 & 3.9 & 0.1 & 0.3 \\
\hline $\begin{array}{l}2-3 C \\
2-4\end{array}$ & 1.5 & 14.7 & 36.8 & 19.8 & 0.7 & 21.1 & 1.0 & 4.1 & 0.1 & 0.1 \\
\hline Ash & 3.03 & 19.5 & 48.2 & 6.05 & 1.05 & 14.5 & 1.20 & 5.27 & 0.77 & 0.34 \\
\hline
\end{tabular}

A further comparison of the point EDX measurements of the embedded material is presented in Figure 38, which is a plot of the percentage change in composition, as determined by averaging point EDX values from November 2005 to March 2006. The figure indicates that the sulfates increased during this time, which is in agreement with the residual dust chemical analyses of Figure 28.

Additional bag cross sections were examined with SEM-EDX to provide spatial information of elemental distributions. Sample images are shown from a cross section of the FF 2-3 bag from March 2006 in Figure 39.

The element mapping presented in Figure 39 provides visual evidence of the location of the accumulated sulfur. When the individual element maps are compared to the original SEM image, the core constituents of the ash, e.g., calcium and aluminum, are present throughout the dust layer, including the clearly discernible particles larger than approximately 5-10 $\mu \mathrm{m}$. In the sulfur map, however, sulfur appears to only be associated with the very fine particles and the spaces between larger particles. In the image, traces of sulfur outline the larger particles and leave "holes" behind where no sulfur was detected in them. The strong sulfur response in the far right-hand side of the image is from a fabric cross section.

The element mapping data imply that sulfur was entering the dust layer either in the gas phase, as $\mathrm{SO}_{2}$, or as fine particulates, for instance as ammonium sulfate/bisulfate. This is qualitatively supported by a high-resolution XRD scan (22-hour duration) of dust from a filter sample. This analysis detected calcium sulfate and a form of ammonium sulfate. Figure 40 shows the diffraction pattern obtained from dust off of the FF 2-3 March 2006 bag sample. 


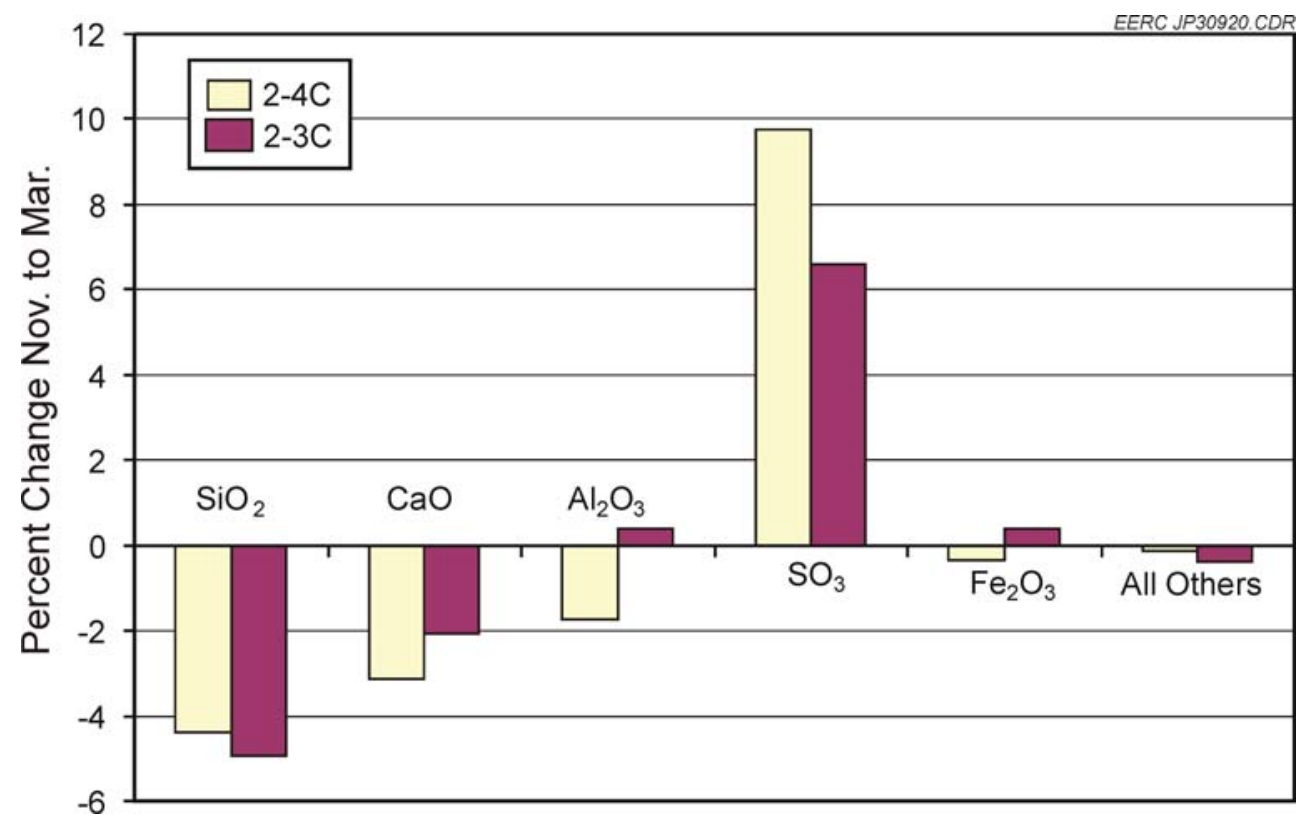

Figure 38. Differences in composition between the embedded dust from the November 2005 to the March 2006 bag samples.

\section{Comparison to Bags in Other Modules}

Comparative data from other FF modules on Unit 2 have been made available in the form of bag samples pulled from Module 2-1, Compartment H. While these bag samples are of the same specification as those from Modules 2-3 and 2-4, they were part of an ongoing test program at Big Brown and do not have a consistent history. The two bag samples from Module 2-1 have been installed for different periods of time. One was in service for approximately 2 years and the other for nearly 3 years. However, significant numbers of the bags in the same module compartment have been changed out at earlier intervals, which likely caused some preferential redistribution of flow away from these bags. These qualifiers aside, the bag samples from $2-1 \mathrm{H}$ were run through the same battery of chemical analyses as the bags from 2-3 and 2-4. The results are presented in Table 17.

Table 17 shows that the trends of increasing sulfate and ammonia levels and decreasing solution $\mathrm{pH}$ continue with flue gas exposure time. The data for sulfate and ammonia levels are shown in Figure 41. However, the amount of residual dust for the 2-1 bags appears to have leveled off at a value between those observed for the November 2005 and March 2006 samples. This could be indicative of a stable operating condition or the result of the preferential flow distributions set up by the installation of newer bags in Compartment 2-1 H. 


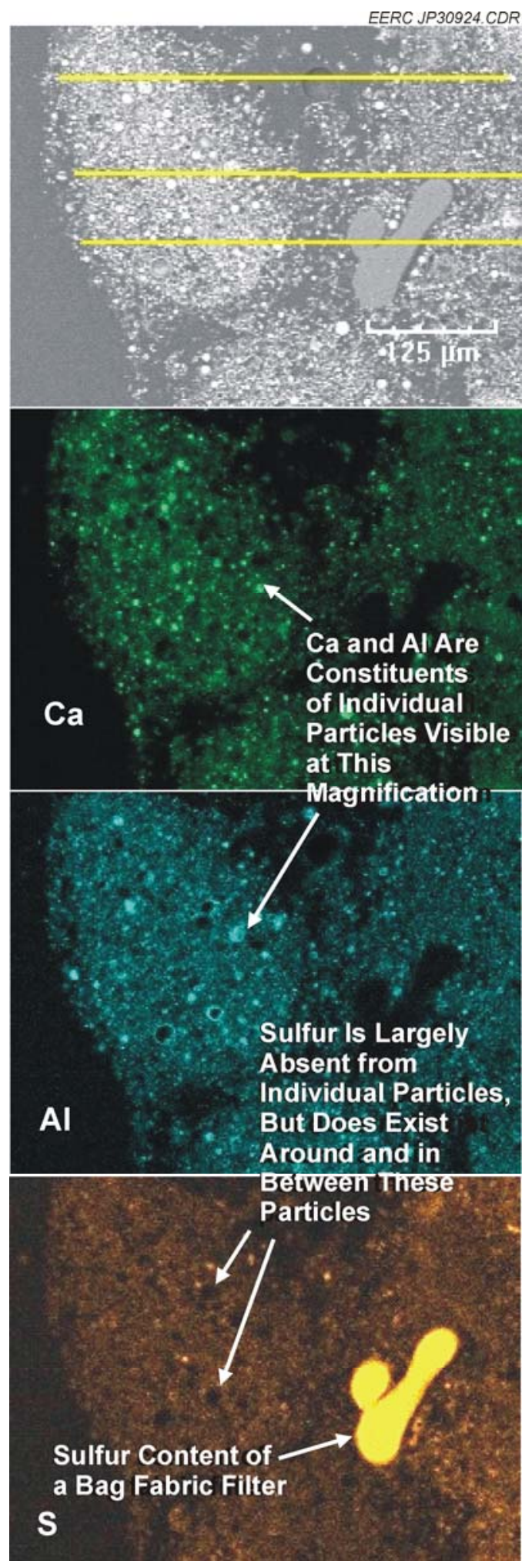

Figure 39. SEM image and element maps for the outer surface of a sample from FF 2-3 March 2006. From the top: SEM image, calcium element map, aluminum element map, and sulfur element map. 


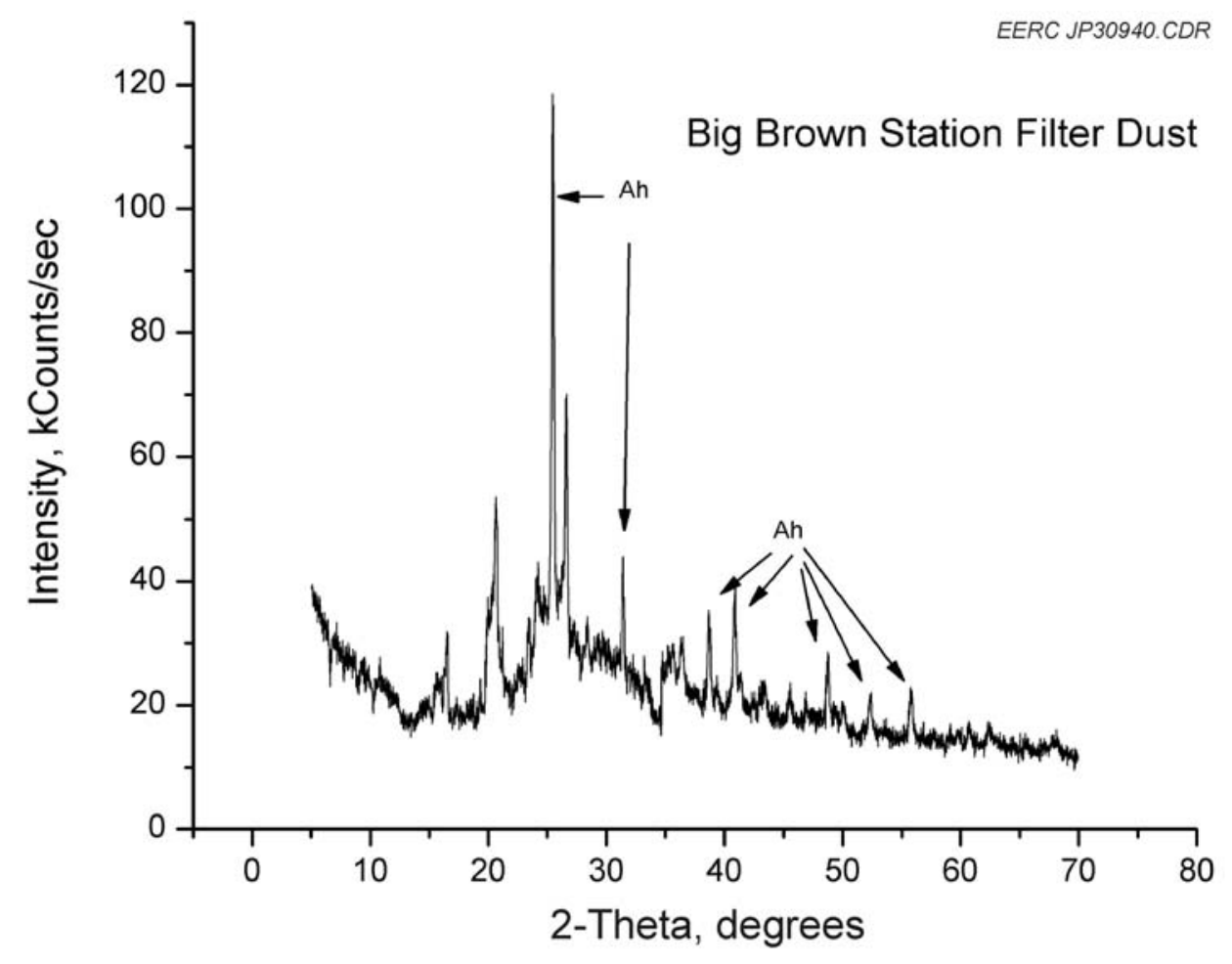

Figure 40. Diffraction pattern of residual dust removed from a FF 2-3 March 2006 filter sample. $\mathrm{Ah}=$ anhydrite $\left(\mathrm{CaSO}_{4}\right)$.

Table 17. Summary of Analyses for the Bag Samples from Module 2-1 Compared to Averages for Modules 2-3 and 2-4

\begin{tabular}{|l|c|c|c|c|c|c|}
\hline $\begin{array}{l}\text { FF Module, Compartment } \\
\text { Bag Sample }\end{array}$ & $\begin{array}{c}2-1 \mathrm{H} \\
\mathrm{C}-1^{\mathrm{a}}\end{array}$ & $\begin{array}{c}2-1 \mathrm{H} \\
\mathrm{C}-2^{\mathrm{a}}\end{array}$ & $\begin{array}{c}2-3 \mathrm{C} \\
\text { Nov. '05 }\end{array}$ & $\begin{array}{c}2-3 \mathrm{C} \\
\text { Mar. '06 }\end{array}$ & $\begin{array}{c}2-4 \mathrm{C} \\
\text { Nov. '05 }\end{array}$ & $\begin{array}{c}2-4 \mathrm{C} \\
\text { Mar. '06 }\end{array}$ \\
\hline $\begin{array}{l}\text { Approximate Months in } \\
\text { Service }\end{array}$ & 35 & 24 & 8 & 12 & 9 & 13 \\
\hline $\begin{array}{l}\text { Residual Ash Sulfate Levels, } \\
\text { ppm }\end{array}$ & 137,000 & 101,000 & 66,200 & 90,600 & 77,100 & 89,900 \\
\hline Residual Ash Ammonia, ppm & 18,400 & 13,100 & 4160 & 9290 & 6890 & 10,300 \\
\hline Residual Ash Solution pH & 4.5 & 5.2 & 8.9 & 6.5 & 8.3 & 6.4 \\
\hline $\begin{array}{l}\text { Ratio of Residual Ash Weight } \\
\text { to Clean Filter Weight, \% }\end{array}$ & 112 & 112 & 61.6 & 125 & 101 & 129 \\
\hline
\end{tabular}

${ }^{a}$ Values for these samples are based on one set of analyses, while values for all other samples are averages of at least six analyses. 


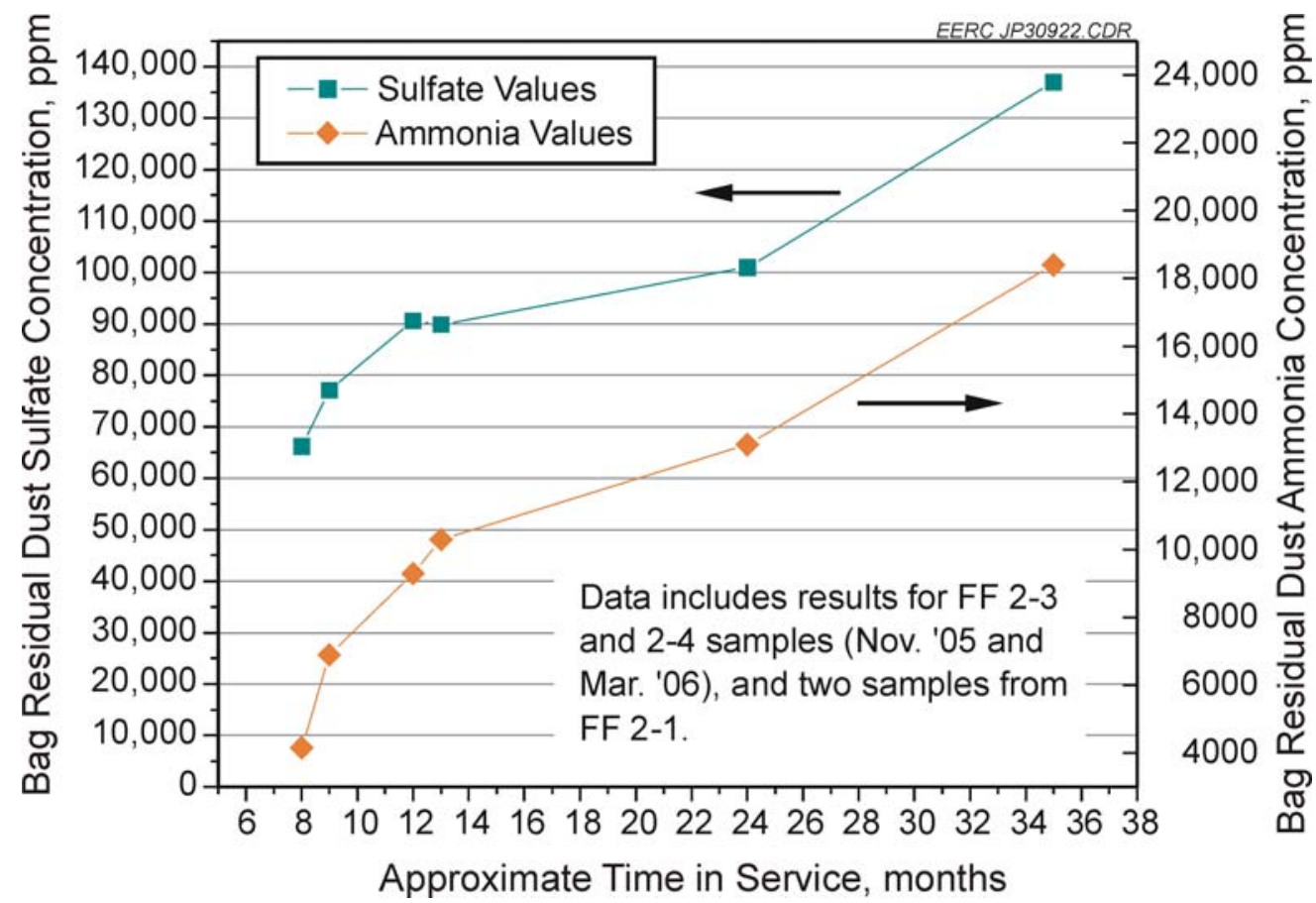

Figure 41. Plot of sulfate and ammonia concentrations in the residual dust for several Unit 2 bag samples.

\section{Plant Data}

\section{Ash Conditioning}

Big Brown employs ash conditioning through injection of sulfur trioxide $\left(\mathrm{SO}_{3}\right)$ prior to the air heater and anhydrous ammonia $\left(\mathrm{NH}_{3}\right)$ at the ESP inlet. These injections are the source of the ammonia (and possibly some of the sulfates) detected in the residual dust of the bags samples. Regarding ESP performance, these injections decrease the resistivity of the ash which increases ash collection, and the ammonium sulfate produced increases the cohesive strength of the dust layer which helps to prevent ash reentrainment during rapping. Sulfur trioxide and ammonia injection rates were proportional to load; nominal values at full-load conditions were approximately $10 \mathrm{ppm}$ for sulfur trioxide and $8 \mathrm{ppm}$ for ammonia. Figure 42 is a plot of the recorded injection levels. As Figure 42 shows, these nominal values were constant throughout the monthlong test, but were changed during the 100\% PRB burn on April 5, 2006, to the nominal rates of $15 \mathrm{ppm}$ sulfur trioxide and $4 \mathrm{ppm}$ ammonia. Injection continued at these rates until May 1, 2006 (coincident with the start of the bag change in FF 2-4), when they were changed back to the original values of $10 \mathrm{ppm}$ for sulfur trioxide and $8 \mathrm{ppm}$ for ammonia. This time line is summarized in Table 18. 


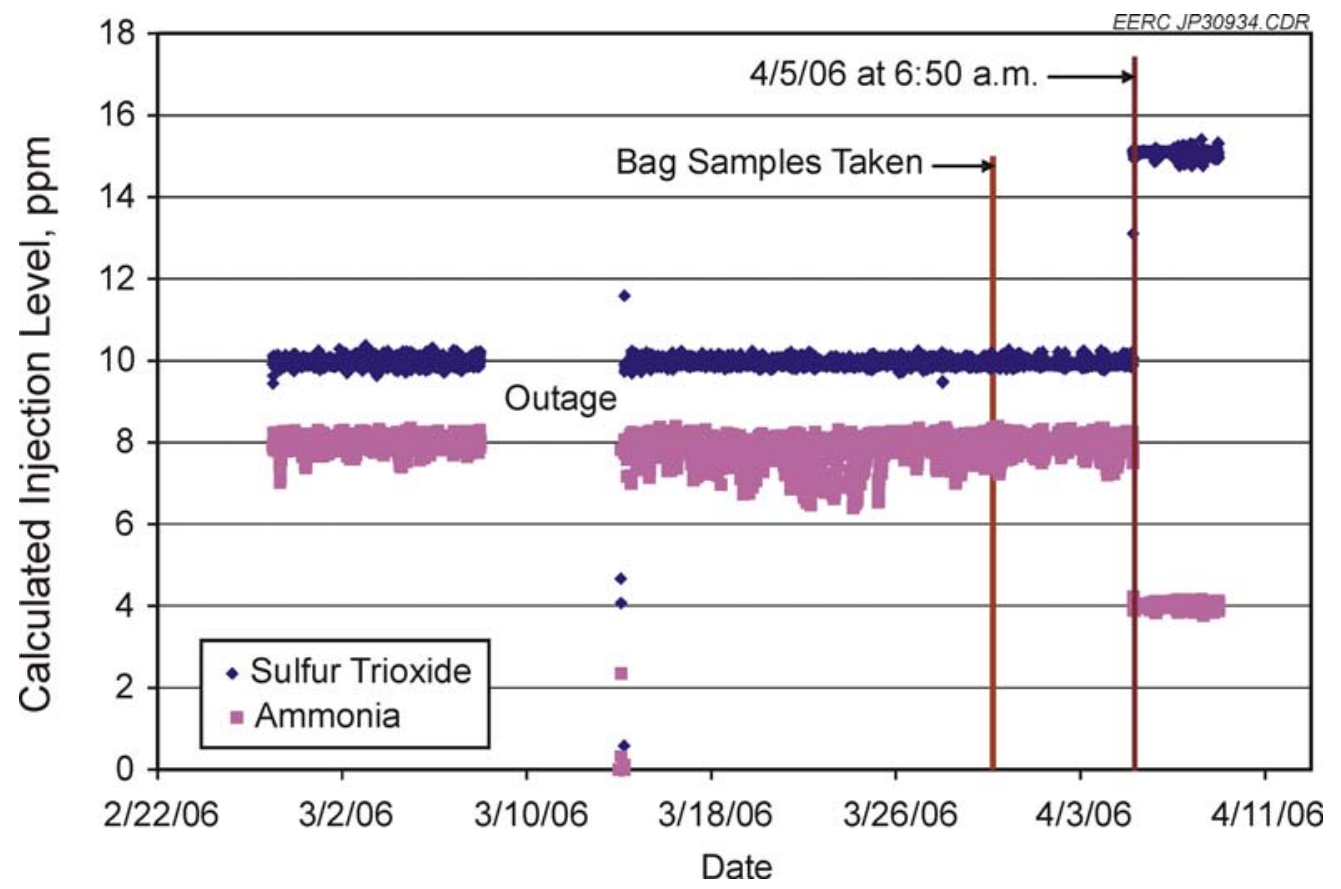

Figure 42. Recorded sulfur trioxide and ammonia injection rates during the period of monthlong and $100 \%$ PRB testing.

Table 18. Summary of Events for the Ash-Conditioning Settings

\begin{tabular}{lc}
\hline Date & Event \\
\hline November 20, 2005 & $\begin{array}{c}\text { Unit 2 comes up after outage, } \mathrm{NH}_{3} \text { injection begins recording, } \\
\text { approximately } 8 \mathrm{ppm} . \mathrm{SO}_{3} \text { rate indicates zero injection. }\end{array}$ \\
$\begin{array}{l}\text { December 2, 2005 } \\
\text { March 30, 2006 }\end{array}$ & $\begin{array}{c}\mathrm{SO}_{3} \text { injection rate begins recording, approximately } 10 \mathrm{ppm} . \\
\text { Post-monthlong test bag samples collected. Unit transitions to } \\
100 \% \mathrm{PRB} \text { coal. }\end{array}$ \\
$\begin{array}{l}\text { April 5, 2006 } \\
\text { Conditioning rates changed to } 15 \mathrm{ppm} \text { for } \mathrm{SO}_{3} \text { and } 4 \mathrm{ppm} \text { for } \\
\text { April 30, 2006 } \\
\begin{array}{l}\mathrm{NH}_{3} . \\
\text { May 1, 2006 }\end{array} \\
\text { Change conditioning rates back to original values of } 10 \mathrm{ppm} \\
\text { for } \mathrm{SO}_{3} \text { and } 8 \text { ppm for } \mathrm{NH}_{3} .\end{array}$ \\
\hline
\end{tabular}

Ammonium sulfates are presumably formed with the injection of sulfur trioxide and ammonia; the molar ratio of ammonia to sulfur trioxide is $2: 1$. The formation of ammonium sulfates is responsible for the improved cohesive strength and is the preferred removal method for the sulfur trioxide. At Big Brown's initial injection rates of 10 and $8 \mathrm{ppm}$ for sulfur trioxide and ammonia, respectively, the molar ratio is 3.8:1 ammonia to sulfur trioxide (mass basis) which indicates that there is excess ammonia available to form the ammonium sulfate. However, after the conditioning system set points were changed to 15 and $4 \mathrm{ppm}$ for sulfur trioxide and 
ammonia, respectively, the molar ratio is computed to be 1.3:1 ammonia to sulfur trioxide, which indicates a deficit of ammonia and that excess sulfur trioxide will be present. While this change occurred very late in the field testing and significant effects had already been observed on the COHPAC bags, the presence of excess sulfur trioxide could have played a role in the inability of the bags to recover after the completion of field testing.

\section{FF 2-4 Temperatures}

Temperatures across the FF were considered as a possible cause for the deterioration in the bag's condition. Both low (below $280^{\circ} \mathrm{F}$ ) and high (above $385^{\circ} \mathrm{F}$ ) temperature excursions were noted during field testing and are documented in Appendix F. Unusually low baghouse temperatures could have encouraged the rapid buildup of material on the bags that was detected during the bag analysis. High temperatures could have caused physical damage to the bag material itself. The high-temperature excursions occurred soon after the monthlong test bag sampling on March 30, 2006. Bag samples beyond this time were not available for evaluation, so the impact, if any, of the noted temperature excursions could not be determined.

\section{Baghouse Hopper Deposits}

Following the $\mathrm{Hg}$ field testing, the residual $\Delta \mathrm{P}$ across $\mathrm{FF} 2-4$ had reached a point where TXU was not confident in the performance of this baghouse for the upcoming summer season; therefore, the plant initiated a full bag replacement of FF 2-4 in May 2006. During the bag change, it was discovered that two of the eight hoppers (designated $\mathrm{C}$ and $\mathrm{H}$ ) on FF 2-4 were plugged and filled with ash. In the ash filling these hoppers, unusual deposits were found mixed with the loose ash, and the ash itself was reported to be very hot and smoldering.

\section{Hopper Deposit Analysis}

Compartment $\mathrm{C}$ was taken off-line for the filter change on May 1, 2006. It was the first compartment serviced during the bag change since one of the ash-level sensors indicated the compartment was not pulling ash completely. However, when opened, it was discovered that the hopper was plugged and overfilled with ash to a height above the access door. A diagram of a typical baghouse compartment is provided in Figure 43. Based on the observations of the contractors who cleaned compartment 2-4 C, there was no indication that the dust level reached the bottom of the bags; however, dust was found accumulated in the compartment inlet duct. This suggested that the ash had accumulated to at least the level of the inlet duct, possibly as indicated in Detail A of Figure 43. The ash above the access door was dumped out, and the remaining ash was vacuumed and shoveled out by plant contractors. The ash that was dumped and the ash that remained in the bottom of the hopper were reported to be very hot and smoldering. Also, in the bottom of Hopper C, solid deposits were found mixed with the loose ash. Cleaning of the hopper and sorting of the deposits were performed by plant contractors and plant personnel. They categorized the deposits into two general types, of which representative photos are provided in Figure 44. On the left in Figure 44 is a sample received by the EERC and 

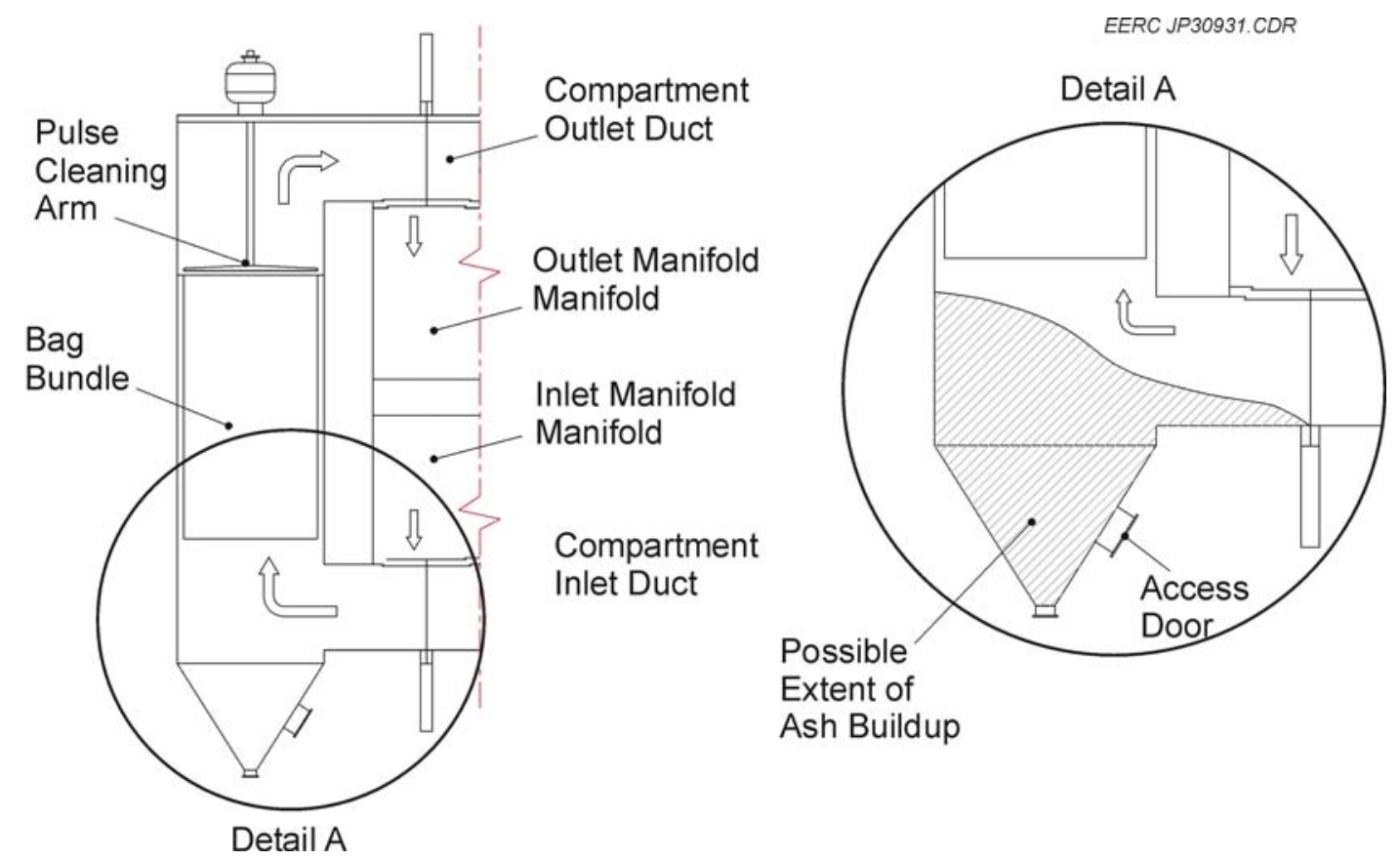

Figure 43. Cross-sectional diagram of a representative baghouse compartment and, in Detail A, a diagram indicating the possible extent of ash accumulation based on observations of the contractors who cleaned Compartment 2-4 C.

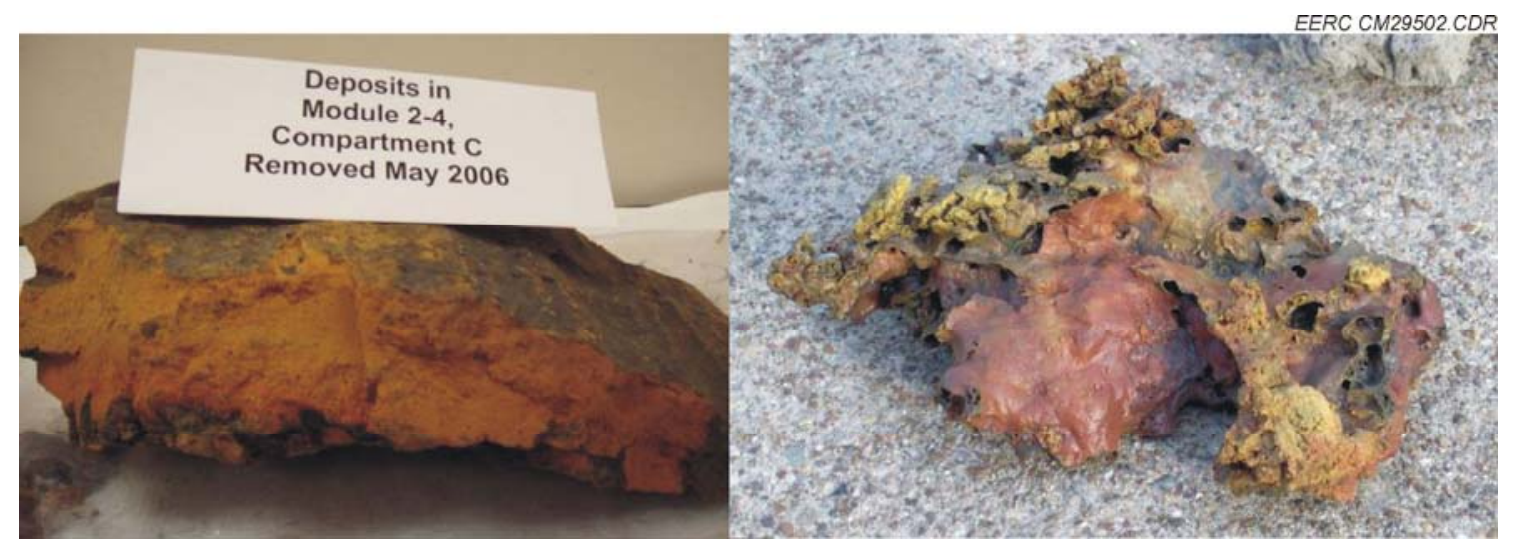

Figure 44. Photos of representative deposit samples collected from Hopper C. On the left is a sample of the monolithic deposit, and on the right is a sample of the hard popcorn deposit that has been rinsed. Images are not to the same scale.

termed the "monolith." This deposit was solid with no internal voids. It possessed good mechanical strength and did not crumble through ordinary handling. The deposit sample on the right was photographed at Big Brown, after being rinsed with water, and is similar to samples received by the EERC for study. This deposit, termed "popcorn," was very strong and hard and 
exhibited significant porositby which resembled trapped gas bubbles. The approximate layering in the bottom of Hopper C, as observed by the plant contractors, is diagrammed in Figure 45.

Hopper $\mathrm{H}$ was taken off-line as part of the normal sequence through the eight compartments since it displayed no abnormal operation. However, when opened on May 16, 2006, it was discovered that this hopper was also plugged and overfilled with ash. Similar to Hopper $\mathrm{C}$, when the ash above the access door was dumped out, it was reported to be hot and smoldering, and deposits were discovered in the hopper. Figure 46 contains images for the two representative deposits. The left deposit in Figure 46, "orange," appears less dense than either deposit from Hopper $\mathrm{C}$ and had some mechanical strength but, again, less than either Hopper $\mathrm{C}$ deposit. It also had a solid interior with no voids. The right deposit, "gray," in Figure 46 possesses very little mechanical strength and has the appearance of a simple agglomeration of the FF ash. According to the plant contractors, the layering in the bottom of the hopper cone for Hopper $\mathrm{H}$ was similar to that in Hopper C, Figure 45, with the orange deposit in the central core and the gray masses on top mixed with the loose ash.

On receipt of the deposit samples, the EERC took representative samples from the deposits and determined bulk composition and carbon content. Samples were also examined by SEM and subjected to XRD to determine the mineral phases present. Additionally, physical observations such as color and mechanical strength were noted during the preparation of the samples for analysis.

Both deposit types recovered from Hopper $\mathrm{C}$ and received by the EERC possessed significant mechanical strength, with the popcorn sample being stronger. Upon examination, it was determined that both deposits from Hopper $\mathrm{C}$ were sintered which gave them mechanical strength. The mineralogy of the two deposit types is very similar, with both having the same minerals present; however, the higher-temperature minerals were not as well developed in the

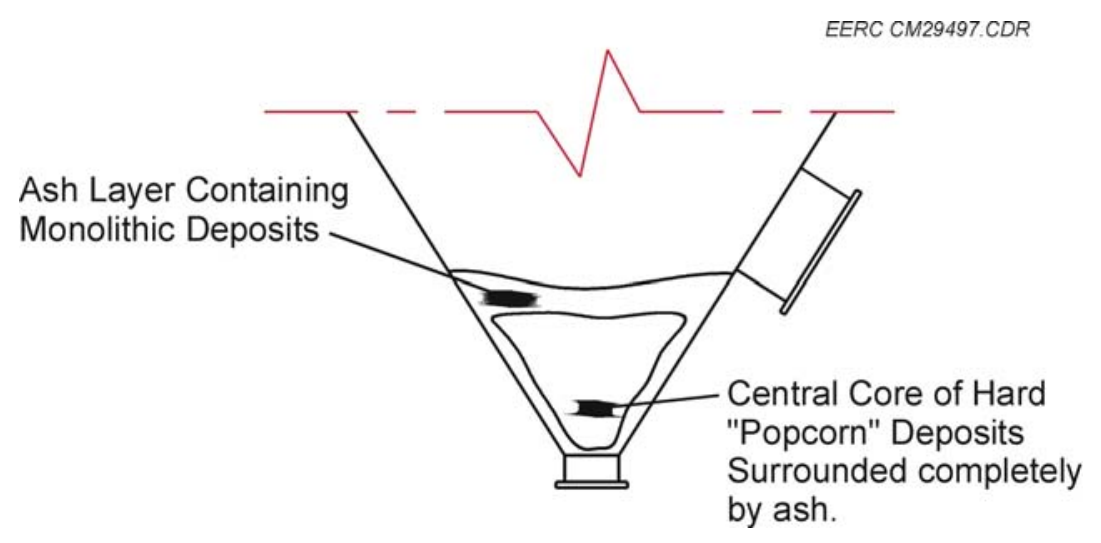

Figure 45. Diagram showing the approximate layering (as observed by plant contractors) in the bottom of Hopper C. 


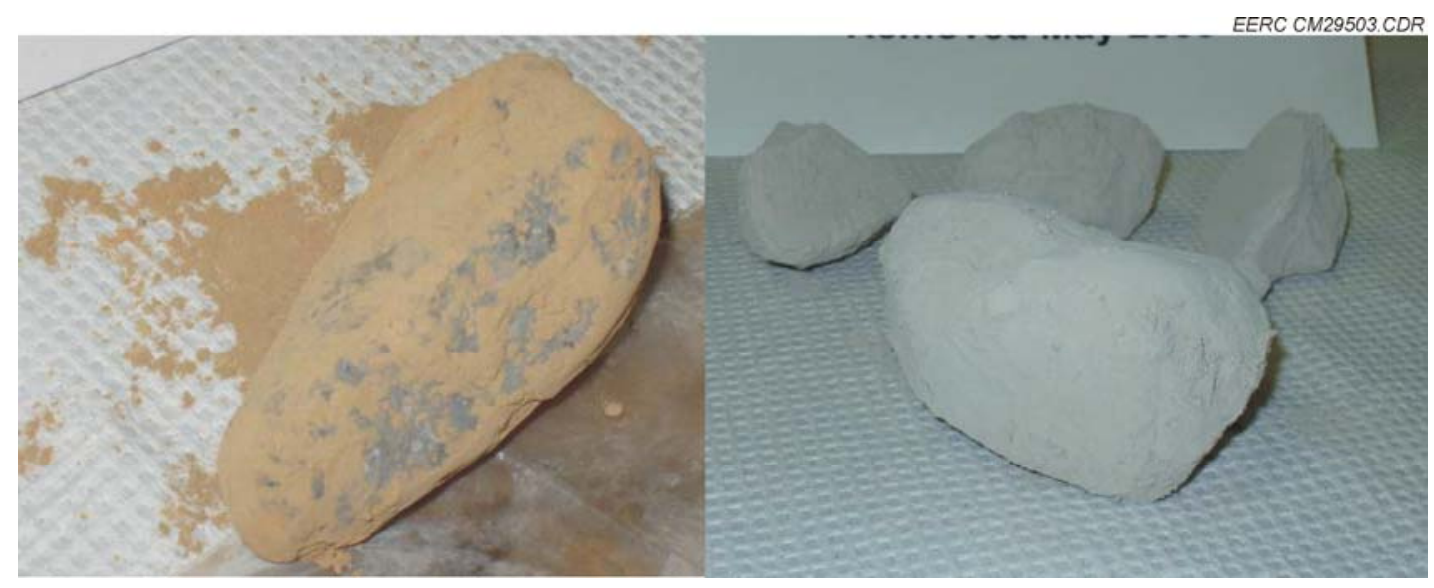

Figure 46. Photos of representative deposit samples collected from Hopper H: the sample on the left is referred to as the "orange" deposit, and those on the right are the "gray" deposits. Images are not to the same scale.

monolith as they were in the popcorn. Figure 47 presents the diffraction patterns for both the popcorn and monolith and shows better anorthite $\left(\mathrm{CaAl}_{2} \mathrm{Si}_{2} \mathrm{O}_{8}\right)$ and diopside $\left(\mathrm{Ca}[\mathrm{Mg}, \mathrm{Al}][\mathrm{Si}, \mathrm{Al}]_{2} \mathrm{O}_{6}\right)$ formation in the popcorn than in the monolith. This indicates that the monolith did not reach as high a temperature as the popcorn, which would explain the differences in the degree of sintering in both deposits and their differences in strength. The mineral apatite $\left(\mathrm{Ca}_{5}\left[\mathrm{PO}_{4}\right]_{3}[\mathrm{OH}]\right)$ was detected in the popcorn deposit; it begins to crystallize from a melt at temperatures near $1800^{\circ} \mathrm{F}$ which suggests that the popcorn deposit formed at this elevated temperature. The average flue gas temperatures across FF 2-4 during field testing were approximately $315^{\circ} \mathrm{F}$ with the $70-30$ blend and $340^{\circ} \mathrm{F}$ with the $100 \% \mathrm{PRB}$.

The representative deposits from Hopper $\mathrm{H}$ were different from those in Hopper $\mathrm{C}$ in that neither sample appeared to have been exposed to extreme heat. The diffraction patterns of Figure 48 show a broad reflection for both samples indicative of amorphous (noncrystalline) material. Neither deposit from Hopper $\mathrm{H}$ possessed much strength, and the lack of crystalline material implies that these deposits were not sintered together like those from Hopper C. It appears that a small amount of moisture may have caused these deposits to stick together. In fact, the gray deposits have almost completely disintegrated from drying while in storage during the investigation. The orange deposit has maintained its shape, but it exhibited more crystalline development, which gave it some added strength. However, the mineral phases present in the orange deposit did not indicate that it was exposed to temperatures as high as those estimated to have occurred in Hopper C. 


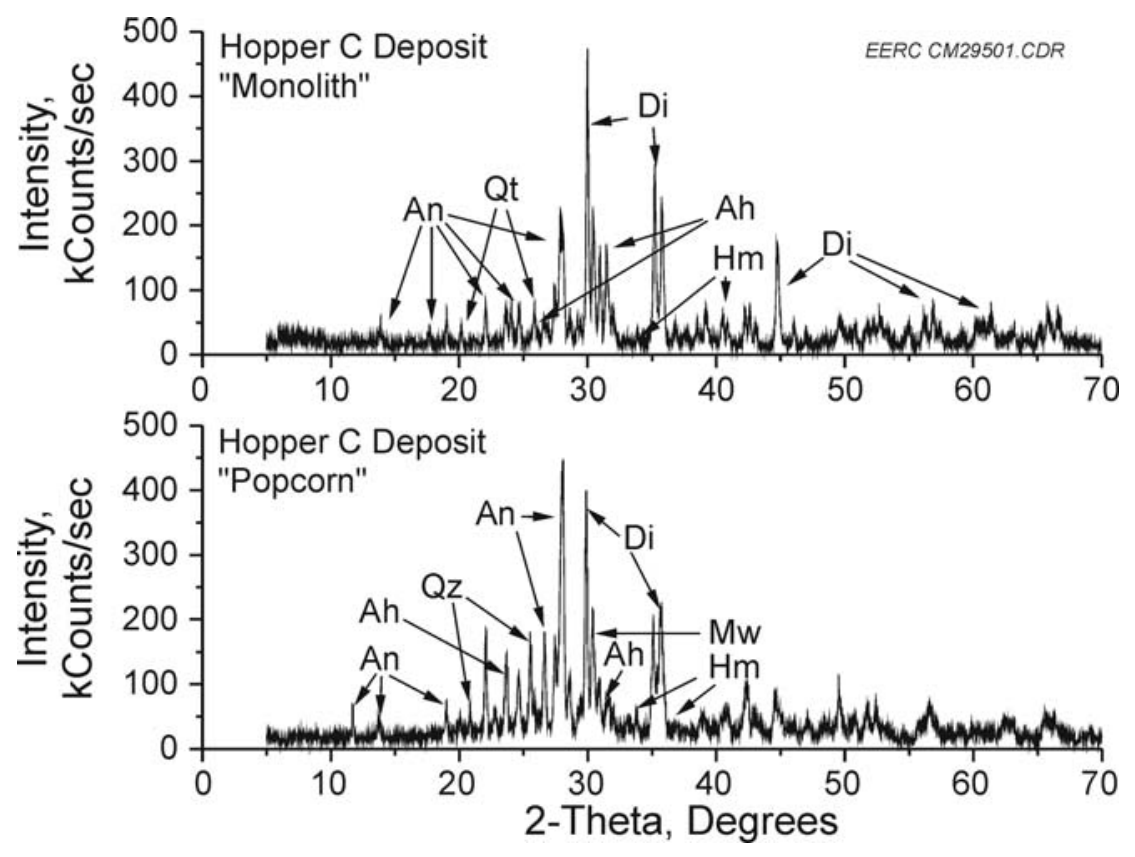

Figure 47. Diffraction patterns for the popcorn and monolith deposits from Hopper C. Mineral identification key: $\mathrm{Ah}=$ anhydrite $\left(\mathrm{CaSO}_{4}\right), \mathrm{An}=$ anorthite $\left(\mathrm{CaAl}_{2} \mathrm{Si}_{2} \mathrm{O}_{8}\right), \mathrm{Di}=$ diopside $\left(\mathrm{Ca}[\mathrm{Mg}, \mathrm{Al}][\mathrm{Si}, \mathrm{Al}]_{2} \mathrm{O}_{6}\right), \mathrm{Hm}=$ hematite $\left(\mathrm{Fe}_{2} \mathrm{O}_{3}\right), \mathrm{Mw}=$ merwinite $\left(\mathrm{Ca}_{3} \mathrm{Mg}\left[\mathrm{SiO}_{4}\right]_{2}\right)$, and $\mathrm{Qz}=$ quartz $\left(\mathrm{SiO}_{2}\right)$.

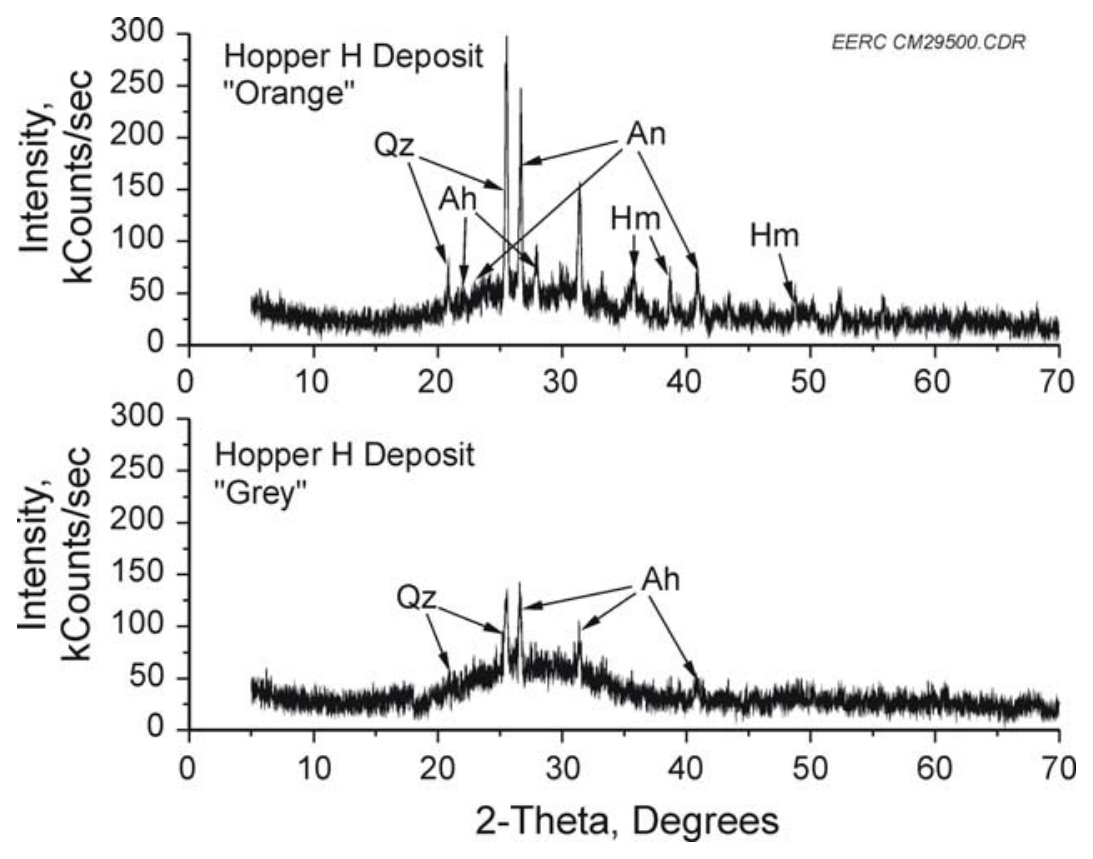

Figure 48. Diffraction patterns for the orange deposit and gray deposit from Hopper H. Mineral identification key: $\mathrm{Ah}=$ anhydrite $\left(\mathrm{CaSO}_{4}\right), \mathrm{An}=$ anorthite $\left(\mathrm{CaAl}_{2} \mathrm{Si}_{2} \mathrm{O}_{8}\right), \mathrm{Hm}=$ hematite $\left(\mathrm{Fe}_{2} \mathrm{O}_{3}\right)$, and $\mathrm{Qz}=$ quartz $\left(\mathrm{SiO}_{2}\right)$. 
Carbon content of the deposits and the related FF 2-4 ashes was determined and results compared. Results for the FF ash under several test conditions are summarized in Table 19. Unburned carbon content in the baseline FF ash was low, less than $0.5 \%$. The carbon content of the $\mathrm{AC}$ used at Big Brown is approximately 67\%, and carbon content of the FF ash samples during carbon injection ranged between $7 \%$ and $20 \%$ and depended on the coal type and the length of continuous time allowed for ACI. Overall, none of the deposit samples had carbon contents above the baseline FF ash values, indicating that they either formed from ash that did not contain carbon from ACI or that during heating any carbon was efficiently burned away. Exceptions were noted for the monolith from Hopper $\mathrm{C}$ and the orange deposit from Hopper $\mathrm{H}$, both of which had noticeable, although extremely thin, dark patches on the surface only. Thin surface samples indicated elevated carbon content, but only baseline levels of carbon were detected in the interiors of these deposits.

An additional comparison was made between the composition of the hopper deposits and the composition of the two types of ash from the two fuels fired at Big Brown during field testing, i.e., the 70-30 lignite-PRB blend and 100\% PRB. XRF measurements for the Hopper C deposits and corresponding ash samples are shown in Figure 49, and results from the Hopper $\mathrm{H}$ deposits are shown in Figure 50. Referring to these figures, a trend between the $\mathrm{SiO}_{2}$ and $\mathrm{CaO}$ compositions of each sample can be observed. The ash samples appear to have a distinct

Table 19. Measured Carbon Content of the FF Ash During Field Testing

\begin{tabular}{lc}
\hline Sample & Carbon Content, \% \\
\hline Baseline 70-30 FF Ash & 0.30 \\
Average 70-30 Ash with Monthlong ACI & 7.9 \\
Average 100\% PRB Ash with ACI & 15.7 \\
\hline
\end{tabular}

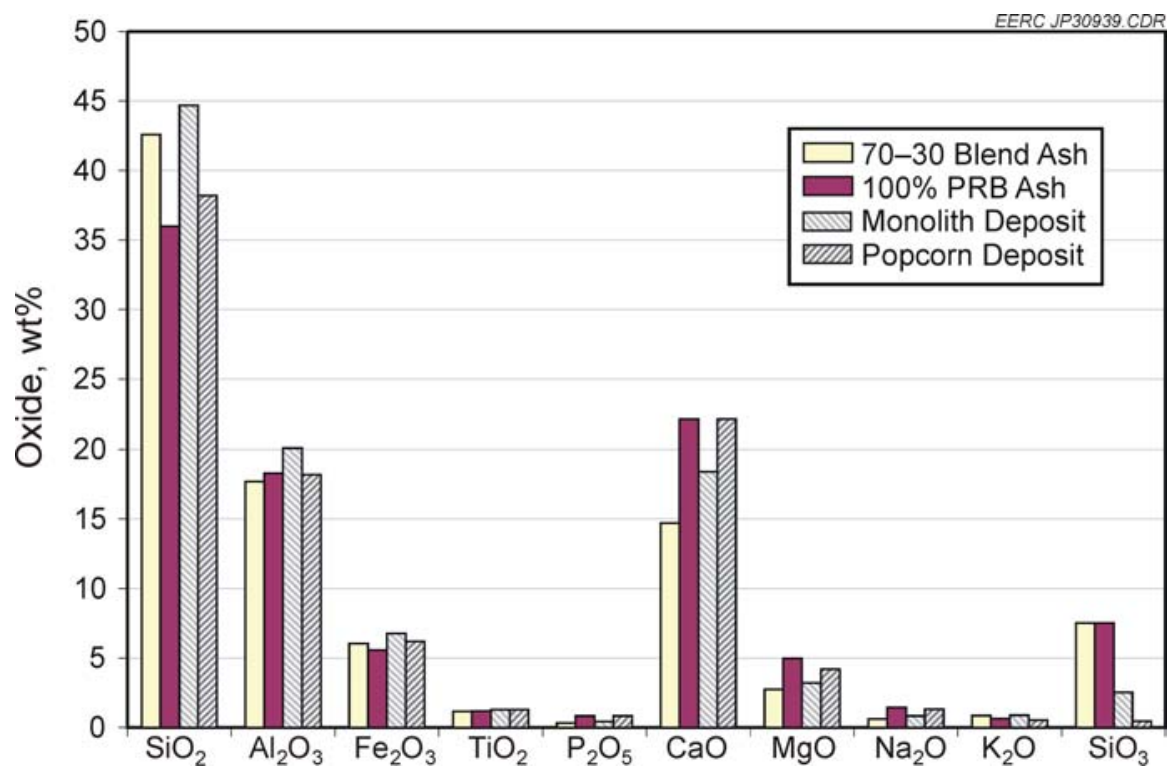

Figure 49. XRF composition data for samples of the Hopper C deposits and the two ash types. 


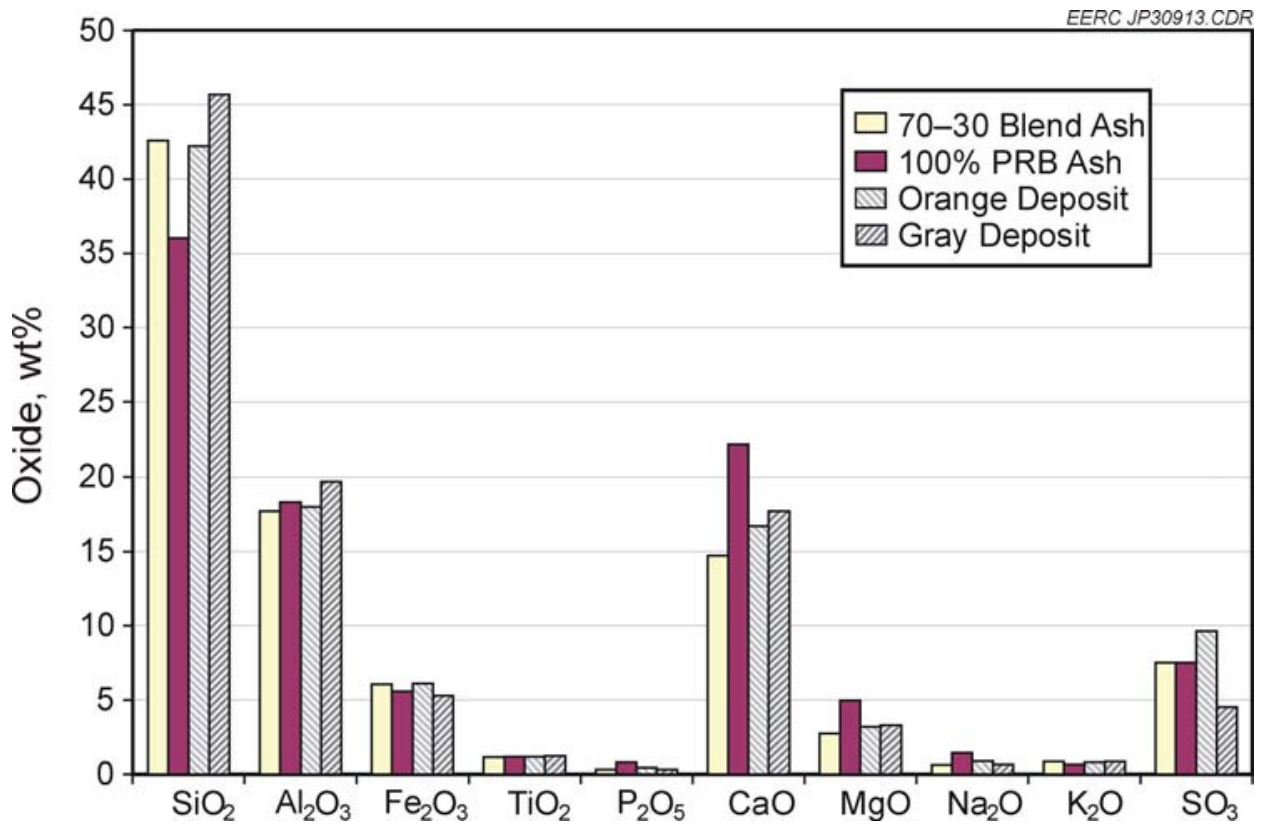

Figure 50. XRF composition data for samples of the Hopper $\mathrm{H}$ deposits and the two ash types.

relationship, with the blend ash having higher $\mathrm{SiO}_{2}$ content but lower $\mathrm{CaO}$ content compared to the $100 \%$ PRB ash. When compared to the Hopper C deposits in Figure 49, a similar trend with $\mathrm{SiO}_{2}-\mathrm{CaO}$ is apparent with the two representative deposit types. Further, it appears that the composition of the monolith deposit has characteristics similar to the blend ash, while the popcorn deposit is similar to the 100\% PRB. The data from the Hopper $\mathrm{H}$ deposits, Figure 50, indicate that both types of deposits are more similar to the 70-30 blend ash.

Results from the hopper deposit investigation indicated at least two separate formation mechanisms. The first is represented by the popcorn of Hopper $\mathrm{C}$, which appears to have formed from a molten state from the $100 \% \mathrm{PRB}$ ash, and the second is represented by all other deposits, which collectively appear to have started as agglomerations of 70-30 blend ash that were sintered with heat to varying degrees. The popcorn deposit shows signs of desorbed gases and extreme heat; therefore, it could have formed from ash containing AC, with the carbon burning away during formation. The lower temperatures indicated for formation of the other deposits, the absence of elevated carbon in their interiors, and their similarity to the 70-30 blend ash suggest that they formed from ash which was generated prior to field testing.

\section{Plant Data}

Maintenance records indicated that level sensors on Hoppers $\mathrm{C}$ and $\mathrm{H}$ were not functioning properly and, therefore, did not report the true ash level in each hopper. This provides some explanation on how ash levels were able to become abnormally high without detection.

Also of interest were temperature data for each compartment of FF 2-4, since results from the deposit investigation indicate the presence of unusually high temperatures. It was determined that the hopper surface temperatures for both $\mathrm{C}$ and $\mathrm{H}$ were unusually low. The bottom cone of 
each hopper on the COHPAC units is heated with hopper heaters to prevent condensation and keep the ash dry and free-flowing. However, plant data indicated that the heaters for Hoppers $\mathrm{C}$ and $\mathrm{H}$ were not functioning and the outside skin of the hopper bottom cone was essentially at ambient temperatures for 2 months prior to and for the duration of field testing. Figure 51 shows the average hopper bottom cone temperatures for Hoppers $\mathrm{C}$ and $\mathrm{H}$ for the time period immediately before and after the bag change in May 2006. The normal outside skin temperature for the hoppers is approximately $200^{\circ}-250^{\circ} \mathrm{F}$, based on the other six hoppers which were working properly. As Figure 51 shows, the heaters for Hoppers $\mathrm{C}$ and $\mathrm{H}$ began working properly when each compartment was brought back online after the bag change.

The lack of heat applied by the electrical heaters to Hoppers $\mathrm{C}$ and $\mathrm{H}$ resulted in cool surfaces which could have facilitated the introduction of moisture into the hoppers. Understanding of and experience with ash collection systems led to the hypothesis that moisture condensed from the flue gas on the unheated surfaces of Hoppers $\mathrm{C}$ and $\mathrm{H}$. This moisture likely led to the formation of the initial ash agglomerations that eventually became the monolith deposit from Hopper $\mathrm{C}$ and the orange and gray deposits from Hopper $\mathrm{H}$. Furthermore, the lack of heat and probable condensation likely contributed to the eventual plugging of Hoppers $\mathrm{C}$ and $\mathrm{H}$.

\section{Self-Heating of Ash-AC}

Heat, at temperatures higher than those of the flue gas, was necessary in varying degrees during the formation of the deposits. This fact along with descriptions of smoldering ash by plant

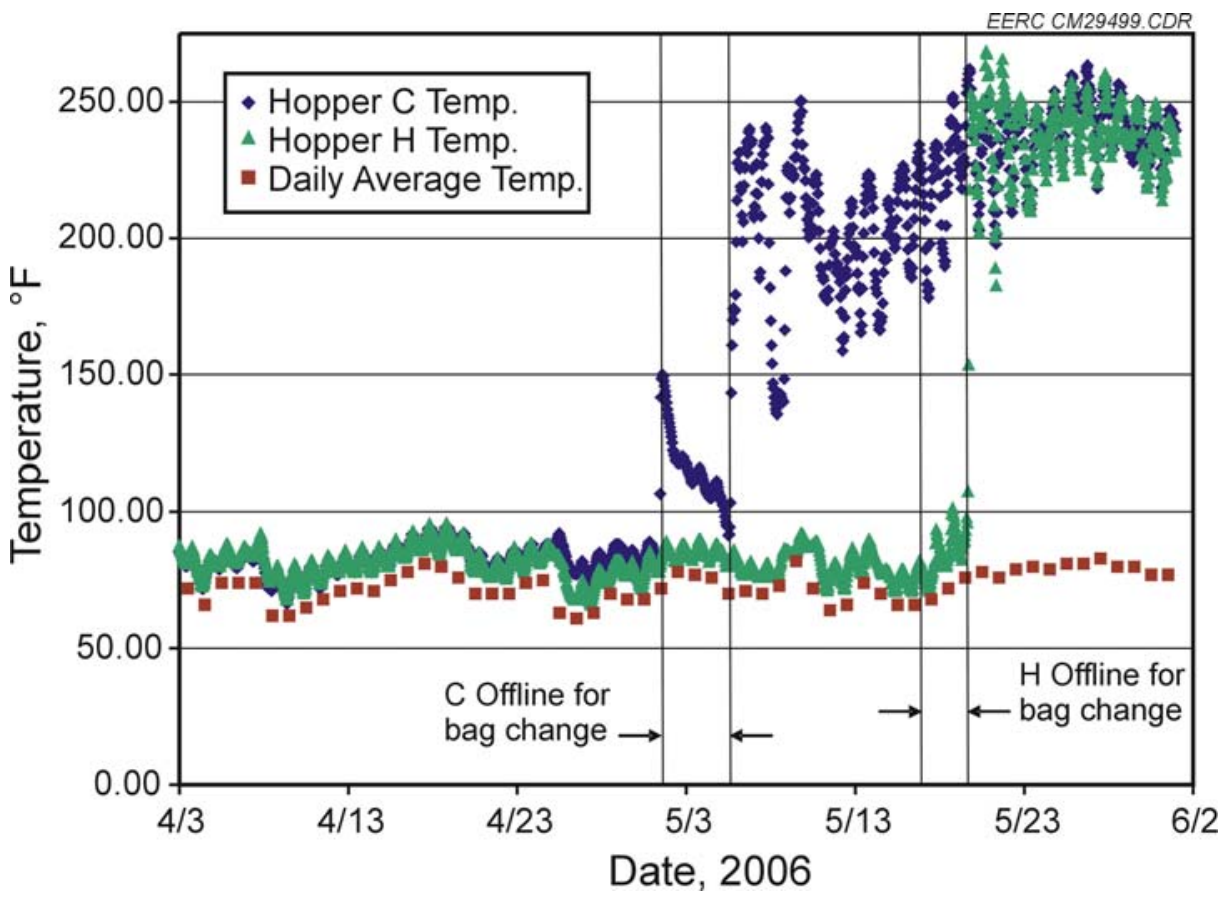

Figure 51. Hopper bottom cone external temperatures for Hoppers $\mathrm{C}$ and $\mathrm{H}$ before and after the May 2006 bag change. 
personnel suggested that the AC had self-ignited in both of the plugged hoppers. The mechanism of self-heating and self-ignition has been suggested as a possibility for stagnant TOXECONTM ash mixtures (23), and it has been implicated in a confirmed case of smoldering TOXECON ${ }^{\mathrm{TM}}$ ash (24). While there are many differences, there are some similarities between the conditions at Big Brown and the cases cited, warranting further investigation into the possibility that selfheating occurred at Big Brown.

The basic concept of the self-heating phenomena is that some combustible materials slowly oxidize and generate heat at temperatures below their ignition temperature; $\mathrm{AC}$ is an example. For these materials, a balance exists between the heat that is generated and the heat that can be dissipated to the surroundings. At ambient conditions, the generated heat is easily dissipated. However, if the heat generation rate is high (generation rate is a strong function of temperature and available oxygen) and the thermal gradient across the material is large (because of a large volume of material with low thermal conductivity) or the ambient temperature is too high (which restricts heat release to the environment), then the generated heat may not be released at a sufficient rate to maintain a constant temperature, and the temperature of the material will rise. In the limiting case, temperatures could rise to the standard ignition temperature, which is the temperature at which self-sustained combustion occurs.

Standard tests exist to classify self-heating behavior for transportation or disposal purposes $(25,26)$; however, these classifications are of limited value since they do not scale to conditions relevant to those observed at Big Brown; therefore, more fundamental data had to be pursued. Differential scanning calorimeter (DSC) measurements of the AC used at Big Brown indicated a standard ignition temperature of approximately $830^{\circ} \mathrm{F}$, when interpreted according to Suzin et al. (27). The same data also indicated that the carbon clearly produced an exothermic response at temperatures as low as $300^{\circ} \mathrm{F}$. For mixtures of $\mathrm{AC}$ and Big Brown FF ash (test mixtures included $10 \%-50 \% \mathrm{AC}$ by weight, but actual mixtures generated during field testing contained less than $25 \% \mathrm{AC}$ ), the ignition temperature appeared to remain unchanged from that of pure $\mathrm{AC}$; however, the heat generation rate was diluted accordingly since the ash was essentially inert at these temperatures. As for other supporting evidence, Derenne et al. have demonstrated that cubic samples (6 inch) of ash-AC can be ignited at ambient temperatures of $430^{\circ} \mathrm{F}(24)$. When scaled to larger volumes of the mixture, these data will imply ignition at even lower ambient temperatures, at an equivalent $\mathrm{O}_{2}$ partial pressure (28).

In the context of Big Brown, the above findings indicate that the $\mathrm{AC}$ content of the ash-AC mixture generated during ACI is sufficient to observe exothermic heat release at typical flue gas temperatures. Furthermore, the large volume of material found in Hoppers $\mathrm{C}$ and $\mathrm{H}$ would suggest that the self-ignition phenomena could have occurred at lower heat source temperatures than those corresponding to the small-scale oven experiments reported by Derenne and others. This supporting evidence indicates that self-ignition is a feasible explanation for the observations from Hoppers $\mathrm{C}$ and $\mathrm{H}$ at Big Brown and that the root cause of the problem was the plugged hoppers that created suitable conditions for heating. For the remaining six hoppers on FF 2-4 that operated normally, no material-handling problems were noted. 


\section{FF Outlet Particulate Emissions}

Limited data were collected regarding changes to the FF outlet dust emissions because of the mercury control technology, but the available observations are documented here since they may indicate an increase in FF outlet particulate emissions as a result of the control technology. The source of dust-loading data are the Method 5-equivalent filter weights that were collected as part of the $\mathrm{OH}$ sampling. The $\mathrm{OH}$-based dust-loading measurements are summarized in Table 20.

The significant trend in Table 20 is that during the baseline period, the outlet particulate emissions were not detectable with the sampling conditions (i.e., sampling time) used. However, subsequent samples (all coincident with one of the sorbent injection options) did measure a detectable outlet dust loading. As a result, the calculated particulate collection efficiency for FF 2-4 appears to quickly degrade after baseline sampling. This could indicate that the observed rise in FF particulate emissions is associated with the application of the mercury control technology. Evidence of AC penetration through the FF was demonstrated by the bias towards particulatebound mercury for many of the $\mathrm{OH}$ samples during sorbent injection. This was specifically noted for the monthlong $\mathrm{OH}$ samples (Figure 9) where the FF outlet mercury speciation data was considered invalid because of a bias caused by AC collecting on the sample filter.

The cleaning cycle of FF 2-4 was changed from being triggered by a drag set point to a continuous cleaning cycle for this testing and could account for changes in FF particulate emissions. However, plant data indicate that the cleaning cycle had been switched to continuous clean prior to the baseline sampling and was operating with the same cleaning cycle time for all of the samples in Table 20. When examined for other associations, no trend was observed between the FF particulate emissions and time of exposure to ACI, FF inlet dust loading, or Unit

Table 20. Summary of Dust-Loading Measurements Across FF 2-4

\begin{tabular}{|c|c|c|c|c|}
\hline Date & Condition & $\begin{array}{l}\text { FF 2-4 Inlet } \\
\text { Dust Load, } \\
\text { gr/dscf } 3 \% \mathrm{O}_{2}\end{array}$ & $\begin{array}{l}\text { FF 2-4 Outlet } \\
\text { Dust Load, } \\
\text { gr/dscf 3\% } \mathrm{O}_{2}\end{array}$ & $\begin{array}{c}\text { FF 2-4 } \\
\text { Collection } \\
\text { Efficiency, \% }\end{array}$ \\
\hline $1 / 18 / 06$ & Baseline & 0.118 & $<0.0005$ & $>99.58$ \\
\hline $1 / 19 / 06$ & Baseline & 0.065 & $<0.0005$ & $>99.23$ \\
\hline $1 / 20 / 06$ & Baseline & 0.170 & $<0.0005$ & $>99.71$ \\
\hline $1 / 23 / 06$ & Parametric, ACI & 0.097 & 0.002 & 98.01 \\
\hline $1 / 24 / 06$ & Parametric, ACI & 0.110 & 0.010 & 91.17 \\
\hline $2 / 2 / 06$ & Parametric, ACI & 0.079 & 0.007 & 90.86 \\
\hline $2 / 4 / 06$ & Parametric, ACI and SEA4 & 0.063 & 0.001 & 97.65 \\
\hline $2 / 6 / 06$ & Parametric, ACI and SEA4 & 0.097 & 0.001 & 98.90 \\
\hline $2 / 27 / 06$ & Monthlong, enhanced ACI & 0.064 & 0.004 & 93.59 \\
\hline $2 / 28 / 06$ & Monthlong, enhanced ACI & 0.047 & 0.001 & 98.86 \\
\hline $3 / 1 / 06$ & Monthlong, enhanced ACI & 0.112 & 0.004 & 96.12 \\
\hline $3 / 16 / 06$ & Monthlong, enhanced ACI & 0.057 & 0.008 & 86.68 \\
\hline $3 / 17 / 06$ & Monthlong, enhanced ACI & 0.069 & 0.006 & 90.70 \\
\hline $3 / 20 / 06(1)$ & Monthlong, enhanced ACI & 0.049 & 0.004 & 91.81 \\
\hline $3 / 20 / 06(2)$ & Monthlong, enhanced ACI & 0.073 & 0.010 & 86.83 \\
\hline $3 / 21 / 06$ & Monthlong, enhanced ACI & 0.049 & 0.004 & 90.97 \\
\hline $3 / 22 / 06$ & Monthlong, enhanced ACI & 0.092 & 0.002 & 98.07 \\
\hline
\end{tabular}


2 load. Additionally, no records were kept regarding damaged bags during the bag change of FF 2-4. At this time, there appears to be insufficient data to conclusively determine if the change in FF particulate emissions is a coincidence or if there is an unidentified mechanism by which $\mathrm{AC}$ enhances particle migration through the high-perm FFs used at Big Brown.

\section{CCB Characterization}

An investigation of the impacts of ACI-based mercury control technologies on coal CCBs was conducted. Composite CCB samples from the combustion of a blend of PRB subbituminous and Texas lignite coal at TXU Big Brown were collected from the FF 2-4 hoppers for use in this evaluation. One fly ash sample was collected under pre-mercury control (baseline) conditions, and four fly ash samples were collected during mercury control technology testing with ACI, SEA4 plus ACI, and an enhanced ACI, as shown in Table 21.

Before leaching, thermal stability, and microbiologically mediated release experiments were performed to evaluate the stability of mercury, the total mercury content and $\mathrm{pH}$ of the solid samples were determined. Results are reported in Table 21. Total mercury content was determined using a DMA-80 (digital mercury analyzer). Slurry $\mathrm{pH}$ measurements were taken after 10-15 minutes and 24 hours of stirring using distilled water.

The total mercury content was significantly higher in the CCB samples collected during mercury control testing than the baseline sample. Additionally, an increase in total mercury content in the fly ash samples is noted in the samples from testing using SEA4 with the AC and from testing using an enhanced AC.

Table 21. CCB Description and Characterization of FF 2-4 Ash Samples

\begin{tabular}{lccccc}
\hline ID No. & $\begin{array}{c}\text { Collection } \\
\text { Date }\end{array}$ & $\begin{array}{c}\text { Mercury } \\
\text { Control }\end{array}$ & $\begin{array}{c}\text { Total Mercury, } \\
\mu \mathrm{g} / \mathrm{g}\end{array}$ & $\begin{array}{c}10-15-\mathrm{min} \\
\mathrm{pH}\end{array}$ & 24-hour $\mathrm{pH}$ \\
\hline $06-004$ & $1 / 19 / 06$ & Baseline & 0.356 & 8.81 & 9.22 \\
$06-005$ & $2 / 6 / 06$ & AC & 12.1 & 12.03 & 11.10 \\
$06-006$ & $2 / 16 / 06$ & SEA4 + AC & 53.8 & 5.73 & 9.05 \\
$06-007$ & $3 / 4 / 06$ & Enhanced AC & 83.7 & 5.28 & 8.49 \\
$06-008$ & $3 / 20 / 06$ & Enhanced AC & 105 & 6.41 & 8.76 \\
\hline
\end{tabular}

The $\mathrm{pH}$ of the fly ash changed with mercury control testing. Most significant is the $\mathrm{pH}$ change of the SEA4 + AC and enhanced AC samples in a 24-hour period. An increase in $\mathrm{pH}$ indicates that more alkali components from the $\mathrm{CCB}$ dissolved over time. A $\mathrm{pH}>10$ indicates that long-term leaching (LTL) should be applied in order to assess the impact of reactivity of the material on the leaching profile of the sample. CCBs exhibiting a high $\mathrm{pH}$ have the potential to undergo hydration reactions that can change the leaching profile with time. 


\section{Direct Leaching of Mercury}

The leaching tests performed on the samples in this project were the synthetic groundwater leaching procedure (SGLP), which is an 18-hour test, and LTL using 30- and 60-day equilibration periods (29). The SGLP batch-leaching procedure is a relatively simple test that follows many of the conditions of the toxicity characteristic leaching procedure (TCLP) (30) and ASTM D3987 (31). The test utilizes a 20:1 liquid-to-solid ratio, end-over-end agitation at approximately $30 \mathrm{rpm}$, and an 18-hour equilibration time and usually employs a leaching solution consisting of water from the site, water that has been prepared in the lab similar to water likely to contact the ash, or distilled DI water. Distilled DI water was used in this effort, making the test equivalent to ASTM D3987. For the long-term component of this procedure, multiple bottles are set up and analyzed at different time intervals. A typical SGLP and LTL test set consisting of 18-hour, 30-day, and 60-day equilibration times was performed in this effort. Although 60 days is often not long enough to have achieved complete equilibrium, it is generally long enough to determine the concentration evolution of individual parameters. The most important factor when LTL is performed is to have at least three equilibration times to determine a true trend.

The solids were filtered from the leaching solution through a $0.45-\mu \mathrm{m}$ filter, the $\mathrm{pH}$ of the resulting leachate was measured, and the leachate was preserved with hydrochloric acid for mercury determination. Mercury leachate concentrations were determined using a CVAAS technique. Results are shown in Table 22.

All leachate mercury concentrations were below $0.03 \mu \mathrm{g} / \mathrm{L}$. This confirms previous results indicating that the total mercury content does not correlate with the leachable mercury (32-34). Mercury leachate concentrations are not generally affected by the duration of the leaching test.

Although only the fly ash + AC sample (Sample 06-005) had a $\mathrm{pH}$ value greater than 10 , LTL was performed on all samples since the $\mathrm{pH}$ was increasing over the 24-hour $\mathrm{pH}$ measurement period. The trend in leachate $\mathrm{pH}$ values over the SGLP and 30- and 60-day LTL tests are shown in Table 23. The fly ash + AC sample (Sample 06-005) exhibited a decreasing leachate $\mathrm{pH}$ while all other samples exhibited increasing leachate $\mathrm{pH}$ from the 18-hour SGLP to the 60-day LTL tests. Although no change in mercury concentration was noted in the samples with LTL, the change in $\mathrm{pH}$ indicates that other elements such as arsenic, chromium, and selenium may decrease in leachate concentration with LTL as has been observed in previous fly ash leaching studies.

Table 22. CCB Leachate Mercury Concentrations

\begin{tabular}{llccc}
\hline ID No. & Sample Description & 18-hour SGLP & 30-day LTL & 60-day LTL \\
\hline 06-004 & Baseline fly ash & $<0.01$ & $<0.01$ & $<0.01$ \\
$06-005$ & Fly ash + AC & $<0.01$ & $<0.01$ & 0.011 \\
$06-006$ & Fly ash + SEA4 + AC & $<0.01$ & $<0.01$ & $<0.01$ \\
$06-007$ & Fly ash + enhanced AC & $<0.02$ & $<0.03$ & $<0.03$ \\
$06-008$ & Fly ash + enhanced AC & $<0.03$ & $<0.03$ & $<0.03$ \\
\hline
\end{tabular}


Table 23. CCB Leachate pH Values

\begin{tabular}{llccc}
\hline ID No. & Sample Description & 18-hour SGLP & 30-day LTL & 60-day LTL \\
\hline $06-004$ & Baseline fly ash & 9.62 & 10.73 & 10.88 \\
$06-005$ & Fly ash + AC & 11.47 & 11.20 & 11.18 \\
$06-006$ & Fly ash + SEA4 + AC & 9.21 & 10.28 & 10.49 \\
$06-007$ & Fly ash + enhanced AC & 8.31 & 8.80 & 8.93 \\
$06-008$ & Fly ash + enhanced AC & 9.24 & 10.36 & 10.77 \\
\hline
\end{tabular}

\section{Elevated-Temperature Mercury Release}

An apparatus for the controlled thermal desorption of mercury and mercury compounds was assembled and is shown schematically in Figure 52. The apparatus was constructed using an atomic absorption (AA) spectrophotometer for mercury detection and included a small tube furnace and temperature controller for thermal desorption. A Hewlett Packard 3395 integrator was used for data collection. Detection of thermally desorbed mercury and mercury compounds was accomplished in an electrically heated quartz cell operated at $800^{\circ} \mathrm{C}$. The use of a heated cell allowed detection of mercury compounds by thermally decomposing compounds to form elemental mercury, which can be detected by AA. Nitrogen gas flow was maintained at $5 \mathrm{~cm}^{3} /$ min through the AA. The temperature controller was ramped from ambient temperature to $800^{\circ} \mathrm{C}$ at a rate of $25^{\circ} \mathrm{C}$ per minute.

Typically, a 1-g aliquot of conventional fly ash is required to release a measurable amount of mercury in elevated-temperature mercury release experiments. The high total mercury content of the CCB samples in this project made analysis difficult. An aliquot of 3-5 $\mathrm{mg}$ of the four CCB samples containing $\mathrm{AC}$ was sufficient to generate data without releasing a total amount of

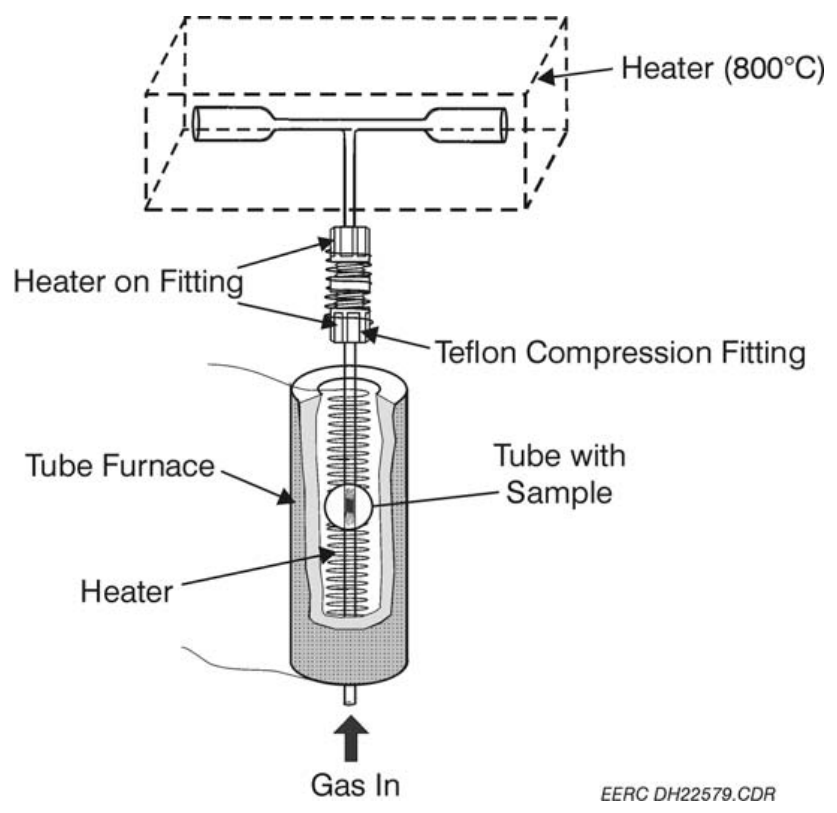

Figure 52. Mercury thermal desorption apparatus. 
mercury outside the measurement range of the AA. However, homogeneity of the sample cannot be guaranteed at this level.

As mercury and mercury compounds are released from the CCB sample through heating, a peak is recorded on the integrator, and the peak temperature is recorded. This peak temperature indicates the temperature at which a majority of each mercury compound or elemental mercury is released from the fly ash sample. The fly ash samples in this project produced one to three separate mercury peaks. Generally, only this first peak temperature is evaluated. Table 24 lists the temperature at which the first mercury peak was noted for each sample.

The first peak for all samples was sharp, with any additional peaks being broad. It is assumed that the first peak is mostly elemental mercury and additional peaks are mercury compounds that have broken bonds during the heating process. The results indicate that the mercury has a tighter bond to the fly ash or AC particles in the CCB samples from mercury control testing with SEA4 and AC or with treated AC. These results indicated that a large portion of the mercury on the CCB samples is not likely to be released unless the fly ash is used in a high-temperature application, such as use as a raw material in a cement kiln.

\section{Microbiologically Mediated Mercury Release}

The effect of microbes on the release of mercury from CCBs has been the subject of ongoing research at the EERC. However, previous experimental protocols were ineffective for highly alkaline fly ash samples and difficult for other CCBs $(33,35)$. Therefore, an experimental protocol was developed to evaluate microbiologically mediated mercury release from CCB-soil mixtures since addition of CCBs to soil is a real-world application.

A mixture of a $20 \%$ addition of CCB to soil was mixed thoroughly. The soil consisted of a mixture of potting soil and pelletized gypsum and had moisture added to increase existing microbial activity. Approximately 90 grams of the CCB-soil mixture or soil only was placed in sample containers. Each CCB-soil mixture and soil was evaluated in triplicate. Mercury-free air entered the sample container, swept over the sample, and exited through an inverted glass funnel with any releases from the CCB-soil mixture. Breathing-quality air from a cylinder was passed through several sets of gold-coated quartz traps for mercury removal and admitted to each of the

\section{Table 24. First Mercury Release Peak Noted in Elevated-Temperature Mercury Release} Experiments

\begin{tabular}{lcccc}
\hline ID No. & Sample Description & First Peak Temp., ${ }^{\circ} \mathrm{C}$ & Number of Peaks & Total Hg, $\mu \mathrm{g} / \mathrm{g}$ \\
\hline $06-004$ & Baseline fly ash & 368 & 3 & 0.356 \\
$06-005$ & Fly ash + AC & 335 & 2 & 12.1 \\
$06-006$ & Fly ash + SEA4 + AC & 422 & 3 & 53.8 \\
$06-007$ & Fly ash + enhanced AC & 524 & 1 & 83.7 \\
$06-008$ & Fly ash + enhanced AC & 472 & 1 & 105 \\
\hline
\end{tabular}


bottles through a gas distribution manifold that routed the gas through 0.25 -mm-i.d. GC capillary tubing to each of the individual bottles. The pressure drop across the GC capillary tubing allowed for the regulation of airflow through each bottle by simply adjusting the length of tubing to each bottle. The tubing, when pressurized to between 1 and 2 psig through a gas distribution manifold, provided a convenient means of regulating gas flow to approximately $5 \mathrm{~cm}^{3} / \mathrm{min}$. Organomercury compounds were captured on a collection trap containing Supelco Carbotrap ${ }^{\mathrm{TM}}$, and elemental mercury was captured on gold-coated quartz. The second outlet or top trap was used to prevent mercury contamination from atmospheric mercury. A schematic is shown in Figure 53.

Supelco Carbotrap ${ }^{\mathrm{TM}}$ collection traps were analyzed for total mercury by heating the trap to approximately $300^{\circ} \mathrm{C}$, passing the released organomercury through a tube held at about $800^{\circ} \mathrm{C}$, and collecting the mercury on a gold-coated quartz trap. All gold-coated quartz traps were analyzed by desorption at $500^{\circ} \mathrm{C}$ and atomic fluorescence detection.

The CCB-soil microbiologically mediated mercury release experiment was designed to simulate typical management scenarios, both disposal and utilization, where the fly ash would become incorporated with soil. The wide distribution and variety of microorganisms in the environment can promote the rerelease of mercury in these scenarios through oxidation/reduction and alkylation/dealkylation reactions, which may result in the formation of organomercury compounds such as methylmercury compounds. In order for microbes to be metabolically active,

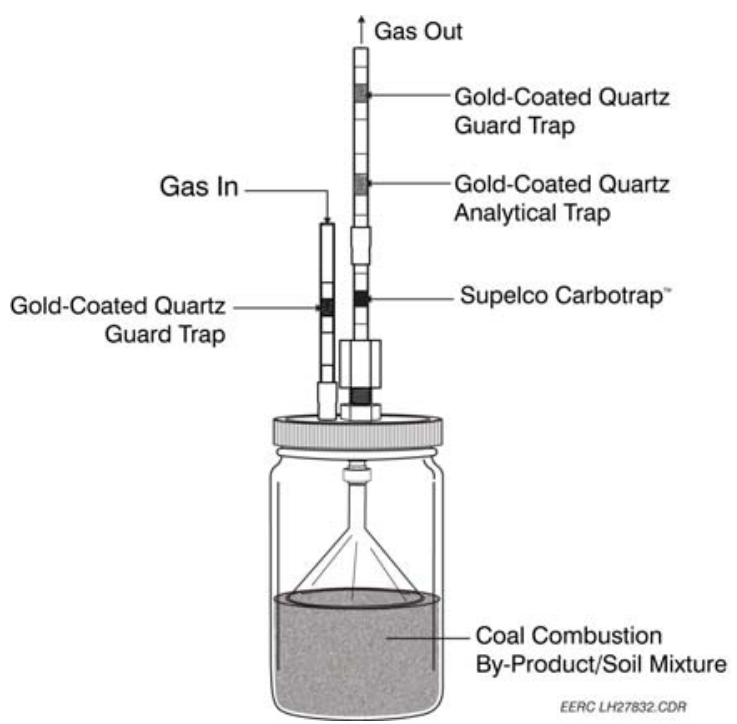

Figure 53. CCB-soil mercury vapor release collection apparatus. 
a few constraints must be satisfied, including a food or energy source, water, and an appropriate $\mathrm{pH}$. The increased carbon content in fly ash with AC addition may serve as an energy source. For some $\mathrm{CCBs}$ and in some $\mathrm{CCB}$ management scenarios, these criteria are unlikely to be met; however, for scenarios where these can be met, laboratory experiments can be used to simulate management techniques. Since the chemistry of mercury is unique in that it can form toxic organomercury compounds when exposed to a variety of microorganisms, the rerelease of mercury from CCBs exposed to microbes is of great interest both from the fundamental chemistry standpoint and from the CCB management standpoint.

The fly ash + enhanced AC samples were evaluated in this experiment. Characterization data, including total mercury and $\mathrm{pH}$ values, for the $\mathrm{CCBs}$, soil, and $\mathrm{CCB}$-soil mixtures are shown in Table 25. The $\mathrm{pH}$ values of the $\mathrm{CCB}$-soil mixtures and soil remaining relatively stable over the duration of the experiment thus are not reported separately.

Elemental mercury results from the microbiologically mediated mercury release from the CCB-soil mixtures experiment are shown in Figure 54. Before sample addition, all sample containers went through a blanking process to account for elemental mercury present in the empty container and the scrubbed air entering the system. Based on the blank value before sample introduction, measurements during each period indicate either a sorption or release of elemental mercury. Elemental mercury vapor collection was measured during three consecutive periods for a total of 24 days. The mercury collection periods were 12 days, followed by 5 days, followed by 7 days.

The results indicate that $\mathrm{CCB}$-soil mixture samples released elemental mercury, whereas the soil was effectively neutral. The average rate of elemental mercury release from the CCBsoil mixtures, measured as pg mercury per gram mixture per day (pg/g/day), increased over the duration of the experiment. As indicated by error bars included in Figure 54, the mercury release measurements exhibited significant variability. The variability likely reflects variability in moisture content and the presence of molds and fungi in addition to microbes.

Organomercury results from the microbiologically mediated mercury release from the $\mathrm{CCB}$-soil mixtures experiment are shown in Figure 55. No organomercury blank value measurements were performed since preparation of the experimental vessel (heating to $>500^{\circ} \mathrm{C}$ )

Table 25. CCB-Soil Experiment Characterization Data of CCBs, Soil, and CCB-Soil Mixtures Consisting of a $20 \%$ Addition of CCB to Soil

\begin{tabular}{llcccc}
\hline CCB ID & Sample Description & $\begin{array}{c}\text { CCB-Soil } \\
\text { Mixture or Soil } \\
\text { Total Hg, } \mu \mathrm{g} / \mathrm{g}\end{array}$ & $\begin{array}{c}\text { CCB } \\
\text { Total } \\
\text { Hg, } \mu \mathrm{g} / \mathrm{g}\end{array}$ & $\begin{array}{c}\text { CCB-Soil } \\
\text { Mixture or Soil } \\
\text { 24-hour } \mathrm{pH}\end{array}$ & $\begin{array}{c}\text { CCB } \\
\text { 24-hour } \mathrm{pH}\end{array}$ \\
\hline $06-007$ & Fly ash + enhanced AC & 18.2 & 83.7 & 6.80 & 8.49 \\
$06-008$ & Fly ash + enhanced AC & 19.8 & 105 & 7.48 & 8.76 \\
NA & Soil & 0.0119 & NA & 4.72 & NA \\
\hline
\end{tabular}




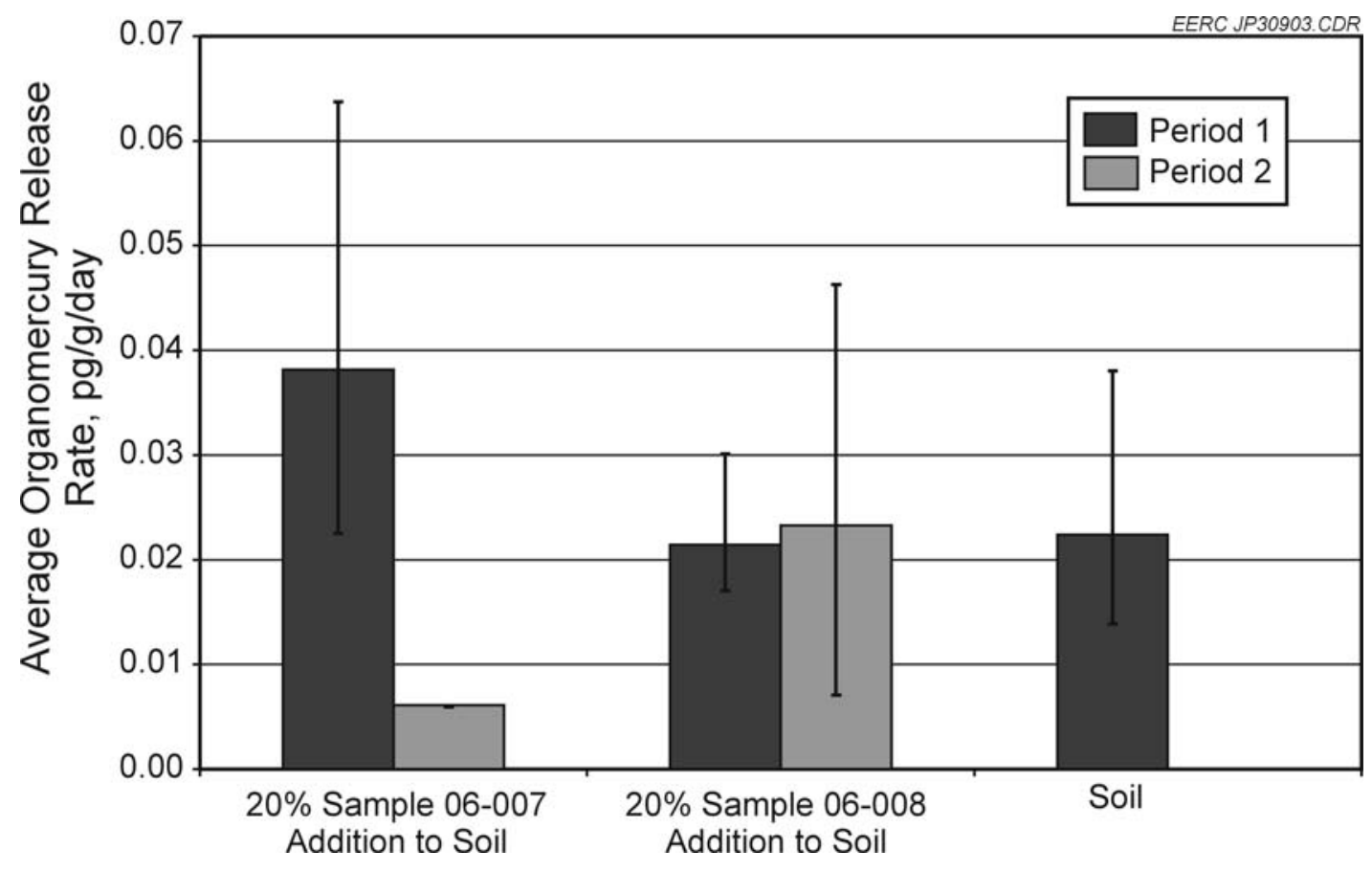

Figure 54. Elemental mercury vapor release rate in CCB-soil microbiologically mediated release experiment, $\mathrm{pg} / \mathrm{g} / \mathrm{day}$. Positive values indicate release and negative values indicate sorption of elemental mercury. Triplicate evaluations are averaged.

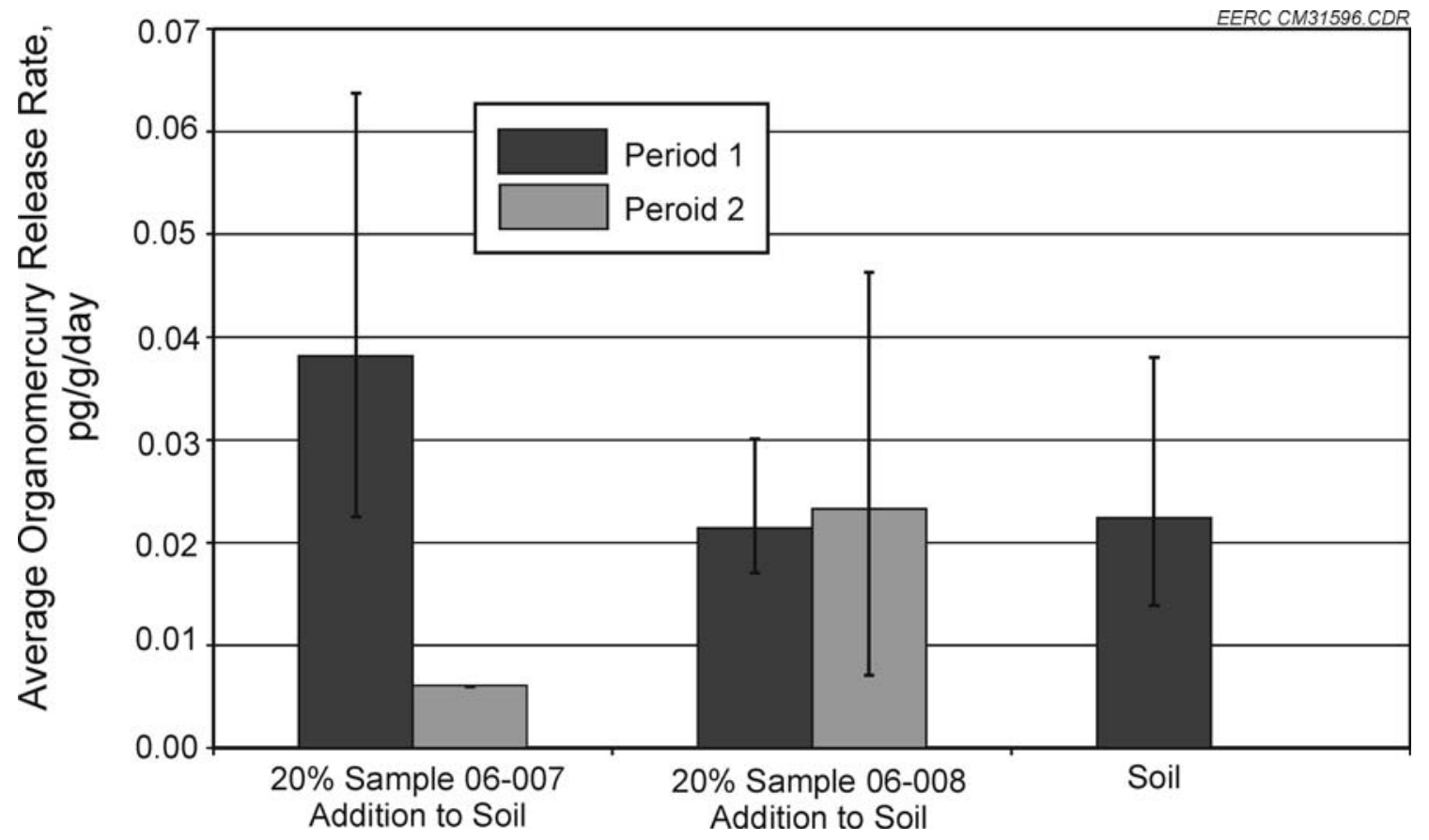

Figure 55. Organomercury vapor release rate in CCB-soil microbiologically mediated release experiment, $\mathrm{pg} / \mathrm{g} / \mathrm{day}$. Triplicate evaluations are averaged. 
was expected to eliminate any organomercury from the container. Therefore, the organomercury collected from the soil-only bottle served as the blank for the experiment. This allowed for a determination of the impact of each $\mathrm{CCB}$ in each $\mathrm{CCB}$-soil mixture. Organomercury vapor collection was measured during two consecutive periods for a total of 27 days. The mercury collection periods were 19 days followed by 8 days.

Organomercury vapor releases were measured at low concentrations. The organomercury releases in the CCB-soil mixture samples were similar to the soil-only sample. No organomercury vapor was detected in the soil over the second collection period. Eight days may not have been sufficient for quantifiable organomercury vapor release or the system characteristics were not conducive to continued organomercury vapor release. Microbial activity was not measured in these experimental systems after the second collection period, so the suggested explanations cannot be confirmed or refuted.

Although these results indicate the potential for mercury release in $\mathrm{CCB}$-soil mixtures, the amount of mercury released is low and not expected to impact CCB management options.

\section{ECONOMIC EVALUATION}

This section provides a preliminary cost analysis for mercury control based on the field test program conducted on the FF 2-4 module at TXU Big Brown Unit 2. The cost analysis is based on a nominal load operation of $600 \mathrm{MW}$, and it is presumed that similar costs would be incurred for mercury control on Unit 1 . The cost of mercury control was estimated as a function of AC and SEA injection rates (lb/Macf) based on parametric tests performed during Unit 2 firing of the 70-30 blend fuel.

Economic analysis was performed for three scenarios accounting for various mercury capture targets and modifications to the plant to address observed BOP impacts. The first scenario entailed principally the addition of AC and SEA systems with operating costs reflecting the utilization of these injection systems through purchased sorbents, additional COHPAC fly ash disposal, lost revenue from COHPAC fly ash sales, and utilities associated with injection system operation. Stand-alone cost analysis was prepared for BOP impacts-bag life and differential pressure - and for the installation and operation of CMMs.

The second scenario evaluated capital and operating costs for add-on systems to provide more reliable and safe operation of the Unit $2 \mathrm{FF}$ as a consequence of $\mathrm{AC}$ addition and other BOP impacts to the plant not included in the direct analysis of Scenario 1. Possible upgrades and/or modifications to the FF included 1) enhanced temperature monitoring, both within the hopper and under hopper heaters; 2) monitoring of carbon monoxide (CO) levels inside the hopper to possibly indicate smoldering/self-heating of the AC-laden fly ash; 3) improved or more reliable hopper level detection; 4) improved fly ash discharge or flow aids; and 5) fire suppression within the hopper in the instance of heat release conditions that could threaten equipment or nearby personnel. The additional BOP impacts considered in this scenario include additional ID fan power because of increased $\triangle \mathrm{P}$ with $\mathrm{ACI}$ and increased COHPAC maintenance 
to cover a higher ash-loading operation and ensure proper operation of the COHPAC which will be essential to avoid self-heating issues.

The third scenario evaluated included adding capacity to the Big Brown Unit 2 COHPAC to lower the AC ratio from a nominal value of $12 \mathrm{ft} / \mathrm{min}$ net $(10.5 \mathrm{ft} / \mathrm{min}$ gross $)$ to 10 , 8 , and $6 \mathrm{ft} / \mathrm{min}$ net at $600-\mathrm{MW}$ load.

A discussion of the inputs and assumptions for the cost analysis plus results are presented in the following sections.

\section{Scenario 1}

\section{Capital Cost Items}

The major add-on capital cost items for this analysis scenario consisted principally of the control technologies-ACI system, AC enhancement system, and the SEA4 injection systemwhich have been previously described. It was assumed that the only major upgrade to the current COHPAC system would be adding a dedicated storage and load-out silo to collect the AC-laden fly ash. This would allow separation of the potentially nonsalable fly ash from the ESP-derived fly ash. Further, it was assumed that upgrades would not be required for the COHPAC system booster fans, pulse air capacity, or ash conveyance. Additional cost items included operating and maintenance (O\&M) costs associated with labor, utilities (power, water, natural gas), AC and additives, fly ash disposal and lost fly ash sales, and mercury monitoring and reporting costs.

Additional factors (or assumptions), pertinent to evaluation of the levelized annual capital and operating costs associated with mercury control at TXU Big Brown include the following:

- Unit capacity factor, $80 \%$

- Heat rate, 11,000 Btu/kWh for the blend fuel

- Economic life, 20 years

- Discount rate, $7.5 \%$

- Escalation factor, 3\%/yr (for all material and labor items)

Cost estimates for the AC and the SEA4 injection systems were obtained from vendor quotations, while the cost estimate for the AC enhancement system, which does not exist commercially, was produced by the EERC. Cost components for these sorbent injection systems include the following:

- Base equipment cost

- Instrumentation and controls

- Injection lances (and distribution modeling for AC system)

- Shipping

- Installation costs

- Earthwork, foundation, and structural support

- Labor (general, technical, and supervisory)

- Checkout testing 
- Contingency (for AC enhancement system)

- Taxes

Project engineering and supervision (by TXU personnel) for installation of the sorbent injection systems was assumed to be $5 \%$ of total purchased equipment cost for each control scenario. Details of the equipment quotations and assumed values are described in Appendix I.

Regarding sorbent consumption, trends identified from parametric testing (Figure 8) were used to estimate consumption rates as a function of desired mercury control across the COHPAC. The range of mercury removal considered was $50 \%$ to $90 \%$. Compiled ACI and SEA feed rate data are presented for the 70-30 blend fuel in Table 26 for mercury capture over the range of $50 \%$ to $90 \%$.

\section{Fly Ash Disposal (and lost revenue)}

As all evaluated control scenarios relied on the injection of $\mathrm{AC}$ with or without an enhancement additive, the potential exists to render the COHPAC fly ash unsuitable for market. Consequently, conservative estimates were produced to reflect the incremental cost to dispose of the mixed COHPAC ash (fly ash, AC, and enhancement additive), plus show the revenue lost from not being able to sell the fly ash. For this analysis the disposal cost (fly ash and added sorbent) was assumed to be $\$ 3 /$ ton, and lost revenue was assumed to be $\$ 7 /$ ton (fly ash only).

Nominal COHPAC inlet dust-loading and annual collection rates (without carbon or enhancement additive addition) were estimated to be $7 \mathrm{lb} / \mathrm{Macf}$ and 3100 tons/yr for the blend fuel and $2.5 \mathrm{lb} / \mathrm{Macf}$ and 1100 tons/yr for the 100\% PRB. As mentioned previously, it was assumed that the current COHPAC ash conveyance and load-out systems were sufficiently sized to handle the increased loading from AC (and additive). For comparison, at an enhanced AC rate

Table 26. ACI and SEA Rates for 70-30 Blend Firing

\begin{tabular}{lcccc}
\hline $\begin{array}{l}\text { Control } \\
\text { Scenario }\end{array}$ & $\begin{array}{c}\text { Mercury } \\
\text { Removal }^{1}\end{array}$ & $\begin{array}{c}\mathrm{ACI}^{2} \text { Rate, } \\
\mathrm{lb} / \mathrm{Macf}(\mathrm{lb} / \mathrm{hr})\end{array}$ & $\begin{array}{c}\text { SEA2 } \\
\mathrm{lb} / \mathrm{Macf}(\mathrm{lb} / \mathrm{hr})\end{array}$ & $\begin{array}{c}\text { SEA4 Rate, } \\
\mathrm{lb} / \mathrm{Macf}(\mathrm{lb} / \mathrm{hr})\end{array}$ \\
\hline ACI & $50 \%$ & $1.55(252)$ & & \\
ACI & $70 \%$ & $2.80(454)$ & & \\
ACI & $90 \%$ & $6.44(1050)$ & & \\
\hline Enhanced ACI & $50 \%$ & $0.82(130)$ & $0.052(8.5)$ & \\
Enhanced ACI & $70 \%$ & $1.37(222)$ & $0.089(14.4)$ & $1.70(260)$ \\
Enhanced ACI & $90 \%$ & $2.32(376)$ & $0.153(24.9)$ & $1.70(260)$ \\
\hline ACI + SEA4 & $50 \%$ & $0.32(52)$ & & $1.70(260)$ \\
ACI + SEA4 & $70 \%$ & $1.13(183)$ & & \\
ACI + SEA4 & $90 \%$ & $2.37(385)$ & & \\
${ }^{1}$ Based on a flue gas flow rate of 2.7 Macfm. & & \\
${ }^{2} \mathrm{AC}$ is standard NORIT DARCO Hg activated carbon. & & \\
${ }^{3} \mathrm{SEA} 2$ is an additive used in the AC enhancement process. &
\end{tabular}


of $1.5 \mathrm{lb} /$ Macf, to achieve mercury removal over $70 \%$, the added sorbent is approximately $17 \%$ of the total particulate loading to the COHPAC. Further, presuming that operation of the COHPAC was not $\triangle \mathrm{P}$-limited, injection of $\mathrm{AC}$ alone to achieve $90 \%$ mercury removal would approximately double the mass load on the COHPAC system.

\section{Mercury Monitoring and Reporting}

The EERC produced preliminary estimates for the annual costs associated with mercury monitoring, separate from the costs of the control technology. This estimate was prepared on a per-stack basis. The analysis assumed that one corporate-level position would be responsible for supporting PS 12A documentation requirements, determining proper allowances based on state specific mercury budgets, and establishing a recordkeeping system that meets CAMR requirements.

The total capital requirement (TCR) was estimated at approximately $\$ 311,000$ (or $\$ 0.52 / \mathrm{kW}$ for a single boiler unit at Big Brown), with roughly $50 \%$ of the TCR consisting of the mercury-monitoring instrument and its supporting calibration unit. Approximately $16 \%$ of the TCR was based on an estimate for an enclosure to house the instrument in a temperaturecontrolled environment. Another $18 \%$ of the TCR is for the initial mercury monitor certification (i.e., Performance Certification 12A), while initial training and installation comprise $14 \%$. Details of the monitoring cost estimates are provided in Table 27.

Table 27. Summary of Compliance Monitoring System Costs (per unit)

\begin{tabular}{lc}
\hline & Compliance Monitoring \\
\hline Capital Cost, \$ & \\
Enclosure & 50,000 \\
Monitor and Calibration Unit & 157,000 \\
PS12A & 55,000 \\
Training and Installation & 44,000 \\
Engineering & 5,000 \\
TCR & 311,000 \\
TCR, \$/kW & 0.52 \\
Operating Cost, \$/yr & \\
Annual Certification & 55,000 \\
O\&M Labor & 42,100 \\
Reporting and Recordkeeping & 17,700 \\
Replacement Parts & 39,300 \\
Utilities & 9500 \\
Overhead & 25,300 \\
Total & 188,900 \\
Levelized Annual Costs & \\
Charge for Capital Investment & 30,500 \\
Operating, $\$$ & 236,700 \\
Total Annual Cost, \$ & 267,200 \\
Total Annual Cost, $/ \mathrm{MWh}$ & 0.064 \\
\hline
\end{tabular}


Primary operating cost components consist of annual certification or relative accuracy test audit (RATA), labor associated with monitor operations, corporate reporting and recordkeeping, and replacements parts and depreciation. The levelized annual operating cost is estimated to be $\$ 236,700$, and the total annual monitoring cost per stack is $\$ 267,200$. Presented in terms of incremental electricity cost or mercury reduction cost, the cost of monitoring for a single stack system at Big Brown is estimated to be \$0.064/MWh.

\section{Scenario 1 Results}

The results summary using the Scenario 1 assumptions is presented in Table 28. The costs are estimated for each control technology at three levels of mercury removal: $50 \%, 70 \%$, and $90 \%$. The TCR was estimated to range from $\$ 2.29 / \mathrm{kW}$ for a system using ACI only to $\$ 2.58 / \mathrm{kW}$ and $\$ 3.10 / \mathrm{kW}$ for systems implementing enhanced ACI and ACI/SEA4, respectively. Figure 56 graphically presents the estimated incremental cost of electricity $(\$ / \mathrm{MWh})$ and the cost of mercury reduction (\$/lb $\mathrm{Hg}$ removed) as a function of percent $(\%)$ mercury reduction for the 70-30 blend fuel. With ACI only, costs varied from approximately $\$ 0.39$ to $\$ 1.25 / \mathrm{MWh}$ (\$3410 to $\$ 6080 / \mathrm{lb} \mathrm{Hg}$ removed) over the range of $50 \%$ to $90 \%$ mercury reduction.

Significant reductions in mercury control cost were obtained through utilization of SEAs, with the benefits becoming more dramatic as the level of mercury reduction increased. Figure 56 shows that at $90 \%$ mercury reduction, enhancement of the $\mathrm{AC}$ allowed a $52 \%$ reduction in control cost. With the enhanced ACI at $90 \%$ removal, the incremental cost of electricity and the cost of mercury reduction were lowered to $\$ 0.60 / \mathrm{MWh}$ and $\$ 2890 / \mathrm{lb} \mathrm{Hg}$ removed, respectively. Based on a single test, coinjection of SEA4 appeared to show slightly greater potential-relative to the enhanced ACI-for improving mercury capture and reducing mercury control costs for the 70-30 blend fuel.

Figure 57 illustrates the influence of sorbent costs and operating costs on the levelized annual cost of $90 \%$ mercury control for the 70-30 blend fuel. As anticipated, the principal operating cost for all levels of mercury capture was the sorbent consumption, either as ACI alone or in combination with SEA. For the ACI-only mercury control scenario, 93\% of the operating cost was associated with the sorbent cost. For the enhanced ACI and ACI/SEA4 injection systems, respectively, approximately $85 \%$ and $82 \%$ of the overall sorbent utilization cost were due to the sorbents. Figure 57 illustrates this further in that although implementation of SEA coinjection produced significant reductions in the levelized annual cost of mercury control, sorbent (i.e., AC) costs still predominate.

\section{Scenario 2}

A second economic scenario was considered that uses the costs from Scenario 1 and adds estimated expenses due to BOP impacts that were observed during field testing at Big Brown. The BOP issues included added $\triangle \mathrm{P}$ across the COHPAC with $\mathrm{ACI}$, increased dust load with $\mathrm{ACI}$, and a change in dust load composition which potentially can create self-heating hazards. 
Table 28. Summary of Costs for Mercury Control: 70-30 Fuel Blend, Scenario 1 Assumptions

\begin{tabular}{|c|c|c|c|c|c|c|c|c|c|}
\hline Mercury Removal, \% & 50 & 70 & 90 & 50 & 70 & 90 & 50 & 70 & 90 \\
\hline Control Method & ACI & $\mathrm{ACI}$ & ACI & $\begin{array}{l}\text { ACI + } \\
\text { SEA4 }\end{array}$ & $\begin{array}{l}\text { ACI + } \\
\text { SEA4 }\end{array}$ & $\begin{array}{l}\text { ACI + } \\
\text { SEA4 } \\
\end{array}$ & $\begin{array}{c}\text { Enhanced } \\
\text { ACI }\end{array}$ & $\begin{array}{c}\text { Enhanced } \\
\text { ACI }\end{array}$ & $\begin{array}{c}\text { Enhanced } \\
\text { ACI }\end{array}$ \\
\hline \multicolumn{10}{|l|}{ Capital Cost, \$ } \\
\hline Purchased Equipment & $1,181,000$ & $1,181,000$ & $1,181,000$ & $1,572,000$ & $1,572,000$ & $1,572,000$ & $1,316,000$ & $1,316,000$ & $1,316,000$ \\
\hline Installation & 174,000 & 174,000 & 174,000 & 249,000 & 249,000 & 249,000 & 201,000 & 201,000 & 201,000 \\
\hline Engineering & 20,000 & 20,000 & 20,000 & 35,000 & 35,000 & 35,000 & 27,500 & 27,500 & 27,500 \\
\hline TCR & $1,375,000$ & $1,375,000$ & $1,375,000$ & $1,856,000$ & $1,856,000$ & $1,856,000$ & $1,544,500$ & $1,544,500$ & $1,544,500$ \\
\hline TCR, $\$ / \mathrm{kW}$ & 2.29 & 2.29 & 2.29 & 3.10 & 3.10 & 3.10 & 2.58 & 2.258 & 2.258 \\
\hline \multicolumn{10}{|l|}{ Operating Cost, \$/yr } \\
\hline $\mathrm{AC}$ & 918,000 & $1,655,000$ & $3,808,000$ & 189,000 & 668,000 & $1,401,000$ & 484,000 & 810,000 & $1,372,000$ \\
\hline Enhancement or SEA4 & 0 & 0 & 0 & 116,000 & 116,000 & 116,000 & 96,600 & 165,000 & 284,000 \\
\hline O\&M Labor & 50,700 & 50,700 & 50,700 & 59,300 & 59,300 & 59,300 & 54,400 & 54,400 & 54,400 \\
\hline Utilities & 25,200 & 25,200 & 25,200 & 53,300 & 53,300 & 53,300 & 32,300 & 32,300 & 32,300 \\
\hline Overhead & 30,500 & 30,500 & 30,500 & 35,600 & 35,600 & 35,600 & 32,700 & 32,700 & 32,700 \\
\hline Replacement Parts & 58,800 & 58,800 & 58,800 & 66,600 & 66,600 & 66,600 & 61,500 & 61,500 & 61,500 \\
\hline Fly Ash Disposal & 14,500 & 16,600 & 22,800 & 15,300 & 16,700 & 18,800 & 13,300 & 14,300 & 16,100 \\
\hline Lost Fly Ash Sales & 27,600 & 27,600 & 27,600 & 27,600 & 27,600 & 27,600 & 27,600 & 27,600 & 27,600 \\
\hline RATA (annual certification) & 55,000 & 55,000 & 55,000 & 55,000 & 55,000 & 55,000 & 55,000 & 55,000 & 55,000 \\
\hline Reporting and Recordkeeping & 17,700 & 17,700 & 17,700 & 17,700 & 17,700 & 17,700 & 17,700 & 17,700 & 17,700 \\
\hline Total & $1,198,000$ & $1,937,100$ & $4,096,300$ & 635,400 & $1,115,800$ & $1,850,900$ & 875,100 & $1,270,500$ & $1,953,300$ \\
\hline \multicolumn{10}{|l|}{ Levelized Annual Costs } \\
\hline Charge for Capital Investment, \$ & 134,900 & 134,900 & 134,900 & 182,100 & 182,100 & 182,100 & 151,500 & 151,500 & 151,500 \\
\hline Operating, $\$$ & $1,500,700$ & $2,427,900$ & $5,132,400$ & 794,200 & $1,396,000$ & $2,317,300$ & $1,096,800$ & $1,591,700$ & $2,447,000$ \\
\hline Total Annual Cost, $\$$ & $1,635,600$ & $2,562,800$ & $5,267,300$ & 976,300 & $1,578,100$ & $2,499,400$ & $1,248,300$ & $1,743,200$ & $2,598,500$ \\
\hline Total Annual Cost, \$/MWh & 0.389 & 0.609 & 1.253 & 0.232 & 0.375 & 0.594 & 0.297 & 0.415 & 0.618 \\
\hline Cost of Mercury Reduction, \$/lb Hg & 3410 & 3810 & 6080 & 2030 & 2340 & 2890 & 2600 & 2590 & 3000 \\
\hline Mercury Reduction, $\mathrm{lb} / \mathrm{yr}$ & 480 & 673 & 866 & 480 & 673 & 866 & 480 & 673 & 866 \\
\hline
\end{tabular}




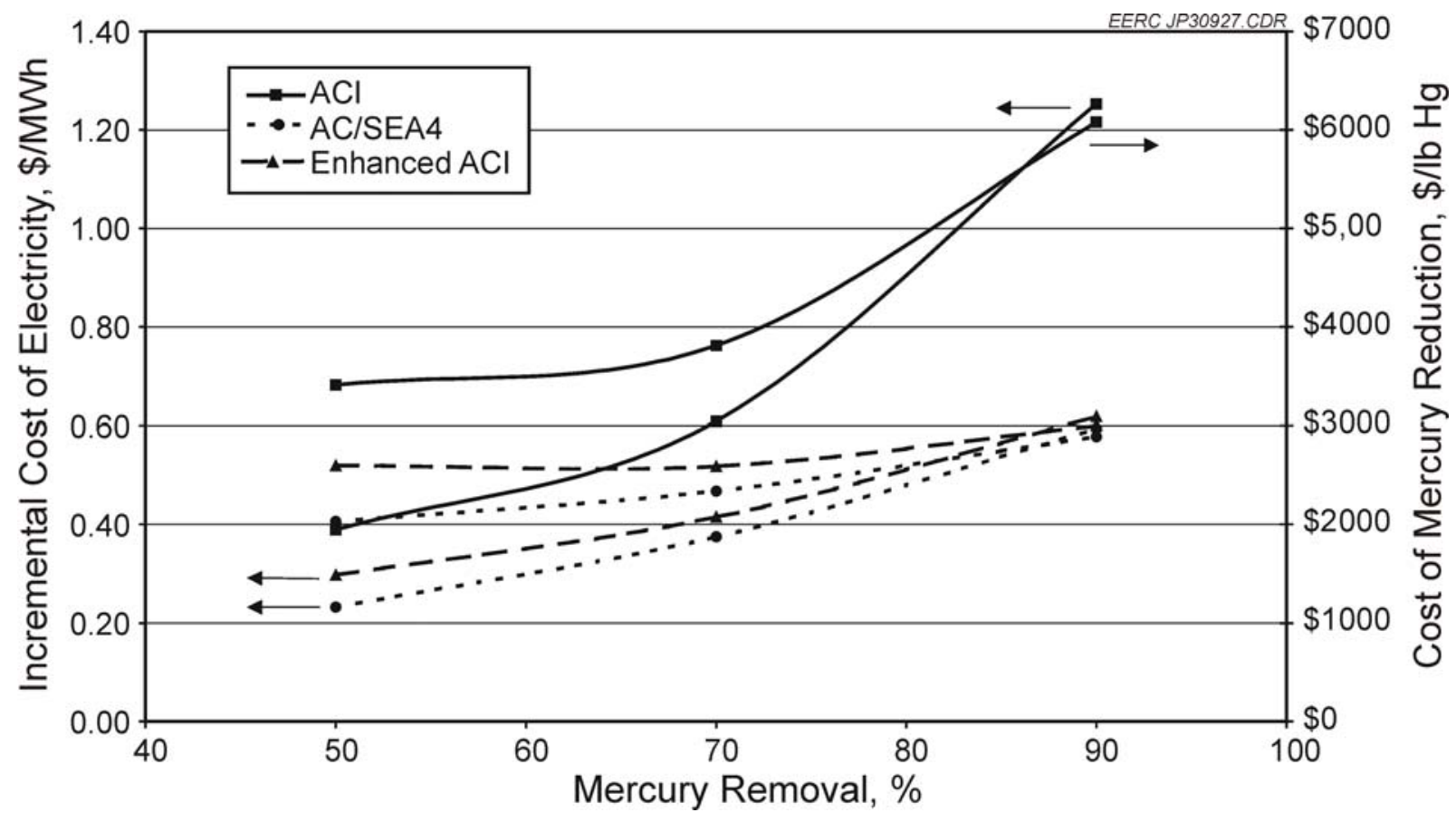

Figure 56. Incremental cost of electricity and cost of mercury reduction for sorbent injection for the 70-30 lignite-PRB fuel blend.

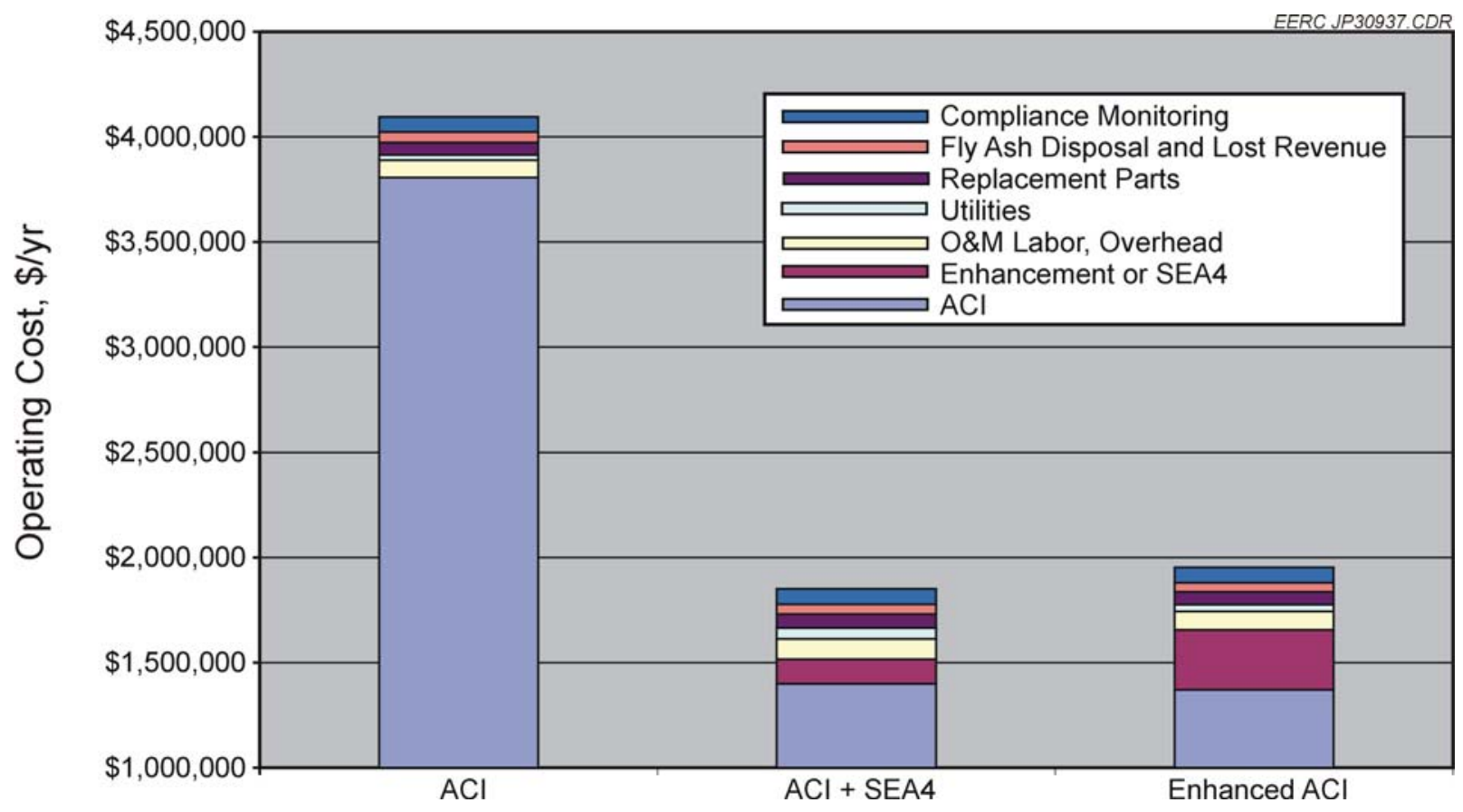

Figure 57. Distribution of operating costs for $90 \%$ mercury removal with the $70-30$ lignite-PRB fuel blend. 
Estimates for the added cost due to each effect are based on conservative assumptions about the impact of the effect and design changes that may need to be required. These assumptions are outlined in this section followed by a summary of the Scenario 2 economic results. While no conclusive results can be drawn from field testing about bag lives with ACI, a sensitivity study has also been performed to show the cost impact of shortened bag lives.

\section{Incremental Fan Power}

The added dust loading due to $\mathrm{ACI}$ will increase the COHPAC $\triangle \mathrm{P}$ which will require more input energy to drive flow through the baghouse. The incremental power requirement for the COHPAC booster fan was calculated using the following fundamental relationship presented as Equation 2.

$$
P_{\text {inc }}=\frac{0.0001575 \cdot Q \cdot \Delta P \cdot 0.746}{\eta / 100}
$$

where $\mathrm{P}_{\text {inc }}$ is the incremental fan power requirement in $\mathrm{kW}, \mathrm{Q}$ is the flue gas flow rate in acfm (assumed to be $2.7 \mathrm{Macfm}$ at $600 \mathrm{MW}$ ), $\Delta \mathrm{P}$ is the increase in differential pressure across the FF in inches $\mathrm{H}_{2} \mathrm{O}, 0.746$ is the factor to convert from horsepower (hp) to kilowatts, and $\eta$ is the fanto-fluid efficiency in \% (assumed $70 \%$ for the analysis).

For the cost analysis, estimates of incremental booster fan electricity cost were made over a range of assumed $\Delta \mathrm{P}$. Parametric tests were of insufficient duration to allow establishment of steady $\Delta \mathrm{P}$. This was evidenced in the monthlong test with the blend fuel where, using a load of $600 \mathrm{MW}$ as a reference, the $\Delta \mathrm{P}$ increased by over 1 inch $\mathrm{H}_{2} \mathrm{O}$ (at $1.5 \mathrm{lb} / \mathrm{Macf} \mathrm{AC}$ injection and no bypass).

Conservative estimates of added $\Delta \mathrm{P}$ due to sorbent injection were used. For $50 \%, 70 \%$, and $90 \%$ mercury removal, the assumed added values of FF differential pressure are $0.5,1.3$, and 3.0 inches $\mathrm{H}_{2} \mathrm{O}$.

Based on this equation, each additional inch of differential pressure requires $454 \mathrm{~kW}$ of power that costs, on an annual levelized basis, $\$ 200,000$.

\section{Increased Maintenance of Existing COHPAC}

Mercury control with sorbent injection into the COHPAC units will change the status quo for FF operations by adding additional dust loading and changing the composition of the fly ash. Furthermore, with the increase in risk associated with the ash-AC mixture, because of its selfheating potential, additional maintenance and inspection time will be needed to ensure proper operation of the COHPAC dust-handling equipment. Estimates for increased COHPAC maintenance have been included with Scenario 2 to account for the increased maintenance associated with handling increased volumes of ash-AC. The assumptions for this added cost included 240 hours per year of maintenance labor and annual expenditures for replacement parts. Parts costs were based on $0.5 \%$ of the original COHPAC equipment costs (which were assumed 
to be $40 \%$ of the original construction cost, approximately $\$ 50$ million per unit in 1996) and escalated to 2006 dollars using the Marshall \& Swift process industry cost index.

\section{COHPAC Upgrades for Improved Safety and Performance with ACI}

During the BOP investigation, some potential issues with ACI were noted with the material-handling properties of the ash-AC mixture. These included COHPAC dust hopper plugging and self-heating of the ash-AC mixture. While the root cause of the hopper plugging was determined to be malfunctioning equipment (hopper heaters on two of the eight compartments of F 2-4), additional monitoring, process enhancement, and protection equipment will reduce the risk of self-heating in the future. This scenario evaluated the capital and operating costs associated with add-on systems to the current COHPAC that may improve reliability and safe operation of the Unit $2 \mathrm{FF}$ as a consequence of $\mathrm{AC}$ addition. Upgrades to the FF that were evaluated included 1) enhanced temperature monitoring, both within the hopper and under hopper heaters; 2) monitoring of $\mathrm{CO}$ levels inside the hopper to possibly indicate smoldering/self-heating of the AC-laden fly ash; 3) improved or more reliable hopper dust level detection; 4) improved fly ash discharge or flow aids; and 5) fire suppression within the hopper in the instance of heat release conditions that could threaten equipment or nearby operating personnel.

Summary economic data for these options are presented in Table 29; the design details regarding each option are provided in Appendix I. However, while specific equipment has been selected to estimate costs, component testing, on a compartment or module scale, would be necessary to ensure that the proposed systems either provide enhanced reliability relative to original hardware or that the systems provide a level of monitoring critical to safe operation of the COHPAC.

\section{Scenario 2 Results}

A comparison of the costs associated with the Scenario 2 changes versus the Scenario 1 baseline is shown in Table 30 for the three levels of mercury capture using enhanced ACI. For each level of removal, including the BOP costs and associated COHPAC upgrades the Scenario 2 assumptions, increases the cost of mercury control by approximately $35 \%$. When the distribution of operating costs is examined for the $90 \%$ removal, Scenario 2 case, Figure 58, the incremental fan power is the largest contributor followed by replacement part costs due to ACI. The sorbent consumption (AC and enhancement consumable) is still the largest component of the operating cost, accounting for over $60 \%$ of the operating costs.

\section{Bag Life Sensitivity}

For this analysis, the nominal life for COHPAC bags at Big Brown-without sorbent injection - is assumed to be 2 years; that is, on a rotating basis, all bags in a compartment or module are changed out once over the course of 2 years. The incremental cost for bag 
Table 29. Summary Economic Data for BOP Upgrades

\begin{tabular}{|c|c|c|c|c|c|c|}
\hline & $\begin{array}{c}\text { CO } \\
\text { Monitoring }\end{array}$ & $\begin{array}{c}\text { Level } \\
\text { Detection }\end{array}$ & $\begin{array}{c}\text { Fly Ash } \\
\text { Discharge }\end{array}$ & $\begin{array}{l}\text { Temperature } \\
\text { Monitoring }\end{array}$ & $\begin{array}{c}\text { Fire } \\
\text { Protection }\end{array}$ & Total \\
\hline \multicolumn{7}{|l|}{ Capital Cost, $\$$} \\
\hline Purchased Equipment & 401,800 & 21,500 & 78,700 & 20,400 & 76,800 & 599,200 \\
\hline Installation & 14,700 & 11,000 & 25,800 & 14,700 & 22,100 & 88,300 \\
\hline Engineering & 5000 & 2500 & 3800 & 2500 & 3800 & 17,600 \\
\hline TCR & 421,500 & 35,000 & 108,300 & 37,600 & 102,700 & 705,100 \\
\hline TCR, \$/kW & 0.70 & 0.06 & 0.18 & 0.06 & 0.17 & 1.18 \\
\hline \multicolumn{7}{|l|}{ Operating Cost, $\$ / y r$} \\
\hline $\mathrm{O} \& \mathrm{M}$ & 11,000 & 5500 & 5500 & 3300 & 5500 & 30,800 \\
\hline Replacement Parts & 20,100 & 1100 & 3900 & 1000 & 3800 & 29,900 \\
\hline Utilities & & & 5000 & & & 5000 \\
\hline Overhead & 6600 & 3300 & 3300 & 2000 & 3300 & 18,500 \\
\hline Total & 37,700 & 9900 & 17,700 & 6300 & 12,600 & 84,200 \\
\hline \multicolumn{7}{|l|}{ Levelized Annual Costs } \\
\hline $\begin{array}{l}\text { Charge for Capital } \\
\text { Investment }\end{array}$ & 41,400 & 3400 & 10,600 & 3700 & 10,100 & 69,200 \\
\hline Operating, $\$$ & 47,300 & 12,400 & 22,300 & 7900 & 15,900 & 105,800 \\
\hline Total Annual Cost, \$ & 88,700 & 15,800 & 32,900 & 11,600 & 26,000 & 175,000 \\
\hline $\begin{array}{l}\text { Total Annual Cost, } \\
\text { \$/MWh }\end{array}$ & 0.0211 & 0.0038 & 0.0078 & 0.0028 & 0.0062 & 0.0416 \\
\hline
\end{tabular}

replacement then represents costs brought on by more frequent bag changeout as a consequence of sorbent injection. However, further analysis is required regarding actual bag life as a function of injection conditions for mercury control, i.e., sorbent type and injection rate. No assumptions have been drawn regarding actual reduction in bag life.

Bags were assumed to cost approximately $\$ 75$ each with replacement requiring 10 minutes per bag. This is consistent with the time required to complete bag changeout in the eight compartments of Module 2-4 after long-term testing. Each compartment is assumed to hold 312 bags; with eight (8) compartments per module and four (4) modules per boiler unit, there are 9984 filtering bags. Bag replacement was assumed to be conducted at maintenance labor rates (plus overhead). Other costs that could be incurred, such as mobilization of bag changeout equipment, engineering prior to changeout, and safety and maintenance planning, were not included in the cost analysis.

Cost estimates were produced for hypothetical changes in bag life as a consequence of sorbent injection for mercury control. A plot of levelized annual cost for bag replacement (including labor) as a function of actual bag life is presented in Figure 59. The trend shown in Figure 59 is an exponential increase in bag replacement cost as actual bag life is reduced from the assumed baseline of 2 years for current COHPAC operation without sorbent injection. A $50 \%$ reduction in bag life produces an incremental cost of $\sim \$ 511,000$ a year $(\$ 0.122 / \mathrm{MWh})$, while a $75 \%$ reduction in bag life - to one-half year between changes-produces an annual incremental cost of $\sim \$ 1.53$ million $(\$ 0.365 / \mathrm{MWh})$. 
Table 30. Mercury Control Cost Comparisons for Scenarios 1 and 2, Not Including and Including Costs for BOP and COHPAC Upgrade Costs, Respectively

\begin{tabular}{|c|c|c|c|c|c|c|}
\hline Mercury Removal, \% & 50 & 70 & 90 & 50 & 70 & 90 \\
\hline Control Method & $\begin{array}{c}\text { Enhanced } \\
\text { ACI }\end{array}$ & $\begin{array}{c}\text { Enhanced } \\
\text { ACI }\end{array}$ & $\begin{array}{c}\text { Enhanced } \\
\text { ACI }\end{array}$ & $\begin{array}{c}\text { Enhanced } \\
\text { ACI }\end{array}$ & $\begin{array}{c}\text { Enhanced } \\
\text { ACI }\end{array}$ & $\begin{array}{c}\text { Enhanced } \\
\text { ACI }\end{array}$ \\
\hline Scenario & 1 & 1 & 1 & 2 & 2 & 2 \\
\hline \multicolumn{7}{|l|}{ Capital Cost, $\$$} \\
\hline Purchased Equipment & $1,316,000$ & $1,316,000$ & $1,316,000$ & $1,915,000$ & $1,915,000$ & $1,915,000$ \\
\hline Installation & 201,000 & 201,000 & 201,000 & 289,300 & 289,300 & 289,300 \\
\hline Engineering & 27,500 & 27,500 & 27,500 & 45,100 & 45,100 & 45,100 \\
\hline TCR & $1,544,500$ & $1,544,500$ & $1,544,500$ & $2,249,400$ & $2,249,400$ & $2,249,400$ \\
\hline TCR, \$/kW & 2.58 & 2.58 & 2.58 & 3.75 & 3.75 & 3.75 \\
\hline \multicolumn{7}{|l|}{ Operating Cost, $\$ / y r$} \\
\hline $\mathrm{AC}$ & 484,000 & 810,000 & $1,372,000$ & 484,000 & 810,000 & $1,372,000$ \\
\hline Enhancement & 96,600 & 165,000 & 284,000 & 96,600 & 165,000 & 248,000 \\
\hline Other & 294,500 & 295,500 & 297,300 & 294,500 & 295,500 & 297,300 \\
\hline Add-On Equipment O\&M & 0 & 0 & 0 & 73,600 & 73,600 & 73,600 \\
\hline Incremental ID Fan Power & 0 & 0 & 0 & 79,500 & 206,800 & 477,100 \\
\hline $\begin{array}{l}\text { Maintenance Labor Due to } \\
\text { ACI }\end{array}$ & 0 & 0 & 0 & 12,400 & 12,400 & 12,400 \\
\hline Replacement Parts Due to ACI & 0 & 0 & 0 & 128,800 & 128,800 & 128,800 \\
\hline Total & 875,100 & $1,270,500$ & $1,953,300$ & $1,169,400$ & $1,692,100$ & $2,645,200$ \\
\hline \multicolumn{7}{|l|}{ Levelized Annual Costs } \\
\hline $\begin{array}{l}\text { Charge for Capital } \\
\text { Investment, } \$\end{array}$ & 151,500 & 151,500 & 151,500 & 220,600 & 220,600 & 220,600 \\
\hline Operating, \$ & $1,096,800$ & $1,591,700$ & $2,447,000$ & $1,465,500$ & $2,120,000$ & $3,313,900$ \\
\hline Total Annual Cost, \$ & $1,248,300$ & $1,743,200$ & $2,598,500$ & $1,686,100$ & $2,340,600$ & $3,534,500$ \\
\hline $\begin{array}{l}\text { Total Annual Cost, } \\
\text { \$/MWh }\end{array}$ & 0.297 & 0.415 & 0.618 & 0.401 & 0.557 & 0.841 \\
\hline $\begin{array}{l}\text { Cost of Mercury } \\
\text { Reduction, } \$ / \mathrm{lb} \mathrm{Hg}\end{array}$ & 2600 & 2590 & 3000 & 3510 & 3480 & 4080 \\
\hline Mercury Reduction, lb/yr & 480 & 673 & 866 & 480 & 673 & 866 \\
\hline
\end{tabular}

Note: the "other" operating cost includes Scenario 1 costs for operations and maintenance, labor, utilities, overhead, replacement parts, fly ash disposal and lost revenue, and compliance monitoring.

These preliminary estimates indicate that, as with increases in operating $\Delta \mathrm{P}$, reductions in bag life have the potential to significantly impact annual operating cost. Long-term testing of 6 months or longer would be necessary to better address these issues.

\section{Scenario 3}

In theory, potential benefits to operating at a reduced $\mathrm{A} / \mathrm{C}$ ratio - with or without $\mathrm{ACI}-$ would be a lower $\Delta \mathrm{P}$ across the $\mathrm{FF}$ as well as longer bag life. Options to achieve a reduced $\mathrm{A} / \mathrm{C}$ ratio would be 1) sustained lower-load operation, 2) high-surface-area filtering elements such as the pleated elements investigated in the slipstream baghouse (SSBH) program (19), and 3 ) addition of filtering capacity. In the instance of ACI for mercury control at Big Brown, one of these options may be a necessity in order to achieve stable operation (i.e., differential pressure) within COHPAC design limits. 


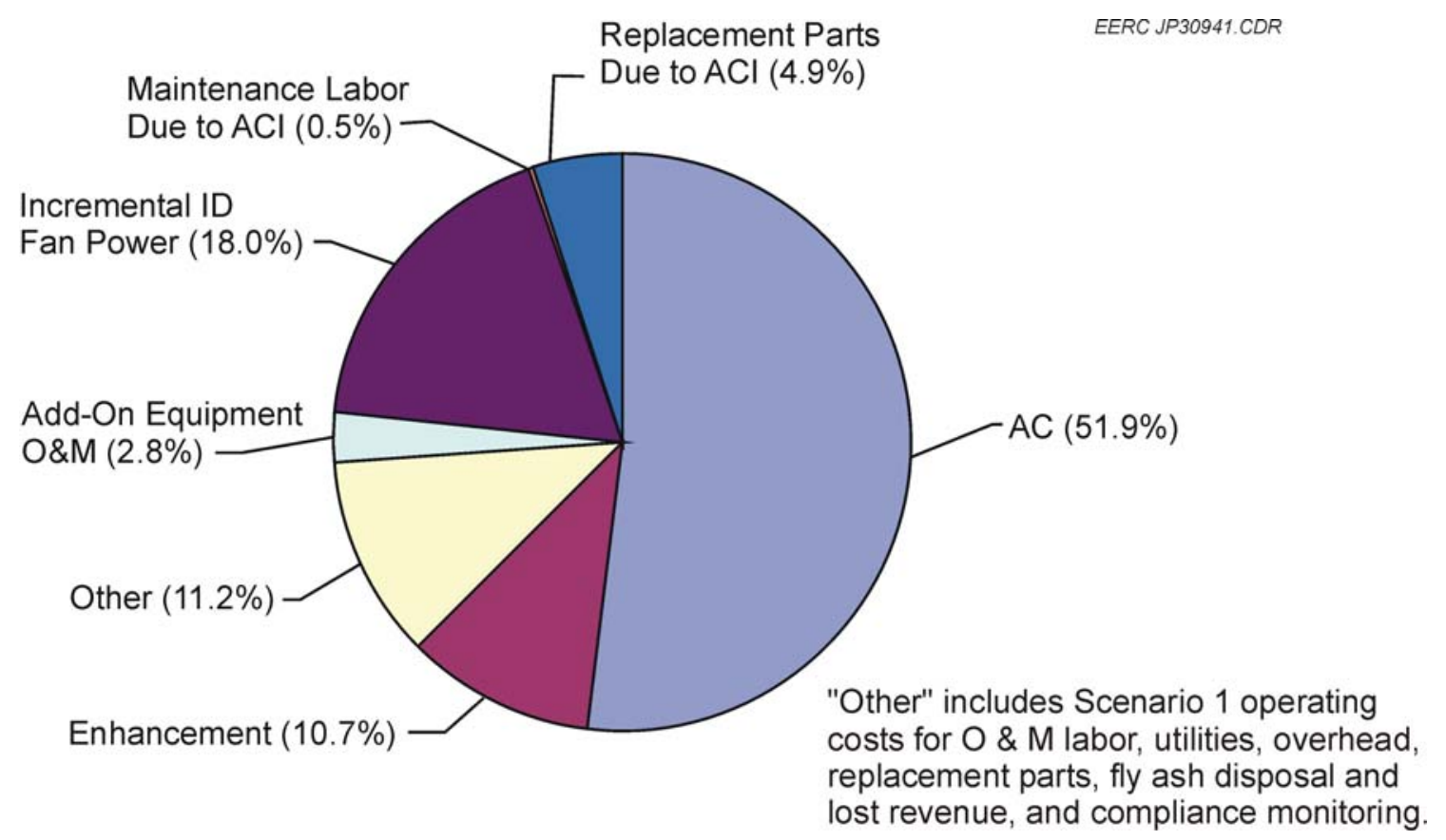

Figure 58. Distribution of operating costs when considering BOP costs and COHPAC upgrades under Scenario 2 with 90\% mercury control using enhanced ACI.

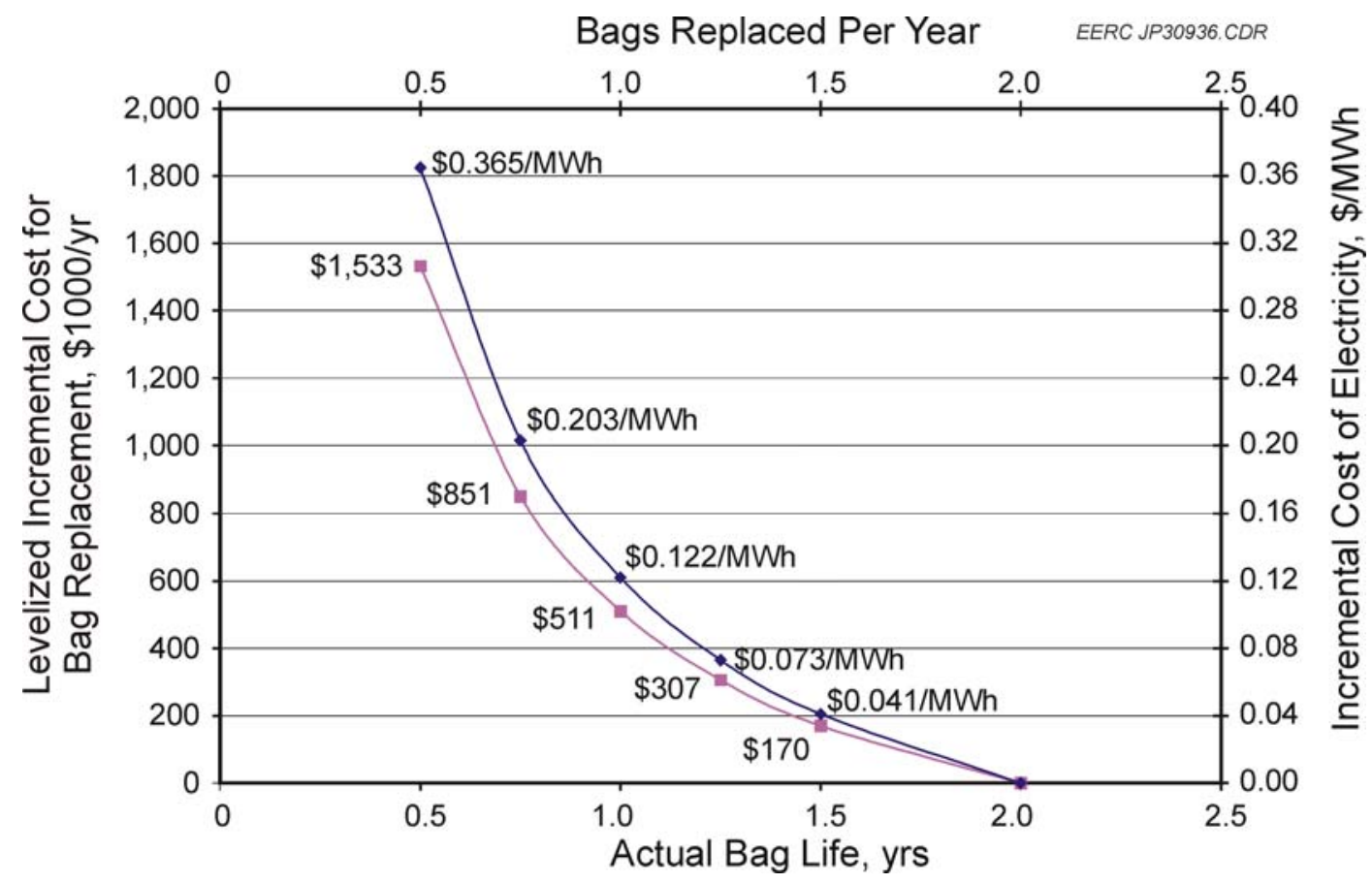

Figure 59. Impact of reduction in bag life on the cost of mercury control. 


\section{COHPAC Expansion}

For the analysis of Scenario 3, only the addition of COHPAC capacity was considered. The baseline A/C ratio was estimated at $12 \mathrm{ft} / \mathrm{min}$ net $(10.5 \mathrm{ft} / \mathrm{min}$ gross) at $600-\mathrm{MW}$ load when the 70-30 blend fuel was fired. The net and gross filtering areas of the four modules of Unit 2 were estimated at 218,400 and $249,600 \mathrm{ft}^{2}$, respectively. The cost of adding COHPAC capacity was evaluated at net $\mathrm{A} / \mathrm{C}$ ratios of 10,8 , and $6 \mathrm{ft} / \mathrm{min}$. Reduction to $10 \mathrm{ft} / \mathrm{min}$, for example, would require an added COHPAC filtering area of 43,680 $\mathrm{ft}^{2}$. Similarly, reducing the net A/C ratio to 8 and $6 \mathrm{ft} / \mathrm{min}$ would require added COHPAC capacity of 109,200 and 218,400 $\mathrm{ft}^{2}$, respectively.

Preliminary estimates for the cost of adding COHPAC capacity were made assuming a turnkey cost of $\$ 150 / \mathrm{ft}^{2}$ of filtering area. This value is consistent with recent costs for 1) We Energies Presque Isle - the first full-scale commercial TOXECON system $\left(\$ 153 / \mathrm{ft}^{2}\right)$, 2) recent estimates by Alstom and the EERC for a greenfield TOXECON system at a lignite-fired plant (in the approximate range of $\$ 99-\$ 159 / \mathrm{ft}^{2}$ depending on $\mathrm{A} / \mathrm{C}$ ratio), and 3) initial costs for the Big Brown COHPAC in 1995/1996 (approximately $\$ 200 / \mathrm{ft}^{2}$ ).

A COHPAC expansion would result in a lower differential pressure across the baghouse and could, therefore, consume less fan power than the baseline case. To estimate the power savings due to a lower net $\mathrm{A} / \mathrm{C}$, the following corresponding reductions in $\Delta \mathrm{P}$ were used for the 90\% removal case with enhanced ACI:

Baseline $\mathrm{A} / \mathrm{C}=12 \mathrm{ft} / \mathrm{min}$, added $\Delta \mathrm{P}$ is 3.0 inches $\mathrm{H}_{2} \mathrm{O}$

COHPAC expansion $\mathrm{A} / \mathrm{C}=10 \mathrm{ft} / \mathrm{min}$, added $\Delta \mathrm{P}$ is 1.0 inch $\mathrm{H}_{2} \mathrm{O}$

COHPAC expansion $\mathrm{A} / \mathrm{C}=8 \mathrm{ft} / \mathrm{min}$, added $\Delta \mathrm{P}$ is -1.0 inch $\mathrm{H}_{2} \mathrm{O}$

COHPAC expansion $\mathrm{A} / \mathrm{C}=6 \mathrm{ft} / \mathrm{min}$, added $\Delta \mathrm{P}$ is -3.0 inches $\mathrm{H}_{2} \mathrm{O}$

Negative values of added $\Delta \mathrm{P}$ indicate a reduction to a $\Delta \mathrm{P}$ below the baseline value without ACI. The amount of reduced $\Delta \mathrm{P}$ compared to the baseline case was used in Equation 2 to calculate the power savings for the economic model. No cost adjustments related to O\&M labor or parts were made since increased capacity would reduce wear on individual components because of lower gas velocities and pressure drop, but with the increased capacity there would be more equipment to maintain.

A summary of the added costs from COHPAC expansion is presented in Table 31 for the evaluated net $\mathrm{A} / \mathrm{C}$ ratios of 6,8 , and $10 \mathrm{ft} / \mathrm{min}$. The baseline case of $12 \mathrm{ft} / \mathrm{min}$ is also presented in Table 31. To add the COHPAC capacity to achieve $10 \mathrm{ft} / \mathrm{min}$ net A/C, the TCR would be approximately $\$ 7.5$ million. Annual costs, aside from those associated with ACI and SEA injection, would increase by $\$ 0.10 / \mathrm{MWh}$ to cover the capital investment. Similarly, to achieve net $\mathrm{A} / \mathrm{C}$ values of 8 and $6 \mathrm{ft} / \mathrm{min}$, the TCR for the added COHPAC area would be approximately $\$ 19$ million and $\$ 38$ million, respectively. The levelized annual costs would increase by approximately $\$ 0.31$ to $\$ 0.71 / \mathrm{MWh}$ for net $\mathrm{A} / \mathrm{C}$ values of 8 and $6 \mathrm{ft} / \mathrm{min}$, respectively. Note also that in the data of Table 31, the reduced ID fan power requirement for $\mathrm{A} / \mathrm{C}$ ratios of 6 and 
Table 31. Cost Summary Associated with COHPAC Expansion, Scenario 3

\begin{tabular}{lcccc}
\hline A/C Ratio & 12 & 10 & 8 & 5 \\
\hline & Enhanced & Enhanced & Enhanced & Enhanced \\
Control Method & ACI & ACI & ACI & ACI \\
\hline Capital Cost, \$ & & & & \\
Purchased Equipment & $1,915,000$ & $4,915,000$ & $9,415,000$ & $16,915,000$ \\
Installation & 289,300 & $4,039,300$ & $9,664,300$ & $19,039,300$ \\
Engineering & 45,100 & 795,100 & $1,920,100$ & $3,795,100$ \\
TCR & $2,249,400$ & $9,749,400$ & $20,999,400$ & $39,749,400$ \\
TCR, \$/kW & 3.75 & 16.25 & 35.00 & 66.25 \\
Operating Cost, \$/yr & & & & \\
AC & $1,372,000$ & $1,372,000$ & $1,372,000$ & $1,372,000$ \\
Enhancement & 284,000 & 284,000 & 284,000 & 284,000 \\
Other & 297,300 & 297,300 & 297,300 & 297,300 \\
Add-On Equipment O\&M & 73,600 & 73,600 & 73,600 & 73,600 \\
Incremental ID Fan Power & 477,100 & 159,000 & $-159,000$ & $-477,100$ \\
Maintenance Labor Due to ACI & 12,400 & 12,400 & 12,400 & 12,400 \\
Replacement Parts Due to ACI & 128,800 & 128,800 & 128,800 & 128,800 \\
Bag Replacement Due to ACI & 0 & 82,500 & 206,300 & 412,700 \\
Total & $2,645,200$ & $2,409,600$ & $2,215,400$ & $2,103,700$ \\
Levelized Annual Costs & & & & \\
Charge for Capital Investment, \$ & 220,600 & 956,300 & $2,059,900$ & $3,899,100$ \\
Operating, \$ & $3,313,900$ & $3,018,700$ & $2,775,400$ & $2,635,400$ \\
Total Annual Cost, \$ & $3,534,500$ & $3,975,000$ & $4,835,300$ & $6,534,500$ \\
Total Annual Cost, \$/MWh & 0.841 & 0.945 & 1.150 & 1.554 \\
Cost of Mercury Reduction, \$/lb Hg & 4080 & 4590 & 5580 & 7550 \\
Mercury Reduction, lb/yr & 866 & 866 & 866 & 866 \\
\hline Note bag & & & &
\end{tabular}

Note: bag life was assumed to be 2 years for cases in this table.

$8 \mathrm{ft} / \mathrm{min}$ results in a cost savings below the current operating cost with no ACI. While this lowers the annual operating costs, the overall cost of mercury reduction is higher because of the added capital expense. The trends of mercury reduction cost and incremental electricity cost, while assuming constant bag life, are presented in Figure 60.

\section{Bag Life Sensitivity}

To investigate the possible economic benefit of extended bag life with added COHPAC capacity, a sensitivity calculation was performed for an assumed range of bag life extensions. The case considered was a doubling of COHPAC capacity to achieve a net A/C ratio of $6 \mathrm{ft} / \mathrm{min}$. The economic assumptions regarding bag costs and replacement charges are consistent with those used in the analysis of Figure 59. Results of the sensitivity study are provided in Figure 61, where the base case is represented by the 2-year bag life which has zero values for the incremental cost for bag replacement and the incremental cost for electricity. As shown, values to the left of the baseline point, shorter bag lives, result in higher costs, and values to the right, extended bag lives, provide cost savings. However, when the cost savings associated with longer 


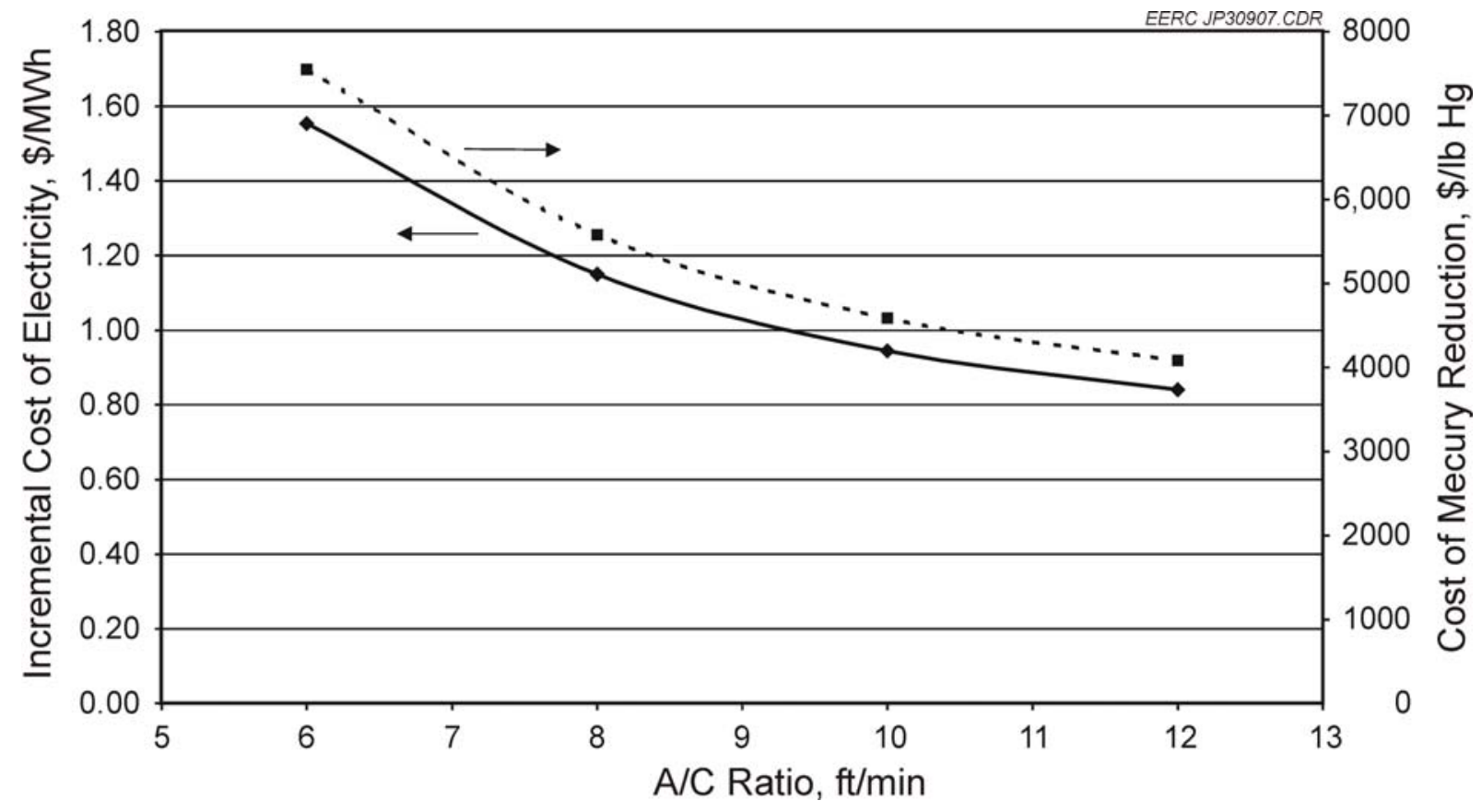

Figure 60. Added cost for mercury control as a function of COHPAC A/C ratio. The targeted mercury removal is $90 \%$ using enhanced ACI, and the bag lives are assumed to be 2 years.

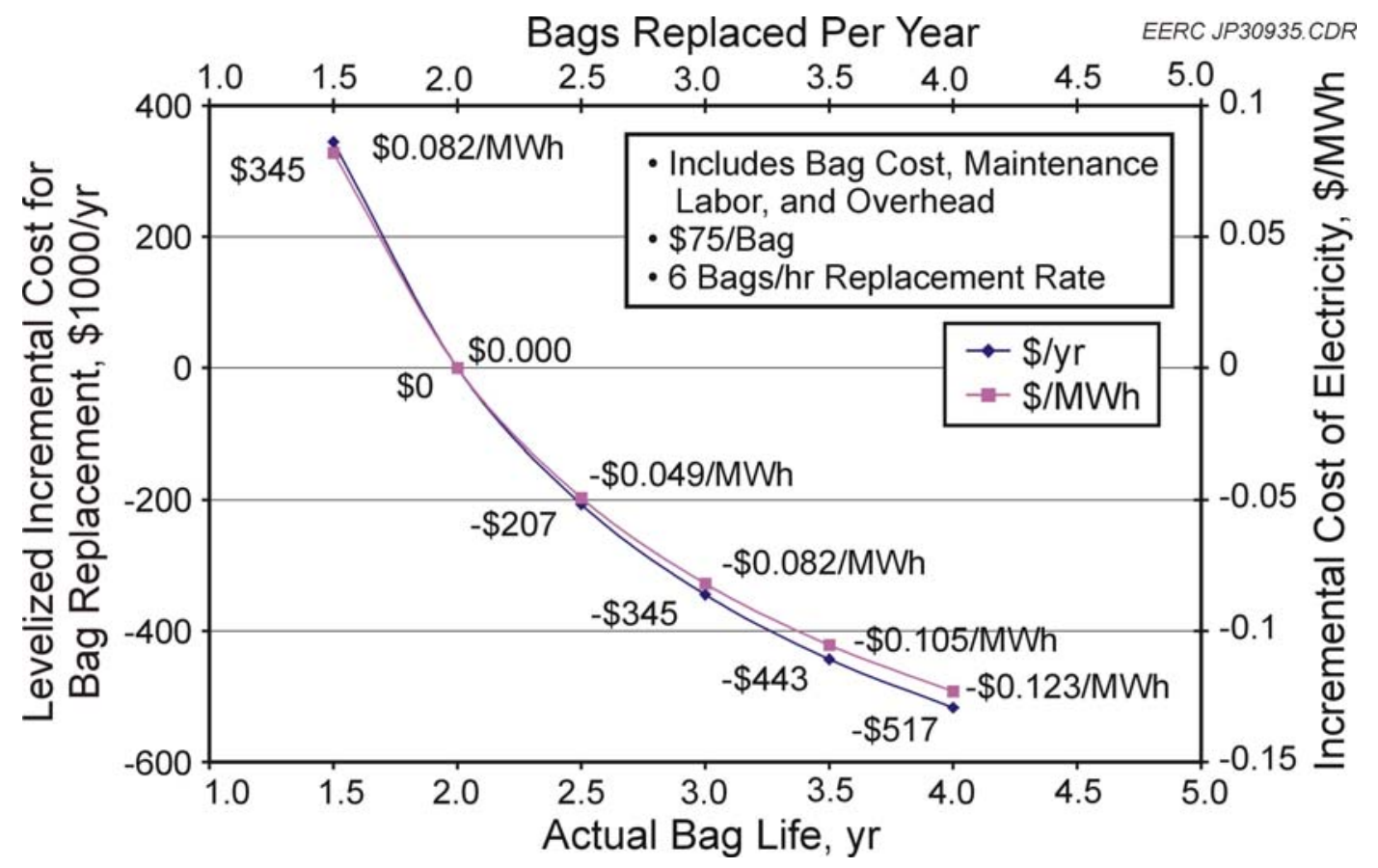

Figure 61. Sensitivity of the incremental cost for bag replacement and the incremental cost of electricity as a function of bag life. The conditions are an expanded COHPAC to an A/C ratio of $6 \mathrm{ft} / \mathrm{min}$ and a mercury removal of $90 \%$ using enhanced ACI. 
bag lives are compared to the added incremental cost of electricity resulting from COHPAC expansion (Figure 61), there is roughly an order of magnitude difference between the figures, indicating that improvements in bag life (over the range considered feasible) will not offset COHPAC capital expenses.

\section{Comparison of Economic Scenarios}

To summarize results of the economic study, a comparison of all three scenarios is presented for the case of $90 \%$ mercury removal using enhanced ACI. Table 32 is a summary of the economic data, and Figure 62 presents the incremental cost of electricity because of mercury control and the cost of removed mercury for the cases considered. As shown in Figure 62, the least expensive scenario is Scenario 1 with an A/C of $12 \mathrm{ft} / \mathrm{min}$, but this scenario does not account for observed BOP impacts and the economic penalty that they will likely carry, so Scenario 2 with an $\mathrm{A} / \mathrm{C}$ of $12 \mathrm{ft} / \mathrm{min}$ is more representative of a least-possible-cost scenario.

Table 32. Summary of Economic Data for the Scenarios Considered. The target mercury removal is $\mathbf{9 0 \%}$ using enhanced ACI.

\begin{tabular}{|c|c|c|c|c|c|}
\hline Control Method & $\begin{array}{c}\text { Enhanced } \\
\text { ACI }\end{array}$ & $\begin{array}{c}\text { Enhanced } \\
\text { ACI }\end{array}$ & $\begin{array}{c}\text { Enhanced } \\
\text { ACI }\end{array}$ & $\begin{array}{c}\text { Enhanced } \\
\text { ACI }\end{array}$ & $\begin{array}{c}\text { Enhanced } \\
\text { ACI }\end{array}$ \\
\hline Scenario & 1 & 2 & 3 & 3 & 3 \\
\hline A/C Ratio & 12 & 10 & 10 & 8 & 6 \\
\hline \multicolumn{6}{|l|}{ Capital Cost, $\$$} \\
\hline Purchased Equipment & $1,316,000$ & $1,915,000$ & $4,915,000$ & $9,415,000$ & $16,915,000$ \\
\hline Installation & 201,000 & 289,300 & $4,039,300$ & $9,664,300$ & $19,039,300$ \\
\hline Engineering & 27,500 & 45,100 & 795,100 & $1,920,100$ & $3,795,100$ \\
\hline TCR & $1,544,500$ & $2,249,400$ & $9,749,400$ & $20,999,400$ & $39,749,400$ \\
\hline TCR, \$/kW & 2.58 & 3.75 & 16.25 & 35.00 & 66.25 \\
\hline \multicolumn{6}{|l|}{ Operating Cost, $\$ / y r$} \\
\hline $\mathrm{AC}$ & $1,372,000$ & $1,372,000$ & $1,372,000$ & $1,372,000$ & $1,372,000$ \\
\hline Enhancement & 284,000 & 284,000 & 284,000 & 284,000 & 284,000 \\
\hline Other & 297,300 & 297,300 & 297,300 & 297,300 & 297,300 \\
\hline Add-On Equipment O\&M & 0 & 73,600 & 73,600 & 73,600 & 73,600 \\
\hline Incremental ID Fan Power & 0 & 477,100 & 159,000 & $-159,000$ & $-477,100$ \\
\hline $\begin{array}{l}\text { Maintenance Labor Due to } \\
\text { ACI }\end{array}$ & 0 & 12,400 & 12,400 & 12,400 & 12,400 \\
\hline $\begin{array}{l}\text { Replacement Parts Due to } \\
\text { ACI }\end{array}$ & 0 & 128,800 & 128,800 & 128,800 & 128,800 \\
\hline $\begin{array}{l}\text { Bag Replacement Due to } \\
\text { ACI }\end{array}$ & 0 & 0 & 82,500 & 206,300 & 412,700 \\
\hline Total & $1,953,300$ & $2,645,200$ & $2,409,600$ & $2,215,400$ & $2,103,700$ \\
\hline \multicolumn{6}{|l|}{ Levelized Annual Costs } \\
\hline $\begin{array}{l}\text { Charge for Capital } \\
\text { Investment, } \$\end{array}$ & 151,500 & 220,600 & 956,300 & $2,059,900$ & $3,899,100$ \\
\hline Operating, $\$$ & $2,447,000$ & $3,313,900$ & $3,018,700$ & $2,775,400$ & $2,635,400$ \\
\hline Total Annual Cost, \$ & $2,598,500$ & $3,534,500$ & $3,975,000$ & $4,835,300$ & $6,534,500$ \\
\hline $\begin{array}{l}\text { Total Annual Cost, } \\
\text { \$/MWh }\end{array}$ & 0.618 & 0.841 & 0.945 & 1.150 & 1.554 \\
\hline $\begin{array}{l}\text { Cost of Mercury } \\
\text { Reduction, \$/lb Hg }\end{array}$ & 3000 & 4080 & 4590 & 5580 & 7550 \\
\hline Mercury Reduction, lb/yr & 866 & 866 & 866 & 866 & 866 \\
\hline
\end{tabular}




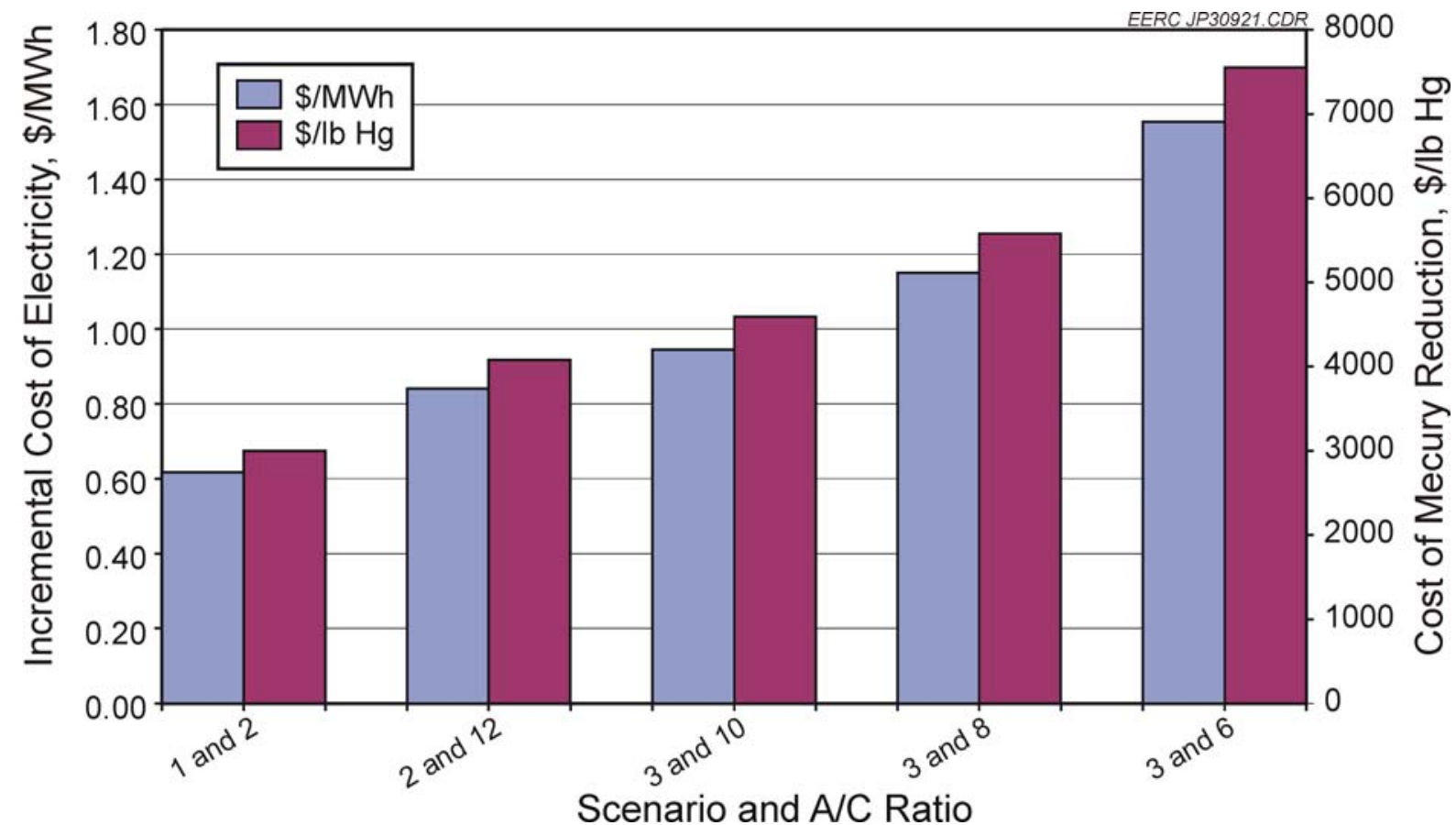

Figure 62. Incremental cost of electricity because of mercury control and the cost for removed mercury for the scenarios considered. Target mercury removal is $90 \%$ using the enhanced ACI.

However, as discovered during field testing, operation of Scenario 2 with an $\mathrm{A} / \mathrm{C}$ ratio of $12 \mathrm{ft} / \mathrm{min}$ does not appear sustainable without limiting the maximum load output, so other options need to be considered. The option considered in Scenario 3 involved expanding the COHPAC to allow sustainable baghouse operation with ACI. The estimated expenses for this option are presented in Table 31 and Figure 60.

\section{CONCLUSIONS}

This project tested the ability to substantially enhance the ability of AC sorbents to remove $\mathrm{Hg}$ from lignite combustion gases and achieve a high level of cost-effective control for this challenging coal. These results allowed determination of the commercial economics for $\mathrm{Hg}$ removal, quantification of the BOP impacts of the control technologies, and investigation of the commercialization potential, particularly for Texas lignite blends. A preliminary economic analysis was performed using the test data to assess the cost of implementing TOXECON for $\mathrm{Hg}$ control using the most promising sorbent technology as identified in this project.

Conclusions from the project at Big Brown are summarized in three categories: mercury control, economics, and BOP issues. 


\section{Mercury Control}

- Baseline sampling indicated very little native mercury removal across the ESP or FF 2-4. The baseline mercury mass balance indicates less than $10 \%$ removal, with most of this occurring across the ESP. As expected, the flue gas mercury was mostly in the elemental form, comprising an average of $62 \%$ in the FF $2-4$ inlet $\mathrm{Hg}$.

- Parametric testing showed that the enhanced AC and AC with SEA4 performed better than $\mathrm{AC}$ alone, but all options achieved the minimum targeted value of 55\% removal above baseline. Up to $90 \%$ removal was possible with higher injection rates, although long-term unit operation could not be sustained at these rates:

- With standard AC, only 55\% removal could be obtained at an approximate injection rate of $2 \mathrm{lb} / \mathrm{Macf}$, and for $90 \%$ removal, over $6 \mathrm{lb} /$ Macf was needed.

- For the enhanced AC, 55\% removal could be obtained at an approximate injection rate of $1 \mathrm{lb} /$ Macf and 90\% removal with approximately $2 \mathrm{lb} /$ Macf injection rate.

- The injection of additive SEA4 was not effective by itself at the rate tested; however, a synergistic effect was observed when injected with AC. 55\% removal could be achieved with approximately $0.5 \mathrm{lb} /$ Macf of AC and $1.5 \mathrm{lb} /$ Macf of SEA4; 90\% removal appears possible with $1.5 \mathrm{lb} / \mathrm{Macf}$ of $\mathrm{AC}$ and 1.5-2 lb/Macf of SEA4.

- Monthlong testing with the enhanced $\mathrm{AC}$ at a nominal rate of $1.5 \mathrm{lb} / \mathrm{Macf}$ resulted in an overall average removal value of $74 \%$ across FF $2-4$ when only considering the time enhanced $\mathrm{AC}$ was injected. When considering the total time the plant was operating, with and without enhanced ACI, the average removal value was $64 \%$.

- A wide range of variation was observed in the monthlong mercury removal values across FF 2-4. Results of the data analysis indicate that the ACI rate was the key factor affecting removal, and interruptions to ACI caused transients to appear in the removal values for up to 8-10 hours, after which removals appeared to converge to consistent values.

- While the observed mercury removals met the stated objectives, results from the monthlong test indicate that sorbent injection in the TOXECON configuration at Big Brown does not appear to be a viable option because of the $\Delta \mathrm{P}$ limits of the high $\mathrm{A} / \mathrm{C} \mathrm{FF}$.

\section{Economics}

- BOP impacts and operational limits were observed leading to unsustainable long-term operation and the need for plant modifications, should the mercury control technology be implemented. 
- By addressing BOP impacts but not including increased filtering capacity, the estimated total costs (Scenario 2) for mercury control would be around $0.84 \$ / \mathrm{kWh}$, or $\$ 4000 / \mathrm{lb} \mathrm{Hg}$ removed, assuming a targeted removal rate of $90 \%$ and using enhanced ACI.

- Based on test data, it appears unlikely that the COHPAC at Big Brown will have enough $\Delta \mathrm{P}$ operating margin to allow $\mathrm{ACI}$ on a continual basis. Reducing the $\mathrm{A} / \mathrm{C}$ ratio down to current TOXECON design values of approximately $6 \mathrm{ft} / \mathrm{min}$ would likely result in sustainable operation but is costly and would increase the cost of mercury removed by over $85 \%$. The estimated cost for mercury removal is $1.55 \$ / \mathrm{MWh}$ levelized and $7550 \$ / \mathrm{lb} \mathrm{Hg}$ removed.

\section{Balance of Plant}

- The data show that $\mathrm{AC}$ behaved much like additional fly ash in terms of dust cake $\Delta \mathrm{P}$. At the monthlong injection rate (nominally $1.5 \mathrm{lb} / \mathrm{Macf}$ ), the enhanced $\mathrm{AC}$ added to the $\mathrm{FF} \Delta \mathrm{P}$ approximately 1 inch $\mathrm{H}_{2} \mathrm{O}$ at $600-\mathrm{MW}$ load. The increase was more substantial at higher loads, i.e., at $650 \mathrm{MW}$, it would be approximately 1.5 inch $\mathrm{H}_{2} \mathrm{O}$.

- While the amount of added $\Delta \mathrm{P}$ from sorbent injection appears manageable, when combined with high $\mathrm{A} / \mathrm{C}$ operation and the continual increase of residual $\Delta \mathrm{P}$, there is little to no operating margin before encountering $\Delta \mathrm{P}$ limits, especially at high loads. This finding limits sustainable injection of $\mathrm{AC}$ without appropriate modifications to the plant or its operations.

- Throughout testing, there was a gradual increase in residual $\Delta \mathrm{P}$ across the FF bags. This increase resulted from accumulated dust on the bags that is not cleaned away by the lowpressure pulse-cleaning system. The increase in residual $\Delta \mathrm{P}$ appeared to increase at the same rate during testing compared to the rate prior to testing. Thus enhanced ACI appeared to have minimal to no effect on this rate.

- Essentially no conclusions can be drawn about the effect of ACI on bag life since the duration of testing was limited.

- Indirect evidence (OH FF outlet data) suggests that, with ACI, small amounts of AC may penetrate the FF and result in slightly higher FF outlet emissions.

- Handling and storage issues were observed for the TOXECON ash-AC mixture. Malfunctioning equipment led to hopper plugging, and storage of the stagnant material at flue gas temperatures resulted in self-heating and ignition of the $\mathrm{AC}$ in the ash. In the hoppers that worked properly, no such problems were reported. It, therefore, appears essential that proper monitoring and emptying of ash levels will be needed to avoid self-heating issues.

- Analysis of ash-AC samples collected during the field testing at Big Brown indicate that leaching and thermal release of mercury is unlikely under normal disposal conditions. Only high-temperature applications of the fly ash, such as use as a raw material in a cement kiln, would present problems. 


\section{PROJECT RECOGNITION AND TECHNOLOGY TRANSFER}

The following items pertain to publications or press releases that are related to the project entitled "Field Testing of Activated Carbon Injection Options for Mercury Control at TXU's Big Brown Station."

\section{Presentations/Conferences}

- Martin, C.L.; Pavlish, J.H. Predicting the Self-Heating Potential of Ash-Activated Carbon Mixtures Resulting from Mercury Control Technologies. Presented at the 11th Annual EUEC, Tucson, AZ, Jan 27-30, 2008.

- Pavlish, J.H.; Thompson, J.S.; Martin, C.L.; Wiemuth, R.W.; Noceti, P. Field Testing of Activated Carbon Injection Options for Mercury Control at TXU's Big Brown Station. Presented at the 2007 DOE-NETL Mercury Control Technology Conference (DOE Contractor's Review), Pittsburgh, PA, Dec 11-13, 2007.

- Pavlish, J.H.; Thompson, J.S.; Martin, C.L.; Wiemuth, R.W.; Pletcher, S.M. Fabric Filter Bag Investigation Following Field Testing of Sorbent Injection for Mercury Control at TXU's Big Brown Station. Presented at the 2007 International Conference on Air Quality (Air Quality VI), Arlington, VA, Sept 24-27, 2007.

- Martin, C.L.; Pavlish, J.H.; Thompson, J.S.; Wiemuth, R.W.; Pletcher, S.M. Investigation into the Self-Heating of TOXECON Baghouse Ash-Activated Carbon Mixtures from TXU's Big Brown Station. Poster presentation at the 2007 International Conference on Air Quality (Air Quality VI), Arlington, VA, Sept 24-27, 2007.

- Thompson, J.S.; Pavlish, J.H.; Martin, C.L.; Wiemuth, R.W.; Pletcher, S.M. Enhanced Sorbent Injection for Mercury Control at TXU Power's Big Brown Station. Presented at the 2007 Electric Power Conference, Chicago, IL, May 1-2, 2007.

- Martin, C.L.; Pavlish, J.H.; Thompson, J.S.; Wiemuth, R.W.; Pletcher, S.M. Self-Heating Risk of TOXECON Baghouse Ash Mixtures When Using Activated Carbon Injection for Mercury Control. Presented at the 32nd International Technical Conference on Coal Utilization \& Fuel Systems, Clearwater, FL, June 10-15, 2007.

- Pavlish, J.H.; Thompson, J.S.; Martin, C.L.; Wiemuth, R.W.; Pletcher, S.M. Baghouse Balance of Plant Effects at TXU's Big Brown Station During Field Testing of Sorbent Injection for Mercury Control. Presented at the 10th Annual EUEC, Tucson, AZ, Jan 21-24, 2007.

- Pavlish, J.H.; Thompson, J.S.; Martin, C.L.; Wiemuth, R.W.; Pletcher, S.M. Field Testing of Mercury Control at TXU's Big Brown Station. Presented at the 2006 DOE NETL Mercury Control Technology Conference (DOE Contractor's Review), Pittsburgh, PA, Dec 13, 2006 
- John Pavlish served on a panel to discuss BOP effects when using ACI for mercury control (session at the same conference).

- Pavlish, J.H.; Thompson, J.S.; Martin, C.L.; Wiemuth, R.W.; Pletcher, S.M. Field Testing of Activated Carbon Injection Options for Mercury Control at TXU's Big Brown Station. Presented at the Mega Symposium 2006, Baltimore, MD, Aug 28-31, 2006.

- Pavlish, J.H. Mercury Control Options for Lignite-Fired Utilities. Presented at the 2006 Air \& Waste Management Association's Annual Meeting, Minneapolis, MN, June 23, 2005.

- Feeley, T.J. Update on the U.S. Department of Energy's Phase II and Phase III Mercury Control Technology R\&D Program. Presented at the 3rd Mercury Emissions from Coal International Conference, Katowice, Poland, June 6, 2006.

- Almlie, J.C.; Pavlish, J.H.; Wiemuth, R.W.; Pletcher, S.M. Pilot-Scale Testing in Support of Activated Carbon Injection at TXU Power's Big Brown Station. Presented at the Electric Utility Environmental Conference, Tucson, AZ, Jan 22-25, 2006.

\section{Print Media}

- "UND Group to Lead Research on Lignite Electricity Plants," Valley City Times Record, Nov 23, 2004.

- “UND Group to Lead Research on Plant," Jamestown Sun, Nov 23, 2004.

- “UND Group to Lead Research on Lignite Plant,” Williston Herald, Nov 23, 2004.

- “Group to Research New Lignite Plant," Bismarck Tribune, Nov 24, 2004.

- “Trade Talk: UND Center Leads \$2.3 Million Project," Forum of Fargo-Moorhead, Nov 23, 2004.

- "UND Group to Lead Research on Lignite Plant," Grand Forks Herald, Nov 23, 2004.

\section{Online Articles}

- Removing Mercury from Lignite Burning Plants, Waterfalls Institute of Technology Transfer (WITT) Technology Review, www.witts.org/env_audit_37_feb04/ wista_eva_funding.htm (accessed Feb 2005).

- UND Group to Lead Research on Lignite Plant, Energy Central Professional (accessed Nov 23, 2004).

- EERC Selected to Lead a $\$ 2.3$ Million Project in Mercury Control, Power Engineering Magazine (accessed Nov 2004). 
- EERC Awarded \$2.3 Million Mercury Research Project, www.AZom.com (accessed Nov 23, 2004).

- EERC Awarded \$2.3 Million Mercury Research Project, Newswise (accessed Nov 22, 2004).

- UND Group to Lead Research on Lignite Plant, Associated Press (accessed Nov 2004).

- EERC Awarded \$2.3 Million Mercury Research Project, ENN (accessed Nov 2004).

- DOE Announces Further Field Testing of Advanced Mercury Control Technologies, TECHnews from DOE NETL (accessed Nov 2004).

\section{REFERENCES}

1. National Research Council. Toxicological Effects of Methylmercury; Report for U.S. Environmental Protection Agency; National Academy Press: Washington, DC, Aug 2000.

2. U.S. Environmental Protection Agency. Mercury Study Report to Congress Volume I: Executive Summary; EPA-452/R-97-003; Office of Air Quality Planning and Standards and Office of Research and Development: Dec 1997.

3. U.S. Environmental Protection Agency. Utility Hazardous Air Pollutant Report to Congress; Office of Air Quality Planning and Standards and Office of Research and Development; Feb 1998.

4. U.S. Environmental Protection Agency. Information Collection Request; 1999.

5. Laudal D.L.; Roberson, R. JV Task 42 - Longer-Term Testing of Continuous Mercury Monitors; U.S. Department of Energy: Pittsburgh, PA, and EPRI: Palo Alto, CA, 2003.

6. Feeley, T., DOE. DOE-NETL's Mercury Control Technology R\&D Program Presented at the Subbituminous Energy Coalition General Meeting, Denver, CO, March 30, 2004.

7. U.S. Department of Energy. Large-Scale Mercury Control Technology Field Testing Program - Phase II Solicitation DE-PS26-03NT41718-00, 2003, Amendment 002.

8. U.S. Environmental Protection Agency. Control of Mercury Emissions from Coal-Fired Electric Utility Boilers; www.epa.gov/ttnatw01/utility/hgwhitepaperfinal.pdf; Air Pollution Prevention and Control Division, National Risk Management Research Laboratory Office of Research and Development: March 2004.

9. Pavlish, J.H.; Holmes, M.J.; Benson, S.A.; Crocker, C.R.; Galbreath, K.C. Application of Sorbents for Mercury Control for Utilities Burning Lignite Coal. AQIII Proceedings, Special Issue of Fuel Processing, Sept 2002. 
10. Pavlish, J.H. Challenges of Controlling Mercury Emissions from Lignite and Subbituminous Coal Combustion Sources. EPA Mercury Roundtable, June 17, 2003.

11. Zygarlicke, C.J.; Galbreath, K.C.; Toman, D.L. Coal Combustion Mercury Transformations. Presented at the Air Quality II: Mercury Trace Elements, and Particulate Matter Conference, McLean, VA, Sept 19-21, 2000.

12. Pavlish, J.H.; Holmes, M.J. Mercury Control for Lignite-Fired Power Plants Poses a Challenge. Center for Air Toxic Metals Newsletter 2002, 8 (1), 6.

13. Pavlish, J.H.; Holmes, M.J.; Galbreath, K.C.; Pavlish, B.M. Pilot-Scale Investigation of Mercury Control Technologies for Utilities Burning Lignite Coal. Presented at the Combined Power Plant Air Pollutant Control Mega Symposium, May 19-22, 2003.

14. Pavlish, J.P.; Sondreal, E.A.; Mann, M.D.; Olson, E.S.; Galbreath, K.C.; Laudal, D.L.; Benson, S.A. A Status Review of Mercury Control Options for Coal-Fired Power Plants. Special Mercury Issue of Fuel Process. Technol. 2003, 82 (2-3), 89-165.

15. U.S. Environmental Protection Agency National Risk Management Research Laboratory. Control of Mercury Emissions from Coal-Fired Electric Utility Boilers; Interim Report (including errata dated 3-31-02) for Office of Air Quality Planning and Standards; EPA600/R-01-109; April 2002.

16. Pavlish, J.H. Mercury Control Technologies for Electric Utilities Burning Lignite Coal. U.S. DOE NETL Mercury Control Technology R\&D Review Meeting, Aug 2003.

17. Bustard, J.; Grubb, T.; Merritt, R.; Sjostrom, S.; Chang, R.; Casey, A.; Turchi, K.; Jeanes, R. TXU Big Brown COHPAC Performance Improvement with High-Permeability Fabric. Presented at the Mega Symposium 2001, Chicago, IL, Aug 20-23, 2001.

18. Thompson, J.T.; Martin, C.L; Pavlish, J.H. Site-Specific Test Plan-Full-Scale and Slipstream Testing of Activated Carbon Injection for Mercury Control at TXU's Big Brown Station; Jan 2006.

19. Pavlish, J.H.; Laumb, J.D.; Jensen, R.R.; Thompson, J.S.; Martin, C.L.; Musich, M.A.; Pavlish, B.M.; Miller, S.J.; Hamre, L.L. Baghouse Slipstream Testing at TXU's Big Brown Station; Final Report; DOE Cooperative Agreement No. DE-FC26-98FT40321, April 2007.

20. Laudal, D.L.; Wocken, C.A.; Fritze, M.J.; Reilkoff, T.E. JV Task 72-Evaluation of Mercury Speciation and Emissions at TXU's Coal-Fired Power Plants. Final Report for Cooperative Agreement No. DE-FC26-98FT40321. Energy \& Environmental Research Center: Grand Forks, ND, Feb 2005.

21. Jones, A.P.; Hoffmann, J.W.; Smith, D.N.; Feeley, T.J.; Murphy, J.T. DOE/NETL's Phase II Mercury Control Technology Field Testing Program, Preliminary Economic Analysis of Activated Carbon Injection, 2006. 
22. Pavlish, J.H.; Almlie, J.C.; Hamre, L.L.; Zhuang, Y., JV Task 71-Pilot-Scale Testing of Potential Mercury Control Technologies for TXU Generation Company LP; Final Report; DOE Cooperative Agreement No. DE-FC26-98FT40321. Aug 2005.

23. Lindau, L. Operating Experiences of Mercury Collection by PAC Injection in Bag Filters. Presented at the 2003 Power Plant Air Pollutant Control "MEGA" Symposium, 2003.

24. Derenne, S.; Sartorelli, P.; Bustard, J.; Stewart, R.; Schlager, R.; Sjostrom, S.; Chang, R.; Utter, R.; Cummings, J.; McMahon, T.; Sudhoff, F. TOXECONTM Clean Coal Demonstration for Mercury and Multi-Pollutant Control at We Energies Presque Isle Power Plant. Presented at the Power Plant Air Pollutant Control "MEGA" Symposium, Aug 28-31, 2006; Paper 109.

25. Jones, J.C. A New and More Reliable Test for the Propensity of Coals and Carbons to Spontaneous Heating. Journal of Loss Prevention in the Process Industries 2000, 13, 6971.

26. U.S. Environmental Protection Agency. Method 1050-Test Methods to Determine Substances Likely to Spontaneously Combust; Revision 0; 2000.

27. Suzin, Y.; Buettner, L.C.; LeDuc, C.A. Characterizing the Ignition Process of Activated Carbon. Carbon 1999, 37, 335-346.

28. Beever, P.F. Self-Heating and Spontaneous Combustion. In Society of Fire Protection Engineers Handbook of Fire Protection Engineering; DiNenno, P.J., Ed.; National Fire Protection Association: Quincy, MA, 1988; Section 1/Chapter 22.

29. Hassett, D.J. Synthetic Groundwater Leaching Procedure, In Encyclopedia of Environmental Analysis and Remediation; Meyers, R.A., Ed.; John Wiley \& Sons, Inc., 1998; pp 4797-4803.

30. U.S. EPA Method 1311. Toxicity Characteristic Leaching Procedure; Test Methods for Evaluating Solid Waste, Physical/Chemical Methods; EPA Publication SW-846, Third Edition, as amended by Updates I, II, IIB, and III, finalized in the Federal Register on June 13, 1997.

31. ASTM International. Standard Method for Shake Extraction of Solid Waste with Water. In Annual Book of ASTM Standards; Section 11: Water and Environmental Technology, ASTM D3987-06, 2006.

32. Heebink, L.V.; Pflughoeft-Hassett, D.F.; Hassett, D.J.; Buckley, T.D.; Zacher, E.J. Laboratory Assessment of the Impact of Carbon-Based Sorbents on the Management of Fort Union Lignite CCBs; In Proceedings of the 20th Symposium on Western Fuels; Denver, CO, Oct 24-26, 2006. 
33. Hassett, D.J.; Heebink, L.V.; Pflughoeft-Hassett, D.F.; Zacher, E.J.; Buckley, T.D.; Eylands, K.E. Mercury and Air Toxic Element Impacts of Coal Combustion By-Product Disposal and Utilization; Final Year 2 Annual Report; EERC Publication 2005-EERC-0609; Energy \& Environmental Research Center: Grand Forks, ND, June 2005.

34. Hassett, D.; Heebink, L.; Zacher, E.; Buckley, T.; Jung, R. Mercury and Air Toxic Element Impacts of Coal Combustion By-Product Disposal and Utilization. In 2005 Annual Report of the Center for Air Toxic Metals; Energy \& Environmental Research Center: Grand Forks, ND, 2006.

35. Pflughoeft-Hassett, D.F.; Hassett, D.J.; Gallagher, J.R.; Heebink, L.V.; Zacher, E.J.; Jung, R.; Buckley, T.D. Microbiologically Mediated Mercury and Air Toxic Element Rereleases from Coal Combustion By-Products; Topical Report for the U.S. Department of Energy National Energy Technology Laboratory; Energy \& Environmental Research Center: Grand Forks, ND, Feb 2006. 
APPENDIX A

\section{SAMPLE CALCULATIONS}




\section{ONTARIO HYDRO (OH) METHOD SAMPLING}

\section{Volume of Gas Sample}

$\mathrm{Vm}(\mathrm{std}) \quad=\quad$ Volume of gas sample measured by the dry-gas meter, corrected to standard conditions, dscf

$\mathrm{Vm}(\mathrm{std})(\mathrm{dscf}) \quad=\quad \frac{\mathrm{K}_{1} \times \mathrm{Vmc} \times \mathrm{Pm}}{\mathrm{Tm}+460}$

$\mathrm{Vm}(\mathrm{std}) \quad=\quad \frac{17.64 \times 45.472 \times 1 \times 29.665}{104+460}=42.190 \mathrm{dscf}$

Where:

$\mathrm{K}_{1} \quad=\quad 17.64 \mathrm{R} / \mathrm{in} . \mathrm{Hg}$

Vmc $\quad=\quad \mathrm{Vm} \times \mathrm{Cm}=$ Volume of gas sample as measured by dry-gas meter, corrected for meter calibration

$\mathrm{Pm} \quad=\quad$ Meter pressure (in. $\mathrm{Hg}$ )

$\mathrm{Tm} \quad=\quad$ Meter temperature $\left({ }^{\circ} \mathrm{F}\right)$

Volume of Water Vapor

$\mathrm{Vw}(\mathrm{std}) \quad=\quad$ Volume of water vapor in the gas sample, corrected to

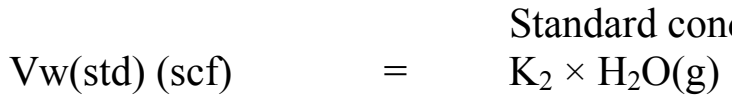

$\mathrm{Vw}(\mathrm{std}) \quad=0.04715 \times 137.5=6.483 \mathrm{scf}$

Where:

$\mathrm{K}_{2} \quad=\quad 0.04715 \mathrm{ft}^{3} / \mathrm{g}$

$\mathrm{H}_{2} \mathrm{O}(\mathrm{g}) \quad=\quad$ Mass of liquid collected in impingers and silica gel $(\mathrm{g})$

Water Vapor in the Gas Stream

Bws $\quad=\quad$ Water vapor in the gas stream, proportion by volume

Bws

$=\frac{\mathrm{Vw}(\mathrm{std})}{\mathrm{Vm}(\mathrm{std})+\mathrm{Vw}(\mathrm{std})}$

Bws $\quad=\quad \frac{6.483}{42.190+6.483}=0.1332$ 


\section{Dry Molecular Weight}

$\begin{array}{lll}\operatorname{Md} & = & \text { Dry molecular weight of stack gas, lb/lb-mol } \\ \mathrm{Md}(\mathrm{lb} / \mathrm{lb}-\mathrm{mol}) & = & 0.440 \times\left(\% \mathrm{CO}_{2}\right)+0.320 \times\left(\% \mathrm{O}_{2}\right)+0.280 \times\left(\% \mathrm{~N}_{2}+\% \mathrm{CO}\right) \\ \mathrm{Md} & = & 0.440 \times 15.9+0.320 \times 3.1+0.280 \times 81.0=30.7 \mathrm{lb} / \mathrm{lb}-\mathrm{mol}\end{array}$

Where:

$\%\left(\mathrm{CO}_{2}, \mathrm{O}_{2}, \mathrm{~N}_{2}, \mathrm{CO}\right)=\quad$ Percent $\left(\mathrm{CO}_{2}, \mathrm{O}_{2}, \mathrm{~N}_{2}, \mathrm{CO}\right)$ by volume, dry basis

\section{Molecular Weight}

Ms $\quad=\quad$ Molecular weight of stack gas, wet basis, lb/lb-mol

$\mathrm{Ms}(\mathrm{lb} / \mathrm{lb}-\mathrm{mol})=\mathrm{Md} \times(1-\mathrm{Bws})+18.0 \times \mathrm{Bws}$

Ms $\quad=\quad 30.7 \times(1-0.1332)+18.0 \times 0.1332=29.0 \mathrm{lb} / \mathrm{lb}-\mathrm{mol}$

\section{Average Stack Gas Velocity}

Vs $\quad=\quad$ Average stack gas velocity, $\mathrm{ft} / \mathrm{sec}$

$\mathrm{Vs}(\mathrm{ft} / \mathrm{sec}) \quad=\quad \mathrm{K}_{3} \times \mathrm{Cp} \times(\Delta \mathrm{p})^{1 / 2}(\operatorname{avg}) \times\left[\frac{\mathrm{Ts}+460}{\mathrm{Ps} \times \mathrm{Ms}}\right]^{1 / 2}$

Vs

$=\quad 85.49 \times 0.84 \times 0.4472 \times\left[\frac{685+460}{30.49 \times 29.0}\right]^{1 / 2}=36.6 \mathrm{ft} / \mathrm{sec}$

Where:

\begin{tabular}{|c|c|c|c|}
\hline $\mathrm{K}_{3}$ & $=$ & $85.49 \mathrm{ft} / \mathrm{sec} \times$ & $\left.\frac{\frac{\mathrm{lb}}{\mathrm{lb}-\text { mole }} \times \text { in. } \mathrm{Hg}}{\mathrm{R} \times \text { in. } \mathrm{H}_{2} \mathrm{O}}\right]^{1 / 2}$ \\
\hline $\mathrm{Cp}$ & $=$ & Pitot tube coef & fficient, dimensionless \\
\hline$\Delta \mathrm{p}$ & $=$ & Velocity head & of stack gas (in. Hg) \\
\hline$(\Delta \mathrm{p})^{1 / 2}(\operatorname{avg})$ & $=$ & Average of the & square root of $\Delta p$ values \\
\hline Ts & $=$ & Stack gas tem! & perature $\left({ }^{\circ} \mathrm{F}\right)$ \\
\hline Ps & $=$ & Stack pressure & (in. $\mathrm{Hg})$ \\
\hline
\end{tabular}

Isokinetic Sampling Rate

I $=\quad$ Percent of isokinetic sampling, $\%$

$\mathrm{I}(\%)=\frac{\mathrm{K}_{4} \times(\mathrm{Ts}+460) \times \mathrm{Vm}(\mathrm{std}) \times 144}{\mathrm{Ps} \times \mathrm{Vs} \times \mathrm{An} \times \theta \times(1-\mathrm{Bws})}$ 


$$
=\frac{0.09450 \times(685+460) \times 42.190 \times 144}{30.49 \times 36.6 \times 0.0707 \times 90 \times(1-0.1332)}=107 \%
$$

Where:

$$
\begin{array}{lll}
\mathrm{K}_{4} & = & \frac{0.09450 \%(\mathrm{in} . \mathrm{Hg})(\mathrm{min})}{\mathrm{R} \times \mathrm{sec}} \\
\mathrm{An} & = & \text { Cross-sectional area of nozzle }\left(\text { in. }^{2}\right) \\
\theta & = & \text { Total sampling time }(\mathrm{min})
\end{array}
$$

Volume of Gas Sample Corrected to $3 \% \mathrm{O}_{2}$

$\begin{array}{ll}\mathrm{Vm} *(\mathrm{std}) & =\begin{array}{l}\text { Volume of gas sample measured by the dry-gas meter }(\mathrm{Vm}[\mathrm{std}]), \\ * \text { corrected to } 3 \% \text { oxygen, } \mathrm{Nm}^{3}\end{array} \\ \mathrm{Vm} *(\mathrm{std}) & \mathrm{K}_{5} \times \mathrm{Vm}(\mathrm{std}) \times \frac{21-\% \mathrm{O}_{2}}{18} \\ \mathrm{Vm}^{*}(\mathrm{std}) & =\end{array}$

Where:

$\mathrm{K}_{5} \quad=\quad 0.02832 \mathrm{~m}^{3} / \mathrm{ft}^{3}$

\section{Mercury}

$\operatorname{Hg}\left(\mu \mathrm{g} / \mathrm{Nm}^{3}\right) \quad=\quad \frac{\mu \mathrm{g}}{\mathrm{Vm}^{*}(\mathrm{std})}$

$\mathrm{Hg} \quad=\frac{6.99}{1.188}=5.88 \mu \mathrm{g} / \mathrm{Nm}^{3}$

Particulate $\mathrm{Hg} \quad=\quad$ Sum of mercury from filter and nozzle rinse

Oxidized $\mathrm{Hg}=$ Sum of mercury from $\mathrm{KCl}$ impingers

Elemental $\mathrm{Hg}=$ Sum of mercury from $\mathrm{H}_{2} \mathrm{O}_{2}$ and $\mathrm{KMnO}_{4}$ impingers

MERCURY CMMS

Corrections for mercury CMM data are discussed in Appendix D.

\section{ACTIVATED CARBON INJECTION}

PAC Injection $\quad=\quad$ Amount of PAC injected into duct, based on gas flow, $\mathrm{lb} / \mathrm{Macf}$ 
PAC Injection (lb/Macf)

$$
=\frac{\mathrm{F}_{\mathrm{PAC}}}{60} \times \frac{1000}{\mathrm{~F}_{\mathrm{S}}}
$$

PAC Injection $\quad=\quad \frac{60.3}{60} \times \frac{1000}{670}=1.5 \mathrm{lb} / \mathrm{Macf}$

Where:

$\mathrm{F}_{\mathrm{PAC}} \quad=\quad \mathrm{PAC}$ feed rate $(\mathrm{lb} / \mathrm{hr})$

$\mathrm{F}_{\text {Stack }} \quad=\quad$ Stack gas flow (kacfm)

\section{COAL ANALYSIS}

\section{Heat Input}

$\mathrm{Fd}$

$=\quad$ Heat input of fuel, dry basis, dscf $/ 10^{6}$ Btu

$\mathrm{Fd}\left(\mathrm{dscf} / 10^{6} \mathrm{Btu}\right)=10^{6} \times \frac{3.64 \times\left(\% \mathrm{H}_{2}\right)+1.53 \times(\% \mathrm{C})+0.57 \times(\% \mathrm{~S})+0.14 \times\left(\% \mathrm{~N}_{2}\right)-0.46 \times\left(\% \mathrm{O}_{2}\right)}{\mathrm{HV}}$

$\mathrm{Fd}\left(\mathrm{dscf} / 10^{6} \mathrm{Btu}\right)=10^{6} \times \frac{3.64 \times 5.37+1.53 \times 47.32+0.57 \times 0.88+0.14 \times 0.91-0.46 \times 35.79}{8079}$

$\mathrm{Fd}$

$=9421 \mathrm{dscf} / 10^{6} \mathrm{Btu}$

Where:

$\%\left(\mathrm{H}_{2}, \mathrm{C}, \mathrm{S}, \mathrm{N}_{2}, \mathrm{O}_{2}\right)=$ Percent $\left(\mathrm{H}_{2}, \mathrm{C}, \mathrm{S}, \mathrm{N}_{2}, \mathrm{O}_{2}\right)$ by weight

$\mathrm{HV} \quad=\quad$ Heating value $(\mathrm{Btu} / \mathrm{lb})$

\section{Sulfur}

$\mathrm{S}_{(\mathrm{dry})} \quad=\quad$ Sulfur, dry basis, $\%$

$\mathrm{S}_{(\mathrm{dry})}(\%)$

$=\frac{\% \mathrm{~S}}{\left(1-\frac{\% \mathrm{H}_{2} \mathrm{O}}{100}\right)}$

$\mathrm{S}_{(\mathrm{dry})}$

$=\quad \frac{0.88}{\left(1-\frac{20.20}{100}\right)}=1.10 \%$ 


\section{Heating Value}

$$
\begin{array}{ll}
\mathrm{HV}_{(\text {dry })} & =\text { Heating value, dry basis, Btu/lb } \\
\mathrm{HV}_{(\text {dry })}(\%) & =\frac{\mathrm{HV}}{\left(1-\frac{\% \mathrm{H}_{2} \mathrm{O}}{100}\right)} \\
\mathrm{HV}_{(\text {dry })} & =\frac{8079}{\left(1-\frac{20.20}{100}\right)}=10,124 \mathrm{Btu} / \mathrm{lb}
\end{array}
$$

\section{Mercury, Volume Based}

$\mathrm{Hg}_{(\mathrm{FGB})} \quad=\quad \mathrm{Hg}$, flue gas basis, $\mu \mathrm{g} / \mathrm{Nm}^{3}$

$\operatorname{Hg}_{(\mathrm{FGB})}\left(\mu \mathrm{g} / \mathrm{Nm}^{3}\right)=\quad \mathrm{Hg}_{(\mathrm{dry})} \times 10^{6} \times\left(1-\frac{\% \mathrm{H}_{2} \mathrm{O}}{100}\right) \times 453.6 \times\left(\frac{18}{21 \times \mathrm{HV} \times \mathrm{F}_{\mathrm{d}} \times 0.02832}\right)$

$\mathrm{Hg}_{(\mathrm{FGB})} \quad=0.0534 \times 10^{6} \times\left(1-\frac{20.20}{100}\right) \times 453.6 \times\left(\frac{18}{21 \times 8079 \times 9421 \times 0.02832}\right)$

$\mathrm{Hg}_{(\mathrm{FGB})} \quad=\quad 7.69 \mu \mathrm{g} / \mathrm{dNm}^{3}$

Where:

$\mathrm{Hg}_{(\mathrm{dry})} \quad=\quad$ Mercury measured in coal, dry basis $(\mathrm{ppm})$

\section{Fate of Mercury During Baseline and Monthlong Test Conditions (Mass Balance)}

Coal Inlet $\mathrm{Hg}$ (baseline and monthlong)

Inputs

- Coal feed computed to be 400.5 ton/hr at $600 \mathrm{MW}$

- Mercury in dry coal measured to be $0.232 \mathrm{ppm}$, using average moisture value of $31.66 \%$, the as-received coal mercury content is $0.159 \mathrm{ppm}$

Conversion

\begin{tabular}{l|l|l|l}
400.5 ton coal & $2000 \mathrm{lb}$ coal & $0.159 \mathrm{lb} \mathrm{Hg}$ & Mlb coal \\
\hline hour & ton coal & Mlb coal & $1,000,000 \mathrm{lb}$ coal
\end{tabular}

$=0.127 \mathrm{lb} \mathrm{Hg} /$ hour 
ESP Outlet Ash Hg (baseline and monthlong)

Inputs

- Average measured grain loading at the ESP inlet (valid samples measured 1/19/06 and $1 / 20 / 06)$ of $5.06 \mathrm{gr} / \mathrm{dscf}$ at $3 \% \mathrm{O}_{2}$, the computed efficiency of the ESP was approximately $98 \%$ so the collected ash was $(0.98)(5.06)=4.96 \mathrm{gr} / \mathrm{dscf}$.

- Computed Unit 2 flue gas flow rate of 1,106,826 dscf/min at $600 \mathrm{MW}$ and 3\% excess $\mathrm{O}_{2}$.

- ESP ash mercury content of 0.136 ppm measured during baseline sampling (average computed in TXUBB OH.xls).

Conversion

\begin{tabular}{|l|c|c|c|c|c|}
\hline 4.96 grain & lb ash & $1,106,826 \mathrm{dscf}$ & $60 \mathrm{~min}$ & $0.136 \mathrm{lb} \mathrm{Hg}$ & Mlb ash \\
\hline dscf & 7000 grain & min & hour & Mlb ash & $1,000,000 \mathrm{lb}$ ash \\
\hline
\end{tabular}

$=0.006 \mathrm{lb} \mathrm{Hg} / \mathrm{hour}$

FF Outlet Ash Hg (baseline)

- Ash loading into FF 2-4 was estimated to be $2 \%$ of the ESP inlet dust load, capture efficiency was assumed to be $100 \%$ for the purposes of this mass balance, FF ash collection rate is then $(0.02)(5.06)=0.101 \mathrm{gr} / \mathrm{dscf}$.

- Average mercury concentration of the FF ash was taken for all of the monthlong ash samples, 0.479 ppm (based on 1/19/06 and 1/20/06 samples).

- Computed Unit 2 flue gas flow rate of 1,106,826 dscf/min at $600 \mathrm{MW}$ and 3\% excess $\mathrm{O}_{2}$.

Conversion

\begin{tabular}{|l|c|c|c|c|c|}
\hline 0.101 grain & lb ash & $1,106,826 \mathrm{dscf}$ & $60 \mathrm{~min}$ & $0.479 \mathrm{lb} \mathrm{Hg}$ & Mlb ash \\
\hline dscf & 7000 grain & min & hour & Mlb ash & $1,000,000 \mathrm{lb}$ ash \\
\hline
\end{tabular}

$=0.000 \mathrm{lb} \mathrm{Hg} /$ hour

FF Outlet Ash Hg (monthlong condition)

- Ash loading into FF 2-4 was estimated to be $2 \%$ of the ESP inlet dust load, capture efficiency was assumed to be $100 \%$ for the purposes of this mass balance, FF ash collection rate is then $(0.02)(5.06)=0.101 \mathrm{gr} / \mathrm{dscf}$.

- The average carbon content of the FF ash was 7.9\% and the approximate amount of carbon in activated carbon is $67 \%$, so the AC comprises $11.8 \%$ of the collected ash that is not 
accounted for in the inlet dust load measurement. The total ash collected is $13 \%$ higher due to the $\mathrm{AC}$ content or $(0.101)(1.13)=0.115 \mathrm{gr} / \mathrm{dscf}$.

- Average mercury concentration of the FF ash was taken for all of the monthlong ash samples, $57.7 \mathrm{ppm}$.

- Computed Unit 2 flue gas flow rate of 1,106,826 dscf/min at $600 \mathrm{MW}$ and 3\% excess $\mathrm{O}_{2}$.

Conversion

\begin{tabular}{|l|c|c|c|c|c|}
\hline 0.115 grain & lb ash & $1,106,826 \mathrm{dscf}$ & $60 \mathrm{~min}$ & $57.7 \mathrm{lb} \mathrm{Hg}$ & Mlb ash \\
\hline dscf & 7000 grain & min & hour & Mlb ash & $1,000,000 \mathrm{lb}$ ash \\
\hline
\end{tabular}

$=0.063 \mathrm{lb} \mathrm{Hg}$ /hour

FF Outlet Flue Gas Hg (baseline)

- Average FF 2-4 outlet CMM value during the baseline sampling on $1 / 18 / 06,1 / 19 / 06$, and $1 / 20 / 06$, which was $28 \mu \mathrm{g} / \mathrm{dNm}^{3}$ at $3 \% \mathrm{O}_{2}$ (averages can be found in the spreadsheets: TXU BB2 Hg Plant data 1/18/06, 1/19/06, and 1/20/06).

- Computed Unit 2 flue gas flow rate of 1,106,826 dscf/min at $600 \mathrm{MW}$ and 3\% excess $\mathrm{O}_{2}$.

\section{Conversion}

\begin{tabular}{|l|c|c|c|c|c|}
\hline $28 \mu \mathrm{g}$ & $\mathrm{g}$ & $\mathrm{lb}$ & $\mathrm{dNm}^{3}$ & $1,106,826 \mathrm{dscf}$ & $60 \mathrm{~min}$ \\
\hline $\mathrm{dNm}^{3}$ & $1,000,000 \mu \mathrm{g}$ & $454 \mathrm{~g}$ & $35.29 \mathrm{dscf}$ & min & hour \\
\hline
\end{tabular}

$=0.116 \mathrm{lb} \mathrm{Hg} /$ hour

FF Outlet Flue Gas Hg (monthlong condition)

- Average FF 2-4 outlet CMM value during the monthlong test with the control technology active (average found in the LT Hg summary.xls spreadsheet), $5.2 \mu \mathrm{g} / \mathrm{dNm}^{3}$ at $3 \% \mathrm{O}_{2}$

- Computed Unit 2 flue gas flow rate of 1,106,826 dscf/min at $600 \mathrm{MW}$ and 3\% excess $\mathrm{O}_{2}$

Conversion

\begin{tabular}{|l|c|c|c|c|c|}
\hline $5.2 \mu \mathrm{g}$ & $\mathrm{g}$ & $\mathrm{lb}$ & $\mathrm{dNm}^{3}$ & $1,106,826 \mathrm{dscf}$ & $60 \mathrm{~min}$ \\
\hline $\mathrm{dNm}^{3}$ & $1,000,000 \mu \mathrm{g}$ & $454 \mathrm{~g}$ & $35.29 \mathrm{dscf}$ & min & hour \\
\hline
\end{tabular}

$=0.022 \mathrm{lb} \mathrm{Hg} /$ hour 
$\mathrm{Hg}_{\text {(balance) }} \quad=\quad$ Percentage of $\mathrm{Hg}$ accounted for during baseline conditions and monthlong testing, $\%$

$\mathrm{Hg}_{\text {(balance) }}(\%)=\frac{\mathrm{Hg}_{(\mathrm{ESPASH})}+\mathrm{Hg}_{(\mathrm{FF} \mathrm{ASH})}+\mathrm{Hg}_{(\mathrm{FLUE} \mathrm{GAS})}}{\mathrm{Hg}_{(\mathrm{COAL})}} \times 100 \%$

$\mathrm{Hg}_{\text {(balance) }}$

$=\frac{0.006+0.000+0.116}{0.127} \times 100=96 \%$

Where:

$\mathrm{Hg}_{(\mathrm{COAL})} \quad=\quad$ Mass rate of $\mathrm{Hg}$ in the coal, $\mathrm{lb} / \mathrm{hr}$

$\mathrm{Hg}_{\text {(ESP ASH) }} \quad=\quad$ Mass rate of $\mathrm{Hg}$ in the ESP ash, $\mathrm{lb} / \mathrm{hr}$

$\mathrm{Hg}_{\text {(FF ASH) }} \quad=\quad$ Mass rate of $\mathrm{Hg}$ in the ash from FF 2-4, lb/hr

$\mathrm{Hg}_{\text {(FLUE GAS) }}=\quad$ Mass rate of $\mathrm{Hg}$ in the flue gas at the FF 2-4 outlet, $\mathrm{lb} / \mathrm{hr}$

\section{Mercury Capture Across FF 2-4}

$\mathrm{Hg}_{(\text {capture, FF 2-4) }} \quad=\quad \mathrm{Hg}$ captured, on coal basis, $\%$

$\mathrm{Hg}_{\text {(capture, FF 2-4) }}(\%)=\frac{H g_{(F F 2-4 I N)}-H g_{(F F 2-4 \text { OUT })}}{H g_{(F F 2-4 I N)}} \times 100$

$\mathrm{Hg}_{(\text {capture, FF 2-4) }} \quad=\quad \frac{11.6-3.0}{11.6} \times 100=74 \%$

Where:

$\mathrm{Hg}_{(\mathrm{FF} 2-4 \mathrm{IN})} \quad=\quad \mathrm{Hg}$ measured by $\mathrm{CMM}$ at FF $2-4$ inlet, $\mu \mathrm{g} / \mathrm{dNm}^{3}$

$\mathrm{Hg}_{\text {(FF 2-4 OUT) }}=\mathrm{Hg}$ measured by CMM at FF $2-4$ outlet, $\mu \mathrm{g} / \mathrm{dNm}^{3}$

\section{Coal-Based Mercury Capture}

$\mathrm{Hg}_{\text {(capture, coal) }}=\quad \mathrm{Hg}$ captured, on coal basis, $\%$

$\mathrm{Hg}_{\text {(capture, coal })}(\%)=\frac{H g_{(\text {Coal IN })}-H g_{(F F 2-4 \text { OUT })}}{H g_{(\text {Coal IN })}} \times 100$

$\mathrm{Hg}_{(\text {capture, coal) }} \quad=\frac{30.8-4.8}{30.8} \times 100=84 \%$

Where:

$\mathrm{Hg}_{(\text {Coal IN })} \quad=\quad$ Overall average $\mathrm{Hg}$ in coal, $\mu \mathrm{g} / \mathrm{dNm}^{3}$

$\mathrm{Hg}_{\text {(FF 2-4 OUT) }}=\mathrm{Hg}$ measured by CMM at FF $2-4$ outlet, $\mu \mathrm{g} / \mathrm{dNm}^{3}$ 


\section{Coal Mercury Emissions}

$\mathrm{Hg}$ emissions $=\quad \mathrm{Hg}$, as-received basis, $\mathrm{lb} / \mathrm{TBtu}$

Hg emissions

$\begin{array}{ll}(\mathrm{lb} / \mathrm{TBtu}) & =\frac{\mathrm{Hg}_{(\mathrm{dry})} \times 10^{6}}{\mathrm{HV}} \times\left(1-\frac{\% \mathrm{H}_{2} \mathrm{O}}{100}\right) \\ \mathrm{Hg} \text { emissions } & =\frac{0.232 \times 10^{6}}{7194} \times\left(1-\frac{31.66}{100}\right)=22.0 \mathrm{lb} / \mathrm{TBtu}\end{array}$ 
APPENDIX B

COAL DATA 
Table B-1. Coal Sample Data for the 70-30 Blend of Lignite-PRB

\begin{tabular}{|c|c|c|c|c|c|c|c|c|c|c|c|c|}
\hline Sample Date & $1 / 18 / 06$ & $1 / 19 / 06$ & $1 / 20 / 06$ & $1 / 23 / 06$ & $1 / 24 / 06$ & $2 / 2 / 06$ & $2 / 4 / 06$ & $2 / 6 / 06$ & $2 / 8 / 06$ & $2 / 27 / 06$ & $2 / 28 / 06$ & $3 / 1 / 06$ \\
\hline Hg, ppm (dry) & 0.266 & 0.262 & 0.333 & 0.204 & 0.263 & 0.275 & 0.219 & 0.231 & 0.278 & 0.22 & 0.261 & 0.216 \\
\hline \multicolumn{13}{|l|}{ Se, ppm (dry) } \\
\hline $\mathrm{Cl}, \mathrm{ppm}$ (dry) & & & 17 & & & & & & & & 20 & 17 \\
\hline \multicolumn{13}{|l|}{$\begin{array}{l}\text { Proximate Analysis, } \\
\text { wt } \%\end{array}$} \\
\hline Moisture & 32.2 & 30.6 & 30.7 & 31.6 & 32.3 & 31.2 & 32.6 & 32.3 & 31.2 & 30.7 & 31.4 & 31.3 \\
\hline Volatile Matter & 30.2 & 28.99 & 30.21 & 29.43 & 28.84 & 30.34 & 28.49 & 28.27 & 30.21 & 28.59 & 29.31 & 28.47 \\
\hline Fixed Carbon & 29.92 & 28.13 & 29.32 & 28.95 & 28.01 & 27.95 & 28.37 & 28.98 & 27.62 & 28.85 & 29.13 & 28.87 \\
\hline Ash & 7.68 & 12.28 & 9.77 & 10.02 & 10.86 & 10.52 & 10.54 & 10.45 & 10.96 & 11.86 & 10.15 & 11.36 \\
\hline \multicolumn{13}{|l|}{ Ultimate Analysis, wt $\%$} \\
\hline Hydrogen & 6.79 & 6.61 & 6.72 & 6.75 & 6.6 & 6.63 & 6.63 & 6.64 & 6.63 & 6.67 & 6.73 & 6.51 \\
\hline Carbon & 44.09 & 41.66 & 43.39 & 42.12 & 40.57 & 41.98 & 41.32 & 40.91 & 41 & 41.83 & 41.81 & 42.16 \\
\hline Nitrogen & 0.93 & 0.89 & 0.89 & 0.96 & 1.06 & 1.08 & 1.05 & 1.06 & 0.96 & 0.98 & 0.96 & 1.09 \\
\hline Sulfur & 0.66 & 0.75 & 0.62 & 0.68 & 0.67 & 0.66 & 0.71 & 0.83 & 0.71 & 0.85 & 0.81 & 0.96 \\
\hline Oxygen & 39.85 & 37.81 & 38.61 & 39.47 & 40.25 & 39.13 & 39.75 & 40.11 & 39.73 & 37.82 & 39.54 & 37.92 \\
\hline Heating Value, Btu/lb & 7728 & 7240 & 7626 & 7362 & 7099 & 7567 & 6981 & 7131 & 7014 & 7127 & 7083 & 7081 \\
\hline
\end{tabular}

1 Note: all values on an as-received basis unless otherwise indicated. 
Table B-1. Coal Sample Data for the 70-30 Blend of Lignite-PRB (continued)

\begin{tabular}{|c|c|c|c|c|c|c|c|c|c|c|c|c|}
\hline Sample Date & $3 / 2 / 06$ & $3 / 3 / 06$ & $3 / 4 / 06$ & $3 / 5 / 06$ & $3 / 6 / 06$ & $3 / 7 / 06$ & $3 / 15 / 06$ & $3 / 16 / 06$ & $3 / 17 / 06$ & $3 / 18 / 06$ & $3 / 20 / 06$ & $3 / 21 / 06$ \\
\hline Hg, ppm (dry) & 0.239 & 0.258 & 0.229 & 0.214 & 0.188 & 0.254 & 0.259 & 0.253 & 0.22 & 0.179 & 0.232 & 0.185 \\
\hline Se, ppm (dry) & & & 4.48 & 3.47 & 3.3 & 4.63 & 3.78 & & & 3.34 & & \\
\hline $\mathrm{Cl}$, ppm (dry) & & & & & & & & 26 & 21 & & 31 & 17 \\
\hline \multicolumn{13}{|l|}{$\begin{array}{l}\text { Proximate Analysis, } \\
\text { wt } \%\end{array}$} \\
\hline Moisture & 31.8 & 30.6 & 31.9 & 33 & 32 & 31.2 & 32.1 & 31.8 & 32.3 & 31.5 & 30.9 & 31.1 \\
\hline Volatile Matter & 29.91 & 29.93 & 29.06 & 29.03 & 28.54 & 28.3 & 28.74 & 31.18 & 29.27 & 28.59 & 28.22 & 26.53 \\
\hline Fixed Carbon & 30.55 & 26.65 & 30.61 & 28.73 & 29.02 & 28.19 & 27.96 & 26.62 & 29.47 & 28.58 & 28.31 & 27.77 \\
\hline Ash & 7.74 & 12.82 & 8.43 & 9.24 & 10.43 & 12.31 & 11.19 & 10.39 & 8.96 & 11.34 & 12.56 & 14.6 \\
\hline \multicolumn{13}{|l|}{$\begin{array}{l}\text { Ultimate Analysis, } \\
\text { wt } \%\end{array}$} \\
\hline Hydrogen & 6.72 & 6.5 & 6.92 & 6.92 & 6.72 & 6.73 & 6.91 & 6.71 & 6.83 & 6.74 & 6.64 & 6.35 \\
\hline Carbon & 42.24 & 40.4 & 42.45 & 40.74 & 40.57 & 40.47 & 41.82 & 40.68 & 41.98 & 40.43 & 41.27 & 40.07 \\
\hline Nitrogen & 0.91 & 0.93 & 0.83 & 0.87 & 0.82 & 0.84 & 0.87 & 0.95 & 0.99 & 0.84 & 0.98 & 0.99 \\
\hline Sulfur & 0.72 & 0.74 & 0.79 & 0.91 & 1.03 & 1.05 & 0.8 & 0.7 & 0.65 & 1.01 & 0.62 & 0.71 \\
\hline Oxygen & 41.67 & 38.61 & 40.58 & 41.32 & 40.43 & 38.6 & 38.4 & 40.57 & 40.59 & 39.66 & 37.93 & 37.28 \\
\hline Heating Value, Btu/lb & 7535 & 7135 & 7532 & 7155 & 7146 & 6983 & 7181 & 7244 & 7160 & 7095 & 7114 & 6305 \\
\hline
\end{tabular}


Table B-1. Coal Sample Data for the 70-30 Blend of Lignite-PRB (continued)

\begin{tabular}{|c|c|c|c|c|c|c|c|c|c|}
\hline Sample Date & $3 / 22 / 06$ & $3 / 23 / 06$ & $3 / 24 / 06$ & $3 / 25 / 06$ & $3 / 26 / 06$ & $3 / 27 / 06$ & $3 / 28 / 06$ & Average & Std. Dev. \\
\hline Hg, ppm (dry) & 0.145 & 0.211 & 0.227 & 0.206 & 0.223 & 0.209 & 0.223 & 0.232 & 0.036 \\
\hline Se, ppm (dry) & & 3.81 & 3.97 & 3.47 & 3.53 & 2.67 & 2.83 & $3.61^{\mathrm{a}}$ & $0.58^{\mathrm{a}}$ \\
\hline $\mathrm{Cl}, \mathrm{ppm}$ (dry) & 12 & & & & & & & $20^{\mathrm{b}}$ & $6^{\mathrm{b}}$ \\
\hline \multicolumn{10}{|l|}{$\begin{array}{l}\text { Proximate Analysis, } \\
\mathrm{wt} \%\end{array}$} \\
\hline Moisture & 31.6 & 32.1 & 31.9 & 32 & 31.4 & 31.7 & 32.5 & 31.66 & 0.62 \\
\hline Ash & 9.97 & 10.3 & 11.39 & 12.15 & 11.2 & 8.54 & 10.89 & 10.67 & 1.52 \\
\hline \multicolumn{10}{|l|}{$\begin{array}{l}\text { Ultimate Analysis, } \\
\mathrm{wt} \%\end{array}$} \\
\hline Hydrogen & 6.75 & 6.85 & 6.9 & 6.82 & 6.74 & 6.81 & 6.69 & 6.71 & 0.13 \\
\hline Carbon & 42.58 & 41.16 & 40.66 & 40.66 & 40.13 & 44.06 & 39.64 & 41.45 & 1.11 \\
\hline Heating Value, Btu/lb & 7573 & 7286 & 7031 & 7098 & 6973 & 7456 & 6978 & 7194 & 271 \\
\hline
\end{tabular}

\footnotetext{
Note: all values on an as-receiv

${ }^{\text {a }}$ Based on 12 measurements.
}

${ }^{\mathrm{b}}$ Based on 8 measurements. 
APPENDIX C

\section{ONTARIO HYDRO MEASUREMENT DATA}


Table C1. Results from the OH Sampling at Big Brown Unit 2

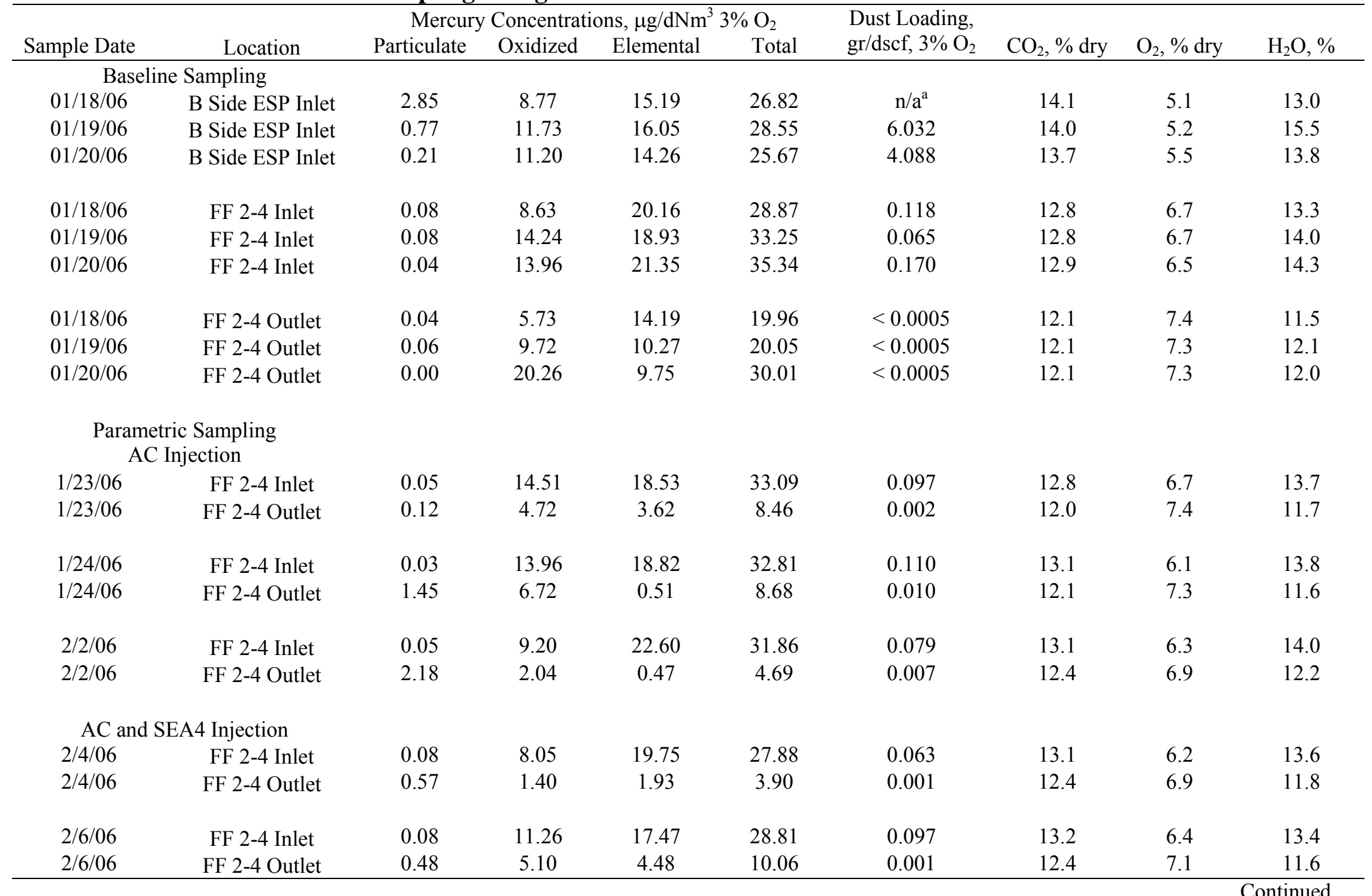


Table C1. Results from the OH Sampling at Big Brown Unit 2 (continued)

\begin{tabular}{|c|c|c|c|c|c|c|c|c|c|}
\hline \multirow[b]{2}{*}{ Sample Date } & & \multicolumn{4}{|c|}{ Mercury Concentrations, $\mu \mathrm{g} / \mathrm{dNm}^{3} 3 \% \mathrm{O}_{2}$} & \multirow{2}{*}{$\begin{array}{l}\text { Dust Loading, } \\
\text { gr/dscf, } 3 \% \mathrm{O}_{2}\end{array}$} & \multirow[b]{2}{*}{$\mathrm{CO}_{2}, \%$ dry } & \multirow[b]{2}{*}{$\mathrm{O}_{2}, \%$ dry } & \multirow[b]{2}{*}{$\mathrm{H}_{2} \mathrm{O}, \%$} \\
\hline & Location & Particulate & Oxidized & Elemental & Total & & & & \\
\hline \multicolumn{10}{|c|}{ Enhanced AC Injection } \\
\hline $2 / 8 / 06$ & FF 2-4 Inlet & 0.11 & 15.03 & 19.18 & 34.32 & $0.240^{\mathrm{b}}$ & 13.0 & 6.3 & 13.1 \\
\hline $2 / 8 / 06$ & FF 2-4 Outlet & 2.25 & 11.96 & 0.31 & 14.52 & $0.014^{\mathrm{b}}$ & 12.3 & 7.1 & 11.3 \\
\hline \multicolumn{10}{|c|}{ Monthlong Sampling } \\
\hline $2 / 27 / 06$ & FF 2-4 Inlet & 0.09 & 12.71 & 14.74 & 27.54 & 0.064 & 12.4 & 7.0 & 13.1 \\
\hline $2 / 27 / 06$ & FF 2-4 Outlet & 2.64 & 4.52 & 0.41 & 7.57 & 0.004 & 11.5 & 8.0 & 11.5 \\
\hline $2 / 28 / 06$ & FF 2-4 Inlet & 0.10 & 15.54 & 16.77 & 32.41 & 0.047 & 12.2 & 7.2 & 13.6 \\
\hline $2 / 28 / 06$ & FF 2-4 Outlet & 0.49 & 0.90 & 0.59 & 1.98 & 0.001 & 12.7 & 6.7 & 11.8 \\
\hline $3 / 1 / 06$ & FF 2-4 Inlet & 0.06 & 10.96 & 19.10 & 30.13 & 0.112 & 13.4 & 5.9 & 14.2 \\
\hline $3 / 1 / 06$ & FF 2-4 Outlet & 1.39 & 16.83 & 0.67 & 18.89 & 0.004 & 12.4 & 7.0 & 12.5 \\
\hline $3 / 16 / 06$ & FF 2-4 Inlet & 0.08 & 6.95 & 21.90 & 28.92 & 0.057 & 13.1 & 6.4 & 13.9 \\
\hline $3 / 16 / 06$ & FF 2-4 Outlet & 5.56 & 1.15 & 2.15 & 8.86 & 0.008 & 12.5 & 6.8 & 12.1 \\
\hline $3 / 17 / 06$ & FF 2-4 Inlet & 0.23 & 6.53 & 16.56 & 23.32 & 0.069 & 13.2 & 6.2 & 13.2 \\
\hline $3 / 17 / 06$ & FF 2-4 Outlet & 3.47 & 0.46 & 0.24 & 4.18 & 0.006 & 12.5 & 6.9 & 11.0 \\
\hline $3 / 20 / 2006(1)$ & FF 2-4 Inlet & 0.13 & 3.60 & 18.74 & 22.47 & 0.049 & 12.2 & 7.1 & 14.9 \\
\hline $3 / 20 / 2006(1)$ & FF 2-4 Outlet & 3.07 & 0.28 & 0.05 & 3.40 & 0.004 & 11.9 & 7.6 & 12.3 \\
\hline $3 / 20 / 2006(2)$ & FF 2-4 Inlet & 0.08 & 5.12 & 16.19 & 21.40 & 0.073 & 13.3 & 6.0 & 13.8 \\
\hline $3 / 20 / 2006(2)$ & FF 2-4 Outlet & 5.18 & 0.45 & 0.13 & 5.76 & 0.010 & 11.9 & 7.6 & 11.2 \\
\hline $3 / 21 / 06$ & FF 2-4 Inlet & 0.10 & 3.57 & 12.86 & 16.53 & 0.049 & 12.5 & 6.9 & 13.1 \\
\hline $3 / 21 / 06$ & FF 2-4 Outlet & 2.57 & 0.65 & 0.35 & 3.57 & 0.004 & 12.1 & 7.3 & 10.4 \\
\hline $3 / 22 / 06$ & FF 2-4 Inlet & 0.14 & 5.23 & 12.42 & 17.79 & 0.092 & 12.9 & 6.7 & 13.8 \\
\hline $3 / 22 / 06$ & FF 2-4 Outlet & 3.09 & 1.04 & 0.21 & 4.34 & 0.002 & 12.3 & 7.1 & 11.3 \\
\hline
\end{tabular}

${ }^{a}$ Sample did not meet isokinetic requirements.

b Measurement prior to ESP failure, which is the explanation for the abnormally high dust loadings. 
APPENDIX D

CMM AND ACI DATA 
Table D1. Corrected CMM and ACI, 10-minute Averaged Data During the Monthlong Field Test

\begin{tabular}{|c|c|c|c|c|c|c|}
\hline Date, Time & $\begin{array}{c}\text { FF Inlet } \mathrm{HgT}, \\
\mu \mathrm{g} / \mathrm{dNm}^{3}, \\
3 \% \mathrm{O}_{2}\end{array}$ & $\begin{array}{c}\text { FF Outlet } \mathrm{HgT} \text {, } \\
\mu \mathrm{g} / \mathrm{dNm}^{3}, \\
3 \% \mathrm{O}_{2} \\
\end{array}$ & $\begin{array}{c}\text { HgT Removal } \\
\text { Across } \\
\text { FF 2-4, } \% \\
\end{array}$ & $\begin{array}{c}\text { FF 2-4 Activated } \\
\text { Carbon Injection } \\
\text { Rate, lb/Macf } \\
\end{array}$ & $\begin{array}{c}\text { FF Inlet } \mathrm{Hg}^{0}, \\
\mu \mathrm{g} / \mathrm{dNm}^{3}, \\
3 \% \mathrm{O}_{2} \\
\end{array}$ & $\begin{array}{c}\text { FF Outlet } \mathrm{Hg}^{0}, \\
\mu \mathrm{g} / \mathrm{dNm}^{3}, \\
3 \% \mathrm{O}_{2}\end{array}$ \\
\hline $2 / 27 / 0615: 30$ & 19.11 & & & 1.29 & 9.08 & \\
\hline $2 / 27 / 0615: 40$ & 18.15 & & & 1.20 & 9.29 & \\
\hline $2 / 27 / 0615: 50$ & 19.41 & & & 1.20 & 9.10 & \\
\hline $2 / 27 / 0616: 00$ & 18.28 & 5.21 & 71.50 & 1.19 & 8.83 & 1.43 \\
\hline $2 / 27 / 0616: 10$ & 19.70 & 4.17 & 78.84 & 1.20 & 9.20 & 1.03 \\
\hline $2 / 27 / 0616: 20$ & 19.99 & 4.22 & 78.89 & 1.20 & 8.52 & 0.67 \\
\hline $2 / 27 / 0616: 30$ & 21.00 & 3.80 & 81.90 & 1.22 & 8.47 & 0.61 \\
\hline $2 / 27 / 0616: 40$ & 18.24 & 3.74 & 79.48 & 1.21 & 8.31 & 0.65 \\
\hline $2 / 27 / 0616: 50$ & & 14.60 & & 1.22 & & 0.62 \\
\hline 2/27/06 17:00 & 27.65 & 4.44 & 83.93 & 1.22 & 9.48 & 0.98 \\
\hline $2 / 27 / 0617: 10$ & 25.82 & 4.05 & 84.31 & 1.15 & 10.23 & 1.18 \\
\hline $2 / 27 / 06 \quad 17: 20$ & 24.17 & 5.79 & 76.03 & 1.19 & 10.74 & 1.05 \\
\hline $2 / 27 / 0617: 30$ & 23.83 & 7.92 & 66.75 & 1.15 & 10.38 & 0.85 \\
\hline $2 / 27 / 0617: 40$ & 24.96 & 4.79 & 80.81 & 1.11 & 10.13 & 0.82 \\
\hline $2 / 27 / 0617: 50$ & 23.42 & 3.42 & 85.38 & 1.16 & 9.92 & 0.46 \\
\hline $2 / 27 / 0618: 00$ & 21.80 & & & 1.16 & 9.96 & \\
\hline $2 / 27 / 0618: 10$ & 22.10 & & & 1.16 & 10.71 & \\
\hline $2 / 27 / 0618: 20$ & 21.77 & & & 1.16 & 10.24 & \\
\hline $2 / 27 / 0618: 30$ & 21.10 & & & 1.21 & 10.85 & \\
\hline $2 / 27 / 0618: 40$ & 21.06 & & & 1.17 & 10.51 & \\
\hline $2 / 27 / 0618: 50$ & 21.87 & & & 1.20 & 10.37 & \\
\hline 2/27/06 19:00 & 22.60 & 5.17 & 77.10 & 1.21 & 10.55 & 0.96 \\
\hline 2/27/06 19:10 & 30.13 & 4.56 & 84.86 & 1.20 & 10.43 & 0.98 \\
\hline $2 / 27 / 0619: 20$ & & 4.90 & & 1.19 & & 1.00 \\
\hline 2/27/06 19:30 & & 4.96 & & 1.18 & & 0.94 \\
\hline 2/27/06 19:40 & & 5.19 & & 1.19 & & 0.74 \\
\hline $2 / 27 / 0619: 50$ & & 5.48 & & 1.20 & & 0.65 \\
\hline $2 / 27 / 0620: 00$ & & 4.61 & & 1.14 & & 0.78 \\
\hline $2 / 27 / 0620: 10$ & & 4.54 & & 1.14 & & 1.00 \\
\hline $2 / 27 / 0620: 20$ & & 4.83 & & 1.18 & & 0.89 \\
\hline $2 / 27 / 0620: 30$ & & 6.04 & & 1.16 & & 0.80 \\
\hline $2 / 27 / 0620: 40$ & & 6.00 & & 1.16 & & 0.83 \\
\hline $2 / 27 / 0620: 50$ & & 4.90 & & 1.13 & & 0.95 \\
\hline 2/27/06 21:00 & & 4.21 & & 1.14 & & 0.82 \\
\hline $2 / 27 / 0621: 10$ & & 3.86 & & 1.12 & & 0.70 \\
\hline $2 / 27 / 0621: 20$ & & 3.35 & & 1.15 & & 0.56 \\
\hline $2 / 27 / 0621: 30$ & & 4.01 & & 1.16 & & 0.76 \\
\hline $2 / 27 / 0621: 40$ & & 4.07 & & 1.14 & & 0.95 \\
\hline $2 / 27 / 0621: 50$ & & 6.76 & & 1.13 & & 1.02 \\
\hline 2/27/06 22:00 & & 3.71 & & 1.06 & & 0.85 \\
\hline $2 / 27 / 0622: 10$ & & 4.33 & & 1.15 & & 0.76 \\
\hline $2 / 27 / 0622: 20$ & & 3.93 & & 1.17 & & 0.72 \\
\hline $2 / 27 / 0622: 30$ & & 3.98 & & 1.20 & & 0.88 \\
\hline $2 / 27 / 0622: 40$ & & 4.76 & & 1.19 & & 1.02 \\
\hline $2 / 27 / 0622: 50$ & & 5.61 & & 1.16 & & 1.05 \\
\hline $2 / 27 / 0623: 00$ & & & & 1.14 & & \\
\hline $2 / 27 / 0623: 10$ & & & & 1.16 & & \\
\hline $2 / 27 / 0623: 20$ & & & & 1.12 & & \\
\hline $2 / 27 / 0623: 30$ & & & & 1.12 & & \\
\hline $2 / 27 / 0623: 40$ & & & & 1.05 & & \\
\hline $2 / 27 / 0623: 50$ & & & & 1.04 & & \\
\hline 2/28/06 0:00 & & & & 1.09 & & \\
\hline
\end{tabular}


Table D1. Corrected CMM and ACI, 10-minute Averaged Data During the Monthlong Field Test (continued)

\begin{tabular}{|c|c|c|c|c|c|c|}
\hline Date, Time & $\begin{array}{c}\text { FF Inlet } \mathrm{HgT}, \\
\mu \mathrm{g} / \mathrm{dNm}^{3}, \\
3 \% \mathrm{O}_{2}\end{array}$ & $\begin{array}{c}\text { FF Outlet } \mathrm{HgT}, \\
\mu \mathrm{g} / \mathrm{dNm}^{3} \\
3 \% \mathrm{O}_{2}\end{array}$ & $\begin{array}{c}\text { HgT Removal } \\
\text { Across } \\
\text { FF } 2-4, \%\end{array}$ & $\begin{array}{c}\text { FF 2-4 Activated } \\
\text { Carbon Injection } \\
\text { Rate, lb/Macf }\end{array}$ & $\begin{array}{c}\text { FF Inlet } \mathrm{Hg}^{0}, \\
\mu \mathrm{g} / \mathrm{dNm}^{3} \\
3 \% \mathrm{O}_{2}\end{array}$ & $\begin{array}{c}\text { FF Outlet } \mathrm{Hg}^{0}, \\
\mu \mathrm{g} / \mathrm{dNm}^{3}, \\
3 \% \mathrm{O}_{2}\end{array}$ \\
\hline $2 / 28 / 060: 10$ & & & & 1.07 & & \\
\hline 2/28/06 0:20 & & & & 1.03 & & \\
\hline 2/28/06 0:30 & & & & 0.92 & & \\
\hline 2/28/06 0:40 & & & & 0.90 & & \\
\hline 2/28/06 0:50 & & & & 0.91 & & \\
\hline 2/28/06 1:00 & & & & 0.99 & & \\
\hline 2/28/06 1:10 & & & & 0.94 & & \\
\hline 2/28/06 1:20 & & & & 0.92 & & \\
\hline 2/28/06 1:30 & & & & 0.91 & & \\
\hline 2/28/06 1:40 & & & & 0.92 & & \\
\hline 2/28/06 1:50 & & & & 0.90 & & \\
\hline 2/28/06 2:00 & & & & 0.94 & & \\
\hline 2/28/06 2:10 & & & & 0.91 & & \\
\hline 2/28/06 2:20 & & & & 0.93 & & \\
\hline 2/28/06 2:30 & & & & 0.92 & & \\
\hline 2/28/06 2:40 & & & & 0.89 & & \\
\hline $2 / 28 / 062: 50$ & & & & 0.90 & & \\
\hline 2/28/06 3:00 & & & & 0.91 & & \\
\hline 2/28/06 3:10 & & & & 0.90 & & \\
\hline 2/28/06 3:20 & & & & 0.97 & & \\
\hline 2/28/06 3:30 & & & & 0.94 & & \\
\hline 2/28/06 3:40 & & & & 0.92 & & \\
\hline 2/28/06 3:50 & & & & 0.94 & & \\
\hline 2/28/06 4:00 & & & & 0.92 & & \\
\hline 2/28/06 4:10 & & & & 0.95 & & \\
\hline 2/28/06 4:20 & & & & 0.93 & & \\
\hline 2/28/06 4:30 & & & & 1.01 & & \\
\hline 2/28/06 4:40 & & & & 0.96 & & \\
\hline 2/28/06 4:50 & & & & 0.97 & & \\
\hline 2/28/06 5:00 & & & & 0.95 & & \\
\hline 2/28/06 5:10 & & & & 1.01 & & \\
\hline 2/28/06 5:20 & & & & 1.07 & & \\
\hline 2/28/06 5:30 & & & & 1.09 & & \\
\hline 2/28/06 5:40 & & & & 1.10 & & \\
\hline 2/28/06 5:50 & & & & 1.21 & & \\
\hline 2/28/06 6:00 & & & & 1.17 & & \\
\hline $2 / 28 / 066: 10$ & & & & 1.21 & & \\
\hline $2 / 28 / 066: 20$ & & & & 1.23 & & \\
\hline $2 / 28 / 066: 30$ & & & & 1.53 & & \\
\hline $2 / 28 / 066: 40$ & & & & 1.24 & & \\
\hline $2 / 28 / 066: 50$ & & & & 1.24 & & \\
\hline 2/28/06 7:00 & & & & 1.23 & & \\
\hline 2/28/06 7:10 & & & & 1.22 & & \\
\hline 2/28/06 7:20 & & & & 1.22 & & \\
\hline 2/28/06 7:30 & & & & 1.23 & & \\
\hline 2/28/06 7:40 & & & & 1.21 & & \\
\hline $2 / 28 / 067: 50$ & & & & 1.26 & & \\
\hline 2/28/06 8:00 & & & & 1.22 & & \\
\hline 2/28/06 8:10 & & & & 1.23 & & \\
\hline 2/28/06 8:20 & & & & 1.22 & & \\
\hline 2/28/06 8:30 & & & & 1.26 & & \\
\hline
\end{tabular}


Table D1. Corrected CMM and ACI, 10-minute Averaged Data During the Monthlong Field Test (continued)

\begin{tabular}{|c|c|c|c|c|c|c|}
\hline Date, Time & $\begin{array}{c}\text { FF Inlet } \mathrm{HgT}, \\
\mu \mathrm{g} / \mathrm{dNm}^{3}, \\
3 \% \mathrm{O}_{2} \\
\end{array}$ & $\begin{array}{c}\text { FF Outlet HgT, } \\
\mu \mathrm{g} / \mathrm{dNm}^{3}, \\
3 \% \mathrm{O}_{2} \\
\end{array}$ & $\begin{array}{c}\text { HgT Removal } \\
\text { Across } \\
\text { FF 2-4, \% } \\
\end{array}$ & $\begin{array}{c}\text { FF 2-4 Activated } \\
\text { Carbon Injection } \\
\text { Rate, lb/Macf }\end{array}$ & $\begin{array}{c}\text { FF Inlet } \mathrm{Hg}^{0}, \\
\mu \mathrm{g} / \mathrm{dNm}^{3}, \\
3 \% \mathrm{O}_{2} \\
\end{array}$ & $\begin{array}{c}\text { FF Outlet } \mathrm{Hg}^{0}, \\
\mu \mathrm{g} / \mathrm{dNm}^{3}, \\
3 \% \mathrm{O}_{2}\end{array}$ \\
\hline $2 / 28 / 068: 40$ & & & & 1.26 & & \\
\hline $2 / 28 / 068: 50$ & & & & 1.26 & & \\
\hline 2/28/06 9:00 & & & & 1.22 & & \\
\hline 2/28/06 9:10 & & & & 1.23 & & \\
\hline 2/28/06 9:20 & 33.03 & 9.99 & 69.74 & 1.24 & 10.60 & 4.64 \\
\hline 2/28/06 9:30 & 13.47 & 12.68 & 5.92 & 1.21 & 10.84 & 3.48 \\
\hline 2/28/06 9:40 & 17.98 & 16.38 & 8.92 & 1.23 & 12.15 & 2.86 \\
\hline $2 / 28 / 069: 50$ & 29.14 & 19.42 & 33.35 & 1.22 & 11.22 & 2.83 \\
\hline 2/28/06 10:00 & 29.98 & 17.81 & 40.61 & 1.23 & 11.67 & 3.54 \\
\hline 2/28/06 10:10 & 30.79 & 16.13 & 47.59 & 1.21 & 11.82 & 3.27 \\
\hline 2/28/06 10:20 & 29.31 & 15.16 & 48.29 & 1.22 & 11.09 & 3.09 \\
\hline 2/28/06 10:30 & 30.22 & 13.40 & 55.65 & 1.19 & 11.04 & 2.54 \\
\hline 2/28/06 10:40 & 30.11 & 19.81 & 34.21 & 1.21 & 10.47 & 2.20 \\
\hline 2/28/06 10:50 & 31.83 & 11.97 & 62.39 & 1.21 & 9.74 & 2.28 \\
\hline 2/28/06 11:00 & 33.07 & 15.30 & 53.73 & 1.19 & 8.62 & 1.91 \\
\hline 2/28/06 11:10 & 28.23 & 21.10 & 25.28 & 1.20 & 7.22 & 2.03 \\
\hline 2/28/06 11:20 & 27.33 & 13.46 & 50.75 & 1.21 & 6.70 & 1.91 \\
\hline 2/28/06 11:30 & 24.71 & & & 1.19 & 5.85 & \\
\hline $2 / 28 / 0611: 40$ & 21.56 & & & 1.14 & 5.28 & \\
\hline $2 / 28 / 0611: 50$ & 68.48 & & & 1.15 & 4.85 & \\
\hline 2/28/06 12:00 & & 7.98 & & 1.16 & & 0.16 \\
\hline 2/28/06 12:10 & & 5.73 & & 1.17 & & 0.00 \\
\hline 2/28/06 12:20 & & 6.84 & & 1.17 & & 0.00 \\
\hline $2 / 28 / 0612: 30$ & & 5.81 & & 1.17 & & 0.00 \\
\hline 2/28/06 12:40 & & 6.09 & & 1.25 & & 0.00 \\
\hline $2 / 28 / 0612: 50$ & & 6.38 & & 1.23 & & 0.00 \\
\hline 2/28/06 13:00 & & 6.58 & & 1.22 & & 0.00 \\
\hline $2 / 28 / 0613: 10$ & & 11.70 & & 1.22 & & 0.21 \\
\hline 2/28/06 13:20 & & 12.72 & & 1.20 & & 0.13 \\
\hline 2/28/06 13:30 & & 8.63 & & 1.20 & & 0.13 \\
\hline 2/28/06 13:40 & & 6.71 & & 1.19 & & 0.00 \\
\hline $2 / 28 / 0613: 50$ & 21.74 & 17.93 & 17.54 & 1.17 & 8.34 & 0.00 \\
\hline 2/28/06 14:00 & 27.67 & 2.63 & 90.48 & 1.13 & 8.91 & 0.00 \\
\hline $2 / 28 / 0614: 10$ & 25.29 & 2.92 & 88.45 & 1.15 & 8.69 & 0.22 \\
\hline $2 / 28 / 0614: 20$ & 24.73 & 2.62 & 89.39 & 1.19 & 8.98 & 0.13 \\
\hline $2 / 28 / 0614: 30$ & 26.46 & 2.88 & 89.13 & 1.17 & 7.89 & 0.13 \\
\hline $2 / 28 / 0614: 40$ & 27.04 & 2.82 & 89.56 & 1.18 & 8.60 & 0.21 \\
\hline $2 / 28 / 0614: 50$ & 28.16 & 2.17 & 92.29 & 1.19 & 8.40 & 0.00 \\
\hline 2/28/06 15:00 & 25.24 & 1.45 & 94.25 & 1.14 & 7.45 & 0.00 \\
\hline $2 / 28 / 06$ 15:10 & 24.96 & 3.42 & 86.28 & 1.21 & 9.11 & 4.99 \\
\hline $2 / 28 / 0615: 20$ & 24.17 & 3.01 & 87.54 & 1.26 & 8.76 & 6.05 \\
\hline $2 / 28 / 0615: 30$ & 24.88 & & & 1.18 & 9.47 & \\
\hline $2 / 28 / 0615: 40$ & 24.64 & & & 1.18 & 9.43 & \\
\hline $2 / 28 / 0615: 50$ & 21.86 & & & 1.20 & 9.58 & \\
\hline 2/28/06 16:00 & 28.05 & & & 1.18 & 10.60 & \\
\hline 2/28/06 16:10 & 20.37 & & & 1.16 & 9.43 & \\
\hline $2 / 28 / 0616: 20$ & 19.69 & 2.34 & 88.12 & 1.19 & 9.42 & 1.52 \\
\hline $2 / 28 / 0616: 30$ & 25.79 & 3.68 & 85.74 & 1.17 & 8.85 & 1.95 \\
\hline $2 / 28 / 0616: 40$ & 21.25 & 5.22 & 75.46 & 1.15 & 7.83 & 3.03 \\
\hline $2 / 28 / 0616: 50$ & & 3.56 & & 1.13 & & 1.92 \\
\hline 2/28/06 17:00 & & 3.45 & & 1.14 & & 1.81 \\
\hline 2/28/06 17:10 & 22.96 & 3.55 & 84.56 & 1.17 & 9.88 & 1.50 \\
\hline
\end{tabular}


Table D1. Corrected CMM and ACI, 10-minute Averaged Data During the Monthlong Field Test (continued)

\begin{tabular}{|c|c|c|c|c|c|c|}
\hline Date, Time & $\begin{array}{c}\text { FF Inlet } \mathrm{HgT}, \\
\mu \mathrm{g} / \mathrm{dNm}^{3}, \\
3 \% \mathrm{O}_{2}\end{array}$ & $\begin{array}{c}\text { FF Outlet } \mathrm{HgT}, \\
\mu \mathrm{g} / \mathrm{dNm}^{3} \\
3 \% \mathrm{O}_{2}\end{array}$ & $\begin{array}{c}\text { HgT Removal } \\
\text { Across } \\
\text { FF 2-4, } \% \\
\end{array}$ & $\begin{array}{c}\text { FF 2-4 Activated } \\
\text { Carbon Injection } \\
\text { Rate, lb/Macf } \\
\end{array}$ & $\begin{array}{c}\text { FF Inlet } \mathrm{Hg}^{0}, \\
\mu \mathrm{g} / \mathrm{dNm}^{3}, \\
3 \% \mathrm{O}_{2} \\
\end{array}$ & $\begin{array}{c}\text { FF Outlet } \mathrm{Hg}^{0}, \\
\mu \mathrm{g} / \mathrm{dNm}^{3}, \\
3 \% \mathrm{O}_{2}\end{array}$ \\
\hline $2 / 28 / 0617: 20$ & 22.26 & 3.82 & 82.86 & 1.19 & 9.44 & 1.27 \\
\hline $2 / 28 / 06$ 17:30 & 21.85 & 3.93 & 82.03 & 1.19 & 9.17 & 1.11 \\
\hline 2/28/06 17:40 & 29.08 & 4.09 & 85.94 & 1.19 & 8.79 & 0.94 \\
\hline 2/28/06 17:50 & 26.97 & 4.07 & 84.91 & 1.16 & 9.06 & 0.66 \\
\hline 2/28/06 18:00 & 23.25 & 3.56 & 84.69 & 1.17 & 9.00 & 1.49 \\
\hline $2 / 28 / 0618: 10$ & 26.10 & 3.81 & 85.40 & 1.17 & 9.55 & 1.91 \\
\hline 2/28/06 18:20 & 26.49 & 3.97 & 85.02 & 1.17 & 11.05 & 1.85 \\
\hline 2/28/06 18:30 & 23.83 & 3.62 & 84.82 & 1.18 & 11.87 & 2.11 \\
\hline 2/28/06 18:40 & 25.29 & 3.16 & 87.51 & 1.20 & 10.34 & 1.90 \\
\hline $2 / 28 / 0618: 50$ & 23.51 & 3.31 & 85.92 & 1.18 & 10.72 & 2.02 \\
\hline 2/28/06 19:00 & 24.28 & 3.24 & 86.64 & 1.19 & 10.48 & 1.66 \\
\hline 2/28/06 19:10 & 21.69 & 2.88 & 86.72 & 1.19 & 9.41 & 1.59 \\
\hline 2/28/06 19:20 & 24.03 & 4.92 & 79.52 & 1.22 & 9.53 & 1.83 \\
\hline 2/28/06 19:30 & 23.13 & 4.95 & 78.59 & 1.21 & 10.73 & 2.20 \\
\hline 2/28/06 19:40 & 26.07 & 4.70 & 81.99 & 1.21 & 11.50 & 2.24 \\
\hline 2/28/06 19:50 & 25.40 & 5.24 & 79.37 & 1.19 & 11.65 & 2.52 \\
\hline 2/28/06 20:00 & 23.81 & 2.23 & 90.65 & 1.17 & 13.14 & 1.78 \\
\hline 2/28/06 20:10 & 26.09 & & & 1.15 & 9.20 & \\
\hline 2/28/06 20:20 & 21.27 & & & 1.14 & 8.36 & \\
\hline 2/28/06 20:30 & 22.41 & & & 1.10 & 8.10 & \\
\hline 2/28/06 20:40 & 25.33 & & & 1.10 & 8.57 & \\
\hline $2 / 28 / 0620: 50$ & 21.05 & & & 1.15 & 8.00 & \\
\hline 2/28/06 21:00 & 21.65 & & & 1.14 & 7.29 & \\
\hline 2/28/06 21:10 & 24.53 & & & 1.20 & 7.87 & \\
\hline 2/28/06 21:20 & 23.06 & & & 1.18 & 7.14 & \\
\hline 2/28/06 21:30 & 27.50 & & & 1.19 & 8.74 & \\
\hline 2/28/06 21:40 & 24.81 & & & 1.17 & 7.64 & \\
\hline 2/28/06 21:50 & 25.26 & & & 1.17 & 8.66 & \\
\hline 2/28/06 22:00 & 22.61 & & & 1.18 & 9.99 & \\
\hline 2/28/06 22:10 & 41.26 & & & 1.20 & 8.87 & \\
\hline 2/28/06 22:20 & & & & 1.20 & & \\
\hline $2 / 28 / 0622: 30$ & & & & 1.22 & & \\
\hline 2/28/06 22:40 & & & & 1.19 & & \\
\hline $2 / 28 / 0622: 50$ & & & & 1.19 & & \\
\hline $2 / 28 / 0623: 00$ & & & & 1.21 & & \\
\hline 2/28/06 23:10 & & & & 1.19 & & \\
\hline $2 / 28 / 0623: 20$ & & & & 1.19 & & \\
\hline 2/28/06 23:30 & & & & 1.17 & & \\
\hline 2/28/06 23:40 & & & & 1.09 & & \\
\hline $2 / 28 / 0623: 50$ & & & & 1.10 & & \\
\hline $3 / 1 / 06$ 0:00 & & & & 1.07 & & \\
\hline 3/1/06 0:10 & & & & 1.08 & & \\
\hline 3/1/06 0:20 & & & & 1.11 & & \\
\hline 3/1/06 0:30 & & & & 1.11 & & \\
\hline 3/1/06 0:40 & & & & 1.10 & & \\
\hline $3 / 1 / 060: 50$ & & & & 1.05 & & \\
\hline 3/1/06 1:00 & & & & 1.04 & & \\
\hline $3 / 1 / 061: 10$ & & & & 1.10 & & \\
\hline $3 / 1 / 061: 20$ & & & & 1.15 & & \\
\hline 3/1/06 1:30 & & & & 1.15 & & \\
\hline 3/1/06 1:40 & & & & 1.20 & & \\
\hline $3 / 1 / 061: 50$ & & & & 1.18 & & \\
\hline
\end{tabular}


Table D1. Corrected CMM and ACI, 10-minute Averaged Data During the Monthlong Field Test (continued)

\begin{tabular}{|c|c|c|c|c|c|c|}
\hline Date, Time & $\begin{array}{c}\text { FF Inlet } \mathrm{HgT}, \\
\mu \mathrm{g} / \mathrm{dNm}^{3}, \\
3 \% \mathrm{O}_{2}\end{array}$ & $\begin{array}{c}\text { FF Outlet } \mathrm{HgT} \text {, } \\
\mu \mathrm{g} / \mathrm{dNm}^{3}, \\
3 \% \mathrm{O}_{2}\end{array}$ & $\begin{array}{c}\text { HgT Removal } \\
\text { Across } \\
\text { FF } 2-4, \% \\
\end{array}$ & $\begin{array}{c}\text { FF 2-4 Activated } \\
\text { Carbon Injection } \\
\text { Rate, lb/Macf } \\
\end{array}$ & $\begin{array}{c}\text { FF Inlet } \mathrm{Hg}^{0}, \\
\mu \mathrm{g} / \mathrm{dNm}^{3}, \\
3 \% \mathrm{O}_{2}\end{array}$ & $\begin{array}{c}\text { FF Outlet } \mathrm{Hg}^{0}, \\
\mu \mathrm{g} / \mathrm{dNm}^{3}, \\
3 \% \mathrm{O}_{2}\end{array}$ \\
\hline $3 / 1 / 062: 00$ & & & & 1.19 & & \\
\hline $3 / 1 / 062: 10$ & & & & 1.24 & & \\
\hline $3 / 1 / 062: 20$ & & & & 1.19 & & \\
\hline $3 / 1 / 062: 30$ & & & & 1.14 & & \\
\hline $3 / 1 / 062: 40$ & & & & 1.21 & & \\
\hline $3 / 1 / 062: 50$ & & & & 1.21 & & \\
\hline 3/1/06 3:00 & & & & 1.22 & & \\
\hline 3/1/06 3:10 & & & & 1.21 & & \\
\hline 3/1/06 3:20 & & & & 1.21 & & \\
\hline $3 / 1 / 063: 30$ & & & & 1.19 & & \\
\hline $3 / 1 / 063: 40$ & & & & 1.19 & & \\
\hline $3 / 1 / 063: 50$ & & & & 1.22 & & \\
\hline 3/1/06 4:00 & & & & 1.19 & & \\
\hline $3 / 1 / 064: 10$ & & & & 1.20 & & \\
\hline $3 / 1 / 064: 20$ & & & & 1.19 & & \\
\hline 3/1/06 4:30 & & & & 1.18 & & \\
\hline $3 / 1 / 064: 40$ & & & & 1.20 & & \\
\hline $3 / 1 / 064: 50$ & & & & 1.22 & & \\
\hline 3/1/06 5:00 & & & & 1.20 & & \\
\hline $3 / 1 / 065: 10$ & & & & 1.20 & & \\
\hline $3 / 1 / 065: 20$ & & & & 1.23 & & \\
\hline $3 / 1 / 065: 30$ & & & & 1.22 & & \\
\hline $3 / 1 / 065: 40$ & & & & 1.23 & & \\
\hline $3 / 1 / 065: 50$ & & & & 1.22 & & \\
\hline $3 / 1 / 066: 00$ & & & & 1.22 & & \\
\hline $3 / 1 / 066: 10$ & & & & 1.19 & & \\
\hline $3 / 1 / 066: 20$ & & & & 1.21 & & \\
\hline $3 / 1 / 066: 30$ & & & & 1.19 & & \\
\hline $3 / 1 / 066: 40$ & & & & 1.22 & & \\
\hline $3 / 1 / 066: 50$ & & & & 1.24 & & \\
\hline 3/1/06 7:00 & & & & 1.22 & & \\
\hline $3 / 1 / 067: 10$ & & & & 1.22 & & \\
\hline $3 / 1 / 067: 20$ & & & & 1.20 & & \\
\hline $3 / 1 / 067: 30$ & & & & 1.26 & & \\
\hline $3 / 1 / 067: 40$ & & & & 1.22 & & \\
\hline $3 / 1 / 067: 50$ & & & & 1.26 & & \\
\hline 3/1/06 8:00 & & & & 1.22 & & \\
\hline $3 / 1 / 068: 10$ & 40.24 & & & 1.20 & 6.57 & \\
\hline $3 / 1 / 068: 20$ & 30.85 & & & 1.22 & 9.33 & \\
\hline 3/1/06 8:30 & 15.42 & & & 1.22 & 11.87 & \\
\hline $3 / 1 / 068: 40$ & 26.74 & & & 1.21 & 9.89 & \\
\hline 3/1/06 8:50 & 26.96 & & & 1.20 & 7.96 & \\
\hline 3/1/06 9:00 & 28.90 & 12.90 & 55.37 & 1.24 & 7.88 & 1.91 \\
\hline 3/1/06 9:10 & 27.52 & 12.84 & 53.36 & 1.22 & 7.46 & 1.60 \\
\hline 3/1/06 9:20 & 25.12 & 11.74 & 53.26 & 1.22 & 6.94 & 1.25 \\
\hline 3/1/06 9:30 & 25.18 & 12.41 & 50.74 & 1.21 & 6.04 & 1.06 \\
\hline $3 / 1 / 069: 40$ & 23.47 & 11.75 & 49.95 & 1.22 & 5.58 & 0.67 \\
\hline 3/1/06 9:50 & 24.35 & 12.18 & 49.96 & 1.21 & 4.84 & 0.49 \\
\hline $3 / 1 / 0610: 00$ & 22.43 & 11.50 & 48.76 & 1.21 & 5.48 & 0.53 \\
\hline $3 / 1 / 0610: 10$ & 20.85 & 11.65 & 44.11 & 1.23 & 5.76 & 1.68 \\
\hline $3 / 1 / 0610: 20$ & 20.15 & 14.85 & 26.29 & 1.21 & 5.34 & 1.47 \\
\hline $3 / 1 / 0610: 30$ & 22.44 & 13.23 & 41.05 & 1.22 & 5.16 & 1.25 \\
\hline
\end{tabular}


Table D1. Corrected CMM and ACI, 10-minute Averaged Data During the Monthlong Field Test (continued)

\begin{tabular}{|c|c|c|c|c|c|c|}
\hline Date, Time & $\begin{array}{c}\text { FF Inlet } \mathrm{HgT}, \\
\mu \mathrm{g} / \mathrm{dNm}^{3}, \\
3 \% \mathrm{O}_{2} \\
\end{array}$ & $\begin{array}{c}\text { FF Outlet HgT, } \\
\mu \mathrm{g} / \mathrm{dNm}^{3}, \\
3 \% \mathrm{O}_{2}\end{array}$ & $\begin{array}{c}\text { HgT Removal } \\
\text { Across } \\
\text { FF 2-4, \% } \\
\end{array}$ & $\begin{array}{c}\text { FF 2-4 Activated } \\
\text { Carbon Injection } \\
\text { Rate, lb/Macf }\end{array}$ & $\begin{array}{c}\text { FF Inlet } \mathrm{Hg}^{0}, \\
\mu \mathrm{g} / \mathrm{dNm}^{3}, \\
3 \% \mathrm{O}_{2} \\
\end{array}$ & $\begin{array}{c}\text { FF Outlet } \mathrm{Hg}^{0}, \\
\mu \mathrm{g} / \mathrm{dNm}^{3}, \\
3 \% \mathrm{O}_{2}\end{array}$ \\
\hline $3 / 1 / 0610: 40$ & 19.42 & 11.80 & 39.22 & 1.21 & 4.69 & 1.06 \\
\hline $3 / 1 / 0610: 50$ & 21.63 & 12.79 & 40.90 & 1.22 & 5.18 & 0.94 \\
\hline 3/1/06 11:00 & 19.03 & 11.39 & 40.13 & 1.19 & 5.33 & 0.78 \\
\hline $3 / 1 / 0611: 10$ & 22.07 & 13.35 & 39.50 & 1.20 & 5.28 & 1.72 \\
\hline $3 / 1 / 0611: 20$ & 57.00 & 10.90 & 80.87 & 1.24 & 5.21 & 1.50 \\
\hline $3 / 1 / 0611: 30$ & 33.45 & 10.55 & 68.47 & 1.22 & 4.64 & 1.26 \\
\hline $3 / 1 / 0611: 40$ & 24.48 & 11.52 & 52.93 & 1.24 & 4.52 & 1.10 \\
\hline $3 / 1 / 0611: 50$ & 28.39 & 10.48 & 63.09 & 1.22 & 4.14 & 0.98 \\
\hline $3 / 1 / 06$ 12:00 & 26.88 & 10.05 & 62.61 & 1.22 & 4.83 & 0.90 \\
\hline $3 / 1 / 0612: 10$ & 25.00 & 12.52 & 49.89 & 1.19 & 5.30 & 1.57 \\
\hline $3 / 1 / 0612: 20$ & 25.87 & 10.46 & 59.58 & 1.21 & 5.26 & 1.35 \\
\hline $3 / 1 / 0612: 30$ & 25.67 & 14.33 & 44.19 & 1.19 & 5.05 & 1.23 \\
\hline $3 / 1 / 0612: 40$ & 45.10 & 11.72 & 74.00 & 1.18 & 7.83 & 0.79 \\
\hline $3 / 1 / 0612: 50$ & 21.30 & 9.71 & 54.43 & 1.16 & 5.68 & 0.31 \\
\hline $3 / 1 / 0613: 00$ & 18.30 & 11.08 & 39.47 & 1.17 & 5.28 & 0.00 \\
\hline $3 / 1 / 0613: 10$ & 20.59 & 8.59 & 58.26 & 1.24 & 4.85 & 0.68 \\
\hline $3 / 1 / 0613: 20$ & 21.27 & 11.63 & 45.31 & 1.22 & 4.88 & 1.12 \\
\hline $3 / 1 / 0613: 30$ & 22.88 & 10.39 & 54.60 & 1.21 & 4.85 & 0.97 \\
\hline $3 / 1 / 0613: 40$ & 22.49 & 9.84 & 56.26 & 1.21 & 4.96 & 0.72 \\
\hline $3 / 1 / 0613: 50$ & 21.73 & 9.61 & 55.79 & 1.21 & 5.01 & 0.60 \\
\hline $3 / 1 / 0614: 00$ & 21.46 & 11.07 & 48.42 & 1.21 & 5.25 & 0.43 \\
\hline $3 / 1 / 0614: 10$ & 24.73 & 10.24 & 58.62 & 1.20 & 5.39 & 1.24 \\
\hline $3 / 1 / 0614: 20$ & 23.07 & 11.39 & 50.62 & 1.20 & 5.06 & 1.17 \\
\hline $3 / 1 / 0614: 30$ & 26.06 & 14.14 & 45.72 & 1.37 & 5.78 & 4.18 \\
\hline $3 / 1 / 0614: 40$ & 25.35 & 23.62 & 6.83 & 1.22 & 5.84 & 6.78 \\
\hline $3 / 1 / 0614: 50$ & 22.47 & 12.80 & 43.00 & 1.23 & 5.95 & 1.15 \\
\hline $3 / 1 / 06$ 15:00 & 21.96 & 12.86 & 41.44 & 1.22 & 6.21 & 1.27 \\
\hline $3 / 1 / 0615: 10$ & 24.35 & 15.35 & 36.94 & 1.20 & 6.74 & 3.91 \\
\hline $3 / 1 / 0615: 20$ & 23.23 & 14.91 & 35.84 & 1.24 & 6.55 & 3.58 \\
\hline $3 / 1 / 0615: 30$ & 22.31 & 17.89 & 19.83 & 1.28 & 6.16 & 4.98 \\
\hline $3 / 1 / 0615: 40$ & 103.00 & 15.88 & 84.59 & 1.24 & 8.10 & 4.67 \\
\hline $3 / 1 / 0615: 50$ & 26.18 & 16.50 & 36.97 & 1.25 & 6.31 & 2.80 \\
\hline $3 / 1 / 0616: 00$ & 34.04 & 15.37 & 54.86 & 1.25 & 7.86 & 2.71 \\
\hline $3 / 1 / 0616: 10$ & 28.23 & 16.83 & 40.38 & 1.23 & 9.58 & 3.56 \\
\hline $3 / 1 / 0616: 20$ & 22.91 & 15.60 & 31.89 & 1.25 & 9.26 & 3.31 \\
\hline $3 / 1 / 0616: 30$ & 21.28 & 18.10 & 14.96 & 0.14 & 9.00 & 3.51 \\
\hline $3 / 1 / 0616: 40$ & 24.44 & 22.91 & 6.25 & 0.00 & 9.86 & 4.22 \\
\hline $3 / 1 / 0616: 50$ & 22.51 & 25.74 & 0 & 0.00 & 10.70 & 4.67 \\
\hline $3 / 1 / 06$ 17:00 & 23.65 & 28.16 & 0 & 0.00 & 11.42 & 4.71 \\
\hline $3 / 1 / 0617: 10$ & 23.36 & 42.03 & 0 & 0.00 & 12.56 & 6.57 \\
\hline $3 / 1 / 06$ 17:20 & 25.57 & 37.30 & 0 & 0.00 & 12.04 & 7.11 \\
\hline $3 / 1 / 0617: 30$ & 24.41 & 37.14 & 0 & 0.00 & 12.77 & 7.83 \\
\hline $3 / 1 / 06 \quad 17: 40$ & 24.49 & 42.68 & 0 & 0.00 & 14.59 & 6.44 \\
\hline $3 / 1 / 0617: 50$ & 26.01 & 32.84 & 0 & 0.00 & 13.79 & 5.61 \\
\hline $3 / 1 / 06$ 18:00 & 26.64 & 39.47 & 0 & 0.00 & 13.97 & 5.94 \\
\hline $3 / 1 / 0618: 10$ & 33.02 & 35.74 & 0 & 0.00 & 14.11 & 5.64 \\
\hline $3 / 1 / 0618: 20$ & 25.75 & 43.74 & 0 & 0.00 & 14.67 & 6.24 \\
\hline $3 / 1 / 0618: 30$ & 24.90 & 32.33 & 0 & 0.00 & 14.71 & 6.59 \\
\hline $3 / 1 / 0618: 40$ & 24.73 & 37.68 & 0 & 0.00 & 15.20 & 6.53 \\
\hline $3 / 1 / 0618: 50$ & 26.10 & 31.00 & 0 & 0.00 & 15.20 & 8.02 \\
\hline 3/1/06 19:00 & 25.52 & 38.63 & 0 & 0.00 & 18.00 & 6.71 \\
\hline 3/1/06 19:10 & 26.28 & 34.89 & 0 & 0.00 & 16.46 & 7.76 \\
\hline
\end{tabular}


Table D1. Corrected CMM and ACI, 10-minute Averaged Data During the Monthlong Field Test (continued)

\begin{tabular}{|c|c|c|c|c|c|c|}
\hline Date, Time & $\begin{array}{c}\text { FF Inlet } \mathrm{HgT}, \\
\mu \mathrm{g} / \mathrm{dNm}^{3} \\
3 \% \mathrm{O}_{2}\end{array}$ & $\begin{array}{c}\text { FF Outlet } \mathrm{HgT}, \\
\mu \mathrm{g} / \mathrm{dNm}^{3} \\
3 \% \mathrm{O}_{2}\end{array}$ & $\begin{array}{l}\text { HgT Removal } \\
\text { Across } \\
\text { FF } 2-4, \% \\
\end{array}$ & $\begin{array}{l}\text { FF 2-4 Activated } \\
\text { Carbon Injection } \\
\text { Rate, lb/Macf }\end{array}$ & $\begin{array}{c}\text { FF Inlet } \mathrm{Hg}^{0}, \\
\mu \mathrm{g} / \mathrm{dNm}^{3}, \\
3 \% \mathrm{O}_{2}\end{array}$ & $\begin{array}{c}\text { FF Outlet } \mathrm{Hg}^{0}, \\
\mu \mathrm{g} / \mathrm{dNm}^{3}, \\
3 \% \mathrm{O}_{2}\end{array}$ \\
\hline $3 / 1 / 06$ 19:20 & 26.57 & 40.31 & 0 & 0.00 & 17.76 & 6.08 \\
\hline 3/1/06 19:30 & 36.08 & & & 0.00 & 16.59 & \\
\hline 3/1/06 19:40 & 27.56 & & & 0.00 & 17.35 & \\
\hline 3/1/06 19:50 & 25.46 & & & 0.00 & 16.31 & \\
\hline 3/1/06 20:00 & 29.47 & & & 0.00 & 16.37 & \\
\hline $3 / 1 / 0620: 10$ & 30.05 & & & 0.00 & 17.53 & \\
\hline 3/1/06 20:20 & 27.00 & & & 0.00 & 20.67 & \\
\hline $3 / 1 / 0620: 30$ & 25.46 & & & 0.00 & 15.17 & \\
\hline $3 / 1 / 0620: 40$ & & & & 0.00 & & \\
\hline 3/1/06 20:50 & & & & 0.00 & & \\
\hline 3/1/06 21:00 & & & & 0.00 & & \\
\hline 3/1/06 21:10 & & & & 0.00 & & \\
\hline 3/1/06 21:20 & & & & 0.00 & & \\
\hline $3 / 1 / 0621: 30$ & & & & 0.00 & & \\
\hline 3/1/06 21:40 & & & & 0.00 & & \\
\hline 3/1/06 21:50 & & & & 0.00 & & \\
\hline 3/1/06 22:00 & & & & 0.00 & & \\
\hline 3/1/06 22:10 & & & & 0.00 & & \\
\hline 3/1/06 22:20 & & & & 0.00 & & \\
\hline 3/1/06 22:30 & & & & 0.00 & & \\
\hline 3/1/06 22:40 & & & & 0.00 & & \\
\hline $3 / 1 / 0622: 50$ & & & & 0.00 & & \\
\hline 3/1/06 23:00 & & & & 0.00 & & \\
\hline 3/1/06 23:10 & & & & 0.00 & & \\
\hline 3/1/06 23:20 & & & & 0.00 & & \\
\hline 3/1/06 23:30 & & & & 0.00 & & \\
\hline 3/1/06 23:40 & & & & 0.00 & & \\
\hline 3/1/06 23:50 & & & & 0.00 & & \\
\hline 3/2/06 0:00 & & & & 0.00 & & \\
\hline 3/2/06 0:10 & & & & 0.00 & & \\
\hline 3/2/06 0:20 & & & & 0.00 & & \\
\hline 3/2/06 0:30 & & & & 0.00 & & \\
\hline 3/2/06 0:40 & & & & 0.00 & & \\
\hline $3 / 2 / 060: 50$ & & & & 0.00 & & \\
\hline 3/2/06 1:00 & & & & 0.00 & & \\
\hline 3/2/06 1:10 & & & & 0.00 & & \\
\hline 3/2/06 1:20 & & & & 0.00 & & \\
\hline 3/2/06 1:30 & & & & 0.00 & & \\
\hline 3/2/06 1:40 & & & & 0.00 & & \\
\hline 3/2/06 1:50 & & & & 0.00 & & \\
\hline 3/2/06 2:00 & & & & 0.00 & & \\
\hline $3 / 2 / 062: 10$ & & & & 0.00 & & \\
\hline 3/2/06 2:20 & & & & 0.00 & & \\
\hline $3 / 2 / 062: 30$ & & & & 0.00 & & \\
\hline $3 / 2 / 062: 40$ & & & & 0.00 & & \\
\hline $3 / 2 / 062: 50$ & & & & 0.00 & & \\
\hline 3/2/06 3:00 & & & & 0.00 & & \\
\hline 3/2/06 3:10 & & & & 0.00 & & \\
\hline 3/2/06 3:20 & & & & 0.00 & & \\
\hline 3/2/06 3:30 & & & & 0.00 & & \\
\hline 3/2/06 3:40 & & & & 0.00 & & \\
\hline $3 / 2 / 063: 50$ & & & & 0.00 & & \\
\hline
\end{tabular}


Table D1. Corrected CMM and ACI, 10-minute Averaged Data During the Monthlong Field Test (continued)

\begin{tabular}{|c|c|c|c|c|c|c|}
\hline Date, Time & $\begin{array}{c}\text { FF Inlet } \mathrm{HgT}, \\
\mu \mathrm{g} / \mathrm{dNm}^{3}, \\
3 \% \mathrm{O}_{2} \\
\end{array}$ & $\begin{array}{c}\text { FF Outlet HgT, } \\
\mu \mathrm{g} / \mathrm{dNm}^{3}, \\
3 \% \mathrm{O}_{2}\end{array}$ & $\begin{array}{c}\text { HgT Removal } \\
\text { Across } \\
\text { FF 2-4, \% }\end{array}$ & $\begin{array}{c}\text { FF 2-4 Activated } \\
\text { Carbon Injection } \\
\text { Rate, lb/Macf }\end{array}$ & $\begin{array}{c}\text { FF Inlet } \mathrm{Hg}^{0}, \\
\mu \mathrm{g} / \mathrm{dNm}^{3}, \\
3 \% \mathrm{O}_{2} \\
\end{array}$ & $\begin{array}{c}\text { FF Outlet } \mathrm{Hg}^{0}, \\
\mu \mathrm{g} / \mathrm{dNm}^{3}, \\
3 \% \mathrm{O}_{2}\end{array}$ \\
\hline $3 / 2 / 064: 10$ & & & & 0.00 & & \\
\hline $3 / 2 / 064: 20$ & & & & 0.00 & & \\
\hline $3 / 2 / 064: 30$ & & & & 0.00 & & \\
\hline $3 / 2 / 064: 40$ & & & & 0.00 & & \\
\hline $3 / 2 / 064: 50$ & & & & 0.00 & & \\
\hline $3 / 2 / 065: 00$ & & & & 0.00 & & \\
\hline $3 / 2 / 065: 10$ & & & & 0.00 & & \\
\hline $3 / 2 / 065: 20$ & & & & 0.00 & & \\
\hline $3 / 2 / 065: 30$ & & & & 0.00 & & \\
\hline $3 / 2 / 065: 40$ & & & & 0.00 & & \\
\hline $3 / 2 / 065: 50$ & & & & 0.00 & & \\
\hline $3 / 2 / 06$ 6:00 & & & & 0.00 & & \\
\hline $3 / 2 / 066: 10$ & & & & 0.00 & & \\
\hline $3 / 2 / 066: 20$ & & & & 0.00 & & \\
\hline $3 / 2 / 066: 30$ & & & & 0.00 & & \\
\hline $3 / 2 / 066: 40$ & & & & 0.00 & & \\
\hline $3 / 2 / 066: 50$ & & & & 0.00 & & \\
\hline $3 / 2 / 067: 00$ & & & & 0.00 & & \\
\hline $3 / 2 / 067: 10$ & & & & 0.00 & & \\
\hline $3 / 2 / 067: 20$ & & & & 0.00 & & \\
\hline $3 / 2 / 067: 30$ & & & & 0.00 & & \\
\hline $3 / 2 / 067: 40$ & & & & 0.00 & & \\
\hline $3 / 2 / 067: 50$ & & & & 0.00 & & \\
\hline $3 / 2 / 068: 00$ & & & & 0.00 & & \\
\hline $3 / 2 / 068: 10$ & & & & 0.00 & & \\
\hline $3 / 2 / 068: 20$ & & & & 0.00 & & \\
\hline $3 / 2 / 068: 30$ & & 16.10 & & 0.00 & & 8.76 \\
\hline $3 / 2 / 068: 40$ & & 19.17 & & 0.00 & & 6.75 \\
\hline $3 / 2 / 068: 50$ & & 22.05 & & 0.00 & & 6.73 \\
\hline $3 / 2 / 069: 00$ & & 23.04 & & 0.00 & & 6.40 \\
\hline $3 / 2 / 069: 10$ & 18.37 & 27.43 & 0 & 0.00 & 8.00 & 11.81 \\
\hline $3 / 2 / 069: 20$ & 21.50 & 17.61 & 18.12 & 0.00 & 8.55 & 11.82 \\
\hline $3 / 2 / 069: 30$ & 21.55 & 19.60 & 9.07 & 0.00 & 8.92 & 6.62 \\
\hline $3 / 2 / 069: 40$ & 21.06 & 20.86 & 0.96 & & 8.88 & 5.86 \\
\hline $3 / 2 / 069: 50$ & 20.57 & 20.32 & 1.22 & 0.00 & 8.94 & 5.53 \\
\hline $3 / 2 / 0610: 00$ & 20.67 & 17.79 & 13.89 & 1.20 & 8.96 & 4.72 \\
\hline $3 / 2 / 0610: 10$ & 21.48 & 18.16 & 15.48 & 0.11 & 9.12 & 4.73 \\
\hline $3 / 2 / 0610: 20$ & 19.52 & 19.52 & 0 & 0.00 & 8.94 & 5.85 \\
\hline $3 / 2 / 0610: 30$ & 18.61 & 18.55 & 0.31 & 0.00 & 8.00 & 5.19 \\
\hline $3 / 2 / 0610: 40$ & 17.25 & 18.01 & 0 & 0.00 & 7.03 & 5.19 \\
\hline $3 / 2 / 0610: 50$ & 16.29 & 18.38 & 0 & 0.00 & 5.83 & 4.73 \\
\hline $3 / 2 / 0611: 00$ & 17.19 & 17.16 & 0.16 & 0.00 & 5.95 & 4.82 \\
\hline $3 / 2 / 0611: 10$ & 16.37 & 17.89 & 0 & 0.00 & 6.38 & 5.07 \\
\hline $3 / 2 / 0611: 20$ & 15.40 & 18.18 & 0 & 0.00 & 5.83 & 5.15 \\
\hline $3 / 2 / 0611: 30$ & 19.32 & 18.46 & 4.46 & 0.00 & 5.29 & 4.99 \\
\hline $3 / 2 / 0611: 40$ & 15.79 & 18.99 & 0 & 0.00 & 5.34 & 4.88 \\
\hline $3 / 2 / 0611: 50$ & 14.63 & 18.33 & 0 & 0.00 & 5.20 & 4.71 \\
\hline $3 / 2 / 0612: 00$ & 13.29 & 18.48 & 0 & 0.00 & 3.29 & 4.78 \\
\hline $3 / 2 / 0612: 10$ & 18.10 & 17.06 & 5.78 & 0.00 & 5.36 & 5.29 \\
\hline $3 / 2 / 0612: 20$ & 13.23 & 18.12 & 0 & 0.00 & 6.16 & 5.02 \\
\hline $3 / 2 / 0612: 30$ & 17.01 & 18.98 & 0 & 0.00 & 6.33 & 5.58 \\
\hline $3 / 2 / 06 \quad 12: 40$ & 15.19 & 18.15 & 0 & 0.26 & 6.84 & 5.45 \\
\hline
\end{tabular}


Table D1. Corrected CMM and ACI, 10-minute Averaged Data During the Monthlong Field Test (continued)

\begin{tabular}{|c|c|c|c|c|c|c|}
\hline Date, Time & $\begin{array}{c}\text { FF Inlet } \mathrm{HgT}, \\
\mu \mathrm{g} / \mathrm{dNm}^{3}, \\
3 \% \mathrm{O}_{2} \\
\end{array}$ & $\begin{array}{c}\text { FF Outlet HgT, } \\
\mu \mathrm{g} / \mathrm{dNm}^{3}, \\
3 \% \mathrm{O}_{2} \\
\end{array}$ & $\begin{array}{c}\text { HgT Removal } \\
\text { Across } \\
\text { FF 2-4, \% }\end{array}$ & $\begin{array}{c}\text { FF 2-4 Activated } \\
\text { Carbon Injection } \\
\text { Rate, lb/Macf }\end{array}$ & $\begin{array}{c}\text { FF Inlet } \mathrm{Hg}^{0}, \\
\mu \mathrm{g} / \mathrm{dNm}^{3}, \\
3 \% \mathrm{O}_{2} \\
\end{array}$ & $\begin{array}{c}\text { FF Outlet } \mathrm{Hg}^{0}, \\
\mu \mathrm{g} / \mathrm{dNm}^{3}, \\
3 \% \mathrm{O}_{2}\end{array}$ \\
\hline $3 / 2 / 0613: 00$ & 17.75 & 14.05 & 20.85 & 1.18 & 7.57 & 2.81 \\
\hline $3 / 2 / 0613: 10$ & 17.44 & 11.62 & 33.36 & 1.18 & 8.20 & 2.77 \\
\hline $3 / 2 / 0613: 20$ & 17.50 & 12.99 & 25.76 & 1.18 & 7.88 & 2.62 \\
\hline $3 / 2 / 0613: 30$ & 19.93 & 12.11 & 39.21 & 1.17 & 7.93 & 2.39 \\
\hline $3 / 2 / 0613: 40$ & 18.87 & 10.33 & 45.29 & 1.16 & 7.54 & 2.04 \\
\hline $3 / 2 / 0613: 50$ & 21.01 & 8.56 & 59.23 & 1.18 & 8.20 & 1.71 \\
\hline $3 / 2 / 0614: 00$ & 21.76 & 8.92 & 59.01 & 1.19 & 8.25 & 1.86 \\
\hline $3 / 2 / 0614: 10$ & 19.12 & 8.70 & 54.49 & 1.19 & 8.79 & 2.21 \\
\hline $3 / 2 / 0614: 20$ & 19.06 & 8.23 & 56.82 & 1.19 & 9.00 & 1.98 \\
\hline $3 / 2 / 0614: 30$ & 19.43 & 13.84 & 28.77 & 0.06 & 8.72 & 3.93 \\
\hline $3 / 2 / 0614: 40$ & 25.65 & 17.76 & 30.77 & 0.19 & 9.60 & 5.07 \\
\hline $3 / 2 / 0614: 50$ & 22.24 & 10.34 & 53.52 & 1.16 & 9.75 & 2.51 \\
\hline $3 / 2 / 0615: 00$ & 17.91 & 11.29 & 36.94 & 1.14 & 7.78 & 1.54 \\
\hline $3 / 2 / 0615: 10$ & 18.78 & 7.16 & 61.86 & 1.18 & 7.64 & 1.57 \\
\hline $3 / 2 / 06 \quad 15: 20$ & 16.96 & 5.88 & 65.34 & 1.16 & 7.28 & 1.25 \\
\hline $3 / 2 / 0615: 30$ & 17.77 & 4.58 & 74.21 & 1.17 & 8.01 & 0.96 \\
\hline $3 / 2 / 0615: 40$ & 19.16 & 7.20 & 62.41 & 1.19 & 7.78 & 0.81 \\
\hline $3 / 2 / 0615: 50$ & 17.07 & 7.06 & 58.66 & 1.19 & 8.48 & 1.17 \\
\hline $3 / 2 / 0616: 00$ & 15.26 & 5.65 & 63.00 & 1.17 & 8.37 & 1.48 \\
\hline $3 / 2 / 0616: 10$ & 18.61 & 6.47 & 65.26 & 1.19 & 9.07 & 1.77 \\
\hline $3 / 2 / 0616: 20$ & 17.86 & 6.00 & 66.44 & 1.18 & 9.10 & 1.71 \\
\hline $3 / 2 / 0616: 30$ & 16.50 & 5.95 & 63.91 & 1.17 & 9.57 & 1.44 \\
\hline $3 / 2 / 0616: 40$ & 18.06 & 5.96 & 67.01 & 1.17 & 9.74 & 1.50 \\
\hline $3 / 2 / 0616: 50$ & 18.90 & 6.12 & 67.65 & 1.18 & 6.89 & 1.58 \\
\hline $3 / 2 / 0617: 00$ & 18.99 & 4.39 & 76.86 & 1.21 & 7.61 & 1.32 \\
\hline $3 / 2 / 0617: 10$ & 19.36 & 6.18 & 68.08 & 1.17 & 7.60 & 1.07 \\
\hline $3 / 2 / 06 \quad 17: 20$ & 19.30 & 4.61 & 76.12 & 1.18 & 7.30 & 1.13 \\
\hline $3 / 2 / 0617: 30$ & 19.15 & 6.07 & 68.27 & 1.17 & 8.63 & 1.16 \\
\hline $3 / 2 / 06 \quad 17: 40$ & 17.77 & 6.48 & 63.55 & 1.20 & 9.36 & 1.29 \\
\hline $3 / 2 / 0617: 50$ & 18.94 & 6.67 & 64.78 & 1.18 & 7.92 & 1.73 \\
\hline $3 / 2 / 06$ 18:00 & 19.51 & & & 1.17 & 10.56 & \\
\hline $3 / 2 / 0618: 10$ & 19.73 & 7.01 & 64.46 & 1.17 & 11.40 & 1.51 \\
\hline $3 / 2 / 0618: 20$ & 20.10 & 8.35 & 58.48 & 1.17 & 11.35 & 1.73 \\
\hline $3 / 2 / 0618: 30$ & 20.53 & 6.83 & 66.74 & 1.18 & 11.80 & 1.49 \\
\hline $3 / 2 / 0618: 40$ & 20.55 & 6.94 & 66.22 & 1.17 & 11.90 & 1.45 \\
\hline $3 / 2 / 0618: 50$ & 22.43 & 6.68 & 70.23 & 1.18 & 12.48 & 1.48 \\
\hline $3 / 2 / 0619: 00$ & 21.67 & 7.26 & 66.47 & 1.19 & 12.31 & 1.68 \\
\hline $3 / 2 / 0619: 10$ & 22.49 & 8.46 & 62.37 & 1.21 & 12.14 & 2.24 \\
\hline $3 / 2 / 06 \quad 19: 20$ & 22.48 & 9.48 & 57.83 & 1.18 & 12.93 & 2.53 \\
\hline $3 / 2 / 0619: 30$ & 24.95 & 8.43 & 66.20 & 1.16 & 12.02 & 1.75 \\
\hline $3 / 2 / 0619: 40$ & 21.07 & 7.06 & 66.51 & 1.17 & 8.69 & 1.64 \\
\hline $3 / 2 / 0619: 50$ & 18.95 & 6.84 & 63.87 & 1.20 & 7.70 & 1.47 \\
\hline $3 / 2 / 0620: 00$ & 18.48 & 6.77 & 63.35 & 1.18 & 7.42 & 1.24 \\
\hline $3 / 2 / 0620: 10$ & 22.19 & 5.59 & 74.81 & 1.13 & 7.30 & 1.22 \\
\hline $3 / 2 / 0620: 20$ & 23.38 & 5.81 & 75.14 & 1.11 & 8.66 & 1.44 \\
\hline $3 / 2 / 0620: 30$ & 23.26 & 4.58 & 80.30 & 1.15 & 8.01 & 1.32 \\
\hline $3 / 2 / 0620: 40$ & 24.73 & 4.80 & 80.59 & 1.13 & 7.35 & 1.50 \\
\hline $3 / 2 / 0620: 50$ & 22.97 & 4.63 & 79.84 & 1.14 & 8.24 & 1.87 \\
\hline $3 / 2 / 0621: 00$ & 22.13 & 4.27 & 80.72 & 1.09 & 7.45 & 1.58 \\
\hline $3 / 2 / 0621: 10$ & 18.37 & 4.33 & 76.43 & 1.18 & 6.93 & 0.93 \\
\hline $3 / 2 / 0621: 20$ & 17.60 & 4.27 & 75.74 & 1.18 & 6.77 & 0.80 \\
\hline $3 / 2 / 0621: 30$ & 23.17 & 4.78 & 79.38 & 1.19 & 6.79 & 0.87 \\
\hline
\end{tabular}


Table D1. Corrected CMM and ACI, 10-minute Averaged Data During the Monthlong Field Test (continued)

\begin{tabular}{|c|c|c|c|c|c|c|}
\hline Date, Time & $\begin{array}{c}\text { FF Inlet } \mathrm{HgT} \text {, } \\
\mu \mathrm{g} / \mathrm{dNm}^{3}, \\
3 \% \mathrm{O}_{2} \\
\end{array}$ & $\begin{array}{c}\text { FF Outlet } \mathrm{HgT} \text {, } \\
\mu \mathrm{g} / \mathrm{dNm}^{3}, \\
3 \% \mathrm{O}_{2} \\
\end{array}$ & $\begin{array}{c}\text { HgT Removal } \\
\text { Across } \\
\text { FF 2-4, } \% \\
\end{array}$ & $\begin{array}{c}\text { FF 2-4 Activated } \\
\text { Carbon Injection } \\
\text { Rate, lb/Macf }\end{array}$ & $\begin{array}{c}\text { FF Inlet } \mathrm{Hg}^{0}, \\
\mu \mathrm{g} / \mathrm{dNm}^{3}, \\
3 \% \mathrm{O}_{2}\end{array}$ & $\begin{array}{c}\text { FF Outlet } \mathrm{Hg}^{0}, \\
\mu \mathrm{g} / \mathrm{dNm}^{3}, \\
3 \% \mathrm{O}_{2}\end{array}$ \\
\hline $3 / 2 / 0621: 50$ & 16.32 & 5.79 & 64.54 & 1.19 & 6.44 & 1.09 \\
\hline 3/2/06 22:00 & 16.95 & 11.38 & 32.89 & 1.19 & 7.46 & 1.00 \\
\hline 3/2/06 22:10 & 18.31 & 8.26 & 54.87 & 1.14 & 7.55 & 0.00 \\
\hline 3/2/06 22:20 & 18.35 & 5.42 & 70.48 & 1.14 & 7.93 & 0.00 \\
\hline $3 / 2 / 0622: 30$ & 17.97 & 4.08 & 77.27 & 1.10 & 7.34 & 0.00 \\
\hline $3 / 2 / 0622: 40$ & 33.01 & 3.85 & 88.34 & 1.15 & 8.14 & 0.00 \\
\hline $3 / 2 / 0622: 50$ & 20.89 & 5.84 & 72.02 & 1.21 & 7.20 & 0.00 \\
\hline 3/2/06 23:00 & 21.55 & 9.11 & 57.74 & 1.16 & 7.59 & 0.00 \\
\hline $3 / 2 / 0623: 10$ & 21.77 & 4.41 & 79.76 & 1.11 & 8.66 & 0.46 \\
\hline 3/2/06 23:20 & 18.54 & 4.18 & 77.47 & 1.19 & 6.95 & 0.58 \\
\hline $3 / 2 / 0623: 30$ & 18.02 & 8.22 & 54.41 & 1.22 & 7.70 & 0.85 \\
\hline 3/2/06 23:40 & 21.49 & 6.53 & 69.63 & 1.21 & 8.75 & 1.21 \\
\hline $3 / 2 / 0623: 50$ & 19.43 & 4.67 & 75.98 & 1.22 & 8.91 & 1.79 \\
\hline 3/3/06 0:00 & 19.39 & 5.12 & 73.61 & 1.22 & 10.09 & 2.10 \\
\hline 3/3/06 0:10 & & 4.72 & & 1.16 & & 0.61 \\
\hline 3/3/06 0:20 & & 6.25 & & 1.18 & & 0.69 \\
\hline $3 / 3 / 060: 30$ & & 4.33 & & 1.09 & & 0.95 \\
\hline $3 / 3 / 060: 40$ & & 4.04 & & 1.10 & & 1.09 \\
\hline $3 / 3 / 060: 50$ & & 3.95 & & 1.15 & & 1.21 \\
\hline 3/3/06 1:00 & & 3.36 & & 1.11 & & 1.14 \\
\hline $3 / 3 / 061: 10$ & & 3.06 & & 1.19 & & 0.23 \\
\hline $3 / 3 / 061: 20$ & & 3.04 & & 1.18 & & 0.29 \\
\hline $3 / 3 / 061: 30$ & & 3.40 & & 1.12 & & 0.27 \\
\hline $3 / 3 / 061: 40$ & & 5.60 & & 1.14 & & 0.19 \\
\hline $3 / 3 / 061: 50$ & & 4.89 & & 1.13 & & 0.00 \\
\hline $3 / 3 / 062: 00$ & & 3.60 & & 1.15 & & 0.00 \\
\hline $3 / 3 / 062: 10$ & & 3.32 & & 1.23 & & 0.14 \\
\hline $3 / 3 / 062: 20$ & & 4.00 & & 1.16 & & 0.43 \\
\hline $3 / 3 / 062: 30$ & & 4.51 & & 1.16 & & 0.32 \\
\hline $3 / 3 / 062: 40$ & & 4.31 & & 1.14 & & 0.37 \\
\hline $3 / 3 / 062: 50$ & & 3.65 & & 1.15 & & 0.36 \\
\hline 3/3/06 3:00 & & 3.69 & & 1.23 & & 0.33 \\
\hline $3 / 3 / 063: 10$ & & 4.12 & & 1.01 & & 0.13 \\
\hline $3 / 3 / 063: 20$ & & 5.40 & & 1.03 & & 0.17 \\
\hline $3 / 3 / 063: 30$ & & 6.60 & & 1.02 & & 0.32 \\
\hline $3 / 3 / 063: 40$ & & 5.22 & & 1.04 & & 0.39 \\
\hline $3 / 3 / 063: 50$ & & 5.19 & & 1.02 & & 0.66 \\
\hline 3/3/06 4:00 & & 4.67 & & 1.07 & & 0.65 \\
\hline $3 / 3 / 064: 10$ & & 6.91 & & 1.09 & & 0.16 \\
\hline $3 / 3 / 064: 20$ & & 5.80 & & 1.14 & & 0.00 \\
\hline $3 / 3 / 064: 30$ & & 6.52 & & 1.07 & & 0.20 \\
\hline $3 / 3 / 064: 40$ & & 8.25 & & 1.06 & & 0.15 \\
\hline $3 / 3 / 064: 50$ & & 8.69 & & 1.05 & & 0.13 \\
\hline 3/3/06 5:00 & & 7.38 & & 1.13 & & 0.10 \\
\hline $3 / 3 / 065: 10$ & & 8.83 & & 1.06 & & 0.19 \\
\hline $3 / 3 / 065: 20$ & & 7.78 & & 1.04 & & 0.30 \\
\hline $3 / 3 / 065: 30$ & & 7.91 & & 1.10 & & 0.37 \\
\hline $3 / 3 / 065: 40$ & & 9.57 & & 1.05 & & 0.35 \\
\hline $3 / 3 / 065: 50$ & & 8.36 & & 1.06 & & 0.31 \\
\hline $3 / 3 / 066: 00$ & & 8.07 & & 1.08 & & 0.41 \\
\hline $3 / 3 / 066: 10$ & & 8.89 & & 1.05 & & 0.25 \\
\hline $3 / 3 / 066: 20$ & & 10.28 & & 1.09 & & 0.38 \\
\hline
\end{tabular}


Table D1. Corrected CMM and ACI, 10-minute Averaged Data During the Monthlong Field Test (continued)

\begin{tabular}{|c|c|c|c|c|c|c|}
\hline Date, Time & $\begin{array}{c}\text { FF Inlet } \mathrm{HgT}, \\
\mu \mathrm{g} / \mathrm{dNm}^{3}, \\
3 \% \mathrm{O}_{2} \\
\end{array}$ & $\begin{array}{c}\text { FF Outlet HgT, } \\
\mu \mathrm{g} / \mathrm{dNm}^{3}, \\
3 \% \mathrm{O}_{2} \\
\end{array}$ & $\begin{array}{c}\text { HgT Removal } \\
\text { Across } \\
\text { FF 2-4, \% }\end{array}$ & $\begin{array}{c}\text { FF 2-4 Activated } \\
\text { Carbon Injection } \\
\text { Rate, lb/Macf }\end{array}$ & $\begin{array}{c}\text { FF Inlet } \mathrm{Hg}^{0}, \\
\mu \mathrm{g} / \mathrm{dNm}^{3}, \\
3 \% \mathrm{O}_{2} \\
\end{array}$ & $\begin{array}{c}\text { FF Outlet } \mathrm{Hg}^{0}, \\
\mu \mathrm{g} / \mathrm{dNm}^{3}, \\
3 \% \mathrm{O}_{2}\end{array}$ \\
\hline $3 / 3 / 066: 40$ & & 11.60 & & 1.22 & & 0.70 \\
\hline $3 / 3 / 066: 50$ & & 6.87 & & 1.19 & & 0.88 \\
\hline 3/3/06 7:00 & & 6.15 & & 1.12 & & 0.49 \\
\hline $3 / 3 / 067: 10$ & & 6.13 & & 1.13 & & 0.26 \\
\hline $3 / 3 / 067: 20$ & & & & 1.10 & & \\
\hline $3 / 3 / 067: 30$ & & & & 1.11 & & \\
\hline $3 / 3 / 067: 40$ & 23.86 & & & 1.14 & 13.42 & \\
\hline $3 / 3 / 067: 50$ & 24.11 & & & 1.13 & 13.65 & \\
\hline 3/3/06 8:00 & 23.27 & 5.61 & 75.90 & 1.15 & 13.57 & 1.04 \\
\hline $3 / 3 / 068: 10$ & 23.26 & 5.41 & 76.75 & 1.24 & 13.59 & 0.97 \\
\hline $3 / 3 / 068: 20$ & 23.87 & 5.65 & 76.35 & 1.20 & 13.25 & 1.09 \\
\hline $3 / 3 / 068: 30$ & 23.15 & 5.86 & 74.68 & 1.18 & 13.16 & 1.15 \\
\hline $3 / 3 / 068: 40$ & 22.65 & 6.88 & 69.64 & 1.23 & 12.84 & 1.37 \\
\hline $3 / 3 / 068: 50$ & 22.20 & 8.39 & 62.20 & 1.24 & 11.89 & 1.55 \\
\hline $3 / 3 / 069: 00$ & 21.28 & 9.78 & 54.05 & 1.23 & 12.63 & 1.60 \\
\hline $3 / 3 / 069: 10$ & 22.00 & 10.38 & 52.83 & 1.24 & 11.69 & 1.11 \\
\hline 3/3/06 9:20 & 20.42 & 9.57 & 53.13 & 1.19 & 10.07 & 1.02 \\
\hline $3 / 3 / 069: 30$ & 20.92 & 7.80 & 62.72 & 1.20 & 10.06 & 0.93 \\
\hline $3 / 3 / 069: 40$ & 21.15 & 7.38 & 65.11 & 1.23 & 11.03 & 0.89 \\
\hline $3 / 3 / 069: 50$ & 21.08 & 7.24 & 65.64 & 1.23 & 10.94 & 0.74 \\
\hline 3/3/06 10:00 & 22.07 & 7.10 & 67.81 & 1.20 & 10.56 & 0.61 \\
\hline $3 / 3 / 0610: 10$ & 23.84 & 7.53 & 68.44 & 1.14 & 11.12 & 0.79 \\
\hline $3 / 3 / 06 \quad 10: 20$ & 25.16 & 6.73 & 73.24 & 1.11 & 11.72 & 0.70 \\
\hline $3 / 3 / 0610: 30$ & 24.91 & 6.45 & 74.13 & 1.06 & 10.28 & 0.42 \\
\hline $3 / 3 / 0610: 40$ & 26.41 & 6.62 & 74.94 & 1.04 & 11.74 & 0.41 \\
\hline $3 / 3 / 0610: 50$ & 27.46 & 6.96 & 74.64 & 1.08 & 11.45 & 0.32 \\
\hline $3 / 3 / 06$ 11:00 & 22.91 & 6.00 & 73.80 & 1.11 & 8.45 & 0.07 \\
\hline $3 / 3 / 0611: 10$ & 22.78 & 8.53 & 62.57 & 1.13 & 9.83 & 0.90 \\
\hline $3 / 3 / 0611: 20$ & 20.20 & 6.38 & 68.40 & 1.18 & 6.70 & 0.46 \\
\hline $3 / 3 / 0611: 30$ & 21.95 & 7.18 & 67.30 & 1.17 & 7.41 & 0.35 \\
\hline $3 / 3 / 0611: 40$ & 22.51 & 9.65 & 57.14 & 1.12 & 8.47 & 0.41 \\
\hline $3 / 3 / 0611: 50$ & 25.07 & 9.19 & 63.36 & 1.09 & 9.33 & 0.29 \\
\hline $3 / 3 / 0612: 00$ & 27.30 & 9.81 & 64.06 & 1.04 & 10.48 & 0.35 \\
\hline $3 / 3 / 0612: 10$ & 24.32 & 10.20 & 58.07 & 1.19 & 8.90 & 0.94 \\
\hline $3 / 3 / 0612: 20$ & 22.22 & 8.49 & 61.79 & 1.20 & 7.53 & 0.51 \\
\hline $3 / 3 / 0612: 30$ & 25.13 & 13.76 & 45.24 & 1.22 & 10.31 & 0.47 \\
\hline $3 / 3 / 0612: 40$ & 24.23 & 10.03 & 58.60 & 1.22 & 8.51 & 0.44 \\
\hline $3 / 3 / 0612: 50$ & 23.61 & 13.17 & 44.21 & 1.20 & 8.46 & 0.00 \\
\hline 3/3/06 13:00 & 24.53 & 9.38 & 61.75 & 1.20 & 9.18 & 0.00 \\
\hline $3 / 3 / 0613: 10$ & 22.17 & 14.81 & 33.21 & 1.21 & 8.79 & 1.10 \\
\hline $3 / 3 / 0613: 20$ & 23.83 & 10.54 & 55.77 & 1.23 & 10.48 & 0.86 \\
\hline $3 / 3 / 0613: 30$ & 23.53 & 12.13 & 48.43 & 1.22 & 9.92 & 0.93 \\
\hline $3 / 3 / 0613: 40$ & 25.43 & 11.81 & 53.56 & 1.22 & 10.22 & 0.96 \\
\hline $3 / 3 / 0613: 50$ & 26.81 & 22.54 & 15.93 & 1.20 & 10.46 & 0.52 \\
\hline $3 / 3 / 0614: 00$ & 28.79 & 14.44 & 49.82 & 1.20 & 9.70 & 0.48 \\
\hline $3 / 3 / 0614: 10$ & 25.55 & 12.30 & 51.86 & 1.18 & 6.83 & 1.05 \\
\hline $3 / 3 / 0614: 20$ & 26.81 & 12.95 & 51.69 & 1.18 & 8.31 & 0.95 \\
\hline $3 / 3 / 0614: 30$ & 30.06 & 11.28 & 62.46 & 1.17 & 6.39 & 0.61 \\
\hline $3 / 3 / 0614: 40$ & 30.59 & 12.22 & 60.04 & 1.19 & 9.40 & 0.68 \\
\hline $3 / 3 / 0614: 50$ & 26.49 & 12.07 & 54.42 & 1.21 & 8.16 & 0.49 \\
\hline $3 / 3 / 06$ 15:00 & 27.02 & 13.66 & 49.45 & 1.19 & 8.01 & 0.44 \\
\hline $3 / 3 / 0615: 10$ & 30.67 & 11.70 & 61.86 & 1.22 & 8.09 & 0.69 \\
\hline
\end{tabular}


Table D1. Corrected CMM and ACI, 10-minute Averaged Data During the Monthlong Field Test (continued)

\begin{tabular}{|c|c|c|c|c|c|c|}
\hline Date, Time & $\begin{array}{c}\text { FF Inlet } \mathrm{HgT}, \\
\mu \mathrm{g} / \mathrm{dNm}^{3}, \\
3 \% \mathrm{O}_{2} \\
\end{array}$ & $\begin{array}{c}\text { FF Outlet HgT, } \\
\mu \mathrm{g} / \mathrm{dNm}^{3}, \\
3 \% \mathrm{O}_{2}\end{array}$ & $\begin{array}{c}\text { HgT Removal } \\
\text { Across } \\
\text { FF 2-4, \% } \\
\end{array}$ & $\begin{array}{c}\text { FF 2-4 Activated } \\
\text { Carbon Injection } \\
\text { Rate, lb/Macf }\end{array}$ & $\begin{array}{c}\text { FF Inlet } \mathrm{Hg}^{0}, \\
\mu \mathrm{g} / \mathrm{dNm}^{3}, \\
3 \% \mathrm{O}_{2} \\
\end{array}$ & $\begin{array}{c}\text { FF Outlet } \mathrm{Hg}^{0}, \\
\mu \mathrm{g} / \mathrm{dNm}^{3}, \\
3 \% \mathrm{O}_{2}\end{array}$ \\
\hline $3 / 3 / 0615: 30$ & 30.82 & 12.53 & 59.34 & 1.20 & 14.57 & 0.00 \\
\hline $3 / 3 / 0615: 40$ & 29.00 & 14.74 & 49.19 & 1.21 & 12.34 & 0.00 \\
\hline $3 / 3 / 0615: 50$ & 27.98 & 13.15 & 52.98 & 1.20 & 9.86 & 0.00 \\
\hline $3 / 3 / 0616: 00$ & 26.11 & 13.34 & 48.91 & 1.19 & 9.74 & 0.00 \\
\hline $3 / 3 / 0616: 10$ & 26.04 & 11.91 & 54.27 & 1.12 & 8.41 & 0.00 \\
\hline $3 / 3 / 0616: 20$ & 23.03 & 11.97 & 48.04 & 1.15 & 8.30 & 0.38 \\
\hline $3 / 3 / 0616: 30$ & 23.04 & 11.47 & 50.21 & 1.19 & 11.77 & 0.00 \\
\hline $3 / 3 / 0616: 40$ & 24.23 & 11.71 & 51.67 & 1.21 & 10.44 & 0.00 \\
\hline $3 / 3 / 0616: 50$ & 26.17 & 12.85 & 50.90 & 1.18 & 9.04 & 0.00 \\
\hline $3 / 3 / 06$ 17:00 & 21.53 & 16.55 & 23.16 & 1.18 & 8.24 & 0.00 \\
\hline $3 / 3 / 06 \quad 17: 10$ & 22.36 & 8.97 & 59.91 & 1.19 & 5.35 & \\
\hline $3 / 3 / 06 \quad 17: 20$ & 21.20 & 11.65 & 45.07 & 1.20 & 6.24 & 0.12 \\
\hline $3 / 3 / 0617: 30$ & 24.62 & 9.13 & 62.93 & 1.21 & 5.86 & 0.12 \\
\hline $3 / 3 / 06 \quad 17: 40$ & 19.86 & 7.81 & 60.67 & 1.19 & 4.92 & 0.13 \\
\hline $3 / 3 / 06 \quad 17: 50$ & 23.74 & 12.97 & 45.35 & 1.15 & 8.37 & 0.15 \\
\hline $3 / 3 / 06$ 18:00 & 20.43 & 5.86 & 71.30 & 1.17 & 5.82 & 0.25 \\
\hline 3/3/06 18:10 & 19.98 & 5.17 & 74.13 & 1.15 & 5.94 & 0.12 \\
\hline $3 / 3 / 0618: 20$ & 18.04 & 6.45 & 64.24 & 1.18 & 5.08 & 0.16 \\
\hline $3 / 3 / 0618: 30$ & 18.99 & 10.01 & 47.30 & 1.19 & 7.22 & 0.30 \\
\hline $3 / 3 / 0618: 40$ & 19.84 & 7.87 & 60.31 & 1.20 & 9.17 & 0.48 \\
\hline $3 / 3 / 0618: 50$ & 21.23 & 7.63 & 64.05 & 1.22 & 11.44 & 0.67 \\
\hline 3/3/06 19:00 & 20.69 & 9.26 & 55.22 & 1.22 & 11.35 & 0.63 \\
\hline 3/3/06 19:10 & 18.08 & 8.80 & 51.34 & 1.21 & 6.16 & 0.00 \\
\hline $3 / 3 / 0619: 20$ & 16.41 & 20.36 & 0 & 1.20 & 4.06 & 0.20 \\
\hline $3 / 3 / 0619: 30$ & 15.45 & 5.98 & 61.33 & 1.20 & 4.82 & 0.41 \\
\hline $3 / 3 / 0619: 40$ & 16.46 & 6.49 & 60.61 & 1.16 & 4.17 & 0.67 \\
\hline $3 / 3 / 0619: 50$ & 16.31 & 6.57 & 59.73 & 1.17 & 5.42 & 0.93 \\
\hline $3 / 3 / 0620: 00$ & 17.70 & 6.00 & 66.12 & 1.21 & 4.38 & 1.15 \\
\hline $3 / 3 / 0620: 10$ & 16.72 & 4.57 & 72.68 & 1.19 & 4.83 & 0.13 \\
\hline $3 / 3 / 0620: 20$ & 17.49 & 5.33 & 69.56 & 1.17 & 4.47 & 0.29 \\
\hline $3 / 3 / 0620: 30$ & 17.22 & 8.47 & 50.81 & 1.17 & 4.80 & 0.45 \\
\hline $3 / 3 / 0620: 40$ & 16.34 & 5.52 & 66.21 & 1.17 & 5.29 & 0.63 \\
\hline $3 / 3 / 0620: 50$ & 19.27 & 4.32 & 77.57 & 1.17 & 6.01 & 0.79 \\
\hline $3 / 3 / 0621: 00$ & 17.59 & 3.54 & 79.86 & 1.17 & 6.82 & 0.75 \\
\hline $3 / 3 / 0621: 10$ & 15.63 & 3.39 & 78.32 & 1.16 & 4.76 & 0.16 \\
\hline $3 / 3 / 0621: 20$ & 19.12 & 3.38 & 82.31 & 1.15 & 7.96 & 0.36 \\
\hline $3 / 3 / 0621: 30$ & 18.59 & 3.22 & 82.71 & 1.11 & 8.36 & 0.47 \\
\hline $3 / 3 / 0621: 40$ & 20.13 & 3.63 & 81.95 & 1.11 & 8.59 & 0.56 \\
\hline $3 / 3 / 0621: 50$ & 22.16 & 4.34 & 80.43 & 1.08 & 9.81 & 0.71 \\
\hline $3 / 3 / 0622: 00$ & 19.03 & 5.30 & 72.16 & 1.08 & 8.29 & 0.76 \\
\hline $3 / 3 / 0622: 10$ & 21.75 & 5.75 & 73.58 & 1.00 & 9.92 & \\
\hline $3 / 3 / 0622: 20$ & 22.67 & 5.71 & 74.84 & 1.00 & 11.84 & 0.13 \\
\hline $3 / 3 / 0622: 30$ & 22.39 & 5.01 & 77.61 & 1.03 & 10.54 & 0.20 \\
\hline $3 / 3 / 0622: 40$ & 24.77 & 5.87 & 76.32 & 1.07 & 12.28 & 0.30 \\
\hline $3 / 3 / 0622: 50$ & 23.01 & 5.78 & 74.86 & 1.02 & 11.95 & 0.45 \\
\hline $3 / 3 / 0623: 00$ & 22.41 & 6.96 & 68.95 & 1.03 & 11.97 & 0.46 \\
\hline $3 / 3 / 0623: 10$ & 21.83 & 7.07 & 67.61 & 1.05 & 11.32 & 0.00 \\
\hline $3 / 3 / 0623: 20$ & 21.05 & 8.35 & 60.36 & 1.12 & 9.90 & 0.16 \\
\hline $3 / 3 / 0623: 30$ & 16.22 & 7.22 & 55.45 & 1.11 & 6.07 & 0.00 \\
\hline $3 / 3 / 0623: 40$ & 18.33 & 5.27 & 71.27 & 1.14 & 8.52 & 0.32 \\
\hline $3 / 3 / 0623: 50$ & 14.13 & 5.01 & 64.51 & 1.07 & 5.28 & 0.50 \\
\hline 3/4/06 0:00 & 17.32 & 4.53 & 73.85 & 1.01 & 5.55 & 0.63 \\
\hline
\end{tabular}


Table D1. Corrected CMM and ACI, 10-minute Averaged Data During the Monthlong Field Test (continued)

\begin{tabular}{|c|c|c|c|c|c|c|}
\hline Date, Time & $\begin{array}{c}\text { FF Inlet } \mathrm{HgT}, \\
\mu \mathrm{g} / \mathrm{dNm}^{3}, \\
3 \% \mathrm{O}_{2} \\
\end{array}$ & $\begin{array}{c}\text { FF Outlet HgT, } \\
\mu \mathrm{g} / \mathrm{dNm}^{3}, \\
3 \% \mathrm{O}_{2} \\
\end{array}$ & $\begin{array}{c}\text { HgT Removal } \\
\text { Across } \\
\text { FF } 2-4, \% \\
\end{array}$ & $\begin{array}{c}\text { FF 2-4 Activated } \\
\text { Carbon Injection } \\
\text { Rate, lb/Macf }\end{array}$ & $\begin{array}{c}\text { FF Inlet } \mathrm{Hg}^{0}, \\
\mu \mathrm{g} / \mathrm{dNm}^{3}, \\
3 \% \mathrm{O}_{2} \\
\end{array}$ & $\begin{array}{c}\text { FF Outlet } \mathrm{Hg}^{0}, \\
\mu \mathrm{g} / \mathrm{dNm}^{3}, \\
3 \% \mathrm{O}_{2}\end{array}$ \\
\hline $3 / 4 / 060: 20$ & 16.06 & 3.97 & 75.27 & 0.98 & 6.52 & 0.21 \\
\hline $3 / 4 / 060: 30$ & 15.87 & 3.49 & 78.00 & 1.04 & 7.18 & 0.35 \\
\hline $3 / 4 / 060: 40$ & 16.07 & 3.83 & 76.15 & 1.06 & 7.56 & 0.40 \\
\hline $3 / 4 / 060: 50$ & 16.94 & 3.28 & 80.63 & 1.09 & 9.02 & 0.52 \\
\hline $3 / 4 / 061: 00$ & 17.71 & 3.88 & 78.07 & 1.09 & 7.77 & 0.52 \\
\hline $3 / 4 / 061: 10$ & 18.11 & 3.80 & 79.04 & 1.11 & 8.94 & 0.00 \\
\hline $3 / 4 / 061: 20$ & 16.25 & 4.21 & 74.07 & 1.06 & 5.52 & 0.13 \\
\hline $3 / 4 / 061: 30$ & 17.61 & 3.69 & 79.06 & 1.10 & 7.73 & 0.31 \\
\hline $3 / 4 / 061: 40$ & 18.00 & 4.00 & 77.78 & 1.05 & 9.11 & 0.42 \\
\hline $3 / 4 / 061: 50$ & 18.18 & 4.54 & 75.03 & 1.03 & 7.48 & 0.57 \\
\hline $3 / 4 / 062: 00$ & 19.24 & 4.66 & 75.80 & 1.05 & 10.03 & 0.58 \\
\hline $3 / 4 / 062: 10$ & 20.45 & 7.48 & 63.43 & 1.06 & 9.59 & 0.13 \\
\hline $3 / 4 / 062: 20$ & 19.24 & 5.74 & 70.15 & 1.06 & 9.83 & 0.13 \\
\hline $3 / 4 / 062: 30$ & 19.27 & 5.34 & 72.30 & 1.05 & 10.39 & 0.26 \\
\hline $3 / 4 / 062: 40$ & 21.38 & 5.45 & 74.53 & 1.11 & 10.47 & 0.43 \\
\hline $3 / 4 / 062: 50$ & 19.87 & 5.60 & 71.84 & 1.07 & 10.39 & 0.69 \\
\hline 3/4/06 3:00 & 21.85 & 5.88 & 73.10 & 1.03 & 11.40 & 0.72 \\
\hline $3 / 4 / 063: 10$ & 21.05 & 5.65 & 73.14 & 1.00 & 11.54 & 0.00 \\
\hline $3 / 4 / 063: 20$ & 22.21 & 5.68 & 74.44 & 1.05 & 11.81 & 0.00 \\
\hline $3 / 4 / 063: 30$ & 20.43 & 6.53 & 68.05 & 1.04 & 10.95 & 0.13 \\
\hline $3 / 4 / 063: 40$ & 22.04 & 6.00 & 72.76 & 1.06 & 12.15 & 0.26 \\
\hline $3 / 4 / 063: 50$ & 20.57 & 10.83 & 47.34 & 1.11 & 11.45 & 0.27 \\
\hline $3 / 4 / 064: 00$ & 17.45 & 6.13 & 64.87 & 1.07 & 6.30 & 0.18 \\
\hline $3 / 4 / 064: 10$ & 20.51 & 5.58 & 72.78 & 1.13 & 10.26 & 0.06 \\
\hline $3 / 4 / 064: 20$ & 15.09 & 5.26 & 65.15 & 1.10 & 6.05 & 0.26 \\
\hline $3 / 4 / 064: 30$ & 15.23 & 5.50 & 63.90 & 1.16 & 3.69 & 0.50 \\
\hline $3 / 4 / 064: 40$ & 14.31 & 4.95 & 65.41 & 1.12 & 3.84 & 0.60 \\
\hline $3 / 4 / 064: 50$ & 16.37 & 4.67 & 71.47 & 1.10 & 4.77 & 0.76 \\
\hline $3 / 4 / 065: 00$ & 17.05 & 5.79 & 66.05 & 1.08 & 7.86 & 0.73 \\
\hline $3 / 4 / 065: 10$ & 20.00 & 5.44 & 72.79 & 1.04 & 9.08 & 0.00 \\
\hline $3 / 4 / 065: 20$ & 17.35 & 6.09 & 64.92 & 1.05 & 9.33 & 0.20 \\
\hline $3 / 4 / 065: 30$ & 18.96 & 5.22 & 72.47 & 1.12 & 9.27 & 0.27 \\
\hline $3 / 4 / 065: 40$ & 18.48 & 5.41 & 70.71 & 1.05 & 9.24 & 0.26 \\
\hline $3 / 4 / 065: 50$ & 19.43 & 6.62 & 65.92 & 1.03 & 11.35 & 0.27 \\
\hline $3 / 4 / 06$ 6:00 & 19.17 & 5.82 & 69.63 & 1.08 & 11.38 & 0.21 \\
\hline $3 / 4 / 066: 10$ & 20.42 & 6.75 & 66.93 & 1.05 & 10.34 & 0.00 \\
\hline $3 / 4 / 066: 20$ & 20.40 & 6.87 & 66.34 & 1.08 & 10.67 & 0.13 \\
\hline $3 / 4 / 066: 30$ & 19.53 & 6.44 & 67.04 & 1.06 & 9.86 & 0.20 \\
\hline $3 / 4 / 066: 40$ & 21.09 & 10.06 & 52.29 & 1.03 & 10.91 & 0.36 \\
\hline $3 / 4 / 066: 50$ & 20.13 & 6.88 & 65.81 & 1.05 & 10.88 & 0.49 \\
\hline $3 / 4 / 067: 00$ & 21.05 & 7.59 & 63.92 & 1.05 & 10.72 & 0.51 \\
\hline $3 / 4 / 067: 10$ & 19.25 & 7.59 & 60.55 & 1.13 & 9.55 & 0.13 \\
\hline $3 / 4 / 067: 20$ & 16.92 & 6.37 & 62.34 & 1.14 & 5.52 & 0.28 \\
\hline $3 / 4 / 067: 30$ & 77.62 & 6.86 & 91.16 & 1.13 & 9.49 & 0.42 \\
\hline $3 / 4 / 067: 40$ & 23.24 & 7.60 & 67.28 & 1.15 & 9.54 & 0.46 \\
\hline $3 / 4 / 067: 50$ & 19.57 & 7.39 & 62.25 & 1.10 & 7.34 & 0.39 \\
\hline $3 / 4 / 068: 00$ & 20.18 & 8.68 & 56.96 & 1.07 & 9.76 & 0.31 \\
\hline $3 / 4 / 068: 10$ & 23.03 & & & 1.04 & 11.05 & \\
\hline $3 / 4 / 068: 20$ & 19.89 & 13.03 & 34.50 & 1.09 & 11.38 & 0.49 \\
\hline $3 / 4 / 068: 30$ & & 10.37 & & 1.09 & & 0.79 \\
\hline $3 / 4 / 068: 40$ & & 9.09 & & 1.06 & & 1.06 \\
\hline $3 / 4 / 068: 50$ & & 9.59 & & 1.06 & & 0.91 \\
\hline
\end{tabular}


Table D1. Corrected CMM and ACI, 10-minute Averaged Data During the Monthlong Field Test (continued)

\begin{tabular}{|c|c|c|c|c|c|c|}
\hline Date, Time & $\begin{array}{c}\text { FF Inlet } \mathrm{HgT}, \\
\mu \mathrm{g} / \mathrm{dNm}^{3}, \\
3 \% \mathrm{O}_{2}\end{array}$ & $\begin{array}{c}\text { FF Outlet HgT, } \\
\mu \mathrm{g} / \mathrm{dNm}^{3}, \\
3 \% \mathrm{O}_{2} \\
\end{array}$ & $\begin{array}{c}\text { HgT Removal } \\
\text { Across } \\
\text { FF } 2-4, \% \\
\end{array}$ & $\begin{array}{c}\text { FF 2-4 Activated } \\
\text { Carbon Injection } \\
\text { Rate, lb/Macf }\end{array}$ & $\begin{array}{c}\text { FF Inlet } \mathrm{Hg}^{0}, \\
\mu \mathrm{g} / \mathrm{dNm}^{3}, \\
3 \% \mathrm{O}_{2} \\
\end{array}$ & $\begin{array}{c}\text { FF Outlet } \mathrm{Hg}^{0}, \\
\mu \mathrm{g} / \mathrm{dNm}^{3}, \\
3 \% \mathrm{O}_{2}\end{array}$ \\
\hline $3 / 4 / 069: 10$ & & 7.71 & & 1.15 & & 0.71 \\
\hline $3 / 4 / 069: 20$ & 19.33 & 6.28 & 67.53 & 1.19 & 4.37 & 0.18 \\
\hline $3 / 4 / 069: 30$ & 22.42 & 6.19 & 72.41 & 1.12 & 4.30 & 0.00 \\
\hline $3 / 4 / 06$ 9:40 & 13.62 & 5.33 & 60.86 & 1.09 & 4.21 & 0.00 \\
\hline $3 / 4 / 069: 50$ & & 6.17 & & 1.05 & & 0.00 \\
\hline $3 / 4 / 0610: 00$ & & 6.15 & & 1.12 & & 0.00 \\
\hline $3 / 4 / 06 \quad 10: 10$ & & 9.26 & & 1.17 & & 0.45 \\
\hline $3 / 4 / 06 \quad 10: 20$ & & 6.66 & & 1.20 & & 0.23 \\
\hline $3 / 4 / 0610: 30$ & & 8.83 & & 1.27 & & 0.15 \\
\hline $3 / 4 / 0610: 40$ & & 10.69 & & 1.26 & & 0.00 \\
\hline $3 / 4 / 0610: 50$ & & 12.30 & & 1.23 & & 0.00 \\
\hline $3 / 4 / 0611: 00$ & 33.42 & & & 1.25 & 18.98 & \\
\hline $3 / 4 / 0611: 10$ & 28.34 & & & 1.22 & 18.83 & \\
\hline $3 / 4 / 0611: 20$ & 27.44 & 21.88 & 20.26 & 1.23 & 16.84 & 1.91 \\
\hline $3 / 4 / 0611: 30$ & 28.62 & 17.65 & 38.33 & 1.22 & 19.76 & 1.42 \\
\hline $3 / 4 / 0611: 40$ & 28.44 & 17.35 & 39.00 & 1.23 & 19.74 & 1.68 \\
\hline $3 / 4 / 0611: 50$ & 28.72 & 17.44 & 39.26 & 0.98 & 20.34 & 1.40 \\
\hline $3 / 4 / 06 \quad 12: 00$ & 28.41 & 24.24 & 14.67 & 0.00 & 19.59 & 2.18 \\
\hline $3 / 4 / 0612: 10$ & 28.19 & 32.33 & 0 & 0.00 & 20.29 & 4.23 \\
\hline $3 / 4 / 0612: 20$ & 25.93 & 29.18 & 0 & 0.00 & 17.29 & 3.20 \\
\hline $3 / 4 / 06 \quad 12: 30$ & 25.96 & 23.74 & 8.56 & 0.92 & 18.74 & 3.32 \\
\hline $3 / 4 / 0612: 40$ & 24.83 & 16.81 & 32.27 & 1.20 & 16.54 & 1.34 \\
\hline $3 / 4 / 0612: 50$ & 25.95 & 19.46 & 25.02 & 1.21 & 15.91 & 1.47 \\
\hline $3 / 4 / 0613: 00$ & 24.71 & 20.96 & 15.17 & 1.22 & 15.12 & 1.72 \\
\hline $3 / 4 / 0613: 10$ & 24.44 & 22.39 & 8.41 & 1.22 & 15.68 & 0.00 \\
\hline $3 / 4 / 0613: 20$ & 25.45 & 22.48 & 11.69 & 0.44 & 17.84 & 0.00 \\
\hline $3 / 4 / 06 \quad 13: 30$ & 25.77 & 29.48 & 0 & 0.00 & 18.58 & 0.00 \\
\hline $3 / 4 / 0613: 40$ & 25.07 & 30.16 & 0 & 0.00 & 16.98 & 0.00 \\
\hline $3 / 4 / 0613: 50$ & 26.01 & 33.36 & 0 & 0.00 & 18.47 & 0.00 \\
\hline $3 / 4 / 0614: 00$ & 28.02 & 34.76 & 0 & 0.00 & 21.55 & 0.00 \\
\hline $3 / 4 / 0614: 10$ & 30.09 & 33.98 & 0 & 0.00 & 27.18 & 1.11 \\
\hline $3 / 4 / 06 \quad 14: 20$ & 31.38 & 32.11 & 0 & 0.00 & 25.91 & 0.69 \\
\hline $3 / 4 / 0614: 30$ & 29.47 & 31.30 & 0 & 0.69 & 22.91 & 0.44 \\
\hline $3 / 4 / 0614: 40$ & 30.29 & 25.14 & 17.01 & 1.19 & 28.68 & 0.00 \\
\hline $3 / 4 / 0614: 50$ & 29.00 & 22.68 & 21.79 & 1.20 & 27.76 & 0.00 \\
\hline $3 / 4 / 06$ 15:00 & 26.78 & 17.34 & 35.27 & 1.18 & 19.15 & 0.00 \\
\hline $3 / 4 / 0615: 10$ & 28.06 & & & 1.28 & 24.65 & \\
\hline $3 / 4 / 0615: 20$ & 30.99 & & & 1.05 & 28.26 & \\
\hline $3 / 4 / 0615: 30$ & 30.90 & & & 0.98 & 25.52 & \\
\hline $3 / 4 / 0615: 40$ & 29.39 & & & 0.96 & 24.51 & \\
\hline $3 / 4 / 06 \quad 15: 50$ & 28.18 & & & 0.98 & 23.54 & \\
\hline $3 / 4 / 0616: 00$ & 28.65 & 11.28 & 60.61 & 1.00 & 23.74 & 1.65 \\
\hline $3 / 4 / 0616: 10$ & 27.90 & 12.68 & 54.57 & 1.02 & 23.34 & 2.04 \\
\hline $3 / 4 / 0616: 20$ & 27.57 & 10.74 & 61.03 & 1.01 & 22.07 & 1.75 \\
\hline $3 / 4 / 0616: 30$ & 27.62 & 10.37 & 62.44 & 1.08 & 21.88 & 2.22 \\
\hline $3 / 4 / 0616: 40$ & 26.71 & 9.20 & 65.56 & 1.15 & 23.42 & 1.49 \\
\hline $3 / 4 / 0616: 50$ & 26.39 & 9.76 & 63.03 & 1.17 & 21.50 & 1.30 \\
\hline $3 / 4 / 06 \quad 17: 00$ & 26.95 & 10.10 & 62.52 & 1.17 & 22.15 & 1.34 \\
\hline $3 / 4 / 06 \quad 17: 10$ & 27.19 & 12.52 & 53.95 & 1.13 & 22.38 & 2.61 \\
\hline $3 / 4 / 06 \quad 17: 20$ & 26.96 & 14.23 & 47.21 & 1.12 & 22.65 & 2.09 \\
\hline $3 / 4 / 0617: 30$ & 26.12 & 10.23 & 60.84 & 1.17 & 22.08 & 1.50 \\
\hline $3 / 4 / 06 \quad 17: 40$ & 25.56 & 9.64 & 62.26 & 1.17 & 20.68 & 1.32 \\
\hline
\end{tabular}


Table D1. Corrected CMM and ACI, 10-minute Averaged Data During the Monthlong Field Test (continued)

\begin{tabular}{|c|c|c|c|c|c|c|}
\hline Date, Time & $\begin{array}{c}\text { FF Inlet } \mathrm{HgT}, \\
\mu \mathrm{g} / \mathrm{dNm}^{3}, \\
3 \% \mathrm{O}_{2} \\
\end{array}$ & $\begin{array}{c}\text { FF Outlet HgT, } \\
\mu \mathrm{g} / \mathrm{dNm}^{3}, \\
3 \% \mathrm{O}_{2} \\
\end{array}$ & $\begin{array}{c}\text { HgT Removal } \\
\text { Across } \\
\text { FF 2-4, \% }\end{array}$ & $\begin{array}{c}\text { FF 2-4 Activated } \\
\text { Carbon Injection } \\
\text { Rate, lb/Macf }\end{array}$ & $\begin{array}{c}\text { FF Inlet } \mathrm{Hg}^{0}, \\
\mu \mathrm{g} / \mathrm{dNm}^{3}, \\
3 \% \mathrm{O}_{2} \\
\end{array}$ & $\begin{array}{c}\text { FF Outlet } \mathrm{Hg}^{0}, \\
\mu \mathrm{g} / \mathrm{dNm}^{3}, \\
3 \% \mathrm{O}_{2}\end{array}$ \\
\hline $3 / 4 / 06$ 18:00 & 24.20 & 10.35 & 57.23 & 1.15 & 16.36 & 1.19 \\
\hline $3 / 4 / 0618: 10$ & 26.38 & 11.22 & 57.45 & 1.17 & 20.25 & 1.60 \\
\hline $3 / 4 / 0618: 20$ & 25.85 & 10.95 & 57.64 & 1.13 & 21.69 & 1.70 \\
\hline $3 / 4 / 0618: 30$ & 22.78 & 11.94 & 47.58 & 1.18 & 12.79 & 0.97 \\
\hline $3 / 4 / 0618: 40$ & 23.95 & 12.79 & 46.59 & 1.18 & 14.03 & 0.67 \\
\hline $3 / 4 / 0618: 50$ & 23.72 & 14.93 & 37.05 & 1.20 & 16.49 & 0.88 \\
\hline 3/4/06 19:00 & 24.91 & 17.11 & 31.33 & 1.20 & 20.01 & 1.63 \\
\hline $3 / 4 / 06$ 19:10 & 24.86 & 16.93 & 31.88 & 1.12 & 17.84 & 2.17 \\
\hline $3 / 4 / 06 \quad 19: 20$ & 25.57 & 13.31 & 47.94 & 1.15 & 20.04 & 1.73 \\
\hline $3 / 4 / 0619: 30$ & 24.51 & 13.45 & 45.11 & 1.17 & 18.44 & 2.03 \\
\hline $3 / 4 / 06 \quad 19: 40$ & 23.49 & 15.21 & 35.26 & 1.18 & 15.68 & 2.04 \\
\hline $3 / 4 / 0619: 50$ & 22.71 & 14.37 & 36.71 & 1.19 & 13.22 & 2.27 \\
\hline $3 / 4 / 0620: 00$ & 26.67 & 14.33 & 46.26 & 1.19 & 17.51 & 2.79 \\
\hline $3 / 4 / 0620: 10$ & 25.34 & 14.55 & 42.59 & 1.16 & 15.09 & 1.92 \\
\hline $3 / 4 / 0620: 20$ & 23.96 & 13.03 & 45.62 & 1.15 & 14.97 & 2.29 \\
\hline $3 / 4 / 0620: 30$ & 24.34 & 12.18 & 49.99 & 1.17 & 13.90 & 2.05 \\
\hline $3 / 4 / 0620: 40$ & 24.99 & 12.20 & 51.17 & 1.12 & 14.70 & 2.21 \\
\hline $3 / 4 / 0620: 50$ & 23.74 & 13.84 & 41.69 & 1.12 & 12.48 & 2.55 \\
\hline $3 / 4 / 0621: 00$ & 25.50 & 12.53 & 50.88 & 1.09 & 17.70 & 2.74 \\
\hline $3 / 4 / 0621: 10$ & 25.10 & 10.74 & 57.19 & 1.17 & 14.93 & 1.51 \\
\hline $3 / 4 / 0621: 20$ & 22.92 & 10.69 & 53.37 & 1.16 & 11.16 & 1.34 \\
\hline $3 / 4 / 0621: 30$ & 24.06 & 10.65 & 55.75 & 1.14 & 13.78 & 1.30 \\
\hline $3 / 4 / 0621: 40$ & 23.06 & 10.34 & 55.16 & 1.14 & 11.48 & 1.25 \\
\hline $3 / 4 / 0621: 50$ & 23.05 & 10.05 & 56.39 & 1.16 & 13.61 & 1.27 \\
\hline $3 / 4 / 0622: 00$ & 22.98 & 10.01 & 56.44 & 1.13 & 14.46 & 1.41 \\
\hline $3 / 4 / 0622: 10$ & 22.81 & 11.03 & 51.65 & 1.11 & 18.78 & 1.70 \\
\hline $3 / 4 / 0622: 20$ & 25.81 & 9.57 & 62.90 & 1.12 & 18.04 & 1.67 \\
\hline $3 / 4 / 0622: 30$ & 24.01 & 9.92 & 58.68 & 1.11 & 19.84 & 1.89 \\
\hline $3 / 4 / 0622: 40$ & 23.72 & 8.94 & 62.29 & 1.13 & 19.01 & 1.87 \\
\hline $3 / 4 / 0622: 50$ & 25.32 & 15.01 & 40.69 & 1.07 & 18.34 & 2.29 \\
\hline $3 / 4 / 0623: 00$ & 25.42 & 14.89 & 41.45 & 1.02 & 20.00 & 1.79 \\
\hline $3 / 4 / 0623: 10$ & 24.77 & 12.58 & 49.22 & 1.10 & 16.73 & 2.13 \\
\hline $3 / 4 / 0623: 20$ & 26.11 & 14.03 & 46.26 & 1.04 & 18.18 & 2.29 \\
\hline $3 / 4 / 0623: 30$ & 25.77 & 14.60 & 43.34 & 1.09 & 17.31 & 2.29 \\
\hline $3 / 4 / 0623: 40$ & 23.46 & 25.95 & 0 & 1.06 & 11.82 & 0.00 \\
\hline $3 / 4 / 0623: 50$ & 24.77 & 17.04 & 31.21 & 1.06 & 16.57 & 0.00 \\
\hline 3/5/06 0:00 & 24.41 & 14.36 & 41.17 & 1.07 & 15.76 & 0.00 \\
\hline $3 / 5 / 060: 10$ & 25.74 & 18.27 & 29.03 & 1.02 & 17.89 & 0.00 \\
\hline 3/5/06 0:20 & 25.46 & 14.67 & 42.37 & 1.02 & 18.07 & 0.00 \\
\hline $3 / 5 / 060: 30$ & 24.19 & 13.18 & 45.51 & 1.13 & 12.24 & 0.00 \\
\hline $3 / 5 / 060: 40$ & 23.33 & 13.75 & 41.06 & 1.14 & 12.21 & 0.00 \\
\hline $3 / 5 / 060: 50$ & 23.83 & 12.31 & 48.33 & 1.05 & 14.73 & 0.00 \\
\hline 3/5/06 1:00 & 25.99 & 12.89 & 50.41 & 1.05 & 17.85 & 0.00 \\
\hline $3 / 5 / 061: 10$ & 25.45 & 11.92 & 53.15 & 1.12 & 16.18 & 0.00 \\
\hline 3/5/06 1:20 & 26.18 & 16.37 & 37.46 & 1.04 & 16.80 & 0.00 \\
\hline $3 / 5 / 061: 30$ & 25.89 & 11.78 & 54.50 & 1.05 & 18.81 & 0.00 \\
\hline $3 / 5 / 061: 40$ & 25.88 & 11.85 & 54.23 & 1.10 & 18.05 & 0.00 \\
\hline $3 / 5 / 061: 50$ & 26.68 & 11.52 & 56.82 & 1.08 & 17.79 & 0.13 \\
\hline $3 / 5 / 062: 00$ & 24.99 & 11.57 & 53.69 & 1.20 & 14.68 & 0.21 \\
\hline $3 / 5 / 062: 10$ & 24.43 & 12.18 & 50.13 & 1.10 & 16.13 & \\
\hline $3 / 5 / 062: 20$ & 26.14 & 13.94 & 46.67 & 1.04 & 16.49 & \\
\hline $3 / 5 / 062: 30$ & 25.11 & 11.55 & 54.00 & 1.01 & 18.77 & 0.13 \\
\hline
\end{tabular}


Table D1. Corrected CMM and ACI, 10-minute Averaged Data During the Monthlong Field Test (continued)

\begin{tabular}{|c|c|c|c|c|c|c|}
\hline Date, Time & $\begin{array}{c}\text { FF Inlet } \mathrm{HgT}, \\
\mu \mathrm{g} / \mathrm{dNm}^{3}, \\
3 \% \mathrm{O}_{2} \\
\end{array}$ & $\begin{array}{c}\text { FF Outlet HgT, } \\
\mu \mathrm{g} / \mathrm{dNm}^{3}, \\
3 \% \mathrm{O}_{2} \\
\end{array}$ & $\begin{array}{c}\text { HgT Removal } \\
\text { Across } \\
\text { FF } 2-4, \% \\
\end{array}$ & $\begin{array}{c}\text { FF 2-4 Activated } \\
\text { Carbon Injection } \\
\text { Rate, lb/Macf }\end{array}$ & $\begin{array}{c}\text { FF Inlet } \mathrm{Hg}^{0}, \\
\mu \mathrm{g} / \mathrm{dNm}^{3}, \\
3 \% \mathrm{O}_{2} \\
\end{array}$ & $\begin{array}{c}\text { FF Outlet } \mathrm{Hg}^{0}, \\
\mu \mathrm{g} / \mathrm{dNm}^{3}, \\
3 \% \mathrm{O}_{2}\end{array}$ \\
\hline $3 / 5 / 062: 50$ & 26.61 & 12.57 & 52.78 & 1.11 & 19.85 & 0.46 \\
\hline $3 / 5 / 063: 00$ & 26.54 & 10.48 & 60.53 & 1.04 & 20.12 & 0.54 \\
\hline $3 / 5 / 063: 10$ & 25.94 & 9.25 & 64.34 & 1.06 & 20.08 & 0.13 \\
\hline $3 / 5 / 063: 20$ & 25.53 & 8.60 & 66.32 & 1.07 & 18.87 & 0.13 \\
\hline $3 / 5 / 063: 30$ & 25.85 & 14.33 & 44.56 & 1.04 & 20.17 & 0.23 \\
\hline $3 / 5 / 063: 40$ & 26.61 & 9.77 & 63.28 & 1.02 & 20.03 & 0.27 \\
\hline $3 / 5 / 063: 50$ & 26.63 & 9.04 & 66.05 & 1.04 & 20.47 & 0.27 \\
\hline $3 / 5 / 064: 00$ & 26.08 & 10.00 & 61.67 & 1.07 & 20.09 & 0.22 \\
\hline $3 / 5 / 064: 10$ & 25.87 & 9.09 & 64.88 & 1.09 & 18.61 & 0.00 \\
\hline $3 / 5 / 064: 20$ & 25.82 & 10.20 & 60.51 & 1.02 & 19.99 & 0.00 \\
\hline $3 / 5 / 064: 30$ & 26.06 & 9.57 & 63.29 & 1.01 & 20.47 & 0.00 \\
\hline $3 / 5 / 064: 40$ & 26.45 & 10.54 & 60.16 & 1.03 & 20.09 & 0.00 \\
\hline $3 / 5 / 064: 50$ & 26.64 & 9.48 & 64.40 & 1.03 & 19.92 & 0.00 \\
\hline $3 / 5 / 065: 00$ & 26.10 & 9.53 & 63.50 & 1.04 & 20.25 & 0.00 \\
\hline $3 / 5 / 065: 10$ & 26.47 & 9.60 & 63.72 & 1.03 & 19.90 & 0.00 \\
\hline $3 / 5 / 065: 20$ & 26.54 & 10.15 & 61.75 & 1.07 & 20.20 & 0.00 \\
\hline $3 / 5 / 065: 30$ & 26.44 & 10.52 & 60.23 & 1.05 & 20.35 & 0.00 \\
\hline $3 / 5 / 065: 40$ & 26.32 & 9.51 & 63.87 & 1.04 & 20.11 & 0.00 \\
\hline $3 / 5 / 065: 50$ & 27.02 & 9.90 & 63.36 & 1.03 & 19.73 & 0.00 \\
\hline $3 / 5 / 066: 00$ & 26.89 & 9.77 & 63.68 & 0.92 & 20.44 & 0.00 \\
\hline $3 / 5 / 066: 10$ & 27.62 & 11.20 & 59.44 & 0.91 & 20.23 & 0.00 \\
\hline $3 / 5 / 066: 20$ & 28.61 & 12.08 & 57.78 & 0.92 & 19.33 & \\
\hline $3 / 5 / 066: 30$ & 26.87 & 13.28 & 50.59 & 0.90 & 18.84 & 0.14 \\
\hline $3 / 5 / 066: 40$ & 26.88 & 13.96 & 48.07 & 0.92 & 18.76 & 0.14 \\
\hline $3 / 5 / 066: 50$ & 27.65 & 16.08 & 41.85 & 0.90 & 19.46 & 0.15 \\
\hline $3 / 5 / 06$ 7:00 & 27.07 & 12.13 & 55.19 & 0.91 & 19.23 & 0.13 \\
\hline $3 / 5 / 067: 10$ & 27.50 & 12.05 & 56.17 & 0.91 & 18.98 & 0.00 \\
\hline $3 / 5 / 067: 20$ & 27.19 & 11.41 & 58.04 & 0.91 & 18.92 & \\
\hline $3 / 5 / 067: 30$ & 27.31 & 12.50 & 54.24 & 0.91 & 19.50 & \\
\hline $3 / 5 / 067: 40$ & 27.41 & & & 0.91 & 19.88 & \\
\hline $3 / 5 / 067: 50$ & 26.81 & & & 0.93 & 19.52 & \\
\hline $3 / 5 / 068: 00$ & 28.70 & 11.60 & 59.59 & 0.94 & 19.90 & 2.58 \\
\hline $3 / 5 / 068: 10$ & 24.95 & 12.10 & 51.50 & 1.11 & 18.10 & 2.31 \\
\hline $3 / 5 / 068: 20$ & 23.37 & 10.31 & 55.88 & 1.19 & 14.86 & 2.20 \\
\hline $3 / 5 / 068: 30$ & 22.94 & 13.04 & 43.15 & 1.20 & 12.81 & 2.12 \\
\hline $3 / 5 / 068: 40$ & 21.24 & 13.42 & 36.79 & 1.24 & 8.96 & 2.12 \\
\hline $3 / 5 / 068: 50$ & 22.23 & & & 1.23 & 11.05 & \\
\hline $3 / 5 / 069: 00$ & 21.47 & & & 1.23 & 11.23 & \\
\hline $3 / 5 / 069: 10$ & 21.35 & & & 1.18 & 3.50 & \\
\hline $3 / 5 / 069: 20$ & 21.67 & & & 1.19 & 10.50 & \\
\hline $3 / 5 / 069: 30$ & 20.09 & & & 1.21 & 6.72 & \\
\hline $3 / 5 / 069: 40$ & & & & 1.16 & & \\
\hline 3/5/06 9:50 & & 10.83 & & 1.22 & & 3.93 \\
\hline $3 / 5 / 06$ 10:00 & & 10.88 & & 1.15 & & 3.22 \\
\hline $3 / 5 / 0610: 10$ & & 10.64 & & 1.18 & & 2.79 \\
\hline $3 / 5 / 06 \quad 10: 20$ & & 9.75 & & 1.19 & & 2.34 \\
\hline $3 / 5 / 0610: 30$ & 33.79 & 12.71 & 62.39 & 1.17 & 18.02 & 3.12 \\
\hline $3 / 5 / 0610: 40$ & 29.30 & 14.80 & 49.49 & 1.16 & 15.17 & 2.23 \\
\hline $3 / 5 / 0610: 50$ & 26.77 & 15.05 & 43.77 & 1.16 & 14.08 & 1.70 \\
\hline 3/5/06 11:00 & 28.55 & 13.86 & 51.46 & 1.18 & 16.37 & 1.59 \\
\hline $3 / 5 / 0611: 10$ & 27.10 & 12.86 & 52.55 & 1.16 & 19.48 & 2.77 \\
\hline $3 / 5 / 0611: 20$ & 27.57 & 12.84 & 53.43 & 1.14 & 20.99 & 2.95 \\
\hline
\end{tabular}


Table D1. Corrected CMM and ACI, 10-minute Averaged Data During the Monthlong Field Test (continued)

\begin{tabular}{|c|c|c|c|c|c|c|}
\hline Date, Time & $\begin{array}{c}\text { FF Inlet } \mathrm{HgT}, \\
\mu \mathrm{g} / \mathrm{dNm}^{3}, \\
3 \% \mathrm{O}_{2} \\
\end{array}$ & $\begin{array}{c}\text { FF Outlet HgT, } \\
\mu \mathrm{g} / \mathrm{dNm}^{3}, \\
3 \% \mathrm{O}_{2}\end{array}$ & $\begin{array}{c}\text { HgT Removal } \\
\text { Across } \\
\text { FF 2-4, \% }\end{array}$ & $\begin{array}{c}\text { FF 2-4 Activated } \\
\text { Carbon Injection } \\
\text { Rate, lb/Macf }\end{array}$ & $\begin{array}{c}\text { FF Inlet } \mathrm{Hg}^{0}, \\
\mu \mathrm{g} / \mathrm{dNm}^{3}, \\
3 \% \mathrm{O}_{2} \\
\end{array}$ & $\begin{array}{c}\text { FF Outlet } \mathrm{Hg}^{0}, \\
\mu \mathrm{g} / \mathrm{dNm}^{3}, \\
3 \% \mathrm{O}_{2}\end{array}$ \\
\hline 3/5/06 11:40 & 28.65 & 12.12 & 57.70 & 1.12 & 21.84 & 2.81 \\
\hline $3 / 5 / 0611: 50$ & 29.75 & 13.10 & 55.98 & 1.13 & 21.69 & 2.87 \\
\hline $3 / 5 / 0612: 00$ & 28.89 & 12.09 & 58.16 & 1.15 & 20.44 & 2.63 \\
\hline $3 / 5 / 0612: 10$ & 28.42 & 12.75 & 55.15 & 1.15 & 19.27 & 2.22 \\
\hline $3 / 5 / 0612: 20$ & 28.99 & 13.90 & 52.05 & 1.18 & 19.34 & 2.08 \\
\hline $3 / 5 / 0612: 30$ & 28.97 & 14.45 & 50.13 & 1.17 & 17.91 & 1.77 \\
\hline $3 / 5 / 0612: 40$ & 30.23 & 16.15 & 46.57 & 1.14 & 16.19 & 1.42 \\
\hline $3 / 5 / 0612: 50$ & 30.14 & 15.65 & 48.08 & 1.14 & 14.57 & 1.07 \\
\hline 3/5/06 13:00 & 29.95 & 16.55 & 44.75 & 1.16 & 14.18 & 1.03 \\
\hline $3 / 5 / 06$ 13:10 & 30.67 & 17.37 & 43.34 & 1.20 & 17.39 & 2.44 \\
\hline $3 / 5 / 0613: 20$ & 32.73 & 27.01 & 17.46 & 0.06 & 22.37 & 4.83 \\
\hline $3 / 5 / 0613: 30$ & 31.81 & 39.67 & 0 & 0.00 & 22.04 & 7.95 \\
\hline $3 / 5 / 06 \quad 13: 40$ & 29.28 & 41.99 & 0 & 0.00 & 18.53 & 5.82 \\
\hline $3 / 5 / 0613: 50$ & 29.95 & 41.70 & 0 & 0.00 & 19.13 & 6.19 \\
\hline $3 / 5 / 0614: 00$ & 28.37 & 38.41 & 0 & 0.00 & 14.47 & 3.84 \\
\hline $3 / 5 / 0614: 10$ & 29.70 & 38.12 & 0 & 0.00 & 19.19 & 6.37 \\
\hline $3 / 5 / 0614: 20$ & 29.68 & 40.09 & 0 & 0.00 & 22.02 & 10.52 \\
\hline $3 / 5 / 0614: 30$ & 29.93 & 39.09 & 0 & 0.00 & 21.57 & 9.87 \\
\hline $3 / 5 / 0614: 40$ & 28.90 & 37.78 & 0 & 0.00 & 17.55 & 6.40 \\
\hline $3 / 5 / 0614: 50$ & 28.03 & 36.68 & 0 & 0.00 & 18.00 & 7.02 \\
\hline 3/5/06 15:00 & 29.07 & 35.74 & 0 & 0.00 & 18.08 & 6.10 \\
\hline $3 / 5 / 0615: 10$ & 28.97 & 36.15 & 0 & 0.00 & 13.03 & 4.90 \\
\hline $3 / 5 / 06 \quad 15: 20$ & 33.22 & 34.62 & 0 & 0.00 & 22.63 & 6.01 \\
\hline $3 / 5 / 0615: 30$ & 30.16 & 34.48 & 0 & 0.00 & 17.65 & 4.65 \\
\hline $3 / 5 / 06 \quad 15: 40$ & 32.31 & 32.23 & 0.27 & 1.19 & 23.75 & 5.92 \\
\hline $3 / 5 / 0615: 50$ & 35.28 & 26.25 & 25.59 & 1.17 & 24.02 & 4.19 \\
\hline $3 / 5 / 06$ 16:00 & 32.68 & 28.58 & 12.56 & 0.05 & 24.44 & 5.30 \\
\hline $3 / 5 / 0616: 10$ & 31.33 & 41.61 & 0 & 0.00 & 25.36 & 12.27 \\
\hline $3 / 5 / 06$ 16:20 & 30.58 & 40.41 & 0 & 0.00 & 23.50 & 12.50 \\
\hline $3 / 5 / 0616: 30$ & 31.40 & 40.48 & 0 & 0.00 & 23.48 & 12.93 \\
\hline $3 / 5 / 06$ 16:40 & 29.74 & 39.67 & 0 & 0.00 & 22.05 & 11.74 \\
\hline $3 / 5 / 0616: 50$ & 29.85 & 39.07 & 0 & 0.00 & 21.90 & 13.50 \\
\hline $3 / 5 / 06$ 17:00 & 32.29 & 38.73 & 0 & 0.14 & 20.87 & 10.04 \\
\hline $3 / 5 / 06$ 17:10 & 31.36 & 28.88 & 7.93 & 1.02 & 22.20 & 5.38 \\
\hline $3 / 5 / 06 \quad 17: 20$ & 30.81 & 22.98 & 25.41 & 1.03 & 22.79 & 6.62 \\
\hline $3 / 5 / 06 \quad 17: 30$ & 29.80 & 20.05 & 32.71 & 1.06 & 22.49 & 6.24 \\
\hline $3 / 5 / 06 \quad 17: 40$ & 29.10 & 16.02 & 44.97 & 1.06 & 20.43 & 4.50 \\
\hline $3 / 5 / 06$ 17:50 & 29.86 & 14.77 & 50.54 & 1.12 & 19.90 & 4.22 \\
\hline 3/5/06 18:00 & 27.61 & 15.13 & 45.20 & 1.09 & 18.05 & 4.06 \\
\hline $3 / 5 / 0618: 10$ & 27.77 & 14.36 & 48.28 & 1.08 & 17.70 & 2.63 \\
\hline $3 / 5 / 06$ 18:20 & 30.32 & 14.94 & 50.74 & 0.99 & 23.06 & 3.83 \\
\hline $3 / 5 / 0618: 30$ & 29.92 & 17.35 & 42.02 & 1.10 & 20.90 & 3.34 \\
\hline $3 / 5 / 06$ 18:40 & 26.66 & 16.77 & 37.07 & 1.10 & 18.42 & 3.86 \\
\hline $3 / 5 / 0618: 50$ & 25.02 & 22.38 & 10.55 & 1.15 & 16.06 & 2.55 \\
\hline 3/5/06 19:00 & 24.45 & 21.15 & 13.50 & 1.19 & 9.42 & 1.30 \\
\hline $3 / 5 / 0619: 10$ & 25.22 & 20.51 & 18.67 & 0.79 & 14.30 & 2.16 \\
\hline $3 / 5 / 0619: 20$ & 23.62 & 28.02 & 0 & 0.00 & 12.25 & 2.70 \\
\hline $3 / 5 / 0619: 30$ & 24.31 & 32.42 & 0 & 0.00 & 10.69 & 3.33 \\
\hline 3/5/06 19:40 & 23.67 & 30.99 & 0 & 0.00 & 12.57 & 3.23 \\
\hline $3 / 5 / 0619: 50$ & 23.00 & 30.54 & 0 & 0.00 & 12.64 & 3.49 \\
\hline 3/5/06 20:00 & 22.46 & 32.13 & 0 & 0.00 & 10.50 & 3.27 \\
\hline $3 / 5 / 0620: 10$ & 23.38 & 28.47 & 0 & 0.00 & 10.56 & 3.97 \\
\hline
\end{tabular}


Table D1. Corrected CMM and ACI, 10-minute Averaged Data During the Monthlong Field Test (continued)

\begin{tabular}{|c|c|c|c|c|c|c|}
\hline Date, Time & $\begin{array}{c}\text { FF Inlet } \mathrm{HgT}, \\
\mu \mathrm{g} / \mathrm{dNm}^{3}, \\
3 \% \mathrm{O}_{2} \\
\end{array}$ & $\begin{array}{c}\text { FF Outlet HgT, } \\
\mu \mathrm{g} / \mathrm{dNm}^{3}, \\
3 \% \mathrm{O}_{2}\end{array}$ & $\begin{array}{c}\text { HgT Removal } \\
\text { Across } \\
\text { FF } 2-4, \% \\
\end{array}$ & $\begin{array}{c}\text { FF 2-4 Activated } \\
\text { Carbon Injection } \\
\text { Rate, lb/Macf }\end{array}$ & $\begin{array}{c}\text { FF Inlet } \mathrm{Hg}^{0}, \\
\mu \mathrm{g} / \mathrm{dNm}^{3}, \\
3 \% \mathrm{O}_{2} \\
\end{array}$ & $\begin{array}{c}\text { FF Outlet } \mathrm{Hg}^{0}, \\
\mu \mathrm{g} / \mathrm{dNm}^{3}, \\
3 \% \mathrm{O}_{2}\end{array}$ \\
\hline $3 / 5 / 0620: 20$ & 21.61 & 31.59 & 0 & 0.00 & 10.16 & 3.56 \\
\hline $3 / 5 / 0620: 30$ & 21.47 & 27.94 & 0 & 0.00 & 9.18 & 3.59 \\
\hline $3 / 5 / 0620: 40$ & 21.61 & 28.32 & 0 & 0.00 & 11.63 & 3.65 \\
\hline $3 / 5 / 0620: 50$ & 21.86 & 28.75 & 0 & 0.00 & 14.04 & 3.71 \\
\hline $3 / 5 / 0621: 00$ & 25.87 & 24.78 & 4.23 & 0.00 & 13.21 & 3.37 \\
\hline $3 / 5 / 0621: 10$ & 21.98 & 25.97 & 0 & 0.00 & 12.44 & 3.13 \\
\hline $3 / 5 / 0621: 20$ & 23.05 & 25.29 & 0 & 0.00 & 17.76 & 6.27 \\
\hline $3 / 5 / 0621: 30$ & 23.88 & 24.42 & 0 & 0.00 & 17.92 & 7.30 \\
\hline $3 / 5 / 0621: 40$ & 25.74 & 25.65 & 0.35 & 0.00 & 13.13 & 3.75 \\
\hline $3 / 5 / 0621: 50$ & 22.70 & 26.90 & 0 & 0.00 & 11.55 & 3.32 \\
\hline $3 / 5 / 0622: 00$ & 21.75 & 24.82 & 0 & 0.00 & 11.79 & 3.69 \\
\hline $3 / 5 / 0622: 10$ & 23.51 & 24.40 & 0 & 0.00 & 16.45 & 6.76 \\
\hline $3 / 5 / 0622: 20$ & 24.28 & 24.19 & 0.38 & 0.00 & 17.45 & 8.97 \\
\hline $3 / 5 / 0622: 30$ & 25.01 & 28.63 & 0 & 0.00 & 14.89 & 5.83 \\
\hline $3 / 5 / 0622: 40$ & 23.80 & 23.63 & 0.70 & 0.00 & 16.43 & 7.48 \\
\hline $3 / 5 / 0622: 50$ & 25.39 & 24.20 & 4.68 & 0.00 & 17.97 & 10.46 \\
\hline $3 / 5 / 0623: 00$ & 23.89 & 23.91 & 0 & 0.00 & 17.45 & 9.69 \\
\hline $3 / 5 / 0623: 10$ & 24.53 & 23.62 & 3.70 & 0.00 & 17.75 & 10.26 \\
\hline $3 / 5 / 0623: 20$ & 23.96 & 24.05 & 0 & 0.00 & 19.24 & 11.98 \\
\hline $3 / 5 / 0623: 30$ & 24.99 & 23.43 & 6.22 & 0.00 & 18.40 & 11.63 \\
\hline $3 / 5 / 0623: 40$ & 24.20 & 23.84 & 1.48 & 0.00 & 18.67 & 11.49 \\
\hline $3 / 5 / 0623: 50$ & 24.13 & 24.11 & 0.12 & 0.00 & 19.37 & 12.50 \\
\hline 3/6/06 0:00 & 24.97 & 23.59 & 5.55 & 0.00 & 19.47 & 12.96 \\
\hline $3 / 6 / 060: 10$ & 23.87 & 24.21 & 0 & 0.00 & 18.48 & 10.63 \\
\hline 3/6/06 0:20 & 25.61 & 27.59 & 0 & 0.00 & 18.72 & 11.11 \\
\hline $3 / 6 / 060: 30$ & 25.30 & 25.60 & 0 & 0.00 & 18.39 & 10.79 \\
\hline $3 / 6 / 060: 40$ & 24.45 & 27.27 & 0 & 0.00 & 18.95 & 12.08 \\
\hline $3 / 6 / 060: 50$ & 26.48 & 27.17 & 0 & 0.00 & 19.08 & 11.96 \\
\hline $3 / 6 / 061: 00$ & 24.59 & 26.57 & 0 & 0.00 & 18.05 & 9.78 \\
\hline $3 / 6 / 061: 10$ & 25.77 & 27.04 & 0 & 0.00 & 16.49 & 7.66 \\
\hline $3 / 6 / 061: 20$ & 25.11 & 26.65 & 0 & 0.00 & 18.45 & 10.71 \\
\hline $3 / 6 / 061: 30$ & 25.38 & 26.60 & 0 & 0.00 & 18.86 & 10.83 \\
\hline $3 / 6 / 061: 40$ & 26.91 & 25.83 & 4.02 & 0.00 & 20.41 & 12.22 \\
\hline $3 / 6 / 061: 50$ & 25.85 & 25.99 & 0 & 0.00 & 20.93 & 13.72 \\
\hline $3 / 6 / 062: 00$ & 26.31 & 25.12 & 4.51 & 0.00 & 21.13 & 12.90 \\
\hline $3 / 6 / 062: 10$ & 26.11 & 25.33 & 3.01 & 0.00 & 20.18 & 12.41 \\
\hline $3 / 6 / 062: 20$ & 26.60 & 24.59 & 7.55 & 0.00 & 19.96 & 12.34 \\
\hline $3 / 6 / 062: 30$ & 26.10 & 24.78 & 5.05 & 0.00 & 18.68 & 10.36 \\
\hline $3 / 6 / 062: 40$ & 25.08 & 26.22 & 0 & 0.00 & 18.55 & 9.76 \\
\hline $3 / 6 / 062: 50$ & 26.71 & 27.44 & 0 & 0.00 & 16.64 & 7.03 \\
\hline $3 / 6 / 063: 00$ & 25.47 & 27.65 & 0 & 0.00 & 19.10 & 12.12 \\
\hline $3 / 6 / 063: 10$ & 24.96 & 27.27 & 0 & 0.00 & 17.71 & 9.61 \\
\hline $3 / 6 / 063: 20$ & 25.89 & 25.69 & 0.76 & 0.00 & 19.77 & 12.66 \\
\hline $3 / 6 / 063: 30$ & 27.32 & 26.25 & 3.93 & 0.00 & 18.93 & 11.26 \\
\hline $3 / 6 / 063: 40$ & 25.85 & 26.69 & 0 & 0.00 & 19.30 & 11.79 \\
\hline $3 / 6 / 063: 50$ & 25.53 & 25.13 & 1.55 & 0.00 & 19.74 & 12.22 \\
\hline $3 / 6 / 064: 00$ & 26.20 & 25.04 & 4.42 & 0.00 & 19.98 & 12.08 \\
\hline $3 / 6 / 064: 10$ & 25.64 & 24.35 & 5.01 & 0.00 & 19.54 & 11.67 \\
\hline $3 / 6 / 064: 20$ & 25.70 & 24.69 & 3.94 & 0.00 & 19.69 & 12.28 \\
\hline $3 / 6 / 064: 30$ & 25.30 & 24.05 & 4.95 & 0.00 & 19.66 & 12.05 \\
\hline $3 / 6 / 064: 40$ & 26.59 & 24.94 & 6.18 & 0.00 & 19.41 & 12.75 \\
\hline $3 / 6 / 064: 50$ & 25.67 & 24.52 & 4.46 & 0.00 & 19.64 & 12.94 \\
\hline
\end{tabular}


Table D1. Corrected CMM and ACI, 10-minute Averaged Data During the Monthlong Field Test (continued)

\begin{tabular}{|c|c|c|c|c|c|c|}
\hline Date, Time & $\begin{array}{c}\text { FF Inlet } \mathrm{HgT}, \\
\mu \mathrm{g} / \mathrm{dNm}^{3}, \\
3 \% \mathrm{O}_{2} \\
\end{array}$ & $\begin{array}{c}\text { FF Outlet HgT, } \\
\mu \mathrm{g} / \mathrm{dNm}^{3}, \\
3 \% \mathrm{O}_{2} \\
\end{array}$ & $\begin{array}{c}\text { HgT Removal } \\
\text { Across } \\
\text { FF 2-4, \% }\end{array}$ & $\begin{array}{c}\text { FF 2-4 Activated } \\
\text { Carbon Injection } \\
\text { Rate, lb/Macf }\end{array}$ & $\begin{array}{c}\text { FF Inlet } \mathrm{Hg}^{0}, \\
\mu \mathrm{g} / \mathrm{dNm}^{3}, \\
3 \% \mathrm{O}_{2} \\
\end{array}$ & $\begin{array}{c}\text { FF Outlet } \mathrm{Hg}^{0}, \\
\mu \mathrm{g} / \mathrm{dNm}^{3}, \\
3 \% \mathrm{O}_{2}\end{array}$ \\
\hline $3 / 6 / 065: 00$ & 25.80 & 24.09 & 6.61 & 0.00 & 18.93 & 12.57 \\
\hline $3 / 6 / 065: 10$ & 24.38 & 24.74 & 0 & 0.00 & 17.57 & 11.16 \\
\hline $3 / 6 / 065: 20$ & 24.62 & 24.95 & 0 & 0.00 & 17.45 & 10.63 \\
\hline $3 / 6 / 065: 30$ & 26.52 & 26.58 & 0 & 0.00 & 19.30 & 12.07 \\
\hline $3 / 6 / 065: 40$ & 24.78 & 23.97 & 3.30 & 0.00 & 19.96 & 11.85 \\
\hline $3 / 6 / 065: 50$ & 27.26 & 23.28 & 14.59 & 0.00 & 20.77 & 12.30 \\
\hline $3 / 6 / 066: 00$ & 25.31 & 22.90 & 9.52 & 0.00 & 20.55 & 12.31 \\
\hline $3 / 6 / 066: 10$ & 24.87 & 22.36 & 10.08 & 0.00 & 19.53 & 10.60 \\
\hline $3 / 6 / 06$ 6:20 & 25.09 & 23.15 & 7.72 & 0.00 & 19.41 & 10.36 \\
\hline $3 / 6 / 066: 30$ & 25.17 & 23.93 & 4.93 & 0.00 & 19.11 & 10.48 \\
\hline $3 / 6 / 066: 40$ & 25.54 & 23.16 & 9.34 & 0.00 & 19.72 & 11.49 \\
\hline $3 / 6 / 066: 50$ & 26.30 & 23.50 & 10.64 & 0.00 & 20.32 & 11.47 \\
\hline 3/6/06 7:00 & 25.57 & 23.01 & 10.05 & 0.00 & 20.40 & 11.11 \\
\hline $3 / 6 / 067: 10$ & 25.89 & 23.76 & 8.25 & 0.00 & 20.22 & 10.70 \\
\hline $3 / 6 / 067: 20$ & 26.29 & 24.33 & 7.48 & 0.00 & 19.75 & 11.40 \\
\hline $3 / 6 / 067: 30$ & 26.50 & 24.10 & 9.08 & 0.00 & 19.88 & 11.39 \\
\hline $3 / 6 / 067: 40$ & 26.96 & 24.62 & 8.67 & 0.23 & 18.92 & 9.55 \\
\hline $3 / 6 / 067: 50$ & 26.16 & 17.70 & 32.33 & 1.03 & 17.14 & 5.13 \\
\hline 3/6/06 8:00 & 25.47 & 13.49 & 47.03 & 1.03 & 16.54 & 3.36 \\
\hline $3 / 6 / 068: 10$ & 24.31 & 11.09 & 54.40 & 1.10 & 16.00 & 2.65 \\
\hline $3 / 6 / 068: 20$ & 21.95 & 10.46 & 52.35 & 1.13 & 8.94 & 1.07 \\
\hline $3 / 6 / 068: 30$ & 20.27 & 8.41 & 58.49 & 1.13 & 6.76 & 0.90 \\
\hline $3 / 6 / 068: 40$ & 21.53 & 9.76 & 54.68 & 1.13 & 9.95 & 1.01 \\
\hline $3 / 6 / 068: 50$ & 21.75 & 8.61 & 60.39 & 1.14 & 10.02 & 1.04 \\
\hline $3 / 6 / 06$ 9:00 & 21.18 & 9.01 & 57.43 & 1.14 & 7.21 & 0.99 \\
\hline $3 / 6 / 06$ 9:10 & 21.52 & 9.24 & 57.08 & 1.15 & 9.89 & 0.99 \\
\hline $3 / 6 / 06$ 9:20 & 23.37 & 9.94 & 57.48 & 1.05 & 10.96 & 0.84 \\
\hline $3 / 6 / 069: 30$ & 23.09 & 9.06 & 60.78 & 1.02 & 17.64 & 1.40 \\
\hline $3 / 6 / 069: 40$ & 23.35 & 8.96 & 61.62 & 1.03 & 16.94 & 1.57 \\
\hline 3/6/06 9:50 & 24.84 & 9.02 & 63.69 & 1.05 & 16.53 & 1.60 \\
\hline 3/6/06 10:00 & 25.74 & 10.35 & 59.79 & 1.06 & 16.86 & 1.81 \\
\hline 3/6/06 10:10 & 22.80 & 9.36 & 58.94 & 1.22 & 11.46 & 1.60 \\
\hline $3 / 6 / 0610: 20$ & 19.21 & 9.37 & 51.23 & 1.21 & 2.57 & 0.91 \\
\hline $3 / 6 / 0610: 30$ & 21.36 & 11.09 & 48.08 & 1.15 & 7.46 & 1.22 \\
\hline $3 / 6 / 0610: 40$ & 21.36 & 12.09 & 43.40 & 1.16 & 8.34 & 1.20 \\
\hline 3/6/06 10:50 & 22.46 & 12.40 & 44.79 & 1.12 & 9.89 & 1.06 \\
\hline 3/6/06 11:00 & 24.33 & 12.53 & 48.48 & 1.14 & 9.84 & 0.80 \\
\hline $3 / 6 / 0611: 10$ & 21.47 & 13.72 & 36.07 & 1.12 & 9.84 & 1.56 \\
\hline $3 / 6 / 0611: 20$ & 23.90 & 16.12 & 32.57 & 1.12 & 14.03 & 1.58 \\
\hline $3 / 6 / 0611: 30$ & 24.26 & 11.64 & 52.00 & 1.10 & 12.18 & 1.05 \\
\hline $3 / 6 / 0611: 40$ & 27.04 & 12.80 & 52.66 & 1.12 & 15.31 & 1.16 \\
\hline $3 / 6 / 0611: 50$ & 33.64 & 14.07 & 58.16 & 1.12 & 17.19 & 1.29 \\
\hline $3 / 6 / 0612: 00$ & 35.74 & 16.14 & 54.82 & 1.10 & 15.27 & 1.06 \\
\hline $3 / 6 / 0612: 10$ & 27.79 & 14.60 & 47.46 & 1.17 & 9.69 & 1.58 \\
\hline $3 / 6 / 06 \quad 12: 20$ & 25.55 & 13.50 & 47.15 & 1.13 & 3.03 & 1.28 \\
\hline $3 / 6 / 0612: 30$ & 24.67 & 12.05 & 51.14 & 1.14 & 2.94 & 0.88 \\
\hline $3 / 6 / 0612: 40$ & 24.99 & 15.39 & 38.40 & 1.17 & 3.67 & 1.29 \\
\hline $3 / 6 / 0612: 50$ & 29.88 & 12.15 & 59.34 & 1.17 & 2.25 & 0.47 \\
\hline 3/6/06 13:00 & 23.45 & 11.28 & 51.89 & 1.17 & 2.50 & 0.61 \\
\hline $3 / 6 / 0613: 10$ & 23.36 & 25.53 & 0 & 1.18 & 3.11 & 1.52 \\
\hline $3 / 6 / 0613: 20$ & 23.93 & 13.77 & 42.45 & 1.16 & 3.04 & 0.90 \\
\hline $3 / 6 / 0613: 30$ & 25.05 & 13.09 & 47.74 & 1.15 & 3.29 & 1.00 \\
\hline
\end{tabular}


Table D1. Corrected CMM and ACI, 10-minute Averaged Data During the Monthlong Field Test (continued)

\begin{tabular}{|c|c|c|c|c|c|c|}
\hline Date, Time & $\begin{array}{c}\text { FF Inlet } \mathrm{HgT}, \\
\mu \mathrm{g} / \mathrm{dNm}^{3}, \\
3 \% \mathrm{O}_{2} \\
\end{array}$ & $\begin{array}{c}\text { FF Outlet HgT, } \\
\mu \mathrm{g} / \mathrm{dNm}^{3}, \\
3 \% \mathrm{O}_{2}\end{array}$ & $\begin{array}{c}\text { HgT Removal } \\
\text { Across } \\
\text { FF } 2-4, \% \\
\end{array}$ & $\begin{array}{c}\text { FF 2-4 Activated } \\
\text { Carbon Injection } \\
\text { Rate, lb/Macf }\end{array}$ & $\begin{array}{c}\text { FF Inlet } \mathrm{Hg}^{0}, \\
\mu \mathrm{g} / \mathrm{dNm}^{3}, \\
3 \% \mathrm{O}_{2} \\
\end{array}$ & $\begin{array}{c}\text { FF Outlet } \mathrm{Hg}^{0}, \\
\mu \mathrm{g} / \mathrm{dNm}^{3}, \\
3 \% \mathrm{O}_{2}\end{array}$ \\
\hline 3/6/06 13:40 & 27.04 & 11.33 & 58.08 & 1.14 & 3.16 & 0.59 \\
\hline $3 / 6 / 0613: 50$ & 25.55 & 10.51 & 58.87 & 1.16 & 2.51 & 0.29 \\
\hline $3 / 6 / 0614: 00$ & 23.85 & 10.88 & 54.39 & 1.22 & 2.48 & 0.52 \\
\hline $3 / 6 / 0614: 10$ & 23.06 & 10.64 & 53.83 & 1.19 & 3.75 & 1.04 \\
\hline $3 / 6 / 0614: 20$ & 23.39 & 15.69 & 32.90 & 1.20 & 4.54 & 1.43 \\
\hline $3 / 6 / 0614: 30$ & 25.80 & 17.54 & 32.02 & 1.19 & 9.72 & 1.54 \\
\hline $3 / 6 / 06$ 14:40 & 24.64 & 17.04 & 30.82 & 1.21 & 6.95 & 1.24 \\
\hline $3 / 6 / 0614: 50$ & 25.55 & 15.83 & 38.05 & 1.17 & 12.19 & 1.48 \\
\hline $3 / 6 / 06$ 15:00 & 23.61 & 14.88 & 37.00 & 1.17 & 7.25 & 1.00 \\
\hline $3 / 6 / 06 \quad 15: 10$ & 22.53 & 14.81 & 34.28 & 1.20 & 10.14 & 1.89 \\
\hline $3 / 6 / 06 \quad 15: 20$ & 29.69 & 18.88 & 36.42 & 1.19 & 17.70 & 2.51 \\
\hline $3 / 6 / 06 \quad 15: 30$ & 23.71 & 24.04 & 0 & 1.18 & 18.65 & 4.14 \\
\hline $3 / 6 / 06 \quad 15: 40$ & 21.31 & 15.29 & 28.22 & 1.09 & 8.01 & 1.63 \\
\hline $3 / 6 / 06 \quad 15: 50$ & 23.77 & 18.95 & 20.28 & 0.05 & 15.28 & 1.92 \\
\hline $3 / 6 / 0616: 00$ & 28.53 & 24.13 & 15.44 & 1.17 & 12.69 & 2.09 \\
\hline $3 / 6 / 06$ 16:10 & 23.00 & 25.48 & 0 & 1.21 & 13.95 & 1.72 \\
\hline $3 / 6 / 0616: 20$ & 24.48 & 18.86 & 22.93 & 1.27 & 18.54 & 2.11 \\
\hline $3 / 6 / 06 \quad 16: 30$ & 25.75 & 17.95 & 30.27 & 0.70 & 19.92 & 2.56 \\
\hline $3 / 6 / 0616: 40$ & 26.91 & 20.24 & 24.77 & 0.92 & 17.88 & 2.37 \\
\hline $3 / 6 / 0616: 50$ & 32.29 & 22.49 & 30.33 & 0.00 & 19.58 & 2.90 \\
\hline 3/6/06 17:00 & 32.65 & 30.13 & 7.73 & 0.00 & 14.38 & 3.23 \\
\hline $3 / 6 / 0617: 10$ & 37.60 & 31.10 & 17.28 & 0.00 & 19.88 & 4.07 \\
\hline $3 / 6 / 06 \quad 17: 20$ & 33.59 & 30.48 & 9.26 & 0.00 & 14.26 & 3.53 \\
\hline $3 / 6 / 06$ 17:30 & 30.66 & 31.09 & 0 & 0.00 & 13.57 & 3.67 \\
\hline $3 / 6 / 06$ 17:40 & 30.25 & 31.50 & 0 & 0.00 & 17.48 & 4.18 \\
\hline $3 / 6 / 06$ 17:50 & 26.57 & 29.41 & 0 & 0.00 & 11.57 & 3.87 \\
\hline 3/6/06 18:00 & 24.71 & 27.21 & 0 & 0.00 & 4.83 & 3.52 \\
\hline $3 / 6 / 06$ 18:10 & 23.55 & 24.12 & 0 & 0.00 & 31.66 & 5.25 \\
\hline 3/6/06 18:20 & 231.83 & 21.74 & 90.62 & 0.00 & 15.50 & 3.10 \\
\hline $3 / 6 / 0618: 30$ & 21.35 & 23.10 & 0 & 0.00 & 10.34 & 3.15 \\
\hline 3/6/06 18:40 & 21.11 & 24.98 & 0 & 0.00 & 12.94 & 3.63 \\
\hline $3 / 6 / 06$ 18:50 & 18.61 & 25.01 & 0 & 0.00 & 9.00 & 3.41 \\
\hline 3/6/06 19:00 & 19.97 & 25.06 & 0 & 0.00 & 11.74 & 3.59 \\
\hline 3/6/06 19:10 & 21.07 & 29.46 & 0 & 0.00 & 15.48 & 4.31 \\
\hline 3/6/06 19:20 & 21.00 & 27.94 & 0 & 0.00 & 15.33 & 4.25 \\
\hline $3 / 6 / 0619: 30$ & 23.36 & 27.30 & 0 & 0.00 & 16.00 & 4.26 \\
\hline $3 / 6 / 06$ 19:40 & 21.00 & 25.53 & 0 & 0.00 & 14.12 & 4.68 \\
\hline 3/6/06 19:50 & 20.20 & 24.41 & 0 & 0.00 & 11.16 & 4.00 \\
\hline 3/6/06 20:00 & 20.33 & 23.62 & 0 & 0.00 & 14.09 & 4.58 \\
\hline $3 / 6 / 0620: 10$ & 18.75 & 25.94 & 0 & 0.00 & 7.19 & 3.29 \\
\hline $3 / 6 / 0620: 20$ & 20.84 & 23.08 & 0 & 0.00 & 12.60 & 3.84 \\
\hline $3 / 6 / 0620: 30$ & 20.64 & 22.54 & 0 & 0.00 & 11.78 & 3.48 \\
\hline $3 / 6 / 0620: 40$ & 17.77 & 22.54 & 0 & 0.00 & 6.47 & 4.22 \\
\hline $3 / 6 / 0620: 50$ & 17.65 & 26.02 & 0 & 0.00 & 3.47 & 4.30 \\
\hline 3/6/06 21:00 & 16.44 & 23.60 & 0 & 0.00 & 3.47 & 4.02 \\
\hline $3 / 6 / 0621: 10$ & 16.02 & 22.97 & 0 & 0.00 & 2.98 & 3.45 \\
\hline $3 / 6 / 0621: 20$ & 15.97 & 21.20 & 0 & 0.00 & 2.39 & 3.15 \\
\hline $3 / 6 / 0621: 30$ & 16.02 & 21.60 & 0 & 0.00 & 3.15 & 3.17 \\
\hline $3 / 6 / 0621: 40$ & 16.79 & 22.98 & 0 & 0.00 & 3.79 & 3.08 \\
\hline $3 / 6 / 0621: 50$ & 17.09 & 20.41 & 0 & 0.00 & 2.60 & 3.27 \\
\hline $3 / 6 / 0622: 00$ & 16.15 & 21.20 & 0 & 0.00 & 3.06 & 3.27 \\
\hline $3 / 6 / 0622: 10$ & 18.17 & 21.54 & 0 & 0.00 & 5.40 & 3.47 \\
\hline
\end{tabular}


Table D1. Corrected CMM and ACI, 10-minute Averaged Data During the Monthlong Field Test (continued)

\begin{tabular}{|c|c|c|c|c|c|c|}
\hline Date, Time & $\begin{array}{c}\text { FF Inlet } \mathrm{HgT}, \\
\mu \mathrm{g} / \mathrm{dNm}^{3}, \\
3 \% \mathrm{O}_{2} \\
\end{array}$ & $\begin{array}{c}\text { FF Outlet HgT, } \\
\mu \mathrm{g} / \mathrm{dNm}^{3}, \\
3 \% \mathrm{O}_{2}\end{array}$ & $\begin{array}{c}\text { HgT Removal } \\
\text { Across } \\
\text { FF 2-4, \% }\end{array}$ & $\begin{array}{c}\text { FF 2-4 Activated } \\
\text { Carbon Injection } \\
\text { Rate, lb/Macf }\end{array}$ & $\begin{array}{c}\text { FF Inlet } \mathrm{Hg}^{0}, \\
\mu \mathrm{g} / \mathrm{dNm}^{3}, \\
3 \% \mathrm{O}_{2} \\
\end{array}$ & $\begin{array}{c}\text { FF Outlet } \mathrm{Hg}^{0}, \\
\mu \mathrm{g} / \mathrm{dNm}^{3}, \\
3 \% \mathrm{O}_{2}\end{array}$ \\
\hline $3 / 6 / 0622: 20$ & 19.46 & 23.30 & 0 & 0.00 & 7.41 & 3.38 \\
\hline $3 / 6 / 0622: 30$ & 21.34 & 24.40 & 0 & 0.00 & 5.73 & 3.31 \\
\hline $3 / 6 / 0622: 40$ & 22.15 & 24.65 & 0 & 0.00 & 9.06 & 3.63 \\
\hline $3 / 6 / 0622: 50$ & 20.96 & 22.39 & 0 & 0.00 & 9.04 & 3.77 \\
\hline $3 / 6 / 0623: 00$ & 20.57 & 22.45 & 0 & 0.00 & 9.37 & 3.69 \\
\hline $3 / 6 / 0623: 10$ & 17.90 & 23.41 & 0 & 0.00 & 5.70 & 3.62 \\
\hline $3 / 6 / 0623: 20$ & 17.79 & 21.93 & 0 & 0.00 & 2.99 & 3.62 \\
\hline $3 / 6 / 0623: 30$ & 20.29 & 22.11 & 0 & 0.00 & 9.81 & 4.88 \\
\hline $3 / 6 / 0623: 40$ & 18.36 & 22.37 & 0 & 0.00 & 8.96 & 4.13 \\
\hline $3 / 6 / 0623: 50$ & 15.04 & 20.10 & 0 & 0.00 & 3.16 & 3.46 \\
\hline 3/7/06 0:00 & 15.18 & 21.21 & 0 & 0.00 & 3.16 & 3.43 \\
\hline 3/7/06 0:10 & 16.02 & 21.14 & 0 & 0.00 & 3.60 & 2.99 \\
\hline $3 / 7 / 060: 20$ & 16.71 & 19.96 & 0 & 0.00 & 5.25 & 2.89 \\
\hline $3 / 7 / 060: 30$ & 16.24 & 19.32 & 0 & 0.00 & 3.91 & 2.96 \\
\hline $3 / 7 / 060: 40$ & 14.36 & 18.54 & 0 & 0.00 & 3.08 & 3.11 \\
\hline 3/7/06 0:50 & 15.02 & 20.34 & 0 & 0.00 & 2.94 & 3.13 \\
\hline 3/7/06 1:00 & 15.35 & 20.19 & 0 & 0.00 & 3.31 & 3.04 \\
\hline $3 / 7 / 061: 10$ & 14.92 & 20.50 & 0 & 0.00 & 3.15 & 3.68 \\
\hline $3 / 7 / 061: 20$ & 15.16 & 20.64 & 0 & 0.00 & 3.59 & 3.48 \\
\hline $3 / 7 / 061: 30$ & 14.92 & 20.28 & 0 & 0.00 & 2.87 & 3.15 \\
\hline $3 / 7 / 061: 40$ & 14.85 & 20.17 & 0 & 0.00 & 3.04 & 3.11 \\
\hline $3 / 7 / 061: 50$ & 16.85 & 24.29 & 0 & 0.00 & 3.70 & 2.92 \\
\hline $3 / 7 / 062: 00$ & 17.47 & 20.04 & 0 & 0.00 & 5.67 & 2.89 \\
\hline $3 / 7 / 062: 10$ & 16.16 & 20.93 & 0 & 0.00 & 5.13 & 3.18 \\
\hline $3 / 7 / 062: 20$ & 17.04 & 19.74 & 0 & 0.00 & 5.12 & 3.46 \\
\hline $3 / 7 / 062: 30$ & 16.61 & 20.06 & 0 & 0.00 & 5.20 & 3.63 \\
\hline $3 / 7 / 062: 40$ & 17.00 & 19.88 & 0 & 0.00 & 5.44 & 3.94 \\
\hline $3 / 7 / 062: 50$ & 16.90 & 21.16 & 0 & 0.00 & 5.18 & 3.88 \\
\hline 3/7/06 3:00 & 19.38 & 19.69 & 0 & 0.00 & 8.98 & 4.09 \\
\hline $3 / 7 / 063: 10$ & 20.10 & 19.55 & 2.74 & 0.00 & 11.69 & 3.93 \\
\hline $3 / 7 / 063: 20$ & 19.86 & 19.91 & 0 & 0.00 & 11.75 & 3.86 \\
\hline $3 / 7 / 063: 30$ & 20.18 & 19.93 & 1.28 & 0.00 & 11.69 & 4.28 \\
\hline $3 / 7 / 063: 40$ & 19.90 & 21.89 & 0 & 0.00 & 12.04 & 4.23 \\
\hline 3/7/06 3:50 & 18.96 & 20.02 & 0 & 0.00 & 8.96 & 3.62 \\
\hline $3 / 7 / 064: 00$ & 20.86 & 20.99 & 0 & 0.00 & 11.55 & 4.42 \\
\hline $3 / 7 / 064: 10$ & 18.21 & 18.44 & 0 & 0.00 & 10.99 & 4.96 \\
\hline $3 / 7 / 064: 20$ & 15.83 & 17.46 & 0 & 0.00 & 3.96 & 3.33 \\
\hline $3 / 7 / 064: 30$ & 19.47 & 20.98 & 0 & 0.00 & 10.34 & 4.81 \\
\hline $3 / 7 / 064: 40$ & 16.49 & 19.34 & 0 & 0.00 & 5.82 & 3.55 \\
\hline $3 / 7 / 064: 50$ & 16.26 & 18.44 & 0 & 0.00 & 3.92 & 3.71 \\
\hline 3/7/06 5:00 & 15.08 & 19.15 & 0 & 0.00 & 2.56 & 3.37 \\
\hline $3 / 7 / 065: 10$ & 16.67 & 18.77 & 0 & 0.00 & 5.41 & 3.16 \\
\hline 3/7/06 5:20 & 18.64 & 19.18 & 0 & 0.00 & 10.29 & 4.39 \\
\hline $3 / 7 / 065: 30$ & 15.38 & 19.46 & 0 & 0.00 & 5.71 & 3.62 \\
\hline $3 / 7 / 065: 40$ & 14.97 & 19.26 & 0 & 0.00 & 3.66 & 3.37 \\
\hline $3 / 7 / 065: 50$ & 17.04 & 19.07 & 0 & 0.00 & 7.24 & 3.45 \\
\hline 3/7/06 6:00 & 15.95 & 20.25 & 0 & 0.00 & 5.40 & 3.50 \\
\hline 3/7/06 6:10 & 18.15 & 19.34 & 0 & 0.00 & 9.53 & 3.56 \\
\hline $3 / 7 / 066: 20$ & 15.40 & 21.66 & 0 & 0.00 & 5.42 & 3.91 \\
\hline $3 / 7 / 066: 30$ & 15.92 & 20.01 & 0 & 0.00 & 4.79 & 4.10 \\
\hline $3 / 7 / 066: 40$ & 15.72 & 21.18 & 0 & 0.00 & 3.68 & 4.24 \\
\hline $3 / 7 / 066: 50$ & 15.38 & 20.30 & 0 & 0.00 & 3.83 & 4.34 \\
\hline
\end{tabular}


Table D1. Corrected CMM and ACI, 10-minute Averaged Data During the Monthlong Field Test (continued)

\begin{tabular}{|c|c|c|c|c|c|c|}
\hline Date, Time & $\begin{array}{c}\text { FF Inlet } \mathrm{HgT}, \\
\mu \mathrm{g} / \mathrm{dNm}^{3}, \\
3 \% \mathrm{O}_{2} \\
\end{array}$ & $\begin{array}{c}\text { FF Outlet HgT, } \\
\mu \mathrm{g} / \mathrm{dNm}^{3}, \\
3 \% \mathrm{O}_{2}\end{array}$ & $\begin{array}{c}\text { HgT Removal } \\
\text { Across } \\
\text { FF } 2-4, \% \\
\end{array}$ & $\begin{array}{c}\text { FF 2-4 Activated } \\
\text { Carbon Injection } \\
\text { Rate, lb/Macf }\end{array}$ & $\begin{array}{c}\text { FF Inlet } \mathrm{Hg}^{0}, \\
\mu \mathrm{g} / \mathrm{dNm}^{3}, \\
3 \% \mathrm{O}_{2} \\
\end{array}$ & $\begin{array}{c}\text { FF Outlet } \mathrm{Hg}^{0}, \\
\mu \mathrm{g} / \mathrm{dNm}^{3}, \\
3 \% \mathrm{O}_{2}\end{array}$ \\
\hline 3/7/06 7:00 & 17.55 & 23.50 & 0 & 0.00 & 5.94 & 4.25 \\
\hline $3 / 7 / 067: 10$ & 16.86 & 20.06 & 0 & 0.00 & 3.87 & 3.58 \\
\hline $3 / 7 / 067: 20$ & 16.07 & 21.52 & 0 & 0.00 & 3.90 & 3.33 \\
\hline $3 / 7 / 067: 30$ & 17.57 & 20.16 & 0 & 0.00 & 7.30 & 3.42 \\
\hline $3 / 7 / 067: 40$ & 16.93 & 20.53 & 0 & 0.00 & 6.72 & 3.24 \\
\hline $3 / 7 / 067: 50$ & 16.21 & 21.64 & 0 & 0.00 & 4.14 & 3.04 \\
\hline 3/7/06 8:00 & 17.83 & 19.46 & 0 & 1.20 & 8.34 & 2.67 \\
\hline 3/7/06 8:10 & 20.48 & 15.19 & 25.86 & 1.19 & 11.68 & 2.19 \\
\hline $3 / 7 / 068: 20$ & 20.15 & 14.03 & 30.39 & 1.18 & 10.96 & 1.60 \\
\hline $3 / 7 / 068: 30$ & 21.45 & 15.74 & 26.63 & 1.16 & 14.49 & 1.89 \\
\hline $3 / 7 / 068: 40$ & 17.72 & 12.39 & 30.08 & 1.14 & 5.05 & 0.71 \\
\hline $3 / 7 / 068: 50$ & 17.57 & 10.71 & 39.01 & 1.15 & 3.00 & 0.30 \\
\hline $3 / 7 / 069: 00$ & 18.24 & 8.48 & 53.53 & 1.14 & 3.25 & 0.20 \\
\hline 3/7/06 9:10 & 17.40 & 7.98 & 54.15 & 1.13 & 4.60 & 0.74 \\
\hline $3 / 7 / 069: 20$ & 16.55 & 6.73 & 59.31 & 1.15 & 4.44 & 0.52 \\
\hline 3/7/06 9:30 & 15.77 & 6.25 & 60.38 & 1.17 & 4.61 & 0.42 \\
\hline $3 / 7 / 069: 40$ & 15.19 & 6.48 & 57.33 & 1.19 & 3.01 & 0.55 \\
\hline 3/7/06 9:50 & 14.77 & 7.10 & 51.95 & 1.21 & 3.71 & 0.42 \\
\hline 3/7/06 10:00 & 16.35 & 9.23 & 43.55 & 0.71 & 4.90 & 0.70 \\
\hline 3/7/06 10:10 & 18.16 & 18.03 & 0.72 & 0.97 & 6.29 & 1.66 \\
\hline 3/7/06 10:20 & 17.72 & 12.61 & 28.81 & 1.18 & 3.62 & 1.04 \\
\hline $3 / 7 / 06 \quad 10: 30$ & 18.34 & 10.35 & 43.56 & 1.17 & 3.77 & 0.75 \\
\hline $3 / 7 / 0610: 40$ & 17.54 & 9.59 & 45.34 & 1.19 & 5.10 & 0.46 \\
\hline $3 / 7 / 0610: 50$ & 16.41 & 7.36 & 55.18 & 1.17 & 3.69 & 0.29 \\
\hline $3 / 7 / 0611: 00$ & 17.58 & 6.78 & 61.44 & 1.21 & 3.77 & 0.26 \\
\hline 3/7/06 11:10 & 16.16 & 6.30 & 61.03 & 1.22 & 4.11 & 0.65 \\
\hline $3 / 7 / 0611: 20$ & 17.07 & 7.68 & 55.03 & 1.22 & 4.55 & 0.57 \\
\hline $3 / 7 / 0611: 30$ & 18.60 & 8.68 & 53.35 & 0.45 & 3.84 & 0.60 \\
\hline $3 / 7 / 0611: 40$ & 22.20 & 16.94 & 23.70 & 0.00 & 10.66 & 2.69 \\
\hline $3 / 7 / 0611: 50$ & 28.62 & 23.21 & 18.92 & 0.00 & 13.19 & 4.40 \\
\hline 3/7/06 12:00 & 26.25 & 24.19 & 7.84 & 0.00 & 14.33 & 5.62 \\
\hline $3 / 7 / 0612: 10$ & 26.77 & 23.78 & 11.18 & 0.00 & 15.65 & 6.68 \\
\hline $3 / 7 / 0612: 20$ & 26.46 & 23.39 & 11.60 & 0.00 & 16.03 & 7.56 \\
\hline $3 / 7 / 0612: 30$ & 26.09 & 24.96 & 4.31 & 0.00 & 15.33 & 7.39 \\
\hline $3 / 7 / 06 \quad 12: 40$ & 26.68 & 22.87 & 14.29 & 0.00 & 15.29 & 8.13 \\
\hline $3 / 7 / 06 \quad 12: 50$ & 25.76 & 24.12 & 6.35 & 0.00 & 14.41 & 7.96 \\
\hline 3/7/06 13:00 & 24.66 & 24.49 & 0.72 & 0.00 & 13.96 & 8.36 \\
\hline $3 / 7 / 0613: 10$ & 25.05 & 24.07 & 3.93 & 0.00 & 15.43 & 9.49 \\
\hline $3 / 7 / 0613: 20$ & 25.70 & 23.80 & 7.36 & 0.00 & 15.79 & 9.72 \\
\hline $3 / 7 / 0613: 30$ & 22.12 & 23.40 & 0 & 0.00 & 10.18 & 4.63 \\
\hline $3 / 7 / 0613: 40$ & 18.30 & 22.80 & 0 & 0.00 & 3.41 & 3.27 \\
\hline $3 / 7 / 0613: 50$ & 21.05 & 23.52 & 0 & 0.00 & 4.82 & 3.33 \\
\hline 3/7/06 14:00 & 16.98 & 24.44 & 0 & 0.00 & 2.46 & 3.44 \\
\hline $3 / 7 / 0614: 10$ & 17.98 & 23.62 & 0 & 0.00 & 4.76 & 3.92 \\
\hline $3 / 7 / 06 \quad 14: 20$ & 19.15 & 22.67 & 0 & 0.00 & 3.87 & 3.74 \\
\hline $3 / 7 / 0614: 30$ & 17.81 & 22.51 & 0 & 0.00 & 3.78 & 3.74 \\
\hline $3 / 7 / 0614: 40$ & 16.88 & 22.14 & 0 & 0.00 & 2.70 & 3.39 \\
\hline $3 / 7 / 0614: 50$ & 17.01 & 27.20 & 0 & 0.00 & 3.43 & 3.01 \\
\hline $3 / 7 / 0615: 00$ & 16.83 & 21.82 & 0 & 0.00 & 2.90 & 3.15 \\
\hline $3 / 7 / 0615: 10$ & 17.66 & 25.39 & 0 & 0.00 & 4.07 & 4.03 \\
\hline $3 / 7 / 0615: 20$ & 17.37 & 24.02 & 0 & 0.00 & 4.20 & 4.08 \\
\hline $3 / 7 / 0615: 30$ & 20.52 & 27.40 & 0 & 0.00 & 7.46 & 4.23 \\
\hline
\end{tabular}


Table D1. Corrected CMM and ACI, 10-minute Averaged Data During the Monthlong Field Test (continued)

\begin{tabular}{|c|c|c|c|c|c|c|}
\hline Date, Time & $\begin{array}{c}\text { FF Inlet } \mathrm{HgT}, \\
\mu \mathrm{g} / \mathrm{dNm}^{3}, \\
3 \% \mathrm{O}_{2} \\
\end{array}$ & $\begin{array}{c}\text { FF Outlet HgT, } \\
\mu \mathrm{g} / \mathrm{dNm}^{3}, \\
3 \% \mathrm{O}_{2} \\
\end{array}$ & $\begin{array}{c}\text { HgT Removal } \\
\text { Across } \\
\text { FF } 2-4, \% \\
\end{array}$ & $\begin{array}{c}\text { FF 2-4 Activated } \\
\text { Carbon Injection } \\
\text { Rate, lb/Macf }\end{array}$ & $\begin{array}{c}\text { FF Inlet } \mathrm{Hg}^{0}, \\
\mu \mathrm{g} / \mathrm{dNm}^{3}, \\
3 \% \mathrm{O}_{2} \\
\end{array}$ & $\begin{array}{c}\text { FF Outlet } \mathrm{Hg}^{0}, \\
\mu \mathrm{g} / \mathrm{dNm}^{3}, \\
3 \% \mathrm{O}_{2}\end{array}$ \\
\hline $3 / 7 / 06 \quad 15: 40$ & 19.10 & 28.35 & 0 & 0.00 & 6.53 & 4.08 \\
\hline $3 / 7 / 06 \quad 15: 50$ & 17.99 & 24.57 & 0 & 0.00 & 5.40 & 3.56 \\
\hline $3 / 7 / 0616: 00$ & 15.42 & 22.38 & 0 & 0.00 & 2.73 & 3.71 \\
\hline $3 / 7 / 0616: 10$ & 20.46 & 22.76 & 0 & 0.41 & 4.79 & 3.83 \\
\hline $3 / 7 / 0616: 20$ & 15.73 & 13.32 & 15.31 & 1.15 & 4.18 & 1.09 \\
\hline $3 / 7 / 0616: 30$ & 13.26 & 20.29 & 0 & 1.20 & 5.27 & 0.83 \\
\hline $3 / 7 / 06 \quad 16: 40$ & 14.74 & 11.56 & 21.59 & 1.18 & 4.39 & 0.29 \\
\hline $3 / 7 / 0616: 50$ & 14.45 & 6.08 & 57.91 & 1.18 & 4.30 & 0.21 \\
\hline $3 / 7 / 06$ 17:00 & 13.01 & 8.10 & 37.74 & 1.18 & 4.34 & 0.36 \\
\hline $3 / 7 / 06 \quad 17: 10$ & 19.01 & 4.97 & 73.85 & 1.18 & 3.10 & 0.64 \\
\hline $3 / 7 / 06 \quad 17: 20$ & 18.75 & 5.64 & 69.92 & 1.21 & 4.06 & 0.61 \\
\hline $3 / 7 / 06 \quad 17: 30$ & 14.34 & 5.49 & 61.70 & 1.21 & 3.61 & 0.69 \\
\hline $3 / 7 / 06 \quad 17: 40$ & 14.10 & 6.23 & 55.81 & 1.19 & 5.02 & 0.54 \\
\hline $3 / 7 / 06 \quad 17: 50$ & 14.68 & 10.03 & 31.68 & 1.18 & 5.42 & 0.83 \\
\hline 3/7/06 18:00 & 13.33 & 4.50 & 66.28 & 1.22 & 4.57 & 0.74 \\
\hline $3 / 7 / 0618: 10$ & 18.61 & 7.74 & 58.41 & 1.22 & 7.39 & 0.78 \\
\hline $3 / 7 / 0618: 20$ & 14.74 & 5.06 & 65.68 & 1.23 & 4.53 & 1.04 \\
\hline $3 / 7 / 0618: 30$ & 17.04 & 4.94 & 71.01 & 1.19 & 6.13 & 0.85 \\
\hline $3 / 7 / 0618: 40$ & 15.39 & 6.07 & 60.54 & 1.19 & 6.25 & 0.90 \\
\hline $3 / 7 / 06 \quad 18: 50$ & 15.19 & 5.66 & 62.77 & 1.21 & 3.83 & 0.89 \\
\hline 3/7/06 19:00 & 17.31 & 4.79 & 72.32 & 1.21 & 6.72 & 1.03 \\
\hline 3/7/06 19:10 & 13.97 & 12.02 & 13.96 & 1.19 & 5.03 & 0.55 \\
\hline $3 / 7 / 0619: 20$ & 13.40 & 4.42 & 67.00 & 1.17 & 3.45 & 0.75 \\
\hline $3 / 7 / 0619: 30$ & 14.82 & 3.81 & 74.27 & 1.06 & 6.38 & 0.83 \\
\hline $3 / 7 / 06 \quad 19: 40$ & 13.18 & 3.94 & 70.12 & 1.10 & 5.27 & 0.88 \\
\hline $3 / 7 / 0619: 50$ & 14.64 & 3.31 & 77.39 & 1.10 & 4.08 & 0.86 \\
\hline 3/7/06 20:00 & 11.11 & 3.13 & 71.80 & 1.07 & 3.62 & 0.83 \\
\hline $3 / 7 / 0620: 10$ & 13.34 & 2.83 & 78.78 & 1.12 & 5.99 & 0.31 \\
\hline $3 / 7 / 0620: 20$ & 11.46 & 2.73 & 76.16 & 1.13 & 3.81 & 0.30 \\
\hline $3 / 7 / 0620: 30$ & 12.08 & 2.77 & 77.10 & 1.16 & 4.56 & 0.31 \\
\hline $3 / 7 / 0620: 40$ & 11.57 & 3.03 & 73.80 & 1.15 & 4.04 & 0.42 \\
\hline $3 / 7 / 0620: 50$ & 11.47 & 2.41 & 78.97 & 1.16 & 3.90 & 0.43 \\
\hline $3 / 7 / 0621: 00$ & 12.03 & 2.10 & 82.51 & 1.15 & 4.54 & 0.52 \\
\hline $3 / 7 / 0621: 10$ & 12.97 & 2.15 & 83.39 & 1.19 & 4.20 & 0.37 \\
\hline $3 / 7 / 0621: 20$ & 11.37 & 1.98 & 82.63 & 1.17 & 4.27 & 0.45 \\
\hline $3 / 7 / 0621: 30$ & 12.25 & 1.89 & 84.53 & 1.15 & 4.19 & 0.58 \\
\hline $3 / 7 / 0621: 40$ & 11.58 & 2.21 & 80.92 & 1.19 & 4.15 & 0.58 \\
\hline $3 / 7 / 0621: 50$ & 13.10 & 2.70 & 79.40 & 1.19 & 5.38 & 0.71 \\
\hline $3 / 7 / 0622: 00$ & 12.47 & 2.46 & 80.28 & 1.19 & 5.13 & 0.71 \\
\hline $3 / 7 / 0622: 10$ & 13.23 & 2.97 & 77.56 & 1.20 & 4.89 & 0.34 \\
\hline $3 / 7 / 0622: 20$ & 13.34 & 3.00 & 77.51 & 1.21 & 5.59 & 0.43 \\
\hline $3 / 7 / 0622: 30$ & 13.21 & 2.94 & 77.72 & 1.21 & 5.10 & 0.44 \\
\hline $3 / 7 / 0622: 40$ & 12.55 & 4.23 & 66.32 & 1.22 & 4.32 & 0.55 \\
\hline $3 / 7 / 0622: 50$ & 14.15 & 3.52 & 75.12 & 1.21 & 6.78 & 0.62 \\
\hline $3 / 7 / 0623: 00$ & 13.88 & 3.11 & 77.56 & 1.21 & 5.03 & 0.66 \\
\hline $3 / 7 / 0623: 10$ & 15.38 & 3.04 & 80.25 & 1.15 & 7.28 & 0.36 \\
\hline $3 / 7 / 0623: 20$ & 15.48 & 3.19 & 79.42 & 1.00 & 6.75 & 0.56 \\
\hline $3 / 7 / 0623: 30$ & 19.16 & 3.53 & 81.60 & 0.98 & 11.31 & 0.69 \\
\hline $3 / 7 / 0623: 40$ & 19.71 & 4.14 & 78.99 & 0.86 & 12.59 & 0.86 \\
\hline $3 / 7 / 0623: 50$ & 16.94 & 3.89 & 77.03 & 0.78 & 11.98 & 0.88 \\
\hline
\end{tabular}


Table D1. Corrected CMM and ACI, 10-minute Averaged Data During the Monthlong Field Test (continued)

\begin{tabular}{|c|c|c|c|c|c|c|}
\hline Date, Time & $\begin{array}{c}\text { FF Inlet } \mathrm{HgT}, \\
\mu \mathrm{g} / \mathrm{dNm}^{3}, \\
3 \% \mathrm{O}_{2} \\
\end{array}$ & $\begin{array}{c}\text { FF Outlet HgT, } \\
\mu \mathrm{g} / \mathrm{dNm}^{3}, \\
3 \% \mathrm{O}_{2}\end{array}$ & $\begin{array}{c}\text { HgT Removal } \\
\text { Across } \\
\text { FF 2-4, \% } \\
\end{array}$ & $\begin{array}{c}\text { FF 2-4 Activated } \\
\text { Carbon Injection } \\
\text { Rate, lb/Macf }\end{array}$ & $\begin{array}{c}\text { FF Inlet } \mathrm{Hg}^{0}, \\
\mu \mathrm{g} / \mathrm{dNm}^{3}, \\
3 \% \mathrm{O}_{2} \\
\end{array}$ & $\begin{array}{c}\text { FF Outlet } \mathrm{Hg}^{0}, \\
\mu \mathrm{g} / \mathrm{dNm}^{3}, \\
3 \% \mathrm{O}_{2}\end{array}$ \\
\hline \multicolumn{7}{|l|}{ Outage, No } \\
\hline Data & & & & & & \\
\hline $3 / 14 / 068: 50$ & & & & 0.00 & & \\
\hline 3/14/06 9:00 & 19.62 & 21.77 & 0 & 0.00 & 15.89 & 5.55 \\
\hline $3 / 14 / 069: 10$ & 20.49 & 24.85 & 0 & 0.00 & 15.38 & 5.18 \\
\hline $3 / 14 / 069: 20$ & 20.27 & 23.25 & 0 & 0.00 & 15.10 & 5.44 \\
\hline 3/14/06 9:30 & 20.64 & 22.30 & 0 & 0.00 & 15.27 & 5.51 \\
\hline $3 / 14 / 069: 40$ & 19.45 & 23.01 & 0 & 0.00 & 14.55 & 5.82 \\
\hline $3 / 14 / 069: 50$ & 19.45 & 21.86 & 0 & 0.00 & 14.34 & 5.81 \\
\hline 3/14/06 10:00 & 19.14 & 21.48 & 0 & 0.27 & 14.32 & 5.88 \\
\hline $3 / 14 / 0610: 10$ & 19.24 & 17.17 & 10.79 & 1.55 & 14.59 & 2.38 \\
\hline $3 / 14 / 06$ 10:20 & 18.99 & 8.57 & 54.87 & 1.54 & 14.45 & 0.82 \\
\hline $3 / 14 / 0610: 30$ & 19.14 & 6.96 & 63.61 & 1.55 & 14.57 & 0.38 \\
\hline $3 / 14 / 0610: 40$ & 18.76 & 4.67 & 75.10 & 1.54 & 14.59 & 0.16 \\
\hline 3/14/06 10:50 & 19.99 & 4.13 & 79.35 & 1.54 & 14.70 & 0.00 \\
\hline 3/14/06 11:00 & 19.28 & 5.20 & 73.04 & 1.55 & 15.12 & 0.00 \\
\hline 3/14/06 11:10 & 19.68 & 4.77 & 75.75 & 1.53 & 15.41 & 0.22 \\
\hline 3/14/06 11:20 & 19.82 & 4.91 & 75.25 & 1.54 & 15.52 & 0.00 \\
\hline $3 / 14 / 0611: 30$ & 20.04 & 4.34 & 78.32 & 1.53 & 15.51 & 0.00 \\
\hline $3 / 14 / 0611: 40$ & 20.22 & 3.69 & 81.77 & 1.53 & 15.37 & 0.00 \\
\hline $3 / 14 / 0611: 50$ & 20.74 & 2.99 & 85.58 & 1.47 & 15.25 & 0.00 \\
\hline 3/14/06 12:00 & 19.94 & 3.92 & 80.36 & 1.50 & 14.99 & 0.00 \\
\hline $3 / 14 / 0612: 10$ & 19.09 & 3.43 & 82.03 & 1.53 & 14.51 & 0.00 \\
\hline $3 / 14 / 0612: 20$ & 19.58 & 2.81 & 85.63 & 1.52 & 15.03 & 0.00 \\
\hline $3 / 14 / 0612: 30$ & 19.89 & 2.83 & 85.77 & 1.54 & 15.30 & 0.00 \\
\hline $3 / 14 / 0612: 40$ & 20.51 & 3.02 & 85.30 & 1.52 & 15.19 & 0.00 \\
\hline $3 / 14 / 0612: 50$ & 20.57 & 3.32 & 83.87 & 1.53 & 15.65 & 0.00 \\
\hline 3/14/06 13:00 & 20.94 & 3.37 & 83.92 & 1.51 & 16.32 & 0.00 \\
\hline 3/14/06 13:10 & 22.48 & 3.01 & 86.61 & 1.51 & 17.26 & 0.26 \\
\hline $3 / 14 / 06$ 13:20 & 22.19 & 3.05 & 86.25 & 1.45 & 17.70 & 0.20 \\
\hline $3 / 14 / 0613: 30$ & 24.05 & 3.31 & 86.22 & 1.39 & 17.93 & 0.31 \\
\hline $3 / 14 / 06$ 13:40 & 23.49 & 2.95 & 87.46 & 1.26 & 18.66 & 0.47 \\
\hline $3 / 14 / 0613: 50$ & 22.80 & 3.25 & 85.73 & 1.35 & 18.16 & 0.51 \\
\hline 3/14/06 14:00 & 20.01 & 3.04 & 84.80 & 1.48 & 15.05 & 0.26 \\
\hline $3 / 14 / 0614: 10$ & 20.37 & 2.41 & 88.15 & 1.46 & 16.06 & 0.12 \\
\hline $3 / 14 / 0614: 20$ & 20.87 & 1.83 & 91.25 & 1.45 & 16.12 & 0.00 \\
\hline $3 / 14 / 0614: 30$ & 20.84 & 2.39 & 88.53 & 1.44 & 15.47 & 0.00 \\
\hline $3 / 14 / 0614: 40$ & 21.99 & 2.42 & 89.00 & 1.42 & 15.21 & 0.00 \\
\hline $3 / 14 / 0614: 50$ & 21.88 & 2.35 & 89.28 & 1.40 & 14.94 & 0.00 \\
\hline $3 / 14 / 06$ 15:00 & 21.92 & 2.85 & 86.98 & 1.42 & 15.01 & 0.00 \\
\hline $3 / 14 / 0615: 10$ & 20.90 & 2.18 & 89.59 & 1.43 & 15.04 & 0.00 \\
\hline $3 / 14 / 0615: 20$ & 19.92 & 1.53 & 92.30 & 1.50 & 14.38 & 0.00 \\
\hline $3 / 14 / 06$ 15:30 & 20.04 & 1.34 & 93.33 & 1.46 & 14.17 & 0.00 \\
\hline $3 / 14 / 06$ 15:40 & & 1.84 & & 1.42 & & 0.00 \\
\hline $3 / 14 / 0615: 50$ & & 1.67 & & 1.45 & & 0.00 \\
\hline 3/14/06 16:00 & & 2.14 & & 1.42 & & 0.00 \\
\hline $3 / 14 / 06$ 16:10 & 20.61 & 2.27 & 89.01 & 1.44 & 16.79 & 0.12 \\
\hline $3 / 14 / 0616: 20$ & 21.85 & & & 1.45 & 17.70 & \\
\hline $3 / 14 / 0616: 30$ & 21.98 & & & 1.43 & 17.79 & \\
\hline $3 / 14 / 06$ 16:40 & 21.21 & 3.05 & 85.60 & 1.44 & 17.25 & \\
\hline $3 / 14 / 0616: 50$ & 19.78 & 1.99 & 89.93 & 1.44 & 15.87 & 0.00 \\
\hline $3 / 14 / 06$ 17:00 & 19.52 & 1.06 & 94.58 & 1.47 & 16.09 & 0.00 \\
\hline $3 / 14 / 06$ 17:10 & 18.92 & 1.74 & 90.79 & 1.45 & 15.62 & 0.24 \\
\hline
\end{tabular}


Table D1. Corrected CMM and ACI, 10-minute Averaged Data During the Monthlong Field Test (continued)

\begin{tabular}{|c|c|c|c|c|c|c|}
\hline Date, Time & $\begin{array}{c}\text { FF Inlet } \mathrm{HgT}, \\
\mu \mathrm{g} / \mathrm{dNm}^{3}, \\
3 \% \mathrm{O}_{2} \\
\end{array}$ & $\begin{array}{c}\text { FF Outlet HgT, } \\
\mu \mathrm{g} / \mathrm{dNm}^{3}, \\
3 \% \mathrm{O}_{2} \\
\end{array}$ & $\begin{array}{c}\text { HgT Removal } \\
\text { Across } \\
\text { FF } 2-4, \% \\
\end{array}$ & $\begin{array}{c}\text { FF 2-4 Activated } \\
\text { Carbon Injection } \\
\text { Rate, lb/Macf }\end{array}$ & $\begin{array}{c}\text { FF Inlet } \mathrm{Hg}^{0}, \\
\mu \mathrm{g} / \mathrm{dNm}^{3}, \\
3 \% \mathrm{O}_{2} \\
\end{array}$ & $\begin{array}{c}\text { FF Outlet } \mathrm{Hg}^{0}, \\
\mu \mathrm{g} / \mathrm{dNm}^{3}, \\
3 \% \mathrm{O}_{2} \\
\end{array}$ \\
\hline $3 / 14 / 0617: 20$ & 18.60 & 1.95 & 89.53 & 1.48 & 15.47 & 0.00 \\
\hline $3 / 14 / 0617: 30$ & 19.06 & 1.48 & 92.24 & 1.52 & 16.74 & 0.00 \\
\hline $3 / 14 / 0617: 40$ & 19.93 & 1.17 & 94.15 & 1.50 & 17.57 & 0.12 \\
\hline $3 / 14 / 0617: 50$ & 19.65 & 1.92 & 90.25 & 1.51 & 17.63 & 0.20 \\
\hline 3/14/06 18:00 & 20.42 & 1.59 & 92.23 & 1.48 & 18.41 & 0.29 \\
\hline 3/14/06 18:10 & 19.27 & 1.24 & 93.59 & 1.47 & 17.31 & 0.12 \\
\hline $3 / 14 / 06$ 18:20 & 20.28 & 1.75 & 91.39 & 1.46 & 19.12 & 0.16 \\
\hline 3/14/06 18:30 & 19.74 & 0.96 & 95.13 & 1.47 & 18.99 & 0.27 \\
\hline $3 / 14 / 06$ 18:40 & 19.57 & 1.81 & 90.75 & 1.49 & 18.11 & 0.40 \\
\hline $3 / 14 / 06$ 18:50 & 19.44 & 1.33 & 93.17 & 1.43 & 17.64 & 0.46 \\
\hline 3/14/06 19:00 & 18.74 & 0.93 & 95.06 & 1.42 & 16.76 & 0.49 \\
\hline 3/14/06 19:10 & 18.18 & 1.31 & 92.78 & 1.46 & 15.80 & 0.00 \\
\hline 3/14/06 19:20 & 17.97 & 1.01 & 94.39 & 1.45 & 15.92 & 0.12 \\
\hline 3/14/06 19:30 & 18.68 & 0.85 & 95.42 & 1.43 & 16.66 & 0.12 \\
\hline $3 / 14 / 06$ 19:40 & 18.44 & 1.05 & 94.30 & 1.38 & 16.39 & 0.29 \\
\hline $3 / 14 / 0619: 50$ & 18.79 & 1.02 & 94.58 & 1.40 & 16.60 & 0.48 \\
\hline $3 / 14 / 0620: 00$ & 18.73 & 1.08 & 94.23 & 1.39 & 16.56 & 0.65 \\
\hline $3 / 14 / 0620: 10$ & 18.71 & 1.10 & 94.10 & 1.40 & 15.89 & 0.12 \\
\hline $3 / 14 / 0620: 20$ & 18.64 & 0.83 & 95.57 & 1.44 & 16.30 & 0.20 \\
\hline $3 / 14 / 0620: 30$ & 18.92 & 0.87 & 95.39 & 1.43 & 16.60 & 0.41 \\
\hline $3 / 14 / 0620: 40$ & 18.95 & 0.89 & 95.30 & 1.43 & 16.67 & 0.54 \\
\hline $3 / 14 / 0620: 50$ & 18.73 & 2.10 & 88.77 & 1.40 & 15.78 & 0.68 \\
\hline $3 / 14 / 0621: 00$ & 19.52 & 0.93 & 95.25 & 1.42 & 16.17 & 0.68 \\
\hline 3/14/06 21:10 & 19.55 & 0.92 & 95.28 & 1.43 & 16.46 & 0.12 \\
\hline $3 / 14 / 0621: 20$ & 19.07 & 0.79 & 95.85 & 1.41 & 15.85 & 0.13 \\
\hline $3 / 14 / 0621: 30$ & 19.20 & 0.72 & 96.25 & 1.42 & 16.09 & 0.27 \\
\hline $3 / 14 / 0621: 40$ & 19.19 & 0.68 & 96.47 & 1.41 & 16.13 & 0.45 \\
\hline $3 / 14 / 0621: 50$ & 18.74 & 0.99 & 94.71 & 1.42 & 16.18 & 0.58 \\
\hline $3 / 14 / 0622: 00$ & 18.60 & 0.70 & 96.24 & 1.43 & 16.09 & 0.64 \\
\hline $3 / 14 / 0622: 10$ & 19.40 & 0.61 & 96.86 & 1.43 & 15.47 & \\
\hline $3 / 14 / 0622: 20$ & 19.46 & 0.68 & 96.49 & 1.37 & 16.38 & 0.97 \\
\hline $3 / 14 / 0622: 30$ & 19.49 & 0.68 & 96.53 & 1.42 & 15.81 & 1.02 \\
\hline $3 / 14 / 0622: 40$ & 17.39 & 0.67 & 96.17 & 1.45 & 14.35 & 1.15 \\
\hline $3 / 14 / 0622: 50$ & 17.50 & 0.71 & 95.92 & 1.44 & 14.95 & 1.32 \\
\hline $3 / 14 / 0623: 00$ & 17.52 & 0.67 & 96.17 & 1.48 & 14.67 & 1.39 \\
\hline $3 / 14 / 0623: 10$ & 17.02 & 0.78 & 95.43 & 1.49 & 14.24 & \\
\hline $3 / 14 / 0623: 20$ & 18.17 & 0.71 & 96.10 & 1.47 & 15.67 & 0.12 \\
\hline $3 / 14 / 0623: 30$ & 18.29 & 0.67 & 96.35 & 1.45 & 15.83 & 0.20 \\
\hline $3 / 14 / 0623: 40$ & 19.25 & 0.59 & 96.96 & 1.37 & 16.65 & 0.25 \\
\hline $3 / 14 / 0623: 50$ & 19.43 & 0.59 & 96.94 & 1.37 & 15.91 & 0.31 \\
\hline 3/15/06 0:00 & 20.16 & 0.61 & 96.95 & 1.26 & 16.08 & 0.41 \\
\hline $3 / 15 / 060: 10$ & 19.89 & 0.48 & 97.61 & 1.33 & 15.57 & 0.00 \\
\hline $3 / 15 / 060: 20$ & 18.20 & 0.69 & 96.23 & 1.39 & 14.39 & 0.13 \\
\hline $3 / 15 / 060: 30$ & 18.64 & 0.59 & 96.82 & 1.37 & 15.02 & 0.19 \\
\hline $3 / 15 / 060: 40$ & 18.69 & 0.69 & 96.34 & 1.35 & 15.04 & 0.31 \\
\hline $3 / 15 / 060: 50$ & 19.59 & 0.94 & 95.18 & 1.34 & 15.01 & 0.47 \\
\hline $3 / 15 / 061: 00$ & 19.11 & 0.69 & 96.38 & 1.32 & 15.35 & 0.57 \\
\hline $3 / 15 / 061: 10$ & 20.17 & 0.88 & 95.64 & 1.32 & 15.45 & 0.13 \\
\hline $3 / 15 / 061: 20$ & 19.18 & 0.73 & 96.18 & 1.34 & 14.41 & 0.16 \\
\hline $3 / 15 / 061: 30$ & 17.98 & 0.82 & 95.43 & 1.40 & 13.48 & 0.34 \\
\hline $3 / 15 / 061: 40$ & 17.22 & 0.61 & 96.43 & 1.46 & 13.76 & 0.41 \\
\hline $3 / 15 / 061: 50$ & 18.46 & 0.55 & 97.01 & 1.48 & 14.51 & 0.53 \\
\hline
\end{tabular}


Table D1. Corrected CMM and ACI, 10-minute Averaged Data During the Monthlong Field Test (continued)

\begin{tabular}{|c|c|c|c|c|c|c|}
\hline Date, Time & $\begin{array}{c}\text { FF Inlet } \mathrm{HgT}, \\
\mu \mathrm{g} / \mathrm{dNm}^{3}, \\
3 \% \mathrm{O}_{2} \\
\end{array}$ & $\begin{array}{c}\text { FF Outlet HgT, } \\
\mu \mathrm{g} / \mathrm{dNm}^{3}, \\
3 \% \mathrm{O}_{2} \\
\end{array}$ & $\begin{array}{c}\text { HgT Removal } \\
\text { Across } \\
\text { FF 2-4, \% } \\
\end{array}$ & $\begin{array}{c}\text { FF 2-4 Activated } \\
\text { Carbon Injection } \\
\text { Rate, lb/Macf }\end{array}$ & $\begin{array}{c}\text { FF Inlet } \mathrm{Hg}^{0}, \\
\mu \mathrm{g} / \mathrm{dNm}^{3}, \\
3 \% \mathrm{O}_{2} \\
\end{array}$ & $\begin{array}{c}\text { FF Outlet } \mathrm{Hg}^{0}, \\
\mu \mathrm{g} / \mathrm{dNm}^{3}, \\
3 \% \mathrm{O}_{2} \\
\end{array}$ \\
\hline $3 / 15 / 062: 00$ & 18.57 & 0.65 & 96.50 & 1.47 & 15.08 & 0.62 \\
\hline $3 / 15 / 062: 10$ & 19.01 & 0.73 & 96.16 & 1.44 & 15.15 & \\
\hline $3 / 15 / 062: 20$ & 18.84 & 0.56 & 97.05 & 1.50 & 15.05 & 0.12 \\
\hline $3 / 15 / 062: 30$ & 19.00 & 0.53 & 97.23 & 1.44 & 15.36 & 0.12 \\
\hline $3 / 15 / 062: 40$ & 18.24 & 0.82 & 95.49 & 1.40 & 14.79 & 0.18 \\
\hline $3 / 15 / 062: 50$ & 18.14 & 0.60 & 96.69 & 1.42 & 14.90 & 0.13 \\
\hline $3 / 15 / 063: 00$ & 18.01 & 0.57 & 96.81 & 1.42 & 14.67 & 0.21 \\
\hline $3 / 15 / 063: 10$ & 17.92 & 0.54 & 96.99 & 1.42 & 14.69 & 0.00 \\
\hline $3 / 15 / 063: 20$ & 18.00 & 0.83 & 95.37 & 1.46 & 14.81 & 0.00 \\
\hline $3 / 15 / 063: 30$ & 18.21 & 0.56 & 96.94 & 1.53 & 14.62 & 0.00 \\
\hline $3 / 15 / 063: 40$ & 18.09 & 0.67 & 96.31 & 1.46 & 14.64 & 0.00 \\
\hline $3 / 15 / 063: 50$ & 18.39 & 0.69 & 96.24 & 1.49 & 14.81 & \\
\hline $3 / 15 / 064: 00$ & 18.22 & 0.57 & 96.85 & 1.44 & 15.01 & 0.00 \\
\hline $3 / 15 / 064: 10$ & 18.28 & 0.71 & 96.11 & 1.47 & 15.33 & 0.00 \\
\hline $3 / 15 / 064: 20$ & 18.76 & 0.51 & 97.29 & 1.49 & 15.36 & 0.00 \\
\hline $3 / 15 / 064: 30$ & 18.93 & 0.53 & 97.22 & 1.50 & 15.59 & 0.00 \\
\hline $3 / 15 / 064: 40$ & 18.51 & 0.36 & 98.04 & 1.49 & 15.32 & \\
\hline $3 / 15 / 064: 50$ & 18.97 & 0.44 & 97.68 & 1.49 & 15.30 & \\
\hline $3 / 15 / 065: 00$ & 18.44 & 0.45 & 97.55 & 1.44 & 15.26 & 0.00 \\
\hline $3 / 15 / 065: 10$ & 18.28 & 0.56 & 96.92 & 1.46 & 14.61 & 0.00 \\
\hline $3 / 15 / 065: 20$ & 18.02 & 0.45 & 97.49 & 1.48 & 14.41 & \\
\hline $3 / 15 / 065: 30$ & 18.37 & 0.38 & 97.91 & 1.48 & 14.13 & 0.00 \\
\hline $3 / 15 / 065: 40$ & 18.36 & 0.76 & 95.86 & 1.46 & 14.83 & \\
\hline $3 / 15 / 065: 50$ & 18.43 & 0.49 & 97.34 & 1.47 & 14.50 & \\
\hline $3 / 15 / 066: 00$ & 18.33 & 0.55 & 97.03 & 1.45 & 14.57 & 0.00 \\
\hline $3 / 15 / 066: 10$ & 18.61 & 0.50 & 97.31 & 1.47 & 15.03 & 0.00 \\
\hline $3 / 15 / 066: 20$ & 18.50 & 0.45 & 97.56 & 1.47 & 14.20 & 0.00 \\
\hline $3 / 15 / 066: 30$ & 18.28 & 0.41 & 97.76 & 1.50 & 14.77 & 0.00 \\
\hline $3 / 15 / 066: 40$ & 19.04 & 0.53 & 97.21 & 1.48 & 15.74 & \\
\hline $3 / 15 / 066: 50$ & 18.89 & 0.52 & 97.26 & 1.49 & 15.13 & \\
\hline $3 / 15 / 06$ 7:00 & 18.61 & 0.56 & 97.01 & 1.46 & 14.49 & 0.00 \\
\hline $3 / 15 / 067: 10$ & 19.24 & 0.58 & 97.00 & 1.51 & 15.38 & \\
\hline $3 / 15 / 067: 20$ & 20.60 & 0.42 & 97.98 & 1.53 & 16.91 & \\
\hline $3 / 15 / 067: 30$ & 21.76 & 0.50 & 97.70 & 1.53 & 16.85 & \\
\hline $3 / 15 / 067: 40$ & 21.10 & 0.38 & 98.20 & 1.54 & 16.87 & \\
\hline $3 / 15 / 067: 50$ & 20.84 & 0.56 & 97.31 & 1.51 & 16.53 & 0.00 \\
\hline $3 / 15 / 068: 00$ & 20.44 & 0.43 & 97.91 & 1.49 & 15.72 & 0.00 \\
\hline $3 / 15 / 068: 10$ & 19.65 & 0.45 & 97.72 & 1.43 & 15.42 & 0.00 \\
\hline $3 / 15 / 068: 20$ & 18.99 & 0.46 & 97.60 & 1.42 & 14.25 & 0.00 \\
\hline $3 / 15 / 068: 30$ & 18.92 & 0.39 & 97.95 & 1.44 & 13.79 & 0.00 \\
\hline $3 / 15 / 068: 40$ & 18.43 & 0.39 & 97.88 & 1.38 & 13.64 & 0.00 \\
\hline $3 / 15 / 068: 50$ & 18.90 & 2.52 & 86.66 & 1.37 & 13.80 & 0.00 \\
\hline 3/15/06 9:00 & 18.99 & 3.83 & 79.82 & 1.31 & 13.98 & 0.26 \\
\hline $3 / 15 / 069: 10$ & 20.73 & 10.30 & 50.30 & 1.32 & 14.48 & 87.09 \\
\hline $3 / 15 / 06$ 9:20 & 20.60 & 13.52 & 34.39 & 1.40 & 13.96 & 28.36 \\
\hline $3 / 15 / 069: 30$ & 20.08 & 2.18 & 89.15 & 1.42 & 13.74 & 0.69 \\
\hline $3 / 15 / 069: 40$ & 20.07 & 1.21 & 93.97 & 1.43 & 13.50 & 0.05 \\
\hline $3 / 15 / 06$ 9:50 & 19.36 & 1.01 & 94.78 & 1.48 & 14.23 & 0.00 \\
\hline 3/15/06 10:00 & 19.56 & 1.26 & 93.58 & 1.52 & 15.20 & 0.00 \\
\hline $3 / 15 / 0610: 10$ & 20.43 & 1.13 & 94.48 & 1.52 & 15.94 & 0.00 \\
\hline $3 / 15 / 0610: 20$ & 20.45 & 1.20 & 94.15 & 1.52 & 15.62 & 0.00 \\
\hline $3 / 15 / 06 \quad 10: 30$ & 19.80 & 1.18 & 94.02 & 1.49 & 15.29 & 0.00 \\
\hline
\end{tabular}


Table D1. Corrected CMM and ACI, 10-minute Averaged Data During the Monthlong Field Test (continued)

\begin{tabular}{|c|c|c|c|c|c|c|}
\hline Date, Time & $\begin{array}{c}\text { FF Inlet } \mathrm{HgT}, \\
\mu \mathrm{g} / \mathrm{dNm}^{3}, \\
3 \% \mathrm{O}_{2}\end{array}$ & $\begin{array}{c}\text { FF Outlet } \mathrm{HgT}, \\
\mu \mathrm{g} / \mathrm{dNm}^{3} \\
3 \% \mathrm{O}_{2}\end{array}$ & $\begin{array}{c}\text { HgT Removal } \\
\text { Across } \\
\text { FF 2-4, } \% \\
\end{array}$ & $\begin{array}{c}\text { FF 2-4 Activated } \\
\text { Carbon Injection } \\
\text { Rate, lb/Macf } \\
\end{array}$ & $\begin{array}{c}\text { FF Inlet } \mathrm{Hg}^{0}, \\
\mu \mathrm{g} / \mathrm{dNm}^{3}, \\
3 \% \mathrm{O}_{2} \\
\end{array}$ & $\begin{array}{c}\text { FF Outlet } \mathrm{Hg}^{0}, \\
\mu \mathrm{g} / \mathrm{dNm}^{3}, \\
3 \% \mathrm{O}_{2}\end{array}$ \\
\hline $3 / 15 / 06$ 10:40 & 19.19 & 1.10 & 94.28 & 1.52 & 15.23 & 0.00 \\
\hline $3 / 15 / 0610: 50$ & 19.17 & 1.00 & 94.78 & 1.51 & 14.69 & 0.00 \\
\hline 3/15/06 11:00 & & 1.04 & & 1.53 & & 0.00 \\
\hline $3 / 15 / 0611: 10$ & & 0.74 & & 1.54 & & 0.22 \\
\hline $3 / 15 / 0611: 20$ & 21.38 & 2.06 & 90.35 & 1.47 & 14.18 & 1.72 \\
\hline $3 / 15 / 06$ 11:30 & 20.32 & & & 1.46 & 14.59 & \\
\hline $3 / 15 / 06$ 11:40 & & 1.47 & & 1.44 & & 0.12 \\
\hline $3 / 15 / 06$ 11:50 & & 0.46 & & 1.46 & & 0.00 \\
\hline $3 / 15 / 06$ 12:00 & & 0.55 & & 1.44 & & 0.00 \\
\hline $3 / 15 / 0612: 10$ & & 0.66 & & 1.44 & & 0.00 \\
\hline $3 / 15 / 0612: 20$ & & 0.61 & & 1.46 & & 0.00 \\
\hline $3 / 15 / 0612: 30$ & & 0.53 & & 1.44 & & 0.00 \\
\hline $3 / 15 / 0612: 40$ & & 0.68 & & 1.41 & & 0.00 \\
\hline $3 / 15 / 0612: 50$ & & 0.58 & & 1.40 & & 0.00 \\
\hline $3 / 15 / 06$ 13:00 & & 0.68 & & 1.42 & & 0.00 \\
\hline $3 / 15 / 0613: 10$ & & 0.88 & & 1.27 & & 0.00 \\
\hline $3 / 15 / 0613: 20$ & & 0.67 & & 1.48 & & 0.00 \\
\hline $3 / 15 / 06$ 13:30 & & 0.62 & & 1.49 & & 0.00 \\
\hline $3 / 15 / 06$ 13:40 & & 0.67 & & 1.42 & & 0.00 \\
\hline $3 / 15 / 0613: 50$ & & 0.76 & & 1.45 & & 0.00 \\
\hline $3 / 15 / 06$ 14:00 & & 0.66 & & 1.45 & & 0.00 \\
\hline $3 / 15 / 0614: 10$ & & 0.66 & & 1.46 & & 0.00 \\
\hline $3 / 15 / 06$ 14:20 & 28.03 & 0.47 & 98.32 & 1.47 & 13.55 & 0.00 \\
\hline $3 / 15 / 0614: 30$ & 20.40 & 0.58 & 97.18 & 1.50 & 14.34 & 0.00 \\
\hline $3 / 15 / 0614: 40$ & 18.53 & 0.51 & 97.25 & 1.50 & 14.88 & 0.00 \\
\hline $3 / 15 / 0614: 50$ & 18.59 & 0.54 & 97.10 & 1.50 & 15.11 & 0.00 \\
\hline $3 / 15 / 06$ 15:00 & 18.64 & 0.65 & 96.50 & 1.45 & 14.28 & 0.00 \\
\hline $3 / 15 / 0615: 10$ & 17.87 & 0.71 & 96.04 & 1.50 & 14.11 & 0.12 \\
\hline $3 / 15 / 0615: 20$ & 16.82 & 0.72 & 95.72 & 1.47 & 14.15 & \\
\hline $3 / 15 / 0615: 30$ & 16.55 & 0.56 & 96.64 & 1.47 & 14.75 & 0.00 \\
\hline $3 / 15 / 0615: 40$ & 17.26 & 0.97 & 94.38 & 1.48 & 14.45 & 0.00 \\
\hline $3 / 15 / 06$ 15:50 & 16.25 & 0.78 & 95.23 & 1.51 & 15.12 & 0.00 \\
\hline $3 / 15 / 0616: 00$ & 17.08 & 0.70 & 95.90 & 1.50 & 14.88 & 0.00 \\
\hline $3 / 15 / 0616: 10$ & 17.77 & 1.00 & 94.35 & 1.47 & 14.51 & 0.00 \\
\hline $3 / 15 / 0616: 20$ & 15.62 & 1.22 & 92.17 & 1.50 & 14.13 & 0.00 \\
\hline $3 / 15 / 0616: 30$ & 16.66 & 1.00 & 93.99 & 1.46 & 13.08 & 0.00 \\
\hline $3 / 15 / 0616: 40$ & 14.48 & 1.17 & 91.91 & 1.47 & 12.49 & 0.00 \\
\hline $3 / 15 / 0616: 50$ & 14.51 & 1.06 & 92.67 & 1.45 & 12.61 & 0.00 \\
\hline $3 / 15 / 06$ 17:00 & 14.22 & 1.06 & 92.55 & 1.49 & 12.41 & 0.00 \\
\hline $3 / 15 / 06$ 17:10 & 15.69 & 1.19 & 92.39 & 1.46 & 12.73 & 0.12 \\
\hline $3 / 15 / 06$ 17:20 & 14.56 & 1.41 & 90.35 & 1.49 & 12.51 & 0.17 \\
\hline $3 / 15 / 06 \quad 17: 30$ & 14.63 & 0.99 & 93.24 & 1.45 & 12.22 & 0.32 \\
\hline $3 / 15 / 0617: 40$ & 13.49 & 1.02 & 92.43 & 1.43 & 11.90 & 0.48 \\
\hline $3 / 15 / 06$ 17:50 & 13.60 & 0.88 & 93.49 & 1.48 & 12.36 & 0.60 \\
\hline $3 / 15 / 06$ 18:00 & 13.94 & 1.19 & 91.44 & 1.48 & 12.54 & 0.70 \\
\hline $3 / 15 / 0618: 10$ & 13.89 & 0.86 & 93.80 & 1.45 & 12.07 & \\
\hline $3 / 15 / 06$ 18:20 & 14.20 & 0.60 & 95.76 & 1.50 & 12.06 & 0.00 \\
\hline $3 / 15 / 0618: 30$ & 13.55 & 0.80 & 94.08 & 1.48 & 12.58 & 0.00 \\
\hline $3 / 15 / 06$ 18:40 & 13.52 & 0.66 & 95.12 & 1.47 & 12.16 & 0.00 \\
\hline $3 / 15 / 0618: 50$ & 13.39 & 0.79 & 94.07 & 1.45 & 12.31 & 0.00 \\
\hline $3 / 15 / 06$ 19:00 & 14.67 & 0.69 & 95.33 & 1.44 & 12.19 & 0.00 \\
\hline $3 / 15 / 06$ 19:10 & 14.76 & 0.75 & 94.91 & 1.42 & 12.91 & \\
\hline
\end{tabular}


Table D1. Corrected CMM and ACI, 10-minute Averaged Data During the Monthlong Field Test (continued)

\begin{tabular}{|c|c|c|c|c|c|c|}
\hline Date, Time & $\begin{array}{c}\text { FF Inlet } \mathrm{HgT}, \\
\mu \mathrm{g} / \mathrm{dNm}^{3}, \\
3 \% \mathrm{O}_{2}\end{array}$ & $\begin{array}{c}\text { FF Outlet HgT, } \\
\mu \mathrm{g} / \mathrm{dNm}^{3}, \\
3 \% \mathrm{O}_{2}\end{array}$ & $\begin{array}{c}\text { HgT Removal } \\
\text { Across } \\
\text { FF 2-4, \% }\end{array}$ & $\begin{array}{l}\text { FF 2-4 Activated } \\
\text { Carbon Injection } \\
\text { Rate, lb/Macf }\end{array}$ & $\begin{array}{c}\text { FF Inlet } \mathrm{Hg}^{0}, \\
\mu \mathrm{g} / \mathrm{dNm}^{3}, \\
3 \% \mathrm{O}_{2}\end{array}$ & $\begin{array}{c}\text { FF Outlet } \mathrm{Hg}^{0} \text {, } \\
\mu \mathrm{g} / \mathrm{dNm}^{3}, \\
3 \% \mathrm{O}_{2}\end{array}$ \\
\hline $3 / 15 / 06$ 19:20 & 15.28 & 0.96 & 93.75 & 1.45 & 12.77 & \\
\hline $3 / 15 / 06$ 19:30 & 15.87 & 1.02 & 93.55 & 1.47 & 12.86 & 0.12 \\
\hline $3 / 15 / 06$ 19:40 & 14.58 & 0.80 & 94.53 & 1.48 & 13.18 & 0.16 \\
\hline $3 / 15 / 06$ 19:50 & 14.18 & 0.68 & 95.23 & 1.48 & 13.88 & 0.28 \\
\hline 3/15/06 20:00 & 14.76 & 0.71 & 95.19 & 1.51 & 13.92 & 0.37 \\
\hline $3 / 15 / 0620: 10$ & 15.15 & 0.56 & 96.32 & 1.49 & 14.32 & \\
\hline $3 / 15 / 0620: 20$ & 15.68 & 0.71 & 95.46 & 1.48 & 14.18 & \\
\hline $3 / 15 / 0620: 30$ & 15.00 & 0.75 & 94.97 & 1.43 & 13.47 & 0.12 \\
\hline $3 / 15 / 0620: 40$ & 14.43 & 0.81 & 94.38 & 1.45 & 13.38 & 0.12 \\
\hline $3 / 15 / 0620: 50$ & 15.43 & 0.73 & 95.29 & 1.48 & 13.06 & 0.12 \\
\hline $3 / 15 / 0621: 00$ & 14.50 & 0.67 & 95.40 & 1.49 & 13.22 & \\
\hline $3 / 15 / 0621: 10$ & 14.32 & 0.68 & 95.26 & 1.48 & 12.96 & \\
\hline $3 / 15 / 06$ 21:20 & 14.82 & 0.83 & 94.42 & 1.42 & 13.09 & 0.00 \\
\hline $3 / 15 / 0621: 30$ & 14.71 & 0.76 & 94.82 & 1.44 & 12.76 & 0.00 \\
\hline $3 / 15 / 06$ 21:40 & 15.78 & 0.89 & 94.36 & 1.42 & 12.93 & 0.00 \\
\hline $3 / 15 / 0621: 50$ & 16.77 & 0.94 & 94.40 & 1.43 & 12.80 & 0.00 \\
\hline $3 / 15 / 0622: 00$ & 15.61 & 0.89 & 94.30 & 1.43 & 13.24 & 0.00 \\
\hline 3/15/06 22:10 & 16.56 & 0.54 & 96.72 & 1.46 & 13.59 & 0.00 \\
\hline $3 / 15 / 0622: 20$ & 16.05 & 0.57 & 96.47 & 1.44 & 13.64 & 0.00 \\
\hline $3 / 15 / 0622: 30$ & 15.71 & 0.70 & 95.55 & 1.44 & 13.49 & 0.00 \\
\hline $3 / 15 / 0622: 40$ & 15.87 & 0.73 & 95.40 & 1.47 & 13.33 & 0.00 \\
\hline $3 / 15 / 0622: 50$ & 15.59 & 0.66 & 95.78 & 1.46 & 13.98 & 0.00 \\
\hline $3 / 15 / 0623: 00$ & 16.12 & 0.55 & 96.62 & 1.50 & 14.38 & 0.00 \\
\hline $3 / 15 / 0623: 10$ & 16.98 & 0.82 & 95.17 & 1.48 & 15.63 & 0.12 \\
\hline $3 / 15 / 0623: 20$ & 17.07 & 0.70 & 95.93 & 1.49 & 15.28 & 0.17 \\
\hline $3 / 15 / 0623: 30$ & 18.09 & 0.73 & 95.99 & 1.49 & 16.16 & 0.17 \\
\hline $3 / 15 / 0623: 40$ & 18.93 & 0.78 & 95.91 & 1.51 & 17.08 & 0.12 \\
\hline $3 / 15 / 0623: 50$ & 19.27 & 0.77 & 96.01 & 1.50 & 18.10 & 0.00 \\
\hline 3/16/06 0:00 & 19.00 & 0.86 & 95.48 & 1.48 & 16.96 & 0.00 \\
\hline $3 / 16 / 060: 10$ & & 1.00 & & 1.44 & & 0.00 \\
\hline $3 / 16 / 060: 20$ & & 1.04 & & 1.43 & & 0.00 \\
\hline $3 / 16 / 060: 30$ & & 0.86 & & 1.45 & & 0.00 \\
\hline $3 / 16 / 060: 40$ & & 0.82 & & 1.46 & & 0.00 \\
\hline $3 / 16 / 060: 50$ & & 0.88 & & 1.48 & & 0.00 \\
\hline $3 / 16 / 06$ 1:00 & & 0.87 & & 1.44 & & 0.00 \\
\hline $3 / 16 / 061: 10$ & & 0.99 & & 1.48 & & 0.00 \\
\hline $3 / 16 / 06$ 1:20 & & 0.91 & & 1.45 & & 0.00 \\
\hline $3 / 16 / 061: 30$ & & 1.12 & & 1.45 & & 0.00 \\
\hline $3 / 16 / 061: 40$ & & 0.86 & & 1.45 & & 0.00 \\
\hline $3 / 16 / 061: 50$ & & 0.94 & & 1.45 & & 0.00 \\
\hline $3 / 16 / 062: 00$ & & 1.03 & & 1.48 & & 0.00 \\
\hline $3 / 16 / 062: 10$ & & 1.59 & & 1.49 & & \\
\hline $3 / 16 / 062: 20$ & & 0.74 & & 0.41 & & 0.00 \\
\hline $3 / 16 / 062: 30$ & & 1.12 & & 0.00 & & 0.00 \\
\hline $3 / 16 / 062: 40$ & & 1.58 & & 0.00 & & 0.00 \\
\hline $3 / 16 / 062: 50$ & & 3.04 & & 0.00 & & 0.12 \\
\hline $3 / 16 / 063: 00$ & & 2.93 & & 0.00 & & 0.23 \\
\hline $3 / 16 / 063: 10$ & & 4.94 & & 0.00 & & 1.07 \\
\hline $3 / 16 / 063: 20$ & & 8.92 & & 0.00 & & 1.31 \\
\hline $3 / 16 / 063: 30$ & & 9.22 & & 0.00 & & 1.63 \\
\hline $3 / 16 / 063: 40$ & & 11.62 & & 0.00 & & 1.68 \\
\hline $3 / 16 / 063: 50$ & & 13.00 & & 0.00 & & 2.24 \\
\hline
\end{tabular}


Table D1. Corrected CMM and ACI, 10-minute Averaged Data During the Monthlong Field Test (continued)

\begin{tabular}{|c|c|c|c|c|c|c|}
\hline Date, Time & $\begin{array}{c}\text { FF Inlet } \mathrm{HgT}, \\
\mu \mathrm{g} / \mathrm{dNm}^{3}, \\
3 \% \mathrm{O}_{2} \\
\end{array}$ & $\begin{array}{c}\text { FF Outlet HgT, } \\
\mu \mathrm{g} / \mathrm{dNm}^{3}, \\
3 \% \mathrm{O}_{2}\end{array}$ & $\begin{array}{c}\text { HgT Removal } \\
\text { Across } \\
\text { FF } 2-4, \% \\
\end{array}$ & $\begin{array}{c}\text { FF 2-4 Activated } \\
\text { Carbon Injection } \\
\text { Rate, lb/Macf }\end{array}$ & $\begin{array}{c}\text { FF Inlet } \mathrm{Hg}^{0}, \\
\mu \mathrm{g} / \mathrm{dNm}^{3}, \\
3 \% \mathrm{O}_{2} \\
\end{array}$ & $\begin{array}{c}\text { FF Outlet } \mathrm{Hg}^{0} \text {, } \\
\mu \mathrm{g} / \mathrm{dNm}^{3}, \\
3 \% \mathrm{O}_{2} \\
\end{array}$ \\
\hline $3 / 16 / 064: 00$ & & 15.38 & & 0.00 & & 2.16 \\
\hline $3 / 16 / 064: 10$ & & 15.40 & & 0.00 & & 2.58 \\
\hline $3 / 16 / 064: 20$ & & 15.02 & & 0.00 & & 2.49 \\
\hline $3 / 16 / 064: 30$ & & 18.30 & & 0.00 & & 2.44 \\
\hline $3 / 16 / 064: 40$ & & 19.08 & & 0.00 & & 2.90 \\
\hline $3 / 16 / 064: 50$ & & 15.88 & & 0.00 & & 2.41 \\
\hline 3/16/06 5:00 & & 19.66 & & 0.00 & & 3.10 \\
\hline $3 / 16 / 065: 10$ & & 22.22 & & 0.00 & & 4.83 \\
\hline $3 / 16 / 065: 20$ & & 19.07 & & 0.00 & & 2.77 \\
\hline $3 / 16 / 065: 30$ & & 19.68 & & 0.00 & & 5.21 \\
\hline $3 / 16 / 065: 40$ & & 23.73 & & 0.00 & & 4.73 \\
\hline $3 / 16 / 065: 50$ & & 24.29 & & 0.00 & & 6.37 \\
\hline $3 / 16 / 066: 00$ & & 20.44 & & 0.00 & & 4.61 \\
\hline $3 / 16 / 066: 10$ & & 23.14 & & 0.00 & & 3.12 \\
\hline $3 / 16 / 066: 20$ & & 19.98 & & 0.00 & & 2.95 \\
\hline $3 / 16 / 066: 30$ & & 19.54 & & 0.00 & & 3.25 \\
\hline $3 / 16 / 066: 40$ & & 21.82 & & 0.00 & & 4.10 \\
\hline $3 / 16 / 066: 50$ & & 22.99 & & 0.00 & & 5.20 \\
\hline 3/16/06 7:00 & & 21.13 & & 0.00 & & 4.57 \\
\hline $3 / 16 / 067: 10$ & & 24.46 & & 0.00 & & 4.59 \\
\hline $3 / 16 / 067: 20$ & & 22.58 & & 0.00 & & 4.05 \\
\hline 3/16/06 7:30 & & 27.77 & & 0.00 & & 4.96 \\
\hline $3 / 16 / 06$ 7:40 & & & & 0.00 & & \\
\hline $3 / 16 / 067: 50$ & & & & 0.00 & & \\
\hline 3/16/06 8:00 & & & & 0.00 & & \\
\hline $3 / 16 / 068: 10$ & & & & 0.00 & & \\
\hline 3/16/06 8:20 & & 15.53 & & 0.00 & & 4.03 \\
\hline 3/16/06 8:30 & & 15.96 & & 0.00 & & 3.93 \\
\hline $3 / 16 / 068: 40$ & & 16.93 & & 0.00 & & 3.92 \\
\hline $3 / 16 / 068: 50$ & & 15.07 & & 0.00 & & 3.81 \\
\hline 3/16/06 9:00 & & 16.12 & & 0.00 & & 3.96 \\
\hline $3 / 16 / 06$ 9:10 & & 14.69 & & 0.00 & & 2.88 \\
\hline $3 / 16 / 069: 20$ & & 13.77 & & 0.00 & & 3.04 \\
\hline $3 / 16 / 069: 30$ & & 13.84 & & 0.00 & & 3.48 \\
\hline 3/16/06 9:40 & & 13.87 & & 0.09 & & 3.29 \\
\hline 3/16/06 9:50 & & 9.80 & & 1.42 & & 1.47 \\
\hline 3/16/06 10:00 & & 6.61 & & 1.43 & & 0.63 \\
\hline 3/16/06 10:10 & & 5.90 & & 1.43 & & 0.07 \\
\hline $3 / 16 / 06$ 10:20 & & 4.64 & & 1.42 & & 0.00 \\
\hline 3/16/06 10:30 & & 5.20 & & 1.46 & & 0.00 \\
\hline $3 / 16 / 06$ 10:40 & & 4.27 & & 1.47 & & 0.00 \\
\hline $3 / 16 / 0610: 50$ & & 3.87 & & 1.48 & & 0.00 \\
\hline 3/16/06 11:00 & & 3.49 & & 1.46 & & 0.00 \\
\hline 3/16/06 11:10 & & 4.71 & & 1.43 & & 0.24 \\
\hline 3/16/06 11:20 & & 3.59 & & 1.46 & & 0.16 \\
\hline 3/16/06 11:30 & & 3.68 & & 1.48 & & 0.00 \\
\hline 3/16/06 11:40 & & & & 1.49 & & \\
\hline 3/16/06 11:50 & & & & 1.47 & & \\
\hline 3/16/06 12:00 & & & & 0.92 & & \\
\hline 3/16/06 12:10 & & & & 0.12 & & \\
\hline 3/16/06 12:20 & & & & 0.12 & & \\
\hline $3 / 16 / 06$ 12:30 & & & & 0.13 & & \\
\hline
\end{tabular}


Table D1. Corrected CMM and ACI, 10-minute Averaged Data During the Monthlong Field Test (continued)

\begin{tabular}{|c|c|c|c|c|c|c|}
\hline Date, Time & $\begin{array}{c}\text { FF Inlet } \mathrm{HgT}, \\
\mu \mathrm{g} / \mathrm{dNm}^{3}, \\
3 \% \mathrm{O}_{2} \\
\end{array}$ & $\begin{array}{c}\text { FF Outlet } \mathrm{HgT}, \\
\mu \mathrm{g} / \mathrm{dNm}^{3} \\
3 \% \mathrm{O}_{2}\end{array}$ & $\begin{array}{c}\text { HgT Removal } \\
\text { Across } \\
\text { FF 2-4, } \% \\
\end{array}$ & $\begin{array}{c}\text { FF 2-4 Activated } \\
\text { Carbon Injection } \\
\text { Rate, lb/Macf }\end{array}$ & $\begin{array}{c}\text { FF Inlet } \mathrm{Hg}^{0}, \\
\mu \mathrm{g} / \mathrm{dNm}^{3}, \\
3 \% \mathrm{O}_{2}\end{array}$ & $\begin{array}{c}\text { FF Outlet } \mathrm{Hg}^{0}, \\
\mu \mathrm{g} / \mathrm{dNm}^{3}, \\
3 \% \mathrm{O}_{2}\end{array}$ \\
\hline $3 / 16 / 0612: 40$ & & & & 0.12 & & \\
\hline $3 / 16 / 0612: 50$ & & & & 0.13 & & \\
\hline $3 / 16 / 06$ 13:00 & & & & 0.12 & & \\
\hline $3 / 16 / 0613: 10$ & & & & 0.12 & & \\
\hline $3 / 16 / 0613: 20$ & & & & 0.12 & & \\
\hline $3 / 16 / 0613: 30$ & & & & 0.12 & & \\
\hline $3 / 16 / 0613: 40$ & & & & 0.12 & & \\
\hline $3 / 16 / 0613: 50$ & & & & 0.12 & & \\
\hline $3 / 16 / 0614: 00$ & & & & 0.12 & & \\
\hline $3 / 16 / 0614: 10$ & 30.78 & & & 0.14 & & \\
\hline $3 / 16 / 0614: 20$ & 28.49 & & & 0.13 & & \\
\hline $3 / 16 / 0614: 30$ & 26.56 & & & 0.13 & & \\
\hline $3 / 16 / 0614: 40$ & 25.50 & & & 0.14 & & \\
\hline $3 / 16 / 0614: 50$ & 23.17 & & & 0.13 & & \\
\hline $3 / 16 / 0615: 00$ & 22.40 & & & 0.13 & & \\
\hline $3 / 16 / 0615: 10$ & 21.25 & & & 0.13 & & \\
\hline $3 / 16 / 0615: 20$ & 20.47 & & & 0.13 & & \\
\hline $3 / 16 / 0615: 30$ & 20.06 & & & 0.13 & & \\
\hline $3 / 16 / 0615: 40$ & 19.18 & & & 0.12 & & \\
\hline $3 / 16 / 0615: 50$ & 19.08 & & & 0.12 & & \\
\hline $3 / 16 / 0616: 00$ & 19.02 & & & 0.12 & & \\
\hline $3 / 16 / 0616: 10$ & 19.37 & & & 0.13 & & \\
\hline $3 / 16 / 0616: 20$ & 19.49 & & & 0.13 & & \\
\hline $3 / 16 / 0616: 30$ & 18.84 & 15.18 & 19.44 & 0.12 & & 2.60 \\
\hline $3 / 16 / 0616: 40$ & 18.69 & 19.11 & 0 & 0.11 & & 2.97 \\
\hline $3 / 16 / 0616: 50$ & 20.71 & 20.49 & 1.07 & 0.12 & & 3.99 \\
\hline $3 / 16 / 06$ 17:00 & 21.61 & 21.26 & 1.61 & 0.13 & & 3.00 \\
\hline $3 / 16 / 0617: 10$ & 20.29 & 21.18 & 0 & 0.14 & & 2.97 \\
\hline $3 / 16 / 06$ 17:20 & 19.22 & 18.68 & 2.79 & 0.14 & & 3.16 \\
\hline $3 / 16 / 0617: 30$ & 17.59 & 16.18 & 8.02 & 0.51 & & 2.67 \\
\hline $3 / 16 / 06$ 17:40 & 11.51 & 14.10 & 0 & 1.44 & & 1.70 \\
\hline $3 / 16 / 0617: 50$ & 18.79 & 9.56 & 49.15 & 1.40 & & 1.37 \\
\hline $3 / 16 / 0618: 00$ & 21.38 & 7.49 & 64.94 & 1.40 & & 1.16 \\
\hline $3 / 16 / 0618: 10$ & 20.45 & 7.15 & 65.04 & 1.38 & & 0.73 \\
\hline $3 / 16 / 06$ 18:20 & 19.93 & 5.78 & 71.02 & 1.38 & & 0.56 \\
\hline $3 / 16 / 0618: 30$ & 18.62 & 5.97 & 67.91 & 1.40 & & 0.40 \\
\hline $3 / 16 / 0618: 40$ & 18.04 & 4.45 & 75.36 & 1.43 & & \\
\hline $3 / 16 / 0618: 50$ & 17.33 & 5.98 & 65.51 & 1.46 & & \\
\hline $3 / 16 / 06$ 19:00 & 16.63 & 3.24 & 80.52 & 1.44 & & 0.36 \\
\hline $3 / 16 / 06$ 19:10 & 16.87 & 4.30 & 74.53 & 1.40 & & 0.48 \\
\hline $3 / 16 / 06$ 19:20 & 16.59 & 2.79 & 83.19 & 1.39 & & 0.70 \\
\hline $3 / 16 / 0619: 30$ & 16.75 & 3.31 & 80.23 & 1.37 & & 0.82 \\
\hline $3 / 16 / 06$ 19:40 & 16.95 & 3.30 & 80.53 & 1.37 & & 1.09 \\
\hline $3 / 16 / 0619: 50$ & 16.56 & 2.81 & 83.05 & 1.41 & & 1.25 \\
\hline $3 / 16 / 0620: 00$ & 16.92 & 2.83 & 83.26 & 1.37 & & 1.26 \\
\hline $3 / 16 / 0620: 10$ & 16.41 & 2.75 & 83.26 & 1.41 & & 0.35 \\
\hline $3 / 16 / 0620: 20$ & 16.57 & 2.22 & 86.60 & 1.46 & & 0.49 \\
\hline $3 / 16 / 0620: 30$ & 16.84 & 2.39 & 85.81 & 1.46 & & 0.72 \\
\hline $3 / 16 / 0620: 40$ & 16.86 & 2.42 & 85.63 & 1.39 & & 0.88 \\
\hline $3 / 16 / 0620: 50$ & 16.12 & 2.94 & 81.76 & 1.38 & & 0.98 \\
\hline $3 / 16 / 0621: 00$ & 14.98 & 2.42 & 83.83 & 1.40 & & 0.84 \\
\hline $3 / 16 / 0621: 10$ & 14.27 & 1.71 & 88.00 & 1.44 & & 0.12 \\
\hline
\end{tabular}


Table D1. Corrected CMM and ACI, 10-minute Averaged Data During the Monthlong Field Test (continued)

\begin{tabular}{|c|c|c|c|c|c|c|}
\hline Date, Time & $\begin{array}{c}\text { FF Inlet } \mathrm{HgT} \text {, } \\
\mu \mathrm{g} / \mathrm{dNm}^{3}, \\
3 \% \mathrm{O}_{2}\end{array}$ & $\begin{array}{c}\text { FF Outlet } \mathrm{HgT} \text {, } \\
\mu \mathrm{g} / \mathrm{dNm}^{3} \\
3 \% \mathrm{O}_{2}\end{array}$ & $\begin{array}{c}\text { HgT Removal } \\
\text { Across } \\
\text { FF 2-4, } \% \\
\end{array}$ & $\begin{array}{c}\text { FF 2-4 Activated } \\
\text { Carbon Injection } \\
\text { Rate, lb/Macf } \\
\end{array}$ & $\begin{array}{c}\text { FF Inlet } \mathrm{Hg}^{0}, \\
\mu \mathrm{g} / \mathrm{dNm}^{3}, \\
3 \% \mathrm{O}_{2}\end{array}$ & $\begin{array}{c}\text { FF Outlet } \mathrm{Hg}^{0}, \\
\mu \mathrm{g} / \mathrm{dNm}^{3}, \\
3 \% \mathrm{O}_{2}\end{array}$ \\
\hline $3 / 16 / 0621: 20$ & 14.86 & 1.85 & 87.56 & 1.41 & & \\
\hline $3 / 16 / 0621: 30$ & 14.24 & 1.63 & 88.53 & 1.40 & & \\
\hline $3 / 16 / 0621: 40$ & 13.70 & 2.58 & 81.16 & 1.41 & & 0.12 \\
\hline $3 / 16 / 0621: 50$ & 15.36 & 1.69 & 88.97 & 1.39 & & 0.35 \\
\hline $3 / 16 / 0622: 00$ & 15.65 & 1.25 & 92.03 & 1.41 & & 0.65 \\
\hline $3 / 16 / 0622: 10$ & 15.07 & 1.41 & 90.64 & 1.43 & & 0.31 \\
\hline $3 / 16 / 0622: 20$ & 15.02 & 1.55 & 89.65 & 1.40 & & 0.63 \\
\hline $3 / 16 / 0622: 30$ & 14.68 & 1.73 & 88.21 & 1.39 & & 1.08 \\
\hline $3 / 16 / 0622: 40$ & 14.32 & 1.93 & 86.50 & 1.40 & & 1.63 \\
\hline $3 / 16 / 0622: 50$ & 15.26 & 1.45 & 90.52 & 1.39 & & 2.32 \\
\hline $3 / 16 / 0623: 00$ & 15.57 & 1.25 & 91.99 & 1.45 & & 2.50 \\
\hline $3 / 16 / 0623: 10$ & 15.41 & 1.06 & 93.12 & 1.52 & & 0.12 \\
\hline $3 / 16 / 0623: 20$ & 16.12 & 1.19 & 92.59 & 1.49 & & 0.25 \\
\hline $3 / 16 / 0623: 30$ & 16.31 & 1.69 & 89.62 & 1.51 & & 0.61 \\
\hline $3 / 16 / 0623: 40$ & 16.38 & 1.53 & 90.64 & 1.49 & & 1.04 \\
\hline $3 / 16 / 0623: 50$ & & 1.82 & & 1.52 & & 1.47 \\
\hline 3/17/06 0:00 & & 1.87 & & 1.50 & & 1.77 \\
\hline 3/17/06 0:10 & 16.27 & 1.54 & 90.54 & 1.49 & & 0.24 \\
\hline $3 / 17 / 060: 20$ & 16.37 & 1.39 & 91.54 & 1.44 & & 0.48 \\
\hline $3 / 17 / 060: 30$ & 15.54 & 1.26 & 91.89 & 1.44 & & 0.76 \\
\hline 3/17/06 0:40 & 14.98 & 9.36 & 37.48 & 1.42 & & 0.92 \\
\hline 3/17/06 0:50 & 15.04 & 1.61 & 89.27 & 1.41 & & 1.06 \\
\hline 3/17/06 1:00 & 14.71 & 1.29 & 91.25 & 1.42 & & 1.08 \\
\hline 3/17/06 1:10 & 14.76 & 1.32 & 91.07 & 1.43 & & 0.12 \\
\hline $3 / 17 / 061: 20$ & 14.70 & 1.24 & 91.56 & 1.43 & & 0.12 \\
\hline 3/17/06 1:30 & 14.81 & 1.13 & 92.39 & 1.43 & & \\
\hline 3/17/06 1:40 & 15.55 & 1.02 & 93.47 & 1.45 & & \\
\hline 3/17/06 1:50 & 15.95 & 1.21 & 92.41 & 1.43 & & 0.12 \\
\hline $3 / 17 / 062: 00$ & 14.89 & 1.33 & 91.06 & 1.38 & & 0.12 \\
\hline $3 / 17 / 062: 10$ & 14.24 & 1.38 & 90.33 & 1.38 & & 0.19 \\
\hline $3 / 17 / 062: 20$ & 14.14 & 1.67 & 88.19 & 1.43 & & \\
\hline $3 / 17 / 062: 30$ & 13.77 & 1.23 & 91.10 & 1.43 & & \\
\hline $3 / 17 / 062: 40$ & 13.81 & 1.28 & 90.77 & 1.42 & & \\
\hline $3 / 17 / 062: 50$ & 14.33 & 1.13 & 92.11 & 1.43 & & \\
\hline 3/17/06 3:00 & 14.64 & 1.00 & 93.14 & 1.46 & & \\
\hline 3/17/06 3:10 & 16.19 & 1.07 & 93.42 & 1.45 & & \\
\hline 3/17/06 3:20 & 16.43 & 0.89 & 94.60 & 1.50 & & \\
\hline 3/17/06 3:30 & 16.85 & 0.97 & 94.27 & 1.48 & & \\
\hline 3/17/06 3:40 & 16.82 & 0.89 & 94.69 & 1.50 & & \\
\hline 3/17/06 3:50 & 16.62 & 1.03 & 93.80 & 1.51 & & \\
\hline 3/17/06 4:00 & 16.50 & 1.02 & 93.82 & 1.51 & & \\
\hline 3/17/06 4:10 & 15.75 & 4.21 & 73.30 & 1.46 & & \\
\hline $3 / 17 / 064: 20$ & 14.96 & 1.42 & 90.53 & 1.47 & & \\
\hline 3/17/06 4:30 & 14.52 & 1.44 & 90.11 & 1.46 & & \\
\hline 3/17/06 4:40 & 13.95 & 1.22 & 91.27 & 1.48 & & \\
\hline $3 / 17 / 064: 50$ & 13.64 & 1.26 & 90.75 & 1.48 & & \\
\hline $3 / 17 / 065: 00$ & 13.66 & 0.98 & 92.81 & 1.47 & & \\
\hline 3/17/06 5:10 & 14.23 & 1.33 & 90.67 & 1.50 & & 0.12 \\
\hline $3 / 17 / 065: 20$ & 15.45 & 0.91 & 94.11 & 1.51 & & 0.18 \\
\hline $3 / 17 / 065: 30$ & 16.37 & 1.61 & 90.16 & 1.51 & & 0.30 \\
\hline $3 / 17 / 065: 40$ & 16.87 & 1.07 & 93.66 & 1.51 & & 0.41 \\
\hline $3 / 17 / 065: 50$ & 17.40 & 1.16 & 93.31 & 1.50 & & 0.50 \\
\hline
\end{tabular}


Table D1. Corrected CMM and ACI, 10-minute Averaged Data During the Monthlong Field Test (continued)

\begin{tabular}{|c|c|c|c|c|c|c|}
\hline Date, Time & $\begin{array}{c}\text { FF Inlet } \mathrm{HgT}, \\
\mu \mathrm{g} / \mathrm{dNm}^{3}, \\
3 \% \mathrm{O}_{2}\end{array}$ & $\begin{array}{c}\text { FF Outlet } \mathrm{HgT} \text {, } \\
\mu \mathrm{g} / \mathrm{dNm}^{3} \\
3 \% \mathrm{O}_{2}\end{array}$ & $\begin{array}{c}\text { HgT Removal } \\
\text { Across } \\
\text { FF 2-4, } \% \\
\end{array}$ & $\begin{array}{c}\text { FF 2-4 Activated } \\
\text { Carbon Injection } \\
\text { Rate, lb/Macf } \\
\end{array}$ & $\begin{array}{c}\text { FF Inlet } \mathrm{Hg}^{0}, \\
\mu \mathrm{g} / \mathrm{dNm}^{3}, \\
3 \% \mathrm{O}_{2}\end{array}$ & $\begin{array}{c}\text { FF Outlet } \mathrm{Hg}^{0}, \\
\mu \mathrm{g} / \mathrm{dNm}^{3}, \\
3 \% \mathrm{O}_{2}\end{array}$ \\
\hline 3/17/06 6:00 & 17.28 & 1.20 & 93.07 & 1.44 & & 0.66 \\
\hline 3/17/06 6:10 & 16.32 & 1.06 & 93.51 & 1.45 & & 0.12 \\
\hline $3 / 17 / 066: 20$ & 15.01 & 1.18 & 92.14 & 1.44 & & 0.13 \\
\hline $3 / 17 / 066: 30$ & 14.68 & 1.03 & 93.00 & 1.45 & & 0.24 \\
\hline 3/17/06 6:40 & 14.09 & 0.99 & 92.95 & 1.45 & & 0.24 \\
\hline 3/17/06 6:50 & 14.05 & 1.53 & 89.09 & 1.44 & & 0.40 \\
\hline 3/17/06 7:00 & 13.99 & 0.99 & 92.91 & 1.44 & & 0.50 \\
\hline 3/17/06 7:10 & 13.94 & 0.81 & 94.22 & 1.47 & & \\
\hline $3 / 17 / 067: 20$ & 14.07 & 1.87 & 86.71 & 1.50 & & 0.12 \\
\hline 3/17/06 7:30 & 14.38 & 1.54 & 89.32 & 1.50 & & 0.12 \\
\hline 3/17/06 7:40 & 14.73 & & & 1.50 & & \\
\hline 3/17/06 7:50 & 14.77 & & & 1.48 & & \\
\hline 3/17/06 8:00 & 15.45 & & & 1.50 & & \\
\hline 3/17/06 8:10 & 17.26 & & & 1.47 & & \\
\hline 3/17/06 8:20 & 16.90 & & & 1.49 & & \\
\hline 3/17/06 8:30 & 16.69 & & & 1.44 & & \\
\hline 3/17/06 8:40 & 15.53 & & & 1.47 & & \\
\hline 3/17/06 8:50 & 14.80 & & & 1.49 & & \\
\hline 3/17/06 9:00 & 15.00 & & & 1.46 & & \\
\hline 3/17/06 9:10 & 15.33 & & & 1.50 & & \\
\hline 3/17/06 9:20 & 15.32 & & & 1.50 & & \\
\hline 3/17/06 9:30 & 15.45 & & & 1.49 & & \\
\hline 3/17/06 9:40 & 15.72 & & & 1.50 & & \\
\hline 3/17/06 9:50 & 15.72 & & & 1.49 & & \\
\hline $3 / 17 / 06$ 10:00 & 15.69 & & & 1.48 & & \\
\hline $3 / 17 / 0610: 10$ & 15.09 & & & 1.45 & & \\
\hline $3 / 17 / 0610: 20$ & 14.31 & 2.39 & 83.31 & 1.45 & & \\
\hline $3 / 17 / 0610: 30$ & 12.91 & 1.67 & 87.09 & 1.43 & & \\
\hline $3 / 17 / 06$ 10:40 & 12.49 & 2.34 & 81.30 & 1.47 & & \\
\hline $3 / 17 / 0610: 50$ & 12.08 & 1.78 & 85.25 & 1.46 & & \\
\hline $3 / 17 / 06$ 11:00 & 12.37 & 1.99 & 83.93 & 1.48 & & 0.12 \\
\hline $3 / 17 / 0611: 10$ & 13.44 & 2.38 & 82.30 & 1.48 & & \\
\hline $3 / 17 / 06$ 11:20 & 14.81 & 1.90 & 87.18 & 1.50 & & \\
\hline $3 / 17 / 0611: 30$ & 15.29 & 2.72 & 82.22 & 0.39 & & 0.25 \\
\hline $3 / 17 / 06$ 11:40 & 16.18 & 2.78 & 82.80 & 0.12 & & \\
\hline $3 / 17 / 0611: 50$ & 16.33 & 5.11 & 68.73 & 0.12 & & \\
\hline $3 / 17 / 0612: 00$ & 16.76 & 5.43 & 67.60 & 0.12 & & 0.61 \\
\hline $3 / 17 / 0612: 10$ & 17.25 & 6.11 & 64.59 & 0.12 & & 0.74 \\
\hline $3 / 17 / 0612: 20$ & 17.02 & 8.68 & 49.02 & 0.12 & & 0.81 \\
\hline $3 / 17 / 0612: 30$ & 17.05 & 7.63 & 55.26 & 0.12 & & 0.45 \\
\hline $3 / 17 / 0612: 40$ & 16.67 & 10.30 & 38.20 & 0.12 & & 0.68 \\
\hline $3 / 17 / 0612: 50$ & 17.13 & 11.49 & 32.91 & 0.12 & & 0.82 \\
\hline 3/17/06 13:00 & 17.67 & 11.07 & 37.35 & 0.12 & & 0.76 \\
\hline $3 / 17 / 0613: 10$ & 20.28 & 17.16 & 15.34 & 0.12 & & 2.23 \\
\hline $3 / 17 / 0613: 20$ & 21.16 & 14.87 & 29.74 & 0.12 & & 2.02 \\
\hline $3 / 17 / 0613: 30$ & 20.78 & 15.78 & 24.06 & 0.12 & & 1.76 \\
\hline $3 / 17 / 0613: 40$ & 20.69 & 19.58 & 5.36 & 0.12 & & 1.84 \\
\hline $3 / 17 / 0613: 50$ & 20.02 & 19.78 & 1.20 & 0.12 & & 1.78 \\
\hline $3 / 17 / 0614: 00$ & 19.34 & 23.57 & 0 & 0.12 & & 2.74 \\
\hline $3 / 17 / 0614: 10$ & 17.50 & 21.68 & 0 & 0.12 & & 2.52 \\
\hline $3 / 17 / 0614: 20$ & 16.91 & 24.24 & 0 & 0.12 & & 3.18 \\
\hline 3/17/06 14:30 & 16.59 & 24.47 & 0 & 0.12 & & 3.03 \\
\hline
\end{tabular}


Table D1. Corrected CMM and ACI, 10-minute Averaged Data During the Monthlong Field Test (continued)

\begin{tabular}{|c|c|c|c|c|c|c|}
\hline Date, Time & $\begin{array}{c}\text { FF Inlet } \mathrm{HgT}, \\
\mu \mathrm{g} / \mathrm{dNm}^{3} \\
3 \% \mathrm{O}_{2}\end{array}$ & $\begin{array}{c}\text { FF Outlet } \mathrm{HgT}, \\
\mu \mathrm{g} / \mathrm{dNm}^{3} \\
3 \% \mathrm{O}_{2}\end{array}$ & $\begin{array}{c}\text { HgT Removal } \\
\text { Across } \\
\text { FF 2-4, } \% \\
\end{array}$ & $\begin{array}{c}\text { FF 2-4 Activated } \\
\text { Carbon Injection } \\
\text { Rate, lb/Macf }\end{array}$ & $\begin{array}{c}\text { FF Inlet } \mathrm{Hg}^{0}, \\
\mu \mathrm{g} / \mathrm{dNm}^{3}, \\
3 \% \mathrm{O}_{2}\end{array}$ & $\begin{array}{c}\text { FF Outlet } \mathrm{Hg}^{0}, \\
\mu \mathrm{g} / \mathrm{dNm}^{3}, \\
3 \% \mathrm{O}_{2}\end{array}$ \\
\hline $3 / 17 / 06$ 14:40 & 16.20 & 23.83 & 0 & 0.12 & & 2.35 \\
\hline $3 / 17 / 06$ 14:50 & 15.47 & 21.91 & 0 & 0.13 & & 2.37 \\
\hline $3 / 17 / 06$ 15:00 & 13.96 & 19.72 & 0 & 0.14 & & 2.05 \\
\hline $3 / 17 / 0615: 10$ & 14.24 & 17.49 & 0 & 0.14 & & 2.37 \\
\hline $3 / 17 / 06 \quad 15: 20$ & 13.35 & 13.49 & 0 & 0.14 & & 2.13 \\
\hline $3 / 17 / 06$ 15:30 & 13.32 & 15.16 & 0 & 0.14 & & 2.06 \\
\hline $3 / 17 / 06$ 15:40 & 12.89 & 13.16 & 0 & 0.14 & & 1.70 \\
\hline $3 / 17 / 0615: 50$ & 12.34 & 11.70 & 5.24 & 0.14 & & 1.67 \\
\hline $3 / 17 / 0616: 00$ & 12.12 & 10.80 & 10.89 & 1.04 & & 1.34 \\
\hline $3 / 17 / 0616: 10$ & 12.27 & 6.24 & 49.15 & 1.43 & & 0.25 \\
\hline $3 / 17 / 0616: 20$ & 11.55 & 8.56 & 25.91 & 1.41 & & 0.27 \\
\hline $3 / 17 / 0616: 30$ & 11.39 & 6.03 & 47.08 & 1.40 & & 0.36 \\
\hline $3 / 17 / 0616: 40$ & 11.25 & 4.53 & 59.69 & 1.40 & & 0.25 \\
\hline $3 / 17 / 0616: 50$ & 11.30 & 4.45 & 60.59 & 1.41 & & 0.29 \\
\hline $3 / 17 / 06$ 17:00 & 11.18 & 3.53 & 68.44 & 1.42 & & 0.23 \\
\hline $3 / 17 / 06$ 17:10 & 11.42 & 4.01 & 64.90 & 1.40 & & 0.12 \\
\hline $3 / 17 / 06$ 17:20 & 11.60 & 3.77 & 67.49 & 1.42 & & 0.12 \\
\hline $3 / 17 / 06$ 17:30 & 11.39 & 3.24 & 71.56 & 1.44 & & 0.12 \\
\hline $3 / 17 / 06$ 17:40 & 11.32 & 2.63 & 76.79 & 1.46 & & 0.12 \\
\hline $3 / 17 / 06$ 17:50 & 11.90 & 2.48 & 79.12 & 1.46 & & \\
\hline $3 / 17 / 0618: 00$ & 12.49 & 2.45 & 80.42 & 1.47 & & 0.12 \\
\hline $3 / 17 / 06$ 18:10 & 13.96 & 3.11 & 77.73 & 1.44 & & 0.12 \\
\hline $3 / 17 / 0618: 20$ & 14.66 & 2.24 & 84.74 & 1.46 & & 0.12 \\
\hline $3 / 17 / 0618: 30$ & 15.15 & 2.34 & 84.56 & 1.44 & & 0.12 \\
\hline $3 / 17 / 06$ 18:40 & 13.59 & 2.74 & 79.85 & 1.43 & & 0.20 \\
\hline $3 / 17 / 06$ 18:50 & 12.59 & 1.86 & 85.21 & 1.46 & & 0.36 \\
\hline 3/17/06 19:00 & 11.90 & 2.10 & 82.34 & 1.45 & & 0.46 \\
\hline $3 / 17 / 0619: 10$ & 12.42 & 2.41 & 80.58 & 1.46 & & 0.19 \\
\hline $3 / 17 / 06$ 19:20 & 12.48 & 2.08 & 83.36 & 1.46 & & 0.54 \\
\hline $3 / 17 / 06$ 19:30 & 12.27 & 2.06 & 83.19 & 1.46 & & 0.78 \\
\hline $3 / 17 / 06$ 19:40 & 12.56 & 2.55 & 79.65 & 1.46 & & 0.95 \\
\hline $3 / 17 / 06$ 19:50 & 12.43 & 2.35 & 81.08 & 1.44 & & 1.05 \\
\hline $3 / 17 / 0620: 00$ & 11.72 & 1.87 & 84.08 & 1.42 & & 1.11 \\
\hline $3 / 17 / 0620: 10$ & 11.24 & 2.75 & 75.51 & 1.43 & & 0.12 \\
\hline $3 / 17 / 0620: 20$ & 10.59 & 2.11 & 80.06 & 1.45 & & 0.23 \\
\hline $3 / 17 / 0620: 30$ & 10.82 & 1.46 & 86.51 & 1.44 & & 0.12 \\
\hline $3 / 17 / 0620: 40$ & 10.64 & 1.35 & 87.33 & 1.45 & & 0.16 \\
\hline $3 / 17 / 0620: 50$ & 10.78 & 1.72 & 84.06 & 1.45 & & 0.43 \\
\hline $3 / 17 / 0621: 00$ & 10.72 & 1.78 & 83.43 & 1.46 & & 1.04 \\
\hline $3 / 17 / 0621: 10$ & 10.75 & 1.11 & 89.63 & 1.44 & & 0.12 \\
\hline $3 / 17 / 0621: 20$ & 10.69 & 1.31 & 87.72 & 1.45 & & 0.21 \\
\hline $3 / 17 / 0621: 30$ & 11.50 & 1.54 & 86.63 & 1.46 & & 0.28 \\
\hline $3 / 17 / 0621: 40$ & 11.22 & 1.61 & 85.67 & 1.45 & & 0.36 \\
\hline $3 / 17 / 0621: 50$ & 11.48 & 1.40 & 87.77 & 1.49 & & 0.48 \\
\hline $3 / 17 / 0622: 00$ & 11.59 & 1.65 & 85.72 & 1.46 & & 0.50 \\
\hline $3 / 17 / 0622: 10$ & 11.70 & 1.35 & 88.45 & 1.48 & & \\
\hline $3 / 17 / 0622: 20$ & 11.65 & 1.77 & 84.84 & 1.44 & & \\
\hline $3 / 17 / 0622: 30$ & 11.53 & 1.43 & 87.60 & 1.45 & & 0.12 \\
\hline $3 / 17 / 0622: 40$ & 11.50 & 1.47 & 87.18 & 1.46 & & 0.17 \\
\hline $3 / 17 / 0622: 50$ & 11.45 & 1.47 & 87.16 & 1.45 & & 0.30 \\
\hline $3 / 17 / 0623: 00$ & 11.40 & 1.51 & 86.76 & 1.45 & & 0.33 \\
\hline $3 / 17 / 0623: 10$ & 12.09 & 1.64 & 86.46 & 1.42 & & 0.12 \\
\hline
\end{tabular}


Table D1. Corrected CMM and ACI, 10-minute Averaged Data During the Monthlong Field Test (continued)

\begin{tabular}{|c|c|c|c|c|c|c|}
\hline Date, Time & $\begin{array}{c}\text { FF Inlet } \mathrm{HgT}, \\
\mu \mathrm{g} / \mathrm{dNm}^{3}, \\
3 \% \mathrm{O}_{2}\end{array}$ & $\begin{array}{c}\text { FF Outlet HgT, } \\
\mu \mathrm{g} / \mathrm{dNm}^{3}, \\
3 \% \mathrm{O}_{2}\end{array}$ & $\begin{array}{c}\text { HgT Removal } \\
\text { Across } \\
\text { FF 2-4, \% } \\
\end{array}$ & $\begin{array}{l}\text { FF 2-4 Activated } \\
\text { Carbon Injection } \\
\text { Rate, lb/Macf }\end{array}$ & $\begin{array}{c}\text { FF Inlet } \mathrm{Hg}^{0}, \\
\mu \mathrm{g} / \mathrm{dNm}^{3}, \\
3 \% \mathrm{O}_{2} \\
\end{array}$ & $\begin{array}{c}\text { FF Outlet } \mathrm{Hg}^{0}, \\
\mu \mathrm{g} / \mathrm{dNm}^{3}, \\
3 \% \mathrm{O}_{2}\end{array}$ \\
\hline $3 / 17 / 0623: 20$ & 12.14 & 1.43 & 88.23 & 1.44 & & \\
\hline $3 / 17 / 0623: 30$ & 11.70 & 1.30 & 88.92 & 1.45 & & \\
\hline $3 / 17 / 0623: 40$ & 11.57 & 1.17 & 89.88 & 1.49 & & \\
\hline $3 / 17 / 0623: 50$ & 11.25 & 1.16 & 89.65 & 1.47 & & \\
\hline 3/18/06 0:00 & 11.42 & 1.28 & 88.82 & 1.48 & 4.97 & \\
\hline $3 / 18 / 060: 10$ & 11.08 & 0.90 & 91.84 & 1.45 & 4.38 & \\
\hline $3 / 18 / 060: 20$ & 10.95 & 1.08 & 90.16 & 1.44 & 4.31 & \\
\hline $3 / 18 / 060: 30$ & 10.70 & 1.29 & 87.93 & 1.44 & 4.08 & 0.12 \\
\hline $3 / 18 / 060: 40$ & 10.47 & 1.09 & 89.62 & 1.44 & 4.13 & 0.18 \\
\hline $3 / 18 / 060: 50$ & 10.15 & 1.53 & 84.89 & 1.47 & 3.81 & 0.35 \\
\hline 3/18/06 1:00 & 9.88 & 1.35 & 86.35 & 1.46 & 3.67 & 0.42 \\
\hline $3 / 18 / 061: 10$ & 9.91 & 1.14 & 88.47 & 1.44 & 4.21 & \\
\hline $3 / 18 / 061: 20$ & 10.09 & 1.03 & 89.74 & 1.40 & 3.87 & \\
\hline $3 / 18 / 061: 30$ & 10.04 & 1.24 & 87.63 & 1.43 & 3.60 & \\
\hline $3 / 18 / 061: 40$ & 9.84 & 1.32 & 86.54 & 1.46 & 3.85 & 0.12 \\
\hline $3 / 18 / 061: 50$ & 9.89 & 0.97 & 90.16 & 1.48 & 3.62 & \\
\hline $3 / 18 / 062: 00$ & 10.14 & 1.67 & 83.57 & 1.47 & 3.96 & \\
\hline $3 / 18 / 062: 10$ & 9.82 & 0.93 & 90.54 & 1.45 & 3.88 & 0.12 \\
\hline $3 / 18 / 062: 20$ & 9.98 & 1.75 & 82.42 & 1.46 & 4.27 & 0.16 \\
\hline $3 / 18 / 062: 30$ & 10.12 & 1.51 & 85.11 & 1.40 & 4.11 & 0.44 \\
\hline $3 / 18 / 062: 40$ & 9.95 & 1.71 & 82.80 & 1.37 & 4.19 & 0.73 \\
\hline $3 / 18 / 062: 50$ & 9.21 & 1.52 & 83.47 & 1.39 & 4.02 & 0.93 \\
\hline $3 / 18 / 063: 00$ & 9.31 & 1.43 & 84.63 & 1.42 & 4.55 & 1.02 \\
\hline $3 / 18 / 063: 10$ & 9.23 & 1.18 & 87.24 & 1.41 & 3.87 & 0.20 \\
\hline $3 / 18 / 063: 20$ & 8.89 & 2.07 & 76.78 & 1.40 & 4.03 & 0.45 \\
\hline $3 / 18 / 063: 30$ & 8.97 & 0.99 & 88.95 & 1.44 & 4.35 & 0.69 \\
\hline $3 / 18 / 063: 40$ & 9.02 & 0.71 & 92.12 & 1.43 & 4.47 & 0.90 \\
\hline $3 / 18 / 063: 50$ & 8.86 & 0.76 & 91.42 & 1.45 & 4.57 & 1.09 \\
\hline $3 / 18 / 064: 00$ & 9.95 & 1.53 & 84.58 & 1.47 & 5.03 & 1.26 \\
\hline $3 / 18 / 064: 10$ & 10.56 & 1.14 & 89.17 & 1.50 & 4.71 & 0.12 \\
\hline $3 / 18 / 064: 20$ & 10.69 & 1.02 & 90.46 & 1.45 & 4.74 & 0.21 \\
\hline $3 / 18 / 064: 30$ & 9.99 & 0.84 & 91.58 & 1.47 & 4.65 & 0.29 \\
\hline $3 / 18 / 064: 40$ & 9.90 & 0.87 & 91.19 & 1.47 & 4.49 & 0.26 \\
\hline $3 / 18 / 064: 50$ & 10.22 & 0.72 & 92.91 & 1.45 & 5.33 & 0.24 \\
\hline $3 / 18 / 065: 00$ & 10.63 & 0.80 & 92.50 & 1.44 & 4.91 & 0.34 \\
\hline $3 / 18 / 065: 10$ & 10.65 & 0.91 & 91.42 & 0.38 & 5.21 & 0.22 \\
\hline $3 / 18 / 065: 20$ & 11.27 & 1.30 & 88.44 & 0.12 & 5.47 & 0.37 \\
\hline $3 / 18 / 065: 30$ & 11.80 & 1.45 & 87.76 & 0.12 & 5.66 & 0.61 \\
\hline $3 / 18 / 065: 40$ & 11.63 & 1.81 & 84.40 & 0.13 & 5.63 & 0.72 \\
\hline $3 / 18 / 065: 50$ & 11.99 & 2.18 & 81.81 & 0.13 & 5.38 & 0.82 \\
\hline $3 / 18 / 06$ 6:00 & 11.21 & 2.56 & 77.17 & 0.14 & 5.06 & 0.83 \\
\hline $3 / 18 / 066: 10$ & 10.88 & 2.78 & 74.48 & 0.13 & 4.79 & 0.30 \\
\hline $3 / 18 / 066: 20$ & 12.13 & 4.80 & 60.45 & 0.13 & 5.19 & 0.31 \\
\hline $3 / 18 / 066: 30$ & 12.01 & 3.53 & 70.60 & 0.13 & 5.18 & 0.41 \\
\hline $3 / 18 / 066: 40$ & 11.71 & 3.70 & 68.38 & 0.14 & 4.59 & 0.49 \\
\hline $3 / 18 / 066: 50$ & 10.55 & 3.58 & 66.04 & 0.14 & 4.09 & 0.59 \\
\hline 3/18/06 7:00 & 10.52 & 3.40 & 67.67 & 0.14 & 3.91 & 0.62 \\
\hline $3 / 18 / 067: 10$ & 9.74 & 3.49 & 64.18 & 0.14 & 4.18 & 0.58 \\
\hline $3 / 18 / 06$ 7:20 & 9.54 & 3.43 & 64.07 & 0.13 & 4.16 & 0.50 \\
\hline $3 / 18 / 067: 30$ & 10.05 & 2.94 & 70.72 & 0.13 & 4.36 & 0.51 \\
\hline 3/18/06 7:40 & 9.97 & 3.18 & 68.16 & 0.13 & 4.48 & 0.55 \\
\hline $3 / 18 / 067: 50$ & 9.94 & 2.99 & 69.93 & 1.08 & 4.40 & 0.46 \\
\hline
\end{tabular}


Table D1. Corrected CMM and ACI, 10-minute Averaged Data During the Monthlong Field Test (continued)

\begin{tabular}{|c|c|c|c|c|c|c|}
\hline Date, Time & $\begin{array}{c}\text { FF Inlet } \mathrm{HgT}, \\
\mu \mathrm{g} / \mathrm{dNm}^{3}, \\
3 \% \mathrm{O}_{2}\end{array}$ & $\begin{array}{c}\text { FF Outlet } \mathrm{HgT}, \\
\mu \mathrm{g} / \mathrm{dNm}^{3} \\
3 \% \mathrm{O}_{2}\end{array}$ & $\begin{array}{c}\text { HgT Removal } \\
\text { Across } \\
\text { FF 2-4, } \% \\
\end{array}$ & $\begin{array}{c}\text { FF 2-4 Activated } \\
\text { Carbon Injection } \\
\text { Rate, lb/Macf }\end{array}$ & $\begin{array}{c}\text { FF Inlet } \mathrm{Hg}^{0}, \\
\mu \mathrm{g} / \mathrm{dNm}^{3}, \\
3 \% \mathrm{O}_{2}\end{array}$ & $\begin{array}{c}\text { FF Outlet } \mathrm{Hg}^{0}, \\
\mu \mathrm{g} / \mathrm{dNm}^{3}, \\
3 \% \mathrm{O}_{2}\end{array}$ \\
\hline 3/18/06 8:00 & 10.02 & 2.36 & 76.49 & 1.45 & 4.49 & 0.21 \\
\hline 3/18/06 8:10 & 10.48 & 1.83 & 82.51 & 1.46 & 4.88 & \\
\hline 3/18/06 8:20 & 10.61 & 2.37 & 77.67 & 1.45 & 4.54 & 0.12 \\
\hline 3/18/06 8:30 & 10.52 & 2.15 & 79.55 & 1.46 & 4.57 & 0.12 \\
\hline 3/18/06 8:40 & 10.33 & 1.89 & 81.73 & 1.47 & 4.64 & 0.19 \\
\hline 3/18/06 8:50 & & & & 1.46 & & \\
\hline 3/18/06 9:00 & & & & 1.46 & & \\
\hline 3/18/06 9:10 & & & & 1.48 & & \\
\hline 3/18/06 9:20 & & & & 1.46 & & \\
\hline 3/18/06 9:30 & & & & 1.47 & & \\
\hline 3/18/06 9:40 & & & & 1.46 & & \\
\hline 3/18/06 9:50 & & & & 1.49 & & \\
\hline $3 / 18 / 06$ 10:00 & & & & 0.54 & & \\
\hline $3 / 18 / 06$ 10:10 & & & & 0.13 & & \\
\hline $3 / 18 / 06$ 10:20 & 14.14 & 4.23 & 70.07 & 0.14 & 8.01 & 2.09 \\
\hline $3 / 18 / 0610: 30$ & 12.63 & 3.47 & 72.52 & 0.14 & 7.13 & 1.91 \\
\hline $3 / 18 / 06$ 10:40 & 11.57 & 3.08 & 73.38 & 0.14 & 6.62 & 1.56 \\
\hline $3 / 18 / 0610: 50$ & 10.64 & 3.36 & 68.41 & 0.13 & 6.26 & 1.62 \\
\hline $3 / 18 / 06$ 11:00 & 9.97 & 2.94 & 70.56 & 0.13 & 5.56 & 1.16 \\
\hline $3 / 18 / 0611: 10$ & 11.03 & 4.16 & 62.25 & 0.14 & 8.57 & 1.61 \\
\hline $3 / 18 / 0611: 20$ & & 3.71 & & 0.14 & & 0.46 \\
\hline $3 / 18 / 0611: 30$ & & 3.41 & & 0.13 & & \\
\hline $3 / 18 / 0611: 40$ & & 3.53 & & 0.13 & & \\
\hline $3 / 18 / 0611: 50$ & & 3.63 & & 0.13 & & \\
\hline $3 / 18 / 06$ 12:00 & & 3.71 & & 0.13 & & 0.84 \\
\hline $3 / 18 / 0612: 10$ & & 4.10 & & 0.13 & & 0.97 \\
\hline $3 / 18 / 0612: 20$ & & 4.77 & & 0.14 & & 0.90 \\
\hline $3 / 18 / 0612: 30$ & & 4.72 & & 0.14 & & 0.58 \\
\hline $3 / 18 / 0612: 40$ & & 4.87 & & 0.14 & & 0.61 \\
\hline $3 / 18 / 0612: 50$ & & 5.02 & & 0.14 & & 0.45 \\
\hline 3/18/06 13:00 & & 4.82 & & 0.15 & & 0.63 \\
\hline $3 / 18 / 0613: 10$ & & 5.06 & & 0.15 & & 0.99 \\
\hline $3 / 18 / 0613: 20$ & & 4.90 & & 0.15 & & 1.04 \\
\hline $3 / 18 / 0613: 30$ & & 4.52 & & 0.14 & & 1.07 \\
\hline $3 / 18 / 0613: 40$ & & 3.87 & & 1.45 & & 0.66 \\
\hline $3 / 18 / 0613: 50$ & & 2.93 & & 1.46 & & 0.44 \\
\hline $3 / 18 / 0614: 00$ & 13.99 & 2.42 & 82.69 & 1.45 & 11.44 & 0.49 \\
\hline $3 / 18 / 0614: 10$ & 12.76 & 2.29 & 82.07 & 1.45 & 12.63 & 0.12 \\
\hline $3 / 18 / 0614: 20$ & 11.91 & 2.16 & 81.89 & 1.49 & 11.64 & 0.12 \\
\hline $3 / 18 / 0614: 30$ & 11.56 & 1.96 & 83.05 & 1.49 & 12.19 & \\
\hline $3 / 18 / 0614: 40$ & 12.61 & 2.15 & 82.95 & 1.49 & 13.26 & \\
\hline $3 / 18 / 0614: 50$ & 13.14 & 1.89 & 85.61 & 1.49 & 13.48 & \\
\hline $3 / 18 / 06$ 15:00 & 13.01 & 1.86 & 85.68 & 1.49 & 13.59 & \\
\hline $3 / 18 / 0615: 10$ & 13.48 & 1.63 & 87.89 & 1.49 & 13.61 & \\
\hline $3 / 18 / 06$ 15:20 & 13.64 & 1.99 & 85.41 & 1.46 & 14.55 & \\
\hline $3 / 18 / 0615: 30$ & 14.17 & 1.91 & 86.54 & 1.47 & 14.65 & \\
\hline $3 / 18 / 06$ 15:40 & 14.67 & 1.98 & 86.53 & 1.49 & 15.65 & 0.12 \\
\hline $3 / 18 / 0615: 50$ & 14.01 & 1.59 & 88.64 & 1.47 & 14.55 & 0.16 \\
\hline $3 / 18 / 0616: 00$ & 13.45 & 1.79 & 86.66 & 1.47 & 14.10 & 0.33 \\
\hline $3 / 18 / 0616: 10$ & 13.11 & 1.90 & 85.54 & 1.43 & 13.24 & 0.12 \\
\hline $3 / 18 / 0616: 20$ & 12.24 & 1.40 & 88.57 & 1.46 & 11.99 & 0.27 \\
\hline $3 / 18 / 0616: 30$ & 11.74 & 1.49 & 87.33 & 1.46 & 11.51 & 0.39 \\
\hline
\end{tabular}


Table D1. Corrected CMM and ACI, 10-minute Averaged Data During the Monthlong Field Test (continued)

\begin{tabular}{|c|c|c|c|c|c|c|}
\hline Date, Time & $\begin{array}{c}\text { FF Inlet } \mathrm{HgT} \text {, } \\
\mu \mathrm{g} / \mathrm{dNm}^{3}, \\
3 \% \mathrm{O}_{2} \\
\end{array}$ & $\begin{array}{c}\text { FF Outlet } \mathrm{HgT} \text {, } \\
\mu \mathrm{g} / \mathrm{dNm}^{3} \\
3 \% \mathrm{O}_{2}\end{array}$ & $\begin{array}{c}\text { HgT Removal } \\
\text { Across } \\
\text { FF 2-4, } \% \\
\end{array}$ & $\begin{array}{c}\text { FF 2-4 Activated } \\
\text { Carbon Injection } \\
\text { Rate, lb/Macf } \\
\end{array}$ & $\begin{array}{c}\text { FF Inlet } \mathrm{Hg}^{0}, \\
\mu \mathrm{g} / \mathrm{dNm}^{3}, \\
3 \% \mathrm{O}_{2}\end{array}$ & $\begin{array}{c}\text { FF Outlet } \mathrm{Hg}^{0}, \\
\mu \mathrm{g} / \mathrm{dNm}^{3}, \\
3 \% \mathrm{O}_{2}\end{array}$ \\
\hline $3 / 18 / 0616: 40$ & 11.48 & 1.47 & 87.23 & 1.46 & 11.84 & 0.50 \\
\hline $3 / 18 / 0616: 50$ & 11.29 & 1.88 & 83.33 & 1.45 & 11.34 & 0.67 \\
\hline 3/18/06 17:00 & 11.21 & 1.50 & 86.59 & 1.45 & 11.58 & 0.81 \\
\hline $3 / 18 / 06$ 17:10 & 10.91 & 1.30 & 88.09 & 1.46 & 10.72 & 0.16 \\
\hline $3 / 18 / 06$ 17:20 & 10.64 & 1.24 & 88.32 & 1.45 & 10.40 & 0.29 \\
\hline $3 / 18 / 06$ 17:30 & 10.82 & 1.19 & 88.97 & 1.48 & 10.71 & 0.50 \\
\hline $3 / 18 / 06 \quad 17: 40$ & 10.56 & 1.31 & 87.61 & 1.46 & 9.31 & 0.61 \\
\hline $3 / 18 / 06$ 17:50 & 10.41 & 1.16 & 88.83 & 1.39 & 10.02 & 0.64 \\
\hline $3 / 18 / 06$ 18:00 & 12.15 & 1.11 & 90.89 & 1.34 & 11.24 & 0.63 \\
\hline 3/18/06 18:10 & 12.95 & 1.13 & 91.28 & 1.46 & 11.14 & \\
\hline $3 / 18 / 06$ 18:20 & 13.55 & 1.19 & 91.24 & 1.49 & 11.93 & \\
\hline $3 / 18 / 0618: 30$ & 14.13 & 1.05 & 92.54 & 1.45 & 12.25 & \\
\hline $3 / 18 / 06$ 18:40 & 14.15 & 0.99 & 93.00 & 1.45 & 12.52 & \\
\hline $3 / 18 / 06$ 18:50 & 14.08 & 0.88 & 93.78 & 1.45 & 12.50 & \\
\hline $3 / 18 / 06$ 19:00 & 13.40 & 0.85 & 93.68 & 1.48 & 12.46 & \\
\hline $3 / 18 / 06$ 19:10 & 13.75 & 0.96 & 93.02 & 1.44 & 12.75 & \\
\hline 3/18/06 19:20 & 14.40 & 1.24 & 91.35 & 1.48 & 13.03 & \\
\hline $3 / 18 / 06$ 19:30 & 14.35 & 1.02 & 92.86 & 1.47 & 13.12 & \\
\hline $3 / 18 / 06$ 19:40 & 15.02 & 0.88 & 94.14 & 1.47 & 13.74 & \\
\hline $3 / 18 / 06$ 19:50 & 15.39 & 0.96 & 93.75 & 1.43 & 13.65 & \\
\hline $3 / 18 / 0620: 00$ & 14.67 & 0.92 & 93.72 & 1.42 & 12.68 & \\
\hline $3 / 18 / 0620: 10$ & 14.71 & 0.95 & 93.57 & 1.43 & 12.35 & \\
\hline $3 / 18 / 0620: 20$ & 13.45 & 0.88 & 93.46 & 1.47 & 11.89 & \\
\hline $3 / 18 / 0620: 30$ & 13.15 & 0.97 & 92.61 & 1.47 & 11.57 & \\
\hline $3 / 18 / 0620: 40$ & 13.78 & 0.80 & 94.18 & 1.48 & 12.53 & \\
\hline $3 / 18 / 0620: 50$ & 14.01 & 0.85 & 93.95 & 1.49 & 12.41 & \\
\hline $3 / 18 / 0621: 00$ & 13.47 & 1.00 & 92.56 & 1.46 & 11.77 & \\
\hline $3 / 18 / 0621: 10$ & 12.40 & 0.99 & 92.00 & 1.50 & 10.60 & \\
\hline $3 / 18 / 0621: 20$ & 12.49 & 1.09 & 91.30 & 1.47 & 10.66 & \\
\hline $3 / 18 / 0621: 30$ & 11.49 & 1.07 & 90.67 & 1.48 & 10.04 & \\
\hline $3 / 18 / 0621: 40$ & 11.24 & 1.13 & 89.99 & 1.49 & 10.12 & \\
\hline $3 / 18 / 0621: 50$ & 12.14 & 0.95 & 92.20 & 1.46 & 10.72 & \\
\hline 3/18/06 22:00 & 12.22 & 0.86 & 92.94 & 1.47 & 10.74 & \\
\hline $3 / 18 / 0622: 10$ & 11.79 & 1.01 & 91.43 & 1.50 & 10.71 & \\
\hline $3 / 18 / 0622: 20$ & 13.00 & 1.02 & 92.19 & 1.49 & 11.44 & \\
\hline $3 / 18 / 0622: 30$ & 12.92 & 1.13 & 91.26 & 1.47 & 11.29 & \\
\hline $3 / 18 / 0622: 40$ & 12.22 & 1.00 & 91.80 & 1.48 & 10.57 & \\
\hline $3 / 18 / 0622: 50$ & 12.13 & 0.96 & 92.07 & 1.45 & 10.24 & \\
\hline 3/18/06 23:00 & 12.14 & 0.87 & 92.86 & 1.47 & 10.49 & \\
\hline $3 / 18 / 0623: 10$ & 13.52 & 0.94 & 93.03 & 1.50 & 11.07 & \\
\hline $3 / 18 / 0623: 20$ & 14.93 & 0.99 & 93.39 & 1.49 & 11.63 & \\
\hline $3 / 18 / 0623: 30$ & 14.93 & 0.91 & 93.88 & 1.50 & 12.10 & \\
\hline $3 / 18 / 0623: 40$ & 15.16 & 1.02 & 93.27 & 1.47 & 12.61 & \\
\hline $3 / 18 / 0623: 50$ & 14.70 & 0.92 & 93.76 & 1.47 & 12.64 & \\
\hline 3/19/06 0:00 & 14.42 & 0.99 & 93.11 & 1.46 & 12.17 & \\
\hline 3/19/06 0:10 & 13.92 & 0.73 & 94.76 & 1.44 & 11.33 & \\
\hline 3/19/06 0:20 & 12.96 & 0.88 & 93.23 & 1.43 & 10.60 & \\
\hline 3/19/06 0:30 & 12.35 & 0.87 & 93.00 & 1.42 & 10.48 & \\
\hline 3/19/06 0:40 & 13.01 & 0.81 & 93.76 & 1.42 & 10.21 & \\
\hline 3/19/06 0:50 & 11.98 & 0.73 & 93.88 & 1.42 & 9.99 & \\
\hline 3/19/06 1:00 & 12.05 & 0.95 & 92.14 & 1.40 & 9.50 & \\
\hline 3/19/06 1:10 & 11.72 & 0.93 & 92.08 & 1.44 & 9.91 & \\
\hline
\end{tabular}


Table D1. Corrected CMM and ACI, 10-minute Averaged Data During the Monthlong Field Test (continued)

\begin{tabular}{|c|c|c|c|c|c|c|}
\hline Date, Time & $\begin{array}{c}\text { FF Inlet } \mathrm{HgT}, \\
\mu \mathrm{g} / \mathrm{dNm}^{3}, \\
3 \% \mathrm{O}_{2} \\
\end{array}$ & $\begin{array}{c}\text { FF Outlet HgT, } \\
\mu \mathrm{g} / \mathrm{dNm}^{3}, \\
3 \% \mathrm{O}_{2} \\
\end{array}$ & $\begin{array}{c}\text { HgT Removal } \\
\text { Across } \\
\text { FF } 2-4, \% \\
\end{array}$ & $\begin{array}{c}\text { FF 2-4 Activated } \\
\text { Carbon Injection } \\
\text { Rate, lb/Macf }\end{array}$ & $\begin{array}{c}\text { FF Inlet } \mathrm{Hg}^{0}, \\
\mu \mathrm{g} / \mathrm{dNm}^{3}, \\
3 \% \mathrm{O}_{2} \\
\end{array}$ & $\begin{array}{c}\text { FF Outlet } \mathrm{Hg}^{0}, \\
\mu \mathrm{g} / \mathrm{dNm}^{3}, \\
3 \% \mathrm{O}_{2} \\
\end{array}$ \\
\hline $3 / 19 / 061: 20$ & 11.88 & 0.69 & 94.17 & 1.43 & 9.76 & \\
\hline $3 / 19 / 061: 30$ & 12.01 & 0.79 & 93.39 & 1.41 & 9.58 & \\
\hline $3 / 19 / 061: 40$ & 11.37 & 0.90 & 92.12 & 1.43 & 9.47 & 0.21 \\
\hline $3 / 19 / 061: 50$ & 11.34 & 0.87 & 92.36 & 1.41 & 9.28 & 0.51 \\
\hline $3 / 19 / 062: 00$ & 10.99 & 0.89 & 91.85 & 1.45 & 9.45 & 0.62 \\
\hline $3 / 19 / 062: 10$ & 10.74 & 0.69 & 93.58 & 1.44 & 8.69 & 0.12 \\
\hline $3 / 19 / 062: 20$ & 10.32 & 0.75 & 92.69 & 1.43 & 9.09 & 0.12 \\
\hline $3 / 19 / 062: 30$ & 11.26 & 0.66 & 94.13 & 1.44 & 9.81 & 0.15 \\
\hline $3 / 19 / 062: 40$ & 11.21 & 0.78 & 93.09 & 1.48 & 10.04 & 0.22 \\
\hline $3 / 19 / 062: 50$ & 12.10 & 0.62 & 94.86 & 1.49 & 10.53 & 0.25 \\
\hline $3 / 19 / 063: 00$ & 12.76 & 0.65 & 94.94 & 1.47 & 10.96 & 0.33 \\
\hline $3 / 19 / 063: 10$ & 12.93 & 0.65 & 95.01 & 1.48 & 11.06 & \\
\hline $3 / 19 / 063: 20$ & 13.40 & 0.71 & 94.68 & 1.46 & 11.22 & \\
\hline $3 / 19 / 063: 30$ & 13.55 & 1.03 & 92.39 & 1.47 & 11.18 & \\
\hline $3 / 19 / 063: 40$ & 13.04 & 0.88 & 93.25 & 1.43 & 10.53 & \\
\hline $3 / 19 / 063: 50$ & 12.57 & 0.54 & 95.69 & 1.45 & 10.20 & \\
\hline $3 / 19 / 064: 00$ & 12.11 & 0.61 & 94.99 & 1.41 & 9.86 & \\
\hline $3 / 19 / 064: 10$ & 12.81 & 0.71 & 94.48 & 1.48 & 10.02 & \\
\hline $3 / 19 / 064: 20$ & 14.10 & 0.81 & 94.22 & 1.51 & 10.63 & \\
\hline $3 / 19 / 064: 30$ & 14.18 & 0.77 & 94.55 & 1.49 & 11.61 & \\
\hline $3 / 19 / 064: 40$ & 14.09 & 0.53 & 96.23 & 1.50 & 11.72 & \\
\hline $3 / 19 / 064: 50$ & 14.30 & 0.57 & 96.03 & 1.47 & 11.86 & \\
\hline 3/19/06 5:00 & 13.56 & 0.66 & 95.17 & 1.48 & 11.63 & \\
\hline $3 / 19 / 065: 10$ & 13.65 & 0.84 & 93.83 & 1.48 & 11.73 & \\
\hline $3 / 19 / 065: 20$ & 13.78 & 0.60 & 95.63 & 1.48 & 11.53 & \\
\hline $3 / 19 / 065: 30$ & 13.12 & 0.60 & 95.42 & 1.47 & 11.16 & \\
\hline $3 / 19 / 065: 40$ & 13.54 & 0.68 & 95.00 & 1.47 & 10.96 & \\
\hline $3 / 19 / 065: 50$ & 12.87 & 0.84 & 93.44 & 1.45 & 10.38 & \\
\hline $3 / 19 / 066: 00$ & 12.05 & 0.61 & 94.96 & 1.44 & 9.89 & \\
\hline $3 / 19 / 066: 10$ & 11.83 & 0.65 & 94.51 & 1.49 & 10.23 & \\
\hline $3 / 19 / 066: 20$ & 11.78 & 0.77 & 93.48 & 1.49 & 10.99 & 0.13 \\
\hline $3 / 19 / 066: 30$ & 12.78 & 0.90 & 92.96 & 0.13 & 11.85 & 0.32 \\
\hline $3 / 19 / 066: 40$ & 13.95 & 1.34 & 90.42 & 0.14 & 11.59 & 0.70 \\
\hline $3 / 19 / 066: 50$ & 12.59 & 1.33 & 89.44 & 0.14 & 10.65 & 0.97 \\
\hline 3/19/06 7:00 & 12.18 & 1.34 & 89.02 & 0.14 & 10.55 & 1.01 \\
\hline $3 / 19 / 067: 10$ & 11.98 & 1.90 & 84.14 & 0.13 & 10.17 & 0.38 \\
\hline $3 / 19 / 06$ 7:20 & 12.56 & 2.40 & 80.89 & 0.13 & 11.00 & 0.49 \\
\hline $3 / 19 / 067: 30$ & 13.34 & 3.03 & 77.31 & 0.14 & 11.20 & 0.68 \\
\hline $3 / 19 / 067: 40$ & 12.96 & 3.14 & 75.80 & 0.13 & 10.82 & 0.84 \\
\hline $3 / 19 / 067: 50$ & 12.86 & 3.26 & 74.68 & 0.14 & 10.42 & 0.86 \\
\hline 3/19/06 8:00 & 12.18 & 2.92 & 76.03 & 0.14 & 10.76 & 0.89 \\
\hline 3/19/06 8:10 & 12.83 & 3.43 & 73.29 & 0.14 & 10.39 & 0.71 \\
\hline $3 / 19 / 068: 20$ & 12.67 & 3.33 & 73.69 & 0.14 & 10.61 & 0.85 \\
\hline 3/19/06 8:30 & 12.67 & 3.73 & 70.59 & 0.14 & 10.85 & 0.86 \\
\hline 3/19/06 8:40 & 13.25 & 3.45 & 73.94 & 0.14 & 10.56 & 0.92 \\
\hline 3/19/06 8:50 & 13.19 & 3.34 & 74.65 & 0.14 & 10.70 & 0.85 \\
\hline 3/19/06 9:00 & 13.18 & 4.24 & 67.82 & 0.13 & 10.88 & 0.87 \\
\hline 3/19/06 9:10 & 15.22 & 4.63 & 69.56 & 0.12 & 11.68 & 0.95 \\
\hline 3/19/06 9:20 & 16.98 & 4.41 & 74.03 & 0.12 & 12.70 & 0.89 \\
\hline 3/19/06 9:30 & 18.07 & 5.51 & 69.49 & 0.12 & 13.66 & 1.10 \\
\hline 3/19/06 9:40 & 18.02 & 6.10 & 66.14 & 0.12 & 13.59 & 1.29 \\
\hline 3/19/06 9:50 & 17.84 & 7.45 & 58.26 & 0.14 & 13.09 & 1.60 \\
\hline
\end{tabular}


Table D1. Corrected CMM and ACI, 10-minute Averaged Data During the Monthlong Field Test (continued)

\begin{tabular}{|c|c|c|c|c|c|c|}
\hline Date, Time & $\begin{array}{c}\text { FF Inlet } \mathrm{HgT}, \\
\mu \mathrm{g} / \mathrm{dNm}^{3}, \\
3 \% \mathrm{O}_{2} \\
\end{array}$ & $\begin{array}{c}\text { FF Outlet } \mathrm{HgT}, \\
\mu \mathrm{g} / \mathrm{dNm}^{3} \\
3 \% \mathrm{O}_{2}\end{array}$ & $\begin{array}{c}\text { HgT Removal } \\
\text { Across } \\
\text { FF } 2-4, \% \\
\end{array}$ & $\begin{array}{c}\text { FF 2-4 Activated } \\
\text { Carbon Injection } \\
\text { Rate, lb/Macf }\end{array}$ & $\begin{array}{c}\text { FF Inlet } \mathrm{Hg}^{0}, \\
\mu \mathrm{g} / \mathrm{dNm}^{3}, \\
3 \% \mathrm{O}_{2}\end{array}$ & $\begin{array}{c}\text { FF Outlet } \mathrm{Hg}^{0}, \\
\mu \mathrm{g} / \mathrm{dNm}^{3}, \\
3 \% \mathrm{O}_{2}\end{array}$ \\
\hline $3 / 19 / 06$ 10:00 & 16.87 & 7.23 & 57.14 & 0.14 & 12.21 & 1.58 \\
\hline 3/19/06 10:10 & 14.91 & 7.51 & 49.65 & 0.14 & 11.76 & 1.58 \\
\hline $3 / 19 / 0610: 20$ & 14.36 & 7.16 & 50.15 & 0.14 & 11.28 & 1.55 \\
\hline $3 / 19 / 0610: 30$ & 14.10 & 7.38 & 47.69 & 0.14 & 11.13 & 1.55 \\
\hline 3/19/06 10:40 & 13.34 & 7.02 & 47.34 & 0.15 & 10.76 & 1.70 \\
\hline $3 / 19 / 0610: 50$ & 13.17 & 6.00 & 54.49 & 1.47 & 10.66 & 0.67 \\
\hline 3/19/06 11:00 & 12.79 & 4.82 & 62.30 & 1.46 & 10.57 & 0.14 \\
\hline $3 / 19 / 0611: 10$ & 13.27 & 3.40 & 74.36 & 1.48 & 10.66 & \\
\hline $3 / 19 / 0611: 20$ & 12.91 & 3.09 & 76.05 & 1.51 & 11.05 & \\
\hline $3 / 19 / 0611: 30$ & 13.69 & 3.01 & 78.03 & 1.34 & 12.05 & \\
\hline $3 / 19 / 06$ 11:40 & 14.85 & 3.37 & 77.28 & 0.12 & 12.69 & 0.39 \\
\hline $3 / 19 / 0611: 50$ & 16.11 & 4.42 & 72.56 & 0.12 & 13.05 & 0.62 \\
\hline $3 / 19 / 0612: 00$ & 16.21 & 5.19 & 68.00 & 0.14 & 12.67 & 0.78 \\
\hline $3 / 19 / 0612: 10$ & 15.86 & 6.25 & 60.62 & 0.13 & 12.18 & 1.00 \\
\hline $3 / 19 / 0612: 20$ & 15.76 & 5.78 & 63.33 & 0.13 & 11.63 & 0.98 \\
\hline $3 / 19 / 0612: 30$ & 14.51 & 7.92 & 45.43 & 0.13 & 12.12 & 1.04 \\
\hline $3 / 19 / 0612: 40$ & 15.00 & 6.92 & 53.84 & 0.13 & 12.26 & 1.02 \\
\hline $3 / 19 / 0612: 50$ & 16.21 & 8.10 & 50.04 & 0.14 & 12.07 & 1.12 \\
\hline 3/19/06 13:00 & 14.42 & 7.75 & 46.24 & 0.14 & 11.68 & 1.06 \\
\hline $3 / 19 / 0613: 10$ & 14.61 & 7.46 & 48.96 & 0.14 & 11.43 & 1.30 \\
\hline $3 / 19 / 0613: 20$ & 13.67 & 7.86 & 42.46 & 0.14 & 11.44 & 1.11 \\
\hline $3 / 19 / 0613: 30$ & 13.47 & 7.11 & 47.22 & 0.14 & 11.40 & 1.20 \\
\hline $3 / 19 / 0613: 40$ & 13.70 & 8.38 & 38.83 & 0.14 & 11.23 & 1.21 \\
\hline $3 / 19 / 0613: 50$ & 13.27 & 7.50 & 43.44 & 0.14 & 11.02 & 1.10 \\
\hline $3 / 19 / 06$ 14:00 & 13.48 & 7.63 & 43.37 & 0.14 & 11.09 & 1.20 \\
\hline $3 / 19 / 0614: 10$ & 15.25 & 7.67 & 49.69 & 0.14 & 11.58 & 1.17 \\
\hline $3 / 19 / 0614: 20$ & 16.78 & 9.17 & 45.33 & 0.12 & 12.17 & 1.30 \\
\hline $3 / 19 / 0614: 30$ & 17.73 & 9.01 & 49.17 & 0.12 & 13.40 & 1.27 \\
\hline $3 / 19 / 0614: 40$ & 17.59 & 10.49 & 40.34 & 0.13 & 13.32 & 1.45 \\
\hline $3 / 19 / 0614: 50$ & 16.35 & 11.35 & 30.56 & 0.13 & 12.43 & 1.44 \\
\hline 3/19/06 15:00 & 15.33 & 10.91 & 28.87 & 0.12 & 11.88 & 1.50 \\
\hline $3 / 19 / 0615: 10$ & 14.30 & 13.76 & 3.75 & 0.13 & 12.26 & 1.41 \\
\hline $3 / 19 / 06$ 15:20 & 13.51 & 12.58 & 6.89 & 0.14 & 11.89 & 1.51 \\
\hline $3 / 19 / 0615: 30$ & 12.64 & 12.72 & 0 & 0.14 & 11.49 & 1.50 \\
\hline $3 / 19 / 0615: 40$ & 11.90 & 10.60 & 10.89 & 0.14 & 11.01 & 1.38 \\
\hline $3 / 19 / 06$ 15:50 & 12.03 & 11.17 & 7.18 & 0.14 & 10.37 & 1.53 \\
\hline $3 / 19 / 0616: 00$ & 11.30 & 10.50 & 7.00 & 0.14 & 10.44 & 1.34 \\
\hline $3 / 19 / 0616: 10$ & 11.63 & 9.60 & 17.47 & 0.14 & 11.13 & 1.39 \\
\hline $3 / 19 / 0616: 20$ & 12.07 & 9.21 & 23.66 & 0.42 & 10.64 & 1.26 \\
\hline $3 / 19 / 0616: 30$ & 12.52 & 7.51 & 40.02 & 1.46 & 11.03 & 0.52 \\
\hline $3 / 19 / 06$ 16:40 & 12.71 & 5.75 & 54.80 & 1.46 & 11.34 & \\
\hline $3 / 19 / 0616: 50$ & 13.60 & 3.73 & 72.55 & 1.47 & 11.68 & \\
\hline $3 / 19 / 06$ 17:00 & 12.95 & 3.56 & 72.53 & 1.46 & 11.36 & \\
\hline $3 / 19 / 06$ 17:10 & 13.20 & 4.09 & 69.04 & 1.46 & 11.44 & \\
\hline $3 / 19 / 06$ 17:20 & 13.33 & 3.89 & 70.78 & 1.47 & 11.23 & \\
\hline $3 / 19 / 0617: 30$ & 13.02 & 3.50 & 73.10 & 1.50 & 11.39 & \\
\hline $3 / 19 / 06$ 17:40 & 14.03 & 3.13 & 77.67 & 1.51 & 11.88 & \\
\hline $3 / 19 / 06$ 17:50 & 14.20 & 4.15 & 70.77 & 1.49 & 11.10 & \\
\hline 3/19/06 18:00 & 13.43 & & & 1.50 & 10.82 & \\
\hline $3 / 19 / 06$ 18:10 & & & & 1.49 & & \\
\hline $3 / 19 / 06$ 18:20 & & & & 1.50 & & \\
\hline $3 / 19 / 0618: 30$ & & & & 1.49 & & \\
\hline
\end{tabular}


Table D1. Corrected CMM and ACI, 10-minute Averaged Data During the Monthlong Field Test (continued)

\begin{tabular}{|c|c|c|c|c|c|c|}
\hline Date, Time & $\begin{array}{c}\text { FF Inlet } \mathrm{HgT}, \\
\mu \mathrm{g} / \mathrm{dNm}^{3}, \\
3 \% \mathrm{O}_{2} \\
\end{array}$ & $\begin{array}{c}\text { FF Outlet } \mathrm{HgT}, \\
\mu \mathrm{g} / \mathrm{dNm}^{3}, \\
3 \% \mathrm{O}_{2}\end{array}$ & $\begin{array}{c}\text { HgT Removal } \\
\text { Across } \\
\text { FF 2-4, } \% \\
\end{array}$ & $\begin{array}{c}\text { FF 2-4 Activated } \\
\text { Carbon Injection } \\
\text { Rate, lb/Macf } \\
\end{array}$ & $\begin{array}{c}\text { FF Inlet } \mathrm{Hg}^{0}, \\
\mu \mathrm{g} / \mathrm{dNm}^{3}, \\
3 \% \mathrm{O}_{2} \\
\end{array}$ & $\begin{array}{c}\text { FF Outlet } \mathrm{Hg}^{0}, \\
\mu \mathrm{g} / \mathrm{dNm}^{3}, \\
3 \% \mathrm{O}_{2}\end{array}$ \\
\hline $3 / 19 / 0618: 40$ & & 4.66 & & 1.47 & & 0.12 \\
\hline $3 / 19 / 06$ 18:50 & & 4.96 & & 1.50 & & \\
\hline $3 / 19 / 06$ 19:00 & 17.70 & 5.19 & 70.69 & 1.50 & 14.32 & \\
\hline $3 / 19 / 0619: 10$ & 18.56 & 5.84 & 68.52 & 1.49 & 14.15 & \\
\hline $3 / 19 / 06$ 19:20 & 19.73 & 5.62 & 71.50 & 1.46 & 13.97 & \\
\hline $3 / 19 / 0619: 30$ & 18.44 & 5.03 & 72.70 & 1.49 & 12.86 & \\
\hline $3 / 19 / 0619: 40$ & 16.24 & 4.48 & 72.42 & 1.45 & 12.04 & \\
\hline $3 / 19 / 0619: 50$ & 14.61 & 4.61 & 68.46 & 1.48 & 11.61 & \\
\hline $3 / 19 / 0620: 00$ & 12.84 & 3.63 & 71.75 & 1.47 & 11.05 & \\
\hline $3 / 19 / 0620: 10$ & 12.83 & 4.32 & 66.29 & 1.46 & 11.74 & \\
\hline $3 / 19 / 0620: 20$ & 12.01 & 3.83 & 68.06 & 1.47 & 11.80 & \\
\hline $3 / 19 / 0620: 30$ & 11.94 & 3.91 & 67.21 & 1.48 & 11.55 & \\
\hline $3 / 19 / 0620: 40$ & 11.86 & 2.84 & 76.02 & 1.51 & 12.01 & \\
\hline $3 / 19 / 0620: 50$ & 11.94 & 2.91 & 75.61 & 1.49 & 12.50 & \\
\hline $3 / 19 / 0621: 00$ & 12.45 & 3.07 & 75.34 & 1.51 & 12.13 & \\
\hline $3 / 19 / 0621: 10$ & 13.48 & 2.88 & 78.63 & 1.50 & 13.34 & \\
\hline $3 / 19 / 0621: 20$ & 13.19 & 3.48 & 73.60 & 1.51 & 13.52 & \\
\hline $3 / 19 / 0621: 30$ & 13.81 & 2.93 & 78.82 & 1.49 & 13.76 & \\
\hline $3 / 19 / 0621: 40$ & 14.44 & 2.70 & 81.27 & 1.49 & 14.30 & \\
\hline $3 / 19 / 0621: 50$ & 15.48 & 2.36 & 84.73 & 1.45 & 15.07 & \\
\hline $3 / 19 / 0622: 00$ & 17.49 & 2.35 & 86.54 & 1.44 & 14.91 & \\
\hline $3 / 19 / 0622: 10$ & 17.37 & 2.87 & 83.50 & 1.46 & 15.25 & 0.12 \\
\hline $3 / 19 / 0622: 20$ & 16.89 & 3.17 & 81.21 & 1.46 & 15.59 & 0.20 \\
\hline $3 / 19 / 0622: 30$ & 17.93 & 2.63 & 85.34 & 1.49 & 15.80 & 0.27 \\
\hline $3 / 19 / 0622: 40$ & 17.39 & 2.69 & 84.52 & 1.47 & 16.23 & 0.37 \\
\hline $3 / 19 / 0622: 50$ & 18.25 & 2.93 & 83.92 & 1.48 & 16.38 & 0.44 \\
\hline $3 / 19 / 0623: 00$ & 18.76 & 2.70 & 85.61 & 1.45 & 16.17 & 0.59 \\
\hline $3 / 19 / 0623: 10$ & 20.06 & 4.99 & 75.14 & 1.46 & 16.29 & \\
\hline $3 / 19 / 0623: 20$ & 20.18 & 2.55 & 87.38 & 1.44 & 15.54 & 0.12 \\
\hline $3 / 19 / 0623: 30$ & 21.71 & 2.43 & 88.80 & 1.46 & 15.45 & 0.12 \\
\hline $3 / 19 / 0623: 40$ & 18.77 & 3.36 & 82.08 & 1.47 & 14.36 & 0.17 \\
\hline $3 / 19 / 0623: 50$ & 17.19 & 2.39 & 86.11 & 1.45 & 14.05 & 0.32 \\
\hline 3/20/06 0:00 & 16.42 & 3.00 & 81.74 & 1.44 & 15.00 & 0.46 \\
\hline 3/20/06 0:10 & 14.34 & & & 1.40 & 13.65 & \\
\hline 3/20/06 0:20 & 14.00 & & & 1.41 & 12.90 & \\
\hline 3/20/06 0:30 & 12.59 & & & 1.37 & 13.38 & \\
\hline $3 / 20 / 060: 40$ & 12.06 & & & 1.41 & 13.03 & \\
\hline 3/20/06 0:50 & 12.43 & & & 1.41 & 12.96 & \\
\hline 3/20/06 1:00 & 10.90 & & & 1.42 & 11.95 & \\
\hline 3/20/06 1:10 & 11.41 & & & 1.45 & 11.80 & \\
\hline 3/20/06 1:20 & 12.17 & & & 1.46 & 12.51 & \\
\hline 3/20/06 1:30 & 12.44 & & & 1.45 & 13.15 & \\
\hline 3/20/06 1:40 & 13.22 & & & 1.42 & 13.59 & \\
\hline $3 / 20 / 061: 50$ & 13.77 & & & 1.46 & 14.00 & \\
\hline 3/20/06 2:00 & 14.91 & & & 1.40 & 14.02 & \\
\hline $3 / 20 / 062: 10$ & 14.92 & & & 1.42 & 13.73 & \\
\hline $3 / 20 / 062: 20$ & 15.58 & & & 1.44 & 14.14 & \\
\hline $3 / 20 / 062: 30$ & 15.38 & & & 1.45 & 13.48 & \\
\hline 3/20/06 2:40 & 15.11 & & & 1.47 & 14.31 & \\
\hline $3 / 20 / 062: 50$ & 15.75 & & & 1.47 & 14.78 & \\
\hline 3/20/06 3:00 & 15.96 & & & 1.44 & 14.79 & \\
\hline 3/20/06 3:10 & 15.27 & & & 1.49 & 13.25 & \\
\hline
\end{tabular}


Table D1. Corrected CMM and ACI, 10-minute Averaged Data During the Monthlong Field Test (continued)

\begin{tabular}{|c|c|c|c|c|c|c|}
\hline Date, Time & $\begin{array}{c}\text { FF Inlet } \mathrm{HgT}, \\
\mu \mathrm{g} / \mathrm{dNm}^{3}, \\
3 \% \mathrm{O}_{2} \\
\end{array}$ & $\begin{array}{c}\text { FF Outlet HgT, } \\
\mu \mathrm{g} / \mathrm{dNm}^{3}, \\
3 \% \mathrm{O}_{2}\end{array}$ & $\begin{array}{c}\text { HgT Removal } \\
\text { Across } \\
\text { FF } 2-4, \% \\
\end{array}$ & $\begin{array}{c}\text { FF 2-4 Activated } \\
\text { Carbon Injection } \\
\text { Rate, lb/Macf }\end{array}$ & $\begin{array}{c}\text { FF Inlet } \mathrm{Hg}^{0}, \\
\mu \mathrm{g} / \mathrm{dNm}^{3}, \\
3 \% \mathrm{O}_{2} \\
\end{array}$ & $\begin{array}{c}\text { FF Outlet } \mathrm{Hg}^{0}, \\
\mu \mathrm{g} / \mathrm{dNm}^{3}, \\
3 \% \mathrm{O}_{2}\end{array}$ \\
\hline $3 / 20 / 063: 20$ & 13.73 & & & 1.50 & 13.32 & \\
\hline $3 / 20 / 063: 30$ & 15.03 & & & 1.48 & 14.33 & \\
\hline $3 / 20 / 063: 40$ & 16.54 & & & 1.49 & 15.91 & \\
\hline $3 / 20 / 063: 50$ & 18.16 & & & 1.44 & 17.18 & \\
\hline $3 / 20 / 064: 00$ & 20.26 & & & 1.46 & 17.66 & \\
\hline $3 / 20 / 064: 10$ & 22.57 & & & 1.40 & 17.69 & \\
\hline $3 / 20 / 064: 20$ & 21.53 & & & 1.41 & 15.77 & \\
\hline $3 / 20 / 064: 30$ & 18.55 & & & 1.43 & 14.17 & \\
\hline $3 / 20 / 064: 40$ & 17.44 & & & 1.49 & 13.35 & \\
\hline $3 / 20 / 064: 50$ & 16.52 & & & 1.50 & 14.55 & \\
\hline $3 / 20 / 065: 00$ & 16.21 & & & 1.48 & 15.11 & \\
\hline $3 / 20 / 065: 10$ & 16.32 & & & 1.49 & 16.05 & \\
\hline $3 / 20 / 065: 20$ & 16.21 & & & 1.49 & 16.99 & \\
\hline $3 / 20 / 065: 30$ & 16.53 & & & 1.49 & 16.69 & \\
\hline $3 / 20 / 065: 40$ & 15.97 & & & 1.47 & 15.62 & \\
\hline $3 / 20 / 065: 50$ & 15.48 & & & 1.50 & 15.73 & \\
\hline $3 / 20 / 066: 00$ & 16.48 & & & 1.49 & 16.20 & \\
\hline $3 / 20 / 066: 10$ & 16.76 & & & 1.48 & 16.09 & \\
\hline $3 / 20 / 066: 20$ & 17.60 & & & 1.45 & 16.52 & \\
\hline $3 / 20 / 066: 30$ & 17.79 & & & 1.47 & 15.77 & \\
\hline $3 / 20 / 066: 40$ & 17.69 & & & 1.47 & 15.54 & \\
\hline $3 / 20 / 066: 50$ & 17.93 & & & 1.45 & 15.38 & \\
\hline 3/20/06 7:00 & 18.05 & & & 1.46 & 15.04 & \\
\hline $3 / 20 / 067: 10$ & 17.27 & & & 1.46 & 15.58 & \\
\hline $3 / 20 / 067: 20$ & 17.49 & & & 1.42 & 15.74 & \\
\hline $3 / 20 / 067: 30$ & 16.59 & & & 1.39 & 14.92 & \\
\hline $3 / 20 / 067: 40$ & 20.52 & & & 1.32 & 16.54 & \\
\hline $3 / 20 / 067: 50$ & 19.43 & & & 1.30 & 16.25 & \\
\hline $3 / 20 / 068: 00$ & 17.90 & & & 1.33 & 15.43 & \\
\hline $3 / 20 / 068: 10$ & 17.10 & & & 1.34 & 14.88 & \\
\hline $3 / 20 / 068: 20$ & 17.31 & & & 1.36 & 14.82 & \\
\hline $3 / 20 / 068: 30$ & 16.43 & 4.20 & 74.47 & 1.36 & 14.55 & 0.13 \\
\hline $3 / 20 / 068: 40$ & 16.98 & 4.09 & 75.93 & 1.36 & 14.29 & 0.13 \\
\hline $3 / 20 / 068: 50$ & 14.82 & 2.15 & 85.48 & 1.37 & 12.69 & \\
\hline 3/20/06 9:00 & 14.09 & 2.15 & 84.73 & 1.38 & 12.77 & \\
\hline 3/20/06 9:10 & 17.55 & 2.65 & 84.88 & 1.37 & 13.83 & \\
\hline $3 / 20 / 069: 20$ & 18.70 & 2.32 & 87.58 & 1.39 & 13.69 & \\
\hline $3 / 20 / 069: 30$ & 16.07 & 2.32 & 85.55 & 1.42 & 10.61 & \\
\hline 3/20/06 9:40 & 16.89 & 2.47 & 85.39 & 1.40 & 11.41 & \\
\hline 3/20/06 9:50 & 13.46 & 2.44 & 81.86 & 1.38 & 10.81 & \\
\hline $3 / 20 / 06$ 10:00 & 12.39 & 1.92 & 84.52 & 1.40 & 11.14 & \\
\hline $3 / 20 / 0610: 10$ & 11.94 & 2.18 & 81.76 & 1.46 & 12.25 & \\
\hline 3/20/06 10:20 & 12.47 & 2.03 & 83.70 & 1.48 & 12.61 & \\
\hline $3 / 20 / 0610: 30$ & 12.98 & 2.25 & 82.66 & 1.46 & 13.54 & \\
\hline $3 / 20 / 0610: 40$ & 13.86 & 2.07 & 85.06 & 1.47 & 13.62 & \\
\hline $3 / 20 / 0610: 50$ & 13.07 & 2.18 & 83.30 & 1.48 & 13.83 & \\
\hline 3/20/06 11:00 & 13.40 & 1.89 & 85.86 & 1.46 & 15.00 & \\
\hline 3/20/06 11:10 & 14.68 & 1.70 & 88.40 & 1.46 & 14.99 & \\
\hline $3 / 20 / 0611: 20$ & 15.24 & 1.70 & 88.87 & 1.46 & 14.89 & \\
\hline 3/20/06 11:30 & 15.64 & 1.92 & 87.70 & 1.47 & 15.27 & \\
\hline $3 / 20 / 0611: 40$ & 16.01 & 2.11 & 86.84 & 1.47 & 15.54 & \\
\hline $3 / 20 / 0611: 50$ & 16.29 & 2.12 & 86.97 & 1.49 & 15.35 & \\
\hline
\end{tabular}


Table D1. Corrected CMM and ACI, 10-minute Averaged Data During the Monthlong Field Test (continued)

\begin{tabular}{|c|c|c|c|c|c|c|}
\hline Date, Time & $\begin{array}{c}\text { FF Inlet } \mathrm{HgT}, \\
\mu \mathrm{g} / \mathrm{dNm}^{3}, \\
3 \% \mathrm{O}_{2} \\
\end{array}$ & $\begin{array}{c}\text { FF Outlet HgT, } \\
\mu \mathrm{g} / \mathrm{dNm}^{3}, \\
3 \% \mathrm{O}_{2}\end{array}$ & $\begin{array}{c}\text { HgT Removal } \\
\text { Across } \\
\text { FF 2-4, } \% \\
\end{array}$ & $\begin{array}{c}\text { FF 2-4 Activated } \\
\text { Carbon Injection } \\
\text { Rate, lb/Macf }\end{array}$ & $\begin{array}{c}\text { FF Inlet } \mathrm{Hg}^{0}, \\
\mu \mathrm{g} / \mathrm{dNm}^{3}, \\
3 \% \mathrm{O}_{2} \\
\end{array}$ & $\begin{array}{c}\text { FF Outlet } \mathrm{Hg}^{0} \text {, } \\
\mu \mathrm{g} / \mathrm{dNm}^{3}, \\
3 \% \mathrm{O}_{2} \\
\end{array}$ \\
\hline 3/20/06 12:00 & 15.76 & 2.46 & 84.39 & 1.47 & 14.73 & \\
\hline $3 / 20 / 0612: 10$ & 15.75 & 2.14 & 86.41 & 1.46 & 15.46 & \\
\hline 3/20/06 12:20 & 16.03 & 1.97 & 87.72 & 1.44 & 15.45 & \\
\hline $3 / 20 / 0612: 30$ & 15.45 & 2.11 & 86.31 & 1.46 & 14.72 & \\
\hline $3 / 20 / 0612: 40$ & 15.36 & 2.02 & 86.87 & 1.43 & 14.71 & \\
\hline $3 / 20 / 0612: 50$ & 16.05 & 2.32 & 85.57 & 1.44 & 14.60 & \\
\hline 3/20/06 13:00 & 15.65 & 2.09 & 86.64 & 1.44 & 13.93 & \\
\hline 3/20/06 13:10 & 15.17 & 2.14 & 85.89 & 1.45 & 14.29 & \\
\hline $3 / 20 / 06$ 13:20 & 15.49 & 2.41 & 84.41 & 1.48 & 13.92 & \\
\hline $3 / 20 / 0613: 30$ & 15.95 & 2.49 & 84.38 & 1.43 & 13.63 & \\
\hline 3/20/06 13:40 & 16.02 & 2.47 & 84.60 & 1.40 & 13.12 & \\
\hline $3 / 20 / 0613: 50$ & 15.67 & 2.99 & 80.90 & 1.40 & 12.97 & \\
\hline 3/20/06 14:00 & 14.86 & 2.89 & 80.57 & 1.44 & 12.47 & \\
\hline 3/20/06 14:10 & 17.45 & 2.28 & 86.92 & 1.42 & 13.34 & \\
\hline $3 / 20 / 0614: 20$ & 19.15 & 2.25 & 88.27 & 1.47 & 13.30 & \\
\hline 3/20/06 14:30 & 17.56 & 2.03 & 88.42 & 1.44 & 13.11 & \\
\hline $3 / 20 / 0614: 40$ & 17.84 & 1.83 & 89.77 & 1.47 & 12.90 & \\
\hline $3 / 20 / 0614: 50$ & 16.14 & 1.90 & 88.22 & 1.48 & 12.09 & \\
\hline 3/20/06 15:00 & 13.45 & 1.90 & 85.90 & 1.48 & 11.36 & \\
\hline 3/20/06 15:10 & 13.07 & 2.30 & 82.37 & 1.48 & 11.84 & \\
\hline $3 / 20 / 06$ 15:20 & 12.52 & 2.44 & 80.48 & 1.44 & 11.91 & \\
\hline $3 / 20 / 06$ 15:30 & 12.04 & 1.85 & 84.60 & 1.47 & 11.95 & \\
\hline $3 / 20 / 0615: 40$ & 11.59 & 1.69 & 85.43 & 1.45 & 11.20 & \\
\hline $3 / 20 / 0615: 50$ & 11.64 & 1.94 & 83.37 & 1.45 & 10.97 & \\
\hline 3/20/06 16:00 & 11.40 & 2.07 & 81.85 & 1.43 & 10.75 & \\
\hline $3 / 20 / 06$ 16:10 & 11.82 & 2.34 & 80.18 & 1.41 & 12.16 & 0.27 \\
\hline $3 / 20 / 06$ 16:20 & 11.51 & 2.10 & 81.75 & 1.40 & 12.37 & 0.51 \\
\hline $3 / 20 / 0616: 30$ & 12.35 & 2.28 & 81.52 & 1.39 & 12.22 & 0.66 \\
\hline $3 / 20 / 0616: 40$ & 11.94 & 2.17 & 81.81 & 1.41 & 12.10 & 0.70 \\
\hline $3 / 20 / 0616: 50$ & 11.69 & 2.11 & 81.94 & 1.38 & 11.87 & 0.84 \\
\hline 3/20/06 17:00 & 12.21 & 2.44 & 79.98 & 1.40 & 11.93 & 1.13 \\
\hline $3 / 20 / 06$ 17:10 & 11.26 & 2.20 & 80.48 & 1.35 & 7.82 & \\
\hline $3 / 20 / 06$ 17:20 & 15.49 & 2.11 & 86.36 & 1.43 & 16.57 & 0.89 \\
\hline $3 / 20 / 06$ 17:30 & 16.08 & & & 1.44 & 15.15 & \\
\hline $3 / 20 / 06$ 17:40 & 19.53 & & & 1.45 & 13.76 & \\
\hline $3 / 20 / 0617: 50$ & & & & 1.45 & & \\
\hline 3/20/06 18:00 & 16.72 & & & 1.42 & 14.28 & \\
\hline 3/20/06 18:10 & 70.56 & & & 1.46 & 14.51 & \\
\hline 3/20/06 18:20 & 22.10 & & & 1.44 & 12.32 & \\
\hline 3/20/06 18:30 & 92.48 & 1.27 & 98.63 & 1.45 & 11.13 & 0.16 \\
\hline $3 / 20 / 06$ 18:40 & 46.11 & 1.34 & 97.10 & 1.44 & 13.31 & 0.12 \\
\hline $3 / 20 / 0618: 50$ & 29.07 & 1.27 & 95.62 & 1.45 & 14.92 & 0.12 \\
\hline 3/20/06 19:00 & 23.05 & 1.49 & 93.53 & 1.45 & 15.08 & 0.12 \\
\hline 3/20/06 19:10 & 20.92 & 1.77 & 91.56 & 1.45 & 14.75 & 0.12 \\
\hline 3/20/06 19:20 & 26.89 & 2.33 & 91.32 & 1.44 & 15.02 & 0.33 \\
\hline 3/20/06 19:30 & 17.62 & 2.41 & 86.33 & 1.45 & 15.31 & 0.41 \\
\hline $3 / 20 / 06$ 19:40 & 14.70 & 2.66 & 81.92 & 1.47 & 15.23 & 0.46 \\
\hline $3 / 20 / 06$ 19:50 & 15.29 & 3.13 & 79.55 & 1.43 & 15.41 & 0.48 \\
\hline 3/20/06 20:00 & 15.27 & 2.53 & 83.44 & 1.46 & 15.39 & 0.22 \\
\hline 3/20/06 20:10 & 15.24 & 2.77 & 81.79 & 1.43 & 15.52 & 0.15 \\
\hline $3 / 20 / 0620: 20$ & 14.99 & 2.59 & 82.74 & 1.44 & 15.42 & 0.22 \\
\hline $3 / 20 / 0620: 30$ & 15.18 & 2.41 & 84.09 & 1.44 & 15.52 & 0.13 \\
\hline
\end{tabular}


Table D1. Corrected CMM and ACI, 10-minute Averaged Data During the Monthlong Field Test (continued)

\begin{tabular}{|c|c|c|c|c|c|c|}
\hline Date, Time & $\begin{array}{c}\text { FF Inlet } \mathrm{HgT} \text {, } \\
\mu \mathrm{g} / \mathrm{dNm}^{3}, \\
3 \% \mathrm{O}_{2}\end{array}$ & $\begin{array}{c}\text { FF Outlet } \mathrm{HgT}, \\
\mu \mathrm{g} / \mathrm{dNm}^{3} \\
3 \% \mathrm{O}_{2}\end{array}$ & $\begin{array}{c}\text { HgT Removal } \\
\text { Across } \\
\text { FF } 2-4, \% \\
\end{array}$ & $\begin{array}{c}\text { FF 2-4 Activated } \\
\text { Carbon Injection } \\
\text { Rate, lb/Macf }\end{array}$ & $\begin{array}{c}\text { FF Inlet } \mathrm{Hg}^{0}, \\
\mu \mathrm{g} / \mathrm{dNm}^{3}, \\
3 \% \mathrm{O}_{2}\end{array}$ & $\begin{array}{c}\text { FF Outlet } \mathrm{Hg}^{0}, \\
\mu \mathrm{g} / \mathrm{dNm}^{3}, \\
3 \% \mathrm{O}_{2}\end{array}$ \\
\hline $3 / 20 / 0620: 40$ & 15.13 & 2.39 & 84.18 & 1.46 & 15.34 & 0.12 \\
\hline $3 / 20 / 0620: 50$ & 14.82 & 2.22 & 85.01 & 1.46 & 14.83 & \\
\hline $3 / 20 / 0621: 00$ & 18.99 & 2.04 & 89.25 & 1.42 & 14.33 & \\
\hline $3 / 20 / 0621: 10$ & 16.00 & 2.48 & 84.48 & 1.45 & 13.77 & 0.12 \\
\hline $3 / 20 / 0621: 20$ & 15.10 & 2.78 & 81.58 & 1.45 & 12.30 & 0.12 \\
\hline $3 / 20 / 0621: 30$ & 14.84 & 3.07 & 79.31 & 1.45 & 11.73 & 0.22 \\
\hline $3 / 20 / 0621: 40$ & 14.60 & 3.31 & 77.34 & 1.44 & 11.59 & 0.24 \\
\hline $3 / 20 / 0621: 50$ & 14.65 & 3.11 & 78.74 & 1.44 & 11.32 & 0.24 \\
\hline $3 / 20 / 0622: 00$ & 16.80 & 3.16 & 81.20 & 1.45 & 11.19 & 0.18 \\
\hline $3 / 20 / 0622: 10$ & 13.57 & 2.74 & 79.81 & 1.44 & 11.76 & 0.12 \\
\hline $3 / 20 / 0622: 20$ & 12.48 & 2.54 & 79.65 & 1.45 & 11.50 & 0.17 \\
\hline $3 / 20 / 0622: 30$ & 11.27 & 2.17 & 80.72 & 1.46 & 11.62 & 0.29 \\
\hline $3 / 20 / 0622: 40$ & 10.55 & 1.77 & 83.26 & 1.48 & 12.00 & 0.44 \\
\hline $3 / 20 / 0622: 50$ & 10.79 & 1.71 & 84.17 & 1.42 & 12.43 & 0.73 \\
\hline $3 / 20 / 0623: 00$ & 10.11 & 1.55 & 84.64 & 1.42 & 12.86 & 0.43 \\
\hline $3 / 20 / 0623: 10$ & 9.93 & 1.32 & 86.67 & 1.43 & 11.99 & 0.43 \\
\hline $3 / 20 / 0623: 20$ & 10.83 & 0.84 & 92.26 & 1.44 & 12.37 & 0.80 \\
\hline $3 / 20 / 0623: 30$ & 10.64 & 1.21 & 88.62 & 1.43 & 13.25 & 1.13 \\
\hline $3 / 20 / 0623: 40$ & 10.68 & 0.77 & 92.83 & 1.45 & 13.79 & 1.45 \\
\hline $3 / 20 / 0623: 50$ & 10.00 & 0.70 & 93.04 & 1.46 & 14.04 & 1.84 \\
\hline $3 / 21 / 060: 00$ & 11.42 & 0.83 & 92.77 & 1.42 & 13.80 & 2.09 \\
\hline $3 / 21 / 060: 10$ & 10.56 & 0.99 & 90.65 & 1.46 & 12.51 & 0.20 \\
\hline $3 / 21 / 060: 20$ & 12.02 & 0.85 & 92.94 & 1.44 & 13.19 & 0.57 \\
\hline $3 / 21 / 060: 30$ & 12.88 & 0.79 & 93.90 & 1.44 & 12.98 & 0.97 \\
\hline $3 / 21 / 060: 40$ & 11.45 & 0.91 & 92.06 & 1.40 & 12.90 & 1.12 \\
\hline $3 / 21 / 060: 50$ & 11.90 & 0.93 & 92.16 & 1.37 & 12.87 & 1.05 \\
\hline 3/21/06 1:00 & 15.21 & 0.76 & 94.97 & 1.32 & 13.46 & 0.99 \\
\hline $3 / 21 / 061: 10$ & 14.39 & 0.99 & 93.10 & 1.38 & 13.19 & \\
\hline $3 / 21 / 061: 20$ & 12.50 & 1.27 & 89.85 & 1.39 & 10.64 & 0.12 \\
\hline $3 / 21 / 061: 30$ & 12.27 & 1.06 & 91.35 & 1.41 & 10.95 & \\
\hline $3 / 21 / 061: 40$ & 11.13 & 1.07 & 90.35 & 1.46 & 10.94 & \\
\hline $3 / 21 / 061: 50$ & 9.80 & 0.88 & 90.99 & 1.43 & 11.78 & \\
\hline $3 / 21 / 062: 00$ & 9.27 & 1.03 & 88.90 & 1.47 & 11.39 & \\
\hline $3 / 21 / 062: 10$ & 10.36 & 0.97 & 90.64 & 1.47 & 11.39 & \\
\hline $3 / 21 / 062: 20$ & 12.20 & 0.80 & 93.43 & 1.48 & 12.48 & \\
\hline $3 / 21 / 062: 30$ & 12.32 & 0.75 & 93.87 & 1.48 & 12.90 & \\
\hline $3 / 21 / 062: 40$ & 11.27 & 0.83 & 92.66 & 1.46 & 13.17 & \\
\hline $3 / 21 / 062: 50$ & 13.22 & 0.70 & 94.74 & 1.46 & 13.76 & \\
\hline 3/21/06 3:00 & 13.15 & 0.73 & 94.41 & 1.45 & 13.91 & \\
\hline $3 / 21 / 063: 10$ & 14.19 & 0.78 & 94.50 & 1.45 & 13.57 & 0.16 \\
\hline $3 / 21 / 063: 20$ & 14.28 & 0.69 & 95.18 & 1.45 & 13.59 & 0.21 \\
\hline $3 / 21 / 063: 30$ & 14.35 & 5.25 & 63.45 & 1.46 & 13.64 & 0.27 \\
\hline $3 / 21 / 063: 40$ & 14.07 & 36.61 & 0 & 1.45 & 13.43 & 0.70 \\
\hline $3 / 21 / 063: 50$ & 14.95 & 13.06 & 12.59 & 1.48 & 13.45 & 0.98 \\
\hline 3/21/06 4:00 & 13.62 & 6.11 & 55.15 & 1.46 & 13.17 & 0.91 \\
\hline $3 / 21 / 064: 10$ & 13.13 & 3.56 & 72.87 & 1.47 & 12.18 & \\
\hline $3 / 21 / 064: 20$ & 12.63 & 4.61 & 63.47 & 1.43 & 10.88 & \\
\hline $3 / 21 / 064: 30$ & 10.73 & 61.46 & 0 & 1.46 & 11.01 & \\
\hline $3 / 21 / 064: 40$ & 11.76 & & & 1.43 & 11.43 & \\
\hline $3 / 21 / 064: 50$ & 11.18 & & & 1.43 & 10.72 & \\
\hline $3 / 21 / 065: 00$ & 12.28 & & & 1.47 & 10.81 & \\
\hline $3 / 21 / 065: 10$ & 11.93 & & & 1.46 & 11.41 & \\
\hline
\end{tabular}


Table D1. Corrected CMM and ACI, 10-minute Averaged Data During the Monthlong Field Test (continued)

\begin{tabular}{|c|c|c|c|c|c|c|}
\hline Date, Time & $\begin{array}{c}\text { FF Inlet } \mathrm{HgT}, \\
\mu \mathrm{g} / \mathrm{dNm}^{3}, \\
3 \% \mathrm{O}_{2}\end{array}$ & $\begin{array}{c}\text { FF Outlet } \mathrm{HgT}, \\
\mu \mathrm{g} / \mathrm{dNm}^{3}, \\
3 \% \mathrm{O}_{2}\end{array}$ & $\begin{array}{c}\text { HgT Removal } \\
\text { Across } \\
\text { FF 2-4, } \% \\
\end{array}$ & $\begin{array}{c}\text { FF 2-4 Activated } \\
\text { Carbon Injection } \\
\text { Rate, lb/Macf }\end{array}$ & $\begin{array}{c}\text { FF Inlet } \mathrm{Hg}^{0}, \\
\mu \mathrm{g} / \mathrm{dNm}^{3}, \\
3 \% \mathrm{O}_{2}\end{array}$ & $\begin{array}{c}\text { FF Outlet } \mathrm{Hg}^{0}, \\
\mu \mathrm{g} / \mathrm{dNm}^{3}, \\
3 \% \mathrm{O}_{2}\end{array}$ \\
\hline $3 / 21 / 065: 20$ & 11.88 & & & 1.47 & 11.75 & \\
\hline 3/21/06 5:30 & 12.02 & & & 1.44 & 11.92 & \\
\hline $3 / 21 / 065: 40$ & 12.66 & & & 1.46 & 12.36 & \\
\hline $3 / 21 / 065: 50$ & 12.14 & & & 1.46 & 11.68 & \\
\hline 3/21/06 6:00 & 11.91 & & & 1.45 & 11.55 & \\
\hline $3 / 21 / 066: 10$ & 14.75 & & & 1.44 & 11.53 & \\
\hline $3 / 21 / 066: 20$ & 20.26 & & & 1.48 & 10.71 & \\
\hline $3 / 21 / 066: 30$ & & & & 1.47 & 10.99 & \\
\hline $3 / 21 / 066: 40$ & & & & 1.50 & & \\
\hline $3 / 21 / 066: 50$ & & & & 1.50 & & \\
\hline 3/21/06 7:00 & & & & 1.47 & & \\
\hline $3 / 21 / 067: 10$ & & & & 1.47 & & \\
\hline $3 / 21 / 067: 20$ & & & & 1.46 & & \\
\hline $3 / 21 / 067: 30$ & & & & 1.49 & & \\
\hline $3 / 21 / 067: 40$ & & & & 1.52 & & \\
\hline $3 / 21 / 067: 50$ & & & & 1.48 & & \\
\hline 3/21/06 8:00 & & & & 1.46 & & \\
\hline 3/21/06 8:10 & & & & 1.51 & & \\
\hline 3/21/06 8:20 & & & & 1.51 & & \\
\hline $3 / 21 / 068: 30$ & & & & 1.48 & & \\
\hline $3 / 21 / 068: 40$ & & 69.62 & & 1.48 & & \\
\hline $3 / 21 / 068: 50$ & & 64.19 & & 1.42 & & \\
\hline 3/21/06 9:00 & & 64.63 & & 1.44 & & \\
\hline 3/21/06 9:10 & & & & 1.38 & & \\
\hline 3/21/06 9:20 & & & & 1.33 & & \\
\hline $3 / 21 / 069: 30$ & & & & 1.43 & & \\
\hline 3/21/06 9:40 & & & & 1.42 & & \\
\hline $3 / 21 / 069: 50$ & & & & 1.43 & & \\
\hline $3 / 21 / 0610: 00$ & & 14.72 & & 1.43 & & 15.61 \\
\hline $3 / 21 / 0610: 10$ & & & & 1.50 & & \\
\hline $3 / 21 / 06$ 10:20 & & & & 1.48 & & \\
\hline $3 / 21 / 0610: 30$ & & & & 1.51 & & \\
\hline $3 / 21 / 06 \quad 10: 40$ & & & & 1.47 & & \\
\hline $3 / 21 / 0610: 50$ & & & & 1.50 & & \\
\hline $3 / 21 / 0611: 00$ & & 1.30 & & 1.48 & & 24.23 \\
\hline $3 / 21 / 0611: 10$ & & 2.99 & & 1.48 & & 16.70 \\
\hline $3 / 21 / 0611: 20$ & 18.36 & 2.74 & 85.06 & 1.43 & 12.17 & 17.37 \\
\hline $3 / 21 / 0611: 30$ & 18.89 & 1.14 & 93.97 & 1.44 & 11.38 & 16.60 \\
\hline $3 / 21 / 0611: 40$ & 19.48 & 0.92 & 95.27 & 1.48 & 11.14 & 11.86 \\
\hline $3 / 21 / 0611: 50$ & 17.31 & 1.89 & 89.10 & 1.49 & 10.70 & 7.97 \\
\hline $3 / 21 / 0612: 00$ & 16.31 & 8.18 & 49.82 & 1.48 & 10.68 & 6.09 \\
\hline $3 / 21 / 0612: 10$ & 14.84 & & & 1.43 & 10.55 & \\
\hline $3 / 21 / 0612: 20$ & 14.19 & & & 1.45 & 10.66 & \\
\hline $3 / 21 / 0612: 30$ & 14.30 & & & 1.41 & 10.67 & \\
\hline $3 / 21 / 0612: 40$ & 14.07 & & & 1.40 & 10.70 & \\
\hline $3 / 21 / 0612: 50$ & 14.91 & & & 1.38 & 11.22 & \\
\hline $3 / 21 / 0613: 00$ & 15.18 & 1.81 & 88.06 & 1.43 & 10.44 & 3.91 \\
\hline $3 / 21 / 0613: 10$ & 17.47 & 2.14 & 87.74 & 1.46 & 10.41 & 6.49 \\
\hline $3 / 21 / 0613: 20$ & 15.92 & 1.16 & 92.69 & 1.46 & 10.71 & 8.26 \\
\hline $3 / 21 / 0613: 30$ & 18.54 & 1.09 & 94.12 & 1.44 & 10.98 & 7.83 \\
\hline $3 / 21 / 0613: 40$ & 17.74 & & & 1.39 & 11.39 & \\
\hline $3 / 21 / 0613: 50$ & 18.48 & & & 1.38 & 11.60 & \\
\hline
\end{tabular}


Table D1. Corrected CMM and ACI, 10-minute Averaged Data During the Monthlong Field Test (continued)

\begin{tabular}{|c|c|c|c|c|c|c|}
\hline Date, Time & $\begin{array}{c}\text { FF Inlet } \mathrm{HgT}, \\
\mu \mathrm{g} / \mathrm{dNm}^{3}, \\
3 \% \mathrm{O}_{2} \\
\end{array}$ & $\begin{array}{c}\text { FF Outlet HgT, } \\
\mu \mathrm{g} / \mathrm{dNm}^{3}, \\
3 \% \mathrm{O}_{2}\end{array}$ & $\begin{array}{c}\text { HgT Removal } \\
\text { Across } \\
\text { FF 2-4, \% } \\
\end{array}$ & $\begin{array}{c}\text { FF 2-4 Activated } \\
\text { Carbon Injection } \\
\text { Rate, lb/Macf }\end{array}$ & $\begin{array}{c}\text { FF Inlet } \mathrm{Hg}^{0}, \\
\mu \mathrm{g} / \mathrm{dNm}^{3}, \\
3 \% \mathrm{O}_{2} \\
\end{array}$ & $\begin{array}{c}\text { FF Outlet } \mathrm{Hg}^{0}, \\
\mu \mathrm{g} / \mathrm{dNm}^{3}, \\
3 \% \mathrm{O}_{2}\end{array}$ \\
\hline $3 / 21 / 0614: 00$ & 18.12 & 1.41 & 92.20 & 1.37 & 11.63 & 4.43 \\
\hline $3 / 21 / 0614: 10$ & 18.23 & 1.31 & 92.79 & 1.43 & 11.45 & 4.71 \\
\hline 3/21/06 14:20 & 18.63 & 1.47 & 92.09 & 1.45 & 11.52 & 4.66 \\
\hline $3 / 21 / 0614: 30$ & 18.05 & 1.43 & 92.08 & 1.49 & 11.60 & 4.01 \\
\hline $3 / 21 / 0614: 40$ & & 1.67 & & 1.50 & & 3.55 \\
\hline $3 / 21 / 0614: 50$ & & 1.72 & & 1.49 & & 3.22 \\
\hline $3 / 21 / 0615: 00$ & & 1.77 & & 1.50 & & 2.84 \\
\hline $3 / 21 / 0615: 10$ & & 1.83 & & 1.50 & & 2.55 \\
\hline $3 / 21 / 06$ 15:20 & & 2.35 & & 1.49 & & 2.37 \\
\hline $3 / 21 / 0615: 30$ & & 2.16 & & 1.48 & & 2.27 \\
\hline $3 / 21 / 06$ 15:40 & & 2.48 & & 0.67 & & 1.98 \\
\hline $3 / 21 / 0615: 50$ & & 3.46 & & 0.12 & & 2.00 \\
\hline 3/21/06 16:00 & & 4.29 & & 1.20 & & 1.74 \\
\hline 3/21/06 16:10 & & 2.88 & & 1.37 & & 1.80 \\
\hline $3 / 21 / 0616: 20$ & & 2.95 & & 1.35 & & 2.24 \\
\hline 3/21/06 16:30 & & 3.19 & & 1.40 & & 1.80 \\
\hline $3 / 21 / 06$ 16:40 & & 3.15 & & 1.42 & & 1.15 \\
\hline $3 / 21 / 0616: 50$ & & 3.38 & & 1.41 & & 1.13 \\
\hline 3/21/06 17:00 & & 2.76 & & 1.43 & & 0.91 \\
\hline 3/21/06 17:10 & & 2.83 & & 1.45 & & 1.13 \\
\hline $3 / 21 / 0617: 20$ & & 2.47 & & 1.42 & & 1.08 \\
\hline 3/21/06 17:30 & & 3.23 & & 1.40 & & 1.19 \\
\hline $3 / 21 / 0617: 40$ & & 4.65 & & 1.44 & & 1.50 \\
\hline $3 / 21 / 0617: 50$ & 16.49 & 3.77 & 77.15 & 1.39 & 11.91 & 1.60 \\
\hline 3/21/06 18:00 & 18.11 & 3.83 & 78.86 & 1.41 & 11.81 & 1.49 \\
\hline 3/21/06 18:10 & 19.71 & 3.73 & 81.08 & 1.37 & 11.53 & 0.67 \\
\hline $3 / 21 / 06$ 18:20 & 18.41 & 3.41 & 81.45 & 1.43 & 12.16 & 0.43 \\
\hline $3 / 21 / 0618: 30$ & 20.54 & 4.03 & 80.36 & 1.39 & 11.52 & 0.37 \\
\hline $3 / 21 / 0618: 40$ & 22.30 & 3.53 & 84.19 & 1.40 & 11.40 & 0.15 \\
\hline $3 / 21 / 0618: 50$ & 21.33 & 3.19 & 85.04 & 1.38 & 11.64 & 0.14 \\
\hline 3/21/06 19:00 & 19.94 & 2.93 & 85.29 & 1.40 & 11.16 & 0.17 \\
\hline 3/21/06 19:10 & 17.80 & 2.85 & 84.01 & 1.45 & 10.36 & 0.43 \\
\hline $3 / 21 / 06$ 19:20 & 16.88 & 2.78 & 83.53 & 1.49 & 10.69 & 0.35 \\
\hline $3 / 21 / 0619: 30$ & 18.22 & 3.07 & 83.14 & 1.49 & 11.36 & 0.28 \\
\hline $3 / 21 / 06$ 19:40 & 17.49 & 3.33 & 80.97 & 1.48 & 11.57 & 0.34 \\
\hline $3 / 21 / 0619: 50$ & 18.24 & 3.60 & 80.28 & 1.46 & 12.58 & 0.39 \\
\hline $3 / 21 / 06$ 20:00 & 18.56 & 3.70 & 80.07 & 1.42 & 12.92 & 0.35 \\
\hline $3 / 21 / 0620: 10$ & 18.94 & 3.73 & 80.29 & 1.41 & 12.69 & 0.46 \\
\hline $3 / 21 / 0620: 20$ & 17.31 & 3.48 & 79.88 & 1.47 & 11.17 & 0.45 \\
\hline $3 / 21 / 0620: 30$ & 18.68 & 4.01 & 78.53 & 1.21 & 12.05 & 0.30 \\
\hline $3 / 21 / 0620: 40$ & 19.89 & 3.69 & 81.47 & 0.12 & 12.46 & 0.35 \\
\hline $3 / 21 / 0620: 50$ & 23.01 & 4.56 & 80.18 & 0.12 & 13.86 & 0.67 \\
\hline $3 / 21 / 0621: 00$ & 21.76 & 5.07 & 76.71 & 0.12 & 13.17 & 0.74 \\
\hline $3 / 21 / 0621: 10$ & 20.54 & 6.49 & 68.40 & 0.13 & 12.20 & 0.85 \\
\hline $3 / 21 / 0621: 20$ & 19.46 & 6.45 & 66.85 & 0.13 & 11.68 & 0.84 \\
\hline $3 / 21 / 0621: 30$ & 19.44 & 7.10 & 63.49 & 0.13 & 11.57 & 0.82 \\
\hline $3 / 21 / 0621: 40$ & 19.52 & 7.67 & 60.71 & 0.12 & 11.92 & 0.83 \\
\hline $3 / 21 / 0621: 50$ & 20.19 & 7.63 & 62.20 & 0.12 & 11.89 & 0.78 \\
\hline $3 / 21 / 0622: 00$ & 19.68 & 7.39 & 62.44 & 0.12 & 11.83 & 0.74 \\
\hline $3 / 21 / 0622: 10$ & 20.64 & 8.63 & 58.19 & 0.12 & 12.48 & 1.12 \\
\hline $3 / 21 / 0622: 20$ & 21.81 & 9.00 & 58.75 & 0.12 & 13.37 & 1.28 \\
\hline $3 / 21 / 0622: 30$ & 20.22 & 9.93 & 50.88 & 0.65 & 12.30 & 1.10 \\
\hline
\end{tabular}


Table D1. Corrected CMM and ACI, 10-minute Averaged Data During the Monthlong Field Test (continued)

\begin{tabular}{|c|c|c|c|c|c|c|}
\hline Date, Time & $\begin{array}{c}\text { FF Inlet } \mathrm{HgT}, \\
\mu \mathrm{g} / \mathrm{dNm}^{3}, \\
3 \% \mathrm{O}_{2} \\
\end{array}$ & $\begin{array}{c}\text { FF Outlet HgT, } \\
\mu \mathrm{g} / \mathrm{dNm}^{3}, \\
3 \% \mathrm{O}_{2} \\
\end{array}$ & $\begin{array}{c}\text { HgT Removal } \\
\text { Across } \\
\text { FF 2-4, \% }\end{array}$ & $\begin{array}{c}\text { FF 2-4 Activated } \\
\text { Carbon Injection } \\
\text { Rate, lb/Macf }\end{array}$ & $\begin{array}{c}\text { FF Inlet } \mathrm{Hg}^{0}, \\
\mu \mathrm{g} / \mathrm{dNm}^{3}, \\
3 \% \mathrm{O}_{2} \\
\end{array}$ & $\begin{array}{c}\text { FF Outlet } \mathrm{Hg}^{0}, \\
\mu \mathrm{g} / \mathrm{dNm}^{3}, \\
3 \% \mathrm{O}_{2}\end{array}$ \\
\hline $3 / 21 / 0622: 40$ & 20.07 & 10.21 & 49.16 & 1.42 & 11.90 & 1.08 \\
\hline $3 / 21 / 0622: 50$ & 19.48 & 8.28 & 57.50 & 1.36 & 11.90 & 1.27 \\
\hline 3/21/06 23:00 & 19.59 & 7.42 & 62.14 & 1.33 & 11.73 & 1.02 \\
\hline $3 / 21 / 0623: 10$ & 19.61 & 6.16 & 68.57 & 1.34 & 11.31 & 0.58 \\
\hline $3 / 21 / 0623: 20$ & 16.97 & 6.49 & 61.76 & 1.38 & 9.52 & 1.11 \\
\hline $3 / 21 / 0623: 30$ & 13.62 & 5.20 & 61.85 & 1.46 & 8.53 & 0.59 \\
\hline $3 / 21 / 0623: 40$ & 13.86 & 4.91 & 64.58 & 1.48 & 9.20 & 0.61 \\
\hline $3 / 21 / 0623: 50$ & 12.85 & 4.01 & 68.76 & 1.45 & 9.61 & 0.41 \\
\hline 3/22/06 0:00 & 13.19 & 3.77 & 71.39 & 1.48 & 10.40 & 0.44 \\
\hline $3 / 22 / 060: 10$ & 13.24 & 3.82 & 71.13 & 1.47 & 10.70 & 0.36 \\
\hline $3 / 22 / 060: 20$ & 13.51 & 3.89 & 71.18 & 0.39 & 10.45 & 0.47 \\
\hline $3 / 22 / 060: 30$ & 13.63 & 4.55 & 66.61 & 0.12 & 10.84 & 0.56 \\
\hline $3 / 22 / 060: 40$ & 15.03 & 4.43 & 70.52 & 0.12 & 11.47 & 0.62 \\
\hline $3 / 22 / 060: 50$ & 15.19 & 4.98 & 67.23 & 0.12 & 11.75 & 0.68 \\
\hline $3 / 22 / 061: 00$ & 16.53 & 5.25 & 68.22 & 0.12 & 12.02 & 0.70 \\
\hline $3 / 22 / 061: 10$ & 16.34 & 5.77 & 64.67 & 0.13 & 11.71 & 0.64 \\
\hline $3 / 22 / 061: 20$ & 16.40 & 6.17 & 62.41 & 0.13 & 11.01 & 0.75 \\
\hline $3 / 22 / 061: 30$ & 17.44 & 6.21 & 64.40 & 0.13 & 11.09 & 0.66 \\
\hline $3 / 22 / 061: 40$ & 16.60 & 6.62 & 60.13 & 0.13 & 10.64 & 0.82 \\
\hline $3 / 22 / 061: 50$ & 16.20 & 6.28 & 61.20 & 1.04 & 10.15 & 0.68 \\
\hline $3 / 22 / 062: 00$ & 15.68 & 5.87 & 62.56 & 1.42 & 9.70 & 0.63 \\
\hline $3 / 22 / 062: 10$ & 14.95 & 5.04 & 66.25 & 1.45 & 9.36 & 0.41 \\
\hline $3 / 22 / 062: 20$ & 15.03 & 4.42 & 70.59 & 1.41 & 9.73 & 0.28 \\
\hline $3 / 22 / 062: 30$ & 15.86 & 3.69 & 76.76 & 1.43 & 9.73 & 0.26 \\
\hline $3 / 22 / 062: 40$ & 15.25 & 3.51 & 77.02 & 1.44 & 9.22 & 0.26 \\
\hline $3 / 22 / 062: 50$ & 16.65 & 3.65 & 78.10 & 1.22 & 10.52 & 0.17 \\
\hline $3 / 22 / 063: 00$ & 18.41 & 4.13 & 77.57 & 0.12 & 11.42 & 0.65 \\
\hline $3 / 22 / 063: 10$ & 19.26 & 5.18 & 73.11 & 0.12 & 12.22 & 0.67 \\
\hline $3 / 22 / 063: 20$ & 19.72 & 5.40 & 72.62 & 0.12 & 12.45 & 0.73 \\
\hline $3 / 22 / 063: 30$ & 19.60 & 5.89 & 69.97 & 0.12 & 12.65 & 0.72 \\
\hline $3 / 22 / 063: 40$ & 20.01 & 6.32 & 68.39 & 0.12 & 12.81 & 0.74 \\
\hline $3 / 22 / 063: 50$ & 20.40 & 9.24 & 54.73 & 0.12 & 13.37 & 0.80 \\
\hline $3 / 22 / 064: 00$ & 21.09 & 7.72 & 63.38 & 0.12 & 13.39 & 0.86 \\
\hline $3 / 22 / 064: 10$ & 21.50 & 8.07 & 62.48 & 0.12 & 13.87 & 0.89 \\
\hline $3 / 22 / 064: 20$ & 21.77 & 8.87 & 59.27 & 0.13 & 13.74 & 0.96 \\
\hline $3 / 22 / 064: 30$ & 20.14 & 9.68 & 51.95 & 0.13 & 12.59 & 0.94 \\
\hline $3 / 22 / 064: 40$ & 17.75 & 8.13 & 54.19 & 0.13 & 12.17 & 0.95 \\
\hline $3 / 22 / 064: 50$ & 16.50 & 7.33 & 55.59 & 0.13 & 11.48 & 0.99 \\
\hline $3 / 22 / 065: 00$ & 16.20 & 8.15 & 49.65 & 0.13 & 11.80 & 0.98 \\
\hline $3 / 22 / 065: 10$ & 17.06 & 8.06 & 52.77 & 0.12 & 12.48 & 0.91 \\
\hline $3 / 22 / 065: 20$ & 18.14 & 8.30 & 54.26 & 0.12 & 12.82 & 0.98 \\
\hline $3 / 22 / 065: 30$ & 19.02 & 9.62 & 49.45 & 0.12 & 13.67 & 1.12 \\
\hline $3 / 22 / 065: 40$ & 19.38 & 10.47 & 45.99 & 0.13 & 13.52 & 1.02 \\
\hline $3 / 22 / 065: 50$ & 18.86 & 9.77 & 48.20 & 0.14 & 12.46 & 1.13 \\
\hline $3 / 22 / 066: 00$ & 19.16 & 9.42 & 50.83 & 0.14 & 11.67 & 1.03 \\
\hline $3 / 22 / 066: 10$ & 17.07 & 8.87 & 48.02 & 0.14 & 10.66 & 0.95 \\
\hline $3 / 22 / 066: 20$ & 17.65 & 7.94 & 54.99 & 0.14 & 10.78 & 0.90 \\
\hline $3 / 22 / 066: 30$ & 17.06 & 8.79 & 48.51 & 0.14 & 10.59 & 0.88 \\
\hline $3 / 22 / 066: 40$ & 16.43 & 10.27 & 37.51 & 0.13 & 10.30 & 0.86 \\
\hline $3 / 22 / 066: 50$ & 17.01 & 13.06 & 23.22 & 0.13 & 10.89 & 0.65 \\
\hline $3 / 22 / 067: 00$ & 17.58 & 10.31 & 41.36 & 0.12 & 11.11 & 0.80 \\
\hline $3 / 22 / 067: 10$ & 18.25 & 11.13 & 38.98 & 0.12 & 11.80 & 0.93 \\
\hline
\end{tabular}


Table D1. Corrected CMM and ACI, 10-minute Averaged Data During the Monthlong Field Test (continued)

\begin{tabular}{|c|c|c|c|c|c|c|}
\hline Date, Time & $\begin{array}{c}\text { FF Inlet } \mathrm{HgT}, \\
\mu \mathrm{g} / \mathrm{dNm}^{3}, \\
3 \% \mathrm{O}_{2} \\
\end{array}$ & $\begin{array}{c}\text { FF Outlet HgT, } \\
\mu \mathrm{g} / \mathrm{dNm}^{3}, \\
3 \% \mathrm{O}_{2} \\
\end{array}$ & $\begin{array}{c}\text { HgT Removal } \\
\text { Across } \\
\text { FF } 2-4, \% \\
\end{array}$ & $\begin{array}{c}\text { FF 2-4 Activated } \\
\text { Carbon Injection } \\
\text { Rate, lb/Macf }\end{array}$ & $\begin{array}{c}\text { FF Inlet } \mathrm{Hg}^{0}, \\
\mu \mathrm{g} / \mathrm{dNm}^{3}, \\
3 \% \mathrm{O}_{2} \\
\end{array}$ & $\begin{array}{c}\text { FF Outlet } \mathrm{Hg}^{0}, \\
\mu \mathrm{g} / \mathrm{dNm}^{3}, \\
3 \% \mathrm{O}_{2}\end{array}$ \\
\hline $3 / 22 / 067: 20$ & 18.94 & 12.09 & 36.14 & 0.12 & 12.37 & 1.10 \\
\hline $3 / 22 / 067: 30$ & 20.16 & 11.84 & 41.28 & 0.12 & 13.19 & 1.20 \\
\hline $3 / 22 / 067: 40$ & 19.51 & 11.39 & 41.60 & 0.14 & 12.86 & 1.30 \\
\hline $3 / 22 / 067: 50$ & 18.52 & 10.86 & 41.36 & 0.14 & 11.49 & 1.38 \\
\hline $3 / 22 / 068: 00$ & 17.89 & 9.45 & 47.18 & 0.15 & 10.50 & 1.25 \\
\hline $3 / 22 / 068: 10$ & 17.50 & 8.08 & 53.81 & 0.14 & 10.53 & 1.02 \\
\hline $3 / 22 / 068: 20$ & & 9.50 & & 0.13 & & 0.95 \\
\hline $3 / 22 / 068: 30$ & & 9.38 & & 0.13 & & 0.95 \\
\hline $3 / 22 / 068: 40$ & & 11.30 & & 0.14 & & 0.98 \\
\hline $3 / 22 / 068: 50$ & & 11.39 & & 0.14 & & 1.09 \\
\hline 3/22/06 9:00 & & 10.06 & & 0.14 & & 1.20 \\
\hline $3 / 22 / 069: 10$ & 17.02 & 11.30 & 33.59 & 0.15 & 9.99 & 1.24 \\
\hline $3 / 22 / 069: 20$ & 14.56 & & & 0.15 & 9.77 & \\
\hline $3 / 22 / 069: 30$ & 14.44 & & & 0.15 & 9.81 & \\
\hline $3 / 22 / 069: 40$ & 13.67 & & & 0.15 & 9.80 & \\
\hline $3 / 22 / 069: 50$ & 12.42 & & & 0.14 & 9.49 & \\
\hline 3/22/06 10:00 & 12.11 & 12.71 & 0 & 0.15 & 9.19 & 1.98 \\
\hline 3/22/06 10:10 & 11.79 & 14.36 & 0 & 0.15 & 9.48 & 1.82 \\
\hline 3/22/06 10:20 & 11.36 & 14.93 & 0 & 0.15 & 9.47 & 1.59 \\
\hline $3 / 22 / 0610: 30$ & 11.07 & 15.18 & 0 & 0.15 & 9.34 & 1.56 \\
\hline $3 / 22 / 0610: 40$ & 11.78 & 18.97 & 0 & 0.14 & 9.83 & 1.90 \\
\hline $3 / 22 / 0610: 50$ & 12.59 & 18.66 & 0 & 1.20 & 10.34 & 1.68 \\
\hline $3 / 22 / 06$ 11:00 & 12.76 & 12.50 & 2.00 & 1.51 & 10.03 & 0.97 \\
\hline 3/22/06 11:10 & 12.98 & 9.03 & 30.41 & 1.48 & 9.98 & 0.76 \\
\hline $3 / 22 / 0611: 20$ & 13.67 & 8.14 & 40.45 & 1.49 & 9.91 & 0.78 \\
\hline 3/22/06 11:30 & 14.38 & 8.24 & 42.74 & 1.45 & 9.54 & 0.75 \\
\hline $3 / 22 / 0611: 40$ & 14.07 & 6.77 & 51.89 & 1.44 & 9.91 & 1.04 \\
\hline $3 / 22 / 0611: 50$ & 15.03 & 7.64 & 49.16 & 1.39 & 10.31 & 1.33 \\
\hline $3 / 22 / 0612: 00$ & 15.31 & 5.71 & 62.68 & 1.43 & 9.71 & 0.75 \\
\hline $3 / 22 / 0612: 10$ & 13.99 & 5.85 & 58.16 & 1.49 & 9.44 & 0.83 \\
\hline $3 / 22 / 06$ 12:20 & 14.12 & 5.32 & 62.36 & 1.49 & 9.18 & 0.69 \\
\hline $3 / 22 / 0612: 30$ & 14.06 & 6.38 & 54.67 & 1.51 & 9.70 & 0.71 \\
\hline $3 / 22 / 0612: 40$ & 15.26 & 6.92 & 54.66 & 1.49 & 10.08 & 0.71 \\
\hline $3 / 22 / 0612: 50$ & 14.31 & 5.76 & 59.78 & 1.50 & 10.00 & 0.50 \\
\hline $3 / 22 / 06$ 13:00 & 14.16 & 5.46 & 61.47 & 1.49 & 9.69 & 0.42 \\
\hline $3 / 22 / 0613: 10$ & 14.27 & 5.63 & 60.51 & 1.51 & 10.24 & 0.57 \\
\hline 3/22/06 13:20 & 15.06 & 5.96 & 60.39 & 1.50 & 11.05 & 0.68 \\
\hline $3 / 22 / 0613: 30$ & 15.40 & 6.17 & 59.90 & 1.48 & 11.33 & 0.58 \\
\hline $3 / 22 / 06 \quad 13: 40$ & 15.27 & 5.84 & 61.75 & 1.43 & 10.38 & 0.49 \\
\hline $3 / 22 / 0613: 50$ & 14.65 & 5.69 & 61.15 & 1.43 & 10.35 & 0.51 \\
\hline 3/22/06 14:00 & 14.74 & 5.02 & 65.97 & 1.49 & 10.26 & 0.38 \\
\hline $3 / 22 / 0614: 10$ & 15.07 & 5.81 & 61.45 & 1.44 & 10.89 & 0.64 \\
\hline $3 / 22 / 0614: 20$ & 14.45 & 6.20 & 57.10 & 1.48 & 11.01 & 0.61 \\
\hline $3 / 22 / 0614: 30$ & 13.79 & 4.27 & 69.04 & 1.47 & 10.47 & 0.33 \\
\hline $3 / 22 / 0614: 40$ & 13.40 & 4.20 & 68.65 & 1.50 & 10.51 & 0.24 \\
\hline $3 / 22 / 0614: 50$ & 13.66 & 5.00 & 63.42 & 1.51 & 11.17 & 0.25 \\
\hline $3 / 22 / 06$ 15:00 & 14.13 & 5.79 & 59.01 & 1.50 & 11.72 & 0.24 \\
\hline $3 / 22 / 0615: 10$ & 14.42 & 3.96 & 72.52 & 1.49 & 12.92 & 0.85 \\
\hline $3 / 22 / 06$ 15:20 & 15.38 & 4.47 & 70.90 & 1.34 & 12.96 & 0.44 \\
\hline $3 / 22 / 0615: 30$ & 14.93 & 4.51 & 69.80 & 0.12 & 12.85 & 0.73 \\
\hline $3 / 22 / 0615: 40$ & 15.62 & 6.52 & 58.24 & 0.12 & 12.89 & 0.82 \\
\hline $3 / 22 / 06 \quad 15: 50$ & 16.04 & 9.04 & 43.63 & 0.12 & 13.52 & 1.33 \\
\hline
\end{tabular}


Table D1. Corrected CMM and ACI, 10-minute Averaged Data During the Monthlong Field Test (continued)

\begin{tabular}{|c|c|c|c|c|c|c|}
\hline Date, Time & $\begin{array}{c}\text { FF Inlet } \mathrm{HgT} \text {, } \\
\mu \mathrm{g} / \mathrm{dNm}^{3} \\
3 \% \mathrm{O}_{2} \\
\end{array}$ & $\begin{array}{c}\text { FF Outlet } \mathrm{HgT}, \\
\mu \mathrm{g} / \mathrm{dNm}^{3} \\
3 \% \mathrm{O}_{2}\end{array}$ & $\begin{array}{l}\text { HgT Removal } \\
\text { Across } \\
\text { FF } 2-4, \% \\
\end{array}$ & $\begin{array}{c}\text { FF 2-4 Activated } \\
\text { Carbon Injection } \\
\text { Rate, lb/Macf }\end{array}$ & $\begin{array}{c}\text { FF Inlet } \mathrm{Hg}^{0}, \\
\mu \mathrm{g} / \mathrm{dNm}^{3}, \\
3 \% \mathrm{O}_{2}\end{array}$ & $\begin{array}{c}\text { FF Outlet } \mathrm{Hg}^{0}, \\
\mu \mathrm{g} / \mathrm{dNm}^{3}, \\
3 \% \mathrm{O}_{2}\end{array}$ \\
\hline $3 / 22 / 0616: 00$ & 15.39 & 9.35 & 39.23 & 0.12 & 13.08 & 0.92 \\
\hline $3 / 22 / 0616: 10$ & 15.65 & 7.62 & 51.33 & 0.12 & 12.53 & 0.88 \\
\hline $3 / 22 / 0616: 20$ & 15.54 & 9.98 & 35.78 & 0.12 & 11.59 & 1.07 \\
\hline $3 / 22 / 0616: 30$ & 15.03 & 12.62 & 16.03 & 0.12 & 11.68 & 1.32 \\
\hline $3 / 22 / 0616: 40$ & 14.91 & 8.63 & 42.13 & 1.47 & 11.41 & 0.91 \\
\hline $3 / 22 / 0616: 50$ & 13.75 & 5.27 & 61.69 & 1.44 & 10.94 & 0.75 \\
\hline $3 / 22 / 06$ 17:00 & 14.37 & 4.40 & 69.39 & 1.45 & 10.30 & 0.70 \\
\hline $3 / 22 / 0617: 10$ & 12.30 & 3.65 & 70.31 & 1.43 & 10.02 & 0.28 \\
\hline $3 / 22 / 0617: 20$ & 12.25 & 3.23 & 73.64 & 1.44 & 10.07 & 0.64 \\
\hline $3 / 22 / 0617: 30$ & 10.23 & 3.85 & 62.35 & 1.40 & 10.01 & 0.96 \\
\hline $3 / 22 / 0617: 40$ & 16.45 & 3.28 & 80.08 & 1.38 & 10.03 & 0.91 \\
\hline $3 / 22 / 0617: 50$ & 13.50 & 3.52 & 73.91 & 1.38 & 9.95 & 1.03 \\
\hline 3/22/06 18:00 & 15.02 & 6.15 & 59.04 & 1.37 & 10.11 & 0.88 \\
\hline $3 / 22 / 0618: 10$ & 15.93 & 4.72 & 70.35 & 1.39 & 9.94 & 0.23 \\
\hline $3 / 22 / 0618: 20$ & 13.44 & 8.27 & 38.49 & 1.44 & 9.38 & 0.27 \\
\hline $3 / 22 / 0618: 30$ & 12.24 & & & 1.47 & 9.34 & \\
\hline $3 / 22 / 06$ 18:40 & 12.51 & & & 1.49 & 9.74 & \\
\hline $3 / 22 / 0618: 50$ & 13.63 & & & 1.50 & 10.84 & \\
\hline 3/22/06 19:00 & 16.73 & & & 1.47 & 11.59 & \\
\hline $3 / 22 / 0619: 10$ & 16.08 & & & 1.47 & 12.50 & \\
\hline $3 / 22 / 0619: 20$ & 16.02 & & & 1.47 & 12.62 & \\
\hline $3 / 22 / 0619: 30$ & 16.41 & & & 1.46 & 12.71 & \\
\hline $3 / 22 / 06$ 19:40 & 16.57 & & & 1.46 & 12.73 & \\
\hline $3 / 22 / 0619: 50$ & 15.71 & & & 0.53 & 12.58 & \\
\hline 3/22/06 20:00 & 15.24 & & & 0.12 & 12.69 & \\
\hline $3 / 22 / 0620: 10$ & 15.19 & & & 0.12 & 12.88 & \\
\hline $3 / 22 / 0620: 20$ & 15.10 & & & 0.12 & 11.97 & \\
\hline $3 / 22 / 0620: 30$ & 14.78 & & & 0.12 & 12.66 & \\
\hline $3 / 22 / 0620: 40$ & 15.44 & & & 0.12 & 12.78 & \\
\hline $3 / 22 / 0620: 50$ & 14.76 & & & 0.12 & 12.67 & \\
\hline $3 / 22 / 0621: 00$ & 15.64 & & & 0.12 & 13.53 & \\
\hline $3 / 22 / 0621: 10$ & 15.67 & & & 0.12 & 13.21 & \\
\hline $3 / 22 / 0621: 20$ & 16.02 & & & 0.12 & 12.96 & \\
\hline $3 / 22 / 0621: 30$ & 16.32 & & & 0.11 & 13.57 & \\
\hline $3 / 22 / 0621: 40$ & 17.18 & & & 0.12 & 13.38 & \\
\hline $3 / 22 / 0621: 50$ & 17.03 & & & 0.12 & 13.97 & \\
\hline $3 / 22 / 0622: 00$ & 18.81 & & & 0.12 & 14.58 & \\
\hline $3 / 22 / 0622: 10$ & 18.83 & & & 0.12 & 13.63 & \\
\hline $3 / 22 / 0622: 20$ & 18.01 & & & 0.12 & 14.28 & \\
\hline $3 / 22 / 0622: 30$ & 17.99 & & & 0.12 & 13.91 & \\
\hline $3 / 22 / 0622: 40$ & 18.63 & & & 0.12 & 14.12 & \\
\hline $3 / 22 / 0622: 50$ & 18.26 & & & 0.12 & 14.25 & \\
\hline $3 / 22 / 0623: 00$ & 18.34 & & & 0.12 & 14.19 & \\
\hline $3 / 22 / 0623: 10$ & 18.81 & & & 0.12 & 14.67 & \\
\hline $3 / 22 / 0623: 20$ & 18.45 & & & 0.09 & 13.00 & \\
\hline $3 / 22 / 0623: 30$ & 16.99 & & & 0.00 & 12.40 & \\
\hline $3 / 22 / 0623: 40$ & 17.54 & & & 0.00 & 13.15 & \\
\hline $3 / 22 / 0623: 50$ & 18.38 & & & 0.00 & 13.87 & \\
\hline 3/23/06 0:00 & 20.59 & & & 0.00 & 14.47 & \\
\hline 3/23/06 0:10 & 19.66 & & & 0.00 & 15.12 & \\
\hline 3/23/06 0:20 & 20.24 & & & 0.00 & 15.45 & \\
\hline 3/23/06 0:30 & 19.60 & & & 0.00 & 15.20 & \\
\hline
\end{tabular}


Table D1. Corrected CMM and ACI, 10-minute Averaged Data During the Monthlong Field Test (continued)

\begin{tabular}{|c|c|c|c|c|c|c|}
\hline Date, Time & $\begin{array}{c}\text { FF Inlet } \mathrm{HgT}, \\
\mu \mathrm{g} / \mathrm{dNm}^{3}, \\
3 \% \mathrm{O}_{2}\end{array}$ & $\begin{array}{c}\text { FF Outlet HgT, } \\
\mu \mathrm{g} / \mathrm{dNm}^{3}, \\
3 \% \mathrm{O}_{2}\end{array}$ & $\begin{array}{c}\text { HgT Removal } \\
\text { Across } \\
\text { FF 2-4, \% }\end{array}$ & $\begin{array}{c}\text { FF 2-4 Activated } \\
\text { Carbon Injection } \\
\text { Rate, lb/Macf }\end{array}$ & $\begin{array}{c}\text { FF Inlet } \mathrm{Hg}^{0}, \\
\mu \mathrm{g} / \mathrm{dNm}^{3}, \\
3 \% \mathrm{O}_{2}\end{array}$ & $\begin{array}{c}\text { FF Outlet } \mathrm{Hg}^{0} \text {, } \\
\mu \mathrm{g} / \mathrm{dNm}^{3}, \\
3 \% \mathrm{O}_{2}\end{array}$ \\
\hline $3 / 23 / 060: 40$ & 19.60 & & & 0.00 & 15.13 & \\
\hline $3 / 23 / 060: 50$ & 19.18 & & & 0.00 & 14.86 & \\
\hline $3 / 23 / 061: 00$ & 18.93 & & & 0.00 & 14.45 & \\
\hline $3 / 23 / 061: 10$ & 19.14 & & & 0.00 & 15.10 & \\
\hline 3/23/06 1:20 & 18.24 & & & 0.00 & 14.32 & \\
\hline $3 / 23 / 061: 30$ & 17.60 & & & 0.00 & 14.02 & \\
\hline $3 / 23 / 061: 40$ & 17.05 & & & 0.00 & 13.11 & \\
\hline $3 / 23 / 061: 50$ & 16.22 & & & 0.00 & 12.77 & \\
\hline $3 / 23 / 062: 00$ & 16.55 & & & 0.00 & 12.74 & \\
\hline $3 / 23 / 062: 10$ & 16.16 & & & 0.00 & 12.27 & \\
\hline $3 / 23 / 062: 20$ & 16.53 & & & 0.00 & 12.61 & \\
\hline $3 / 23 / 062: 30$ & 17.34 & & & 0.00 & 13.05 & \\
\hline $3 / 23 / 062: 40$ & 17.33 & & & 0.00 & 13.01 & \\
\hline $3 / 23 / 062: 50$ & 18.43 & & & 0.00 & 12.80 & \\
\hline 3/23/06 3:00 & 17.87 & & & 0.00 & 11.73 & \\
\hline $3 / 23 / 063: 10$ & 16.26 & & & 0.00 & 11.17 & \\
\hline $3 / 23 / 063: 20$ & 16.11 & & & 0.00 & 11.34 & \\
\hline $3 / 23 / 063: 30$ & 16.34 & & & 0.00 & 11.63 & \\
\hline $3 / 23 / 063: 40$ & 15.98 & & & 0.00 & 11.06 & \\
\hline $3 / 23 / 063: 50$ & 14.82 & & & 0.00 & 10.67 & \\
\hline $3 / 23 / 064: 00$ & 14.28 & & & 0.00 & 9.63 & \\
\hline $3 / 23 / 064: 10$ & 13.95 & & & 0.00 & 10.25 & \\
\hline $3 / 23 / 064: 20$ & 15.62 & & & 0.00 & 11.40 & \\
\hline $3 / 23 / 064: 30$ & 15.25 & & & 0.00 & 11.22 & \\
\hline $3 / 23 / 064: 40$ & 16.10 & & & 0.00 & 11.86 & \\
\hline $3 / 23 / 064: 50$ & 16.47 & & & 0.00 & 12.02 & \\
\hline 3/23/06 5:00 & 15.35 & & & 0.00 & 11.30 & \\
\hline $3 / 23 / 065: 10$ & 15.72 & & & 0.00 & 11.19 & \\
\hline $3 / 23 / 065: 20$ & 16.40 & & & 0.00 & 11.68 & \\
\hline $3 / 23 / 065: 30$ & 15.87 & & & 0.00 & 12.10 & \\
\hline $3 / 23 / 065: 40$ & 16.53 & & & 0.00 & 12.66 & \\
\hline $3 / 23 / 065: 50$ & 16.10 & & & 0.00 & 12.91 & \\
\hline $3 / 23 / 066: 00$ & 15.52 & & & 0.00 & 12.18 & \\
\hline $3 / 23 / 066: 10$ & 20.24 & & & 0.00 & 10.66 & \\
\hline $3 / 23 / 066: 20$ & 77.41 & & & 0.00 & 10.33 & \\
\hline $3 / 23 / 066: 30$ & 32.60 & & & 0.00 & 10.68 & \\
\hline $3 / 23 / 066: 40$ & 22.90 & & & 0.00 & 10.39 & \\
\hline $3 / 23 / 066: 50$ & 20.27 & & & 0.00 & 10.81 & \\
\hline $3 / 23 / 067: 00$ & 18.02 & & & 0.00 & 11.09 & \\
\hline $3 / 23 / 067: 10$ & 17.37 & & & 0.00 & 10.81 & \\
\hline $3 / 23 / 06$ 7:20 & 16.48 & & & 0.00 & 11.04 & \\
\hline $3 / 23 / 067: 30$ & & & & 0.00 & & \\
\hline $3 / 23 / 067: 40$ & & & & 0.00 & & \\
\hline $3 / 23 / 067: 50$ & & & & 0.00 & & \\
\hline $3 / 23 / 068: 00$ & & & & 0.00 & & \\
\hline $3 / 23 / 068: 10$ & & & & 0.00 & & \\
\hline $3 / 23 / 068: 20$ & & & & 0.00 & & \\
\hline $3 / 23 / 068: 30$ & & & & 0.90 & & \\
\hline $3 / 23 / 068: 40$ & & & & 1.52 & & \\
\hline $3 / 23 / 068: 50$ & & & & 1.53 & & \\
\hline 3/23/06 9:00 & & & & 1.52 & & \\
\hline $3 / 23 / 069: 10$ & & & & 1.51 & & \\
\hline
\end{tabular}


Table D1. Corrected CMM and ACI, 10-minute Averaged Data During the Monthlong Field Test (continued)

\begin{tabular}{|c|c|c|c|c|c|c|}
\hline Date, Time & $\begin{array}{c}\text { FF Inlet } \mathrm{HgT}, \\
\mu \mathrm{g} / \mathrm{dNm}^{3}, \\
3 \% \mathrm{O}_{2} \\
\end{array}$ & $\begin{array}{c}\text { FF Outlet HgT, } \\
\mu \mathrm{g} / \mathrm{dNm}^{3}, \\
3 \% \mathrm{O}_{2}\end{array}$ & $\begin{array}{c}\text { HgT Removal } \\
\text { Across } \\
\text { FF 2-4, \% }\end{array}$ & $\begin{array}{c}\text { FF 2-4 Activated } \\
\text { Carbon Injection } \\
\text { Rate, lb/Macf }\end{array}$ & $\begin{array}{c}\text { FF Inlet } \mathrm{Hg}^{0}, \\
\mu \mathrm{g} / \mathrm{dNm}^{3}, \\
3 \% \mathrm{O}_{2} \\
\end{array}$ & $\begin{array}{c}\text { FF Outlet } \mathrm{Hg}^{0}, \\
\mu \mathrm{g} / \mathrm{dNm}^{3}, \\
3 \% \mathrm{O}_{2}\end{array}$ \\
\hline $3 / 23 / 069: 20$ & & & & 1.49 & & \\
\hline $3 / 23 / 069: 30$ & & & & 1.50 & & \\
\hline 3/23/06 9:40 & & & & 1.50 & & \\
\hline $3 / 23 / 069: 50$ & & & & 1.48 & & \\
\hline 3/23/06 10:00 & & 3.80 & & 1.51 & & 1.93 \\
\hline 3/23/06 10:10 & & 3.45 & & 1.50 & & 1.48 \\
\hline $3 / 23 / 0610: 20$ & & 3.25 & & 1.50 & & 1.19 \\
\hline 3/23/06 10:30 & & 3.03 & & 1.49 & & 0.89 \\
\hline $3 / 23 / 06$ 10:40 & & 2.87 & & 1.52 & & 0.73 \\
\hline $3 / 23 / 0610: 50$ & & 2.53 & & 1.51 & & 0.52 \\
\hline $3 / 23 / 06$ 11:00 & 12.97 & 2.21 & 82.94 & 1.50 & 7.73 & 0.47 \\
\hline 3/23/06 11:10 & 12.66 & 1.92 & 84.79 & 1.53 & 8.01 & 0.37 \\
\hline 3/23/06 11:20 & 11.66 & 1.87 & 83.94 & 1.50 & 7.60 & 0.37 \\
\hline $3 / 23 / 0611: 30$ & 12.26 & 3.16 & 74.21 & 1.53 & 7.76 & 0.48 \\
\hline $3 / 23 / 0611: 40$ & 19.56 & 2.32 & 88.15 & 1.50 & 8.31 & 0.38 \\
\hline $3 / 23 / 0611: 50$ & 15.72 & 3.66 & 76.74 & 1.53 & 7.62 & 0.43 \\
\hline $3 / 23 / 0612: 00$ & 14.87 & 5.74 & 61.39 & 1.51 & 7.38 & 0.62 \\
\hline 3/23/06 12:10 & 15.03 & 6.94 & 53.85 & 1.46 & 7.72 & 0.68 \\
\hline $3 / 23 / 0612: 20$ & 16.12 & 5.25 & 67.46 & 1.42 & 7.58 & 0.70 \\
\hline $3 / 23 / 0612: 30$ & 17.53 & 4.69 & 73.24 & 1.39 & 7.58 & 0.75 \\
\hline $3 / 23 / 0612: 40$ & 17.34 & 6.56 & 62.17 & 1.41 & 7.67 & 0.88 \\
\hline $3 / 23 / 0612: 50$ & 20.15 & 7.07 & 64.89 & 1.39 & 7.85 & 0.93 \\
\hline 3/23/06 13:00 & 19.01 & 5.36 & 71.80 & 1.42 & 8.00 & 0.59 \\
\hline 3/23/06 13:10 & 17.31 & 5.30 & 69.40 & 1.42 & 7.34 & 0.37 \\
\hline $3 / 23 / 0613: 20$ & 17.10 & 4.88 & 71.47 & 1.42 & 7.30 & 0.38 \\
\hline $3 / 23 / 0613: 30$ & 16.78 & 5.09 & 69.67 & 1.41 & 7.18 & 0.33 \\
\hline 3/23/06 13:40 & 16.60 & 4.59 & 72.33 & 1.42 & 7.44 & 0.32 \\
\hline $3 / 23 / 0613: 50$ & 17.13 & 4.33 & 74.71 & 1.40 & 7.39 & 0.42 \\
\hline 3/23/06 14:00 & 17.93 & 4.06 & 77.34 & 1.39 & 7.47 & 0.41 \\
\hline $3 / 23 / 0614: 10$ & 18.32 & 4.85 & 73.53 & 1.47 & 8.05 & 0.32 \\
\hline 3/23/06 14:20 & 17.60 & 3.63 & 79.39 & 1.47 & 7.48 & 0.16 \\
\hline 3/23/06 14:30 & 15.10 & 3.60 & 76.13 & 1.50 & 7.42 & 0.12 \\
\hline $3 / 23 / 0614: 40$ & 15.41 & 3.23 & 79.04 & 1.41 & 7.75 & 0.17 \\
\hline $3 / 23 / 0614: 50$ & 17.81 & 3.19 & 82.11 & 1.42 & 9.93 & 0.29 \\
\hline $3 / 23 / 0615: 00$ & 23.06 & 3.15 & 86.35 & 1.38 & 11.51 & 0.34 \\
\hline $3 / 23 / 0615: 10$ & 25.66 & 3.83 & 85.08 & 1.43 & 11.16 & 0.38 \\
\hline $3 / 23 / 0615: 20$ & 22.56 & 3.20 & 85.83 & 1.41 & 10.62 & 0.42 \\
\hline $3 / 23 / 0615: 30$ & 24.35 & 2.97 & 87.81 & 1.42 & 12.46 & 0.51 \\
\hline $3 / 23 / 06 \quad 15: 40$ & 25.28 & 4.38 & 82.69 & 1.46 & 11.35 & 0.34 \\
\hline $3 / 23 / 0615: 50$ & 22.43 & 3.23 & 85.60 & 1.44 & 9.67 & 0.46 \\
\hline $3 / 23 / 06$ 16:00 & 21.01 & 3.36 & 84.02 & 1.48 & 9.00 & 0.38 \\
\hline $3 / 23 / 0616: 10$ & 18.79 & 4.48 & 76.18 & 1.43 & 8.66 & 0.19 \\
\hline $3 / 23 / 0616: 20$ & 17.96 & 3.10 & 82.72 & 1.48 & 8.40 & 0.15 \\
\hline $3 / 23 / 0616: 30$ & 16.98 & 3.86 & 77.25 & 1.45 & 8.14 & 0.19 \\
\hline $3 / 23 / 06$ 16:40 & 16.58 & 3.29 & 80.14 & 1.44 & 8.16 & 0.26 \\
\hline $3 / 23 / 0616: 50$ & 17.24 & 3.56 & 79.33 & 1.44 & 8.62 & 0.28 \\
\hline $3 / 23 / 06$ 17:00 & 16.32 & 4.19 & 74.29 & 1.44 & 8.14 & 0.22 \\
\hline $3 / 23 / 0617: 10$ & 17.35 & 3.46 & 80.07 & 1.47 & 8.41 & 0.28 \\
\hline $3 / 23 / 06$ 17:20 & 17.93 & 5.48 & 69.45 & 1.46 & 8.74 & 0.32 \\
\hline $3 / 23 / 0617: 30$ & 17.20 & 3.07 & 82.16 & 1.49 & 8.68 & 0.25 \\
\hline $3 / 23 / 06 \quad 17: 40$ & 17.56 & 3.16 & 82.03 & 1.44 & 8.54 & 0.32 \\
\hline $3 / 23 / 0617: 50$ & 18.94 & 4.45 & 76.51 & 1.44 & 8.85 & 0.32 \\
\hline
\end{tabular}


Table D1. Corrected CMM and ACI, 10-minute Averaged Data During the Monthlong Field Test (continued)

\begin{tabular}{|c|c|c|c|c|c|c|}
\hline Date, Time & $\begin{array}{c}\text { FF Inlet } \mathrm{HgT}, \\
\mu \mathrm{g} / \mathrm{dNm}^{3}, \\
3 \% \mathrm{O}_{2} \\
\end{array}$ & $\begin{array}{c}\text { FF Outlet HgT, } \\
\mu \mathrm{g} / \mathrm{dNm}^{3}, \\
3 \% \mathrm{O}_{2} \\
\end{array}$ & $\begin{array}{c}\text { HgT Removal } \\
\text { Across } \\
\text { FF } 2-4, \% \\
\end{array}$ & $\begin{array}{c}\text { FF 2-4 Activated } \\
\text { Carbon Injection } \\
\text { Rate, lb/Macf }\end{array}$ & $\begin{array}{c}\text { FF Inlet } \mathrm{Hg}^{0}, \\
\mu \mathrm{g} / \mathrm{dNm}^{3}, \\
3 \% \mathrm{O}_{2} \\
\end{array}$ & $\begin{array}{c}\text { FF Outlet } \mathrm{Hg}^{0}, \\
\mu \mathrm{g} / \mathrm{dNm}^{3}, \\
3 \% \mathrm{O}_{2}\end{array}$ \\
\hline 3/23/06 18:00 & 18.02 & 3.78 & 79.01 & 1.41 & 8.43 & 0.22 \\
\hline $3 / 23 / 06$ 18:10 & 17.07 & 3.25 & 80.96 & 1.44 & 8.28 & 0.27 \\
\hline 3/23/06 18:20 & 17.13 & 3.20 & 81.33 & 1.44 & 8.30 & 0.24 \\
\hline 3/23/06 18:30 & 16.76 & 3.13 & 81.34 & 1.50 & 7.78 & 0.12 \\
\hline $3 / 23 / 0618: 40$ & 15.58 & 3.35 & 78.53 & 1.52 & 8.05 & 0.12 \\
\hline 3/23/06 18:50 & 15.42 & 2.94 & 80.92 & 1.50 & 8.15 & 0.12 \\
\hline 3/23/06 19:00 & 15.50 & 2.95 & 81.00 & 1.52 & 7.83 & 0.12 \\
\hline 3/23/06 19:10 & 16.28 & 8.41 & 48.36 & 1.50 & 9.35 & 0.23 \\
\hline 3/23/06 19:20 & 19.33 & 3.72 & 80.73 & 0.82 & 9.97 & 0.40 \\
\hline 3/23/06 19:30 & 21.34 & 6.63 & 68.96 & 0.12 & 11.56 & 1.13 \\
\hline 3/23/06 19:40 & 22.03 & 8.64 & 60.76 & 0.12 & 10.52 & 1.02 \\
\hline $3 / 23 / 0619: 50$ & 23.29 & 11.94 & 48.72 & 0.12 & 10.34 & 1.63 \\
\hline 3/23/06 20:00 & 27.46 & 13.21 & 51.88 & 0.12 & 13.49 & 2.45 \\
\hline $3 / 23 / 0620: 10$ & 25.40 & 16.50 & 35.04 & 0.12 & 11.24 & 1.91 \\
\hline $3 / 23 / 0620: 20$ & 26.66 & 17.32 & 35.05 & 0.12 & 12.28 & 3.12 \\
\hline $3 / 23 / 0620: 30$ & 28.59 & 18.56 & 35.10 & 0.12 & 13.91 & 3.09 \\
\hline $3 / 23 / 0620: 40$ & 27.61 & 16.34 & 40.84 & 0.12 & 11.64 & 2.06 \\
\hline $3 / 23 / 0620: 50$ & 28.30 & 14.57 & 48.52 & 0.12 & 13.99 & 2.91 \\
\hline 3/23/06 21:00 & 26.81 & 19.09 & 28.78 & 0.12 & 12.23 & 2.30 \\
\hline $3 / 23 / 0621: 10$ & 26.01 & 19.30 & 25.78 & 0.12 & 12.09 & 2.82 \\
\hline 3/23/06 21:20 & 27.42 & 18.94 & 30.95 & 0.12 & 11.61 & 1.99 \\
\hline $3 / 23 / 0621: 30$ & 23.23 & 22.14 & 4.69 & 0.12 & 10.20 & 1.79 \\
\hline $3 / 23 / 0621: 40$ & 25.70 & 20.81 & 19.01 & 0.12 & 10.28 & 2.24 \\
\hline $3 / 23 / 0621: 50$ & 30.83 & 22.17 & 28.09 & 0.12 & 14.40 & 3.58 \\
\hline $3 / 23 / 0622: 00$ & 26.02 & 26.86 & 0 & 0.12 & 11.18 & 2.38 \\
\hline $3 / 23 / 0622: 10$ & 30.29 & 24.73 & 18.37 & 0.12 & 13.85 & 3.48 \\
\hline $3 / 23 / 0622: 20$ & 34.22 & 22.50 & 34.24 & 0.12 & 15.25 & 3.77 \\
\hline $3 / 23 / 0622: 30$ & 34.37 & 26.13 & 23.96 & 0.12 & 13.98 & 2.93 \\
\hline $3 / 23 / 0622: 40$ & 29.04 & 29.21 & 0 & 0.12 & 10.72 & 2.59 \\
\hline $3 / 23 / 0622: 50$ & 29.91 & 24.74 & 17.28 & 0.12 & 10.88 & 2.14 \\
\hline $3 / 23 / 0623: 00$ & 27.90 & 28.46 & 0 & 0.12 & 10.35 & 2.69 \\
\hline $3 / 23 / 0623: 10$ & 29.90 & 28.45 & 4.83 & 0.12 & 10.95 & 2.38 \\
\hline $3 / 23 / 0623: 20$ & 24.94 & 22.94 & 8.03 & 0.12 & 10.17 & 2.39 \\
\hline $3 / 23 / 0623: 30$ & 26.16 & 33.55 & 0 & 0.12 & 10.75 & 2.81 \\
\hline $3 / 23 / 0623: 40$ & 25.87 & 24.20 & 6.45 & 0.12 & 10.69 & 3.02 \\
\hline $3 / 23 / 0623: 50$ & 26.05 & 23.44 & 10.01 & 0.40 & 10.35 & 2.64 \\
\hline 3/24/06 0:00 & 24.49 & 21.77 & 11.12 & 1.43 & 10.46 & 1.70 \\
\hline $3 / 24 / 060: 10$ & 23.82 & 17.88 & 24.94 & 1.43 & 9.26 & 0.96 \\
\hline $3 / 24 / 060: 20$ & 20.19 & 27.85 & 0 & 1.44 & 8.34 & 0.75 \\
\hline $3 / 24 / 060: 30$ & 18.89 & 12.25 & 35.14 & 1.46 & 7.95 & 0.52 \\
\hline $3 / 24 / 060: 40$ & 18.13 & 10.27 & 43.37 & 1.46 & 7.51 & 0.39 \\
\hline $3 / 24 / 060: 50$ & 16.87 & 7.46 & 55.76 & 1.47 & 7.47 & 0.32 \\
\hline $3 / 24 / 061: 00$ & 16.85 & 5.27 & 68.70 & 1.49 & 7.53 & 0.37 \\
\hline $3 / 24 / 061: 10$ & 18.53 & 7.65 & 58.72 & 1.49 & 8.08 & 0.29 \\
\hline $3 / 24 / 061: 20$ & 18.60 & 19.43 & 0 & 1.46 & 8.16 & 0.36 \\
\hline $3 / 24 / 061: 30$ & 19.54 & 10.74 & 45.04 & 1.46 & 8.02 & 0.31 \\
\hline $3 / 24 / 061: 40$ & 19.00 & 13.49 & 28.98 & 1.45 & 7.76 & 0.23 \\
\hline $3 / 24 / 061: 50$ & 21.71 & 11.63 & 46.43 & 1.36 & 8.76 & 0.53 \\
\hline $3 / 24 / 062: 00$ & 19.66 & 7.07 & 64.06 & 1.34 & 7.84 & 0.45 \\
\hline $3 / 24 / 062: 10$ & 18.78 & 4.68 & 75.07 & 1.39 & 7.49 & 0.24 \\
\hline $3 / 24 / 062: 20$ & 15.09 & 8.96 & 40.62 & 1.42 & 6.52 & 0.19 \\
\hline $3 / 24 / 062: 30$ & 14.28 & 9.88 & 30.85 & 1.41 & 6.86 & 0.31 \\
\hline
\end{tabular}


Table D1. Corrected CMM and ACI, 10-minute Averaged Data During the Monthlong Field Test (continued)

\begin{tabular}{|c|c|c|c|c|c|c|}
\hline Date, Time & $\begin{array}{c}\text { FF Inlet } \mathrm{HgT}, \\
\mu \mathrm{g} / \mathrm{dNm}^{3}, \\
3 \% \mathrm{O}_{2} \\
\end{array}$ & $\begin{array}{c}\text { FF Outlet HgT, } \\
\mu \mathrm{g} / \mathrm{dNm}^{3}, \\
3 \% \mathrm{O}_{2} \\
\end{array}$ & $\begin{array}{c}\text { HgT Removal } \\
\text { Across } \\
\text { FF 2-4, \% }\end{array}$ & $\begin{array}{c}\text { FF 2-4 Activated } \\
\text { Carbon Injection } \\
\text { Rate, lb/Macf }\end{array}$ & $\begin{array}{c}\text { FF Inlet } \mathrm{Hg}^{0}, \\
\mu \mathrm{g} / \mathrm{dNm}^{3}, \\
3 \% \mathrm{O}_{2} \\
\end{array}$ & $\begin{array}{c}\text { FF Outlet } \mathrm{Hg}^{0}, \\
\mu \mathrm{g} / \mathrm{dNm}^{3}, \\
3 \% \mathrm{O}_{2}\end{array}$ \\
\hline $3 / 24 / 062: 40$ & 13.88 & 8.91 & 35.80 & 1.45 & 6.90 & 0.25 \\
\hline $3 / 24 / 062: 50$ & 13.08 & 17.50 & 0 & 1.48 & 7.06 & 0.22 \\
\hline 3/24/06 3:00 & 11.50 & 3.94 & 65.76 & 1.50 & 7.02 & 0.15 \\
\hline $3 / 24 / 063: 10$ & 11.85 & 3.59 & 69.69 & 1.50 & 7.76 & 0.12 \\
\hline $3 / 24 / 063: 20$ & 12.16 & 7.21 & 40.73 & 1.49 & 8.33 & 0.12 \\
\hline $3 / 24 / 063: 30$ & 12.04 & 19.28 & 0 & 1.49 & 8.10 & 0.12 \\
\hline $3 / 24 / 063: 40$ & 12.70 & 6.02 & 52.58 & 0.94 & 8.52 & 0.22 \\
\hline $3 / 24 / 063: 50$ & 14.01 & 5.14 & 63.34 & 0.12 & 8.29 & 0.52 \\
\hline $3 / 24 / 064: 00$ & 13.89 & 6.30 & 54.64 & 0.13 & 8.56 & 0.64 \\
\hline $3 / 24 / 064: 10$ & 13.70 & 7.73 & 43.59 & 0.13 & 8.27 & 0.63 \\
\hline $3 / 24 / 064: 20$ & 15.04 & 6.83 & 54.61 & 1.51 & 8.40 & 0.27 \\
\hline $3 / 24 / 064: 30$ & 16.43 & 5.72 & 65.16 & 1.50 & 9.17 & 0.25 \\
\hline $3 / 24 / 064: 40$ & 17.00 & 5.19 & 69.46 & 1.51 & 8.73 & 0.14 \\
\hline $3 / 24 / 064: 50$ & 16.24 & 4.87 & 70.00 & 1.51 & 8.76 & 0.12 \\
\hline $3 / 24 / 065: 00$ & 17.28 & 3.79 & 78.07 & 1.53 & 9.29 & 0.20 \\
\hline $3 / 24 / 065: 10$ & 19.11 & 15.31 & 19.86 & 1.37 & 9.10 & 3.94 \\
\hline $3 / 24 / 065: 20$ & 18.71 & 14.29 & 23.60 & 0.13 & 9.17 & 2.97 \\
\hline $3 / 24 / 065: 30$ & 19.01 & 14.86 & 21.84 & 0.12 & 9.09 & 4.13 \\
\hline $3 / 24 / 065: 40$ & 20.33 & 13.56 & 33.31 & 0.12 & 10.01 & 2.82 \\
\hline $3 / 24 / 065: 50$ & 19.25 & 10.71 & 44.37 & 0.12 & 9.03 & 1.45 \\
\hline $3 / 24 / 066: 00$ & 19.12 & 12.09 & 36.77 & 0.26 & 9.41 & 1.96 \\
\hline $3 / 24 / 066: 10$ & 21.98 & 12.28 & 44.14 & 1.53 & 10.01 & 2.35 \\
\hline $3 / 24 / 066: 20$ & 24.07 & 10.76 & 55.27 & 1.51 & 10.80 & 2.17 \\
\hline $3 / 24 / 066: 30$ & 23.07 & 9.36 & 59.41 & 1.54 & 11.00 & 1.82 \\
\hline $3 / 24 / 066: 40$ & 22.23 & 8.60 & 61.31 & 1.53 & 10.48 & 1.61 \\
\hline $3 / 24 / 066: 50$ & 22.01 & 8.79 & 60.08 & 1.56 & 10.77 & 1.50 \\
\hline $3 / 24 / 067: 00$ & 20.25 & 8.35 & 58.78 & 1.53 & 9.91 & 1.65 \\
\hline $3 / 24 / 067: 10$ & 19.30 & 8.14 & 57.79 & 1.55 & 10.29 & 1.33 \\
\hline $3 / 24 / 067: 20$ & 18.88 & 7.87 & 58.35 & 1.52 & 11.25 & 1.23 \\
\hline $3 / 24 / 067: 30$ & 20.09 & 7.90 & 60.70 & 0.12 & 11.30 & 1.21 \\
\hline $3 / 24 / 067: 40$ & 18.42 & 7.67 & 58.38 & 0.12 & 11.24 & 1.04 \\
\hline $3 / 24 / 067: 50$ & 18.68 & 7.12 & 61.90 & 0.12 & 10.78 & 1.13 \\
\hline $3 / 24 / 068: 00$ & 20.08 & 6.60 & 67.16 & 0.12 & 10.63 & 0.91 \\
\hline $3 / 24 / 068: 10$ & 22.32 & 6.65 & 70.21 & 0.70 & 11.26 & 0.89 \\
\hline $3 / 24 / 068: 20$ & 21.30 & 5.91 & 72.26 & 1.54 & 10.63 & 1.00 \\
\hline $3 / 24 / 068: 30$ & 18.52 & 5.73 & 69.07 & 1.50 & 9.81 & 0.96 \\
\hline $3 / 24 / 068: 40$ & 18.78 & 5.97 & 68.23 & 1.51 & 9.64 & 0.85 \\
\hline $3 / 24 / 068: 50$ & 17.50 & 6.22 & 64.46 & 1.47 & 8.80 & 0.92 \\
\hline $3 / 24 / 069: 00$ & 17.34 & 5.97 & 65.59 & 1.49 & 9.04 & 0.98 \\
\hline $3 / 24 / 069: 10$ & 18.52 & 6.33 & 65.83 & 1.49 & 9.28 & 1.18 \\
\hline $3 / 24 / 069: 20$ & 17.55 & 7.39 & 57.92 & 1.48 & 8.97 & 1.53 \\
\hline $3 / 24 / 069: 30$ & 19.62 & 7.73 & 60.59 & 1.51 & 9.17 & 1.16 \\
\hline $3 / 24 / 069: 40$ & 22.10 & 7.94 & 64.06 & 1.50 & 9.54 & 0.99 \\
\hline $3 / 24 / 069: 50$ & 11.98 & 7.56 & 36.86 & 1.56 & 5.88 & 0.99 \\
\hline 3/24/06 10:00 & 8.75 & 7.38 & 15.66 & 1.52 & 5.47 & 0.51 \\
\hline 3/24/06 10:10 & 13.23 & 6.55 & 50.46 & 1.51 & 7.96 & 0.55 \\
\hline $3 / 24 / 06$ 10:20 & 16.53 & 7.33 & 55.63 & 1.49 & 8.83 & 0.41 \\
\hline 3/24/06 10:30 & 16.64 & 6.39 & 61.61 & 1.52 & 9.19 & 0.59 \\
\hline $3 / 24 / 06$ 10:40 & 18.90 & 6.54 & 65.41 & 1.50 & 10.20 & 0.37 \\
\hline 3/24/06 10:50 & 18.73 & 6.27 & 66.50 & 1.53 & 9.69 & 0.51 \\
\hline $3 / 24 / 0611: 00$ & 22.07 & 5.27 & 76.13 & 1.51 & 10.87 & 0.49 \\
\hline 3/24/06 11:10 & 27.77 & 6.18 & 77.76 & 1.49 & 11.67 & 0.64 \\
\hline
\end{tabular}


Table D1. Corrected CMM and ACI, 10-minute Averaged Data During the Monthlong Field Test (continued)

\begin{tabular}{|c|c|c|c|c|c|c|}
\hline Date, Time & $\begin{array}{c}\text { FF Inlet } \mathrm{HgT}, \\
\mu \mathrm{g} / \mathrm{dNm}^{3}, \\
3 \% \mathrm{O}_{2}\end{array}$ & $\begin{array}{c}\text { FF Outlet HgT, } \\
\mu \mathrm{g} / \mathrm{dNm}^{3}, \\
3 \% \mathrm{O}_{2}\end{array}$ & $\begin{array}{c}\text { HgT Removal } \\
\text { Across } \\
\text { FF 2-4, \% }\end{array}$ & $\begin{array}{l}\text { FF 2-4 Activated } \\
\text { Carbon Injection } \\
\text { Rate, lb/Macf }\end{array}$ & $\begin{array}{c}\text { FF Inlet } \mathrm{Hg}^{0}, \\
\mu \mathrm{g} / \mathrm{dNm}^{3}, \\
3 \% \mathrm{O}_{2}\end{array}$ & $\begin{array}{c}\text { FF Outlet } \mathrm{Hg}^{0}, \\
\mu \mathrm{g} / \mathrm{dNm}^{3}, \\
3 \% \mathrm{O}_{2}\end{array}$ \\
\hline $3 / 24 / 0611: 20$ & 26.62 & 6.78 & 74.52 & 1.49 & 10.41 & 0.59 \\
\hline $3 / 24 / 06$ 11:30 & 27.71 & 6.52 & 76.47 & 1.46 & 10.75 & 0.59 \\
\hline 3/24/06 11:40 & 23.99 & 7.27 & 69.68 & 1.50 & 9.59 & 0.64 \\
\hline $3 / 24 / 0611: 50$ & 22.19 & 6.43 & 71.02 & 1.50 & 9.55 & 0.46 \\
\hline $3 / 24 / 06$ 12:00 & 21.69 & 5.68 & 73.80 & 1.49 & 10.11 & 0.61 \\
\hline $3 / 24 / 0612: 10$ & 18.61 & 6.21 & 66.62 & 1.48 & 9.83 & 0.54 \\
\hline $3 / 24 / 0612: 20$ & 20.67 & 7.80 & 62.28 & 1.49 & 9.99 & 0.71 \\
\hline $3 / 24 / 0612: 30$ & 20.19 & 7.16 & 64.54 & 1.48 & 10.53 & 0.72 \\
\hline $3 / 24 / 0612: 40$ & 18.98 & 5.48 & 71.15 & 1.48 & 10.31 & 0.57 \\
\hline $3 / 24 / 0612: 50$ & 19.08 & 6.85 & 64.07 & 1.49 & 10.77 & 0.86 \\
\hline $3 / 24 / 0613: 00$ & 19.00 & 9.03 & 52.49 & 1.49 & 10.34 & 1.21 \\
\hline $3 / 24 / 0613: 10$ & 19.15 & 7.40 & 61.37 & 1.50 & 11.40 & 0.77 \\
\hline $3 / 24 / 0613: 20$ & 21.22 & 6.74 & 68.24 & 1.46 & 11.40 & 0.78 \\
\hline $3 / 24 / 0613: 30$ & 24.18 & 7.95 & 67.13 & 1.47 & 11.88 & 0.76 \\
\hline $3 / 24 / 0613: 40$ & 23.31 & 6.77 & 70.96 & 1.46 & 10.34 & 0.50 \\
\hline $3 / 24 / 0613: 50$ & 21.02 & 6.27 & 70.16 & 1.43 & 10.00 & 0.47 \\
\hline $3 / 24 / 0614: 00$ & 20.42 & 7.05 & 65.45 & 1.42 & 9.52 & 0.47 \\
\hline 3/24/06 14:10 & 18.85 & 6.54 & 65.29 & 1.45 & 9.35 & 0.37 \\
\hline $3 / 24 / 06$ 14:20 & 16.73 & 8.42 & 49.66 & 1.46 & 9.64 & 0.19 \\
\hline $3 / 24 / 0614: 30$ & 16.86 & 6.09 & 63.88 & 1.49 & 9.35 & \\
\hline $3 / 24 / 0614: 40$ & 16.57 & 7.40 & 55.37 & 1.50 & 9.59 & \\
\hline $3 / 24 / 0614: 50$ & 18.04 & 5.44 & 69.82 & 1.50 & 10.38 & \\
\hline $3 / 24 / 0615: 00$ & 20.54 & 6.49 & 68.41 & 1.49 & 11.18 & 0.12 \\
\hline $3 / 24 / 0615: 10$ & 26.09 & & & 1.47 & 12.50 & \\
\hline $3 / 24 / 0615: 20$ & 25.04 & & & 1.49 & 11.90 & \\
\hline $3 / 24 / 0615: 30$ & 26.96 & & & 1.49 & 12.46 & \\
\hline $3 / 24 / 0615: 40$ & 28.98 & & & 1.46 & 14.43 & \\
\hline $3 / 24 / 0615: 50$ & 25.16 & & & 1.50 & 11.59 & \\
\hline $3 / 24 / 0616: 00$ & 27.02 & & & 1.45 & 11.52 & \\
\hline $3 / 24 / 0616: 10$ & 32.82 & & & 1.47 & 15.66 & \\
\hline $3 / 24 / 0616: 20$ & 35.94 & & & 1.46 & 13.30 & \\
\hline $3 / 24 / 0616: 30$ & 35.74 & & & 1.48 & 15.53 & \\
\hline $3 / 24 / 0616: 40$ & 33.55 & & & 1.46 & 14.85 & \\
\hline $3 / 24 / 0616: 50$ & 34.95 & & & 1.46 & 15.82 & \\
\hline $3 / 24 / 06$ 17:00 & 36.34 & & & 1.41 & 17.16 & \\
\hline $3 / 24 / 0617: 10$ & 33.91 & & & 1.38 & 14.36 & \\
\hline $3 / 24 / 06$ 17:20 & 31.46 & & & 1.34 & 13.71 & \\
\hline $3 / 24 / 0617: 30$ & 28.92 & & & 1.35 & 13.99 & \\
\hline $3 / 24 / 0617: 40$ & 27.28 & & & 1.35 & 12.37 & \\
\hline $3 / 24 / 0617: 50$ & 26.99 & & & 1.34 & 12.48 & \\
\hline $3 / 24 / 06$ 18:00 & 23.58 & & & 1.39 & 12.04 & \\
\hline $3 / 24 / 06$ 18:10 & 22.79 & & & 1.42 & 12.57 & \\
\hline $3 / 24 / 06$ 18:20 & 23.42 & & & 1.45 & 13.24 & \\
\hline $3 / 24 / 0618: 30$ & 22.06 & & & 1.42 & 12.79 & \\
\hline $3 / 24 / 0618: 40$ & 23.75 & & & 1.42 & 12.89 & \\
\hline $3 / 24 / 0618: 50$ & 21.96 & & & 1.44 & 11.86 & \\
\hline 3/24/06 19:00 & 27.42 & & & 1.40 & 12.22 & \\
\hline 3/24/06 19:10 & 24.84 & & & 1.41 & 11.11 & \\
\hline $3 / 24 / 06$ 19:20 & 21.65 & & & 1.39 & 10.05 & \\
\hline $3 / 24 / 0619: 30$ & 22.94 & & & 1.40 & 11.09 & \\
\hline 3/24/06 19:40 & 29.92 & & & 1.35 & 12.93 & \\
\hline $3 / 24 / 0619: 50$ & 29.73 & & & 1.35 & 15.79 & \\
\hline
\end{tabular}


Table D1. Corrected CMM and ACI, 10-minute Averaged Data During the Monthlong Field Test (continued)

\begin{tabular}{|c|c|c|c|c|c|c|}
\hline Date, Time & $\begin{array}{c}\text { FF Inlet } \mathrm{HgT} \text {, } \\
\mu \mathrm{g} / \mathrm{dNm}^{3}, \\
3 \% \mathrm{O}_{2} \\
\end{array}$ & $\begin{array}{c}\text { FF Outlet } \mathrm{HgT} \text {, } \\
\mu \mathrm{g} / \mathrm{dNm}^{3}, \\
3 \% \mathrm{O}_{2}\end{array}$ & $\begin{array}{c}\text { HgT Removal } \\
\text { Across } \\
\text { FF 2-4, } \% \\
\end{array}$ & $\begin{array}{c}\text { FF 2-4 Activated } \\
\text { Carbon Injection } \\
\text { Rate, lb/Macf }\end{array}$ & $\begin{array}{c}\text { FF Inlet } \mathrm{Hg}^{0}, \\
\mu \mathrm{g} / \mathrm{dNm}^{3}, \\
3 \% \mathrm{O}_{2}\end{array}$ & $\begin{array}{c}\text { FF Outlet } \mathrm{Hg}^{0}, \\
\mu \mathrm{g} / \mathrm{dNm}^{3}, \\
3 \% \mathrm{O}_{2}\end{array}$ \\
\hline $3 / 24 / 0620: 00$ & 32.61 & & & 1.30 & 17.25 & \\
\hline $3 / 24 / 0620: 10$ & 30.92 & & & 1.37 & 12.91 & \\
\hline $3 / 24 / 0620: 20$ & 28.73 & & & 1.37 & 11.95 & \\
\hline $3 / 24 / 0620: 30$ & 27.93 & & & 1.35 & 15.06 & \\
\hline $3 / 24 / 0620: 40$ & 28.12 & & & 1.41 & 11.71 & \\
\hline $3 / 24 / 0620: 50$ & 28.71 & & & 1.40 & 13.23 & \\
\hline $3 / 24 / 0621: 00$ & 29.12 & & & 1.40 & 19.13 & \\
\hline $3 / 24 / 0621: 10$ & 30.88 & & & 1.40 & 19.16 & \\
\hline $3 / 24 / 0621: 20$ & 29.72 & & & 1.41 & 15.88 & \\
\hline $3 / 24 / 0621: 30$ & 31.33 & & & 1.38 & 17.47 & \\
\hline $3 / 24 / 0621: 40$ & 33.12 & & & 1.30 & 21.10 & \\
\hline $3 / 24 / 0621: 50$ & 34.21 & & & 1.33 & 22.14 & \\
\hline $3 / 24 / 0622: 00$ & 35.10 & & & 1.30 & 21.75 & \\
\hline $3 / 24 / 0622: 10$ & 34.54 & & & 1.28 & 21.74 & \\
\hline $3 / 24 / 0622: 20$ & 32.42 & & & 1.27 & 21.38 & \\
\hline $3 / 24 / 0622: 30$ & 34.49 & & & 1.28 & 19.19 & \\
\hline $3 / 24 / 0622: 40$ & 30.95 & & & 1.26 & 18.46 & \\
\hline $3 / 24 / 0622: 50$ & 30.67 & & & 1.28 & 16.96 & \\
\hline $3 / 24 / 0623: 00$ & 28.98 & & & 1.28 & 17.06 & \\
\hline $3 / 24 / 0623: 10$ & 28.39 & & & 1.34 & 16.90 & \\
\hline $3 / 24 / 0623: 20$ & 23.69 & & & 1.39 & 11.33 & \\
\hline $3 / 24 / 0623: 30$ & 23.45 & & & 1.42 & 8.80 & \\
\hline $3 / 24 / 0623: 40$ & 25.24 & & & 1.39 & 12.52 & \\
\hline $3 / 24 / 0623: 50$ & 22.90 & & & 1.40 & 11.09 & \\
\hline 3/25/06 0:00 & 26.99 & & & 1.41 & 13.32 & \\
\hline 3/25/06 0:10 & 23.28 & & & 1.43 & 11.18 & \\
\hline 3/25/06 0:20 & 21.80 & & & 1.44 & 10.42 & \\
\hline $3 / 25 / 060: 30$ & 24.97 & & & 1.37 & 13.82 & \\
\hline 3/25/06 0:40 & 27.13 & & & 1.41 & 14.87 & \\
\hline 3/25/06 0:50 & 27.55 & & & 1.32 & 15.13 & \\
\hline 3/25/06 1:00 & 31.77 & & & 1.37 & 16.80 & \\
\hline $3 / 25 / 061: 10$ & 28.60 & & & 1.35 & 16.85 & \\
\hline $3 / 25 / 061: 20$ & 27.80 & & & 1.36 & 15.86 & \\
\hline $3 / 25 / 061: 30$ & 28.06 & & & 1.37 & 16.41 & \\
\hline 3/25/06 1:40 & 28.70 & & & 1.34 & 16.76 & \\
\hline $3 / 25 / 06 \quad 1: 50$ & 29.57 & & & 1.38 & 16.59 & \\
\hline $3 / 25 / 062: 00$ & 29.38 & & & 1.37 & 17.84 & \\
\hline $3 / 25 / 062: 10$ & 28.92 & & & 1.43 & 16.81 & \\
\hline $3 / 25 / 062: 20$ & 26.54 & & & 1.46 & 13.55 & \\
\hline $3 / 25 / 062: 30$ & 25.65 & & & 1.46 & 13.14 & \\
\hline $3 / 25 / 062: 40$ & 27.66 & & & 1.44 & 14.93 & \\
\hline $3 / 25 / 062: 50$ & 27.72 & & & 1.46 & 15.26 & \\
\hline 3/25/06 3:00 & 28.10 & & & 1.46 & 15.34 & \\
\hline $3 / 25 / 063: 10$ & 25.04 & & & 1.49 & 12.82 & \\
\hline $3 / 25 / 063: 20$ & 27.87 & & & 1.47 & 15.07 & \\
\hline $3 / 25 / 063: 30$ & 27.29 & & & 1.48 & 15.76 & \\
\hline $3 / 25 / 063: 40$ & 26.99 & & & 1.43 & 15.29 & \\
\hline $3 / 25 / 063: 50$ & 26.18 & & & 1.43 & 15.27 & \\
\hline $3 / 25 / 064: 00$ & 27.71 & & & 1.41 & 15.61 & \\
\hline $3 / 25 / 064: 10$ & 25.97 & & & 1.41 & 14.60 & \\
\hline $3 / 25 / 064: 20$ & 25.84 & & & 1.42 & 14.35 & \\
\hline $3 / 25 / 064: 30$ & 25.59 & & & 1.39 & 12.77 & \\
\hline
\end{tabular}


Table D1. Corrected CMM and ACI, 10-minute Averaged Data During the Monthlong Field Test (continued)

\begin{tabular}{|c|c|c|c|c|c|c|}
\hline Date, Time & $\begin{array}{c}\text { FF Inlet } \mathrm{HgT}, \\
\mu \mathrm{g} / \mathrm{dNm}^{3}, \\
3 \% \mathrm{O}_{2}\end{array}$ & $\begin{array}{c}\text { FF Outlet } \mathrm{HgT}, \\
\mu \mathrm{g} / \mathrm{dNm}^{3} \\
3 \% \mathrm{O}_{2}\end{array}$ & $\begin{array}{c}\text { HgT Removal } \\
\text { Across } \\
\text { FF } 2-4, \% \\
\end{array}$ & $\begin{array}{c}\text { FF 2-4 Activated } \\
\text { Carbon Injection } \\
\text { Rate, lb/Macf }\end{array}$ & $\begin{array}{c}\text { FF Inlet } \mathrm{Hg}^{0}, \\
\mu \mathrm{g} / \mathrm{dNm}^{3}, \\
3 \% \mathrm{O}_{2}\end{array}$ & $\begin{array}{c}\text { FF Outlet } \mathrm{Hg}^{0}, \\
\mu \mathrm{g} / \mathrm{dNm}^{3}, \\
3 \% \mathrm{O}_{2}\end{array}$ \\
\hline $3 / 25 / 064: 40$ & 25.50 & & & 1.37 & 12.79 & \\
\hline $3 / 25 / 064: 50$ & 25.11 & & & 1.36 & 12.90 & \\
\hline 3/25/06 5:00 & 23.87 & & & 1.36 & 9.61 & \\
\hline 3/25/06 5:10 & 24.14 & & & 1.46 & 9.05 & \\
\hline $3 / 25 / 065: 20$ & 20.72 & & & 1.49 & 9.04 & \\
\hline $3 / 25 / 065: 30$ & 22.54 & & & 1.52 & 11.04 & \\
\hline $3 / 25 / 065: 40$ & 24.99 & & & 1.49 & 13.75 & \\
\hline $3 / 25 / 065: 50$ & 27.35 & & & 1.48 & 14.26 & \\
\hline 3/25/06 6:00 & & & & 1.48 & & \\
\hline 3/25/06 6:10 & & & & 1.48 & & \\
\hline $3 / 25 / 066: 20$ & & & & 1.47 & & \\
\hline $3 / 25 / 066: 30$ & & & & 1.45 & & \\
\hline $3 / 25 / 066: 40$ & & & & 1.44 & & \\
\hline $3 / 25 / 066: 50$ & & & & 1.45 & & \\
\hline $3 / 25 / 067: 00$ & & & & 1.51 & & \\
\hline $3 / 25 / 067: 10$ & & & & 1.49 & & \\
\hline $3 / 25 / 06$ 7:20 & & & & 1.50 & & \\
\hline $3 / 25 / 067: 30$ & & & & 1.47 & & \\
\hline $3 / 25 / 067: 40$ & & & & 1.51 & & \\
\hline $3 / 25 / 067: 50$ & & & & 1.51 & & \\
\hline 3/25/06 8:00 & & & & 1.52 & & \\
\hline $3 / 25 / 068: 10$ & & & & 1.50 & & \\
\hline $3 / 25 / 068: 20$ & & & & 1.50 & & \\
\hline $3 / 25 / 068: 30$ & & & & 1.53 & & \\
\hline $3 / 25 / 068: 40$ & & & & 1.49 & & \\
\hline $3 / 25 / 068: 50$ & & & & 1.52 & & \\
\hline 3/25/06 9:00 & & & & 1.50 & & \\
\hline 3/25/06 9:10 & & & & 1.52 & & \\
\hline $3 / 25 / 069: 20$ & & & & 1.49 & & \\
\hline 3/25/06 9:30 & & & & 1.52 & & \\
\hline 3/25/06 9:40 & & & & 1.50 & & \\
\hline $3 / 25 / 069: 50$ & & & & 1.51 & & \\
\hline $3 / 25 / 0610: 00$ & & & & 1.52 & & \\
\hline $3 / 25 / 0610: 10$ & & & & 1.48 & & \\
\hline $3 / 25 / 0610: 20$ & & & & 1.48 & & \\
\hline $3 / 25 / 0610: 30$ & & & & 1.47 & & \\
\hline $3 / 25 / 0610: 40$ & & & & 1.49 & & \\
\hline $3 / 25 / 0610: 50$ & & & & 1.45 & & \\
\hline $3 / 25 / 0611: 00$ & & & & 1.48 & & \\
\hline $3 / 25 / 0611: 10$ & & & & 1.41 & & \\
\hline $3 / 25 / 0611: 20$ & & & & 1.48 & & \\
\hline $3 / 25 / 0611: 30$ & & & & 1.48 & & \\
\hline $3 / 25 / 06$ 11:40 & & & & 1.49 & & \\
\hline $3 / 25 / 0611: 50$ & & & & 1.49 & & \\
\hline $3 / 25 / 0612: 00$ & & & & 1.45 & & \\
\hline $3 / 25 / 0612: 10$ & & & & 1.49 & & \\
\hline $3 / 25 / 0612: 20$ & & & & 1.46 & & \\
\hline $3 / 25 / 0612: 30$ & & & & 1.49 & & \\
\hline $3 / 25 / 0612: 40$ & & & & 1.44 & & \\
\hline $3 / 25 / 0612: 50$ & & & & 1.46 & & \\
\hline $3 / 25 / 0613: 00$ & & & & 1.46 & & \\
\hline $3 / 25 / 06 \quad 13: 10$ & & & & 1.41 & & \\
\hline
\end{tabular}


Table D1. Corrected CMM and ACI, 10-minute Averaged Data During the Monthlong Field Test (continued)

\begin{tabular}{|c|c|c|c|c|c|c|}
\hline Date, Time & $\begin{array}{c}\text { FF Inlet } \mathrm{HgT}, \\
\mu \mathrm{g} / \mathrm{dNm}^{3}, \\
3 \% \mathrm{O}_{2}\end{array}$ & $\begin{array}{c}\text { FF Outlet } \mathrm{HgT}, \\
\mu \mathrm{g} / \mathrm{dNm}^{3}, \\
3 \% \mathrm{O}_{2}\end{array}$ & $\begin{array}{c}\text { HgT Removal } \\
\text { Across } \\
\text { FF 2-4, } \% \\
\end{array}$ & $\begin{array}{c}\text { FF 2-4 Activated } \\
\text { Carbon Injection } \\
\text { Rate, lb/Macf }\end{array}$ & $\begin{array}{c}\text { FF Inlet } \mathrm{Hg}^{0}, \\
\mu \mathrm{g} / \mathrm{dNm}^{3}, \\
3 \% \mathrm{O}_{2} \\
\end{array}$ & $\begin{array}{c}\text { FF Outlet } \mathrm{Hg}^{0}, \\
\mu \mathrm{g} / \mathrm{dNm}^{3}, \\
3 \% \mathrm{O}_{2}\end{array}$ \\
\hline $3 / 25 / 0613: 20$ & & & & 1.42 & & \\
\hline $3 / 25 / 0613: 30$ & & & & 1.38 & & \\
\hline $3 / 25 / 0613: 40$ & & & & 1.38 & & \\
\hline $3 / 25 / 0613: 50$ & & & & 1.38 & & \\
\hline $3 / 25 / 0614: 00$ & & & & 1.41 & & \\
\hline $3 / 25 / 0614: 10$ & & & & 1.41 & & \\
\hline $3 / 25 / 0614: 20$ & & & & 1.46 & & \\
\hline $3 / 25 / 0614: 30$ & & & & 1.48 & & \\
\hline $3 / 25 / 0614: 40$ & & & & 1.47 & & \\
\hline $3 / 25 / 0614: 50$ & & & & 1.45 & & \\
\hline $3 / 25 / 0615: 00$ & & & & 1.39 & & \\
\hline $3 / 25 / 0615: 10$ & & & & 1.46 & & \\
\hline $3 / 25 / 0615: 20$ & & & & 1.43 & & \\
\hline $3 / 25 / 0615: 30$ & & & & 1.45 & & \\
\hline $3 / 25 / 0615: 40$ & & & & 1.41 & & \\
\hline $3 / 25 / 0615: 50$ & & & & 1.43 & & \\
\hline $3 / 25 / 0616: 00$ & & & & 1.41 & & \\
\hline $3 / 25 / 0616: 10$ & & & & 1.41 & & \\
\hline $3 / 25 / 0616: 20$ & & & & 1.42 & & \\
\hline $3 / 25 / 0616: 30$ & & & & 1.43 & & \\
\hline $3 / 25 / 0616: 40$ & & & & 1.38 & & \\
\hline $3 / 25 / 0616: 50$ & & & & 1.36 & & \\
\hline $3 / 25 / 06$ 17:00 & & & & 1.38 & & \\
\hline $3 / 25 / 0617: 10$ & & & & 1.37 & & \\
\hline $3 / 25 / 0617: 20$ & & & & 1.35 & & \\
\hline $3 / 25 / 0617: 30$ & & & & 1.36 & & \\
\hline $3 / 25 / 06$ 17:40 & & & & 1.37 & & \\
\hline $3 / 25 / 0617: 50$ & & & & 1.41 & & \\
\hline $3 / 25 / 06$ 18:00 & & & & 1.40 & & \\
\hline $3 / 25 / 0618: 10$ & & & & 1.38 & & \\
\hline $3 / 25 / 06$ 18:20 & & & & 1.39 & & \\
\hline $3 / 25 / 0618: 30$ & & & & 1.41 & & \\
\hline $3 / 25 / 0618: 40$ & & & & 1.40 & & \\
\hline $3 / 25 / 0618: 50$ & & & & 1.42 & & \\
\hline $3 / 25 / 0619: 00$ & & & & 1.44 & & \\
\hline $3 / 25 / 0619: 10$ & & & & 1.41 & & \\
\hline $3 / 25 / 0619: 20$ & & & & 1.35 & & \\
\hline $3 / 25 / 0619: 30$ & & & & 1.36 & & \\
\hline $3 / 25 / 0619: 40$ & & & & 1.37 & & \\
\hline $3 / 25 / 0619: 50$ & & & & 1.36 & & \\
\hline $3 / 25 / 0620: 00$ & & & & 1.38 & & \\
\hline $3 / 25 / 0620: 10$ & & & & 1.36 & & \\
\hline $3 / 25 / 0620: 20$ & & & & 1.41 & & \\
\hline $3 / 25 / 0620: 30$ & & & & 1.40 & & \\
\hline $3 / 25 / 0620: 40$ & & & & 1.41 & & \\
\hline $3 / 25 / 0620: 50$ & & & & 1.38 & & \\
\hline $3 / 25 / 0621: 00$ & & & & 1.36 & & \\
\hline $3 / 25 / 0621: 10$ & & & & 1.38 & & \\
\hline $3 / 25 / 0621: 20$ & & & & 1.39 & & \\
\hline $3 / 25 / 0621: 30$ & & & & 1.39 & & \\
\hline $3 / 25 / 0621: 40$ & & & & 1.28 & & \\
\hline $3 / 25 / 0621: 50$ & & & & 1.28 & & \\
\hline
\end{tabular}


Table D1. Corrected CMM and ACI, 10-minute Averaged Data During the Monthlong Field Test (continued)

\begin{tabular}{|c|c|c|c|c|c|c|}
\hline Date, Time & $\begin{array}{c}\text { FF Inlet } \mathrm{HgT} \text {, } \\
\mu \mathrm{g} / \mathrm{dNm}^{3}, \\
3 \% \mathrm{O}_{2} \\
\end{array}$ & $\begin{array}{c}\text { FF Outlet } \mathrm{HgT} \text {, } \\
\mu \mathrm{g} / \mathrm{dNm}^{3}, \\
3 \% \mathrm{O}_{2}\end{array}$ & $\begin{array}{c}\text { HgT Removal } \\
\text { Across } \\
\text { FF } 2-4, \% \\
\end{array}$ & $\begin{array}{c}\text { FF 2-4 Activated } \\
\text { Carbon Injection } \\
\text { Rate, lb/Macf } \\
\end{array}$ & $\begin{array}{c}\text { FF Inlet } \mathrm{Hg}^{0}, \\
\mu \mathrm{g} / \mathrm{dNm}^{3}, \\
3 \% \mathrm{O}_{2} \\
\end{array}$ & $\begin{array}{c}\text { FF Outlet } \mathrm{Hg}^{0}, \\
\mu \mathrm{g} / \mathrm{dNm}^{3}, \\
3 \% \mathrm{O}_{2}\end{array}$ \\
\hline $3 / 25 / 0622: 00$ & & & & 1.30 & & \\
\hline $3 / 25 / 0622: 10$ & & & & 1.30 & & \\
\hline $3 / 25 / 0622: 20$ & & & & 1.29 & & \\
\hline $3 / 25 / 0622: 30$ & & & & 1.29 & & \\
\hline $3 / 25 / 0622: 40$ & & & & 1.31 & & \\
\hline $3 / 25 / 0622: 50$ & & & & 1.31 & & \\
\hline $3 / 25 / 0623: 00$ & & & & 1.34 & & \\
\hline $3 / 25 / 0623: 10$ & & & & 1.32 & & \\
\hline $3 / 25 / 0623: 20$ & & & & 1.32 & & \\
\hline $3 / 25 / 0623: 30$ & & & & 1.25 & & \\
\hline $3 / 25 / 0623: 40$ & & & & 1.24 & & \\
\hline $3 / 25 / 0623: 50$ & & & & 1.26 & & \\
\hline 3/26/06 0:00 & & & & 1.24 & & \\
\hline 3/26/06 0:10 & & & & 1.40 & & \\
\hline 3/26/06 0:20 & & & & 1.40 & & \\
\hline $3 / 26 / 060: 30$ & & & & 1.28 & & \\
\hline 3/26/06 0:40 & & & & 1.15 & & \\
\hline 3/26/06 0:50 & & & & 1.24 & & \\
\hline 3/26/06 1:00 & & & & 1.25 & & \\
\hline 3/26/06 1:10 & & & & 1.27 & & \\
\hline $3 / 26 / 061: 20$ & & & & 1.29 & & \\
\hline 3/26/06 1:30 & & & & 1.29 & & \\
\hline 3/26/06 1:40 & & & & 1.36 & & \\
\hline 3/26/06 1:50 & & & & 1.29 & & \\
\hline $3 / 26 / 062: 00$ & & & & 1.25 & & \\
\hline 3/26/06 2:10 & & & & 1.23 & & \\
\hline $3 / 26 / 062: 20$ & & & & 1.22 & & \\
\hline $3 / 26 / 062: 30$ & & & & 1.09 & & \\
\hline $3 / 26 / 062: 40$ & & & & 1.06 & & \\
\hline $3 / 26 / 062: 50$ & & & & 1.07 & & \\
\hline 3/26/06 3:00 & & & & 1.10 & & \\
\hline 3/26/06 3:10 & & & & 1.09 & & \\
\hline 3/26/06 3:20 & & & & 1.11 & & \\
\hline 3/26/06 3:30 & & & & 1.27 & & \\
\hline $3 / 26 / 063: 40$ & & & & 1.33 & & \\
\hline 3/26/06 3:50 & & & & 1.23 & & \\
\hline 3/26/06 4:00 & & & & 1.18 & & \\
\hline 3/26/06 4:10 & & & & 1.31 & & \\
\hline $3 / 26 / 064: 20$ & & & & 1.28 & & \\
\hline 3/26/06 4:30 & & & & 1.23 & & \\
\hline 3/26/06 4:40 & & & & 1.35 & & \\
\hline $3 / 26 / 064: 50$ & & & & 1.35 & & \\
\hline 3/26/06 5:00 & & & & 1.36 & & \\
\hline 3/26/06 5:10 & & & & 1.32 & & \\
\hline $3 / 26 / 065: 20$ & & & & 1.32 & & \\
\hline 3/26/06 5:30 & & & & 1.34 & & \\
\hline $3 / 26 / 065: 40$ & & & & 1.31 & & \\
\hline $3 / 26 / 065: 50$ & & & & 1.29 & & \\
\hline 3/26/06 6:00 & & & & 1.30 & & \\
\hline $3 / 26 / 066: 10$ & & & & 1.24 & & \\
\hline $3 / 26 / 066: 20$ & & & & 1.27 & & \\
\hline $3 / 26 / 066: 30$ & & & & 1.25 & & \\
\hline
\end{tabular}


Table D1. Corrected CMM and ACI, 10-minute Averaged Data During the Monthlong Field Test (continued)

\begin{tabular}{|c|c|c|c|c|c|c|}
\hline Date, Time & $\begin{array}{c}\text { FF Inlet } \mathrm{HgT}, \\
\mu \mathrm{g} / \mathrm{dNm}^{3}, \\
3 \% \mathrm{O}_{2}\end{array}$ & $\begin{array}{c}\text { FF Outlet } \mathrm{HgT} \text {, } \\
\mu \mathrm{g} / \mathrm{dNm}^{3}, \\
3 \% \mathrm{O}_{2}\end{array}$ & $\begin{array}{c}\text { HgT Removal } \\
\text { Across } \\
\text { FF } 2-4, \% \\
\end{array}$ & $\begin{array}{c}\text { FF 2-4 Activated } \\
\text { Carbon Injection } \\
\text { Rate, lb/Macf } \\
\end{array}$ & $\begin{array}{c}\text { FF Inlet } \mathrm{Hg}^{0}, \\
\mu \mathrm{g} / \mathrm{dNm}^{3}, \\
3 \% \mathrm{O}_{2}\end{array}$ & $\begin{array}{c}\text { FF Outlet } \mathrm{Hg}^{0}, \\
\mu \mathrm{g} / \mathrm{dNm}^{3}, \\
3 \% \mathrm{O}_{2}\end{array}$ \\
\hline $3 / 26 / 066: 40$ & & & & 1.28 & & \\
\hline $3 / 26 / 066: 50$ & & & & 1.29 & & \\
\hline 3/26/06 7:00 & & & & 1.33 & & \\
\hline $3 / 26 / 067: 10$ & & & & 1.43 & & \\
\hline $3 / 26 / 067: 20$ & & & & 1.37 & & \\
\hline $3 / 26 / 067: 30$ & & & & 1.46 & & \\
\hline $3 / 26 / 067: 40$ & & & & 1.47 & & \\
\hline $3 / 26 / 067: 50$ & & & & 1.49 & & \\
\hline 3/26/06 8:00 & & & & 1.45 & & \\
\hline 3/26/06 8:10 & & & & 1.47 & & \\
\hline $3 / 26 / 068: 20$ & & & & 1.47 & & \\
\hline $3 / 26 / 068: 30$ & & & & 1.48 & & \\
\hline 3/26/06 8:40 & & & & 1.52 & & \\
\hline $3 / 26 / 068: 50$ & & & & 1.49 & & \\
\hline 3/26/06 9:00 & & & & 1.49 & & \\
\hline 3/26/06 9:10 & & & & 1.46 & & \\
\hline 3/26/06 9:20 & & & & 1.44 & & \\
\hline 3/26/06 9:30 & & & & 1.42 & & \\
\hline 3/26/06 9:40 & & & & 1.47 & & \\
\hline $3 / 26 / 069: 50$ & & & & 1.46 & & \\
\hline $3 / 26 / 06$ 10:00 & & & & 1.44 & & \\
\hline $3 / 26 / 0610: 10$ & & & & 1.44 & & \\
\hline $3 / 26 / 0610: 20$ & & & & 1.44 & & \\
\hline $3 / 26 / 0610: 30$ & & & & 1.46 & & \\
\hline $3 / 26 / 06$ 10:40 & & & & 1.42 & & \\
\hline $3 / 26 / 0610: 50$ & & & & 1.42 & & \\
\hline 3/26/06 11:00 & & & & 1.42 & & \\
\hline $3 / 26 / 0611: 10$ & & & & 1.45 & & \\
\hline $3 / 26 / 0611: 20$ & & & & 1.42 & & \\
\hline $3 / 26 / 0611: 30$ & & & & 1.46 & & \\
\hline $3 / 26 / 0611: 40$ & & & & 1.45 & & \\
\hline $3 / 26 / 0611: 50$ & & & & 1.42 & & \\
\hline $3 / 26 / 0612: 00$ & & & & 1.42 & & \\
\hline $3 / 26 / 0612: 10$ & & & & 1.44 & & \\
\hline $3 / 26 / 0612: 20$ & & & & 1.47 & & \\
\hline $3 / 26 / 0612: 30$ & & & & 1.42 & & \\
\hline $3 / 26 / 0612: 40$ & & & & 1.41 & & \\
\hline $3 / 26 / 0612: 50$ & & & & 1.37 & & \\
\hline $3 / 26 / 0613: 00$ & & & & 1.44 & & \\
\hline $3 / 26 / 0613: 10$ & & & & 1.41 & & \\
\hline $3 / 26 / 0613: 20$ & & & & 1.44 & & \\
\hline $3 / 26 / 0613: 30$ & & & & 1.38 & & \\
\hline $3 / 26 / 0613: 40$ & & & & 1.38 & & \\
\hline $3 / 26 / 0613: 50$ & & & & 1.40 & & \\
\hline $3 / 26 / 0614: 00$ & & 2.05 & & 1.37 & & 3.40 \\
\hline $3 / 26 / 0614: 10$ & & 1.80 & & 1.44 & & 4.81 \\
\hline $3 / 26 / 0614: 20$ & & 2.86 & & 1.43 & & 3.53 \\
\hline $3 / 26 / 0614: 30$ & & 3.54 & & 1.46 & & 0.33 \\
\hline $3 / 26 / 0614: 40$ & & 4.42 & & 1.44 & & 0.68 \\
\hline $3 / 26 / 0614: 50$ & & 4.12 & & 1.44 & & 0.29 \\
\hline $3 / 26 / 0615: 00$ & & 3.84 & & 1.42 & & 0.30 \\
\hline $3 / 26 / 06$ 15:10 & & 4.29 & & 1.41 & & 0.75 \\
\hline
\end{tabular}


Table D1. Corrected CMM and ACI, 10-minute Averaged Data During the Monthlong Field Test (continued)

\begin{tabular}{|c|c|c|c|c|c|c|}
\hline Date, Time & $\begin{array}{c}\text { FF Inlet } \mathrm{HgT}, \\
\mu \mathrm{g} / \mathrm{dNm}^{3}, \\
3 \% \mathrm{O}_{2} \\
\end{array}$ & $\begin{array}{c}\text { FF Outlet HgT, } \\
\mu \mathrm{g} / \mathrm{dNm}^{3}, \\
3 \% \mathrm{O}_{2} \\
\end{array}$ & $\begin{array}{c}\text { HgT Removal } \\
\text { Across } \\
\text { FF } 2-4, \% \\
\end{array}$ & $\begin{array}{c}\text { FF 2-4 Activated } \\
\text { Carbon Injection } \\
\text { Rate, lb/Macf }\end{array}$ & $\begin{array}{c}\text { FF Inlet } \mathrm{Hg}^{0}, \\
\mu \mathrm{g} / \mathrm{dNm}^{3}, \\
3 \% \mathrm{O}_{2} \\
\end{array}$ & $\begin{array}{c}\text { FF Outlet } \mathrm{Hg}^{0}, \\
\mu \mathrm{g} / \mathrm{dNm}^{3}, \\
3 \% \mathrm{O}_{2}\end{array}$ \\
\hline $3 / 26 / 06$ 15:20 & & 4.48 & & 1.38 & & 0.46 \\
\hline $3 / 26 / 0615: 30$ & & 6.20 & & 1.29 & & 0.32 \\
\hline $3 / 26 / 06$ 15:40 & & 5.54 & & 1.38 & & \\
\hline $3 / 26 / 0615: 50$ & 10.18 & 5.45 & 46.46 & 1.38 & 17.37 & \\
\hline $3 / 26 / 0616: 00$ & 58.78 & 5.77 & 90.19 & 1.39 & 12.60 & 0.50 \\
\hline 3/26/06 16:10 & 22.28 & 5.04 & 77.38 & 1.39 & 11.43 & 0.42 \\
\hline $3 / 26 / 0616: 20$ & 20.66 & 4.67 & 77.41 & 1.38 & 10.30 & 0.23 \\
\hline $3 / 26 / 0616: 30$ & 16.60 & 4.28 & 74.24 & 1.42 & 9.13 & \\
\hline $3 / 26 / 0616: 40$ & 16.20 & 3.71 & 77.08 & 1.39 & 8.39 & \\
\hline $3 / 26 / 06$ 16:50 & 17.64 & 2.98 & 83.12 & 1.39 & 8.23 & \\
\hline 3/26/06 17:00 & 13.52 & 2.85 & 78.93 & 1.40 & 7.91 & 0.25 \\
\hline $3 / 26 / 06$ 17:10 & 12.84 & 3.59 & 72.01 & 1.43 & 8.67 & 0.17 \\
\hline 3/26/06 17:20 & 11.98 & 3.41 & 71.53 & 1.44 & 9.11 & 0.12 \\
\hline $3 / 26 / 0617: 30$ & 11.08 & 4.00 & 63.92 & 1.44 & 9.08 & \\
\hline $3 / 26 / 06 \quad 17: 40$ & 10.99 & 4.65 & 57.68 & 1.41 & 9.46 & \\
\hline $3 / 26 / 0617: 50$ & 11.55 & 5.70 & 50.67 & 1.43 & 9.79 & 0.15 \\
\hline 3/26/06 18:00 & 11.12 & 7.35 & 33.86 & 1.43 & 9.45 & 0.18 \\
\hline 3/26/06 18:10 & 12.67 & 7.20 & 43.20 & 1.42 & 10.34 & 0.57 \\
\hline 3/26/06 18:20 & 12.74 & 6.89 & 45.94 & 1.39 & 9.81 & 0.65 \\
\hline $3 / 26 / 0618: 30$ & 13.13 & 7.17 & 45.45 & 1.38 & 9.99 & 0.77 \\
\hline $3 / 26 / 06$ 18:40 & 13.19 & 8.32 & 36.94 & 1.31 & 10.11 & 0.93 \\
\hline $3 / 26 / 0618: 50$ & 15.00 & 11.25 & 25.01 & 0.14 & 11.24 & 2.19 \\
\hline 3/26/06 19:00 & 15.40 & 12.36 & 19.69 & 0.13 & 10.75 & 1.87 \\
\hline 3/26/06 19:10 & 14.86 & 12.01 & 19.15 & 0.13 & 9.49 & 0.82 \\
\hline 3/26/06 19:20 & 12.92 & 13.49 & 0 & 0.12 & 9.53 & 0.99 \\
\hline 3/26/06 19:30 & 13.14 & 14.24 & 0 & 0.12 & 9.96 & 1.17 \\
\hline $3 / 26 / 06$ 19:40 & 13.21 & 13.73 & 0 & 0.12 & 10.26 & 1.31 \\
\hline $3 / 26 / 06$ 19:50 & 12.86 & 11.94 & 7.14 & 0.12 & 10.10 & 1.42 \\
\hline $3 / 26 / 0620: 00$ & 14.68 & 10.84 & 26.20 & 0.12 & 10.23 & 1.34 \\
\hline 3/26/06 20:10 & 15.60 & 12.11 & 22.34 & 0.13 & 10.66 & 1.01 \\
\hline $3 / 26 / 0620: 20$ & 16.72 & 11.51 & 31.17 & 0.12 & 10.63 & 1.04 \\
\hline $3 / 26 / 0620: 30$ & 17.58 & 12.42 & 29.31 & 0.13 & 11.16 & 1.18 \\
\hline $3 / 26 / 0620: 40$ & 17.88 & 12.95 & 27.61 & 0.12 & 11.19 & 1.18 \\
\hline $3 / 26 / 0620: 50$ & 17.33 & 13.90 & 19.78 & 0.12 & 11.19 & 1.39 \\
\hline $3 / 26 / 0621: 00$ & 17.35 & 14.07 & 18.90 & 0.12 & 10.56 & 1.37 \\
\hline $3 / 26 / 0621: 10$ & 17.04 & 15.40 & 9.61 & 0.13 & 9.97 & 1.03 \\
\hline 3/26/06 21:20 & 15.60 & 15.70 & 0 & 0.12 & 9.49 & 1.17 \\
\hline $3 / 26 / 0621: 30$ & 15.14 & 15.05 & 0.59 & 0.12 & 9.79 & 1.11 \\
\hline $3 / 26 / 0621: 40$ & 14.72 & 15.46 & 0 & 0.12 & 9.79 & 1.28 \\
\hline $3 / 26 / 0621: 50$ & 14.31 & 15.87 & 0 & 0.12 & 9.94 & 1.30 \\
\hline $3 / 26 / 0622: 00$ & 15.62 & 15.73 & 0 & 0.12 & 9.85 & 1.38 \\
\hline $3 / 26 / 0622: 10$ & 14.10 & 15.58 & 0 & 0.12 & 9.29 & 1.08 \\
\hline $3 / 26 / 0622: 20$ & 14.28 & 15.75 & 0 & 0.13 & 9.29 & 1.18 \\
\hline $3 / 26 / 0622: 30$ & 13.59 & 14.37 & 0 & 0.13 & 8.99 & 1.32 \\
\hline $3 / 26 / 0622: 40$ & 13.67 & 15.45 & 0 & 0.12 & 9.40 & 1.36 \\
\hline $3 / 26 / 0622: 50$ & 14.10 & 15.35 & 0 & 0.13 & 9.61 & 1.52 \\
\hline $3 / 26 / 0623: 00$ & 14.74 & 15.38 & 0 & 0.14 & 9.40 & 1.58 \\
\hline $3 / 26 / 0623: 10$ & 13.62 & 15.89 & 0 & 0.13 & 8.49 & 1.10 \\
\hline $3 / 26 / 06$ 23:20 & 12.54 & 16.86 & 0 & 0.16 & 8.32 & 1.33 \\
\hline $3 / 26 / 0623: 30$ & 13.80 & 13.85 & 0 & 0.18 & 9.82 & 1.61 \\
\hline $3 / 26 / 0623: 40$ & 15.35 & 12.67 & 17.47 & 0.18 & 9.84 & 1.69 \\
\hline $3 / 26 / 0623: 50$ & 18.19 & 14.87 & 18.24 & 0.19 & 11.44 & 2.40 \\
\hline
\end{tabular}


Table D1. Corrected CMM and ACI, 10-minute Averaged Data During the Monthlong Field Test (continued)

\begin{tabular}{|c|c|c|c|c|c|c|}
\hline Date, Time & $\begin{array}{c}\text { FF Inlet } \mathrm{HgT}, \\
\mu \mathrm{g} / \mathrm{dNm}^{3}, \\
3 \% \mathrm{O}_{2} \\
\end{array}$ & $\begin{array}{c}\text { FF Outlet HgT, } \\
\mu \mathrm{g} / \mathrm{dNm}^{3}, \\
3 \% \mathrm{O}_{2} \\
\end{array}$ & $\begin{array}{c}\text { HgT Removal } \\
\text { Across } \\
\text { FF } 2-4, \% \\
\end{array}$ & $\begin{array}{c}\text { FF 2-4 Activated } \\
\text { Carbon Injection } \\
\text { Rate, lb/Macf }\end{array}$ & $\begin{array}{c}\text { FF Inlet } \mathrm{Hg}^{0}, \\
\mu \mathrm{g} / \mathrm{dNm}^{3}, \\
3 \% \mathrm{O}_{2} \\
\end{array}$ & $\begin{array}{c}\text { FF Outlet } \mathrm{Hg}^{0}, \\
\mu \mathrm{g} / \mathrm{dNm}^{3}, \\
3 \% \mathrm{O}_{2}\end{array}$ \\
\hline 3/27/06 0:00 & 19.06 & 15.48 & 18.75 & 0.18 & 12.31 & 2.86 \\
\hline $3 / 27 / 060: 10$ & 18.99 & 14.16 & 25.41 & 0.19 & 11.99 & 1.99 \\
\hline $3 / 27 / 060: 20$ & 19.62 & 12.85 & 34.49 & 0.18 & 12.66 & 2.12 \\
\hline $3 / 27 / 060: 30$ & 18.91 & 11.24 & 40.53 & 0.81 & 12.82 & 2.16 \\
\hline $3 / 27 / 060: 40$ & 19.89 & 11.09 & 44.24 & 1.10 & 13.73 & 1.70 \\
\hline $3 / 27 / 060: 50$ & 19.80 & 10.39 & 47.55 & 1.10 & 13.77 & 1.61 \\
\hline $3 / 27 / 061: 00$ & 20.71 & 9.34 & 54.90 & 1.09 & 14.10 & 1.45 \\
\hline 3/27/06 1:10 & 20.75 & 9.21 & 55.64 & 1.09 & 14.33 & 0.99 \\
\hline $3 / 27 / 061: 20$ & 20.46 & 9.68 & 52.71 & 1.10 & 14.05 & 1.04 \\
\hline $3 / 27 / 061: 30$ & 20.98 & 10.05 & 52.10 & 1.10 & 14.26 & 1.10 \\
\hline $3 / 27 / 061: 40$ & 20.76 & 9.70 & 53.27 & 1.11 & 14.48 & 1.01 \\
\hline $3 / 27 / 061: 50$ & 21.28 & 9.72 & 54.34 & 1.13 & 12.65 & 0.88 \\
\hline $3 / 27 / 062: 00$ & 22.38 & 9.50 & 57.56 & 1.11 & 14.64 & 1.02 \\
\hline $3 / 27 / 062: 10$ & 21.11 & 9.69 & 54.09 & 1.17 & 13.32 & 0.96 \\
\hline $3 / 27 / 062: 20$ & 21.27 & 10.06 & 52.69 & 1.16 & 13.96 & 1.24 \\
\hline $3 / 27 / 062: 30$ & 21.97 & 10.38 & 52.76 & 1.13 & 13.02 & 1.03 \\
\hline $3 / 27 / 062: 40$ & 21.66 & 10.35 & 52.23 & 1.09 & 14.93 & 1.72 \\
\hline $3 / 27 / 062: 50$ & 22.49 & 9.81 & 56.39 & 1.10 & 15.75 & 1.69 \\
\hline $3 / 27 / 063: 00$ & 22.78 & 9.75 & 57.21 & 1.08 & 15.94 & 1.86 \\
\hline $3 / 27 / 063: 10$ & 22.60 & 9.72 & 57.00 & 1.10 & 16.10 & 1.64 \\
\hline $3 / 27 / 063: 20$ & 23.17 & 10.74 & 53.62 & 1.08 & 16.65 & 1.61 \\
\hline $3 / 27 / 063: 30$ & 24.14 & 11.40 & 52.80 & 1.10 & 16.83 & 1.84 \\
\hline $3 / 27 / 063: 40$ & 23.85 & 11.53 & 51.65 & 1.10 & 16.80 & 1.96 \\
\hline $3 / 27 / 063: 50$ & 24.87 & 12.07 & 51.45 & 1.14 & 16.64 & 1.63 \\
\hline $3 / 27 / 064: 00$ & 25.00 & 11.77 & 52.91 & 1.14 & 17.01 & 1.71 \\
\hline $3 / 27 / 064: 10$ & 24.71 & 11.78 & 52.34 & 1.11 & 17.15 & 1.82 \\
\hline $3 / 27 / 064: 20$ & 25.39 & 12.92 & 49.11 & 1.11 & 17.55 & 2.03 \\
\hline $3 / 27 / 064: 30$ & 27.12 & 11.87 & 56.22 & 1.09 & 17.24 & 2.13 \\
\hline $3 / 27 / 064: 40$ & 24.49 & 12.74 & 47.99 & 1.24 & 15.00 & 1.43 \\
\hline $3 / 27 / 064: 50$ & 23.91 & 12.79 & 46.51 & 1.31 & 9.56 & 0.61 \\
\hline $3 / 27 / 065: 00$ & 21.80 & 11.86 & 45.58 & 1.30 & 11.25 & 0.99 \\
\hline $3 / 27 / 065: 10$ & 22.21 & 11.99 & 46.02 & 1.26 & 11.65 & 1.02 \\
\hline $3 / 27 / 065: 20$ & 22.46 & 11.69 & 47.95 & 1.32 & 10.71 & 0.86 \\
\hline $3 / 27 / 065: 30$ & 22.23 & 11.83 & 46.76 & 1.29 & 11.36 & 1.05 \\
\hline $3 / 27 / 065: 40$ & 22.05 & 12.06 & 45.31 & 1.35 & 11.72 & 1.01 \\
\hline $3 / 27 / 065: 50$ & 21.64 & 12.37 & 42.86 & 0.75 & 10.10 & 0.67 \\
\hline $3 / 27 / 066: 00$ & 21.51 & 12.57 & 41.55 & 0.13 & 10.10 & 0.90 \\
\hline $3 / 27 / 066: 10$ & 23.59 & 14.22 & 39.72 & 0.16 & 11.53 & 1.13 \\
\hline $3 / 27 / 066: 20$ & 21.73 & 15.05 & 30.71 & 0.15 & 11.04 & 1.36 \\
\hline $3 / 27 / 066: 30$ & 20.72 & 16.08 & 22.40 & 0.13 & 11.00 & 0.97 \\
\hline $3 / 27 / 066: 40$ & 21.99 & 16.99 & 22.77 & 0.14 & 11.35 & 1.28 \\
\hline $3 / 27 / 066: 50$ & 22.54 & 17.58 & 22.02 & 0.14 & 11.35 & 1.30 \\
\hline 3/27/06 7:00 & 22.13 & 17.11 & 22.68 & 0.15 & 10.83 & 1.17 \\
\hline $3 / 27 / 067: 10$ & 21.29 & 18.13 & 14.86 & 1.32 & 12.13 & 1.53 \\
\hline $3 / 27 / 06$ 7:20 & 20.70 & 15.19 & 26.65 & 1.36 & 10.34 & 0.65 \\
\hline $3 / 27 / 067: 30$ & 20.21 & 14.02 & 30.64 & 1.30 & 9.45 & 0.45 \\
\hline $3 / 27 / 067: 40$ & 19.17 & 13.28 & 30.73 & 1.34 & 10.12 & 0.50 \\
\hline $3 / 27 / 067: 50$ & 18.76 & 13.38 & 28.69 & 1.35 & 9.43 & 0.26 \\
\hline 3/27/06 8:00 & 18.26 & 13.70 & 25.00 & 1.35 & 8.81 & 0.27 \\
\hline 3/27/06 8:10 & 18.98 & 14.95 & 21.24 & 1.32 & 9.24 & 0.72 \\
\hline $3 / 27 / 068: 20$ & 17.33 & 16.39 & 5.47 & 1.35 & 8.36 & 0.54 \\
\hline $3 / 27 / 068: 30$ & 18.35 & 15.62 & 14.91 & 1.34 & 8.14 & 0.43 \\
\hline
\end{tabular}


Table D1. Corrected CMM and ACI, 10-minute Averaged Data During the Monthlong Field Test (continued)

\begin{tabular}{|c|c|c|c|c|c|c|}
\hline Date, Time & $\begin{array}{c}\text { FF Inlet } \mathrm{HgT} \text {, } \\
\mu \mathrm{g} / \mathrm{dNm}^{3} \\
3 \% \mathrm{O}_{2} \\
\end{array}$ & $\begin{array}{c}\text { FF Outlet } \mathrm{HgT} \text {, } \\
\mu \mathrm{g} / \mathrm{dNm}^{3}, \\
3 \% \mathrm{O}_{2}\end{array}$ & $\begin{array}{c}\text { HgT Removal } \\
\text { Across } \\
\text { FF 2-4, } \% \\
\end{array}$ & $\begin{array}{c}\text { FF 2-4 Activated } \\
\text { Carbon Injection } \\
\text { Rate, lb/Macf }\end{array}$ & $\begin{array}{c}\text { FF Inlet } \mathrm{Hg}^{0}, \\
\mu \mathrm{g} / \mathrm{dNm}^{3}, \\
3 \% \mathrm{O}_{2}\end{array}$ & $\begin{array}{c}\text { FF Outlet } \mathrm{Hg}^{0}, \\
\mu \mathrm{g} / \mathrm{dNm}^{3}, \\
3 \% \mathrm{O}_{2}\end{array}$ \\
\hline $3 / 27 / 068: 40$ & 16.99 & 13.85 & 18.52 & 1.37 & 8.04 & 0.16 \\
\hline $3 / 27 / 068: 50$ & 15.47 & 12.92 & 16.50 & 1.35 & 7.42 & 0.12 \\
\hline 3/27/06 9:00 & 13.35 & 14.97 & 0 & 1.32 & 7.04 & 0.18 \\
\hline 3/27/06 9:10 & 13.25 & 14.02 & 0 & 1.38 & 6.98 & 0.39 \\
\hline 3/27/06 9:20 & 13.40 & 11.27 & 15.89 & 1.39 & 6.88 & 0.87 \\
\hline 3/27/06 9:30 & 14.96 & 10.27 & 31.32 & 1.40 & 7.54 & 0.74 \\
\hline 3/27/06 9:40 & & 11.08 & & 1.41 & & 0.73 \\
\hline 3/27/06 9:50 & 24.98 & 11.71 & 53.11 & 1.40 & 11.60 & 0.84 \\
\hline $3 / 27 / 0610: 00$ & 26.01 & & & 1.40 & 13.11 & \\
\hline $3 / 27 / 0610: 10$ & 20.96 & & & 1.40 & 11.95 & \\
\hline $3 / 27 / 0610: 20$ & 17.06 & & & 1.45 & 10.99 & \\
\hline $3 / 27 / 0610: 30$ & 14.91 & & & 1.40 & 9.79 & \\
\hline $3 / 27 / 0610: 40$ & 15.67 & & & 1.41 & 10.92 & \\
\hline $3 / 27 / 0610: 50$ & 16.06 & & & 1.46 & 11.15 & \\
\hline $3 / 27 / 0611: 00$ & 16.03 & & & 1.42 & 10.77 & \\
\hline $3 / 27 / 0611: 10$ & 18.17 & & & 1.47 & 11.70 & \\
\hline $3 / 27 / 0611: 20$ & 17.69 & & & 1.44 & 11.43 & \\
\hline $3 / 27 / 0611: 30$ & 17.84 & & & 1.38 & 10.97 & \\
\hline $3 / 27 / 0611: 40$ & 17.73 & & & 1.41 & 11.09 & \\
\hline $3 / 27 / 0611: 50$ & 17.30 & & & 1.40 & 10.47 & \\
\hline $3 / 27 / 0612: 00$ & 16.26 & & & 1.40 & 10.17 & \\
\hline $3 / 27 / 0612: 10$ & 16.24 & & & 1.40 & 10.31 & \\
\hline $3 / 27 / 0612: 20$ & & & & 1.45 & & \\
\hline $3 / 27 / 0612: 30$ & & & & 1.48 & & \\
\hline $3 / 27 / 0612: 40$ & & & & 1.47 & & \\
\hline $3 / 27 / 0612: 50$ & & & & 1.48 & & \\
\hline $3 / 27 / 0613: 00$ & 18.86 & & & 1.41 & 11.92 & \\
\hline $3 / 27 / 0613: 10$ & 19.13 & 3.37 & 82.37 & 1.47 & 11.35 & 0.17 \\
\hline $3 / 27 / 0613: 20$ & 18.30 & 3.76 & 79.48 & 1.39 & 10.27 & 0.12 \\
\hline $3 / 27 / 0613: 30$ & 17.67 & 4.42 & 74.96 & 1.38 & 10.25 & 0.12 \\
\hline $3 / 27 / 0613: 40$ & 17.11 & 5.03 & 70.59 & 1.44 & 10.18 & \\
\hline $3 / 27 / 0613: 50$ & 16.60 & 4.91 & 70.39 & 1.46 & 9.77 & \\
\hline $3 / 27 / 0614: 00$ & 17.07 & 4.92 & 71.16 & 1.45 & 10.57 & 0.62 \\
\hline $3 / 27 / 0614: 10$ & 18.20 & 6.07 & 66.66 & 1.45 & 12.62 & 0.54 \\
\hline $3 / 27 / 0614: 20$ & 19.22 & 5.01 & 73.93 & 1.45 & 13.30 & 0.52 \\
\hline $3 / 27 / 0614: 30$ & 19.77 & 4.89 & 75.27 & 1.48 & 12.59 & 0.43 \\
\hline $3 / 27 / 0614: 40$ & 20.91 & 5.25 & 74.91 & 1.46 & 12.98 & 0.47 \\
\hline $3 / 27 / 0614: 50$ & 22.05 & 4.93 & 77.63 & 1.43 & 14.56 & 0.48 \\
\hline $3 / 27 / 0615: 00$ & 21.91 & 5.04 & 77.01 & 1.44 & 13.00 & 0.32 \\
\hline $3 / 27 / 0615: 10$ & 21.36 & 4.69 & 78.03 & 1.41 & 12.23 & 0.38 \\
\hline $3 / 27 / 0615: 20$ & 19.86 & 4.52 & 77.26 & 1.39 & 10.44 & 0.22 \\
\hline $3 / 27 / 0615: 30$ & 18.89 & 4.91 & 74.01 & 1.41 & 9.74 & 0.12 \\
\hline $3 / 27 / 0615: 40$ & 17.79 & 4.31 & 75.78 & 1.41 & 9.74 & \\
\hline $3 / 27 / 0615: 50$ & 17.05 & 4.30 & 74.76 & 1.43 & 9.33 & \\
\hline $3 / 27 / 0616: 00$ & 16.95 & 4.12 & 75.70 & 1.42 & 9.56 & 0.25 \\
\hline $3 / 27 / 0616: 10$ & 16.78 & 4.63 & 72.41 & 1.39 & 10.06 & 0.28 \\
\hline $3 / 27 / 0616: 20$ & 16.22 & 4.96 & 69.41 & 1.40 & 9.45 & 0.20 \\
\hline $3 / 27 / 0616: 30$ & 15.84 & 5.34 & 66.26 & 1.38 & 9.58 & 0.15 \\
\hline $3 / 27 / 0616: 40$ & 15.33 & 5.68 & 62.95 & 1.37 & 9.55 & \\
\hline $3 / 27 / 0616: 50$ & 14.35 & 5.34 & 62.79 & 1.43 & 9.47 & \\
\hline $3 / 27 / 0617: 00$ & 14.90 & 5.57 & 62.61 & 1.41 & 10.24 & 0.36 \\
\hline $3 / 27 / 0617: 10$ & 16.67 & 5.93 & 64.43 & 1.43 & 11.25 & 0.37 \\
\hline
\end{tabular}


Table D1. Corrected CMM and ACI, 10-minute Averaged Data During the Monthlong Field Test (continued)

\begin{tabular}{|c|c|c|c|c|c|c|}
\hline Date, Time & $\begin{array}{c}\text { FF Inlet } \mathrm{HgT}, \\
\mu \mathrm{g} / \mathrm{dNm}^{3}, \\
3 \% \mathrm{O}_{2} \\
\end{array}$ & $\begin{array}{c}\text { FF Outlet HgT, } \\
\mu \mathrm{g} / \mathrm{dNm}^{3}, \\
3 \% \mathrm{O}_{2}\end{array}$ & $\begin{array}{c}\text { HgT Removal } \\
\text { Across } \\
\text { FF 2-4, \% }\end{array}$ & $\begin{array}{c}\text { FF 2-4 Activated } \\
\text { Carbon Injection } \\
\text { Rate, lb/Macf }\end{array}$ & $\begin{array}{c}\text { FF Inlet } \mathrm{Hg}^{0}, \\
\mu \mathrm{g} / \mathrm{dNm}^{3}, \\
3 \% \mathrm{O}_{2} \\
\end{array}$ & $\begin{array}{c}\text { FF Outlet } \mathrm{Hg}^{0}, \\
\mu \mathrm{g} / \mathrm{dNm}^{3}, \\
3 \% \mathrm{O}_{2}\end{array}$ \\
\hline $3 / 27 / 06$ 17:20 & 16.15 & 6.32 & 60.85 & 1.44 & 10.77 & 0.67 \\
\hline $3 / 27 / 0617: 30$ & 15.90 & 5.01 & 68.46 & 1.47 & 11.02 & 0.69 \\
\hline $3 / 27 / 0617: 40$ & 15.24 & 5.78 & 62.08 & 0.67 & 11.19 & 1.34 \\
\hline $3 / 27 / 0617: 50$ & 14.36 & 6.49 & 54.80 & 0.12 & 11.83 & 1.93 \\
\hline 3/27/06 18:00 & 14.18 & 9.18 & 35.30 & 0.12 & 12.12 & 3.13 \\
\hline 3/27/06 18:10 & 12.74 & 9.84 & 22.80 & 0.12 & 11.04 & 1.90 \\
\hline $3 / 27 / 06$ 18:20 & 12.32 & 10.03 & 18.60 & 0.12 & 10.46 & 1.67 \\
\hline 3/27/06 18:30 & 12.02 & 10.45 & 13.12 & 0.12 & 10.42 & 1.65 \\
\hline $3 / 27 / 0618: 40$ & 11.70 & 11.11 & 5.03 & 0.12 & 10.04 & 1.58 \\
\hline $3 / 27 / 06$ 18:50 & 11.45 & 14.07 & 0 & 0.12 & 9.78 & 1.52 \\
\hline 3/27/06 19:00 & 11.19 & 13.18 & 0 & 0.12 & 10.25 & 1.97 \\
\hline 3/27/06 19:10 & 11.28 & 13.76 & 0 & 0.12 & 10.17 & 2.85 \\
\hline 3/27/06 19:20 & 11.55 & 13.93 & 0 & 0.12 & 10.17 & 2.87 \\
\hline $3 / 27 / 0619: 30$ & 11.54 & 14.17 & 0 & 0.12 & 10.19 & 2.98 \\
\hline $3 / 27 / 0619: 40$ & 11.39 & 14.26 & 0 & 0.12 & 10.25 & 3.00 \\
\hline 3/27/06 19:50 & 12.04 & 14.91 & 0 & 0.12 & 11.09 & 3.20 \\
\hline $3 / 27 / 0620: 00$ & 12.35 & 14.08 & 0 & 0.12 & 10.83 & 2.97 \\
\hline 3/27/06 20:10 & 12.44 & 15.66 & 0 & 0.12 & 10.49 & 2.78 \\
\hline $3 / 27 / 0620: 20$ & 12.61 & 14.95 & 0 & 0.12 & 10.04 & 2.83 \\
\hline $3 / 27 / 0620: 30$ & 13.05 & 16.40 & 0 & 0.12 & 10.77 & 2.85 \\
\hline $3 / 27 / 0620: 40$ & 13.44 & 16.20 & 0 & 0.12 & 10.46 & 2.98 \\
\hline $3 / 27 / 0620: 50$ & 13.80 & 16.84 & 0 & 0.12 & 10.84 & 3.11 \\
\hline 3/27/06 21:00 & 14.54 & 16.81 & 0 & 0.12 & 10.22 & 3.12 \\
\hline $3 / 27 / 0621: 10$ & 13.27 & 17.79 & 0 & 0.12 & 9.84 & 3.02 \\
\hline $3 / 27 / 0621: 20$ & 12.28 & 17.27 & 0 & 0.12 & 9.71 & 2.98 \\
\hline $3 / 27 / 0621: 30$ & 12.19 & 17.34 & 0 & 0.12 & 9.71 & 3.07 \\
\hline $3 / 27 / 0621: 40$ & 12.12 & 18.48 & 0 & 0.12 & 9.93 & 3.18 \\
\hline $3 / 27 / 0621: 50$ & 11.60 & 18.39 & 0 & 0.12 & 9.41 & 3.25 \\
\hline 3/27/06 22:00 & 10.84 & 16.43 & 0 & 0.13 & 9.03 & 3.13 \\
\hline $3 / 27 / 0622: 10$ & 11.78 & 15.32 & 0 & 0.12 & 9.01 & 2.89 \\
\hline $3 / 27 / 0622: 20$ & 12.21 & 14.86 & 0 & 0.13 & 9.14 & 2.98 \\
\hline $3 / 27 / 0622: 30$ & 12.21 & 14.82 & 0 & 0.14 & 9.47 & 2.90 \\
\hline $3 / 27 / 0622: 40$ & 11.04 & 13.19 & 0 & 0.13 & 9.32 & 2.98 \\
\hline $3 / 27 / 0622: 50$ & 10.35 & 12.43 & 0 & 0.12 & 9.55 & 3.26 \\
\hline $3 / 27 / 0623: 00$ & 10.01 & 12.43 & 0 & 0.13 & 9.36 & 3.30 \\
\hline $3 / 27 / 0623: 10$ & 9.80 & 12.10 & 0 & 0.13 & 9.20 & 2.51 \\
\hline $3 / 27 / 0623: 20$ & 10.02 & 14.44 & 0 & 0.13 & 9.15 & 2.71 \\
\hline $3 / 27 / 0623: 30$ & 9.78 & 12.12 & 0 & 0.14 & 9.25 & 2.78 \\
\hline $3 / 27 / 0623: 40$ & 10.10 & 12.29 & 0 & 0.13 & 9.59 & 3.07 \\
\hline $3 / 27 / 0623: 50$ & 10.39 & 12.37 & 0 & 0.14 & 9.40 & 3.14 \\
\hline 3/28/06 0:00 & 11.12 & 13.20 & 0 & 0.14 & 9.80 & 3.43 \\
\hline $3 / 28 / 060: 10$ & 10.71 & 12.83 & 0 & 0.15 & 8.83 & 2.68 \\
\hline 3/28/06 0:20 & 11.38 & 11.10 & 2.47 & 0.16 & 9.37 & 2.83 \\
\hline $3 / 28 / 060: 30$ & 11.02 & 11.54 & 0 & 0.16 & 8.75 & 2.77 \\
\hline 3/28/06 0:40 & 10.96 & 11.11 & 0 & 0.16 & 8.70 & 2.82 \\
\hline $3 / 28 / 060: 50$ & 11.22 & 10.89 & 2.88 & 0.15 & 8.93 & 2.90 \\
\hline 3/28/06 1:00 & 14.32 & 10.39 & 27.44 & 0.17 & 8.80 & 2.88 \\
\hline $3 / 28 / 061: 10$ & 11.28 & 11.05 & 1.97 & 0.17 & 8.71 & 2.57 \\
\hline 3/28/06 1:20 & 11.26 & 10.34 & 8.17 & 0.17 & 8.56 & 2.30 \\
\hline $3 / 28 / 061: 30$ & 11.60 & 10.41 & 10.25 & 0.17 & 8.48 & 2.40 \\
\hline $3 / 28 / 061: 40$ & 10.82 & 10.34 & 4.49 & 0.15 & 7.98 & 2.31 \\
\hline $3 / 28 / 061: 50$ & 9.53 & 10.42 & 0 & 0.14 & 7.78 & 2.24 \\
\hline
\end{tabular}


Table D1. Corrected CMM and ACI, 10-minute Averaged Data During the Monthlong Field Test (continued)

\begin{tabular}{|c|c|c|c|c|c|c|}
\hline Date, Time & $\begin{array}{c}\text { FF Inlet } \mathrm{HgT}, \\
\mu \mathrm{g} / \mathrm{dNm}^{3}, \\
3 \% \mathrm{O}_{2} \\
\end{array}$ & $\begin{array}{c}\text { FF Outlet } \mathrm{HgT}, \\
\mu \mathrm{g} / \mathrm{dNm}^{3}, \\
3 \% \mathrm{O}_{2}\end{array}$ & $\begin{array}{c}\text { HgT Removal } \\
\text { Across } \\
\text { FF } 2-4, \% \\
\end{array}$ & $\begin{array}{c}\text { FF 2-4 Activated } \\
\text { Carbon Injection } \\
\text { Rate, lb/Macf }\end{array}$ & $\begin{array}{c}\text { FF Inlet } \mathrm{Hg}^{0}, \\
\mu \mathrm{g} / \mathrm{dNm}^{3}, \\
3 \% \mathrm{O}_{2}\end{array}$ & $\begin{array}{c}\text { FF Outlet } \mathrm{Hg}^{0}, \\
\mu \mathrm{g} / \mathrm{dNm}^{3}, \\
3 \% \mathrm{O}_{2}\end{array}$ \\
\hline $3 / 28 / 062: 00$ & 9.64 & 10.16 & 0 & 0.13 & 8.52 & 2.46 \\
\hline $3 / 28 / 062: 10$ & 9.98 & 11.35 & 0 & 0.15 & 8.51 & 2.54 \\
\hline 3/28/06 2:20 & 10.85 & 11.68 & 0 & 0.15 & 8.59 & 2.69 \\
\hline $3 / 28 / 062: 30$ & 10.43 & 13.63 & 0 & 0.14 & 8.46 & 2.75 \\
\hline $3 / 28 / 062: 40$ & 10.53 & 12.77 & 0 & 0.13 & 8.91 & 3.00 \\
\hline $3 / 28 / 062: 50$ & 10.92 & 12.74 & 0 & 0.15 & 8.72 & 2.82 \\
\hline 3/28/06 3:00 & 10.84 & 12.52 & 0 & 0.15 & 8.86 & 2.86 \\
\hline $3 / 28 / 063: 10$ & 11.41 & 11.54 & 0 & 0.15 & 8.62 & 2.31 \\
\hline 3/28/06 3:20 & 11.93 & 9.97 & 16.47 & 0.15 & 8.77 & 2.34 \\
\hline $3 / 28 / 063: 30$ & 11.96 & 10.55 & 11.82 & 0.15 & 8.73 & 2.40 \\
\hline $3 / 28 / 063: 40$ & 11.90 & 10.55 & 11.34 & 0.15 & 8.26 & 2.47 \\
\hline $3 / 28 / 063: 50$ & 10.58 & 10.27 & 2.92 & 0.15 & 8.24 & 2.49 \\
\hline 3/28/06 4:00 & 10.02 & 10.91 & 0 & 0.16 & 8.27 & 2.45 \\
\hline 3/28/06 4:10 & 9.38 & 9.22 & 1.73 & 0.14 & 8.50 & 2.36 \\
\hline $3 / 28 / 064: 20$ & 8.69 & 9.90 & 0 & 0.14 & 8.01 & 2.36 \\
\hline $3 / 28 / 064: 30$ & 9.54 & 10.75 & 0 & 0.14 & 8.59 & 2.65 \\
\hline $3 / 28 / 064: 40$ & 9.05 & 10.80 & 0 & 0.14 & 8.74 & 2.80 \\
\hline $3 / 28 / 064: 50$ & 10.87 & 11.02 & 0 & 0.15 & 8.71 & 2.71 \\
\hline 3/28/06 5:00 & 9.38 & 11.11 & 0 & 0.15 & 8.79 & 2.56 \\
\hline $3 / 28 / 065: 10$ & 9.29 & 10.35 & 0 & 0.15 & 8.54 & 2.46 \\
\hline $3 / 28 / 065: 20$ & 9.71 & 10.14 & 0 & 0.17 & 8.35 & 2.59 \\
\hline $3 / 28 / 065: 30$ & 11.30 & 10.48 & 7.30 & 0.17 & 8.32 & 2.64 \\
\hline $3 / 28 / 065: 40$ & 10.22 & 10.15 & 0.71 & 0.18 & 7.90 & 2.51 \\
\hline $3 / 28 / 065: 50$ & 11.73 & 10.07 & 14.17 & 0.17 & 8.16 & 2.50 \\
\hline $3 / 28 / 066: 00$ & 10.83 & 11.37 & 0 & 0.18 & 8.28 & 2.56 \\
\hline $3 / 28 / 066: 10$ & 10.70 & 9.63 & 10.01 & 0.16 & 8.07 & 2.25 \\
\hline $3 / 28 / 066: 20$ & 8.82 & 9.88 & 0 & 0.14 & 7.26 & 2.23 \\
\hline $3 / 28 / 066: 30$ & 8.68 & 11.05 & 0 & 0.14 & 8.42 & 2.57 \\
\hline $3 / 28 / 066: 40$ & 9.19 & 10.32 & 0 & 0.14 & 8.57 & 2.65 \\
\hline $3 / 28 / 066: 50$ & 9.15 & 11.39 & 0 & 0.14 & 8.34 & 2.84 \\
\hline $3 / 28 / 06$ 7:00 & 9.29 & 11.04 & 0 & 0.14 & 8.54 & 2.82 \\
\hline $3 / 28 / 067: 10$ & 10.70 & 11.75 & 0 & 0.14 & 8.99 & 2.74 \\
\hline $3 / 28 / 067: 20$ & 11.51 & 11.61 & 0 & 0.14 & 9.15 & 2.73 \\
\hline $3 / 28 / 067: 30$ & 12.67 & 12.29 & 3.04 & 0.14 & 9.09 & 2.83 \\
\hline $3 / 28 / 067: 40$ & 12.30 & 12.45 & 0 & 0.14 & 8.98 & 2.74 \\
\hline $3 / 28 / 067: 50$ & 11.74 & 14.77 & 0 & 0.14 & 9.29 & 2.88 \\
\hline 3/28/06 8:00 & 11.90 & 13.05 & 0 & 0.14 & 9.23 & 2.81 \\
\hline $3 / 28 / 068: 10$ & 12.84 & 13.62 & 0 & 0.14 & 9.56 & 2.82 \\
\hline $3 / 28 / 068: 20$ & 13.55 & 14.64 & 0 & 0.12 & 9.86 & 2.99 \\
\hline $3 / 28 / 068: 30$ & 14.49 & 18.14 & 0 & 0.13 & 9.98 & 3.22 \\
\hline $3 / 28 / 068: 40$ & 13.59 & 17.28 & 0 & 0.13 & 10.43 & 3.36 \\
\hline 3/28/06 8:50 & 11.88 & 15.96 & 0 & 0.13 & 9.60 & 3.34 \\
\hline 3/28/06 9:00 & 11.23 & 14.49 & 0 & 0.13 & 9.36 & 3.26 \\
\hline 3/28/06 9:10 & 10.28 & 11.54 & 0 & 1.29 & 8.38 & 1.21 \\
\hline $3 / 28 / 069: 20$ & 8.97 & 6.35 & 29.23 & 1.39 & 7.42 & 0.12 \\
\hline $3 / 28 / 069: 30$ & 8.97 & 4.73 & 47.30 & 1.38 & 7.78 & 0.12 \\
\hline 3/28/06 9:40 & 8.85 & 4.25 & 51.93 & 1.40 & 7.60 & 0.24 \\
\hline $3 / 28 / 069: 50$ & 9.58 & 3.49 & 63.60 & 1.38 & 8.36 & 0.41 \\
\hline $3 / 28 / 06$ 10:00 & 9.79 & 3.46 & 64.65 & 1.44 & 8.74 & 0.45 \\
\hline $3 / 28 / 0610: 10$ & 10.43 & 3.39 & 67.53 & 1.42 & 8.92 & 0.12 \\
\hline $3 / 28 / 0610: 20$ & 11.07 & 3.81 & 65.58 & 1.42 & 8.76 & \\
\hline $3 / 28 / 0610: 30$ & 12.01 & 4.31 & 64.13 & 1.43 & 9.10 & \\
\hline
\end{tabular}


Table D1. Corrected CMM and ACI, 10-minute Averaged Data During the Monthlong Field Test (continued)

\begin{tabular}{|c|c|c|c|c|c|c|}
\hline Date, Time & $\begin{array}{c}\text { FF Inlet } \mathrm{HgT}, \\
\mu \mathrm{g} / \mathrm{dNm}^{3}, \\
3 \% \mathrm{O}_{2} \\
\end{array}$ & $\begin{array}{c}\text { FF Outlet HgT, } \\
\mu \mathrm{g} / \mathrm{dNm}^{3}, \\
3 \% \mathrm{O}_{2} \\
\end{array}$ & $\begin{array}{c}\text { HgT Removal } \\
\text { Across } \\
\text { FF 2-4, \% }\end{array}$ & $\begin{array}{c}\text { FF 2-4 Activated } \\
\text { Carbon Injection } \\
\text { Rate, lb/Macf }\end{array}$ & $\begin{array}{c}\text { FF Inlet } \mathrm{Hg}^{0}, \\
\mu \mathrm{g} / \mathrm{dNm}^{3}, \\
3 \% \mathrm{O}_{2} \\
\end{array}$ & $\begin{array}{c}\text { FF Outlet } \mathrm{Hg}^{0}, \\
\mu \mathrm{g} / \mathrm{dNm}^{3}, \\
3 \% \mathrm{O}_{2}\end{array}$ \\
\hline $3 / 28 / 0610: 40$ & 12.81 & 3.95 & 69.19 & 1.43 & 8.92 & \\
\hline $3 / 28 / 0610: 50$ & 12.91 & 3.86 & 70.12 & 1.45 & 9.19 & \\
\hline 3/28/06 11:00 & 12.78 & 3.53 & 72.39 & 1.44 & 9.36 & 0.25 \\
\hline 3/28/06 11:10 & 13.18 & 4.09 & 68.94 & 1.46 & 9.34 & 0.12 \\
\hline $3 / 28 / 0611: 20$ & 15.49 & 3.81 & 75.43 & 1.45 & 8.78 & \\
\hline 3/28/06 11:30 & 15.70 & 3.92 & 75.04 & 1.42 & 8.99 & \\
\hline $3 / 28 / 0611: 40$ & 12.76 & 3.90 & 69.45 & 1.40 & 8.24 & \\
\hline 3/28/06 11:50 & 11.83 & 3.49 & 70.49 & 1.47 & 7.98 & \\
\hline $3 / 28 / 0612: 00$ & 11.29 & 3.79 & 66.43 & 1.44 & 8.04 & 0.20 \\
\hline 3/28/06 12:10 & 10.73 & 4.10 & 61.79 & 1.44 & 8.34 & 0.12 \\
\hline $3 / 28 / 0612: 20$ & 11.22 & 3.48 & 69.00 & 1.45 & 8.61 & 0.12 \\
\hline $3 / 28 / 0612: 30$ & 10.28 & 3.43 & 66.62 & 1.44 & 8.32 & 0.14 \\
\hline $3 / 28 / 0612: 40$ & 10.42 & 3.29 & 68.42 & 1.44 & 7.59 & 0.13 \\
\hline $3 / 28 / 0612: 50$ & 10.53 & 3.18 & 69.80 & 1.43 & 7.44 & 0.16 \\
\hline $3 / 28 / 06$ 13:00 & 10.79 & 3.42 & 68.28 & 1.45 & 8.23 & 0.14 \\
\hline 3/28/06 13:10 & 13.65 & 3.40 & 75.10 & 1.41 & 9.52 & 0.14 \\
\hline 3/28/06 13:20 & 13.27 & 3.35 & 74.75 & 1.46 & 9.64 & 0.16 \\
\hline $3 / 28 / 0613: 30$ & 9.18 & 5.45 & 40.66 & 0.26 & 6.58 & 1.08 \\
\hline 3/28/06 13:40 & 9.97 & 9.21 & 7.56 & 0.12 & 8.66 & 2.16 \\
\hline $3 / 28 / 0613: 50$ & 10.92 & 11.49 & 0 & 0.12 & 9.22 & 2.55 \\
\hline $3 / 28 / 0614: 00$ & 6.99 & 14.06 & 0 & 0.12 & 5.54 & 3.18 \\
\hline $3 / 28 / 0614: 10$ & 6.79 & 17.62 & 0 & 0.12 & 6.03 & 3.91 \\
\hline $3 / 28 / 0614: 20$ & 8.66 & 17.73 & 0 & 0.12 & 7.78 & 3.42 \\
\hline 3/28/06 14:30 & 7.29 & 18.63 & 0 & 0.12 & 6.28 & 3.40 \\
\hline $3 / 28 / 0614: 40$ & 7.56 & 18.34 & 0 & 0.12 & 6.31 & 3.33 \\
\hline $3 / 28 / 0614: 50$ & 7.33 & 18.23 & 0 & 0.12 & 5.84 & 3.13 \\
\hline $3 / 28 / 0615: 00$ & 7.55 & 18.90 & 0 & 0.12 & 5.35 & 2.88 \\
\hline $3 / 28 / 0615: 10$ & & 20.06 & & 0.12 & & 3.35 \\
\hline $3 / 28 / 06 \quad 15: 20$ & & 20.71 & & 0.12 & & 3.27 \\
\hline $3 / 28 / 0615: 30$ & 8.25 & 19.91 & 0 & 0.12 & 1.59 & 3.40 \\
\hline $3 / 28 / 06$ 15:40 & 19.82 & 20.03 & 0 & 0.12 & 3.55 & 3.45 \\
\hline $3 / 28 / 06$ 15:50 & 24.81 & 20.73 & 16.42 & 0.12 & 1.32 & 4.10 \\
\hline $3 / 28 / 0616: 00$ & 17.50 & 21.67 & 0 & 0.12 & 0.51 & 3.29 \\
\hline $3 / 28 / 0616: 10$ & 27.14 & 27.10 & 0.14 & 0.12 & 1.36 & 3.98 \\
\hline $3 / 28 / 06 \quad 16: 20$ & 34.46 & 23.12 & 32.91 & 0.24 & 3.97 & 4.03 \\
\hline $3 / 28 / 0616: 30$ & 26.95 & 20.90 & 22.45 & 0.12 & 3.65 & 1.82 \\
\hline $3 / 28 / 06$ 16:40 & 17.98 & 19.79 & 0 & 0.13 & 2.71 & 1.79 \\
\hline $3 / 28 / 0616: 50$ & 15.61 & 18.42 & 0 & 0.51 & 3.04 & 1.80 \\
\hline $3 / 28 / 06$ 17:00 & 13.28 & 17.48 & 0 & 1.43 & 2.45 & 0.70 \\
\hline $3 / 28 / 0617: 10$ & 14.47 & 12.91 & 10.79 & 1.42 & 4.53 & 0.89 \\
\hline 3/28/06 17:20 & 12.85 & 11.80 & 8.18 & 1.42 & 3.75 & 0.73 \\
\hline $3 / 28 / 0617: 30$ & 12.61 & 11.04 & 12.49 & 1.45 & 4.51 & 0.81 \\
\hline $3 / 28 / 0617: 40$ & 11.83 & 10.96 & 7.37 & 1.41 & 4.00 & 0.80 \\
\hline $3 / 28 / 0617: 50$ & 13.72 & 10.78 & 21.45 & 1.44 & 4.42 & 0.82 \\
\hline 3/28/06 18:00 & 17.96 & 12.86 & 28.39 & 1.41 & 4.50 & 0.94 \\
\hline 3/28/06 18:10 & 29.34 & 13.55 & 53.84 & 0.52 & 5.14 & 1.21 \\
\hline $3 / 28 / 06$ 18:20 & 50.80 & 15.40 & 69.68 & 0.12 & 7.68 & 2.35 \\
\hline 3/28/06 18:30 & 61.80 & 17.59 & 71.54 & 0.12 & 11.50 & 3.81 \\
\hline $3 / 28 / 06$ 18:40 & 40.72 & 16.84 & 58.66 & 0.12 & 4.48 & 3.98 \\
\hline 3/28/06 18:50 & 28.17 & 20.36 & 27.71 & 0.12 & 7.37 & 3.86 \\
\hline 3/28/06 19:00 & 24.62 & 17.06 & 30.69 & 0.12 & 5.85 & 3.55 \\
\hline 3/28/06 19:10 & 24.51 & 20.84 & 14.96 & 0.12 & 6.29 & 3.53 \\
\hline
\end{tabular}


Table D1. Corrected CMM and ACI, 10-minute Averaged Data During the Monthlong Field Test (continued)

\begin{tabular}{|c|c|c|c|c|c|c|}
\hline Date, Time & $\begin{array}{c}\text { FF Inlet } \mathrm{HgT} \text {, } \\
\mu \mathrm{g} / \mathrm{dNm}^{3}, \\
3 \% \mathrm{O}_{2} \\
\end{array}$ & $\begin{array}{c}\text { FF Outlet HgT, } \\
\mu \mathrm{g} / \mathrm{dNm}^{3}, \\
3 \% \mathrm{O}_{2}\end{array}$ & $\begin{array}{c}\text { HgT Removal } \\
\text { Across } \\
\text { FF } 2-4, \% \\
\end{array}$ & $\begin{array}{c}\text { FF 2-4 Activated } \\
\text { Carbon Injection } \\
\text { Rate, lb/Macf }\end{array}$ & $\begin{array}{c}\text { FF Inlet } \mathrm{Hg}^{0}, \\
\mu \mathrm{g} / \mathrm{dNm}^{3}, \\
3 \% \mathrm{O}_{2} \\
\end{array}$ & $\begin{array}{c}\text { FF Outlet } \mathrm{Hg}^{0}, \\
\mu \mathrm{g} / \mathrm{dNm}^{3}, \\
3 \% \mathrm{O}_{2}\end{array}$ \\
\hline $3 / 28 / 06$ 19:20 & 23.35 & 19.19 & 17.81 & 0.12 & 7.36 & 3.91 \\
\hline $3 / 28 / 0619: 30$ & 25.79 & 19.56 & 24.15 & 0.11 & 5.80 & 3.64 \\
\hline $3 / 28 / 0619: 40$ & 22.65 & 19.76 & 12.77 & 0.11 & 7.80 & 4.43 \\
\hline $3 / 28 / 0619: 50$ & 22.07 & 22.56 & 0 & 0.12 & 6.52 & 4.19 \\
\hline $3 / 28 / 0620: 00$ & 20.87 & 19.13 & 8.35 & 0.12 & 6.17 & 4.01 \\
\hline $3 / 28 / 0620: 10$ & 22.81 & 20.04 & 12.17 & 0.12 & 8.37 & 4.16 \\
\hline $3 / 28 / 0620: 20$ & 21.54 & 19.40 & 9.92 & 0.13 & 7.73 & 3.72 \\
\hline $3 / 28 / 0620: 30$ & 19.28 & 16.13 & 16.33 & 0.13 & 6.38 & 3.25 \\
\hline $3 / 28 / 0620: 40$ & 18.43 & 16.79 & 8.90 & 0.13 & 6.07 & 3.65 \\
\hline $3 / 28 / 0620: 50$ & 18.12 & 16.60 & 8.36 & 0.14 & 5.34 & 3.46 \\
\hline $3 / 28 / 0621: 00$ & 18.14 & 15.56 & 14.18 & 0.14 & 4.65 & 3.40 \\
\hline 3/28/06 21:10 & 15.73 & 13.79 & 12.36 & 0.14 & 3.62 & 2.89 \\
\hline 3/28/06 21:20 & 14.24 & 13.62 & 4.35 & 0.15 & 3.59 & 2.90 \\
\hline $3 / 28 / 0621: 30$ & 12.91 & 12.12 & 6.16 & 0.15 & 4.36 & 2.61 \\
\hline $3 / 28 / 0621: 40$ & 16.22 & 11.88 & 26.74 & 0.15 & 3.81 & 2.75 \\
\hline $3 / 28 / 0621: 50$ & 12.13 & 12.63 & 0 & 0.15 & 3.43 & 2.76 \\
\hline $3 / 28 / 0622: 00$ & 12.28 & 11.39 & 7.30 & 0.13 & 4.08 & 2.94 \\
\hline $3 / 28 / 0622: 10$ & 13.23 & 12.83 & 3.02 & 0.13 & 4.42 & 2.90 \\
\hline $3 / 28 / 06$ 22:20 & 12.75 & 12.58 & 1.36 & 0.13 & 4.87 & 3.04 \\
\hline $3 / 28 / 0622: 30$ & 12.48 & 13.99 & 0 & 0.14 & 4.39 & 3.11 \\
\hline $3 / 28 / 0622: 40$ & 14.90 & 12.58 & 15.55 & 0.13 & 4.11 & 3.09 \\
\hline $3 / 28 / 0622: 50$ & 11.92 & 13.75 & 0 & 0.14 & 4.44 & 3.17 \\
\hline $3 / 28 / 0623: 00$ & 12.25 & 13.12 & 0 & 0.15 & 4.49 & 3.07 \\
\hline $3 / 28 / 0623: 10$ & 10.51 & 12.73 & 0 & 0.14 & 3.82 & 2.79 \\
\hline $3 / 28 / 0623: 20$ & 10.49 & 11.82 & 0 & 0.14 & 3.97 & 2.83 \\
\hline $3 / 28 / 0623: 30$ & 10.34 & 11.55 & 0 & 0.16 & 4.08 & 2.83 \\
\hline $3 / 28 / 0623: 40$ & 11.64 & 10.35 & 11.09 & 0.16 & 4.75 & 2.88 \\
\hline $3 / 28 / 0623: 50$ & 11.49 & 10.56 & 8.11 & 0.16 & 4.75 & 2.95 \\
\hline
\end{tabular}

\section{Corrections Applied to CMM Data}

CMM-based mercury concentrations are provided in the standard units of micrograms of $\mathrm{Hg}$ per dry, normal cubic meter of flue gas, corrected to a $3 \% \mathrm{O}_{2}$ level. Moisture is removed as an inherent part of the CMM operation, so its readings are provided on a dry basis; however, additional corrections are needed for $\mathrm{CO}_{2}$ and $\mathrm{O}_{2}$ levels. Some flue gas $\mathrm{CO}_{2}$ is removed by the conditioning process of the $\mathrm{CMM}$, and this removed gas must be accounted for and added back to the sample volume to obtain a proper $\mathrm{Hg}$ concentration. Flue gas $\mathrm{O}_{2}$ is not altered by the CMM but is typically present at a level higher than the reporting standard of $3 \%$ because of duct in-leakage of ambient air.

To make the corrections just described, measurements of the flue gas levels of $\mathrm{CO}_{2}$ and $\mathrm{O}_{2}$ are needed. Unfortunately, these measurements were not available on a continuous basis for both CMM sampling locations, so correlations were developed to calculate these values using inputs from the continuously logged plant data. It was assumed, and was later supported by the data, that the flue gas levels of $\mathrm{CO}_{2}$ and $\mathrm{O}_{2}$ are primarily influenced by two factors: the combustion conditions and the amount of duct 
in-leakage. Indeed, $\mathrm{CO}_{2}$ and $\mathrm{O}_{2}$ levels were found to have a strong correlation with the $\mathrm{B}$ side $\mathrm{O}_{2}$ levels (an indicator of combustion conditions) and to a lesser extent the FF 2-4 dP (which is an approximate indicator of the gradient causing ambient leakage into the ductwork).

\section{FF 2-4 Inlet Location}

To develop $\mathrm{CO}_{2}$ and $\mathrm{O}_{2}$ correlations at the $\mathrm{FF}$ inlet location, continuous data measured at the inlet between February 13 and 18 was used. As mentioned, there was a good correlation between this data and the plant data parameter of $\mathrm{B}$ side inlet $\mathrm{O}_{2}$ level, Figure D-1. Most of the scatter in the data of Figure D-1 correlates well with plant parameters such as Unit 2 load, FF 2-4 flow, and FF 2-4 differential pressure and suggests that these parameters are approximate indications of the conditions in the duct that drive the in-leakage of ambient air. When these relations were examined in detail, all three were equally well correlated to the leakage effect, so $\mathrm{dP}$ was chosen as a matter of preference. Based on these observations, the approach taken to correlate $\mathrm{CO}_{2}$ and $\mathrm{O}_{2}$ levels is diagrammed in Figure D-2.

For $\mathrm{O}_{2}$ correlation, it is a rather simple matter since inlet $\mathrm{O}_{2}$ (B side) is directly recorded by the plant data system. The needed steps are to correlate ambient air leakage flow with FF 2-4 dP, Equation D-1, and then compute FF inlet $\mathrm{O}_{2}$ using a simple mass balance, Equation D2. $\mathrm{CO}_{2}$ is not as simple since $\mathrm{B}$ side inlet $\mathrm{CO}_{2}$ is not recorded, so an intermediate correlation was developed for it based on inlet $\mathrm{O}_{2}$ levels, Equation D-3. With an estimate of the $\mathrm{B}$ side inlet $\mathrm{CO}_{2}$ and the previously described function for ambient leakage, the $\mathrm{FF}$ inlet $\mathrm{CO}_{2}$ level can also be estimated from a mass balance, Equation D-4.

$$
\begin{gathered}
F_{A}(F F \text { Inlet })=0.0034(D P)^{2}-0.0491(D P)+0.3677 \\
\text { FF } \mathrm{O}_{2}=\frac{B \text { side } \mathrm{O}_{2}+\text { Ambient } \mathrm{O}_{2} \cdot\left(F_{\mathrm{A}}\right)}{1+F_{\mathrm{A}}} \\
\text { B side } \mathrm{CO}_{2}=-1.0422\left(B \text { side } \mathrm{O}_{2}\right)+19.125 \\
\text { FF } \mathrm{CO}_{2}=\frac{B \text { side } \mathrm{CO}_{2}}{1+F_{A}}
\end{gathered}
$$

\section{FF 2-4 Outlet Location}

The outlet $\mathrm{CO}_{2}$ and $\mathrm{O}_{2}$ correlations were developed in an identical manner to those of the inlet. Continuous $\mathrm{CO}_{2}$ and $\mathrm{O}_{2}$ data from the outlet site was collected from February 2 through 12 and is plotted as a function of the B side inlet $\mathrm{O}_{2}$ in Figure D-3. 


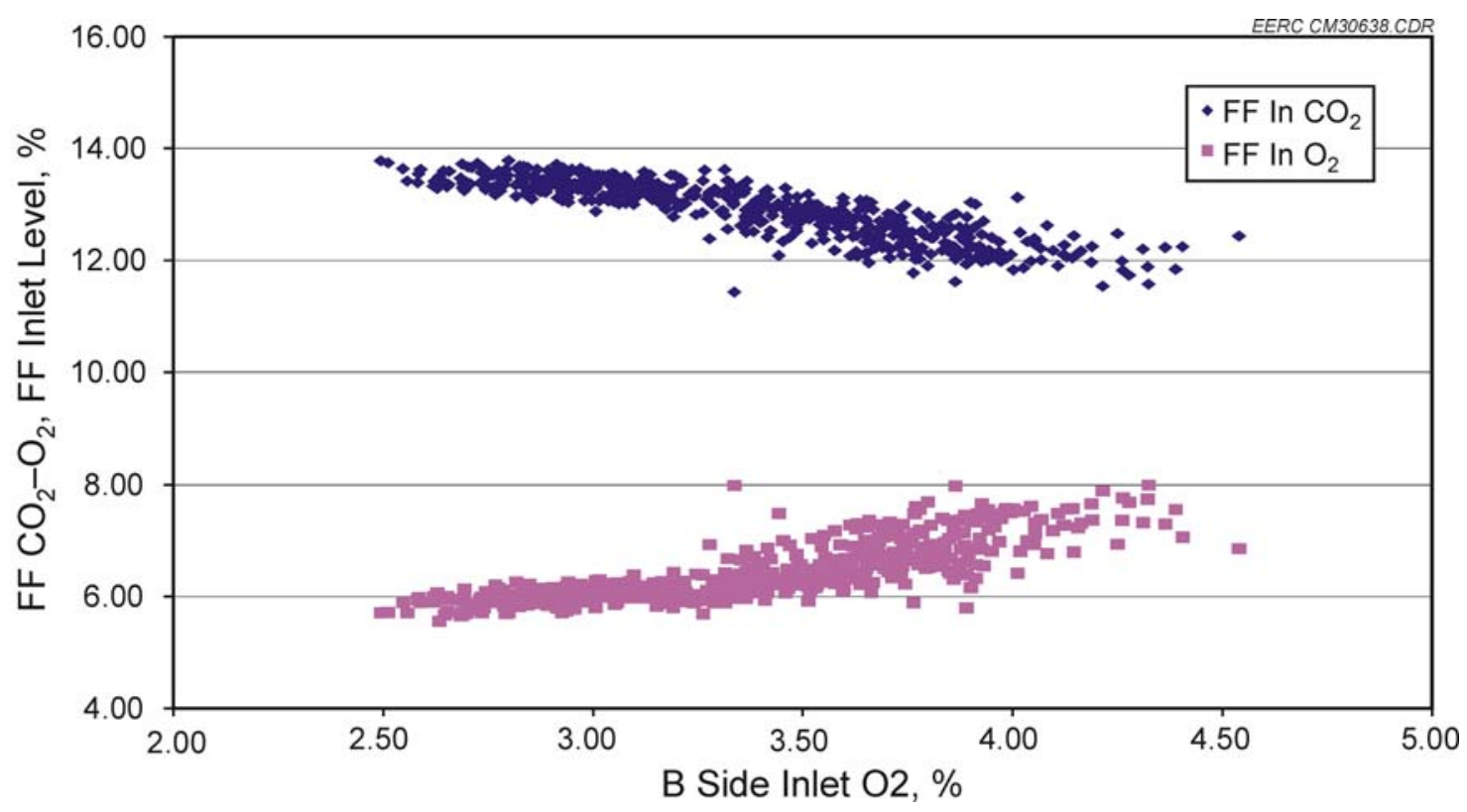

Figure D-1. Relation between $\mathrm{CO}_{2}$ and $\mathrm{O}_{2}$ levels at the $\mathrm{FF}$ inlet and the plant data parameter of $\mathrm{B}$ side inlet $\mathrm{O}_{2}$ level. Data cover the period from February 13 to 18.

EERC CM30639.CDR

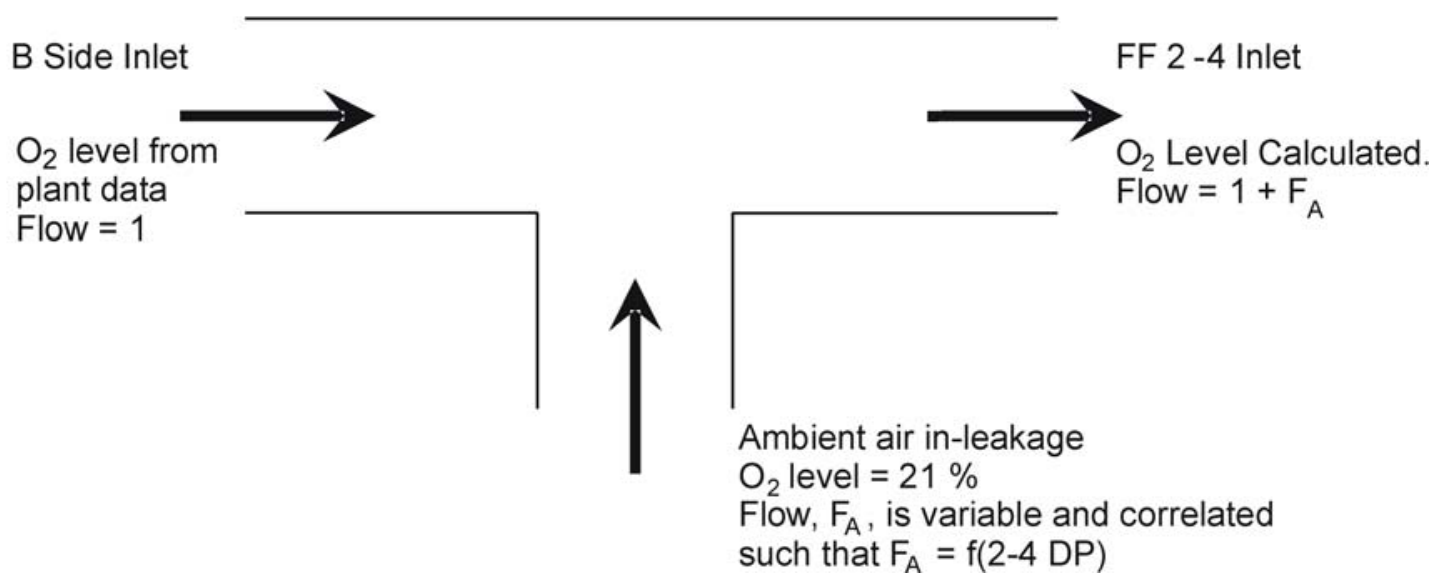

Figure D-2. Diagram used to develop correlations for FF inlet flue gas concentrations. 


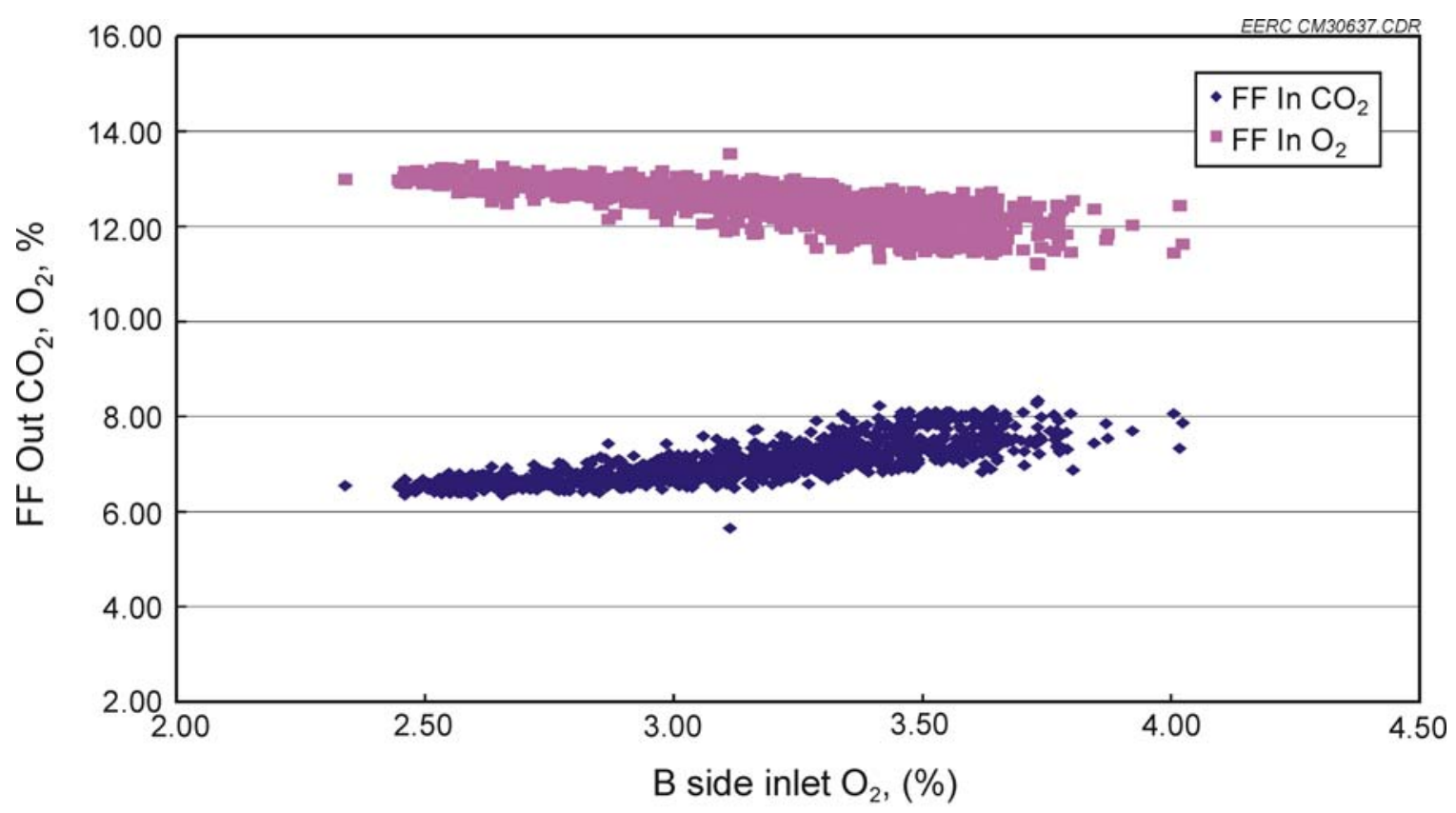

Figure D-3. Relation between $\mathrm{CO}_{2}$ and $\mathrm{O}_{2}$ levels at the $\mathrm{FF}$ outlet and the plant data parameter of $\mathrm{B}$ side inlet $\mathrm{O}_{2}$ level. Data covers the period from February 2 to 12 .

Just as with the inlet data, the FF outlet data is correlated with the B side inlet $\mathrm{O}_{2}$ level and the FF 2-4 dP. The only new expression needed to compute the outlet values is a correlation for ambient air leakage, Equation D-5. With the outlet ambient leakage the $\mathrm{O}_{2}$ level is computed with the mass balance of Equation D-2. Also, to compute outlet $\mathrm{CO}_{2}$ levels, the same estimate for $\mathrm{B}$ side $\mathrm{CO}_{2}$, Equation D-3, is used and is then substituted along with the outlet ambient leakage term into the mass balance of Equation D-4.

$$
F_{A}(F F \text { Outlet })=0.0032(D P)^{2}-0.0467(D P)+0.4372
$$

\section{CMM Corrections}

With a procedure established for estimating flue levels of $\mathrm{CO}_{2}$ and $\mathrm{O}_{2}$ at both the FF inlet and outlet, the CMM readings from these locations can be corrected to standard reporting conditions of micrograms per dry normal cubic meter at $3 \% \mathrm{O}_{2}$ level. Again, the CMM removes moisture as a part of its conditioning so the $\mathrm{Hg}$ readings are already on a dry basis, as are the $\mathrm{CO}_{2}$ and $\mathrm{O}_{2}$ readings.

To estimate the effect of the $\mathrm{CMM}$ conditioning on $\mathrm{CO}_{2}$ and $\mathrm{O}_{2}$ levels, measurements of the CMM exhaust were analyzed. A summary of these measurements, along with the estimated flue gas concentrations, are presented in Table D-2. As shown in Table D-2, the CMM exhaust levels of $\mathrm{O}_{2}$ are consistently higher in $\mathrm{O}_{2}$ than the flue gas estimates. This would indicate that the CMM conditioning unit is not affecting $\mathrm{O}_{2}$ levels 
and that some ambient in-leakage may be occurring. As for the $\mathrm{CO}_{2}$, however, it is evident that the conditioning unit is removing a portion, but not all, of the $\mathrm{CO}_{2}$ present in the flue gas.

Correction of CMM readings for $\mathrm{O}_{2}$ levels are made by completing a mass balance back to an assumed inlet condition containing $3 \% \mathrm{O}_{2}$. The formulation is presented as Equation D-6.

$$
C M M\left(3 \% \mathrm{O}_{2}\right)=C M M \cdot\left(\frac{\text { Ambient } \mathrm{O}_{2}-3 \% \mathrm{O}_{2}}{\text { Ambient } \mathrm{O}_{2}-\text { Flue Gas } \mathrm{O}_{2}}\right)
$$

For $\mathrm{CO}_{2}$ corrections, an estimate is needed regarding the amount of $\mathrm{CO}_{2}$ removed by the $\mathrm{CMM}$ conditioning process. The percentage of $\mathrm{CO}_{2}$ removed, taking into account ambient air in-leakage across the CMM, is presented in Table D-3. All of the CMMs appear to have some variability in the amount of $\mathrm{CO}_{2}$ removed. A correlation that describes this variability has not been identified, so the average removal for each CMM is used as a constant to correct all of the data.

Table D-2. CMM Exhaust Levels of $\mathrm{CO}_{2}$ and $\mathrm{O}_{2}$ and the Estimated Flue Gas Levels of $\mathrm{CO}_{2}$ and $\mathrm{O}_{2}$ for the Corresponding Time Periods

\begin{tabular}{rcccc}
\hline & \multicolumn{2}{c}{ Measured CMM } & \multicolumn{2}{c}{ Estimated Flue } \\
& \multicolumn{2}{c}{ Exhaust Levels } & \multicolumn{2}{c}{ Gas Levels } \\
Date & $\mathrm{CO}_{2}$ & $\mathrm{O}_{2}$ & $\mathrm{CO}_{2}$ & $\mathrm{O}_{2}$ \\
\hline Inlet CMM, Hg & & & & \\
14-Mar & 4.6 & 6.6 & 13.3 & 6 \\
15-Mar & 8.2 & 7.2 & 13.3 & 6.1 \\
16-Mar & 7 & 7.8 & 13.5 & 5.8 \\
20-Mar & 6.2 & 7 & 13.2 & 6.2 \\
21-Mar & 8.6 & 7.4 & 13 & 6.3 \\
Inlet CMM, Hg & & & & \\
14-Mar & 1.8 & 6.2 & 13.3 & 6 \\
15-Mar & 3.8 & 7.6 & 13.3 & 6.1 \\
16-Mar & 5.4 & 6.4 & 13.5 & 5.8 \\
20-Mar & 4 & 6.8 & 13.2 & 6.2 \\
21-Mar & 6 & 7.4 & 13 & 6.3 \\
Outlet CMM, Hg & & & & \\
14-Mar & 6.5 & 9.1 & 12.6 & 6.9 \\
15-Mar & 7 & 8.2 & 12.6 & 7 \\
16-Mar & 3.8 & 8.4 & 12.8 & 6.7 \\
20-Mar & 7.4 & 8.6 & 12.5 & 7 \\
21-Mar & 8 & 8.4 & 12 & 7.5 \\
Outlet CMM, Hg & & & & \\
14-Mar & 2.2 & 9.4 & 12.6 & 6.9 \\
15-Mar & 4.2 & 8.4 & 12.6 & 7 \\
16-Mar & 2 & 8.4 & 12.8 & 6.7 \\
20-Mar & 3.4 & 8.6 & 12.5 & 7 \\
21-Mar & 2.6 & 8.4 & 12 & 7.5 \\
\hline
\end{tabular}


If the average $\mathrm{CO}_{2}$ removal for each $\mathrm{CMM}$ is denoted by $R$ (decimal), then the CMM correction for $\mathrm{CO}_{2}$ removal will have the form of Equation D-7.

$$
C M M\left(\mathrm{CO}_{2} \text { corrected }\right)=C M M \cdot\left(1-\frac{(R)\left(\text { Flue Gas } \mathrm{CO}_{2}\right)}{100}\right)
$$

It is clear from Table D-3 that assuming an average removal value for each CMM will likely result in cases where the factor is too high or low by a significant amount. To estimate the impact of these differences, consider the following sensitivity calculation. Assuming flue gas conditions of $6.5 \% \mathrm{O}_{2}$ and $13 \% \mathrm{CO}_{2}$ and an average $\mathrm{CMM} \mathrm{CO}$ removal of $41 \%$, the total $\mathrm{CMM}$ correction factor would be 1.1752 . By increasing the $\mathrm{CMM} \mathrm{CO}_{2}$ removal to $66 \%$, a $61 \%$ increase, the total correction factor is 1.1349 , which is a $4 \%$ change compared to using the average removal value.

\begin{tabular}{|c|c|c|c|}
\hline Date & $\begin{array}{c}\text { Measured CMM } \\
\text { Exhaust } \\
\mathrm{CO}_{2} \text { Level } \\
\end{array}$ & $\begin{array}{c}\text { Estimated CMM } \\
\text { Exhaust } \mathrm{CO}_{2} \text { Level } \\
\text { with No Leak }\end{array}$ & $\begin{array}{c}\% \mathrm{CO}_{2} \text { Removal from } \\
\text { Flue Gas }\end{array}$ \\
\hline \multicolumn{4}{|c|}{ Inlet $\mathrm{CMM}, \mathrm{Hg}^{0}$} \\
\hline 14-Mar & 4.6 & 4.8 & 64 \\
\hline 15-Mar & 8.2 & 8.9 & 33 \\
\hline 16-Mar & 7 & 8.1 & 40 \\
\hline 20-Mar & 6.2 & 6.5 & 50 \\
\hline \multirow[t]{2}{*}{ 21-Mar } & 8.6 & 9.3 & 28 \\
\hline & & Average & 43 \\
\hline \multicolumn{4}{|c|}{ Inlet $\mathrm{CMM}, \mathrm{Hg}_{\mathrm{T}}$} \\
\hline 14-Mar & 1.8 & 1.8 & 86 \\
\hline 15-Mar & 3.8 & 4.2 & 68 \\
\hline 16-Mar & 5.4 & 5.6 & 58 \\
\hline 20-Mar & 4 & 4.2 & 68 \\
\hline \multirow[t]{2}{*}{ 21-Mar } & 6 & 6.5 & 50 \\
\hline & & Average & 66 \\
\hline \multicolumn{4}{|c|}{ Outlet CMM, $\mathrm{Hg}^{0}$} \\
\hline 14-Mar & 6.5 & 7.7 & 39 \\
\hline 15-Mar & 7 & 7.6 & 39 \\
\hline 16-Mar & 3.8 & 4.3 & 66 \\
\hline 20-Mar & 7.4 & 8.3 & 33 \\
\hline \multirow[t]{2}{*}{ 21-Mar } & 8 & 8.6 & 29 \\
\hline & & Average & 41 \\
\hline \multicolumn{4}{|c|}{ Outlet CMM, $\mathrm{Hg}_{\mathrm{T}}$} \\
\hline 14-Mar & 2.2 & 2.7 & 79 \\
\hline 15-Mar & 4.2 & 4.7 & 63 \\
\hline 16-Mar & 2 & 2.3 & 82 \\
\hline 20-Mar & 3.4 & 3.8 & 69 \\
\hline \multirow[t]{2}{*}{ 21-Mar } & 2.6 & 2.8 & 77 \\
\hline & & Average & 74 \\
\hline
\end{tabular}


APPENDIX E

\section{ESP AND FF ASH DATA}


Table E-1. FF 2-4 Ash Sample Data

\begin{tabular}{|c|c|c|c|c|c|}
\hline Sample Date & $\begin{array}{l}\mathrm{Hg}, \\
\mathrm{ppm}\end{array}$ & $\begin{array}{c}\text { Se, } \\
\text { ppm }\end{array}$ & $\begin{array}{c}\text { Carbon, } \\
\%\end{array}$ & $\begin{array}{c}\text { Hydrogen, } \\
\% \\
\end{array}$ & $\begin{array}{c}\text { Nitrogen, } \\
\% \\
\end{array}$ \\
\hline \multicolumn{6}{|l|}{ Baseline } \\
\hline $1 / 19 / 2006$ & 0.655 & 173 & 0.32 & 0.14 & 0.11 \\
\hline $1 / 20 / 2006$ & 0.303 & 180 & 0.29 & 0.22 & 0.14 \\
\hline \multicolumn{6}{|c|}{ Monthlong Test } \\
\hline $2 / 28 / 2006$ & 48.2 & 827 & 7.76 & 0.16 & 0.26 \\
\hline $3 / 1 / 2006$ & 43.9 & 823 & 9.35 & 0.1 & 0.3 \\
\hline $3 / 2 / 2006$ & 7.82 & 163 & 2.455 & 0.135 & 0.2 \\
\hline $3 / 3 / 2006$ & 65.2 & 1010 & 11.06 & 0.14 & 0.36 \\
\hline $3 / 4 / 2006$ & 89.7 & 1022.5 & 13.84 & 0.32 & 0.38 \\
\hline $3 / 5 / 2006$ & 70.5 & 815 & 13.06 & 0.3 & 0.35 \\
\hline $3 / 6 / 2006$ & 48 & 715 & 6.03 & 0.205 & 0.23 \\
\hline $3 / 7 / 2006$ & 21.3 & 418 & 4.585 & 0.245 & 0.255 \\
\hline $3 / 15 / 2006$ & 132 & 2130 & 11.4 & 0.3 & 0.44 \\
\hline $3 / 17 / 2006$ & 71.9 & 1260 & 9.84 & 0.24 & 0.36 \\
\hline $3 / 18 / 2006$ & 76.4 & 1200 & 6.2 & 0.18 & 0.27 \\
\hline $3 / 20 / 2006$ & 81.1 & 1480 & 13.24 & 0.3 & 0.42 \\
\hline $3 / 21 / 2006$ & 39.7 & 671 & 5.68 & 0.2 & 0.3 \\
\hline $3 / 22 / 2006$ & 34.1 & 556 & 3.78 & 0.17 & 0.28 \\
\hline $3 / 23 / 2006$ & 24.3 & 400 & 2.98 & 0.16 & 0.25 \\
\hline $3 / 24 / 2006$ & 46.5 & 671 & 4.4 & 0.2 & 0.26 \\
\hline $3 / 25 / 2006$ & 62.1 & 809 & 7.03 & 0.2 & 0.31 \\
\hline $3 / 26 / 2006$ & 73.8 & 1210 & 10.82 & 0.15 & 0.36 \\
\hline $3 / 27 / 2006$ & 60.7 & 805 & 7.23 & 0.22 & 0.32 \\
\hline
\end{tabular}


Table E-2. ESP Ash Sample Data

\begin{tabular}{lcc}
\hline Sample & $\mathrm{Hg}, \mathrm{ppm}$ & $\mathrm{Se}, \mathrm{ppm}$ \\
\hline $1 / 21 / 2006$, Row 1 & 0.0966 & 45.7 \\
$1 / 22 / 2006$, Row 2 & 0.2 & 27.3 \\
$1 / 23 / 2006$, Row 1 & 0.125 & 21.1 \\
$1 / 23 / 2006$, Row 2 & 0.141 & 20.5 \\
$1 / 24 / 2006$, Row 1 & 0.155 & 19.8 \\
$1 / 24 / 2006$, Row 2 & 0.361 & 23.9 \\
Average $^{\text {a }}$ & 0.136 & 28.4 \\
\hline${ }^{a}$ Average values were calculated assuming 90\% of the ash was collected in Row 1 and the \\
remaining 10\% in Row 2.
\end{tabular}


APPENDIX F

\section{RELEVANT PLANT OPERATING DATA}


Table F-1. Hourly Average Unit 2 Operation Data During the Monthlong Test

\begin{tabular}{|c|c|c|c|c|c|c|c|c|}
\hline Date, Time & $\begin{array}{l}\text { Unit } 2 \\
\text { Load, } \\
\text { MW }\end{array}$ & $\begin{array}{c}\text { Unit } 2 \\
\text { Coal Flow, } \\
\text { ton/hour }\end{array}$ & $\begin{array}{c}\text { Unit } 2 \\
\text { Stack } \\
\mathrm{NO}_{\mathrm{x}}, \mathrm{ppm}\end{array}$ & $\begin{array}{c}\text { Unit } 2 \\
\text { Stack } \\
\mathrm{SO}_{2}, \mathrm{ppm}\end{array}$ & $\begin{array}{l}\text { FF } 2-3 / 2-4 \\
\text { Inlet } \\
\text { Opacity, \% }\end{array}$ & $\begin{array}{c}\text { Unit } 2 \\
\text { Stack } \\
\text { Opacity, \% }\end{array}$ & $\begin{array}{c}\text { Calculated } \\
\mathrm{SO}_{3} \text { Injection, } \\
\text { ppm }\end{array}$ & $\begin{array}{c}\text { Calculated } \\
\mathrm{NH}_{3} \text { Injection, } \\
\text { ppm }\end{array}$ \\
\hline 2/27/2006 15:00 & 482.55 & 328.30 & 61.05 & 903.60 & 23.72 & 9.24 & 10.01 & 8.00 \\
\hline 2/27/2006 16:00 & 488.00 & 334.50 & 59.45 & 886.40 & 25.82 & 9.34 & 9.97 & 7.97 \\
\hline 2/27/2006 17:00 & 488.53 & 338.25 & 58.39 & 878.54 & 26.00 & 9.51 & 9.98 & 8.00 \\
\hline 2/27/2006 18:00 & 452.38 & 308.98 & 63.14 & 864.86 & 22.80 & 9.45 & 9.97 & 8.02 \\
\hline 2/27/2006 19:00 & 481.95 & 335.37 & 60.84 & 847.33 & 24.53 & 9.52 & 9.98 & 7.99 \\
\hline 2/27/2006 20:00 & 522.91 & 361.79 & 64.99 & 862.49 & 30.69 & 9.69 & 9.99 & 8.01 \\
\hline 2/27/2006 21:00 & 472.62 & 320.34 & 60.02 & 843.34 & 22.25 & 9.54 & 10.02 & 8.04 \\
\hline 2/27/2006 22:00 & 439.16 & 296.67 & 58.96 & 826.95 & 24.42 & 9.55 & 9.95 & 8.03 \\
\hline 2/27/2006 23:00 & 501.01 & 341.15 & 63.00 & 866.35 & 28.99 & 9.66 & 9.96 & 8.07 \\
\hline 2/28/2006 0:00 & 381.44 & 259.23 & 56.94 & 818.98 & 17.85 & 9.26 & 9.99 & 7.99 \\
\hline 2/28/2006 1:00 & 320.26 & 216.78 & 56.89 & 730.68 & 16.06 & 9.10 & 10.00 & 8.02 \\
\hline $2 / 28 / 20062: 00$ & 302.18 & 206.94 & 61.25 & 726.99 & 16.67 & 8.96 & 9.92 & 8.00 \\
\hline 2/28/2006 3:00 & 301.65 & 204.83 & 63.92 & 726.93 & 16.47 & 8.95 & 9.92 & 8.00 \\
\hline 2/28/2006 4:00 & 301.52 & 204.32 & 75.64 & 725.92 & 15.58 & 8.94 & 9.94 & 8.01 \\
\hline $2 / 28 / 20065: 00$ & 302.34 & 206.06 & 71.63 & 725.44 & 14.80 & 9.04 & 9.93 & 7.99 \\
\hline $2 / 28 / 20066: 00$ & 377.00 & 252.80 & 52.78 & 771.34 & 18.22 & 9.16 & 9.93 & 8.01 \\
\hline $2 / 28 / 20067: 00$ & 533.02 & 363.04 & 62.84 & 822.19 & 28.79 & 9.75 & 9.97 & 7.88 \\
\hline 2/28/2006 8:00 & 544.91 & 371.21 & 47.29 & 593.89 & 28.32 & 8.21 & 10.00 & 7.94 \\
\hline 2/28/2006 9:00 & 564.45 & 383.54 & 67.52 & 866.15 & 32.56 & 9.79 & 9.99 & 7.95 \\
\hline 2/28/2006 10:00 & 596.54 & 406.73 & 70.90 & 852.45 & 39.04 & 9.94 & 9.92 & 7.59 \\
\hline 2/28/2006 11:00 & 585.35 & 397.02 & 70.72 & 861.15 & 36.57 & 10.75 & 9.94 & 7.79 \\
\hline 2/28/2006 12:00 & 505.06 & 339.81 & 61.69 & 833.23 & 27.48 & 10.30 & 9.99 & 8.02 \\
\hline 2/28/2006 13:00 & 492.71 & 329.70 & 54.00 & 777.69 & 27.34 & 10.23 & 9.92 & 8.02 \\
\hline 2/28/2006 14:00 & 506.18 & 336.65 & 56.68 & 800.22 & 27.71 & 10.34 & 9.97 & 8.01 \\
\hline $2 / 28 / 2006$ 15:00 & 482.52 & 317.79 & 52.57 & 783.98 & 24.43 & 10.25 & 9.96 & 8.01 \\
\hline $2 / 28 / 200616: 00$ & 504.41 & 336.20 & 56.44 & 788.87 & 28.19 & 10.24 & 9.95 & 8.04 \\
\hline $2 / 28 / 2006$ 17:00 & 480.89 & 325.66 & 55.76 & 768.07 & 26.98 & 10.36 & 9.97 & 8.01 \\
\hline 2/28/2006 18:00 & 511.42 & 351.23 & 57.57 & 781.27 & 31.02 & 10.42 & 9.97 & 8.01 \\
\hline 2/28/2006 19:00 & 528.72 & 363.37 & 60.21 & 778.31 & 33.26 & 10.47 & 9.95 & 7.99 \\
\hline 2/28/2006 20:00 & 583.39 & 403.37 & 71.47 & 806.32 & 37.78 & 11.11 & 9.92 & 7.97 \\
\hline 2/28/2006 21:00 & 471.64 & 325.71 & 58.56 & 794.41 & 27.81 & 9.95 & 10.00 & 8.00 \\
\hline 2/28/2006 22:00 & 534.44 & 367.15 & 62.22 & 840.59 & 30.77 & 10.00 & 9.92 & 8.01 \\
\hline 2/28/2006 23:00 & 578.68 & 399.57 & 70.88 & 888.46 & 31.84 & 10.30 & 9.95 & 8.01 \\
\hline 3/1/2006 0:00 & 500.21 & 344.12 & 66.57 & 910.62 & 32.29 & 10.18 & 9.99 & 8.00 \\
\hline $3 / 1 / 20061: 00$ & 393.46 & 274.19 & 55.67 & 866.91 & 19.39 & 9.56 & 9.99 & 7.99 \\
\hline $3 / 1 / 20062: 00$ & 465.26 & 323.28 & 54.20 & 888.24 & 22.06 & 9.57 & 9.90 & 7.96 \\
\hline $3 / 1 / 20063: 00$ & 550.28 & 378.77 & 68.58 & 910.84 & 32.66 & 10.29 & 9.95 & 7.99 \\
\hline $3 / 1 / 20064: 00$ & 585.59 & 401.26 & 71.04 & 893.68 & 40.33 & 10.88 & 9.92 & 7.83 \\
\hline $3 / 1 / 20065: 00$ & 563.21 & 386.05 & 68.23 & 888.98 & 35.60 & 10.65 & 9.93 & 7.92 \\
\hline $3 / 1 / 20066: 00$ & 584.01 & 400.40 & 69.92 & 914.45 & 35.63 & 10.44 & 9.91 & 7.82 \\
\hline $3 / 1 / 2006$ 7:00 & 570.87 & 389.85 & 68.38 & 930.84 & 33.91 & 10.39 & 9.94 & 7.95 \\
\hline $3 / 1 / 20068: 00$ & 574.42 & 394.67 & 50.80 & 642.75 & 35.40 & 10.28 & 9.96 & 7.89 \\
\hline 3/1/2006 9:00 & 585.66 & 397.46 & 73.03 & 971.85 & 36.01 & 10.26 & 9.96 & 7.80 \\
\hline 3/1/2006 10:00 & 589.15 & 400.67 & 71.68 & 965.58 & 36.11 & 10.47 & 9.95 & 7.91 \\
\hline 3/1/2006 11:00 & 601.30 & 403.27 & 72.32 & 968.81 & 37.53 & 10.78 & 9.92 & 7.89 \\
\hline 3/1/2006 12:00 & 578.21 & 388.94 & 71.19 & 956.17 & 37.24 & 10.32 & 9.94 & 8.02 \\
\hline 3/1/2006 13:00 & 562.34 & 377.34 & 67.84 & 905.88 & 34.86 & 10.43 & 9.96 & 7.99 \\
\hline $3 / 1 / 200614: 00$ & 599.50 & 396.80 & 72.60 & 896.13 & 33.52 & 10.46 & 9.94 & 7.98 \\
\hline 3/1/2006 15:00 & 620.72 & 409.46 & 74.95 & 934.94 & 39.28 & 11.48 & 9.92 & 7.97 \\
\hline $3 / 1 / 2006$ 16:00 & 625.27 & 408.90 & 74.79 & 930.08 & 39.20 & 12.89 & 9.92 & 8.00 \\
\hline $3 / 1 / 2006$ 17:00 & 624.86 & 407.31 & 75.47 & 887.73 & 38.10 & 12.39 & 9.91 & 8.00 \\
\hline 3/1/2006 18:00 & 622.82 & 413.98 & 78.15 & 578.71 & 39.98 & 11.85 & 9.92 & 8.00 \\
\hline
\end{tabular}

Continued... 
Table F-1. Hourly Average Unit 2 Operation Data During the Monthlong Test (continued)

\begin{tabular}{|c|c|c|c|c|c|c|c|c|}
\hline Date, Time & $\begin{array}{l}\text { Unit } 2 \\
\text { Load, } \\
\text { MW }\end{array}$ & $\begin{array}{c}\text { Unit } 2 \\
\text { Coal Flow, } \\
\text { ton/hour }\end{array}$ & $\begin{array}{c}\text { Unit } 2 \\
\text { Stack } \\
\mathrm{NO}_{\mathrm{x}}, \mathrm{ppm}\end{array}$ & $\begin{array}{c}\text { Unit } 2 \\
\text { Stack } \\
\mathrm{SO}_{2}, \mathrm{ppm} \\
\end{array}$ & $\begin{array}{c}\text { FF } 2-3 / 2-4 \\
\text { Inlet } \\
\text { Opacity, } \% \\
\end{array}$ & $\begin{array}{c}\text { Unit 2 } \\
\text { Stack } \\
\text { Opacity, \% }\end{array}$ & $\begin{array}{c}\text { Calculated } \\
\mathrm{SO}_{3} \text { Injection, } \\
\text { ppm }\end{array}$ & $\begin{array}{c}\text { Calculated } \\
\mathrm{NH}_{3} \text { Injection, } \\
\text { ppm }\end{array}$ \\
\hline 3/1/2006 19:00 & 620.79 & 417.56 & 77.27 & 117.92 & 39.43 & 11.66 & 9.92 & 8.00 \\
\hline 3/1/2006 20:00 & 620.03 & 418.63 & 79.67 & 136.31 & 44.65 & 11.45 & 9.92 & 8.00 \\
\hline 3/1/2006 21:00 & 602.66 & 376.52 & 72.91 & 97.82 & 41.70 & 11.29 & 9.92 & 8.00 \\
\hline 3/1/2006 22:00 & 394.76 & 227.08 & 57.42 & 565.16 & 32.58 & 10.35 & 10.06 & 8.06 \\
\hline 3/1/2006 23:00 & 299.07 & 170.21 & 46.79 & 838.86 & 22.85 & 9.29 & 9.92 & 8.01 \\
\hline 3/2/2006 0:00 & 385.15 & 225.97 & 44.57 & 905.13 & 22.46 & 9.31 & 9.93 & 8.00 \\
\hline $3 / 2 / 20061: 00$ & 521.76 & 333.10 & 62.02 & 519.74 & 28.45 & 9.43 & 9.97 & 7.98 \\
\hline $3 / 2 / 20062: 00$ & 585.11 & 393.07 & 73.01 & 960.93 & 30.64 & 9.74 & 9.94 & 7.99 \\
\hline $3 / 2 / 20063: 00$ & 584.21 & 386.71 & 71.47 & 885.28 & 30.57 & 9.79 & 9.93 & 7.90 \\
\hline $3 / 2 / 20064: 00$ & 436.56 & 286.76 & 60.52 & 830.68 & 21.49 & 9.46 & 10.03 & 8.03 \\
\hline $3 / 2 / 20065: 00$ & 400.08 & 267.48 & 55.36 & 795.00 & 18.14 & 9.25 & 9.92 & 7.99 \\
\hline $3 / 2 / 20066: 00$ & 449.02 & 292.21 & 51.77 & 780.66 & 17.99 & 9.27 & 9.95 & 7.99 \\
\hline $3 / 2 / 2006$ 7:00 & 412.99 & 273.68 & 48.74 & 762.29 & 16.56 & 9.36 & 9.96 & 7.98 \\
\hline $3 / 2 / 20068: 00$ & 463.34 & 305.98 & 42.41 & 582.64 & 18.58 & 9.38 & 9.96 & 8.03 \\
\hline $3 / 2 / 20069: 00$ & 618.14 & 410.05 & 75.61 & 868.96 & 34.89 & 9.94 & 9.92 & 7.85 \\
\hline $3 / 2 / 2006$ 10:00 & 630.22 & 412.44 & 77.37 & 822.47 & 37.80 & 10.97 & 9.92 & 7.97 \\
\hline 3/2/2006 11:00 & 567.59 & 364.15 & 67.99 & 770.51 & 28.83 & 10.19 & 10.00 & 8.00 \\
\hline $3 / 2 / 200612: 00$ & 559.15 & 360.48 & 63.77 & 720.34 & 26.37 & 9.29 & 10.03 & 8.00 \\
\hline 3/2/2006 13:00 & 608.15 & 393.91 & 68.80 & 679.61 & 28.23 & 9.30 & 9.91 & 7.78 \\
\hline 3/2/2006 14:00 & 593.52 & 379.51 & 67.84 & 657.75 & 29.64 & 9.65 & 10.00 & 7.91 \\
\hline 3/2/2006 15:00 & 588.22 & 374.07 & 68.48 & 638.09 & 30.74 & 9.79 & 10.03 & 7.89 \\
\hline 3/2/2006 16:00 & 543.76 & 353.68 & 62.58 & 645.08 & 22.41 & 9.54 & 9.95 & 8.00 \\
\hline 3/2/2006 17:00 & 557.52 & 358.48 & 63.83 & 683.45 & 26.79 & 9.78 & 10.00 & 8.01 \\
\hline 3/2/2006 18:00 & 572.68 & 376.75 & 67.04 & 724.80 & 29.38 & 9.71 & 9.96 & 7.96 \\
\hline 3/2/2006 19:00 & 586.82 & 384.82 & 70.14 & 775.69 & 30.73 & 9.69 & 9.92 & 8.00 \\
\hline $3 / 2 / 200620: 00$ & 576.68 & 380.61 & 70.54 & 837.37 & 30.74 & 9.79 & 10.00 & 7.99 \\
\hline 3/2/2006 21:00 & 455.67 & 300.99 & 59.33 & 840.23 & 25.83 & 9.58 & 10.03 & 8.06 \\
\hline $3 / 2 / 200622: 00$ & 524.99 & 350.43 & 63.61 & 827.70 & 25.53 & 9.62 & 9.95 & 8.02 \\
\hline 3/2/2006 23:00 & 476.32 & 315.76 & 61.82 & 800.63 & 24.04 & 9.56 & 10.02 & 8.00 \\
\hline 3/3/2006 0:00 & 529.21 & 357.09 & 64.86 & 788.12 & 24.27 & 9.54 & 9.98 & 7.93 \\
\hline 3/3/2006 1:00 & 444.57 & 294.72 & 61.08 & 766.15 & 20.74 & 9.67 & 10.07 & 8.05 \\
\hline $3 / 3 / 20062: 00$ & 461.19 & 310.90 & 60.16 & 779.10 & 16.55 & 9.53 & 9.97 & 7.99 \\
\hline $3 / 3 / 20063: 00$ & 481.60 & 319.38 & 60.56 & 795.03 & 18.32 & 9.62 & 9.99 & 8.03 \\
\hline $3 / 3 / 20064: 00$ & 356.20 & 236.58 & 52.82 & 747.42 & 15.60 & 9.47 & 9.98 & 7.99 \\
\hline 3/3/2006 5:00 & 392.19 & 261.46 & 58.09 & 752.89 & 16.82 & 9.58 & 9.94 & 7.93 \\
\hline $3 / 3 / 20066: 00$ & 365.70 & 250.62 & 56.85 & 738.48 & 14.34 & 9.57 & 9.98 & 8.00 \\
\hline $3 / 3 / 20067: 00$ & 449.61 & 304.66 & 58.98 & 740.51 & 19.93 & 9.66 & 9.94 & 8.01 \\
\hline 3/3/2006 8:00 & 409.58 & 274.04 & 39.33 & 500.91 & 14.97 & 9.31 & 9.95 & 7.95 \\
\hline 3/3/2006 9:00 & 534.17 & 359.40 & 58.59 & 730.74 & 23.70 & 9.49 & 9.93 & 7.90 \\
\hline 3/3/2006 10:00 & 529.61 & 360.25 & 59.87 & 729.84 & 24.03 & 9.51 & 10.01 & 8.01 \\
\hline 3/3/2006 11:00 & 384.40 & 269.50 & 49.07 & 703.80 & 16.25 & 9.31 & 9.97 & 8.00 \\
\hline 3/3/2006 12:00 & 438.53 & 310.26 & 60.57 & 739.70 & 21.59 & 9.48 & 10.00 & 8.03 \\
\hline 3/3/2006 13:00 & 559.25 & 396.65 & 66.21 & 775.28 & 32.62 & 9.68 & 9.92 & 7.95 \\
\hline $3 / 3 / 200614: 00$ & 587.66 & 410.28 & 69.74 & 797.35 & 30.31 & 10.01 & 9.93 & 7.94 \\
\hline $3 / 3 / 2006$ 15:00 & 554.95 & 381.57 & 64.35 & 775.51 & 30.08 & 9.74 & 9.93 & 8.02 \\
\hline 3/3/2006 16:00 & 574.26 & 388.26 & 66.87 & 765.49 & 26.75 & 9.81 & 9.97 & 7.99 \\
\hline 3/3/2006 17:00 & 563.09 & 376.79 & 64.52 & 777.57 & 26.67 & 9.82 & 10.00 & 8.01 \\
\hline 3/3/2006 18:00 & 535.21 & 357.01 & 62.23 & 746.80 & 28.38 & 9.84 & 10.00 & 8.00 \\
\hline 3/3/2006 19:00 & 566.68 & 381.54 & 65.45 & 726.05 & 32.21 & 9.76 & 9.92 & 7.89 \\
\hline $3 / 3 / 200620: 00$ & 531.16 & 351.09 & 62.05 & 745.77 & 25.90 & 9.73 & 10.00 & 7.99 \\
\hline 3/3/2006 21:00 & 502.44 & 336.47 & 57.92 & 743.26 & 20.99 & 9.51 & 9.95 & 7.99 \\
\hline 3/3/2006 22:00 & 420.99 & 280.02 & 55.60 & 713.12 & 21.02 & 9.46 & 10.01 & 8.03 \\
\hline 3/3/2006 23:00 & 352.21 & 238.86 & 53.39 & 689.36 & 16.26 & 9.35 & 9.96 & 7.99 \\
\hline 3/4/2006 0:00 & 400.90 & 277.92 & 55.89 & 714.09 & 18.58 & 9.36 & 9.97 & 8.01 \\
\hline
\end{tabular}

Continued... 
Table F-1. Hourly Average Unit 2 Operation Data During the Monthlong Test (continued)

\begin{tabular}{|c|c|c|c|c|c|c|c|c|}
\hline Date, Time & $\begin{array}{l}\text { Unit } 2 \\
\text { Load, } \\
\text { MW }\end{array}$ & $\begin{array}{c}\text { Unit } 2 \\
\text { Coal Flow, } \\
\text { ton/hour }\end{array}$ & $\begin{array}{c}\text { Unit } 2 \\
\text { Stack } \\
\mathrm{NO}_{\mathrm{x}}, \mathrm{ppm}\end{array}$ & $\begin{array}{c}\text { Unit } 2 \\
\text { Stack } \\
\mathrm{SO}_{2}, \mathrm{ppm} \\
\end{array}$ & $\begin{array}{c}\text { FF } 2-3 / 2-4 \\
\text { Inlet } \\
\text { Opacity, } \% \\
\end{array}$ & $\begin{array}{c}\text { Unit } 2 \\
\text { Stack } \\
\text { Opacity, \% }\end{array}$ & $\begin{array}{c}\text { Calculated } \\
\mathrm{SO}_{3} \text { Injection, } \\
\text { ppm }\end{array}$ & $\begin{array}{c}\text { Calculated } \\
\mathrm{NH}_{3} \text { Injection, } \\
\text { ppm }\end{array}$ \\
\hline $3 / 4 / 20061: 00$ & 366.74 & 257.28 & 44.36 & 719.39 & 17.23 & 9.22 & 10.01 & 8.00 \\
\hline $3 / 4 / 20062: 00$ & 364.61 & 254.57 & 45.48 & 737.48 & 16.88 & 9.11 & 9.96 & 8.02 \\
\hline $3 / 4 / 20063: 00$ & 353.45 & 246.96 & 44.78 & 740.69 & 16.61 & 9.10 & 9.95 & 8.00 \\
\hline $3 / 4 / 20064: 00$ & 368.63 & 263.64 & 51.93 & 745.39 & 17.68 & 8.97 & 9.96 & 7.99 \\
\hline $3 / 4 / 20065: 00$ & 415.66 & 286.91 & 61.62 & 740.31 & 20.95 & 9.19 & 9.96 & 7.96 \\
\hline $3 / 4 / 20066: 00$ & 361.33 & 252.27 & 62.61 & 716.19 & 16.17 & 9.01 & 9.96 & 7.99 \\
\hline $3 / 4 / 20067: 00$ & 354.09 & 246.05 & 62.54 & 698.52 & 15.67 & 9.03 & 9.99 & 8.00 \\
\hline $3 / 4 / 20068: 00$ & 402.74 & 277.82 & 42.86 & 511.55 & 17.12 & 9.42 & 9.98 & 8.02 \\
\hline 3/4/2006 9:00 & 354.02 & 246.98 & 61.04 & 725.43 & 15.32 & 9.40 & 9.98 & 7.98 \\
\hline 3/4/2006 10:00 & 384.14 & 267.61 & 51.01 & 709.92 & 18.38 & 9.45 & 9.95 & 8.01 \\
\hline 3/4/2006 11:00 & 556.38 & 389.33 & 65.98 & 733.32 & 39.11 & 9.82 & 9.88 & 7.90 \\
\hline $3 / 4 / 200612: 00$ & 621.80 & 422.99 & 77.60 & 737.34 & 37.38 & 11.45 & 9.92 & 7.65 \\
\hline 3/4/2006 13:00 & 586.89 & 396.32 & 87.03 & 755.42 & 37.35 & 11.18 & 9.96 & 7.82 \\
\hline $3 / 4 / 200614: 00$ & 621.42 & 418.08 & 76.43 & 774.83 & 35.88 & 11.03 & 9.92 & 7.47 \\
\hline $3 / 4 / 2006$ 15:00 & 559.33 & 375.99 & 77.59 & 795.08 & 30.82 & 10.69 & 10.00 & 7.99 \\
\hline $3 / 4 / 200616: 00$ & 377.25 & 255.17 & 87.69 & 768.71 & 24.18 & 9.72 & 10.02 & 8.01 \\
\hline $3 / 4 / 200617: 00$ & 431.70 & 289.89 & 97.37 & 774.50 & 24.59 & 9.37 & 9.96 & 7.97 \\
\hline $3 / 4 / 2006$ 18:00 & 494.64 & 335.63 & 100.26 & 799.34 & 24.96 & 9.58 & 9.97 & 7.97 \\
\hline 3/4/2006 19:00 & 550.24 & 374.00 & 88.90 & 795.67 & 31.45 & 9.60 & 9.93 & 7.85 \\
\hline $3 / 4 / 200620: 00$ & 538.64 & 358.51 & 81.94 & 798.78 & 26.30 & 9.71 & 9.94 & 8.03 \\
\hline $3 / 4 / 200621: 00$ & 513.49 & 342.47 & 64.03 & 811.83 & 24.11 & 9.68 & 9.96 & 8.03 \\
\hline $3 / 4 / 200622: 00$ & 471.30 & 313.21 & 62.48 & 805.09 & 21.59 & 9.57 & 9.99 & 8.04 \\
\hline $3 / 4 / 200623: 00$ & 396.89 & 263.45 & 73.66 & 788.21 & 19.53 & 9.59 & 9.96 & 7.96 \\
\hline 3/5/2006 0:00 & 386.05 & 253.37 & 59.91 & 776.05 & 17.34 & 9.57 & 9.99 & 8.04 \\
\hline 3/5/2006 1:00 & 375.09 & 248.34 & 59.89 & 768.62 & 19.13 & 9.60 & 9.92 & 8.04 \\
\hline $3 / 5 / 20062: 00$ & 372.54 & 243.96 & 61.51 & 777.47 & 16.06 & 9.50 & 9.95 & 7.98 \\
\hline $3 / 5 / 20063: 00$ & 375.17 & 247.66 & 58.69 & 786.25 & 17.73 & 9.65 & 9.98 & 7.99 \\
\hline $3 / 5 / 20064: 00$ & 363.26 & 240.78 & 55.84 & 801.01 & 15.98 & 9.48 & 9.95 & 8.00 \\
\hline $3 / 5 / 20065: 00$ & 361.53 & 238.75 & 57.47 & 825.73 & 17.68 & 9.57 & 9.94 & 7.99 \\
\hline $3 / 5 / 20066: 00$ & 349.81 & 229.07 & 65.14 & 833.09 & 17.31 & 9.42 & 9.97 & 8.01 \\
\hline $3 / 5 / 20067: 00$ & 303.88 & 208.89 & 60.53 & 785.07 & 13.93 & 9.34 & 9.92 & 8.00 \\
\hline $3 / 5 / 20068: 00$ & 307.20 & 209.28 & 42.71 & 553.83 & 16.16 & 9.29 & 9.91 & 8.00 \\
\hline 3/5/2006 9:00 & 524.87 & 348.38 & 65.83 & 885.06 & 34.20 & 9.69 & 9.89 & 7.89 \\
\hline 3/5/2006 10:00 & 530.59 & 351.79 & 61.15 & 871.81 & 24.84 & 10.17 & 10.02 & 8.01 \\
\hline 3/5/2006 11:00 & 544.99 & 364.26 & 68.44 & 841.60 & 28.70 & 9.89 & 9.97 & 7.98 \\
\hline $3 / 5 / 2006$ 12:00 & 486.38 & 330.53 & 73.46 & 818.11 & 24.11 & 9.61 & 9.96 & 7.96 \\
\hline $3 / 5 / 2006$ 13:00 & 507.15 & 354.89 & 60.99 & 791.93 & 23.27 & 9.53 & 9.95 & 8.04 \\
\hline $3 / 5 / 200614: 00$ & 581.40 & 395.58 & 72.44 & 772.76 & 30.93 & 9.95 & 9.99 & 7.92 \\
\hline $3 / 5 / 2006$ 15:00 & 581.48 & 397.41 & 72.47 & 738.59 & 30.81 & 9.90 & 10.00 & 8.01 \\
\hline $3 / 5 / 200616: 00$ & 553.07 & 383.67 & 72.34 & 735.27 & 28.74 & 9.72 & 9.94 & 7.92 \\
\hline $3 / 5 / 2006$ 17:00 & 598.53 & 405.75 & 75.64 & 741.84 & 31.91 & 10.46 & 9.97 & 8.05 \\
\hline 3/5/2006 18:00 & 431.04 & 294.96 & 68.40 & 716.79 & 22.89 & 9.65 & 9.99 & 8.00 \\
\hline 3/5/2006 19:00 & 479.17 & 331.05 & 69.23 & 673.09 & 25.90 & 9.51 & 9.94 & 7.97 \\
\hline 3/5/2006 20:00 & 593.86 & 400.30 & 68.77 & 692.83 & 32.54 & 10.24 & 9.99 & 7.95 \\
\hline $3 / 5 / 200621: 00$ & 510.77 & 347.44 & 58.32 & 639.39 & 21.45 & 9.84 & 9.96 & 8.00 \\
\hline 3/5/2006 22:00 & 427.89 & 283.90 & 57.42 & 619.73 & 20.33 & 9.32 & 10.03 & 7.99 \\
\hline 3/5/2006 23:00 & 371.19 & 249.22 & 56.24 & 600.47 & 13.11 & 9.27 & 10.03 & 8.04 \\
\hline 3/6/2006 0:00 & 362.30 & 242.53 & 77.86 & 585.93 & 17.61 & 9.19 & 9.96 & 7.99 \\
\hline 3/6/2006 1:00 & 447.71 & 304.50 & 61.00 & 601.44 & 20.17 & 9.23 & 9.96 & 7.98 \\
\hline $3 / 6 / 20062: 00$ & 389.18 & 260.40 & 67.66 & 603.60 & 16.93 & 9.24 & 9.98 & 8.03 \\
\hline $3 / 6 / 20063: 00$ & 398.72 & 267.27 & 62.70 & 603.35 & 17.12 & 9.05 & 9.94 & 7.99 \\
\hline $3 / 6 / 20064: 00$ & 383.70 & 255.55 & 69.43 & 587.77 & 16.44 & 9.16 & 9.99 & 8.01 \\
\hline
\end{tabular}


Table F-1. Hourly Average Unit 2 Operation Data During the Monthlong Test (continued)

\begin{tabular}{|c|c|c|c|c|c|c|c|c|}
\hline Date, Time & $\begin{array}{l}\text { Unit } 2 \\
\text { Load, } \\
\text { MW }\end{array}$ & $\begin{array}{c}\text { Unit } 2 \\
\text { Coal Flow, } \\
\text { ton/hour }\end{array}$ & $\begin{array}{c}\text { Unit } 2 \\
\text { Stack } \\
\mathrm{NO}_{\mathrm{x}}, \mathrm{ppm} \\
\end{array}$ & $\begin{array}{c}\text { Unit } 2 \\
\text { Stack } \\
\mathrm{SO}_{2}, \mathrm{ppm} \\
\end{array}$ & $\begin{array}{c}\text { FF } 2-3 / 2-4 \\
\text { Inlet } \\
\text { Opacity, } \% \\
\end{array}$ & $\begin{array}{c}\text { Unit } 2 \\
\text { Stack } \\
\text { Opacity, \% }\end{array}$ & $\begin{array}{c}\text { Calculated } \\
\mathrm{SO}_{3} \text { Injection, } \\
\text { ppm }\end{array}$ & $\begin{array}{c}\text { Calculated } \\
\mathrm{NH}_{3} \text { Injection, } \\
\text { ppm }\end{array}$ \\
\hline $3 / 6 / 2006$ 5:00 & 356.91 & 239.80 & 82.33 & 573.40 & 17.20 & 9.04 & 9.95 & 8.00 \\
\hline $3 / 6 / 20066: 00$ & 384.96 & 260.68 & 78.91 & 576.90 & 18.47 & 9.26 & 9.98 & 7.99 \\
\hline $3 / 6 / 2006$ 7:00 & 377.07 & 252.33 & 78.18 & 577.51 & 18.44 & 9.50 & 9.96 & 7.97 \\
\hline 3/6/2006 8:00 & 354.31 & 237.65 & 45.50 & 434.89 & 15.61 & 9.23 & 9.92 & 8.00 \\
\hline 3/6/2006 9:00 & 438.44 & 297.60 & 51.71 & 626.93 & 20.61 & 9.52 & 9.93 & 8.01 \\
\hline 3/6/2006 10:00 & 375.98 & 249.15 & 45.86 & 635.92 & 15.56 & 9.34 & 9.96 & 7.98 \\
\hline 3/6/2006 11:00 & 484.11 & 326.10 & 55.12 & 667.56 & 23.79 & 9.56 & 9.94 & 7.99 \\
\hline 3/6/2006 12:00 & 450.47 & 301.16 & 65.25 & 703.39 & 19.41 & 9.54 & 10.00 & 8.03 \\
\hline 3/6/2006 13:00 & 476.32 & 316.89 & 52.54 & 738.14 & 20.22 & 9.56 & 9.94 & 7.96 \\
\hline 3/6/2006 14:00 & 477.57 & 318.73 & 52.40 & 751.29 & 17.78 & 9.88 & 9.93 & 7.98 \\
\hline 3/6/2006 15:00 & 567.07 & 379.33 & 65.91 & 732.24 & 26.22 & 9.92 & 9.96 & 7.99 \\
\hline $3 / 6 / 2006$ 16:00 & 587.32 & 388.08 & 68.24 & 700.90 & 36.05 & 10.29 & 9.96 & 8.01 \\
\hline 3/6/2006 17:00 & 589.47 & 391.88 & 68.58 & 709.25 & 40.93 & 9.68 & 9.99 & 7.96 \\
\hline 3/6/2006 18:00 & 576.97 & 382.29 & 66.14 & 718.27 & 29.14 & 10.09 & 9.95 & 8.03 \\
\hline 3/6/2006 19:00 & 548.18 & 365.00 & 63.31 & 719.23 & 28.40 & 10.09 & 9.94 & 7.96 \\
\hline $3 / 6 / 200620: 00$ & 592.38 & 395.90 & 69.69 & 743.54 & 31.44 & 12.70 & 10.01 & 7.90 \\
\hline $3 / 6 / 200621: 00$ & 462.64 & 305.86 & 59.88 & 731.36 & 22.87 & 12.36 & 10.00 & 8.02 \\
\hline $3 / 6 / 200622: 00$ & 461.57 & 305.41 & 50.18 & 723.74 & 20.53 & 10.16 & 9.98 & 7.95 \\
\hline 3/6/2006 23:00 & 452.29 & 299.87 & 50.81 & 722.26 & 17.93 & 9.78 & 9.99 & 8.05 \\
\hline 3/7/2006 0:00 & 453.09 & 301.54 & 59.75 & 719.95 & 19.51 & 9.21 & 9.97 & 7.98 \\
\hline $3 / 7 / 20061: 00$ & 438.99 & 287.87 & 51.68 & 714.25 & 19.11 & 9.17 & 9.99 & 8.02 \\
\hline $3 / 7 / 20062: 00$ & 456.33 & 296.04 & 52.77 & 731.88 & 18.05 & 9.17 & 9.99 & 8.00 \\
\hline $3 / 7 / 20063: 00$ & 423.08 & 273.13 & 48.95 & 727.56 & 18.79 & 9.17 & 10.01 & 8.00 \\
\hline 3/7/2006 4:00 & 374.94 & 246.67 & 51.98 & 715.55 & 16.04 & 9.05 & 9.97 & 7.98 \\
\hline $3 / 7 / 20065: 00$ & 436.51 & 289.87 & 53.61 & 727.16 & 20.04 & 9.20 & 9.94 & 8.01 \\
\hline $3 / 7 / 20066: 00$ & 402.28 & 267.00 & 50.81 & 725.79 & 15.41 & 8.98 & 10.00 & 8.00 \\
\hline $3 / 7 / 2006$ 7:00 & 445.84 & 294.35 & 48.89 & 734.30 & 18.58 & 9.01 & 9.94 & 8.00 \\
\hline 3/7/2006 8:00 & 484.41 & 318.63 & 41.63 & 533.59 & 21.63 & 9.13 & 9.91 & 7.98 \\
\hline 3/7/2006 9:00 & 511.73 & 329.81 & 61.49 & 779.07 & 21.57 & 9.27 & 9.97 & 8.03 \\
\hline 3/7/2006 10:00 & 517.58 & 340.38 & 57.88 & 758.94 & 25.71 & 9.28 & 9.89 & 7.95 \\
\hline 3/7/2006 11:00 & 560.11 & 364.41 & 62.37 & 769.57 & 28.04 & 9.71 & 9.96 & 8.00 \\
\hline 3/7/2006 12:00 & 601.25 & 394.17 & 73.75 & 733.07 & 34.08 & 9.59 & 9.90 & 7.99 \\
\hline 3/7/2006 13:00 & 592.17 & 378.15 & 78.57 & 643.39 & 33.34 & 10.62 & 9.95 & 7.90 \\
\hline 3/7/2006 14:00 & 618.90 & 392.25 & 71.22 & 662.69 & 29.00 & 10.39 & 9.92 & 7.94 \\
\hline 3/7/2006 15:00 & 593.52 & 376.48 & 63.27 & 660.25 & 27.27 & 10.27 & 9.98 & 8.00 \\
\hline $3 / 7 / 2006$ 16:00 & 548.17 & 347.40 & 60.00 & 645.94 & 22.56 & 9.75 & 9.99 & 8.02 \\
\hline $3 / 7 / 2006$ 17:00 & 515.18 & 322.06 & 52.56 & 598.86 & 21.64 & 9.34 & 9.94 & 8.02 \\
\hline 3/7/2006 18:00 & 557.68 & 355.97 & 58.89 & 617.58 & 24.38 & 9.54 & 9.94 & 8.02 \\
\hline 3/7/2006 19:00 & 599.61 & 378.23 & 63.46 & 626.84 & 25.33 & 9.57 & 9.93 & 7.98 \\
\hline 3/7/2006 20:00 & 484.55 & 299.87 & 57.11 & 586.00 & 20.17 & 9.51 & 10.03 & 8.06 \\
\hline $3 / 7 / 200621: 00$ & 475.53 & 301.09 & 55.82 & 599.23 & 16.72 & 9.35 & 9.93 & 7.98 \\
\hline $3 / 7 / 200622: 00$ & 547.68 & 347.43 & 61.01 & 616.59 & 21.50 & 9.34 & 9.92 & 8.04 \\
\hline 3/7/2006 23:00 & 597.50 & 379.17 & 64.56 & 628.78 & 25.36 & 9.48 & 9.93 & 7.97 \\
\hline \multicolumn{9}{|l|}{ Outage, No Data } \\
\hline 3/14/2006 6:00 & 152.82 & 99.73 & 106.58 & 443.33 & 59.98 & 85.52 & 5.30 & 3.96 \\
\hline $3 / 14 / 2006$ 7:00 & 378.40 & 255.94 & 54.83 & 835.56 & 23.43 & 47.74 & 9.90 & 7.98 \\
\hline $3 / 14 / 20068: 00$ & 412.18 & 274.37 & 38.01 & 587.07 & 14.01 & 16.99 & 9.92 & 8.01 \\
\hline 3/14/2006 9:00 & 582.47 & 387.24 & 65.59 & 865.87 & 33.90 & 13.03 & 9.90 & 7.70 \\
\hline 3/14/2006 10:00 & 617.07 & 400.72 & 67.73 & 866.50 & 29.81 & 11.13 & 9.92 & 8.01 \\
\hline 3/14/2006 11:00 & 618.91 & 400.75 & 77.69 & 822.36 & 28.96 & 10.37 & 9.93 & 7.97 \\
\hline 3/14/2006 12:00 & 604.61 & 389.69 & 59.70 & 829.09 & 27.69 & 10.45 & 9.92 & 7.84 \\
\hline 3/14/2006 13:00 & 630.42 & 409.65 & 60.61 & 784.95 & 32.97 & 10.38 & 9.92 & 7.03 \\
\hline 3/14/2006 14:00 & 490.84 & 317.34 & 51.61 & 761.33 & 20.04 & 10.08 & 9.96 & 7.84 \\
\hline 3/14/2006 15:00 & 497.01 & 321.21 & 49.32 & 737.84 & 18.23 & 10.21 & 9.98 & 7.99 \\
\hline
\end{tabular}

Continued... 
Table F-1. Hourly Average Unit 2 Operation Data During the Monthlong Test (continued)

\begin{tabular}{|c|c|c|c|c|c|c|c|c|}
\hline Date, Time & $\begin{array}{l}\text { Unit } 2 \\
\text { Load, } \\
\text { MW }\end{array}$ & $\begin{array}{c}\text { Unit } 2 \\
\text { Coal Flow, } \\
\text { ton/hour }\end{array}$ & $\begin{array}{c}\text { Unit } 2 \\
\text { Stack } \\
\mathrm{NO}_{\mathrm{x}}, \mathrm{ppm} \\
\end{array}$ & $\begin{array}{c}\text { Unit } 2 \\
\text { Stack } \\
\mathrm{SO}_{2}, \mathrm{ppm} \\
\end{array}$ & $\begin{array}{c}\text { FF } 2-3 / 2-4 \\
\text { Inlet } \\
\text { Opacity, } \% \\
\end{array}$ & $\begin{array}{c}\text { Unit } 2 \\
\text { Stack } \\
\text { Opacity, \% }\end{array}$ & $\begin{array}{c}\text { Calculated } \\
\mathrm{SO}_{3} \text { Injection, } \\
\text { ppm }\end{array}$ & $\begin{array}{c}\text { Calculated } \\
\text { NH3 Injection, } \\
\text { ppm }\end{array}$ \\
\hline $3 / 14 / 2006$ 16:00 & 501.62 & 332.03 & 48.57 & 709.33 & 19.52 & 9.79 & 9.91 & 8.00 \\
\hline $3 / 14 / 2006$ 17:00 & 501.76 & 331.50 & 50.97 & 707.52 & 18.79 & 9.90 & 9.95 & 7.97 \\
\hline 3/14/2006 18:00 & 559.16 & 374.16 & 58.52 & 698.03 & 24.21 & 9.84 & 9.98 & 7.97 \\
\hline 3/14/2006 19:00 & 569.15 & 376.66 & 59.15 & 693.29 & 26.84 & 10.22 & 9.95 & 7.81 \\
\hline 3/14/2006 20:00 & 498.62 & 333.67 & 53.86 & 705.90 & 19.01 & 9.95 & 9.94 & 7.99 \\
\hline 3/14/2006 21:00 & 486.15 & 326.03 & 53.25 & 701.24 & 18.30 & 9.68 & 9.93 & 8.02 \\
\hline 3/14/2006 22:00 & 480.92 & 327.59 & 51.23 & 695.51 & 18.97 & 9.77 & 9.92 & 8.00 \\
\hline 3/14/2006 23:00 & 481.39 & 330.88 & 54.66 & 703.30 & 20.51 & 9.69 & 9.97 & 8.03 \\
\hline 3/15/2006 0:00 & 468.20 & 312.69 & 54.76 & 693.98 & 20.47 & 9.91 & 10.00 & 8.04 \\
\hline $3 / 15 / 20061: 00$ & 407.70 & 274.55 & 45.58 & 652.71 & 15.45 & 9.43 & 9.91 & 8.00 \\
\hline $3 / 15 / 20062: 00$ & 450.15 & 300.01 & 48.93 & 675.10 & 17.55 & 9.57 & 9.94 & 7.96 \\
\hline $3 / 15 / 20063: 00$ & 481.68 & 323.64 & 55.92 & 671.96 & 18.24 & 9.76 & 9.94 & 8.01 \\
\hline $3 / 15 / 20064: 00$ & 490.52 & 333.10 & 54.34 & 678.85 & 19.07 & 9.59 & 9.97 & 7.95 \\
\hline 3/15/2006 5:00 & 533.46 & 356.50 & 58.47 & 685.57 & 24.00 & 9.86 & 10.02 & 7.91 \\
\hline $3 / 15 / 20066: 00$ & 500.25 & 337.85 & 53.64 & 669.31 & 18.48 & 9.60 & 9.96 & 7.98 \\
\hline $3 / 15 / 20067: 00$ & 527.21 & 355.19 & 56.37 & 660.32 & 21.57 & 9.48 & 9.95 & 7.86 \\
\hline $3 / 15 / 20068: 00$ & 587.74 & 397.30 & 46.73 & 499.48 & 28.87 & 9.54 & 9.95 & 7.37 \\
\hline 3/15/2006 9:00 & 456.39 & 302.23 & 57.30 & 671.46 & 17.78 & 9.82 & 10.05 & 8.06 \\
\hline 3/15/2006 10:00 & 481.70 & 327.56 & 53.86 & 658.86 & 21.70 & 9.62 & 9.88 & 7.98 \\
\hline 3/15/2006 11:00 & 609.51 & 407.79 & 65.86 & 693.01 & 30.63 & 10.40 & 9.92 & 7.82 \\
\hline 3/15/2006 12:00 & 529.46 & 351.73 & 56.94 & 683.00 & 20.95 & 10.15 & 9.99 & 7.95 \\
\hline 3/15/2006 13:00 & 471.45 & 312.97 & 54.69 & 667.66 & 19.84 & 9.72 & 9.96 & 8.02 \\
\hline $3 / 15 / 200614: 00$ & 459.22 & 309.05 & 55.20 & 680.82 & 19.16 & 9.89 & 10.00 & 7.96 \\
\hline $3 / 15 / 2006$ 15:00 & 553.01 & 374.61 & 60.21 & 695.61 & 27.49 & 10.05 & 9.97 & 7.93 \\
\hline $3 / 15 / 2006$ 16:00 & 566.57 & 385.96 & 62.26 & 707.63 & 29.22 & 10.19 & 9.96 & 7.90 \\
\hline $3 / 15 / 200617: 00$ & 555.59 & 378.21 & 60.38 & 680.27 & 29.75 & 10.07 & 10.01 & 7.97 \\
\hline 3/15/2006 18:00 & 518.56 & 346.78 & 55.64 & 626.99 & 23.70 & 10.10 & 10.00 & 8.03 \\
\hline 3/15/2006 19:00 & 522.98 & 342.65 & 55.15 & 596.94 & 21.80 & 9.86 & 9.95 & 8.02 \\
\hline 3/15/2006 20:00 & 536.31 & 351.86 & 56.21 & 604.34 & 23.55 & 9.82 & 9.93 & 7.96 \\
\hline $3 / 15 / 200621: 00$ & 540.87 & 354.10 & 56.74 & 607.35 & 23.21 & 10.02 & 9.98 & 7.98 \\
\hline 3/15/2006 22:00 & 494.96 & 322.19 & 52.94 & 599.33 & 19.72 & 10.01 & 9.99 & 8.01 \\
\hline 3/15/2006 23:00 & 520.33 & 347.30 & 55.12 & 626.04 & 22.10 & 9.94 & 9.97 & 7.94 \\
\hline 3/16/2006 0:00 & 576.86 & 380.08 & 62.26 & 645.68 & 28.58 & 10.08 & 9.96 & 7.89 \\
\hline 3/16/2006 1:00 & 520.68 & 348.76 & 55.59 & 633.58 & 21.11 & 9.94 & 9.93 & 7.95 \\
\hline 3/16/2006 2:00 & 549.82 & 369.27 & 61.40 & 662.16 & 23.13 & 9.89 & 9.92 & 7.99 \\
\hline $3 / 16 / 20063: 00$ & 621.35 & 421.26 & 68.96 & 695.76 & 38.78 & 10.21 & 9.88 & 7.46 \\
\hline $3 / 16 / 20064: 00$ & 631.86 & 427.50 & 69.80 & 709.05 & 39.67 & 11.35 & 9.95 & 7.31 \\
\hline $3 / 16 / 20065: 00$ & 630.65 & 423.79 & 69.85 & 689.10 & 37.59 & 11.25 & 9.92 & 7.43 \\
\hline $3 / 16 / 20066: 00$ & 627.34 & 418.26 & 68.97 & 674.43 & 41.89 & 11.18 & 9.91 & 7.40 \\
\hline $3 / 16 / 20067: 00$ & 613.17 & 414.31 & 68.53 & 676.92 & 34.96 & 10.83 & 9.92 & 7.65 \\
\hline $3 / 16 / 20068: 00$ & 572.09 & 384.16 & 46.95 & 485.62 & 31.03 & 10.69 & 9.99 & 7.81 \\
\hline 3/16/2006 9:00 & 543.78 & 370.62 & 61.14 & 666.44 & 25.00 & 9.68 & 9.92 & 7.94 \\
\hline 3/16/2006 10:00 & 500.87 & 339.90 & 56.17 & 648.13 & 20.52 & 9.34 & 9.94 & 7.97 \\
\hline 3/16/2006 11:00 & 545.04 & 370.14 & 62.70 & 654.70 & 25.13 & 9.44 & 9.96 & 7.97 \\
\hline 3/16/2006 12:00 & 587.84 & 394.84 & 65.41 & 655.12 & 32.87 & 9.73 & 9.94 & 7.78 \\
\hline 3/16/2006 13:00 & 614.37 & 408.56 & 66.85 & 646.62 & 33.74 & 11.43 & 9.92 & 7.68 \\
\hline $3 / 16 / 200614: 00$ & 615.13 & 410.87 & 66.89 & 666.79 & 31.50 & 10.77 & 9.94 & 7.86 \\
\hline $3 / 16 / 2006$ 15:00 & 550.35 & 366.68 & 63.02 & 667.63 & 22.91 & 10.40 & 9.98 & 8.01 \\
\hline $3 / 16 / 2006$ 16:00 & 588.26 & 397.78 & 64.63 & 657.82 & 28.57 & 9.82 & 9.92 & 7.95 \\
\hline $3 / 16 / 2006$ 17:00 & 592.82 & 393.17 & 65.89 & 642.00 & 30.92 & 9.94 & 10.03 & 8.04 \\
\hline 3/16/2006 18:00 & 518.02 & 342.37 & 57.12 & 627.84 & 22.62 & 9.54 & 9.96 & 8.01 \\
\hline $3 / 16 / 2006$ 19:00 & 521.82 & 350.93 & 56.34 & 614.76 & 23.27 & 9.59 & 9.94 & 8.00 \\
\hline 3/16/2006 20:00 & 480.58 & 318.78 & 51.98 & 612.47 & 18.05 & 9.57 & 9.95 & 7.99 \\
\hline 3/16/2006 21:00 & 487.85 & 329.06 & 52.85 & 615.59 & 21.20 & 9.56 & 9.96 & 8.00 \\
\hline
\end{tabular}

Continued... 
Table F-1. Hourly Average Unit 2 Operation Data During the Monthlong Test (continued)

\begin{tabular}{|c|c|c|c|c|c|c|c|c|}
\hline Date, Time & $\begin{array}{l}\text { Unit } 2 \\
\text { Load, } \\
\text { MW }\end{array}$ & $\begin{array}{l}\text { Unit } 2 \\
\text { Coal Flow, } \\
\text { ton/hour }\end{array}$ & $\begin{array}{c}\text { Unit 2 } \\
\text { Stack } \\
\text { NOx, ppm }\end{array}$ & $\begin{array}{c}\text { Unit } 2 \\
\text { Stack } \\
\text { SO2, ppm }\end{array}$ & $\begin{array}{l}\text { FF 2-3/2-4 } \\
\text { Inlet } \\
\text { Opacity, \% }\end{array}$ & $\begin{array}{c}\text { Unit } 2 \\
\text { Stack } \\
\text { Opacity, \% }\end{array}$ & $\begin{array}{c}\text { Calculated } \\
\text { SO3 Injection, } \\
\text { ppm }\end{array}$ & $\begin{array}{c}\text { Calculated } \\
\text { NH3 Injection, } \\
\text { ppm }\end{array}$ \\
\hline 3/16/2006 22:00 & 478.68 & 322.83 & 51.48 & 613.36 & 17.65 & 9.76 & 9.94 & 7.99 \\
\hline 3/16/2006 23:00 & 491.82 & 328.72 & 53.19 & 618.17 & 19.57 & 9.73 & 9.93 & 7.99 \\
\hline 3/17/2006 0:00 & 598.19 & 392.39 & 63.72 & 651.25 & 32.58 & 9.97 & 9.92 & 7.85 \\
\hline 3/17/2006 1:00 & 527.65 & 349.53 & 56.56 & 636.68 & 21.72 & 9.84 & 9.98 & 8.02 \\
\hline $3 / 17 / 20062: 00$ & 530.56 & 348.51 & 60.27 & 645.18 & 22.56 & 9.82 & 9.97 & 8.02 \\
\hline 3/17/2006 3:00 & 496.16 & 330.86 & 55.12 & 625.66 & 19.26 & 9.67 & 9.93 & 7.97 \\
\hline 3/17/2006 4:00 & 592.19 & 389.39 & 63.86 & 644.65 & 30.04 & 9.81 & 9.92 & 7.59 \\
\hline 3/17/2006 5:00 & 543.95 & 355.38 & 57.55 & 629.14 & 21.62 & 9.71 & 9.98 & 7.99 \\
\hline $3 / 17 / 20066: 00$ & 601.79 & 395.34 & 65.00 & 619.14 & 34.21 & 9.98 & 9.93 & 7.42 \\
\hline 3/17/2006 7:00 & 534.92 & 352.16 & 55.99 & 610.06 & 21.35 & 9.70 & 9.97 & 8.01 \\
\hline 3/17/2006 8:00 & 539.89 & 358.78 & 43.12 & 446.42 & 22.96 & 9.64 & 9.93 & 7.95 \\
\hline 3/17/2006 9:00 & 565.57 & 374.48 & 50.81 & 458.18 & 25.64 & 9.75 & 9.92 & 7.74 \\
\hline 3/17/2006 10:00 & 612.37 & 404.91 & 59.51 & 504.61 & 32.32 & 10.11 & 9.93 & 7.33 \\
\hline 3/17/2006 11:00 & 542.94 & 362.03 & 60.47 & 632.48 & 22.14 & 9.81 & 9.95 & 7.97 \\
\hline 3/17/2006 12:00 & 628.92 & 414.23 & 69.74 & 626.42 & 35.34 & 10.34 & 9.92 & 7.59 \\
\hline 3/17/2006 13:00 & 633.22 & 418.80 & 69.42 & 625.42 & 34.68 & 10.74 & 9.92 & 7.94 \\
\hline $3 / 17 / 200614: 00$ & 631.77 & 416.25 & 68.46 & 633.17 & 35.22 & 10.70 & 9.91 & 7.80 \\
\hline 3/17/2006 15:00 & 605.02 & 394.42 & 64.69 & 634.21 & 35.65 & 10.84 & 9.97 & 7.87 \\
\hline 3/17/2006 16:00 & 534.75 & 356.12 & 56.61 & 635.56 & 22.42 & 9.99 & 9.93 & 7.99 \\
\hline 3/17/2006 17:00 & 536.03 & 357.37 & 58.20 & 639.97 & 23.13 & 9.80 & 9.94 & 7.98 \\
\hline 3/17/2006 18:00 & 549.62 & 368.07 & 60.31 & 657.02 & 29.15 & 9.68 & 9.92 & 8.03 \\
\hline 3/17/2006 19:00 & 583.91 & 391.17 & 64.63 & 673.37 & 30.87 & 9.83 & 9.92 & 7.80 \\
\hline 3/17/2006 20:00 & 590.25 & 395.22 & 68.03 & 687.58 & 30.13 & 9.83 & 9.94 & 7.69 \\
\hline 3/17/2006 21:00 & 558.43 & 377.85 & 62.63 & 682.47 & 30.18 & 9.68 & 9.96 & 7.95 \\
\hline 3/17/2006 22:00 & 576.55 & 389.71 & 65.00 & 696.49 & 32.82 & 9.90 & 10.01 & 7.91 \\
\hline 3/17/2006 23:00 & 575.68 & 390.64 & 64.72 & 716.53 & 34.95 & 9.92 & 9.96 & 7.93 \\
\hline 3/18/2006 0:00 & 573.95 & 389.70 & 64.39 & 719.32 & 33.27 & 9.94 & 9.96 & 7.86 \\
\hline 3/18/2006 1:00 & 541.51 & 362.76 & 57.99 & 707.64 & 32.96 & 9.96 & 10.03 & 8.00 \\
\hline $3 / 18 / 20062: 00$ & 524.12 & 353.73 & 59.94 & 698.95 & 28.24 & 9.75 & 9.97 & 8.00 \\
\hline 3/18/2006 3:00 & 517.74 & 344.86 & 59.82 & 681.94 & 23.71 & 9.78 & 9.97 & 8.03 \\
\hline 3/18/2006 4:00 & 525.62 & 351.05 & 61.00 & 671.71 & 23.69 & 9.77 & 9.94 & 7.93 \\
\hline 3/18/2006 5:00 & 576.39 & 384.16 & 63.57 & 681.92 & 31.38 & 10.01 & 9.97 & 7.75 \\
\hline $3 / 18 / 20066: 00$ & 601.55 & 399.31 & 66.27 & 698.13 & 35.10 & 10.42 & 9.94 & 7.49 \\
\hline 3/18/2006 7:00 & 573.58 & 385.41 & 61.58 & 694.63 & 33.23 & 10.29 & 9.94 & 7.70 \\
\hline 3/18/2006 8:00 & 564.35 & 375.52 & 46.15 & 487.53 & 26.74 & 10.10 & 9.97 & 7.88 \\
\hline 3/18/2006 9:00 & 546.40 & 364.44 & 59.41 & 695.06 & 26.79 & 9.95 & 9.92 & 7.94 \\
\hline 3/18/2006 10:00 & 566.61 & 384.44 & 63.49 & 685.14 & 33.47 & 9.80 & 9.93 & 7.70 \\
\hline 3/18/2006 11:00 & 565.26 & 376.70 & 61.96 & 699.82 & 27.38 & 12.66 & 9.98 & 7.78 \\
\hline 3/18/2006 12:00 & 563.11 & 368.59 & 60.24 & 693.29 & 28.81 & 10.36 & 9.97 & 7.90 \\
\hline 3/18/2006 13:00 & 540.39 & 352.16 & 57.86 & 670.80 & 28.13 & 9.86 & 10.00 & 7.96 \\
\hline $3 / 18 / 2006$ 14:00 & 504.52 & 332.33 & 54.32 & 691.85 & 22.68 & 9.63 & 9.92 & 8.01 \\
\hline 3/18/2006 15:00 & 576.58 & 382.68 & 62.32 & 704.61 & 33.97 & 9.73 & 9.91 & 7.88 \\
\hline 3/18/2006 16:00 & 589.95 & 391.19 & 63.41 & 715.79 & 30.79 & 10.09 & 9.93 & 7.95 \\
\hline 3/18/2006 17:00 & 535.30 & 357.53 & 56.24 & 717.78 & 25.11 & 9.85 & 9.93 & 8.00 \\
\hline 3/18/2006 18:00 & 509.19 & 338.89 & 56.19 & 723.08 & 24.19 & 9.93 & 9.95 & 7.97 \\
\hline 3/18/2006 19:00 & 554.29 & 366.45 & 60.77 & 726.79 & 28.71 & 9.92 & 9.96 & 7.84 \\
\hline 3/18/2006 20:00 & 552.01 & 356.64 & 61.21 & 755.92 & 31.95 & 9.99 & 9.94 & 7.80 \\
\hline 3/18/2006 21:00 & 558.81 & 369.54 & 63.48 & 759.45 & 28.50 & 9.83 & 9.91 & 7.66 \\
\hline 3/18/2006 22:00 & 545.77 & 359.30 & 64.71 & 778.48 & 26.42 & 9.78 & 9.97 & 7.95 \\
\hline 3/18/2006 23:00 & 543.53 & 351.95 & 61.91 & 779.07 & 26.56 & 9.92 & 9.98 & 7.90 \\
\hline 3/19/2006 0:00 & 568.60 & 364.74 & 63.72 & 768.10 & 27.41 & 9.90 & 9.94 & 7.70 \\
\hline 3/19/2006 1:00 & 487.45 & 312.17 & 53.44 & 750.91 & 19.17 & 9.84 & 9.93 & 7.98 \\
\hline 3/19/2006 2:00 & 487.49 & 314.79 & 53.93 & 751.72 & 19.35 & 9.78 & 9.92 & 8.01 \\
\hline $3 / 19 / 20063: 00$ & 529.14 & 335.84 & 57.97 & 749.84 & 25.05 & 9.80 & 9.93 & 7.91 \\
\hline
\end{tabular}

Continued... 
Table F-1. Hourly Average Unit 2 Operation Data During the Monthlong Test (continued)

\begin{tabular}{|c|c|c|c|c|c|c|c|c|}
\hline Date, Time & $\begin{array}{l}\text { Unit } 2 \\
\text { Load, } \\
\text { MW }\end{array}$ & $\begin{array}{c}\text { Unit } 2 \\
\text { Coal Flow, } \\
\text { ton/hour }\end{array}$ & $\begin{array}{c}\text { Unit } 2 \\
\text { Stack } \\
\mathrm{NO}_{\mathrm{x}}, \mathrm{ppm}\end{array}$ & $\begin{array}{c}\text { Unit } 2 \\
\text { Stack } \\
\mathrm{SO}_{2}, \mathrm{ppm} \\
\end{array}$ & $\begin{array}{c}\text { FF } 2-3 / 2-4 \\
\text { Inlet } \\
\text { Opacity, } \% \\
\end{array}$ & $\begin{array}{c}\text { Unit 2 } \\
\text { Stack } \\
\text { Opacity, \% }\end{array}$ & $\begin{array}{c}\text { Calculated } \\
\mathrm{SO}_{3} \text { Injection, } \\
\text { ppm }\end{array}$ & $\begin{array}{c}\text { Calculated } \\
\text { NH3 Injection, } \\
\text { ppm }\end{array}$ \\
\hline 3/19/2006 4:00 & 533.29 & 339.78 & 58.27 & 779.53 & 23.38 & 10.09 & 9.99 & 7.87 \\
\hline $3 / 19 / 20065: 00$ & 578.13 & 375.05 & 64.04 & 806.91 & 28.92 & 9.96 & 9.91 & 7.79 \\
\hline 3/19/2006 6:00 & 554.07 & 354.94 & 60.73 & 831.66 & 26.25 & 10.16 & 9.98 & 7.96 \\
\hline 3/19/2006 7:00 & 568.46 & 370.51 & 61.98 & 805.20 & 28.97 & 10.31 & 9.96 & 7.67 \\
\hline 3/19/2006 8:00 & 566.84 & 371.55 & 47.09 & 553.26 & 27.83 & 10.25 & 9.94 & 7.77 \\
\hline 3/19/2006 9:00 & 546.19 & 357.82 & 58.80 & 799.83 & 28.89 & 10.14 & 9.94 & 7.91 \\
\hline 3/19/2006 10:00 & 602.70 & 390.22 & 69.02 & 790.40 & 43.40 & 10.93 & 9.92 & 7.14 \\
\hline 3/19/2006 11:00 & 541.94 & 353.56 & 57.33 & 782.55 & 30.34 & 10.77 & 9.95 & 7.93 \\
\hline 3/19/2006 12:00 & 601.77 & 392.13 & 68.08 & 796.59 & 36.30 & 9.75 & 9.93 & 7.30 \\
\hline 3/19/2006 13:00 & 577.07 & 376.06 & 63.75 & 797.13 & 30.59 & 10.05 & 9.92 & 7.52 \\
\hline 3/19/2006 14:00 & 541.74 & 359.31 & 58.81 & 814.87 & 26.70 & 9.88 & 9.94 & 7.99 \\
\hline 3/19/2006 15:00 & 601.99 & 401.73 & 68.11 & 805.03 & 33.01 & 10.12 & 9.92 & 7.15 \\
\hline $3 / 19 / 2006$ 16:00 & 554.14 & 361.09 & 62.60 & 786.64 & 28.14 & 10.31 & 9.96 & 7.81 \\
\hline 3/19/2006 17:00 & 538.32 & 353.83 & 59.92 & 757.10 & 26.88 & 9.80 & 9.93 & 7.99 \\
\hline 3/19/2006 18:00 & 577.14 & 380.44 & 64.42 & 741.84 & 32.34 & 9.54 & 9.93 & 7.56 \\
\hline 3/19/2006 19:00 & 612.26 & 396.06 & 66.82 & 706.43 & 33.35 & 9.68 & 9.97 & 7.11 \\
\hline 3/19/2006 20:00 & 557.37 & 357.68 & 61.59 & 697.20 & 26.58 & 9.72 & 9.96 & 7.85 \\
\hline 3/19/2006 21:00 & 551.99 & 354.47 & 59.19 & 653.65 & 23.71 & 9.57 & 9.93 & 7.93 \\
\hline 3/19/2006 22:00 & 577.18 & 364.35 & 62.31 & 633.45 & 26.97 & 9.90 & 9.95 & 7.72 \\
\hline 3/19/2006 23:00 & 569.24 & 363.25 & 63.02 & 628.73 & 27.50 & 9.81 & 9.95 & 7.65 \\
\hline 3/20/2006 0:00 & 546.99 & 350.55 & 65.47 & 634.28 & 25.69 & 9.76 & 10.00 & 7.83 \\
\hline 3/20/2006 1:00 & 476.88 & 303.62 & 57.11 & 620.98 & 22.91 & 9.78 & 9.93 & 8.01 \\
\hline $3 / 20 / 20062: 00$ & 518.08 & 333.83 & 59.56 & 633.92 & 23.58 & 9.86 & 9.93 & 7.98 \\
\hline 3/20/2006 3:00 & 529.52 & 336.72 & 59.40 & 630.85 & 25.70 & 9.86 & 9.97 & 7.90 \\
\hline $3 / 20 / 20064: 00$ & 563.68 & 364.76 & 61.19 & 633.55 & 28.75 & 9.47 & 9.91 & 7.84 \\
\hline $3 / 20 / 20065: 00$ & 521.81 & 340.49 & 59.15 & 636.20 & 26.35 & 9.67 & 9.94 & 7.87 \\
\hline $3 / 20 / 20066: 00$ & 588.12 & 388.93 & 65.84 & 645.71 & 30.22 & 9.77 & 9.96 & 7.51 \\
\hline $3 / 20 / 20067: 00$ & 542.18 & 358.96 & 61.49 & 632.40 & 24.12 & 9.69 & 9.93 & 8.03 \\
\hline $3 / 20 / 20068: 00$ & 486.24 & 318.27 & 43.16 & 458.95 & 22.34 & 8.04 & 9.98 & 8.00 \\
\hline 3/20/2006 9:00 & 436.62 & 286.29 & 53.41 & 630.52 & 18.96 & 9.54 & 9.95 & 8.00 \\
\hline 3/20/2006 10:00 & 476.69 & 320.23 & 57.38 & 629.82 & 19.83 & 9.65 & 9.92 & 7.96 \\
\hline 3/20/2006 11:00 & 544.51 & 366.72 & 62.75 & 649.24 & 24.97 & 9.93 & 9.94 & 7.99 \\
\hline 3/20/2006 12:00 & 561.80 & 373.72 & 64.50 & 648.62 & 28.83 & 10.04 & 9.93 & 7.98 \\
\hline 3/20/2006 13:00 & 527.48 & 351.00 & 58.18 & 651.71 & 22.65 & 9.92 & 9.95 & 8.00 \\
\hline 3/20/2006 14:00 & 541.62 & 357.39 & 59.87 & 670.04 & 25.95 & 10.10 & 9.94 & 7.99 \\
\hline 3/20/2006 15:00 & 547.02 & 362.63 & 58.77 & 681.18 & 25.69 & 9.91 & 9.95 & 7.99 \\
\hline $3 / 20 / 2006$ 16:00 & 583.77 & 382.48 & 63.73 & 705.53 & 29.26 & 10.48 & 9.96 & 7.99 \\
\hline $3 / 20 / 2006$ 17:00 & 510.34 & 331.75 & 53.98 & 715.52 & 19.68 & 9.70 & 9.93 & 8.02 \\
\hline 3/20/2006 18:00 & 548.90 & 359.25 & 60.25 & 721.54 & 25.65 & 9.77 & 9.95 & 7.96 \\
\hline 3/20/2006 19:00 & 616.87 & 398.83 & 67.02 & 709.79 & 33.15 & 10.06 & 9.92 & 7.79 \\
\hline 3/20/2006 20:00 & 600.73 & 392.42 & 69.12 & 749.64 & 32.44 & 10.01 & 9.94 & 7.97 \\
\hline 3/20/2006 21:00 & 579.03 & 378.94 & 66.62 & 789.89 & 32.33 & 9.86 & 10.00 & 8.00 \\
\hline 3/20/2006 22:00 & 576.38 & 384.49 & 65.74 & 817.01 & 31.40 & 9.88 & 9.98 & 7.99 \\
\hline 3/20/2006 23:00 & 541.74 & 361.47 & 60.14 & 825.88 & 27.63 & 9.89 & 9.94 & 8.01 \\
\hline 3/21/2006 0:00 & 563.91 & 379.80 & 63.20 & 822.63 & 30.13 & 9.78 & 9.95 & 7.98 \\
\hline 3/21/2006 1:00 & 515.47 & 348.52 & 59.26 & 823.67 & 27.02 & 9.98 & 9.98 & 8.00 \\
\hline $3 / 21 / 20062: 00$ & 524.07 & 356.35 & 62.58 & 826.47 & 28.35 & 9.73 & 9.93 & 7.93 \\
\hline $3 / 21 / 20063: 00$ & 593.43 & 396.98 & 68.74 & 835.35 & 40.94 & 10.03 & 9.93 & 7.67 \\
\hline 3/21/2006 4:00 & 595.81 & 391.75 & 68.31 & 819.04 & 38.70 & 9.90 & 9.92 & 7.53 \\
\hline $3 / 21 / 20065: 00$ & 554.10 & 363.94 & 60.21 & 777.44 & 29.58 & 9.69 & 9.95 & 7.83 \\
\hline $3 / 21 / 20066: 00$ & 602.43 & 392.85 & 67.93 & 730.82 & 33.52 & 9.88 & 9.93 & 7.28 \\
\hline $3 / 21 / 20067: 00$ & 562.24 & 365.89 & 59.07 & 706.98 & 28.43 & 9.66 & 10.01 & 7.79 \\
\hline 3/21/2006 8:00 & 509.67 & 329.81 & 40.18 & 506.50 & 22.78 & 9.78 & 9.93 & 7.97 \\
\hline
\end{tabular}


Table F-1. Hourly Average Unit 2 Operation Data During the Monthlong Test (continued)

\begin{tabular}{|c|c|c|c|c|c|c|c|c|}
\hline Date, Time & $\begin{array}{l}\text { Unit } 2 \\
\text { Load, } \\
\text { MW }\end{array}$ & $\begin{array}{c}\text { Unit } 2 \\
\text { Coal Flow, } \\
\text { ton/hour }\end{array}$ & $\begin{array}{c}\text { Unit } 2 \\
\text { Stack } \\
\mathrm{NO}_{\mathrm{x}}, \mathrm{ppm} \\
\end{array}$ & $\begin{array}{c}\text { Unit } 2 \\
\text { Stack } \\
\mathrm{SO}_{2}, \mathrm{ppm} \\
\end{array}$ & $\begin{array}{c}\text { FF } 2-3 / 2-4 \\
\text { Inlet } \\
\text { Opacity, } \% \\
\end{array}$ & $\begin{array}{c}\text { Unit } 2 \\
\text { Stack } \\
\text { Opacity, \% }\end{array}$ & $\begin{array}{c}\text { Calculated } \\
\mathrm{SO}_{3} \text { Injection, } \\
\text { ppm }\end{array}$ & $\begin{array}{c}\text { Calculated } \\
\text { NH3 Injection, } \\
\text { ppm }\end{array}$ \\
\hline 3/21/2006 9:00 & 528.31 & 340.30 & 55.50 & 733.47 & 22.16 & 10.24 & 9.95 & 7.95 \\
\hline $3 / 21 / 2006$ 10:00 & 468.14 & 303.49 & 55.15 & 730.60 & 22.06 & 10.00 & 9.95 & 7.99 \\
\hline 3/21/2006 11:00 & 613.60 & 402.31 & 72.47 & 769.00 & 35.38 & 10.69 & 9.91 & 7.12 \\
\hline 3/21/2006 12:00 & 529.15 & 343.19 & 58.42 & 806.90 & 22.24 & 10.84 & 10.00 & 7.94 \\
\hline $3 / 21 / 2006$ 13:00 & 455.00 & 295.80 & 54.24 & 786.34 & 23.49 & 10.57 & 9.97 & 7.98 \\
\hline $3 / 21 / 200614: 00$ & 500.95 & 323.47 & 56.37 & 809.16 & 25.29 & 10.63 & 10.00 & 8.02 \\
\hline $3 / 21 / 2006$ 15:00 & 539.15 & 351.02 & 58.71 & 811.13 & 32.00 & 10.89 & 9.96 & 7.80 \\
\hline $3 / 21 / 200616: 00$ & 615.18 & 395.54 & 70.55 & 816.45 & 43.07 & 10.90 & 9.96 & 7.17 \\
\hline $3 / 21 / 2006$ 17:00 & 489.86 & 311.93 & 53.08 & 801.32 & 26.31 & 10.51 & 9.99 & 8.09 \\
\hline 3/21/2006 18:00 & 489.64 & 312.87 & 51.25 & 762.97 & 26.70 & 10.51 & 9.98 & 8.00 \\
\hline $3 / 21 / 2006$ 19:00 & 476.86 & 311.00 & 49.87 & 753.79 & 21.89 & 10.30 & 9.93 & 8.00 \\
\hline $3 / 21 / 200620: 00$ & 610.96 & 402.81 & 66.87 & 778.28 & 39.32 & 10.70 & 9.92 & 7.51 \\
\hline $3 / 21 / 200621: 00$ & 608.79 & 400.36 & 65.10 & 791.95 & 43.24 & 10.54 & 9.95 & 7.32 \\
\hline 3/21/2006 22:00 & 607.76 & 398.19 & 65.74 & 779.83 & 40.00 & 11.21 & 9.96 & 7.26 \\
\hline $3 / 21 / 200623: 00$ & 553.73 & 356.48 & 61.85 & 734.46 & 39.52 & 11.59 & 10.01 & 7.54 \\
\hline 3/22/2006 0:00 & 538.32 & 352.30 & 60.33 & 670.95 & 34.55 & 10.22 & 9.89 & 7.52 \\
\hline $3 / 22 / 20061: 00$ & 632.76 & 415.80 & 68.14 & 678.34 & 43.78 & 10.89 & 9.95 & 6.76 \\
\hline $3 / 22 / 20062: 00$ & 577.98 & 382.70 & 60.52 & 710.28 & 35.39 & 11.27 & 9.95 & 7.48 \\
\hline 3/22/2006 3:00 & 577.39 & 391.08 & 61.09 & 724.70 & 38.24 & 10.25 & 9.94 & 7.44 \\
\hline $3 / 22 / 20064: 00$ & 638.72 & 431.15 & 72.37 & 756.26 & 49.45 & 12.19 & 9.91 & 6.57 \\
\hline $3 / 22 / 20065: 00$ & 585.98 & 395.02 & 65.41 & 765.59 & 42.69 & 12.23 & 9.95 & 7.28 \\
\hline $3 / 22 / 20066: 00$ & 586.77 & 390.70 & 65.66 & 736.76 & 43.88 & 11.95 & 9.98 & 7.26 \\
\hline $3 / 22 / 2006$ 7:00 & 571.57 & 383.64 & 61.92 & 707.48 & 41.80 & 11.25 & 9.92 & 7.43 \\
\hline 3/22/2006 8:00 & 586.48 & 387.63 & 46.37 & 501.13 & 41.61 & 10.97 & 9.98 & 7.13 \\
\hline 3/22/2006 9:00 & 542.73 & 359.46 & 57.96 & 690.73 & 32.38 & 10.42 & 9.94 & 7.60 \\
\hline $3 / 22 / 2006$ 10:00 & 507.51 & 335.48 & 52.00 & 674.61 & 27.19 & 10.02 & 9.95 & 7.99 \\
\hline 3/22/2006 11:00 & 536.98 & 354.37 & 57.35 & 667.75 & 32.53 & 10.00 & 9.91 & 7.69 \\
\hline 3/22/2006 12:00 & 504.86 & 328.33 & 57.20 & 675.31 & 29.99 & 9.86 & 9.99 & 7.89 \\
\hline 3/22/2006 13:00 & 554.90 & 366.73 & 61.82 & 684.89 & 30.35 & 9.78 & 9.91 & 7.81 \\
\hline $3 / 22 / 200614: 00$ & 584.96 & 377.18 & 64.58 & 692.36 & 35.14 & 10.13 & 9.96 & 7.50 \\
\hline $3 / 22 / 2006$ 15:00 & 580.93 & 379.06 & 63.02 & 688.19 & 31.68 & 9.98 & 9.95 & 7.56 \\
\hline $3 / 22 / 200616: 00$ & 629.68 & 408.22 & 71.43 & 695.73 & 40.22 & 10.26 & 9.91 & 6.92 \\
\hline $3 / 22 / 2006$ 17:00 & 590.03 & 383.08 & 63.82 & 705.24 & 34.01 & 10.28 & 9.94 & 7.50 \\
\hline 3/22/2006 18:00 & 473.71 & 309.15 & 53.14 & 688.49 & 24.94 & 9.90 & 9.99 & 7.99 \\
\hline $3 / 22 / 2006$ 19:00 & 556.95 & 372.97 & 61.40 & 692.86 & 32.88 & 9.89 & 9.93 & 7.57 \\
\hline 3/22/2006 20:00 & 636.72 & 417.16 & 72.50 & 722.44 & 39.45 & 10.30 & 9.92 & 6.87 \\
\hline 3/22/2006 21:00 & 636.13 & 414.17 & 71.78 & 751.70 & 37.93 & 10.87 & 9.92 & 6.93 \\
\hline 3/22/2006 22:00 & 636.18 & 415.46 & 72.03 & 783.37 & 39.75 & 10.35 & 9.92 & 6.92 \\
\hline $3 / 22 / 200623: 00$ & 629.74 & 414.34 & 73.24 & 812.14 & 40.62 & 10.36 & 9.91 & 6.97 \\
\hline 3/23/2006 0:00 & 613.77 & 410.65 & 71.65 & 851.93 & 37.34 & 10.07 & 9.92 & 7.20 \\
\hline $3 / 23 / 20061: 00$ & 626.84 & 427.22 & 74.13 & 865.69 & 42.73 & 9.97 & 9.93 & 7.03 \\
\hline $3 / 23 / 20062: 00$ & 625.68 & 431.79 & 75.38 & 874.64 & 41.23 & 10.03 & 9.92 & 6.95 \\
\hline $3 / 23 / 20063: 00$ & 627.51 & 435.87 & 76.20 & 848.43 & 44.25 & 9.94 & 9.92 & 6.96 \\
\hline $3 / 23 / 20064: 00$ & 573.77 & 394.30 & 67.76 & 816.81 & 40.98 & 9.92 & 9.93 & 7.62 \\
\hline $3 / 23 / 20065: 00$ & 598.55 & 410.09 & 70.55 & 758.65 & 38.63 & 9.59 & 9.95 & 7.17 \\
\hline $3 / 23 / 20066: 00$ & 611.40 & 410.21 & 72.51 & 753.28 & 45.00 & 9.44 & 9.94 & 6.99 \\
\hline $3 / 23 / 20067: 00$ & 621.91 & 408.30 & 70.28 & 743.07 & 41.21 & 9.49 & 9.92 & 6.85 \\
\hline $3 / 23 / 20068: 00$ & 632.81 & 405.13 & 52.05 & 515.80 & 40.29 & 10.26 & 9.93 & 6.71 \\
\hline 3/23/2006 9:00 & 625.98 & 398.00 & 68.81 & 739.93 & 36.15 & 10.58 & 9.91 & 6.93 \\
\hline 3/23/2006 10:00 & 553.99 & 358.87 & 58.48 & 746.04 & 29.82 & 10.48 & 9.95 & 7.78 \\
\hline 3/23/2006 11:00 & 572.37 & 369.39 & 63.38 & 743.82 & 25.53 & 9.99 & 9.98 & 7.46 \\
\hline $3 / 23 / 200612: 00$ & 563.59 & 367.69 & 61.04 & 717.97 & 26.18 & 9.76 & 9.94 & 7.68 \\
\hline 3/23/2006 13:00 & 446.36 & 294.34 & 53.34 & 648.64 & 24.09 & 9.70 & 9.98 & 8.05 \\
\hline $3 / 23 / 200614: 00$ & 429.03 & 281.69 & 47.48 & 592.34 & 19.02 & 9.52 & 9.97 & 8.01 \\
\hline
\end{tabular}

Continued... 
Table F-1. Hourly Average Unit 2 Operation Data During the Monthlong Test (continued)

\begin{tabular}{|c|c|c|c|c|c|c|c|c|}
\hline Date, Time & $\begin{array}{l}\text { Unit } 2 \\
\text { Load, } \\
\text { MW }\end{array}$ & $\begin{array}{l}\text { Unit } 2 \\
\text { Coal Flow, } \\
\text { ton/hour }\end{array}$ & $\begin{array}{c}\text { Unit } 2 \\
\text { Stack } \\
\mathrm{NO}_{\mathrm{x}}, \mathrm{ppm} \\
\end{array}$ & $\begin{array}{c}\text { Unit } 2 \\
\text { Stack } \\
\mathrm{SO}_{2}, \mathrm{ppm} \\
\end{array}$ & $\begin{array}{c}\text { FF } 2-3 / 2-4 \\
\text { Inlet } \\
\text { Opacity, \% } \\
\end{array}$ & $\begin{array}{c}\text { Unit } 2 \\
\text { Stack } \\
\text { Opacity, \% } \\
\end{array}$ & $\begin{array}{c}\text { Calculated } \\
\mathrm{SO}_{3} \text { Injection, } \\
\text { ppm }\end{array}$ & $\begin{array}{c}\text { Calculated } \\
\text { NH3 Injection, } \\
\text { ppm }\end{array}$ \\
\hline 3/23/2006 15:00 & 467.20 & 310.09 & 61.53 & 584.64 & 19.61 & 9.53 & 9.96 & 7.99 \\
\hline 3/23/2006 16:00 & 454.55 & 305.34 & 57.72 & 600.47 & 22.48 & 9.56 & 9.91 & 7.99 \\
\hline 3/23/2006 17:00 & 460.38 & 308.72 & 55.52 & 640.12 & 23.53 & 9.47 & 10.00 & 7.99 \\
\hline 3/23/2006 18:00 & 470.31 & 320.09 & 56.51 & 684.46 & 23.67 & 9.59 & 9.95 & 8.00 \\
\hline 3/23/2006 19:00 & 524.50 & 358.21 & 59.41 & 724.78 & 30.50 & 9.78 & 9.92 & 7.94 \\
\hline 3/23/2006 20:00 & 634.88 & 433.71 & 79.09 & 782.43 & 39.69 & 10.50 & 9.92 & 6.96 \\
\hline 3/23/2006 21:00 & 636.61 & 435.71 & 77.42 & 788.58 & 40.39 & 11.11 & 9.91 & 7.00 \\
\hline $3 / 23 / 200622: 00$ & 636.04 & 436.27 & 76.53 & 776.37 & 44.39 & 11.24 & 9.92 & 6.96 \\
\hline 3/23/2006 23:00 & 637.57 & 438.53 & 76.72 & 745.32 & 43.50 & 11.23 & 9.92 & 6.96 \\
\hline 3/24/2006 0:00 & 618.72 & 422.59 & 74.38 & 696.28 & 41.22 & 11.19 & 9.95 & 7.24 \\
\hline $3 / 24 / 2006$ 1:00 & 509.69 & 349.93 & 54.18 & 649.10 & 30.06 & 9.96 & 9.95 & 7.97 \\
\hline $3 / 24 / 20062: 00$ & 458.77 & 304.81 & 51.07 & 606.06 & 23.55 & 9.59 & 9.94 & 8.04 \\
\hline $3 / 24 / 20063: 00$ & 479.99 & 325.79 & 53.06 & 608.92 & 25.99 & 9.43 & 9.91 & 7.71 \\
\hline $3 / 24 / 20064: 00$ & 630.62 & 419.05 & 73.10 & 646.26 & 43.15 & 9.96 & 9.92 & 6.49 \\
\hline $3 / 24 / 20065: 00$ & 612.75 & 404.40 & 69.53 & 650.77 & 38.52 & 10.58 & 9.92 & 6.78 \\
\hline $3 / 24 / 20066: 00$ & 634.33 & 416.25 & 72.47 & 704.97 & 41.26 & 11.93 & 9.92 & 6.53 \\
\hline $3 / 24 / 2006$ 7:00 & 636.78 & 420.46 & 73.63 & 756.48 & 36.56 & 11.78 & 9.91 & 6.58 \\
\hline 3/24/2006 8:00 & 637.12 & 421.31 & 53.98 & 567.14 & 37.86 & 12.07 & 9.92 & 6.60 \\
\hline 3/24/2006 9:00 & 581.34 & 385.14 & 66.27 & 832.52 & 33.20 & 11.53 & 10.02 & 7.34 \\
\hline 3/24/2006 10:00 & 595.39 & 400.27 & 49.87 & 586.88 & 31.31 & 10.58 & 9.92 & 7.19 \\
\hline 3/24/2006 11:00 & 592.67 & 402.55 & 71.39 & 765.70 & 33.01 & 10.25 & 9.93 & 7.14 \\
\hline $3 / 24 / 200612: 00$ & 531.89 & 365.76 & 59.50 & 734.63 & 31.36 & 10.41 & 9.97 & 7.95 \\
\hline 3/24/2006 13:00 & 574.82 & 399.79 & 66.85 & 723.93 & 32.35 & 10.52 & 9.92 & 7.53 \\
\hline $3 / 24 / 2006$ 14:00 & 576.63 & 399.61 & 68.37 & 753.86 & 44.61 & 10.88 & 9.96 & 7.49 \\
\hline $3 / 24 / 2006$ 15:00 & 565.51 & 393.34 & 64.86 & 766.28 & 38.43 & 10.68 & 9.95 & 7.56 \\
\hline 3/24/2006 16:00 & 581.25 & 408.64 & 68.02 & 770.52 & 38.41 & 10.69 & 9.92 & 7.45 \\
\hline 3/24/2006 17:00 & 579.53 & 411.82 & 69.00 & 805.14 & 43.49 & 10.73 & 9.95 & 7.61 \\
\hline 3/24/2006 18:00 & 486.08 & 350.21 & 58.03 & 818.49 & 33.98 & 10.31 & 9.95 & 8.02 \\
\hline 3/24/2006 19:00 & 545.95 & 388.60 & 63.14 & 818.97 & 36.54 & 10.52 & 9.97 & 7.97 \\
\hline $3 / 24 / 200620: 00$ & 473.26 & 337.42 & 62.11 & 800.67 & 33.77 & 10.22 & 9.98 & 7.98 \\
\hline 3/24/2006 21:00 & 471.67 & 332.44 & 59.45 & 748.44 & 26.59 & 10.34 & 9.97 & 8.03 \\
\hline 3/24/2006 22:00 & 445.39 & 306.65 & 59.23 & 705.45 & 28.45 & 9.92 & 9.97 & 8.00 \\
\hline 3/24/2006 23:00 & 378.73 & 260.14 & 61.71 & 658.21 & 28.30 & 9.73 & 9.92 & 7.97 \\
\hline 3/25/2006 0:00 & 457.34 & 313.89 & 56.47 & 657.74 & 27.67 & 9.82 & 9.95 & 7.99 \\
\hline $3 / 25 / 20061: 00$ & 455.19 & 306.72 & 57.49 & 689.98 & 19.97 & 9.81 & 10.04 & 8.00 \\
\hline 3/25/2006 2:00 & 402.16 & 276.16 & 58.67 & 701.37 & 19.08 & 9.85 & 9.98 & 8.00 \\
\hline $3 / 25 / 20063: 00$ & 469.49 & 323.20 & 57.37 & 730.43 & 23.18 & 9.78 & 9.92 & 7.99 \\
\hline $3 / 25 / 20064: 00$ & 500.09 & 339.15 & 60.98 & 762.29 & 24.44 & 9.88 & 9.98 & 8.03 \\
\hline $3 / 25 / 2006$ 5:00 & 449.13 & 301.32 & 55.83 & 750.48 & 19.21 & 10.05 & 10.01 & 8.00 \\
\hline $3 / 25 / 20066: 00$ & 595.40 & 381.31 & 70.94 & 756.09 & 39.13 & 10.35 & 9.92 & 6.95 \\
\hline $3 / 25 / 20067: 00$ & 557.31 & 353.22 & 64.12 & 748.62 & 30.44 & 10.25 & 9.99 & 7.47 \\
\hline $3 / 25 / 20068: 00$ & 572.19 & 357.03 & 47.66 & 527.50 & 30.35 & 9.99 & 9.93 & 7.40 \\
\hline 3/25/2006 9:00 & 581.20 & 359.08 & 66.97 & 759.26 & 31.79 & 9.81 & 9.94 & 7.31 \\
\hline 3/25/2006 10:00 & 580.27 & 358.33 & 65.36 & 780.24 & 28.37 & 9.85 & 9.95 & 7.66 \\
\hline 3/25/2006 11:00 & 570.17 & 350.62 & 64.17 & 788.56 & 29.22 & 10.08 & 9.93 & 7.96 \\
\hline $3 / 25 / 200612: 00$ & 549.62 & 336.23 & 64.55 & 790.06 & 27.13 & 9.78 & 10.01 & 7.89 \\
\hline 3/25/2006 13:00 & 544.16 & 334.57 & 62.76 & 787.53 & 26.00 & 10.13 & 9.99 & 8.01 \\
\hline 3/25/2006 14:00 & 501.57 & 301.22 & 57.95 & 773.00 & 24.02 & 10.01 & 9.96 & 8.01 \\
\hline 3/25/2006 15:00 & 546.89 & 333.40 & 63.58 & 753.43 & 25.87 & 10.12 & 9.95 & 7.99 \\
\hline $3 / 25 / 2006$ 16:00 & 564.80 & 343.10 & 66.14 & 721.99 & 31.98 & 10.33 & 9.99 & 7.98 \\
\hline 3/25/2006 17:00 & 529.59 & 323.35 & 61.63 & 697.89 & 27.48 & 9.85 & 9.98 & 8.01 \\
\hline 3/25/2006 18:00 & 503.63 & 336.38 & 60.19 & 683.52 & 25.43 & 9.92 & 9.98 & 8.01 \\
\hline
\end{tabular}


Table F-1. Hourly Average Unit 2 Operation Data During the Monthlong Test (continued)

\begin{tabular}{|c|c|c|c|c|c|c|c|c|}
\hline Date, Time & $\begin{array}{l}\text { Unit } 2 \\
\text { Load, } \\
\text { MW }\end{array}$ & $\begin{array}{c}\text { Unit } 2 \\
\text { Coal Flow, } \\
\text { ton/hour }\end{array}$ & $\begin{array}{c}\text { Unit } 2 \\
\text { Stack } \\
\mathrm{NO}_{\mathrm{x}}, \mathrm{ppm} \\
\end{array}$ & $\begin{array}{c}\text { Unit } 2 \\
\text { Stack } \\
\mathrm{SO}_{2}, \mathrm{ppm} \\
\end{array}$ & $\begin{array}{c}\text { FF 2-3/2-4 } \\
\text { Inlet } \\
\text { Opacity, \% } \\
\end{array}$ & $\begin{array}{c}\text { Unit } 2 \\
\text { Stack } \\
\text { Opacity, \% } \\
\end{array}$ & $\begin{array}{c}\text { Calculated } \\
\mathrm{SO}_{3} \text { Injection, } \\
\text { ppm }\end{array}$ & $\begin{array}{c}\text { Calculated } \\
\text { NH3 Injection, } \\
\text { ppm }\end{array}$ \\
\hline 3/25/2006 19:00 & 518.49 & 351.72 & 62.01 & 671.45 & 28.13 & 9.78 & 9.97 & 8.00 \\
\hline 3/25/2006 20:00 & 485.33 & 333.42 & 58.27 & 671.42 & 24.50 & 9.73 & 9.96 & 8.02 \\
\hline 3/25/2006 21:00 & 487.09 & 340.54 & 58.17 & 680.84 & 24.19 & 9.64 & 10.01 & 8.05 \\
\hline 3/25/2006 22:00 & 459.09 & 315.58 & 60.92 & 673.49 & 30.90 & 9.92 & 9.98 & 8.03 \\
\hline 3/25/2006 23:00 & 414.35 & 300.65 & 59.76 & 670.78 & 25.05 & 9.61 & 9.95 & 8.02 \\
\hline 3/26/2006 0:00 & 380.34 & 271.45 & 81.17 & 687.82 & 23.94 & 9.67 & 9.96 & 8.01 \\
\hline 3/26/2006 1:00 & 411.66 & 293.14 & 72.94 & 727.02 & 22.68 & 9.63 & 9.97 & 8.04 \\
\hline 3/26/2006 2:00 & 368.15 & 261.87 & 76.08 & 763.34 & 18.34 & 9.50 & 9.95 & 8.01 \\
\hline 3/26/2006 3:00 & 317.56 & 226.97 & 73.03 & 750.88 & 19.45 & 9.43 & 9.94 & 8.01 \\
\hline 3/26/2006 4:00 & 338.02 & 241.36 & 71.89 & 742.50 & 19.91 & 9.36 & 9.93 & 7.98 \\
\hline $3 / 26 / 20065: 00$ & 407.89 & 289.96 & 61.22 & 780.61 & 21.16 & 9.50 & 9.92 & 8.01 \\
\hline $3 / 26 / 20066: 00$ & 396.75 & 271.30 & 57.60 & 768.01 & 18.68 & 9.71 & 10.02 & 8.07 \\
\hline $3 / 26 / 2006$ 7:00 & 352.61 & 244.46 & 45.09 & 728.27 & 17.40 & 9.46 & 9.94 & 7.97 \\
\hline 3/26/2006 8:00 & 478.57 & 335.09 & 44.28 & 527.38 & 28.47 & 9.85 & 9.95 & 7.87 \\
\hline 3/26/2006 9:00 & 545.36 & 376.17 & 64.04 & 778.10 & 29.23 & 10.61 & 10.00 & 7.86 \\
\hline 3/26/2006 10:00 & 510.53 & 356.11 & 57.97 & 758.35 & 28.64 & 10.44 & 9.97 & 8.02 \\
\hline 3/26/2006 11:00 & 507.41 & 351.58 & 59.67 & 729.75 & 26.44 & 10.64 & 9.97 & 8.00 \\
\hline 3/26/2006 12:00 & 516.93 & 360.11 & 58.14 & 728.79 & 28.07 & 10.49 & 9.96 & 8.00 \\
\hline 3/26/2006 13:00 & 521.26 & 363.25 & 57.91 & 711.80 & 29.11 & 10.60 & 10.00 & 8.00 \\
\hline 3/26/2006 14:00 & 511.49 & 355.45 & 57.23 & 719.31 & 26.66 & 10.59 & 10.01 & 8.00 \\
\hline 3/26/2006 15:00 & 535.39 & 378.45 & 60.46 & 730.92 & 31.00 & 10.67 & 9.99 & 8.01 \\
\hline 3/26/2006 16:00 & 479.62 & 331.96 & 63.34 & 724.52 & 28.41 & 10.49 & 9.93 & 7.99 \\
\hline 3/26/2006 17:00 & 503.87 & 352.52 & 59.18 & 699.98 & 28.92 & 10.56 & 9.98 & 8.01 \\
\hline 3/26/2006 18:00 & 574.10 & 393.96 & 66.17 & 678.91 & 37.46 & 11.04 & 9.93 & 7.93 \\
\hline 3/26/2006 19:00 & 578.81 & 395.53 & 66.06 & 641.41 & 36.96 & 11.05 & 9.97 & 8.07 \\
\hline 3/26/2006 20:00 & 595.84 & 404.96 & 67.75 & 631.96 & 36.87 & 11.84 & 9.92 & 7.72 \\
\hline 3/26/2006 21:00 & 607.32 & 410.67 & 68.95 & 618.11 & 35.64 & 11.30 & 9.91 & 7.66 \\
\hline 3/26/2006 22:00 & 609.05 & 414.94 & 68.78 & 600.49 & 35.26 & 11.14 & 9.92 & 7.58 \\
\hline 3/26/2006 23:00 & 573.26 & 392.78 & 64.91 & 597.14 & 33.89 & 10.94 & 9.98 & 7.87 \\
\hline 3/27/2006 0:00 & 388.55 & 268.52 & 58.26 & 590.32 & 24.69 & 10.47 & 10.05 & 8.02 \\
\hline 3/27/2006 1:00 & 300.49 & 212.11 & 53.07 & 549.24 & 20.92 & 9.69 & 9.95 & 8.00 \\
\hline $3 / 27 / 20062: 00$ & 300.50 & 213.66 & 55.72 & 557.30 & 16.41 & 9.54 & 9.93 & 8.00 \\
\hline 3/27/2006 3:00 & 310.26 & 218.75 & 77.42 & 556.52 & 13.99 & 9.67 & 9.94 & 7.99 \\
\hline $3 / 27 / 20064: 00$ & 307.00 & 218.82 & 93.71 & 563.97 & 14.79 & 9.62 & 9.92 & 8.00 \\
\hline $3 / 27 / 20065: 00$ & 350.01 & 247.78 & 78.75 & 584.36 & 16.87 & 9.71 & 9.92 & 7.97 \\
\hline $3 / 27 / 20066: 00$ & 466.82 & 333.48 & 62.06 & 634.91 & 24.83 & 10.11 & 9.94 & 8.00 \\
\hline $3 / 27 / 20067: 00$ & 483.29 & 335.51 & 58.54 & 626.39 & 24.53 & 10.21 & 9.98 & 7.99 \\
\hline $3 / 27 / 20068: 00$ & 459.29 & 318.28 & 41.82 & 440.47 & 21.08 & 9.76 & 9.98 & 8.01 \\
\hline 3/27/2006 9:00 & 479.01 & 325.41 & 56.00 & 586.36 & 19.81 & 9.74 & 9.89 & 8.00 \\
\hline 3/27/2006 10:00 & 452.56 & 305.56 & 18.49 & 190.95 & 20.83 & 9.62 & 9.92 & 7.99 \\
\hline 3/27/2006 11:00 & 471.89 & 318.00 & 2.16 & -0.01 & 20.97 & 9.58 & 9.96 & 8.01 \\
\hline 3/27/2006 12:00 & 465.91 & 313.74 & 31.83 & 59.92 & 18.17 & 9.85 & 9.96 & 7.97 \\
\hline 3/27/2006 13:00 & 509.28 & 339.29 & 33.82 & 218.46 & 23.18 & 9.77 & 9.98 & 7.98 \\
\hline 3/27/2006 14:00 & 504.27 & 332.45 & 51.36 & 571.74 & 21.59 & 9.77 & 9.97 & 8.04 \\
\hline 3/27/2006 15:00 & 541.28 & 353.57 & 59.74 & 569.06 & 22.62 & 10.01 & 9.98 & 7.98 \\
\hline 3/27/2006 16:00 & 493.78 & 326.94 & 39.22 & 403.12 & 20.46 & 9.75 & 9.97 & 8.04 \\
\hline 3/27/2006 17:00 & 478.46 & 316.19 & 15.08 & 162.98 & 19.82 & 9.78 & 9.98 & 8.00 \\
\hline 3/27/2006 18:00 & 583.30 & 389.96 & 32.20 & 313.67 & 32.24 & 10.04 & 9.93 & 7.73 \\
\hline 3/27/2006 19:00 & 623.94 & 410.52 & 65.32 & 616.57 & 35.24 & 12.28 & 9.92 & 7.43 \\
\hline 3/27/2006 20:00 & 626.92 & 412.48 & 65.92 & 598.65 & 32.65 & 11.37 & 9.91 & 7.46 \\
\hline 3/27/2006 21:00 & 626.44 & 410.44 & 66.09 & 580.80 & 32.21 & 11.05 & 9.92 & 7.48 \\
\hline 3/27/2006 22:00 & 612.17 & 398.09 & 64.54 & 566.42 & 32.16 & 10.90 & 9.95 & 7.58 \\
\hline 3/27/2006 23:00 & 593.46 & 388.22 & 65.57 & 567.95 & 28.29 & 10.88 & 9.95 & 7.76 \\
\hline 3/28/2006 0:00 & 552.19 & 357.75 & 61.46 & 581.43 & 24.68 & 10.61 & 9.99 & 7.97 \\
\hline
\end{tabular}

Continued... 
Table F-1. Hourly Average Unit 2 Operation Data During the Monthlong Test (continued)

\begin{tabular}{|c|c|c|c|c|c|c|c|c|}
\hline Date, Time & $\begin{array}{l}\text { Unit } 2 \\
\text { Load, } \\
\text { MW }\end{array}$ & $\begin{array}{c}\text { Unit } 2 \\
\text { Coal Flow, } \\
\text { ton/hour }\end{array}$ & $\begin{array}{c}\text { Unit } 2 \\
\text { Stack } \\
\mathrm{NO}_{\mathrm{x}}, \mathrm{ppm}\end{array}$ & $\begin{array}{c}\text { Unit } 2 \\
\text { Stack } \\
\mathrm{SO}_{2}, \mathrm{ppm} \\
\end{array}$ & $\begin{array}{l}\text { FF } 2-3 / 2-4 \\
\text { Inlet } \\
\text { Opacity, \% }\end{array}$ & $\begin{array}{c}\text { Unit } 2 \\
\text { Stack } \\
\text { Opacity, \% }\end{array}$ & $\begin{array}{c}\text { Calculated } \\
\mathrm{SO}_{3} \text { Injection, } \\
\text { ppm }\end{array}$ & $\begin{array}{c}\text { Calculated } \\
\text { NH3 Injection, } \\
\text { ppm }\end{array}$ \\
\hline $3 / 28 / 20061: 00$ & 451.31 & 298.58 & 50.96 & 577.53 & 20.20 & 10.38 & 9.85 & 8.02 \\
\hline $3 / 28 / 20062: 00$ & 473.50 & 312.63 & 53.10 & 595.15 & 23.61 & 9.98 & 9.90 & 7.92 \\
\hline 3/28/2006 3:00 & 515.27 & 330.20 & 55.84 & 609.49 & 23.61 & 10.67 & 10.00 & 8.02 \\
\hline $3 / 28 / 20064: 00$ & 469.06 & 311.84 & 52.55 & 609.87 & 20.63 & 10.22 & 9.98 & 8.05 \\
\hline $3 / 28 / 20065: 00$ & 526.78 & 349.08 & 59.63 & 618.19 & 31.86 & 10.67 & 9.93 & 7.95 \\
\hline $3 / 28 / 20066: 00$ & 410.29 & 271.73 & 50.05 & 604.42 & 19.69 & 10.27 & 9.98 & 7.97 \\
\hline $3 / 28 / 20067: 00$ & 520.75 & 352.78 & 57.23 & 615.90 & 25.79 & 10.31 & 9.93 & 7.97 \\
\hline 3/28/2006 8:00 & 531.54 & 357.13 & 45.80 & 390.29 & 25.85 & 10.41 & 9.92 & 8.03 \\
\hline 3/28/2006 9:00 & 578.21 & 390.69 & 81.90 & 236.89 & 31.63 & 11.26 & 9.91 & 7.65 \\
\hline 3/28/2006 10:00 & 534.84 & 361.81 & 68.92 & 382.74 & 30.91 & 10.46 & 9.98 & 7.97 \\
\hline $3 / 28 / 200611: 00$ & 552.22 & 373.69 & 46.59 & 441.58 & 32.20 & 10.41 & 10.00 & 7.98 \\
\hline 3/28/2006 12:00 & 543.68 & 367.38 & 40.08 & 407.16 & 27.79 & 10.28 & 9.96 & 7.92 \\
\hline 3/28/2006 13:00 & 549.07 & 367.64 & 63.08 & 672.77 & 31.92 & 10.45 & 9.97 & 7.98 \\
\hline $3 / 28 / 2006$ 14:00 & 607.39 & 414.77 & 93.14 & 440.86 & 42.19 & 11.42 & 9.89 & 7.37 \\
\hline $3 / 28 / 2006$ 15:00 & 635.99 & 428.03 & 84.42 & 349.52 & 37.17 & 13.29 & 9.94 & 7.69 \\
\hline $3 / 28 / 200616: 00$ & 635.46 & 426.76 & 94.56 & 303.85 & 38.31 & 12.14 & 9.92 & 7.91 \\
\hline $3 / 28 / 200617: 00$ & 577.11 & 388.02 & 39.67 & 419.05 & 30.27 & 11.56 & 9.99 & 7.94 \\
\hline 3/28/2006 18:00 & 551.82 & 377.49 & 71.52 & 568.30 & 28.56 & 9.80 & 9.91 & 7.95 \\
\hline 3/28/2006 19:00 & 624.00 & 424.61 & 87.85 & 140.89 & 36.88 & 10.93 & 9.92 & 7.37 \\
\hline 3/28/2006 20:00 & 631.53 & 428.91 & 80.47 & 407.78 & 37.08 & 11.79 & 9.92 & 7.27 \\
\hline $3 / 28 / 200621: 00$ & 553.80 & 372.90 & 63.36 & 697.07 & 33.34 & 11.38 & 9.95 & 7.93 \\
\hline $3 / 28 / 200622: 00$ & 501.06 & 338.29 & 55.96 & 684.67 & 25.73 & 10.64 & 9.97 & 8.03 \\
\hline 3/28/2006 23:00 & 546.04 & 363.13 & 59.79 & 663.23 & 28.22 & 10.70 & 9.96 & 7.98 \\
\hline 3/29/2006 0:00 & 484.26 & 321.69 & 53.06 & 632.64 & 22.14 & 10.45 & 9.98 & 8.03 \\
\hline
\end{tabular}


Table F-2. Hourly Averaged Operation Data for FF 2-3 and 2-4

\begin{tabular}{|c|c|c|c|c|c|c|c|c|}
\hline Date, Time & $\begin{array}{c}\text { FF 2-4 } \Delta \mathrm{P}, \\
\text { inches } \\
\text { of } \mathrm{H}_{2} \mathrm{O}\end{array}$ & $\begin{array}{l}\text { FF 2-4 } \\
\text { Gas Flow, } \\
\text { kacfm }\end{array}$ & $\begin{array}{c}\text { FF 2-4 } \\
\text { Inlet Flue Gas } \\
\text { Temp., }{ }^{\circ} \mathrm{F}\end{array}$ & $\begin{array}{c}\text { FF 2-4 } \\
\text { Outlet Flue Gas } \\
\text { Temp., }{ }^{\circ} \mathrm{F}\end{array}$ & $\begin{array}{l}\text { FF 2-4 } \\
\text { Bypass, } \\
\text { \% Open }\end{array}$ & $\begin{array}{c}\text { FF 2-3 } \Delta \mathrm{P}, \\
\text { inches } \\
\text { of } \mathrm{H}_{2} \mathrm{O}\end{array}$ & $\begin{array}{l}\text { FF 2-3 } \\
\text { Gas Flow, } \\
\text { kacfm }\end{array}$ & $\begin{array}{l}\text { FF 2-3 } \\
\text { Bypass, } \\
\% \text { Open }\end{array}$ \\
\hline 2/27/2006 15:00 & 5.22 & 533.54 & 313.46 & 300.96 & 2.59 & 4.22 & 521.70 & 3.51 \\
\hline 2/27/2006 16:00 & 4.92 & 537.83 & 312.38 & 299.53 & 2.59 & 4.25 & 523.44 & 3.51 \\
\hline 2/27/2006 17:00 & 4.98 & 532.31 & 312.18 & 299.19 & 2.59 & 4.22 & 523.11 & 3.51 \\
\hline 2/27/2006 18:00 & 4.40 & 508.59 & 311.55 & 298.47 & 2.59 & 3.74 & 487.15 & 3.51 \\
\hline 2/27/2006 19:00 & 4.85 & 536.66 & 313.04 & 300.11 & 2.59 & 4.17 & 517.15 & 3.51 \\
\hline 2/27/2006 20:00 & 5.57 & 576.23 & 315.65 & 302.17 & 2.59 & 4.82 & 560.03 & 3.51 \\
\hline 2/27/2006 21:00 & 4.50 & 534.24 & 312.30 & 300.19 & 2.59 & 3.97 & 507.82 & 3.51 \\
\hline 2/27/2006 22:00 & 4.05 & 497.87 & 315.50 & 300.80 & 2.59 & 3.66 & 483.89 & 3.51 \\
\hline 2/27/2006 23:00 & 5.20 & 561.11 & 322.92 & 308.45 & 2.59 & 4.61 & 542.63 & 3.51 \\
\hline 2/28/2006 0:00 & 3.33 & 442.45 & 311.85 & 299.08 & 2.59 & 2.94 & 429.48 & 3.51 \\
\hline 2/28/2006 1:00 & 2.72 & 407.83 & 308.15 & 294.19 & 2.59 & 2.40 & 393.82 & 3.51 \\
\hline 2/28/2006 2:00 & 2.50 & 405.88 & 293.23 & 281.01 & 2.59 & 2.26 & 384.77 & 3.51 \\
\hline 2/28/2006 3:00 & 2.48 & 408.44 & 280.04 & 268.40 & 2.59 & 2.20 & 383.42 & 3.51 \\
\hline 2/28/2006 4:00 & 2.50 & 399.98 & 276.20 & 263.12 & 2.59 & 2.20 & 382.04 & 3.51 \\
\hline $2 / 28 / 20065: 00$ & 2.54 & 390.76 & 273.48 & 260.37 & 2.59 & 2.19 & 375.12 & 3.51 \\
\hline $2 / 28 / 20066: 00$ & 2.99 & 433.49 & 275.41 & 260.86 & 2.59 & 2.78 & 421.72 & 3.51 \\
\hline $2 / 28 / 20067: 00$ & 5.29 & 561.26 & 302.60 & 285.50 & 2.51 & 4.81 & 564.58 & 3.51 \\
\hline 2/28/2006 8:00 & 5.83 & 583.48 & 311.97 & 297.78 & 2.34 & 5.11 & 578.89 & 3.51 \\
\hline 2/28/2006 9:00 & 6.55 & 602.07 & 319.04 & 304.26 & 2.47 & 5.54 & 600.20 & 3.51 \\
\hline 2/28/2006 10:00 & 7.74 & 642.92 & 329.57 & 314.01 & 2.59 & 6.58 & 644.81 & 3.51 \\
\hline 2/28/2006 11:00 & 8.04 & 636.88 & 336.96 & 322.55 & 2.59 & 6.70 & 635.33 & 3.51 \\
\hline 2/28/2006 12:00 & 5.86 & 556.41 & 328.10 & 315.22 & 2.59 & 4.91 & 545.36 & 3.51 \\
\hline 2/28/2006 13:00 & 5.11 & 536.19 & 322.68 & 310.06 & 2.59 & 4.45 & 525.67 & 3.51 \\
\hline 2/28/2006 14:00 & 5.31 & 552.89 & 327.37 & 313.82 & 2.59 & 4.58 & 539.05 & 3.51 \\
\hline 2/28/2006 15:00 & 4.75 & 535.28 & 324.64 & 311.94 & 2.59 & 4.23 & 521.01 & 3.59 \\
\hline 2/28/2006 16:00 & 5.17 & 553.10 & 325.16 & 311.84 & 2.59 & 4.51 & 536.94 & 3.74 \\
\hline $2 / 28 / 200617: 00$ & 4.87 & 539.06 & 326.13 & 313.51 & 2.59 & 4.23 & 520.56 & 3.65 \\
\hline 2/28/2006 18:00 & 5.25 & 568.70 & 325.13 & 311.66 & 2.59 & 4.66 & 549.48 & 3.65 \\
\hline 2/28/2006 19:00 & 5.87 & 585.47 & 328.07 & 314.71 & 2.59 & 5.00 & 567.95 & 3.74 \\
\hline 2/28/2006 20:00 & 7.66 & 640.70 & 336.90 & 322.39 & 2.59 & 6.57 & 640.30 & 3.58 \\
\hline 2/28/2006 21:00 & 5.16 & 540.01 & 321.63 & 310.39 & 2.59 & 4.38 & 523.21 & 3.51 \\
\hline 2/28/2006 22:00 & 5.64 & 591.75 & 329.37 & 314.72 & 2.59 & 5.02 & 575.87 & 3.51 \\
\hline 2/28/2006 23:00 & 6.96 & 638.70 & 334.32 & 320.15 & 2.59 & 6.15 & 630.43 & 3.51 \\
\hline 3/1/2006 0:00 & 5.95 & 568.90 & 328.20 & 316.37 & 2.59 & 5.01 & 555.54 & 3.51 \\
\hline $3 / 1 / 2006$ 1:00 & 3.74 & 466.05 & 311.28 & 298.50 & 2.59 & 3.18 & 448.53 & 3.51 \\
\hline $3 / 1 / 20062: 00$ & 4.48 & 520.51 & 312.79 & 299.18 & 2.59 & 3.90 & 508.87 & 3.51 \\
\hline $3 / 1 / 20063: 00$ & 6.50 & 603.61 & 325.44 & 310.13 & 2.59 & 5.44 & 596.66 & 3.51 \\
\hline 3/1/2006 4:00 & 8.00 & 642.66 & 331.79 & 317.16 & 2.59 & 6.60 & 643.74 & 3.51 \\
\hline $3 / 1 / 20065: 00$ & 7.13 & 615.10 & 328.26 & 314.91 & 2.59 & 6.13 & 615.56 & 3.51 \\
\hline $3 / 1 / 20066: 00$ & 7.45 & 631.09 & 328.41 & 314.39 & 2.59 & 6.43 & 634.90 & 3.51 \\
\hline $3 / 1 / 2006$ 7:00 & 7.14 & 619.10 & 328.04 & 314.62 & 2.59 & 6.13 & 619.09 & 3.51 \\
\hline 3/1/2006 8:00 & 7.02 & 619.30 & 326.36 & 313.06 & 2.59 & 6.16 & 619.75 & 3.51 \\
\hline 3/1/2006 9:00 & 7.79 & 635.52 & 329.78 & 315.62 & 2.59 & 6.56 & 637.65 & 3.51 \\
\hline 3/1/2006 10:00 & 8.31 & 639.00 & 331.91 & 317.60 & 2.59 & 6.73 & 639.66 & 3.51 \\
\hline $3 / 1 / 2006$ 11:00 & 8.60 & 652.49 & 338.31 & 323.40 & 2.59 & 6.94 & 654.05 & 3.51 \\
\hline 3/1/2006 12:00 & 7.83 & 626.54 & 335.87 & 322.07 & 2.59 & 6.30 & 626.52 & 3.51 \\
\hline 3/1/2006 13:00 & 8.36 & 623.62 & 337.22 & 323.39 & 2.59 & 6.15 & 617.78 & 3.59 \\
\hline $3 / 1 / 200614: 00$ & 9.13 & 652.22 & 339.91 & 324.54 & 2.59 & 6.77 & 657.69 & 3.71 \\
\hline $3 / 1 / 2006$ 15:00 & 8.37 & 663.09 & 350.42 & 335.32 & 16.89 & 7.25 & 682.16 & 3.66 \\
\hline $3 / 1 / 200616: 00$ & 8.48 & 664.46 & 354.15 & 339.62 & 42.37 & 7.49 & 686.79 & 3.65 \\
\hline 3/1/2006 17:00 & 8.82 & 672.08 & 354.18 & 339.77 & 23.40 & 7.53 & 690.81 & 3.66 \\
\hline $3 / 1 / 200618: 00$ & 8.92 & 686.06 & 356.14 & 341.54 & 20.47 & 7.65 & 695.31 & 3.66 \\
\hline
\end{tabular}


Table F-2. Hourly Averaged Operation Data for FF 2-3 and 2-4 (continued)

\begin{tabular}{|c|c|c|c|c|c|c|c|c|}
\hline Date, Time & $\begin{array}{l}\text { FF 2-4 } \Delta \mathrm{P}, \\
\text { inches } \\
\text { of } \mathrm{H}_{2} \mathrm{O}\end{array}$ & $\begin{array}{c}\text { FF 2-4 } \\
\text { Gas Flow, } \\
\text { kacfm }\end{array}$ & $\begin{array}{c}\text { FF 2-4 } \\
\text { Inlet Flue Gas } \\
\text { Temp., }{ }^{\circ} \mathrm{F}\end{array}$ & $\begin{array}{c}\text { FF 2-4 } \\
\text { Outlet Flue Gas } \\
\text { Temp., }{ }^{\circ} \mathrm{F}\end{array}$ & $\begin{array}{l}\text { FF 2-4 } \\
\text { Bypass, } \\
\text { \% Open }\end{array}$ & $\begin{array}{c}\text { FF 2-3 } \Delta \text { P, } \\
\text { inches } \\
\text { of } \mathrm{H}_{2} \mathrm{O}\end{array}$ & $\begin{array}{c}\text { FF 2-3 } \\
\text { Gas Flow, } \\
\text { kacfm }\end{array}$ & $\begin{array}{l}\text { FF 2-3 } \\
\text { Bypass, } \\
\text { \% Open }\end{array}$ \\
\hline 3/1/2006 19:00 & 9.40 & 687.76 & 354.73 & 340.41 & 10.75 & 7.84 & 696.60 & 3.66 \\
\hline 3/1/2006 20:00 & 9.64 & 699.05 & 353.65 & 338.99 & 8.22 & 8.15 & 700.44 & 3.74 \\
\hline $3 / 1 / 200621: 00$ & 8.74 & 667.30 & 346.74 & 333.66 & 7.75 & 7.46 & 663.33 & 3.60 \\
\hline 3/1/2006 22:00 & 4.97 & 493.76 & 335.33 & 321.27 & 3.79 & 3.81 & 485.02 & 3.51 \\
\hline 3/1/2006 23:00 & 3.24 & 414.55 & 315.26 & 304.67 & 3.51 & 2.43 & 384.58 & 3.51 \\
\hline 3/2/2006 0:00 & 3.62 & 455.79 & 291.78 & 281.05 & 3.51 & 2.93 & 428.32 & 3.51 \\
\hline $3 / 2 / 20061: 00$ & 6.04 & 578.79 & 309.98 & 293.93 & 3.51 & 4.79 & 561.18 & 3.51 \\
\hline $3 / 2 / 20062: 00$ & 7.75 & 654.52 & 329.96 & 313.99 & 3.51 & 6.21 & 642.04 & 3.51 \\
\hline 3/2/2006 3:00 & 7.85 & 650.48 & 336.48 & 321.65 & 3.51 & 6.25 & 644.17 & 3.51 \\
\hline 3/2/2006 4:00 & 4.70 & 515.68 & 320.48 & 309.39 & 3.51 & 3.68 & 493.40 & 3.51 \\
\hline $3 / 2 / 20065: 00$ & 3.59 & 473.08 & 305.24 & 292.45 & 3.51 & 3.01 & 447.03 & 3.51 \\
\hline $3 / 2 / 20066: 00$ & 4.12 & 508.93 & 310.66 & 296.18 & 3.51 & 3.51 & 481.72 & 3.51 \\
\hline $3 / 2 / 2006$ 7:00 & 3.64 & 487.08 & 305.26 & 292.21 & 3.51 & 3.11 & 456.11 & 3.51 \\
\hline $3 / 2 / 20068: 00$ & 4.28 & 512.56 & 304.60 & 290.82 & 3.51 & 3.68 & 488.69 & 3.51 \\
\hline 3/2/2006 9:00 & 8.04 & 671.90 & 327.06 & 309.82 & 4.20 & 6.70 & 673.42 & 3.51 \\
\hline 3/2/2006 10:00 & 9.07 & 694.21 & 342.83 & 326.13 & 5.29 & 7.51 & 702.12 & 3.51 \\
\hline 3/2/2006 11:00 & 7.74 & 622.71 & 339.33 & 325.60 & 6.17 & 6.03 & 623.49 & 3.51 \\
\hline $3 / 2 / 200612: 00$ & 6.72 & 617.16 & 331.10 & 317.52 & 2.59 & 5.35 & 592.63 & 3.51 \\
\hline 3/2/2006 13:00 & 7.76 & 673.38 & 341.08 & 325.18 & 2.59 & 6.46 & 663.37 & 3.51 \\
\hline $3 / 2 / 200614: 00$ & 7.76 & 665.87 & 351.28 & 335.96 & 2.59 & 6.35 & 653.71 & 3.51 \\
\hline $3 / 2 / 2006$ 15:00 & 8.02 & 664.28 & 353.53 & 337.79 & 4.68 & 6.37 & 659.19 & 3.51 \\
\hline 3/2/2006 16:00 & 6.43 & 615.11 & 342.65 & 329.45 & 2.59 & 5.12 & 589.96 & 3.51 \\
\hline 3/2/2006 17:00 & 6.50 & 626.36 & 343.58 & 329.56 & 2.59 & 5.33 & 608.93 & 3.51 \\
\hline $3 / 2 / 200618: 00$ & 7.18 & 644.69 & 341.23 & 327.12 & 2.59 & 5.82 & 626.44 & 3.51 \\
\hline 3/2/2006 19:00 & 8.03 & 661.28 & 342.99 & 328.73 & 2.59 & 6.25 & 651.72 & 3.51 \\
\hline $3 / 2 / 200620: 00$ & 7.64 & 645.53 & 342.00 & 327.78 & 2.59 & 6.07 & 637.95 & 3.51 \\
\hline 3/2/2006 21:00 & 5.04 & 528.40 & 324.76 & 313.71 & 2.59 & 3.93 & 509.30 & 3.51 \\
\hline $3 / 2 / 200622: 00$ & 6.12 & 589.31 & 320.55 & 306.72 & 2.59 & 4.76 & 568.26 & 3.51 \\
\hline $3 / 2 / 200623: 00$ & 5.34 & 540.95 & 319.59 & 306.69 & 2.59 & 4.04 & 514.11 & 3.51 \\
\hline 3/3/2006 0:00 & 5.89 & 586.61 & 314.20 & 300.98 & 2.59 & 4.74 & 564.78 & 3.51 \\
\hline 3/3/2006 1:00 & 4.51 & 509.62 & 314.21 & 301.83 & 2.59 & 3.55 & 479.04 & 3.51 \\
\hline $3 / 3 / 20062: 00$ & 4.46 & 525.11 & 307.91 & 294.26 & 2.59 & 3.62 & 493.91 & 3.51 \\
\hline 3/3/2006 3:00 & 4.65 & 536.68 & 312.04 & 297.85 & 2.59 & 3.88 & 510.22 & 3.51 \\
\hline 3/3/2006 4:00 & 3.12 & 440.89 & 308.95 & 294.57 & 2.59 & 2.59 & 412.75 & 3.51 \\
\hline $3 / 3 / 20065: 00$ & 3.42 & 466.04 & 305.97 & 291.01 & 2.59 & 2.94 & 441.07 & 3.51 \\
\hline $3 / 3 / 20066: 00$ & 3.04 & 440.75 & 308.39 & 293.11 & 2.59 & 2.61 & 415.42 & 3.51 \\
\hline $3 / 3 / 2006$ 7:00 & 4.13 & 512.48 & 307.04 & 292.41 & 2.59 & 3.53 & 473.13 & 3.51 \\
\hline 3/3/2006 8:00 & 3.64 & 472.56 & 304.57 & 291.06 & 2.59 & 3.00 & 446.78 & 3.51 \\
\hline 3/3/2006 9:00 & 5.35 & 579.58 & 312.87 & 296.53 & 2.59 & 4.53 & 560.67 & 3.51 \\
\hline 3/3/2006 10:00 & 5.68 & 571.71 & 325.58 & 310.44 & 2.59 & 4.61 & 554.33 & 3.51 \\
\hline 3/3/2006 11:00 & 3.60 & 453.24 & 313.60 & 300.58 & 2.59 & 2.93 & 428.65 & 3.51 \\
\hline $3 / 3 / 200612: 00$ & 4.33 & 505.72 & 313.60 & 298.43 & 2.59 & 3.58 & 477.50 & 3.51 \\
\hline 3/3/2006 13:00 & 6.52 & 616.74 & 326.20 & 310.15 & 2.59 & 5.50 & 586.66 & 3.51 \\
\hline 3/3/2006 14:00 & 7.58 & 641.45 & 337.11 & 321.70 & 2.59 & 6.12 & 630.25 & 3.51 \\
\hline 3/3/2006 15:00 & 6.90 & 616.90 & 332.40 & 319.05 & 2.59 & 5.40 & 587.18 & 3.51 \\
\hline $3 / 3 / 200616: 00$ & 7.23 & 628.82 & 337.25 & 322.63 & 2.59 & 5.73 & 619.32 & 3.51 \\
\hline 3/3/2006 17:00 & 6.96 & 635.66 & 338.72 & 324.73 & 2.59 & 5.53 & 615.37 & 3.51 \\
\hline 3/3/2006 18:00 & 6.31 & 594.28 & 331.85 & 319.16 & 2.59 & 4.98 & 572.56 & 3.51 \\
\hline 3/3/2006 19:00 & 7.07 & 629.09 & 327.44 & 313.43 & 2.59 & 5.74 & 612.27 & 3.51 \\
\hline $3 / 3 / 200620: 00$ & 6.74 & 585.68 & 327.74 & 314.84 & 2.59 & 5.07 & 572.55 & 3.51 \\
\hline $3 / 3 / 200621: 00$ & 5.47 & 562.51 & 318.42 & 305.70 & 2.59 & 4.33 & 536.59 & 3.51 \\
\hline $3 / 3 / 200622: 00$ & 4.02 & 486.97 & 311.90 & 298.36 & 2.59 & 3.27 & 458.93 & 3.51 \\
\hline 3/3/2006 23:00 & 3.07 & 439.69 & 314.09 & 298.10 & 2.59 & 2.59 & 409.02 & 3.51 \\
\hline
\end{tabular}

Continued... 
Table F-2. Hourly Averaged Operation Data for FF 2-3 and 2-4 (continued)

\begin{tabular}{|c|c|c|c|c|c|c|c|c|}
\hline Date, Time & $\begin{array}{c}\mathrm{FF} 2-4 \Delta \mathrm{P}, \\
\text { inches } \\
\text { of } \mathrm{H}_{2} \mathrm{O}\end{array}$ & $\begin{array}{c}\text { FF 2-4 } \\
\text { Gas Flow, } \\
\text { kacfm }\end{array}$ & $\begin{array}{c}\text { FF 2-4 } \\
\text { Inlet Flue Gas } \\
\text { Temp., }{ }^{\circ} \mathrm{F}\end{array}$ & $\begin{array}{c}\text { FF 2-4 } \\
\text { Outlet Flue Gas } \\
\text { Temp., }{ }^{\circ} \mathrm{F}\end{array}$ & $\begin{array}{l}\text { FF 2-4 } \\
\text { Bypass, } \\
\% \text { Open }\end{array}$ & $\begin{array}{c}\text { FF 2-3 } \Delta \mathrm{P}, \\
\text { inches } \\
\text { of } \mathrm{H}_{2} \mathrm{O}\end{array}$ & $\begin{array}{c}\text { FF 2-3 } \\
\text { Gas Flow, } \\
\text { kacfm }\end{array}$ & $\begin{array}{l}\text { FF 2-3 } \\
\text { Bypass, } \\
\% \text { Open }\end{array}$ \\
\hline $3 / 4 / 20060: 00$ & 3.74 & 477.25 & 307.20 & 293.52 & 2.59 & 3.12 & 452.73 & 3.51 \\
\hline 3/4/2006 1:00 & 3.11 & 447.05 & 291.83 & 280.55 & 2.59 & 2.69 & 418.32 & 3.51 \\
\hline $3 / 4 / 20062: 00$ & 2.97 & 437.37 & 285.78 & 272.53 & 2.59 & 2.59 & 412.42 & 3.51 \\
\hline 3/4/2006 3:00 & 2.79 & 422.19 & 283.10 & 269.69 & 2.59 & 2.43 & 405.83 & 3.51 \\
\hline 3/4/2006 4:00 & 3.05 & 447.13 & 282.61 & 268.11 & 2.59 & 2.60 & 419.66 & 3.51 \\
\hline 3/4/2006 5:00 & 3.57 & 481.62 & 288.46 & 273.49 & 2.59 & 3.15 & 459.70 & 3.51 \\
\hline $3 / 4 / 20066: 00$ & 2.91 & 436.76 & 289.73 & 274.97 & 2.59 & 2.55 & 410.14 & 3.51 \\
\hline $3 / 4 / 2006$ 7:00 & 2.87 & 429.89 & 289.03 & 273.63 & 2.59 & 2.41 & 404.57 & 3.51 \\
\hline 3/4/2006 8:00 & 3.37 & 464.80 & 290.63 & 275.39 & 2.59 & 2.93 & 440.75 & 3.51 \\
\hline 3/4/2006 9:00 & 2.92 & 423.53 & 289.48 & 274.80 & 2.59 & 2.46 & 405.59 & 3.51 \\
\hline $3 / 4 / 200610: 00$ & 3.30 & 441.40 & 285.44 & 271.77 & 2.59 & 2.82 & 422.82 & 3.51 \\
\hline 3/4/2006 11:00 & 6.40 & 598.54 & 303.71 & 285.73 & 2.59 & 5.48 & 582.21 & 3.51 \\
\hline $3 / 4 / 200612: 00$ & 8.89 & 668.85 & 332.74 & 315.02 & 2.59 & 7.29 & 673.10 & 3.51 \\
\hline 3/4/2006 13:00 & 8.30 & 645.53 & 334.45 & 319.56 & 2.59 & 6.64 & 636.59 & 3.51 \\
\hline $3 / 4 / 200614: 00$ & 9.32 & 679.30 & 341.16 & 325.11 & 2.59 & 7.39 & 678.41 & 3.51 \\
\hline $3 / 4 / 200615: 00$ & 7.50 & 616.66 & 334.07 & 320.97 & 2.59 & 5.94 & 607.49 & 3.51 \\
\hline $3 / 4 / 200616: 00$ & 4.11 & 461.72 & 323.84 & 310.19 & 2.59 & 3.21 & 438.58 & 3.51 \\
\hline $3 / 4 / 2006$ 17:00 & 4.43 & 503.61 & 312.48 & 299.60 & 2.59 & 3.62 & 475.61 & 3.51 \\
\hline 3/4/2006 18:00 & 5.33 & 555.80 & 314.11 & 300.73 & 2.59 & 4.34 & 530.25 & 3.51 \\
\hline 3/4/2006 19:00 & 6.69 & 613.46 & 321.18 & 306.29 & 2.59 & 5.54 & 591.76 & 3.51 \\
\hline $3 / 4 / 200620: 00$ & 6.62 & 601.46 & 326.48 & 312.66 & 2.59 & 5.31 & 580.84 & 3.51 \\
\hline $3 / 4 / 200621: 00$ & 5.93 & 584.18 & 323.04 & 310.11 & 2.59 & 4.65 & 544.08 & 3.51 \\
\hline $3 / 4 / 200622: 00$ & 4.73 & 527.58 & 310.56 & 298.27 & 2.59 & 3.87 & 498.46 & 3.51 \\
\hline 3/4/2006 23:00 & 3.56 & 459.03 & 302.75 & 289.64 & 2.59 & 2.95 & 428.33 & 3.51 \\
\hline 3/5/2006 0:00 & 3.48 & 456.81 & 310.57 & 294.04 & 2.59 & 2.86 & 429.43 & 3.51 \\
\hline 3/5/2006 1:00 & 3.25 & 442.32 & 304.30 & 290.55 & 2.59 & 2.72 & 414.19 & 3.51 \\
\hline $3 / 5 / 20062: 00$ & 3.20 & 427.85 & 299.56 & 285.33 & 2.59 & 2.70 & 414.68 & 3.51 \\
\hline 3/5/2006 3:00 & 3.34 & 443.50 & 297.92 & 284.67 & 2.59 & 2.83 & 427.03 & 3.51 \\
\hline 3/5/2006 4:00 & 3.13 & 434.92 & 286.42 & 274.20 & 2.59 & 2.63 & 408.98 & 3.51 \\
\hline $3 / 5 / 20065: 00$ & 2.96 & 436.44 & 286.04 & 272.34 & 2.59 & 2.57 & 402.42 & 3.51 \\
\hline $3 / 5 / 20066: 00$ & 3.06 & 425.49 & 283.88 & 270.14 & 2.59 & 2.52 & 398.21 & 3.51 \\
\hline $3 / 5 / 2006$ 7:00 & 2.75 & 410.62 & 291.34 & 274.74 & 2.59 & 2.20 & 384.57 & 3.51 \\
\hline 3/5/2006 8:00 & 2.83 & 410.99 & 286.64 & 272.35 & 2.59 & 2.25 & 381.47 & 3.51 \\
\hline 3/5/2006 9:00 & 6.03 & 572.26 & 300.69 & 282.70 & 2.59 & 4.92 & 557.16 & 3.51 \\
\hline $3 / 5 / 200610: 00$ & 7.14 & 584.17 & 317.87 & 302.90 & 2.59 & 5.11 & 571.05 & 3.51 \\
\hline 3/5/2006 11:00 & 7.82 & 605.08 & 319.31 & 303.90 & 2.59 & 5.50 & 597.45 & 3.51 \\
\hline $3 / 5 / 200612: 00$ & 6.56 & 557.83 & 311.26 & 298.05 & 2.59 & 4.45 & 537.11 & 3.51 \\
\hline 3/5/2006 13:00 & 6.44 & 570.91 & 313.78 & 298.55 & 2.59 & 4.59 & 547.12 & 3.51 \\
\hline $3 / 5 / 200614: 00$ & 8.74 & 646.25 & 332.84 & 315.72 & 2.59 & 6.45 & 648.54 & 3.51 \\
\hline $3 / 5 / 2006$ 15:00 & 8.42 & 635.32 & 338.21 & 323.80 & 15.83 & 6.51 & 649.95 & 3.65 \\
\hline 3/5/2006 16:00 & 8.25 & 631.34 & 334.92 & 320.15 & 4.61 & 6.07 & 625.44 & 3.70 \\
\hline $3 / 5 / 2006$ 17:00 & 8.82 & 657.01 & 349.29 & 334.08 & 16.47 & 6.97 & 670.91 & 3.55 \\
\hline $3 / 5 / 2006$ 18:00 & 5.51 & 523.11 & 324.66 & 314.24 & 2.59 & 3.73 & 479.49 & 3.51 \\
\hline 3/5/2006 19:00 & 6.31 & 563.88 & 321.82 & 305.92 & 2.59 & 4.57 & 540.19 & 3.51 \\
\hline $3 / 5 / 200620: 00$ & 8.80 & 651.24 & 341.37 & 325.78 & 10.76 & 6.64 & 654.80 & 3.51 \\
\hline $3 / 5 / 200621: 00$ & 6.42 & 581.17 & 326.20 & 314.70 & 9.01 & 4.82 & 553.41 & 3.51 \\
\hline $3 / 5 / 200622: 00$ & 4.81 & 499.40 & 319.37 & 305.36 & 3.20 & 3.42 & 472.14 & 3.51 \\
\hline $3 / 5 / 200623: 00$ & 3.63 & 458.82 & 313.95 & 300.49 & 3.20 & 2.67 & 416.49 & 3.51 \\
\hline 3/6/2006 0:00 & 3.51 & 455.76 & 303.44 & 290.24 & 3.20 & 2.60 & 413.53 & 3.51 \\
\hline 3/6/2006 1:00 & 4.85 & 538.29 & 304.47 & 289.54 & 3.08 & 3.59 & 496.83 & 3.51 \\
\hline $3 / 6 / 20062: 00$ & 4.14 & 470.07 & 307.05 & 292.38 & 3.01 & 2.91 & 433.29 & 3.51 \\
\hline 3/6/2006 3:00 & 3.83 & 474.20 & 303.01 & 287.94 & 3.15 & 2.94 & 440.37 & 3.51 \\
\hline 3/6/2006 4:00 & 3.62 & 458.50 & 304.41 & 289.59 & 3.20 & 2.79 & 435.65 & 3.51 \\
\hline
\end{tabular}

Continued... 
Table F-2. Hourly Averaged Operation Data for FF 2-3 and 2-4 (continued)

\begin{tabular}{|c|c|c|c|c|c|c|c|c|}
\hline Date, Time & $\begin{array}{l}\text { FF 2-4 } \Delta \mathrm{P}, \\
\text { inches } \\
\text { of } \mathrm{H}_{2} \mathrm{O}\end{array}$ & $\begin{array}{c}\text { FF 2-4 } \\
\text { Gas Flow, } \\
\text { kacfm }\end{array}$ & $\begin{array}{c}\text { FF 2-4 } \\
\text { Inlet Flue Gas } \\
\text { Temp., }{ }^{\circ} \mathrm{F}\end{array}$ & $\begin{array}{c}\text { FF 2-4 } \\
\text { Outlet Flue Gas } \\
\text { Temp., }{ }^{\circ} \mathrm{F}\end{array}$ & $\begin{array}{l}\text { FF 2-4 } \\
\text { Bypass, } \\
\text { \% Open }\end{array}$ & $\begin{array}{c}\text { FF 2-3 } \Delta \mathrm{P}, \\
\text { inches } \\
\text { of } \mathrm{H}_{2} \mathrm{O}\end{array}$ & $\begin{array}{c}\text { FF 2-3 } \\
\text { Gas Flow, } \\
\text { kacfm }\end{array}$ & $\begin{array}{l}\text { FF 2-3 } \\
\text { Bypass, } \\
\% \text { Open }\end{array}$ \\
\hline $3 / 6 / 20065: 00$ & 3.38 & 440.68 & 299.65 & 285.06 & 3.20 & 2.49 & 409.44 & 3.51 \\
\hline $3 / 6 / 20066: 00$ & 3.79 & 467.43 & 296.35 & 282.33 & 3.20 & 2.82 & 429.83 & 3.51 \\
\hline 3/6/2006 7:00 & 3.66 & 461.15 & 293.22 & 278.58 & 3.20 & 2.69 & 422.44 & 3.51 \\
\hline $3 / 6 / 20068: 00$ & 3.14 & 430.72 & 292.48 & 277.78 & 3.10 & 2.36 & 404.87 & 3.51 \\
\hline 3/6/2006 9:00 & 4.37 & 500.64 & 288.86 & 275.37 & 2.95 & 3.40 & 475.38 & 3.51 \\
\hline 3/6/2006 10:00 & 3.75 & 445.88 & 290.01 & 276.42 & 3.01 & 2.67 & 418.77 & 3.51 \\
\hline 3/6/2006 11:00 & 5.49 & 538.83 & 300.70 & 284.28 & 3.16 & 4.08 & 522.99 & 3.51 \\
\hline 3/6/2006 12:00 & 5.01 & 519.56 & 308.00 & 293.23 & 3.20 & 3.62 & 493.22 & 3.51 \\
\hline 3/6/2006 13:00 & 5.35 & 533.94 & 312.60 & 296.98 & 3.20 & 3.86 & 510.45 & 3.51 \\
\hline 3/6/2006 14:00 & 5.33 & 529.75 & 318.21 & 303.32 & 3.18 & 3.97 & 508.84 & 3.51 \\
\hline 3/6/2006 15:00 & 7.56 & 626.15 & 329.71 & 313.56 & 3.06 & 5.64 & 611.83 & 3.51 \\
\hline $3 / 6 / 2006$ 16:00 & 8.96 & 648.68 & 335.89 & 320.35 & 3.15 & 6.28 & 648.26 & 3.51 \\
\hline 3/6/2006 17:00 & 9.20 & 637.46 & 335.18 & 320.32 & 4.38 & 6.37 & 650.09 & 3.51 \\
\hline 3/6/2006 18:00 & 8.24 & 625.37 & 337.57 & 323.26 & 8.28 & 5.90 & 630.41 & 3.51 \\
\hline 3/6/2006 19:00 & 7.31 & 602.48 & 328.49 & 315.30 & 7.93 & 5.20 & 594.19 & 3.51 \\
\hline 3/6/2006 20:00 & 8.85 & 650.97 & 336.63 & 321.29 & 7.93 & 6.35 & 653.60 & 3.51 \\
\hline 3/6/2006 21:00 & 5.54 & 528.04 & 326.48 & 312.62 & 8.09 & 3.94 & 508.09 & 3.51 \\
\hline 3/6/2006 22:00 & 5.08 & 519.72 & 319.71 & 306.42 & 8.30 & 3.72 & 501.22 & 3.51 \\
\hline 3/6/2006 23:00 & 4.96 & 517.70 & 318.81 & 304.55 & 7.49 & 3.64 & 489.82 & 3.51 \\
\hline 3/7/2006 0:00 & 5.07 & 525.66 & 311.79 & 297.44 & 2.66 & 3.62 & 490.31 & 3.51 \\
\hline 3/7/2006 1:00 & 4.72 & 502.50 & 311.04 & 296.44 & 2.59 & 3.42 & 472.55 & 3.51 \\
\hline $3 / 7 / 20062: 00$ & 5.16 & 522.03 & 315.78 & 300.31 & 2.59 & 3.66 & 507.47 & 3.51 \\
\hline $3 / 7 / 20063: 00$ & 4.63 & 501.70 & 311.07 & 296.68 & 2.59 & 3.20 & 462.09 & 3.51 \\
\hline 3/7/2006 4:00 & 3.81 & 454.45 & 303.97 & 289.77 & 2.59 & 2.69 & 420.47 & 3.51 \\
\hline 3/7/2006 5:00 & 4.70 & 507.45 & 299.82 & 285.64 & 2.59 & 3.37 & 477.52 & 3.51 \\
\hline $3 / 7 / 20066: 00$ & 4.02 & 472.39 & 300.41 & 285.94 & 2.59 & 2.98 & 439.97 & 3.51 \\
\hline 3/7/2006 7:00 & 4.76 & 507.33 & 302.86 & 287.50 & 2.59 & 3.42 & 477.12 & 3.51 \\
\hline 3/7/2006 8:00 & 5.60 & 541.34 & 307.44 & 292.16 & 2.59 & 3.93 & 513.61 & 3.51 \\
\hline 3/7/2006 9:00 & 6.30 & 570.71 & 320.97 & 304.85 & 2.59 & 4.43 & 545.79 & 3.51 \\
\hline 3/7/2006 10:00 & 6.37 & 574.56 & 319.49 & 303.70 & 2.59 & 4.68 & 556.20 & 3.51 \\
\hline 3/7/2006 11:00 & 7.66 & 615.13 & 332.26 & 316.86 & 2.59 & 5.38 & 596.89 & 3.51 \\
\hline 3/7/2006 12:00 & 8.82 & 647.84 & 335.96 & 319.57 & 11.62 & 6.53 & 659.80 & 3.51 \\
\hline 3/7/2006 13:00 & 7.95 & 640.79 & 341.71 & 328.25 & 27.92 & 6.62 & 659.48 & 3.54 \\
\hline 3/7/2006 14:00 & 7.71 & 644.23 & 347.51 & 333.10 & 27.92 & 6.51 & 658.62 & 3.69 \\
\hline 3/7/2006 15:00 & 6.94 & 615.86 & 348.46 & 335.20 & 27.06 & 5.75 & 624.24 & 3.77 \\
\hline 3/7/2006 16:00 & 6.27 & 578.46 & 340.84 & 328.61 & 18.00 & 4.97 & 574.04 & 3.62 \\
\hline 3/7/2006 17:00 & 6.06 & 567.78 & 337.34 & 323.05 & 4.44 & 4.43 & 543.04 & 3.64 \\
\hline 3/7/2006 18:00 & 7.11 & 609.99 & 333.94 & 319.70 & 2.69 & 5.04 & 589.75 & 3.71 \\
\hline 3/7/2006 19:00 & 8.35 & 649.66 & 343.63 & 327.53 & 2.59 & 5.97 & 641.73 & 3.67 \\
\hline 3/7/2006 20:00 & 6.34 & 555.36 & 335.46 & 322.26 & 2.59 & 4.22 & 525.99 & 3.53 \\
\hline 3/7/2006 21:00 & 5.63 & 541.30 & 326.93 & 313.13 & 2.59 & 3.84 & 506.56 & 3.51 \\
\hline 3/7/2006 22:00 & 7.06 & 608.50 & 325.12 & 309.91 & 2.59 & 4.91 & 579.18 & 3.51 \\
\hline 3/7/2006 23:00 & 8.73 & 647.39 & 338.83 & 322.62 & 2.59 & 5.99 & 639.79 & 3.51 \\
\hline \multicolumn{9}{|l|}{ Outage, No Data } \\
\hline 3/14/2006 6:00 & 0.55 & 145.76 & 214.62 & 206.32 & 95.98 & 0.51 & 143.92 & 98.73 \\
\hline 3/14/2006 7:00 & 1.37 & 228.34 & 252.16 & 242.78 & 95.98 & 1.34 & 227.16 & 98.73 \\
\hline 3/14/2006 8:00 & 2.77 & 396.02 & 281.26 & 252.03 & 35.40 & 2.31 & 387.57 & 33.68 \\
\hline 3/14/2006 9:00 & 7.34 & 618.42 & 305.89 & 283.44 & 2.46 & 6.00 & 609.14 & 3.51 \\
\hline 3/14/2006 10:00 & 7.90 & 649.36 & 328.13 & 309.95 & 2.58 & 6.46 & 650.08 & 3.51 \\
\hline 3/14/2006 11:00 & 7.89 & 653.70 & 334.81 & 318.30 & 2.59 & 6.40 & 656.66 & 3.51 \\
\hline $3 / 14 / 200612: 00$ & 8.00 & 649.73 & 341.29 & 324.96 & 2.59 & 6.29 & 650.97 & 3.51 \\
\hline 3/14/2006 13:00 & 8.58 & 675.45 & 343.53 & 327.04 & 2.59 & 6.83 & 681.09 & 3.51 \\
\hline 3/14/2006 14:00 & 5.93 & 560.79 & 342.87 & 327.59 & 2.59 & 4.56 & 547.41 & 3.51 \\
\hline
\end{tabular}


Table F-2. Hourly Averaged Operation Data for FF 2-3 and 2-4 (continued)

\begin{tabular}{|c|c|c|c|c|c|c|c|c|}
\hline Date, Time & $\begin{array}{c}\mathrm{FF} 2-4 \Delta \mathrm{P}, \\
\text { inches } \\
\text { of } \mathrm{H}_{2} \mathrm{O}\end{array}$ & $\begin{array}{c}\text { FF 2-4 } \\
\text { Gas Flow, } \\
\text { kacfm }\end{array}$ & $\begin{array}{c}\text { FF 2-4 } \\
\text { Inlet Flue Gas } \\
\text { Temp., }{ }^{\circ} \mathrm{F}\end{array}$ & $\begin{array}{c}\text { FF 2-4 } \\
\text { Outlet Flue Gas } \\
\text { Temp., }{ }^{\circ} \mathrm{F}\end{array}$ & $\begin{array}{l}\text { FF 2-4 } \\
\text { Bypass, } \\
\text { \% Open }\end{array}$ & $\begin{array}{c}\text { FF 2-3 } \Delta P \\
\text { inches } \\
\text { of } \mathrm{H}_{2} \mathrm{O}\end{array}$ & $\begin{array}{c}\text { FF 2-3 } \\
\text { Gas Flow, } \\
\text { kacfm }\end{array}$ & $\begin{array}{l}\text { FF 2-3 } \\
\text { Bypass, } \\
\% \text { Open }\end{array}$ \\
\hline 3/14/2006 15:00 & 5.58 & 559.51 & 330.25 & 317.09 & 2.59 & 4.23 & 534.51 & 3.51 \\
\hline 3/14/2006 16:00 & 5.43 & 562.80 & 321.37 & 307.74 & 2.59 & 4.20 & 540.30 & 3.51 \\
\hline 3/14/2006 17:00 & 5.39 & 562.77 & 321.47 & 307.64 & 2.59 & 4.25 & 541.06 & 3.51 \\
\hline 3/14/2006 18:00 & 6.37 & 609.05 & 326.38 & 311.21 & 2.59 & 5.19 & 598.64 & 3.51 \\
\hline 3/14/2006 19:00 & 7.48 & 634.33 & 337.35 & 322.10 & 2.59 & 5.80 & 623.16 & 3.51 \\
\hline 3/14/2006 20:00 & 5.96 & 569.03 & 324.57 & 312.04 & 2.59 & 4.48 & 550.50 & 3.51 \\
\hline 3/14/2006 21:00 & 5.41 & 555.96 & 315.53 & 302.40 & 2.59 & 4.15 & 533.16 & 3.51 \\
\hline 3/14/2006 22:00 & 5.20 & 549.28 & 313.32 & 299.43 & 2.59 & 4.05 & 526.62 & 3.51 \\
\hline 3/14/2006 23:00 & 5.20 & 544.67 & 316.88 & 301.78 & 2.59 & 4.11 & 531.04 & 3.51 \\
\hline 3/15/2006 0:00 & 5.31 & 534.74 & 320.33 & 304.52 & 2.59 & 4.12 & 526.23 & 3.51 \\
\hline 3/15/2006 1:00 & 4.05 & 486.49 & 312.24 & 298.20 & 2.59 & 3.17 & 463.55 & 3.51 \\
\hline $3 / 15 / 20062: 00$ & 4.63 & 517.44 & 306.61 & 291.49 & 2.59 & 3.68 & 502.06 & 3.51 \\
\hline 3/15/2006 3:00 & 5.20 & 543.13 & 312.76 & 298.12 & 2.59 & 4.14 & 535.02 & 3.51 \\
\hline $3 / 15 / 20064: 00$ & 5.29 & 544.23 & 308.12 & 293.58 & 2.59 & 4.22 & 539.55 & 3.51 \\
\hline $3 / 15 / 20065: 00$ & 6.30 & 585.28 & 316.50 & 300.74 & 2.59 & 4.99 & 581.41 & 3.51 \\
\hline $3 / 15 / 20066: 00$ & 5.85 & 554.55 & 309.45 & 295.90 & 2.47 & 4.46 & 551.28 & 3.51 \\
\hline $3 / 15 / 20067: 00$ & 6.42 & 579.04 & 312.48 & 297.28 & 2.40 & 4.91 & 575.43 & 3.51 \\
\hline $3 / 15 / 20068: 00$ & 8.09 & 631.74 & 322.60 & 305.76 & 2.44 & 6.17 & 642.21 & 3.51 \\
\hline 3/15/2006 9:00 & 5.60 & 525.61 & 314.25 & 301.01 & 2.36 & 4.12 & 514.03 & 3.51 \\
\hline 3/15/2006 10:00 & 5.76 & 547.17 & 316.15 & 298.91 & 2.52 & 4.46 & 534.76 & 3.51 \\
\hline 3/15/2006 11:00 & 8.82 & 656.76 & 335.98 & 318.70 & 2.59 & 6.81 & 669.68 & 3.51 \\
\hline 3/15/2006 12:00 & 7.15 & 583.33 & 329.80 & 316.06 & 2.59 & 5.39 & 584.90 & 3.51 \\
\hline 3/15/2006 13:00 & 5.74 & 533.40 & 317.86 & 304.56 & 2.59 & 4.28 & 520.54 & 3.51 \\
\hline 3/15/2006 14:00 & 5.42 & 512.19 & 310.64 & 296.84 & 2.66 & 4.02 & 504.21 & 3.51 \\
\hline 3/15/2006 15:00 & 7.58 & 605.66 & 322.95 & 306.18 & 2.59 & 5.63 & 602.52 & 3.51 \\
\hline 3/15/2006 16:00 & 8.05 & 618.68 & 331.86 & 316.27 & 2.59 & 6.08 & 624.15 & 3.51 \\
\hline 3/15/2006 17:00 & 7.96 & 610.72 & 333.39 & 318.59 & 2.59 & 5.94 & 612.50 & 3.51 \\
\hline 3/15/2006 18:00 & 6.85 & 573.17 & 325.04 & 311.76 & 2.59 & 5.12 & 569.22 & 3.51 \\
\hline 3/15/2006 19:00 & 6.75 & 579.67 & 322.77 & 308.41 & 2.59 & 5.08 & 572.16 & 3.51 \\
\hline 3/15/2006 20:00 & 6.89 & 592.99 & 325.18 & 310.30 & 2.59 & 5.28 & 584.83 & 3.51 \\
\hline 3/15/2006 21:00 & 7.17 & 595.81 & 328.93 & 314.60 & 2.59 & 5.46 & 585.58 & 3.51 \\
\hline 3/15/2006 22:00 & 6.26 & 556.18 & 322.97 & 309.35 & 2.59 & 4.66 & 546.03 & 3.51 \\
\hline 3/15/2006 23:00 & 6.77 & 578.13 & 318.53 & 304.31 & 2.59 & 5.09 & 571.25 & 3.51 \\
\hline 3/16/2006 0:00 & 8.31 & 628.04 & 332.26 & 315.93 & 2.59 & 6.37 & 635.09 & 3.51 \\
\hline 3/16/2006 1:00 & 7.03 & 582.06 & 326.51 & 312.88 & 2.59 & 5.26 & 577.26 & 3.51 \\
\hline 3/16/2006 2:00 & 7.91 & 611.98 & 333.09 & 317.05 & 2.59 & 5.86 & 613.98 & 3.51 \\
\hline 3/16/2006 3:00 & 9.88 & 675.57 & 341.89 & 325.28 & 9.51 & 7.91 & 699.28 & 3.51 \\
\hline 3/16/2006 4:00 & 9.36 & 676.90 & 348.38 & 332.54 & 23.24 & 8.33 & 704.71 & 3.51 \\
\hline 3/16/2006 5:00 & 9.34 & 677.66 & 347.85 & 332.24 & 23.08 & 8.33 & 705.36 & 3.51 \\
\hline $3 / 16 / 20066: 00$ & 9.15 & 678.04 & 347.66 & 332.52 & 23.27 & 8.32 & 700.27 & 3.51 \\
\hline 3/16/2006 7:00 & 8.59 & 656.53 & 343.11 & 328.30 & 23.12 & 7.65 & 681.43 & 3.51 \\
\hline 3/16/2006 8:00 & 7.58 & 617.17 & 343.27 & 329.08 & 22.35 & 6.71 & 634.32 & 3.51 \\
\hline 3/16/2006 9:00 & 6.89 & 595.59 & 332.20 & 318.55 & 8.09 & 5.71 & 600.33 & 3.51 \\
\hline 3/16/2006 10:00 & 6.02 & 564.06 & 323.74 & 310.42 & 6.06 & 4.73 & 553.43 & 3.51 \\
\hline 3/16/2006 11:00 & 7.13 & 611.58 & 326.24 & 310.93 & 2.76 & 5.55 & 601.49 & 3.51 \\
\hline 3/16/2006 12:00 & 8.60 & 651.87 & 339.90 & 323.02 & 3.97 & 6.72 & 657.98 & 3.51 \\
\hline 3/16/2006 13:00 & 8.58 & 663.41 & 351.04 & 335.29 & 25.79 & 7.66 & 685.00 & 3.51 \\
\hline 3/16/2006 14:00 & 8.30 & 662.70 & 354.06 & 338.40 & 25.82 & 7.46 & 683.61 & 3.51 \\
\hline 3/16/2006 15:00 & 6.54 & 609.00 & 353.78 & 339.21 & 22.51 & 5.85 & 608.48 & 3.51 \\
\hline 3/16/2006 16:00 & 8.08 & 650.24 & 354.39 & 338.95 & 8.28 & 6.68 & 659.04 & 3.51 \\
\hline 3/16/2006 17:00 & 8.74 & 666.64 & 353.92 & 338.47 & 8.22 & 7.01 & 665.53 & 3.51 \\
\hline 3/16/2006 18:00 & 6.86 & 589.52 & 345.34 & 332.28 & 5.20 & 5.34 & 577.39 & 3.51 \\
\hline 3/16/2006 19:00 & 6.49 & 600.84 & 336.66 & 323.42 & 2.59 & 5.23 & 576.03 & 3.51 \\
\hline
\end{tabular}

Continued... 
Table F-2. Hourly Averaged Operation Data for FF 2-3 and 2-4 (continued)

\begin{tabular}{|c|c|c|c|c|c|c|c|c|}
\hline Date, Time & $\begin{array}{c}\text { FF 2-4 } \Delta \mathrm{P}, \\
\text { inches } \\
\text { of } \mathrm{H}_{2} \mathrm{O}\end{array}$ & $\begin{array}{c}\text { FF 2-4 } \\
\text { Gas Flow, } \\
\text { kacfm }\end{array}$ & $\begin{array}{c}\text { FF 2-4 } \\
\text { Inlet Flue Gas } \\
\text { Temp., }{ }^{\circ} \mathrm{F}\end{array}$ & $\begin{array}{c}\text { FF 2-4 } \\
\text { Outlet Flue Gas } \\
\text { Temp., }{ }^{\circ} \mathrm{F}\end{array}$ & $\begin{array}{l}\text { FF 2-4 } \\
\text { Bypass, } \\
\text { \% Open }\end{array}$ & $\begin{array}{c}\text { FF 2-3 } \Delta \text { P, } \\
\text { inches } \\
\text { of } \mathrm{H}_{2} \mathrm{O}\end{array}$ & $\begin{array}{c}\text { FF 2-3 } \\
\text { Gas Flow, } \\
\text { kacfm }\end{array}$ & $\begin{array}{l}\text { FF 2-3 } \\
\text { Bypass, } \\
\% \text { Open }\end{array}$ \\
\hline 3/16/2006 20:00 & 5.85 & 563.50 & 330.85 & 318.18 & 2.59 & 4.54 & 536.12 & 3.51 \\
\hline 3/16/2006 21:00 & 6.00 & 559.36 & 324.04 & 310.71 & 2.59 & 4.57 & 539.01 & 3.51 \\
\hline 3/16/2006 22:00 & 5.72 & 551.56 & 318.05 & 304.88 & 2.59 & 4.36 & 529.06 & 3.51 \\
\hline 3/16/2006 23:00 & 5.90 & 566.51 & 316.60 & 302.91 & 2.59 & 4.56 & 538.59 & 3.51 \\
\hline 3/17/2006 0:00 & 8.31 & 646.91 & 330.47 & 314.01 & 2.59 & 6.62 & 645.77 & 3.51 \\
\hline 3/17/2006 1:00 & 7.17 & 592.96 & 330.46 & 316.65 & 2.59 & 5.36 & 582.85 & 3.51 \\
\hline 3/17/2006 2:00 & 7.33 & 601.31 & 330.87 & 314.57 & 2.59 & 5.29 & 582.86 & 3.51 \\
\hline 3/17/2006 3:00 & 6.20 & 564.24 & 326.10 & 311.93 & 2.59 & 4.65 & 542.37 & 3.51 \\
\hline 3/17/2006 4:00 & 8.50 & 645.81 & 333.81 & 317.67 & 2.59 & 6.43 & 642.64 & 3.51 \\
\hline 3/17/2006 5:00 & 7.50 & 600.41 & 328.39 & 314.49 & 2.59 & 5.52 & 592.81 & 3.51 \\
\hline $3 / 17 / 20066: 00$ & 9.12 & 655.43 & 333.43 & 317.19 & 2.59 & 7.00 & 660.42 & 3.51 \\
\hline $3 / 17 / 2006$ 7:00 & 7.24 & 601.98 & 322.84 & 309.67 & 2.59 & 5.41 & 585.28 & 3.51 \\
\hline 3/17/2006 8:00 & 7.29 & 590.84 & 318.79 & 304.27 & 2.59 & 5.40 & 587.54 & 3.51 \\
\hline 3/17/2006 9:00 & 7.82 & 625.62 & 324.87 & 309.05 & 2.59 & 6.00 & 614.16 & 3.51 \\
\hline 3/17/2006 10:00 & 9.67 & 667.24 & 339.89 & 322.08 & 2.59 & 7.44 & 678.36 & 3.51 \\
\hline 3/17/2006 11:00 & 7.75 & 606.26 & 333.81 & 319.45 & 2.59 & 5.86 & 600.75 & 3.51 \\
\hline 3/17/2006 12:00 & 9.49 & 674.29 & 344.08 & 326.74 & 12.89 & 8.05 & 698.84 & 3.51 \\
\hline 3/17/2006 13:00 & 9.32 & 679.78 & 355.09 & 337.92 & 18.00 & 8.21 & 702.69 & 3.51 \\
\hline 3/17/2006 14:00 & 9.48 & 692.22 & 359.66 & 343.10 & 18.00 & 8.31 & 706.28 & 3.51 \\
\hline 3/17/2006 15:00 & 8.74 & 660.54 & 355.62 & 340.69 & 18.01 & 7.68 & 670.19 & 3.51 \\
\hline 3/17/2006 16:00 & 6.36 & 585.33 & 337.45 & 325.30 & 16.45 & 5.52 & 582.56 & 3.51 \\
\hline 3/17/2006 17:00 & 7.57 & 615.08 & 332.56 & 318.52 & 2.59 & 5.62 & 592.85 & 3.51 \\
\hline 3/17/2006 18:00 & 8.03 & 617.67 & 331.54 & 317.01 & 2.59 & 5.99 & 610.30 & 3.51 \\
\hline 3/17/2006 19:00 & 9.07 & 654.34 & 337.65 & 321.86 & 2.59 & 6.87 & 651.92 & 3.51 \\
\hline 3/17/2006 20:00 & 9.54 & 659.76 & 343.02 & 326.63 & 2.59 & 7.25 & 659.19 & 3.51 \\
\hline 3/17/2006 21:00 & 8.54 & 625.61 & 333.72 & 319.72 & 2.59 & 6.30 & 617.60 & 3.51 \\
\hline 3/17/2006 22:00 & 9.25 & 641.46 & 336.17 & 320.69 & 2.59 & 6.89 & 639.85 & 3.51 \\
\hline 3/17/2006 23:00 & 9.52 & 639.89 & 336.12 & 320.87 & 2.59 & 7.11 & 641.18 & 3.51 \\
\hline 3/18/2006 0:00 & 9.30 & 637.68 & 332.95 & 317.89 & 2.59 & 6.96 & 637.05 & 3.51 \\
\hline 3/18/2006 1:00 & 8.27 & 600.84 & 329.43 & 315.22 & 2.59 & 6.12 & 600.00 & 3.51 \\
\hline $3 / 18 / 20062: 00$ & 7.51 & 583.39 & 322.66 & 308.54 & 2.59 & 5.59 & 573.11 & 3.51 \\
\hline 3/18/2006 3:00 & 7.25 & 586.87 & 319.96 & 305.91 & 2.59 & 5.38 & 567.91 & 3.51 \\
\hline 3/18/2006 4:00 & 7.13 & 590.32 & 317.58 & 302.84 & 2.59 & 5.38 & 572.64 & 3.51 \\
\hline 3/18/2006 5:00 & 8.67 & 637.06 & 325.78 & 309.33 & 2.59 & 6.67 & 632.98 & 3.51 \\
\hline $3 / 18 / 20066: 00$ & 9.46 & 653.80 & 337.28 & 320.43 & 12.57 & 7.71 & 666.76 & 3.51 \\
\hline 3/18/2006 7:00 & 8.41 & 616.78 & 330.64 & 316.23 & 13.12 & 6.82 & 629.80 & 3.51 \\
\hline 3/18/2006 8:00 & 7.84 & 610.77 & 325.20 & 310.22 & 10.46 & 6.40 & 617.34 & 3.51 \\
\hline 3/18/2006 9:00 & 8.07 & 605.25 & 324.53 & 309.43 & 3.20 & 6.15 & 604.00 & 3.51 \\
\hline 3/18/2006 10:00 & 8.24 & 619.09 & 323.73 & 307.86 & 7.48 & 6.58 & 626.50 & 3.51 \\
\hline 3/18/2006 11:00 & 6.71 & 595.02 & 332.43 & 317.16 & 28.15 & 6.52 & 614.22 & 3.51 \\
\hline 3/18/2006 12:00 & 7.13 & 604.84 & 336.75 & 321.29 & 11.86 & 6.36 & 613.98 & 3.51 \\
\hline 3/18/2006 13:00 & 6.87 & 587.37 & 335.20 & 320.40 & 8.09 & 5.93 & 596.78 & 3.51 \\
\hline 3/18/2006 14:00 & 6.01 & 556.60 & 325.08 & 311.23 & 5.55 & 5.03 & 551.85 & 3.51 \\
\hline 3/18/2006 15:00 & 8.20 & 628.05 & 329.15 & 313.13 & 2.75 & 6.73 & 633.08 & 3.51 \\
\hline 3/18/2006 16:00 & 9.05 & 645.65 & 333.09 & 317.73 & 2.61 & 7.30 & 652.42 & 3.51 \\
\hline 3/18/2006 17:00 & 7.36 & 596.85 & 322.28 & 308.68 & 2.59 & 5.76 & 587.46 & 3.51 \\
\hline 3/18/2006 18:00 & 6.59 & 572.95 & 319.54 & 304.75 & 2.59 & 5.26 & 563.67 & 3.51 \\
\hline 3/18/2006 19:00 & 7.61 & 611.07 & 326.43 & 310.03 & 2.59 & 6.11 & 600.21 & 3.51 \\
\hline 3/18/2006 20:00 & 8.03 & 610.86 & 331.30 & 315.22 & 2.59 & 6.34 & 610.44 & 3.51 \\
\hline 3/18/2006 21:00 & 8.17 & 614.29 & 325.48 & 310.42 & 2.59 & 6.42 & 614.74 & 3.51 \\
\hline 3/18/2006 22:00 & 7.84 & 595.51 & 325.98 & 310.90 & 2.59 & 6.07 & 601.34 & 3.51 \\
\hline 3/18/2006 23:00 & 7.88 & 592.26 & 325.90 & 310.31 & 2.59 & 5.99 & 593.79 & 3.51 \\
\hline 3/19/2006 0:00 & 8.71 & 617.04 & 327.35 & 311.30 & 2.59 & 6.50 & 623.36 & 3.51 \\
\hline
\end{tabular}


Table F-2. Hourly Averaged Operation Data for FF 2-3 and 2-4 (continued)

\begin{tabular}{|c|c|c|c|c|c|c|c|c|}
\hline Date, Time & $\begin{array}{c}\text { FF 2-4 } \Delta \mathrm{P}, \\
\text { inches } \\
\text { of } \mathrm{H}_{2} \mathrm{O}\end{array}$ & $\begin{array}{l}\text { FF 2-4 } \\
\text { Gas Flow, } \\
\text { kacfm }\end{array}$ & $\begin{array}{c}\text { FF 2-4 } \\
\text { Inlet Flue Gas } \\
\text { Temp., }{ }^{\circ} \mathrm{F}\end{array}$ & $\begin{array}{c}\text { FF 2-4 } \\
\text { Outlet Flue Gas } \\
\text { Temp., }{ }^{\circ} \mathrm{F}\end{array}$ & $\begin{array}{l}\text { FF 2-4 } \\
\text { Bypass, } \\
\text { \% Open }\end{array}$ & $\begin{array}{c}\text { FF 2-3 } \Delta \text { P, } \\
\text { inches } \\
\text { of } \mathrm{H}_{2} \mathrm{O}\end{array}$ & $\begin{array}{l}\text { FF 2-3 } \\
\text { Gas Flow, } \\
\text { kacfm }\end{array}$ & $\begin{array}{l}\text { FF 2-3 } \\
\text { Bypass, } \\
\% \text { Open }\end{array}$ \\
\hline 3/19/2006 1:00 & 6.34 & 548.00 & 319.82 & 306.02 & 2.59 & 4.79 & 535.50 & 3.51 \\
\hline 3/19/2006 2:00 & 5.99 & 545.55 & 315.07 & 300.51 & 2.59 & 4.71 & 534.88 & 3.51 \\
\hline 3/19/2006 3:00 & 6.96 & 582.14 & 317.68 & 301.70 & 2.59 & 5.52 & 578.00 & 3.51 \\
\hline 3/19/2006 4:00 & 7.65 & 588.81 & 325.14 & 309.48 & 2.59 & 5.84 & 583.99 & 3.51 \\
\hline 3/19/2006 5:00 & 8.40 & 627.60 & 326.66 & 310.23 & 2.59 & 6.66 & 629.31 & 3.51 \\
\hline 3/19/2006 6:00 & 7.94 & 605.37 & 329.19 & 313.93 & 2.59 & 6.21 & 604.98 & 3.51 \\
\hline 3/19/2006 7:00 & 8.16 & 619.26 & 325.33 & 310.87 & 12.51 & 6.65 & 626.56 & 3.51 \\
\hline 3/19/2006 8:00 & 7.49 & 611.50 & 321.52 & 307.17 & 18.00 & 6.42 & 615.26 & 3.51 \\
\hline 3/19/2006 9:00 & 6.87 & 592.65 & 317.08 & 302.98 & 18.01 & 6.01 & 592.43 & 3.51 \\
\hline 3/19/2006 10:00 & 8.82 & 647.75 & 329.21 & 312.57 & 23.63 & 7.98 & 663.62 & 3.51 \\
\hline 3/19/2006 11:00 & 6.69 & 580.75 & 319.28 & 306.14 & 19.74 & 6.12 & 589.29 & 3.51 \\
\hline 3/19/2006 12:00 & 8.99 & 647.87 & 326.35 & 309.61 & 10.12 & 7.63 & 665.33 & 3.51 \\
\hline 3/19/2006 13:00 & 7.65 & 612.23 & 328.42 & 313.72 & 18.00 & 6.85 & 633.72 & 3.51 \\
\hline 3/19/2006 14:00 & 6.54 & 580.31 & 322.05 & 308.33 & 18.00 & 5.84 & 592.92 & 3.51 \\
\hline 3/19/2006 15:00 & 8.30 & 640.69 & 328.15 & 312.13 & 18.01 & 7.47 & 664.31 & 3.51 \\
\hline 3/19/2006 16:00 & 7.05 & 592.89 & 326.99 & 313.11 & 18.01 & 6.33 & 605.33 & 3.51 \\
\hline 3/19/2006 17:00 & 6.89 & 586.10 & 320.51 & 305.97 & 7.38 & 5.77 & 591.15 & 3.51 \\
\hline 3/19/2006 18:00 & 7.93 & 627.87 & 323.45 & 307.99 & 2.59 & 6.72 & 633.73 & 3.51 \\
\hline 3/19/2006 19:00 & 9.45 & 664.78 & 334.55 & 317.91 & 2.59 & 7.85 & 678.85 & 3.51 \\
\hline 3/19/2006 20:00 & 7.81 & 609.49 & 330.57 & 316.09 & 2.59 & 6.34 & 613.83 & 3.51 \\
\hline 3/19/2006 21:00 & 7.30 & 601.00 & 323.78 & 309.27 & 2.59 & 5.88 & 602.34 & 3.51 \\
\hline 3/19/2006 22:00 & 7.71 & 628.14 & 328.17 & 313.21 & 2.59 & 6.51 & 631.58 & 3.51 \\
\hline 3/19/2006 23:00 & 7.50 & 625.39 & 327.84 & 313.22 & 2.59 & 6.41 & 624.64 & 3.51 \\
\hline 3/20/2006 0:00 & 6.92 & 606.11 & 329.86 & 314.42 & 2.59 & 5.86 & 604.81 & 3.51 \\
\hline 3/20/2006 1:00 & 5.64 & 542.91 & 318.61 & 305.76 & 2.59 & 4.54 & 523.35 & 3.51 \\
\hline $3 / 20 / 20062: 00$ & 6.51 & 577.57 & 313.76 & 297.59 & 2.59 & 5.20 & 565.68 & 3.51 \\
\hline 3/20/2006 3:00 & 7.04 & 585.78 & 317.65 & 301.11 & 2.59 & 5.56 & 580.36 & 3.51 \\
\hline $3 / 20 / 20064: 00$ & 8.08 & 616.68 & 323.08 & 306.08 & 2.59 & 6.44 & 622.86 & 3.51 \\
\hline 3/20/2006 5:00 & 7.61 & 577.40 & 321.30 & 305.18 & 2.59 & 5.73 & 580.55 & 3.51 \\
\hline $3 / 20 / 20066: 00$ & 8.66 & 637.60 & 328.85 & 312.18 & 2.59 & 7.26 & 653.65 & 3.51 \\
\hline $3 / 20 / 2006$ 7:00 & 7.40 & 598.02 & 327.30 & 312.52 & 2.59 & 6.15 & 605.21 & 3.51 \\
\hline $3 / 20 / 20068: 00$ & 5.91 & 568.06 & 326.08 & 310.81 & 2.59 & 4.95 & 545.07 & 3.51 \\
\hline 3/20/2006 9:00 & 4.48 & 511.12 & 316.19 & 302.44 & 2.59 & 3.91 & 485.30 & 3.51 \\
\hline 3/20/2006 10:00 & 5.17 & 550.49 & 316.11 & 301.08 & 2.59 & 4.49 & 523.24 & 3.51 \\
\hline 3/20/2006 11:00 & 6.63 & 600.69 & 325.53 & 310.24 & 2.59 & 5.77 & 595.29 & 3.51 \\
\hline 3/20/2006 12:00 & 7.54 & 619.86 & 331.65 & 316.44 & 2.59 & 6.51 & 620.44 & 3.51 \\
\hline 3/20/2006 13:00 & 6.82 & 588.69 & 332.19 & 318.52 & 2.59 & 5.65 & 581.83 & 3.51 \\
\hline 3/20/2006 14:00 & 6.70 & 609.21 & 331.05 & 316.91 & 2.59 & 5.70 & 590.12 & 3.51 \\
\hline 3/20/2006 15:00 & 6.78 & 605.83 & 331.68 & 318.02 & 2.59 & 5.80 & 593.77 & 3.51 \\
\hline 3/20/2006 16:00 & 8.19 & 647.20 & 341.97 & 326.59 & 2.59 & 6.90 & 649.13 & 3.51 \\
\hline 3/20/2006 17:00 & 6.01 & 586.86 & 333.63 & 320.73 & 2.59 & 5.07 & 559.27 & 3.51 \\
\hline 3/20/2006 18:00 & 6.63 & 622.33 & 334.62 & 320.26 & 2.59 & 5.72 & 595.77 & 3.51 \\
\hline 3/20/2006 19:00 & 8.78 & 690.47 & 344.60 & 328.67 & 2.59 & 7.58 & 684.15 & 3.51 \\
\hline 3/20/2006 20:00 & 8.57 & 672.72 & 345.02 & 330.54 & 2.59 & 7.27 & 667.51 & 3.51 \\
\hline 3/20/2006 21:00 & 8.69 & 649.59 & 340.91 & 326.68 & 2.59 & 6.85 & 643.57 & 3.51 \\
\hline 3/20/2006 22:00 & 8.59 & 644.65 & 335.55 & 321.19 & 2.59 & 6.72 & 637.29 & 3.51 \\
\hline 3/20/2006 23:00 & 7.19 & 606.57 & 330.91 & 317.20 & 2.59 & 5.81 & 595.56 & 3.51 \\
\hline 3/21/2006 0:00 & 7.69 & 634.68 & 326.70 & 312.60 & 2.59 & 6.27 & 618.30 & 3.51 \\
\hline $3 / 21 / 20061: 00$ & 6.57 & 586.49 & 321.88 & 308.25 & 2.59 & 5.48 & 569.73 & 3.51 \\
\hline $3 / 21 / 20062: 00$ & 6.34 & 595.12 & 317.55 & 302.90 & 2.59 & 5.39 & 576.30 & 3.51 \\
\hline $3 / 21 / 20063: 00$ & 8.53 & 653.90 & 320.50 & 305.05 & 2.52 & 7.16 & 649.93 & 3.51 \\
\hline $3 / 21 / 20064: 00$ & 9.10 & 661.08 & 323.87 & 308.51 & 2.45 & 7.49 & 656.27 & 3.51 \\
\hline 3/21/2006 5:00 & 7.81 & 618.09 & 314.97 & 300.95 & 2.48 & 6.28 & 602.61 & 3.51 \\
\hline
\end{tabular}


Table F-2. Hourly Averaged Operation Data for FF 2-3 and 2-4 (continued)

\begin{tabular}{|c|c|c|c|c|c|c|c|c|}
\hline Date, Time & $\begin{array}{c}\mathrm{FF} 2-4 \Delta \mathrm{P}, \\
\text { inches } \\
\text { of } \mathrm{H}_{2} \mathrm{O}\end{array}$ & $\begin{array}{c}\text { FF 2-4 } \\
\text { Gas Flow, } \\
\text { kacfm }\end{array}$ & $\begin{array}{c}\text { FF 2-4 } \\
\text { Inlet Flue Gas } \\
\text { Temp., }{ }^{\circ} \mathrm{F}\end{array}$ & $\begin{array}{c}\text { FF 2-4 } \\
\text { Outlet Flue Gas } \\
\text { Temp., }{ }^{\circ} \mathrm{F}\end{array}$ & $\begin{array}{l}\text { FF 2-4 } \\
\text { Bypass, } \\
\text { \% Open }\end{array}$ & $\begin{array}{c}\text { FF 2-3 } \Delta P \\
\text { inches } \\
\text { of } \mathrm{H}_{2} \mathrm{O}\end{array}$ & $\begin{array}{c}\text { FF 2-3 } \\
\text { Gas Flow, } \\
\text { kacfm }\end{array}$ & $\begin{array}{l}\text { FF 2-3 } \\
\text { Bypass, } \\
\text { \% Open }\end{array}$ \\
\hline $3 / 21 / 20066: 00$ & 9.00 & 668.99 & 320.94 & 304.60 & 2.47 & 7.46 & 660.72 & 3.51 \\
\hline $3 / 21 / 20067: 00$ & 7.44 & 613.40 & 318.14 & 303.52 & 2.32 & 6.30 & 606.69 & 3.51 \\
\hline 3/21/2006 8:00 & 6.03 & 551.48 & 307.37 & 294.10 & 2.29 & 5.06 & 548.16 & 3.51 \\
\hline 3/21/2006 9:00 & 6.27 & 576.73 & 307.59 & 292.97 & 2.35 & 5.35 & 564.30 & 3.51 \\
\hline 3/21/2006 10:00 & 5.39 & 533.36 & 311.59 & 295.03 & 2.44 & 4.52 & 512.08 & 3.51 \\
\hline 3/21/2006 11:00 & 9.18 & 667.16 & 324.74 & 307.68 & 2.41 & 7.78 & 676.99 & 3.51 \\
\hline $3 / 21 / 200612: 00$ & 6.97 & 579.20 & 320.27 & 306.55 & 2.40 & 5.61 & 574.25 & 3.51 \\
\hline 3/21/2006 13:00 & 4.92 & 509.51 & 307.04 & 294.12 & 2.55 & 4.17 & 492.78 & 3.51 \\
\hline 3/21/2006 14:00 & 5.61 & 565.88 & 305.43 & 290.84 & 2.59 & 4.82 & 535.36 & 3.51 \\
\hline 3/21/2006 15:00 & 6.63 & 585.90 & 311.63 & 296.47 & 2.59 & 5.68 & 580.15 & 3.51 \\
\hline 3/21/2006 16:00 & 9.38 & 664.19 & 327.77 & 310.66 & 5.44 & 7.92 & 671.20 & 3.51 \\
\hline 3/21/2006 17:00 & 6.10 & 559.54 & 316.96 & 304.31 & 3.20 & 5.00 & 530.73 & 3.51 \\
\hline 3/21/2006 18:00 & 5.59 & 549.90 & 310.87 & 297.15 & 3.20 & 4.72 & 527.44 & 3.51 \\
\hline 3/21/2006 19:00 & 5.20 & 545.46 & 306.53 & 292.92 & 3.20 & 4.50 & 514.15 & 3.51 \\
\hline 3/21/2006 20:00 & 9.16 & 673.91 & 324.42 & 306.59 & 3.20 & 7.63 & 668.48 & 3.51 \\
\hline 3/21/2006 21:00 & 9.45 & 660.67 & 331.81 & 315.80 & 10.92 & 7.99 & 671.05 & 3.51 \\
\hline $3 / 21 / 200622: 00$ & 8.87 & 656.66 & 331.17 & 316.55 & 18.01 & 7.84 & 659.70 & 3.51 \\
\hline 3/21/2006 23:00 & 8.39 & 618.06 & 330.02 & 315.03 & 8.53 & 7.11 & 610.54 & 3.51 \\
\hline 3/22/2006 0:00 & 7.81 & 604.98 & 318.64 & 303.53 & 2.41 & 6.36 & 589.59 & 3.51 \\
\hline $3 / 22 / 20061: 00$ & 9.89 & 680.92 & 329.37 & 312.68 & 14.75 & 8.82 & 691.64 & 3.51 \\
\hline $3 / 22 / 20062: 00$ & 8.05 & 627.63 & 323.90 & 310.14 & 13.82 & 7.21 & 623.91 & 3.51 \\
\hline $3 / 22 / 20063: 00$ & 8.49 & 638.60 & 315.13 & 300.17 & 6.26 & 7.22 & 629.18 & 3.51 \\
\hline $3 / 22 / 20064: 00$ & 10.02 & 691.28 & 330.23 & 313.44 & 23.19 & 9.30 & 699.27 & 3.51 \\
\hline 3/22/2006 5:00 & 8.24 & 638.07 & 322.51 & 308.97 & 23.19 & 7.77 & 632.24 & 3.51 \\
\hline $3 / 22 / 20066: 00$ & 8.03 & 627.98 & 320.87 & 306.41 & 23.06 & 7.76 & 633.86 & 3.51 \\
\hline $3 / 22 / 20067: 00$ & 7.37 & 610.12 & 310.17 & 296.36 & 18.77 & 6.95 & 611.11 & 3.51 \\
\hline $3 / 22 / 20068: 00$ & 8.55 & 623.46 & 320.33 & 304.82 & 16.82 & 7.68 & 636.01 & 3.51 \\
\hline 3/22/2006 9:00 & 7.02 & 588.25 & 310.83 & 297.22 & 18.01 & 6.37 & 583.85 & 3.51 \\
\hline 3/22/2006 10:00 & 5.84 & 545.00 & 306.50 & 292.65 & 18.00 & 5.41 & 545.39 & 3.51 \\
\hline 3/22/2006 11:00 & 6.76 & 582.58 & 309.66 & 294.32 & 5.89 & 5.85 & 577.54 & 3.51 \\
\hline 3/22/2006 12:00 & 6.70 & 558.38 & 314.07 & 299.55 & 2.59 & 5.37 & 548.93 & 3.51 \\
\hline 3/22/2006 13:00 & 7.32 & 600.71 & 315.27 & 299.52 & 2.59 & 6.10 & 597.62 & 3.51 \\
\hline $3 / 22 / 2006$ 14:00 & 8.34 & 640.04 & 328.34 & 312.46 & 2.59 & 6.96 & 631.91 & 3.51 \\
\hline 3/22/2006 15:00 & 8.07 & 636.05 & 325.94 & 310.75 & 2.59 & 6.80 & 632.24 & 3.51 \\
\hline 3/22/2006 16:00 & 9.94 & 679.32 & 337.95 & 321.80 & 7.22 & 8.59 & 696.29 & 3.51 \\
\hline 3/22/2006 17:00 & 8.76 & 643.29 & 335.59 & 320.87 & 5.41 & 7.40 & 647.66 & 3.51 \\
\hline 3/22/2006 18:00 & 5.56 & 540.38 & 317.11 & 305.15 & 2.59 & 4.76 & 521.26 & 3.51 \\
\hline 3/22/2006 19:00 & 7.15 & 618.25 & 313.21 & 298.22 & 2.59 & 6.20 & 607.43 & 3.51 \\
\hline 3/22/2006 20:00 & 9.79 & 699.29 & 335.40 & 317.99 & 8.08 & 8.67 & 706.20 & 3.51 \\
\hline 3/22/2006 21:00 & 9.18 & 687.18 & 337.22 & 321.93 & 13.84 & 8.58 & 699.36 & 3.51 \\
\hline $3 / 22 / 200622: 00$ & 9.82 & 698.03 & 336.80 & 320.97 & 8.09 & 8.82 & 694.25 & 3.51 \\
\hline 3/22/2006 23:00 & 9.67 & 689.56 & 333.80 & 318.71 & 8.09 & 8.73 & 694.52 & 3.51 \\
\hline 3/23/2006 0:00 & 9.10 & 676.27 & 329.77 & 314.88 & 8.09 & 8.22 & 673.62 & 3.51 \\
\hline 3/23/2006 1:00 & 9.83 & 688.16 & 331.67 & 315.92 & 8.09 & 8.76 & 692.56 & 3.51 \\
\hline $3 / 23 / 20062: 00$ & 9.83 & 681.45 & 332.06 & 316.61 & 8.09 & 8.71 & 692.35 & 3.51 \\
\hline 3/23/2006 3:00 & 9.76 & 681.77 & 331.89 & 316.18 & 8.09 & 8.70 & 693.16 & 3.51 \\
\hline 3/23/2006 4:00 & 8.17 & 629.60 & 326.36 & 312.73 & 7.42 & 7.24 & 623.32 & 3.51 \\
\hline $3 / 23 / 20065: 00$ & 9.09 & 664.53 & 322.14 & 306.74 & 2.50 & 7.61 & 661.07 & 3.51 \\
\hline $3 / 23 / 20066: 00$ & 9.49 & 672.66 & 322.76 & 307.26 & 2.35 & 7.99 & 660.85 & 3.51 \\
\hline $3 / 23 / 2006$ 7:00 & 9.68 & 682.17 & 323.05 & 307.24 & 3.65 & 8.33 & 684.53 & 3.51 \\
\hline 3/23/2006 8:00 & 9.14 & 678.30 & 327.13 & 311.46 & 11.29 & 8.24 & 686.52 & 7.31 \\
\hline 3/23/2006 9:00 & 8.68 & 668.76 & 326.22 & 310.60 & 2.29 & 6.78 & 654.09 & 23.04 \\
\hline 3/23/2006 10:00 & 7.09 & 599.96 & 316.11 & 302.36 & 2.29 & 5.18 & 575.97 & 20.70 \\
\hline
\end{tabular}


Table F-2. Hourly Averaged Operation Data for FF 2-3 and 2-4 (continued)

\begin{tabular}{|c|c|c|c|c|c|c|c|c|}
\hline Date, Time & $\begin{array}{c}\text { FF 2-4 } \Delta \mathrm{P}, \\
\text { inches } \\
\text { of } \mathrm{H}_{2} \mathrm{O}\end{array}$ & $\begin{array}{l}\text { FF 2-4 } \\
\text { Gas Flow, } \\
\text { kacfm }\end{array}$ & $\begin{array}{c}\text { FF 2-4 } \\
\text { Inlet Flue Gas } \\
\text { Temp., }{ }^{\circ} \mathrm{F}\end{array}$ & $\begin{array}{c}\text { FF 2-4 } \\
\text { Outlet Flue Gas } \\
\text { Temp., }{ }^{\circ} \mathrm{F}\end{array}$ & $\begin{array}{l}\text { FF 2-4 } \\
\text { Bypass, } \\
\text { \% Open }\end{array}$ & $\begin{array}{c}\text { FF 2-3 } \Delta \text { P, } \\
\text { inches } \\
\text { of } \mathrm{H}_{2} \mathrm{O}\end{array}$ & $\begin{array}{l}\text { FF 2-3 } \\
\text { Gas Flow, } \\
\text { kacfm }\end{array}$ & $\begin{array}{l}\text { FF 2-3 } \\
\text { Bypass, } \\
\% \text { Open }\end{array}$ \\
\hline 3/23/2006 11:00 & 7.33 & 617.99 & 314.66 & 299.69 & 2.29 & 5.70 & 601.99 & 10.35 \\
\hline 3/23/2006 12:00 & 6.94 & 602.78 & 314.29 & 299.61 & 2.29 & 5.73 & 596.36 & 6.10 \\
\hline 3/23/2006 13:00 & 5.18 & 503.90 & 305.67 & 291.13 & 2.29 & 4.04 & 493.82 & 6.10 \\
\hline 3/23/2006 14:00 & 4.92 & 485.57 & 306.86 & 290.91 & 2.30 & 3.70 & 478.54 & 6.10 \\
\hline $3 / 23 / 2006$ 15:00 & 5.29 & 520.55 & 308.01 & 291.47 & 2.46 & 4.20 & 517.82 & 6.10 \\
\hline $3 / 23 / 200616: 00$ & 5.02 & 506.14 & 299.21 & 285.85 & 2.44 & 4.09 & 501.04 & 6.10 \\
\hline $3 / 23 / 2006$ 17:00 & 5.16 & 510.97 & 295.94 & 281.30 & 2.43 & 4.17 & 503.39 & 6.10 \\
\hline 3/23/2006 18:00 & 5.40 & 522.07 & 296.05 & 281.40 & 2.45 & 4.34 & 511.45 & 6.10 \\
\hline 3/23/2006 19:00 & 6.61 & 572.86 & 300.84 & 284.75 & 2.47 & 5.37 & 566.05 & 6.11 \\
\hline 3/23/2006 20:00 & 9.56 & 679.66 & 326.25 & 307.97 & 17.89 & 8.54 & 699.91 & 3.93 \\
\hline 3/23/2006 21:00 & 9.50 & 680.80 & 334.20 & 317.78 & 23.04 & 8.91 & 702.81 & 3.51 \\
\hline 3/23/2006 22:00 & 9.58 & 682.80 & 335.61 & 319.38 & 23.20 & 9.01 & 702.37 & 3.51 \\
\hline 3/23/2006 23:00 & 9.89 & 682.06 & 334.82 & 319.09 & 24.99 & 9.26 & 705.29 & 3.51 \\
\hline 3/24/2006 0:00 & 9.34 & 669.02 & 333.95 & 318.21 & 21.34 & 8.68 & 683.06 & 4.00 \\
\hline $3 / 24 / 20061: 00$ & 6.48 & 564.28 & 312.15 & 299.73 & 2.29 & 5.29 & 546.73 & 9.20 \\
\hline $3 / 24 / 20062: 00$ & 5.17 & 511.45 & 306.03 & 291.45 & 2.29 & 4.46 & 508.83 & 3.67 \\
\hline 3/24/2006 3:00 & 5.39 & 536.65 & 301.40 & 286.21 & 2.29 & 4.68 & 531.16 & 3.53 \\
\hline $3 / 24 / 20064: 00$ & 9.56 & 679.44 & 322.95 & 305.12 & 6.67 & 8.21 & 689.27 & 3.78 \\
\hline $3 / 24 / 20065: 00$ & 9.49 & 655.25 & 323.81 & 307.69 & 4.13 & 6.83 & 651.51 & 23.76 \\
\hline $3 / 24 / 20066: 00$ & 9.67 & 665.62 & 326.04 & 309.57 & 11.83 & 6.86 & 667.30 & 33.75 \\
\hline $3 / 24 / 2006$ 7:00 & 9.89 & 674.28 & 328.95 & 311.97 & 2.29 & 6.64 & 672.94 & 39.98 \\
\hline $3 / 24 / 20068: 00$ & 9.81 & 663.21 & 329.51 & 313.02 & 6.33 & 6.70 & 670.16 & 39.98 \\
\hline 3/24/2006 9:00 & 8.33 & 622.13 & 322.17 & 307.89 & 3.55 & 5.92 & 609.14 & 21.87 \\
\hline 3/24/2006 10:00 & 8.46 & 640.37 & 321.23 & 305.32 & 3.11 & 6.35 & 624.37 & 15.80 \\
\hline 3/24/2006 11:00 & 8.63 & 634.56 & 324.77 & 309.18 & 3.20 & 6.87 & 639.69 & 6.12 \\
\hline 3/24/2006 12:00 & 7.05 & 578.01 & 318.55 & 304.97 & 3.20 & 5.58 & 574.00 & 6.10 \\
\hline 3/24/2006 13:00 & 8.16 & 626.57 & 320.57 & 304.91 & 3.20 & 6.52 & 622.06 & 6.10 \\
\hline $3 / 24 / 200614: 00$ & 9.01 & 639.18 & 326.10 & 310.80 & 3.18 & 7.15 & 634.20 & 5.29 \\
\hline $3 / 24 / 2006$ 15:00 & 8.38 & 618.26 & 320.12 & 305.56 & 3.20 & 6.68 & 618.25 & 6.00 \\
\hline $3 / 24 / 2006$ 16:00 & 9.02 & 636.44 & 326.33 & 310.91 & 3.20 & 7.17 & 634.68 & 5.42 \\
\hline $3 / 24 / 2006$ 17:00 & 8.95 & 642.47 & 327.36 & 312.40 & 3.20 & 7.21 & 639.27 & 5.03 \\
\hline 3/24/2006 18:00 & 7.00 & 573.00 & 316.71 & 303.80 & 3.20 & 5.15 & 543.58 & 6.10 \\
\hline $3 / 24 / 200619: 00$ & 7.83 & 615.15 & 318.44 & 303.24 & 3.20 & 6.19 & 598.73 & 6.10 \\
\hline 3/24/2006 20:00 & 6.05 & 554.44 & 312.83 & 299.42 & 3.20 & 4.86 & 530.63 & 5.13 \\
\hline 3/24/2006 21:00 & 5.52 & 548.22 & 302.75 & 290.22 & 3.20 & 4.62 & 529.48 & 3.73 \\
\hline 3/24/2006 22:00 & 4.82 & 525.35 & 293.58 & 281.74 & 3.20 & 4.15 & 497.73 & 3.57 \\
\hline $3 / 24 / 200623: 00$ & 3.98 & 474.47 & 280.51 & 268.80 & 3.20 & 3.32 & 440.48 & 3.51 \\
\hline 3/25/2006 0:00 & 4.99 & 527.81 & 280.69 & 267.12 & 3.19 & 4.14 & 504.19 & 3.51 \\
\hline 3/25/2006 1:00 & 4.44 & 523.36 & 284.48 & 271.63 & 2.85 & 3.99 & 504.70 & 3.51 \\
\hline $3 / 25 / 20062: 00$ & 3.80 & 470.10 & 276.04 & 263.56 & 2.44 & 3.40 & 456.05 & 3.51 \\
\hline $3 / 25 / 20063: 00$ & 4.66 & 519.76 & 280.53 & 265.94 & 2.44 & 4.21 & 511.76 & 3.51 \\
\hline 3/25/2006 4:00 & 5.45 & 553.87 & 292.83 & 278.57 & 2.51 & 4.78 & 545.76 & 3.51 \\
\hline 3/25/2006 5:00 & 4.72 & 518.90 & 285.75 & 272.56 & 2.38 & 4.00 & 498.12 & 3.51 \\
\hline $3 / 25 / 20066: 00$ & 8.21 & 652.00 & 307.70 & 289.28 & 2.29 & 7.04 & 653.77 & 3.51 \\
\hline $3 / 25 / 20067: 00$ & 7.83 & 613.90 & 317.53 & 302.57 & 2.29 & 6.44 & 618.38 & 3.51 \\
\hline 3/25/2006 8:00 & 7.62 & 618.85 & 315.04 & 299.64 & 2.29 & 6.46 & 622.20 & 3.51 \\
\hline 3/25/2006 9:00 & 7.94 & 625.21 & 318.54 & 303.04 & 2.29 & 6.74 & 632.14 & 3.52 \\
\hline 3/25/2006 10:00 & 8.23 & 623.79 & 324.35 & 308.77 & 2.38 & 6.55 & 630.27 & 3.68 \\
\hline 3/25/2006 11:00 & 8.14 & 625.54 & 327.01 & 312.14 & 2.43 & 6.34 & 624.27 & 3.69 \\
\hline 3/25/2006 12:00 & 7.49 & 606.33 & 322.34 & 308.33 & 2.57 & 5.89 & 598.43 & 3.66 \\
\hline 3/25/2006 13:00 & 7.30 & 596.81 & 323.37 & 309.09 & 2.59 & 5.73 & 589.69 & 3.66 \\
\hline $3 / 25 / 200614: 00$ & 6.33 & 577.44 & 318.36 & 305.17 & 2.59 & 4.94 & 551.60 & 3.66 \\
\hline $3 / 25 / 2006$ 15:00 & 7.20 & 610.56 & 325.62 & 310.13 & 2.59 & 5.75 & 587.95 & 3.66 \\
\hline
\end{tabular}


Table F-2. Hourly Averaged Operation Data for FF 2-3 and 2-4 (continued)

\begin{tabular}{|c|c|c|c|c|c|c|c|c|}
\hline Date, Time & $\begin{array}{l}\text { FF 2-4 } \Delta \mathrm{P}, \\
\text { inches } \\
\text { of } \mathrm{H}_{2} \mathrm{O}\end{array}$ & $\begin{array}{c}\text { FF 2-4 } \\
\text { Gas Flow, } \\
\text { kacfm }\end{array}$ & $\begin{array}{c}\text { FF 2-4 } \\
\text { Inlet Flue Gas } \\
\text { Temp., }{ }^{\circ} \mathrm{F}\end{array}$ & $\begin{array}{c}\text { FF 2-4 } \\
\text { Outlet Flue Gas } \\
\text { Temp., }{ }^{\circ} \mathrm{F}\end{array}$ & $\begin{array}{l}\text { FF 2-4 } \\
\text { Bypass, } \\
\text { \% Open }\end{array}$ & $\begin{array}{l}\text { FF 2-3 } \Delta \mathrm{P}, \\
\text { inches } \\
\text { of } \mathrm{H}_{2} \mathrm{O}\end{array}$ & $\begin{array}{c}\text { FF 2-3 } \\
\text { Gas Flow, } \\
\text { kacfm }\end{array}$ & $\begin{array}{l}\text { FF 2-3 } \\
\text { Bypass, } \\
\text { \% Open }\end{array}$ \\
\hline $3 / 25 / 200616: 00$ & 8.04 & 635.62 & 331.67 & 317.09 & 2.59 & 6.35 & 626.23 & 3.66 \\
\hline 3/25/2006 17:00 & 7.35 & 609.62 & 329.02 & 315.02 & 2.59 & 5.65 & 590.47 & 3.66 \\
\hline 3/25/2006 18:00 & 6.81 & 587.77 & 320.24 & 307.99 & 2.59 & 5.17 & 561.69 & 3.67 \\
\hline $3 / 25 / 200619: 00$ & 6.93 & 594.01 & 313.00 & 300.15 & 2.59 & 5.29 & 572.66 & 3.66 \\
\hline $3 / 25 / 200620: 00$ & 6.27 & 567.99 & 309.59 & 297.39 & 2.59 & 4.82 & 540.11 & 3.67 \\
\hline $3 / 25 / 200621: 00$ & 5.93 & 564.37 & 302.81 & 290.03 & 2.59 & 4.70 & 539.41 & 3.66 \\
\hline $3 / 25 / 200622: 00$ & 5.55 & 549.35 & 307.32 & 294.00 & 2.59 & 4.46 & 522.49 & 3.66 \\
\hline $3 / 25 / 200623: 00$ & 4.71 & 508.59 & 288.43 & 277.56 & 2.59 & 3.74 & 472.25 & 3.66 \\
\hline 3/26/2006 0:00 & 4.04 & 474.85 & 294.89 & 279.78 & 2.59 & 3.27 & 441.70 & 3.64 \\
\hline 3/26/2006 1:00 & 4.51 & 508.83 & 299.80 & 284.32 & 2.59 & 3.69 & 474.00 & 3.66 \\
\hline 3/26/2006 2:00 & 3.66 & 453.13 & 295.77 & 280.93 & 2.59 & 3.03 & 430.44 & 3.70 \\
\hline 3/26/2006 3:00 & 3.35 & 443.39 & 300.80 & 284.77 & 2.58 & 2.77 & 410.09 & 3.55 \\
\hline 3/26/2006 4:00 & 3.45 & 446.86 & 283.70 & 270.72 & 2.42 & 2.92 & 416.26 & 3.51 \\
\hline 3/26/2006 5:00 & 4.09 & 496.78 & 284.71 & 269.95 & 2.42 & 3.44 & 462.86 & 3.51 \\
\hline $3 / 26 / 20066: 00$ & 4.04 & 481.35 & 288.15 & 273.60 & 2.46 & 3.32 & 452.79 & 3.51 \\
\hline $3 / 26 / 2006$ 7:00 & 3.41 & 439.51 & 280.88 & 266.93 & 2.44 & 2.85 & 415.02 & 3.51 \\
\hline 3/26/2006 8:00 & 5.47 & 535.04 & 292.34 & 275.00 & 2.42 & 4.58 & 525.66 & 3.51 \\
\hline 3/26/2006 9:00 & 7.28 & 594.65 & 311.64 & 295.26 & 2.38 & 5.82 & 591.70 & 3.56 \\
\hline $3 / 26 / 2006$ 10:00 & 6.67 & 570.30 & 315.86 & 301.50 & 2.50 & 5.23 & 562.48 & 3.65 \\
\hline 3/26/2006 11:00 & 6.60 & 571.37 & 317.87 & 303.61 & 2.59 & 5.20 & 560.25 & 3.66 \\
\hline $3 / 26 / 200612: 00$ & 6.73 & 581.58 & 318.77 & 304.66 & 2.59 & 5.34 & 565.16 & 3.66 \\
\hline 3/26/2006 13:00 & 7.00 & 590.00 & 322.95 & 308.58 & 2.59 & 5.55 & 573.37 & 3.59 \\
\hline 3/26/2006 14:00 & 6.76 & 592.02 & 323.67 & 310.11 & 2.59 & 5.33 & 565.89 & 3.72 \\
\hline $3 / 26 / 2006$ 15:00 & 7.67 & 600.94 & 327.42 & 312.70 & 2.59 & 5.98 & 594.06 & 3.81 \\
\hline $3 / 26 / 2006$ 16:00 & 6.51 & 562.57 & 327.74 & 313.64 & 2.59 & 4.99 & 541.35 & 3.81 \\
\hline 3/26/2006 17:00 & 6.80 & 583.68 & 323.46 & 310.99 & 2.59 & 5.35 & 560.73 & 3.81 \\
\hline 3/26/2006 18:00 & 8.76 & 649.21 & 329.84 & 314.61 & 2.59 & 6.88 & 637.58 & 3.81 \\
\hline $3 / 26 / 2006$ 19:00 & 7.90 & 638.41 & 335.57 & 321.71 & 22.71 & 7.15 & 640.11 & 3.67 \\
\hline $3 / 26 / 200620: 00$ & 8.46 & 662.43 & 336.76 & 322.36 & 18.00 & 7.50 & 657.59 & 3.66 \\
\hline 3/26/2006 21:00 & 8.81 & 670.22 & 338.67 & 324.28 & 18.00 & 7.82 & 671.86 & 3.66 \\
\hline 3/26/2006 22:00 & 8.99 & 673.82 & 339.37 & 324.77 & 18.01 & 7.90 & 667.06 & 3.66 \\
\hline 3/26/2006 23:00 & 7.90 & 637.26 & 335.13 & 321.56 & 18.00 & 6.90 & 634.46 & 3.67 \\
\hline 3/27/2006 0:00 & 4.82 & 488.51 & 324.90 & 310.92 & 18.01 & 3.91 & 470.18 & 3.66 \\
\hline 3/27/2006 1:00 & 3.63 & 436.56 & 307.44 & 295.77 & 6.57 & 2.67 & 403.73 & 3.70 \\
\hline 3/27/2006 2:00 & 3.59 & 429.16 & 289.21 & 276.12 & 2.59 & 2.53 & 391.49 & 3.66 \\
\hline 3/27/2006 3:00 & 3.59 & 438.58 & 301.88 & 283.79 & 2.59 & 2.59 & 400.32 & 3.66 \\
\hline 3/27/2006 4:00 & 3.69 & 437.39 & 312.91 & 292.57 & 2.59 & 2.59 & 402.93 & 3.67 \\
\hline $3 / 27 / 20065: 00$ & 4.32 & 467.61 & 327.51 & 307.16 & 2.59 & 3.00 & 438.71 & 3.66 \\
\hline $3 / 27 / 20066: 00$ & 6.50 & 560.15 & 330.64 & 313.08 & 3.91 & 4.60 & 542.37 & 3.66 \\
\hline 3/27/2006 7:00 & 6.81 & 567.71 & 338.04 & 321.54 & 8.25 & 4.92 & 559.62 & 3.66 \\
\hline 3/27/2006 8:00 & 6.44 & 553.92 & 333.81 & 318.49 & 2.66 & 4.42 & 532.36 & 3.66 \\
\hline 3/27/2006 9:00 & 6.59 & 575.55 & 331.26 & 316.38 & 2.59 & 4.55 & 540.59 & 3.66 \\
\hline 3/27/2006 10:00 & 5.93 & 522.48 & 313.60 & 301.60 & 2.59 & 4.01 & 505.42 & 3.66 \\
\hline 3/27/2006 11:00 & 6.30 & 534.91 & 309.60 & 295.64 & 2.59 & 4.23 & 518.29 & 3.66 \\
\hline $3 / 27 / 200612: 00$ & 6.21 & 529.80 & 311.58 & 297.65 & 2.59 & 4.20 & 513.04 & 3.66 \\
\hline 3/27/2006 13:00 & 7.13 & 568.17 & 314.24 & 298.82 & 2.59 & 4.91 & 557.06 & 3.66 \\
\hline $3 / 27 / 200614: 00$ & 7.26 & 567.86 & 320.04 & 305.27 & 2.59 & 4.89 & 555.19 & 3.66 \\
\hline $3 / 27 / 2006$ 15:00 & 8.51 & 602.13 & 326.72 & 311.23 & 2.59 & 5.76 & 602.79 & 3.61 \\
\hline $3 / 27 / 2006$ 16:00 & 7.51 & 564.29 & 324.80 & 310.61 & 2.59 & 4.94 & 550.34 & 3.68 \\
\hline 3/27/2006 17:00 & 7.04 & 551.95 & 321.40 & 307.42 & 2.59 & 4.62 & 536.67 & 3.69 \\
\hline 3/27/2006 18:00 & 8.86 & 636.92 & 327.59 & 312.30 & 14.15 & 6.77 & 645.11 & 4.15 \\
\hline 3/27/2006 19:00 & 9.94 & 676.65 & 340.99 & 325.11 & 24.82 & 8.07 & 697.66 & 4.73 \\
\hline 3/27/2006 20:00 & 9.54 & 675.00 & 344.16 & 329.16 & 32.95 & 8.22 & 703.03 & 4.73 \\
\hline
\end{tabular}


Table F-2. Hourly Averaged Operation Data for FF 2-3 and 2-4 (continued)

\begin{tabular}{|c|c|c|c|c|c|c|c|c|}
\hline Date, Time & $\begin{array}{c}\text { FF 2-4 } \Delta \mathrm{P}, \\
\text { inches } \\
\text { of } \mathrm{H}_{2} \mathrm{O}\end{array}$ & $\begin{array}{c}\text { FF 2-4 } \\
\text { Gas Flow, } \\
\text { kacfm }\end{array}$ & $\begin{array}{c}\text { FF 2-4 } \\
\text { Inlet Flue Gas } \\
\text { Temp., }{ }^{\circ} \mathrm{F} \\
\end{array}$ & $\begin{array}{c}\text { FF 2-4 } \\
\text { Outlet Flue Gas } \\
\text { Temp., }{ }^{\circ} \mathrm{F} \\
\end{array}$ & $\begin{array}{l}\text { FF 2-4 } \\
\text { Bypass, } \\
\text { \% Open }\end{array}$ & $\begin{array}{c}\text { FF 2-3 } \Delta P, \\
\text { inches } \\
\text { of } \mathrm{H}_{2} \mathrm{O}\end{array}$ & $\begin{array}{c}\text { FF 2-3 } \\
\text { Gas Flow, } \\
\text { kacfm }\end{array}$ & $\begin{array}{l}\text { FF 2-3 } \\
\text { Bypass, } \\
\text { \% Open }\end{array}$ \\
\hline 3/27/2006 21:00 & 9.61 & 681.63 & 345.18 & 330.34 & 32.99 & 8.30 & 706.79 & 4.73 \\
\hline 3/27/2006 22:00 & 8.95 & 667.75 & 346.16 & 331.59 & 32.97 & 7.68 & 684.16 & 5.06 \\
\hline 3/27/2006 23:00 & 7.57 & 641.69 & 339.94 & 326.42 & 32.97 & 6.41 & 638.33 & 12.25 \\
\hline 3/28/2006 0:00 & 6.65 & 615.12 & 335.66 & 322.64 & 32.96 & 5.63 & 594.29 & 12.97 \\
\hline 3/28/2006 1:00 & 4.64 & 519.26 & 322.18 & 310.02 & 33.00 & 3.86 & 501.35 & 12.97 \\
\hline $3 / 28 / 20062: 00$ & 4.90 & 524.24 & 322.75 & 307.10 & 32.96 & 4.16 & 511.04 & 12.97 \\
\hline 3/28/2006 3:00 & 5.73 & 561.27 & 328.78 & 313.77 & 32.96 & 4.71 & 546.25 & 12.97 \\
\hline $3 / 28 / 20064: 00$ & 4.70 & 527.07 & 319.11 & 306.07 & 32.96 & 4.18 & 502.67 & 12.97 \\
\hline $3 / 28 / 20065: 00$ & 5.61 & 568.19 & 319.11 & 305.05 & 32.96 & 4.96 & 554.72 & 12.97 \\
\hline $3 / 28 / 20066: 00$ & 3.94 & 484.21 & 311.93 & 297.71 & 32.97 & 3.37 & 448.62 & 12.97 \\
\hline $3 / 28 / 20067: 00$ & 5.59 & 570.65 & 314.63 & 299.60 & 32.96 & 4.78 & 548.97 & 12.97 \\
\hline 3/28/2006 8:00 & 5.83 & 586.61 & 321.15 & 306.12 & 32.96 & 5.02 & 561.75 & 12.97 \\
\hline 3/28/2006 9:00 & 7.17 & 629.79 & 331.86 & 315.91 & 32.89 & 6.33 & 623.79 & 12.97 \\
\hline 3/28/2006 10:00 & 8.44 & 618.37 & 325.46 & 311.07 & 2.86 & 5.57 & 589.21 & 12.97 \\
\hline 3/28/2006 11:00 & 9.19 & 624.30 & 325.00 & 309.28 & 2.59 & 5.93 & 607.93 & 12.97 \\
\hline 3/28/2006 12:00 & 9.02 & 611.54 & 324.64 & 309.74 & 2.59 & 5.68 & 597.11 & 12.97 \\
\hline 3/28/2006 13:00 & 9.29 & 615.78 & 323.93 & 308.50 & 2.59 & 5.79 & 598.95 & 12.97 \\
\hline 3/28/2006 14:00 & 9.74 & 658.02 & 332.66 & 316.25 & 26.99 & 7.36 & 669.27 & 15.28 \\
\hline 3/28/2006 15:00 & 9.04 & 674.11 & 344.42 & 328.56 & 51.21 & 8.59 & 704.20 & 3.66 \\
\hline 3/28/2006 16:00 & 9.43 & 679.36 & 348.43 & 332.49 & 38.16 & 8.66 & 710.24 & 3.67 \\
\hline 3/28/2006 17:00 & 8.97 & 634.76 & 342.65 & 328.80 & 17.15 & 7.09 & 644.16 & 3.66 \\
\hline 3/28/2006 18:00 & 9.02 & 624.49 & 331.08 & 317.30 & 2.59 & 6.26 & 617.70 & 3.66 \\
\hline 3/28/2006 19:00 & 9.66 & 683.68 & 342.31 & 326.14 & 28.90 & 8.18 & 702.10 & 3.66 \\
\hline 3/28/2006 20:00 & 9.92 & 695.58 & 348.09 & 332.29 & 32.96 & 8.62 & 716.48 & 3.66 \\
\hline 3/28/2006 21:00 & 7.47 & 619.96 & 336.97 & 324.61 & 32.96 & 6.32 & 616.92 & 3.66 \\
\hline 3/28/2006 22:00 & 5.77 & 559.60 & 317.91 & 306.54 & 32.96 & 4.91 & 549.11 & 3.66 \\
\hline 3/28/2006 23:00 & 6.37 & 590.87 & 322.30 & 307.95 & 32.96 & 5.52 & 589.52 & 3.68 \\
\hline 3/29/2006 0:00 & 4.65 & 534.64 & 315.98 & 304.01 & 32.97 & 4.44 & 525.97 & 3.61 \\
\hline
\end{tabular}


Table F-3. Hourly Average FF 2-4 Average Hopper Surface Temperatures During the Monthlong Test

\begin{tabular}{|c|c|c|c|c|c|c|c|c|}
\hline Date, Time & $\begin{array}{c}\text { FF 2-4 A } \\
\text { Hopper } \\
\text { Temp., }{ }^{\circ} \mathrm{F}\end{array}$ & $\begin{array}{l}\text { FF 2-4 B } \\
\text { Hopper } \\
\text { Temp., }{ }^{\circ} \mathrm{F}\end{array}$ & $\begin{array}{c}\text { FF 2-4 C } \\
\text { Hopper } \\
\text { Temp., }{ }^{\circ} \mathrm{F}\end{array}$ & $\begin{array}{l}\text { FF 2-4 D } \\
\text { Hopper } \\
\text { Temp., }{ }^{\circ} \mathrm{F}\end{array}$ & $\begin{array}{c}\text { FF 2-4 E } \\
\text { Hopper } \\
\text { Temp., }{ }^{\circ} \mathrm{F}\end{array}$ & $\begin{array}{c}\text { FF 2-4 F } \\
\text { Hopper } \\
\text { Temp., }{ }^{\circ} \mathrm{F}\end{array}$ & $\begin{array}{c}\text { FF 2-4 G } \\
\text { Hopper } \\
\text { Temp., }{ }^{\circ} \mathrm{F}\end{array}$ & $\begin{array}{c}\text { FF 2-4 H } \\
\text { Hopper } \\
\text { Temp., }{ }^{\circ} \mathrm{F}\end{array}$ \\
\hline $2 / 27 / 200615: 00$ & 30.98 & 172.84 & 73.19 & 191.54 & 245.55 & 242.21 & 257.60 & 74.80 \\
\hline $2 / 27 / 200616: 00$ & 30.98 & 176.44 & 74.19 & 190.67 & 245.96 & 240.43 & 264.04 & 76.42 \\
\hline $2 / 27 / 200617: 00$ & 30.98 & 173.98 & 75.33 & 190.80 & 244.03 & 239.24 & 258.49 & 77.50 \\
\hline $2 / 27 / 200618: 00$ & 30.98 & 173.53 & 76.14 & 191.45 & 243.05 & 239.20 & 254.40 & 77.97 \\
\hline $2 / 27 / 200619: 00$ & 30.98 & 172.75 & 76.14 & 192.07 & 242.46 & 238.97 & 251.92 & 77.97 \\
\hline $2 / 27 / 200620: 00$ & 30.98 & 172.88 & 76.14 & 192.47 & 241.12 & 239.02 & 248.54 & 77.97 \\
\hline $2 / 27 / 200621: 00$ & 30.98 & 178.34 & 76.14 & 192.01 & 242.87 & 239.24 & 256.63 & 77.97 \\
\hline $2 / 27 / 200622: 00$ & 30.98 & 180.03 & 75.38 & 189.34 & 242.49 & 236.96 & 260.37 & 77.97 \\
\hline $2 / 27 / 200623: 00$ & 30.98 & 180.67 & 76.14 & 189.03 & 243.05 & 236.45 & 255.63 & 77.97 \\
\hline 2/28/2006 0:00 & 30.98 & 178.55 & 75.31 & 189.47 & 239.46 & 236.10 & 242.86 & 77.71 \\
\hline $2 / 28 / 20061: 00$ & 30.98 & 173.68 & 74.92 & 185.29 & 235.66 & 232.96 & 237.48 & 77.06 \\
\hline $2 / 28 / 20062: 00$ & 30.98 & 167.86 & 74.25 & 179.40 & 230.47 & 227.06 & 229.77 & 76.75 \\
\hline $2 / 28 / 20063: 00$ & 30.98 & 156.33 & 73.96 & 173.27 & 224.34 & 220.22 & 221.33 & 76.14 \\
\hline $2 / 28 / 20064: 00$ & 30.98 & 148.07 & 73.06 & 167.89 & 219.72 & 215.46 & 214.81 & 74.62 \\
\hline $2 / 28 / 20065: 00$ & 30.98 & 143.32 & 71.87 & 164.21 & 213.99 & 210.21 & 212.52 & 74.57 \\
\hline $2 / 28 / 20066: 00$ & 30.98 & 138.81 & 71.61 & 162.03 & 214.48 & 210.83 & 206.69 & 73.94 \\
\hline $2 / 28 / 2006$ 7:00 & 30.98 & 151.00 & 70.66 & 167.83 & 219.42 & 217.78 & 218.34 & 73.09 \\
\hline $2 / 28 / 20068: 00$ & 30.98 & 164.53 & 70.04 & 176.75 & 226.48 & 226.58 & 230.12 & 71.97 \\
\hline $2 / 28 / 20069: 00$ & 30.98 & 174.53 & 70.49 & 183.23 & 233.63 & 232.93 & 238.62 & 72.38 \\
\hline $2 / 28 / 200610: 00$ & 30.98 & 183.40 & 71.69 & 190.15 & 241.47 & 240.37 & 242.22 & 73.58 \\
\hline $2 / 28 / 200611: 00$ & 30.98 & 193.87 & 73.60 & 198.16 & 250.97 & 248.81 & 256.11 & 75.16 \\
\hline $2 / 28 / 200612: 00$ & 30.98 & 196.64 & 75.04 & 199.86 & 252.53 & 249.45 & 254.52 & 76.65 \\
\hline $2 / 28 / 200613: 00$ & 30.98 & 196.11 & 76.73 & 199.65 & 251.22 & 248.32 & 251.47 & 78.42 \\
\hline $2 / 28 / 200614: 00$ & 30.98 & 195.71 & 78.04 & 200.67 & 252.02 & 250.05 & 254.98 & 80.03 \\
\hline $2 / 28 / 2006$ 15:00 & 30.98 & 195.62 & 79.46 & 201.88 & 252.36 & 250.55 & 248.12 & 81.37 \\
\hline $2 / 28 / 2006$ 16:00 & 30.98 & 194.10 & 80.62 & 201.83 & 252.71 & 251.04 & 254.83 & 82.33 \\
\hline $2 / 28 / 200617: 00$ & 30.98 & 196.29 & 81.03 & 203.09 & 252.79 & 251.75 & 253.69 & 83.77 \\
\hline $2 / 28 / 200618: 00$ & 30.98 & 197.04 & 81.91 & 202.61 & 252.19 & 250.58 & 254.42 & 84.99 \\
\hline 2/28/2006 19:00 & 30.98 & 197.53 & 81.93 & 202.87 & 253.50 & 250.49 & 258.10 & 84.90 \\
\hline $2 / 28 / 200620: 00$ & 30.98 & 201.87 & 81.05 & 204.59 & 255.38 & 252.76 & 256.62 & 84.08 \\
\hline $2 / 28 / 200621: 00$ & 30.98 & 202.66 & 81.03 & 202.98 & 252.08 & 250.17 & 249.88 & 84.08 \\
\hline $2 / 28 / 200622: 00$ & 30.98 & 201.07 & 80.50 & 200.82 & 250.97 & 247.61 & 250.52 & 83.28 \\
\hline $2 / 28 / 200623: 00$ & 30.98 & 202.71 & 80.11 & 202.33 & 251.85 & 249.78 & 254.08 & 82.69 \\
\hline 3/1/2006 0:00 & 30.98 & 202.25 & 79.80 & 202.35 & 251.25 & 249.24 & 256.67 & 81.16 \\
\hline 3/1/2006 1:00 & 30.98 & 181.23 & 78.89 & 195.60 & 244.49 & 240.60 & 243.50 & 81.85 \\
\hline 3/1/2006 2:00 & 30.98 & 163.51 & 78.43 & 191.51 & 240.77 & 237.71 & 239.86 & 81.01 \\
\hline 3/1/2006 3:00 & 30.98 & 162.12 & 77.97 & 192.98 & 242.86 & 240.82 & 239.15 & 80.11 \\
\hline 3/1/2006 4:00 & 30.98 & 171.92 & 77.62 & 196.76 & 246.56 & 242.48 & 249.63 & 80.11 \\
\hline 3/1/2006 5:00 & 30.98 & 187.62 & 77.06 & 194.89 & 247.40 & 245.33 & 250.55 & 79.17 \\
\hline 3/1/2006 6:00 & 30.98 & 197.17 & 76.32 & 196.35 & 248.06 & 243.93 & 254.19 & 78.88 \\
\hline 3/1/2006 7:00 & 30.98 & 196.58 & 76.14 & 196.66 & 248.11 & 243.81 & 249.79 & 77.97 \\
\hline 3/1/2006 8:00 & 30.98 & 199.93 & 76.14 & 196.55 & 247.64 & 243.17 & 247.83 & 77.97 \\
\hline 3/1/2006 9:00 & 30.98 & 199.42 & 76.14 & 197.53 & 249.24 & 245.72 & 250.74 & 77.97 \\
\hline $3 / 1 / 200610: 00$ & 30.98 & 201.55 & 76.85 & 197.91 & 252.44 & 248.23 & 250.44 & 78.30 \\
\hline $3 / 1 / 2006$ 11:00 & 30.98 & 208.02 & 77.72 & 199.68 & 255.55 & 253.24 & 256.03 & 79.50 \\
\hline $3 / 1 / 200612: 00$ & 30.98 & 211.67 & 78.82 & 201.37 & 258.63 & 255.13 & 258.37 & 80.65 \\
\hline $3 / 1 / 200613: 00$ & 30.98 & 212.17 & 80.28 & 202.70 & 261.08 & 256.81 & 262.26 & 82.02 \\
\hline $3 / 1 / 200614: 00$ & 30.98 & 212.02 & 81.62 & 201.90 & 261.47 & 258.08 & 265.64 & 83.65 \\
\hline $3 / 1 / 2006$ 15:00 & 30.98 & 213.91 & 83.34 & 207.12 & 266.72 & 262.59 & 269.41 & 85.12 \\
\hline $3 / 1 / 200616: 00$ & 30.98 & 218.54 & 84.08 & 209.87 & 269.81 & 266.34 & 269.41 & 86.16 \\
\hline $3 / 1 / 2006$ 17:00 & 30.98 & 225.55 & 84.89 & 212.00 & 272.30 & 265.16 & 282.74 & 87.39 \\
\hline
\end{tabular}


Table F-3. Hourly Average FF 2-4 Average Hopper Surface Temperatures During the Monthlong Test (continued)

\begin{tabular}{|c|c|c|c|c|c|c|c|c|}
\hline Date, Time & $\begin{array}{c}\text { FF 2-4 A } \\
\text { Hopper } \\
\text { Temp., }{ }^{\circ} \mathrm{F}\end{array}$ & $\begin{array}{l}\text { FF 2-4 B } \\
\text { Hopper } \\
\text { Temp., }{ }^{\circ} \mathrm{F}\end{array}$ & $\begin{array}{c}\text { FF 2-4 C } \\
\text { Hopper } \\
\text { Temp., }{ }^{\circ} \mathrm{F}\end{array}$ & $\begin{array}{l}\text { FF 2-4 D } \\
\text { Hopper } \\
\text { Temp., }{ }^{\circ} \mathrm{F}\end{array}$ & $\begin{array}{c}\text { FF 2-4 E } \\
\text { Hopper } \\
\text { Temp., }{ }^{\circ} \mathrm{F}\end{array}$ & $\begin{array}{c}\text { FF 2-4 F } \\
\text { Hopper } \\
\text { Temp., }{ }^{\circ} \mathrm{F}\end{array}$ & $\begin{array}{l}\text { FF 2-4 G } \\
\text { Hopper } \\
\text { Temp., }{ }^{\circ} \mathrm{F}\end{array}$ & $\begin{array}{l}\text { FF 2-4 H } \\
\text { Hopper } \\
\text { Temp., }{ }^{\circ} \mathrm{F}\end{array}$ \\
\hline $3 / 1 / 2006$ 18:00 & 30.98 & 224.21 & 85.04 & 213.50 & 272.77 & 270.03 & 275.51 & 87.78 \\
\hline $3 / 1 / 2006$ 19:00 & 30.98 & 225.64 & 85.46 & 214.19 & 273.01 & 272.10 & 278.24 & 88.76 \\
\hline $3 / 1 / 200620: 00$ & 30.98 & 225.97 & 84.99 & 213.37 & 272.92 & 271.79 & 273.20 & 88.04 \\
\hline $3 / 1 / 200621: 00$ & 30.98 & 221.81 & 84.61 & 211.43 & 270.23 & 269.87 & 274.12 & 87.67 \\
\hline $3 / 1 / 200622: 00$ & 30.98 & 217.10 & 84.08 & 203.69 & 264.59 & 263.56 & 265.03 & 87.13 \\
\hline $3 / 1 / 200623: 00$ & 30.98 & 207.71 & 84.06 & 186.70 & 255.63 & 255.30 & 257.85 & 86.39 \\
\hline 3/2/2006 0:00 & 30.98 & 193.10 & 83.16 & 172.62 & 242.63 & 241.71 & 244.73 & 85.83 \\
\hline 3/2/2006 1:00 & 30.98 & 186.76 & 82.40 & 171.06 & 239.91 & 239.51 & 243.05 & 84.74 \\
\hline $3 / 2 / 20062: 00$ & 30.98 & 194.09 & 81.74 & 179.68 & 246.86 & 247.25 & 251.30 & 84.06 \\
\hline 3/2/2006 3:00 & 30.98 & 198.90 & 80.84 & 187.32 & 252.42 & 252.87 & 259.54 & 83.12 \\
\hline $3 / 2 / 20064: 00$ & 30.98 & 196.78 & 80.11 & 186.57 & 250.45 & 250.00 & 256.86 & 81.94 \\
\hline 3/2/2006 5:00 & 30.98 & 188.34 & 78.89 & 175.04 & 242.58 & 241.71 & 242.46 & 81.18 \\
\hline $3 / 2 / 20066: 00$ & 30.98 & 184.75 & 77.97 & 168.26 & 240.47 & 238.58 & 246.72 & 80.11 \\
\hline 3/2/2006 7:00 & 30.98 & 182.86 & 77.97 & 165.38 & 239.64 & 236.35 & 242.18 & 80.11 \\
\hline 3/2/2006 8:00 & 30.98 & 180.55 & 77.33 & 163.31 & 238.50 & 235.95 & 245.59 & 78.97 \\
\hline 3/2/2006 9:00 & 30.98 & 184.66 & 77.06 & 170.53 & 243.55 & 242.83 & 255.31 & 78.89 \\
\hline $3 / 2 / 200610: 00$ & 30.98 & 194.05 & 77.04 & 183.13 & 251.20 & 251.74 & 259.83 & 78.87 \\
\hline $3 / 2 / 200611: 00$ & 30.98 & 198.72 & 77.17 & 190.26 & 253.11 & 256.14 & 269.60 & 78.89 \\
\hline $3 / 2 / 200612: 00$ & 30.98 & 198.57 & 77.97 & 189.94 & 255.30 & 256.56 & 266.84 & 79.71 \\
\hline $3 / 2 / 200613: 00$ & 30.98 & 201.62 & 79.24 & 191.73 & 257.06 & 258.34 & 269.40 & 80.88 \\
\hline $3 / 2 / 200614: 00$ & 30.98 & 208.22 & 80.57 & 198.89 & 260.88 & 263.32 & 273.37 & 82.52 \\
\hline $3 / 2 / 2006$ 15:00 & 30.98 & 210.59 & 81.40 & 202.54 & 264.27 & 265.62 & 274.84 & 83.43 \\
\hline $3 / 2 / 200616: 00$ & 30.98 & 208.44 & 82.58 & 202.38 & 264.29 & 264.91 & 277.21 & 83.98 \\
\hline $3 / 2 / 200617: 00$ & 30.98 & 210.79 & 83.50 & 200.75 & 261.50 & 262.53 & 277.44 & 85.85 \\
\hline $3 / 2 / 2006$ 18:00 & 30.98 & 211.22 & 84.08 & 199.59 & 259.96 & 260.17 & 269.95 & 85.91 \\
\hline $3 / 2 / 2006$ 19:00 & 30.98 & 211.67 & 84.03 & 200.14 & 259.25 & 259.98 & 270.87 & 85.91 \\
\hline $3 / 2 / 200620: 00$ & 30.98 & 212.31 & 83.16 & 199.84 & 258.56 & 259.34 & 267.57 & 85.69 \\
\hline $3 / 2 / 200621: 00$ & 30.98 & 207.40 & 82.89 & 193.77 & 254.41 & 251.54 & 264.67 & 84.96 \\
\hline $3 / 2 / 200622: 00$ & 30.98 & 198.84 & 81.94 & 185.60 & 249.51 & 248.02 & 256.28 & 84.08 \\
\hline $3 / 2 / 200623: 00$ & 30.98 & 189.69 & 81.20 & 182.40 & 248.23 & 247.40 & 254.93 & 82.58 \\
\hline 3/3/2006 0:00 & 30.98 & 185.99 & 80.46 & 178.58 & 244.11 & 244.01 & 246.61 & 81.83 \\
\hline 3/3/2006 1:00 & 30.98 & 189.34 & 78.80 & 176.01 & 242.92 & 243.20 & 245.38 & 80.35 \\
\hline $3 / 3 / 20062: 00$ & 30.98 & 186.40 & 77.97 & 169.52 & 238.34 & 239.79 & 241.83 & 79.43 \\
\hline 3/3/2006 3:00 & 30.98 & 185.65 & 77.40 & 167.59 & 235.77 & 237.99 & 243.83 & 78.89 \\
\hline 3/3/2006 4:00 & 30.98 & 184.70 & 76.63 & 161.96 & 233.81 & 237.47 & 238.44 & 78.04 \\
\hline 3/3/2006 5:00 & 30.98 & 182.72 & 76.14 & 156.33 & 231.97 & 234.16 & 238.67 & 77.76 \\
\hline 3/3/2006 6:00 & 30.98 & 181.71 & 76.14 & 152.83 & 231.11 & 234.01 & 238.88 & 77.06 \\
\hline 3/3/2006 7:00 & 30.98 & 182.91 & 75.65 & 151.18 & 228.62 & 232.52 & 233.33 & 77.04 \\
\hline 3/3/2006 8:00 & 30.98 & 181.87 & 74.92 & 154.44 & 230.67 & 230.62 & 235.96 & 76.14 \\
\hline 3/3/2006 9:00 & 30.98 & 183.67 & 74.92 & 157.02 & 230.44 & 232.90 & 233.75 & 76.14 \\
\hline 3/3/2006 10:00 & 30.98 & 192.16 & 74.92 & 166.69 & 236.43 & 240.59 & 245.03 & 76.59 \\
\hline 3/3/2006 11:00 & 30.98 & 188.53 & 75.07 & 167.49 & 237.08 & 240.80 & 240.97 & 77.46 \\
\hline $3 / 3 / 200612: 00$ & 30.98 & 188.41 & 76.57 & 165.06 & 236.93 & 238.91 & 242.91 & 77.97 \\
\hline 3/3/2006 13:00 & 30.98 & 192.72 & 77.69 & 169.72 & 240.59 & 243.96 & 245.95 & 78.85 \\
\hline $3 / 3 / 2006$ 14:00 & 30.98 & 203.66 & 78.50 & 180.77 & 248.17 & 251.79 & 252.90 & 80.11 \\
\hline $3 / 3 / 200615: 00$ & 30.98 & 206.52 & 79.83 & 186.86 & 252.42 & 254.25 & 258.53 & 80.99 \\
\hline $3 / 3 / 2006$ 16:00 & 30.98 & 209.71 & 80.24 & 189.97 & 253.80 & 256.45 & 253.72 & 81.90 \\
\hline $3 / 3 / 2006$ 17:00 & 30.98 & 213.23 & 81.03 & 192.33 & 255.36 & 258.01 & 262.39 & 82.79 \\
\hline $3 / 3 / 2006$ 18:00 & 30.98 & 211.54 & 81.03 & 191.97 & 255.42 & 256.34 & 257.51 & 84.08 \\
\hline 3/3/2006 19:00 & 30.98 & 207.06 & 80.99 & 187.74 & 251.76 & 252.55 & 249.16 & 83.66 \\
\hline $3 / 3 / 200620: 00$ & 30.98 & 207.26 & 80.11 & 186.69 & 250.56 & 248.73 & 247.68 & 82.24 \\
\hline 3/3/2006 21:00 & 30.98 & 202.30 & 79.35 & 180.57 & 246.24 & 246.96 & 249.04 & 81.46 \\
\hline
\end{tabular}


Table F-3. Hourly Average FF 2-4 Average Hopper Surface Temperatures During the Monthlong Test (continued)

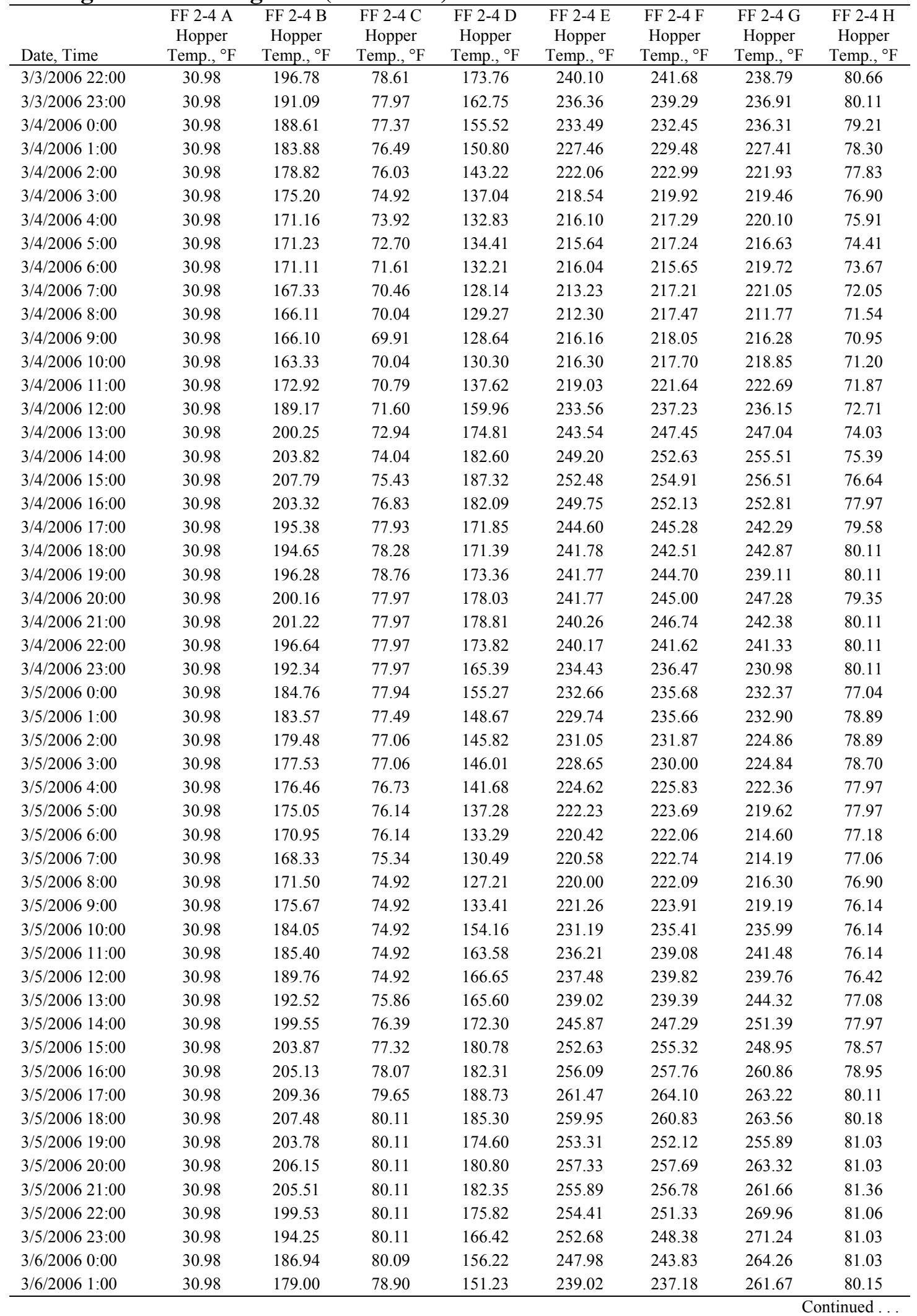


Table F-3. Hourly Average FF 2-4 Average Hopper Surface Temperatures During the Monthlong Test (continued)

\begin{tabular}{|c|c|c|c|c|c|c|c|c|}
\hline Date, Time & $\begin{array}{c}\text { FF 2-4 A } \\
\text { Hopper } \\
\text { Temp., }{ }^{\circ} \mathrm{F}\end{array}$ & $\begin{array}{l}\text { FF 2-4 B } \\
\text { Hopper } \\
\text { Temp., }{ }^{\circ} \mathrm{F}\end{array}$ & $\begin{array}{c}\text { FF 2-4 C } \\
\text { Hopper } \\
\text { Temp., }{ }^{\circ} \mathrm{F}\end{array}$ & $\begin{array}{l}\text { FF 2-4 D } \\
\text { Hopper } \\
\text { Temp., }{ }^{\circ} \mathrm{F}\end{array}$ & $\begin{array}{c}\text { FF 2-4 E } \\
\text { Hopper } \\
\text { Temp., }{ }^{\circ} \mathrm{F}\end{array}$ & $\begin{array}{c}\text { FF 2-4 F } \\
\text { Hopper } \\
\text { Temp., }{ }^{\circ} \mathrm{F}\end{array}$ & $\begin{array}{c}\text { FF 2-4 G } \\
\text { Hopper } \\
\text { Temp., }{ }^{\circ} \mathrm{F}\end{array}$ & $\begin{array}{c}\text { FF 2-4 H } \\
\text { Hopper } \\
\text { Temp., }{ }^{\circ} \mathrm{F}\end{array}$ \\
\hline $3 / 6 / 20062: 00$ & 30.98 & 176.94 & 78.24 & 151.09 & 238.46 & 235.67 & 248.58 & 79.96 \\
\hline 3/6/2006 3:00 & 30.98 & 180.97 & 77.96 & 144.85 & 226.92 & 235.35 & 241.93 & 78.89 \\
\hline 3/6/2006 4:00 & 30.98 & 183.39 & 77.14 & 142.19 & 233.11 & 235.34 & 242.12 & 78.14 \\
\hline 3/6/2006 5:00 & 30.98 & 179.96 & 77.06 & 137.44 & 232.48 & 234.08 & 232.90 & 77.97 \\
\hline 3/6/2006 7:00 & 30.98 & 173.74 & 74.49 & 131.74 & 224.80 & 230.00 & 233.61 & 76.14 \\
\hline 3/6/2006 8:00 & 30.98 & 172.29 & 74.01 & 128.59 & 226.85 & 227.98 & 233.23 & 75.24 \\
\hline 3/6/2006 9:00 & 30.98 & 171.63 & 74.01 & 131.04 & 225.41 & 224.73 & 228.89 & 74.92 \\
\hline $3 / 6 / 200610: 00$ & 30.98 & 169.60 & 74.01 & 136.10 & 225.09 & 226.05 & 230.46 & 74.92 \\
\hline $3 / 6 / 2006$ 11:00 & 30.98 & 175.87 & 74.47 & 139.89 & 224.76 & 227.97 & 229.99 & 76.07 \\
\hline $3 / 6 / 200615: 00$ & 30.98 & 195.31 & 77.97 & 167.82 & 246.36 & 247.92 & 257.34 & 79.02 \\
\hline $3 / 6 / 200616: 00$ & 30.98 & 200.01 & 77.97 & 177.63 & 252.67 & 252.60 & 264.15 & 80.11 \\
\hline $3 / 6 / 2006$ 17:00 & 30.98 & 203.23 & 78.51 & 183.37 & 254.22 & 254.20 & 259.89 & 80.25 \\
\hline 3/6/2006 18:00 & 30.98 & 204.74 & 78.89 & 186.41 & 254.93 & 256.10 & 259.92 & 81.21 \\
\hline $3 / 6 / 2006$ 19:00 & 30.98 & 202.34 & 78.91 & 183.10 & 254.48 & 254.12 & 260.70 & 81.58 \\
\hline $3 / 6 / 200620: 00$ & 30.98 & 199.94 & 78.89 & 182.77 & 255.25 & 254.75 & 264.84 & 80.10 \\
\hline $3 / 6 / 200621: 00$ & 30.98 & 199.11 & 77.98 & 177.48 & 249.02 & 251.20 & 253.89 & 80.11 \\
\hline $3 / 6 / 200622: 00$ & 30.98 & 197.02 & 77.97 & 169.70 & 248.77 & 248.12 & 252.43 & 80.11 \\
\hline $3 / 6 / 200623: 00$ & 30.98 & 191.68 & 77.97 & 164.30 & 246.29 & 246.08 & 256.21 & 79.70 \\
\hline $3 / 7 / 20066: 00$ & 30.98 & 178.66 & 76.14 & 144.04 & 233.85 & 232.55 & 241.07 & 77.06 \\
\hline 3/7/2006 7:00 & 30.98 & 177.38 & 76.14 & 143.42 & 234.10 & 231.91 & 241.14 & 77.06 \\
\hline 3/7/2006 8:00 & 30.98 & 178.26 & 76.14 & 147.93 & 235.19 & 233.76 & 238.32 & 77.06 \\
\hline 3/7/2006 9:00 & 30.98 & 182.15 & 76.14 & 156.15 & 240.24 & 239.28 & 248.82 & 77.06 \\
\hline $3 / 7 / 2006$ 10:00 & 30.98 & 185.63 & 76.14 & 159.53 & 244.26 & 240.76 & 259.33 & 77.25 \\
\hline $3 / 7 / 200611: 00$ & 30.98 & 192.71 & 76.93 & 168.34 & 248.13 & 246.01 & 262.17 & 77.97 \\
\hline $3 / 7 / 200612: 00$ & 30.98 & 197.08 & 77.75 & 174.38 & 249.94 & 249.57 & 259.28 & 78.78 \\
\hline 3/7/2006 13:00 & 30.98 & 202.48 & 78.83 & 181.66 & 254.30 & 256.07 & 260.16 & 79.46 \\
\hline $3 / 7 / 200614: 00$ & 30.98 & 204.83 & 80.23 & 185.95 & 260.06 & 261.29 & 267.05 & 81.62 \\
\hline $3 / 7 / 2006$ 15:00 & 30.98 & 208.32 & 81.62 & 188.02 & 264.50 & 265.08 & 267.45 & 82.72 \\
\hline $3 / 7 / 200616: 00$ & 30.98 & 209.43 & 81.94 & 186.17 & 264.01 & 264.33 & 271.08 & 84.03 \\
\hline $3 / 7 / 2006$ 17:00 & 30.98 & 205.56 & 82.27 & 181.68 & 263.76 & 262.96 & 273.29 & 84.08 \\
\hline 3/7/2006 18:00 & 30.98 & 205.93 & 83.16 & 181.14 & 261.03 & 257.96 & 270.78 & 84.75 \\
\hline $3 / 7 / 2006$ 19:00 & 30.98 & 209.20 & 83.28 & 184.52 & 261.02 & 259.50 & 265.59 & 85.01 \\
\hline 3/7/2006 20:00 & 30.98 & 208.39 & 83.16 & 185.59 & 260.28 & 259.64 & 264.02 & 84.65 \\
\hline $3 / 7 / 200621: 00$ & 30.98 & 205.55 & 82.91 & 177.38 & 255.21 & 254.25 & 254.12 & 84.08 \\
\hline $3 / 7 / 200622: 00$ & 30.98 & 201.73 & 81.94 & 173.80 & 251.18 & 250.25 & 249.65 & 84.08 \\
\hline $3 / 7 / 200623: 00$ & 30.98 & 204.49 & 81.15 & 178.53 & 254.28 & 254.77 & 255.50 & 83.97 \\
\hline
\end{tabular}


Table F-3. Hourly Average FF 2-4 Average Hopper Surface Temperatures During the Monthlong Test (continued)

\begin{tabular}{|c|c|c|c|c|c|c|c|c|}
\hline Date, Time & $\begin{array}{c}\text { FF 2-4 A } \\
\text { Hopper } \\
\text { Temp., }{ }^{\circ} \mathrm{F}\end{array}$ & $\begin{array}{l}\text { FF 2-4 B } \\
\text { Hopper } \\
\text { Temp., }{ }^{\circ} \mathrm{F}\end{array}$ & $\begin{array}{c}\text { FF 2-4 C } \\
\text { Hopper } \\
\text { Temp., }{ }^{\circ} \mathrm{F}\end{array}$ & $\begin{array}{c}\text { FF 2-4 D } \\
\text { Hopper } \\
\text { Temp., }{ }^{\circ} \mathrm{F}\end{array}$ & $\begin{array}{c}\text { FF 2-4 E } \\
\text { Hopper } \\
\text { Temp., }{ }^{\circ} \mathrm{F}\end{array}$ & $\begin{array}{c}\text { FF 2-4 F } \\
\text { Hopper } \\
\text { Temp., }{ }^{\circ} \mathrm{F}\end{array}$ & $\begin{array}{c}\text { FF 2-4 G } \\
\text { Hopper } \\
\text { Temp., }{ }^{\circ} \mathrm{F}\end{array}$ & $\begin{array}{c}\text { FF 2-4 H } \\
\text { Hopper } \\
\text { Temp., }{ }^{\circ} \mathrm{F}\end{array}$ \\
\hline $3 / 14 / 200611: 00$ & 30.98 & 183.56 & 64.85 & 181.40 & 232.28 & 240.69 & 242.35 & 66.26 \\
\hline $3 / 14 / 200612: 00$ & 30.98 & 192.74 & 65.97 & 192.48 & 240.49 & 249.77 & 250.11 & 67.11 \\
\hline $3 / 14 / 200613: 00$ & 30.98 & 199.55 & 66.86 & 199.99 & 245.75 & 254.53 & 252.86 & 67.90 \\
\hline $3 / 14 / 200614: 00$ & 30.98 & 204.93 & 68.09 & 205.28 & 249.66 & 259.88 & 255.63 & 69.14 \\
\hline $3 / 14 / 200616: 00$ & 30.98 & 198.21 & 70.04 & 199.82 & 242.77 & 250.33 & 240.87 & 71.23 \\
\hline $3 / 14 / 200617: 00$ & 30.98 & 197.30 & 70.76 & 199.08 & 240.61 & 249.16 & 242.15 & 72.44 \\
\hline $3 / 14 / 2006$ 18:00 & 30.98 & 197.25 & 71.20 & 199.50 & 242.12 & 249.32 & 248.91 & 74.33 \\
\hline $3 / 14 / 200619: 00$ & 30.98 & 199.26 & 71.76 & 204.17 & 245.49 & 254.12 & 249.82 & 74.43 \\
\hline $3 / 14 / 200620: 00$ & 30.98 & 195.28 & 70.95 & 202.74 & 245.34 & 250.48 & 250.06 & 73.67 \\
\hline $3 / 15 / 20060: 00$ & 30.98 & 192.37 & 67.96 & 191.10 & 233.42 & 239.03 & 234.77 & 70.19 \\
\hline $3 / 15 / 20061: 00$ & 30.98 & 187.48 & 67.42 & 188.12 & 236.43 & 235.65 & 250.38 & 69.33 \\
\hline $3 / 15 / 20062: 00$ & 30.98 & 182.44 & 66.07 & 182.76 & 230.70 & 228.22 & 228.86 & 67.90 \\
\hline $3 / 15 / 20063: 00$ & 30.98 & 184.86 & 65.72 & 184.00 & 228.73 & 232.16 & 226.09 & 67.29 \\
\hline $3 / 15 / 20064: 00$ & 30.98 & 184.92 & 64.48 & 182.59 & 225.17 & 229.97 & 222.41 & 66.48 \\
\hline $3 / 15 / 20065: 00$ & 30.98 & 186.50 & 63.94 & 184.05 & 226.74 & 231.81 & 226.76 & 66.07 \\
\hline $3 / 15 / 20066: 00$ & 30.98 & 185.43 & 63.43 & 184.29 & 227.89 & 231.38 & 227.51 & 64.89 \\
\hline $3 / 15 / 2006$ 7:00 & 30.98 & 185.13 & 62.86 & 183.77 & 225.41 & 230.41 & 222.17 & 64.40 \\
\hline $3 / 15 / 20068: 00$ & 30.98 & 186.83 & 62.10 & 186.22 & 233.10 & 234.38 & 234.25 & 63.94 \\
\hline $3 / 15 / 200615: 00$ & 30.98 & 192.02 & 70.04 & 196.30 & 238.61 & 243.14 & 239.73 & 71.46 \\
\hline $3 / 15 / 200616: 00$ & 30.98 & 200.45 & 70.22 & 201.97 & 246.57 & 250.46 & 245.41 & 73.65 \\
\hline $3 / 15 / 200617: 00$ & 30.98 & 206.43 & 70.95 & 205.39 & 250.70 & 253.89 & 251.34 & 74.01 \\
\hline $3 / 15 / 2006$ 18:00 & 30.98 & 205.95 & 71.00 & 204.73 & 248.70 & 250.53 & 244.64 & 74.01 \\
\hline $3 / 15 / 200619: 00$ & 30.98 & 202.71 & 71.63 & 202.07 & 245.11 & 248.21 & 239.60 & 74.01 \\
\hline $3 / 15 / 200620: 00$ & 30.98 & 202.27 & 71.87 & 201.28 & 245.04 & 247.98 & 242.07 & 74.01 \\
\hline $3 / 15 / 200621: 00$ & 30.98 & 204.95 & 71.76 & 202.02 & 246.08 & 249.80 & 245.69 & 74.01 \\
\hline $3 / 15 / 200622: 00$ & 30.98 & 204.07 & 70.95 & 200.84 & 244.58 & 247.74 & 237.92 & 74.01 \\
\hline $3 / 15 / 200623: 00$ & 30.98 & 200.22 & 70.95 & 197.99 & 242.35 & 244.67 & 235.70 & 74.01 \\
\hline 3/16/2006 0:00 & 30.98 & 202.64 & 70.95 & 200.23 & 247.59 & 249.25 & 245.23 & 74.01 \\
\hline $3 / 16 / 20061: 00$ & 30.98 & 205.48 & 70.95 & 201.88 & 248.65 & 250.94 & 240.49 & 74.01 \\
\hline $3 / 16 / 20062: 00$ & 30.98 & 203.97 & 70.53 & 202.63 & 248.11 & 251.59 & 242.28 & 74.01 \\
\hline $3 / 16 / 20063: 00$ & 30.98 & 206.76 & 71.82 & 206.16 & 253.21 & 256.76 & 249.29 & 74.01 \\
\hline $3 / 16 / 20064: 00$ & 30.98 & 211.14 & 71.57 & 208.58 & 256.94 & 260.45 & 258.54 & 74.01 \\
\hline 3/16/2006 5:00 & 30.98 & 209.42 & 70.95 & 208.42 & 258.65 & 259.74 & 254.63 & 73.59 \\
\hline $3 / 16 / 20066: 00$ & 30.98 & 207.08 & 70.95 & 206.55 & 258.41 & 258.83 & 258.48 & 73.09 \\
\hline $3 / 16 / 2006$ 7:00 & 30.98 & 203.55 & 70.95 & 203.70 & 256.77 & 253.74 & 251.51 & 73.09 \\
\hline $3 / 16 / 20068: 00$ & 30.98 & 201.63 & 70.95 & 202.17 & 256.53 & 256.82 & 253.62 & 73.09 \\
\hline
\end{tabular}


Table F-3. Hourly Average FF 2-4 Average Hopper Surface Temperatures During the Monthlong Test (continued)

\begin{tabular}{|c|c|c|c|c|c|c|c|c|}
\hline Date, Time & $\begin{array}{c}\text { FF 2-4 A } \\
\text { Hopper } \\
\text { Temp., }{ }^{\circ} \mathrm{F}\end{array}$ & $\begin{array}{l}\text { FF 2-4 B } \\
\text { Hopper } \\
\text { Temp., }{ }^{\circ} \mathrm{F}\end{array}$ & $\begin{array}{c}\text { FF 2-4 C } \\
\text { Hopper } \\
\text { Temp., }{ }^{\circ} \mathrm{F}\end{array}$ & $\begin{array}{c}\text { FF 2-4 D } \\
\text { Hopper } \\
\text { Temp., }{ }^{\circ} \mathrm{F}\end{array}$ & $\begin{array}{c}\text { FF 2-4 E } \\
\text { Hopper } \\
\text { Temp., }{ }^{\circ} \mathrm{F}\end{array}$ & $\begin{array}{c}\text { FF 2-4 F } \\
\text { Hopper } \\
\text { Temp., }{ }^{\circ} \mathrm{F}\end{array}$ & $\begin{array}{l}\text { FF 2-4 G } \\
\text { Hopper } \\
\text { Temp., }{ }^{\circ} \mathrm{F}\end{array}$ & $\begin{array}{c}\text { FF 2-4 H } \\
\text { Hopper } \\
\text { Temp., }{ }^{\circ} \mathrm{F}\end{array}$ \\
\hline $3 / 16 / 200615: 00$ & 30.98 & 210.66 & 75.50 & 207.66 & 268.94 & 268.58 & 274.49 & 77.56 \\
\hline $3 / 16 / 200616: 00$ & 30.98 & 211.59 & 76.27 & 209.30 & 269.54 & 269.51 & 267.86 & 78.15 \\
\hline $3 / 16 / 2006$ 17:00 & 30.98 & 209.68 & 77.06 & 212.18 & 270.43 & 270.69 & 270.42 & 79.18 \\
\hline $3 / 16 / 2006$ 18:00 & 30.98 & 208.25 & 77.66 & 211.68 & 269.15 & 269.16 & 270.45 & 80.83 \\
\hline $3 / 16 / 200620: 00$ & 30.98 & 203.60 & 77.62 & 204.08 & 258.57 & 259.72 & 258.50 & 80.15 \\
\hline $3 / 16 / 200621: 00$ & 30.98 & 198.36 & 77.06 & 199.40 & 254.11 & 253.72 & 254.59 & 79.94 \\
\hline $3 / 16 / 200622: 00$ & 30.98 & 194.59 & 76.41 & 195.69 & 249.75 & 250.32 & 250.60 & 78.60 \\
\hline $3 / 16 / 200623: 00$ & 30.98 & 190.43 & 76.14 & 192.54 & 246.49 & 247.30 & 249.28 & 77.94 \\
\hline 3/17/2006 0:00 & 30.98 & 192.69 & 74.58 & 193.72 & 246.01 & 250.24 & 249.31 & 76.87 \\
\hline $3 / 17 / 20064: 00$ & 30.98 & 194.03 & 70.90 & 196.53 & 246.98 & 251.36 & 247.10 & 72.21 \\
\hline $3 / 17 / 20065: 00$ & 30.98 & 194.89 & 70.04 & 197.62 & 243.09 & 251.81 & 242.39 & 71.82 \\
\hline $3 / 17 / 20066: 00$ & 30.98 & 195.66 & 68.86 & 196.92 & 244.60 & 250.12 & 246.16 & 70.64 \\
\hline $3 / 17 / 20067: 00$ & 30.98 & 194.84 & 67.90 & 195.18 & 242.43 & 247.69 & 244.78 & 69.24 \\
\hline $3 / 17 / 20068: 00$ & 30.98 & 190.37 & 66.99 & 191.43 & 239.95 & 243.00 & 235.76 & 69.12 \\
\hline 3/17/2006 9:00 & 30.98 & 190.73 & 67.22 & 190.74 & 240.83 & 242.66 & 241.79 & 69.17 \\
\hline $3 / 17 / 200610: 00$ & 30.98 & 199.09 & 67.90 & 195.98 & 244.37 & 248.35 & 241.30 & 70.04 \\
\hline $3 / 17 / 2006$ 11:00 & 30.98 & 204.72 & 68.69 & 199.87 & 247.00 & 251.39 & 243.71 & 71.45 \\
\hline $3 / 17 / 2006$ 12:00 & 30.98 & 206.08 & 70.04 & 201.79 & 249.65 & 249.61 & 252.23 & 71.87 \\
\hline $3 / 17 / 200619: 00$ & 30.98 & 203.08 & 73.15 & 202.10 & 250.86 & 254.35 & 254.59 & 76.14 \\
\hline $3 / 17 / 200620: 00$ & 30.98 & 205.88 & 73.05 & 203.56 & 252.92 & 255.45 & 254.09 & 76.14 \\
\hline $3 / 17 / 200621: 00$ & 30.98 & 204.56 & 72.93 & 202.75 & 252.86 & 254.34 & 254.69 & 75.74 \\
\hline $3 / 17 / 200622: 00$ & 30.98 & 205.01 & 72.34 & 201.89 & 251.76 & 253.71 & 252.35 & 75.41 \\
\hline $3 / 17 / 200623: 00$ & 30.98 & 206.19 & 73.09 & 203.12 & 250.64 & 253.50 & 254.28 & 76.14 \\
\hline 3/18/2006 0:00 & 30.98 & 205.95 & 72.13 & 202.06 & 250.75 & 251.85 & 255.00 & 75.36 \\
\hline $3 / 18 / 20061: 00$ & 30.98 & 206.02 & 71.87 & 201.36 & 249.86 & 250.33 & 247.64 & 74.92 \\
\hline $3 / 18 / 20062: 00$ & 30.98 & 202.60 & 71.87 & 199.10 & 246.48 & 248.21 & 247.92 & 74.46 \\
\hline $3 / 18 / 20063: 00$ & 30.98 & 198.84 & 71.27 & 196.67 & 243.96 & 245.73 & 240.87 & 74.01 \\
\hline $3 / 18 / 20064: 00$ & 30.98 & 195.99 & 70.46 & 193.45 & 238.82 & 240.22 & 239.05 & 73.83 \\
\hline $3 / 18 / 20065: 00$ & 30.98 & 196.27 & 69.82 & 193.35 & 238.59 & 241.10 & 237.11 & 72.29 \\
\hline $3 / 18 / 20066: 00$ & 30.98 & 198.10 & 68.31 & 196.84 & 243.86 & 246.88 & 244.38 & 71.87 \\
\hline $3 / 18 / 2006$ 7:00 & 30.98 & 196.93 & 67.90 & 197.91 & 243.38 & 246.74 & 245.41 & 71.87 \\
\hline 3/18/2006 8:00 & 30.98 & 196.12 & 67.90 & 196.29 & 239.61 & 241.89 & 239.10 & 71.87 \\
\hline 3/18/2006 9:00 & 30.98 & 200.11 & 67.90 & 195.61 & 238.60 & 241.14 & 237.38 & 71.87 \\
\hline $3 / 18 / 200610: 00$ & 30.98 & 199.44 & 67.90 & 194.10 & 238.04 & 240.41 & 241.14 & 71.87 \\
\hline $3 / 18 / 200611: 00$ & 30.98 & 199.32 & 68.66 & 196.20 & 239.39 & 243.90 & 237.04 & 72.69 \\
\hline $3 / 18 / 200612: 00$ & 30.98 & 203.47 & 69.12 & 198.39 & 243.11 & 247.92 & 241.67 & 73.09 \\
\hline
\end{tabular}


Table F-3. Hourly Average FF 2-4 Average Hopper Surface Temperatures During the Monthlong Test (continued)

\begin{tabular}{|c|c|c|c|c|c|c|c|c|}
\hline Date, Time & $\begin{array}{c}\text { FF 2-4 A } \\
\text { Hopper } \\
\text { Temp., }{ }^{\circ} \mathrm{F}\end{array}$ & $\begin{array}{l}\text { FF 2-4 B } \\
\text { Hopper } \\
\text { Temp., }{ }^{\circ} \mathrm{F}\end{array}$ & $\begin{array}{c}\text { FF 2-4 C } \\
\text { Hopper } \\
\text { Temp., }{ }^{\circ} \mathrm{F}\end{array}$ & $\begin{array}{c}\text { FF 2-4 D } \\
\text { Hopper } \\
\text { Temp., }{ }^{\circ} \mathrm{F}\end{array}$ & $\begin{array}{c}\text { FF 2-4 E } \\
\text { Hopper } \\
\text { Temp., }{ }^{\circ} \mathrm{F}\end{array}$ & $\begin{array}{c}\text { FF 2-4 F } \\
\text { Hopper } \\
\text { Temp., }{ }^{\circ} \mathrm{F}\end{array}$ & $\begin{array}{c}\text { FF 2-4 G } \\
\text { Hopper } \\
\text { Temp., }{ }^{\circ} \mathrm{F}\end{array}$ & $\begin{array}{c}\text { FF 2-4 H } \\
\text { Hopper } \\
\text { Temp., }{ }^{\circ} \mathrm{F}\end{array}$ \\
\hline $3 / 18 / 2006$ 19:00 & 30.98 & 195.07 & 66.47 & 191.73 & 236.45 & 239.53 & 234.41 & 70.04 \\
\hline $3 / 18 / 200620: 00$ & 30.98 & 197.03 & 66.07 & 194.17 & 239.62 & 243.47 & 242.94 & 70.04 \\
\hline $3 / 18 / 200621: 00$ & 30.98 & 197.81 & 66.07 & 194.05 & 238.92 & 242.91 & 238.10 & 70.04 \\
\hline $3 / 18 / 200622: 00$ & 30.98 & 198.70 & 66.07 & 194.61 & 238.13 & 242.32 & 242.22 & 70.04 \\
\hline 3/19/2006 0:00 & 30.98 & 194.00 & 66.07 & 195.30 & 239.73 & 242.45 & 239.73 & 69.70 \\
\hline $3 / 19 / 20061: 00$ & 30.98 & 192.32 & 66.07 & 193.85 & 238.30 & 241.32 & 236.18 & 68.75 \\
\hline $3 / 19 / 20062: 00$ & 30.98 & 195.16 & 66.07 & 189.95 & 234.40 & 237.85 & 234.81 & 67.90 \\
\hline $3 / 19 / 20063: 00$ & 30.98 & 194.75 & 66.07 & 188.85 & 232.27 & 236.48 & 231.81 & 68.35 \\
\hline $3 / 19 / 20064: 00$ & 30.98 & 195.65 & 66.07 & 192.24 & 235.28 & 240.84 & 235.12 & 68.06 \\
\hline 3/19/2006 8:00 & 30.98 & 190.99 & 63.94 & 192.57 & 237.91 & 239.80 & 235.32 & 66.99 \\
\hline 3/19/2006 9:00 & 30.98 & 185.74 & 63.94 & 189.09 & 230.21 & 231.73 & 228.90 & 66.36 \\
\hline 3/19/2006 10:00 & 30.98 & 186.59 & 63.94 & 188.51 & 235.27 & 236.09 & 239.01 & 66.07 \\
\hline 3/19/2006 11:00 & 30.98 & 188.85 & 63.94 & 187.36 & 232.52 & 235.17 & 228.89 & 66.97 \\
\hline $3 / 19 / 200612: 00$ & 30.98 & 190.12 & 63.94 & 186.61 & 232.15 & 232.13 & 232.62 & 67.90 \\
\hline $3 / 19 / 2006$ 13:00 & 30.98 & 193.94 & 63.94 & 188.49 & 234.22 & 238.51 & 240.63 & 67.90 \\
\hline $3 / 19 / 200614: 00$ & 30.98 & 192.92 & 64.26 & 186.93 & 234.19 & 237.65 & 237.24 & 68.19 \\
\hline $3 / 19 / 2006$ 15:00 & 30.98 & 190.45 & 64.85 & 186.24 & 234.62 & 238.77 & 240.23 & 69.12 \\
\hline $3 / 19 / 2006$ 16:00 & 30.98 & 191.85 & 64.85 & 187.09 & 234.85 & 240.88 & 238.55 & 69.12 \\
\hline $3 / 19 / 200623: 00$ & 30.98 & 191.38 & 64.01 & 188.38 & 238.67 & 245.03 & 241.28 & 67.90 \\
\hline 3/20/2006 0:00 & 30.98 & 190.81 & 63.94 & 188.63 & 239.85 & 246.26 & 240.23 & 67.27 \\
\hline $3 / 20 / 20061: 00$ & 30.98 & 192.25 & 63.75 & 188.82 & 236.45 & 240.68 & 230.63 & 67.23 \\
\hline $3 / 20 / 20062: 00$ & 30.98 & 186.86 & 63.02 & 180.75 & 225.48 & 222.12 & 217.48 & 66.73 \\
\hline $3 / 20 / 20063: 00$ & 30.98 & 188.80 & 63.02 & 180.19 & 223.82 & 228.78 & 222.81 & 66.97 \\
\hline $3 / 20 / 20064: 00$ & 30.98 & 191.69 & 63.02 & 181.38 & 226.54 & 232.36 & 219.13 & 66.43 \\
\hline $3 / 20 / 20065: 00$ & 30.98 & 188.75 & 63.50 & 183.87 & 213.77 & 232.11 & 204.19 & 66.98 \\
\hline $3 / 20 / 20066: 00$ & 30.98 & 192.32 & 63.94 & 187.64 & 230.48 & 237.87 & 235.04 & 67.90 \\
\hline $3 / 20 / 2006$ 7:00 & 30.98 & 193.84 & 64.32 & 189.97 & 234.03 & 240.30 & 232.69 & 67.90 \\
\hline $3 / 20 / 20068: 00$ & 30.98 & 194.49 & 65.55 & 193.44 & 236.75 & 242.17 & 237.95 & 68.42 \\
\hline 3/20/2006 9:00 & 30.98 & 193.65 & 66.07 & 190.84 & 235.85 & 239.49 & 232.23 & 69.12 \\
\hline $3 / 20 / 200610: 00$ & 30.98 & 189.85 & 66.07 & 186.35 & 234.43 & 238.36 & 227.11 & 69.12 \\
\hline $3 / 20 / 2006$ 11:00 & 30.98 & 193.28 & 66.62 & 188.85 & 238.32 & 243.27 & 240.58 & 69.37 \\
\hline $3 / 20 / 200612: 00$ & 30.98 & 198.70 & 67.57 & 194.27 & 242.18 & 248.88 & 241.11 & 70.42 \\
\hline $3 / 20 / 200613: 00$ & 30.98 & 200.94 & 69.39 & 200.19 & 243.65 & 253.41 & 248.26 & 71.94 \\
\hline $3 / 20 / 200614: 00$ & 30.98 & 204.23 & 70.16 & 203.01 & 244.98 & 253.88 & 244.40 & 73.80 \\
\hline $3 / 20 / 200615: 00$ & 30.98 & 207.51 & 71.57 & 206.93 & 249.23 & 254.11 & 252.62 & 75.45 \\
\hline $3 / 20 / 200616: 00$ & 30.98 & 213.29 & 72.73 & 210.99 & 253.96 & 258.22 & 253.32 & 76.39 \\
\hline
\end{tabular}


Table F-3. Hourly Average FF 2-4 Average Hopper Surface Temperatures During the Monthlong Test (continued)

\begin{tabular}{|c|c|c|c|c|c|c|c|c|}
\hline Date, Time & $\begin{array}{c}\text { FF 2-4 A } \\
\text { Hopper } \\
\text { Temp., }{ }^{\circ} \mathrm{F}\end{array}$ & $\begin{array}{l}\text { FF 2-4 B } \\
\text { Hopper } \\
\text { Temp., }{ }^{\circ} \mathrm{F}\end{array}$ & $\begin{array}{c}\text { FF 2-4 C } \\
\text { Hopper } \\
\text { Temp., }{ }^{\circ} \mathrm{F}\end{array}$ & $\begin{array}{c}\text { FF 2-4 D } \\
\text { Hopper } \\
\text { Temp., }{ }^{\circ} \mathrm{F}\end{array}$ & $\begin{array}{c}\text { FF 2-4 E } \\
\text { Hopper } \\
\text { Temp., }{ }^{\circ} \mathrm{F}\end{array}$ & $\begin{array}{c}\text { FF 2-4 F } \\
\text { Hopper } \\
\text { Temp., }{ }^{\circ} \mathrm{F}\end{array}$ & $\begin{array}{l}\text { FF 2-4 G } \\
\text { Hopper } \\
\text { Temp., }{ }^{\circ} \mathrm{F}\end{array}$ & $\begin{array}{c}\text { FF 2-4 H } \\
\text { Hopper } \\
\text { Temp., }{ }^{\circ} \mathrm{F}\end{array}$ \\
\hline $3 / 20 / 200623: 00$ & 30.98 & 208.24 & 71.87 & 207.85 & 250.60 & 253.62 & 245.57 & 76.75 \\
\hline 3/21/2006 0:00 & 30.98 & 203.10 & 71.11 & 206.94 & 247.32 & 251.71 & 244.99 & 76.06 \\
\hline $3 / 21 / 20061: 00$ & 30.98 & 202.18 & 69.31 & 202.23 & 241.61 & 245.16 & 249.96 & 74.42 \\
\hline $3 / 21 / 20062: 00$ & 30.98 & 197.08 & 67.29 & 194.92 & 235.92 & 241.75 & 229.88 & 72.34 \\
\hline $3 / 21 / 20064: 00$ & 30.98 & 194.41 & 64.02 & 191.78 & 233.44 & 240.09 & 224.38 & 69.21 \\
\hline $3 / 21 / 20065: 00$ & 30.98 & 188.12 & 62.84 & 190.58 & 231.32 & 237.64 & 227.58 & 67.84 \\
\hline $3 / 21 / 20066: 00$ & 30.98 & 185.40 & 61.73 & 189.55 & 229.83 & 235.99 & 225.22 & 66.69 \\
\hline $3 / 21 / 20067: 00$ & 30.98 & 188.90 & 59.81 & 187.34 & 230.22 & 235.08 & 230.76 & 65.56 \\
\hline $3 / 21 / 20068: 00$ & 30.98 & 185.57 & 59.97 & 184.36 & 226.37 & 230.95 & 219.64 & 64.80 \\
\hline $3 / 21 / 200612: 00$ & 30.98 & 195.68 & 59.64 & 192.12 & 232.96 & 240.57 & 230.57 & 66.14 \\
\hline $3 / 21 / 200613: 00$ & 30.98 & 192.75 & 59.97 & 189.30 & 230.20 & 236.74 & 224.65 & 67.14 \\
\hline $3 / 21 / 200614: 00$ & 30.98 & 189.67 & 60.58 & 186.59 & 226.26 & 233.92 & 221.93 & 67.90 \\
\hline $3 / 21 / 200615: 00$ & 30.98 & 191.70 & 61.72 & 187.45 & 226.88 & 236.52 & 221.87 & 68.95 \\
\hline $3 / 21 / 200616: 00$ & 30.98 & 196.20 & 62.25 & 192.36 & 234.61 & 243.34 & 230.37 & 69.91 \\
\hline $3 / 21 / 2006$ 17:00 & 30.98 & 193.79 & 63.02 & 192.05 & 237.04 & 245.02 & 235.60 & 70.04 \\
\hline $3 / 21 / 200618: 00$ & 30.98 & 187.32 & 63.02 & 187.28 & 231.91 & 240.30 & 227.06 & 70.04 \\
\hline $3 / 21 / 200619: 00$ & 30.98 & 186.69 & 63.39 & 183.13 & 228.05 & 235.19 & 221.89 & 68.96 \\
\hline $3 / 21 / 200620: 00$ & 30.98 & 185.84 & 62.65 & 184.16 & 229.84 & 236.11 & 224.15 & 67.84 \\
\hline $3 / 22 / 20063: 00$ & 30.98 & 182.05 & 57.32 & 177.57 & 230.48 & 233.78 & 228.50 & 59.57 \\
\hline $3 / 22 / 20064: 00$ & 30.98 & 179.69 & 56.18 & 177.90 & 230.83 & 233.70 & 230.56 & 58.58 \\
\hline $3 / 22 / 20065: 00$ & 30.98 & 179.27 & 55.95 & 177.86 & 232.25 & 237.12 & 237.69 & 57.68 \\
\hline $3 / 22 / 20066: 00$ & 30.98 & 177.93 & 54.96 & 176.28 & 230.05 & 230.99 & 236.19 & 56.58 \\
\hline $3 / 22 / 20067: 00$ & 30.98 & 174.85 & 53.86 & 172.09 & 224.37 & 228.47 & 230.77 & 55.84 \\
\hline 3/22/2006 8:00 & 30.98 & 174.47 & 53.86 & 170.54 & 230.44 & 231.75 & 232.65 & 55.08 \\
\hline $3 / 22 / 20069: 00$ & 30.98 & 172.70 & 53.86 & 165.95 & 228.61 & 230.06 & 220.58 & 55.68 \\
\hline $3 / 22 / 200610: 00$ & 30.98 & 171.52 & 54.77 & 162.12 & 227.17 & 226.66 & 230.18 & 57.08 \\
\hline $3 / 22 / 200611: 00$ & 30.98 & 173.44 & 55.90 & 161.58 & 224.99 & 226.60 & 238.72 & 58.51 \\
\hline $3 / 22 / 200612: 00$ & 30.98 & 175.02 & 56.77 & 165.30 & 227.89 & 229.69 & 229.56 & 59.61 \\
\hline $3 / 22 / 200613: 00$ & 30.98 & 177.81 & 58.14 & 166.46 & 228.56 & 230.55 & 231.09 & 60.41 \\
\hline $3 / 22 / 200614: 00$ & 30.98 & 185.67 & 58.68 & 172.55 & 234.38 & 237.70 & 238.50 & 61.86 \\
\hline $3 / 22 / 2006$ 15:00 & 30.98 & 186.98 & 59.97 & 176.67 & 238.26 & 241.07 & 237.56 & 62.82 \\
\hline $3 / 22 / 200616: 00$ & 30.98 & 193.17 & 60.35 & 181.13 & 240.20 & 247.44 & 248.94 & 63.68 \\
\hline $3 / 22 / 2006$ 17:00 & 30.98 & 195.70 & 60.88 & 182.71 & 242.99 & 248.95 & 249.27 & 63.94 \\
\hline $3 / 22 / 2006$ 18:00 & 30.98 & 192.53 & 60.88 & 179.14 & 237.77 & 240.98 & 242.14 & 63.94 \\
\hline $3 / 22 / 200619: 00$ & 30.98 & 185.27 & 60.88 & 170.88 & 231.64 & 233.15 & 237.38 & 63.94 \\
\hline $3 / 22 / 200620: 00$ & 30.98 & 189.63 & 60.02 & 174.07 & 235.55 & 240.17 & 240.26 & 63.24 \\
\hline
\end{tabular}


Table F-3. Hourly Average FF 2-4 Average Hopper Surface Temperatures During the Monthlong Test (continued)

\begin{tabular}{|c|c|c|c|c|c|c|c|c|}
\hline Date, Time & $\begin{array}{c}\text { FF 2-4 A } \\
\text { Hopper } \\
\text { Temp., }{ }^{\circ} \mathrm{F}\end{array}$ & $\begin{array}{l}\text { FF 2-4 B } \\
\text { Hopper } \\
\text { Temp., }{ }^{\circ} \mathrm{F}\end{array}$ & $\begin{array}{c}\text { FF 2-4 C } \\
\text { Hopper } \\
\text { Temp., }{ }^{\circ} \mathrm{F}\end{array}$ & $\begin{array}{c}\text { FF 2-4 D } \\
\text { Hopper } \\
\text { Temp., }{ }^{\circ} \mathrm{F}\end{array}$ & $\begin{array}{c}\text { FF 2-4 E } \\
\text { Hopper } \\
\text { Temp., }{ }^{\circ} \mathrm{F}\end{array}$ & $\begin{array}{c}\text { FF 2-4 F } \\
\text { Hopper } \\
\text { Temp., }{ }^{\circ} \mathrm{F}\end{array}$ & $\begin{array}{c}\text { FF 2-4 G } \\
\text { Hopper } \\
\text { Temp., }{ }^{\circ} \mathrm{F}\end{array}$ & $\begin{array}{c}\text { FF 2-4 H } \\
\text { Hopper } \\
\text { Temp., }{ }^{\circ} \mathrm{F}\end{array}$ \\
\hline $3 / 23 / 20063: 00$ & 30.98 & 183.45 & 56.92 & 176.04 & 239.42 & 241.86 & 248.35 & 59.05 \\
\hline $3 / 23 / 20064: 00$ & 30.98 & 182.25 & 56.73 & 179.25 & 239.68 & 241.16 & 252.79 & 58.50 \\
\hline $3 / 23 / 20065: 00$ & 30.98 & 180.51 & 56.00 & 176.18 & 233.02 & 238.08 & 250.54 & 58.14 \\
\hline $3 / 23 / 20066: 00$ & 30.98 & 176.78 & 55.68 & 174.71 & 234.23 & 236.85 & 252.53 & 58.14 \\
\hline $3 / 23 / 20068: 00$ & 30.98 & 178.92 & 53.86 & 170.53 & 231.74 & 236.11 & 241.68 & 56.70 \\
\hline $3 / 23 / 2006$ 9:00 & 30.98 & 177.63 & 53.86 & 167.62 & 233.96 & 239.65 & 243.34 & 56.78 \\
\hline $3 / 23 / 200610: 00$ & 30.98 & 178.19 & 53.86 & 164.23 & 231.89 & 238.01 & 235.23 & 56.92 \\
\hline $3 / 23 / 200611: 00$ & 30.98 & 174.48 & 53.86 & 165.58 & 228.48 & 234.72 & 238.38 & 56.98 \\
\hline $3 / 23 / 200612: 00$ & 30.98 & 176.53 & 53.30 & 165.70 & 228.09 & 233.48 & 229.91 & 58.01 \\
\hline $3 / 23 / 200616: 00$ & 30.98 & 175.56 & 53.86 & 161.92 & 220.87 & 228.71 & 224.01 & 59.05 \\
\hline $3 / 23 / 200617: 00$ & 30.98 & 174.45 & 53.86 & 162.80 & 218.62 & 222.21 & 212.89 & 59.24 \\
\hline $3 / 23 / 200618: 00$ & 30.98 & 171.39 & 53.31 & 164.20 & 217.38 & 223.60 & 215.63 & 59.66 \\
\hline $3 / 23 / 200619: 00$ & 30.98 & 166.22 & 52.95 & 162.64 & 214.97 & 223.85 & 214.56 & 59.05 \\
\hline $3 / 23 / 200620: 00$ & 30.98 & 174.75 & 52.95 & 169.48 & 223.94 & 232.79 & 227.64 & 58.48 \\
\hline $3 / 23 / 200621: 00$ & 30.98 & 180.67 & 52.95 & 177.40 & 230.14 & 240.54 & 231.37 & 57.85 \\
\hline $3 / 23 / 200622: 00$ & 30.98 & 184.21 & 52.44 & 182.24 & 234.62 & 242.55 & 242.67 & 56.92 \\
\hline $3 / 23 / 200623: 00$ & 30.98 & 183.19 & 52.95 & 184.64 & 234.26 & 241.35 & 244.91 & 56.92 \\
\hline 3/24/2006 0:00 & 30.98 & 183.66 & 52.94 & 183.70 & 237.81 & 243.85 & 247.34 & 56.13 \\
\hline $3 / 24 / 20067: 00$ & 30.98 & 173.44 & 48.07 & 170.11 & 230.83 & 232.68 & 226.72 & 50.27 \\
\hline $3 / 24 / 20068: 00$ & 30.98 & 172.89 & 48.07 & 172.61 & 234.61 & 233.49 & 232.61 & 49.92 \\
\hline $3 / 24 / 20069: 00$ & 30.98 & 174.01 & 48.71 & 174.20 & 234.46 & 234.33 & 224.91 & 51.57 \\
\hline $3 / 24 / 200610: 00$ & 30.98 & 174.80 & 49.81 & 174.53 & 233.82 & 234.20 & 229.71 & 52.04 \\
\hline $3 / 24 / 2006$ 11:00 & 30.98 & 181.06 & 51.04 & 175.24 & 235.35 & 237.43 & 233.82 & 53.40 \\
\hline $3 / 24 / 200612: 00$ & 30.98 & 181.17 & 52.17 & 178.99 & 235.15 & 237.59 & 236.50 & 55.07 \\
\hline $3 / 24 / 2006$ 13:00 & 30.98 & 185.52 & 53.40 & 182.98 & 235.16 & 236.45 & 236.38 & 56.79 \\
\hline $3 / 24 / 200614: 00$ & 30.98 & 186.92 & 54.07 & 186.73 & 238.25 & 241.07 & 243.66 & 58.14 \\
\hline $3 / 24 / 200615: 00$ & 30.98 & 186.15 & 54.93 & 186.95 & 238.06 & 239.74 & 244.80 & 59.26 \\
\hline $3 / 24 / 200616: 00$ & 30.98 & 187.98 & 56.43 & 190.53 & 240.05 & 241.44 & 244.50 & 60.09 \\
\hline $3 / 24 / 2006$ 17:00 & 30.98 & 191.29 & 57.55 & 193.63 & 240.94 & 243.92 & 245.28 & 61.64 \\
\hline $3 / 24 / 200618: 00$ & 30.98 & 186.97 & 58.14 & 192.16 & 240.29 & 238.48 & 247.80 & 63.20 \\
\hline $3 / 24 / 200619: 00$ & 30.98 & 186.46 & 58.98 & 189.84 & 238.54 & 238.65 & 245.98 & 63.72 \\
\hline $3 / 24 / 200620: 00$ & 30.98 & 186.05 & 58.52 & 188.43 & 238.84 & 233.25 & 246.42 & 63.00 \\
\hline $3 / 24 / 200621: 00$ & 30.98 & 180.69 & 58.14 & 185.75 & 234.05 & 210.48 & 250.72 & 62.13 \\
\hline $3 / 24 / 200622: 00$ & 30.98 & 173.39 & 58.14 & 183.17 & 231.56 & 220.00 & 249.59 & 62.10 \\
\hline $3 / 24 / 200623: 00$ & 30.98 & 159.24 & 58.14 & 174.99 & 224.40 & 216.70 & 231.66 & 62.06 \\
\hline 3/25/2006 0:00 & 30.98 & 151.32 & 57.66 & 167.40 & 220.11 & 213.29 & 226.42 & 60.90 \\
\hline
\end{tabular}


Table F-3. Hourly Average FF 2-4 Average Hopper Surface Temperatures During the Monthlong Test (continued)

\begin{tabular}{|c|c|c|c|c|c|c|c|c|}
\hline Date, Time & $\begin{array}{c}\text { FF 2-4 A } \\
\text { Hopper } \\
\text { Temp., }{ }^{\circ} \mathrm{F}\end{array}$ & $\begin{array}{l}\text { FF 2-4 B } \\
\text { Hopper } \\
\text { Temp., }{ }^{\circ} \mathrm{F}\end{array}$ & $\begin{array}{c}\text { FF 2-4 C } \\
\text { Hopper } \\
\text { Temp., }{ }^{\circ} \mathrm{F}\end{array}$ & $\begin{array}{c}\text { FF 2-4 D } \\
\text { Hopper } \\
\text { Temp., }{ }^{\circ} \mathrm{F}\end{array}$ & $\begin{array}{c}\text { FF 2-4 E } \\
\text { Hopper } \\
\text { Temp., }{ }^{\circ} \mathrm{F}\end{array}$ & $\begin{array}{c}\text { FF 2-4 F } \\
\text { Hopper } \\
\text { Temp., }{ }^{\circ} \mathrm{F}\end{array}$ & $\begin{array}{c}\text { FF 2-4 G } \\
\text { Hopper } \\
\text { Temp., }{ }^{\circ} \mathrm{F}\end{array}$ & $\begin{array}{c}\text { FF 2-4 H } \\
\text { Hopper } \\
\text { Temp., }{ }^{\circ} \mathrm{F}\end{array}$ \\
\hline $3 / 25 / 20067: 00$ & 30.98 & 176.28 & 52.03 & 173.80 & 226.34 & 228.71 & 231.21 & 55.08 \\
\hline $3 / 25 / 20068: 00$ & 30.98 & 178.21 & 52.03 & 177.68 & 228.82 & 228.53 & 231.93 & 54.75 \\
\hline $3 / 25 / 2006$ 9:00 & 30.98 & 182.14 & 52.33 & 179.40 & 233.28 & 232.24 & 231.47 & 55.13 \\
\hline $3 / 25 / 200610: 00$ & 30.98 & 185.96 & 53.92 & 185.89 & 238.30 & 238.04 & 235.48 & 56.34 \\
\hline $3 / 25 / 200612: 00$ & 30.98 & 184.21 & 57.65 & 194.86 & 243.90 & 243.39 & 254.08 & 60.02 \\
\hline $3 / 25 / 200613: 00$ & 30.98 & 181.91 & 59.38 & 194.71 & 244.54 & 244.47 & 245.38 & 61.74 \\
\hline $3 / 25 / 200614: 00$ & 30.98 & 178.36 & 60.38 & 193.18 & 243.40 & 244.21 & 240.08 & 63.07 \\
\hline $3 / 25 / 200615: 00$ & 30.98 & 178.17 & 61.99 & 196.06 & 245.92 & 245.88 & 244.90 & 64.37 \\
\hline $3 / 25 / 200616: 00$ & 30.98 & 183.12 & 63.13 & 200.95 & 247.00 & 252.03 & 249.88 & 65.90 \\
\hline $3 / 25 / 200620: 00$ & 30.98 & 171.90 & 65.01 & 193.38 & 239.81 & 237.94 & 238.79 & 69.68 \\
\hline $3 / 25 / 200621: 00$ & 30.98 & 164.34 & 64.85 & 190.76 & 236.14 & 233.74 & 243.04 & 68.00 \\
\hline $3 / 25 / 200622: 00$ & 30.98 & 161.02 & 64.34 & 193.78 & 235.85 & 233.67 & 256.33 & 67.90 \\
\hline $3 / 25 / 200623: 00$ & 30.98 & 151.12 & 63.94 & 185.04 & 228.63 & 223.55 & 236.19 & 67.89 \\
\hline 3/26/2006 0:00 & 30.98 & 144.37 & 63.32 & 177.19 & 225.85 & 222.59 & 231.03 & 67.04 \\
\hline $3 / 26 / 20061: 00$ & 30.98 & 141.05 & 63.34 & 176.91 & 225.47 & 224.19 & 228.48 & 66.17 \\
\hline $3 / 26 / 20062: 00$ & 30.98 & 135.85 & 63.02 & 169.58 & 224.35 & 223.24 & 220.01 & 66.07 \\
\hline 3/26/2006 3:00 & 30.98 & 132.15 & 62.20 & 169.51 & 222.87 & 223.18 & 220.18 & 65.12 \\
\hline $3 / 26 / 20064: 00$ & 30.98 & 127.52 & 60.90 & 164.82 & 217.60 & 216.25 & 214.49 & 63.94 \\
\hline $3 / 26 / 200611: 00$ & 30.98 & 156.87 & 62.98 & 188.86 & 237.51 & 238.79 & 236.23 & 64.94 \\
\hline $3 / 26 / 200612: 00$ & 30.98 & 162.41 & 64.73 & 195.05 & 241.01 & 239.04 & 244.00 & 67.13 \\
\hline $3 / 26 / 200613: 00$ & 30.98 & 167.55 & 66.61 & 198.46 & 245.57 & 244.98 & 244.36 & 69.24 \\
\hline $3 / 26 / 200614: 00$ & 30.98 & 170.98 & 67.97 & 201.59 & 247.92 & 247.74 & 248.62 & 70.75 \\
\hline $3 / 26 / 200615: 00$ & 30.98 & 173.89 & 69.45 & 204.49 & 249.85 & 250.08 & 249.83 & 72.04 \\
\hline $3 / 26 / 200616: 00$ & 30.98 & 174.96 & 70.10 & 206.91 & 251.32 & 251.95 & 252.53 & 73.77 \\
\hline $3 / 26 / 2006$ 17:00 & 30.98 & 174.79 & 70.95 & 207.05 & 251.18 & 251.23 & 251.39 & 74.71 \\
\hline $3 / 26 / 200618: 00$ & 30.98 & 177.48 & 71.49 & 207.12 & 250.90 & 252.22 & 245.30 & 76.30 \\
\hline $3 / 26 / 200619: 00$ & 30.98 & 182.00 & 71.87 & 211.43 & 252.09 & 255.23 & 254.20 & 76.52 \\
\hline $3 / 26 / 200620: 00$ & 30.98 & 178.99 & 71.30 & 209.31 & 251.82 & 253.38 & 246.61 & 76.14 \\
\hline $3 / 26 / 200621: 00$ & 30.98 & 181.05 & 70.95 & 211.86 & 252.17 & 254.87 & 255.22 & 75.20 \\
\hline $3 / 26 / 200622: 00$ & 30.98 & 181.46 & 69.85 & 211.46 & 252.56 & 254.80 & 257.64 & 74.69 \\
\hline $3 / 26 / 200623: 00$ & 30.98 & 178.07 & 70.04 & 208.49 & 251.41 & 252.96 & 252.60 & 74.01 \\
\hline 3/27/2006 0:00 & 30.98 & 168.78 & 69.65 & 203.03 & 247.05 & 247.62 & 245.96 & 73.22 \\
\hline $3 / 27 / 20061: 00$ & 30.98 & 154.39 & 69.12 & 192.66 & 236.77 & 238.75 & 228.79 & 71.78 \\
\hline $3 / 27 / 20062: 00$ & 30.98 & 144.80 & 68.67 & 182.46 & 230.33 & 225.07 & 212.85 & 71.87 \\
\hline $3 / 27 / 20063: 00$ & 30.98 & 139.22 & 67.90 & 180.28 & 228.65 & 226.69 & 216.98 & 71.81 \\
\hline $3 / 27 / 20064: 00$ & 30.98 & 136.31 & 67.90 & 177.44 & 230.28 & 227.20 & 203.54 & 70.95 \\
\hline
\end{tabular}


Table F-3. Hourly Average FF 2-4 Average Hopper Surface Temperatures During the Monthlong Test (continued)

\begin{tabular}{|c|c|c|c|c|c|c|c|c|}
\hline Date, Time & $\begin{array}{c}\text { FF 2-4 A } \\
\text { Hopper } \\
\text { Temp., }{ }^{\circ} \mathrm{F}\end{array}$ & $\begin{array}{c}\text { FF 2-4 B } \\
\text { Hopper } \\
\text { Temp., }{ }^{\circ} \mathrm{F}\end{array}$ & $\begin{array}{c}\text { FF 2-4 C } \\
\text { Hopper } \\
\text { Temp., }{ }^{\circ} \mathrm{F}\end{array}$ & $\begin{array}{l}\text { FF 2-4 D } \\
\text { Hopper } \\
\text { Temp., }{ }^{\circ} \mathrm{F} \\
\end{array}$ & $\begin{array}{c}\text { FF 2-4 E } \\
\text { Hopper } \\
\text { Temp., }{ }^{\circ} \mathrm{F}\end{array}$ & $\begin{array}{c}\text { FF 2-4 F } \\
\text { Hopper } \\
\text { Temp., }{ }^{\circ} \mathrm{F} \\
\end{array}$ & $\begin{array}{c}\text { FF 2-4 G } \\
\text { Hopper } \\
\text { Temp., }{ }^{\circ} \mathrm{F}\end{array}$ & $\begin{array}{c}\text { FF 2-4 H } \\
\text { Hopper } \\
\text { Temp., }{ }^{\circ} \mathrm{F} \\
\end{array}$ \\
\hline $3 / 27 / 200611: 00$ & 30.98 & 156.26 & 69.12 & 191.56 & 238.79 & 237.57 & 215.56 & 70.49 \\
\hline $3 / 27 / 200612: 00$ & 30.98 & 156.01 & 69.19 & 192.09 & 238.26 & 238.32 & 217.92 & 71.87 \\
\hline $3 / 27 / 200613: 00$ & 30.98 & 155.68 & 70.04 & 192.35 & 239.86 & 238.20 & 214.05 & 71.87 \\
\hline $3 / 27 / 200614: 00$ & 30.98 & 159.69 & 70.04 & 196.18 & 242.80 & 244.10 & 218.51 & 71.87 \\
\hline $3 / 27 / 200615: 00$ & 30.98 & 165.05 & 70.33 & 201.30 & 246.27 & 248.16 & 224.34 & 73.34 \\
\hline $3 / 27 / 200616: 00$ & 30.98 & 167.25 & 70.95 & 202.33 & 248.46 & 249.46 & 218.89 & 74.01 \\
\hline $3 / 27 / 2006$ 17:00 & 30.98 & 166.33 & 71.46 & 203.75 & 248.18 & 248.10 & 224.18 & 74.01 \\
\hline $3 / 27 / 200618: 00$ & 30.98 & 167.99 & 71.87 & 203.82 & 249.79 & 251.90 & 224.41 & 74.01 \\
\hline $3 / 27 / 200619: 00$ & 30.98 & 175.27 & 71.15 & 209.75 & 252.27 & 256.45 & 229.93 & 74.02 \\
\hline $3 / 27 / 200620: 00$ & 30.98 & 180.19 & 71.87 & 213.84 & 253.34 & 257.88 & 230.55 & 74.01 \\
\hline $3 / 27 / 200621: 00$ & 30.98 & 181.95 & 71.19 & 217.43 & 256.04 & 257.79 & 238.73 & 74.01 \\
\hline $3 / 27 / 200622: 00$ & 30.98 & 181.44 & 70.95 & 215.66 & 257.09 & 258.43 & 229.35 & 74.01 \\
\hline $3 / 27 / 200623: 00$ & 30.98 & 177.82 & 70.95 & 212.45 & 255.09 & 256.61 & 237.38 & 74.01 \\
\hline 3/28/2006 0:00 & 30.98 & 172.81 & 70.95 & 208.04 & 252.14 & 253.59 & 242.42 & 74.01 \\
\hline $3 / 28 / 20061: 00$ & 30.98 & 162.07 & 70.95 & 200.61 & 247.52 & 247.66 & 234.72 & 74.01 \\
\hline $3 / 28 / 20062: 00$ & 30.98 & 150.15 & 70.19 & 189.45 & 241.78 & 240.87 & 214.08 & 73.71 \\
\hline $3 / 28 / 20063: 00$ & 30.98 & 150.25 & 70.04 & 190.16 & 242.30 & 242.43 & 219.83 & 73.09 \\
\hline $3 / 28 / 20064: 00$ & 30.98 & 145.31 & 70.04 & 188.95 & 241.10 & 239.77 & 222.36 & 71.44 \\
\hline $3 / 28 / 20065: 00$ & 30.98 & 142.44 & 70.04 & 188.12 & 239.02 & 237.50 & 241.04 & 71.87 \\
\hline $3 / 28 / 20066: 00$ & 30.98 & 138.50 & 69.33 & 183.95 & 236.73 & 235.13 & 226.83 & 71.87 \\
\hline $3 / 28 / 2006$ 7:00 & 30.98 & 136.31 & 69.45 & 181.98 & 232.44 & 233.95 & 222.62 & 71.87 \\
\hline 3/28/2006 8:00 & 30.98 & 139.63 & 69.12 & 182.51 & 235.69 & 236.36 & 222.52 & 71.87 \\
\hline $3 / 28 / 20069: 00$ & 30.98 & 144.82 & 68.54 & 187.40 & 240.05 & 239.62 & 242.71 & 71.78 \\
\hline $3 / 28 / 200610: 00$ & 30.98 & 150.33 & 69.12 & 184.74 & 240.73 & 240.66 & 238.57 & 71.61 \\
\hline $3 / 28 / 200611: 00$ & 30.98 & 153.70 & 69.12 & 195.04 & 241.40 & 240.58 & 232.68 & 70.25 \\
\hline $3 / 28 / 200612: 00$ & 30.98 & 157.48 & 69.12 & 200.76 & 241.45 & 242.69 & 234.56 & 70.95 \\
\hline $3 / 28 / 200613: 00$ & 30.98 & 159.09 & 69.12 & 203.96 & 241.76 & 242.28 & 234.71 & 70.95 \\
\hline $3 / 28 / 200614: 00$ & 30.98 & 161.79 & 69.39 & 207.49 & 242.27 & 245.04 & 227.70 & 71.70 \\
\hline $3 / 28 / 2006$ 15:00 & 30.98 & 164.46 & 70.04 & 212.44 & 248.00 & 251.45 & 238.21 & 71.87 \\
\hline $3 / 28 / 200616: 00$ & 30.98 & 167.20 & 70.38 & 216.12 & 252.37 & 255.87 & 246.66 & 73.11 \\
\hline $3 / 28 / 2006$ 17:00 & 30.98 & 169.68 & 71.10 & 214.58 & 253.77 & 256.78 & 249.75 & 74.09 \\
\hline $3 / 28 / 200618: 00$ & 30.98 & 168.27 & 71.87 & 212.85 & 250.94 & 252.10 & 242.07 & 75.21 \\
\hline 3/28/2006 19:00 & 30.98 & 169.98 & 71.87 & 214.87 & 251.01 & 253.02 & 241.80 & 75.18 \\
\hline $3 / 28 / 200620: 00$ & 30.98 & 172.83 & 71.70 & 216.51 & 253.79 & 256.44 & 241.00 & 74.35 \\
\hline $3 / 28 / 200621: 00$ & 30.98 & 170.58 & 70.66 & 214.18 & 252.38 & 254.66 & 239.42 & 73.93 \\
\hline $3 / 28 / 200622: 00$ & 30.98 & 158.66 & 70.04 & 205.99 & 245.52 & 242.32 & 230.98 & 73.09 \\
\hline $3 / 28 / 200623: 00$ & 30.98 & 153.49 & 70.04 & 200.98 & 242.04 & 237.86 & 225.16 & 71.91 \\
\hline 3/29/2006 0:00 & 30.98 & 146.05 & 69.53 & 197.61 & 238.83 & 239.52 & 239.25 & 71.87 \\
\hline
\end{tabular}

\section{FF 2-4 Operating Temperatures}

Fabric filter inlet and outlet temperatures were monitored for any trends. Unusually low and unusually high temperatures were identified.

The highest temperatures observed during the period occurred when the unit switched to firing $100 \%$ PRB coal, which resulted in an increase in flue gas temperatures compared to operation with the 70-30 lignite-PRB blend. Typical operation with the blended coal resulted in FF 2-4 inlet temperature swings of $40^{\circ}$ to $60^{\circ} \mathrm{F}$ on a diurnal cycle. Daily temperature swing decreased with increasing nighttime plant load. For the month of March 2006, minimum 
recorded inlet temperatures were approximately $275^{\circ} \mathrm{F}$, maximums were near $360^{\circ} \mathrm{F}$, and the monthlong average was $322^{\circ} \mathrm{F}$. However, shortly after the switch to $100 \% \mathrm{PRB}$, inlet temperature maximums exceeded $375^{\circ} \mathrm{F}$ for periods of approximately 8 hours and peak temperatures reached $400^{\circ} \mathrm{F}$ (see Figure F-1). Once this transitory period passed, around April 3, temperature profiles stabilized and had an average value of $343^{\circ} \mathrm{F}$, an increase of 21 degrees compared to the $70-30$ blend.

Low and high temperature excursion lines have been added to Figure $\mathrm{F}-1$ for $280^{\circ} \mathrm{F}$ and $390^{\circ} \mathrm{F} ; 280^{\circ} \mathrm{F}$ is the approximate dewpoint for $10 \mathrm{ppm} \mathrm{SO}$, at temperatures below this, acid condensation could be an issue. The high temperature of $390^{\circ} \mathrm{F}$ is the maximum temperature excursion specified in the bag's fabric specification. Sustained temperatures above this temperature could result in damage to the bag fibers.

Correction applied to FF 2-4 flow values prior to January 24, 2006

Figure F-2 is a plot of the FF 2-4 compartment dP's from January 23, 2006. Figure F-2 shows that three of the eight transducers were reading abnormal; the transducer in compartment A was reading too high and the transducers in compartments $\mathrm{C}$ and $\mathrm{G}$ were reading too low. The graph also clearly shows the 18-minute cleaning cycle for each compartment, i.e., each compartment $\mathrm{dP}$ drops to zero when it is taken off-line for cleaning.

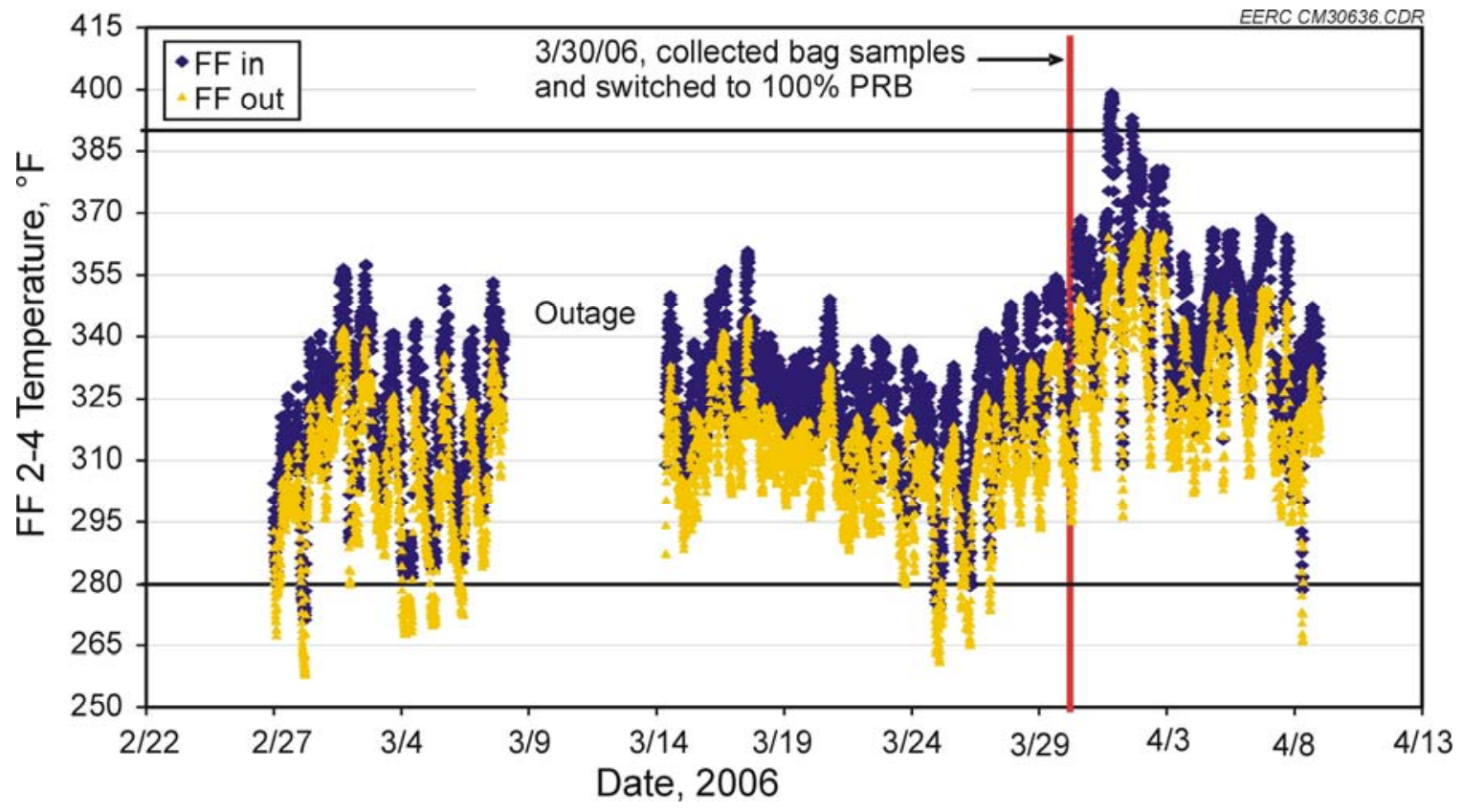

Figure F-1. FF 2-4 inlet and outlet temperatures for the duration of the monthlong test and the transition to $100 \%$ PRB fuel. 


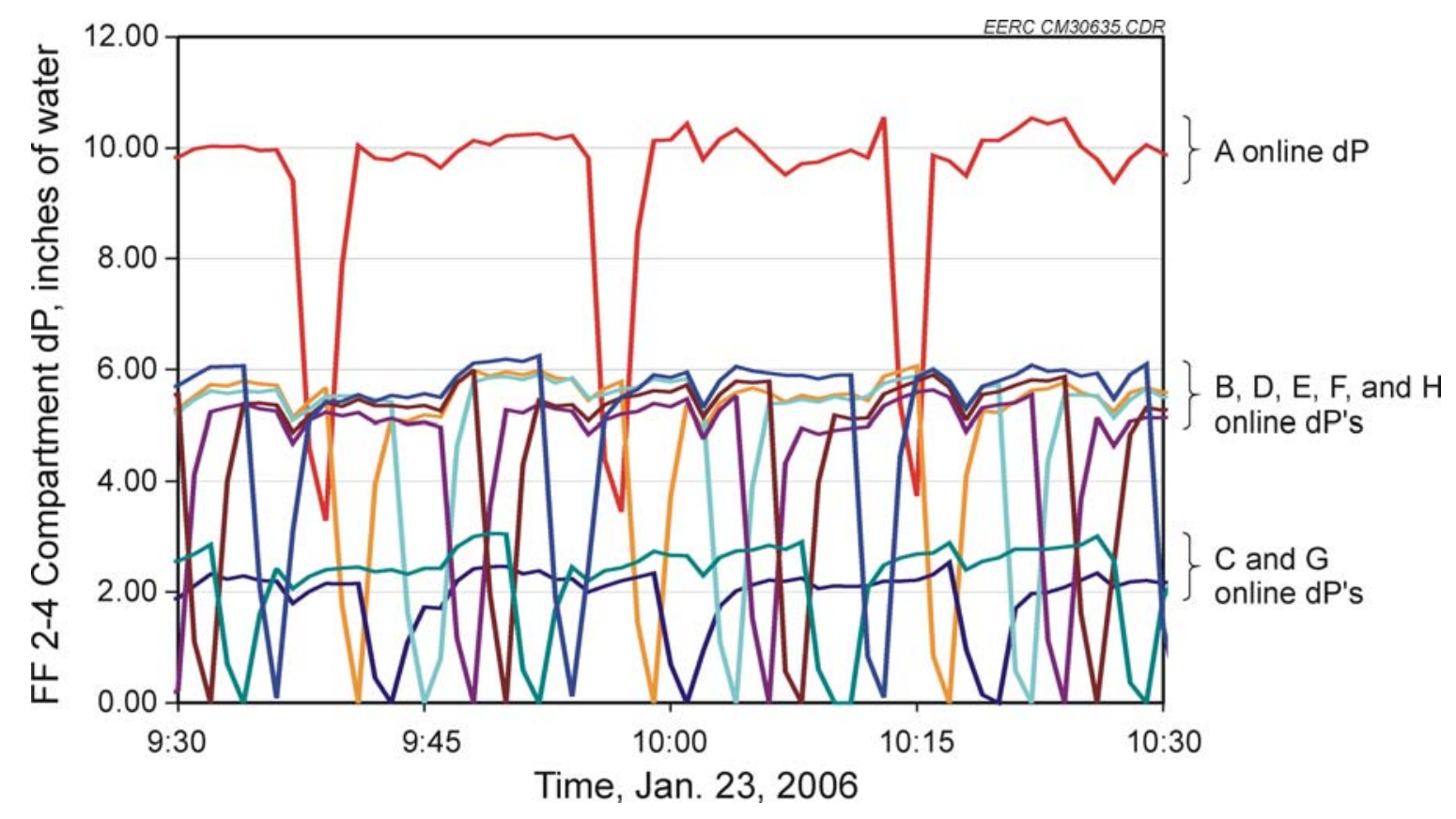

Figure F-2. Segment of FF 2-4 compartment dP readings prior to the recalibration of the transducers in compartments $\mathrm{A}, \mathrm{C}$, and $\mathrm{G}$.

The plant was informed of these abnormalities and staff calibrated the questionable transducers. All three were corrected by the afternoon of January 24, 2006. However, since the baghouse flow is computed using the compartment $\mathrm{dP}$ average, flow values prior to the calibration are in error.

The flow calculation for the COHPAC modules at Big Brown is based on the computation of flow through an orifice and has the form presented in Equation F-1.

$$
\text { Module Flow } \approx \frac{\sqrt{2 T_{\text {inlet }}(\text { Mechanical } \Delta P)}}{K_{\text {factor }}}
$$

In Equation F-1 the module inlet temperature is used to compensate for density changes (the effect of pressure on density is not considered), the mechanical dP is computed from measured pressures and the factor $\mathrm{K}$ has been empirically determined by the plant. The mechanical $\mathrm{dP}$ is calculated as the difference in the module $\mathrm{dP}$ and the average compartment $\mathrm{dP}$.

To estimate a correction factor for flow data prior to January 24, the data of Figure F-2 were analyzed and a compartment average $\mathrm{dP}$ both with and without the abnormal transducers was computed. Furthermore, the "mechanical dP" component was also calculated with and without these transducers. The results are presented in Table F-4. The first entry of Table F-4 is the average of the transducers that were not recalibrated. These transducers had good agreement and their average is considered to be representative of the true compartment average $\mathrm{dP}$. The subsequent entries compute the compartment average $\mathrm{dP}$ without the indicated compartment 
included. These calculations reproduce the range of mechanical dP discrepancies that would be observed in one 18-minute cleaning cycle of FF 2-4. Knowing that each compartment will be off-line for equal periods of time (approximately 2.25 minutes) during a cleaning cycle, the timeweighted average mechanical $\mathrm{dP}$ difference for a cleaning cycle is simply the average of the differences with each compartment off. This results in an overall value of $11.2 \%$ and indicates that, averaged over an entire cleaning cycle, the mechanical $\mathrm{dP}$ is $11.2 \%$ too high. Referring to Equation F-1, this implies that the flow is approximately $6 \%$ too high. Therefore, to compute corrected flow values, the data prior to January 24 has been scaled by 0.94 .

Table F4. Online Compartment dP Averages for the Period of 9:30 to 10:30 on January 23, 2006

\begin{tabular}{|c|c|c|c|}
\hline Compartments & $\begin{array}{l}\text { Online } \mathrm{dP} \text { average } \\
\text { (inches of water) }\end{array}$ & $\begin{array}{l}\text { Mechanical dP } \\
\text { (inches of water) }\end{array}$ & $\begin{array}{l}\text { Mechanical dP } \\
\text { (\% difference) }\end{array}$ \\
\hline $\mathrm{B}, \mathrm{D}, \mathrm{E}, \mathrm{F}, \mathrm{H}$ only & 5.52 & 2.04 & 0 \\
\hline Without $\mathrm{A}^{\mathrm{c}}$ & 4.62 & 2.94 & 44.1 \\
\hline Without B & 5.26 & 2.31 & 13.1 \\
\hline Without $C^{\mathrm{c}}$ & 5.74 & 1.82 & -10.9 \\
\hline Without D & 5.25 & 2.31 & 13.2 \\
\hline Without E & 5.31 & 2.25 & 10.4 \\
\hline Without F & 5.27 & 2.29 & 12.4 \\
\hline Without $G^{c}$ & 5.68 & 1.88 & -7.69 \\
\hline Without $\mathrm{H}$ & 5.22 & 2.34 & 14.7 \\
\hline $\begin{array}{l}\text { Cleaning Cycle } \\
\text { Average }\end{array}$ & 5.30 & 2.27 & 11.2 \\
\hline
\end{tabular}

${ }^{\mathrm{a}}$ The mechanical dP was computed by using the corresponding average module $\mathrm{dP}$, which was 7.56 inches of water.

${ }^{\mathrm{b}}$ These compartments were not recalibrated and their average is assumed to be the true compartment $\mathrm{dP}$ value for the computation of the mechanical dP.

${ }^{\mathrm{c}}$ Recalibrated transducer. 


\section{APPENDIX G}

\section{FILTER BAG DATA}




\section{APPENDIX G-1}

\section{GRUBB FILTRATION TESTING SERVICES, INC., LABORATORY REPORT NO. 4226/4282, MAY 22, 2006}




\section{Grubb Filtration \\ Testing Services, Inc.}

Laboratory Report No. 4226/4282

Date: May 22, 2006

Prepared For: $\quad$ ADA-ES, INC. 8100 SouthPark Way, Unit B Littleton, Colorado 80120

Reference:

ADA-ES Agreement No. 002-2006; TASK ORder No. 03; EPRI CONSULTING

Subject:

TXU Big Brown SES Unit 2 - Analysis of Used COHPAC Bags

Removed Before and After EERC Carbon Injection Tests

\section{Background}

EERC conducted additive injection testing (primarily activated carbon for mercury removal) in COHPAC Module (Baghouse) 2-4 at TXU's Big Brown Steam Electric Station (BBSES) during January - March 2006. Module 2-3, which filters the flue gas from the B-side train of Unit 2 along with Module 2-4, acted as the control baghouse; i.e., with no additive injection. Information about the 7-denier Torcon felt filter bags that were in service in these two modules during the test period is presented below.

Although these bags were ordered using the same fabric specification, there were differences in the fabric properties between the two suppliers. The Albany felt (2-3 bags) had a much more fleecy/fuzzy surface than the Southern felt (2-4 bags). This was the case even on the singed (external) face of the bags, because the Albany felt was singed to a much lesser degree than the Southern felt. Although the Albany felt was $1.1 \mathrm{oz} / \mathrm{yd}^{2}(7 \%)$ lighter in weight, it actually had a 15 $\mathrm{cfm}(12 \%)$ lower permeability and a $68 \mathrm{psi}(22 \%)$ greater Mullen burst strength than the Southern felt. 
Grubb Filtration Testing Services, Inc.

Laboratory Report No. 4018

Page 2

7-denier Torcon (PPS) Felt; Scrim-Supported; Singed Surface Out

\begin{tabular}{|l|c|c|}
\hline BBSES Module No. & $\mathbf{2 - 3}$ & $\mathbf{2 - 4}$ \\
\hline Replacement Bag Batch & $\# 04-2$ & $\# 04-1$ \\
\hline Installation Dates & Feb - Mar 2005 & Jan - Feb 2005 \\
\hline Bag/Fabric Supplier & Albany/Albany & Midwesco/Southern Felt \\
\hline Fabric QC Data (Avg.): & & \\
Weight & $14.9 \mathrm{oz}^{\prime} \mathrm{yd}^{2}$ & $16.0 \mathrm{oz} / \mathrm{yd}^{2}$ \\
Thickness & $0.102^{\prime \prime}$ & $0.105^{\prime \prime}$ \\
Permeability & $113 \mathrm{cfm}$ & $128 \mathrm{cfm}$ \\
Mullen Burst (net) & $378 \mathrm{psi}$ & $310 \mathrm{psi}$ \\
Shrinkage (2 hr @ 425 $\left.{ }^{\circ} \mathrm{F}\right)$ & $-1.01 \% \mathrm{x}+0.58 \%$ & $-0.78 \% \mathrm{x}+0.18 \%$ \\
\hline Bag Dimensions *: & & \\
Length & $245.0^{\prime \prime}$ & $244.7^{\prime \prime}$ \\
Flat Width & $7.69^{\prime \prime}$ & $7.63^{\prime \prime}$ \\
Weight & $3.2 \mathrm{lb}$ & $3.6 \mathrm{lb}$ \\
\hline
\end{tabular}

"Average QC data for Batch \#04-1; data on a single sample bag for Batch \#04-2

\section{Used Bag Samples Tested}

Compartment $\mathrm{C}$ of each baghouse was selected arbitrarily for used bag testing in conjunction with the EERC test program. One bag was removed from each during our annual fall inspection visit, several months prior to initiation of the EERC test, and one bag was removed from each by TXU at the conclusion of the EERC test, as shown below. High $\Delta \mathrm{P}$ operation, which necessitated partial bypassing, had been encountered in Module 2-4, and to a lesser extent in 2-3, during this test period.

\begin{tabular}{|l|c|c|c|c|}
\hline BBSES Compt No. & \multicolumn{2}{|c|}{ 2-3C } & \multicolumn{2}{c|}{ 2-4C } \\
\hline Bags Installed & \multicolumn{2}{|c|}{$3 / 18 / 05$} & \multicolumn{2}{c|}{$1 / 31 / 05$} \\
\hline GFTS Sample No. & $4226-3$ & $4282-3$ & $4226-4$ & $4282-4$ \\
\hline Date Test Bag Removed & $11 / 3 / 05$ & $3 / 31 / 05$ & $11 / 3 / 05$ & $3 / 31 / 05$ \\
\hline Test Bag Location (Row-Bag) & $9-35$ & $7-17$ & $9-35$ & $7-17$ \\
\hline Installed Life (months) & $71 / 2$ & $12 \frac{1}{2}$ & 9 & 14 \\
\hline Operating Life & $4720 \mathrm{hr}$ & $?$ & $5824 \mathrm{hr}$ & $?$ \\
\hline
\end{tabular}


Grubb Filtration Testing Services, Inc.

Laboratory Report No. 4018

Page 3

In situ drag testing was performed by ADA-ES on 22 bags in each of the test compartments on $11 / 3 / 05$, and the average drag was 0.21 inches $\mathrm{H}_{2} \mathrm{O} /(\mathrm{ft} / \mathrm{min})$ for both compartments. No drag testing was performed in March 2006.

\section{Summary and Conclusions}

During the five months of service from Nov-05 to Mar-06, the residual dust cake had increased substantially and the fabric permeability had decreased substantially on the bags in both 2-3C and 2-4C, as shown in Table 1. Although the physical measurements did show that this phenomenon was somewhat more severe on the 2-4 bags (exposed to additive injection) than on the 2-3 bags (no additive injection), the difference was not as great as one would have deduced from their vastly different appearance.

The 2-4 bag removed in Mar-06 had a much thicker and crustier residual cake than any of the other bags tested. This dust was dark gray in color, due to the activated carbon that had been injected in 2-4, compared to the beige-colored dust on the other bags tested. The external crust on this bag was relatively soft except at the bottom where it was much harder. After vacuuming, the fabric from both bags removed in Mar-06 (from 2-3 and 2-4) had more residual crust (thin and whitish) than the bags removed in Nov-05 from the same compartments. The bag from 2-4 appeared to have more residual crust after vacuuming than the bag from $2-3$, but this observation was biased to some extent by the much darker (carbon stained) background fabric in the 2-4 bag.

Both bags removed in Mar-06 were much dustier on their internal surfaces than the bags removed from the same compartments in Nov-05. However, the dust inside the 2-4 bag was blackish and the dust inside the 2-3 bag was beige. This degree of dust bleed-through is not uncommon with the high-permeability, 7-denier PPS felt bags that are used in the Low-Pressure/High-Volume baghouses on existing COHPAC applications. It should be noted that the internal surfaces of the bags that had not been exposed to carbon injection (both bags from 2-3, and the bag removed in Nov-05 from 2-4), were stained black in their top couple of feet. This is also not unprecedented and may be attributed to a combination of contaminants in the pulse air and greater penetration of the carbonaceous fraction of the fly ash due to the intensive cleaning force at the top of the bags.

The as-received fabric $\mathrm{pH}$ values $\left(5 \mathrm{~g}\right.$ per $100 \mathrm{ml}$ distilled $\left.\mathrm{H}_{2} \mathrm{O}\right)$ were essentially the same on both bags removed Mar-06, 4.38 on the 2-3 bag and 4.34 on the 2-4 bag. The $\mathrm{pH}$ had decreased modestly on the $2-4$ bags (from 4.96) since Nov-05. An anomalously high $\mathrm{pH}$ value (8.32) was obtained on the 2-3 bag removed in Nov-05, and it was deemed to be non-representative.

The bags were all in very good condition physically, with no excessive wear except for some thread damage on the inside of the vertical seams at the contact points with the top three cage rings, which was worse on the two bags removed in Nov-05 than on the two bags removed in Mar-06.

Although the Albany (2-3) fabric was initially stronger than the Southern (2-4) fabric, and the 2-3 bags had been installed for 1.5 months longer; the average Mullen burst strength was significantly lower (128 vs. 162 psi, net) and the strength loss significantly greater (-65\% vs. $-47 \%)$ on the $2-3$ fabric than on the 2-4 fabric. However, during the five month period between removal of the two sets of test bags, no additional strength loss had occurred in either module, regardless of whether or not additives had been injected, as shown in Table 1. 
Grubb Filtration Testing Services, Inc.

Laboratory Report No. 4018

Page 4

Table 1

\section{BBSES Unit 2 - Used 7.0-denier PPS Bags Removed Before and After EERC Carbon Injection Tests}

\begin{tabular}{|c|c|c|c|c|}
\hline Module & $2-3$ & $2-3$ & $2-4$ & $2-4$ \\
\hline Date Removed & $11 / 3 / 05$ & $3 / 31 / 06$ & $11 / 3 / 05$ & $3 / 31 / 06$ \\
\hline Installed Life (months) & $7 \frac{1}{2}$ & $12 \frac{1}{2}$ & 9 & 14 \\
\hline Carbon Injection Exposure & No & No & No & Yes \\
\hline $\begin{array}{l}\text { Permeability }\left(\mathrm{cfm} / \mathrm{ft}^{2}\right) \text { : } \\
\text { As Received } \\
\text { Vacuumed } \\
\text { Washed }\end{array}$ & $\begin{array}{c}5.30^{*} \\
53.5 \\
108\end{array}$ & $\begin{array}{c}3.03 \\
26.3 \\
116\end{array}$ & $\begin{array}{c}5.84 \\
50.4 \\
139\end{array}$ & $\begin{array}{c}2.43 \\
33.9 \\
137\end{array}$ \\
\hline $\begin{array}{l}\text { Fabric Weight }\left(\mathrm{oz} / \mathrm{yd}^{2}\right) \text { : } \\
\text { Washed }\end{array}$ & 14.8 & 13.9 & 15.0 & 16.5 \\
\hline $\begin{array}{c}\text { Residual Dust Load }\left(\mathrm{oz} / \mathrm{yd}^{2}\right) \text { : } \\
\text { Removable by Vacuuming } \\
\text { Removable by Washing } \\
\text { Total (As-Received) }\end{array}$ & $\begin{array}{r}8.2^{*} \\
\underline{4.6}^{*} \\
12.8^{*}\end{array}$ & $\begin{array}{r}10.7 \\
6.7 \\
17.4\end{array}$ & $\begin{array}{r}8.1 \\
6.7 \\
14.8\end{array}$ & $\begin{array}{l}11.1 \\
\frac{10.4}{21.5}\end{array}$ \\
\hline $\begin{array}{l}\text { Bag Weight, as received (lb) } \\
\text { Residual Dust Weight }(\mathrm{lb})\end{array}$ & $\begin{array}{l}6.4 \\
3.2\end{array}$ & $\begin{array}{l}7.6 \\
4.4\end{array}$ & $\begin{array}{l}7.3 \\
3.7\end{array}$ & $\begin{array}{l}9.1 \\
5.5\end{array}$ \\
\hline $\begin{array}{l}\text { Mullen Burst Strength (psi, net): } \\
\text { Average (actual) } \\
\text { Normalized to } 15.5 \mathrm{oz} / \mathrm{yd}^{2} \\
\% \text { Loss (vs. new fabric) }\end{array}$ & $\begin{array}{c}132 \\
138 \\
0-65 \%\end{array}$ & $\begin{array}{c}124 \\
138 \\
0-65 \%\end{array}$ & $\begin{array}{c}164 \\
169 \\
0-44 \%\end{array}$ & $\begin{array}{c}161 \\
151 \\
0-50 \%\end{array}$ \\
\hline $\begin{array}{c}\text { Fabric pH }(5 \mathrm{~g} / 100 \mathrm{ml}): \\
\text { As Received, Middle }\end{array}$ & 8.32 & 4.38 & 4.96 & 4.34 \\
\hline
\end{tabular}

* These are averages of data on the middle and bottom sections of this bag. The top of this bag was abnormally clean as received (dust cake disturbed during removal?); its dirty permeability was very high $(41.4 \mathrm{cfm})$; and its residual dust load very low $\left(1.4 \mathrm{oz} / \mathrm{yd}^{2}\right.$ removed by vacuuming and $3.2 \mathrm{oz} / \mathrm{yd}^{2}$ removed by washing, for a total of $\left.4.6 \mathrm{oz} / \mathrm{yd}^{2}\right)$. The total weight of this bag would have also been reduced by any excessive dust lost during removal. All other values in this table are averages of data on top, middle, and bottom sections.

No additional bag shrinkage had occurred in either module from November ' 05 to March ' 06 , based on these bags. The overall bag shrinkage is about 1.5 " in the length and essentially nil in the width. 
Grubb Filtration Testing Services, Inc.

Laboratory Report No. 4018

Page 5

\section{Bag Measurements and Construction}

\begin{tabular}{|l|c|c|c|c|}
\hline Used Bag & $\mathbf{4 2 2 6 - 3}$ & $\mathbf{4 2 8 2 - 3}$ & $\mathbf{4 2 2 6 - 4}$ & $\mathbf{4 2 8 2 - 4}$ \\
\hline Length (inches) $^{*}$ & $2431 / 2$ & $2431 / 2$ & 243 & 243 \\
\hline Flat Width (inches) $^{* *}$ & 7.71 & 7.71 & 7.56 & 7.60 \\
\hline Circumference (inches) & 15.50 & 15.42 & 15.12 & 15.33 \\
\hline Bag Weight (lb) & 6.4 & 7.6 & 7.3 & 9.1 \\
\hline
\end{tabular}

* Measured at the seam, from top of bag to the upper row of disc stitching.

** Average; top, middle, and bottom sections.

The bags were constructed of $15.5 \mathrm{oz} / \mathrm{yd}^{2}, 7$-denier Torcon felt, singed on one side (facing out), according to the TXU bag specification except for the thread in the Albany (2-3) bags as noted below. They had a separate woven fabric top cuff containing a double-beaded snap band, a lapped and sewn vertical seam, a 4 " high bottom reinforcement made of the bag material, and an oval bottom disc made of $100 \%$ PTFE felt. The Albany bags had woven PPS top cuffs, and they were sewn entirely with multifilament PPS thread (not in compliance with the spec, but variance given by TXU?). The Midwesco (2-4) bags had woven glass (acid-resistant finished) top cuffs, and they were sewn with PTFE thread in their circumferential stitching and PTFE-coated glass thread in their vertical seams, both as specified. Midwesco used PTFE felt with a PTFE membrane laminated to one side (facing out) for the bottom discs.

\section{Observations and Data Profiles}

All four bags were intact as received, and none of them exhibited any excessive wear either externally or internally (top, middle, and bottom sections), except for some worn thread on the internal surface of some of the bags where the vertical seam contacted the top three cage rings. Oddly, this wear was much more severe on the bags that were removed in Nov-05 (from Rows \#9) than on the bags removed in Mar-06 (from Rows \#7). Bag 4226-3 (sewn with PPS thread) had the worst thread wear. Bag 4282-3 (sewn with glass thread) had less severe thread wear. Bag 4282-4 had only slight thread wear, and bag 4226-4 had no thread wear.

All four bags had similar cage wire impressions, typical of these observed on 7-denier PPS bags at BBSES. The ring impressions are well-set and full-circumference at the bag tops, but they become less pronounced down the length of the bag until becoming very indistinct at the bag bottoms. The vertical wire impressions are more indented/darkened in the curved portions of the bags than in the flat portions, for their full length. The excess bag circumference (vs. that of the cage) was uniformly distributed (fabric draped between the vertical cage wires) around the full circumference of the cage for all the bags; i.e., there were no distinct vertical pinches.

All of the bags were nominally $3 "-4$ " longer than their installed cages, and the unsupported bottom sections were crumpled as a result. However, no severe wear had occurred due to the bottom reinforcement and to the use of PTFE felt discs. (This is why the are used!) Both of the Midwesco 
Grubb Filtration Testing Services, Inc.

Laboratory Report No. 4018

Page 6

bags, from 2-4, had twisted bottoms due to crooked seams (a typical problem with "oval" bags made with 7-denier PPS felt). Neither of the Albany bags, from 2-3, had twisted bottoms.

External Dust Cake: Bag 4226-3 had an unusually thin, beige dust cake with some bronze fabric showing through, especially toward its top. Bags 4226-4 and 4282-3 were very similar in appearance. They had uniform, moderately thin, beige dust cakes with no fabric showing through. Bag 4282-4 had a much thicker and crustier cake which was dark gray in color. The crust was fairly soft except at its bottom where it was much harder, especially on its reinforcement. The bag (\#4226-4) removed from 2-4 in Nov-05 had some light, soft crust on its bottom reinforcement (only). Neither of the bags from 2-3 had any crust on them, but both had some blackish staining on their bottom reinforcements.

External Surface After Vacuuming: Bag 4226-3 had essentially no crust. Bag 4226-4 had some whitish crust imbedded in its external surface. Bag 4282-3 had much more whitish crust imbedded in its surface (vs. 4226-4). Bag 4282-4 appeared to have much more imbedded crust than 4282-3, but it stood out more because of the much darker (carbon-stained) fabric background.

Except for the AC-injected bag (4282-4), the bags had a bronze color, except where carbon-stained (uniformly at the top and locally at the bottom). Bag 4282-4 was a dark brown color (with the whitish crust described above) along its full length.

Internal Surface After Vacuuming: All of the bags were blackish inside their top sections (uniformly, except blacker at the cage ring impressions), but the AC-injection bag (4282-4) was much darker than the rest. Except for 4282-4, the middle and bottom sections of the bags were bronzecolored with blackish-stained vertical wire impressions which were more pronounced in the curved portions and in the middle sections. The middle and bottom sections of bag 4282-4 were a much darker brown (blackish dust bleed-through combined with the bronze fabric) and had much blacker vertical wire impressions.

Washed Fabric Appearance: Externally, except for a slight blackish tinge remaining in the top specimens, all of the washed samples of each fabric type were similar in appearance. The -3 (Albany fabric) specimens were "fuzzier" and a lighter bronze color (due to being singed to a lesser degree) than the -4 (Midwesco/Southern Felt fabric). Faded Miswesco stamps were present on the -4 top specimens.

Internally, blackish stains remained in all of the top specimens after washing, especially at the cage wire impressions. (The AC-injection bag, \#4282-4, was no more stained than other bags.) The middle and bottom sections were all generally the same bronze color (unsinged, so no difference in color between the -3 and -4 bags), and all had residual blackish stains at some vertical wire impressions (in the curves). The -3 (Albany) fabric was much fuzzier than the -4 (Midwesco) fabric.

Data Profiles: The individual used bag data profiles are presented below. The as-received and vacuumed permeability and Mullen Burst values for each section are averages of four readings, two each in flat and curved bag portions. The washed permeability and all weight data were obtained on single specimens from the top, middle, and bottom of each bag. 
Fabric Weight and Residual Dust Load Profiles (oz/yd²)

\begin{tabular}{|c|c|c|c|c|c|}
\hline \multicolumn{2}{|l|}{ Used Bag } & $4226-3$ & $4282-3$ & $4226-4$ & $4282-4$ \\
\hline $\begin{array}{l}\text { Weight (oz/yd²): } \\
\text { As Received, }\end{array}$ & $\begin{array}{l}\text { Top } \\
\text { Middle } \\
\text { Bottom } \\
\text { Average }\end{array}$ & $\begin{array}{l}19.9 \\
28.6 \\
26.1 \\
24.9\end{array}$ & \begin{tabular}{|l|l|}
30.6 & \\
33.8 \\
29.5 \\
31.3
\end{tabular} & $\begin{array}{l}32.2 \\
31.4 \\
25.7 \\
29.8\end{array}$ & $\begin{array}{l}43.0 \\
39.5 \\
31.4 \\
38.0\end{array}$ \\
\hline Vacuumed, & $\begin{array}{l}\text { Top } \\
\text { Middle } \\
\text { Bottom } \\
\text { Average }\end{array}$ & $\begin{array}{l}18.5 \\
19.9 \\
18.4 \\
18.9\end{array}$ & $\begin{array}{l}22.6 \\
20.8 \\
18.4 \\
20.6\end{array}$ & $\begin{array}{l}25.0 \\
22.3 \\
17.8 \\
21.7\end{array}$ & $\begin{array}{l}33.3 \\
26.5 \\
20.9 \\
26.9\end{array}$ \\
\hline Washed, & $\begin{array}{l}\text { Top } \\
\text { Middle } \\
\text { Bottom } \\
\text { Average }\end{array}$ & $\begin{array}{l}15.3 \\
14.3 \\
\underline{14.8} \\
14.8\end{array}$ & $\begin{array}{l}13.5 \\
14.0 \\
14.3 \\
13.9\end{array}$ & $\begin{array}{l}16.0 \\
14.6 \\
14.3 \\
15.0\end{array}$ & $\begin{array}{l}16.2 \\
16.3 \\
17.1 \\
16.5\end{array}$ \\
\hline $\begin{array}{r}\text { Residual Dust Lo } \\
\text { Removed by } \\
\text { vacuumi }\end{array}$ & $\begin{array}{l}\text { gd }\left(o z / y d^{2}\right): \\
\text { giddle } \\
\text { Mop } \\
\text { Bottom } \\
\text { Average }\end{array}$ & $\begin{array}{l}1.4 \\
8.7 \\
7.7 \\
6.0\end{array}$ & \begin{tabular}{c|}
8.0 \\
13.0 \\
11.1 \\
10.7
\end{tabular} & $\begin{array}{l}7.2 \\
9.1 \\
7.9 \\
8.1\end{array}$ & \begin{tabular}{c|}
9.7 \\
13.0 \\
10.5 \\
11.1
\end{tabular} \\
\hline $\begin{array}{l}\text { Removed by } \\
\text { washing, }\end{array}$ & $\begin{array}{l}\text { Top } \\
\text { Middle } \\
\text { Bottom } \\
\text { Average }\end{array}$ & $\begin{array}{l}3.2 \\
5.6 \\
3.6 \\
4.1\end{array}$ & $\begin{array}{l}9.1 \\
6.8 \\
4.1 \\
6.7\end{array}$ & $\begin{array}{l}9.0 \\
7.7 \\
3.5 \\
6.7\end{array}$ & $\begin{array}{r}17.1 \\
10.2 \\
3.8 \\
10.4\end{array}$ \\
\hline Total, & $\begin{array}{l}\text { Top } \\
\text { Middle } \\
\text { Bottom } \\
\text { Average }\end{array}$ & \begin{tabular}{c|}
4.6 \\
14.3 \\
$\underline{11.3}$ \\
10.1
\end{tabular} & $\begin{array}{l}17.1 \\
19.8 \\
\underline{15.2} \\
17.4\end{array}$ & $\begin{array}{l}16.2 \\
16.8 \\
11.4 \\
14.8\end{array}$ & $\begin{array}{l}26.8 \\
23.2 \\
14.3 \\
21.5\end{array}$ \\
\hline
\end{tabular}




\section{Permeability Profiles}

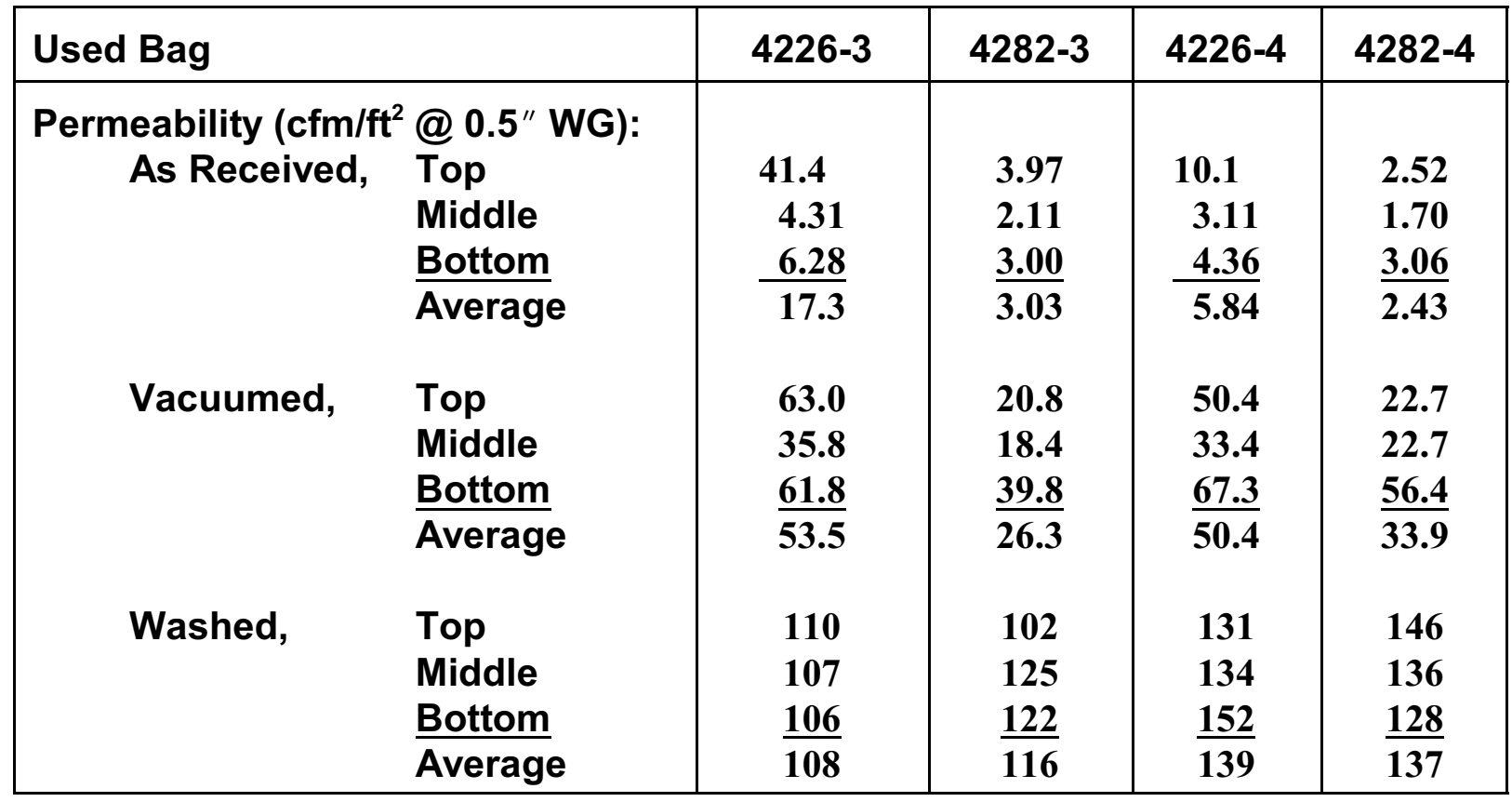

\section{Mullen Burst Profiles}

\begin{tabular}{|c|c|c|c|c|}
\hline Used Bag & $4226-3$ & $4282-3$ & $4226-4$ & $4282-4$ \\
\hline $\begin{array}{c}\text { Mullen Burst (psi, net): } \\
\text { Vacuumed, Top }\end{array}$ & 138 & 134 & 179 & 154 \\
Middle & 127 & 115 & 158 & 171 \\
Bottom & $\underline{132}$ & $\underline{124}$ & $\underline{156}$ & $\underline{159}$ \\
Average & 132 & 124 & 164 & 161 \\
\hline
\end{tabular}




\section{APPENDIX G-2}

\section{ADA-ES, TRIP REPORT MAY 23-24, 2006, JUNE 5, 2006}


ADA-ES, Inc.

8100 SouthPark Way, Unit B

Littleton, Colorado 80120

Fax: 303.734 .0330

303.734.1727 or 1.888 .822 .8617

\title{
ADA-ES memorandum
}

\author{
To: $\quad$ Elton Hughes, Keith Turchi, Ramsay Chang \\ From: Jean Bustard and Theron Grubb \\ CC: \\ Date: February 27, 2008 \\ RE: $\quad$ Trip Report May 23 and 242006
}

This memo presents a summary of the results from testing conducted on May 23 and 24 in the COHPAC ${ }^{\circledR}$ baghouses at Big Brown. Robin Stewart and Jean Bustard were on site to perform drag measurements in support of the investigation into the cause of the crusty dustcake on a bag removed from compartment 2-4C and high pressure drop across baghouse 2-4. All of the efforts on this trip were made with assistance from Fluor laborers.

\section{Summary of Testing:}

In-situ drag was measured in the following compartments:

- $\quad 2-1 \mathbf{H}$ - Measured in-situ drag of 22 standard bags and seven test bags.

- 2-1G - Measured in-situ drag of 22 bags. Tests in this compartment were added because the cleaning system was not working in $2-1 \mathrm{H}$, which made the results invalid.

- 2-2C - Measured in-situ drag of 22 bags.

- 2-3C - Measured in-situ drag of 22 bags.

- 2-4F - Measured in-situ drag of 22 bags. Tests in this compartment were added to the original test plan.

\section{Background}

During sorbent and additive injection testing into the 2-4 baghouse in January - April 2006, pressure drop increased across both the 2-3 and 2-4 baghouses, requiring operation with the bypass dampers partially opened. At the end of testing on the typical fuel blend of lignite and PRB, one bag each was removed from compartments 2-3C and 2-4C. Per Report No. 4226/4282 issued by Grubb Filtration Testing Services, the "residual dust cake had increased substantially and the fabric permeability had decreased substantially on the bags in both 2-3C and 2-4C." Immediately after these bags were removed, Unit 2 started a month long test burn of 100\% PRB coal. Sorbent and additive was injected intermittently for the first couple of weeks of this test burn. During this test, pressure drop increased even further and temperatures were high enough that the dilution dampers opened. Based on observations and operating 
conditions, a decision was made to begin replacing the 2-4 bags to assure that this baghouse would not be pressure drop limited during the high demand, summer season. To help understand the condition of the bags in the other baghouses and the cause of the pressure drop increase, this trip was scheduled to measure the residual drag in one compartment each of the 2-1, 2-2, and 2-3 baghouses.

\section{Results and Observations and Analysis}

- Bags are replaced on a rotating schedule, depending on fabric wear and pressure drop in a particular baghouse. Table 1 presents a summary of the months of service for the bags in each baghouse.

- Drag measurements were conducted on test and standard bags in compartment 2$1 \mathrm{H}$ and on standard bags in compartments 2-1G, 2-2C, 2-3C, and 2-4F. Drag measurements were made in and bags removed from compartments $2-3 C$ and $2-4 C$ in November 2005 to gather baseline information of fabric strength and permeability prior to the sorbent injection tests.

- $\quad$ Figure 1 presents drag measurements made on standard high-perm bags in 2004 and 2005. The trends to note from these data are:

- Barring other upset conditions, such as some kind of failure in the cleaning system, the residual drag of the Unit 2 bags does not increase and stays within a range considered ideal for this site, less than 0.3 inches $\mathrm{H}_{2} \mathrm{O} / \mathrm{ft} / \mathrm{min}$.

- Over the past two years, we have not seen any difference in residual drag between the A- and B-side bags on Unit 2.

- Measurements in 2005 showed higher residual drag in the Unit 1 bags compared to the Unit 2 bags, especially the bags in compartment 1-2D in November 2005. There were indications that the cleaning system in 1-2D may not have been working properly. A discussion of the results can be found in the previous trip report.

- Table 2 presents average drag and operating hours for bags tested during this trip and, when available, drag measurements made in May 2005 and November 2005. The oldest bags were in compartment 2-2C with just over two years of operation. The bags in the other three baghouses had between 12 and 15 months of operation. Because the cleaning system was not working in compartment $2-1 \mathrm{H}$, these drag values are not included in any of the following discussions.

- $\quad$ Figure 2 graphically shows drag measurements made in Unit 2 compartments during this trip and from previous measurements in the same baghouse or compartment.

- Residual drag increased in all baghouses. On average, the drag in the A-side baghouses increased by about 0.1 inches $\mathrm{H}_{2} \mathrm{O} / \mathrm{ft} / \mathrm{min}$, which is at the high end of expected increases, versus 0.17 inches $\mathrm{H}_{2} \mathrm{O} / \mathrm{ft} / \mathrm{min}$ in the $\mathrm{B}$-side baghouses, which is higher than expected.

- The drag of the A-side bags is acceptable, although the average drag in $2-2 \mathrm{C}$ is at the upper limit. 
- The drag in baghouses 2-3 and 2-4 was similar. The drag of both are in a range where pressure drop will become a problem at full load operation, especially for extended periods and with higher summer temperatures.

\section{Discussion}

- It appears that operating conditions between November 2005 and May 2006 have caused an increase in the residual drag in all Unit 2 baghouses. The causes could include:

- Operational upsets, especially ones that resulted in the boiler tripping off line. Excursions through dew point can cause the dustcake to become sticky and more difficult to remove.

- Operation with 100\% PRB coal. Industry experience with reverse gas baghouses and PRB ash has shown that additional energy is needed to maintain an acceptable pressure drop. This is why most reverse gas baghouses on PRB coal have sonic horns. The cleaning energy from the pulse-jet system should be adequate to clean off the dustcake; however, the dustcake formed with the $100 \%$ PRB ash may have lower permeability and be more difficult to remove.

- Operational upsets with the flue gas condition systems. Different ratios of $\mathrm{SO}_{3}$ to $\mathrm{NH}_{3}$ can drive the reaction to a stickier particle. In theory, these particles should be captured in the ESP, unless injection rates were higher than the recommended levels.

- The B-side bags experienced a higher average increase in drag then the A-side bags. The causes could include:

- Increasing the particulate loading into 2-4 from sorbent injection will result in a higher pressure drop. These baghouses are marginally sized and any additional loading is usually seen as an unacceptable increase in pressure drop. As the pressure drop increased across 2-4, flow to the 2-3 baghouse probably increased to balance pressure drop. In this scenario, both 2-3 and 2-4 would have experienced more challenging operating conditions than the A-side baghouses. This could have resulted in an accelerated degradation in drag because the cleaning system may not have been able to overcome the increased loading and flow. The impact on the dustcake of the chemical additive is unknown.

- I did take a look at the bags that were being removed from compartments 2-4F and 2-4G. The dustcake on the bags was not crusty. It is possible that crusty cake in 2$4 \mathrm{C}$ could have been an anomaly caused either when the large clinker formed or because the large clinker formed. It is unclear to me whether the clinker formed before or after the bag was removed. 
Table 1

Bag Service Summary

\begin{tabular}{|c|c|c|}
\hline Compartment & Last Bag Replacement & Months in Service \\
\hline $1-1$ & April 2004 & $\sim 25$ \\
\hline $1-2$ & May 2004 & $\sim 24$ \\
\hline $1-3$ & May 2005 & $\sim 11$ \\
\hline $1-4$ & April 2005 & $\sim 12$ \\
\hline $2-1$ & May 2005 & $\sim 10$ \\
\hline $2-2$ & May 2004 & $\sim 24$ \\
\hline $2-3$ & March 2005 & $\sim 13$ \\
\hline $2-4$ & February 2005 & $\sim 15$ (before bag replacement in May) \\
\hline
\end{tabular}

Table 2

Drag Measurements, 05/23-24/06

Drag Unit $=$ inches $\mathrm{H}_{2} \mathrm{O} / \mathrm{ft} / \mathrm{min}$

Comp. Bag Type/Bag Batch

Comp. Bag TypelBag Batch
Average Drag Average Drag Average Drag 05/17/05
11/02/05

0.19

0.22

0.25

0.17

0.24

T1 - High Perm Tefaire PTFE scrim

2-1G 7-denier Torcon (May 2005)

2-2C 7-denier Torcon (April 2004)

0.18

NA

0.31

$0.47^{\mathrm{a}}$

$0.45^{\mathrm{a}}$

$0.52^{\mathrm{a}}$

7,711

Estimated Operating Hours 05/23/06

7,711

2-3C 7-denier Torcon (March 2005)

NA

0.21

0.37

9,392

2-4F 7-denier Torcon (Jan 2005)

NA

$0.21^{b}$

0.39

10,064

a. Cleaning system not working

b. Measurements made compartment $2-4 \mathrm{C}$ not $2-4 \mathrm{~F}$ 


\section{Big Brown In-Situ Drag \\ 7-Denier Bags \\ 2004 - 2005}

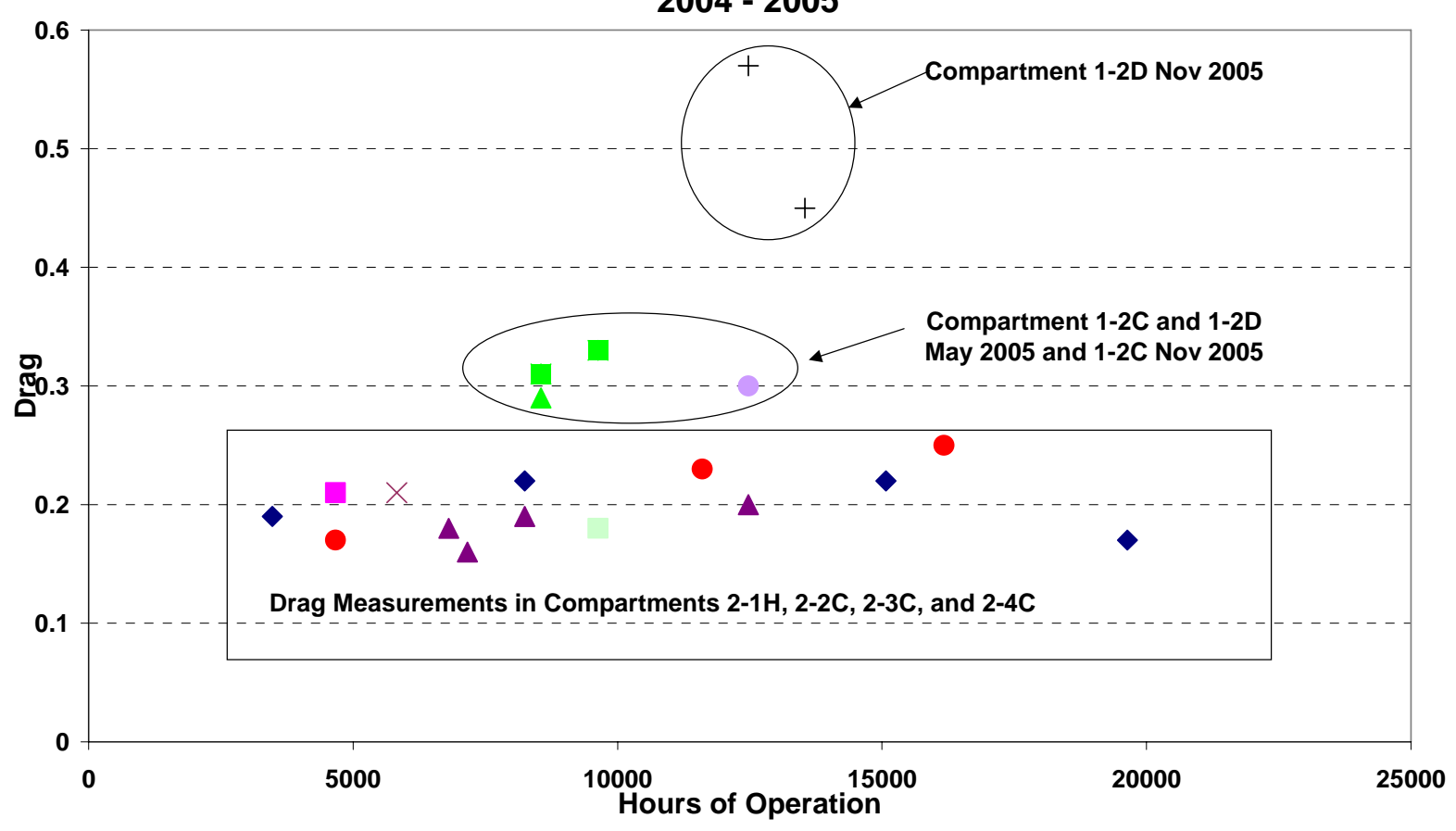

Figure 1. Drag measurements made in 2004 and 2005 on high perm bags installed in TXU Big Brown COHPAC Units 1 and 2. 


\section{Big Brown In-Situ Drag}

Unit 2, 2005 - 2006

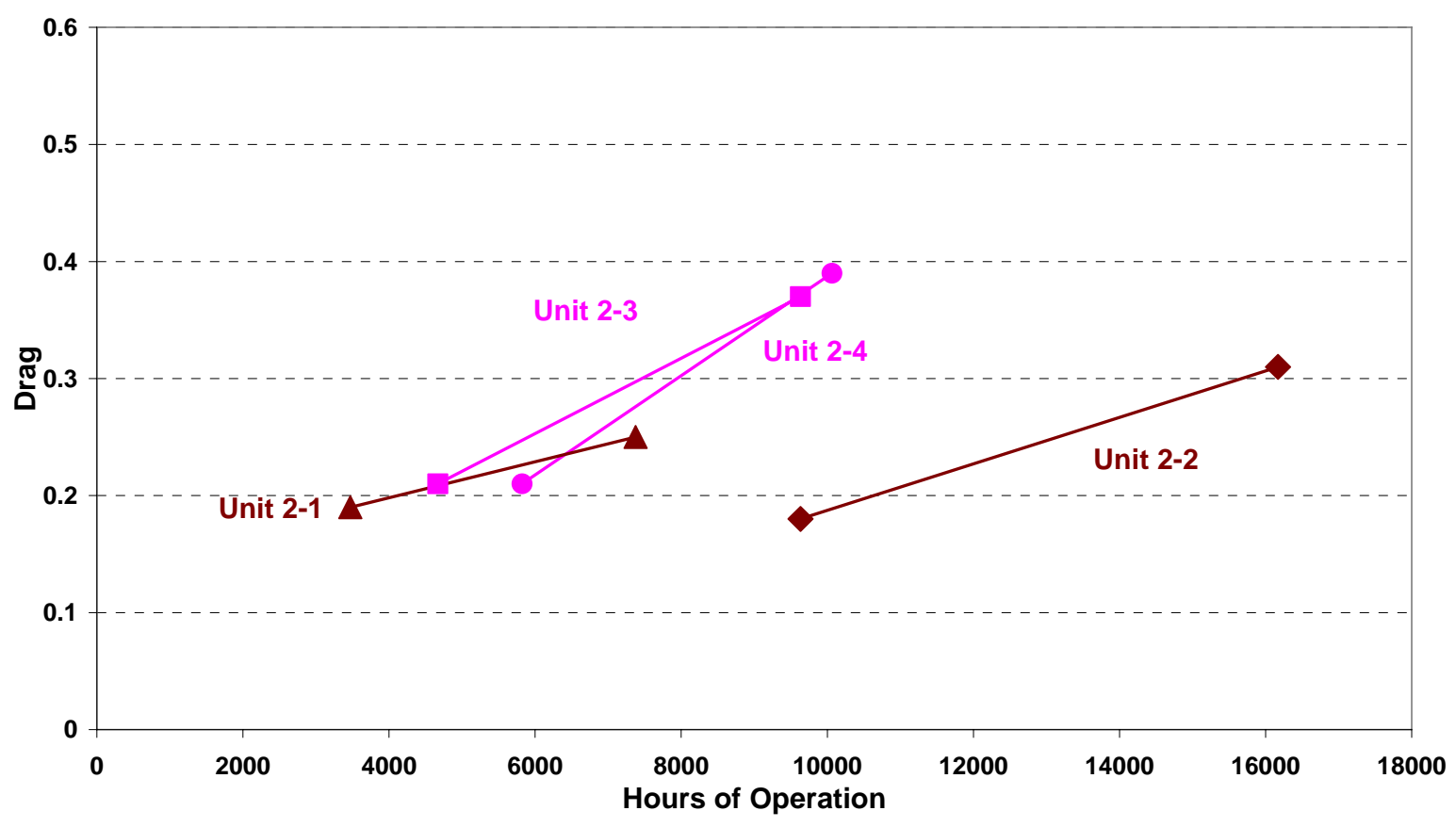

Figure 2. Average drag data from Unit 2 baghouses in May 2006 and select data from May and November 2005. 


\section{APPENDIX G-3}

\section{SEM-EDX ANALYSIS OF FILTER CROSS SECTIONS AND ELEMENT MAPPING OF BAG SAMPLE CROSS SECTIONS}


Filter Bag Data

SEM-EDX Analysis of Filter Cross Sections

FF 2-3C Sample, pulled 11-3-05

Image Number:

EERC CM30647.CDR

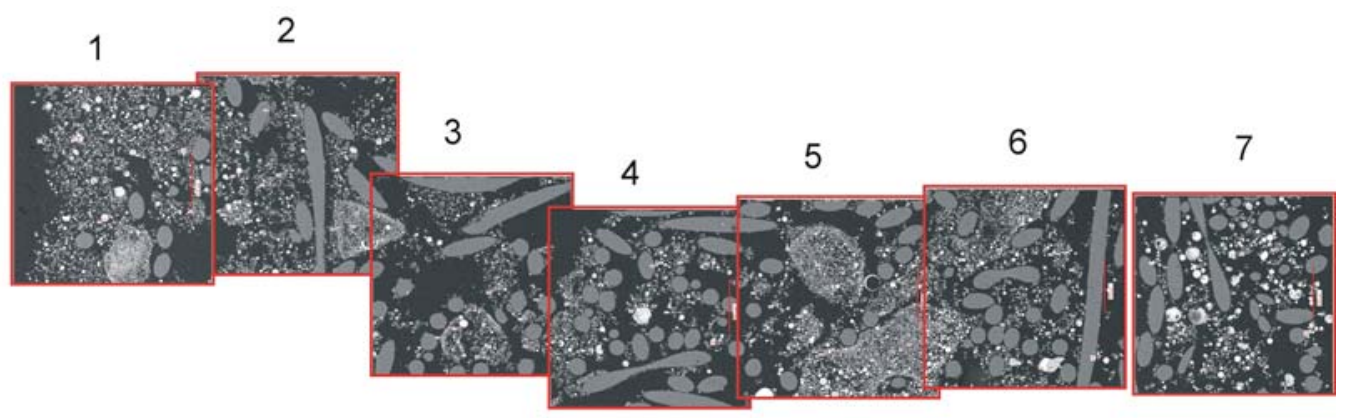

Flow

Figure G3-1. Bag cross-section composite image, FF 2-3C sample from 11-3-05.

Table G3-1. Oxide Weight Averages of the Sample Points in Each Image of Figure G3-1

\begin{tabular}{lcccccccccc}
\hline Image & $\mathrm{MgO}$ & $\mathrm{Al}_{2} \mathrm{O}_{3}$ & $\mathrm{SiO}_{2}$ & $\mathrm{SO}_{3}$ & $\mathrm{~K}_{2} \mathrm{O}$ & $\mathrm{CaO}$ & $\mathrm{TiO}_{2}$ & $\mathrm{Fe}_{2} \mathrm{O}_{3}$ & $\mathrm{Na}_{2} \mathrm{O}$ & $\mathrm{P}_{2} \mathrm{O}_{5}$ \\
\hline 1 & 1.4 & 14.3 & 45.7 & 13.4 & 0.9 & 19.8 & 0.4 & 3.5 & 0.3 & 0.2 \\
2 & 1.7 & 13.5 & 33.9 & 17.6 & 0.3 & 27.9 & 1.3 & 3.3 & 0.1 & 0.4 \\
3 & 1.7 & 13.7 & 33.5 & 20.7 & 0.6 & 24.3 & 1.1 & 3.8 & 0.0 & 0.5 \\
4 & 1.5 & 15.5 & 47.4 & 10.2 & 1.1 & 19.9 & 0.8 & 3.3 & 0.1 & 0.1 \\
5 & 1.6 & 14.8 & 43.2 & 12.3 & 1.1 & 21.3 & 1.1 & 4.5 & 0.1 & 0.0 \\
6 & 1.4 & 15.2 & 52.5 & 6.6 & 1.4 & 17.5 & 0.7 & 4.5 & 0.2 & 0.0 \\
7 & 3.6 & 13.2 & 35.8 & 11.8 & 0.4 & 31.4 & 0.3 & 3.3 & 0.1 & 0.1 \\
Average & 1.9 & 14.3 & 41.7 & 13.2 & 0.8 & 23.2 & 0.8 & 3.7 & 0.1 & 0.2 \\
\hline
\end{tabular}




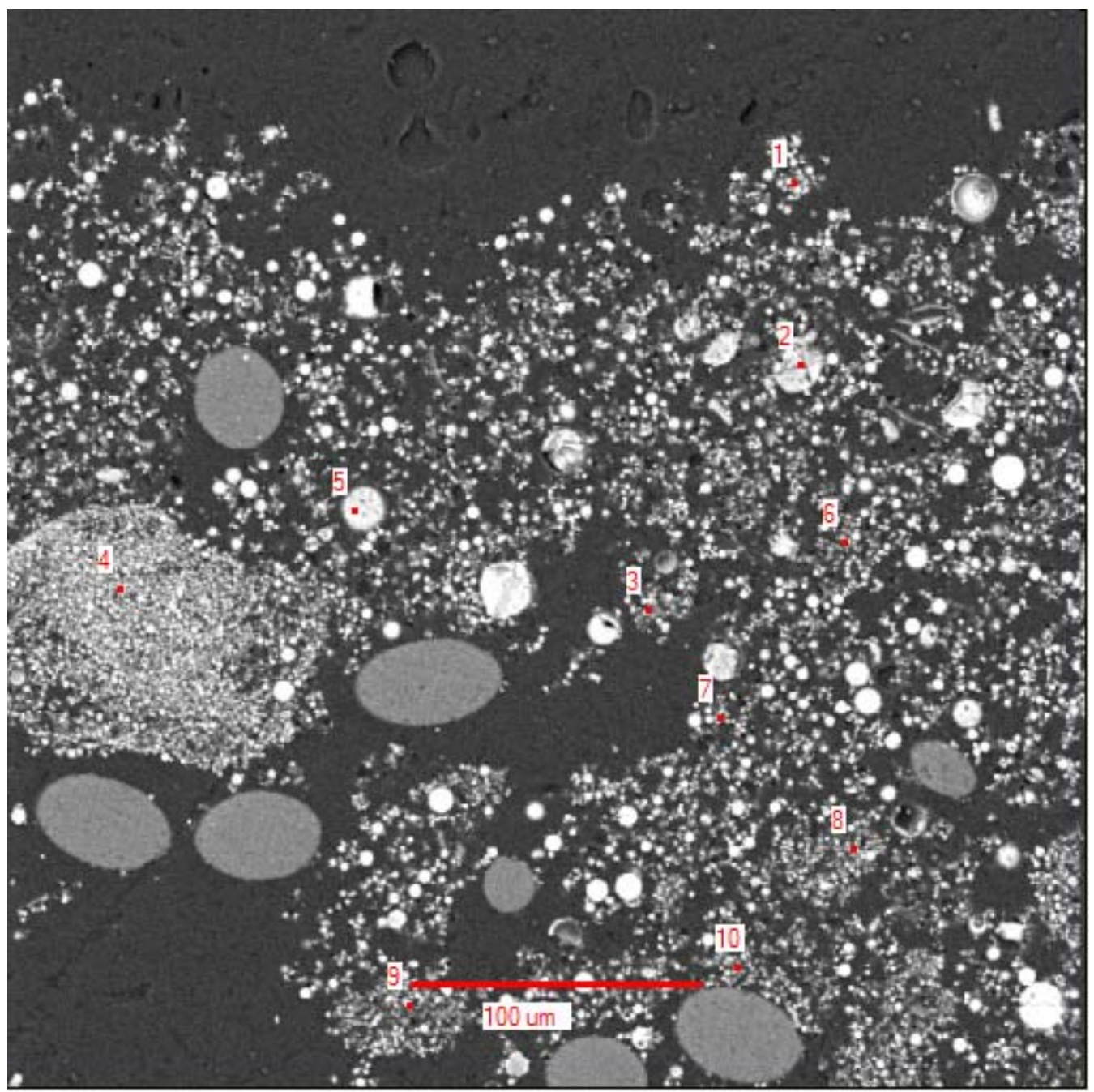

Figure G3-2. Image number 1 from FF 2-3C sample, 11-3-05.

Table G3-2. Oxide Weight Percentages for the Sample Points of Figure G2

\begin{tabular}{lcccccccccc}
\hline Image & $\mathrm{MgO}$ & $\mathrm{Al}_{2} \mathrm{O}_{3}$ & $\mathrm{SiO}_{2}$ & $\mathrm{SO}_{3}$ & $\mathrm{~K}_{2} \mathrm{O}$ & $\mathrm{CaO}$ & $\mathrm{TiO}_{2}$ & $\mathrm{Fe}_{2} \mathrm{O}_{3}$ & $\mathrm{Na}_{2} \mathrm{O}$ & $\mathrm{P}_{2} \mathrm{O}_{5}$ \\
\hline 1 & 2.5 & 14.3 & 30.9 & 13.8 & 0.9 & 27.6 & 3.2 & 6.7 & 0.2 & 0.0 \\
2 & 0.0 & 0.6 & 99.3 & 0.0 & 0.0 & 0.0 & 0.0 & 0.0 & 0.1 & 0.0 \\
3 & 1.0 & 16.6 & 36.0 & 16.9 & 1.4 & 21.8 & 0.0 & 4.0 & 0.4 & 1.8 \\
4 & 2.1 & 16.5 & 32.7 & 15.6 & 0.0 & 30.1 & 0.0 & 3.1 & 0.0 & 0.0 \\
5 & 0.9 & 18.7 & 66.0 & 0.6 & 2.9 & 5.8 & 1.1 & 3.5 & 0.5 & 0.0 \\
6 & 0.0 & 15.3 & 53.4 & 10.9 & 2.4 & 17.0 & 0.0 & 0.0 & 1.0 & 0.0 \\
7 & 2.0 & 13.4 & 38.1 & 13.9 & 0.0 & 28.1 & 0.0 & 4.5 & 0.0 & 0.0 \\
8 & 2.8 & 13.0 & 28.8 & 21.9 & 0.9 & 28.4 & 0.0 & 4.3 & 0.0 & 0.0 \\
9 & 1.6 & 21.1 & 38.7 & 12.1 & 0.0 & 21.7 & 0.0 & 4.4 & 0.4 & 0.0 \\
10 & 1.1 & 13.9 & 33.0 & 28.6 & 1.0 & 17.2 & 0.0 & 4.7 & 0.4 & 0.0 \\
Ave & 1.4 & 14.3 & 45.7 & 13.4 & 0.9 & 19.8 & 0.4 & 3.5 & 0.3 & 0.2 \\
\hline
\end{tabular}




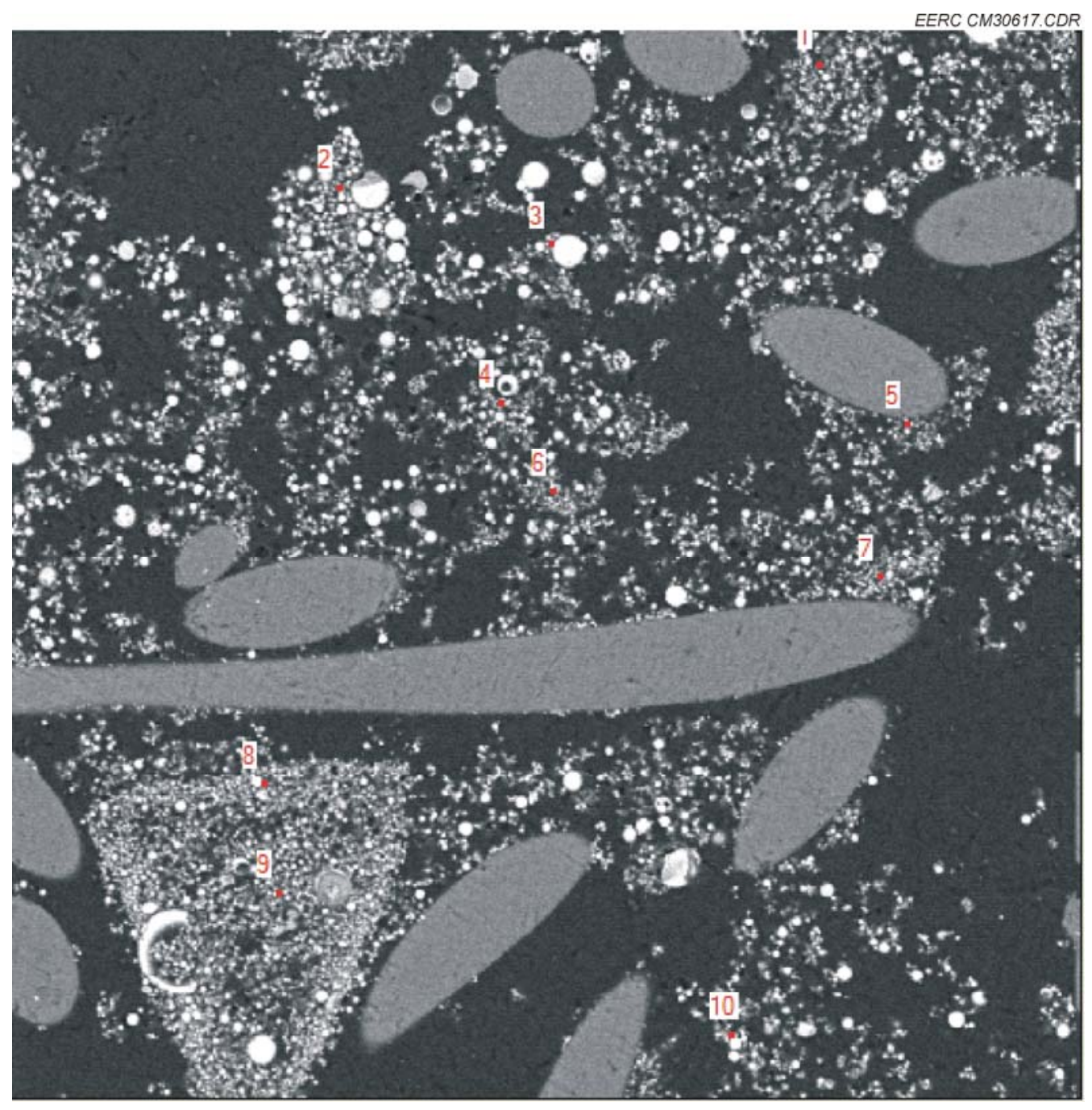

Figure G3-3. Image number 2 from FF 2-3C sample, 11-3-05.

Table G3-3. Oxide Weight Percentages for the Sample Points of Figure G3-3

\begin{tabular}{lcccccccccc}
\hline Image & $\mathrm{MgO}$ & $\mathrm{Al}_{2} \mathrm{O}_{3}$ & $\mathrm{SiO}_{2}$ & $\mathrm{SO}_{3}$ & $\mathrm{~K}_{2} \mathrm{O}$ & $\mathrm{CaO}$ & $\mathrm{TiO}_{2}$ & $\mathrm{Fe}_{2} \mathrm{O}_{3}$ & $\mathrm{Na}_{2} \mathrm{O}$ & $\mathrm{P}_{2} \mathrm{O}_{5}$ \\
\hline 1 & 1.7 & 15.5 & 26.9 & 24.1 & 0.0 & 28.6 & 0.0 & 3.3 & 0.0 & 0.0 \\
2 & 1.8 & 9.6 & 35.1 & 19.4 & 0.9 & 26.0 & 0.0 & 7.2 & 0.0 & 0.0 \\
3 & 0.7 & 22.4 & 57.2 & 5.5 & 1.5 & 12.6 & 0.0 & 0.0 & 0.0 & 0.0 \\
4 & 2.8 & 7.4 & 9.2 & 19.2 & 0.0 & 45.6 & 9.0 & 6.8 & 0.0 & 0.0 \\
5 & 2.2 & 8.3 & 25.6 & 33.5 & 0.8 & 24.6 & 0.0 & 3.1 & 0.0 & 1.8 \\
6 & 0.0 & 18.6 & 36.2 & 16.3 & 0.0 & 25.3 & 3.6 & 0.0 & 0.0 & 0.0 \\
7 & 1.7 & 7.3 & 59.1 & 8.3 & 0.0 & 20.7 & 0.0 & 2.7 & 0.0 & 0.0 \\
8 & 2.2 & 14.8 & 27.1 & 15.3 & 0.0 & 34.8 & 0.0 & 5.7 & 0.0 & 0.0 \\
9 & 2.0 & 14.3 & 29.2 & 23.4 & 0.0 & 29.3 & 0.0 & 0.0 & 0.0 & 1.9 \\
10 & 1.6 & 17.0 & 33.2 & 11.6 & 0.0 & 31.8 & 0.0 & 4.3 & 0.6 & 0.0 \\
Ave & 1.7 & 13.5 & 33.9 & 17.6 & 0.3 & 27.9 & 1.3 & 3.3 & 0.1 & 0.4 \\
\hline
\end{tabular}




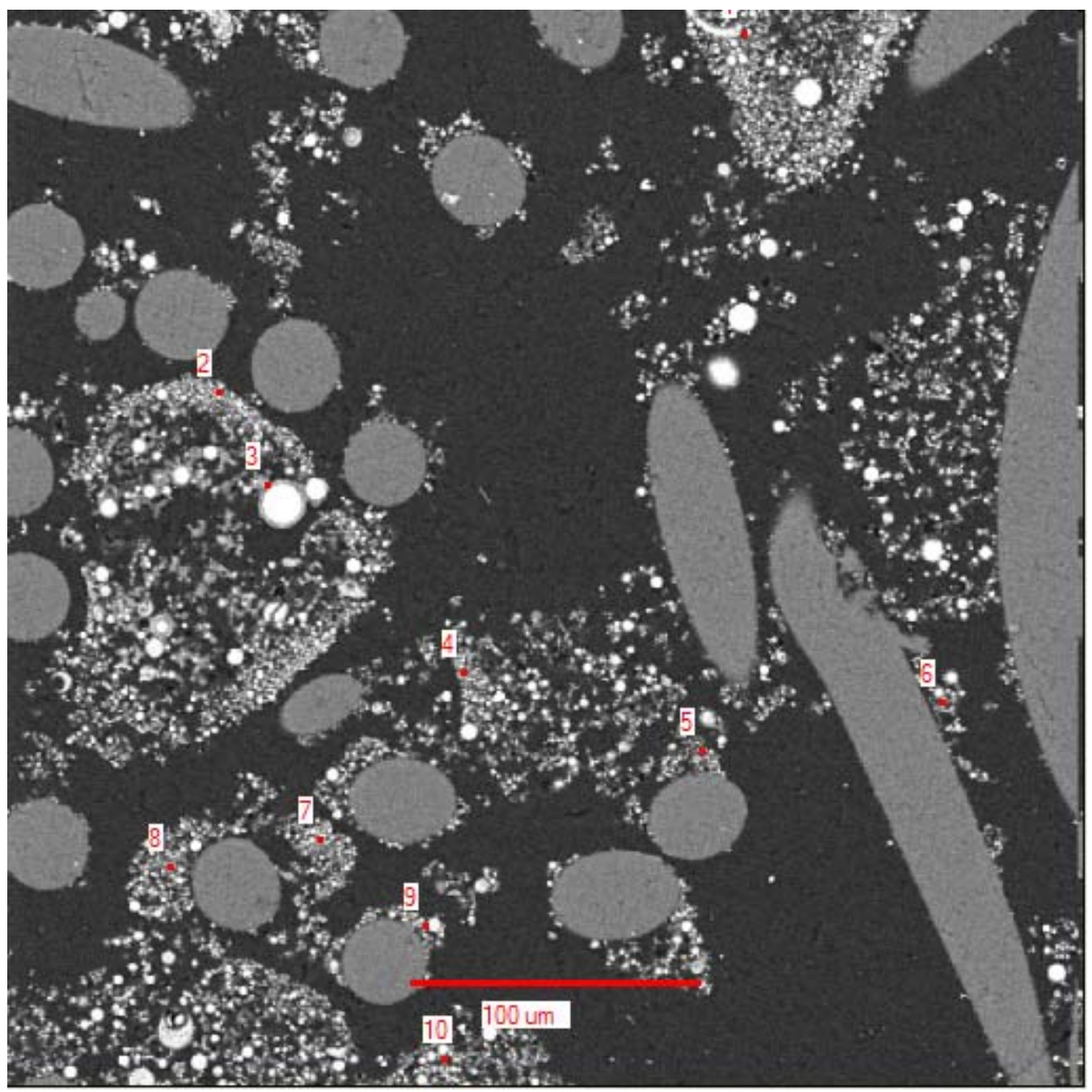

Figure G3-4. Image number 3 from FF 2-3C sample, 11-3-05.

Table G3-4. Oxide Weight Percentages for the Sample Points of Figure G3-4

\begin{tabular}{lcccccccccc}
\hline Image & $\mathrm{MgO}$ & $\mathrm{Al}_{2} \mathrm{O}_{3}$ & $\mathrm{SiO}_{2}$ & $\mathrm{SO}_{3}$ & $\mathrm{~K}_{2} \mathrm{O}$ & $\mathrm{CaO}$ & $\mathrm{TiO}_{2}$ & $\mathrm{Fe}_{2} \mathrm{O}_{3}$ & $\mathrm{Na}_{2} \mathrm{O}$ & $\mathrm{P}_{2} \mathrm{O}_{5}$ \\
\hline 1 & 1.2 & 19.4 & 51.4 & 8.6 & 1.4 & 17.9 & 0.0 & 0.0 & 0.0 & 0.0 \\
2 & 1.2 & 10.0 & 61.8 & 5.5 & 2.1 & 12.4 & 3.0 & 3.8 & 0.3 & 0.0 \\
3 & 1.3 & 5.2 & 9.4 & 59.7 & 0.5 & 23.6 & 0.0 & 0.0 & 0.2 & 0.0 \\
4 & 1.0 & 15.1 & 36.4 & 22.2 & 0.0 & 20.9 & 1.7 & 2.8 & 0.0 & 0.0 \\
5 & 1.5 & 17.9 & 36.2 & 16.1 & 0.0 & 22.5 & 0.0 & 5.7 & 0.0 & 0.0 \\
6 & 1.9 & 11.6 & 26.7 & 20.0 & 0.7 & 29.2 & 3.6 & 6.1 & 0.0 & 0.0 \\
7 & 2.8 & 10.9 & 21.2 & 24.3 & 0.0 & 33.8 & 0.0 & 5.0 & 0.0 & 1.9 \\
8 & 2.7 & 16.7 & 30.4 & 11.9 & 0.0 & 30.4 & 1.5 & 5.1 & 0.0 & 1.3 \\
9 & 1.5 & 15.5 & 30.9 & 22.2 & 1.3 & 20.6 & 1.5 & 4.7 & 0.0 & 1.7 \\
10 & 2.0 & 14.3 & 31.0 & 16.6 & 0.0 & 31.5 & 0.0 & 4.8 & 0.0 & 0.0 \\
Ave & 1.7 & 13.7 & 33.5 & 20.7 & 0.6 & 24.3 & 1.1 & 3.8 & 0.0 & 0.5 \\
\hline
\end{tabular}




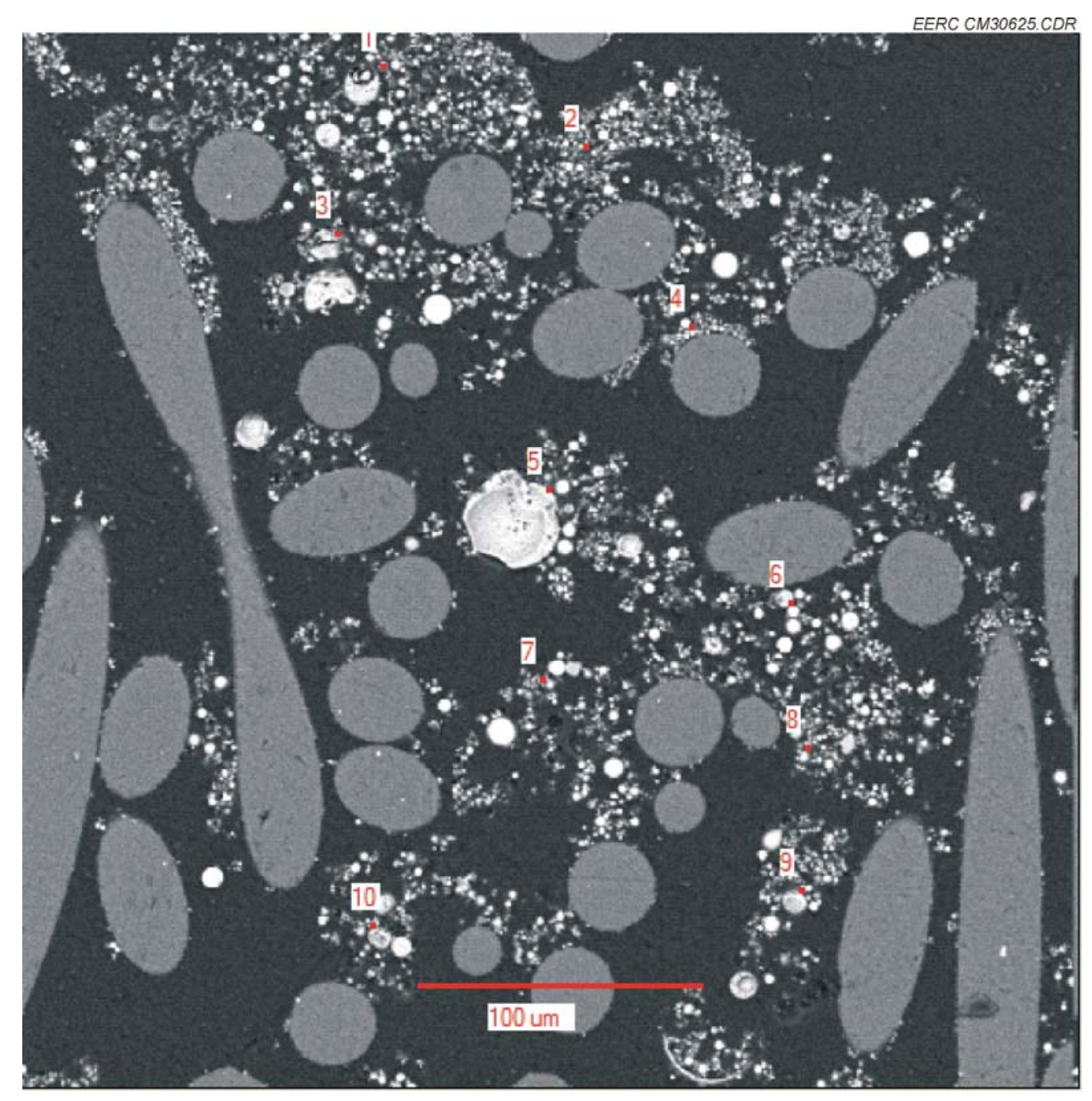

Figure G3-5. Image number 4 from FF 2-3C sample, 11-3-05.

Table G3-5. Oxide Weight Percentages for the Sample Points of Figure G3-5

\begin{tabular}{lcccccccccc}
\hline Image & $\mathrm{MgO}$ & $\mathrm{Al}_{2} \mathrm{O}_{3}$ & $\mathrm{SiO}_{2}$ & $\mathrm{SO}_{3}$ & $\mathrm{~K}_{2} \mathrm{O}$ & $\mathrm{CaO}$ & $\mathrm{TiO}_{2}$ & $\mathrm{Fe}_{2} \mathrm{O}_{3}$ & $\mathrm{Na}_{2} \mathrm{O}$ & $\mathrm{P}_{2} \mathrm{O}_{5}$ \\
\hline 1 & 1.2 & 5.0 & 72.7 & 5.3 & 1.5 & 11.8 & 2.5 & 0.0 & 0.0 & 0.0 \\
2 & 1.3 & 15.0 & 36.9 & 16.4 & 0.0 & 24.9 & 0.0 & 4.8 & 0.6 & 0.0 \\
3 & 3.8 & 16.2 & 40.3 & 11.8 & 0.0 & 27.9 & 0.0 & 0.0 & 0.0 & 0.0 \\
4 & 1.0 & 9.9 & 63.2 & 11.6 & 2.4 & 11.9 & 0.0 & 0.0 & 0.0 & 0.0 \\
5 & 1.3 & 18.4 & 48.9 & 5.7 & 2.5 & 19.0 & 0.0 & 4.1 & 0.0 & 0.0 \\
6 & 1.6 & 19.6 & 40.9 & 8.8 & 1.5 & 21.9 & 0.0 & 5.7 & 0.0 & 0.0 \\
7 & 2.2 & 22.2 & 40.3 & 8.2 & 1.1 & 21.5 & 1.5 & 2.8 & 0.2 & 0.0 \\
8 & 0.7 & 9.4 & 59.0 & 10.5 & 0.0 & 15.1 & 0.0 & 5.3 & 0.0 & 0.0 \\
9 & 1.7 & 14.8 & 25.9 & 16.4 & 0.6 & 31.0 & 2.3 & 6.2 & 0.0 & 1.2 \\
10 & 0.5 & 25.2 & 45.8 & 7.3 & 1.7 & 13.8 & 1.7 & 3.6 & 0.4 & 0.0 \\
Ave & 1.5 & 15.5 & 47.4 & 10.2 & 1.1 & 19.9 & 0.8 & 3.3 & 0.1 & 0.1 \\
\hline
\end{tabular}




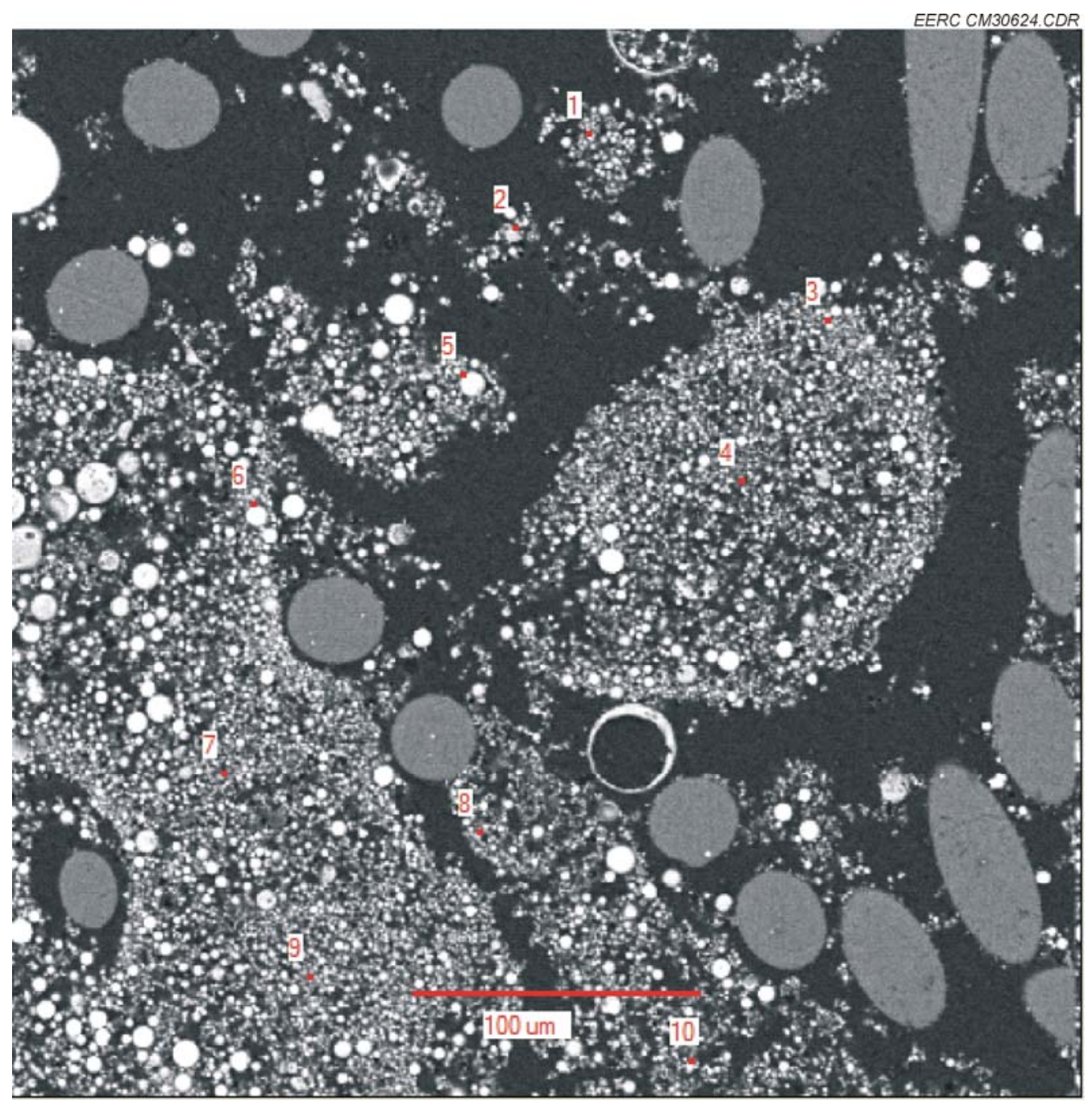

Figure G3-6. Image number 5 from FF 2-3C sample, 11-3-05.

Table G3-6. Oxide Weight Percentages for the Sample Points of Figure G3-6

\begin{tabular}{lcccccccccc}
\hline Image & $\mathrm{MgO}$ & $\mathrm{Al}_{2} \mathrm{O}_{3}$ & $\mathrm{SiO}_{2}$ & $\mathrm{SO}_{3}$ & $\mathrm{~K}_{2} \mathrm{O}$ & $\mathrm{CaO}$ & $\mathrm{TiO}_{2}$ & $\mathrm{Fe}_{2} \mathrm{O}_{3}$ & $\mathrm{Na}_{2} \mathrm{O}_{2}$ & $\mathrm{P}_{2} \mathrm{O}_{5}$ \\
\hline 1 & 1.7 & 17.4 & 38.3 & 8.6 & 0.7 & 24.7 & 1.5 & 7.1 & 0.0 & 0.0 \\
2 & 2.2 & 13.4 & 43.6 & 9.7 & 0.9 & 26.3 & 0.0 & 3.9 & 0.0 & 0.0 \\
3 & 1.5 & 13.8 & 41.4 & 25.7 & 1.5 & 13.4 & 0.0 & 2.8 & 0.0 & 0.0 \\
4 & 1.6 & 17.6 & 45.6 & 14.1 & 1.3 & 14.8 & 0.0 & 4.8 & 0.3 & 0.0 \\
5 & 1.5 & 19.8 & 40.4 & 5.9 & 1.4 & 21.8 & 1.5 & 7.3 & 0.5 & 0.0 \\
6 & 1.0 & 14.6 & 28.6 & 14.1 & 0.8 & 33.4 & 4.1 & 3.4 & 0.0 & 0.0 \\
7 & 2.3 & 15.9 & 44.7 & 12.0 & 1.1 & 18.1 & 0.0 & 5.6 & 0.3 & 0.0 \\
8 & 2.2 & 9.8 & 35.2 & 17.2 & 1.1 & 29.1 & 1.6 & 3.8 & 0.0 & 0.0 \\
9 & 0.4 & 6.3 & 77.9 & 5.1 & 1.7 & 8.6 & 0.0 & 0.0 & 0.0 & 0.0 \\
10 & 2.1 & 19.0 & 36.4 & 10.5 & 0.9 & 22.7 & 1.9 & 6.6 & 0.0 & 0.0 \\
Ave & 1.6 & 14.8 & 43.2 & 12.3 & 1.1 & 21.3 & 1.1 & 4.5 & 0.1 & 0.0 \\
\hline
\end{tabular}




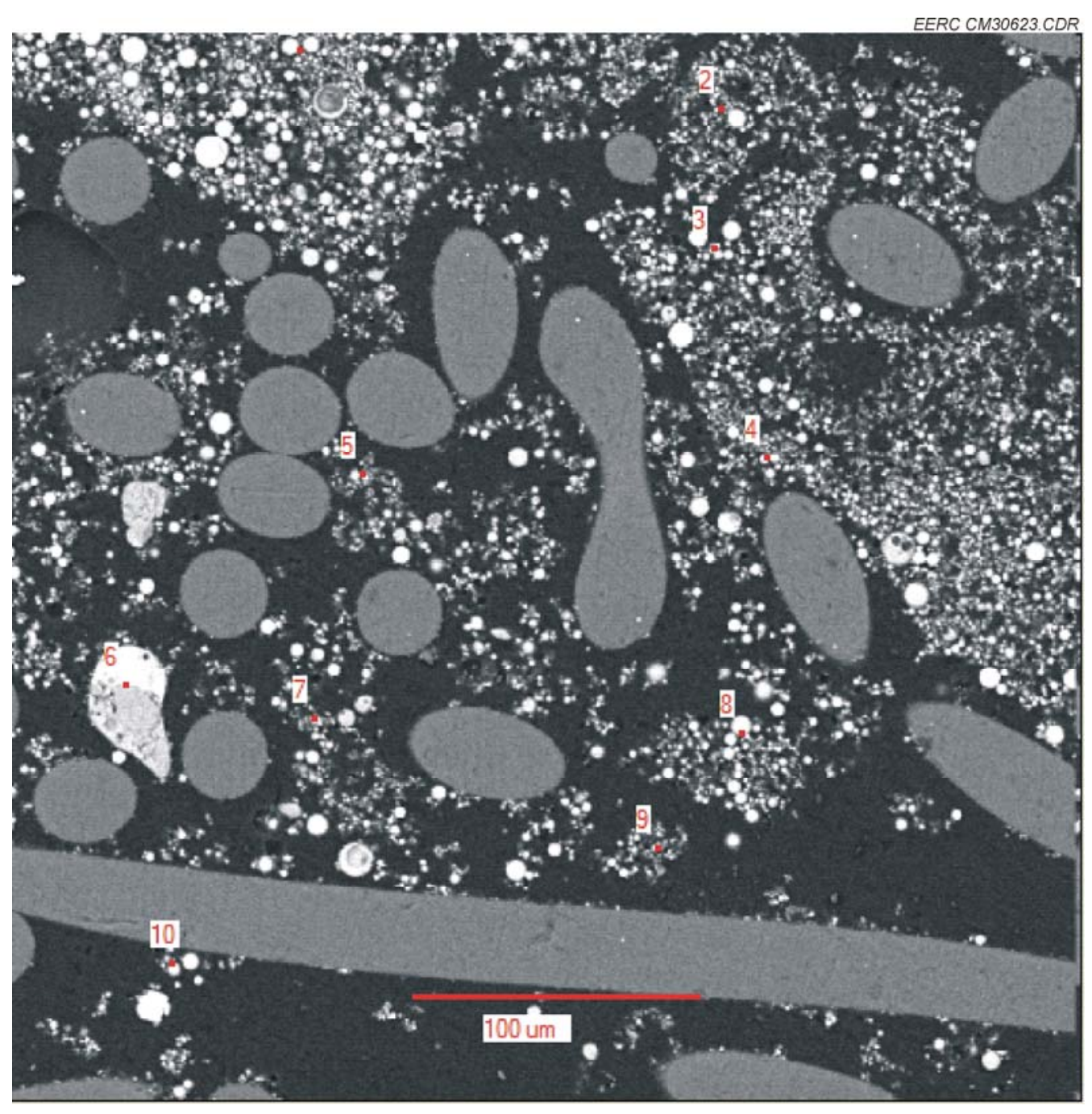

Figure G3-7. Image number 6 from FF 2-3C sample, 11-3-05.

Table G3-7. Oxide Weight Percentages for the Sample Points of Figure G3-7

\begin{tabular}{lcccccccccc}
\hline Image & $\mathrm{MgO}$ & $\mathrm{Al}_{2} \mathrm{O}_{3}$ & $\mathrm{SiO}_{2}$ & $\mathrm{SO}_{3}$ & $\mathrm{~K}_{2} \mathrm{O}$ & $\mathrm{CaO}$ & $\mathrm{TiO}_{2}$ & $\mathrm{Fe}_{2} \mathrm{O}_{3}$ & $\mathrm{Na}_{2} \mathrm{O}$ & $\mathrm{P}_{2} \mathrm{O}_{5}$ \\
\hline 1 & 1.2 & 19.0 & 58.1 & 3.4 & 2.1 & 8.0 & 1.7 & 6.4 & 0.2 & 0.0 \\
2 & 2.1 & 17.6 & 39.5 & 15.5 & 1.8 & 14.3 & 1.8 & 7.5 & 0.0 & 0.0 \\
3 & 2.4 & 12.7 & 37.6 & 7.9 & 0.0 & 34.7 & 0.0 & 4.7 & 0.0 & 0.0 \\
4 & 1.6 & 11.4 & 40.4 & 14.3 & 0.8 & 26.6 & 1.3 & 3.5 & 0.0 & 0.0 \\
5 & 2.0 & 13.4 & 48.6 & 6.5 & 0.9 & 22.6 & 0.0 & 5.4 & 0.6 & 0.0 \\
6 & 1.1 & 6.1 & 72.4 & 0.0 & 0.0 & 19.6 & 0.8 & 0.0 & 0.0 & 0.0 \\
7 & 0.8 & 12.5 & 73.6 & 1.0 & 4.1 & 3.6 & 1.3 & 2.8 & 0.5 & 0.0 \\
8 & 1.0 & 15.5 & 64.8 & 1.7 & 2.5 & 10.9 & 0.0 & 3.4 & 0.2 & 0.0 \\
9 & 0.8 & 22.7 & 42.9 & 6.6 & 1.7 & 21.2 & 0.0 & 4.0 & 0.0 & 0.0 \\
10 & 1.5 & 21.4 & 47.0 & 8.9 & 0.0 & 13.7 & 0.0 & 7.0 & 0.5 & 0.0 \\
Ave & 1.4 & 15.2 & 52.5 & 6.6 & 1.4 & 17.5 & 0.7 & 4.5 & 0.2 & 0.0 \\
\hline
\end{tabular}




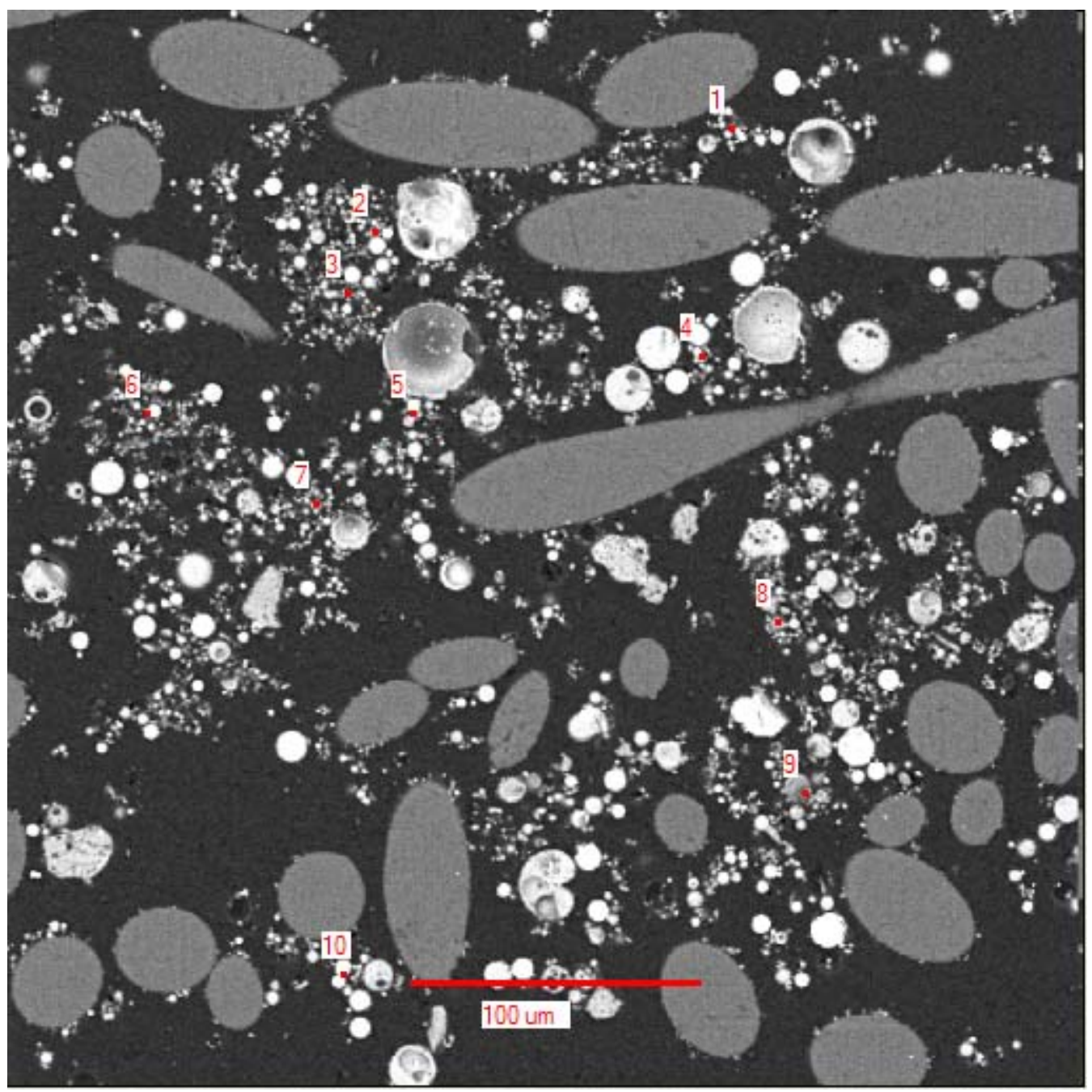

Figure G3-8. Image number 7 from FF 2-3C sample, 11-3-05.

Table G3-8. Oxide Weight Percentages for the Sample Points of Figure G3-8

\begin{tabular}{lcccccccccc}
\hline Image & $\mathrm{MgO}$ & $\mathrm{Al}_{2} \mathrm{O}_{3}$ & $\mathrm{SiO}_{2}$ & $\mathrm{SO}_{3}$ & $\mathrm{~K}_{2} \mathrm{O}$ & $\mathrm{CaO}$ & $\mathrm{TiO}_{2}$ & $\mathrm{Fe}_{2} \mathrm{O}_{3}$ & $\mathrm{Na}_{2} \mathrm{O}$ & $\mathrm{P}_{2} \mathrm{O}_{5}$ \\
\hline 1 & 3.3 & 14.6 & 33.6 & 22.5 & 0.0 & 26.1 & 0.0 & 0.0 & 0.0 & 0.0 \\
2 & 1.7 & 16.3 & 37.2 & 18.8 & 0.9 & 20.5 & 0.0 & 4.3 & 0.3 & 0.0 \\
3 & 1.6 & 22.4 & 46.8 & 11.4 & 0.0 & 17.2 & 0.0 & 0.0 & 0.5 & 0.0 \\
4 & 5.2 & 11.9 & 16.2 & 7.3 & 0.7 & 49.3 & 1.1 & 8.3 & 0.0 & 0.0 \\
5 & 17.1 & 5.3 & 13.1 & 4.8 & 0.0 & 50.9 & 1.6 & 7.4 & 0.0 & 0.0 \\
6 & 2.4 & 7.5 & 21.0 & 4.3 & 0.0 & 59.4 & 0.0 & 5.4 & 0.0 & 0.0 \\
7 & 3.5 & 19.6 & 36.1 & 6.5 & 0.0 & 30.2 & 0.0 & 4.1 & 0.0 & 0.0 \\
8 & 0.0 & 0.0 & 94.1 & 2.9 & 0.5 & 2.5 & 0.0 & 0.0 & 0.0 & 0.0 \\
9 & 0.8 & 25.6 & 51.7 & 6.9 & 1.8 & 7.9 & 0.0 & 3.8 & 0.5 & 1.1 \\
10 & 0.0 & 8.9 & 8.2 & 33.2 & 0.0 & 49.7 & 0.0 & 0.0 & 0.0 & 0.0 \\
Ave & 3.6 & 13.2 & 35.8 & 11.8 & 0.4 & 31.4 & 0.3 & 3.3 & 0.1 & 0.1 \\
\hline
\end{tabular}


FF 2-4C sample, pulled 11-3-05

Image Number:

EERC CM30645.CDR

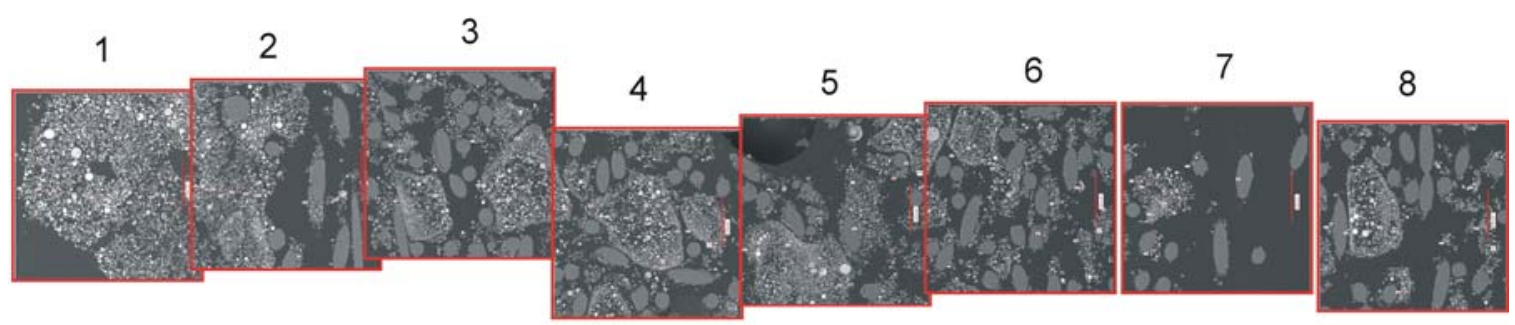

Flow

Figure G3-9. Bag cross section composite image, FF 2-4C sample from 11-3-05.

Table G3-9. Oxide Weight Averages of the Sample Points in Each Image of Figure G3-9

\begin{tabular}{lcccccccccc}
\hline Image & $\mathrm{MgO}$ & $\mathrm{Al}_{2} \mathrm{O}_{3}$ & $\mathrm{SiO}_{2}$ & $\mathrm{SO}_{3}$ & $\mathrm{~K}_{2} \mathrm{O}$ & $\mathrm{CaO}$ & $\mathrm{TiO}_{2}$ & $\mathrm{Fe}_{2} \mathrm{O}_{3}$ & $\mathrm{Na}_{2} \mathrm{O}$ & $\mathrm{P}_{2} \mathrm{O}_{5}$ \\
\hline 1 & 1.6 & 17.3 & 46.9 & 5.2 & 0.9 & 22.8 & 0.7 & 4.4 & 0.0 & 0.2 \\
2 & 1.6 & 17.2 & 41.5 & 11.2 & 0.9 & 22.7 & 0.7 & 3.8 & 0.2 & 0.3 \\
3 & 1.9 & 13.4 & 30.6 & 25.6 & 0.5 & 22.1 & 1.1 & 4.2 & 0.2 & 0.4 \\
4 & 1.1 & 13.8 & 37.1 & 21.5 & 1.1 & 20.7 & 0.7 & 3.9 & 0.0 & 0.0 \\
5 & 1.7 & 13.4 & 37.5 & 19.4 & 0.6 & 22.4 & 0.9 & 4.0 & 0.0 & 0.1 \\
6 & 1.6 & 15.9 & 48.8 & 7.8 & 0.7 & 18.6 & 1.9 & 4.3 & 0.2 & 0.1 \\
7 & 1.8 & 14.3 & 37.0 & 17.7 & 0.8 & 22.0 & 0.8 & 4.5 & 0.1 & 0.9 \\
8 & 1.2 & 15.5 & 41.3 & 12.1 & 0.7 & 21.9 & 1.1 & 4.6 & 0.1 & 1.5 \\
Average & 1.6 & 15.1 & 40.1 & 15.1 & 0.8 & 21.6 & 1.0 & 4.2 & 0.1 & 0.4 \\
\hline
\end{tabular}




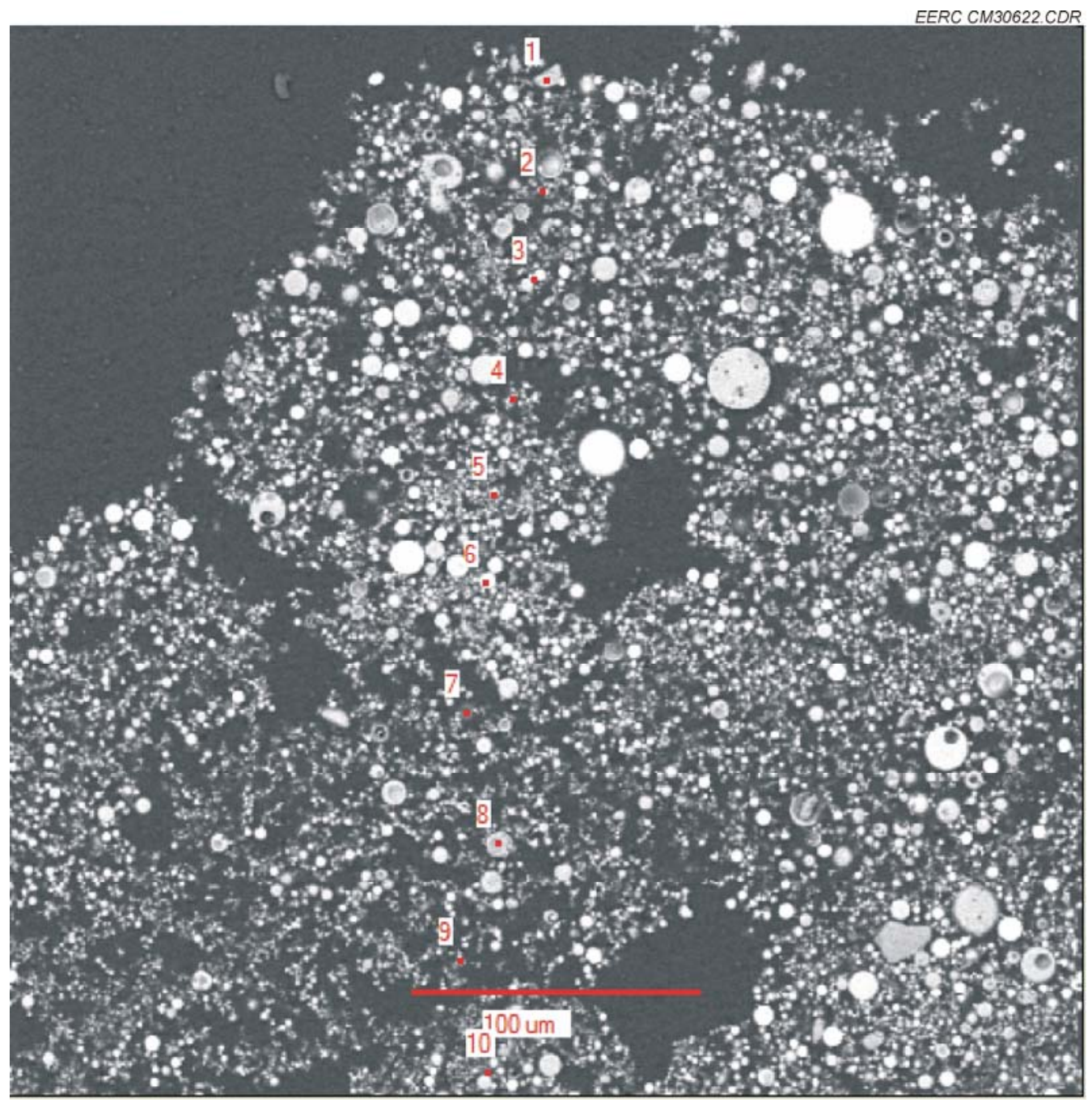

Figure G3-10. Image number 1 from FF 2-4C sample, 11-3-05.

Table G3-10. Oxide Weight Percentages for the Sample Points of Figure G3-10

\begin{tabular}{lcccccccccc}
\hline Image & $\mathrm{MgO}$ & $\mathrm{Al}_{2} \mathrm{O}_{3}$ & $\mathrm{SiO}_{2}$ & $\mathrm{SO}_{3}$ & $\mathrm{~K}_{2} \mathrm{O}$ & $\mathrm{CaO}$ & $\mathrm{TiO}_{2}$ & $\mathrm{Fe}_{2} \mathrm{O}_{3}$ & $\mathrm{Na}_{2} \mathrm{O}$ & $\mathrm{P}_{2} \mathrm{O}_{5}$ \\
\hline 1 & 0.0 & 0.6 & 99.0 & 0.0 & 0.3 & 0.0 & 0.0 & 0.0 & 0.0 & 0.0 \\
2 & 2.2 & 12.8 & 24.7 & 15.2 & 0.0 & 37.6 & 1.5 & 5.0 & 0.0 & 1.1 \\
3 & 2.3 & 18.1 & 44.6 & 3.5 & 0.5 & 25.6 & 0.0 & 5.4 & 0.0 & 0.0 \\
4 & 3.0 & 10.9 & 19.5 & 17.4 & 0.0 & 40.6 & 0.0 & 8.6 & 0.0 & 0.0 \\
5 & 3.0 & 11.5 & 26.8 & 2.4 & 0.0 & 49.0 & 2.3 & 4.3 & 0.0 & 0.6 \\
6 & 2.3 & 17.2 & 40.0 & 0.0 & 0.0 & 33.6 & 1.7 & 5.1 & 0.0 & 0.0 \\
7 & 0.0 & 34.4 & 55.0 & 0.0 & 4.2 & 2.3 & 0.0 & 4.2 & 0.0 & 0.0 \\
8 & 0.0 & 34.6 & 62.1 & 0.0 & 1.7 & 1.2 & 0.0 & 0.0 & 0.5 & 0.0 \\
9 & 2.2 & 18.2 & 45.4 & 2.1 & 0.9 & 21.4 & 1.4 & 8.3 & 0.0 & 0.0 \\
10 & 1.0 & 14.2 & 52.3 & 11.5 & 1.2 & 17.2 & 0.0 & 2.7 & 0.0 & 0.0 \\
Ave & 1.6 & 17.3 & 46.9 & 5.2 & 0.9 & 22.8 & 0.7 & 4.4 & 0.0 & 0.2 \\
\hline
\end{tabular}




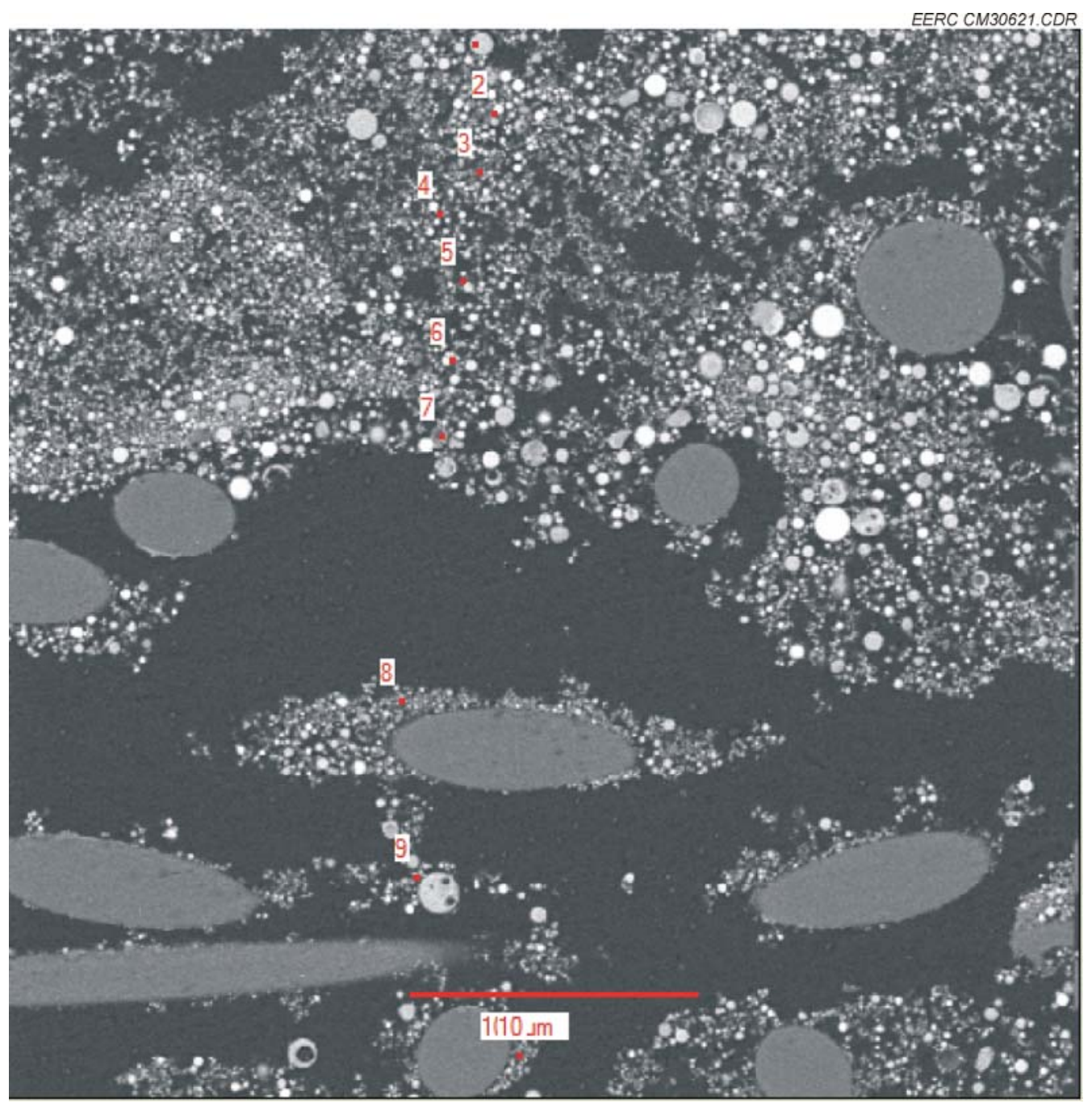

Figure G3-11. Image number 2 from FF 2-4C sample, 11-3-05.

Table G3-11. Oxide Weight Percentages for the Sample Points of Figure G3-11

\begin{tabular}{lcccccccccc}
\hline Image & $\mathrm{MgO}$ & $\mathrm{Al}_{2} \mathrm{O}_{3}$ & $\mathrm{SiO}_{2}$ & $\mathrm{SO}_{3}$ & $\mathrm{~K}_{2} \mathrm{O}$ & $\mathrm{CaO}$ & $\mathrm{TiO}_{2}$ & $\mathrm{Fe}_{2} \mathrm{O}_{3}$ & $\mathrm{Na}_{2} \mathrm{O}$ & $\mathrm{P}_{2} \mathrm{O}_{5}$ \\
\hline 1 & 0.5 & 31.0 & 50.5 & 1.1 & 2.0 & 11.5 & 0.0 & 3.0 & 0.5 & 0.0 \\
2 & 2.6 & 15.2 & 26.6 & 1.7 & 0.0 & 47.8 & 1.7 & 4.4 & 0.0 & 0.0 \\
3 & 1.4 & 19.3 & 50.6 & 8.1 & 1.3 & 15.6 & 0.0 & 3.3 & 0.3 & 0.0 \\
4 & 2.7 & 11.2 & 28.7 & 16.1 & 0.0 & 35.0 & 3.3 & 2.9 & 0.0 & 0.0 \\
5 & 1.3 & 4.6 & 66.7 & 0.7 & 0.6 & 21.0 & 0.0 & 4.9 & 0.2 & 0.0 \\
6 & 2.2 & 14.2 & 25.1 & 29.6 & 0.0 & 27.9 & 0.0 & 0.0 & 0.0 & 1.0 \\
7 & 0.6 & 23.4 & 53.7 & 5.9 & 3.3 & 7.0 & 0.0 & 5.4 & 0.7 & 0.0 \\
8 & 1.9 & 15.6 & 32.7 & 18.4 & 0.0 & 24.8 & 0.0 & 6.5 & 0.0 & 0.0 \\
9 & 1.0 & 22.0 & 52.0 & 6.7 & 2.1 & 11.6 & 0.0 & 4.4 & 0.3 & 0.0 \\
10 & 1.5 & 15.2 & 28.5 & 23.4 & 0.0 & 24.9 & 1.8 & 3.2 & 0.0 & 1.5 \\
Ave & 1.6 & 17.2 & 41.5 & 11.2 & 0.9 & 22.7 & 0.7 & 3.8 & 0.2 & 0.3 \\
\hline
\end{tabular}




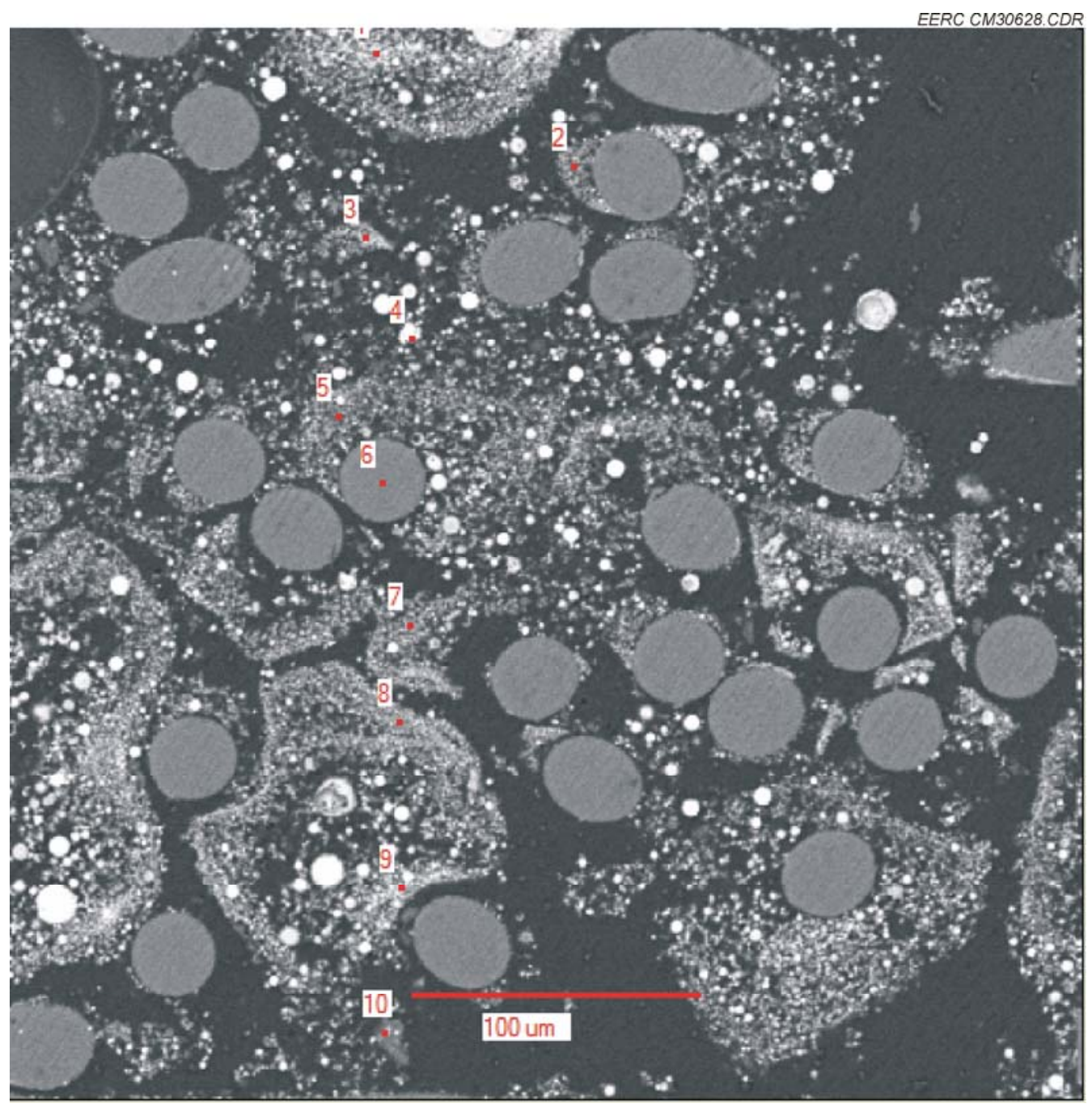

Figure G3-12. Image number 3 from FF 2-4C sample, 11-3-05.

Table G3-12. Oxide Weight Percentages for the Sample Points of Figure G3-12

\begin{tabular}{lcccccccccc}
\hline Image & $\mathrm{MgO}$ & $\mathrm{Al}_{2} \mathrm{O}_{3}$ & $\mathrm{SiO}_{2}$ & $\mathrm{SO}_{3}$ & $\mathrm{~K}_{2} \mathrm{O}$ & $\mathrm{CaO}$ & $\mathrm{TiO}_{2}$ & $\mathrm{Fe}_{2} \mathrm{O}_{3}$ & $\mathrm{Na}_{2} \mathrm{O}_{2}$ & $\mathrm{P}_{2} \mathrm{O}_{5}$ \\
\hline 1 & 1.3 & 14.4 & 35.4 & 28.3 & 0.0 & 20.2 & 0.0 & 0.0 & 0.4 & 0.0 \\
2 & 2.5 & 13.6 & 21.4 & 17.9 & 0.0 & 34.8 & 3.9 & 5.0 & 0.0 & 0.8 \\
3 & 1.5 & 13.6 & 38.6 & 23.3 & 1.0 & 15.7 & 1.2 & 4.8 & 0.4 & 0.0 \\
4 & 2.2 & 12.4 & 28.6 & 28.9 & 0.0 & 21.5 & 2.6 & 3.6 & 0.2 & 0.0 \\
5 & 1.7 & 15.6 & 30.5 & 28.1 & 1.0 & 21.1 & 0.0 & 0.0 & 0.0 & 1.9 \\
6 & 1.5 & 16.0 & 35.8 & 32.5 & 1.6 & 7.7 & 0.0 & 4.6 & 0.5 & 0.0 \\
7 & 2.2 & 11.8 & 28.2 & 17.2 & 0.0 & 33.0 & 1.8 & 4.6 & 0.0 & 1.2 \\
8 & 2.0 & 6.3 & 11.8 & 61.5 & 0.7 & 11.5 & 0.0 & 6.2 & 0.0 & 0.0 \\
9 & 2.7 & 10.9 & 23.1 & 13.9 & 0.0 & 42.2 & 2.0 & 5.1 & 0.0 & 0.0 \\
10 & 1.5 & 19.2 & 52.5 & 3.9 & 1.2 & 13.1 & 0.0 & 8.0 & 0.6 & 0.0 \\
Ave & 1.9 & 13.4 & 30.6 & 25.6 & 0.5 & 22.1 & 1.1 & 4.2 & 0.2 & 0.4 \\
\hline
\end{tabular}




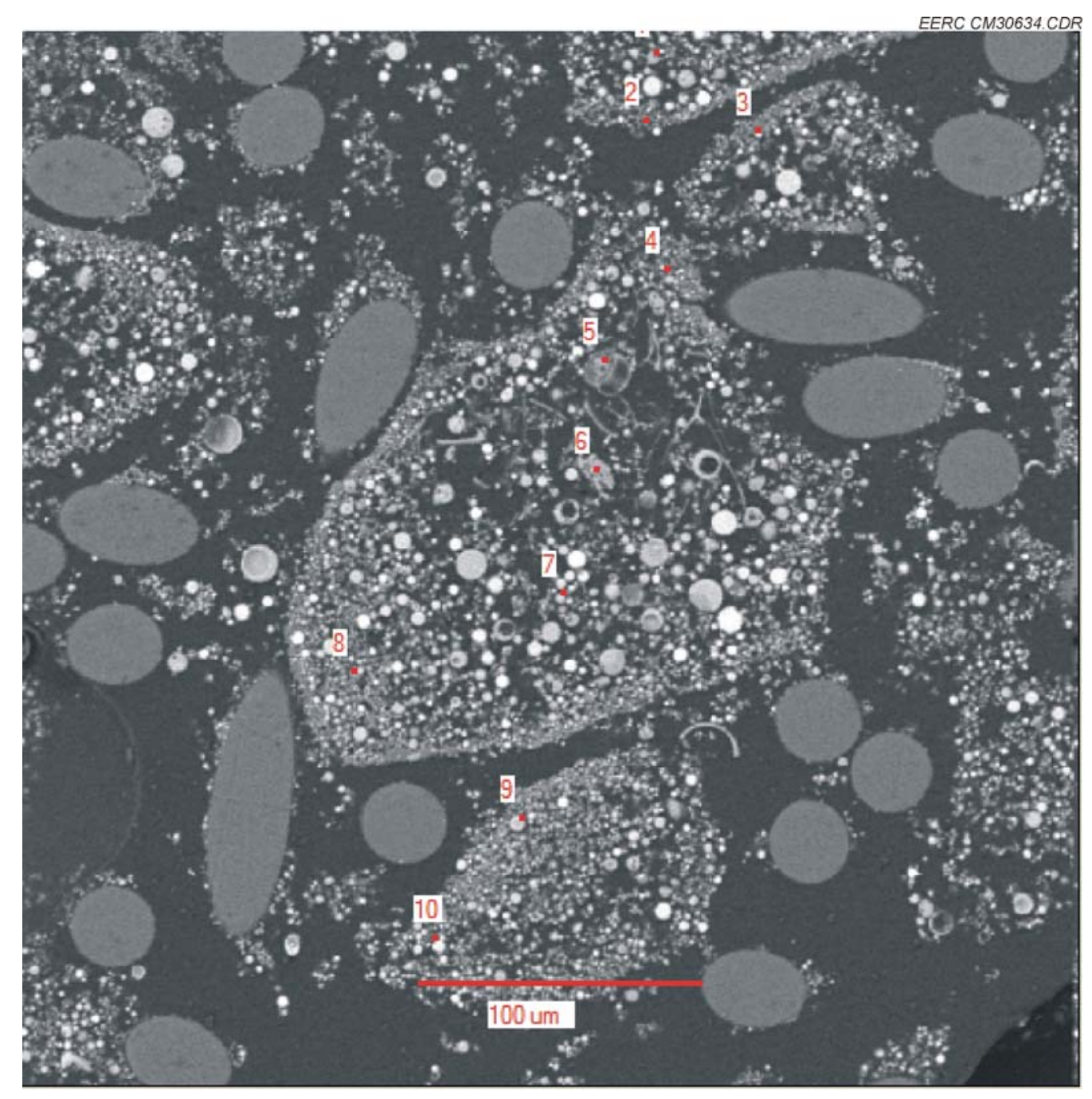

Figure G3-13. Image number 4 from FF 2-4C sample, 11-3-05.

Table G3-13. Oxide Weight Percentages for the Sample Points of Figure G3-13

\begin{tabular}{lcccccccccc}
\hline Image & $\mathrm{MgO}$ & $\mathrm{Al}_{2} \mathrm{O}_{3}$ & $\mathrm{SiO}_{2}$ & $\mathrm{SO}_{3}$ & $\mathrm{~K}_{2} \mathrm{O}$ & $\mathrm{CaO}$ & $\mathrm{TiO}_{2}$ & $\mathrm{Fe}_{2} \mathrm{O}_{3}$ & $\mathrm{Na}_{2} \mathrm{O}$ & $\mathrm{P}_{2} \mathrm{O}_{5}$ \\
\hline 1 & 0.0 & 3.8 & 80.5 & 6.3 & 0.0 & 7.4 & 0.0 & 2.0 & 0.0 & 0.0 \\
2 & 1.8 & 12.3 & 20.8 & 28.1 & 0.0 & 29.0 & 1.8 & 6.1 & 0.0 & 0.0 \\
3 & 1.9 & 14.0 & 30.0 & 29.6 & 0.0 & 19.6 & 0.0 & 4.8 & 0.0 & 0.0 \\
4 & 0.7 & 11.6 & 21.7 & 38.1 & 0.8 & 20.8 & 3.4 & 2.9 & 0.0 & 0.0 \\
5 & 0.0 & 8.0 & 77.0 & 3.6 & 9.0 & 2.5 & 0.0 & 0.0 & 0.0 & 0.0 \\
6 & 0.0 & 36.1 & 62.5 & 1.5 & 0.0 & 0.0 & 0.0 & 0.0 & 0.0 & 0.0 \\
7 & 1.5 & 13.0 & 23.3 & 28.9 & 0.0 & 29.2 & 0.0 & 4.1 & 0.0 & 0.0 \\
8 & 1.4 & 13.9 & 25.2 & 26.5 & 0.7 & 24.0 & 1.5 & 6.7 & 0.3 & 0.0 \\
9 & 2.7 & 9.8 & 5.0 & 26.6 & 0.0 & 48.8 & 0.0 & 7.2 & 0.0 & 0.0 \\
10 & 1.6 & 15.6 & 25.5 & 25.5 & 0.9 & 25.4 & 0.0 & 5.6 & 0.0 & 0.0 \\
Ave & 1.1 & 13.8 & 37.1 & 21.5 & 1.1 & 20.7 & 0.7 & 3.9 & 0.0 & 0.0 \\
\hline
\end{tabular}




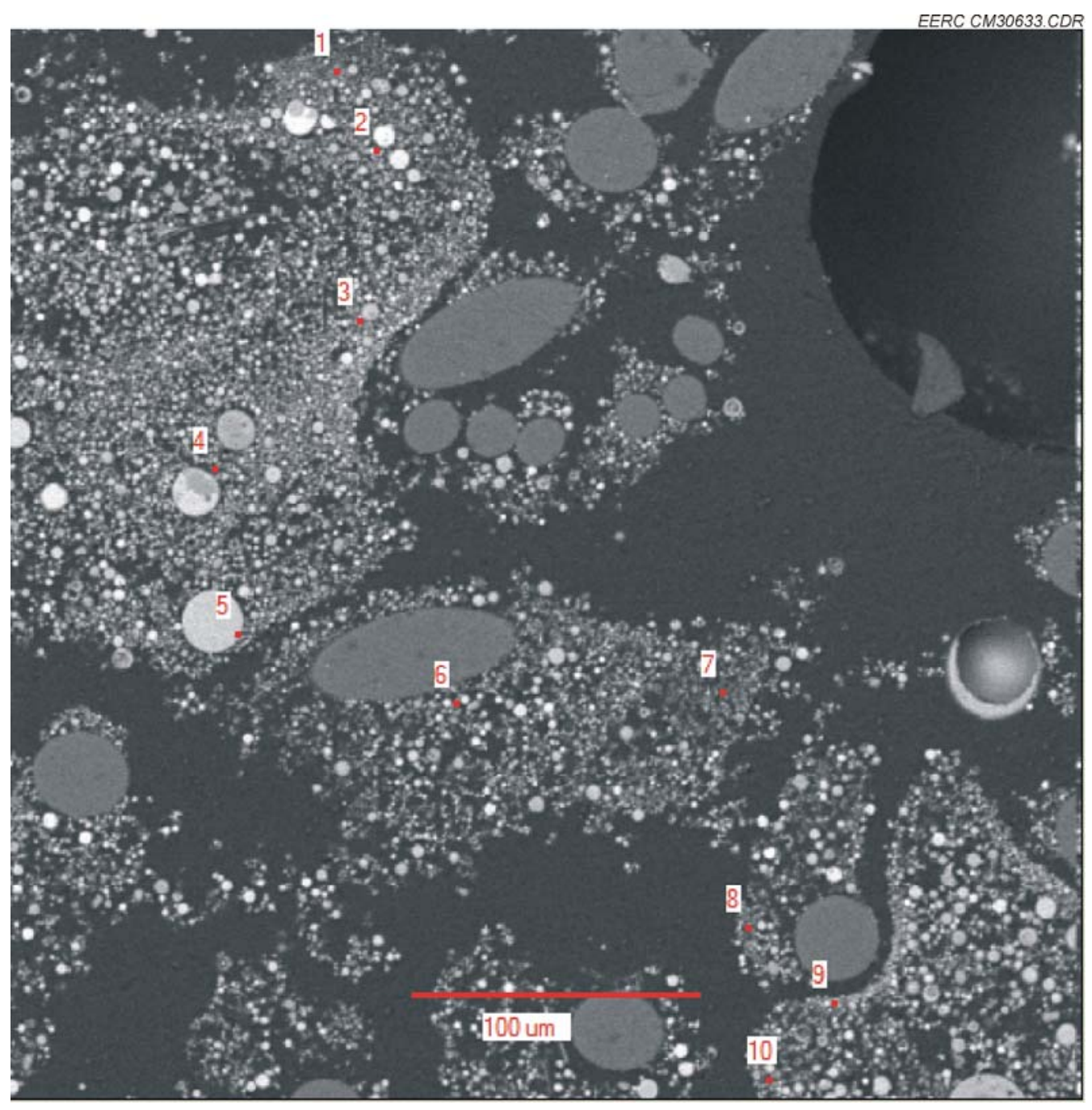

Figure G3-14. Image number 5 from FF 2-4C sample, 11-3-05.

Table G3-14. Oxide Weight Percentages for the Sample Points of Figure G3-14

\begin{tabular}{lcccccccccc}
\hline Image & $\mathrm{MgO}$ & $\mathrm{Al}_{2} \mathrm{O}_{3}$ & $\mathrm{SiO}_{2}$ & $\mathrm{SO}_{3}$ & $\mathrm{~K}_{2} \mathrm{O}$ & $\mathrm{CaO}$ & $\mathrm{TiO}_{2}$ & $\mathrm{Fe}_{2} \mathrm{O}_{3}$ & $\mathrm{Na}_{2} \mathrm{O}$ & $\mathrm{P}_{2} \mathrm{O}_{5}$ \\
\hline 1 & 1.8 & 10.5 & 22.1 & 37.6 & 0.0 & 22.7 & 1.8 & 3.5 & 0.0 & 0.0 \\
2 & 2.2 & 12.3 & 22.7 & 23.4 & 0.6 & 28.1 & 1.9 & 7.9 & 0.0 & 1.0 \\
3 & 1.2 & 17.1 & 47.9 & 11.7 & 2.3 & 11.3 & 2.1 & 6.3 & 0.0 & 0.0 \\
4 & 1.1 & 17.7 & 44.3 & 18.6 & 1.5 & 12.0 & 1.6 & 3.1 & 0.0 & 0.0 \\
5 & 1.5 & 15.7 & 44.6 & 10.0 & 0.7 & 23.3 & 0.0 & 4.2 & 0.0 & 0.0 \\
6 & 2.7 & 14.4 & 33.3 & 2.4 & 0.0 & 41.4 & 1.6 & 4.3 & 0.0 & 0.0 \\
7 & 1.3 & 12.9 & 24.0 & 32.9 & 0.0 & 29.0 & 0.0 & 0.0 & 0.0 & 0.0 \\
8 & 1.1 & 13.5 & 32.4 & 30.8 & 0.0 & 16.6 & 0.0 & 5.6 & 0.0 & 0.0 \\
9 & 0.7 & 5.3 & 68.2 & 18.1 & 0.9 & 6.8 & 0.0 & 0.0 & 0.0 & 0.0 \\
10 & 3.5 & 14.8 & 35.7 & 8.9 & 0.0 & 32.3 & 0.0 & 4.9 & 0.0 & 0.0 \\
Ave & 1.7 & 13.4 & 37.5 & 19.4 & 0.6 & 22.4 & 0.9 & 4.0 & 0.0 & 0.1 \\
\hline
\end{tabular}




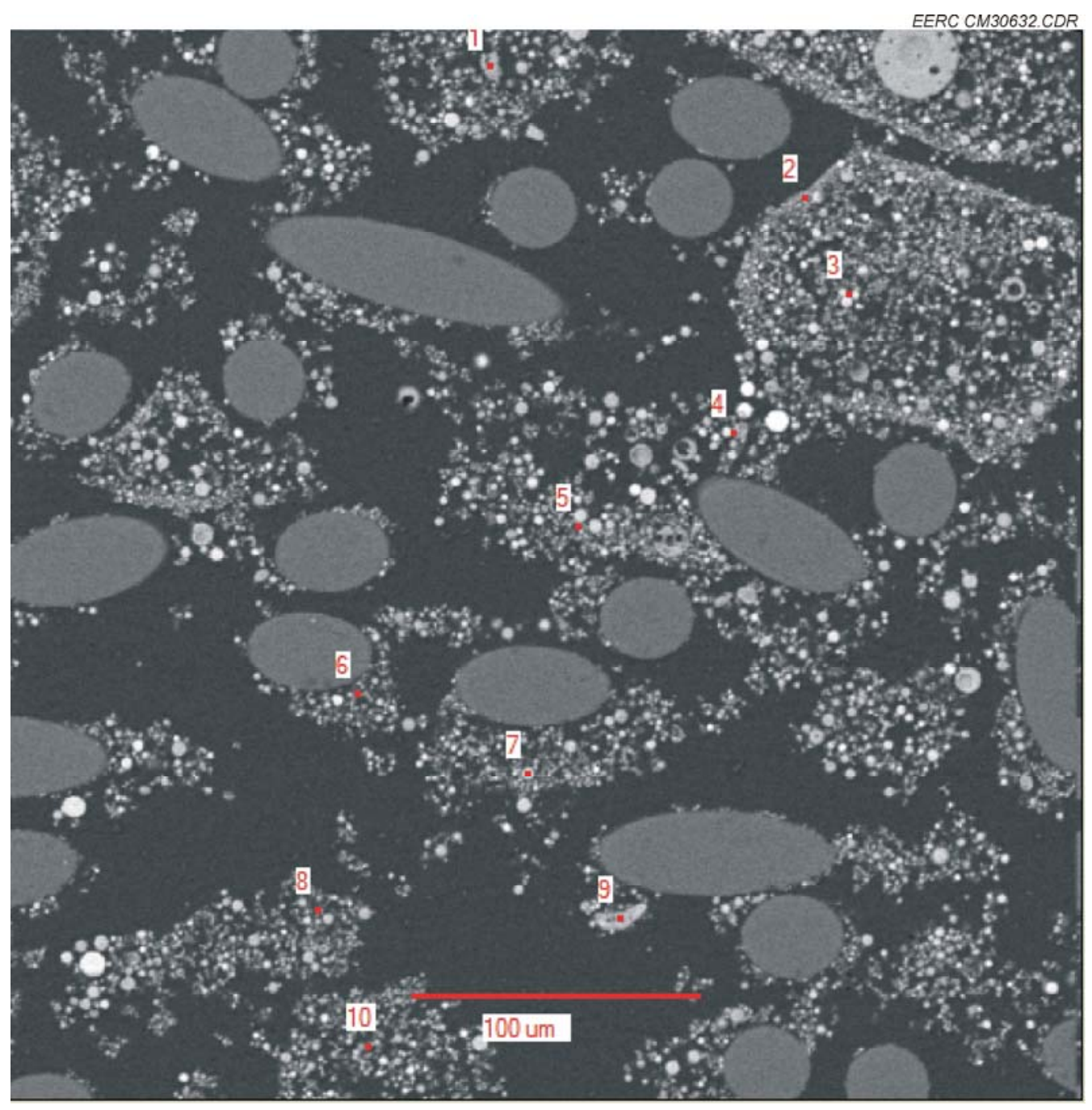

Figure G3-15. Image number 6 from FF 2-4C sample, 11-3-05.

Table G3-15. Oxide Weight Percentages for the Sample Points of Figure G3-15

\begin{tabular}{lcccccccccc}
\hline Image & $\mathrm{MgO}$ & $\mathrm{Al}_{2} \mathrm{O}_{3}$ & $\mathrm{SiO}_{2}$ & $\mathrm{SO}_{3}$ & $\mathrm{~K}_{2} \mathrm{O}$ & $\mathrm{CaO}$ & $\mathrm{TiO}_{2}$ & $\mathrm{Fe}_{2} \mathrm{O}_{3}$ & $\mathrm{Na}_{2} \mathrm{O}$ & $\mathrm{P}_{2} \mathrm{O}_{5}$ \\
\hline 1 & 0.0 & 2.6 & 89.0 & 0.0 & 0.6 & 0.9 & 6.7 & 0.0 & 0.2 & 0.0 \\
2 & 1.9 & 15.0 & 29.3 & 23.5 & 0.0 & 24.5 & 0.0 & 4.3 & 0.0 & 1.5 \\
3 & 4.2 & 14.3 & 22.1 & 4.4 & 0.0 & 47.0 & 2.8 & 5.2 & 0.0 & 0.0 \\
4 & 0.4 & 26.5 & 49.2 & 9.4 & 1.3 & 10.2 & 0.0 & 2.6 & 0.3 & 0.0 \\
5 & 2.1 & 11.9 & 50.6 & 0.0 & 0.4 & 26.1 & 3.8 & 5.1 & 0.0 & 0.0 \\
6 & 1.6 & 14.6 & 26.2 & 24.7 & 0.0 & 23.3 & 2.2 & 7.5 & 0.0 & 0.0 \\
7 & 1.6 & 20.6 & 48.0 & 0.0 & 0.6 & 18.2 & 0.9 & 10.0 & 0.0 & 0.0 \\
8 & 1.8 & 19.7 & 52.9 & 1.4 & 1.1 & 17.2 & 1.0 & 4.6 & 0.4 & 0.0 \\
9 & 0.7 & 21.5 & 65.4 & 1.3 & 2.8 & 2.3 & 1.8 & 3.9 & 0.4 & 0.0 \\
10 & 1.6 & 12.7 & 55.0 & 13.7 & 0.0 & 16.0 & 0.0 & 0.0 & 1.0 & 0.0 \\
Ave & 1.6 & 15.9 & 48.8 & 7.8 & 0.7 & 18.6 & 1.9 & 4.3 & 0.2 & 0.1 \\
\hline
\end{tabular}




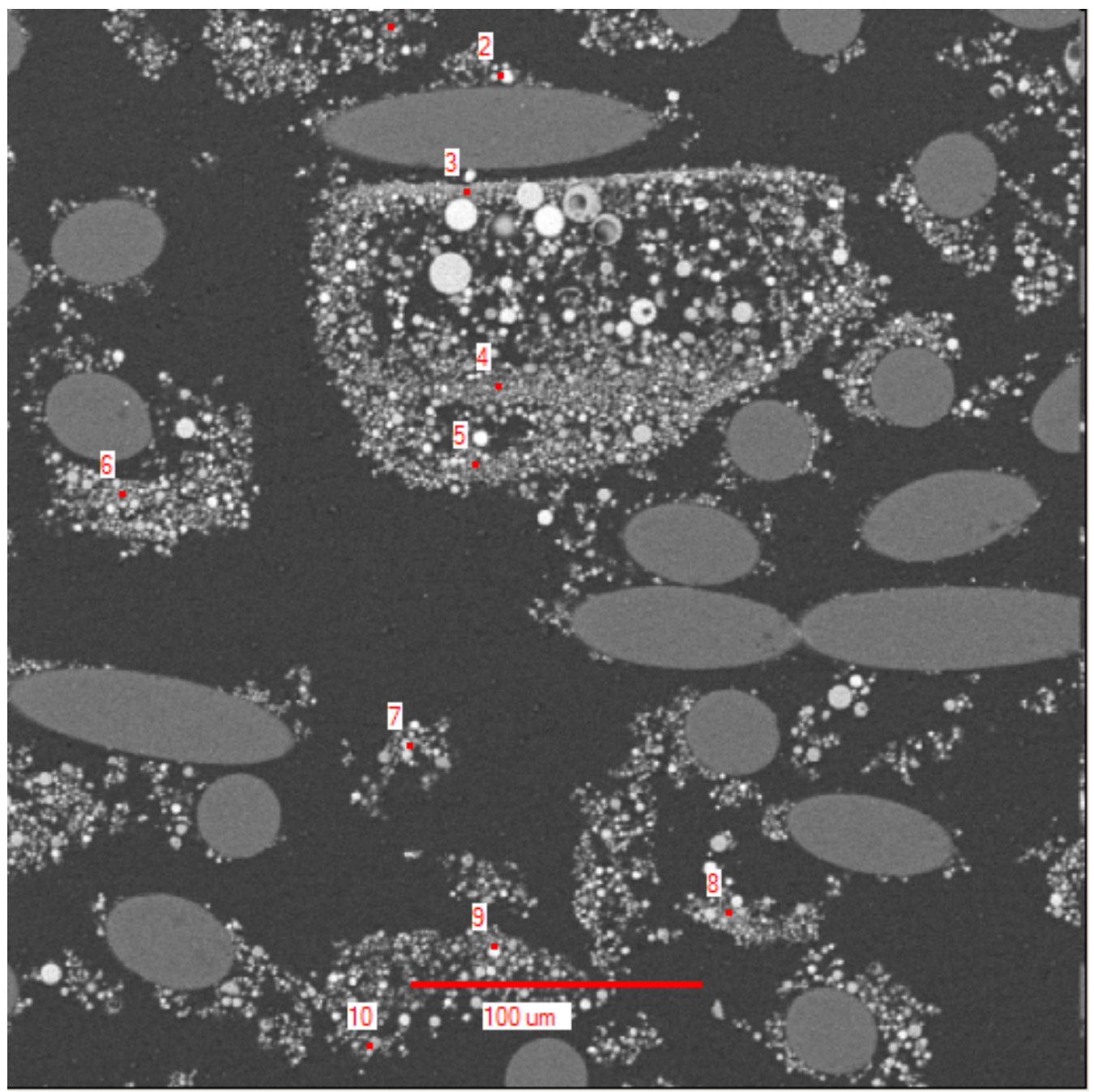

Figure G3-16. Image number 7 from FF 2-4C sample, 11-3-05

Table G3-16. Oxide Weight Percentages for the Sample Points of Figure G3-16

\begin{tabular}{lcccccccccc}
\hline Image & $\mathrm{MgO}$ & $\mathrm{Al}_{2} \mathrm{O}_{3}$ & $\mathrm{SiO}_{2}$ & $\mathrm{SO}_{3}$ & $\mathrm{~K}_{2} \mathrm{O}$ & $\mathrm{CaO}$ & $\mathrm{TiO}_{2}$ & $\mathrm{Fe}_{2} \mathrm{O}_{3}$ & $\mathrm{Na}_{2} \mathrm{O}$ & $\mathrm{P}_{2} \mathrm{O}_{5}$ \\
\hline 1 & 1.8 & 19.0 & 37.8 & 16.4 & 2.2 & 16.8 & 0.0 & 6.0 & 0.0 & 0.0 \\
2 & 2.9 & 27.6 & 4.3 & 1.7 & 0.0 & 48.7 & 1.9 & 5.8 & 0.0 & 7.3 \\
3 & 1.5 & 16.2 & 45.7 & 17.9 & 1.1 & 12.9 & 0.0 & 4.8 & 0.0 & 0.0 \\
4 & 1.4 & 8.4 & 22.8 & 39.5 & 0.0 & 22.5 & 1.6 & 3.8 & 0.0 & 0.0 \\
5 & 2.1 & 12.8 & 34.1 & 21.1 & 0.8 & 20.7 & 1.5 & 6.8 & 0.0 & 0.0 \\
6 & 1.9 & 13.3 & 36.2 & 18.7 & 0.0 & 26.5 & 0.0 & 3.5 & 0.0 & 0.0 \\
7 & 1.4 & 18.4 & 47.2 & 14.2 & 2.8 & 10.0 & 0.0 & 5.7 & 0.4 & 0.0 \\
8 & 2.7 & 12.1 & 19.3 & 33.9 & 0.5 & 25.8 & 0.0 & 4.0 & 0.5 & 1.1 \\
9 & 2.8 & 13.3 & 27.6 & 13.0 & 0.0 & 35.0 & 2.9 & 4.5 & 0.0 & 1.0 \\
10 & 0.0 & 2.0 & 94.6 & 1.1 & 0.7 & 1.5 & 0.0 & 0.0 & 0.1 & 0.0 \\
Ave & 1.8 & 14.3 & 37.0 & 17.7 & 0.8 & 22.0 & 0.8 & 4.5 & 0.1 & 0.9 \\
\hline
\end{tabular}




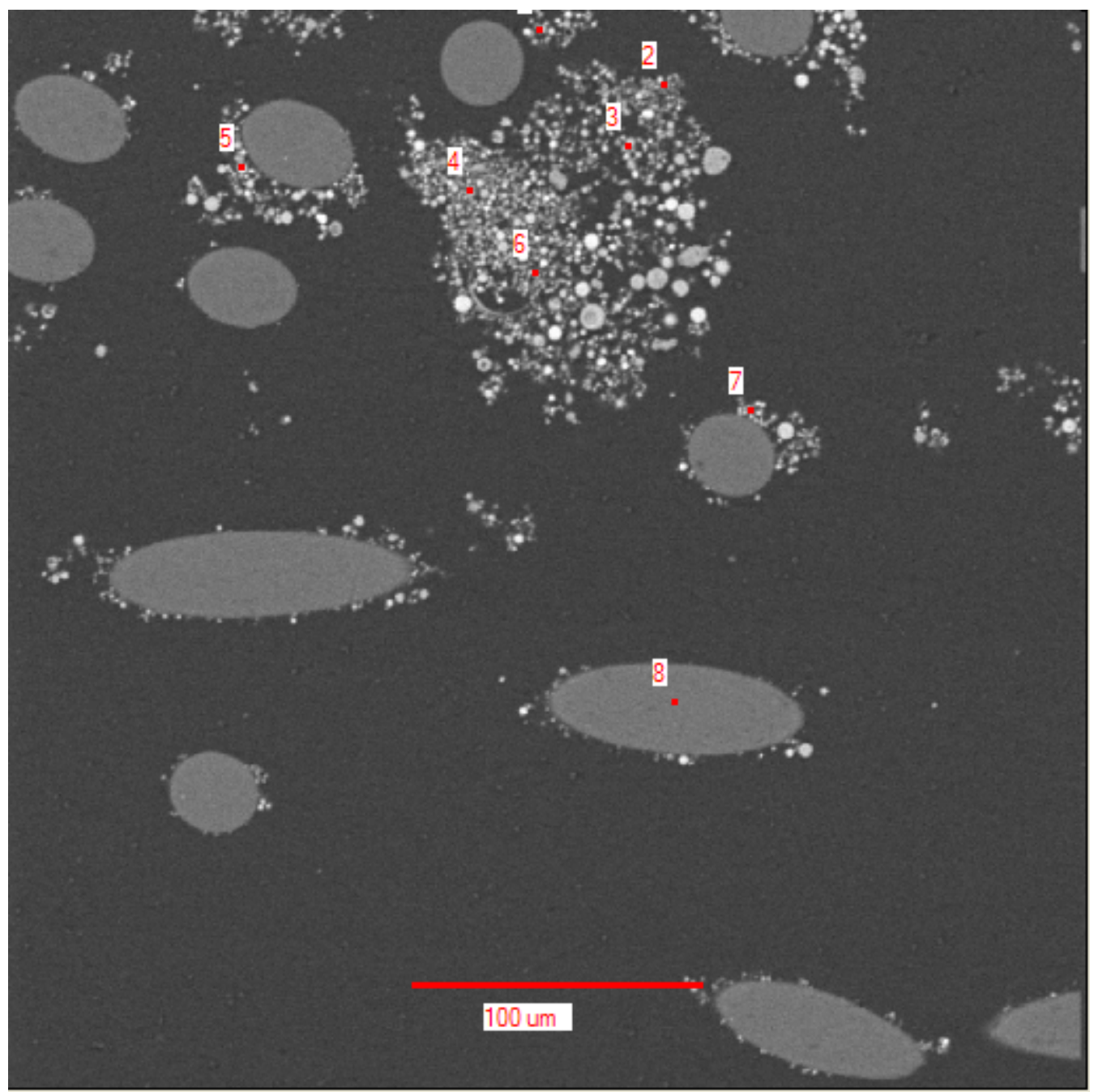

Figure G3-17. Image number 8 from FF 2-4C sample, 11-3-05.

Table G3-17. Oxide Weight Percentages for the Sample Points of Figure G3-17

\begin{tabular}{lcccccccccc}
\hline Image & $\mathrm{MgO}$ & $\mathrm{Al}_{2} \mathrm{O}_{3}$ & $\mathrm{SiO}_{2}$ & $\mathrm{SO}_{3}$ & $\mathrm{~K}_{2} \mathrm{O}$ & $\mathrm{CaO}$ & $\mathrm{TiO}_{2}$ & $\mathrm{Fe}_{2} \mathrm{O}_{3}$ & $\mathrm{Na}_{2} \mathrm{O}$ & $\mathrm{P}_{2} \mathrm{O}_{5}$ \\
\hline 1 & 1.1 & 7.2 & 65.4 & 3.8 & 0.0 & 19.4 & 0.0 & 3.1 & 0.0 & 0.0 \\
2 & 1.5 & 16.9 & 36.2 & 14.3 & 1.4 & 22.1 & 2.7 & 4.6 & 0.3 & 0.0 \\
3 & 1.0 & 20.1 & 45.7 & 12.4 & 2.7 & 9.6 & 2.4 & 5.6 & 0.6 & 0.0 \\
4 & 0.9 & 15.4 & 41.6 & 13.1 & 0.0 & 24.5 & 0.0 & 4.6 & 0.0 & 0.0 \\
5 & 2.2 & 9.8 & 46.4 & 0.0 & 0.0 & 37.1 & 0.0 & 4.5 & 0.0 & 0.0 \\
6 & 0.6 & 17.6 & 35.6 & 23.5 & 1.2 & 15.8 & 0.0 & 5.7 & 0.0 & 0.0 \\
7 & 0.9 & 21.6 & 18.0 & 17.9 & 0.0 & 24.9 & 2.3 & 4.0 & 0.0 & 10.3 \\
Ave & 1.2 & 15.5 & 41.3 & 12.1 & 0.7 & 21.9 & 1.1 & 4.6 & 0.1 & 1.5 \\
\hline
\end{tabular}


FF 2-3C sample, pulled 3-30-06

Image Number:

EERC CM30646.CDR

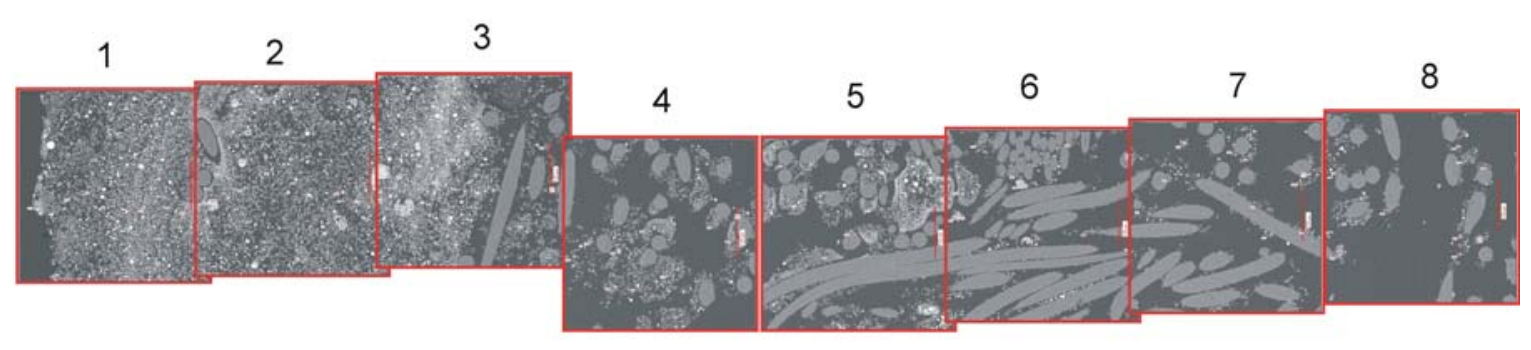

Flow

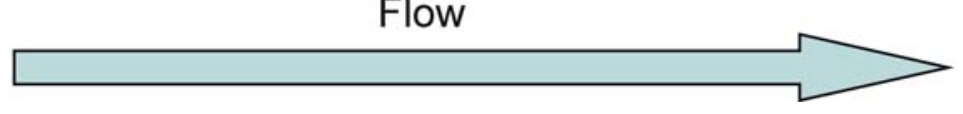

Figure G3-18. Bag cross section composite image, FF 2-3C sample from 3-30-06.

Table G3-18. Oxide Weight Averages of the Sample Points in Each Image of Figure G3-18

\begin{tabular}{lcccccccccc}
\hline Image & $\mathrm{MgO}$ & $\mathrm{Al}_{2} \mathrm{O}_{3}$ & $\mathrm{SiO}_{2}$ & $\mathrm{SO}_{3}$ & $\mathrm{~K}_{2} \mathrm{O}$ & $\mathrm{CaO}$ & $\mathrm{TiO}_{2}$ & $\mathrm{Fe}_{2} \mathrm{O}_{3}$ & $\mathrm{Na}_{2} \mathrm{O}$ & $\mathrm{P}_{2} \mathrm{O}_{5}$ \\
\hline 1 & 1.3 & 14.2 & 35.8 & 22.1 & 0.4 & 21.2 & 1.1 & 3.7 & 0.1 & 0.1 \\
2 & 1.5 & 16.3 & 39.0 & 19.5 & 1.4 & 18.4 & 0.6 & 3.1 & 0.1 & 0.2 \\
3 & 1.5 & 13.4 & 35.2 & 21.5 & 0.5 & 23.2 & 0.7 & 4.0 & 0.0 & 0.0 \\
4 & 1.6 & 14.4 & 34.0 & 19.6 & 0.6 & 22.4 & 2.2 & 5.1 & 0.1 & 0.0 \\
5 & 1.6 & 14.3 & 29.1 & 28.3 & 0.4 & 21.9 & 0.5 & 3.4 & 0.1 & 0.4 \\
6 & 1.5 & 12.9 & 40.1 & 18.5 & 0.3 & 20.6 & 0.7 & 5.1 & 0.1 & 0.3 \\
7 & 1.8 & 15.8 & 37.6 & 14.8 & 0.8 & 23.9 & 0.9 & 4.2 & 0.1 & 0.0 \\
8 & 1.4 & 16.5 & 43.4 & 14.5 & 0.9 & 17.2 & 1.3 & 4.6 & 0.2 & 0.0 \\
Average & 1.5 & 14.7 & 36.8 & 19.8 & 0.7 & 21.1 & 1.0 & 4.1 & 0.1 & 0.1 \\
\hline
\end{tabular}




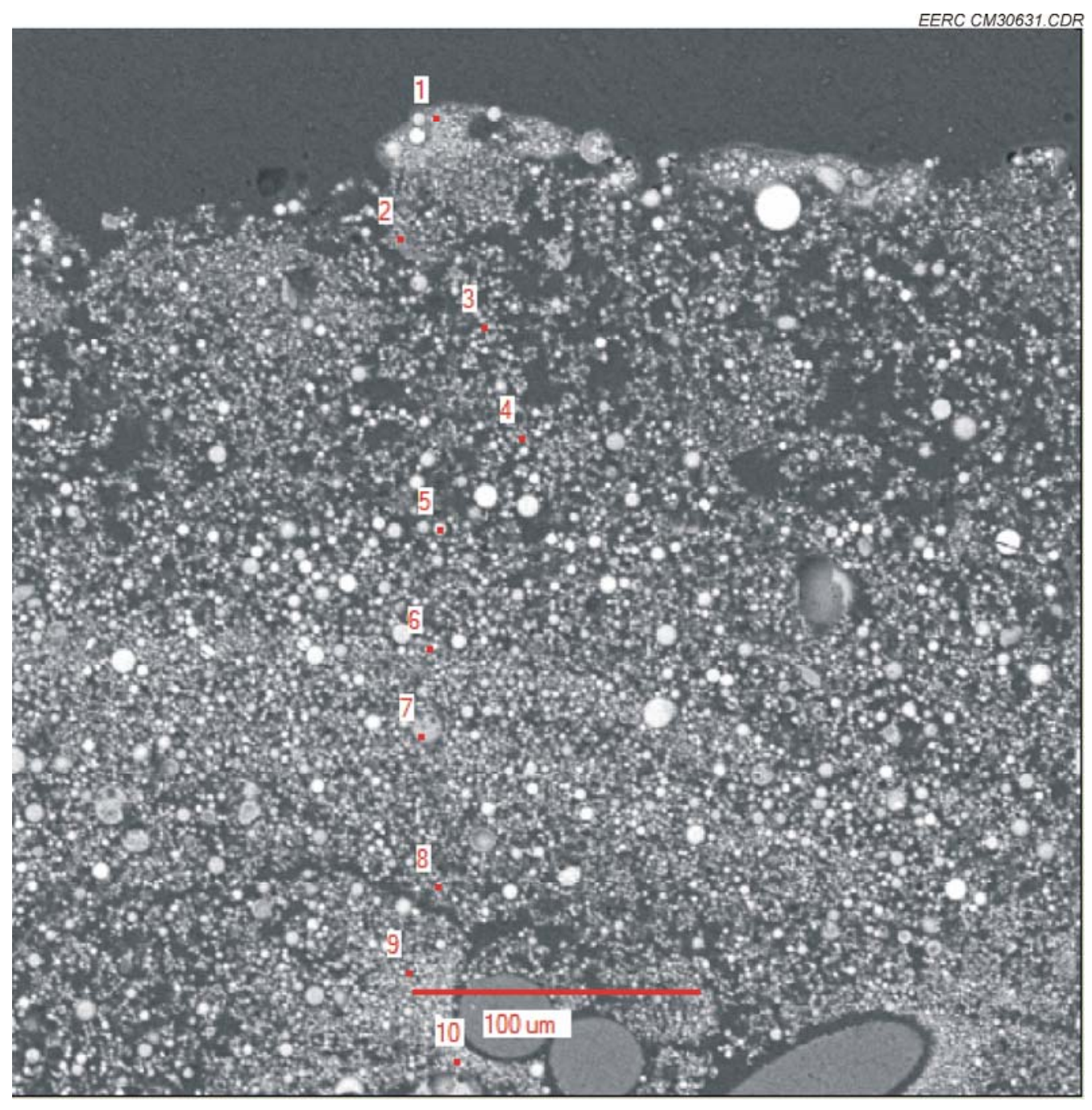

Figure G3-19. Image number 1 from FF 2-3C sample, 3-30-06.

Table G3-19. Oxide Weight Percentages for the Sample Points of Figure G3-19

\begin{tabular}{lcccccccccc}
\hline Image & $\mathrm{MgO}$ & $\mathrm{Al}_{2} \mathrm{O}_{3}$ & $\mathrm{SiO}_{2}$ & $\mathrm{SO}_{3}$ & $\mathrm{~K}_{2} \mathrm{O}$ & $\mathrm{CaO}$ & $\mathrm{TiO}_{2}$ & $\mathrm{Fe}_{2} \mathrm{O}_{3}$ & $\mathrm{Na}_{2} \mathrm{O}_{2}$ & $\mathrm{P}_{2} \mathrm{O}_{5}$ \\
\hline 1 & 1.1 & 14.2 & 26.2 & 29.1 & 0.0 & 27.5 & 1.8 & 0.0 & 0.0 & 0.0 \\
2 & 1.6 & 10.5 & 21.2 & 38.4 & 0.0 & 24.7 & 0.0 & 3.3 & 0.2 & 0.0 \\
3 & 0.6 & 3.4 & 76.6 & 10.2 & 0.9 & 5.9 & 0.0 & 2.4 & 0.0 & 0.0 \\
4 & 1.8 & 15.4 & 41.5 & 15.4 & 0.8 & 17.3 & 0.0 & 7.8 & 0.0 & 0.0 \\
5 & 1.6 & 18.2 & 48.1 & 0.0 & 0.5 & 24.8 & 3.1 & 3.7 & 0.0 & 0.0 \\
6 & 2.4 & 12.8 & 21.9 & 20.9 & 0.0 & 35.5 & 1.4 & 5.0 & 0.0 & 0.0 \\
7 & 0.0 & 34.5 & 60.9 & 0.0 & 1.4 & 1.7 & 0.0 & 1.1 & 0.3 & 0.0 \\
8 & 1.8 & 11.4 & 16.1 & 38.9 & 0.0 & 27.1 & 1.7 & 2.9 & 0.0 & 0.0 \\
9 & 1.3 & 12.7 & 29.8 & 31.5 & 0.0 & 16.8 & 1.7 & 6.2 & 0.0 & 0.0 \\
10 & 0.8 & 9.4 & 15.9 & 36.3 & 0.5 & 30.4 & 1.5 & 4.6 & 0.0 & 0.6 \\
Ave & 1.3 & 14.2 & 35.8 & 22.1 & 0.4 & 21.2 & 1.1 & 3.7 & 0.1 & 0.1 \\
\hline
\end{tabular}




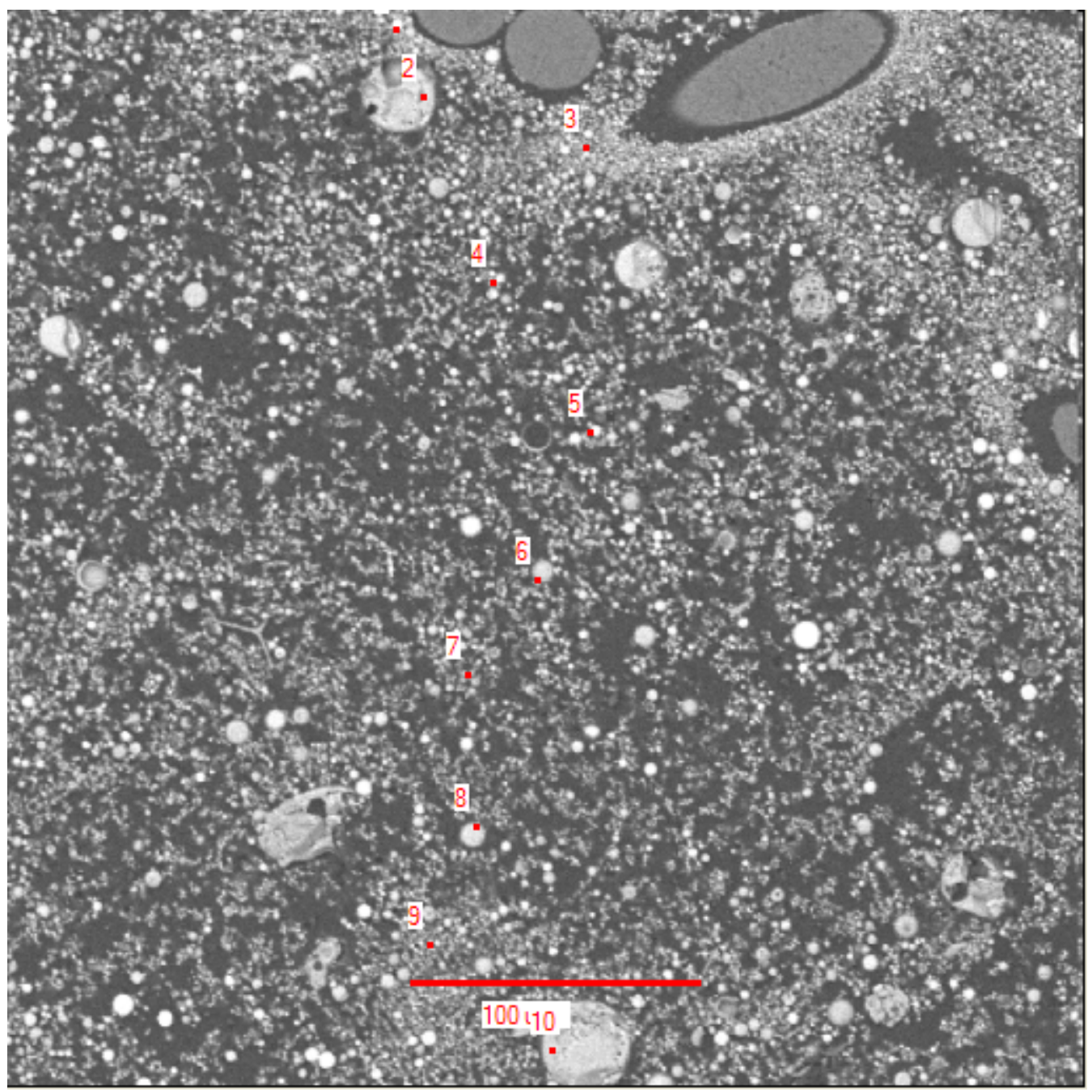

Figure G3-20. Image number 2 from FF 2-3C sample, 3-30-06.

Table G3-20. Oxide Weight Percentages for the Sample Points of Figure G3-20

\begin{tabular}{lcccccccccc}
\hline Image & $\mathrm{MgO}$ & $\mathrm{Al}_{2} \mathrm{O}_{3}$ & $\mathrm{SiO}_{2}$ & $\mathrm{SO}_{3}$ & $\mathrm{~K}_{2} \mathrm{O}$ & $\mathrm{CaO}$ & $\mathrm{TiO}_{2}$ & $\mathrm{Fe}_{2} \mathrm{O}_{3}$ & $\mathrm{Na}_{2} \mathrm{O}$ & $\mathrm{P}_{2} \mathrm{O}_{5}$ \\
\hline 1 & 1.8 & 14.8 & 18.7 & 23.0 & 0.0 & 34.6 & 2.3 & 3.3 & 0.0 & 1.5 \\
2 & 1.5 & 23.1 & 56.8 & 0.0 & 1.6 & 14.4 & 0.0 & 2.1 & 0.5 & 0.0 \\
3 & 1.4 & 15.6 & 25.8 & 33.5 & 0.7 & 23.0 & 0.0 & 0.0 & 0.0 & 0.0 \\
4 & 4.3 & 6.1 & 9.9 & 36.5 & 0.5 & 33.8 & 2.7 & 6.2 & 0.0 & 0.0 \\
5 & 1.0 & 8.9 & 19.6 & 43.6 & 0.5 & 26.4 & 0.0 & 0.0 & 0.0 & 0.0 \\
6 & 0.9 & 23.2 & 58.2 & 0.7 & 4.7 & 6.1 & 0.0 & 5.9 & 0.4 & 0.0 \\
7 & 0.8 & 21.2 & 49.5 & 14.8 & 2.0 & 6.9 & 1.3 & 3.5 & 0.0 & 0.0 \\
8 & 0.8 & 20.2 & 50.3 & 9.5 & 1.4 & 13.9 & 0.0 & 3.9 & 0.0 & 0.0 \\
9 & 1.9 & 8.0 & 37.6 & 33.3 & 0.7 & 18.4 & 0.0 & 0.0 & 0.0 & 0.0 \\
10 & 0.9 & 21.5 & 63.3 & 0.0 & 2.1 & 6.2 & 0.0 & 5.8 & 0.1 & 0.0 \\
Ave & 1.5 & 16.3 & 39.0 & 19.5 & 1.4 & 18.4 & 0.6 & 3.1 & 0.1 & 0.2 \\
\hline
\end{tabular}




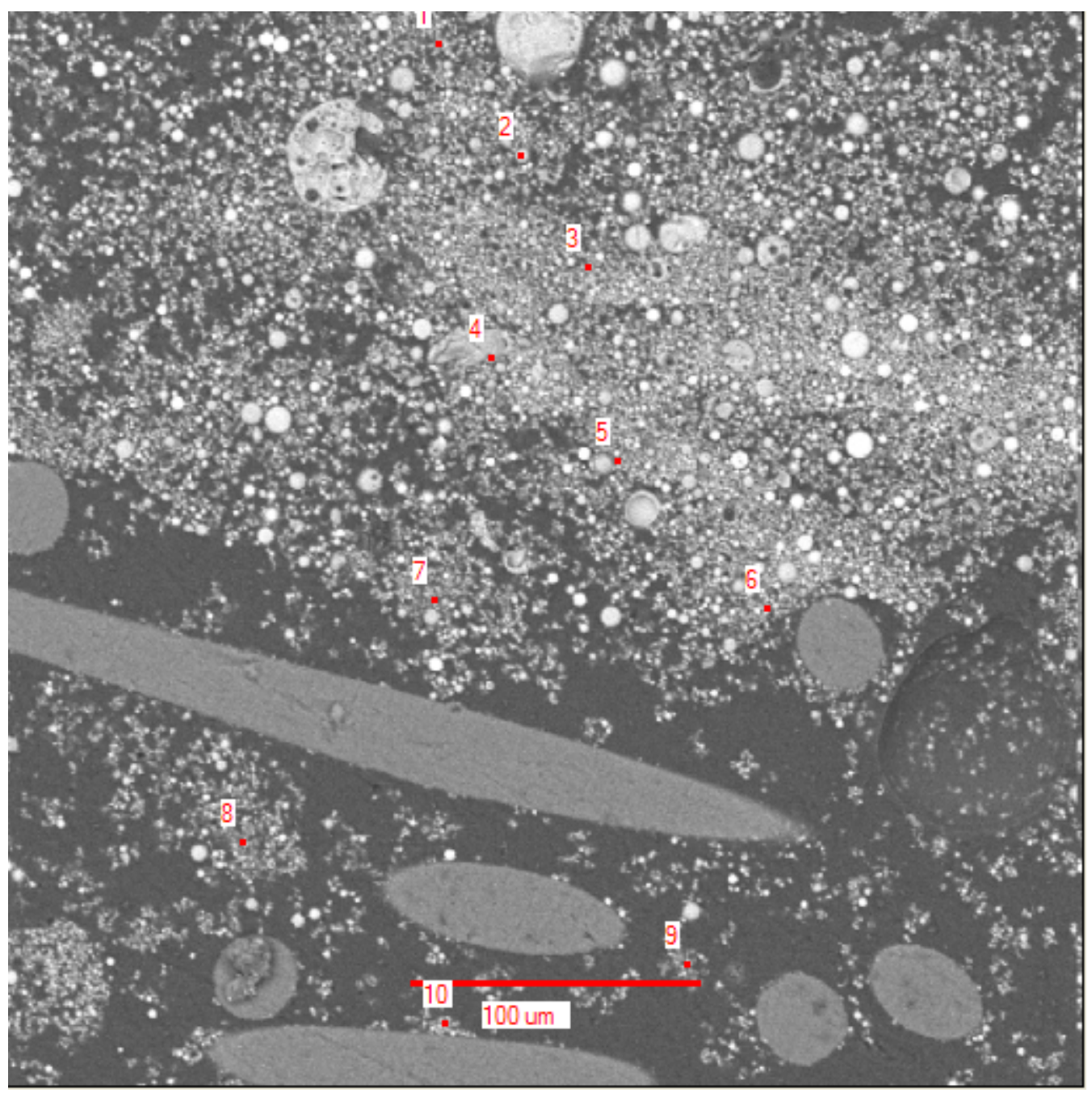

Figure G3-21. Image number 3 from FF 2-3C sample, 3-30-06.

Table G3-21. Oxide Weight Percentages for the Sample Points of Figure G3-21

\begin{tabular}{lcccccccccc}
\hline Image & $\mathrm{MgO}$ & $\mathrm{Al}_{2} \mathrm{O}_{3}$ & $\mathrm{SiO}_{2}$ & $\mathrm{SO}_{3}$ & $\mathrm{~K}_{2} \mathrm{O}$ & $\mathrm{CaO}$ & $\mathrm{TiO}_{2}$ & $\mathrm{Fe}_{2} \mathrm{O}_{3}$ & $\mathrm{Na}_{2} \mathrm{O}$ & $\mathrm{P}_{2} \mathrm{O}_{5}$ \\
\hline 1 & 2.1 & 13.6 & 26.5 & 26.5 & 0.0 & 26.4 & 1.9 & 3.1 & 0.0 & 0.0 \\
2 & 0.3 & 33.3 & 52.9 & 0.0 & 3.0 & 4.4 & 0.0 & 5.9 & 0.1 & 0.0 \\
3 & 1.3 & 12.5 & 23.1 & 28.7 & 0.0 & 28.7 & 2.2 & 3.2 & 0.2 & 0.0 \\
4 & 0.0 & 0.5 & 99.0 & 0.0 & 0.5 & 0.0 & 0.0 & 0.0 & 0.0 & 0.0 \\
5 & 1.6 & 14.8 & 33.6 & 27.1 & 0.0 & 18.8 & 0.0 & 4.1 & 0.0 & 0.0 \\
6 & 4.1 & 10.1 & 14.3 & 10.1 & 0.0 & 54.0 & 1.4 & 6.0 & 0.0 & 0.0 \\
7 & 1.0 & 13.6 & 32.1 & 20.2 & 0.9 & 24.6 & 1.6 & 5.9 & 0.0 & 0.0 \\
8 & 2.0 & 12.3 & 24.7 & 32.8 & 0.0 & 28.3 & 0.0 & 0.0 & 0.0 & 0.0 \\
9 & 1.6 & 13.3 & 27.2 & 34.9 & 0.8 & 18.2 & 0.0 & 4.0 & 0.0 & 0.0 \\
10 & 1.1 & 10.0 & 18.6 & 34.7 & 0.0 & 28.4 & 0.0 & 7.3 & 0.0 & 0.0 \\
Ave & 1.5 & 13.4 & 35.2 & 21.5 & 0.5 & 23.2 & 0.7 & 4.0 & 0.0 & 0.0 \\
\hline
\end{tabular}




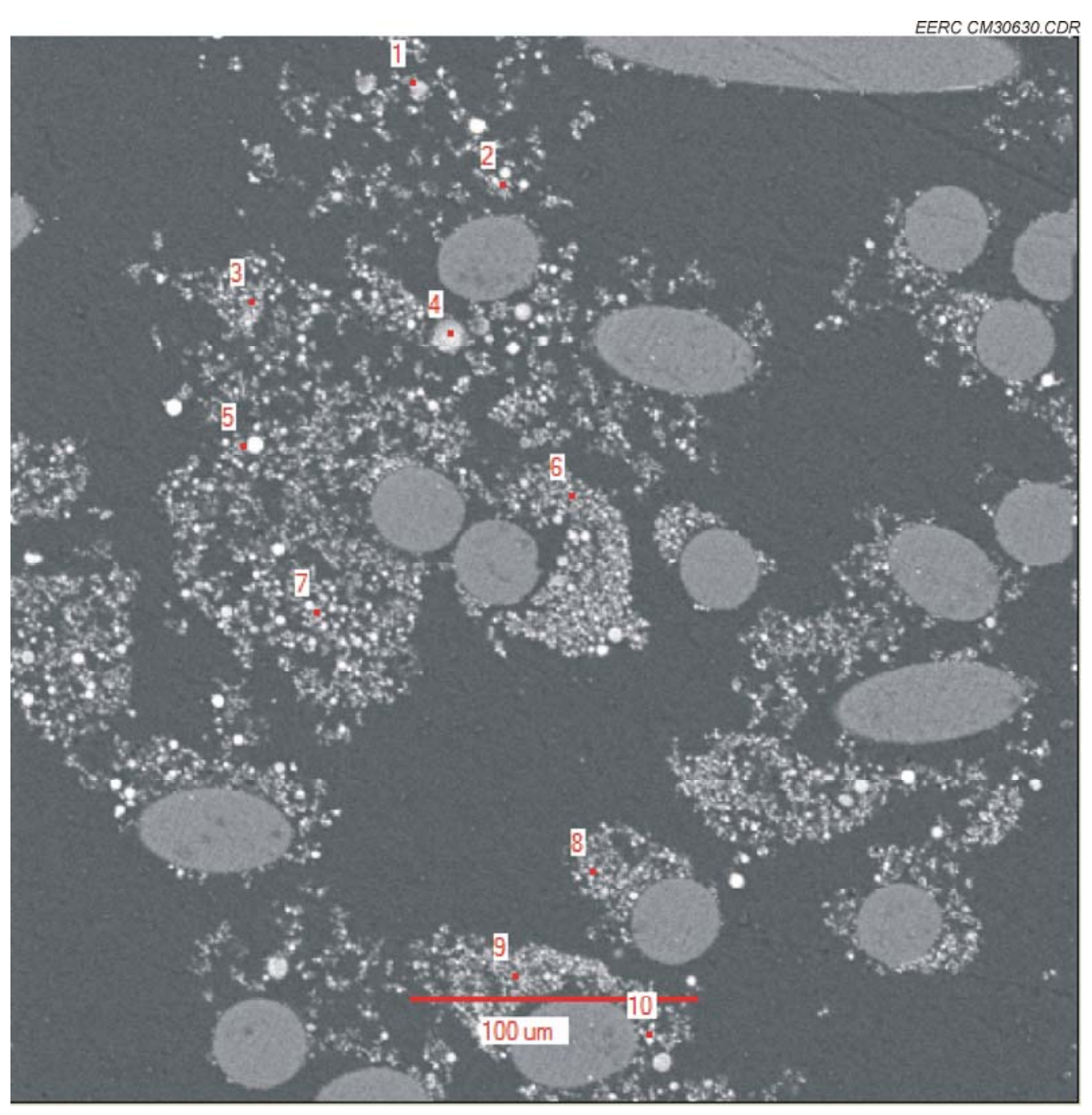

Figure G3-22. Image number 4 from FF 2-3C sample, 3-30-06.

Table G3-22. Oxide Weight Percentages for the Sample Points of Figure G3-22

\begin{tabular}{lcccccccccc}
\hline Image & $\mathrm{MgO}$ & $\mathrm{Al}_{2} \mathrm{O}_{3}$ & $\mathrm{SiO}_{2}$ & $\mathrm{SO}_{3}$ & $\mathrm{~K}_{2} \mathrm{O}$ & $\mathrm{CaO}$ & $\mathrm{TiO}_{2}$ & $\mathrm{Fe}_{2} \mathrm{O}_{3}$ & $\mathrm{Na}_{2} \mathrm{O}$ & $\mathrm{P}_{2} \mathrm{O}_{5}$ \\
\hline 1 & 1.8 & 17.5 & 29.6 & 16.8 & 0.0 & 22.1 & 3.6 & 8.6 & 0.0 & 0.0 \\
2 & 1.1 & 9.6 & 37.6 & 27.9 & 0.0 & 19.9 & 0.0 & 3.9 & 0.0 & 0.0 \\
3 & 2.3 & 11.3 & 22.9 & 29.5 & 0.0 & 26.5 & 1.7 & 5.8 & 0.0 & 0.0 \\
4 & 0.0 & 26.3 & 47.4 & 8.5 & 2.8 & 8.1 & 0.0 & 6.5 & 0.4 & 0.0 \\
5 & 3.1 & 12.5 & 18.0 & 3.3 & 0.0 & 53.7 & 2.9 & 6.5 & 0.0 & 0.0 \\
6 & 2.2 & 9.9 & 30.1 & 27.3 & 1.0 & 17.4 & 8.0 & 3.7 & 0.3 & 0.0 \\
7 & 1.9 & 19.9 & 44.9 & 4.1 & 0.6 & 19.6 & 3.0 & 5.9 & 0.0 & 0.0 \\
8 & 1.3 & 15.4 & 22.7 & 29.7 & 0.0 & 25.7 & 0.0 & 5.3 & 0.0 & 0.0 \\
9 & 1.4 & 14.7 & 29.0 & 26.6 & 0.0 & 22.1 & 1.9 & 4.3 & 0.0 & 0.0 \\
10 & 0.9 & 7.4 & 57.5 & 22.4 & 1.1 & 9.4 & 1.3 & 0.0 & 0.0 & 0.0 \\
Ave & 1.6 & 14.4 & 34.0 & 19.6 & 0.6 & 22.4 & 2.2 & 5.1 & 0.1 & 0.0 \\
\hline
\end{tabular}




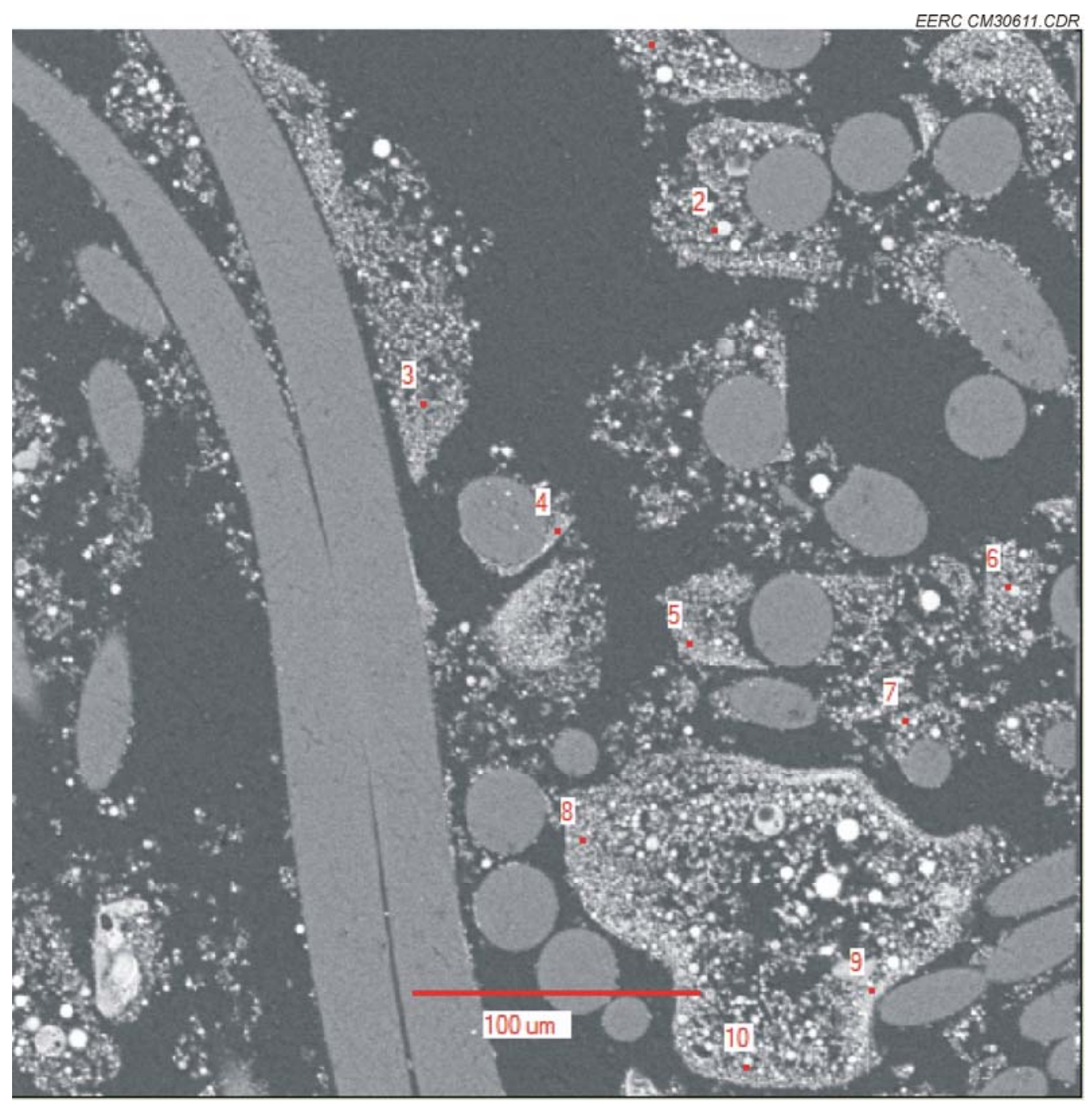

Figure G3-23. Image number 5 from FF 2-3C sample, 3-30-06.

Table G3-23. Oxide Weight Percentages for the Sample Points of Figure G3-23

\begin{tabular}{lcccccccccc}
\hline Image & $\mathrm{MgO}$ & $\mathrm{Al}_{2} \mathrm{O}_{3}$ & $\mathrm{SiO}_{2}$ & $\mathrm{SO}_{3}$ & $\mathrm{~K}_{2} \mathrm{O}$ & $\mathrm{CaO}$ & $\mathrm{TiO}_{2}$ & $\mathrm{Fe}_{2} \mathrm{O}_{3}$ & $\mathrm{Na}_{2} \mathrm{O}$ & $\mathrm{P}_{2} \mathrm{O}_{5}$ \\
\hline 1 & 1.6 & 14.1 & 34.4 & 20.5 & 0.0 & 25.2 & 0.0 & 4.1 & 0.0 & 0.0 \\
2 & 1.8 & 14.0 & 28.2 & 30.0 & 0.8 & 23.9 & 0.0 & 0.0 & 0.4 & 1.1 \\
3 & 1.9 & 16.7 & 34.3 & 20.2 & 1.0 & 21.8 & 0.0 & 3.3 & 0.0 & 0.9 \\
4 & 2.2 & 9.9 & 15.6 & 44.1 & 0.0 & 23.6 & 0.0 & 3.7 & 0.0 & 0.8 \\
5 & 1.0 & 14.9 & 33.5 & 25.6 & 0.7 & 15.7 & 1.0 & 7.3 & 0.3 & 0.0 \\
6 & 1.6 & 14.6 & 38.7 & 21.2 & 0.7 & 19.8 & 0.0 & 3.4 & 0.0 & 0.0 \\
7 & 2.0 & 12.6 & 22.9 & 33.4 & 0.0 & 24.8 & 1.2 & 3.0 & 0.0 & 0.0 \\
8 & 2.0 & 13.3 & 26.8 & 23.4 & 0.5 & 29.6 & 1.6 & 2.8 & 0.0 & 0.0 \\
9 & 1.2 & 13.3 & 21.8 & 38.5 & 0.0 & 19.8 & 1.4 & 2.9 & 0.2 & 0.8 \\
10 & 0.9 & 20.0 & 34.4 & 26.4 & 0.0 & 14.7 & 0.0 & 3.4 & 0.3 & 0.0 \\
Ave & 1.6 & 14.3 & 29.1 & 28.3 & 0.4 & 21.9 & 0.5 & 3.4 & 0.1 & 0.4 \\
\hline
\end{tabular}




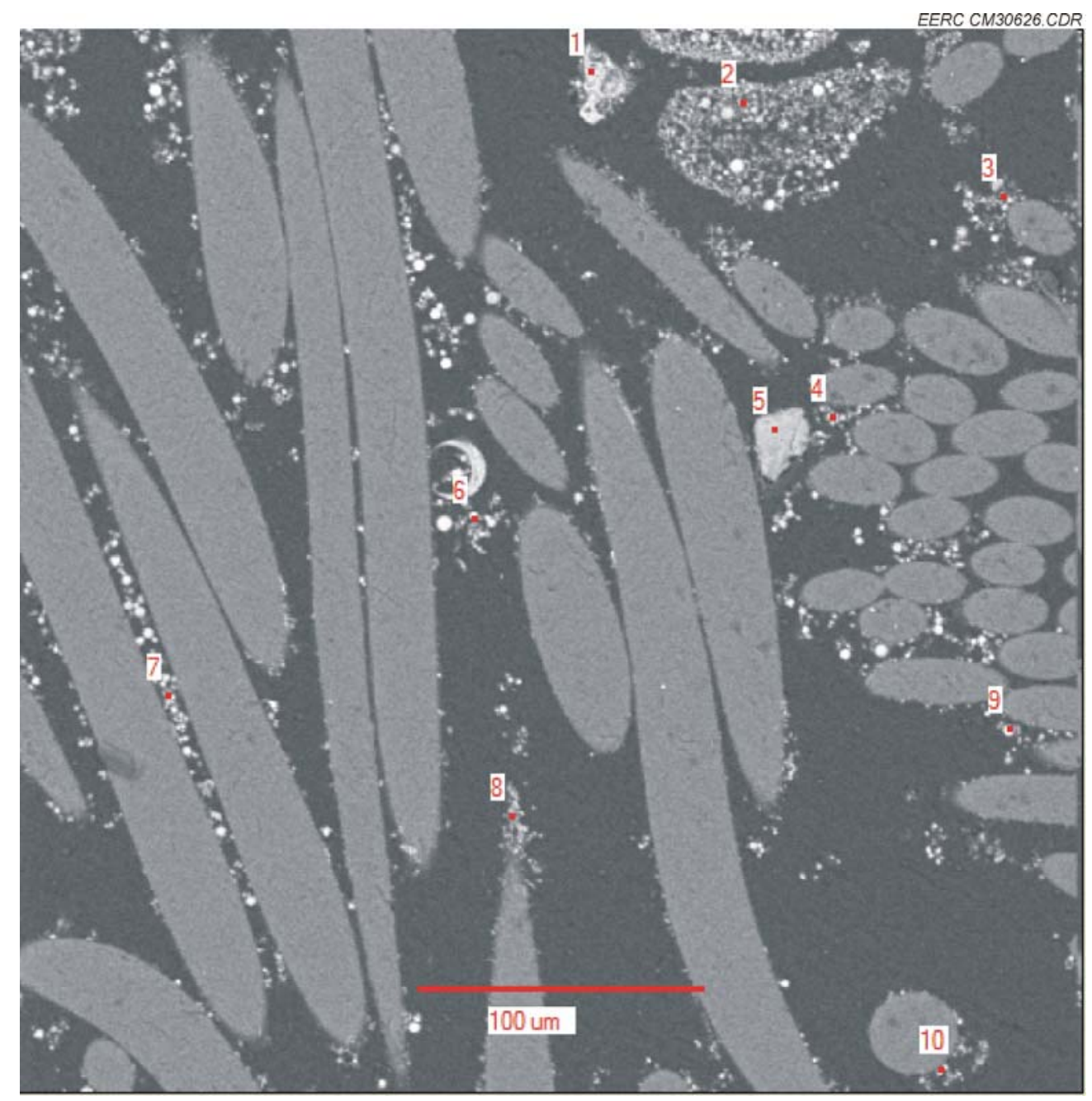

Figure G3-24. Image number 6 from FF 2-3C sample, 3-30-06.

Table G3-24. Oxide Weight Percentages for the Sample Points of Figure G3-24

\begin{tabular}{lcccccccccc}
\hline Image & $\mathrm{MgO}$ & $\mathrm{Al}_{2} \mathrm{O}_{3}$ & $\mathrm{SiO}_{2}$ & $\mathrm{SO}_{3}$ & $\mathrm{~K}_{2} \mathrm{O}$ & $\mathrm{CaO}$ & $\mathrm{TiO}_{2}$ & $\mathrm{Fe}_{2} \mathrm{O}_{3}$ & $\mathrm{Na}_{2} \mathrm{O}_{2}$ & $\mathrm{P}_{2} \mathrm{O}_{5}$ \\
\hline 1 & 0.7 & 18.9 & 54.7 & 2.9 & 1.7 & 15.6 & 0.0 & 5.0 & 0.5 & 0.0 \\
2 & 0.7 & 18.8 & 39.7 & 19.3 & 1.5 & 14.5 & 1.5 & 2.8 & 0.3 & 1.1 \\
3 & 1.4 & 9.1 & 18.5 & 42.6 & 0.0 & 22.2 & 1.9 & 3.0 & 0.0 & 1.3 \\
4 & 2.4 & 17.6 & 42.4 & 11.0 & 0.0 & 17.4 & 0.0 & 9.1 & 0.0 & 0.0 \\
5 & 0.0 & 0.0 & 100.0 & 0.0 & 0.0 & 0.0 & 0.0 & 0.0 & 0.0 & 0.0 \\
6 & 2.3 & 14.0 & 30.1 & 12.3 & 0.0 & 32.3 & 1.9 & 6.3 & 0.0 & 0.8 \\
7 & 1.1 & 14.7 & 33.5 & 25.7 & 0.0 & 19.4 & 0.0 & 5.3 & 0.3 & 0.0 \\
8 & 1.5 & 8.2 & 17.6 & 47.0 & 0.0 & 20.1 & 0.0 & 5.5 & 0.0 & 0.0 \\
9 & 3.1 & 10.6 & 26.5 & 4.1 & 0.0 & 48.6 & 1.5 & 5.6 & 0.0 & 0.0 \\
10 & 1.7 & 16.7 & 38.1 & 19.8 & 0.0 & 15.7 & 0.0 & 7.9 & 0.0 & 0.0 \\
Ave & 1.5 & 12.9 & 40.1 & 18.5 & 0.3 & 20.6 & 0.7 & 5.1 & 0.1 & 0.3 \\
\hline
\end{tabular}




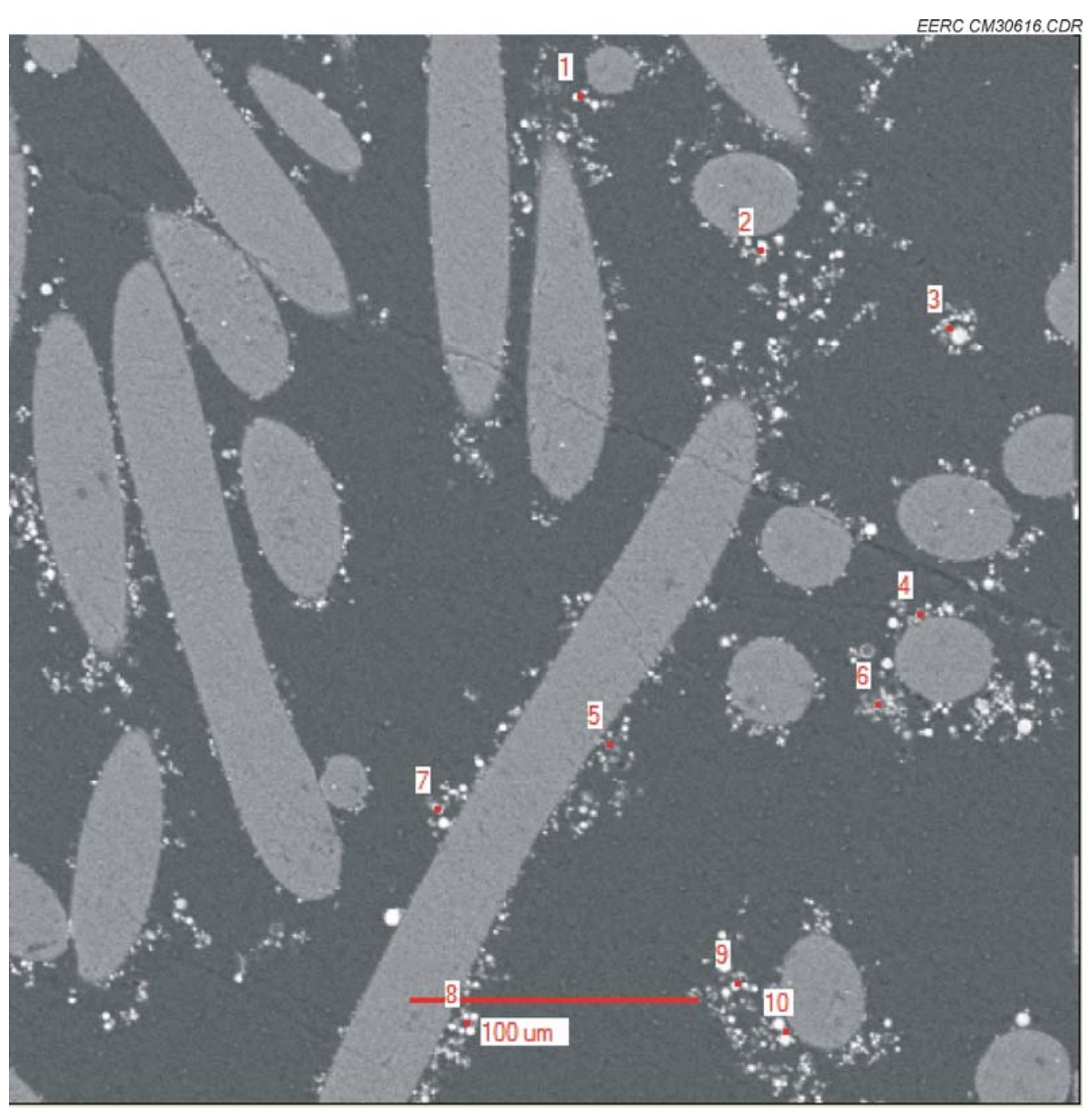

Figure G3-25. Image number 7 from FF 2-3C sample, 3-30-06.

Table G3-25. Oxide Weight Percentages for the Sample Points of Figure G3-25

\begin{tabular}{lcccccccccc}
\hline Image & $\mathrm{MgO}$ & $\mathrm{Al}_{2} \mathrm{O}_{3}$ & $\mathrm{SiO}_{2}$ & $\mathrm{SO}_{3}$ & $\mathrm{~K}_{2} \mathrm{O}$ & $\mathrm{CaO}$ & $\mathrm{TiO}_{2}$ & $\mathrm{Fe}_{2} \mathrm{O}_{3}$ & $\mathrm{Na}_{2} \mathrm{O}$ & $\mathrm{P}_{2} \mathrm{O}_{5}$ \\
\hline 1 & 1.4 & 11.1 & 19.8 & 40.3 & 0.0 & 22.8 & 0.0 & 4.5 & 0.0 & 0.0 \\
2 & 4.1 & 12.7 & 13.7 & 13.0 & 0.3 & 50.0 & 0.0 & 6.2 & 0.0 & 0.0 \\
3 & 1.0 & 21.5 & 61.8 & 0.9 & 3.3 & 3.1 & 1.6 & 6.2 & 0.6 & 0.0 \\
4 & 0.0 & 13.8 & 25.0 & 39.0 & 0.0 & 22.2 & 0.0 & 0.0 & 0.0 & 0.0 \\
5 & 2.2 & 17.9 & 38.1 & 4.4 & 0.0 & 31.5 & 1.2 & 4.6 & 0.0 & 0.0 \\
6 & 1.8 & 15.3 & 48.3 & 6.7 & 0.5 & 22.0 & 2.3 & 3.0 & 0.0 & 0.0 \\
7 & 1.1 & 13.8 & 53.8 & 13.6 & 2.4 & 10.8 & 1.2 & 2.8 & 0.5 & 0.0 \\
8 & 2.2 & 15.7 & 28.4 & 17.3 & 0.5 & 30.1 & 1.9 & 3.9 & 0.0 & 0.0 \\
9 & 1.9 & 18.9 & 53.9 & 0.0 & 1.1 & 16.3 & 1.2 & 6.5 & 0.2 & 0.0 \\
10 & 2.3 & 17.0 & 33.4 & 12.8 & 0.0 & 29.9 & 0.0 & 4.6 & 0.0 & 0.0 \\
Ave & 1.8 & 15.8 & 37.6 & 14.8 & 0.8 & 23.9 & 0.9 & 4.2 & 0.1 & 0.0 \\
\hline
\end{tabular}




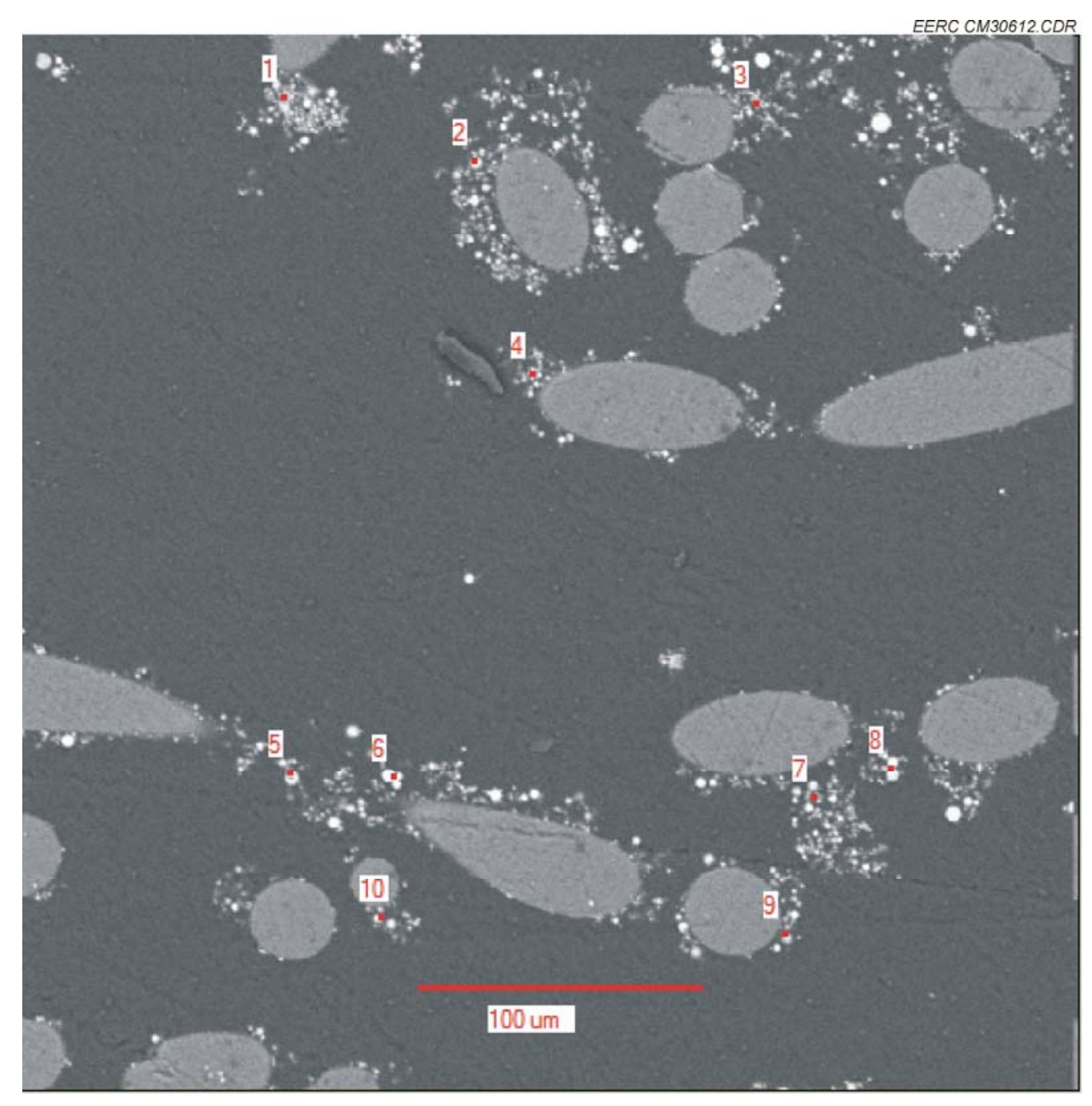

Figure G3-26. Image number 8 from FF 2-3C sample, 3-30-06.

Table G3-26. Oxide Weight Percentages for the Sample Points of Figure G3-26

\begin{tabular}{lcccccccccc}
\hline Image & $\mathrm{MgO}$ & $\mathrm{Al}_{2} \mathrm{O}_{3}$ & $\mathrm{SiO}_{2}$ & $\mathrm{SO}_{3}$ & $\mathrm{~K}_{2} \mathrm{O}$ & $\mathrm{CaO}$ & $\mathrm{TiO}_{2}$ & $\mathrm{Fe}_{2} \mathrm{O}_{3}$ & $\mathrm{Na}_{2} \mathrm{O}$ & $\mathrm{P}_{2} \mathrm{O}_{5}$ \\
\hline 1 & 3.1 & 12.3 & 28.8 & 31.9 & 0.0 & 19.3 & 1.4 & 3.1 & 0.0 & 0.0 \\
2 & 0.8 & 16.7 & 40.5 & 20.4 & 1.0 & 17.6 & 0.0 & 2.9 & 0.2 & 0.0 \\
3 & 1.3 & 18.7 & 46.3 & 15.2 & 1.1 & 11.6 & 0.0 & 5.4 & 0.3 & 0.0 \\
4 & 1.7 & 16.2 & 33.0 & 22.6 & 0.0 & 21.6 & 2.1 & 2.7 & 0.0 & 0.0 \\
5 & 0.6 & 26.6 & 55.5 & 0.7 & 3.1 & 4.6 & 1.1 & 7.4 & 0.5 & 0.0 \\
6 & 2.4 & 11.3 & 29.8 & 9.2 & 0.0 & 38.9 & 4.7 & 3.5 & 0.2 & 0.0 \\
7 & 0.5 & 13.7 & 54.3 & 17.7 & 1.2 & 9.4 & 0.0 & 3.1 & 0.0 & 0.0 \\
8 & 1.7 & 22.4 & 42.2 & 3.7 & 0.0 & 22.8 & 1.2 & 5.7 & 0.2 & 0.0 \\
9 & 0.6 & 11.6 & 67.9 & 6.4 & 2.3 & 7.2 & 0.0 & 3.5 & 0.5 & 0.0 \\
10 & 1.6 & 15.1 & 36.1 & 16.7 & 0.0 & 19.3 & 2.5 & 8.7 & 0.0 & 0.0 \\
Ave & 1.4 & 16.5 & 43.4 & 14.5 & 0.9 & 17.2 & 1.3 & 4.6 & 0.2 & 0.0 \\
\hline
\end{tabular}

FF 2-4C sample, pulled 3-30-06 


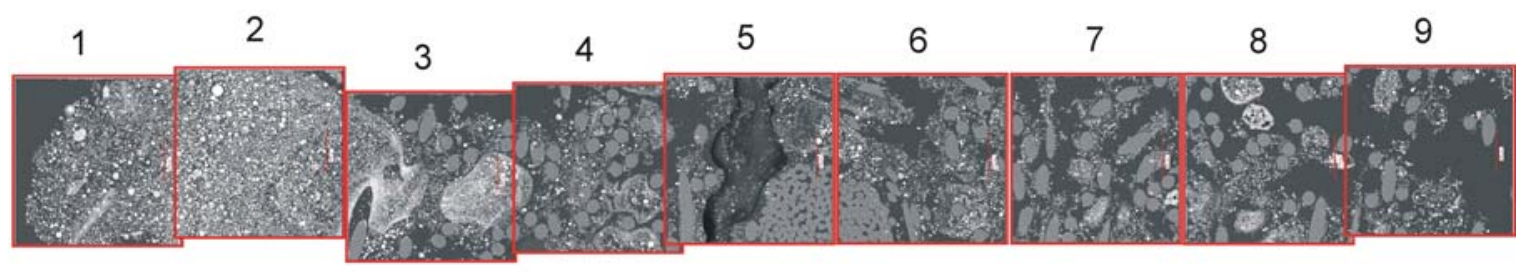

Flow

Figure G3-27. Bag cross section composite image, FF 2-4C sample from 3-30-06.

Table G3-27. Oxide Weight Averages of the Sample Points in Each Image of Figure G3-27

\begin{tabular}{lcccccccccc}
\hline Image & $\mathrm{MgO}$ & $\mathrm{Al}_{2} \mathrm{O}_{3}$ & $\mathrm{SiO}_{2}$ & $\mathrm{SO}_{3}$ & $\mathrm{~K}_{2} \mathrm{O}$ & $\mathrm{CaO}$ & $\mathrm{TiO}_{2}$ & $\mathrm{Fe}_{2} \mathrm{O}_{3}$ & $\mathrm{Na}_{2} \mathrm{O}$ & $\mathrm{P}_{2} \mathrm{O}_{5}$ \\
\hline 1 & 1.4 & 12.5 & 45.3 & 17.4 & 0.9 & 16.8 & 1.6 & 4.0 & 0.2 & 0.0 \\
2 & 1.0 & 19.8 & 50.0 & 12.5 & 1.5 & 10.2 & 0.3 & 4.3 & 0.4 & 0.0 \\
3 & 1.6 & 11.1 & 28.1 & 32.2 & 0.3 & 21.9 & 1.0 & 3.5 & 0.0 & 0.3 \\
4 & 1.2 & 10.5 & 28.6 & 30.4 & 0.4 & 22.3 & 2.1 & 3.9 & 0.1 & 0.6 \\
5 & 1.1 & 12.7 & 29.7 & 29.8 & 0.3 & 19.4 & 3.3 & 2.9 & 0.0 & 0.6 \\
6 & 1.3 & 11.0 & 25.7 & 37.0 & 0.4 & 19.4 & 1.0 & 3.8 & 0.2 & 0.3 \\
7 & 1.3 & 13.9 & 30.0 & 29.5 & 0.4 & 20.8 & 0.4 & 3.0 & 0.0 & 0.6 \\
8 & 1.3 & 14.0 & 34.4 & 24.5 & 0.7 & 18.6 & 1.6 & 4.7 & 0.1 & 0.1 \\
9 & 1.7 & 14.7 & 49.5 & 10.1 & 0.7 & 17.2 & 1.2 & 4.7 & 0.1 & 0.0 \\
Average & 1.3 & 13.3 & 35.7 & 24.8 & 0.6 & 18.5 & 1.4 & 3.9 & 0.1 & 0.3 \\
\hline
\end{tabular}




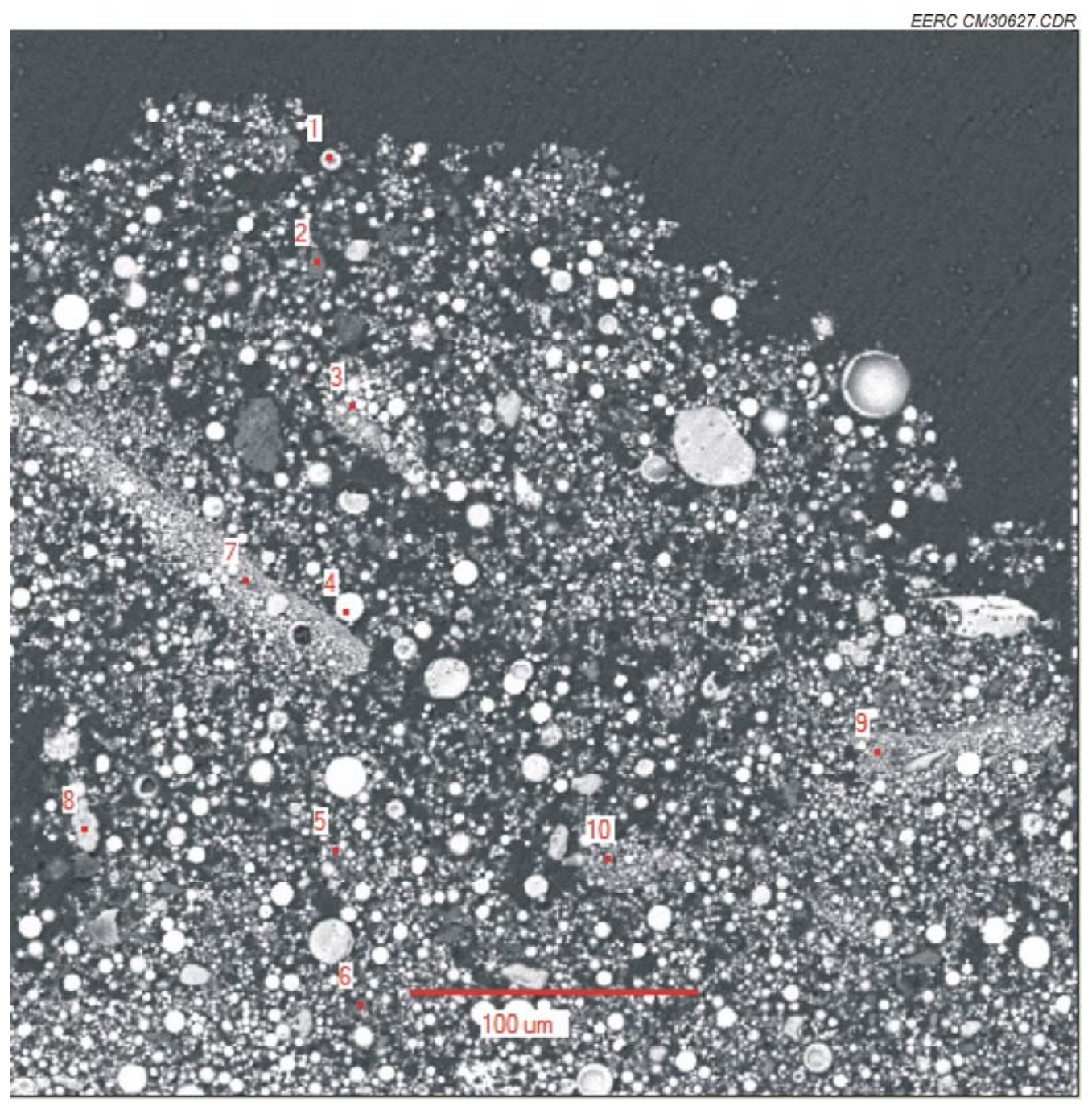

Figure G3-28. Image number 1 from FF 2-4C sample, 3-30-06.

Table G3-28. Oxide Weight Percentages for the Sample Points of Figure G3-28

\begin{tabular}{lcccccccccc}
\hline Image & $\mathrm{MgO}$ & $\mathrm{Al}_{2} \mathrm{O}_{3}$ & $\mathrm{SiO}_{2}$ & $\mathrm{SO}_{3}$ & $\mathrm{~K}_{2} \mathrm{O}$ & $\mathrm{CaO}$ & $\mathrm{TiO}_{2}$ & $\mathrm{Fe}_{2} \mathrm{O}_{3}$ & $\mathrm{Na}_{2} \mathrm{O}$ & $\mathrm{P}_{2} \mathrm{O}_{5}$ \\
\hline 1 & 0.0 & 29.3 & 61.6 & 0.0 & 2.9 & 2.9 & 0.0 & 3.0 & 0.3 & 0.0 \\
2 & 0.7 & 3.7 & 4.2 & 68.1 & 0.0 & 19.1 & 0.0 & 3.2 & 0.9 & 0.0 \\
3 & 0.9 & 20.8 & 62.6 & 3.0 & 4.2 & 3.6 & 0.0 & 4.5 & 0.6 & 0.0 \\
4 & 2.2 & 4.3 & 54.1 & 0.0 & 0.0 & 33.0 & 3.2 & 3.2 & 0.0 & 0.0 \\
5 & 1.6 & 15.1 & 42.6 & 20.2 & 0.9 & 14.8 & 0.0 & 4.5 & 0.4 & 0.0 \\
6 & 1.6 & 10.8 & 26.1 & 36.5 & 0.0 & 19.6 & 1.6 & 3.7 & 0.0 & 0.0 \\
7 & 1.9 & 17.5 & 37.5 & 17.8 & 0.8 & 18.0 & 1.3 & 5.1 & 0.0 & 0.0 \\
8 & 0.0 & 0.5 & 98.0 & 0.0 & 0.0 & 1.5 & 0.0 & 0.0 & 0.0 & 0.0 \\
9 & 2.8 & 9.4 & 36.6 & 17.2 & 0.4 & 26.7 & 0.0 & 6.9 & 0.0 & 0.0 \\
10 & 2.0 & 13.2 & 29.7 & 11.3 & 0.0 & 28.6 & 9.7 & 5.5 & 0.0 & 0.0 \\
Ave & 1.4 & 12.5 & 45.3 & 17.4 & 0.9 & 16.8 & 1.6 & 4.0 & 0.2 & 0.0 \\
\hline
\end{tabular}




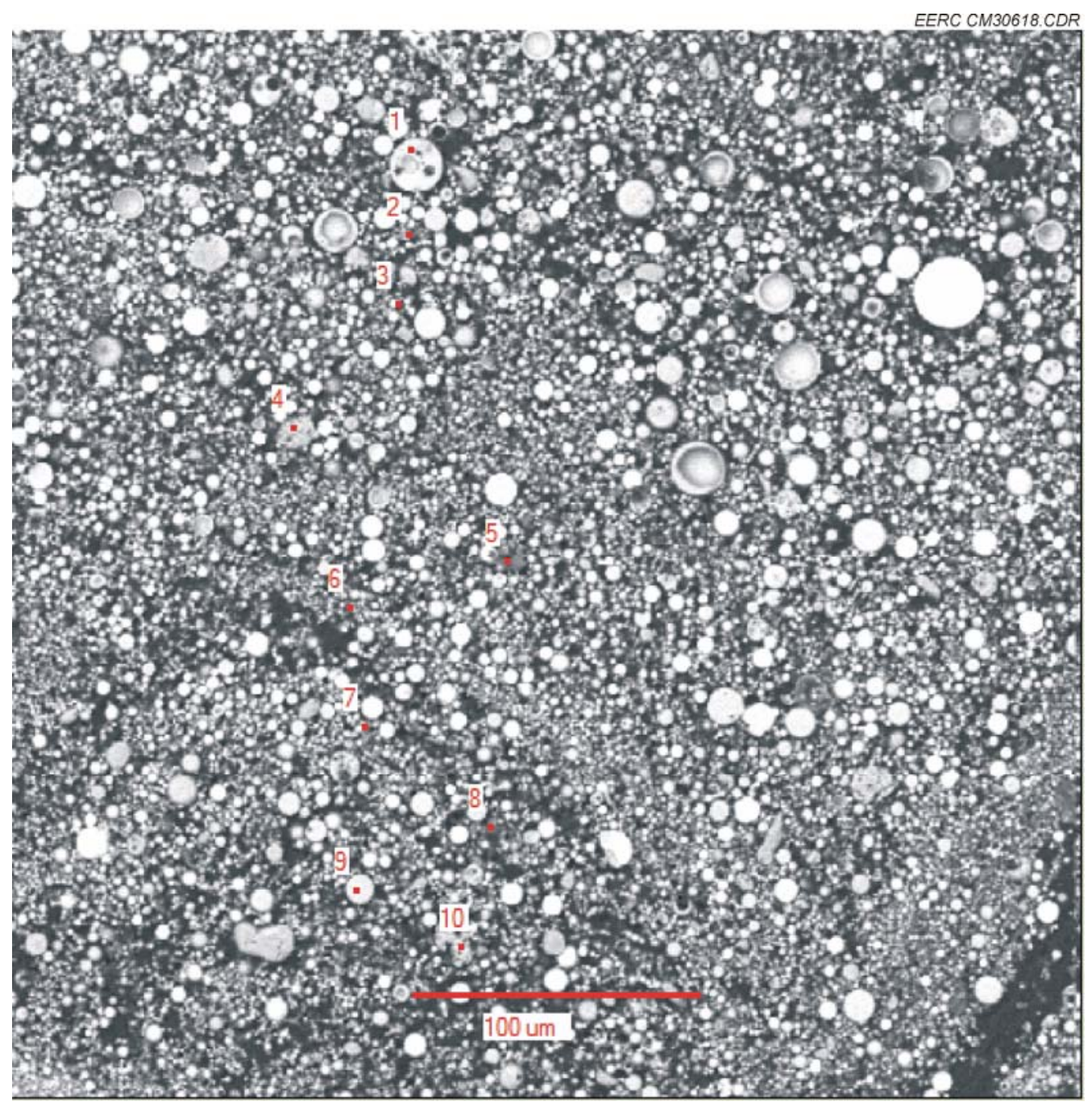

Figure G3-29. Image number 2 from FF 2-4C sample, 3-30-06.

Table G3-29. Oxide Weight Percentages for the Sample Points of Figure G3-29

\begin{tabular}{lcccccccccc}
\hline Image & $\mathrm{MgO}$ & $\mathrm{Al}_{2} \mathrm{O}_{3}$ & $\mathrm{SiO}_{2}$ & $\mathrm{SO}_{3}$ & $\mathrm{~K}_{2} \mathrm{O}$ & $\mathrm{CaO}$ & $\mathrm{TiO}_{2}$ & $\mathrm{Fe}_{2} \mathrm{O}_{3}$ & $\mathrm{Na}_{2} \mathrm{O}$ & $\mathrm{P}_{2} \mathrm{O}_{5}$ \\
\hline 1 & 0.6 & 12.2 & 80.2 & 1.0 & 2.1 & 3.7 & 0.0 & 0.0 & 0.2 & 0.0 \\
2 & 1.3 & 21.1 & 41.4 & 11.4 & 1.2 & 13.0 & 0.9 & 9.4 & 0.3 & 0.0 \\
3 & 1.5 & 16.4 & 34.9 & 21.3 & 1.1 & 19.9 & 0.0 & 4.6 & 0.3 & 0.0 \\
4 & 0.0 & 35.4 & 62.4 & 0.0 & 0.6 & 0.4 & 0.0 & 1.0 & 0.2 & 0.0 \\
5 & 1.6 & 16.8 & 47.2 & 15.0 & 2.0 & 16.3 & 0.0 & 0.0 & 1.2 & 0.0 \\
6 & 1.3 & 16.7 & 34.0 & 31.2 & 1.0 & 11.9 & 0.0 & 3.8 & 0.3 & 0.0 \\
7 & 1.4 & 13.2 & 31.2 & 30.3 & 0.4 & 16.4 & 1.0 & 5.7 & 0.2 & 0.0 \\
8 & 0.7 & 18.1 & 51.4 & 15.1 & 2.9 & 3.2 & 0.0 & 8.3 & 0.3 & 0.0 \\
9 & 0.9 & 26.1 & 53.3 & 0.0 & 1.0 & 13.6 & 0.0 & 4.5 & 0.6 & 0.0 \\
10 & 1.2 & 21.7 & 64.1 & 0.0 & 2.1 & 3.9 & 1.1 & 5.9 & 0.0 & 0.0 \\
Ave & 1.0 & 19.8 & 50.0 & 12.5 & 1.5 & 10.2 & 0.3 & 4.3 & 0.4 & 0.0 \\
\hline
\end{tabular}




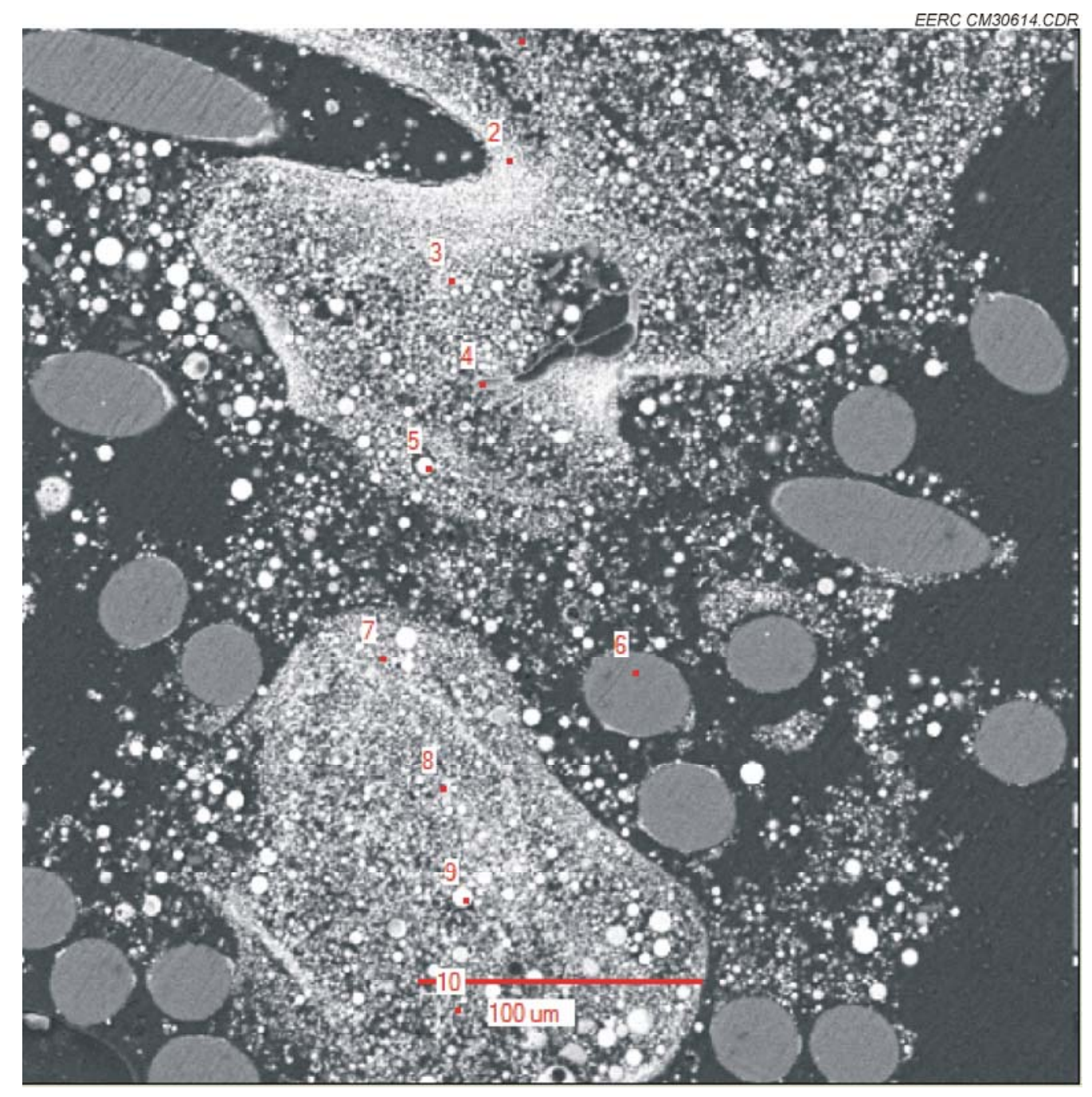

Figure G3-30. Image number 3 from FF 2-4C sample, 3-30-06

Table G3-30. Oxide Weight Percentages for the Sample Points of Figure G3-30

\begin{tabular}{lcccccccccc}
\hline Image & $\mathrm{MgO}$ & $\mathrm{Al}_{2} \mathrm{O}_{3}$ & $\mathrm{SiO}_{2}$ & $\mathrm{SO}_{3}$ & $\mathrm{~K}_{2} \mathrm{O}$ & $\mathrm{CaO}$ & $\mathrm{TiO}_{2}$ & $\mathrm{Fe}_{2} \mathrm{O}_{3}$ & $\mathrm{Na}_{2} \mathrm{O}$ & $\mathrm{P}_{2} \mathrm{O}_{5}$ \\
\hline 1 & 1.4 & 10.0 & 21.1 & 44.4 & 0.5 & 18.2 & 1.2 & 2.4 & 0.0 & 0.7 \\
2 & 2.4 & 7.8 & 13.4 & 50.5 & 0.0 & 21.0 & 1.4 & 2.0 & 0.0 & 1.5 \\
3 & 1.4 & 9.1 & 16.2 & 46.0 & 0.4 & 22.0 & 1.9 & 2.5 & 0.0 & 0.6 \\
4 & 0.0 & 9.7 & 56.9 & 16.8 & 2.1 & 11.0 & 0.0 & 3.3 & 0.2 & 0.0 \\
5 & 2.4 & 13.2 & 37.0 & 4.1 & 0.0 & 35.7 & 1.3 & 6.4 & 0.0 & 0.0 \\
Fabric & & & & & & & & & & \\
7 & 0.9 & 12.2 & 30.6 & 31.1 & 0.0 & 21.1 & 0.0 & 4.1 & 0.0 & 0.0 \\
8 & 1.8 & 9.8 & 17.7 & 44.9 & 0.0 & 20.4 & 1.8 & 3.6 & 0.1 & 0.0 \\
9 & 2.0 & 19.5 & 40.1 & 1.0 & 0.0 & 32.2 & 1.4 & 3.8 & 0.0 & 0.0 \\
10 & 2.1 & 8.2 & 19.4 & 50.7 & 0.0 & 15.6 & 0.0 & 3.9 & 0.0 & 0.0 \\
Ave & 1.6 & 11.1 & 28.1 & 32.2 & 0.3 & 21.9 & 1.0 & 3.5 & 0.0 & 0.3 \\
\hline
\end{tabular}




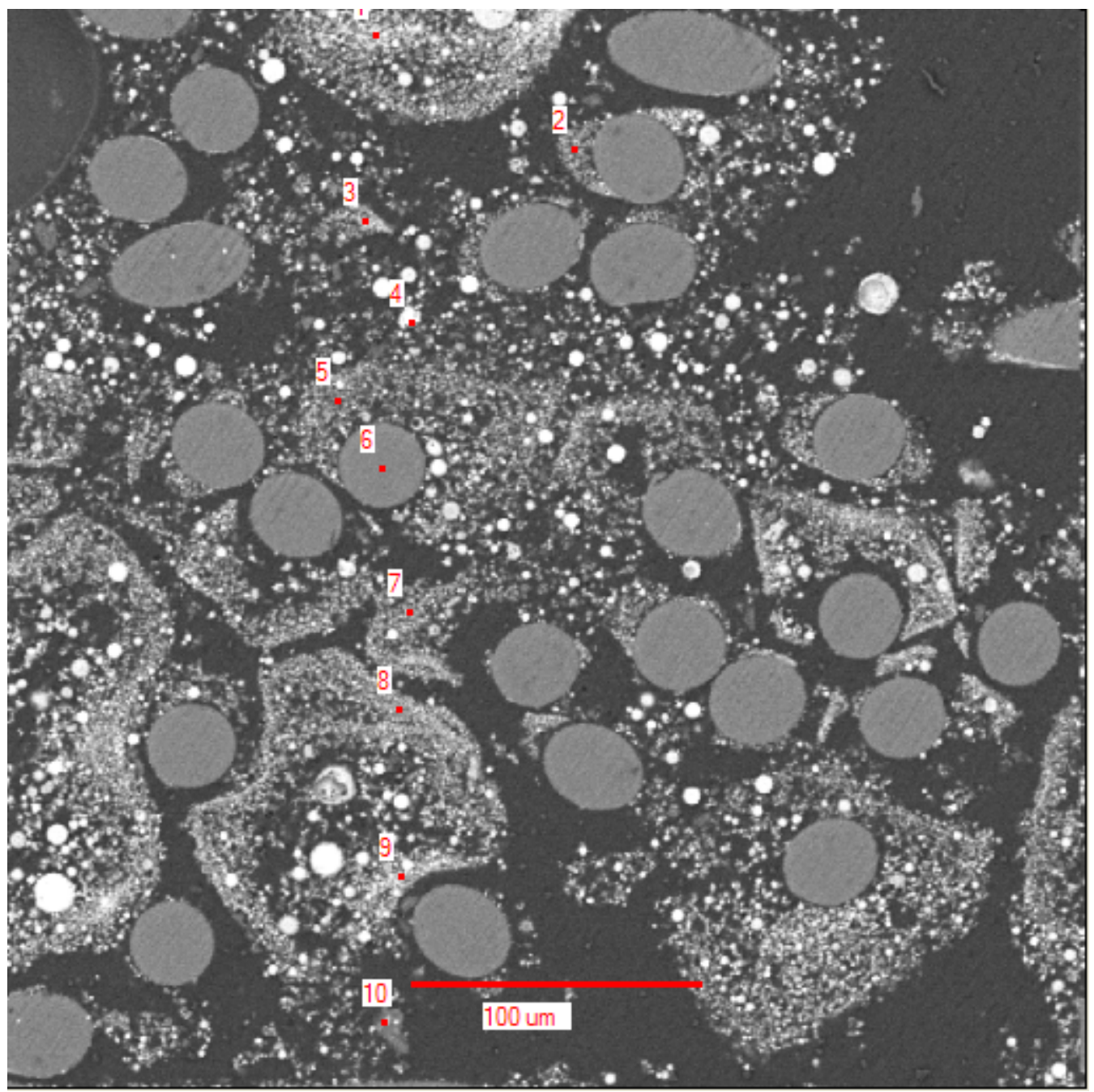

Figure G3-31. Image number 4 from FF 2-4C sample, 3-30-06.

Table G3-31. Oxide Weight Percentages for the Sample Points of Figure G3-31

\begin{tabular}{lcccccccccc}
\hline Image & $\mathrm{MgO}$ & $\mathrm{Al}_{2} \mathrm{O}_{3}$ & $\mathrm{SiO}_{2}$ & $\mathrm{SO}_{3}$ & $\mathrm{~K}_{2} \mathrm{O}$ & $\mathrm{CaO}$ & $\mathrm{TiO}_{2}$ & $\mathrm{Fe}_{2} \mathrm{O}_{3}$ & $\mathrm{Na}_{2} \mathrm{O}$ & $\mathrm{P}_{2} \mathrm{O}_{5}$ \\
\hline 1 & 0.9 & 24.3 & 49.8 & 3.0 & 3.4 & 4.0 & 7.2 & 7.3 & 0.0 & 0.0 \\
2 & 1.2 & 7.1 & 37.9 & 34.3 & 0.0 & 16.4 & 0.0 & 2.0 & 0.0 & 1.0 \\
3 & 2.5 & 9.8 & 19.2 & 38.9 & 0.0 & 23.9 & 1.8 & 2.2 & 0.0 & 1.7 \\
4 & 0.6 & 5.7 & 9.3 & 15.8 & 0.0 & 61.2 & 1.4 & 6.0 & 0.0 & 0.0 \\
5 & 1.4 & 10.4 & 20.0 & 37.9 & 0.0 & 22.5 & 3.1 & 3.0 & 0.0 & 1.7 \\
Fabric & & & & & & & & & & \\
7 & 1.1 & 11.6 & 37.9 & 28.3 & 0.0 & 15.9 & 1.1 & 4.1 & 0.0 & 0.0 \\
8 & 1.3 & 10.2 & 21.2 & 41.4 & 0.0 & 21.6 & 1.3 & 2.3 & 0.2 & 0.6 \\
9 & 1.5 & 15.2 & 27.6 & 30.8 & 0.0 & 18.8 & 1.3 & 4.5 & 0.3 & 0.0 \\
10 & 0.3 & 0.0 & 34.3 & 43.5 & 0.0 & 16.4 & 1.3 & 3.4 & 0.7 & 0.0 \\
Ave & 1.2 & 10.5 & 28.6 & 30.4 & 0.4 & 22.3 & 2.1 & 3.9 & 0.1 & 0.6 \\
\hline
\end{tabular}




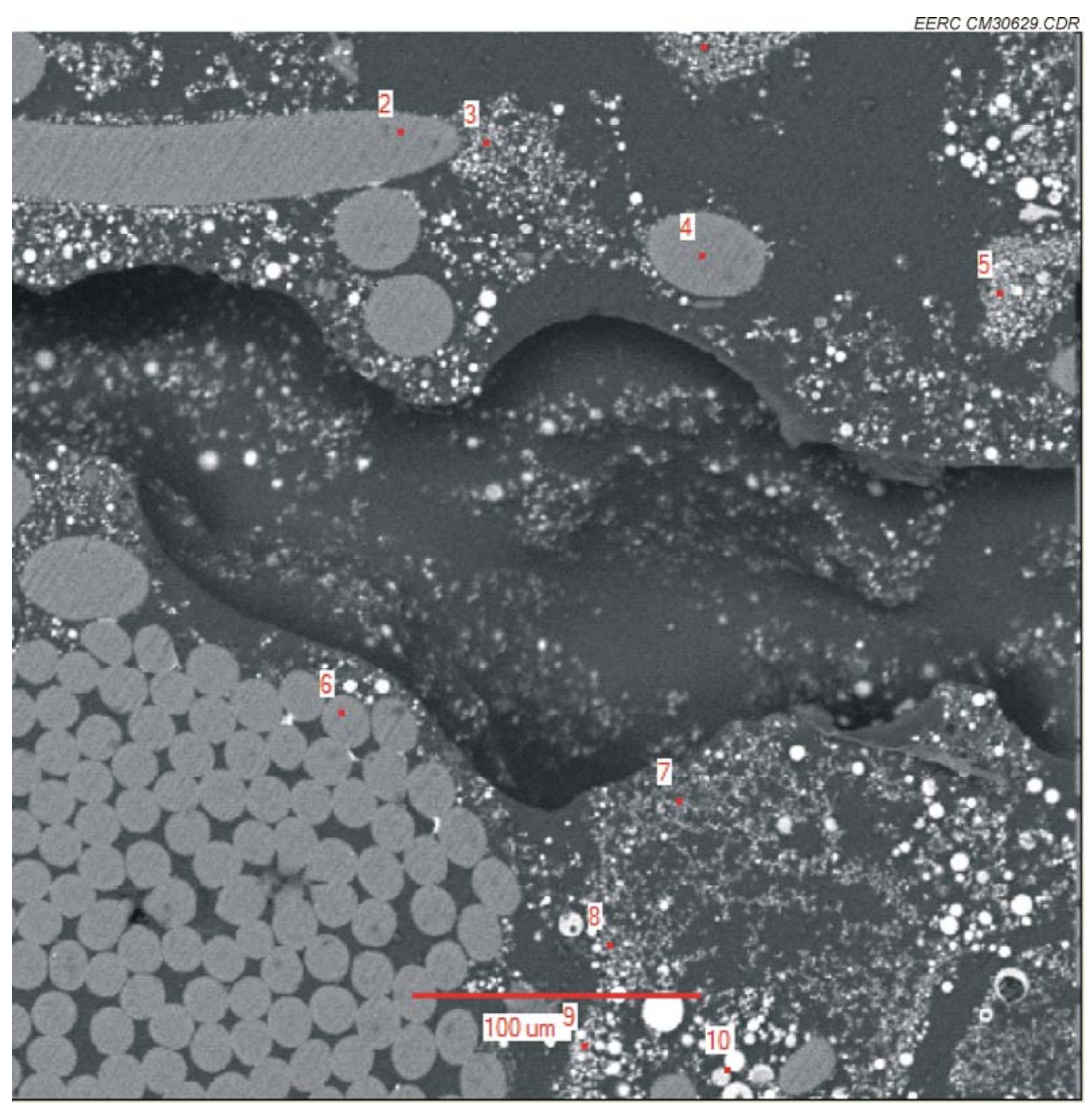

Figure G3-32. Image number 5 from FF 2-4C sample, 3-30-06.

Table G3-32. Oxide Weight Percentages for the Sample Points of Figure G3-32

\begin{tabular}{lcccccccccc}
\hline Image & $\mathrm{MgO}$ & $\mathrm{Al}_{2} \mathrm{O}_{3}$ & $\mathrm{SiO}_{2}$ & $\mathrm{SO}_{3}$ & $\mathrm{~K}_{2} \mathrm{O}$ & $\mathrm{CaO}$ & $\mathrm{TiO}_{2}$ & $\mathrm{Fe}_{2} \mathrm{O}_{3}$ & $\mathrm{Na}_{2} \mathrm{O}$ & $\mathrm{P}_{2} \mathrm{O}_{5}$ \\
\hline 1 & 1.2 & 13.3 & 27.5 & 32.3 & 0.0 & 21.0 & 0.0 & 4.7 & 0.0 & 0.0 \\
Fabric & & & & & & & & & & \\
3 & 1.7 & 12.7 & 30.3 & 30.0 & 0.0 & 20.5 & 1.8 & 3.0 & 0.0 & 0.0 \\
Fabric & & & & & & & & & & \\
5 & 1.2 & 12.6 & 26.1 & 38.1 & 0.9 & 19.0 & 0.0 & 2.3 & 0.0 & 0.0 \\
Fabric & & & & & & & & & & \\
7 & 0.0 & 11.2 & 33.3 & 35.0 & 0.0 & 17.3 & 0.0 & 0.0 & 0.0 & 3.3 \\
8 & 1.3 & 13.5 & 28.3 & 35.8 & 0.8 & 15.7 & 1.3 & 2.9 & 0.3 & 0.0 \\
9 & 0.8 & 8.5 & 28.7 & 27.5 & 0.0 & 14.4 & 17.1 & 3.1 & 0.0 & 0.0 \\
10 & 1.5 & 17.5 & 34.1 & 10.2 & 0.4 & 27.7 & 3.3 & 4.5 & 0.0 & 1.0 \\
Ave & 1.1 & 12.7 & 29.7 & 29.8 & 0.3 & 19.4 & 3.3 & 2.9 & 0.0 & 0.6 \\
\hline
\end{tabular}




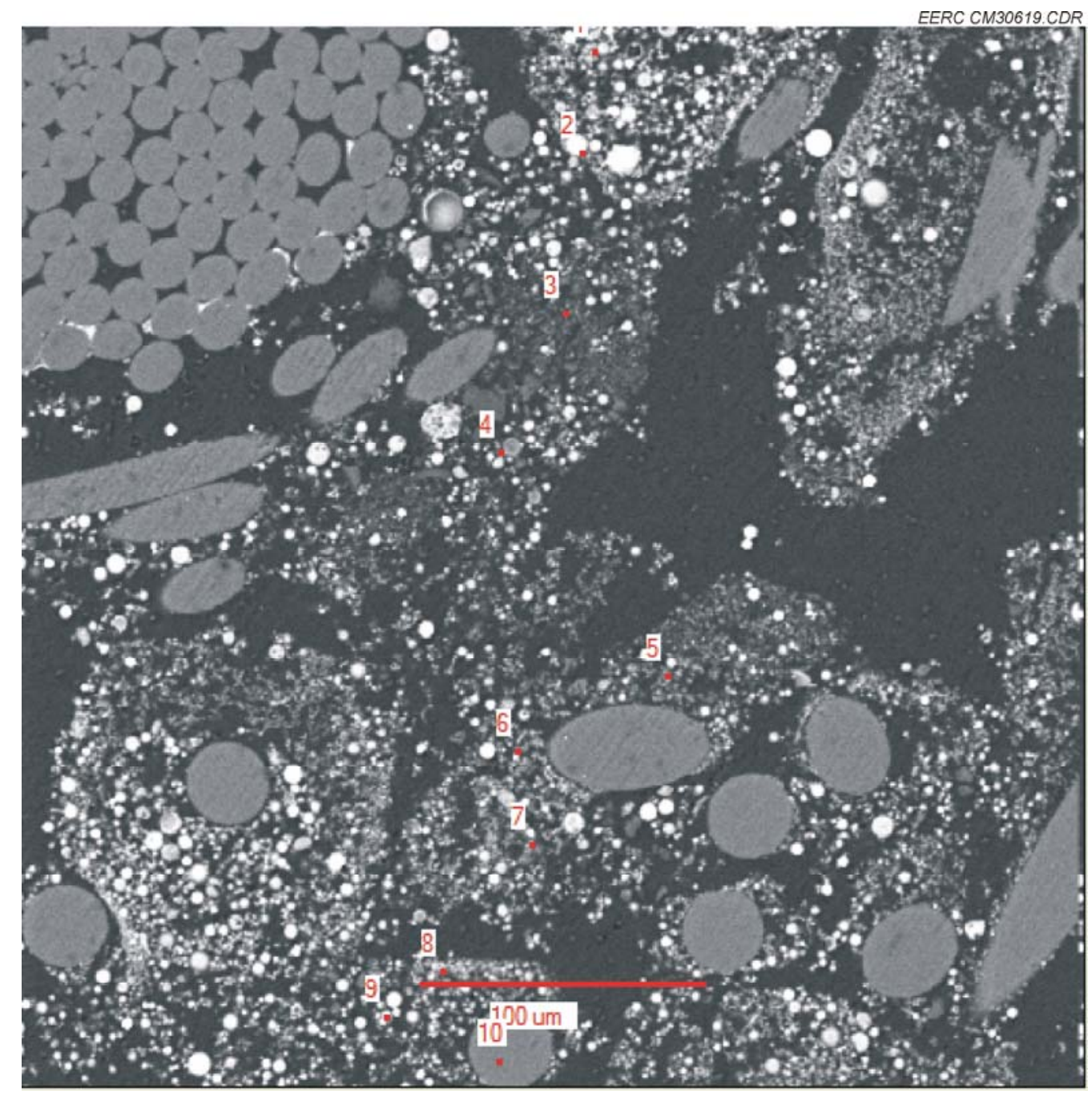

Figure G3-33. Image number 6 from FF 2-4C sample, 3-30-06.

Table G3-33. Oxide Weight Percentages for the Sample Points of Figure G3-33

\begin{tabular}{lcccccccccc}
\hline Image & $\mathrm{MgO}$ & $\mathrm{Al}_{2} \mathrm{O}_{3}$ & $\mathrm{SiO}_{2}$ & $\mathrm{SO}_{3}$ & $\mathrm{~K}_{2} \mathrm{O}$ & $\mathrm{CaO}$ & $\mathrm{TiO}_{2}$ & $\mathrm{Fe}_{2} \mathrm{O}_{3}$ & $\mathrm{Na}_{2} \mathrm{O}$ & $\mathrm{P}_{2} \mathrm{O}_{5}$ \\
\hline 1 & 1.4 & 11.8 & 23.2 & 37.1 & 0.9 & 14.8 & 1.0 & 9.7 & 0.0 & 0.0 \\
2 & 1.3 & 10.6 & 23.2 & 27.5 & 0.0 & 27.6 & 1.8 & 8.1 & 0.0 & 0.0 \\
3 & 1.5 & 10.1 & 15.1 & 49.3 & 0.0 & 22.3 & 0.0 & 0.0 & 0.0 & 1.6 \\
4 & 1.5 & 9.4 & 39.5 & 26.6 & 1.5 & 18.1 & 0.0 & 3.0 & 0.4 & 0.0 \\
5 & 0.9 & 7.7 & 19.9 & 50.1 & 0.0 & 18.1 & 2.6 & 0.0 & 0.6 & 0.0 \\
6 & 1.7 & 11.0 & 22.4 & 45.9 & 0.0 & 17.5 & 0.0 & 0.0 & 0.3 & 1.3 \\
7 & 0.7 & 10.0 & 25.4 & 46.2 & 0.7 & 14.5 & 0.0 & 2.5 & 0.0 & 0.0 \\
8 & 1.2 & 10.7 & 24.7 & 38.4 & 0.0 & 19.8 & 1.7 & 3.5 & 0.0 & 0.0 \\
9 & 1.7 & 18.1 & 38.0 & 11.6 & 0.0 & 21.6 & 1.6 & 7.1 & 0.2 & 0.0 \\
Fabric & & & & & & & & & & \\
Ave & 1.3 & 11.0 & 25.7 & 37.0 & 0.4 & 19.4 & 1.0 & 3.8 & 0.2 & 0.3 \\
\hline
\end{tabular}




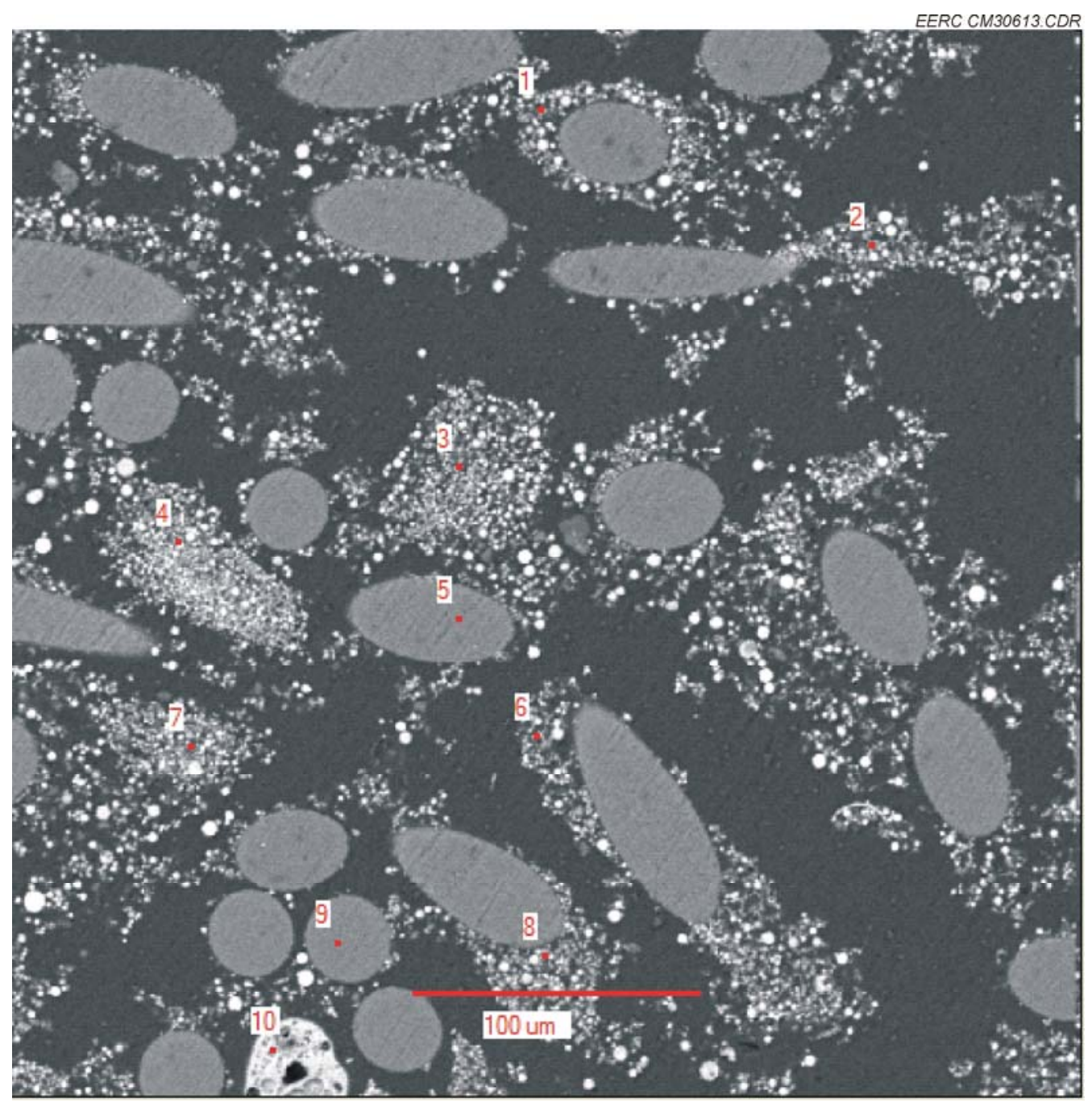

Figure G3-34. Image number 7 from FF 2-4C sample, 3-30-06.

Table G3-34. Oxide Weight Percentages for the Sample Points of Figure G3-34

\begin{tabular}{lcccccccccc}
\hline Image & $\mathrm{MgO}$ & $\mathrm{Al}_{2} \mathrm{O}_{3}$ & $\mathrm{SiO}_{2}$ & $\mathrm{SO}_{3}$ & $\mathrm{~K}_{2} \mathrm{O}$ & $\mathrm{CaO}$ & $\mathrm{TiO}_{2}$ & $\mathrm{Fe}_{2} \mathrm{O}_{3}$ & $\mathrm{Na}_{2} \mathrm{O}$ & $\mathrm{P}_{2} \mathrm{O}_{5}$ \\
\hline 1 & 0.8 & 14.4 & 27.5 & 38.7 & 0.0 & 18.7 & 0.0 & 0.0 & 0.0 & 0.0 \\
2 & 1.7 & 14.3 & 30.8 & 33.3 & 0.6 & 14.8 & 0.0 & 4.5 & 0.0 & 0.0 \\
3 & 1.6 & 10.7 & 22.3 & 29.5 & 0.0 & 30.6 & 0.0 & 3.5 & 0.0 & 1.6 \\
4 & 1.4 & 9.7 & 18.7 & 37.6 & 0.0 & 25.9 & 1.2 & 3.6 & 0.0 & 1.8 \\
Fabric & & & & & & & & & & \\
6 & 1.7 & 10.8 & 20.8 & 38.3 & 0.0 & 28.4 & 0.0 & 0.0 & 0.0 & 0.0 \\
7 & 1.5 & 14.6 & 26.3 & 26.1 & 0.0 & 25.9 & 0.0 & 4.3 & 0.3 & 1.1 \\
8 & 1.6 & 16.0 & 25.2 & 32.7 & 0.0 & 20.0 & 0.0 & 4.6 & 0.0 & 0.0 \\
Fabric & & & & & & & & & & \\
10 & 0.4 & 20.4 & 68.4 & 0.0 & 2.9 & 2.1 & 2.1 & 3.7 & 0.0 & 0.0 \\
Ave & 1.3 & 13.9 & 30.0 & 29.5 & 0.4 & 20.8 & 0.4 & 3.0 & 0.0 & 0.6 \\
\hline
\end{tabular}




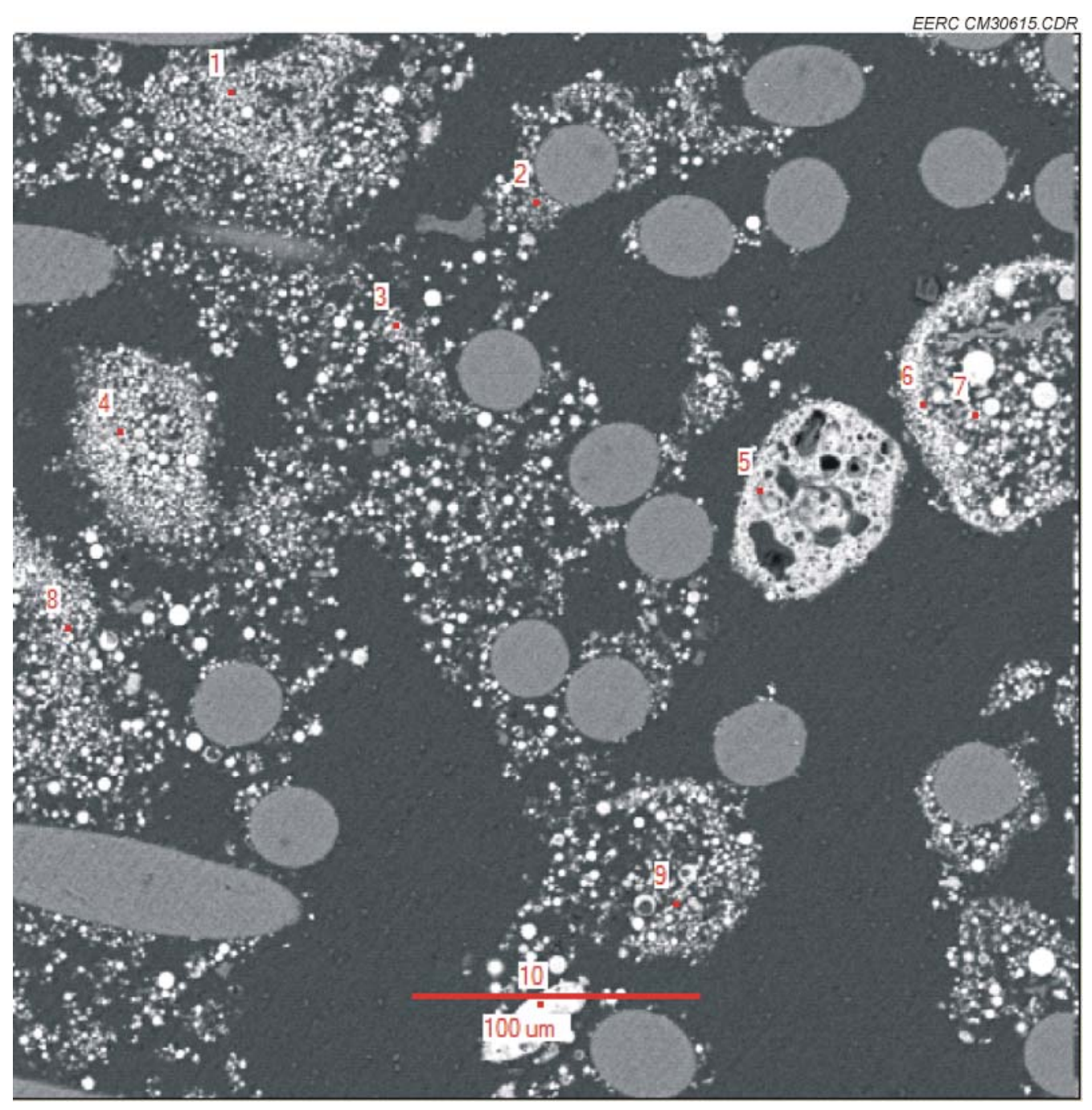

Figure G3-35. Image number 8 from FF 2-4C sample, 3-30-06.

Table G3-35. Oxide Weight Percentages for the Sample Points of Figure G3-35

\begin{tabular}{lcccccccccc}
\hline Image & $\mathrm{MgO}$ & $\mathrm{Al}_{2} \mathrm{O}_{3}$ & $\mathrm{SiO}_{2}$ & $\mathrm{SO}_{3}$ & $\mathrm{~K}_{2} \mathrm{O}$ & $\mathrm{CaO}$ & $\mathrm{TiO}_{2}$ & $\mathrm{Fe}_{2} \mathrm{O}_{3}$ & $\mathrm{Na}_{2} \mathrm{O}$ & $\mathrm{P}_{2} \mathrm{O}_{5}$ \\
\hline 1 & 0.8 & 11.4 & 33.2 & 35.8 & 0.7 & 14.7 & 0.0 & 3.5 & 0.0 & 0.0 \\
2 & 0.8 & 11.0 & 26.5 & 38.2 & 0.0 & 20.5 & 0.0 & 3.1 & 0.0 & 0.0 \\
3 & 2.0 & 12.3 & 11.8 & 11.0 & 0.0 & 51.5 & 4.2 & 7.3 & 0.0 & 0.0 \\
4 & 2.1 & 21.6 & 44.6 & 4.8 & 0.3 & 17.4 & 2.3 & 6.8 & 0.1 & 0.0 \\
5 & 0.8 & 22.8 & 65.4 & 0.6 & 3.0 & 1.6 & 1.8 & 4.1 & 0.0 & 0.0 \\
6 & 1.4 & 11.7 & 22.0 & 45.2 & 0.5 & 14.4 & 0.0 & 4.8 & 0.0 & 0.0 \\
7 & 1.0 & 10.2 & 24.3 & 43.0 & 0.5 & 16.2 & 1.3 & 3.1 & 0.3 & 0.0 \\
8 & 1.2 & 19.3 & 42.7 & 18.2 & 1.9 & 11.4 & 0.0 & 5.1 & 0.2 & 0.0 \\
9 & 1.6 & 8.5 & 20.1 & 48.5 & 0.5 & 17.0 & 2.8 & 0.0 & 0.0 & 0.9 \\
10 & 1.7 & 11.1 & 53.1 & 0.0 & 0.0 & 21.8 & 3.4 & 8.9 & 0.0 & 0.0 \\
Ave & 1.3 & 14.0 & 34.4 & 24.5 & 0.7 & 18.6 & 1.6 & 4.7 & 0.1 & 0.1 \\
\hline
\end{tabular}




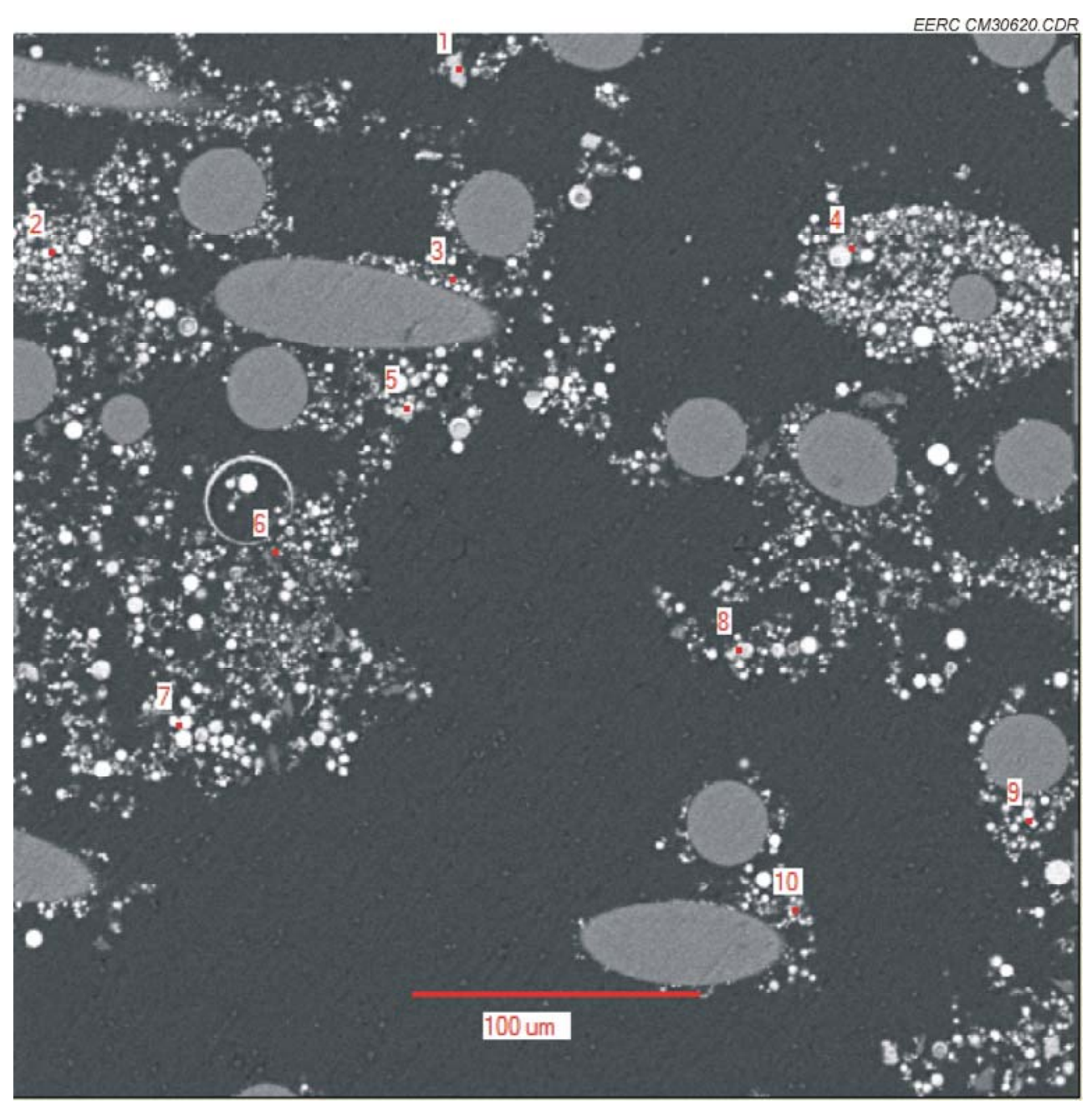

Figure G3-36. Image number 9 from FF 2-4C sample, 3-30-06.

Table G3-36. Oxide Weight Percentages for the Sample Points of Figure G3-36

\begin{tabular}{lcccccccccc}
\hline Image & $\mathrm{MgO}$ & $\mathrm{Al}_{2} \mathrm{O}_{3}$ & $\mathrm{SiO}_{2}$ & $\mathrm{SO}_{3}$ & $\mathrm{~K}_{2} \mathrm{O}$ & $\mathrm{CaO}$ & $\mathrm{TiO}_{2}$ & $\mathrm{Fe}_{2} \mathrm{O}_{3}$ & $\mathrm{Na}_{2} \mathrm{O}$ & $\mathrm{P}_{2} \mathrm{O}_{5}$ \\
\hline 1 & 0.0 & 0.0 & 99.0 & 0.0 & 0.0 & 0.0 & 0.0 & 1.0 & 0.0 & 0.0 \\
2 & 0.7 & 38.1 & 35.8 & 2.8 & 0.8 & 6.1 & 5.2 & 10.0 & 0.4 & 0.0 \\
3 & 3.2 & 14.5 & 27.8 & 14.0 & 0.5 & 33.7 & 1.3 & 4.9 & 0.0 & 0.0 \\
4 & 2.3 & 12.2 & 27.2 & 39.9 & 0.9 & 14.8 & 0.0 & 2.5 & 0.2 & 0.0 \\
5 & 3.6 & 6.2 & 23.4 & 10.3 & 0.0 & 47.5 & 1.0 & 8.0 & 0.0 & 0.0 \\
6 & 2.0 & 17.3 & 35.9 & 21.1 & 0.0 & 18.8 & 1.6 & 3.3 & 0.0 & 0.0 \\
7 & 2.6 & 17.0 & 40.4 & 1.6 & 0.0 & 31.9 & 1.6 & 5.0 & 0.0 & 0.0 \\
8 & 0.0 & 0.4 & 99.3 & 0.0 & 0.4 & 0.0 & 0.0 & 0.0 & 0.0 & 0.0 \\
9 & 1.7 & 20.3 & 55.9 & 2.3 & 2.8 & 8.7 & 1.3 & 6.7 & 0.4 & 0.0 \\
10 & 1.0 & 21.5 & 50.2 & 8.6 & 2.0 & 10.3 & 0.0 & 5.9 & 0.5 & 0.0 \\
Ave & 1.7 & 14.7 & 49.5 & 10.1 & 0.7 & 17.2 & 1.2 & 4.7 & 0.1 & 0.0 \\
\hline
\end{tabular}


Element Mapping of Bag Sample Cross Sections

FF 2-3C sample, pulled 11-3-05

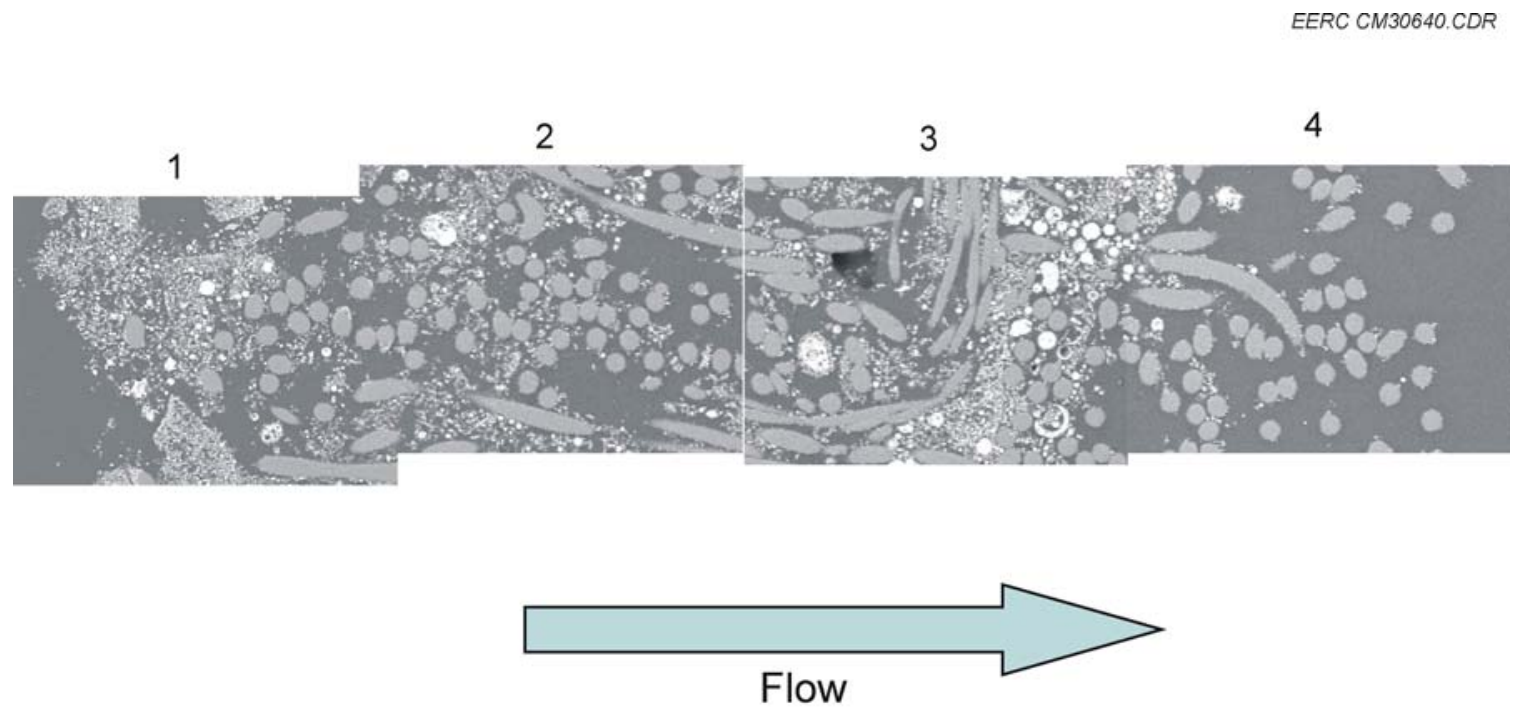

Figure G3-37. Bag cross-section composite image, FF 2-3C sample from 11-3-05. 

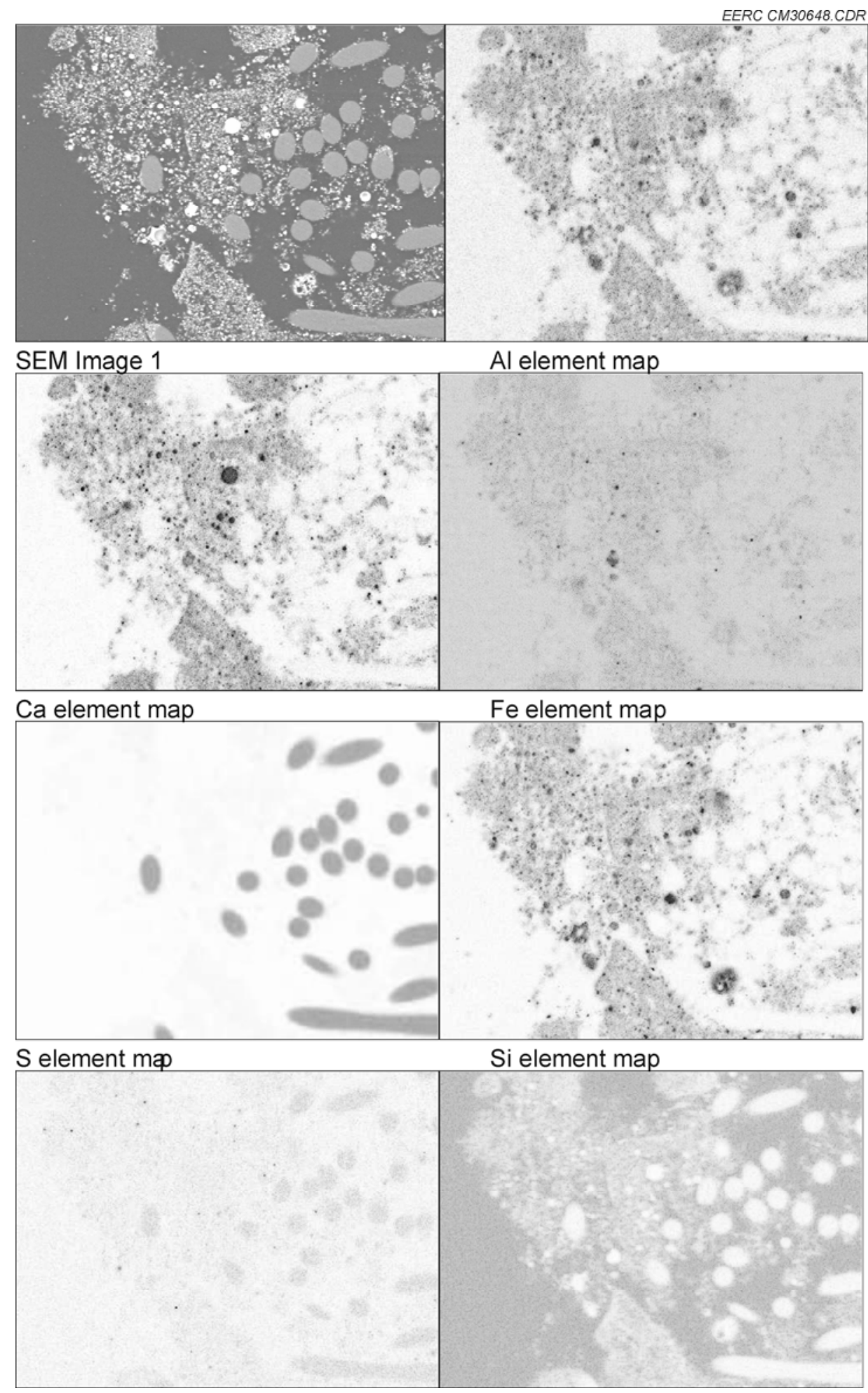

Figure G3-38. Element maps for image number 1 from FF 2-3C sample, 11-3-05. 


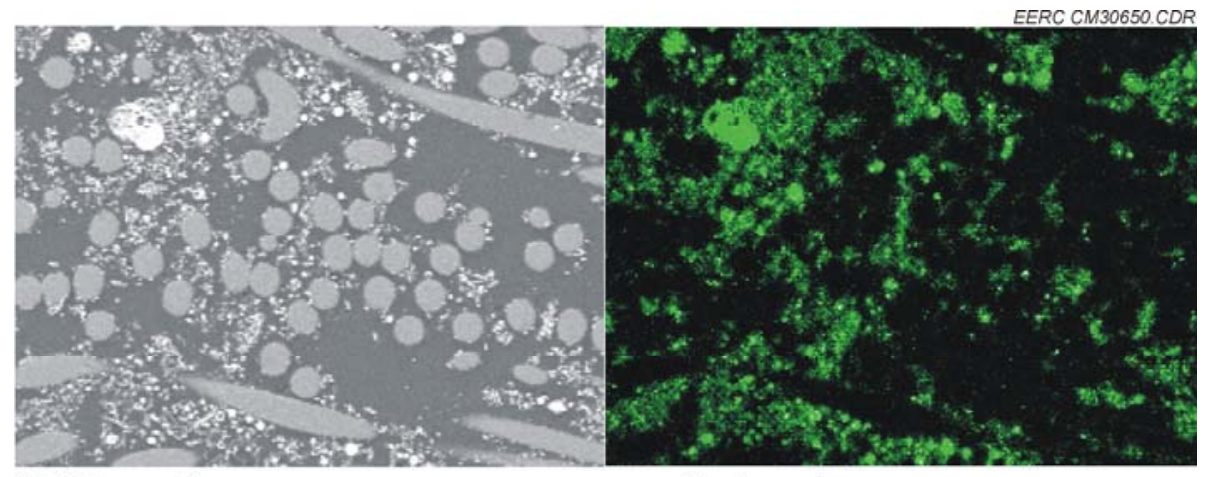

SEM Image 2

$\mathrm{Al}$ element map

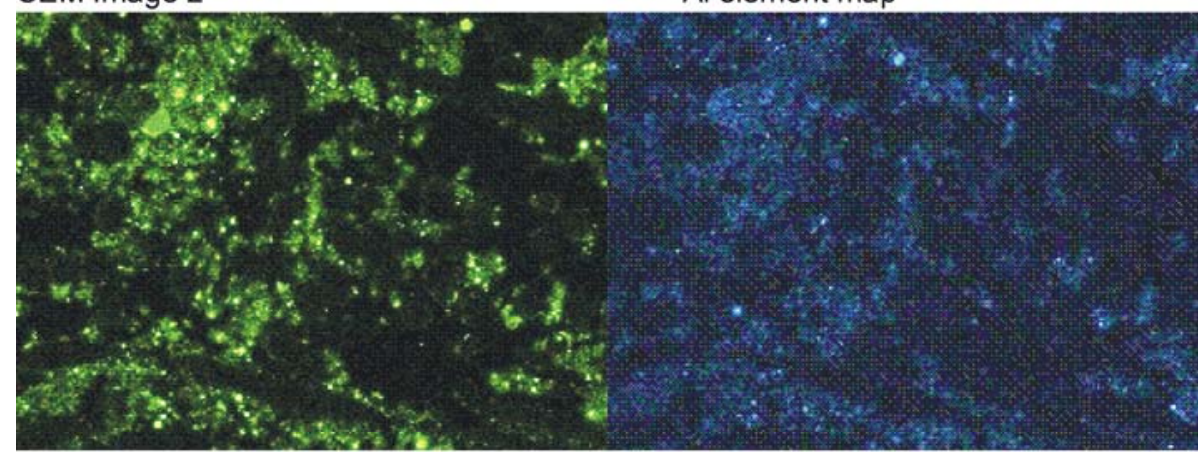

Ca element map

Fe element map

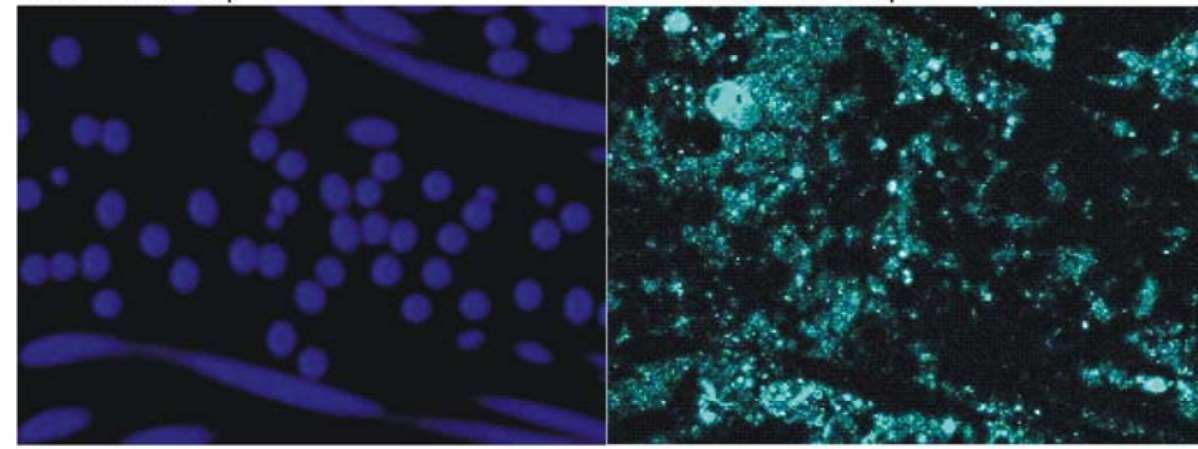

S element map

Si element map

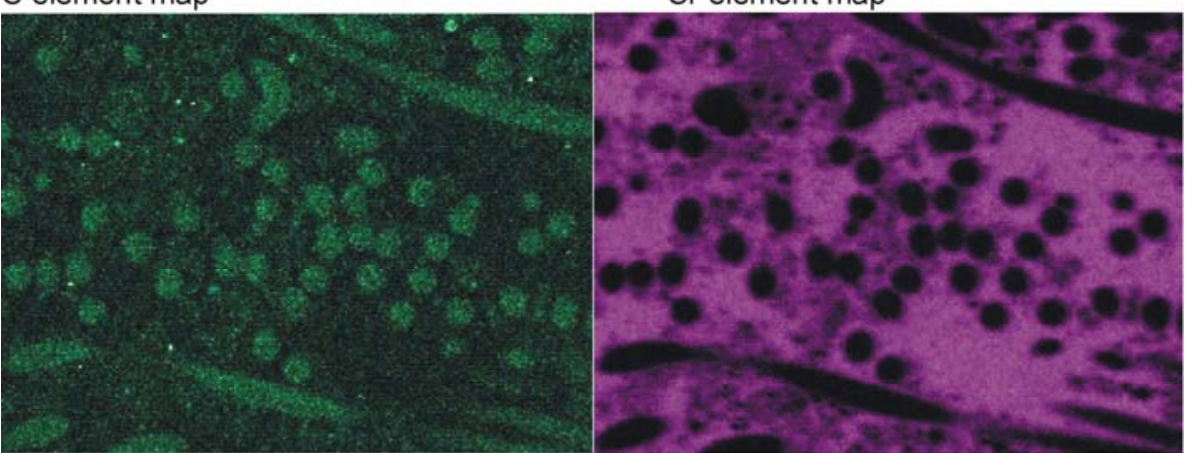

Ti element map

$\mathrm{Cl}$ element map

Figure G3-39. Element maps for image number 2 from FF 2-3C sample, 11-3-05. 

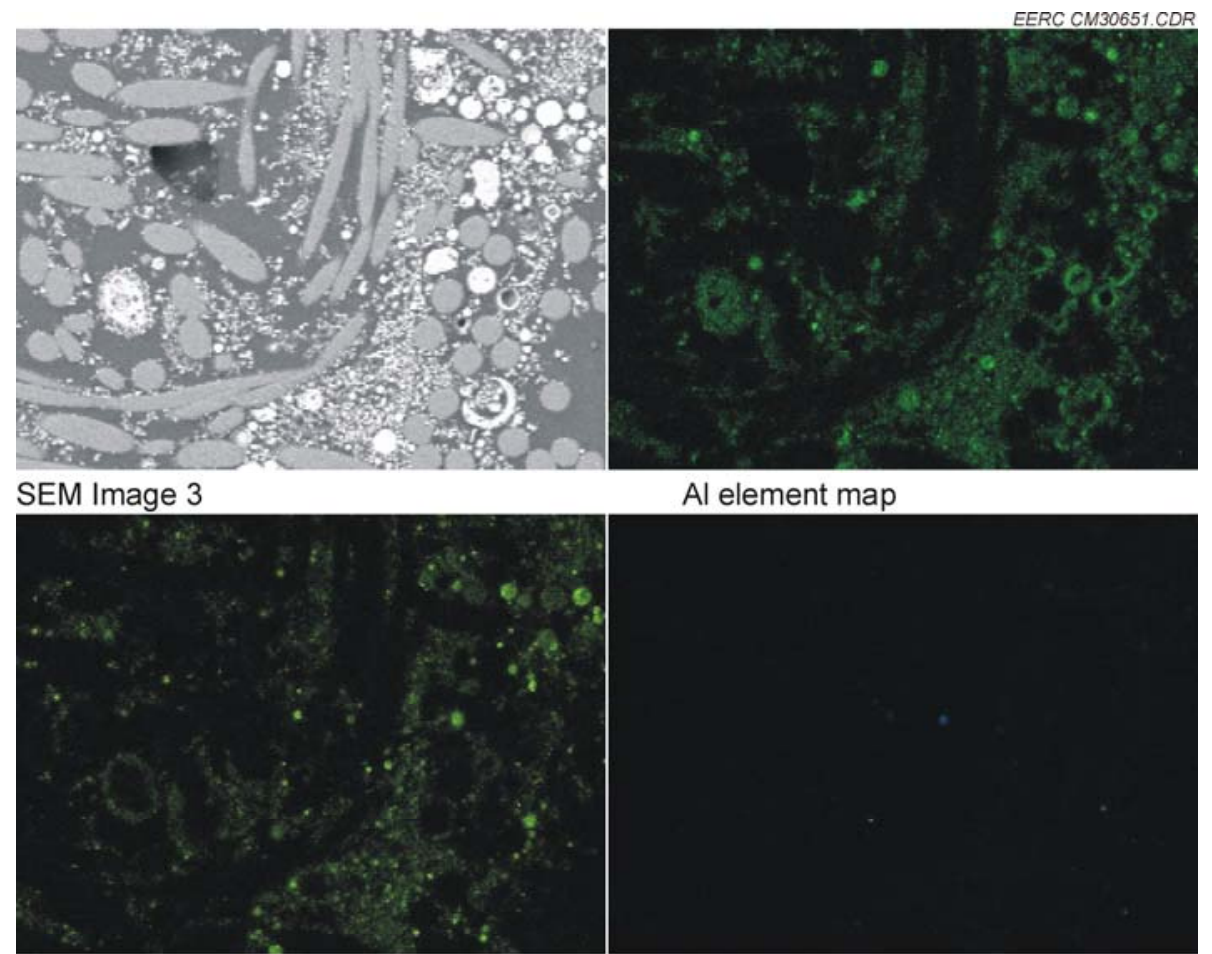

Al element map

Ca element map

Fe element map
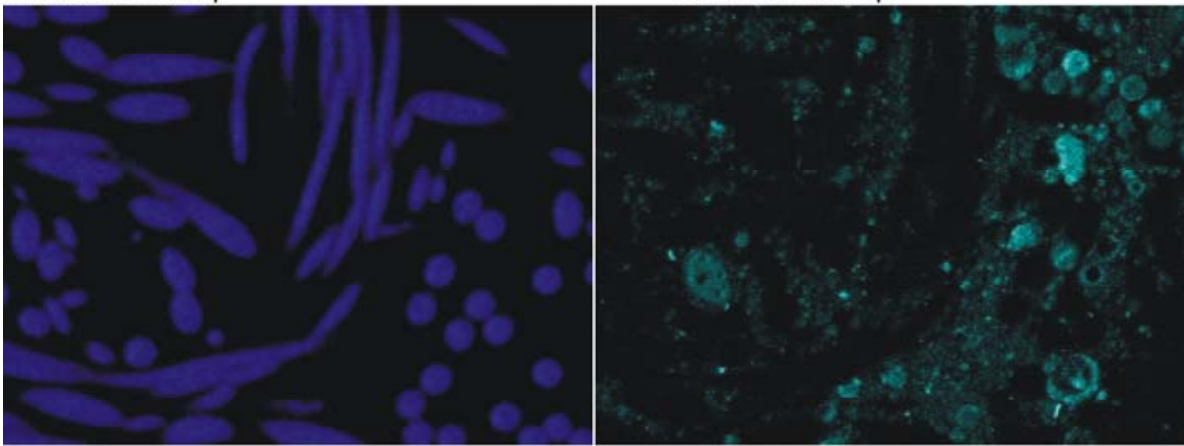

S element map

Si element map

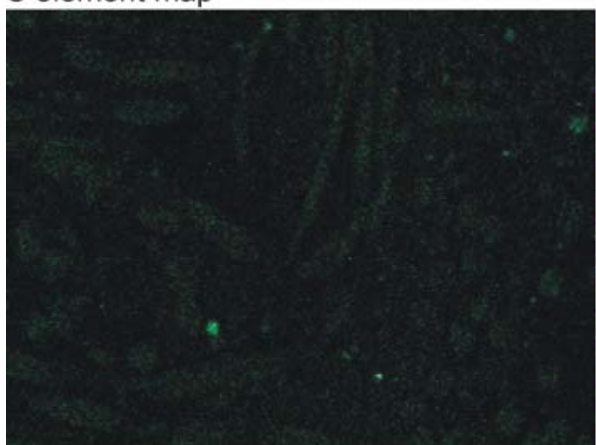

Ti element map

$\mathrm{Cl}$ element map

Figure G3-40. Element maps for image number 3 from FF 2-3C sample, 11-3-05. 

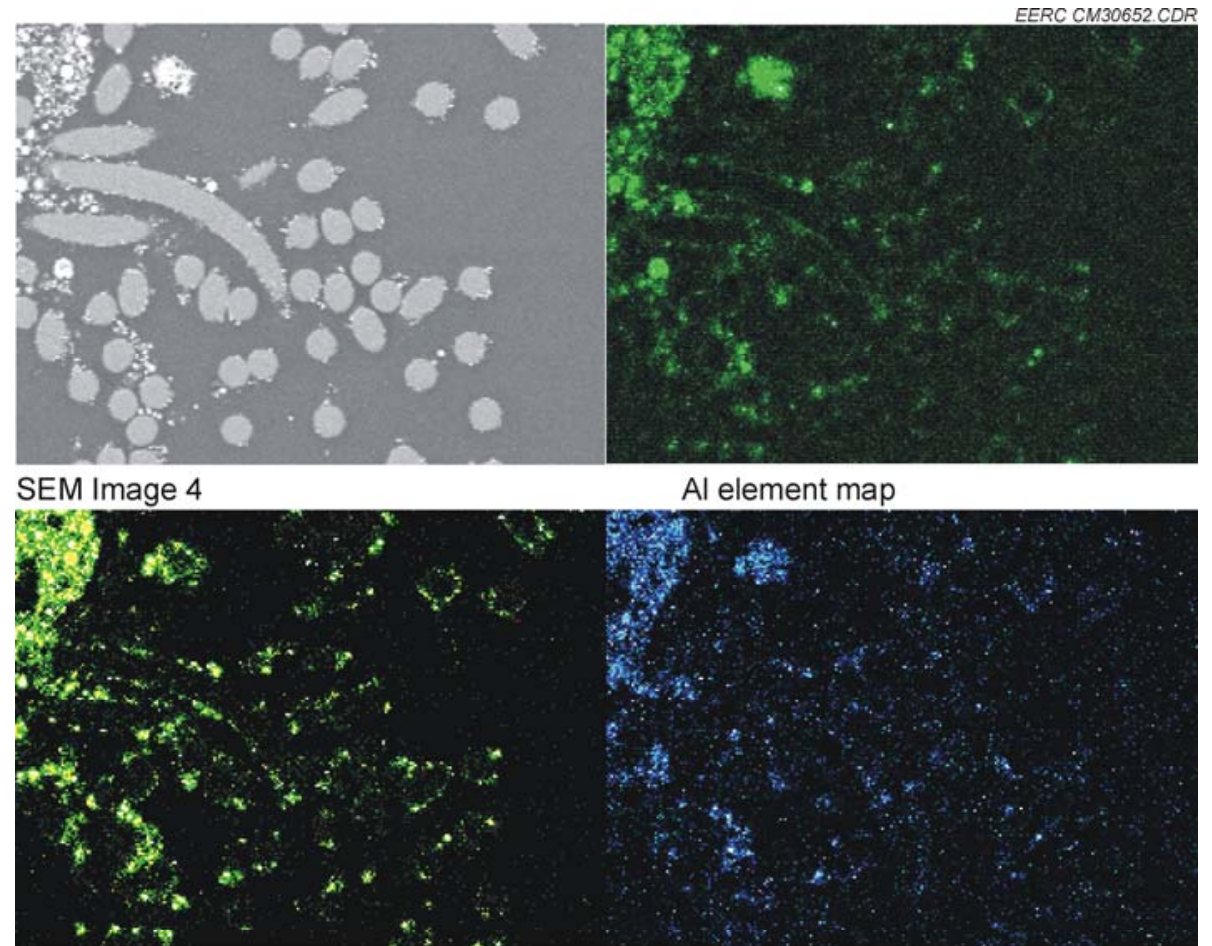

Ca element map

Fe element map

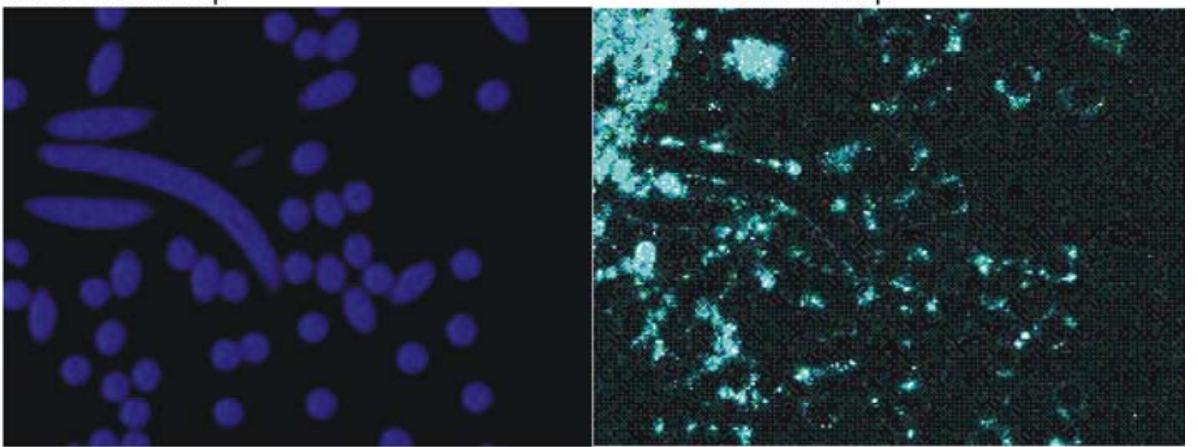

S element map

Si element map

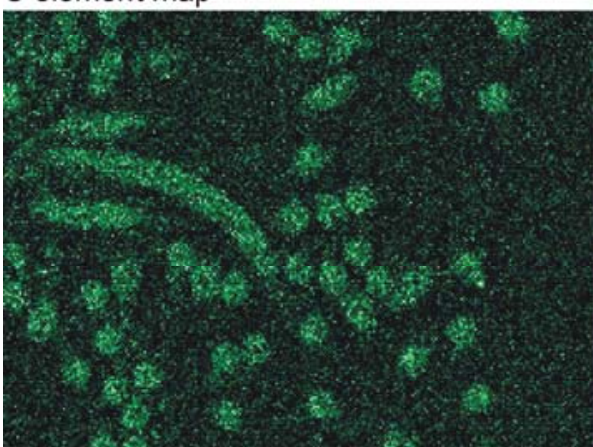

Ti element map

$\mathrm{Cl}$ element map

Figure G3-41. Element maps for image number 4 from FF 2-3C sample, 11-3-05. 
FF 2-4C sample, pulled 11-3-05

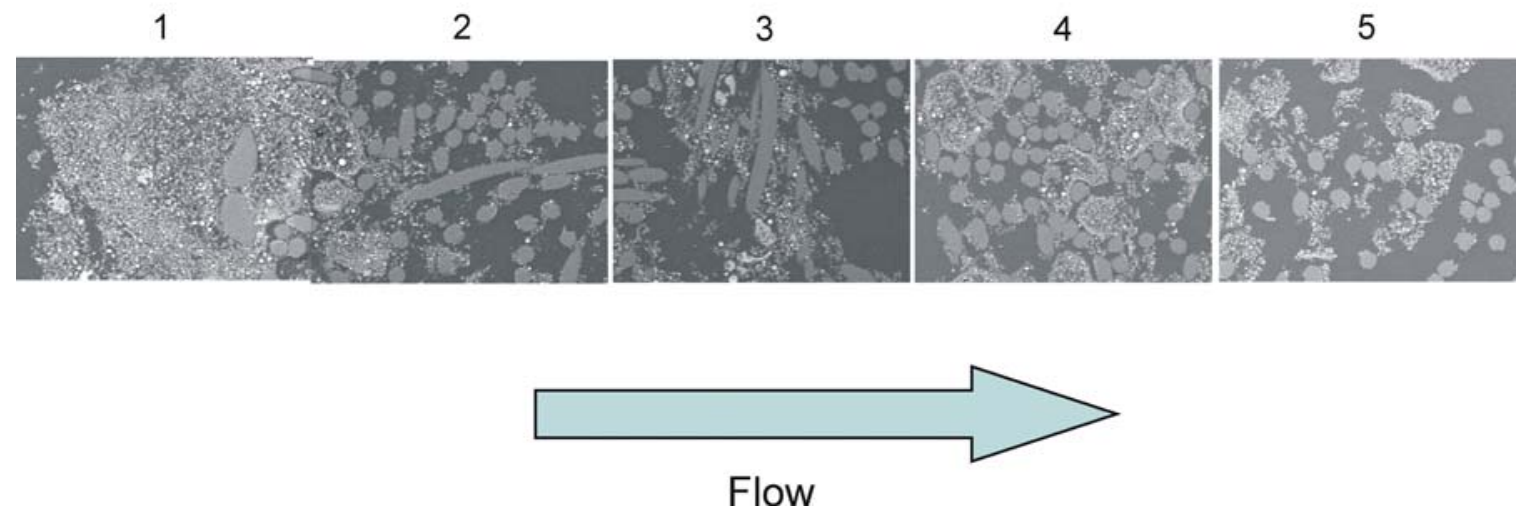

Figure G3-42. Bag cross-section composite image, FF 2-4C sample from 11-3-05. 


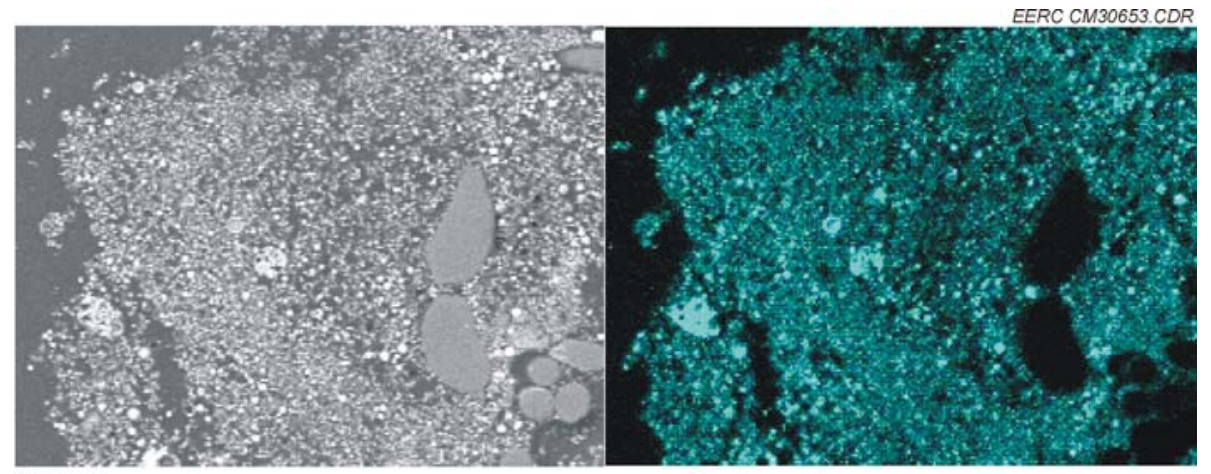

SEM Image 1

Al element map

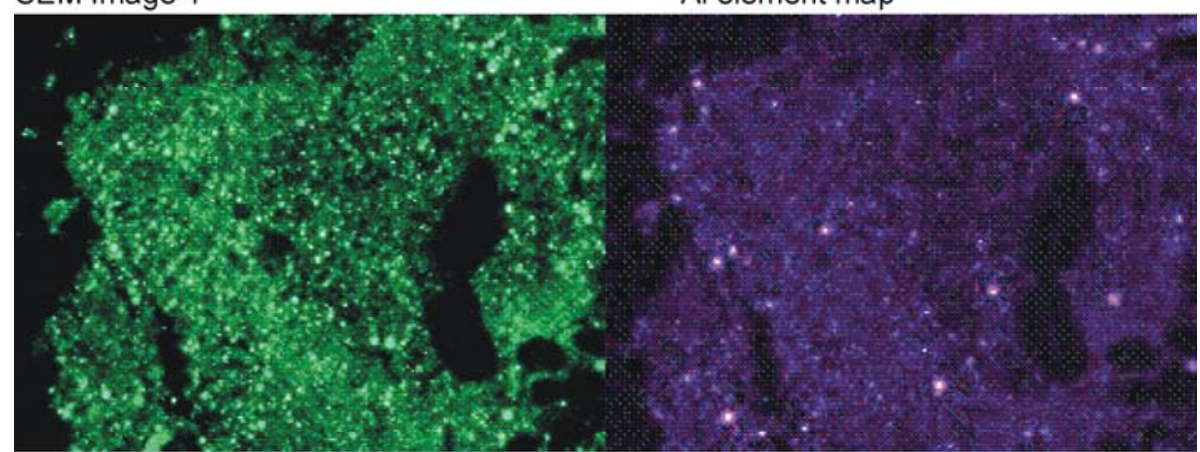

Ca element map

Fe element map

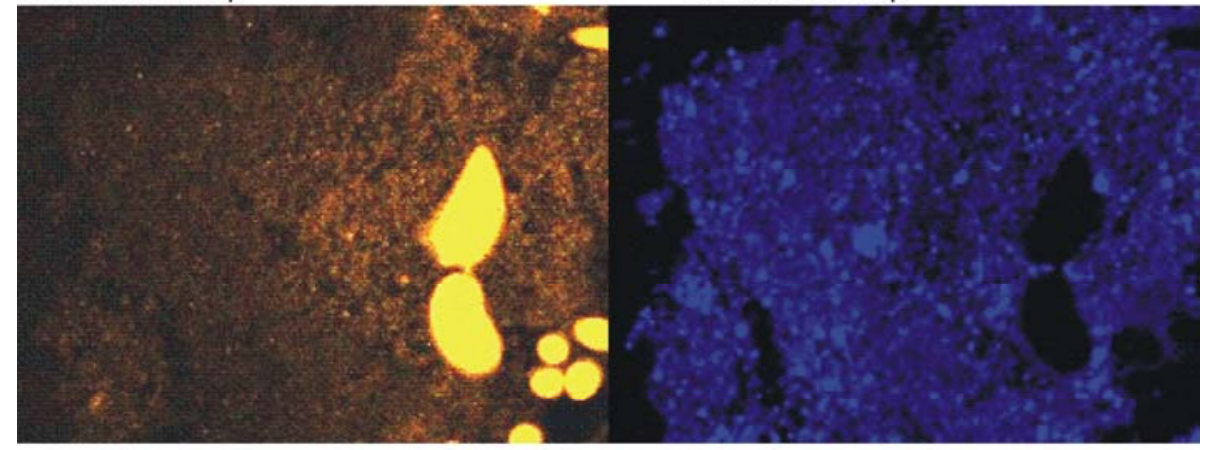

S element map

Si element map

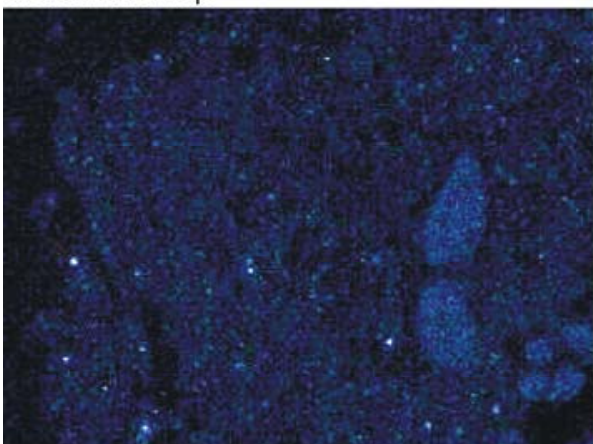

Ti element map

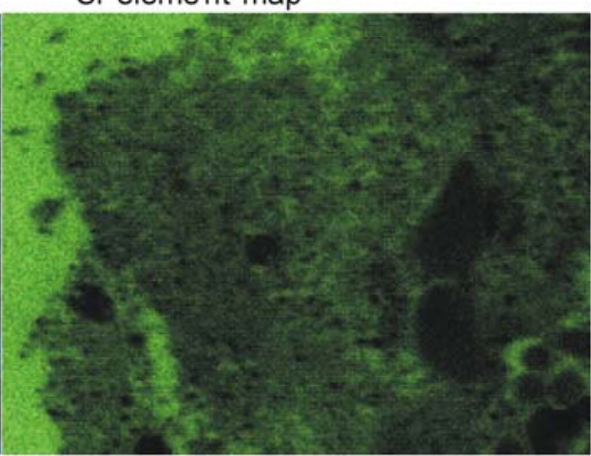

$\mathrm{Cl}$ element map

Figure G3-43. Element maps for image number 1 from FF 2-4C sample, 11-3-05. 

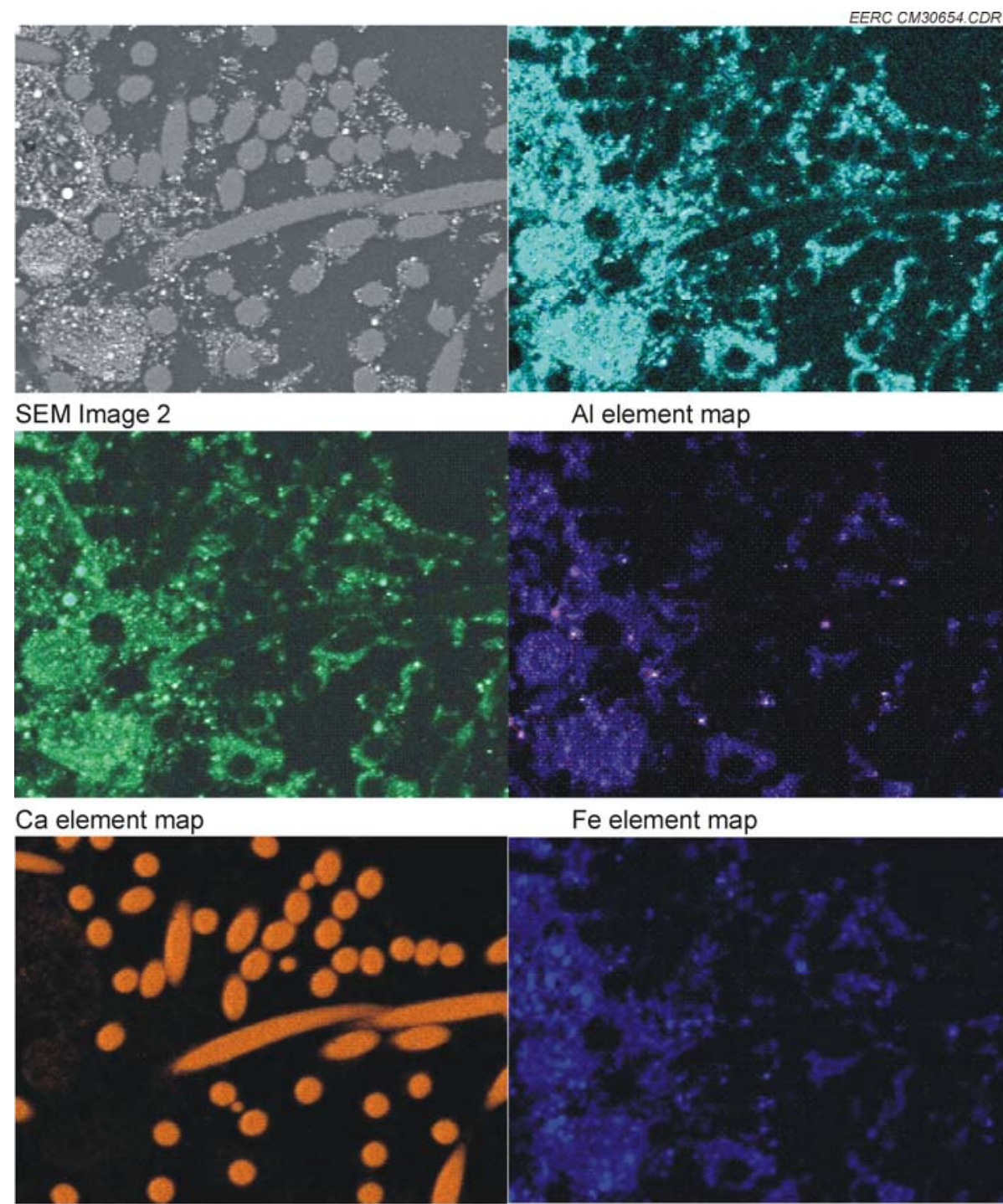

S element map

Si element map

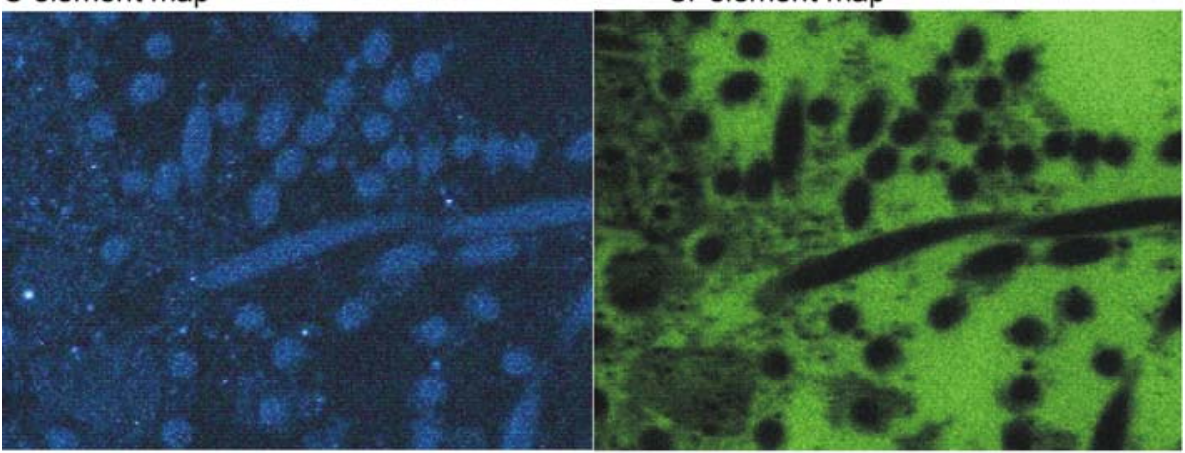

Ti element map

$\mathrm{Cl}$ element map

Figure G3-44. Element maps for image number 2 from FF 2-4C sample, 11-3-05. 

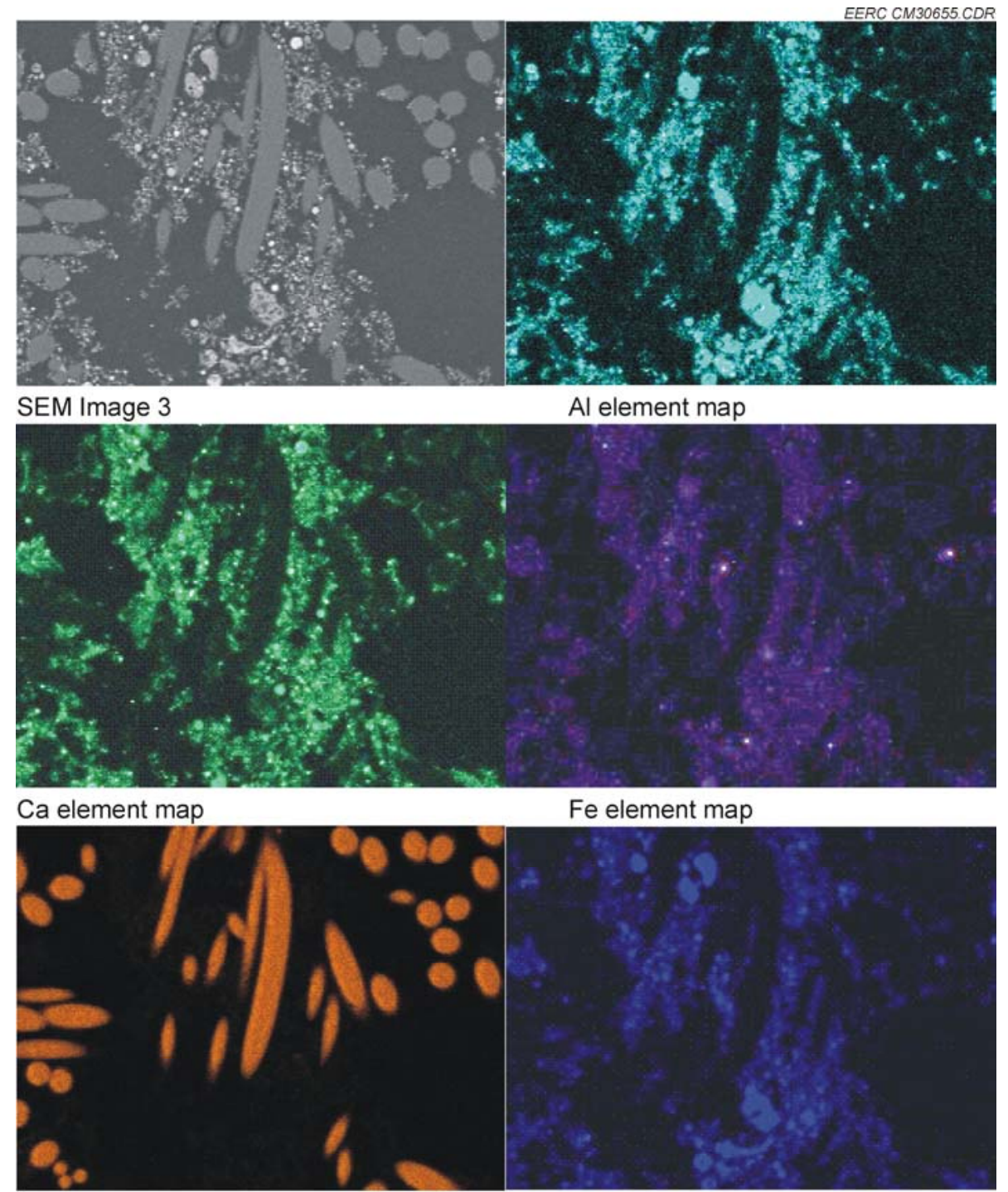

Fe element map

S element map

Si element map

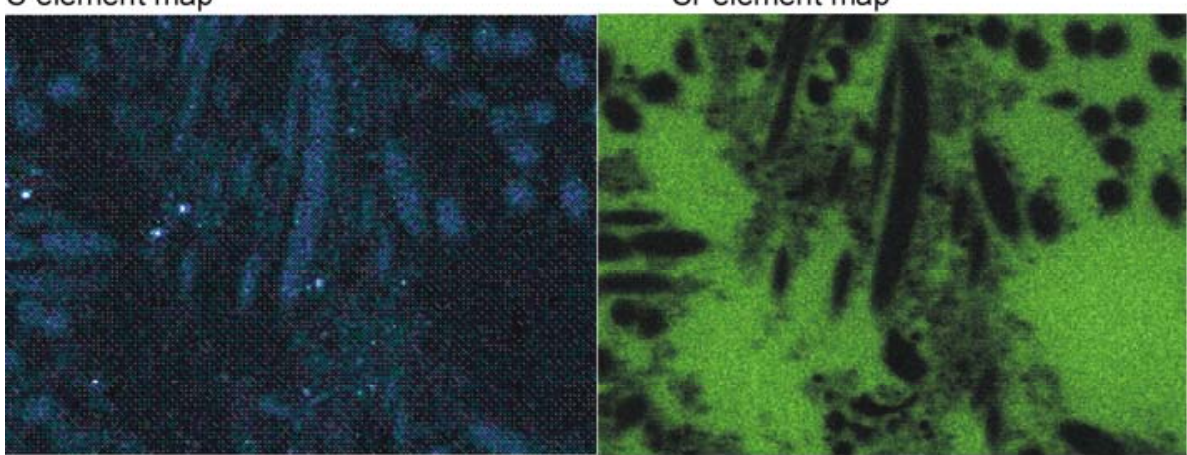

Ti element map

$\mathrm{Cl}$ element map

Figure G3-45. Element maps for image number 3 from FF 2-4C sample, 11-3-05. 


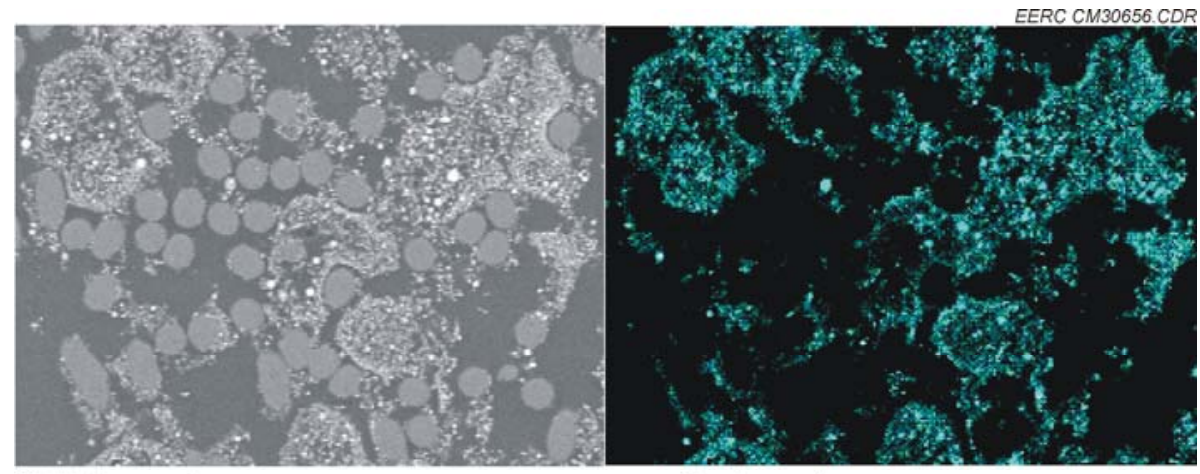

SEM Image 4

Al element map

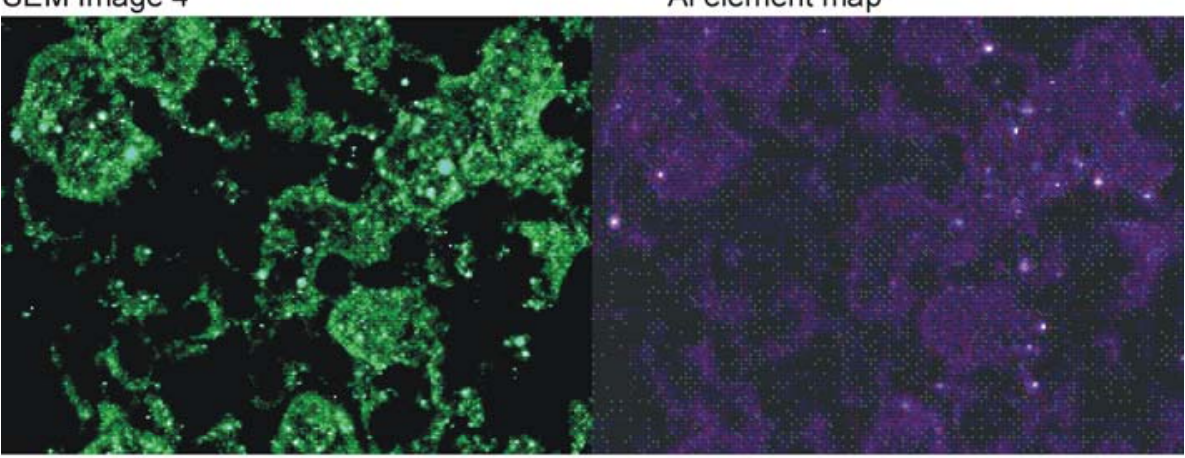

Ca element map

Fe element map

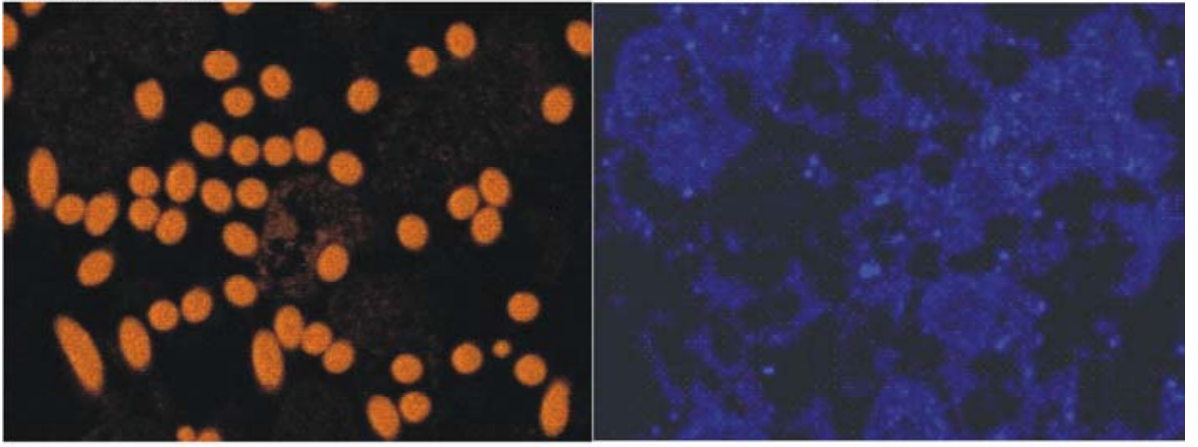

S element map

Si element map

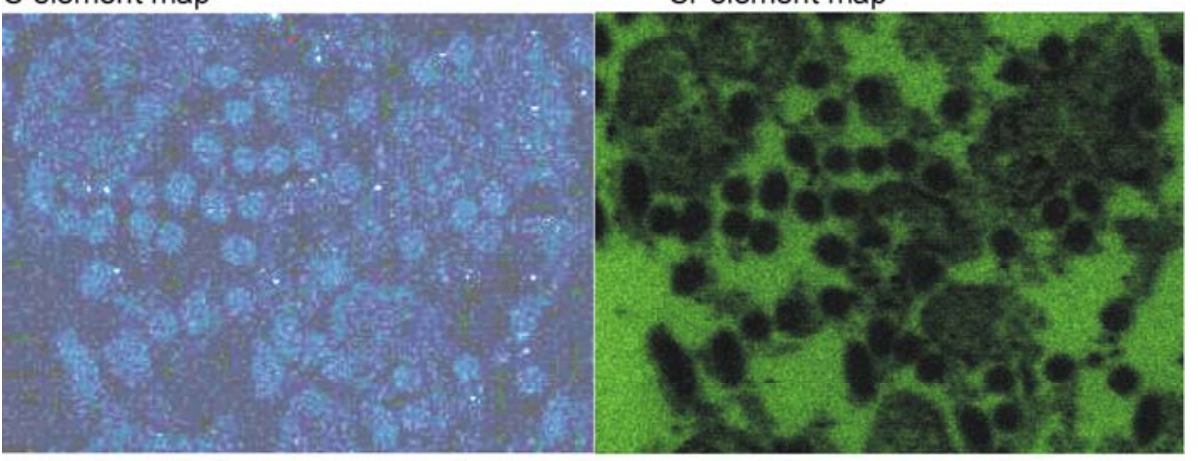

Ti element map

$\mathrm{Cl}$ element map

Figure G3-46. Element maps for image number 4 from FF 2-4C sample, 11-3-05. 


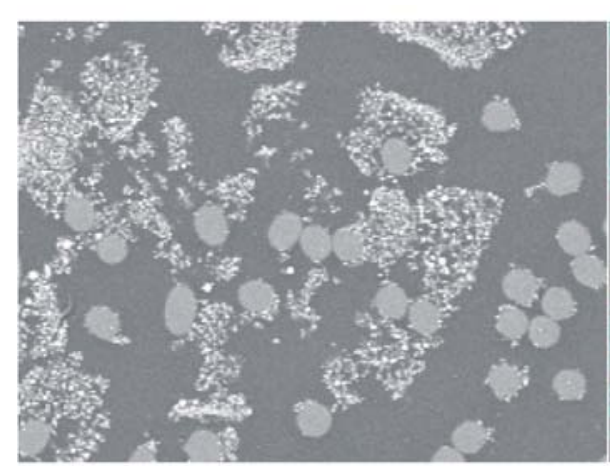

SEM Image 5

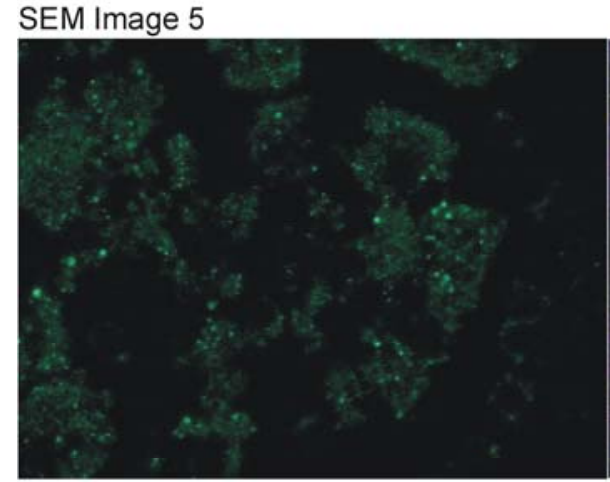

Ca element map

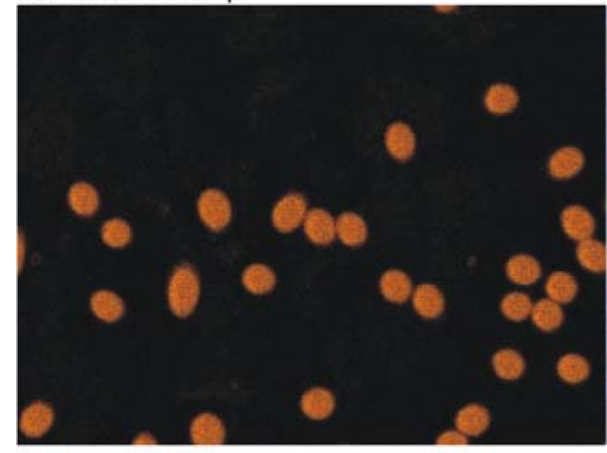

S element map

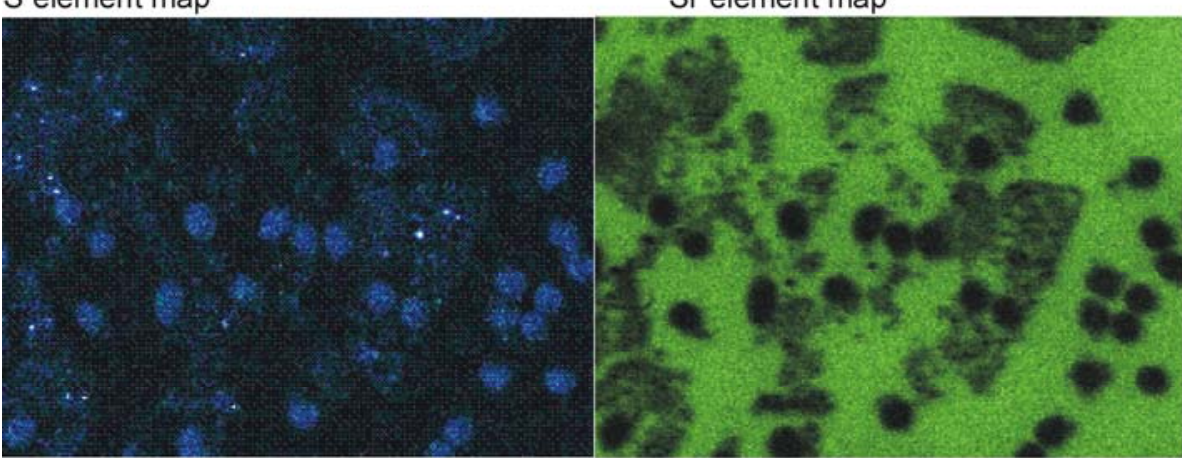

Ti element map

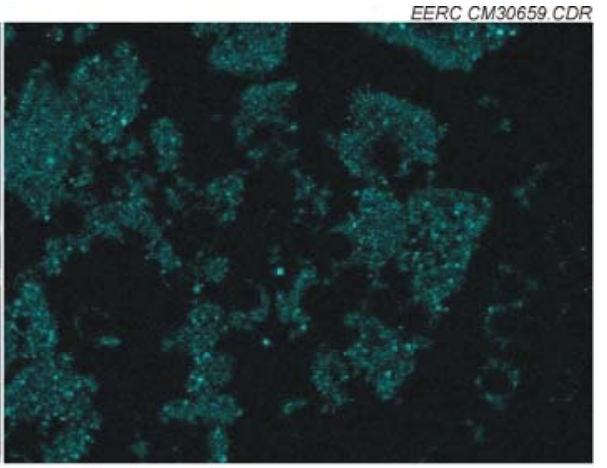

Al element map

Fe element map

Figure G3-47. Element maps for image number 5 from FF 2-4C sample, 11-3-05. 
FF 2-3C sample, pulled 3-30-06

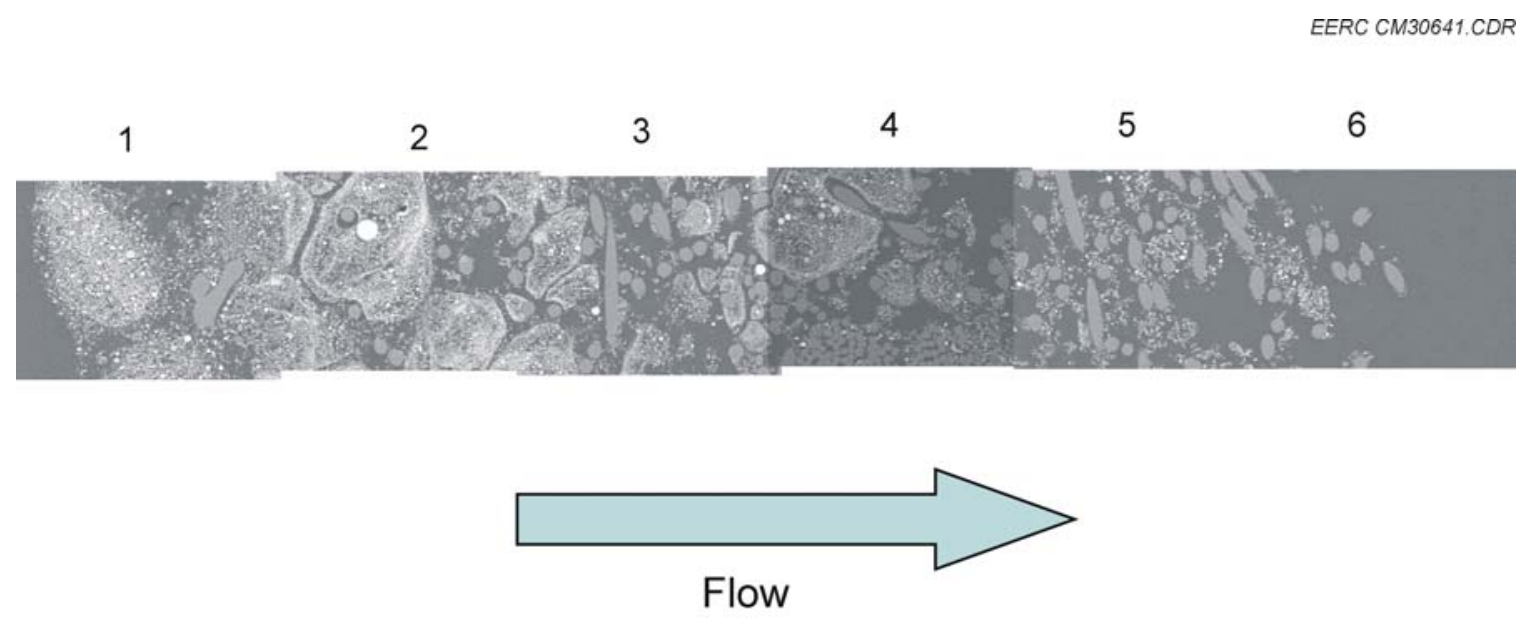

Figure G3-48. Bag cross-section composite image, FF 2-3C sample from 3-30-06. 


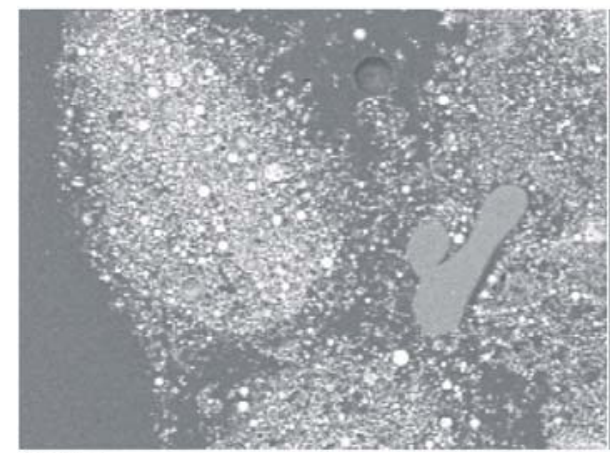

SEM Image 1

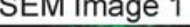

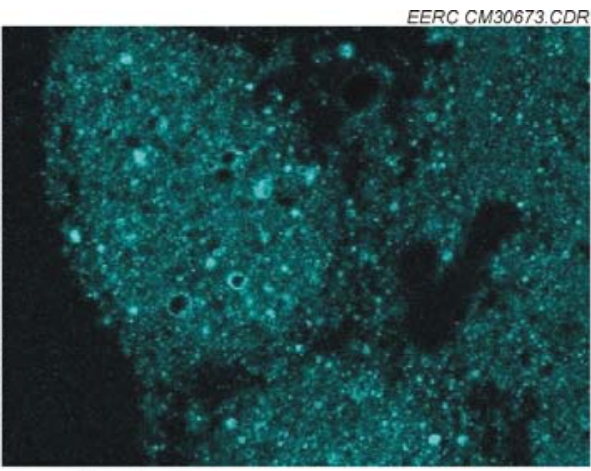

Al element map

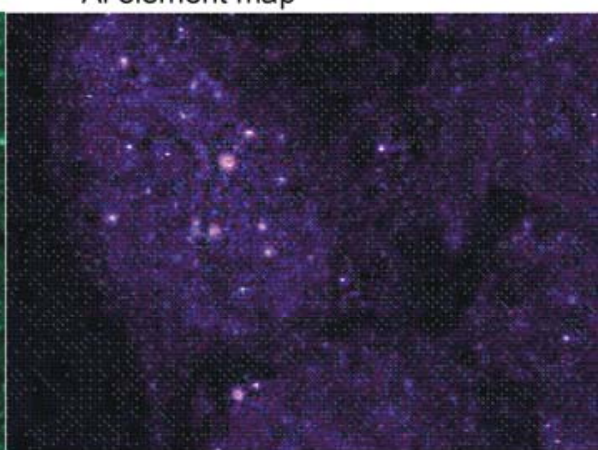

Fe element map

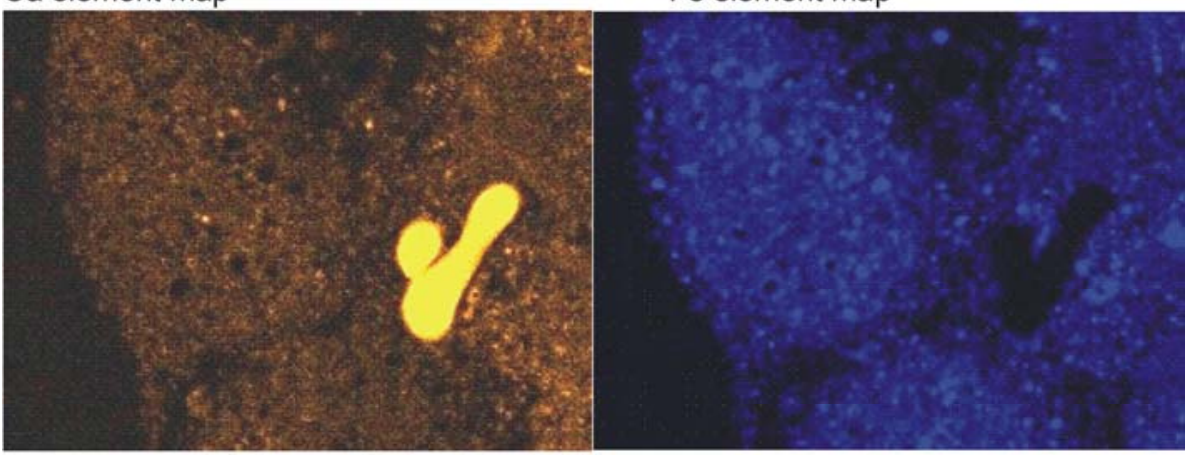

S element map

Si element map

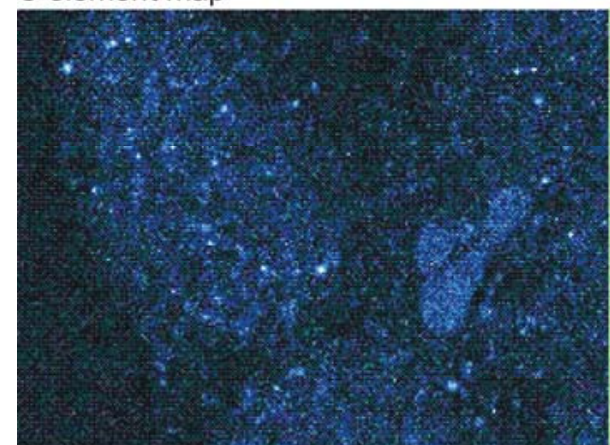

Ti element map

$\mathrm{Cl}$ element map

Figure G3-49. Element maps for image number 1 from FF 2-3C sample, 3-30-06. 


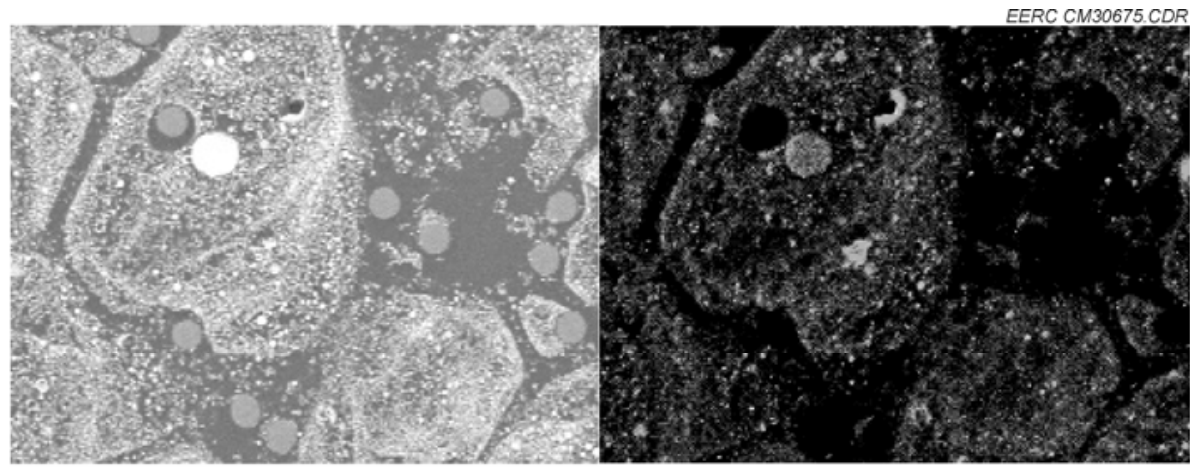

SEM Image 2

Al element map

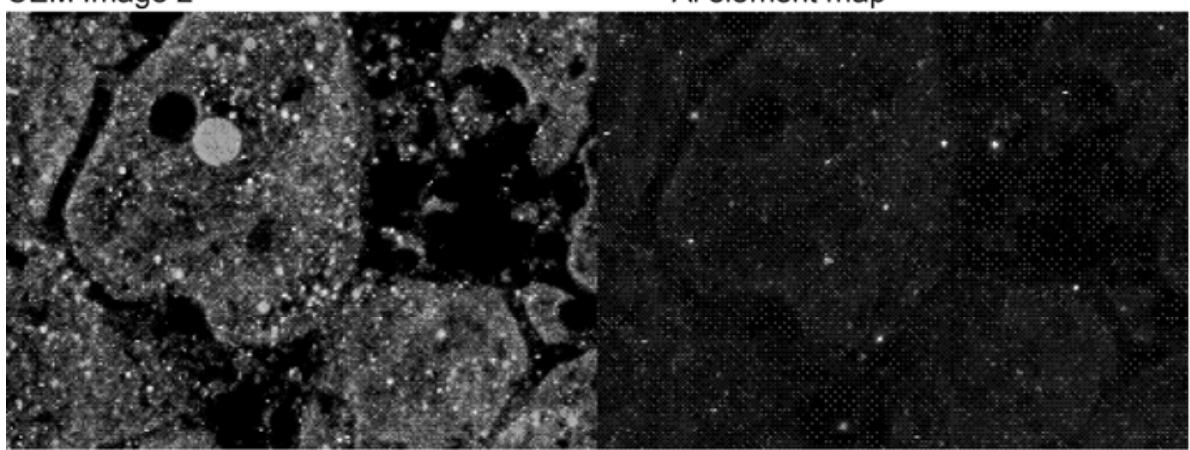

Ca element map

Fe element map

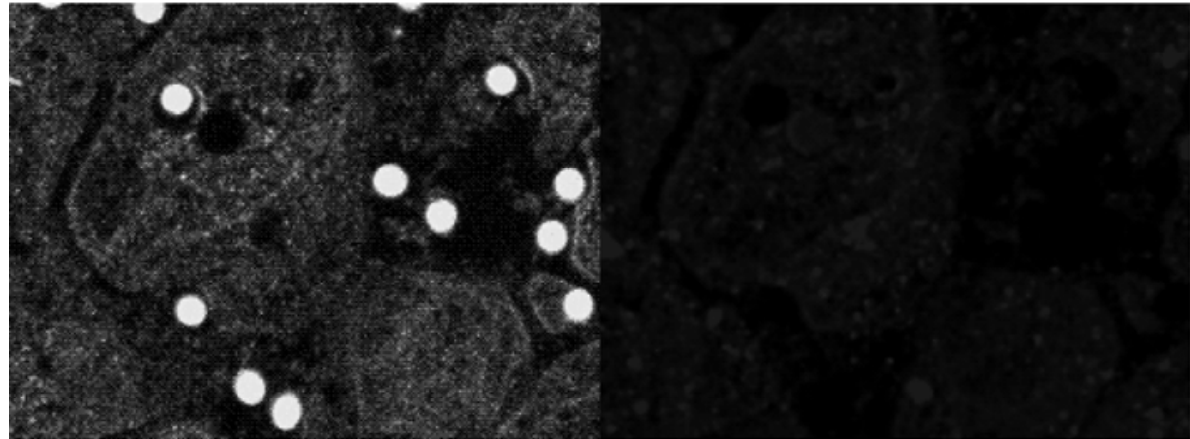

S element map

Si element map

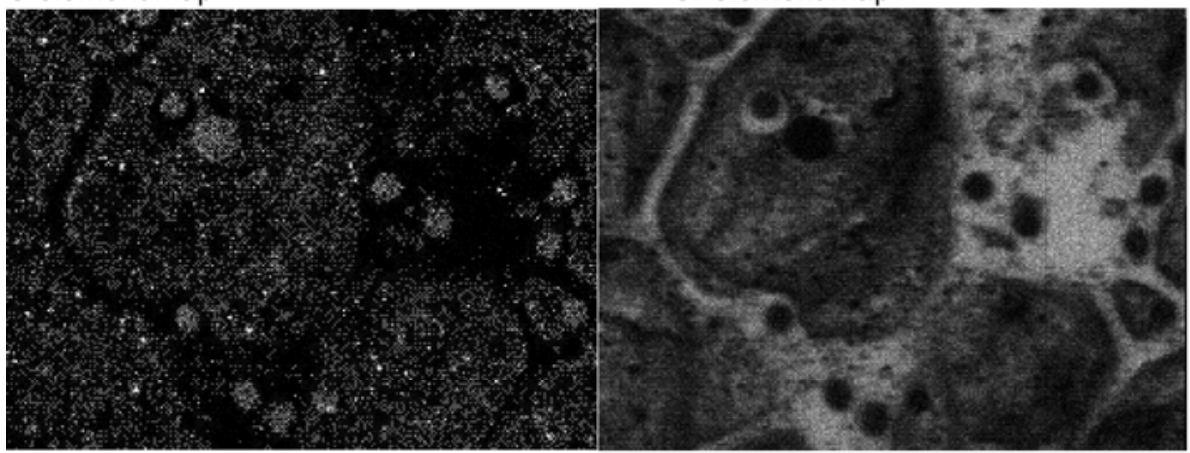

Ti element map

$\mathrm{Cl}$ element map

Figure G3-50. Element maps for image number 2 from FF 2-3C sample, 3-30-06. 


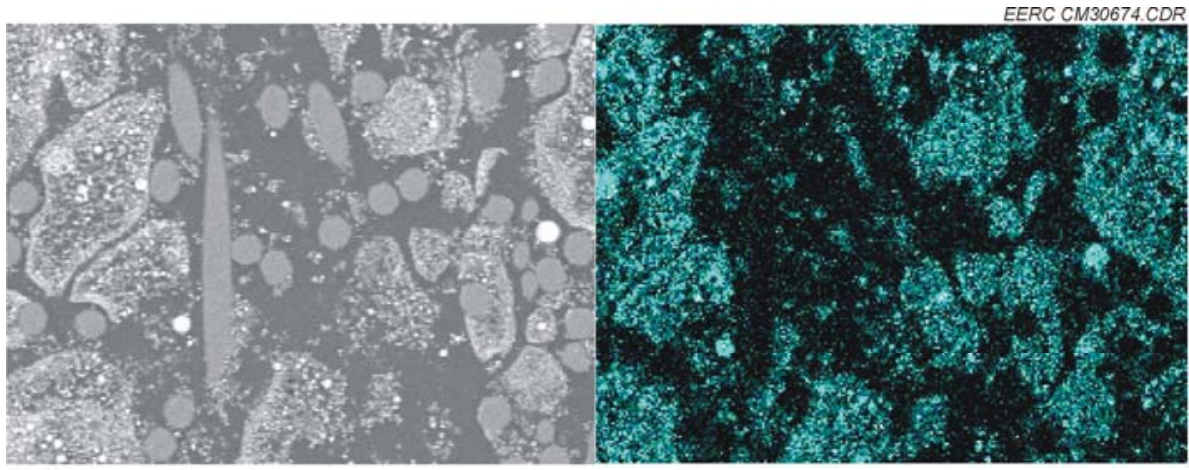

SEM Image 3

Al element map

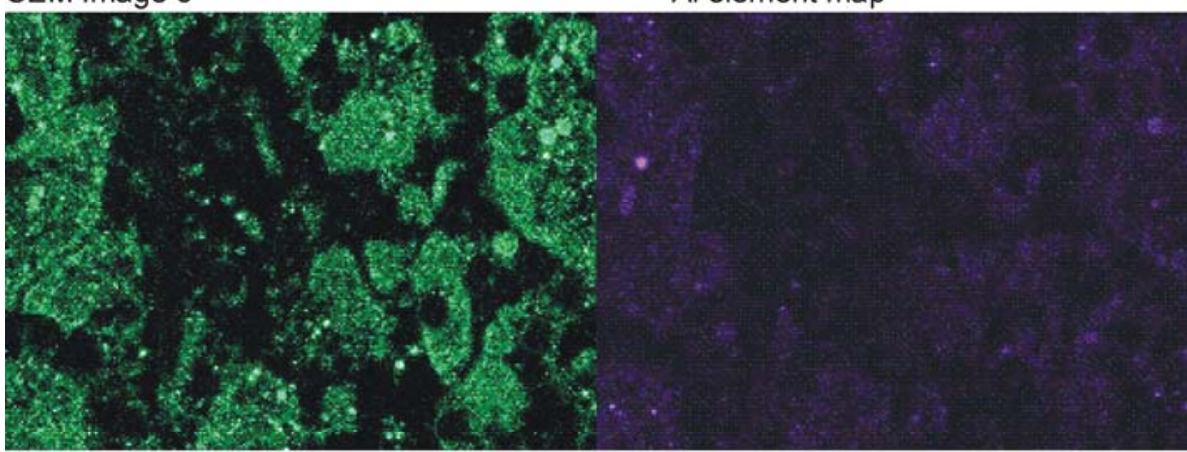

Ca element map

Fe element map

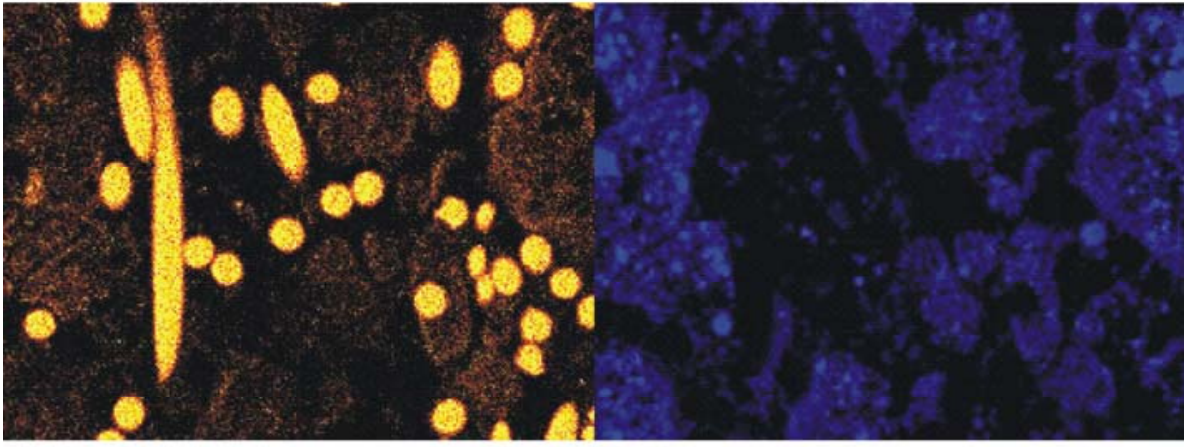

S element map

Si element map

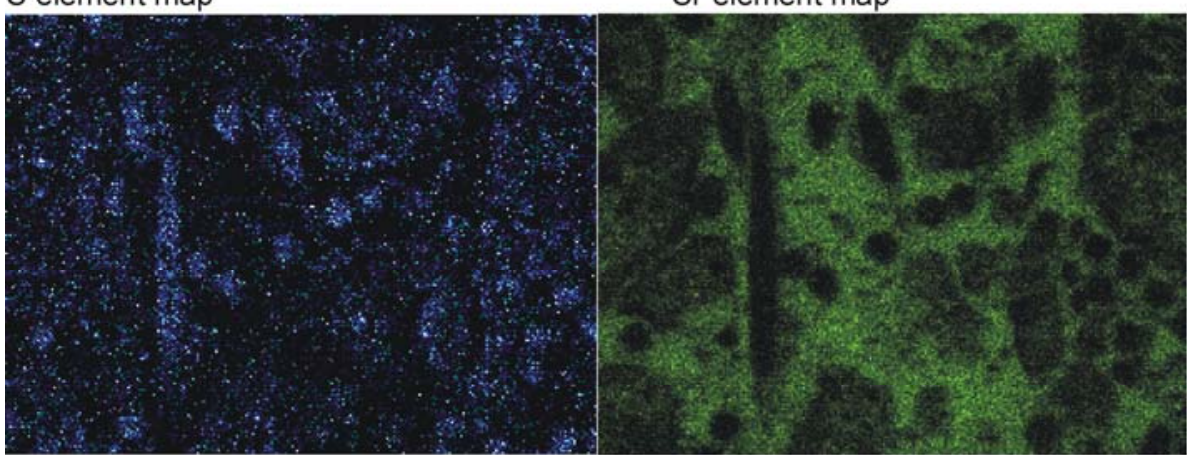

Ti element map

$\mathrm{Cl}$ element map

Figure G3-51. Element maps for image number 3 from FF 2-3C sample, 3-30-06. 

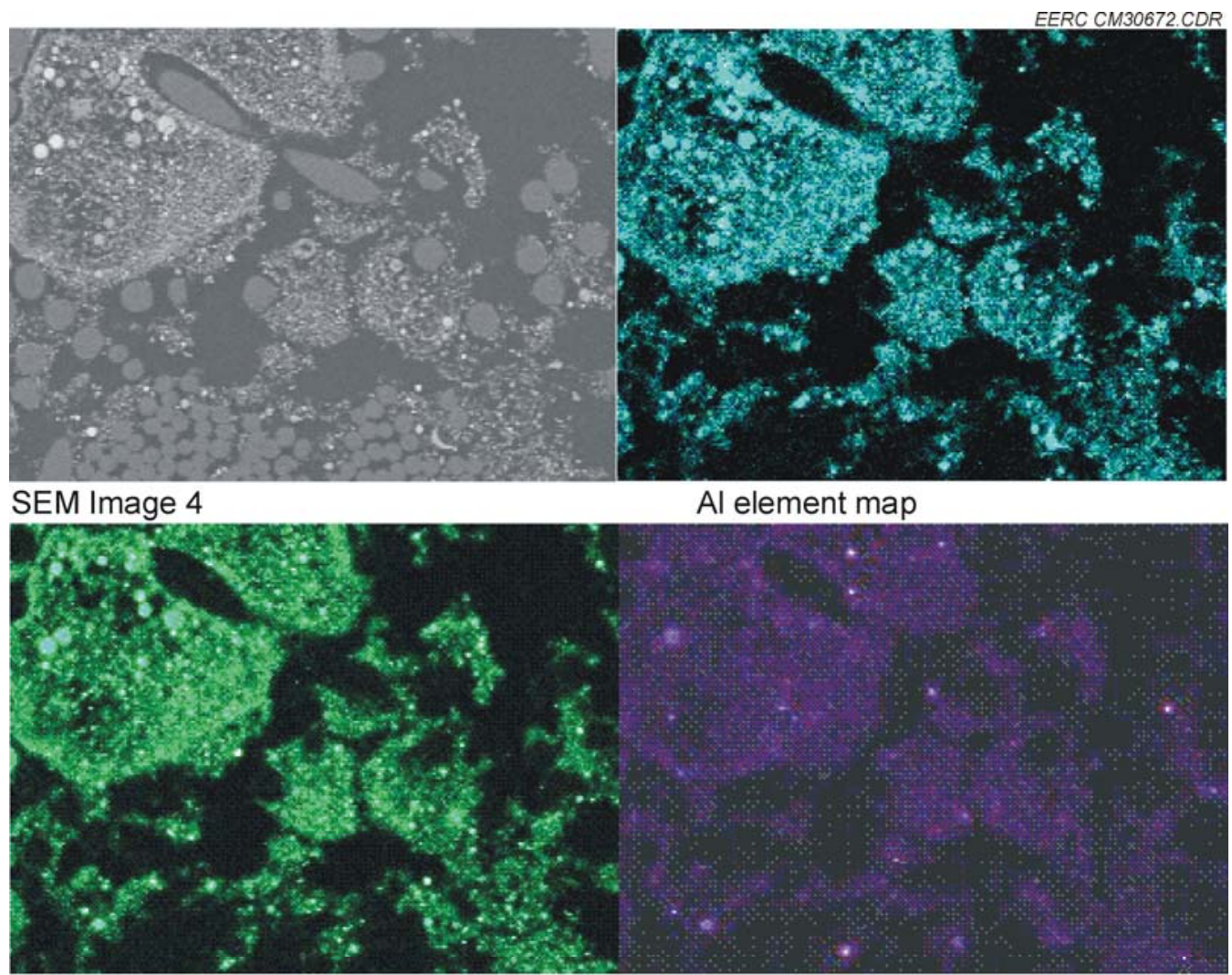

Al element map

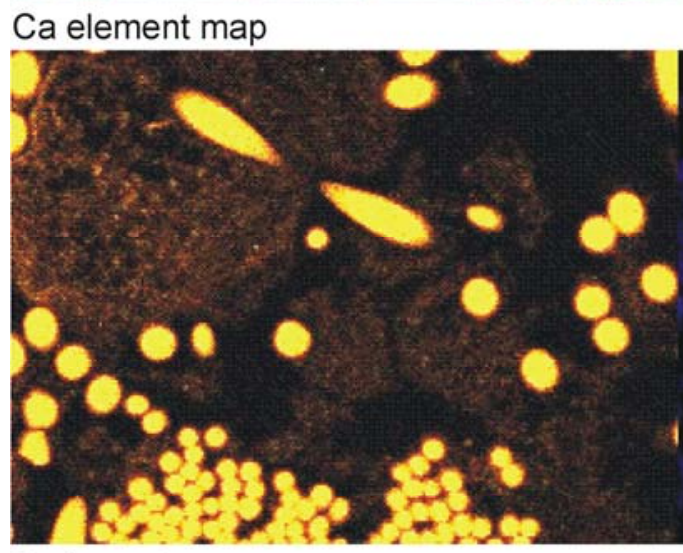

S element map

Si element map

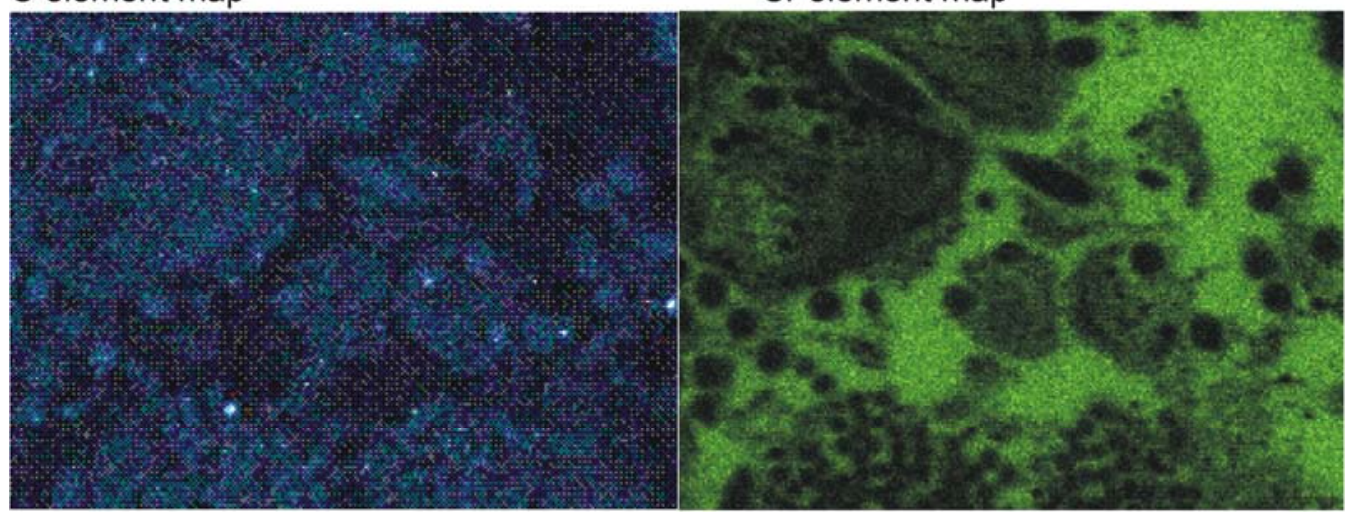

Ti element map

$\mathrm{Cl}$ element map

Fe element map

Figure G3-52. Element maps for image number 4 from FF 2-3C sample, 3-30-06. 


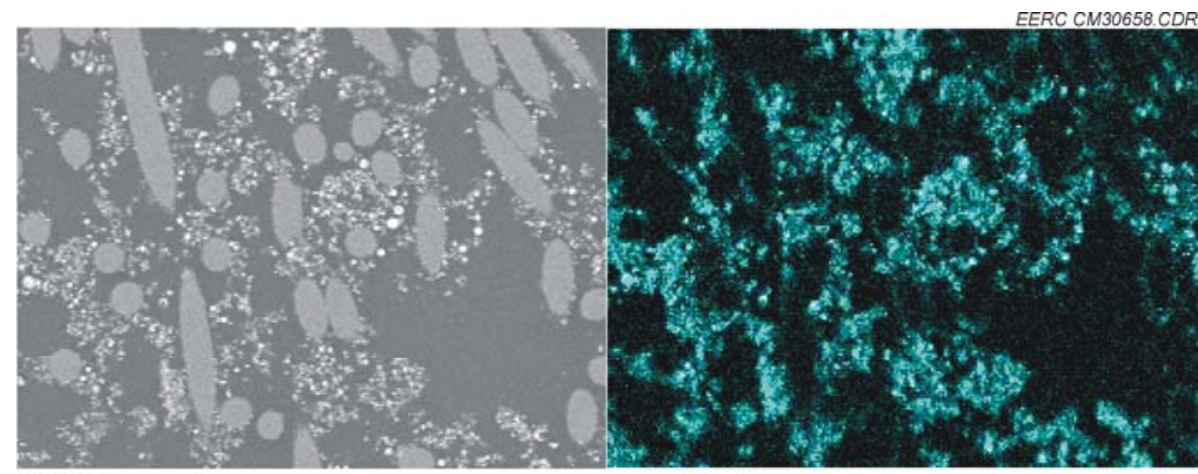

SEM Image 5

Al element map

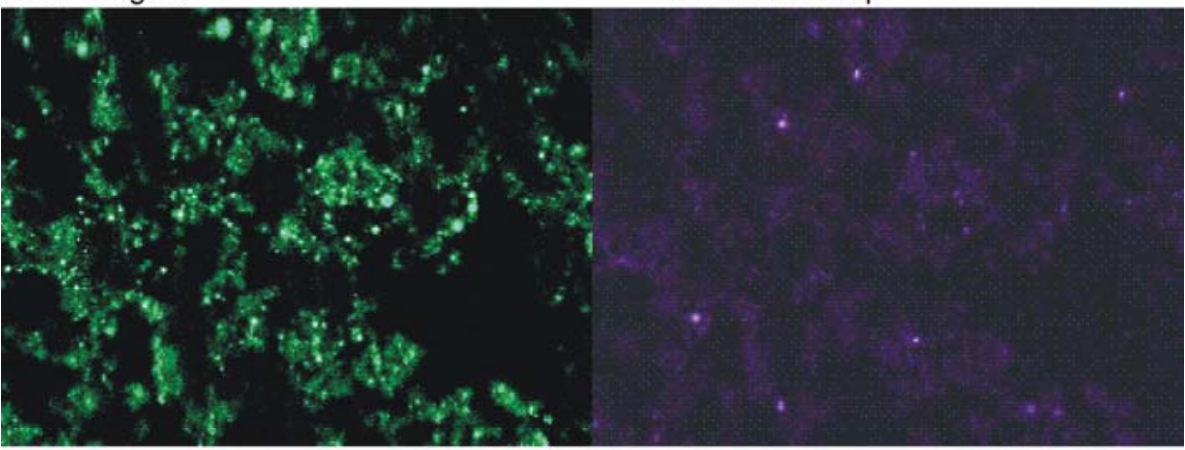

Ca element map

Fe element map

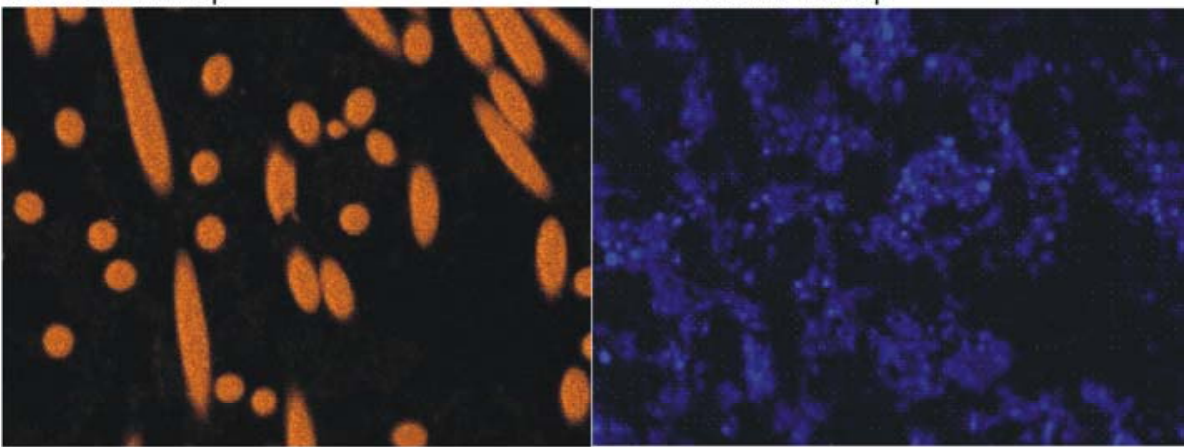

S element map

Si element map

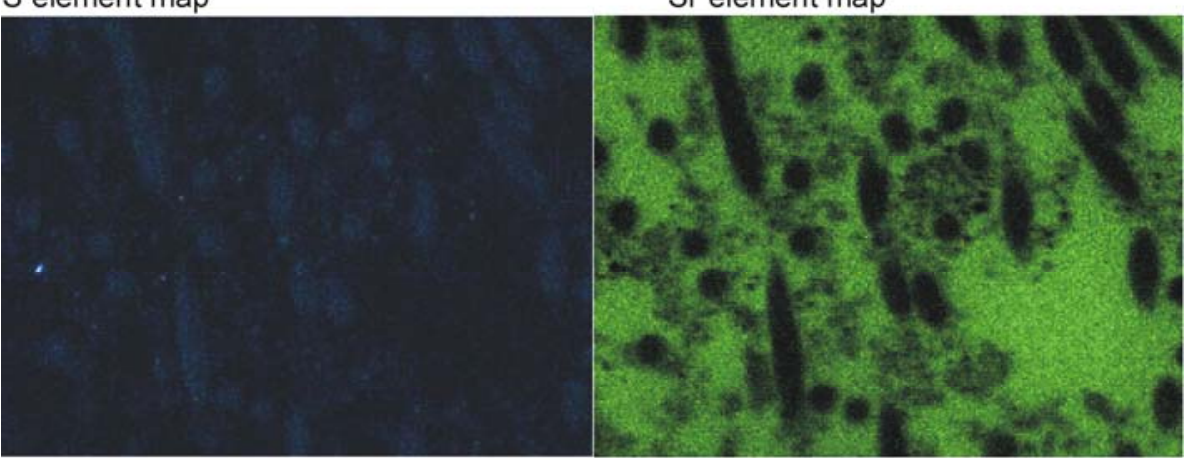

Ti element map

$\mathrm{Cl}$ element map

Figure G3-53. Element maps for image number 5 from FF 2-3C sample, 3-30-06. 


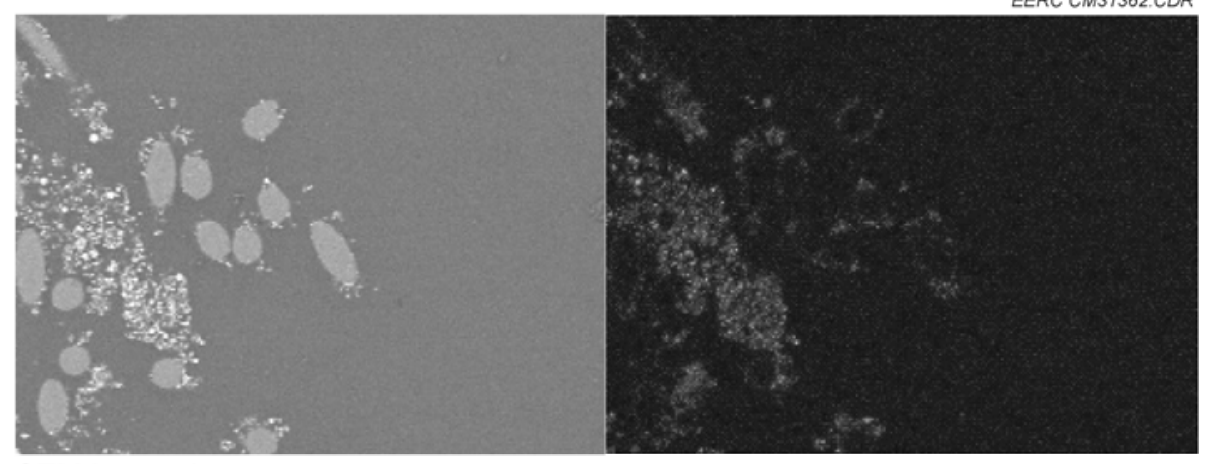

SEM Image 6

Al Element Map

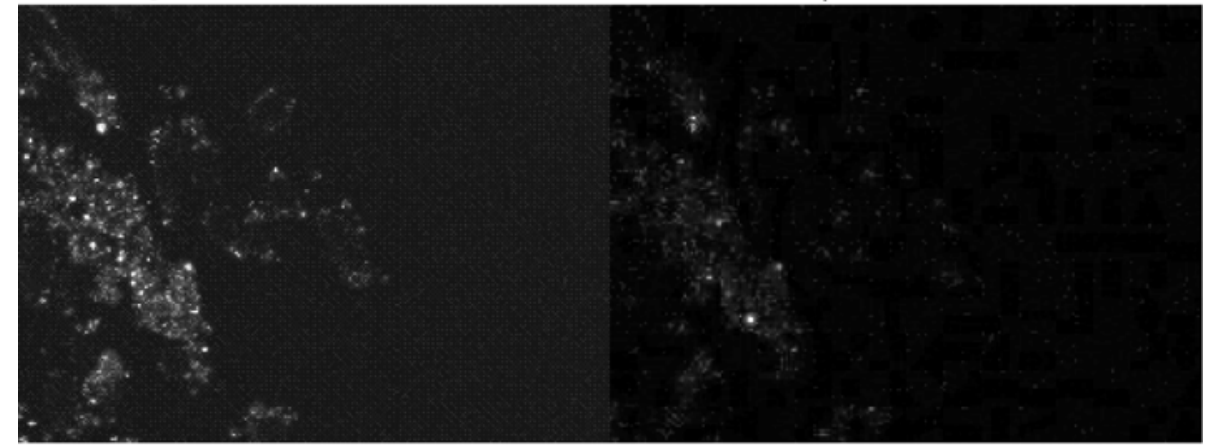

Ca Element Map

Fe Element Map

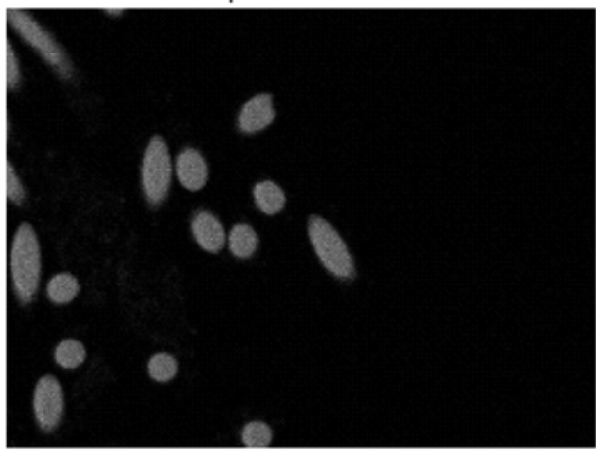

S Element Map

Si Element Map

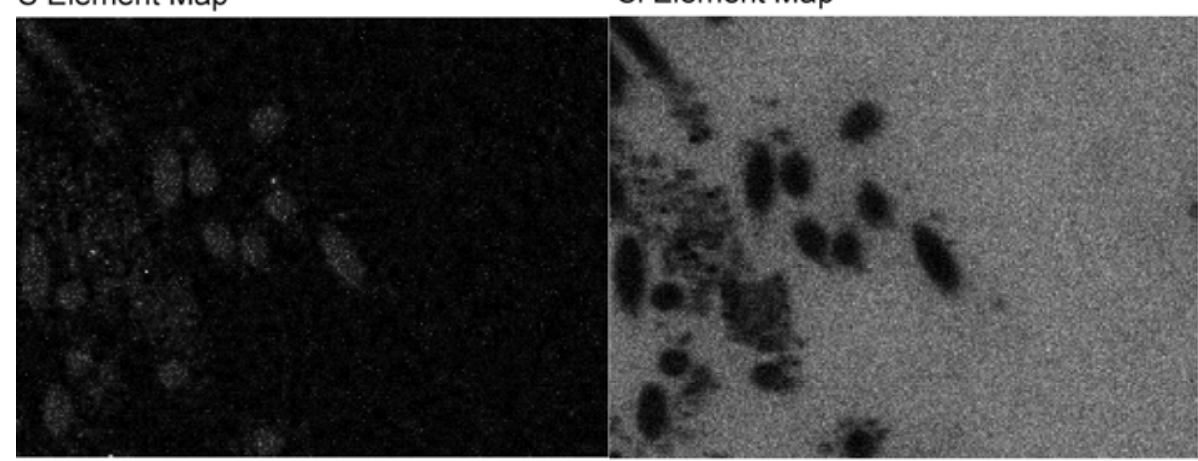

Ti Element Map

Cl Element Map

Figure G3-54. Element maps for image number 6 from FF 2-3C sample, 3-30-06. 
FF 2-4C sample, pulled 3-30-06

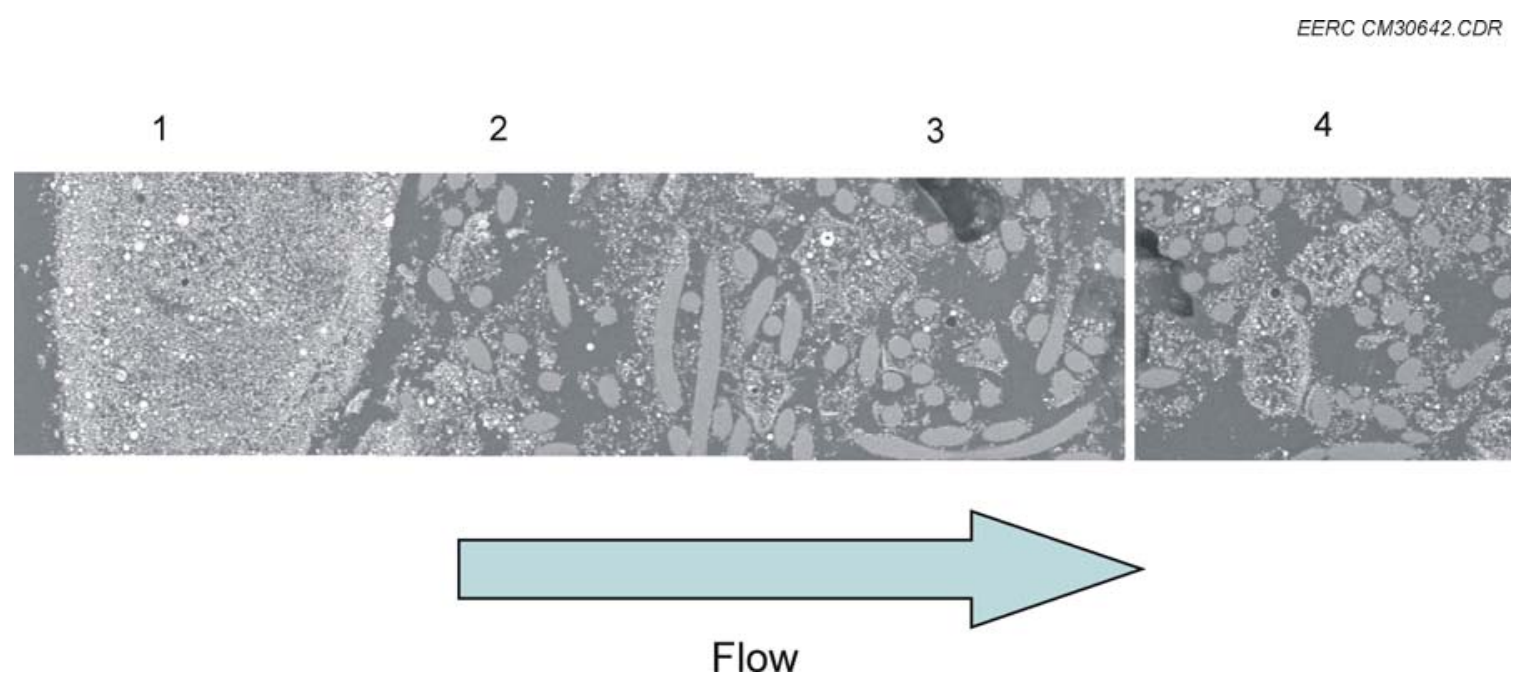

Figure G3-55. Bag cross-section composite image, FF 2-4C sample from 3-30-06. 


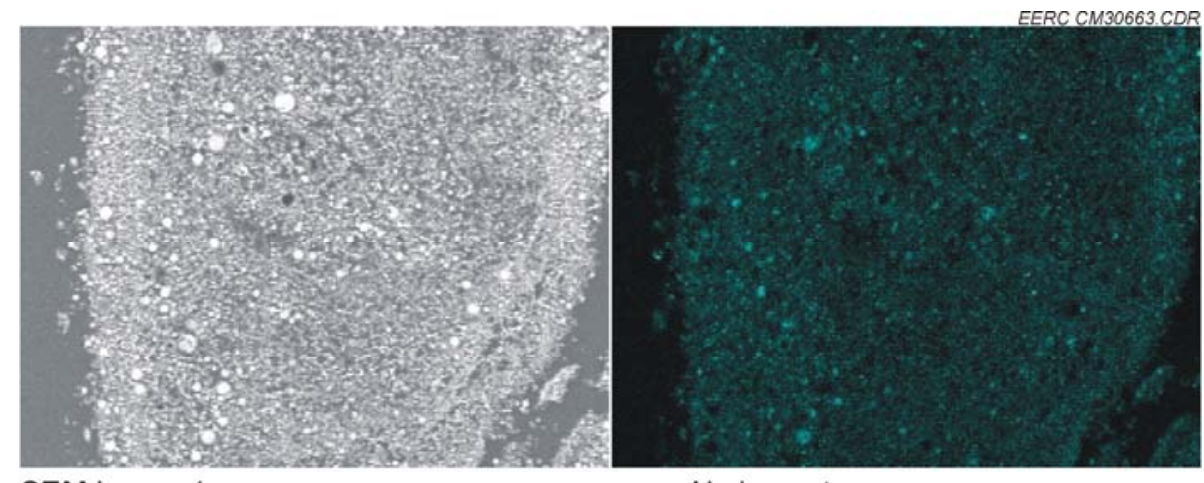

SEM Image 1

Al element map

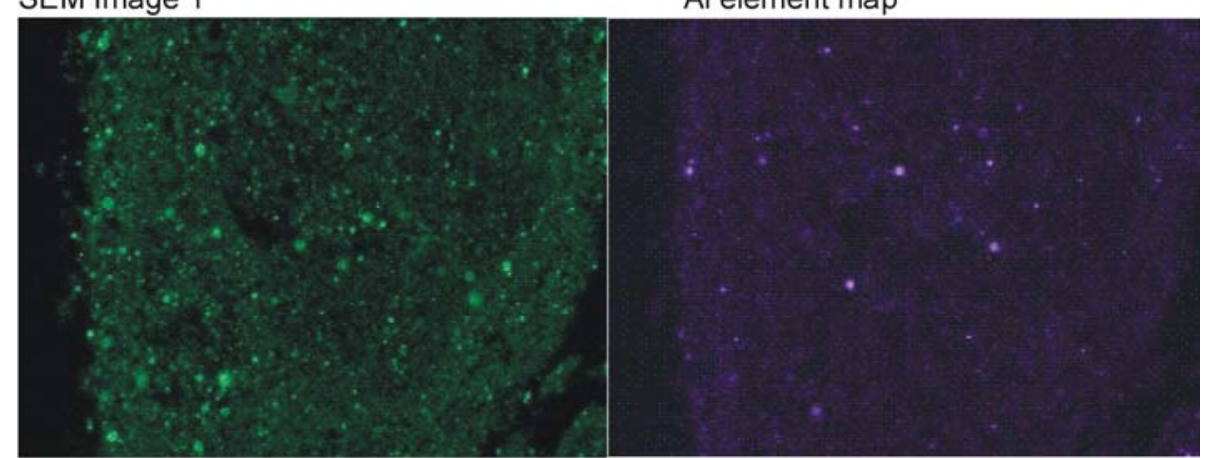

Ca element map

Fe element map

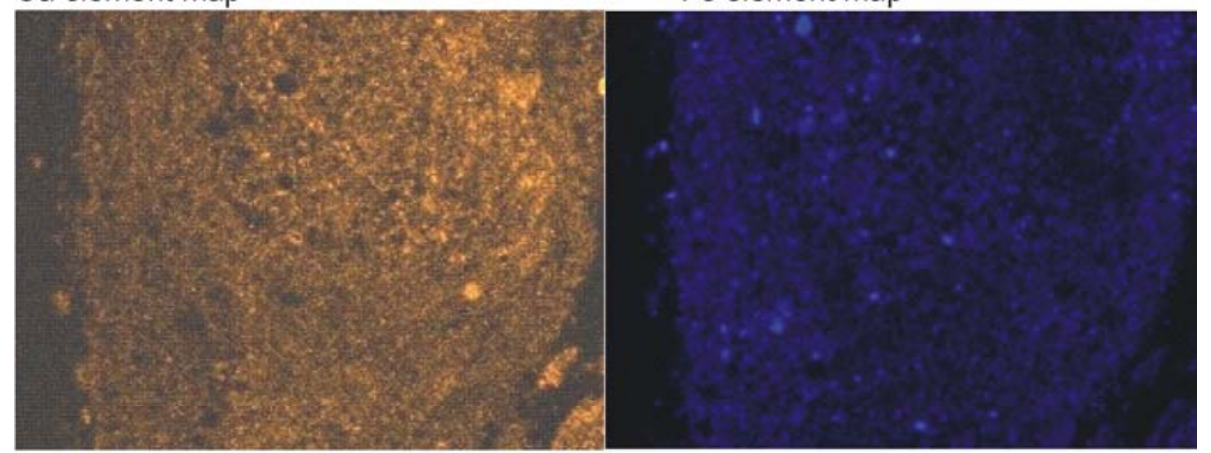

S element map

Si element map

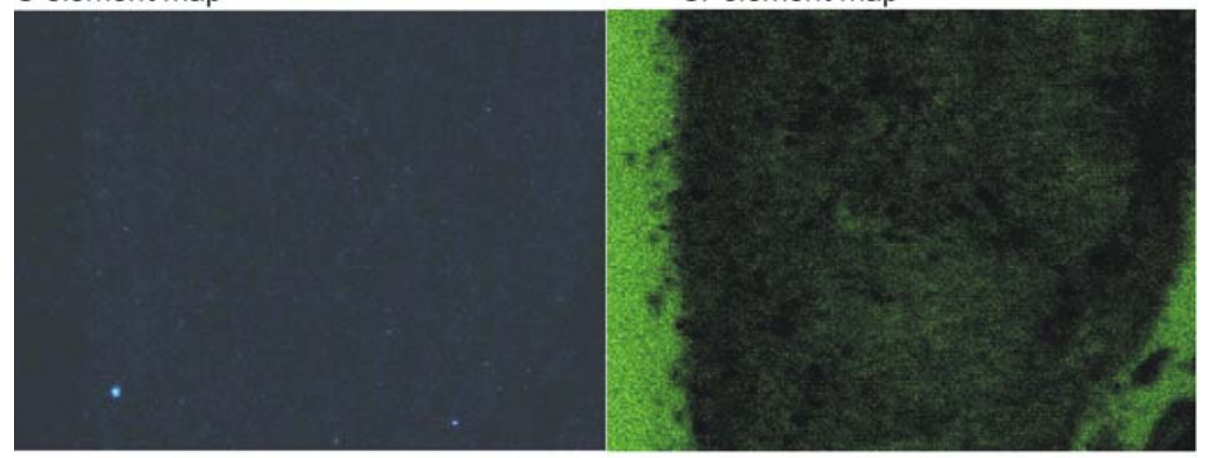

Ti element map

$\mathrm{Cl}$ element map

Figure G3-56. Element maps for image number 1 from FF 2-4C sample, 3-30-06. 


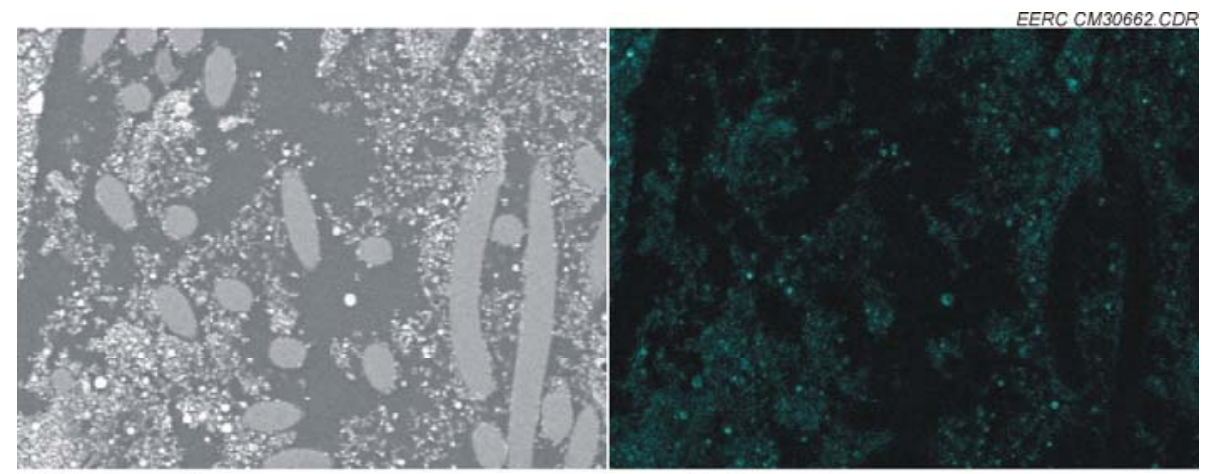

SEM Image 2

Al element map

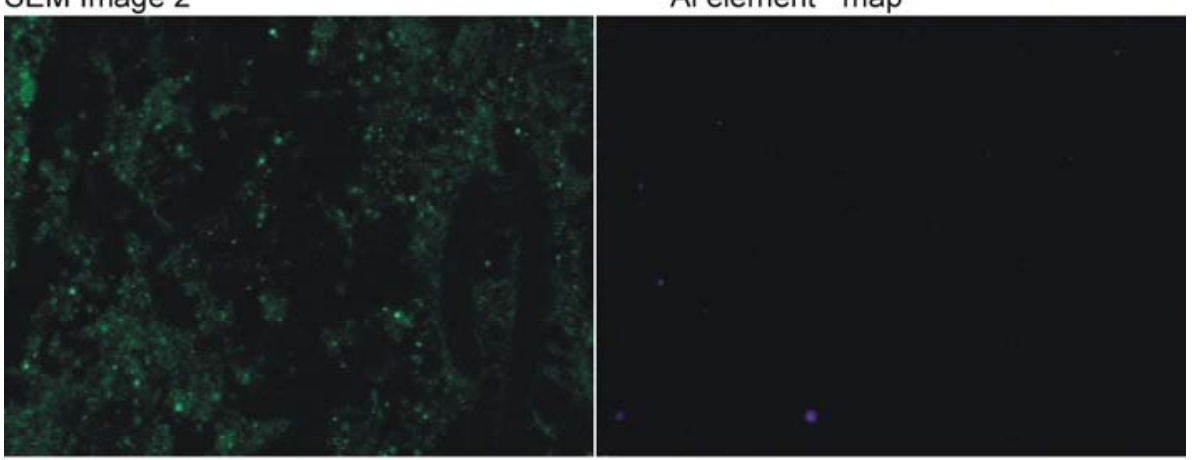

Ca element map

Fe element map

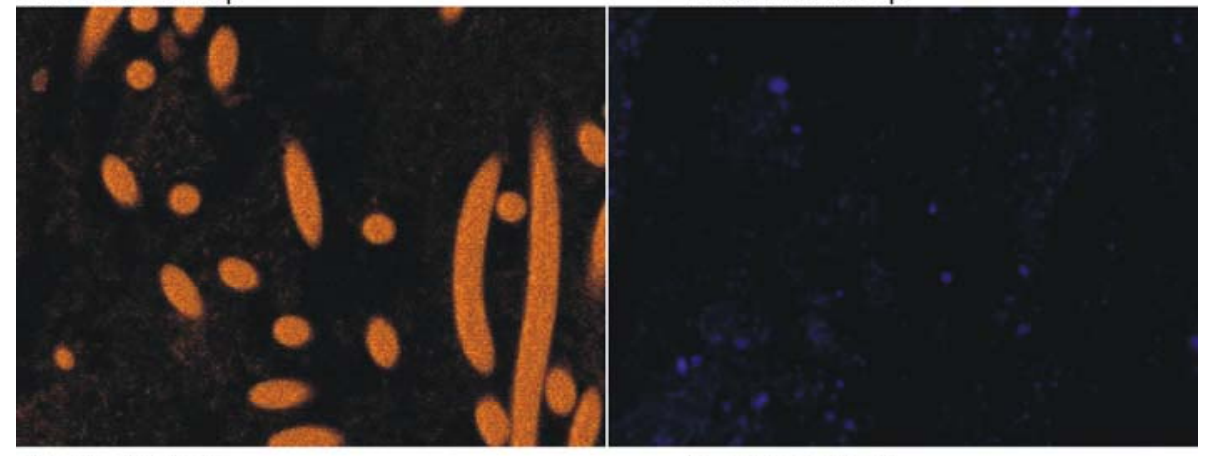

S element map

Si element map

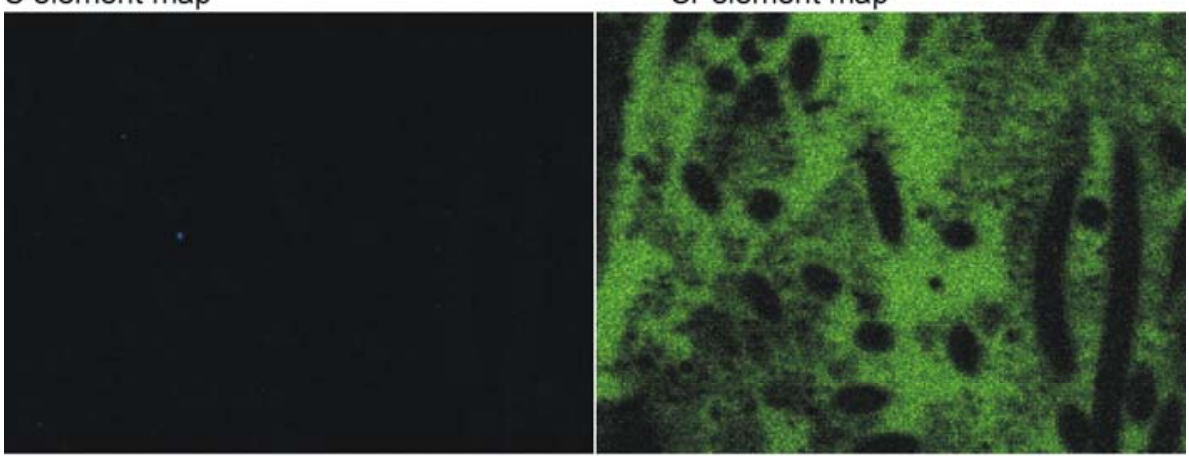

Ti element map

$\mathrm{Cl}$ element map

Figure G3-57. Element maps for image number 2 from FF 2-4C sample, 3-30-06. 


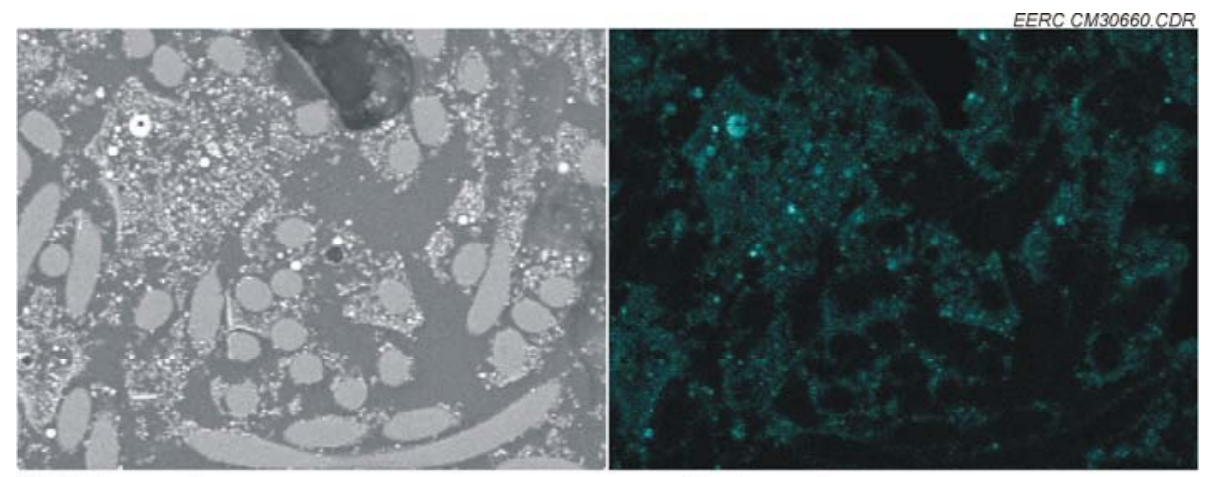

SEM Image 3

Al element map

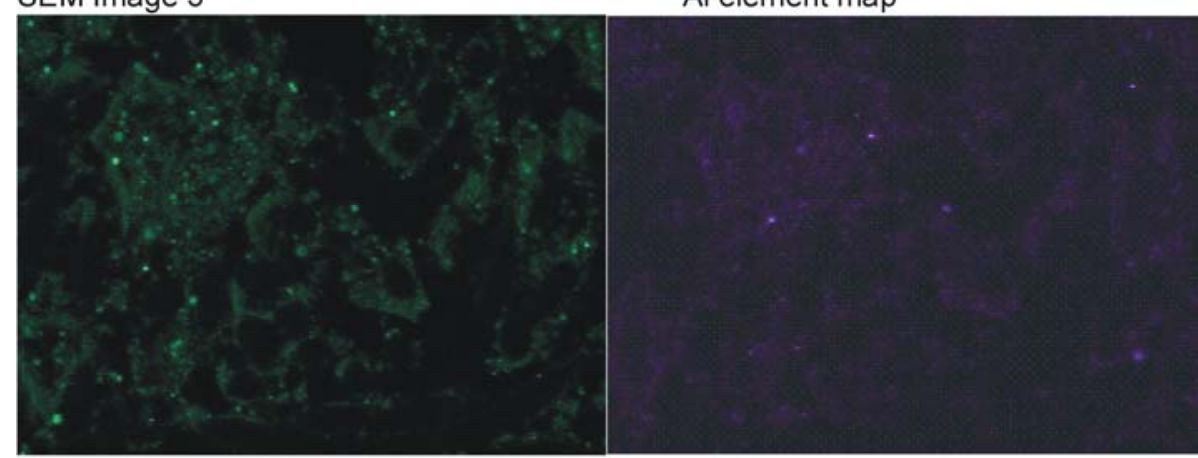

\section{Ca element map}

Fe element map

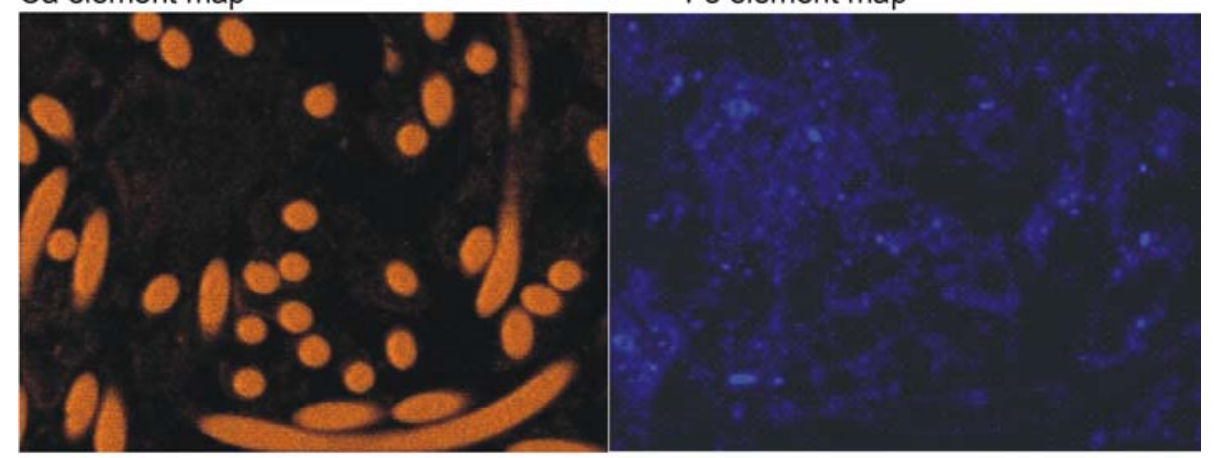

S element map

Si element map

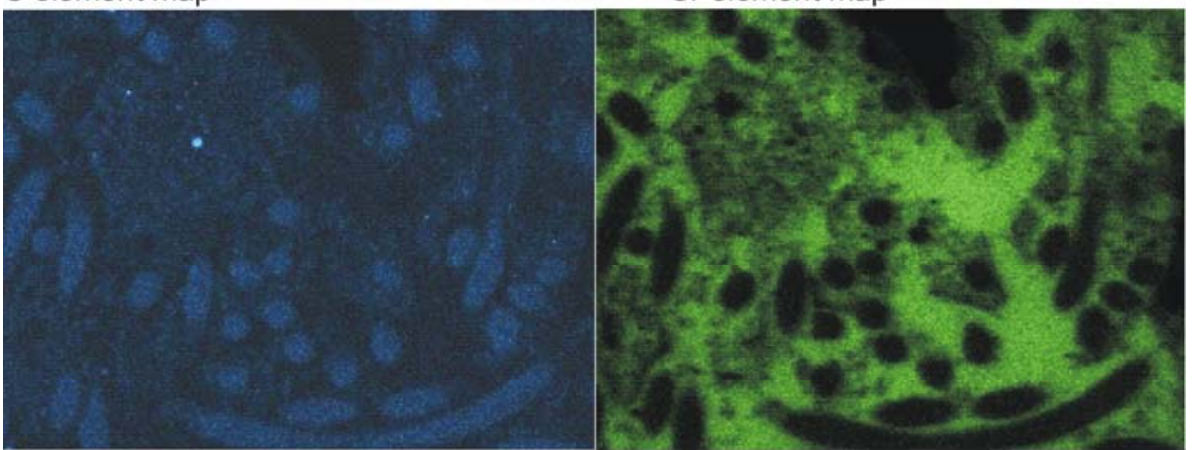

Ti element map

$\mathrm{Cl}$ element map

Figure G3-58. Element maps for image number 3 from FF 2-4C sample, 3-30-06. 


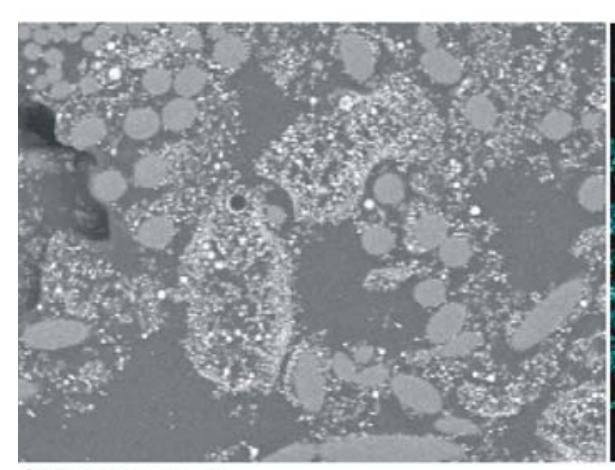

SEM Image 4

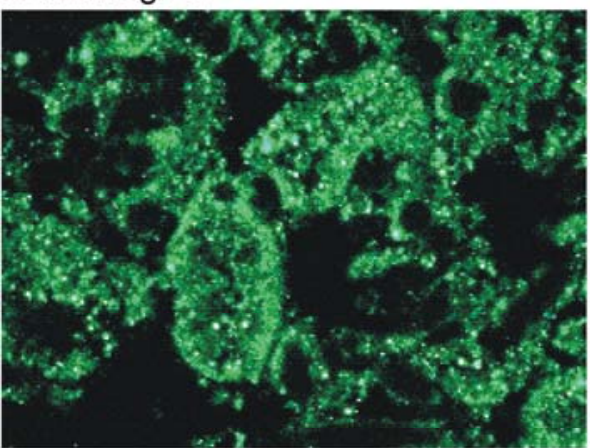

Ca element map

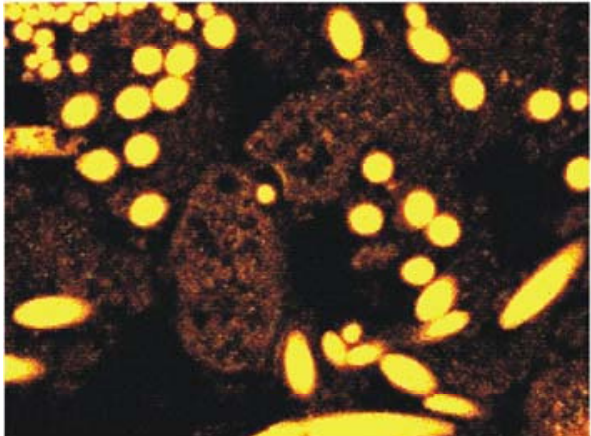

S element map

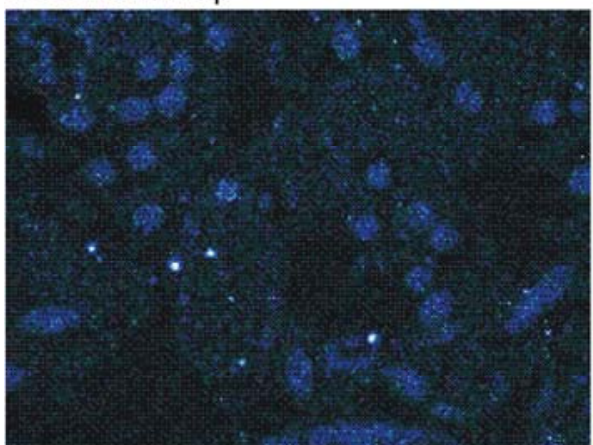

Ti element map

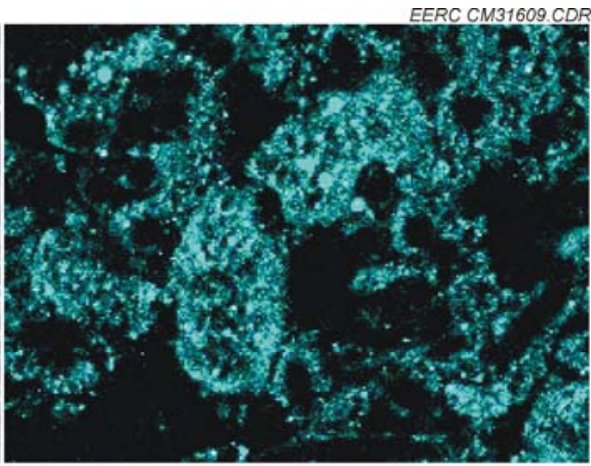

Al element map

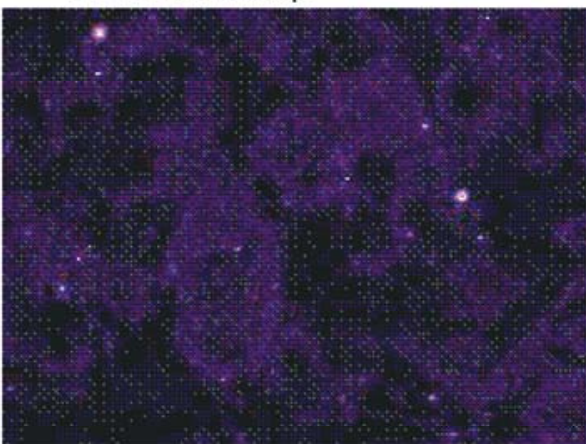

Fe element map

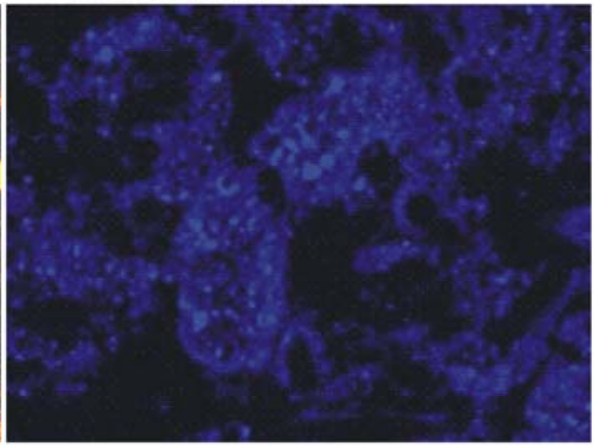

Si element map

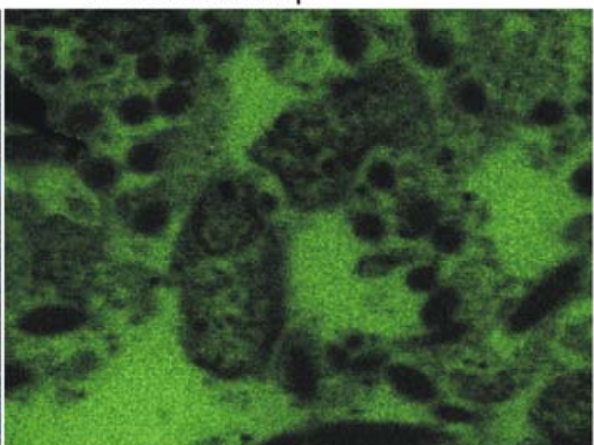

$\mathrm{Cl}$ element map

Figure G3-59. Element maps for image number 4 from FF 2-4C sample, 3-30-06. 
APPENDIX H

\section{HOPPER DEPOSIT DATA}


Table H-1. Oxide Compositions (WDXRF analysis) of the Hopper Deposits

\begin{tabular}{lcccc}
\hline Oxide & $\begin{array}{c}\text { Hopper } \mathrm{C} \\
\text { "Monolith” }\end{array}$ & $\begin{array}{c}\text { Hopper C } \\
\text { “Popcorn” }\end{array}$ & $\begin{array}{c}\text { Hopper } \mathrm{H} \\
\text { “Orange” }\end{array}$ & $\begin{array}{c}\text { Hopper } \mathrm{H} \\
\text { “Gray” }\end{array}$ \\
\hline $\mathrm{SiO}_{2}$ & 44.7 & 38.2 & 42.2 & 45.7 \\
$\mathrm{Al}_{2} \mathrm{O}_{3}$ & 20.1 & 18.2 & 18 & 19.7 \\
$\mathrm{Fe}_{2} \mathrm{O}_{3}$ & 6.77 & 6.21 & 6.11 & 5.29 \\
$\mathrm{TiO}_{2}$ & 1.31 & 1.3 & 1.18 & 1.23 \\
$\mathrm{P}_{2} \mathrm{O}_{5}$ & 0.44 & 0.83 & 0.43 & 0.32 \\
$\mathrm{CaO}$ & 18.4 & 22.2 & 16.7 & 17.7 \\
$\mathrm{MgO}$ & 3.2 & 4.2 & 3.21 & 3.33 \\
$\mathrm{Na}$ & 0.85 & 1.33 & 0.92 & 0.66 \\
$\mathrm{~K}_{2} \mathrm{O}$ & 0.89 & 0.56 & 0.83 & 0.89 \\
$\mathrm{SO}_{3}$ & 2.53 & 0.46 & 9.62 & 4.53 \\
\hline
\end{tabular}


APPENDIX I

SUPPLEMENTARY ECONOMIC INFORMATION 


\section{ASSUMPTIONS REGARDING CONTROL TECHNOLOGIES}

\section{Activated Carbon (AC) Storage and Injection System}

For a recent project, a price quote was obtained from NORIT Americas Inc., to provide a complete activated carbon injection (ACI) system for a 450-MW plant. The typical design of the NORIT system allows application across a wide mass rate range — 50 to $1080 \mathrm{lb} / \mathrm{hr}$ - for each of two parallel feed trains. The AC storage hopper volume will be dictated by the ACI rate and the desired time between AC deliveries. The highest possible ACI rate for a 600-MW load at BB (for $90 \%$ mercury capture) was estimated at approximately $1000 \mathrm{lb} / \mathrm{hr}$ (500 lb/hr from each of the two trains) when firing the 70/30 blend fuel and without enhancement for mercury capture. When using SEA coinjection, the maximum total ACI (for $90 \%$ mercury capture) is approximately $370 \mathrm{lb} / \mathrm{hr}$ when firing the blend fuel or $260 \mathrm{lb} / \mathrm{hr}$ when firing the $100 \% \mathrm{PRB}$ fuel.

Using the injection configuration of the field test program as an example, it is envisioned that one feed train will inject AC into the common inlet duct of modules FF 2-3 and 2-4 while the second train would supply AC to an identical duct location upstream of modules FF 2-1 and 2-2. Included in the AC system design and price are the following items:

- Integral storage silo and all associated equipment

- Dual, parallel feed trains, each consisting of:

- Volumetric feeder, hopper, and associated equipment

- Eductors and blower

- All structural steel and piping

- Control panel and associated software and hardware

- Feeder controller

- Programmable logic controller

- Operator interface terminal

- Level and pressure sensors

- Power system (480-volt system)

- Injection distribution system (injection lances) and flow/distribution modeling

- Field support services (NORIT will provide the services of a technician to support installation and start-up of the equipment)

The total quoted cost for the ACI system was $\$ 974,000$. In addition to capital equipment provided by a vendor, TXU personnel would need to perform certain site preparation and infrastructure upgrades prior to AC system erection. An estimated \$75,000 would be required to provide the following:

- Concrete foundation for the silo, feeders, and blowers 
- AC transport piping and installation (to the point of injection)

- Unloading and assembly of vendor-supplied equipment with support from the NORIT on-site technician

- Piping to provide dry compressed air to the feeder and silo

- Drainage and containment as required by the site to collect and dispose of wash-down and any other wastes generated by the AC system

- Electrical service including single-phase $120-\mathrm{V}$ and three-phase $480-\mathrm{V}$ power

- Communication wiring to the plant process and data control system

- General lighting

- Applicable permits

The total cost for the ACI system, including both the vendor-supplied process equipment and site preparation work, was $\$ 1,049,000$.

\section{AC Enhancement Skid}

The form, chemical makeup, and method of delivery of the AC enhancement system are proprietary, and the most recently tested process for enhancement is in the demonstration phase. A commercial, vendor-serviced system does not yet exist. It is envisioned that production of the enhancement system will be based on existing, commercially available components. An industrial process vendor could perform shop assembly of a skid-mounted system. The cost estimate for this analysis was produced at the Energy \& Environmental Research Center (EERC) and was based on time and materials effort to produce a finished system from commercially available components.

The estimated direct equipment cost for a vendor-supplied and supported commercial system with full process control and plant integration would be $\$ 92,500$. Since this system is in the development stages, a conservative contingency factor of $45 \%$ has been added, bringing the total purchase cost for the AC enhancement system to $\$ 135,000$. This cost figure does not include vendor profit.

TXU incurred costs to install an enhancement skid include labor and materials for site preparation, foundation installation, and piping and electrical connection. For this application, the enhancement system is integrated with the ACI system transport piping. The total installation cost has presently been estimated at $\$ 27,000$ for a total installed cost of $\$ 162,000$. 


\section{SEA4 STORAGE AND INJECTION SYSTEM}

A budgetary price quote was obtained from Nol-Tec Systems for a stand-alone dilutephase pneumatic conveying system for the injection of SEA4. As with the ACI system, the points of injection would be into the common inlet duct for FF 2-1 and FF 2-2 and the inlet duct serving FF 2-3 and FF 2-4. However, in contrast to SEA2 injection, separate piping runs from the Nol-Tec feeder system to the duct injection points would be required. Included in the SEA4 storage and injection system design and price are the following items:

- Truck unloading system

- Integral storage silo and all associated equipment

- Level sensors

- Dust collectors

- Fluidizing-bin bottom and air controls

- Isolation valves

- Silo discharge

- Dual, parallel feed trains each consisting of:

- Loss-in-weight hoppers

- Rotary valve (for metering)

- Rotary air-lock

- Hopper dust control

- Blower package

- Desiccant dehumidifier air-drying skid

- Conveying line (to injection points)

- Steel support structure

- Control panel and associated software and hardware

- Programmable logic controller

- Operator interface terminal

- Weigh controller

- Motor starters and variable frequency drives

- Power system (480-volt system)

- Injection distribution system and injection lances

The total quoted cost for the SEA4 injection system was $\$ 391,000$. As with the ACI system, TXU personnel would need to perform certain site preparation and infrastructure upgrades prior to SEA4 system erection. An estimated $\$ 75,000$ would be required to provide the following:

- Concrete foundations

- Assembly of SEA4 transport piping (to the point of injection) 
- Unloading and assembly of vendor-supplied equipment

- Piping to provide dry compressed air

- Electrical service including single-phase $120-\mathrm{V}$ and three-phase $480-\mathrm{V}$ power.

- Communication wiring to the plant process and data control system.

- Field support services by Nol-Tec for installation and start-up

The total cost for the SEA4 system, including both the vendor-supplied process equipment and site preparation work, was $\$ 466,000$.

\section{OPERATING COSTS}

The primary operating cost components include purchase of AC and sorbent enhancement additives, operations and maintenance (labor and materials), utilities (electricity, water, natural gas) and COHPAC fly ash disposal (and lost revenue). For this analysis, all operating costs are estimated as incremental costs above that currently incurred by TXU.

\section{AC and Sorbent Enhancement Additive (SEA) Costs}

Quotes (in 2006) from NORIT Americas for AC and Chemtura (formerly Great Lakes Chemical) for SEA2 put the purchase cost for these two items at $\$ 0.45 / \mathrm{lb}$ and $\$ 1.70 / \mathrm{lb}$, respectively. The delivered cost of NORIT AC (formerly DARCO FGD, currently NORIT Hg) would be $\$ 0.58 / \mathrm{lb}$ and the delivered cost of SEA2 (an additive used in the AC enhancement process) would be $\$ 1.83 / \mathrm{lb}$. Based on communication with Acid Gas Solutions, the average price of SEA4 in 2005 was $\$ 0.0475 / \mathrm{lb}$; with delivery, it is estimated that the price would be approximately $\$ 0.055 / \mathrm{lb}$.

\section{Operations and Maintenance}

Operation of the ACI system alone and in conjunction with AC enhancement or SEA4 injection was assumed to average 0.25 and 0.5 staff hours/shift, respectively. Maintenance (routine and specialized) labor was estimated based on $60 \mathrm{hr} / \mathrm{yr}$ and $100 \mathrm{hr} / \mathrm{yr}$, respectively, for the AC-alone, enhanced AC, and AC with SEA injection systems. Operations and maintenance labor rates were assumed $\$ 20$ and $\$ 25 / \mathrm{hr}$, respectively. The supervisory labor cost was assumed to be $15 \%$ of the total operations, and maintenance labor cost and maintenance materials were assumed to be $100 \%$ of maintenance labor cost. The overhead cost was assumed to be $60 \%$ of the total operations, maintenance, and supervisory labor and maintenance materials cost. The cost for general replacement parts was based on a percentage of the total capital cost for the skids and is set at $1 \%$ of the total capital cost on an annual basis.

\section{Utility Requirements and Costs}

Principal utility requirements (excluding incremental power for the COHPAC booster fans) included electrical power for the COHPAC bag-cleaning system blowers and the ACI and SEA injection systems. Other utilities include cooling water and natural gas, which are all assumed to be available in sufficient quantity at the TXU Big Brown site. 
The overall utility cost for AC, enhanced AC, and SEA4 injection is a product of the feed rate. However changing the feed rates for AC, enhanced AC, and SEA4 are not likely to have a significant impact on the overall utility cost, and as a consequence, the energy costs are based on the maximum capacity of the equipment. Each of the process systems contains one or more electrical components (motors for fans and blowers, heaters, lights) each of which contribute to the overall energy consumption. The specific utility requirements for the various components on each skid are outlined below.

The electrical requirements for the components of the AC skid include the following:

- Rotary valves are driven by $1 / 2-\mathrm{hp} 480-\mathrm{V}$ motor

- Volumetric feeders (2) driven by 1-hp 480-V motors

- Blowers (2) each, 10-hp 480-V

- $10-\mathrm{kW}$ heater (for underskirt heating)

- Miscellaneous process control and communication power supplied by a 480-V control center

The following utilities are necessary to operate the enhancement skid:

- Propane or natural gas $2.5 \mathrm{~kg} / \mathrm{hr}\left(50 \mathrm{ft}^{3} / \mathrm{hr}\right)$

- A 7-hp 480-V blower

- Miscellaneous process control and communication power, likely provided through the AC system

- 5-gal/min cooling water

The electrical requirements for the components of the SEA4 skid include the following:

- Rotary valves (4) each driven by $1 / 2-\mathrm{hp} 480-\mathrm{V}$ motors

- Silo exhauster driven by 3-hp 480-V motor

- Desiccant dehumidifiers (2) with reactivation heater

- Blowers (2) each, 25-hp 480-V

- Miscellaneous process control and communication power supplied by a $480-\mathrm{V}$ control center 
The total power requirements for the AC, enhanced AC, and SEA4 systems are approximately 35, 10, and $80 \mathrm{~kW}$, respectively. For the SEA2 system, the usage rate for propane or natural gas is $50 \mathrm{scfh}$. Assumed utility costs used for the cost analysis included the following:

- $\$ 0.05 / \mathrm{kWh}$ for electricity

- $\$ 1.00 /$ ccf ( $\$ 10 / \mathrm{MBtu})$ for natural gas

- $\$ 2 / 1000$ gal for water

\section{SCENARIO 2 ASSUMPTIONS - ADD-ON SYSTEM UPGRADES FOR COHPAC}

\section{Enhanced Temperature Monitoring}

Enhanced temperature monitoring would be performed on a per-compartment basis and would consist of adding thermocouples at critical points within the compartment hoppers. Two thermocouples would be placed inside the hopper against the wall, opposite the hopper heaters. These thermocouples would be used to detect situations where the hopper heaters may operate improperly, producing hopper skin temperatures that can contribute to conditions for self-heating of the AC within the fly ash. Two additional thermocouples would be placed so as to measure the bulk fly ash temperature within the compartment hopper. Elevated bulk fly ash temperatures would signal an event that should be investigated.

Purchased Equipment

Thermocouples, $1 / 4$ ” 304 SS sheath with weld pad

Thermocouples, $1 / 4$ " 304 SS sheath

Polyvinyl wire, 18 gauge

Fieldpoint system or equivalent
Qty $\quad \underline{\text { Unit Price }} \underline{\text { Total }}$

$\begin{array}{lll}64 & \$ 56 & \$ 3584 \\ 64 & \$ 45 & \$ 2880 \\ 4000 \mathrm{ft} & \$ 7.7 / \mathrm{ft} & \$ 3080 \\ 128 \mathrm{pt} & \$ 60 / \mathrm{pt} & \$ 7680\end{array}$

Other materials (conduit, connectors, hopper penetrations) are assumed to be $10 \%$ and taxes $6 \%$, respectively, of the total purchased equipment.

\section{Installation}

Installation labor is assumed at 6 hours per COHPAC compartment hopper at maintenance rates of $\$ 25 / \mathrm{hr}$ and with $60 \%$ overhead. Engineering (including programming of additional data points in the plant data acquisition system) was assumed to be $\$ 7500$.

\section{Utilities}

Annual utilities associated with operating the enhanced temperature-monitoring systems are assumed minimal. 


\section{Annual Maintenance}

Maintenance labor is assumed at 10 hours per year (at maintenance rates of \$25/hr and with $60 \%$ overhead) per COHPAC module. Replacement parts are assumed to be $20 \%$ of the total purchased equipment cost.

\section{Carbon Monoxide Monitoring}

Monitoring of carbon monoxide (CO) levels in the hopper section of each baghouse compartment would be performed using a Forney Corporation CO detection system, based on its commercial technology for monitoring in coal pulverizers, storage silos/bunkers/hoppers, coal dust filters, and coal transport systems. One Forney Corporation 8-point (8-sensor) CO detection system would be used with each baghouse module, for a total of four CO detection systems. Each detection system would be connected to their respective compartment hoppers via heat traced sample tubing.

The CO detection system has been evaluated at the Forney Corporation on the bench-scale and as of the writing of this report, a 4-point system will be evaluated at WE Energies Presque Isle TOXECON system in one hopper of the 10-compartment baghouse. Pending determination of the proper sampling point within a hopper, the 4-point system and an additional 6-point system will be implemented to monitor all 10 hoppers.

\begin{tabular}{lllll} 
Purchased Equipment & Qty & Unit Price & & Total \\
\cline { 1 - 2 } & & & & \\
Forney Corporation CO Detection System & 4 & $\$ 90,000$ & & $\$ 360,000$ \\
Heat-traced sample tubing & $800 \mathrm{ft}$ & $15 / \mathrm{ft}$ & & $\$ 12,000$ \\
Heater controllers, fuses, holders & 32 & 275 & & $\$ 8,800$
\end{tabular}

Other materials (fittings, hopper penetrations, field enclosures) are assumed to be $5 \%$ and taxes $6 \%$, respectively, of the total purchased equipment.

\section{Installation}

Installation labor is assumed at 60 hours per COHPAC module at maintenance rates of $\$ 25 /$ hr and with $60 \%$ overhead. Engineering (including programming of additional data points into the plant data acquisition system) was assumed to be $\$ 5000$.

\section{Utilities}

Annual utilities associated with operating the Forney Corporation CO monitoring/detection systems are assumed minimal. 


\section{Annual Maintenance}

Maintenance labor is assumed at 40 hours per year (at maintenance rates of $\$ 25 / \mathrm{hr}$ and with $60 \%$ overhead) per COHPAC module detector. Replacement parts are assumed to be $5 \%$ of the total purchased equipment cost.

\section{Hopper Fly Ash Level Detection}

The utilization of rotary-type level detectors has been evaluated as a possible replacement of the current level detection system. For this cost analysis, principal modifications would be to the mounting pads or penetrations through the hopper walls. It is assumed that the existing power/signal wiring can be used with the replacement flow aid system. Two rotary level detectors will be used on each compartment hopper, one each for low- and high-level detection.

\section{Purchased Equipment}

Garner Industries BinMaster Rotary

Level Detector

\section{Qty Unit Price $\quad \underline{\text { Total }}$}

$64 \$ 254 \quad \$ 16,256$

Other materials (fittings, hopper penetrations) are assumed to be $15 \%$ and taxes $6 \%$, respectively, of the total purchased equipment.

\section{Installation}

Installation labor is assumed at 4 hours per compartment hopper at maintenance rates of $\$ 25 / \mathrm{hr}$ and with 60\% overhead. Engineering (including reprogramming of data points in the plant data acquisition system) was assumed to be $\$ 5000$.

\section{Utilities}

Annual utilities associated with operating the Garner Industries BinMaster Rotary Level Detector systems are assumed minimal.

\section{Annual Maintenance}

Maintenance labor is assumed at 40 hours per year (at maintenance rates of $\$ 25 / \mathrm{hr}$ and with $60 \%$ overhead) per COHPAC module. Replacement parts are assumed to be $10 \%$ of the total purchased equipment cost.

\section{Hopper Fire Protection}

The cost of adding a fire extinguishing system to each baghouse hopper was estimated. This system would monitor for signs of overheating and/or fire caused by self-heating of the AC and activate a water flood to extinguish the AC. This quotation is not based on a detailed engineering analysis of extinguishing AC fires, and may not be the best choice for 
implementation. It is merely an estimate to highlight the impact of this externality on mercury control cost.

The monitoring and extinguishing system considered here was a Globe Fire Deluge System, which would be used to monitor two hoppers and activate the extinguishing agent in the event of an alarm condition. Four 2-zone control panels would be required per baghouse module. Other materials includes fittings, supply water piping, and hopper penetrations.

\begin{tabular}{|c|c|c|c|}
\hline Purchased Equipment & Qty & $\underline{\text { Unit Price }}$ & Total \\
\hline Globe Fire Deluge System & 16 & $\$ 4430$ & $\$ 70,800$ \\
\hline Other Materials & $\mathrm{n} / \mathrm{a}$ & $\$ 6000$ & $\$ 6000$ \\
\hline Total & & & $\$ 76,800$ \\
\hline
\end{tabular}

$\underline{\text { Installation }}$

Installation labor is assumed at 120 hours per baghouse module at maintenance rates of $\$ 25 / \mathrm{hr}$ and with $60 \%$ overhead. Engineering was assumed to require 60 hours for the entire retrofit.

\section{Annual Maintenance}

Maintenance labor is assumed at 40 hours per year (at maintenance rates of $\$ 25 / \mathrm{hr}$ and with $60 \%$ overhead) per COHPAC module. Replacement parts are assumed to be $5 \%$ of the total purchased equipment cost. 